
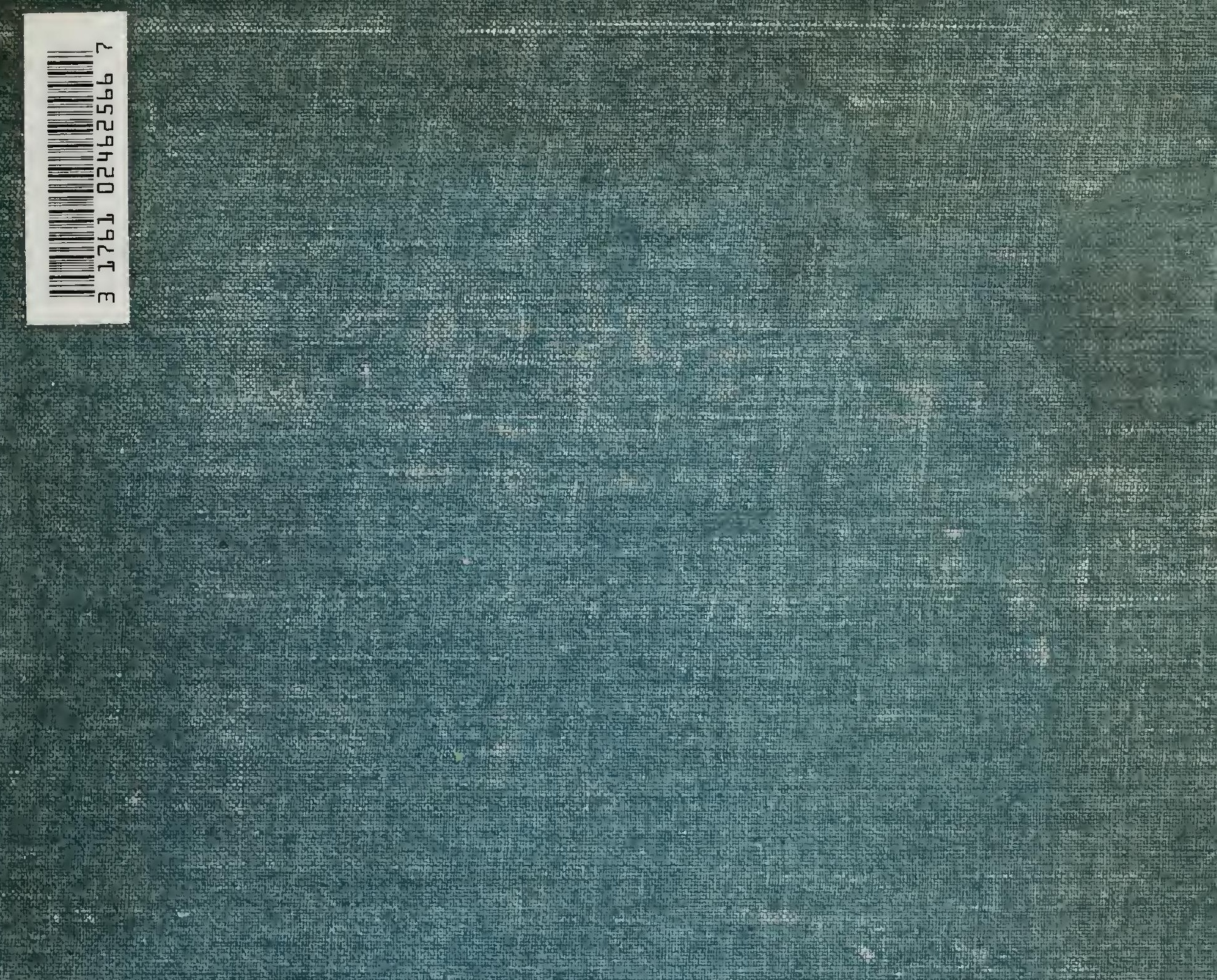

Unwe: bohetis lighapy 





\title{
Bacteria in Relation to Plant Diseases
}

\author{
BY \\ ERWIN F. SMITH \\ In charge of Laboratory of Plant Pathology, Bureau of Plant Industry, U. S. Department of Agriculture
}

VOLUME THREE

VASCULAR DISEASES (CONTINUED)

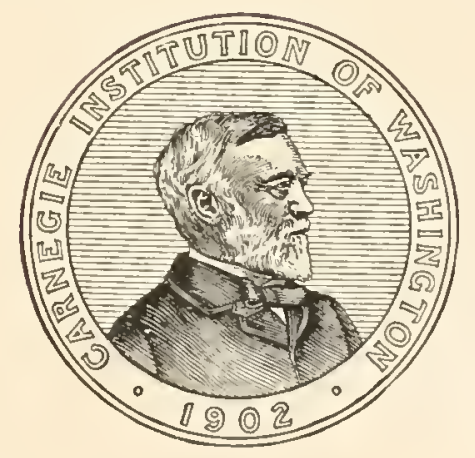

$1490-38$

$17 / 4 / 19$

WASHINGTON, D. C.

Published by the Carnegie Institution of Washington

1914 
CARNEGIE INSTITUTION OF WASHINGTON Pliblication No. 27, Vol. THREE

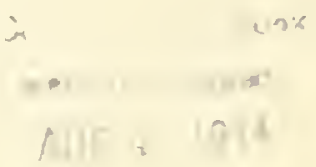

PRESS OF CIBSON BROTHERS,

WASHINGTON, D. C. 


\section{CONTENTS.}

\section{VASCULAR DISEASES-Continued.}

CobB's DIsEase of SUgar-Cane ......... 3

Definition..................... 3

Host-plants..................... 3

Geographical Distribution.............. 3

History . . . . . . . . . . . . . . . . . . 3

Sigus of the Disease................ 15

Fitiologr. . . . . . . . . . . . . . . . 2 I

Inoculations. . . . . . . . . . . . . . . . 2 I

Series 1, 1903... . . . . . . . . . . . . . . 21

Series II, $1903 \ldots \ldots \ldots \ldots \ldots \ldots . \ldots \ldots$

Series III, $1903 \ldots \ldots \ldots \ldots \ldots \ldots \ldots . \ldots \ldots$

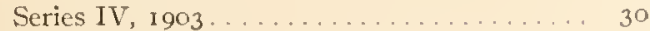

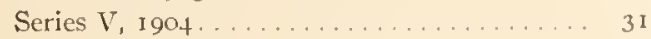

Series VI, I905................... 33

Series VII, I906............... . 46

General Remarks on the Inoculations. . . . . 46

Acid Canes Less Susceptible. . . . . . . . . . 47

Conditions Favoring Spread of the Disease. 48

The Red Stain..................... 49

Relation to Sereh............... 52

Morbid Anatomy . . . . . . . . ...... 52

Tle Parasite-Baclerinm vusculurum RGS.... 54

Résumé of Salient Characters........... 66

Treatment..................... 68

Taljle of Susceptible and Resistant Tarieties. 69

Pecuniary Losses... . . . . . . . . . . . . 70

Literature...................... 71

THE SEREH DISEASE OF Sugar-Cane ....... 72

Iiterature. . . . . . . . . . . . . 79

TOP-ROT OF SUGAR-CANE IN JAVA......... 8 I

Literature.

The Humid Gangrene or Polvillo of SUgarCANE IN ARGENTINA ........... $\$_{5}$

Literature........................ 88

STEWART'S DISEASE OF SWEET-CORN (MAIZE) .. 89

Definition........................ 89

Host-plants . . . . . . . . . . . . . . . . . . . 89

Geographical Distributiot. . . . . . . . . . . . . . 89

Signs of the Disease................. . 89

Etiology . . ..................... gI

Field Observations in $1902 \ldots . . \ldots . . . .94$

Inoculation Experiments. . . . . . . . . . 96

Series I and II, 1902 . . . . . . . . . . 96

Series III to VII, $1902 \ldots \ldots \ldots \ldots \ldots \ldots$. . . . . .

Series VIII and IX, Igo3 ........... I 1 I

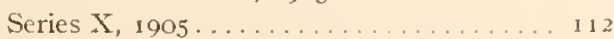

Infected Seed as a Means of Distribution ... I It

Field Observations of $1903 \ldots \ldots \ldots \ldots$ i 14
STEWART'S DISEASE OF SWEET CORN (MAIZE)

Continned.

Eitiology-Continued.

Susceptible and Resistant Varieties.... I I 7

Series $\mathrm{XI}$ to $\mathbf{X V}, \mathbf{1 9 0 3} \ldots . . \ldots \ldots \ldots$. I 21

Summary. . . . . . . . . . . . . . . . 123

1ixperiments of $1908 \ldots \ldots \ldots \ldots \ldots \ldots \ldots \ldots \ldots$

Series XVI to XIX, $1908 \ldots \ldots \ldots \ldots \ldots 125$

General Remarks on Series XVI to XIX 127

Series XX to XXIV, 1908.......... 128

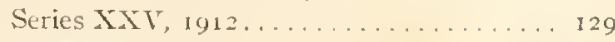

Morbid Anatomy. . . . . . . . . . . . . . . . . . 130

The Parasite-Bactorium stewarli FifS ...... 132

Résumé of Salient Characters........... I 44

Treatment ........................ 145

Pecuniary Losses... . . . . . . . . . . . . . 146

History. . . . . . . . . . . . . . . . . . . 147

Literature....................... 147

SHITH'S DISEASE OF AMARANTHS Buclerim amaranthi IFES ............... 148

Literature..................... I 50

VAN BREDA DE HAAN'S WILT OF PEANUT ..... I5 I

Literature....................... . . 153

ENGLISI DISEASE OF MANGULDS AND SUGARBLETS . . . . . . . . . . . 154

Literature.................... $\mathbf{I}_{54}$

Blight of Young Rose Shoots .......... I 54

BACTERIA IN VESSELS OF FLAX STEMS ....... 154

RÁTHAY'S DISEASE; OF ORCHARD-GRASS-Aplanobacter rathayi Ii IS ............. 155

Description of Disease............... I55

Comment. .................. 157

Personal Observations................. 157

Literatire....................... 160

ThE GRand Rapids TOMato DISEASE-.1planobacter michiganense EFS........ . 16I

Preliminary Studies.................. I6

Totes on Cultural Characters............ 162

Additional Observations, Inoculation Fsperiments, and Inferences... . . . ... I 163

Résumé of Salient Characters . . . . I 64

Literature .............. . . I65

SPIECkERMANn's German POTATo Disease. ... I 66

Literature..................... 167

Fascular Diseases of Banana ... 168

I. Farle's Jamaican Disease........ . I68

2. Smith's Cuban Disease........... . 168

3. Rorer's Trinidad Disease-Bucillus musae Kr. I 70

4. The Panama Disease... . . . . . . . . . 172

5. South American Diseases............... I 73

6. Old World Diseases ................ 173

Literature...................... I73 
VAsCUlar DISEASES-Continued

BROWN ROT OF SOlanaCEAE.

Definition

Ilost-plants

Geographical Distrilution

Signs of the Disease ............. 175

littiology . 175

Synopsis of Inoeulations ... . . . . $\quad 182$

Morbid Anatomy

The Parasite-Bacterium solanacearum Iifs

Résumé of Salient Cluaracters...........

Treatment.

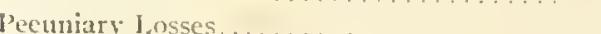

History. . . . . . . . . . . . . . . . . 203

APPENDIX . . . ........... . . . . . 207

The New Zealand Disease......... . 207

The Australian Disease. ....... 207

The Dutel Fast Indian Disease. . . 209

The Malay States Disease.... . . 2 II

The Mysore Ring-Diseast ... . 212

The Ceylon Disease. . . . . . 214

The African Disease. . ...... 214

The Russian Disease. . . . . $2 \mathrm{I}_{4}$

The French Disease.... 2 It

The Italian Disease. ..... 215

The German Ring-Disease

The English Disease....

Malkoff's Disease of Sesammm

Literature.

WILT-DISEASES OF TOBACCO

The Duteh liast Indian Disease. History and Fitiology
VAscutar Drseasts-Continued

PAGE.

Wilt-Diseases of POBAcCo-Continued.

The North Anerican Disease...... . . 227

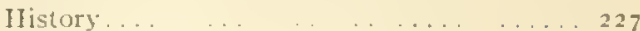

Morphology and Cultural Characters of the

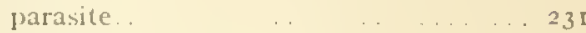

Eitiology - 233

Fixperiments of 1907 . 233

lixperiments of 1908 . 233

lixperiments of rooy $\quad 236$

I.osses; Treatment ... $\quad 237$

The Japanese Disease . $\quad . .2 \quad 238$

Honing's Sumatran Studies ... ...... $24 t$

American Studies of the Sumatran Organism . 263

The Russian Disease. . . . . . . . . . . . . . . 265

The Italian Disease . . . . . . . . 266

T'lue I'rench I lisease $\quad \ldots \ldots \ldots 266$

The Indian Disease . . . . . . . 267

The South African Discase . . . . . . . 268

literature.................... 270

ScIIUSTER's German I'OTATO Disease-Baclerium xanhochlorum Schuster.......... 272

Observations by Schuster ... . . . . 272

lixperiments in Washington .. . 274

Literature.... . . . . . 276

IIIE Ditch DISEASE OF WALLFLOWER _. . . 277

Literature. . . . . . . . . . . . . . . . . . 277

THE ITALIAN DISEASE OF STOCK-Bucterium matthiolae Briosi and Pavarino.... . . 278

Gitcrature ....................... 279

Tul Brazilian Disease of Manihot-Bacillus manihotus Arthand Berthet........ 280

hiterature .................. 28 I

ADUENDYM. . . . . . . . . . . . 282 


\section{LIST OF ILLUSTRATIONS.}

PLATE.

\section{PLATES.}

1. Cross-sections of Diseased Cane-stems, showing Ooze of Bacterinm zascularum and Red Stain

2, 3. Cane Plants Destroyed by Bact. zascularum as a Result of Needic-prick Inoculations on 3 feet from the Nodes.

4. Longitudinal Section, slowing Top-rot of Cane Due to the Introduction of Bact. sascularum by Needlepricks 4 months earlier on Leaf-blades lower down

5. Bacterial Ooze from Vessels of Cane-plant No. 40, Inoculated with Bact. zascularum (second time through plant).

6. Two Plants of Sweet Maize Dried Up and Destroyed by Bact. stewarti (natural infection)....

7. First Cases of Stewart's Disease Obtained from Pure-culture Inoculations-early signs....

8. Sweet-corn Plants Drying Up from Stewart's Disease, 66 days after Inoculation-late signs.

9. I ongitudinal Radial Sections through Stems of Inoculated Sweet-corn, showing Nodal Stain, Pockets in Parenchyma, and Yellow Bundles (dark lines in the photograph)............

10. Base of Inoculated Plants XLII and XLVI or XLVIf Affected by Stewart's Disease, showing Nodal Stain, Absence of Stain in Cortex, Fxternally Sound Roots, etc.

I 1. Cross-sections of Inoculated Cane-Stems, showing Red Stain and Yellow Ooze. Also Cultures of Bact. :ascularum, Bact. stewarti, and A planobacter michiganense (colored).

1 1 a. Cross section of two spikelets of Dactylis glamerata attacked by Rathay's disease.

$11 b$. Ponred plate agar cultures of A planabacter ráthayi.

12 to 15. Grand Rapids Tomato Disease. Hot-house Plants Inoculated from Pure Cultures.

16. Inoculated Chinese Banana Plants Destroyed by Bacillus musae.

17. One clump from Plate I6; Inoculated Parent Plant Killed, Sucker Diseased.

18. Inoculated Moko Plantain Destroyed by Bacillus musae.

19. Red Banana Inoculated with Bacillus musae, showing Characteristic Break of Leaves at Top of Plant

20. (1) Cross-sections of Diseased Fruit-stalks of Banana. (2) Longitudinal Section of a Sucker, slıowing Rhizome and Base of Pseudo-Stem witl Infected (Black) Bundles.

21. (1) Section of Root-stock of Red Banana, showing Blackened Vascular Bundles. (2) Same Rhizome as fig. 1, but here there are Bacterial Cavities as well as Blackened Bundles.

22. (1) Pseudo-Sten of Chinese Banana in Cross-section, showing Bacterial Destruction of Inner Leaves (2) Same as fig. 1, but a Cross-section at the Base of the Psendo-Stem, showing many Infected Bundles (black specks)

23. Potatoes Attacked by Bact. solanacearnm; also Cultures of this Organism, of Bacillus solanisaprus, of Bacillus phytophtharus, and of Aplanobacter rathayi (colored).

24. Salanum tuberosum, Solonum commersoni, and Lycopersicum esculentum, attacked by Bact. solanacearum.

25. Potato-plants from a Field in Virginia, showing Effect of Bact. solanacearum.

26, 27. Two Plates illustrating the Progressive Effect of Bact. solanacearmm (South Carolina strain) upon the Tomato (left-hand shoot infected by needle-pricks).

28. Tomato-plant which did not Wiit on being Inoculated with Bact. solanacearum, altlougl other Signs developed

29. Another Tonato-plant Somewhat Resistant to Bact. solanacearum

30. District of Columbia Potato from which was Isolated a very virulent Strain of Bact. salanacearum.

31. Potato Shoots Inoculated with a Pure-culture of Bact. solanacearum from Plant shown in Plate 30

32. Effect of Liquid Air on Bact. solanacearum. Checks at left

33. Inoculated Tobacco-plant No. S (1905), showing the Granville Tobacco Wilt

34. Leaf from an Inoculated Tobacco-plant, showing irregular Action of the Wilt

35. Diseased Leaf from Inoculated Tobacco-plant No. 34 (1905)

36. Group of 9 Inoculated Tobacco-plants Destroyed by the North Carolina Tobacco Wilt

37. Petri-dish Agar Poured-plates of the North Carolina Tobacco-wilt Organism

38. Collapsed Tobacco-plant from the Second Set of Inoculations No. 3 r (I905)

39. Surface and Sectional Views of Stems of Inoculated Tobacco-plants 35 and 36 (1905)

4o. Results Similar to Plate 39 Obtained by Inoculating Tobacco with Bact. solanacearum from a Potato.

4I. Tobacco Wilt; also enlarged spikelets of orchard grass showing Ráthay's disease (colored)

42. Brown Stripes on Tobacco-stems Attacked by North Carolina Tobacco Wilt (Igo8)

43. The Jimpson Weed, Datura stramonium Attacked by the Granville Tobacco Wilt (1908)

44. Tobacco wilt (action of Medan organsm on cream) and for comparison it planobacter michiganense, Bacterium campestre, and Bacterinm mori.

45. I.oss of virulence in Bacterium solanacearum 


\section{TEX'T FIGURES.}

Fis.

PAGI:

I. Oozing of Bact. iascularum from Cut Surface of Australian Sugar-cane.... . . . . . . . . . . . .

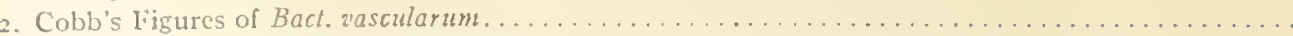

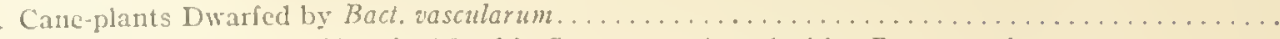

. Bacterial Cavity under Terminal Bud in Sugar-eane Attacked by Bact. aascularum..............

5. Radial I,ongitudinal Section through Leaf-sheath of Sugar-cane No. 4, Attacked by Bact. vuscularum.

6. Detail from fig. 5, showing how the Bacteria reach the Surface through Stomata.

7. Ciross-scction of fig. 5 , including two vascular bundles.

Inoculated Cane No. 9, showing Sidewise Pushing of the Terminal Bud.

. Cane Stripped of I,eaves to show Dwarfing and Twisting of Terminal Bud (zigzag growth) due to Bact. I'ascularum?

I0. I'ushing of Buds in lnoculated Purple Cane No. 38 . .

1. 1.ongitudinal Section Showing P'ushing of Buds and Red Nodal Stain in Stem of Sugar-cane Attacked loy Bact. a ascularum. .

12, 13. Microscopic Appearance of Reddened Vascular Bundles of Sugar-cane Attacked by Bact.

14. Pure Culture of Bact. :ascularum Plated in 1902 from Australian Cane..................

15. Nanism of Inoculated Sugar-cane. . . . . . . . . . . . . . . . . . . . . . . . .

16. Teaf of Sugar-cane showing White Stripes due to Bact. a ascularum......................

17. A Pure Poured I'late Culture of Bacterium ascularum from inoculated Cane No. 9...........

18. Contents of Red Slime from Interior of Sugar-cane 9 months after Inoculating with Bact. zuscularum

19, 2n. Cross-sections of Tascular Bundles of Sugar-cane, showing Parts Occupied by Cobb's Organism. 49 , 50

21. Itarly Stage in Occupation of a Bundle, Cane-plant No. 6

22, 23. I, Ongitudin:1 Sections through Inoculated Cane No. 6, showing Destruction of the Vascular Bundles. 52, 53

24. I.ongitudinal Section through Inoculated and sliglnty Diseased Purple Cane No. 30, showing Red Bundles as Dark Lines.

25. Cross-section of Vascular Bundle of Sugar-canc Oceupicd by Bact. vascularum (the dark portions surrounding the yellow slime were a decp red color) . . . . . . . . . . . . . . . . . . .

26, 27. Bacteria (highiy magnified) from Different Parts of Inoculated Cane-plaut No.6..........

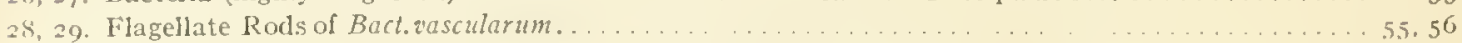

30. Rods of Bact. iascularum from a Joung Culture on Nutrient Agar. . . . . . . . . . . . . . . . . 56

31. A Pure Culture, Agar Poured Plate, of Bact. zascularum from Plant No. I . . . . . . . . . . . . . 57

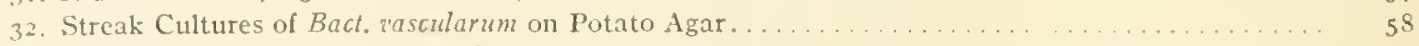

33. Magnified Colony of Bact. sascularum on Glucose Gelatiu. . . . . . . . . . . . . . . . . . . . . 5 59

34. Growth of Bact. rascularum on Cane-juice-gelatin with and without Peptone............... 59

35. Tear-drop Formation of Bact. vascularum on Slant Gelatin with Cane-juice................ 6o

36. Streak Cultures of Bact. iascularum ou Potato................................. $6 .$.

37. Bacterium zascularum in a Tetri-dish Agar Poured-plate (one-hall exposed to sunliglit) ........... 66

38. Crystals from an Agar Streak Culture of Bact. a scularum . . . . . . . . . . . . . . . . . . 67

39, 40, 41. Cross-scetions of Maize Stens, showing Bact. stezrerti Ooziug from Vascular I3undles. lïigs. 39 , 40 , from plants shown in pi. 6 (natural infections), fig. 41 , from artificially infected plants... 91, 92, 95

42. Radial I,ungitudinal Section through Basal Part of Stem of Diseased Swect Corn from I,ong Island. . 98

43, 44. Iellow Bacteria from Smear I'reparations MIade from Stens of Long Island Swcet Corn ........ 98

45. 46. Periphery of I'ortion of Corn-cob in Cross-section, showing Bacteria under and in Kernels.... I i 4 , Is

47. Section through a very immature Corn Kernel and its Supporting Tissues (the area oceupied by Bact. stciarti in the base of the Kernel is drawn in solid black) . . . . . . . . . . . . . . . .

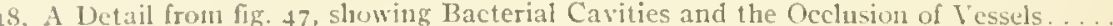

19. Cross-sectiun of the Infected Corn-husk shown in Vol. 11, fig. It. Inoculations of I9u2

5n. A J hetaif from fig. 49 , in the Vicinity of $x, i . c$, from another section in the series, showing stomatal

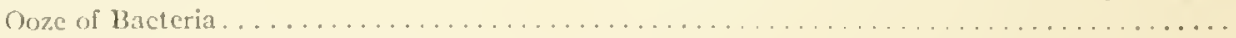

51. Surface View of an lnfeeted Corn-husk showing Bact. slewarti oozing from a Stuma. (Itor appear-

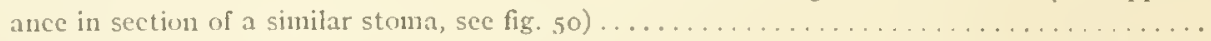

52. Longitudiual Tangential Section through a Diseased Corn-husk, showing Sulustomatic Chanbers filled by Bact. stewarti.

53. Bacterially Spotted IIusks, sane as Vol. I1, fig. \$4, but from a Naturally Infected Plant, $i$. e., one grown in the hot-house in roos from diseased seed.

54. Oeclusion of Single Spiral Vessel Jy̧ Bact. stequarti on the Periplery of a Col, (longitudinal view)..

55. Cross-scetion of Sten of Swect Corn from I.ong Isiand, showing one I3undle witi Occlusion of a Single Vessel by Bact. steu'arti.

56. Section similar to fig. 55, Dut from Sweet Corn Inoculated by tlie Writer in Washington, in 1902, and showing entire Xylem Portion of the Bundle Oceupied by the Bacteria (phloem free)......

57. Section through lower part of a Diseased Sweet Corn Kernel, sliowing Relation of Parts, elc.....

116

119

119

120

120

$12 \mathrm{I}$

129

129

130

130 
58. Details from base of sweet corn kernels showing bactcrial occupation

PAGE.

59. (a) Bact. stewarti from Margin of a Hanging Drop after 52 Hours in Bouillon at $30^{\circ} \mathrm{C}$. (b) Bact. stcwarti from Yellow Slime on Potato after 3 Days at $30^{\circ} \mathrm{C}$.

6o. Flagella of Bact. stew'arti. . . . . . . . . . . . . . . . . . . . . . . . . . .

6r. (a) Gelatin-stab-culture of Bacl. slewarti (110n-liquefying). (b) Gelatin-stab-cultures of Liquefying Non-pathogenic Yellow Organism from Surface of Corn Keruels.

62. Agar-streak-cultures of Bacl. slewarti.

63. Top of an Old Agar-stab-culture of Bact. stewarti enlarged to show Crystals in Sur face Growth....

64. Bact. stewarti on Potato (at left), with Bact. campestre for Comparison

64a. Cirri of Bact. Stewarti oozing from stomata (pedicel of ear)

65. Bacterium amaranthi occupying Intercellular Spaces in the Pith of an Amaranth.

66. Interior of a Pith-cell Occupied by Bact. amaranthi....

67. Xylem Vessels of Amaranth Occupied by Bact. amaranthi

67a. Photomicrograph of Bact. amaranthi in the tissues.

68. Cross-section of Root of Javan Peanut, showing Bacteria Confined to the Bundles

69. Cross-section of Stem of Peanut from Java, showing Bacteria Restricted to the Xylem Part.

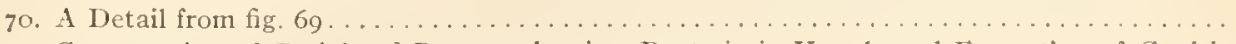

71. Cross-section of Petiole of Peanut, showing Bacteria in Vessels and Formation of Cavities.

$7 \mathbf{I}$ a. Danish Orchard grass attacked by Ráthay's disease..........

7ib. Austrian Orchard grass showing Ráthay's disease: stem pushing out sidewise from leaf-sheaths..

7Ic. Ráthay's disease: cross-sections of culns, showing bacterial layer between leaf and stem, etc

$71 d$. Cross-section of upper part of Dactylis showing dense bacterial growth between the leaves.

71e. Small portion of margin of leaf, showing multiplication of bacteria in intercellular spaces

$7 \mathrm{f}$. Detail of Dactylis leaf more highly magnified, from a section similar to that shown in fig. 7 I $e$.

7I $g$. Capsules of A planabacter rathayi.....

$7 \mathrm{r} h$. Rods of 1 planobacicr rathay adhering to the surface of a leaf of Dactylis.

72. Cross-section of a Tomato Stem from lipidermis to Pith, showing effect of the Grand Rapids Disease-Cavities in Plalocn

73. A Detail from Margin of Bacterial Cavity in the Outer Phlocm shown in fig. 72

74. Longitudinal Section through Phloem of Tomato Stem (fig. 72, inner cavity) showing Bacterial Masses wedging apart the Sieve-tubes.

75. Grand Rapids Tomato Disease, showing Avidity of the Bacteria for Meristematic Tissues.

75a. Streaks of (i) Apl. rathayi and (2) Apl. michiganense on steamed potato

76. Cross-section of Banana Fruit-stalk, showing Bucillus musae oozing from the Cut Bundles

77. Rorer's Bacterial Disease of Banana-Leaf Inoculated in Washington

78. Behavior of Bacillus musae in Gelatin-stab-cultures (compare with fig. III)

79. Irongitudinal Section of Leaf-stalk of Banana, showing some Parenchyma Cells Occupied by the Bacteria and Others Free.

8o. (a) Longitıdinal Section through Bundle in Leaf-stalk of Banana, showing Parasitisn of Fusarium

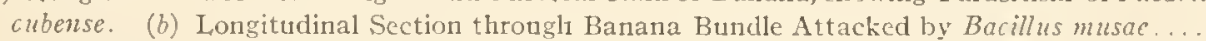

81. Bact. solanaccarmm occupying Vessels in the Root of an Egg-plant from Porto Rico.

82. Section through Iixternal Part of Infected Tuber of Inoculated Potato Plant No. I (1 896), showing Bacterial Infection Restricted to the Vascular System (V).

83. Cross-section of Small Potato-tuber Infected naturally by Bact. solanacearum, showing Partial Disappearance of Starch and Restriction of Bacteria to Vicinity of the Vascular System.

84. Cross-section of Underground Tuber-bearing Stem of Potato Infected in the Vascular Riug by Bact. solanaccarum, the MIovement of the Bacterial Growth being loward the Tuber

85. A Detail from fig. 8 , showing the Character of the Bacteria occupying the Vessels.

86. Cross-section of Stem of Inoculated Potato Plant No. I4 (1 895), showing Vascular Bundle Occupied by Bact. solanacearum, and Cavities in the outer Phloem...

87. Transmission of Bacterial Brown Rot to Potato by Insects

88. Cross-section of Bundle of Datura stramonium from Plant 23 (I895), showing Bacterial Cavity.

89. Cross-section of Stem of Solanum nigrum from Inoculated Plant No. 3t (1896) showing Bacterial Occlusion of the Bundles. .

90. A Detail from One of the Bundles in fig. 89 , showing the Bacteria inore Clearly.

91. Radial Longitndinal Section of Stem of Nightshade (fig. 89), showing Destruction of Bundle

92. A Detail from fig. 91, showing bacterial Occlusion of a Pitted Vessel

93. Cross-section of Stem of Physalis from Plant No. 57 (1896), showing Pacteria in Bundles.

94. A Radial Longitudinal Section from the same Physalis Stem as fig. 93.

95. Cross-section of Petiole of Potato from Inoculated Plant No. 23 (1901)

96. Tomato Plant No. Io (1903), 7 Days after Inoculation with Bact. solanacearum.

131

133

13.3

134

134

I 35

147

148

149

I 49

150

151

I 51

152

152
$\mathrm{I} 52$

158

J 58

I 58

159

159

150

159

159

I 63

I 63

16.

I 64

165

I 69

169

170

I 7 I

172

175

176

176

177

177

180

I 81

I 82

${ }_{1} S_{3}$

${ } 8_{4}$

I $S_{4}$

$18_{5}$

I 85

ง 86

187

I 88 
97. Tomato Plant No. 67 (1904), 3 Day's after Introducing Bact. solanacearm into the Stem lwy means of a few Needle-pricks (control on left).

98. Cross-section of Stern of Tomato No. 26 (1895), showing Bacterial Cavities and lneipicnt Roots.

99. A Detail from one of the Cavities in fig. 98 .

100. I ongitudinal Section of Stem of Inoculated Potato No. 5 (1896), showing Bact. solanacearum Restricted to a Single Vessel

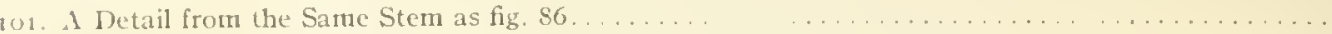

I02. Cross-section of Stem from Potato No. $5(1 S 96)$, ro Days after lnoeulation. . . . . . . . . . . .

103. A Dctail fronn fig. 102

104. A Detail from fig. 82 of Inoculated Plant No. $1+$ (1896), showing Starch-grains Lndestroyed by the Bacteria in which they lie Eimbedded.

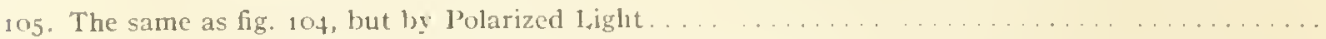

106. A Detail from fig. 83 at $x$, showing Starch Undestroyed in Cells Occupied by Bact. solanacearum..

107, 108. Details from fig. 83 at $A$ and $B$, showing Nature of the Tissues, varying Extent of Infection, and Absence of Starch in the Vicinity of the Bacteria.

109. (a), (b), (c) Flagellate Rods of Bacl. solanacearum Stained by Different Methods; (d) Non-flagellate Rods of Bact. solanaccorum Stained with Silver Nitrate.

to. Figure Designed to Slow Translucency of an Old Culture of Bacl. solanaccarum in Milk

111. Gelatin Stabs of Bact. solanacearum.

112. Agar-poured-plate of Bact. solonaccarum (South Carolina)

113. Agar-poured-plate of Bacl. solanaccurum (Porto Rico).

114. Australian Sore Eye or Spewey Fye of Potato ......

I 1 qu. Margin of a hanging drop showing Bacillus solanincola

$11-7 b, c$. Sesamum plants showing Malkof's discase (after Malkoff)

11 fd. Bacteria from Malkoff's disease of Sesamum (after Malkof)

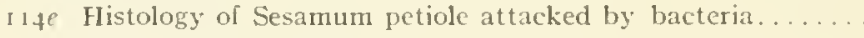

114 . Bacteria from Austrian discase of sesamum. $\ldots \ldots$

115. Tomatoes following Tobacco in a North Carolina Field and Subject cqually to the Gransille Wilt

116. Cross-section of Petiole of a Tobacco-plant Attacked by the Granville Wilt (North Caroliua) ....

117. A Detail from fig. 116

11S. Bacterially Infected Tobacco-stem Attacked by Fusarium in Hot-honse, 5 months after Inoculation

119. Granville Tobacco Wilt: Leaf showing Dead Apex and Brown Veins in the part not dead.

120. Cross-sections of Base of Petiole of Inoculated Tobacco Plant No. $3+$ (1905).

121. Midrib of Inoculated Tobacco Sliced Longitudinally to show Vascular Stain Due to Bacteria

122. Agar-plate from Interior of Plant 31, showing the Presence of a Secondary Soft-rot Organism. .

123. Acrial Roots on Tobacco Induced by lnoculating with North Carolina Tobacco-wilt Bactcrium.

124. Crystal from an Old Culture of North Carolina Tobacco Bacterim in 1,ituus Milk

125. Cross-section of Base of Stem of Datura stramonium (plate +3), showing Extent of Gray-white Bacterial Ooze from the Vascular System about one-half Hour after Cutting. . . . . . . . . . . . .

126. Field of Tobacco in Japan Attacked by Bacterial Wilt

127. Agar Cultures of Bacillus nicolianae (stab and streak).

128. Agar Plate of $B$. nicotianae, showing Riuged Colonies and Brown Stain around (hen

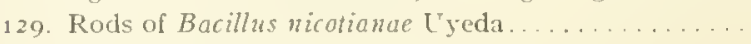

130. Agar-poured-plate of Bucillus nicotianac.

131. Cross-section of Stem of Japanese Tobacco Received from Uyeda, showing Bacteria in Vissels

132. Bacteria froma Sten of Japanese Tolyacco Attacked by Wilt, for comprarison with Bat. solanacearum.

133. The same, Stained for Flagella, and more highly magnified

134. Honing's Figure showing Effect of a Bacterial Saproplyte on the Sumatran Tobacco Bacterium

134a. Flagella of Sumatran tobacco organism

134b. 'Tobacco plant wilted by motile bacteria, check on Fig. 134a, i. c", inoculated from samc culure.

135. Potatoes Inoculated with Bactcrium xanthochlorum.

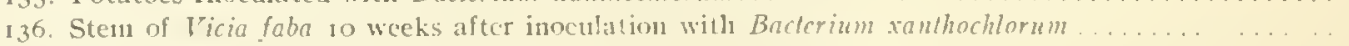

137. Brazilian manilot wilting from attack of bacterial disease.

138. Manihot: (a) stem showing bacterial blister and exudite; (b) cross-sectim of stem slowing upper part diseased; (c) bacteria from same.

(Total figures 155.)

l'AGI:. 


\section{Bacteria In Relation to Plant Diseases}

Br ERWIN F. SMITH 



\section{VASCULAR DISEASES-Continued.}

\section{COBB'S DISEASE OF SUGAR-CANE.}

Synonyms: Gumming of Cane, Sereh in part (?), Top- rot in part (?), Polvillo (?).

\section{DEFINITION.}

This is a specific communicable disease of sugar-cane, due to a yellow, one-flagellate schizomycete. The most conspicuous signs are dwarfing, etiolation, stripes on the leares, reduction of sugar-content, decay of the terminal bud, and the appearance in the fibrovascular bundles of a yellow slime and a red stain. In early stages of the disease this slime is inconspicuous, but in later stages it is one of the most striking features of the disease (sce plate I I, fig. 2), and frequently gives trouble in the sugar-factory, gumming the machinery, interfering with the clarification, and delaying the boiling in the vacuum-pans.

\section{HOST PLANTS.}

So far as known, the disease is confined to the sugar-cane (Saccharmm officinarmm).

\section{GEOGRAPHICAL DISTRIBUTION.}

This disease oceurs in New South Wales (Cobb, Greig Smith), Queensland (Tryon, Cobb), Fiji Islands (Clark), Mauritius (Bonâme), Java (Went), Borneo (Krüger), New Guinea (Cobb), and Brazil (Dränert). From various statements in Spegazzini's paper on Polvillo or humid gangrene of the cane I believe this disease is also present in Argentina, Tucuman province (see Polvillo, p. 85). It is probably not in North America. No complaints have been received from the cane-fields of Louisiana. Dr. Went did not find it, or hear of it, in his tour of inspection in the Dutch West Indies in r 902 . It has not been reported from the British West Indies nor from Porto Rico. The writer did not see it, or hear of it, in Cuba in 1904 , nor was it seen in 1907 by John R. Johnston, assistant in the I aboratory of Plant Pathology, who spent six months in the West Indies, visiting Cuba, Jamaica, Trinidad, Guiana, Venezuela, Barbados, and Porto Rico, and who was instructed to look for it especially. Recently a top-rot of sugar-cane has been reported from Cuba by Cook and Horne, but their account of it leaves very much to be desired. It does not occur in the Sandwich Islands (Cobb). Sereh and cane-gummosis are said by Dr. E. J. Butler to be "unknown or rare" in India (letter to our Secretary of Agriculture, April 2 I, 1903). It is a disease most prevalent in the Southern Hemisphere, but one likely to occur wherever cane is grown. The Javan top-rot as described and figured by Wakker is not this disease. Possibly, however, it may have been confused with the Javan heart-rot or with the pokka-bong.

\section{HISTORY.}

Dränert was probably the first person to describe this disease in a scientific publication, and certainly the first one to find bacteria in connection with it. His observations were made more than 40 years ago in the great sugar region of the province of Bahia, in Brazil (S. lat. $13^{\circ}$ ). This disease had been present at the time of this first paper (1S69) to a very alarming extent for about 6 years, and recognized as a distinct disease for a much longer period. During the "past three years," in the comarca of Nazareth, near the city of Bahia, 
he says "the crops have been almost entirely destroyed by this disease." During the same time the disease made very serious inroads into the cane-fields of the northern parts of the province. He also says that the disease occurs farther south, in the province of Santa Catharina (S. lat. $26^{\circ}$ to $28^{\circ}$ ), although a part of the injury to cane in that region is aseribed to mfavorable clincte, the cold heing occasionally too severe in winter $\left(4^{\circ} \mathrm{C}\right.$.) and the mean annual temperature too low, $i, c, 21.5^{\circ} \mathrm{C}$. at Blumenau, whereas cane requires a mean of $24^{\circ} \mathrm{C}$. He also seems to think the disease occurs in Cuba, but his only eridence appears to be "much complaint of a sugar disease some years ago." At that time cane was generally reproduced in Brazil by planting the tops of the culms, including the terminal bud. The fiscase is said to have been most prevalent in a rainy year, and to have caused least complaint in a very ory year. "Repeated investigations at the instigation of the Government have thus far led to no results."

Inasmuch as the disease had been ascribed to insects by one of the Commissions, 1)rinert first exannined for borers, Cocens sp., etc., but could not in any way connect them causally with the disease. The disease oceurred when they were absent and vice rersa. On the other hand, as a result of microscopic exaninations, he found rarious minute regetable organisms in the languishing cane, and to them he ascribed the disease. Accepting Hallier's peculiar view of polymorphism, he believed all these to be various stages of one organism, and experinenting in the sanne crude way as Hallier, believed he had demonstrated that one grew out of the other. He speaks mostly of an alga as the cause of the disease, but this is only because he believed that to be the terminal stage in the development of the nicroscopic organisms (hacteria) seen by lim in the yellow gum. These latter were considered to be the spores of the alga, or the reduced forms of the spores. He figures a micrococcus, a cryptococcus (yeast), and one or more fungous or algal (?) borlies as stages of this parasite. Owing to the imperfect teclnic of the time he was unable to obtain from his cultures results of any rahe and sone of his reasoning is of the fost hoc sort. Nevertheless, I believe we may safely accept such of his statements as are based on fiefl observations, and also some of the simpler conclusions he drew from his microscopic examinations. He figures nothing resembling Bacterimm vascularmm, but his micrococcus is about the right size and it is very easy to understand how he should have mistaken short rods for a coccus, especially with the crude nicroscope he is likely to have used. There is no doubt whatever in nyy own mind that the Brazilian cane-clisease studied by him was really that subsequently described from Australia by Cobb. He saw the top-rot, the bacterial sline, and the red stain in the bundles. I translate from his short papers in Hallier's 7,eitsehrift all that is pertinent to the signs of the disease:

On the contrary, as an infallible sign of the clisease there appears in the first place a red stain in the wood and the surrounding cambium tissue of the nocles. As the discase progresses this stain spreads in the same bundles through the whole shaft of the canc, while the parenchyma for a time retains its natural clearness. In the fully developed disease a yellow, thick, fluid substance flows out of the bundles. 'This substance hardens in the air, but clissolves in water, and under the microscope, with very ligh magnifications, is secn to have only a granular structure. When dissolved in water one can make out very minute cells lying in amorphous lieaps, or attached to each other in necklace fashion.

He goes on to tell how after six to eight days, in the expressed cane-juice, these little cells, which he identifies and ligures as a micrococcus, grow out into an alga which produces swarnispores and ferments the cane-juice, with production of hydrogen and carbon dioxide and organic acids. 'This "alga" he afterwards found in the diseased eane and identified it as the cause of the discase. The yellow masses filling the bundles are regarded as its spores.

I'arther on he mentions the fact that under the influence of this disease the leaves turn yellow and the terminal bud rots. "The "spore dust" ninght enter the plant, he thinks, through insect injuries. 
In a second brief communication (an excerpt from a letter to Hallier), after speaking of the discovery of a cryptococcus (yeast) in the juice freshly squeezed from diseased cane, Dränert goes on to say: "In the same juice there are, however, in much greater numbers, that little cell (fig. $5 s, a$ ), probably the same that you name Micrococcus." A little farther on we have the following confirmatory sentence: "From such cane the yellow material was collected which, dissolved in water, appears as a micrococcus." He then goes on to state as facts what in the light of our present more exact knowledge we know to be only inferences drawn from inexact observation, to-wit, how these micrococei in $2+$ hours grow ont into those algal threads he has already described and figured.

Renewed attention was ealled to this disease in I 893 by Dr. N. A. Cobb, who found it present to an alarming extent in eastern Australia.

Dr. Cobb observed this disease in the Richmond River district and the Clarence River district in New South Wales (S. lat. $29^{\circ}$ to $30^{\circ}$ ). He has also seen gummed cane from one district in Queensland and says: "It is altogether improbable that it is confined to a small district in Australia." The chief complaint had been from the Clarence River region: "There is scarcely a farm on the lower Clarence where gunming is not abundant, and on many of them its ravages are only too apparent." As to the earliest appearance of the disease we have the following:

A farmer on the Lower Clarence told me that he saw gummed cane sixteen years ago $[1876]$ on his farm; I have no donbt of it. The disease is probably nothing new; in fact, is very likely as old as the sugar-cane plant itself. I think it very likely that the disease occurs wherever cane is grown.

Tryon, in Queensland, also found a number of persons who renembered having seen the disease earlier, one man as early as iss 4 , to a slight extent in Rappoe cane.

The signs of this disease observed by Cobb in Australia are best stated in the author's own words:

When a cane crop is ginmmed it presents a variety of symptoms that vary according to the severity of the disease. When only slightly gummed the crop appears to be in a fair condition. Here and there, however, will be seen stools containing one or more stalks with clead tops. The base of the arrow [terminal shoot or flower-stalk] in such cases will be found to be rotten, and usually one or more cavities of considerable size are to be seen near the top of the stalk, filled, or partially filled, with offensive matter. At first one is inclined to attribute these cavities to the inroads of grubs or borers. This idea is soon scen to be mistaken, for there is no entrance or outlet to the

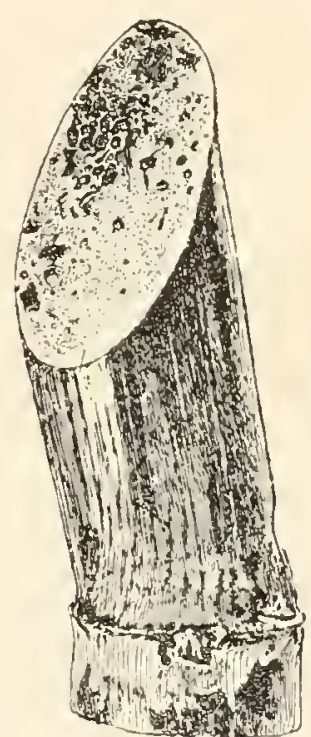

Fig. 1.* cavity, nor are there any traces of excrement, both which facts prove conclusively that the cause lies in some other direction. The tissue about these cavities is generally brown, black, or dark red in color, and reeking with a slimy offensive substance which varies from nearly colorless, through yellow, to brown. Plants whose tops have died from gumming of ten shoot from buds half way down, but this symptom is not peculiar to gumming. It occurs also in plants nipped by frost or by borers.

If a stock which has died at the top in the manner described be cut into pieces with a very sharp knife, in such a manner as to leave the cut surface quite smooth, a honey-colored gummy matter will, in a few minutes, be seen to ooze slowly out and form in droplets on the end of the cut fibers [see fig. I]. This gum is sometimes nearly transparent, sometimes rather opaque, and varies also in color from nearly colorless into various tints of yellow according to the stage reached by the disease. This gummy matter is usually more abundant near the top of the stalk than near the bottom, or at least oozes out more freely. In the course of an hour or thereabouts these droplets of gum become so large as to run together and form large drops, and if two or three dozen cuttings from badly diseased stalks be laid in a closely covered box over night one may in the morning collect from their ends a teaspoonful of yellow mucilaginous gum.

*FIG. 1.-Oozing of Bacterium :'ascularum in drops from cut surface of diseased Australian sugar-cane. After Cobb. 
The gun which thus oozes out in such quantities, if allowed to (lo so, at last becomes dry, owing to the evaporation of its water. In this state it appears as bright yellow stains on the end of the cutting. Sonnetimes the gum oozes out in a state so nearly dry that it hardens as it issues from the fibers into a vellow, coiled-11p, hair-like body, and inasmuch as each fiber gives rise to one such body, all the fibers together originate a yellow, mossy appearance on the end of the cutting.

If another stalk, which is apparently sound, be taken from a stool in which one or more stalks have been already blighted by gumming, as above described, such stock will be found to exhibit the same svinptoms, except that the cavities and rottenness at the base of the arrow are wanting. Moreover, if other stalks be removed from shoots of cane standing nearby in the same field, but which, as yet, show no outward symptoms of this disease, the chances are that some of them will also be found to be more or less gunmed.

In some cases the amount of gum is so small as to ooze out in but a trifling quantity, to be detected only with a magnifying glass. Finally, the quantity of gum may be so small as not to ooze ont at all; in such cases a good microscope is necessary to demonstrate that the gum is present.

"Gumming" is considered by Dr. Cobb to be a good descriptive term for this disease, although he states that the substance is not a true gum. I continue to quote from Dr. Cabb's paper:

After the cane is cut and ready for the 1nill, gummed stalks can be recognized not only by the yellow dried-up gum that exists on the cut ends, but also by their color. Gummed stalks generally have an over-ripe appearance. Green and yellow canes, when badly gummed become yellowish or orange, or even somewliat purple in color. 'The ribbon canes show similar alterations in their yellow stripes while their purple or black stripes tend to take on a reddish cast. 'The waxy bloom, usually

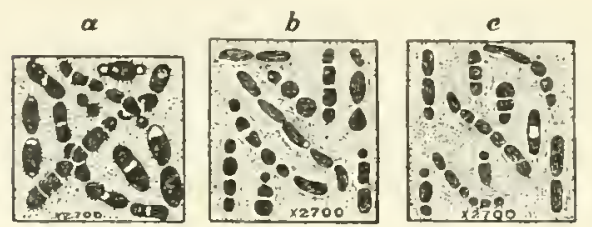

Fig. $2 . \dagger$ to be seen on perfectly sound cane, has disappeared on badly gummed cane. All symptoms of gumming secm to be inore pronounced when they occur in plant cane than when they occur in ratoons.* An cxplanation of this fact will be offered later on.

In the sugar mill the juice of gummed cane may be recognized by the greater anount of lime required for its clarification, and there seems to be reason to suppose that the crystallization of the jellies is slower and less perfect when they are derived from gummed cane. The sieves used to separate the fiber from the juice are apt to clog up when gummed cane is being crushed. 'l'hey are easily cleaned with soda.

The foregoing symptoms are those connected with cane so attacked as to produce a marketable crop. In some cases, however, the gumming prevents the growth of the sets. 'lhe plants may reach a height of a foot or two feet, but they then die back and shoot again from the base, or from buds half-way down the stalk. In such a case the loss is total or nearly so. 'The gum presents the same features in this case as in milder ones.

So much for the gross appearance of this disease. A microscopic examination gave the following additional facts, which seem to have been made out very satisfactorily:

A microscopic examination of a thin slice across a gummed cane shows at once that the disease is not general, but local. The gun, except in certain cases, is confined to the fibers; in fact, to the sap-ressels, these latter being plugged up with gum. A cross-section of a healthy fiber shows the sap-vessels as empty spaces, the sap having flowed out [?] in the process of cutting the section; a cross-section of a gummed cane on the other liand shows the sap-ressels to be filled with yellow grantular matter, in other words, gum. 'This confinement of the gum to the sap-vessels is one of the most striking microscopic features of gummed cane. In advanced cases, and in the more tender tissues at the top of the canc, the gum is not so loeal in its distribution; it may, under such circumstances, be founcl outsicle the fiber.

*I'lant-cane is the first year's crop) from buried cane or cane cuttings. Ratoon-cane is the second crop from a stool or any subsecunent crop. In the rich cane-lands of Australia sometimes as many as jo or 15 successive crops are obtained without senewal of the soot-system. In Cuba it is customary to plant some cane annually, but ratoon crops are alco common.

†rig. 2,-a, Bacterium anscularm from sugar-cane stained with methyl violet withont heat, and mounted in water; $b$, Bact. iascularum from a culture on eane-sugar agar; $c$, Bact. vascularum from sugar-cane, stained with fuchsin and mounted in balsan. $\times 2,700$. After Cobb. 
Lenses of high power show the gum to be swarming with microlses of the form known as bacilli [fig. 2]. When the gum is fresh and yellow in appcarance, the microbes are all of one kind whose features are well shown in the illustrations. *** 'This microbe appears to be one not hitherto described, and I propose to call it Bacillus z'ascularum, in consequcnce of its occurrence in the vessels of the sugar-cane. Each microbe has about it a small amount of gummy matter, which is a product of its growtl. The gum described above as issuing from the sap-vessels of the cane has, therefore, two component parts, namely, microbes and a viscous gummy matter. This gummy matter appears to be a new substance, and to it I have applied the name vasculin.

This substance, which is probably made up of the bacteria themselves or of soluble substances in great part derived from the outer wall of the bacteria, is described as follows:

Vasculin, the substance formed by the growth of the Bacillus vascularum as it occurs in sugarcane, is a yellowish, non-crystallizable, viscid substance, having an almost imperceptible acid reaction. The taste is that of a slightly soured solution of gum arabic. A short time after oozing out from the ends of cut cane, by solution it converts ten times its weight of water into a fluid of the consistency of mucilage as used for adhesion purposes. Thougl soluble in water it is insoluble in alcohol. The addition of absolute alcohol to the raw substance converts it into a hard mass, but this is only owing to the abstraction of water; on placing the hardened mass in water it soon resumes its former consistency and appearance. Vasculin is not coagnlated by alcohol.

Watery solutions of the yellow exudate from the vessels of the cane were tested in various ways. Lime-water precipitated it and the precipitate was redissolved on addition of hydrochloric acid. The exudate was also precipitated by the hydrates of potassium, sodium, barium, and strontium, but not by ammonium hydrate. All of the above precipitates were redissolved by hydrochloric acid. Watery solutions were also precipitated by lead acetate and ferric chloride, but not by ferrous sulphate, barium chloride, or silver nitrate. The dissolved substance has little or no action on polarized light. The raw gum contains only a sliglit amount of nitrogen.

Badly gummed cane contains less sugar than very slightly gummed cane according to the tests slown in table $I$.

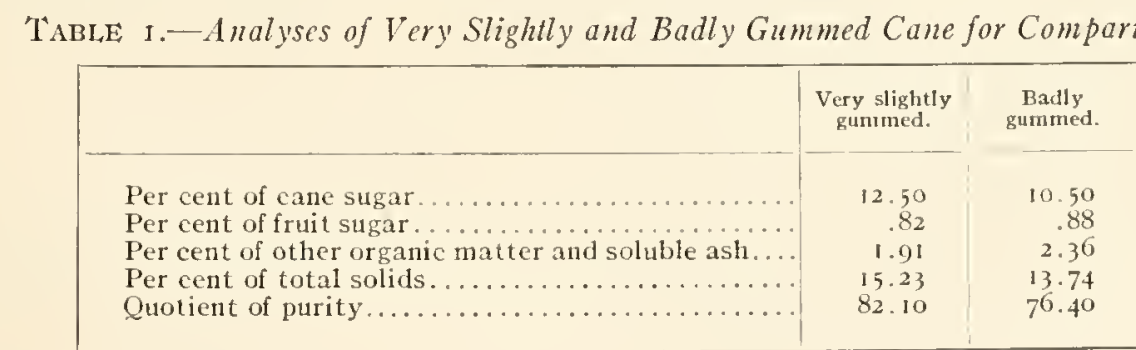

Some of the same chips wcre pressed by hand, and the juice thus expressed was tested for sugar, with the following results:

\begin{tabular}{|c|c|c|}
\hline & Very slightly gummed. & Badly gummed. \\
\cline { 1 - 2 } Per cent of cane sugar................... & 14.90 & 11.50 \\
\hline
\end{tabular}

The raw juice squeezed out by hand having stood 48 lours, was tested witl decinormal solution of sodium hydrate.

\begin{tabular}{|c|c|c|}
\hline 100 c.c. required of $\frac{\mathrm{N}}{10} \mathrm{NaOH} \ldots . . . . . .$. & Very badly gummed. & Slightly gummed. \\
\hline
\end{tabular}

The greatest care was taken that the two lots of eanes subjected to analysis should be strictly comparable in all respects other than the amount of gummining. 
To test the pathogenicity of the organisin Dr. Cobb inoctlated a few sugar-canes. He writes as follows:

In order to show whether the disease is caused by the microbes healthy plants were inoculated with gummy matter from diseased cane. I found it to be unnecessary to first make pure cultures in the way usually adopted, for the reason that a pure growth of microbes could be obtained without this prceaution. Plenty of cane could be found containing no other organism in its interior tissues and advantage was taken of this fact in making inoculations.

This is good as far as it goes, but to complete the proof and satisfy the skeptic, pureculture inoculations are necessary.

Concerning the pathogenic nature of his Bacillus vascularmm, Dr. Cobb also has the following:

What we wish mainly to know is whether the microbes are the cause of the disease. As a resuit of hundreds of careful examinations, I am able to say that the disease of gumming, as described, never occurs witlont the yellow gummy matter in the sap-vessels.

The result of even a much greater number of exaninations made with equal eare showed that the yellow gunmy matter never occurred without the microbes, indeed it is very cvident that the gum is a product of the growth of the mierobes. This leads to the conclusion that the disease never ocenrs without the microbes being present, and it may be added that many cases were examined in which, in spite of long and careful search, none but the merest traces of otler foreign organisms could be found. This is very strong evidence that the microbes are the cause of the discase, but it does not amount to proof.

Dr. Cobb's methods of inoculation are quite carefully described. Pure cultures were not used, but all inoculations were dirct (see this monograph, vol. I, p. 9). They were made in healthy canes by means of a needle which was thrust into vertical slits made with a needle-chisel. 'The surface of the cane was first covered with hot wax, the chisel was thrust through this a half inch or more into the cane, then the needle-thrust followed. The bacteria on the tip of the needle were obtained directly from the fresh ooze out of the ends of cut bundles. The following precautions were used: Needle and chisel were sterilized by heat and protected till ready for use. Cane was selected which was occupied apparently only by a pure growth of this yellow organism; the rind was removed, and the segment was placed in a large glass-stoppered jar the inside of which had been smeared with glycerin over night; all the operations were performed in a room as free from drafts and dist as possible. When all was ready the protected segment of diseased eane was slortened with a sterile knife and the yellow ooze from the freshly exposed surface of the bundles was then tonclied with the inoculating needle and some of the slime was transferred to the interior of the healthy canes. The lips of the wounds were then covered with more hot wax. This paper contains 110 hint as to the result of these inoculations.

All that relates to the morphology of this organism is given in the three cuts here reproduced from Dr. Cobb's paper. 'The magnification is said to be $\times 2,700$, which would make the organisn about the sane size as Bacterimm campestrc. Judging from these figures it is also variable in form like the latter.

We are told by Dr. Cobb next to nothing about the cultural characters of his Bacillus i'dscularum. All I can find is the following:

Cultures on agar-agar containing about 5 per cent cane-sugar gave at first roundish colonics on the surface, laving to the unassisted eye no structure either radiated or concentric. In the course of a few weeks the yellowish-white and somewhat opalescent growth had extended several inches along the edge of the tube on the surface of the agar-agar and between the tube and the agar-agar, witlout causing any liquefaction. On gelatin the growtl was much slower and remained circular and almost imperceptibly concentric. Its color, \&c., were as on agar-agar.

If the "Se." is entirely inclusive, then we nust assume that this organisn did not licutuefy gelatin. From its slower growth on this mediun, it is not unlikely that litnus neutral gelatin exerts on it a retarding influence the same as it does on Bact. campestre. Iigure 3, which shows the dwarfing effect on cane, is borrowed from Cobb's paper. 
In 1894 , a correspondent of The Stigar Cane described a serious disease of cane at Pernambuco, Brazil (lat. $8^{\circ}$ S.). His account n11akes it still nore certain that the Brazilian disease is none other than the one here under consideration. The Pernambuco disease is described as follows:

It may interest some of your readers to remind them of some features of the disease which for many years threatened the existence of the sugar industry in the Province of Pernambuco, and in other provinces of Brazil.

Unfortunately, in one sense, before the observations which are the subject of this note were made, the evil had so far diminished that it was difficult to obtain sufficient specimens to permit of a thorough investigation, and other circumstances cut short the proposed investigation almost at the commencement.

"The unfortunate "Otaheite" cane, or "Cayanna" cane, as it is called in Brazil, was here as elsewhere the principal victim, and nine-tenths of the cane grown was of this kind. A green striped cane called here Imperial, and a small yellow cane, called Creoula, also suffered.

The most striking symptoms were:

Gum.-The formation of a bright yellow, gummy substance, exuding apparently from the ends of the fibres on cutting the cane across. Sometimes this yellow gmm, which turned orange colour on drying, appeared only after half an hour or more, at other times it appeared immediately on cutting the cane, and in such quantities as to drip from the cut ends, and in very bad times is said to have frequently choked the straincrs of the raw-juice tank.

Premature death.--Indicated by the early drying up of the leaf tips; by the successive joints becoming shorter and less in diameter as the cane grew, giving it the appearance of the joints having been telescoped one into another; by some internal parts turning red, denoting fermentation, which may have set in before or after the cane had succumbed, and by the death of the eyes.

Any or all of these symptoms may have occurred together, and some canes, which to all ontward appearance were perfectly healthy and well developed,

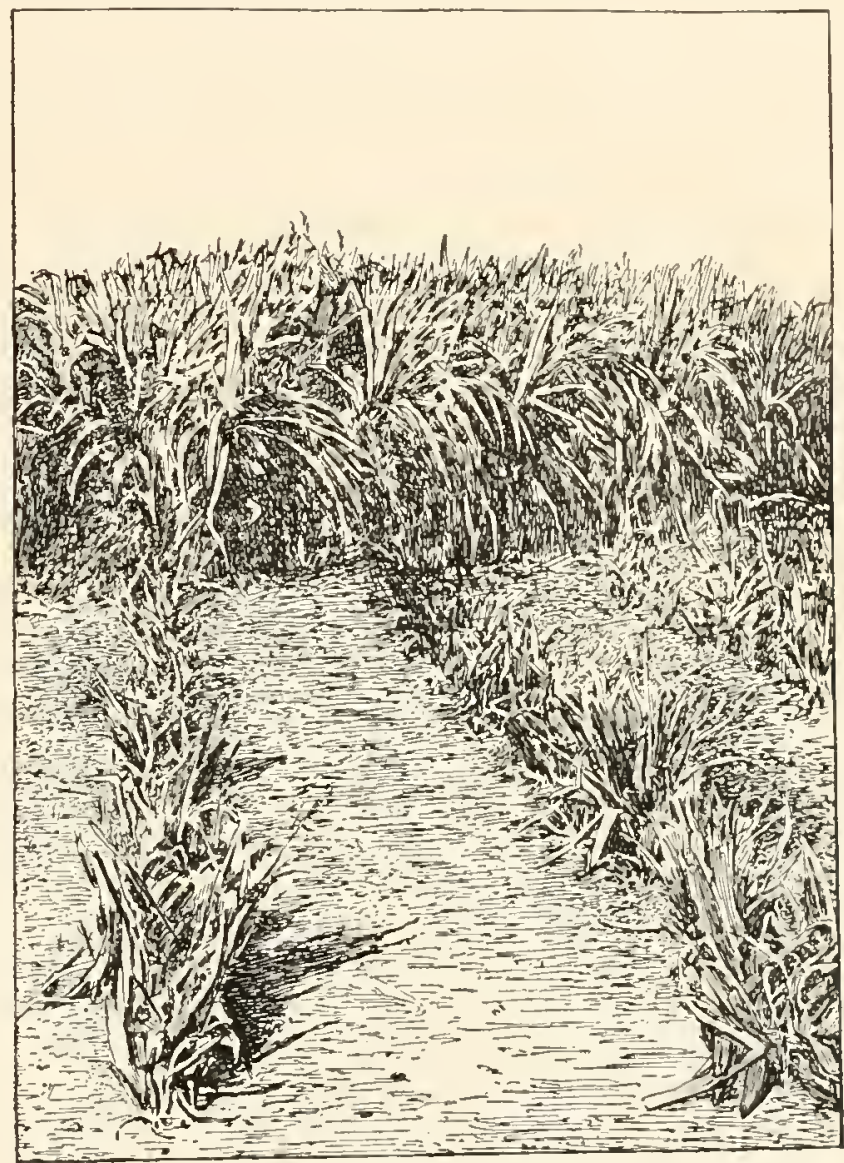

Fig. 3.* contained a quantity of the yellow gum, together with a normal pereentage of sugar.

The canes which did not die before maturity gave no ratoons, and the juice was n1ost diflicult to work, refusing to crystallize in the ordinary way, sometimes in any way. 'The greatest difficulty' was encountered in the "old process" factories, probably on account of the great heat accompanying open evaporation. The Usines, with their lower temperatures, could work better, but they also at times got the "devil in the house," especially if they did not take care to 11se but little lime in the defecation. 'The lime was frequently reduced to 10 grammes per hectolitre, and in this way the juice worked best.

'The appearance of this disease has not been assigned to any clistinct causes.

All the varieties attacked have been cultivated for many years in the most primitive manner. The usual method still generally followed in Brazil is to dig shallow narrow holes very close to one

\footnotetext{
* [i IG. 3.-Field of sugar-cane in New South Wales. The plants in the foreground grew from sets which were slightly
} diseased by Bacterim vascularum when planted; those in background grew from healthy sets. After Cobb. 
another in fields barely cleaned of the brushwood, still less of weeds, unploughed, undrained, needless to say never manured, seldon weeded, the eanes being never trashed, the ratoons uneared for. After taking off one or two ratoon erops, the land is abandoned for a period of not less than 3 years. 'The seed canc is frequently taken from any old abandoned jiece; no selection is ever made.

All the themes as to causes suggested by the planters and others were flatly contradicted in actual practical experience; some said, for instance, that the salt air was to blame, and the disease flid first make its appearance on the coast, but when it afterwards erept farther up country it should have died out, which it did not.

Some suggested exliausted soil, but the disease appeared in canes grown from uninfected sources in virgin and rich soil. Others put it on degenerate seed cane, and certainly to judge from the seed cane often used any imaginable disease might result, but the offspring of fine liealthy cane brought from far inland districts also suffered.

The planting of pieces of cane and tops also made no difference; the former is the alnost invariable eustom here.

In a wet season more cane was nsually attacked than in a dry season.

It is probable tlat, as has been suggested in other cases, the responsibility of its appearance must be laid on a combination of causes inducing general debility and aptitude for catching disease, rather than to any one particular cause. 'These elements of disease, if they may be so called, are like malaria in a swamp, always present and only awaiting suitable subjects.

In the absence of definite evidence as to the cause of the disease, improved methods of cultivation, namuring, advisedly not indiscriminately done, regeneration of stock by selection, the rearing of seed-cane in nurseries, were advised.

'The method adopted, however, was more heroic; as the planters could not find a cure, they threw out the Cayanna and other canes affected, and introduced varieties of foreign origin.

The dark claret coloured cane with a still darker stripe, ealled here "L,ouzier," was the prineipal kind introduced, also the "Jalanjore," and some 7o others. (As the names of these when first received were much mixed up, it is possible that "I,ouzier" is not the correct name for this cane.)

None of these new varieties had been attacked, though now growing 15 years under precisely similar circumstances as regards bad methods of cultivation, and the Cayanna is again being successfully cultivated on lands which ten years ago could not grow it. As it is a far better cane as regards yield and early maturity than the new ones, it is to be hoped this improved state of things will continue.

In 1894, M. Bonâme reported Cobb's bacterial disease of sugar-cane as common in the Nauritius, especially on a variety called La canne Bambon.

In the beginning there are no external signs. As the disease progresses growth ceases, the head shortens, the 5 or 6 green leaves remaining at the top grow paler, bleach, become yellow, and dry out. Sometimes shoots (ailerons) in greater or less abundance are pushed out of the upper nodes, but more often the whole cane dries out and dies. When the leaves begin to turn yellow, if the stem is cut transversely, little masses of viseid grayish yellow matter appear on its cnt surface and dry yellow. This gum is generally more abundant toward the top of the stem. In early stages of the disease the gum is extruded only from isolated points. In bad eases the gum is very abundant and the gummy foci unite to form large, sticky masses covering a considerable part of the section. The gun is not disseminated throngh all the tissues of the stem. It is seen only in the interior of the two large ressels wlich form the center of the fibro-vascular bundle, and is not found in the sugar-cells.

Anong other results, chemical analysis proved the amount of sugar to be less in diseased canes than in liealthy canes grown under otherwise identical conditions, as shown in table 2.

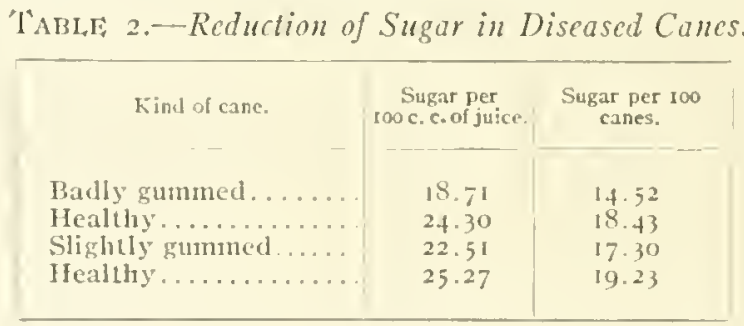


There is no record of any enltures or inoculation experiments.

In 1895 in an article on gumming of cane in the Annual Report of the Qneensland Department of Agriculture, Tryon states that the disease occurs in Queensland, and says of Cobb's Bacillus iasculamm: "Personally I also liave failed to produce the disease in healtly plants by the method of inoculation with the pure culture of the bacillus." But Tryon also says that Cobb says someone else in New Sonth Wales, wliose name is not mentioned, has succeeded in inducing the disease by means of pure-culture inoculations.

The writer of this abstract asked Dr. Cobb for details, but was unable to learn the name of this experimenter, if such there was.

Tryon studied this disease in the Burnett district and Wide-bay district (S. lat. $25^{\circ}$ to $\left.26^{\circ}\right), i$. $e$, on the castern coast of Anstralia, a few hundred niles north of the localities examined by Cobb.

His description of the signs of the disease on the foliage is in some respects confirmatory of Cobb's. They are in many respects so strikingly like those obtained by the writer from pure-culture inoculations that I quote in full, as follows:

When the presence of the disease has becn determined by the use of sets derived from a badly "gummed" crop, some of them will fail after having emitted attenuated shoots, that fail to reach the surface. Others will give rise to slender and weakly plants, which apparently struggle to survive, whilst a few will develop foliage with the individual leaves narrower and more irregular in size than if they were healthy, with the central ones yellow-green and more or less crinkled and contorted, with, at times, the central leaves interlaced in a tangled mass. A few of these leaves, again, especially the inner ones, may exhibit bright rust-red streaks in their tissue, and this may constitute a conspicuous feature. If any such plant is cut longitudinally through the point of growth, it will be generally observed that the central shoot beyond where it joins the cane proper, instead of arising in a straight, erect manner, is more or less bent and contorted, its upward tendency having been apparently hindered. Moreover, the young cane itself, immediately below the shoot, will present one or more cavities, each containing a semi-fluid tenacious pale brown substance.

Should the "sets" be the progeny of a crop of cane affected but slightly by the disease, nothing very abnormal may be noticed until the cane proper has commenced to form. Then, althongh the bulk of the plants will appear well-grown and perfectly healthy, others, though at first fully developed, will evince the presence of the affection in varying degree. The first symptom in a plant of its occurrence will then probably be afforded by a thin, pale longitudinal stripe arising in one of the onter leaves, in which the green colouration being discharged may gradually be giving place to brown. If this plant is divided by a longitudinal cut through its growing apex, nothing abnormal may yet be recognized. A plant in which the disease has made further progress will exhibit brown stripes of dead tissue one side of the central nerve, or along the margins of the outermost leaves, whilst on two or three of the inner ones will have appeared elongated rust-red streaks. If this plant be cut as beforc, very marked changes will be noticed in the tissue immediately below the growing apex. These are afforded by the presence of several cavities having ill-defined walls partly filled with an odorous yellowish substance of the consistence of pus, as well as of spots where the external tissue is becoming soft and brown to mark the site where subsequent ones may arise. 'These cavities occur in the intervals between nodes, whilst the denser tissue of which these latter are composed nnay exhibit - in small number - specks, or thread-like lines of a red colour. When still furtler advanced we may have a strong, healthy-looking plant, with a stem measuring some 2 feet 6 inches in height from the ground to where the green foliage commences. In this several of the outer leaves, and the central ones as well, have longitudinal brown stripes or bands of dead tissue extending for the greater part of their length; and, as will be seen by a longitudinal cut, the joints or internodes immediately below the apex, to a distance of from i to 2 inches, are quite hollowed out, and there is considerable discolouration and softening of the tissue generally and incipient decay, both in them and in the nodes also. In such a plant the central shoot, now almost dead, may readily be pulled ont. * * *

The disease may appear at any period in the growth of the cane, and even when it is fourteen or more months old; but these late manifestations probably generally arise when the malady is of spontaneous origin. * * * In the first instance the central leaves are quite normal in appearance, and perfectly green and turgid, but the lateral leaves are marked by broad brown longitudinal bands of dead tissue, the lowcrmost having evidently prematurely died. The eyes on that part of the stem from which the leaves have naturally fallen have shot out, and the slender shoots thus formed are already dead; the uppermost eyes, however, are still alive, and have not as yet spronted. 
As an illustration of a still further advance in the progress of the malady, a plant may exlibit the following symptoms: The central shoot and leaves are already quite dead, though still flaceid, and readily yield to a slight pull. 'There occurs also in those, on either side of it, that are still partly green, a brown band of clead tissue, proceeding along each margin; this band widens in the case of the onter leaves, whilst the outermost of all are all involved in it, being quite dead. 'The cane itself, instead of exhibiting that yellowish colonr indicative of the fact that it is already ripe, is of a dull bright-green colour above; nearer the ground it is clouded, with the same hue, but at the extreme base evinees little unusual in this respect. All the buds except those situate lowest on the cane liave spronted, some having given rise to peculiar elongated slender shoots; beneath the leaf-sheaths the buds are already dead or apparently dying. * * * On cutting any of these canes across, small bright droplets of a canary-yellow thick adhesive substance will arise from the pores distributed over the surface of the section, and in many instances will run together and coalesce. When the disease is advanced to the stage above described, some of the buds within an inch or so of the decaying sumnit of the shoot may shoot out and develop a tuft of narrow leaves; but no further growth takes place in the eane itself, tlough the lat ter may be some time before it aetually dies.

All the canes that arise from a single stool may not be affected simultaneously and to an equal extent. As an instance of this, the following occurrences were remarked in the case of an affeeted plant: All the canes liad been checked by cold when they had experienced from six to seven months' growth, otherwise the plant was remarkably robust. 'Three of then had the central shoot, and several of the lateral ones already dead. A fourth liad the leaves as well as the central shoot quite green, and all of these canes exuded droplets of gummy substance when their stems were cut across. A fifth cane - the stoutest of all -was entirely wanting in the gummy exudate, as was seen when after lopping off its top and allowing it to renain still connected with the ground, none of this gum was observable even after the lapse of some hours. In addition to these five canes, there were several suckers, some of which had formed cane, and were almost as higli as the stalks that surronnded them. These, however, even when arising alongside gummy canes, were themselves apparently quite free from disease, as no "guml" emanated fronn their cut ends.

In October I 895, in the Agricultural Gazette of New South Wales, Dr. Cobl) reported on his inoenlation experiments. The cane-disease was produced, apparently at least, by means of his Bacillus vascularm, but the inoculations were too few to be very conclusive, becanse they were made in a region much subject to this disease and also because not enough plants were held as checks.

Under the cirenmstances, $i, c$, much diseased cane in the vicinity, not less than 100 canes shonld have been inoculated and as many more held as cheeks. Cultures derived from single colonies should also liave been used for purposes of infection rather than ooze from diseased canes, althongh the author quite agrees with Cobb that the organism of ten ocenrs in practically pure culture in the interior of the diseased canes.

The reader will be able to judge of the quality of the evidence by reading the following, from Dr. Cabb's report, whicli contains all that is pertinent:

Six inoculations were made, one a check-that is, pricked with a sterilized needle only. The stools were in charge of Mr. C. N. Stevens, Manager of the Colonial Sngar Refining Company's mill at llarwood. At the time of inoculation all the stools appeared to be liealthy.

'The canes [which were inoculater in August 1893 ] were forwarded to me at Sydney in September, 1894 , and examined with the following result:

I. Mr. Stevens reported the check lost. 2. Of the inoculated canes, four were still alive, the other was dead.

All the four living canes were gummed-one slightly, but very manifestly; two very markedly; the fourth dying, and evidently from gum, though fungi had made their appearance. The gumming was most marked in the neigliborhood of the point of inoculation and above it, though it appeared throughout the culin.

Concerning the dead and dying canes, Mr. Stevens writes: "The dead canes have probably" some time or other been broken of or shaken at the root, which wonld account for their demise." 'The fact that one of the still living stalks, as reported above, was dying, and to all appearances from grmming, would suggest that death may have been caused by gumming. It is impossible to say, lowever, from the dead and dying canes in their present dry condition, what was the cause of deatli. the cances were in five different stools. Mr. Stevens writes: "All the canes in those stools are now 
more or less gummed." The question arises: Would these five canes have become diseased if they had not been inoculated? As stated above they appeared at the time of inoculation to be perfectly healthy, and this, of course, was the reason why they were chosen for the experiment. This facttheir apparent healthiness-is in favor of their remaining healthy. The gunming in the canes forwarded to me was most marked near the point of inoculation and above it. 'This fact is in favor of the disease originating from the inoculation. As reported below, canes were also inoculated with a fungus. In the same stool two stalks were inoculated with microbes. In the case of this stool the two stalks inoculated with the fungus showed no trace of gumming, thongh they were examined minutely. * * * This fact is again strongly in favor of the gumming which appeared in this stool having originated from the [bacterial] inoculation.

Against these facts and deductions must be set the fact that a large part of the cane on the Lower Clarence, where these experiments were made, suffers from gumming. I think it may fairly be said that the canes taken for experiment were not very liable to beconne gummed, as they were in good garden soil not before under cane, and had good care and were derived from what were supposed to be sound crops.

To the writer the strongest evidence adduced by Cobb is that the gumming was nost pronounced in the vicinity of the inoculations and upward therefrom. I might also add that after seeing gummed cane and examining the yellow ooze microscopically, I became at once less skeptical, and an $110 \mathrm{w}$ [this paragrapl was written in I902] strongly inclined to believe that Dr. Cobb is correct in his conclusion as to the eause of this disease, although his inoculation experinents are not entirely conclusive.

At the close of this paper, which is largely a repetition of statements made in the previous one, Dr. Cobb says that as a result of lis former publication it has been shown that cane in Java, New Guinea, Brazil, Mauritius, etc., either suffers now or has in the past suffered from what is beyond reasonable doubt the same discase-gumning.

In I 902, R. Greig Smith published, in Australia, a paper on "Gummosis" of the sugarcane. He isolated the organism and described its growth on various culture-nedia, but said nothing of any inoculations. His studies were mostly on the nature and origin of the gum and were carried on along the lines of qualitative chemistry. Through the reactions of the gum, which were for the most part the same as those of the bacterial slime obtained from pure eultures on agar, he came to the conclusion that the two were identical and consequently that the gum in the diseased canes was of bacterial origin and not a pathogenic secretion of the plant upon which the bacteria lived saprophytically. The following paragraph is quoted from his paper:

When a pure culture of the bacterium is smeared over the surface of neutral cane-gelatin or agar in a suitable vessel and incubated, a luxuriant growth is obtained after the lapse of about a week. The culture is precisely similar in appearance and consistency to cane-gum. Both have the same soft buttery appearance and gummy consistency and both slowly mix with water to form a pale yellow opalescent solution. The opalescence is due to the suspended bacteria, from which [solution] it is rather difficult to separate [them] without at the same time removing the gum. The separation can not be effected by filtering throngh paper, and the usual coagulating agents coagulate both gum and bacteria. Aluminum hydrate, for example, forms an insoluble compound with the gum. An attempt was made to clarify the suspension by heating it up to three atmospheres in the autoclave, a proceeding which was successful with another gum-forming bacterium, but the suspension was unaltered. Eiventually the bacteria were separated by filtration through porous porcelain. A clear solution of the gum was thus obtained, but at the same time it was noted that a considerable amount of the gum remained on the porcelain, adhering to the bacteria, even after the suspension had been boiled for some time to diffuse the gum. The filtered and clear solution was tested sinniltaneously with an opalescent suspension, and it was found that the two behaved similarly to the addition of the various reagents, from which we must conclude that in the suspension the bacteria are inert, and for purposes of identification of the gum it is unnecessary to separate them.

He gives the following table (table 3 ), showing the chemical reactions of the gum taken from cane and of the bacterial slime formed in laboratory cultures: 
TABLE 3.-Chemical Behavior of Cane Gum and Bacterial Slime.

\begin{tabular}{|c|c|c|}
\hline Substance. & Cane-gum. & Bacterial slime. \\
\hline 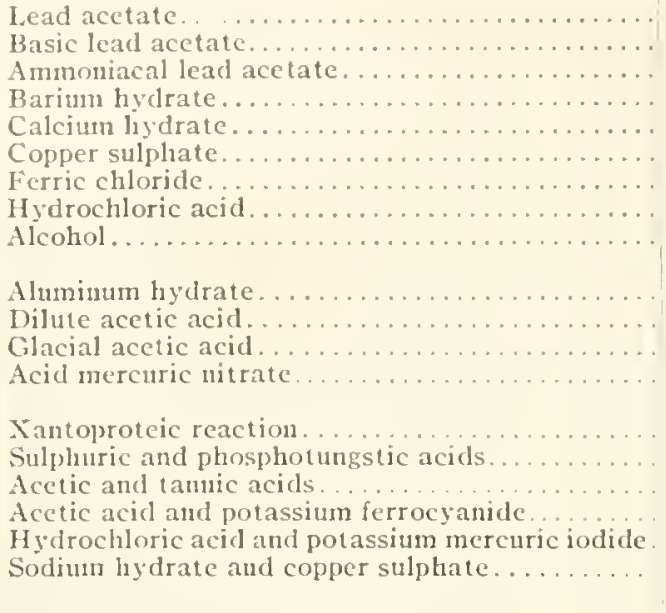 & 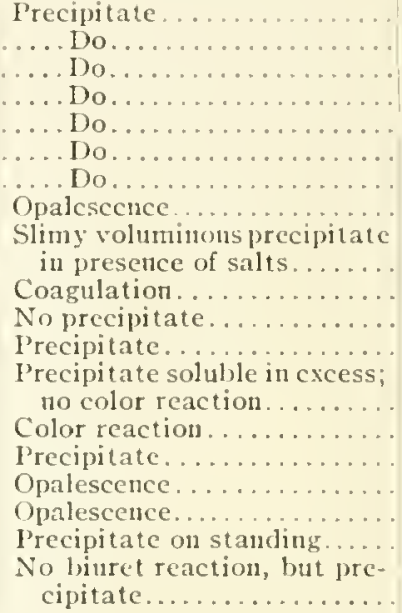 & $\begin{array}{l}\text { Precipitate. } \\
\text { Do. } \\
\text { Do. } \\
\text { Do. } \\
\text { Do. } \\
\text { Do. } \\
\text { Do. } \\
\text { Opalescence. } \\
\text { Slimy voluminous precipitate } \\
\text { in presence of salts. } \\
\text { Coagulation. } \\
\text { Opalescence } \\
\text { Precipitate. } \\
\text { Precipitate soluble in cxcess; } \\
\text { no color reaction. } \\
\text { Color reaction. } \\
\text { Precipitate. } \\
\text { Opalescence and prccipitatc. } \\
\text { Opalescence. } \\
\text { Prccipitate. } \\
\text { No biuret reaction, but pre- } \\
\text { cipitate. }\end{array}$ \\
\hline
\end{tabular}

The weakness of the solutions, owing to the linited amount of cane-gun at the disposal of the experimenter, accounts, he says, for the absence of perecptible precipitates on the addition of clinte acetic acid, and a mixture of acetic acid and tannic acid. No reactions were obtained with $\mathrm{KI}_{3}, \mathrm{AgNO}_{3}, \mathrm{KOH}, \mathrm{BaCl}_{2}, \mathrm{NaOH}$, conc. $\mathrm{HCl}$, picric acid, and Adamkiewicz reagent.

On precipitating the aqueons suspension [of the gum] three or four times with alcolrol an opalescent alcoholic solution is obtained, from which the gum can be precipitated by small quantities of ncutral salts, such as $\mathrm{NaCl}$. 'This fact, together with the reactions obtained with sone of the albuminoid reagents, suggested the similarity of the gum to the Mucins. 'That the Zoogloea-slime of bacteria consists of mucin, or a substance nearly allied to it, has already been suggested, but there are many points of difference between the bacterial slime and the mucins. 'The crude gun obtained by precipitating the cultures with alcohol contains 6.1 per cent of ash and 3.08 per cent nitrogen in the asli-free, clry substance. Repeated precipitation with alcohol, and also filtration of the gum from the accompanying bacteria, would undoubtedly lower this percentage. It is, therefore, apparent that the nitrogen content alone is sufficient to distinguish the slime from mucin or the allied mucinoids.

In connection with this work Greig Smith made a variety of observations on the cultural characters of the organism, and citations will be found under the heading "The Parasite."

When Dr. Went visited the West Indies for the Dutch government in the winter of 1902, the writer asked him to look particularly for this disease, but he reported that he did not find it, although he said he had seen it in Java, where he had not regarded the organism as a parasite.

In 1904, following some very successful inoculation experiments, the writer published a slıort paper on this disease, in the second part of the Centralblatt für Bakteriologie. This was subsequently translated into English and published in full by Cobb in his Third [Hawaiian] Report on Gumming of the Sugar-cane (pp. 12-22).

Cobb's Hawainan report closes the listory of this subject so far as known to the writer. It contains a summary of Cobb's earlier papers, the transhation referred to, a review of Greig Snith's work, and sonne additional observations which will be made use of elsewhere. See also in this connection "Sereh" (p. 72), "Top-rot" (p. 81), and "Polvillo" (p. S5) 


\section{SIGNS OF THE DISEASE.}

The most conspicuous signs of this disease are dwarfing, striping of the leaves, dying of the tops, decay of the heart (terminal bud), and the appearance of a yellow sline or gum in the bundles of the stem and leaves. Many of the bundles are also stained red. Microscopic examination shows that this gum contains millions of bacteria. Cobb and Bonâme agree that there is also a reduction of the sugar-content.

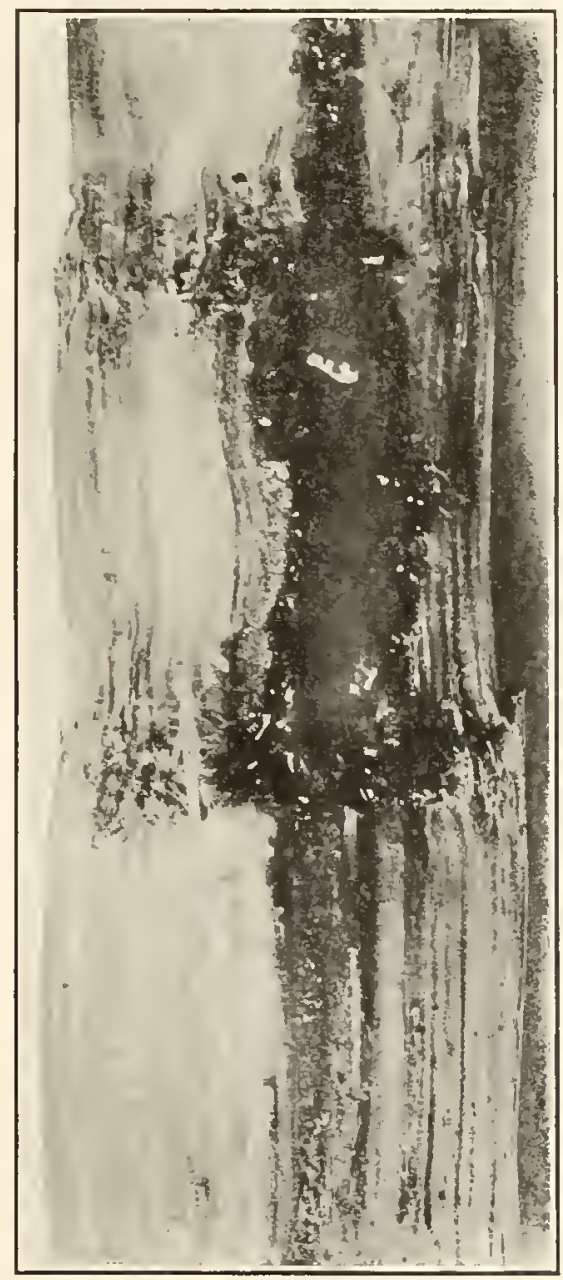

Fig. 4.*

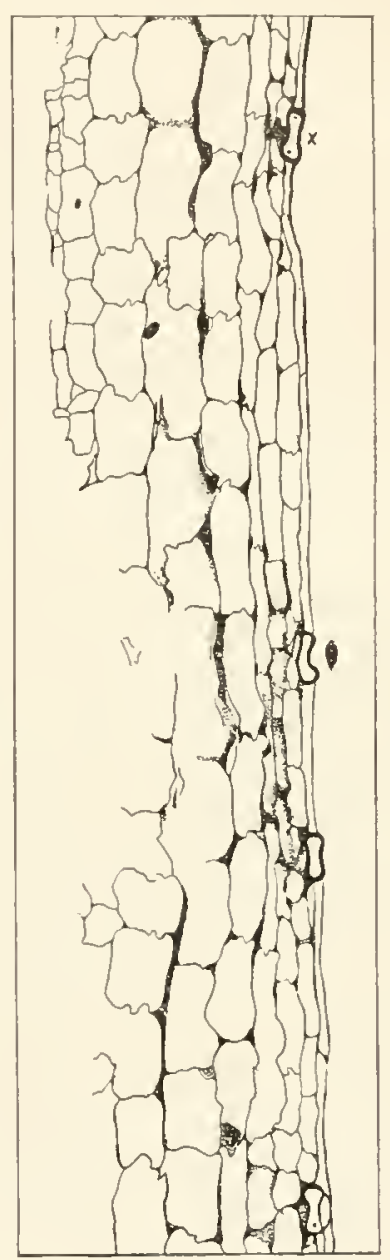

Fig. 5.†

The disease is primarily one of the vaseular system, but in advanced stages the parenchyma is attacked, especially the soft tissues just below the terminal bud, and cavities are formed which are filled with the yellow bacterial slime. Sometimes these cavities contain as much as a teaspoonful of the slime (fig. 4). In the later stages of the disease, the

*FIG. 4.-Rot of sugar-cane due to Cobb's disease (Baclerium zascularum). Longitudinal section through the upper part of stem of plant No. 6 just under terminal bud, showing a closed bacterial cavity which was filled with yellow slime (bacteria). Enlarged 3 times.

$\uparrow$ Fig. 5. - Radial longitudinal section through a leaf-sheath of sugar-cane from inoculated plant No. 4 , showitug general occupation of the intercellular spaces by bacteria, which are oozing to the surface through stomata, 2 months from date of inoculation, and several feet from places inoculated (see text). Outer face of sheath at left. Section taken between vascular bundles which are filled with the bacteria. For condition of bundles in sheath as shown on cross-section, see fig. 7. Drawn with Abbe camera, Zeiss 3 mm. I. 4o 11. a. apochromatic objective, and No. 2 compensating ocular. Slide $466 \mathrm{H}_{9}$. For a detail at $\mathrm{x}$, see fig. 6 . 
interior of the leaf-sheaths is rusty brown and covered with the sticky bacterial slime, which is also sometimes seen oozing from other portions of the leaf. 'This slime oozes from the stomata (figs. 5, 6, 7). In very bad cases the leaf-sheatlis above the terminal bud are completely stuck together, so that the growing shoot can not elongate naturally, but is forced to bend on itself repeatedly and push out sidewise through the sheaths (figs. 8, 9). 'the gumming together and pressure of the outer leaves around the terminal bud result in the doubling, twisting, and bulging of the main axis and eventually the stopping of the terminal growth. In the most pronounced cases the terminal shoot enveloped in its wrappings has a club-shaped appearance. In such cases there is sometines a development of lateral shoots (figs. 1O, I1) and of aerial roots.

A very interesting sign, also mentioned by 'Tryon in his paper, is that of the red bundles. Wre liave heard much about red bundles in connection with the "Sereln" disease of sugarcane in Java, and, indeed, this reddening has been known as a subordinate (oxidation)

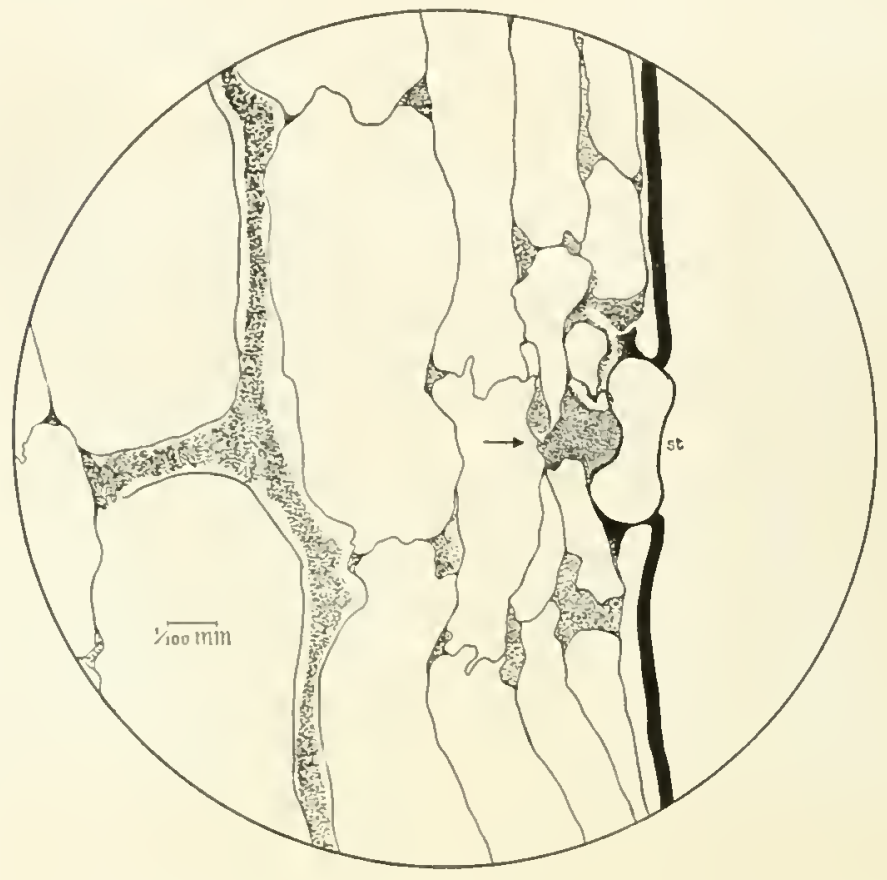

Fig. 6.* phenomenon in many diseases of the sugar-cane, but never has the writer seen it more beautifully developed than in canes inoculated with pure cultures of Bactorium zascularmm. In all the "common green" canes, diseased as a result of these inoculations, many red bundles were present (see plates I, fig. 4 , and I I, fig. I). It was a very striking sign of the infection and could be ascribed to no other cause. The writer regards it as a reaction on the part of the plant. According to Prinsen Geerlings, there exists in the cellulose of the normal sugar-cane a nentral, colorless substance, not easily soluble, which becomes yellow in an alkali but changes to red and funally to brown when brought into contact with air. The nature of this substance is unknown. In the niajority of these red bundles bacteria were no longer to be seen: In place of them was a red formless mass (figs. 12, 13). Red and yellow bundles were intermingled in the stems, however, and often the same bundle would be both red and yellow, i.c., variegated, the yellow parts being filled with bacteria, $c$. g., lower part of fig. I 2 . The same phenomenon has been observed in maize inoculated with Bactcrim stewarti, except that in the latter case the variegated bundles were yellow and brown. The red pigment was most pronomnced in the nodes and immediately under them (fig. $1 \mathrm{r}$ ). This was observed in many canes. Without exception there was more pigment in the upper part of the internode than in the central or basal portion, but by far the greater part was in the nodes, where often nearly all of the bundles were as red as blood. Probably this localized pigmentation is due to greater aeration through the leaf-traces centering in and immediately under the nodes. $\dagger$ In the sugar-cane, as in the sweet corn, the pigment does

${ }^{*} \mathrm{~F}_{\mathrm{rg}}$ 6, $-\mathrm{A}$ detail from fig. 5 at $\mathrm{x}$, showing the baeteria multiplying in the intercellular spaces and pushing toward the inner surface of the leaf-sheath, $i$. $e_{\text {. }}$, in the dircetion of the arrow. st, stoma.

tWent has shown that the leaf-iraces take a downward direction soon after entering the node. 


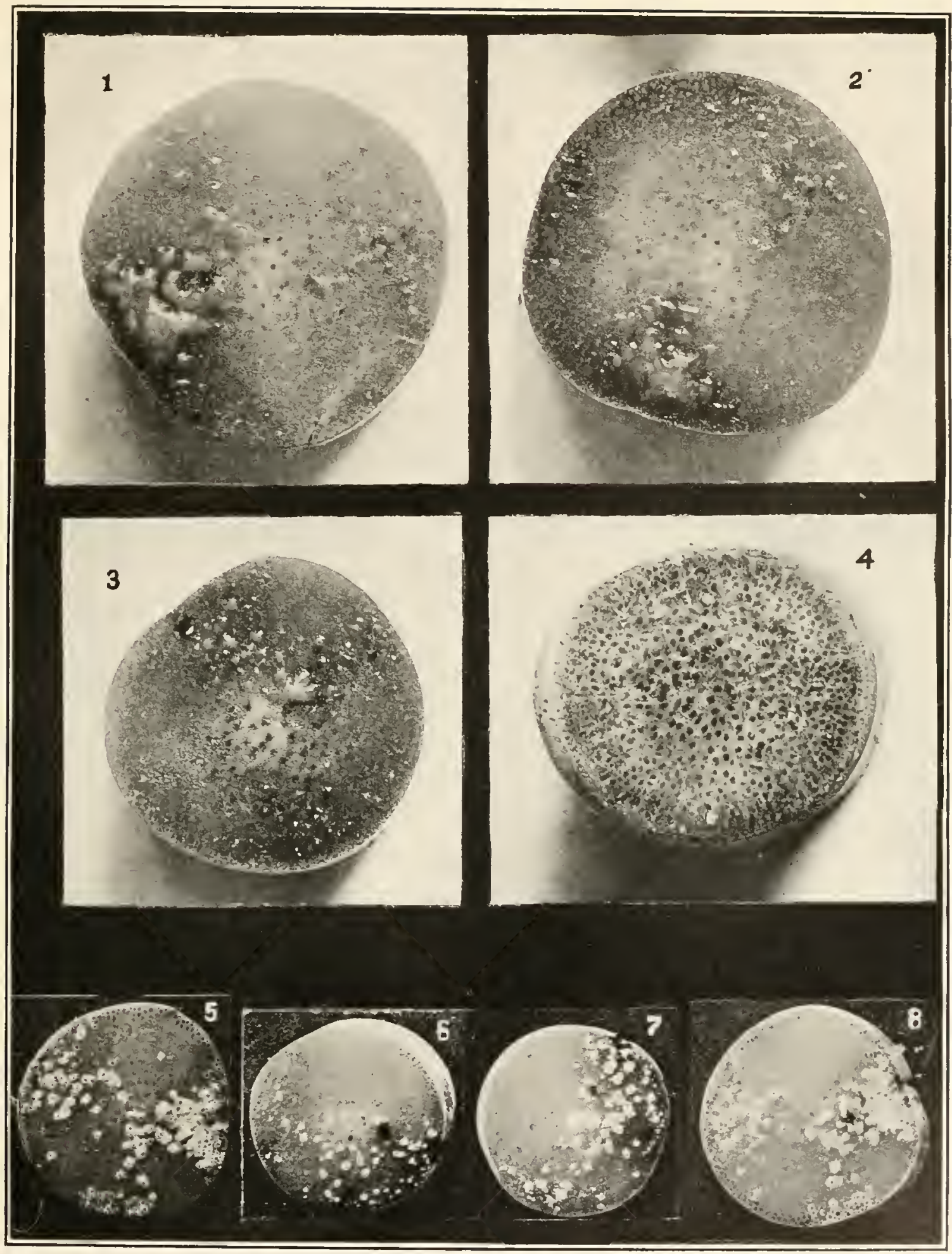

Cross-sections of sugar-cane inoculated with Bacterium vascularum.

Figs, 1, 2, 3 show bacterial ooze from vascular bundles of fresthly cut stems. Figs. I and 2 are from plant 6 , fig. 3 from plant 8 . $\times 3$. Fig. 4, section in vicinity of a lower node, sbowing dark red stain in vascular strands. From plant $6 . \times 3 .$, Figs. $5,6,7,8$, sections of reddened bundles; on one side is a bacterial cavity npening to the surface. $\times 1.75$ circa. Plants inoculated by needle-pricks, Feb. 6 . 1903, on the blades of the leaves, 2 to 3 feet away. Time about 2.5 months. 
. 
not appear in the first stages of the disease, and the writer is inclined to think that the reddening of the bundles is a later stage tlan the yellowing. Valeton makes the same observation respecting Sereh. Plates poured from bundles showing red ooze yielded only

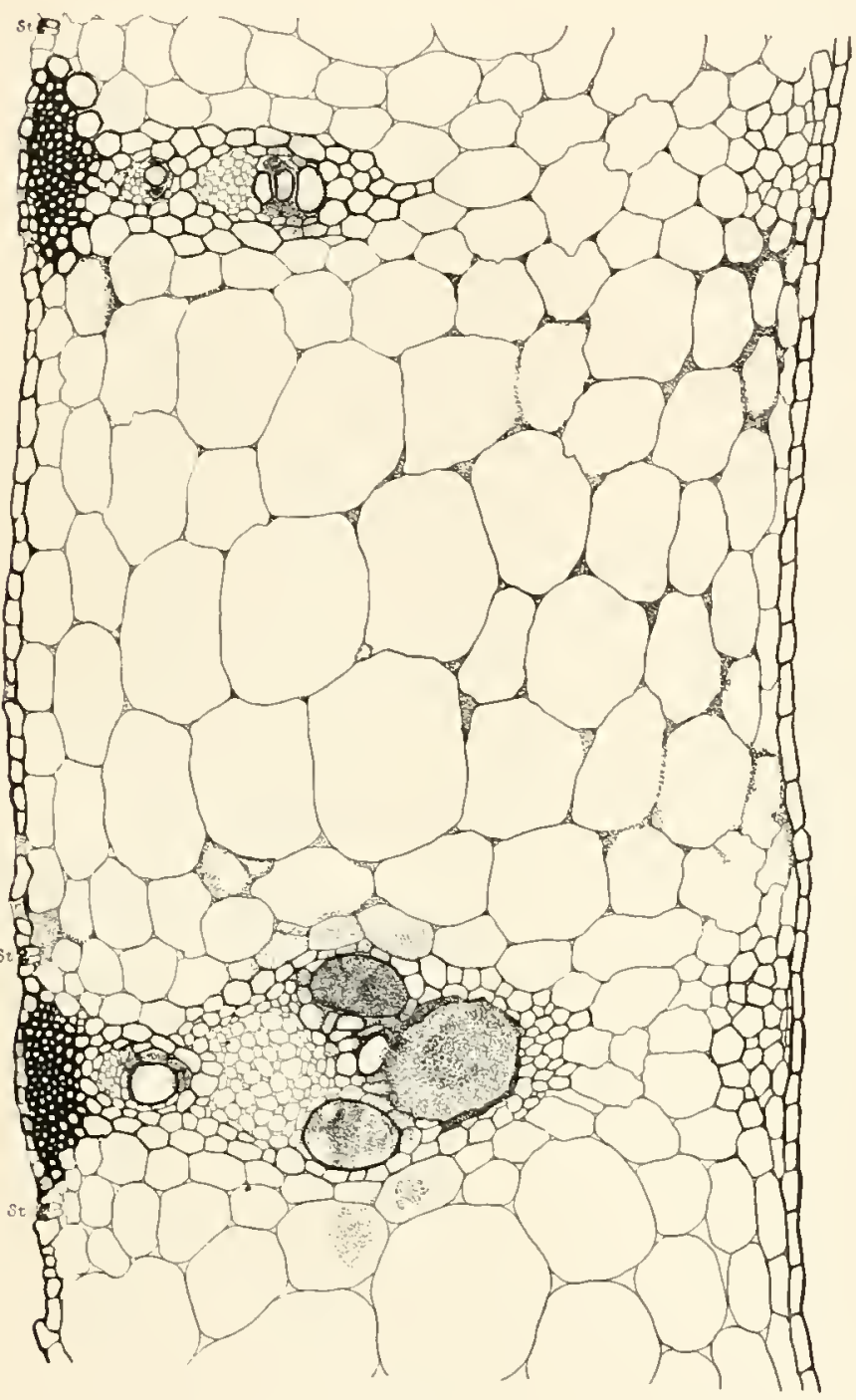

Fig. 7.*

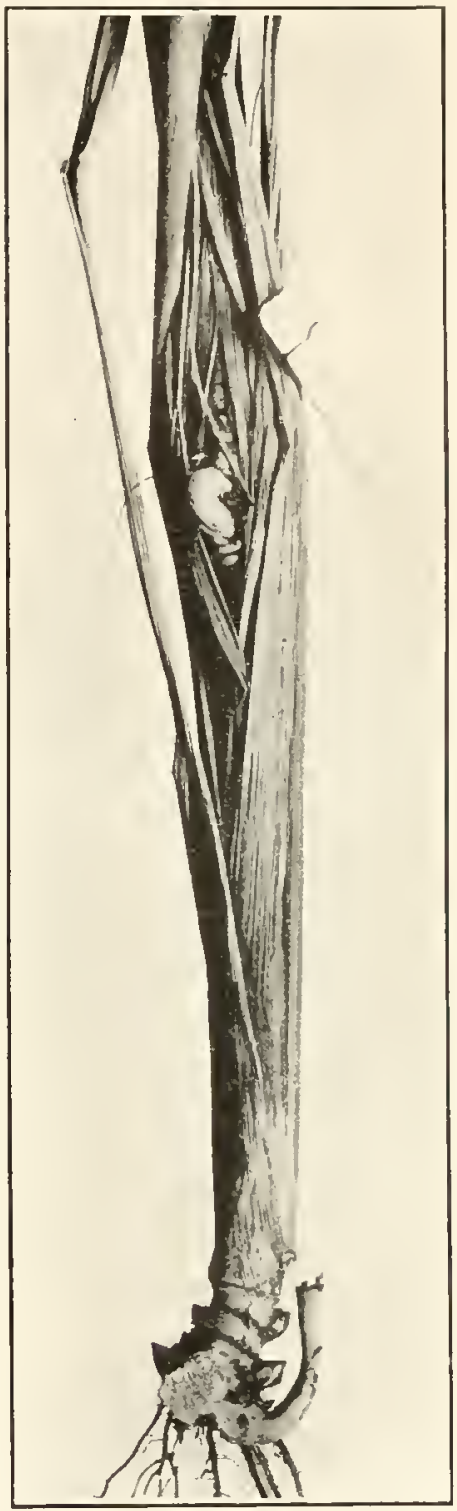

Fig. $8 . \dagger$

the yellow colonies of Bucterinm z'ascularmm, indicating that this red ooze was due not to red bacteria, but to a red reaction on the part of the host-plant. Perliaps the formation of this pigment would not be as noticeable in all varieties of sugar-cane as in "conmon

*FIG. 7.-Cross-section of a leaf-sheath of inoculated sugar-cane No. 4. showing bacterial occupation of bundles and of intercellular spaces of the parenchyma. This is not an inoculated leaf, but one higher up and infected from the vascular bundles of the stem. There was abundant bacterial ooze on the inner face of this slieath (right side). Slide $466 \mathrm{~K} \mathrm{I} 2$, upper row, sccond section from the left. Drawn with Zeiss $8 \mathrm{~mm}$, apochromatic objective, No. 12 compensating oeular, and Abbe camera.

$\nmid$ Fig. 8. - Inoculated cane-plant No. 9 at the end of 10 weeks, showing the doubled-up terminal bud pushing through sidewise, owing to the fact that the leaves above it were gummed together by the bacteria. Buds at base pushing abnormally. 


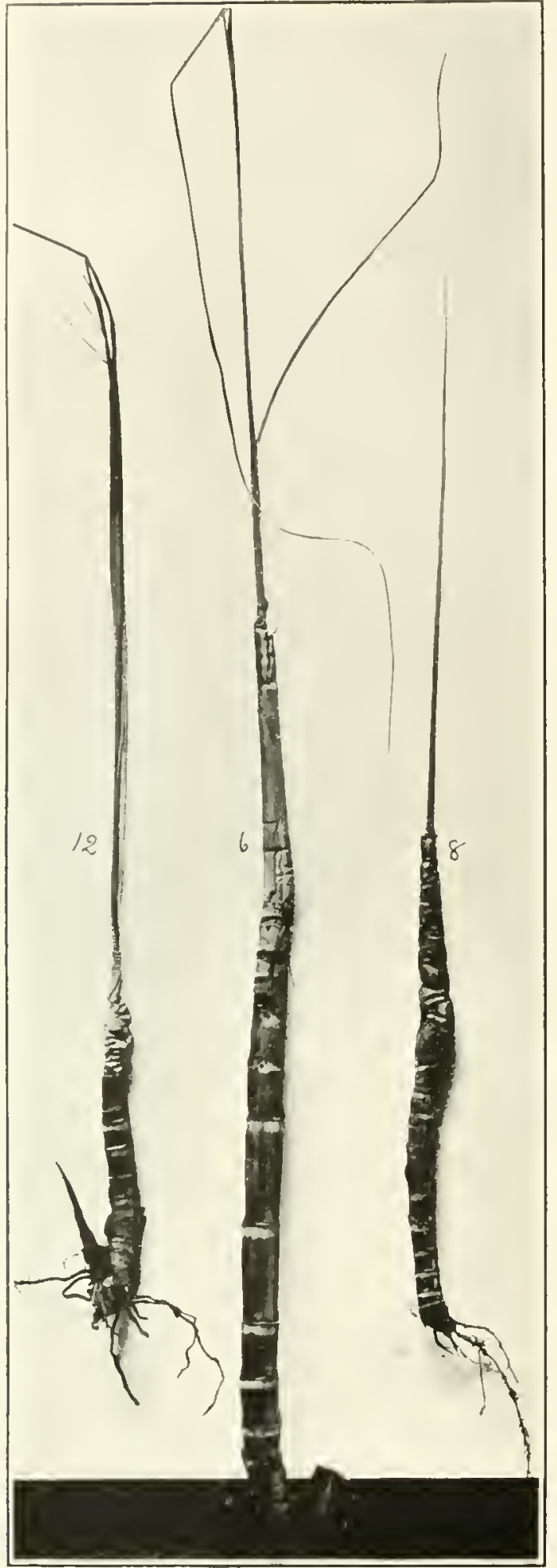

Fig. 9.* green" cane. It is not a sign peeuliar to this disease, but appears in diseases of an entirely different nature. The writer saw well-marked cases of it at the Harvard Gardens, on the Soledad Estate near Cienfuegos in Southern Cuba, in the

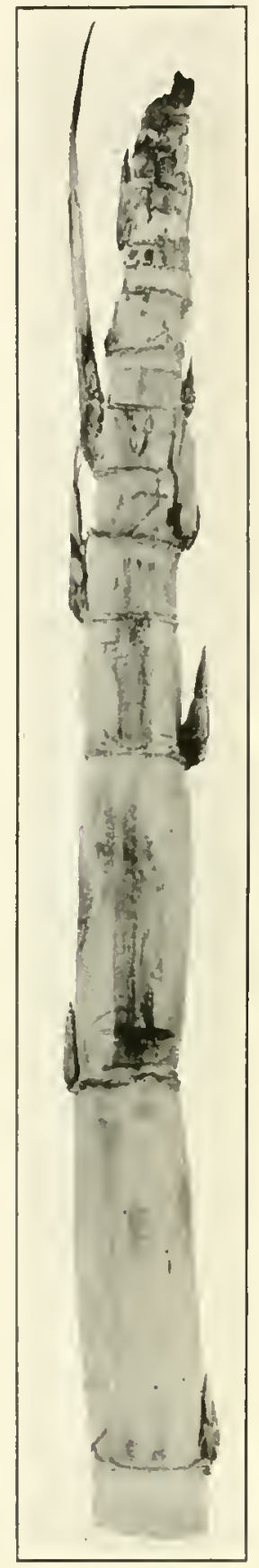

Fig. 10.† progeny of canes in1ported from the last Indies, but there was no accompanying yellow bacterial ooze. Possibly this disease was Serel. In order to be sure one is dealing with the gumdisease, one must find the vellow hacterial slime in the bnndles. This is usually an easy task, except in the case of very resistant canes. When one is in doubt samples of the suspected canes slould be steamed ancl then examined (Clark).

A very conspicuous sign of the disease in the "common green" cane 11sed for the writer's first set of inoculations was striping of the leaves. In the inoculated leaves white or yellowish-white stripes extended upward and downward from the pricks. In places, in the white stripes, there were very often rust-brown spots and streaks. Later these becane reddishbrown and finally dull-brown and dead, but the etiolation always preceded the drying out. Similar

*Fig. 9--Cobb's disease of sugar-eane: l'ants 6,8, and a stripped of leaves to show abnormally short internodes and zigzagging of shoot-axis on itself in efforts to grow through the gummy inclosing leaf-sheatlis. These plants are shown in pls. 2 and 3 . Nos. 6 and 12 have sent out basal shoots. The bacterial cavity in fig. 4 was from No. 6.

tFIG. 10.-Common purple cane stripped of leaves to show abrormal pusling of buds. IJant No. 38 , inoculated May 5, 1903, pholographed Aug. 8, 1903. 
white or pale stripes appeared as secondary signs in the uninoculated leaves of the same shoot and in young shoots from stools bearing inoculated diseased canes. Etiolation has been less marked in the other varieties tested, but they liave in erery case been more resistant to the disease.

All of these conclusions are based upon pure-culture inoculations made in Waslington hot-houses, the writer never having seen the disease in the field.

Since premature development of the male in-

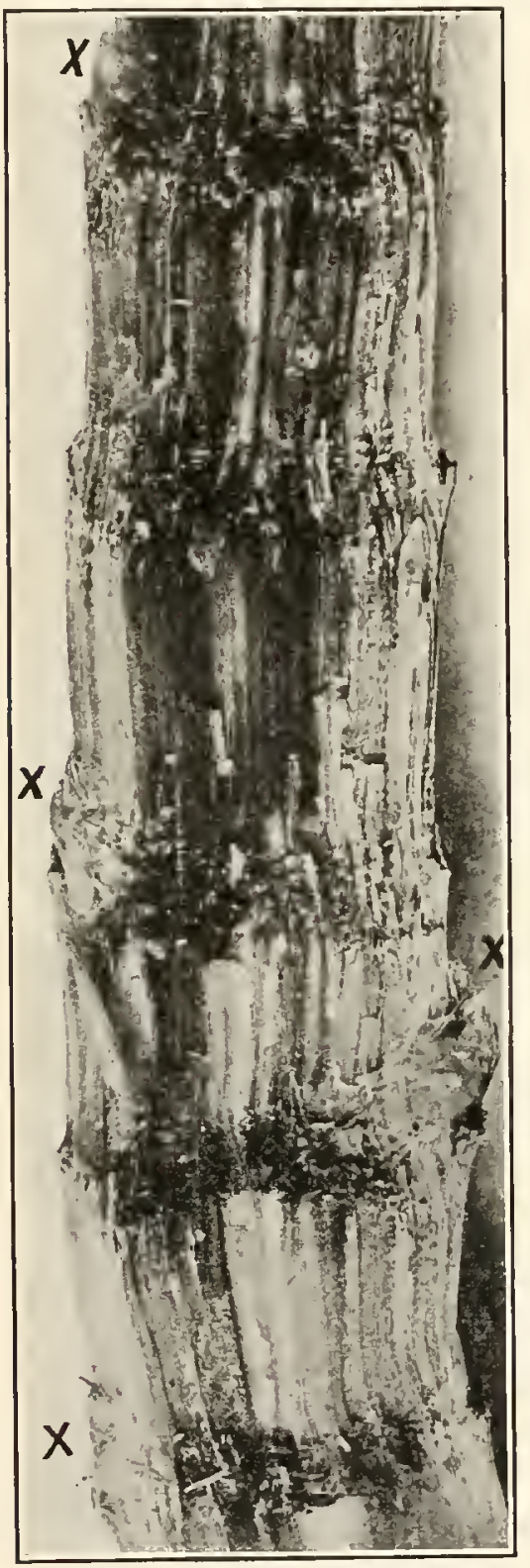

Fig. 11.* florescence is one of the striking signs in sweet maize attacked by Bacterium stewarti, and since an inclination to bloom is also a conspicuous feature of sugar-cane attacked by Serel, the writer has been at some pains to learn whether it occurs in Cobb's disease. Cobb does not mention it, neither does Tryon himself, but in Tryon's paper "arrowing" is mentioned by several

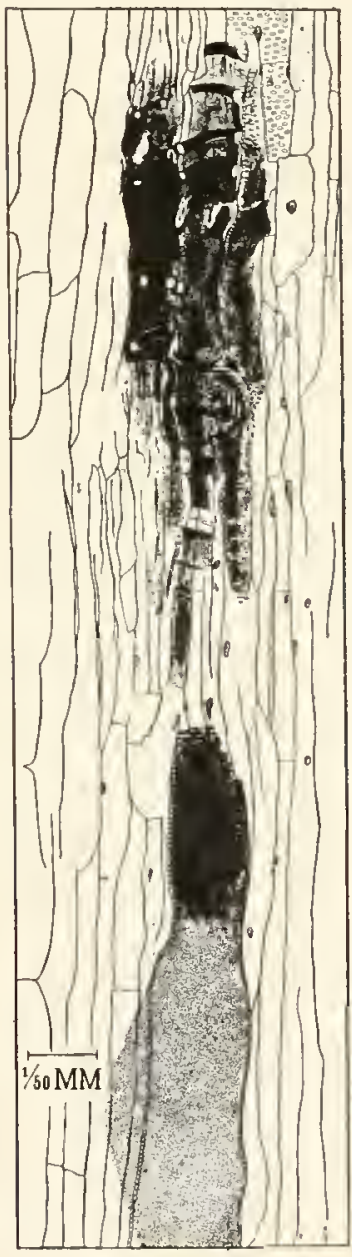

Fig. $12 . \dagger$ planters as one of the ge11eral signs of deterioration in the widely planted Rappoe or Rose Bamboo cane, and these men were planters in just those districts of Queensland where the "gum disease" prevails extensively. I quote from them as follows respecting this variety, which, at that time, was the common cane of Queensland :

Moreover, the plant was tending to beconne shorter lived, a feature that appeared to be evinced by its frequent arrowing. Arrowing seemed to be the last event in the life of the plant-anindication that it had arrived at its term of life. Formerly an "arrow" was quite a curiosity, especially in the case of cane grown upon rich scrub soil. In fact it might be said that Rappoe generally did not arrow. Now it arrowed conmonly. (E. Young, of Tiairymead.)

Until three seasons ago he scarcely remembered to have ever seen an arrow; now, if the plants were mature, nearly the whole plantation arrowed. (H. O. Nott, of Windemere.)

For some years past the cane has arrowed to a larger extent, especially in the sandy flats, and much more so than in former years. (Mr. McGuigan, Island Plantation, Mary River.)

*FIG. II.- I, ongitudinal section through basal part of inoculated sugar-cane 8 or 12 , showing red nodies (dark cross-stripes) and buds pushing at $\mathbf{x}, \mathbf{x}, \mathbf{x}, \mathbf{x}$. Photographed about May $6,190,3, i . e, 3$ months from date of inoculation.

$\lceil$ FIG. I 2. - Longitudinal section throngh a mottled (red and yellow) bundle from the stem of a sugar-eane inoculated with Bact. vascularum, showing how the bacteria fade out above into an amorphous red mass. Slide 310 ( 17. for a detail see fig. 26 . 
Others, as might be expected, state that they have observed no evidence of deterioration in the Rappoe cane. Arrowing is considered by one of these men as a sign of early ripening. Another had observed is years before that the cane would arrow where the land was dry and sandy and nowhere else on the plantation.

'To the following question: Have youn noticed any ten-

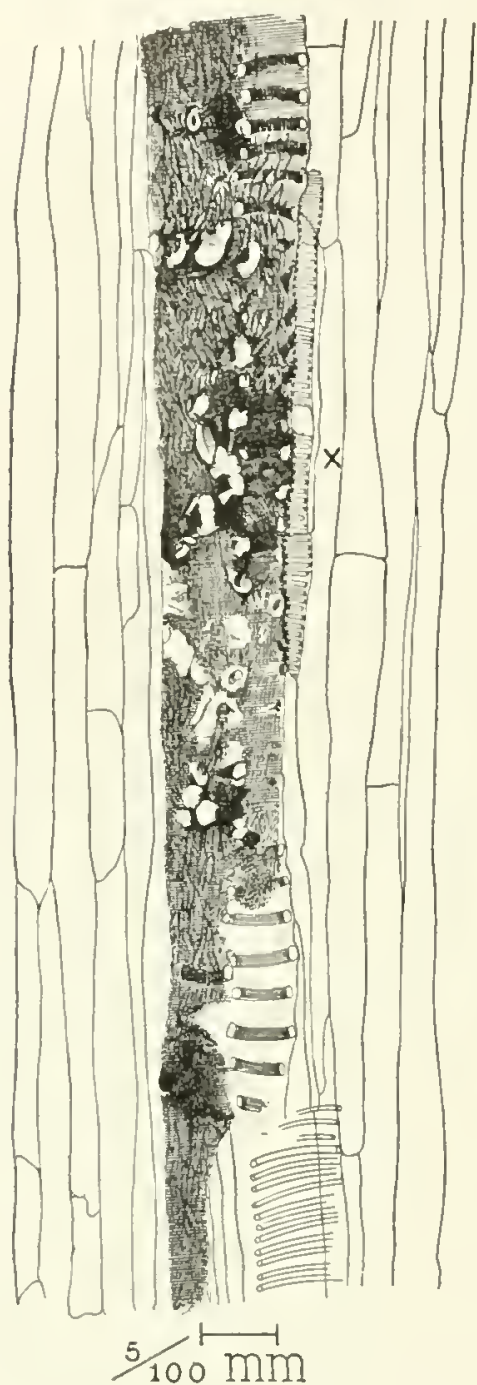

Fig. 13.* dency toward premature blossoming in sugar-cane attacked by your bacterial gun-disease? Cobb replied as follows:

No; I can not say that I havenoticed any earlier blossoming, but it might have occurred without my liaving noticed it. 'The clances of blossoming are reduced by the method of growing cane, the object being to prevent blossoning. Nevertheless the tendeney might be there and, as the actual blossoming is prevented by the harvest, the tendency might escape notice. 'There is a tendency to what might be termed premature ripening of the cane, that is, the stalk takes on the ripe colors at an earlier stage. 'This of course is a feature of many plant diseases.

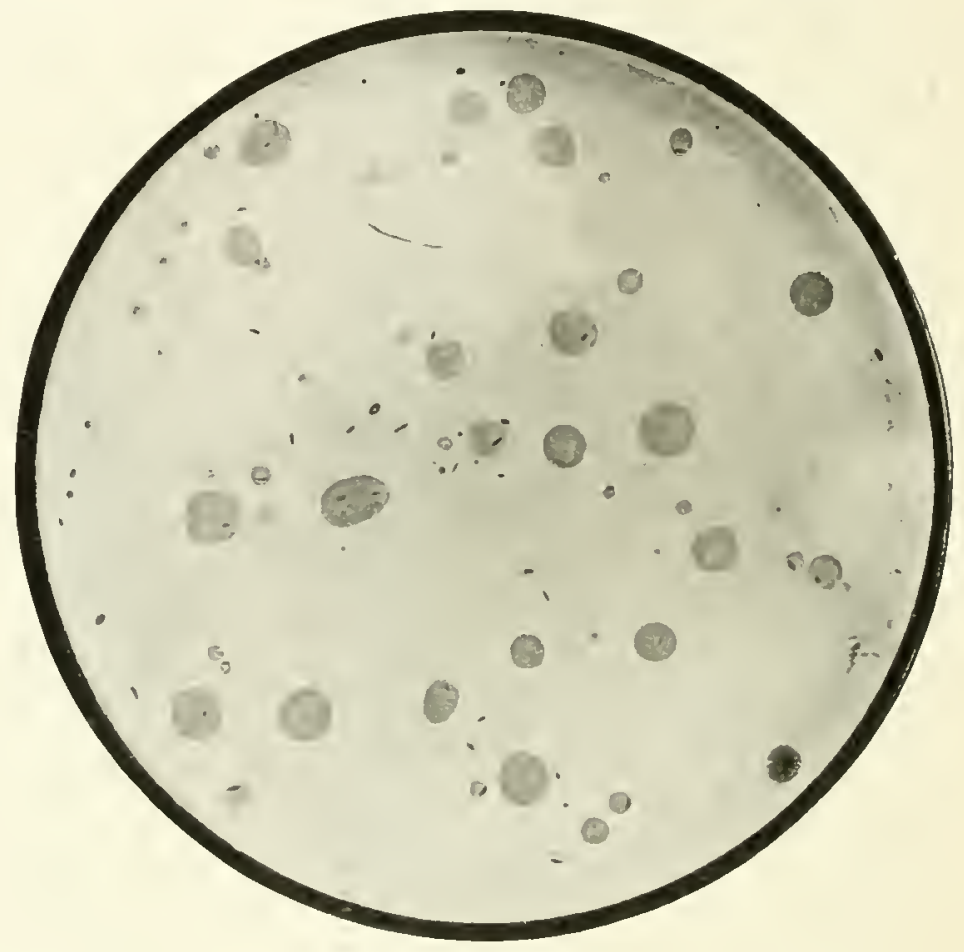

Fig 14. $\dagger$

*l"IG. 13.--I.ongitudinal section of stem of sugar-eane inoculated liehruary 6,1903 , showing red stain in an affected bundle. There are no lacteria in the part here shown except the vague ontlines of some at level of $\mathbf{x}$. Slide 310 (20, lower left-hand eorner.

†ig. It - Petri-dish poured-plate of Bucterimm vascularmm in nutrient agar, stock 716 . This plate was made directly from yellow sline taken from the interior of "gummed" sugar-cane received from New Sontl Wales in Oetober 1902. Plate poured Oet. 16 , photographeled Oet. 30 lyg transmitled light. The organism grew slowly (temperature alout $23^{\circ} \mathrm{C}$.). 


\section{ETIOLOGY.}

This disease is caused by Bacterimm vascularmm (Cobb) Greig Smith, a honey-yellow, one-flagellate organism, which forms the yellow slime always present in the vessels of diseased plants. It is a short rod occurring singly, in pairs, fours, or eights (end to end), and it often exists in practically pure culture in the fibro-vascular bundles of the diseased sugar-cane. The constant presence of this particular yellow organism in the discased cane goes a long way toward establishing a causal relation, or would if it could be shown that nothing else is constantly or usually present. The writer knows, however, from personal observation, that other bacteria are sometimes present in the vessels, and Dr. Cobb's paper leads one to suppose that "traces" of other organisms are usually present in some part of each discased cane. There are many parts of the cane, however, where Bact. vascularum exists in pure culture (Cobb, EFS.), and the fact that no other organism is necessary to the production of the disease has been proved conclusively by the writer's successful pureculture inoculations.

In October 1902, the writer received from the Richmond River district, Australia, through the courtesy of the Commissioner of Agriculture of New South Wales, three diseased canes, from two of which he had no difficulty in obtaining pure cultures of the organism by means of Petri-dish poured plates. No attempt was made to get cultures from the most badly decayed of these canes, because in places the bacterial ooze was nearly white, indicating an extensive mixture of organisms in the stem.* Nine Petri-dish poured plates were made from the interior of each of the other canes. One set of plates gave in addition to Cobb's organism a mixture of other things, mostly white bacteria of several sorts, but also colored colonies and molds; the other set of plates yielded practically pure cultures of Cobb's organism (fig. 14).

Cuttings from healthy canes were obtained in November I 902 from southern Georgia and were planted in a hot-house in Washington. Before planting, the canes were shortened at each end and inspected critically by the writer. All were frce from Cobb's disease and otherwise sound. Shoots from these canes were inoculated early in February 1903, witl slime from potato subeultures of the yellow organism derived from the Australian cane. These inoculations succeded beyond expectation, the canes developing local signs in a few days. Stripes extended up and down from the pricked part of the leaves and in one variety constitutional signs of a pronounced and typical sort appeared a few weeks later, tlie same being preceded by the enormous multiplication of the honey-yellow bacterium, first in the bundles of the inoculated leaves and later in those of the main axis of the cane and those of the uninoculated leaves. From the interior of the stem of several of these inoculated plants the organism was again obtained in pure culture. Inoculations made with subcultures of the organism thus isolated from the artificially infected cane were likewise successful, and the bacterium was again isolated fron the discased cane in pure cultures.

\section{INOCULATIONS.}

SERIES 1, 1903.

The first set of inoculations ( 12 in all) was made on February 6, into common green cane. The inoculations were made by means of ncedle-pricks on the leaf blades about I to 2 feet from the stcm. Two leaves were inoculated on each plant, those selected being about the tenth or eleventh from the base of the plant. About 20 to 30 fine prichs were

*Respecting these canes Dr. Cobb makes the following statement in his Third Report: "There can not be the slightest doubt as to the identity of the organism eultivated by Dr. Smith and inoeulated by him into American canes. * * * The second shipment was attended to personally by myself after it had been forwarded to me by my friend Mr. A. C. Barry, manager of the Broadwater sugar-mill, Richmond River, who at my request seleeted the eanes and forwarded the same to Sydney. They were there unpacked, and sealed up with sealing wax and repacked at my laboratory. I examined the gum. The organism was the same species as that described in 1893 and reported on subsequently as the cause of the newly discovered disease for which I proposed the name "Gumming of the sugar-eane." 
made on each leaf. some in the midrib, but the majority in the tissue on either side of it. The pricked area covered abont $+\mathrm{sq}$. cun. Three subcultures fron as many separate yellow colonies on the plates poured from the Anstralian cane were used. Many leaves were pricked as checks, but these never developed any disease. Until nightfall the inoculated leaves were protected from the light by paper, but the air was not shut off. A senitropical temperature was maintained in the greenhouse and the plants grew rapidly, an important factor. Three weeks after the bacteria were introduced by the needle-pricks the inoculated leaves showed white stripes, in which reddish or brown dead spots and stripes soon appeared. These stripes had their beginning in the inoculated part of the leaf and slowly spread upward and downward. For some weeks there were no further signs of infection; then white stripes appeared on other leares (uninoctulated ones on the same shoots) and, somewhat later, the red or brown stripes, with shriveling of the leaf-parenchyma. At this time the plants were considerably dwarfed, and this nanism finally became very marked (fig. I 5 ).

The condition of these plants at the end of two months (April 3) was as follows:

(1) The leaf $I b$ is dead from the punctures down to the sten on each side of the midrib. The distance from the pricked area to the top of the sheath is 19 inches. 'The length of the slieath itself

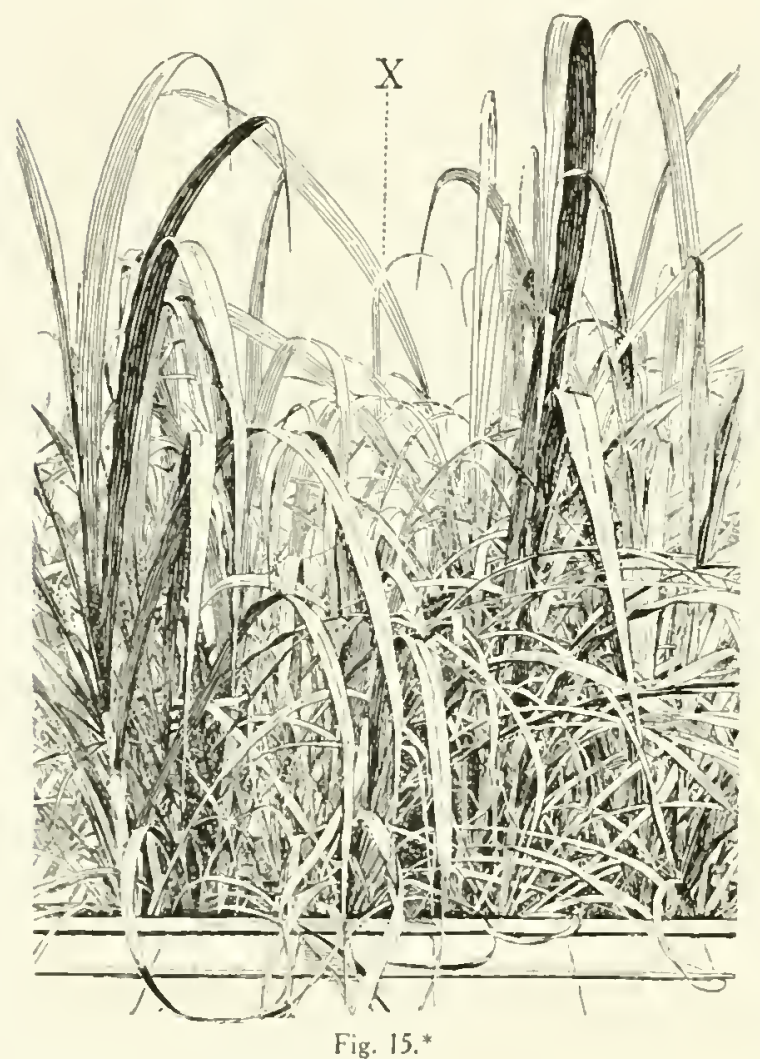
is about I foot. 'The leaf is dried out on the margins and browil above the pricked area for a distance of 2.5 feet. The terminal one foot of the leaf is bright green, and the midrib is green throughont its whole length.

The signs on leaf $I$, which is about the same length as the other, are the same, namely, dry brown margins about 0.25 inch or more in width extending down to the sheatl 1 and upward to within a foot of the tip. 'The only marked difference in the upper end is that the extreme tip has lost its chlorophyl and a portion of the leaf inside of the dry brown margins is also yellow. The midrib is green throughout. The yellow bacterial gun is oozing out of the green midrib about 9 inches above the top of the

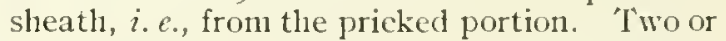
three little, bright yellow gumny masses are present on the inner face of the leaf at this point. 'This leaf was severed from the stem 3 inches above the sheath. Photograph nade. The stem of the plant 1.5 feet from the ground is about an inch in diameter. It has 17 leares and the height of the plant is about 7 feet. The secondary signs of the disease are conspicuous on most of the upper leaves. They have appeared as white or yellowish-white longitudinal stripes, which in some cases have already become reddish-brown, not nillike the signs I obtained some years ago by inoculating Bact. hyacinthi into amaryllis leares. They extend in many cases from the base of the leaf-blade, in some instances half-way up, and in others entirely to the apex. 'This striping shows on five of the upper leaves. One of the most conspicuously striped leaves was eut off and photographed (fig. I6).

(2) 'This plant is about 6 feet ligh and bears 13 leaves. 'The check-leaf is normal; that is, only the tissues in the immediate vicinity of the punctures have turned white. 'The tissue in the pricked area as a whole is bright green and normal in appearance. This is the plant from which a pricked (inoculated) leaf was cut off some weeks ago and found to contain the organism. That leaf (the foot-long stub) now has dry-shriveled nearly to the sheath. 'This is $2 a$.

The other inoculated leaf $(2 b)$ is dried out and has become brown on the margins from the pricked area domn to the sheath and up to within 1.5 feet of the tip on one side, and entirely to the

*Iig. 15.- Row of inoculated badly dwarfed sugar-cane (at $x$ ) with a row of taller, sound, uninoculated cane of same age lo eillier sicle. Hot-house, Waslington, D. C., I903. Irawn from a broken negative. 
tip on the other side. The midrib is bright green the whole length. The needle-punctures were made about a foot from the leaf-sheath. Secondary signs are visible on three of the upper leaves of this plant as long yellowish stripes, interrupted in one of the leaves. In places on one leaf the stripe is dead and reddish-brown for a distance of 8 inches and a breadth of one-sixteenth to one-eighth inch. On another there is a marginal dead stripe 2 feet long.

(3) I,eaf $3 a$ is dead entirely from the tip down for a distance of 3 feet, and the rest of the way it is dead on the margins, but the midrib is green. It was pricked about 18 inches from the top of the leaf-sheath. 'The leaf-sheath itself is about a foot long.

Leaf $3 b$ is dead at the tip and down for a distance of 3 feet and the midrib is dead a foot farther down, but the margins are green. In the lowest foot both midrib and margins seem to be normal. there are no secondary signs on this plant, which is 6 feet tall and bears 13 leaves.

(4) Leaf $4 a$ is dead from the apex down a distance of about 3 feet, while for an additional 2 feet it is dead on the margins but green in the midrib. Punctures made about 9 inches from leaf-sheath. Leaf-sheath is about 9 inches long.

I.eaf $4 b$ is dead from the apex down a distance of about 4 feet. A foot farther down it joins the stem. The lowest foot of the leaf is dead on both margins but green in the midrib. 'The plant itself is about 5 feet high and shows conspicuous secondary signs; is inches from the ground the diameter of the stem, inchding the leaf-sheaths, is about half an inch. It bears 12 leaves. 'Two of the upper leaves are dead almost all the way down and two more show brown striping on one side. The upper two are flabby. Plant brought in and photographed. It is the larger of the two of this date. Bact. vascularum was plated from the stem of this plant. A white gas-forming organism was also obtained from two places in this stem, 8 inches apart.

(5) This plant is about + feet high and is rather small. Diameter of the stem a foot from the ground is a little more than 0.25 inch. Both inoculated leaves are dried up throughout. The plant bears io leaves, not counting some small basal ones which are dried out. It shows distinet secondary signs, which consist of whitening and striping of the leaves

(6) Plant 6 is about 6 feet high. At a foot from the ground the diameter of the stem is nearly an inch. It bears it leaves. Inoculated leaf-blade $6 a$, which is about 5 feet long, has dried out thronghout, except about a foot at the extreme base, and even here there are brown spots on the margins running down to the leaf-sheath. 'The midrib, however, is bright green.

Leaf-blade $6 b$ is dead throughout, except about 9 inches of the miclrib at the base. 'The sheath itself is also drying out. 'This plant shows also conspicuous white, yellow, and brown striping on 3 of the upper leaves (secondary signs).

(7) Plant 7 is about 6 feet high. A foot from the ground the stem is 0.75 inch in diameter. It bears 13 leaves. Leaf $7 a$, which is about 5 feet long (or 6 feet if the leaf-sheath be included), is dead thronghout, including everything except the base of the leaf-sheath.

Leaf-blade $7 b$, which is like $7 a$ in size, is also dead throughont, including most of the leaf-sheath. 'There is distinct etiolation of the margins of two of the uninoculated upper leaves, and there are also red lines and specks in these etiolated parts for a distance of a foot in one leaf near the base and a less distance on the other.

(8) The diameter of the stem of this plant a foot from the ground is about 0.625 inch. It bears 13 leaves. The check-leaf pricked on Marcl 2

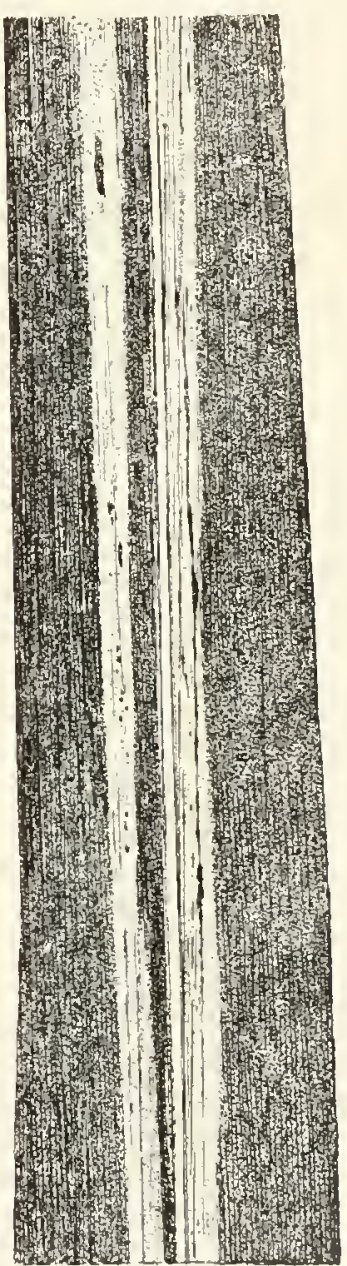

Fig, 16,* with more than 100 needle punctures at 6 inches from the stem, is bright green in the pricked area, the only dead parts being the tissue immediately around the punctures, which is white. Leaf $\delta a$, which is about + feet long ( 5 feet with sheath), is dead throughout, except extreme base of sheath.

Leaf-blade $\delta b$ is dead for a distance of + feet down. The basal 1 foot is dead on the margin but green in the midrib. There are distinet signs of secondary infection on the upper leares which are

*FIG. I6.-Middle part of one of the uninoculated higher leaves of the common green cane, showing etiolation due to secondary infection with Baclerium vascularum: Margins green and normal in appearance, midrib green. To either side of the midrib are white stripes with red-brown dead spots and stripes in them. 'The white striping continued to the apex of the leaf. In this stage of striping bacteria are usually present in some of the bundles of the affected part of the leaf. Drawn from a broken negative. 
whitening in stripes along the margin. Four leaves show these signs and a fifth shows median white striping with dead brown patches toward the base, in the stripes.

(9) Plant 9 is about 4 feet high and about half an inch in dianeter at 18 inches above the ground. It bears if leaves. Leaf $g a$, which is about 5 feet long, is dead throughout, except possibly the extreme base of the sheath.

$I_{\text {eaf }} g b$, which is about 5 feet long, is dead throughout, except a snuall portion of the basal part of the midrib and a part of the sheath. The plant shows distinct secondary signs. One entire upper leaf, which is about 6 feet long, is dead throughout. Another large leaf is drying out on one margin for a distance of 3 or 4 feet and the apex is flabby. A third leaf is dry from the base upward to the tip on one side. A fourth small central leaf is flabby.

(10) No. 10 is a small plant. Height 3.5 feet; diameter a foot from the ground 0.25 inch; number of leaves II. Inoculated leaf $I O$ a is dead throughout, including all the visible part of the leaf-sheath. Leaf $I 0 b$ is dead throughout, including all the visible part of the leaf-sheatin. 'The top of the plant is also dead; that is, three leaves. Three additional upper leaves are dying in stripes. photograph made. It is the smaller of the two plants photographed to-day (April 3).

(11) No. 11 is nearly an inch in diancter at I foot from the ground. It is about 5 feet high. It bears It leaves. Leaf $I I a$ is dead throughout, unless it be a portion of the leaf-sheath. Inoculated leaf $I I b$, which is about 6 feet long, is dead and dry throughout, except the basal i foot of the midrib and a portion of the middle part of the sheath. This plant also shows conspicuous secondary signs. Of the upper leaves, five are distinctly striped and the two uppermost are flabby. One long leat is dead throughout, except the basal, foot, and even this part is dead on the margin, the midrib being the only live part. 'There is conspicuous etiolation of the margins of some of these leaves. 'This sign precedes the drying out. 'There are also distinct, narrow, brown or red-brown interrupted stripings in the basal portion of the etiolated part. One of these upper leaves was pricked with about 1 5o needle-pricks (sterile) at 3 feet from the leaf-sheath on March 2, as a check: No striping has resulted. The needle-punctures themselves have a narrow white margin around them but the tissue between the pricks, which are set in close together, is still bright green. I mean by this that the pricked area is not over 1.25 inches broad (width of the leaf) by 4.5 inches long, and yet with all this number of punctures in it there has been no general death of the tissue, and no up or down striping such as took place within a few days in case of every one of the inoculated leaves.

(12) Plant 12 is about 3.5 feet high; the diameter at I foot from the ground is about 0.5 inch; it has 12 leaves. Inoculated leaf $12 a$ is dead from the tip down a distance of about 3 feet. From there to the sheath, a distance of another foot, the midrib is green, but the margins are dead.

Inoculated leaf $I 2 b$, which is 4 feet long, is dead in the upper $t$ foot and dead on both margins all the rest of the way down to the sheath, but the midrib in this part is green. 'This plant also shows distinct secondary signs on five leares. One uninoculated leaf is dead from the apex down a distance of 3 feet. Another is dead on both margins for a long distance down and also has reddish-brown, narrow, interrupted stripes in the green part farther down, and a third has conspicuous etiolation near the midrib on one side, and there are a great number of narrow interrupted reddish-brown spots in this etiolated part.

'The two rows of cane to either side of this row are at least 3 feet higher and are altogether thriftier, showing no signs whatever comparable to those just described (fig. 15). Neither of these vigorous rows to either side are onter rows, but they are at the same time not of the same variety, one of then being Purple Striped cane and the other Striped Green cane.

At the end of 2.5 to 3 months all of the inoculated leaves and some other large leaves were sliriveled and the tip of the terminal bud liad gone over into a bacterial decay. All of the inoculated plants succumbed. 'The leaves at this time were not all dead and the welldeveloped lower part of the stem was green and sound externally. The internodes were shortence and the basal buds were either much swollen or beginning to push. The plants stood in a dry house and had not received an excessive anount of water. During the progress of the disease sone sloots and roots puslıed out from the nodes at the base of the cane.

When the first signs appeared on the inoculated leaves one was renoved and thin crosssections were examined under the nicroscope for the presence of the bacteria. 'These were found in great numbers in the bundles about is $\mathrm{cm}$. above and for some distance ( $10 \mathrm{~cm}$., perliaps) below the pricked area. Later the bacteria becane very abundant in the stems. They were also found in bundles in the etiolated parts of the nuinoculated leaves. Plates of nutrient agar poured from several plants and from different heights in the sten yielded 


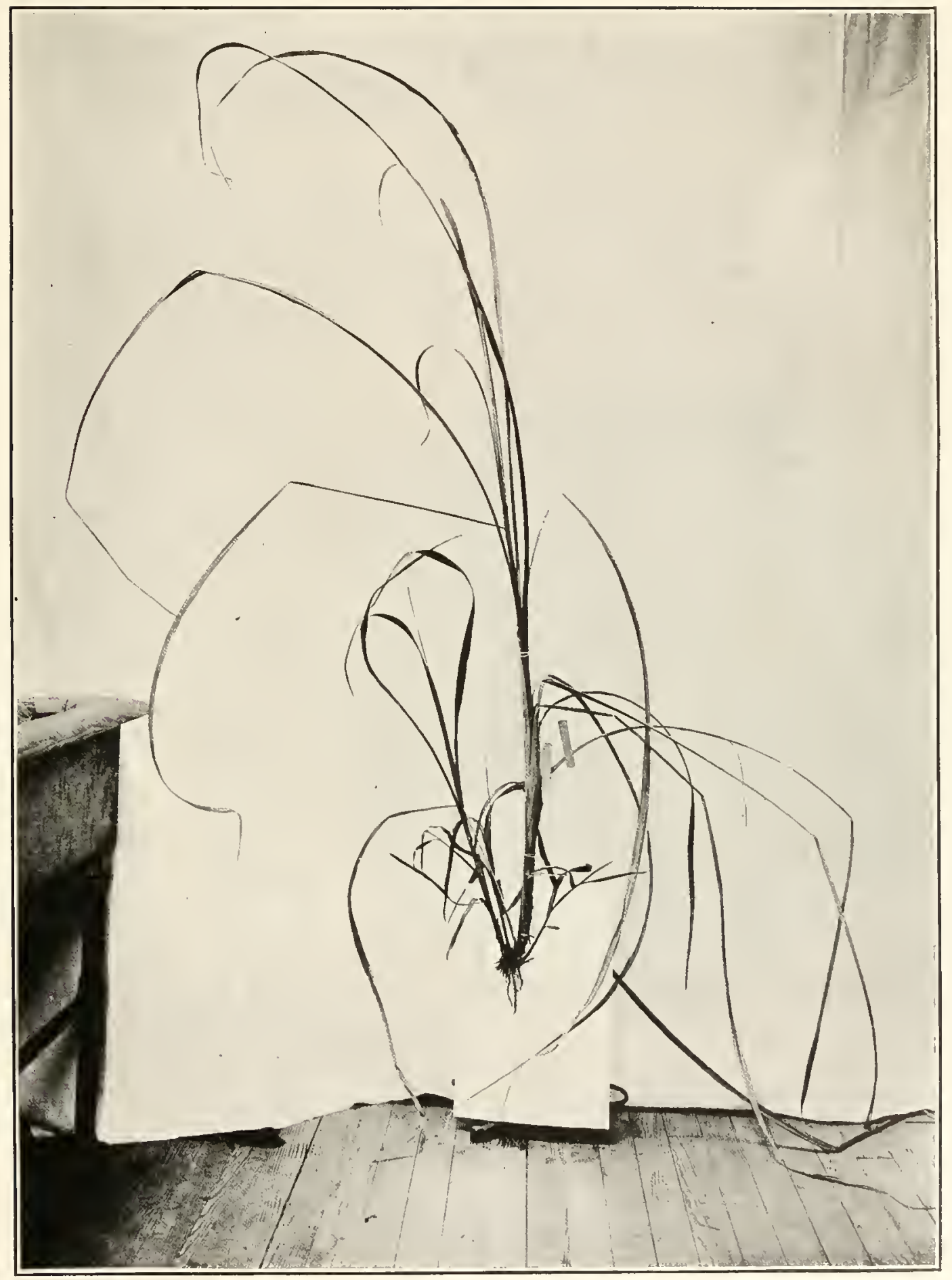

Cobb's disease of sugar-cane.

Plant No 6, inoculated on the blades of two leaves by needle pricks, Feb. 6, Igo3, with a pure culture of Barlerium vuscularum derived from Australian cane. The yessels of the stem from its base nearly to the terminal bud were filled with the yellow Variety, Common Green cane. 

in pure culture great numbers of the same yellow organisun which had been isolated from the Australian cane (fig. I 7 ). The bacteria were present in very great numbers and usually in pure culture in the yellow bundles of these stems. The extent of this stem infection (resulting, be it remembered, from a few needle-pricks on leaf-blades several feet renoved from the 11odes) will be better appreciated if transeripts are inserted from notes made at the time the canes were cut. For this purpose son1e observations made at the end of the third month will suffice.

Brought in to-day (May 6, 1903) 4 sugar-cane plants, inoculated Feb. 6. They are all badly' diseased. Photographs were made of No. 6 (plate 2) and of Nos. 8 and 12 together (plate 3).

No. 6. - The height of this plant is about 70 inches to the curve of the top leaves. 'The lieiglit to the youngest leaf is 40 inches, $i . e$., the plant is small for its age ( 6 months, nearly). Botll of the inoculated leaves are dead and dried, incliding the leaf-sheaths. Of the leaves lower down one is dead and dry and has fallen off, and three others are partly dead - that is, dead at the tips and along one margin but green in the midrib and on the other margin. Farther up, three large leaves are dead throughout, except the sheatl. Four others are dead at the tips and in the case of one for 4 feet downward. Thie small terminal leaf is also dead at the tip. The diameter of the stem at the surface of the earth is 0.68 inch. The diameter of the stem a foot from the ground is I inch, including the leafsheaths. At the base of this plant there are three young shoots which are healthy in appearance, and five buds in various stages of pushing, one of them being an inch long. Signs of disease in the shape of bacterial slime are present under the leaf-sheaths a few inches from the base of the stem, the inner surface being guimmy and wet. The internodes are short; the longest ones are only about 2 inches in length, but the surface of the lower internodes looks healthy. Gumniling of the inner surface of the sheaths continnes up a distance of several feet, and on the inner surface of one sheath the bacteria are abundant enough to look

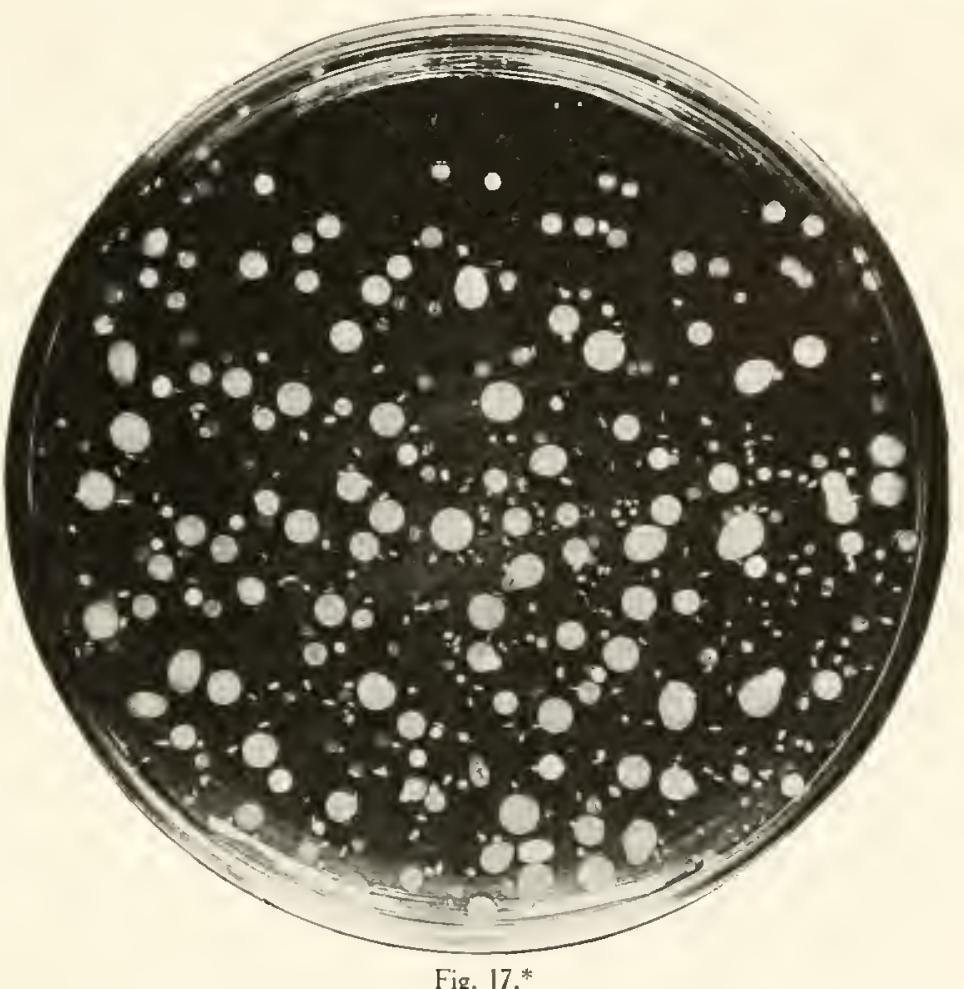

Fig. 17.* yellowish; the organisms have

also broken through from the interior of the stem in three places and come to the surface as yellow slime on as many internodes. The sheatlis are more or less rusty-brown spotted, especially in the gummy parts on the inner surface. There is no indication of rottenness, but a considerable quantity of gum covers the inner face of many of the leaf-sheaths, while the main axis is still green. Aphides are not present. Most of this bacterial slime has come from the interior of the leaf-sheath, but some from the interior of the stem. There is a tendency in this, just as in two other plants bronglit in to-day, for the terminal bud to push out sidewise. In the interior of the plant above the terminal bud there is much red-brown spotting of the tissues and much bacterial gumming. 'T'his rusty-red spotting of the inner, rolled-up leaves - those that are protected from the light and from surface contaminations - is very conspicuous. Terminal bud seems alive, but is crowded down on itself (zigzag) by the drying up and gumming together of the sheaths above it. 'The base of the uppermost young leaf is alive and wraps around another smaller leaf, the top of which is dead and gummy.

*Fig. 17.-A pure agar culture of Bacterium vascularum poured from the interior of plant No. 9. Age 8.5 days at $20^{\circ}$ to $28^{\circ} \mathrm{C}$. 
On cutting across the basal secondary shoots an inch from the stem their tissues seem to be sound (hand-lens). The main axis was then eut open and examined.

The stem was first eut erosswise in the middle of an internode about 6 inclies from the base and then in other places. Some of the vessels are gummy (yellow) and others are distinetly red stained. 'This red staining, as in the stems previonsly disseeted, is much more conspicuous innediately below a nole tlian it is above a node. A few numutes after cutting, the yellow bacterial ooze was very distinct from many of the bundles. 'There are eavities in the upper part of the sten. In other places, as well as those lirst recorded, the red stain is greater just below the node than it is above.

'l'he middle 3 inches of the stem was slit longitudinally and fonnd to contain a closed bacterial carity which is 0.75 incli long (estimated) and 0.1875 incli wide in the widest part, full of pale yellow slime.

Slit the basal 3 inches longitudinally and found the disease in the base in the shape of reddened vascular bundles and yellowed ones from whicl ooze the yellow bacteria. 'l'he longitudinal seetion shows marked red-browning in the vicinity of the nodes and some red vessels in the internodes and, quite interestingly, there is in many cases a red and yellow stain in the same ascular bundle-red in one place and yellow in anotler, showing elearly that the red stain is closely associated with the yellow slime. 'This material was saved in alcohol and may be identified by the fact that it is eut in the form of thin slabs.

To. S. - I"he lieiglit of this plant is about 58 inclies to the eurve of the top leaves. It is badly diseased, both of the inoculated leaves being dead to the stem and also all of the lower leaves, while the upper leaves are dead at the tips and dried up along one or both sides, but with the midrib living. 'The terminal leaflet is flabby. The stem is rery short. 'This plant is especially interesting from the fact that 6 inches above the ground the main axis is doubled and twisted and wrinkled crosswise in a swollen mass, the terminal growth being stopped by a drying and gumming of the tissues above the terminal shoot. Lower down the terminal shoot zigzagged and tried to push out sidewise in the sane manner as shown in fig. 8. Around this swollen, bulged portion the leaf-sheatlis are rustybrown or pale green and very gummy; the bacterial slime occurring in sufficient quantity to show itself distinetly yellow. The gum does not string up much, but it is sticky to the fungers and so copious that both of my liands are covered with it. The interrupted rusty-brown striping is conspicuous in the leaf-slieaths that are buried deep in the interior of the shoot, and soine very interesting and conspicuous examples of this have been saved in alcohol. 'The terminal bud is not killed-only gummy and glued up and squeezed together (endwise) by the effect of the disease on the sheaths outside of it.

There is an abundant yellow bacterial ooze from eross-sections of the stem of No. 8 . Some of the vaseular bundles are also reddened. There is distinctly more reddening of the vaseular bundles immediately under the nodes than there is immediately above the nodes. 'These red vessels are mixed in with those giving rise to the yellow ooze.

Slit the stem longitudinally. Some of the vessels are bright yellow from the presence of tle bacteria and others are red. 'These are mixed in. Specimens put into alcohol. I am inclined to think that the reddening of the bundles is a later stage in the disease than the yellowing.

'I"hree cross-sections were cut from No. 6 and one from No. 8 (smaller) and a photograph $\left(X_{3}\right)$ made of them together, designed to show the yellow bacterial ooze and also the red bundles (plate 1 ).

A plotograph was also made of a longitudinal section of No. 6, showing the bacterial cavity (fig. 4). On the same negative is a longitudinal section of No. 12 (fig. I I), showing red stain in the nodes, and red and yellow bundles in tlie internodes.

Yo. I2.- This plant is a little smaller than No. S. The two inoculated leaves are dead and dry and all the upper leaves are dead, including the terminal one. I,ower lown there are two partially green leaves. Both, however, are dead at the tip and have dead stripes on the margin. This plant has been allowed to stand too long and some of the onter, dead leaf-sheaths are molly, which was not the case with either of the others. 'l'he inner slieatlis are rusty-red spotted, as in ease of the others, and there is much bacterial gumning between them. ln some cases the spotting is quite brilliant-almost a vermilion red. The gumming here also is abundant enougl to stick up my fingers very markedly. About 6 inches from the ground there is the same effort of the sloot (terninal bud) to wrinkle, swell, and pusl out sidewise. Above this swelling ( 6 inches to a foot) the sheaths surrounding the young leaves are very gummy, and there can be no doubt that this sidewise bulging is due to the gumming and pressure of the outer leaves around the terminal bud. Unwrapping the youngest leaf visible, which was dead at the tip, I lind inside of it a younger leaf, also dead at the tip, and the terminal bud is in worse conclition than in either of the other plants. 'The basal buds to the number of seven liave begun to push.

These three stems $(6,8$, and 12$)$, stripped of their leaves, were plotographed together (fig. 9), and 8 and 12 were photographed together before removal of the leaves (plate 3 ). 


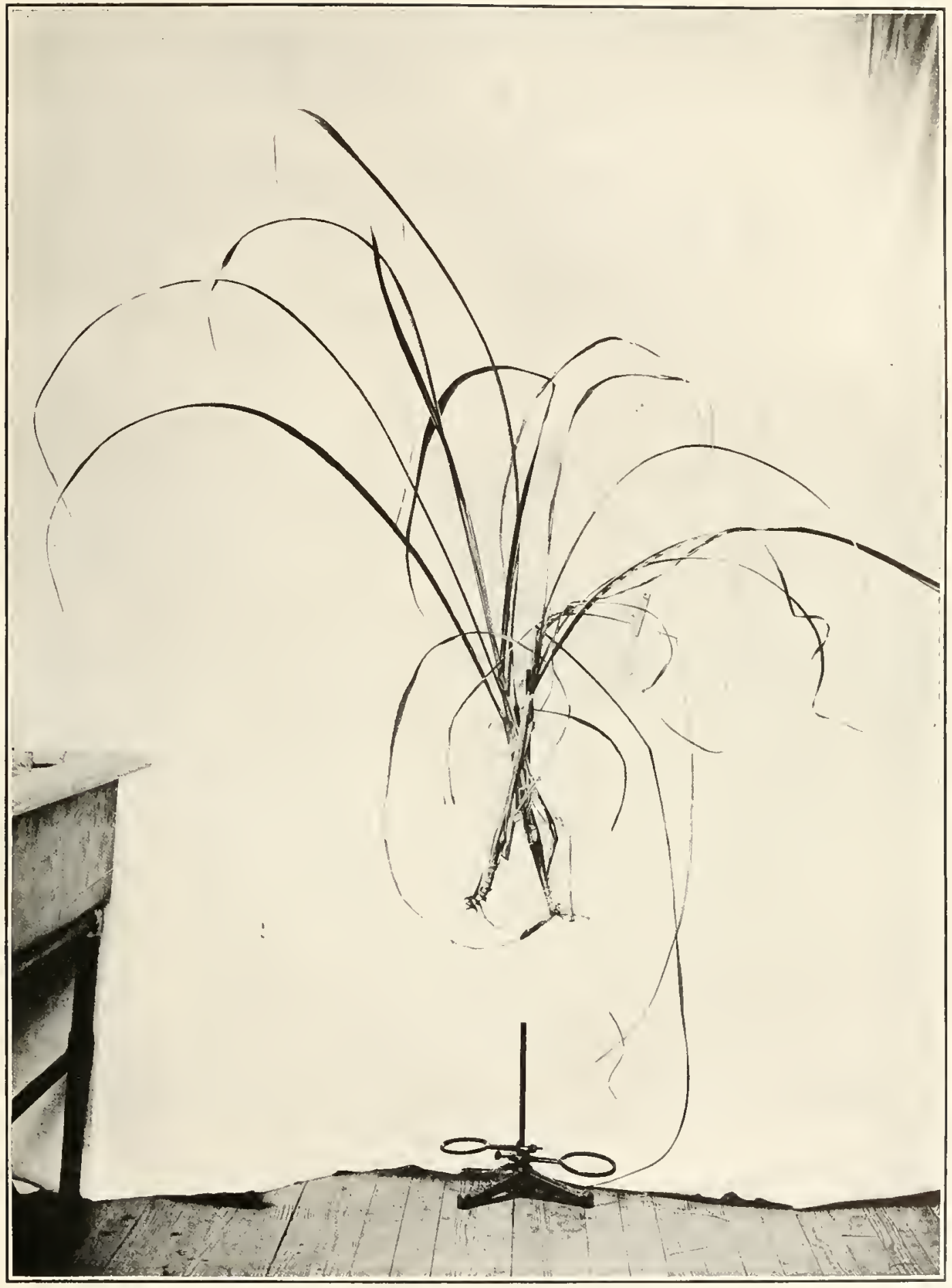

Cobb's disease of sugar-cane.

Plants 8 and 12, inoculated Feb, 6. 1903, with a pure culture of Bactermm vascularum plated out of sugar-cane received from New South Wales. Inoculated hy needle-pricks only, each plant in two leaf-blades at some distance from the stern. Most of the leaves dead and dry when photographed, stem bundles filled with the honey-yellow slime. The terminal bud pushing out sidewise may he seen near the base of each cane. Photographed May roo3. About one-twelfth aatural size. Common Green cane. 

On cutting open the stem of No. 12, red bundles were found to the extreme base. These are mixed in with yellow ones, from which there is a distinct bacterial ooze.

Slit the basal + inches longitudinally. Here again the stem shows a series of red cross-stripes corresponding to the nodes. In the internodes some of the bundles are bright yellow, others are red, and still others are mixed (mottled) red and yellow, and there are bacterial cavities.

The red stain is evidently a later stage, just as the black stain is a later stage in sweet corn attacked by Bacterium stewarti.

No. 5. - This plant is a little smaller than No. 12. All the basal leaves are dead. Both of the inoculated leaves are dead, including the sheaths. 'The terminal leaf is flabby and all the other leaves are more or less diseased, being dead at the tips and with dead margins for a long distance down. The base of the plant for a foot up inside the sheaths is very wet and gummy, just like the others. These sheaths are rusty spottecl. There is a peculiar smell to the disease not unlike that of some bacterial cultures, but I am not able to define it any closer. The inner sheaths are green and some of them are badly rusty spotted. The color of the spots is a brick red.

Cut open the stem at the base; the vaseular system is stained a reddish-brown. This reddishbrown staining is very conspicuous. The terminal bud appears to be normal. The tissues in its vicinity appear to be sound in places, diseased in others.

Other plants in this series gave similar results. These were examined in April or else later on, in May and June (plate 4).

January 5, igo4, only one good ratoon cane has come up from the stools. In addition there are two small eanes and a shoot a foot high. The large canse is free from signs of disease at the base, or nearly free. The little shoot is free. Had these stools been liealthy they would have given many tall shoots.

\section{SERIES II, 1903.}

Fourteen shoots of Louisiana cane, Variety No. 74, were inoculated February 9, 1903, from two potato cultures i I days old by making needle-pricks on two leaves of eacli plant, as in case of the first series of inoculations. At the end of 5 weeks all showed local signs of the disease and six of the shoots also developed constitutional signs, but on the most of them these were not pronounced.

The greater number of these plants proved very resistant, $i . c$., subsequently they grew ont of the disease, although they were somewhat dwarfed by it. At the date of inoculation these canes were the most vigorous ones in the patch, but when they were cut out for examination, on July 2o, the largest and best canes were the sixteen uninoculated ones. These big canes were small and inferior at the time the others were inocnlated.

From the inoculated canes dwarfed cuttings, containing red vascular bundles, were saved for planting, but no yellow slime was present in the bundles of these stens; at least none that could be detected with the hand-lens, and only one reddish-yellow bundle was seen.

\section{SERIES III, I903.}

Eight shoots of common purple cane planted in the greenhouse on November 15, r 902, were inoculated with Bact. vascularm on May 4, I903. The organism used for these inoculations was from cultures 7 days old on potato cylinders kept at room-temperatures. These were subcultures made from colonies on Petri-disl1 plate No.9, ponred April i6, I903, from plant No. I 1 of the common green cane inoculated February 6, 1903. The plate was absolutely a pure culture of Bact. vascularm.

The inoculations were made by spreading tliree or four $3 \mathrm{~mm}$. loops of the organism over about 6 or $8 \mathrm{sq}$. cm. of leaf-surface, generally abont a foot above the top of the leafsheath, and then making about 100 to i 50 needle-pricks through this area. After the pricks were made, two or three more loops of the organism were rubbed over the pricked area. Two leaves on each plant were inoculated. Leaves near the top of the plant were chosen when possible. The canes were quite tall at this time-averaging perhaps 6 feet, and many of the leaves reached to the top of the greenlouse ( $10 \mathrm{ft}$.?). The inoculated areas were protected from the sun for a day by cuffs of manila paper. Five cheeks were made. The 
inoculated plants were given numbers from 27 to $3+$ inclusive, and the inoculated leaves were labeled $27 a, 27 b ; 28 a, 28 b$, etc. For these inoculations tubes Nos. I and 3 of April 27 , 1903 , were 11 sed.

On May 5, I903, finished inoculating the row of common purple cane. Four plants, Nos. $35,36,37$, and 38 , were inoculated in just the sane way as those of preceding day, with one exception; in this case the plant was inoculated in the stem and on one leaf instead of two leaves. This was plant No. 38. Tube No. 4 of April 27, 1903, from poured plate No. 6, of April 16, 1903, was used for these four plants.

On May I 4, 1903, all these plants slowed the effects of the inoculation. A distinct discoloration about the punctures was noticed three days earlier and to-day the punctured area is dead, entirely or in great part, on at least eight of the inoculated leaves. All the other inoculated leaves slow a marked reddish-brown streaking or spotting in the punctured areas.

The clieck leaves slow no such discoloration. The punctures on these leaves show simply as small white points.

On June i3, I go3, common purple cane No. 33, inoculated May 4, 1903, from tube No. 3, April 27, was broken over by accident and brought in for examination.

It is a sloot about 9 or ro feet high, with a thick stem and large green leares, but the basal ones are mostly dead (normal). 'The inoculations were on the blades of two leares about midway down the stem, and the pricks were about 8 inches from the sheath on both leaves. The midrib of each inoculated leaf is alive throughout. 'To eitlıer side of the midrib on one leaf are dead areas for a distance of 2 to 3 feet. The other leaf is much the same, except that on one side the dead portion is not so long, perhaps 18 inches. Above this, however, in the green part are yellowish and rustyyellow dead stripes for a distance of another is 8 inches. Thie onter edges of the sheaths are also dead nearly or quite to the nodes. 'The ends of both leaves are wholly alive.

Made cross-section of the sheath at the extreme base and examined it under hand-lens for baeteria. In one they seem to be present in small quantities, but nothing very definite in either one under the land-lens. These must be looked at under the microscope to determine the presence of bacteria in the ressels of the inoculated leaves.

Cut the stem 6 inches above the base. No evidence under the hand-lens of bacteria in the bundles.

Cut 6 inches higher up and examined again. No bacteria visible in thestem when examined under the liand-lens.

Cut another 6 inches up. Here, also, the stem appears to be perfectly sound under hand-lens.

Cut another 6 inclies up. The whole stem appears liere also to be sound.

We are now getting into the vicinity where the inoenlated leaves join on to the stem. 'The whole stem appears to be sound.

Slit the 6-incli segment below the last longitudinally and examined. No evidence of disease.

Cut another 6 inches up (cross-section). One red bundle in the internode, which is indicative of the disease. Slit this segment longitudinally and examined: Distinct reddening at both the included nodes, but very sliglit in comparison with the effect on the common green canc. At eacll node there are a dozen or more red bundles. No ooze. This is a very resistant variety.

Cut another 6 inches up. No eridence of disease. Slit tlie stem longitudinally. No eridence.

T'he whole upper part of the stem for a distance of several feet was now slit longitudinally and examined for the presence of bacteria. No stain in the bundles; no evidence of disease.

"l"le disease is confined to the two inoculated leaves, to the two nodes which bear these leaves, and to the inmediate vicinity of these two nodes.

On subsequent examination there seems to be a rery light red stain on one side of two nodes next farther up. 'These also were put into alcohol for further study.

A microscopic examination showed the bacteria to be present in the bundles of the 1nidrib of the inoculated leaf-blades and in the bases of the leaf-sheaths.

On Angust 8, 1903, two of the plants of common purple cane which were inoculated with Bact. casculamm, May 5, 1903 , broke off with their own weight. The two plants are Nos. 37 and 38 . No. 37 was inoculated in two leaves, while No. 38 was inoculated in one leaf $(3 S b)$; and through various leaf-sheaths into the stem $(38 a)$. On examination the conditions were as follows: 


$$
11
$$



Externally, plant 38 shows much more disease than 37.

Plant 38 is about 7 feet high and is almost entirely dead as regards leaves. The basal part is devoid of leaves for a distance of 2 feet from the ground and the stem is about 1.5 inches in diameter. The first leaf is partially green, but is beginning to die along the margin. 'The next leaf is entircly dead. The slreath of this leaf was pricked throngh when the stem was inoculated. The next two leaves are about half dead, while the next (which is the inoculated one, $38 b$ ) is about three-fourths dead. Two or three of the leaves higher up show traces of green, but the entire terminal bud, comprising about 15 leaves, is entirely dead and dry. All these leaves are rotted at the base, so that the whole mass of them cane loose from the stem.

On removing the leaves from the stem, 10 or 11 of the uppermost buds are seen to be well started, some of the upper shoots being 4 inches long.

Half of the internode into which pricks were made has a water-soaked appearance and there is a large black wound at one end of it. The outside of this internode is sticky to the touch. None of the internodes above this point are healthy. 'They show water-soaked areas all along one side.

In the lower foot of this stem there are no red bundles, but above that point one or two red bundles appear. The number of diseased bundles increases from this point up, until at a distance of 4 feet from base of stem there are at least 30 diseased bundles. Some are black, others red, while still otliers are yellow, and after a few minutes standing show a yellow ooze from the cut surface. The upper 1.5 feet of this stem was photographed in toto to show development of shoots (fig. to). The diseased bundles in the stem are all on one side, which corresponds to the needle pricks in the stem higher up. In the internode next below the pricked one there is a large group of diseased bundles, black, red, and yellow. Yellow ooze shows quite distinctly from abont 20 of these. There are at least 100 bundles affected in the inoculated internode. About half of these are black and a few red, but there are a large number which show the yellow bacterial ooze. All of the internodes above this point, 12 in number, are very badly diseased. About one-quarter of the bundles are entirely black in these, and nearly all the others show yellow ooze. There is a small cavity along one side of the stem in three of these internodes, which contains yellow slime. The plates poured from the first internode below the inoeulated one misearried. I did not split the sten1 longitudinally, as I wished to save it for planting.

On sectioning: 'Two cuttings apparently not diseased; four cuttings sliglitly diseased; five cuttings badly diseased.

Plant 37 is about 8 feet lighl and externally looks to be a very healthy cane. Both inoculated leaves are entirely dead, but with one or two exceptions all the otlier leaves seem all right except one or two of the tuper, which were torn in the ventilator. The basal part of the stem is 1.5 inelies in diameter. On eutting the cane, the first red bundle appeared about 2 feet above the base of the stem. In the cut a foot higher there seemed to be no diseased bundles. None showed farther up at all. Cuttings saved for planting: 3 very slightly diseased ( 1 or 2 bundles red); 6 not at all diseased.

On January 5, 1904, the remainder of these canes were cut ont, with the following results:

$27 a$ and $b$.- Very large cane, no trace of red bundles, nor other signs of disease in either of the nodes into which inoculated leaves ran.

Another cane, apparently inoculated, is sound.

$34 a$ and $b$.- Excellent cane about ro feet long. A few red bundles run in at two nodes, whicl probably bore the inoculated leaves.

$35 a$ and $b$. - No evidence of the starting of buds in tlis or the other canes examined. A large cane, at least 10 feet tall and $\mathbf{1} .25$ inclies in diameter. No ooze not red bundles in the internode close below the lower inoculated leaf. In internode above the upper inoenlated leaf there are fred bundles, from one of which comes a yellow ooze. This was examined under the compound microscope and found to consist of bacteria. In the red bundles of this stem there were comparatively few bacteria, eacl separate in the field, mostly in pairs and very distinet, the feeble inotion probably Brownian. Cover and slide stained. Saved for poured plates.

$36 a$ and $b$. - Cane about ro feet. Plain evidence of red staining. In one place 1.5 feet from the ground there are at least 12 red bundles. A little lower down only 1 or 2 . One foot farther up there are 7 red bundles and i yellowisl one. Another foot higher up and immediately under an inoculated leaf are 15 affected bundles; 1 is black, some are red, and some yellow. Apparently an ooze from some. Cutting down from top of stem, abont $1+$ inches above last previous cut, there are about a dozen bundles stained and apparently bacterial ooze from I bundle at least. Cut 8 inches lower down, same phenomenon. Slight disease here as compared with that of last year in the Common Greet variety. This cane is the inost badly-diseased in this lot. Intend to plate out to find if the 
organism is alive in cane after having been inoculated 8 months. Split longitudinally, bundles red in some places, yellow in others, and black in still others. Material saved for plates. Cane perfectly sound externally for many feet in the region of the diseased bundles; the affected portion is in the middle of the cane-not at top or botton. Longitudinally split, it shows bundles both yellow and red. Up towards the top the cane is free from stain, healthy and sonnd.

One large cane apparently inoculated, but labels are gone; at least to feet long and 1.5 inclies in diameter; not badly affected. Only a few red bundles at the nodes; they do not run down into the intemodes at all. I argest cane we have cut. Has been no interference with growtl. Red staining in only 2 nodes - probably those to which inoculated leaves ran, but these have fallen. Upper internodes perfectly sound and white.

Another cane without labels but with leaf with label $30 b$ lying near its base. Cane 10 feet high; diameter 1 to 1.25 inches. Perfectly sound outside, and well grown. At height of 5 feet from ground 3 red bundles, 1 of which shows a yellow ooze. Extreme base of cane sound inside and out. Buds are well developed, but they are not pusling. Leafy portion cut away, leaving 5 or 6 feet; sound at cut. Stem shortened $\mathrm{I}$ foot, beginning at top. Two bundles red. Another foot, there is increase in number of red bundles, about ten, all in a group in the center of the cane. Yellow bacterial ooze from some. Shortened another foot, same diseased area continues. Bundles red and brownish in perfectly sound tissue. Basal 3 feet of cane split longitudinally. Disease runs out about 20 inches from the base. Excellent evidence that the bacteria got in through the inoculated leaves.

$29 a$ and $b$.-Cane 12 feet long, 1.5 inches in diameter; it has fallen down and rooted in places and sent up some shoots, which are healthy. 'Top of canc sound. Base of cane, two red bundles in sound tissue. Exterior of cane sound from base to top. At 4 inches above the base there are no red or yellow bundles; 9 inches above base cane sound; 12 inches above base cane sound; 2 feet above base cane has one red bundle, which continues down the stem 8 inches and there disappears. At 1 foot higher, $i . e$, in the internode below one of the inoculated leaves, cane is sound. Location of other inoculated leaf not known. Signs of disease are very slight, as there is discoloration in only one internode.

A cane about ro feet high, 1 inch in diameter, no labels. Sound at top and base; probably an inoculated cane, but can not tell. In middle part of cane there are three red bundles in sound tissue. Outside of the cane sound. Trouble is confined to one node which looks sound outside. No stain in flesh.

Another cane to feet high, 1.25 inches in diameter. 'Top and base sound; 8 inches up sound; 1 foot up sound; 18 inclies up sound; 2 feet up sound; entire cane sound.

There were 5 large canes besides those above noted. All were sound at the top and base, and none liad labels.

About an hour after cutting, four or frve little yellow cirri pushed out from the ends of cut bundles of cane No. 36. 'These ranged from 1 to $5 \mathrm{~mm}$. long and were about $0.25 \mathrm{~mm}$. in diameter. 'The red stain present in the bundles was carried out on these cirri so that they were in sone places red and in others yellow. I.ooked at under the microscope, these cirri were simply masses of bacteria, enormous numbers, in wliat seemed to be a pure growth. They were short rods, single, in pairs, fours, or eights. Most of them were paired, i.e., rods with a plain constriction mid-way. None were motile. Stained a cover and a slide. From the other end of this cane there were also drops of ooze which were masses of bacteria.

The cutting from No. 30 also slows drops of yellow and red ooze, which under the microscope are seen to be made up of masses of bacteria. 'They' are like those in 36 , but more of them are in small clumps (pseudozoogloeæ).

The plates which were poured from plants 30 and 36 were made as follows:

A tube of bouillon was inoculated abundantly by putting into it a good-sized piece of the inner tissue containing vessels determined by the microscopic examination to be filled with the bacteria, and letting it stand one hour. This tissue was then mashed with a sterile glass rod. As already stated, these plants liad not suffered materially from the disease, but sone of the vessels showed immense numbers of bacteria. 'The tissue was cut out with a cold, sterile knife. Neutral beef agar poured at $41^{\circ}$ to $38^{\circ} \mathrm{C}$. was used; seven plates were poured direct and seven from the first dilution. Of those poured directly from tubes in which the tissue was maslied, one received six $3 \mathrm{~mm}$. loops of the bouillion and two others received each three $3 \mathrm{~mm}$. loops, $i . e$., an enormous number of the bacteria.

Result: All dead. Not a colony developed on the agar plates. Canes, therefore, may lave this disease and recover from it.

SERIES IV, 1903.

The field experinent miscarried, owing, perhaps, to defective soil (a barren sand) on which the cancs from series 2 and 3 were set. 


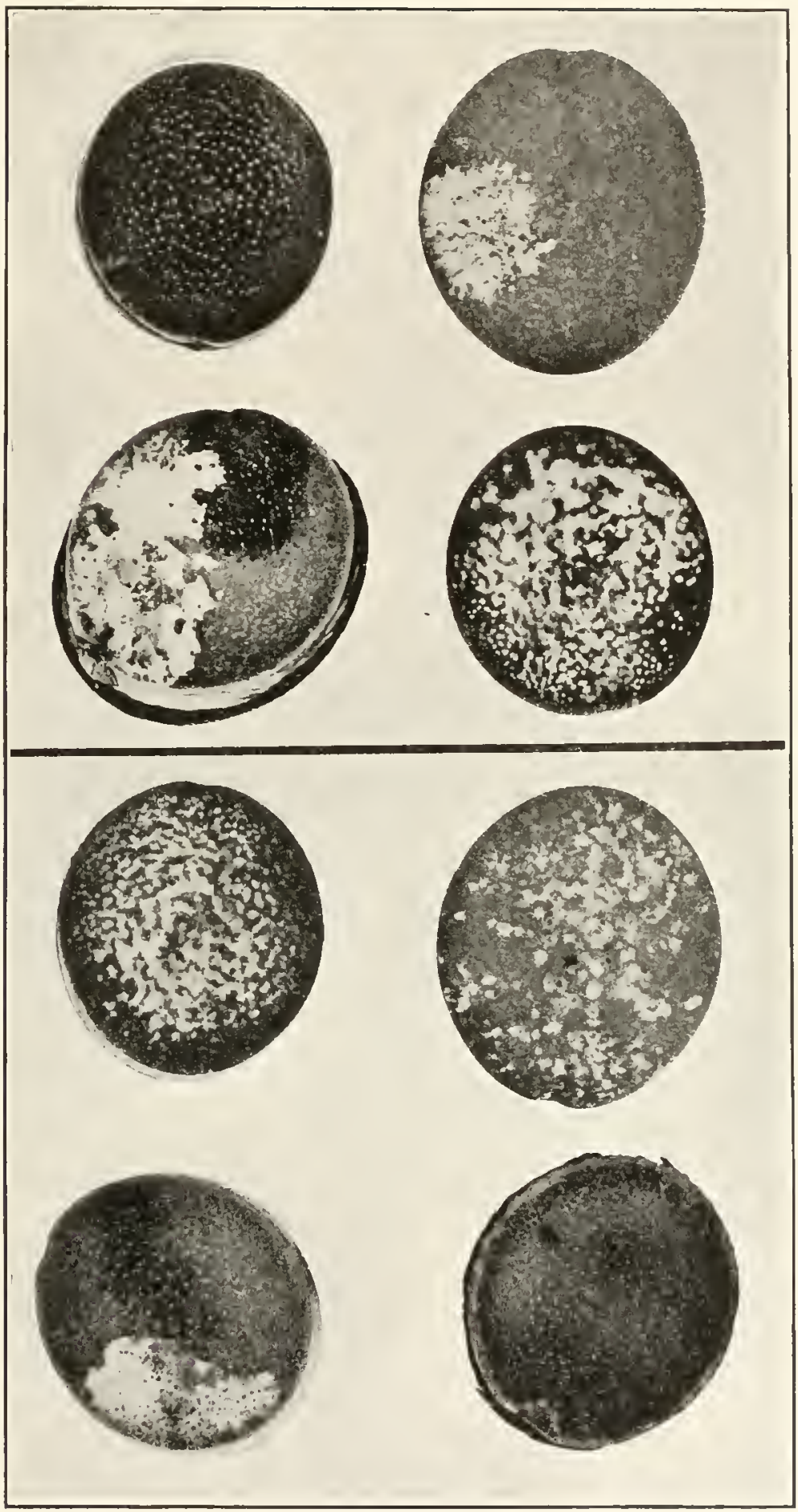

Cross-sections of stem of sugar-cane plant No, 4o, inoculated June 22, 190.4 .

Cut and fixed in alcohol Sept. 27, 1904. Photographed under alcohol Jan, 23, 1905. Nearly every bundle full of the bacterial slime. This plant was inoculated by needle pricks in the stem. The organisms used were descendants of colonies plated from plunt No.7.
inoculated Feb. 6, 1903, and cut out Apr. 22, 1903, for examination, cultures, and photographs. 

SERIES V, 1904.

The fourth set of inoculations was made June 22, 1904, on canes planted in Decenber, 1903.

All inoculations were by needle-pricks through the leaf-sheaths into the stem. The cultures used were strains plated out of plants Nos. 7, 9, and 11 , inoculated February 6 , 1903. Only cultures from plant No. 7 gave positive results, and it is probable that the two subcultures from plant No. 9 and the one from plant No. 11 were made from non-infectious yellow colonies resembling Bacterium vascularmm on agar, but not identical. It was thought at the time of inoculation that these might be different, as they browned the agar in a way the true organism does not. The plants inoculated from these suspected tubes have starred numbers.

In making the inoculations the surface bloom and the prickles were first rubbed of the lower part of the selected leaf-sheath; the surface was then rubbed with a few loops of the yellow organism scraped from the slant agar, and eight or ten needle-pricks were made througl the sheaths into the center of the stem. Check-pricks were made on each variety. These are the inoculations referred to at the end of my German paper.

On September 27,1904 , the condition of the sugar-cane inoculated June 22, 1904, was as follows:

\section{Striped Green. $\dagger$}

No. $39^{*}$.- A large-sized cane, 8 feet long and 1.5 inches in diameter. The inoculated in ternode is about 2 feet from the base of the cane. No signs of infection in the internodes directly above or below the inoculated internode. Splitting the inoculated internode longitudinally, the tissues about the needle-pricks are discolored, but the discoloration does not spread for more than 0.125 inch in either direction. All the leaves are green in this cane, and from the top to the bottom it seems to be perfectly healtly. On dissecting out the terminal bud, however, the very youngest leaves are dead, but this injury, 1 think, has been done by the ventilating apparatus in the greenhouse.

No. 40.- This cane is 7 feet long and about 1.25 inches in diameter. 'The basal 15 leaves are entircly dead and brown, while the upper leaves are gradually dying from the tip toward the base. The terminal bud is entirely dead and brown. There is a large quantity of yellow gummy ooze exuding from the base of this stem, which has been cut about 2 hours. It is 10 internodes below the one inoculated. This cane was carried to the laboratory in toto, where it was dissected.

LABORATORY NOTE.-The yellow ooze from many bundles has coalesced at the basal cut, so that the surface is just a mass of yellow gum. All of the leaves are in an unliealthy condition, some being entirely dried up, while others are drying from the tip down and along the margins. The leaves enveloping the terminal bud are all dead. On sectioning there is abundant bacterial ooze from practically all bundles in all the internodes below the inoculated internode. The ooze does not show much in the upper internodes, however. It runs out completely in the fiftl above the point of inoculation. Plates were poured from this cane. Sections of the stem were saved in alcohol and photographs were made (plate 5).

Inoculation No. $4^{1}$ could not be found. The label was lying on the gronnd.

No. 42. - This is a cane about the same size as No. 39. It seems to be very healthy. The internodes are from 6 to 8 inches long. The upper leaves are all healthy except the topmost ones, which lave been torn by the ventilating apparatus. At the basal cut there are at least 15 or 20 discolored bundles. These run all the way up to the top of the stem-apparently as many at the top as there are at the base. The discoloration (red stain) of the vascular system is much more marked at the nodes than in the internodes. When the stem was split longitudinally, some of the bundles were observed to be red, while otlers were yellow.

A large number of the bundles in this stem, when examined microscopically, showed enormous masses of bacteria. Plates were poured from this stem.

No. $43^{*}$. - A medium-sized cane, about 5 feet high and 1.25 inches in diameter at the base. There is no sign of discoloration in the tissues in any of the basal nodes. From top to bottom the stem seems to be perfectly sound. The inoculation has not taken at all.

No. $44^{*}$. - This is a very large cane, about 9 feet in height and 1.25 inches in diameter at the base. The cane externally seems to be perfectly healthy. All the leaves are green from the bottom to the top. The terminal bud is perfectly sound. On sectioning the inoculated internode, the discolor-

†This row of eane was labeled "Common Green, " but it looks very mueh like "Striped Green." The labels may have been mixed in the transplanting. 
ation of the tissue does not extend for more than 0.125 incl either way from the needle-pricks. There is 110 sign that the inoculation has been effective.

No. $45^{*}$. - ' ' $h$ his is an excellent cane, being about 9 feet long and 1.25 inches in diameter. The lower internodes are about 6 inches long, while some of the upper ones are at least 8 inches in length. 'The whole stem, with the exception of the inoculated internode, is perfectly white within, there being no discolored bundles. In the inoculated internode a red cliscoloration las extended in one or two eases about an inch from the needle-pricks. There is no sign of a gencral infection, however.

Check.-The stem containing the cleek-pricks is rather small, as it has been crowded by the larger canes in the stool. There are no discolored bundles, however. The needle-pricks present much the same appearance as they did in canes Nos. 47,45 , ete.

No. 46. - This is a small cane, about ${ }_{4}$ feet in length and 0.75 inch in diameter. It has not made much growth. Some of the leaf-sheaths in the upper part of the stem are brown and dead. 'The terminal bud seems to be healthy. There are very many discolored bundles, however, in all the leafsheaths which envelop the bud, and in the upper part of the stem much of the vascular system is discolored, there being at least roo red and yellow bundles. The portion of the stem below the inoculated internode, however, seems to be perfectly white, the infection having run up rather than down the stem. 'Thlere seems to be a little yellow ooze from many of the bundles in an internode which is at least 4 feet above the one inoculated. 'This cane was taken to the laboratory for microscopic examination.

LABORATORY NOTE.-This stem shows abundant bacterial ooze in the ninth internode above the point of inoculation. It comes from at least 100 bundles. Plates were poured from this stem.

No. 47. - This is a very small, stunted cane. It has made scarcely any growth since it was inoculated. 'The basal leaves are dead, but the upper ones are green and seem to be perfectly healthy. There are five or six discolored bundles in the basal part of the stem. In the upper part of the stem there are at least zo discolored bundles. This cane has very little juice in it. It seems to have entirely dried up.

\section{Common Green.†}

No. 48.-This is a very small and stunted plant. The terminal bud and terminal leaflets are dead and shriveled. 'The basal three or four lcaves are green along the midrib, but the leaf-sheath and edges of the leaves are dead. The cane lias made scarcely any growth since it was inoculated. In the basal internode there are ten or fifteen yellow bundles. In the uppermost internodes the number of discolored bundles has increased. Whether or not the condition of this stem is due to bacterial infection is uncertain, for there seems to be no yellow ooze. 1 'The terminal bud seems to have been killed from some external cause rather than an internal one.

To. 49. - This cane is quite short, being about 3 feet in height. It is very thick at the base, however. 'The terminal bud is entirely dead and the surrounding leaflets brown and dried up. The basal internodes are very short, some of them being not more than an inch in length. 'T'he tissue throughout, however, is white, except in the inoculated internode and the one immechiately above it. In the latter there is one red bundle, which extends throughout its entire length. There is quite a little discoloration within the inoculated internode, but it has not spread far in either direction from the needle-pricks. There are no cavities in this internode. The tissue seems to be intact throughout. A few of the bundles are discolored for two or three inches. This is the only sign of infection.

No. 50. - This is a very long cane, being about 9 feet in height. Many of the basal leaves are brown, while some of the upper ones are dying at the tips and along the margins. The topmost leaves have been crushed by the ventilating apparatus. 'The terminal bud is dead and dried up. 'The cane at the base is abont 1.5 inches in diameter and externally seens to be very healthy throughout its entire length. The only cliscoloration in the tissues of the stem oceurs in the inoculated internode and the two adjacent ones. Other than this, the cane is perfectly healthy. 'The central part of the tissue in the inoculated internocle has a water-soaked appearance and contains one or two red bunclles.

LABORATORY NOTF.-A few of the bundles in the first internodes above and below the point of inoculation show the presence of bacteria. In two of them, little yellow cirri about 0.25 incli long liave been pushed out, and these, when examined microscopieally, were found to be made up of a solid niass of bacteria.

No.51. - 'This is another long eane, which has made an exceptionally good growth. Some of the internodes near the base are to inches long. 'The leaves are all green and perfectly sound, with the exception of those at the top, which have been crushed by the ventilator. 'The stem in no portion

fWhether or not this is "Common Grecn" is a question. It may be "Striped Green." The latter is the more likely hypothesis, as the rest of the row is of this variety.

†Although a microscopic examination was not made it is probable that the cane was bacterially diseased. 
shows any discoloration in the interior cxcept in the imnediate vicinity of the needle-pricks. The discoloration has not extended either up or down into any of the internodes.

\section{Caledonia Queen.}

No. 52. This is a fairly good eane. It is about 8 feet in length. The basal leaves are brown and shriveled, but the upper ones are all perfeetly healthy. The stem is about 1.5 inches in diameter at the base. There is no discoloration in the stem except in the inoculated internode, where it does not extend at all from the needle-pricks. The cane seems to be perfectly healthy throughout its entire length.

No. 53. - This cane is about 5 feet in length and has much the same general appearance as the preceding one. The cane is perfectly healthy throughout.

No. 54--Presents the same external appearance as the two preceding canes and is about the same size. Rumning through the four internodes above the point of inoculation is a small number of yellow bundles. Whether or not these contain bacteria could not be determined with the hand-lens. The cane has made a very good growth and is about the same size as the uninoculated canes of this variety.

LABORATORY NOTE.- The section taken from this cane showed a distinct yellow ooze from a small group of bundles in the center of the stem. This was made up of masses of bacteria. Plates were poured from this stem.

No. 55.-This cane is about the same size as the others and presents the same general appearance. In three of the basal internodes there are a few red bundles, but these soon run ont, not extending as high as the point of inoculation. The only other discoloration in the stem is in the inoculated internode. Presents exactly the same character as that in check. Is simply a local oxidation.

\section{Crystalina.}

No. $56^{*}$. This is a cane which has made a fairly good growth, although it is of a rather small diameter. It is perfectly healthy throughout its entire length.

No. $57^{*}$. - This is an exceedingly small cane. It is very sickly looking. Although the inoculation was made in very young internodes, it has given no result. 'The stunting of the eane may be due to the fact that some of the pricks pierced the terminal bud.

\section{Jamaica.}

No. $58^{*}$. - This is a cane about 6 feet in length. The basal leaves are all dead. This is probably due to the fact that they have been strangled by the wire with which the label was fastened on. The majority of the upper leaves are beginning to brown at the tips, while the terminal bud is entirely dead and the surrounding leaves are covered with fungi. The cane internally is perfectly healthy throughout.

10. $59^{*}$.- This cane is about 7 feet long and seems to be perfectly healthy, with the exception of the uppermost leaves enveloping the terminal bud, which are dead and brown. This injury, however, is due to the ventilating iron. Perfectly healthy throughout internally.

No. $60^{*}$. - This cane is much like No.59, except that it is not quite as long. Externally it seems to be very healthy. The tissue of this cane is perfectly healthy throughout.

Check. - The check presents exactly the same appearance as all the other canes of this variety.

General Note.-The distribution of the bacteria from the point of inoculation in the diseased canes can not be judged accurately, however, in any of these cases, as the needlepricks were made through many leaf-sheaths as well as through the stem. In all cases where bacteria were found in the stem the organism used was of the same parentage. At the time of inoculation it was known that there were in our cultures at least two kinds of yellow organisms, some of the stock tubes behaving differently from the others.

Cane-plants 40, 42, and 46, inoculated June 22, 1904, and cut September 27, 1904, yielded from the interior of the stems numerous colonies of Bacterim vascularm in practically pure culture ( 14 poured plates). I do not find any record respecting No. 54 .

SERIES VI, 1905.

Inoculations of Sugar-cane in Hot-house No. 4.

On May 22, 1905, two assistants, Miss Florence Hedges and Miss Harriett Thomson, were set at work inoculating sugar-cane with Cobb's organism. I planned to inoculate several shoots on every other row, 2 leares to be selected and 30 or to punctures to be made 
on eacli one at a distance of 6 inches to a foot from the stem, that is, on the basal portion of the blade of the leaf. None to be pricked in to the stem. The rows cxtend east and west. 'I he rows selected are the first row on the north, third row from the north, fifth row from the north, etc., until we reach the south end. This leaves as checks, beginning at the north, the second, fourth, sixth, etc., rows. Each variety of cane is represented in the bed by two rows, and there are eight varieties. This cane was planted in the autumn of 1904 and had grown very' slowly. 'This statement should be borne in mind, as it was evidently the governing factor in what followed.

One-half the sugar-cane was inoculated May 22, using five potato cultures inarked \# made May 17 from an old indigo-bhne litmus-nilk-culture \# of Mareh 25, descended from inoculated cane-plant No. 40. The other onc-lialf was inoculated May 23 from six potato cultures called $X^{*}$, made May i 7 from an old indigo-blue litmus-milk-culture $\mathrm{X}$, made March 25 and descended from cane plant No. to (pl. 11, fig. 12). All of these potato cultures were covered with a briglit yellow growth and were in good condition for use. Transfers from then were ninde to as many nore tubes of potato before beginning. The inoculations were made as follows:

The potato cultures were shaken until the yellow surface growth was washed off into the fluid. Loops of this fluid were then spread on the surface of the leaf, and thirty or forty delicate needle-pricks were made through this wet surface into the leaf. Generally four $3 \mathrm{~mm}$. loops of the clondy fluid were placed on the surface of each leaf, one to the right of the midrib, one to the left, and two along the groove of the nidrib over an area of about 1.5 to 2 inches in length. Then the pricks were nade through this fluid. Afterward about three $3 \mathrm{~mm}$. loops of the fluid were rubbed over the pricked surface on the under side of the leaf, that previously mentioned being put on the upper surface. As soon as the leaf was pricked it was covered from the bright light by pinning a piece of manila paper around it. 'Two leaves were inoculated on each shoot. All were inoculated on the blade of the leaf at a distance of 6 to 12 inches from the leaf-sheatl. The varieties inoculated, and the nnnber of sloots on each variety, beginning at the north end, are as follows: Cinta, 61 to 67 (7 shoots); Caledonia Queen, 68 to 77 (ro shoots); Louisiana No. 74,78 to 82 (5 shoots); Common Green, 83 to 87 (5 shoots); Blanca, 88 to 90 (3 sloots); Jamaica, 91 to 96 (6 shoots); Striped Green, 97 to 99 (3 shoots); Crystalina, 100 to ro5 (6 shoots). Each leaf las a wooden label bearing its inoculation number.

O11 June 13, 1905, the condition of the cane leares inoculated May 22 was as follows, all of the uninoculated leaves being somin:

Cinta.

$61 \mathrm{~A}$. Begins to show white stripes in and above the pricked area. The stripes are visible 6 inches above the pricks.

$61 \mathrm{R}$. Stripes are visible 9 inches above the pricks.

$62 \mathrm{~A}$. Hegins to be white; bleached in pricked area and above it for a few inches.

$62 \mathrm{n}$. White stripes in the pricked area and extending downward some inches.

$63 \mathrm{~A}$. White stripes in the pricked area, and up and flown for a slort distance (2 to 3 inches).

$63 \mathrm{n}$. Shows white striping in pricked area.

$64 \mathrm{~A}$. White striping in the pricked area, extending upward 2 or 3 inches.

$6+13$. Same as $6+A$

$65 \mathrm{~A}$. Same as $64 \mathrm{~A}$

65 w. White striping, and a red stain in the midrib above and below the pricks

$66 \mathrm{~A}$. Faint striping in the pricked area and extending upwarl 4 inches, downward I or 2 inches.

66 B. Faint white striping in the pricked area.

$67 \mathrm{~A}$. I'ricked area dead to either side of the inidrib, and white around the dead area.

$67 \mathrm{~B}$. White striping in the pricked area and red stain in the midrib for abont an inch.

\section{Caledonia Queen.}

$68 \mathrm{~A}$. White stripes in the pricked area, extending upward $f$ inches and downward about 3 inches. There are litile brown dead specks in some of these white stripes, not only on this plant but on the preceding plants.

68 13. Slight signs in the pricked area.

69 A. Same as 68 H.

$60 \mathrm{~B}$. Yellow and red striping in the pricked area.

zo A. White striping in the pricked area.

7o $\mathrm{n}$. Same as $70 \mathrm{~A}$. 
$71 \mathrm{~A}$. Same as $70 \mathrm{~A}$.

71 B. Same as $70 \mathrm{~A}$.

$72 \mathrm{~A}$. Same as $70 \mathrm{~A}$.

$72 \mathrm{R}$. White and red striping in the pricked area, and a white stripe with a few little brown dead patcles on it + inches above the pricked area.

$73 \mathrm{~A}$. White striping in the pricked area.

$73 \mathrm{~B}$. White and red striping in the pricked area 2 inches above and 2 inches below

$74 \mathrm{~A}$. Dead on both sides of the midrib in the pricked area, and white striping, which extends 4 or 5 inches above on either side.

$7+\mathrm{B}$. White striped or dead in the pricked area.

75 A. White striping in the pricked area, extending above 6 inches, and below + inches. Occasionally, sunall rusty patches in the white stripes.

75 B. Like 75 A. White striping extends at least 4 inches below pricked area, and as far above on both sides of midrib.

$76 \mathrm{~A}$. Dead in the pricked area on both sides of the midrib. White striped for several inches above the pricks and a few inches below. There are some stains in the midrib.

$76 \mathrm{~B}$. Dead in pricked area on both sides of the midrib. N1hite striped for several inches above the pricks and a few inches below.

$77 \mathrm{~A}$. White in the pricked area, rmining up abont an inch.

$77 \mathrm{~B}$. Brown dead spots in the pricked area. White stripes run about 2 to 3 inches up and down.

\section{Louisiana No.7f.}

78 A. Faint white striping in the pricked area, red striping in the midrib, and a rusty stain along one edge of the leaf for a distance of $S$ inches, beginning in the pricked area.

$78 \mathrm{~s}$. Conspicuons red stain in the pricked part of the midrib, extending upward for 2 inches and downward for 1 inch.

70 A. Slight white striping in the pricked area. Faint red stain in the midrib.

$79 \mathrm{~B}$. Slight white striping in the pricked area. Faint red stain in the nidrib.

$80 \mathrm{~A}$. Conspictous red stain in the midrib in the pricked part, also I inch above and 2 inches below.

So B. Like $80 \mathrm{~A}$, but also some white dead stripes in the blade to either side of the midrib (pricked part).

8 I A. No signs.

81 B. Slight red stain in the pricked part of the midrib.

82 A. No distinct signs.

82 B. Same as $82 \mathrm{~A}$.

\section{Common Green.}

83 A. Dead in the pricked area to either side of the midrib, and yellowish stripes with brown specks in then extending upward 3 inches on one side and 6 inches on the other.

$83 \mathrm{~B}$. Same as $83 \mathrm{~A}$, but signs mure extensive, and traceable above the pricked area for about $S$ inches, and downward a lesser distance.

8. A. Distinct white striping in the pricked area, with red specks in the wlite stripes. These run interruptedly to a distance of a foot above the pricked area on one side, and about 4 or 5 inclies on the other side.

8. $\mathrm{R}$. Same as $8 .+\mathrm{A}$.

$85 \mathrm{~A}$. White striping in the pricked area. Some of the tisste dead. White striping, with brown specks in it, runs up interruptedly to a distance of a foot on one side of the midrib above the pricked area, and nearly as high ut) on the other side.

$85 \mathrm{~B}$. Same as $8.5 \mathrm{~A}$. The striping is not so extensive.

$86 \mathrm{~A}$. Dead in the pricked area in places, and white stripes extending tpward about 6 inches.

$86 \mathrm{~B}$. Same as $86 \mathrm{~A}$.

$87 \mathrm{~A}$. White stripes in the pricked area and for ro inches above; 2 inches below. Red specks in the white stripes.

$87 \mathrm{~B}$. White striping in the pricked area for to inches above and 2 inches below. A few red spots in the wlite stripes, and red striping in the pricked area of the midrib.

Blanca.

$88 \mathrm{~A}$. White striping in the pricked area, extending upward 4 inches on one side; downward a lesser distance.

88 B. Sigtts less conspicuous than in the others.

$89 \mathrm{~A}$. White striping in the pricked area, runuing up interruptedly 6 inclıes, and down a lesser distance.

$89 \mathrm{~B}$. Same as $89 \mathrm{~A}$.

$90 \mathrm{~A}$. White striping in the pricked area. Some of the tissue dead. On one side it extends upward from the pricks 5 inches, with little rusty brown specks in the white.

$90 \mathrm{~B}$. Sanle as $90 \mathrm{~A}$, only striping more conspicuous. The stripes extend downward a lesser distance than upward, and this remark is true of all so far examined.

The checks appear to be sound.

\section{Jamaica.}

9I A. A little red stain in the midrib of the pricked part.

91 B. Same as 91 A. Signs not conspicuous.

$92 \mathrm{~A}$. Red stain in the midrib of the pricked part about 0.06 inch wide and about 1 incl long.

92 B. Same as $92 \mathrm{~A}$, but red stain in the midrib 2 inches long. No other signs.

93 A. Slight red stain in the pricked part of the midrib about 0.5 incl long and o.125 inch wide. No other signs.

93 B. Less signs than in $93 \mathrm{~A}$.

9. A. Slight signs in the midrib, that is, a red stain 2 inches long and a little of the tissue dead.

$9+\mathrm{B}$. Same as $9+\mathrm{A}$.

95 A. Same as 94 A.

$95 \mathrm{~B}$. Same as $94 \mathrm{~A}$

$96 \mathrm{~A}$. Signs slight. Red in the midrib for 2 to 3 inclies.

96 B. Same as 96 A.

The signs on this variety are inconspicuous. 


\section{Striped Green.}

97 A. White striped in the prieked area. Small strip of dead tissue on either side of the midrib. White stripes run up and down 5 inches. Sliglit red stripes.

$97 \mathrm{~B}$. White stripe in the pricked area, extending upward 3 inches.

$98 \mathrm{~A}$. Sllows distinct white stripes in the pricked area and some dead tissue on one side of the white stripe, extending upward 8 inches above the pricks.

98 8. Conspicuous red stain in the pricked part of the midrib, extending downward 2 inches below the pricks. Some dead tissue to either side in the prieked part. Interrupted white stripe on one side extends upwarcl 8 inches and downward abont 6 inches.

99 A. Dead tissue in the pricked area. Red stain in the midrib of that part, extending upward interruptedly 4 inches above the pricks. White stripe to either side of the midrib, extending upward about 4 inches above the pricks.

99 л. Sone dead tissue in the pricked area. Conspicuous narrow white stripe to either side, extending upward 4 or 5 inches.

\section{Crystalina.}

$100 \mathrm{~A}$. Slight signs confined to the pricked area. Some red stain in the midrib.

$100 \mathrm{~B}$. Signs less than in $100 \mathrm{~A}$. No red stain.

$101 \mathrm{~A}$. Slight signs in the pricked area.

101 ค. Slight sigus in the pricked area. Plant evidently quite resistant.

$102 \mathrm{~A}$. Slight signs in the pricked area.

$102 \mathrm{~B}$. Very inconspicnons signs in the pricked area. None above or below.

$103 \mathrm{~A}$. Yery inconspicuous signs in the pricked area.

103 B. Same as 103 A.

104 A. Slight striping in the pricked area. Very faint red in the midrib.

104 в. More conspieuous striping in the pricked area; runs upward 2 or 3 inches; downward 4 or 5 inches. More conspicuous red in the midrib.

105 A. Slight white striping in the pricked area; runs upward 2 inches.

$105 \mathrm{~B}$. White striping in the pricked area; runs upward 3 to 4 inches; downward 2 inches. Very slight red mark in midrib.

General Remark. - The disease is taking quite generally, but the signs are not yet very conspicuous.

On June 20, the sigus were progressing slowly. I cottld see increased striping since June 13 , but no secondary signs.

On June 28, 1905, the inoenlations of May 22, on the leaves of the different varieties of sugar-cane in this house, were progressing finely. The signs of the disease on the inoculated leaves had becone more pronotneed in most eases than they were when the last records were made. One inoculated leaf on the Common Green cane had now entirely dried out, and many of the inoculated leaves on several varieties showed long yellowish-white stripes, much longer than at the last writing. The Crystalina, which appeared at first to be quite resistant, now showed marked striping on its inoculated leaves. The most resistant varieties at this time appeared to be Jamaica and Louisiana No. 74.

On July 7,1905 , the condition of the sugar-cane, inoculated May 22 in liot-hotse No.4, was as follows:

\section{Cinta.}

61 A. Leaf plainly discased for a distance of I foot below the pricks and 2 feet above. Yellowish-white stripes with small red-brown spots on them. No secondary signs.

61 1 . Whole leaf diseased. Dying from the apex back, and yellow striping toward the base.

$62 \mathrm{~A}$. Signs on the leaf now extend down to the base of the blade and up a distance of 4 feet. No secondary signs.

62 R. Same as 62 A.

$63 \mathrm{~A}$. Whole leaf diseased. Dead striping extends up at least 4 feet. No signs on the uninoeulated leaves.

63 B. Signs extend to the base of the blade and up a distance of several feet.

64. No record.

$65 \mathrm{~A}$. The striping is visible on this leaf for a distance of 3 feet upward from the pricks, and downward nearly to the base of the blade. No constitutional signs.

65 13. Whole leaf diseased; nearly all of it dried ont.

66 A. White striping for about 2 feet. No general signs.

$66 \mathrm{~m}$. White striping extcnding to the base of the leaf from the prieks, and upward 2 feet.

$67 \mathrm{~A}$. White striping extending from the base 2.5 feet above the pricks. Dead on one side for a Inng distance.

67 13. White striping extending from the base about 2 feet up. Dead on one side for about to inclies. No sccondary signs.

\section{Caledonia Queen.}

$68 \mathrm{~A}$. Inoculated leaf. White striping from base to within a few feet of the top. Half of the blacle dead.

$68 \mathrm{n}$. White striping the whole length of the leaf. No secondary signs.

$69 \mathrm{~A}$. White striping the whole length of the leaf. One edge of the leaf dead to within about a foot of the top.

$69 \mathrm{R}$. White striping extending above the pricks 2.5 feet and only about 1 inch below. No secondary signs. 
$70 \mathrm{~A}$. White striping extending from the base of the leaf to within about a foot of the top. Both edges of the leaf dead from the base to 2 feet above the pricks. No secondary signs.

$70 \mathrm{~B}$. White striping extending from the base of the leaf to within a foot of the top. One edge dead to within 2 feet of the top.

7 I A. Comparatively little white striping; extends only about 10 inches above the pricks and to the base. No secondary signs.

7 I B. Diseased to within 2 feet of the top. Diseased downward to the leaf-sheath.

72 A. Leaf diseased the whole length; a good part of it on one side, for a distance of 3 or 4 fect. No secondary signs.

$72 \mathrm{~B}$. Dead, including the sheath.

73 A. Entire leaf dried out; not only the blade, but the sheath as well. No secondary signs, $i$. $e$, as yet none of the uninoculated leaves are involved.

$73 \mathrm{~B}$. Can not locate the inoculated leaf. The label is on a leaf which appears not to have been inoculated. Pricked leaf may have fallen.

$74 \mathrm{~A}$. Diseased to the apex. Dried up along both sides toward the base, and yellow on one side almost to the apex. Diseased condition extends down into the sleath.

$74 \mathrm{~B}$. Inoculated leaf badly diseased on both sides, nearly to the apex. Diseased condition extends nearly to the base. No distinct constitutional signs.

75 A. Signs extend up a distance of 2 feet above the pricks and a few inches below.

$75 \mathrm{~B}$. Narrow yellow stripes extend up a distance of more than 2 feet above the pricks and downward nearly to the stem. No secondary signs.

76 A. Entire inoculated leaf dead and dried out. No constitutional signs.

76 в. Entire inoculated leaf dead and dried ont.

$77 \mathrm{~A}$. Entire inoculated leaf dead. No secondary signs.

77 в. Not found. Possibly fallen off, or removed by the gardeners.

\section{Louisiana No. 74.}

78 A. Very little white striping through the pricks. Some red stain.

$78 \mathrm{~B}$. Tissue is white around the pricks. No general signs.

$79 \mathrm{~A}$. Rad stain around the pricks in the midrib and about 6 inches above. Small white stripes rutıning through the pricks in the blade. No other signs.

79 B. Red stain around the pricks in the midrib. White stripes through the pricks in the blade. No secondary signs. The check-pricks on these plants show no signs of disease.

$80 \mathrm{~A}$. Red stain in the midrib, passing through the pricks and extending about 2 inches above and below. 'Tissue white around the pricks in the blade. No other signs.

$8 \cap \mathrm{B}$. Red stain around the pricks in the midrib and white stripes through the pricks in the blade. No other signs.

8I A. No signs.

81 в. Slight red stain in the pricked area of the midrib.

$82 \mathrm{~A}$. Slight red stain in the pricked area of the midrib. Tissue white around the pricks in the bladc. No other signs.

$82 \mathrm{~B}$. Same as $82 \mathrm{~A}$.

$83 \mathrm{~A}$. Dead stripes in the pricked area, extending upward a foot or two and downward to the sheath.

83 в. No record.

\section{Common Green.}

84 A. Signs confined mostly to the pricked area and a foot or so above it.

84 B. Entirely dead, including most of the sheath. The leaves immediately below this and immediately above are alive.

85 A. Dead stripes in the inoculated leaf, extending upward a distance of 2 feet.

$85 \mathrm{~B}$. Dead stripes in the inoculated leaf, extending to the leaf-sheath and upward a distance of about a foot

86 A. Dead stripes in the pricked area, extending down to the sheath and upward a distance of a foot. Slight yellow striping further ont.

86 B. Signs less conspicuous, but dead in pricked area, and yellow stripes above and below. No constitutional signs. $87 \mathrm{~A}$. Dead striping in the pricked area, and yellow stripes with small reddish specks in them, extending upward above the pricked area 15 inches.

$87 \mathrm{~B}$. Much like A, but rather more diseased. No secondary signs.

Broke off examinations here owing to the extreme heat. No constitutional signs on any of these varieties. These notes are given in full because of what followed.

This lot of cane has been examined from time to time all the summer and autumn, but has shown no secondary signs of the bacterial disease, or at least none which could be attributed to it beyond doubt. Now (Oetober 9, 1905), quite a good many of the canes have lost many of their lower leaves, and some of them have sprouted out at the base, but there is not any distinct white striping of the uninoctlated leaves which ean be aseribed to the disease. The eanes are all tall and jammed up against the roof of the house, which is too low for them. My impression is that the inoculations were made when the canes were too old, and particularly after they had made a slow growth through the whole of the winter, which would undoubtedly result in hardened tissues in the basal nodes, so that the bacteria would have difficulty in passing from the inoculated leaves into this part of the stem and into the upper and softer tissues. It was a new lot-house and it was not known that there would be great inequalities in the temperature. As a matter of fact we selected the cold end for the cane, but did not know it until it was too late to transplant it. 
The following final observations were made January i3, rgo6: These eanes, planted in the fall of $190+$ and inoculated May 22, 1905, grew very slowly through the first winter season and were rather old and woody at the base when inoenlated at the end of May. 'The primary signs developed first on the inoculated leaves in the vicinity of the needle-prieks and rin down to the stem, but secondary signs lave not been visible. The canes which lrave been inoculated $S$ months are large and have been large and leafy all summer, too tall in fact for the house in which they were grown. They are still quite leafy, although a good many basal leaves liave died. I looked repeatedly througl the summer and autumn for distinct signs of white striping in the uninoculated leaves and could not satisfy myself that there were any. Some of the labels have clropped off, and it is now hardly possible in many instances to know to which eane of the row the label belonged.

I cut out the inocnlated rows first and dissected all of the canes, dictating results to the stenograplier from time to time as I cut and made examinations under the liand-lens:

Cinta.

First row to the north (inoculated row):

Removed a large stem, which is leafy to the base. Find it somd witlin. From its soft texture it is probably a younger shoot which has developed since the date of the inoculations. Split the base carefully and examined for presence of yellow stain or red stain in the sten; there is none.

Removed another stem, basal leaves of which are dead. It has not reached nearly the diameter of the preceding. It appears to be an olcler stem. The top looks sound, and there are no indications of disease in the stem.

Neither of these canes had any label on them.

Removed a cane that is labeled $62 b$. It is a large old eane which has lost its leaves nearly to the top. As before remarked, I do not have nuch confidence in the labels now being on the particular canes which were inoculated, since in some instances at least the gardeners picked up fallen labels and wired them to any convenient place. To disease in the upper part of the eane. Cross-sectioned every internode; no disease in any part of the cane.

l.arge leafy cane, upper part of which is quite soft, showing that it has grown sinee the date of the inoculation. Sound within. No recent sprouts from the base of this clump.

Next clump: Removed 2 young sprouts which may be about 6 feet high. They are both sound at the base, and also further up. These have grown within the last 2 or 3 months.

A very large cane; extremely thrifty leaves, except the basal ones, which are dead. This also is a cane which has grown since the sprouts were inoculated. 'Tissue soft and immature (in the lower part). Perfectly sonnd.

'There remain in this clump 2 old canes; these are leafy at the top, leafless for the lower 4 feet or so. Stems snall, firm. First cane sonnd in the upper part; also in all other parts. No yellow sline in the vessels, and no red stain. 'The second old cane is like the first, but has lost inore leaves. It is leafless to a height of 6 feet. 'Iop' part sound. In the basal part I find a brown stain in one group of vessels, which, however, is very slight, and soon runs out.

Third clump on this row: I abel $63 a$. This is a cane dating from the time of inoculation. It is leafless for a height of 6 feet. It is sound at the top. It has red bundles in the stem at the base. There are a dozen or fifteen of these. The stain in the vessels disappears 15 inclies higher up. There is 110 reasonable doubt that the inoculation has taken slightly in this stem. The staining seems to be most extensive in the vicinity of the basal half dozen nodes. 'The cane is sound externally. Under the hand-lens I see bacterial ooze from some of the red-stained vessels. On splitting the stem some portions of the bundles are seen to be red and other portions to be pale yellow, the stain being irregularly distributed in then, just as it was in the set of canes previonsly inoculated.

This third chmp has quite a number of young shoots coming out of the ground. These are sound at the base.

OHl cane. It dates from the time of inoculation and is leafless for a distance of 6 feet. Sound throughont.

OH cane, leafless for a height of 6 feet. Sonnd throughout.

A large cane, leafless for the first 4 feet. V'ery green above. Upper part sound. Middle portion rather undereloped. Cane has probably grown since the last inoculation. Basal part sound. All the rest sonind.

The next clump, same row: Young sloot. Sound at base and all the rest of the way.

Old shoot, leafless for a distance of 5 feet. Whole cane sound.

These eanes are purple-striped. 
Next elump: 3 young shoots. Sound. Older shoot, very leafy nearly to the base. Must have grown since the date of inoculation. Sound throughout.

Old shoot, bears label of $67 a$ and $67 b$. It is leafless to a height of 6 feet. It is sound throughout. $\mathrm{My}$ custom is to section top and base and every internode between before deciding.

Old cane, leafless for first 6 feet. Sound throughout.

Another clump on same row: 3 young shoots. Sound at the base and above.

Old shoot, leafless for a distance of 6 feet. Sound at the top; sound at the base. In the second internode above the base there is a red stain in one bundle, which soon runs out; plant sound otherwise.

General Remark.-All that precedes relates to first (north) row of Cinta.

Only one plant on this row (No.63) shows any distinct indications of bacterialinfection, and in this the signs are slight and confined to five internodes. They are here, however, beyond any dispute. Having waited some little time there is now a distinct, yellow, bacterial ooze from the discased vessels of this stem, which for the most part are central vessels rather than peripheral ones. The nodal infection is most abundant in two of the nodes, which probably correspond to the two inoculated leaves. Mr. Johnston made plates from No. 63, and got numerous, round, yellow colonies of typical appearance. They came up rather slowly. Cultures were saved from six colonies on January 24, and subcultures from three of them were used to make inoculations 106 to 140 of February 9, 1906.

On January 17 I continued my examination of canes. (Labels misplaced in some instances, no doubt.)

\section{Caledonia Queen.}

North (inoculated) row:

'Two recent shoots. Very green; leafy; sound inside. Five more young shoots from the same clump, all about 6 to 8 feet high. Sound both externally and within. One more young shoot of the same character. No signs of disease.

There are three old canes in the clump. 'The first one bears label No. 77a. It is a tall cane, leafless for the first 8 feet, leafy the next 4 feet. The cane is greenish colored on the surface. The upper leaves do not show any white striping. Some undeveloped leaves around the terminal bud are dead. Shortening the cane several internodes; these dead leaves continue, and are surrounded at this level by five healthy leaves and by the inner living bud. Shortened another 2 feet. Stem sound. Stem continues sound in every internode for a distance of more than 9 feet. There is no indication of disease anywhere in the eane beyond a slight red stain in two of the vascular bundles near the base.

Another large cane, like the last in external appearance. 'Terminal bud dead. Some red stain in the central tissues under the terminal bud. This soon runs out and does not look like the bacterial eane disease. Shortened the stem in every node for many feet. There is no indication of yellow or red staining in the vessels, except close to the ground, where two or three bundles have a slight red stain. No disease.

Third cane: This is also an old cane, not labeled. Sound externally. Leafy only at the top. First red stain in the bundles was met at a distance of 4 feet from the ground. Runs only a short distance. No other stained bundles were encountered anywhere in the stem, whiel was sound.

The next clump: Two young vigorous shoots. Very leafy. Sound externally and internally.

Three old canes. One bears label $75^{a}$, and is leafless for a distance of about 6 feet. This one has two or three red bundles in an internode close to the ground; 2 feet higher up the leaves are dying at the margin, but are not white striped. Sound at the top within; continues sound for many feet. Every internode cross-sectioned. Continties sound down to the third node from the ground, which has the before-mentioned red stain in a few of the vascular bundles. In the node above this and the node above that one also tliere is a little red stain. No bacterial ooze.

Next cane: A few red bundles in the third internode from the ground. 'The first three internodes are very short. This is an old cane. 'The leaves are all dear up close to the top. 'Terminal bud dead. Leafy under the terminal bud. Sectioned every internode from top to base. Sound down to within 3 inches of the ground. At about this height there is a small cavity in the center of the stem and slight red staining of some bundles. Injury very slight. This cavity is in no way connected with the surface of the stem at this level, and is due, I think, to the inoculations.

Third old cane from same clump: No red stain at the base. 'This is a large cane, naked to to a height of about ro feet, and has only a few good leaves. Sound within from the top downward a distance of many feet, in fact entirely to the base. 
As noted the other day, the labels are lost in many cases, and we can not tell whether this was an inoculated cane or not.

Next clump: Young shoot, very leafy and green. Sound within.

An old shoot. Sound at the base. Cane destitute of leaves for the first 9 feet. Sound within at the top; sound all the way down.

Next clump: Small old cane. Sound at the base. Stem naked for the first 8 feet. Leaves above not striped. 'Terminal bud sound. Stem sound within all the way down.

Anotler old cane. Three red bundles at the base on cross-section. Stem naked nearly to the top. No white striping of the foliage. The gardener topped this cane some weeks ago in order to shut the ventilators of the louse; the result is that there are purple-red bundles under this topped part for a distance of about a foot down. Six inches under they are 40 in number; 6 inches further they are reduced to 3 in number; below the next node they are reduced to $I$; under the next node this one disappears. 'These are clearly due to topping the cane. The cane from this point is sound downward for many feet, until within a few inches of the ground (the last 5 or 6 nodes). In these there are a few bundles stained yellowish-red, and from these on cross-section there is a slight yellow bacterial ooze.

Another old cane: Sound at the base, except that there are three red-stained bundles. Destitute of leaves for the first \& feet; leafy the rest of the way, but some of the leaves dead on one margin. No distinct white striping. Sound at the top on cross-section, and for many feet, that is, down to the extreme base.

Another chump: Two young shoots about 6 feet ligh. Very leafy, sound within.

Old shoot. Very woody at the base and hard to cut. Stem much larger 2 feet above the base. Bucls pushing slowly. Naked the first 4 feet; very leafy the rest of the way. No external signs of disease. Cross-sectioned from the top downward. Sound at the top; continues so for many feet, that is, entirely to the ground.

Old cane. Destitute of leaves for the first 6 feet. Sound at the top on cross-section, and all the way down.

Another old cane. Nearly destitute of leaves. Sound at the top on cross-section; continues sound for many feet. No indications of disease anywhere in the interior of the stem,

'The remark about labels remains in force, that is, they have fallen off in most eases.

Another old stem leafless for many feet. Sound at the base. Top leaves not white-striped; terminal bud dead. Sound under the terninal bud. Stem continues to be sound on cross-section for a distance of many feet down. First sign of red bundles abont 6 inclies from the ground. 'These are very few in number and soon run out. No signs of any yellowing of the vessels, or of bacterial ooze.

Another old stem; leafless nearly the whole length. Sound at the ground; also at the top and for many feet down. I find no red stain or yellow slime anywhere in the vascular system.

Another old stem; leafless nearly the whole length. Sound at the ground, with the exception of a red stain in one or two bundles. Upper leaves not white-striped. Sonnd within at the top; continues sound for many feet. No evidence of disease in any part.

Young shoot. Dwarfed and tough at the ground, expanded above. Very leafy at the top. Sound externally; sound within. within.

Another clump. Young shoot. About 6 feet high. Very leafy. Sound externally. Sound

Old shoot. Sound at the base. I.eafless nearly to the top. Upper leaves not white-striped. Terminal bud dead. Sound just under the terminal bud. Stem continues sound for many feet. The only signs of disease are near the ground, where there are a few red bundles beginning in one of the nodes.

Old cane. Sound at the ground. Leafless for 6 feet. Upper leaves not white-striped. Crosssectioned from top downward; sound within all the way down.

Another old cane, last one of this row. Sound at the base. Leafless for many feet. Upper leaves not white-striped. Sound at the top on cross-section. Continues sound all the way down, except in one node and internode near the base, where there are a few reddened bundles, and very slight evidence of bacterial occupation.

General Remark on this I ariety. There is no doubt whatever that the bacteria entered the stem in some of these plants, but they were not able to make their way through these stems so as to induce any general disease. If one did not know that they had been inoculated and did not search critically for the presence of the red bundles and the bacterial ooze, he would never suspect that anything had been done to the canes. 
Louisiana No. 74.

Inoculated row of tall cane (same remarks about loss of labels apply as before):

Cut out from first clump 3 young, very leafy shoots, varying from 3 to 6 fect in height. Sound externally and within. Observed also 2 or 3 buds just pushing out of the ground.

Old shoot, sound at the base, leafless for about 4 feet. Very leafy above; leaves green. Crosssectioned from the top downward. Stem sound within all the way down.

Another old shoot. A few red bundles at the base of the stem on cross-section. Stem leafless for lower 6 feet, and most of the leaves above are only partly alive. 'Terminal bud dead, evidently due to injury by jamming against the top of the house, $i . e$., cut by closing the ventilators, as in the other cases of dead terminal leaves and buds. Sonnd immediately under the terminal bud. Stem continues sound on cross-section for a distance of many feet. liirst evidence of a reddened vascular bundle about a foot from the ground. 'This stain runs ont, and t1o others are visible. Stem sound.

Another old cane. Sound at the base. This bears label $82 a$. I,eafless for the first 6 feet; leafy above. Leaves not white-striped. Cross-sectioned from the top downward. Stem sound within for a distance of many fect. No evidence anywhere of anything wrong.

'The next cane (apparently an old one) is rotted, nearly to the ground. Sound under the rotted part. The rot, I believe, is not due to any inoculation; in fact, I think the cane grew after the date of the inoculation; it is hardly tall enough to have dated from so long back.

Next cane, an old onc. Sound at the base; naked for a distance of 5 feet. Upper leaves green, battered somewhat, and red-striped in some places along the midrib. Sound within from the top downward a distance of many feet.

Next clump: Five young shoots of varying heights ( 3 to 5 feet). All very leafy and healthy looking. Sound within.

Old shoot. Sound at the base. This bears label soa. Sinall diameter. Leafless for the first 5 feet. Most of the upper leaves dead. Sound at the top on cross-section; continues sound for a distance of many feet. No internal evidence of disease anywhere in the stem.

Another old stem. This is a large cane, leafless nearly to the top. 'Top deacl and rotted. Stem sound under the rotted portion. Continues sound for a distance of many feet. Sound at the base. Within about one foot of the ground a red bundle appears, and a little lower down there are several others. These continue through the next internode, but there are not many of them. I believe these particular red bundles are due to the bacterial inoculation; at least they have all appearances of being that type of disease. They are few in number and the stem as a whole is sound. The bundles have the charateristic of being red and yellow by turns.

Another old cane. Large cane leafless nearly to the top. This has been topped within the last few weeks to shut the house, and some of the bundles under this top part have red stains in them. A little lower down this red stain disappears. Stem continues sotnd on cross-section for many feet. 'The first indications of anything wrong are about 2 feet from the earth. 'There are some dead cells in the center and red stain in a very few bundles. This runs out about 6 inches lower and the stem from that point down is sound.

Another clump: Some very young shoots; these are sound.

An old cane leafless nearly to the top. Has two labels, Nos. $97 a$ and $97 b$. Sound at the earth and within from the top downward a distance of many feet. First red stain about 2 feet from the ground, restricted to a few bundles in the middle of the stem. This disappears a little further down, that is, it is restricted to one node and two internodes.

Another old stem, naked nearly to the top. Upper leaves not white-striped. Stem at the top sound on cross-section; continues sound all the way down. within.

Another clump: Four young shoots of varying ages, 2 to 5 feet high, and very leafy. Sound

Shoot about 8 feet high. Very leafy, except near the base; leaves very healthy. Sound within. This undoubtedly grew after the inoculation.

Old, large shoot, naked for the first + feet, top leaves green. On cross-section the top is sound and the stem continues sound for a distance of many feet. No indications anywhere of bacterial ooze or red stain in the vessels.

Another old stem. Leafless for the first + feet. Green leaves above. Sonnd at the base. Cross-section of the upper part of the stem sound. Stem continues to be sound on cross-section all the way down.

Another old stem. Leafless to the top. 'Top part rotted. 'The rot is not like the bacterial rot; it is a soft, pale brown uniform rot. It stops quite suddenly at a certain nocte, and from this on the stem is sound on cross-section clear to the base.

Old stem. Sound at the base. Leafless to the top. Top part soft-rotted. It had been shortened to get it inside of the house, and like some others that have rotted at the top, it may have been 
frosted sonnewliat before the house was shut, $i, e_{.}$, it projected through the ventilators. 'The rot ceases sudclenly at a distance of about 7 feet from the ground, and the rest of the way the stem is entirely sound.

Kemark. - This ends the first (110rth row) of the Louisiana No. 74. There are no indications of bacterial disease in it beyoud the very slight ones mentioned under particular cancs.

On January 19, exannination of the inoculated cane was continued, as follows:

\section{Common Green.}

Nortli (inoculated) row:

Six young shoots from the base in a rather unlealthy condition; heiglit 2 to 3 feet. 'I'he leaves are not white-striped, but niny of them are dead on the margins.

1. Center lead. No red or yellow stain in the bundles.

2. Center dead. No red or yellow stain in the bundles.

3. 'l'wo middle leaves dead. Brown, water-soaked. No sign of the gum-disease.

4. Onter leaves dead. Center of the stem sound. Fiurtler up the terminal bud is dead and softrotted, but there are 110 signs of the yellow gum-disease.

5. Central bud rotted out. I see no evidence of Cobb's disease.

6. A few red bundles at the extreme base. Further up the whole stem is dead and soft-rotted; not Cobb's disease; it seens to be a brown soft rot which has run in from the terminal bud.

Old large cane. 'l'his bears label $S_{3} a$. All the lower leaves are dead, that is, up to a height of $S$ feet. Sound at the base. Sound at the top on cross-section; continues sound on cross-section for many feet. The only evidence of disease in the vascular system is about a foot from the ground and confined to one node, a bundle of which is stained brownish, and to another node about 6 inches lower, where there is a red-stained bundle; that is, disease absent or extremely slight. No internodal stains, so far as I can see.

Anotler old stem. Sound at the base. Basal buds well developed. Very leafy and green for many feet. It is undoubtedly a shoot which grew after the date of inoculation. Sound at the top on cross-section, and throughout.

Young shoot from the next clump. Heart rotted out. No evidence of yellow bacterial ooze in this stem.

Another young sloot. Heart rotted out in the same way.

Old shoot, very tall. Leafless for the first 6 feet. Upper part of the shoot has sound, green leaves. The length of this cane is abont 10 feet (that is, of the stem itself). On cross-section not a trace of disease eitlier in the nodes or internodes.

Another old cane. 'This bears label No. $S_{4} b$. All of the leaves are dead, except a few at the top. It is a large cane, and mature for a distance of at least 8 feet. Cross-sectioned each internode iron the top downward. Cane sound for many feet. Basal buds well developed. At about a foot from the gromel there is one internodal bundle stained red-yellow, and the node below has several vessels in it which are stained red and yellow. Signs of disease very slight indeed. "They seem to be restricted to this node and internode, and are scarcely worth mentioning.

I. arge ripe old stem. It bears label $s_{5} a$. It is sound at the base. The basal buds are well developed. 'The leaves are dead nearly to the top. It is a tall cane, and sound externally. Crosssectioned from the top downward. No signs of discase anvwhere.

Old stem. Sound at the base. Basal buds well developed. I,eafless except for a few green leaves at the top. Cross-sectioned from the top downward in every node: No signs of disease in any part of the cane.

Old cane. Sound at tle base. Basal buds well developed. Stem sound externally. Leafy toward the top, leaves healthy looking. Cross-sectioned: Interior of the stem healthy throughout.

Ilealthy young shoot, about 5 feet high. Stem sound on cross-section.

Old cane, leafless nearly to the top. Sound at the base. Basal buds well developed. This bears label $S 6 b$. The diameter of this cane is about r.5 inches. On cross-section, one or two red vessels in the stem 6 feet from the ground; these soon run ont to appear again a little lower down; they extend through several nodes, and a larger number appear at a level of about 3 feet, but are not numerous even there. General appearance of the stem is good. Red stain runs out again a little lower down. Basal 2 feet of the stem entirely sound. I.aid aside a piece of this stem to see if there would be any bacterial ooze.

Cane about 8 fect high, evidently developed since the inoculation. Sound externally and within.

Old cane, quite leafy at the top, naked below. Basal buds well developed. Sound at the base and within its whole length. 
Old mature stem. Sound at base. Basal buds well developed. Upper part leafy. Crosssectioned every internode. One red bundle about 4 feet from the ground. 'The stain passes from the node in to the internode below and runs out; it is slight, and confined to 2 or 3 bundles. Down 2 internodes there are two bundles with red stain; this also runs through the node into the upper portion of the next internode and then ceases. The lower 2 feet of the cane has occasional red bundles, very few and scattered.

Old eane. Bears label $87 a$. Sound at the base. Basal buds well developed. Only a few living leaves. Top of cane dead and a sort of water-soaked brown rot (frost?). No bacterial rot. 'This condition runs out about 4 feet from the ground. From this point down the cane throughout is sound within. No evidence of infection with Cobb's disease.

General Remark.-Under the hand-lens I can see no indications of bacterial ooze from these stained bundles. No distinct indication of Cobb's disease in these plants.

'This completes observations on the inoculated row of the Common Green cane.

Blanca.

North (inoculated) row of this variety:

Old cane. Sound at the base. Leafy in upper half of the stem, the leaves quite green and of good appearance. On cross-sectioning the stem, found no signs of disease, with the exception of one red bindle about 4 feet from the ground, which soon runs out.

Old stem. Sound at the base. Bears labels $90 a$ and $90 b$. Leafless nearly to the top. Basal buds well developed. Stem looks sound externally and ripe. Made cross-sections and found tle whole interior sound. A very juicy, sweet cane.

A large old cane. Sound at the base. Basal buds well developed. Leaves on the lower half dead. Stem looks sound externally. Cross-sectioned the stem and found the interior sound in every internode from top to base.

Old cane. Sound at the base. Bears label $89 b$. Only upper leaves living. Cane is sound externally and appears to be mature. Basal buds well developed but not pushing. Cross-sectioned stem in every internode and found the interior sound.

Old shoot. Sound at the base. Leafy only near the top. Stem well developed. Sound externally. Basal buds well developed, but not pushing. Cross-sections of stem show interior to be sound throughout.

Old stem. Sound throughout.

Old mature stem. Only the upper leaves living. Bears label 8 Sa. Basal buds well developed but not pushing. Looks healthy. Cross-sectioned every internode; stem free from disease. A very juicy, sweet cane.

Old sten. Sound on eross-section at the base. Upper part leafy and leaves healthy. Basal part of the cane looks healthy also. Cross-sectioned every internode and found the whole plant healthy.

There are 4 or 5 young shoots from this stool, but all look so healthy that 1 have refrained from cutting them out.

General Remark.-No evidence of Cobb's disease in this row. This is the end of the inoculated Blanca.

Jamaica.

The two rows of Jamaica have sent out a great many suckers, which now bear green leaves and are about 4 or 5 feet high. 'The notes are on the north (inoculated) row.

Old cane. Sound at base. Rotted at the top, but not with Cobb's disease.

Another old cane. Label $91 a$ and 916 . Ireafy above. Leaves green. Cane looks sound externally. Basal buds well developed. Made cross-sections of stem from top downward in every internode and found cane sound until about 4 feet from the ground, when a few red bundles appeared, which soon ran out. These red bundles showed no bacterial ooze. Sound at base. No certain indications of Cobb's disease. Cane very tender, juicy, and sweet.

Old cane. Sound at base. Basal buds well developed. Cane mature. 'Top bears green leaves. Made cross-sections from the top downward. Found the interior sound for a number of feet, then came to an internode about 5 feet from the ground with some red bundles. 'These continue through several internodes, becoming more numerous at about 3 feet from the ground. At this level there are about is of these unsound bundles. Disease continues in the next internode below and the one below that, but runs out in the next lower one. 'Throughout this region the exterior of the cane appears to be almost perfectly sound, there being only a trace of reddening liere and there in the nodes and inter- 
nodes. Iixamined these red bundles under the hand-lens, and thus far find no distinet evidence of bacterial ooze. Nost evidence of disease in this stem of any examined this morning, but it is not serionsly diseased.

The numerous young shoots look so healthy that I will not cut them out.

old shoot. Bears label 92b. Sound at base. Cane well matured. Sound on the surface. Leafy toward the top and leaves healthy looking. Buds well matured. Cross-sections of the stem from the top downward show the upper portion to be sound. At a distance of about 6 feet from the ground stained ressels appear ( 3 or 4 in number) although the surface of the cane is sound in that internode. Stain runs out in the next internode and appears in the third one below. Here again it is confined to the middle of the stem and the middle of the internode, 3 or 4 bundles being reddened. It appears again in the next internode, and runs out in the next below that. Appears again with a greater number of ressels stained in the node below that. All the way down the exterior of the stem is perfectly sonnd. The basal 2 feet of the stem appears to be free from stain. The cane is very sweet and juicy. lixanined these stained internodes under the hand-lens. I find no distinct evidence of bacterial ooze; will look at it under the microscope later.

Old cane. Sonnd at the base. Basal buds well developed. Healthy looking, well-developed, mature cane. Upper leaves green and healthy. On cross-section, find top perfectly healthy. About 6 feet from the ground I begin to get red-stained ressets in the middle of the stem (a few only); these increase in number in the next internode, run out in the one below that, appear again in the next one, are still more abundant in tle one below that (always in the middle of the cane), run out in the one below that, appear again in the next one, appear again in the next three, and disappear about i5 inches from the ground. The external portion of this part of the stem appears to be sound. 'The interior of the basal portion of the stem is somnd. Examined these red vessels under the hand-lens. No immediate bacterial ooze.

Old cane. Sonnd at the base. Good size. Sound externally. Leafy at the top only. Upper leaves healthy looking. Cross-section of the upper part of the stem perfectly sound. Stem contintres to be sound until one reaches a level of about 6 feet, when a few red bundles appear; these run ont a little lower down. Stem very tender, juiey and sweet. The red bundles appear again in the third internode. They appear again in the next one sparingly, and in the next one below that; I am not sure that it may not be due to the age of the cane. The cane is fully ripe, if not over ripe. Basal part of the cane sound.

Old cane. Sound at base. Buds well developed. Stem sound externally. Leafy at the top and leaves liealthy. Only the lower + feet of the cane is naked. Cross-sections at the top show the interior of the stem to be perfeetly healthy. This state continues downward the whole length of the cane. I believe this cane grew after the plants were inoculated.

old rather small cane. Sound at the base. Basal buds well developed. Stem sound externally. Upper part very leafy and perfectly healthy. Evidently grew after the inoculations. It bears if healthy leaves. Cross-sections at the top perfectly sound. Whole interior of the eane sound.

()ld cane. Bears labels $9+a$ and $94 b$. Sound at the base on cross-section and externally. Basal bucls well dereloped; not pushing. Basal portion of sten naked. Only the upper part bears liealthy green leares, the midlde portion of the cane being eovered with dead leaves. 'This cane is well developed and mature for a distance of more than 6 feet. On cross-section perfeetly sound at the top and for several feet, then a few red bundles begin to appear; these run out in the next internode, appear again in the second one, continue in the third and fourth one, are more abundant in the fifth one, and still more in the sixth one. Much less in the seventh and eighth one, and run out in the ninth one at a distance of 16 inches from the ground. The rest of the stem is free from internal stain until the fifth short uode from the ground, which also has a few red-stained bundles; these run out in the next internode under. Examined under the hand-lens: No distinct evidence of bacterial ooze.

Old eane. Sound at the base. Basal buds well developed. Very leafy at the top, and leaves healthy. I believe the plant grew after the inoculations were made. Cross-section at the top perfectly healthy; continues so for the whole length of the sten.

Large old eane. Sonnd at the base. Leafy onity near the top. Extreme upper leaves green. Sten frealthy within for a distance of many feet, that is, until one reaches a lieight of about 4 feet fron the ground, when sone red bundles appear in several internodes. These continue until one comes to about a foot from the ground, where they disappear. Basal part of the stem perfectly healthy. Cane very tender, juicy, and sweet. lixanined the red bundles under the hand-lens: No distinct eviclence of bacterial ooze.

(Old cane. Sound at the base. Basal buds well developed. Cane mature. Bears label 956 . Upper leaves well developed and green. On section of the stem upper part sonnd. Abont 5 feet from the gronnd red stain begins in the middle of the stem and continues througl several internodes, 
getting worse and worse. In the third one down there are 30 or fo stained bundles. The surface of this internode looks perfectly sound. 'Tle next node below contains fewer stained bundles; the next one down is very bad, mostly in the middle; the next one below that is also very badly stained; the next one below that shows less stain; the next one below that is free from stain, except one or two bundles. The next one (about a foot from the ground) shows no stain. From this point down the cane seems to be perfectly sound. Examined these red vessels under the hand-lens; result: no distinct bacterial ooze, except possibly in one place, and it will take the conpound microscope to settle this.

A large old cane, 2 inches in diameter at the base. Basal buds well developed. Stem naked up to about 6 feet. Cross-section at the top of stem sound; continues sound for many feet. The cane is so soft on cutting that I belicve it grew since the date of inoculation. It is sound throughout.

Old cane. Bears label 766. Basal buds well developed. Cross-section at base sound. Leafy only in the upper part. Leaves are not white-striped. Stem sound on cross-section for many feet. First signs of red stain in the middle of the stem at a level of about 3 feet; slight in the next internode, and in the next two. It seens to run out in the next one about a foot from tlic ground. From liere downward the stem shows no signs of disease, except a bright red bundle in one of the basal internodes. Examined under the hand-lens. No evidence of bacterial ooze. Staining comparatively slight in this plant.

I have left all of the numerous young shoots, they look so healthy.

General Remark.-There is more red stain in these stems tha11 any otlier lot thus far examined, but whether it means that there is a slight bacterial infection or only tliat the stems are very old and going naturally over into a condition preceding decay is what I do not know. The general appearance of the pale reddened bundles is non-typical for Cobb's disease as I have seen it in other varieties. Fxamined the suspected stems 111icroscopically, and was not definitely certain of bacteria in any of them.

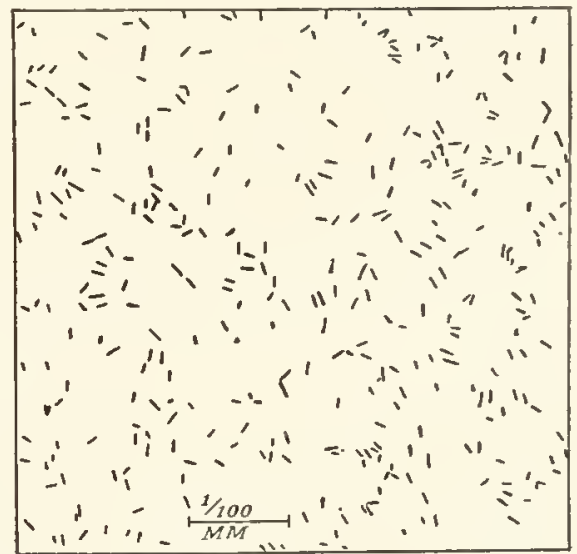

Fig. 18.*

On February 9, 1906, the examination of canes inoculated in house No. 4, May 22, 1905, was contiliued as follows:

\section{Striped Green.}

North (inoculated) row:

Several old canes. Well developed ripe buds; large. No external signs in canes eitler at top or bottom. The canes were now cut open (every internode). One cane showed traces of red and yellow bundles in the basal part: Confined to a few bundles in a few nodes and internodes. Signs so slight that only the use of the microscope will settle it. Doubtful under microscope; seem to be some bacteria. Johnston thought them bacteria. The young healtly shoots not cut out.

North (inoculated) row:

Crystalina.

Sixteen large canes, most of them fully mature. Young healthy sloots not cut out. All canes large and sound looking. Free on cross-section at top and bottom from any signs of gum disease. A very few red bundles in one cane- a node near the base. One cane (less mature than the other) slows distinct red and yellow bundles (a few) in some of the basal nodes and internodes, and what looks like bacterial slime is oozing from some of the bundles, yellow slime from some and red slime from others. Will examine microscopically. Three other canes show a trace of red and yellow bundles in one or two basal nodes (very slight, hardly to be called diseased).

LABORATORY NOTE.- Under the microscope the one most affected showed great quantities of bacteria (short rods, single or paired) in the yellow ooze, and also in the red ooze. Stained and mounted the latter (fig. 18). Mr. Johnston has made plates from this stem.

*FIG, I 8.-Contents of red slime from a vascular bundle in the intcrior of the stem of a sugar-cane (variety Crystalina) 9 months after inoculations with Bact. 'ascularm. Surface of stem sound. Slide ss, Feb. 9 , 1906. Stained with carbol fuchsin. Drawn with a Zeiss $3 \mathrm{~mm}$. 1.40 n. a. oil-immersion objective, No. 12 compensating ocular, and Abbe camera. 
February 14. Johnston's plates miscarried (probably too thinly sown). Miss Hedges then poured plates from Johnston's second bouillon dilution, which had been saved and was now moderately clouded, and got Bacterium vascularum in pure culture. Probably by far the larger part of the bacteria in this stem were dead, as in case of canes Nos. 30 and 36.

February 19, 1906. The plates poured January 13 from inoculated plant No. 63 (Cinta) showed nothing for quite a number of days, so that we thought they had been inoculated too thinly. Afterwards numerons yellow colonies came up, but it required a week or more.

General Remark.-When I finished cutting out the cane on February 9 a stalk of Crystalina was selected which showed yellow ooze from some bundles, and dark purple-red ooze from others. Two sets of plates were poured: one from the red ooze, one from the yellow ooze. Just as in the previous set of plates there was for a number of days no indication of colonies, but afterwards the plates showed numerous typical colonies of Bacterium vascularmm. The plates poured from the red ooze showed no red colonies, but only yellow ones.

This indicates two things: First, that the dark red ooze was due not to red-colored bacteria, but to a red reaction of the lost plant; and, second, that when the bacteria have lain dormant for many months in old canes they are not resuscitated as early as from fresh growths. The same remark applies to other bacteria catsing plant diseases.

The results from this series of inoculations indicates also very clearly that it is difficult to obtain secondary (stem) infections on old canes by means of leaf-inoculation unless such canes have grown rapidly. The primary signs on these plants were entirely satisfactory, the constitutional ones so scanty that I had great reason to be thankful that it was not my first series of inoculations. As it was, the experinent proved more instructive than if it had been an exact duplicate of the first one.

\section{SERIES VII, 1906.}

On February 9, I 9o6, thirty-five young green shoots (second growth) were inoculated with Bacterim vascularm by means of hypodermic injections. To each of the slant agar cultures ( 1 to 3 , February 7 , descended from three separate colonies on Mr. Johnston's plate 2, January 13, poured from artificially infected sugar-cane No.63) ro c.c. of autoclaved redistilled water were added. The tubes were shaken until most of the pale yellow slime was washed off and this milky fluid was injected into the plants in 2 to 4 c.c. quantities.

Most of the inoculations were nade in or above the heart ( 2 to 4 pricks in each plant), but some of each variety were pricked in the leaves only with 6 to $\mathrm{S}$ pricks. The varieties inoculated were as follows:

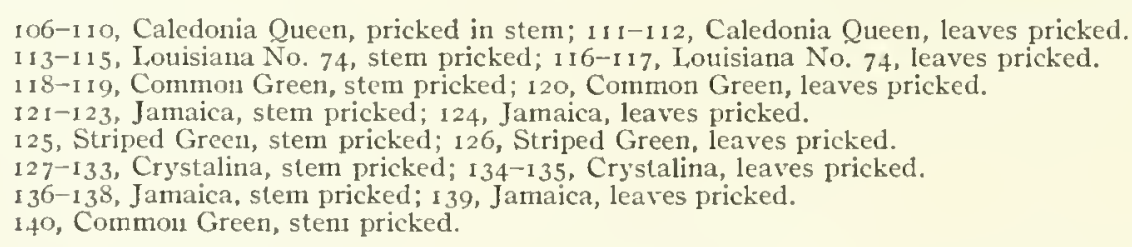

Local signs appeared on some of these plants within a few weeks, but constitutional ones never developed, at least not so as to be conspicuous, and the plants after minaking a tall growth and standing for 18 months were finally cut down to make room for other things, witlout being examined internally.

\section{GENERAL REMARKS ON THE INOCULATIONS.}

In all, 140 canes have been inoculated in the greenhouses in Waslington, 26 with Bact. vascularmm, plated from the Australian cane, the renainder (except as noted under Series V) with descendants of this strain isolated from stem-bundles of the artificially infected plants at long distances from the point of inoculation ( 3 to 5 feet). The results have varied according to the variety and the condition of the plants at the time of inoculation. Canes, even of sensitive varieties, which had grown very slowly or were old and woody at the time of inoculation, were not susceptible to general infection. 
Of all varieties tested Com11011 Green has shown itself nost susceptible. Louisiana variety No. 74 and Common Purple were very resistant, and all the others under the conditions of the tests were more or less so. Unfavorable conditions of growth rendered the variety test unsatisfactory, and the writer does not consider the results trustworthy.

\section{ACID CANES LESS SUSCEPTIBLE.}

The question of immunity is perhaps the most interesting one. To what is the inmunity of resistant varieties due? or of susceptible varieties under speeial conditions? It is a very interesting and perhaps a very complex problem, but also perhaps one relatively simple. Only a few observations will be noted here. Before making the first inoculations on Common Green cane, Common Purple cane, and Louisiana variety No. 74 (Feb. 1903), the freslily expressed juices of well-grown, sound canes of the three varieties were titrated with phenolphthalein and sodium liydroxide to determine their acidity. According to thesc titrations the sap of the Common Green cane was the least acid. Bacterinm vascularm also grew very much better on steamed cylinders of this variety than on those made from the otler two varieties. The cane used for this latter purpose was pared, cut into cylinders, put into test-tubes containing an amount of distilled water sufficient to cover less than half the cylinder, and heated a few minutes on three successive days in the steam sterilizer. The cut surface of the cane was then streaked copiously and the anount of growth noted. It was these unexpected results which led the writer to ehoose Common Green cane for his first inoculations. He believed it would be more susceptible than the other varieties, and such proved to be the case. The others were a hundred, yes, a thousand times more resistant to infection. The majority showed only local signs on the inoculated leaves or stems. Signs were not observed on the uninoculated canes from these stools, not even after many inonths. A few of the inoculated canes of these resistant varieties slowed dwarfing with secondary signs on the leaves, but after 6 months, when the plants were eut down, there were to be seen for the most part only a few red bundles without distinct bacterial ooze, although in two stems there were a very few bundles containing yellow bacterial slime. The red bundles appeared only in the nodes giving rise to the inoculated leaves and in the adjacent internodes; they were not to be found in the greater part of the well-developed stems either above or below. These facts can be tabulated as follows:

TABLE 4.-Relation of Bacterial Growth to Acidity of Cane Juice.

\begin{tabular}{|c|c|c|c|}
\hline Variety. & $\begin{array}{c}\text { Acidity of sap } \\
\left(\frac{N}{I} \mathrm{NaOH} \text { per liter }\right) .\end{array}$ & $\begin{array}{c}\text { Growth of bacteria on } \\
\text { sterilized cane cylinders. }\end{array}$ & Susceptibility. \\
\hline $\begin{array}{l}\text { Common Green cane......... } \\
\text { Common Purple cane........ } \\
\text { Louisiana No. } 74 \ldots \ldots \ldots \ldots . . .\end{array}$ & $\begin{array}{l}c . c . \\
19.00 \\
32.00 \\
31.00\end{array}$ & $\begin{array}{l}\text { Good. } \\
\text { Poor. } \\
\text { Poor. }\end{array}$ & $\begin{array}{l}\text { Very great. } \\
\text { Very slight. } \\
\text { Do. }\end{array}$ \\
\hline
\end{tabular}

It may be noted here also that the Common Green cane is the one which is most cultivated for eating, which would not be the case if the juice were very acid.

On steamed cylinders of Striped Green cane and Striped Purple cane, which titrated +20 and +32 respectively, the organism also grew very feebly.

Another titration experiment was made in April 1906 (by Mr. Johnston and Miss Hedges) on the nine varieties of uninoculated canes whicl had been growing (very slowly) in the greenhouse since the winter of $1904-5$. Eight of these canes were from the lot used for a variety test in the inoculations of May 22, I 905, which resulted rather unsatisfactorily even on the Common Green cane, due, no doubt, to the condition of the plants at the time of inoculation (slow growth, hard nodes). The nintlı was a Cuban variety which had been growing in the greenhouse about the sane length of time. The old uninoculated canes 
were cut out on March $2 \mathrm{I}$, and the central or lower portions saved for planting. The juice titrated was taken from canes belonging to these cuttings. Between the date of cutting and the time of extraction of the juice for titration a period of $\mathrm{I} 7$ days elapsed, during which the canes were kept in the ice-box, the cut ends sealed with paraffin. The titration was performed in the same manner as previously. Two titrations were nuade of each variety. 'The results were as follows (Fuller's scale):

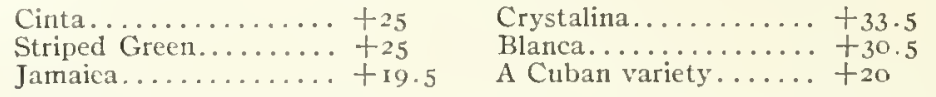

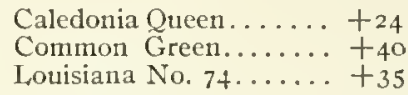

Caledonia Queen....... + +24

Louisiana No. $74 \ldots \ldots+35$

The writer has had no opportunity to repeat these tests on fresh canes.

A sugar chemist, with whon the writer discussed the matter after the first titration, did not believe that well-grounded conclusions could be drawn from single canes; the next titration might give very different results, as, in fact, proved to be the case (but so also did the inoculations). He said that in order to determine the comparative acidity of different varieties of sugar-cane, the mixed sap of many canes of each variety must be titrated. This I am ready to concede. So much depends on varying factors, $c . g$., soil, manure, sunshine, rain, time of year, degree of maturity, lodging, etc. The writer does not know whether any chemist has tested the comparative acidity of the sap of different varieties of sugar-cane. From a pathological standpoint, he believes that it would be very interesting. Many bacteria do not thrive in acid culture-media and often a strong antiseptic influence is exerted. That there should be an average higher degree of acidity in some varieties of eane than in others is in accord with many facts in plant physiology, and perliaps the great susceptibility of some varieties is due to weak acidity, i.e., low total acidity, or else to a smaller amount of some particular acid unfavorable to the growth of the organism and more abundant in resistant varieties. It is conceivable that the cane may contain mixed acids in varying proportions, one more antiseptic than the other, and this fact would not be brought out by ordinary titrations, but might be fundamental. This might explain why Jamaica was resistant to the disease when from its low total acidity I had anticipated that it would be sensitive. The difference in immunity is evident, whatever the explanation may be. The acidity of the cane-juice explains, furthermore, to the writer at least, why the bacteria tend to avoid the parenchyma and inhabit by preference the vascular system, the juices of which (Greig Smith) are only slightly acid or neutral. They do finally make cavities in the parenchyma, especially in late stages of the disease and in the upper part of the stem, but in this part of the plant there is an excess of water, favoring rapid growth of the bacteria, and with this more vigorous growth there would be produced sufficient alkali to nentralize the inhibiting acids. Another reason, perhaps, why the bacteria are more abundant in the vessels is the better aeration, $i$.. ., presence of nore free oxygen in the vessels than in the parenchyma.

\section{CONDITIONS FAVORING THE SPREAD OF THE DISEASE.}

The writer luas seen nothing to indicate that the disease is very infectious. In very bad cases, younger canes from the same stools sometines showed etiolation, which the writer believed to be due to the secondary effect of the bacteria in the mother stem underground, but 110 signs were observed among canes growing from stools bearing no inoculated canes, althougl of ten these were for months in close proximity to infected canes. So far as it goes, and it must be admitted this is not a very great way, since insect enemies of the cane were absent and water did not rest long on the foliage, this indicates that the disease generally originates with the sets. We can well imagine, however, that under ordinary field conditions, with an abundance of dew or rainfall, and plenty of insect depredators, diseased plants might readily infect neighboring liealthy ones, especially when young. Wet soil would tend to waterlog the plant, and would also favor the deposit of dew, in both ways favoring infection. 
According to Cobb, an exeess of moisture scems to favor the developunent of this discase. The condition below Maclean, on the Clarenee River (New Sonth Wales), where the disease is rery prevalent, differ from these aluse Matedu, where the dinealse is rate, in the following ways: There is a greater rainfall down the river; the lanks of the river are lower; the surface drainage is not rapod; and the nearly inpervious elayey subsoil is within a few fect of the surface. He says also:

In the diseased fickds it is alparent that the better frained parts sulfer less than the others, thonghl all the conditions except this one al drainige are the sante.

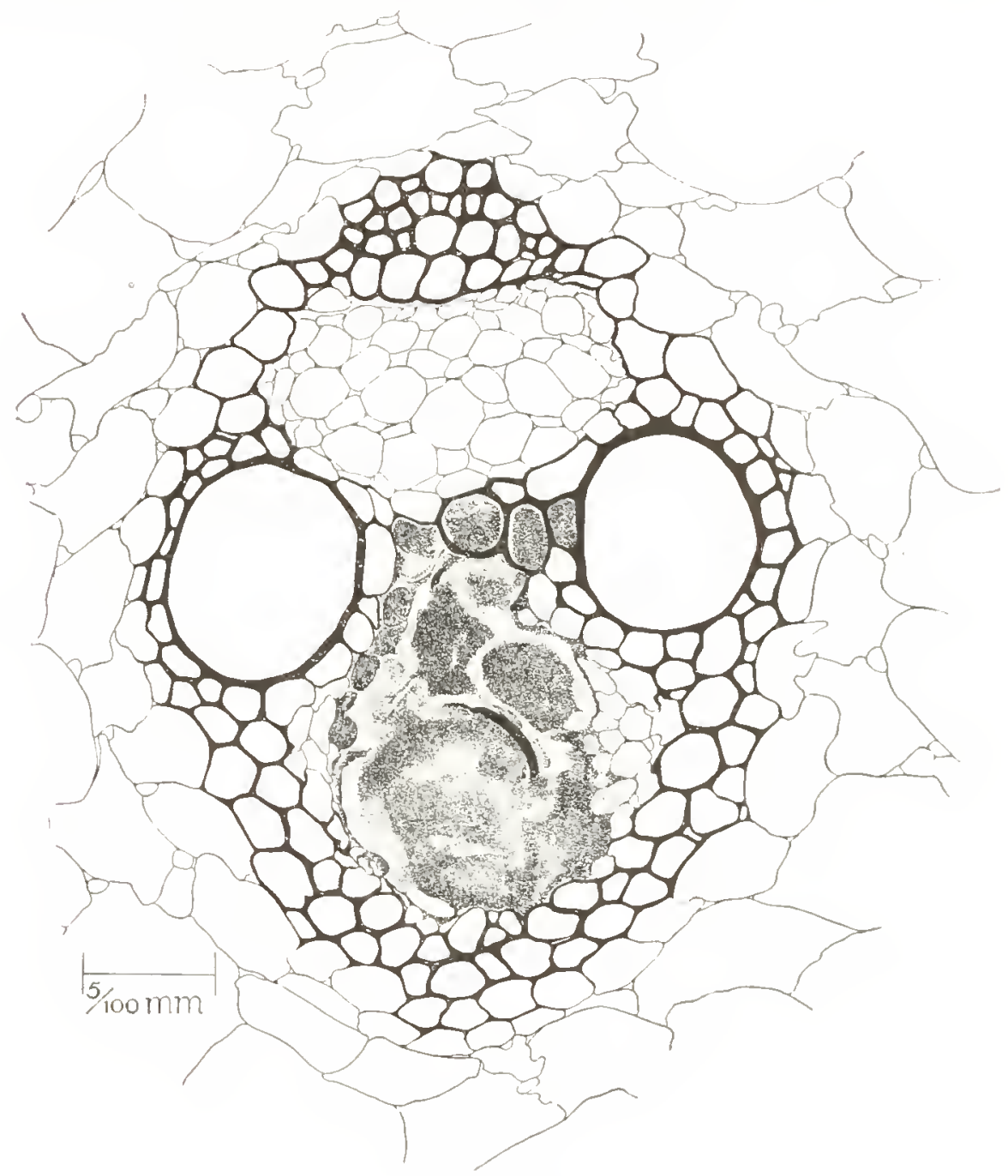

Fig. 19.*

TIIE RI:D STAIN

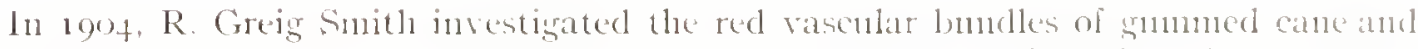
reached the conclusion that the stain must be due to the symbiotic aetion of an mudeter mined pyenidia-bearing fungus and a white sline-producing bacillus, naned by hins

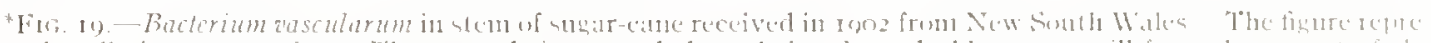

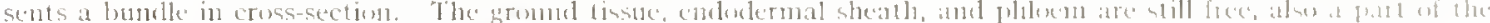

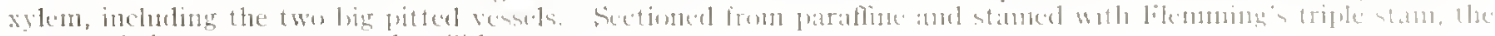
contrast being not exiggerated. Slicke 121 (a). 
B. psendarabinus. This is peritrichiate and non-sporiferous, liquefies gelatin slowly, and does not stain by Gram. He says of the fungus:

In glucose-gelatin the mould produced a brilliant crimson-scarlet color, and it undoubtedly was the agent which was primarily responsible for the color of the strings. But from the presence of gum in the vessels I was of the opinion that the mould was accompanied by a slime bacterium, and that the complete phenomenon of red gum was brought about by the simultaneous growth of two organisms, a mould and a bacterium. This view was confirmed during the research. It may, however, be mentioned here that every portion of red vascular bundle that was taken did not contain the mould, but did contain slime-forming bacteria; and from this we must conclude that the mould does not accompany the gum along the whole length of the string, but colors the gum which is carried along the ves-

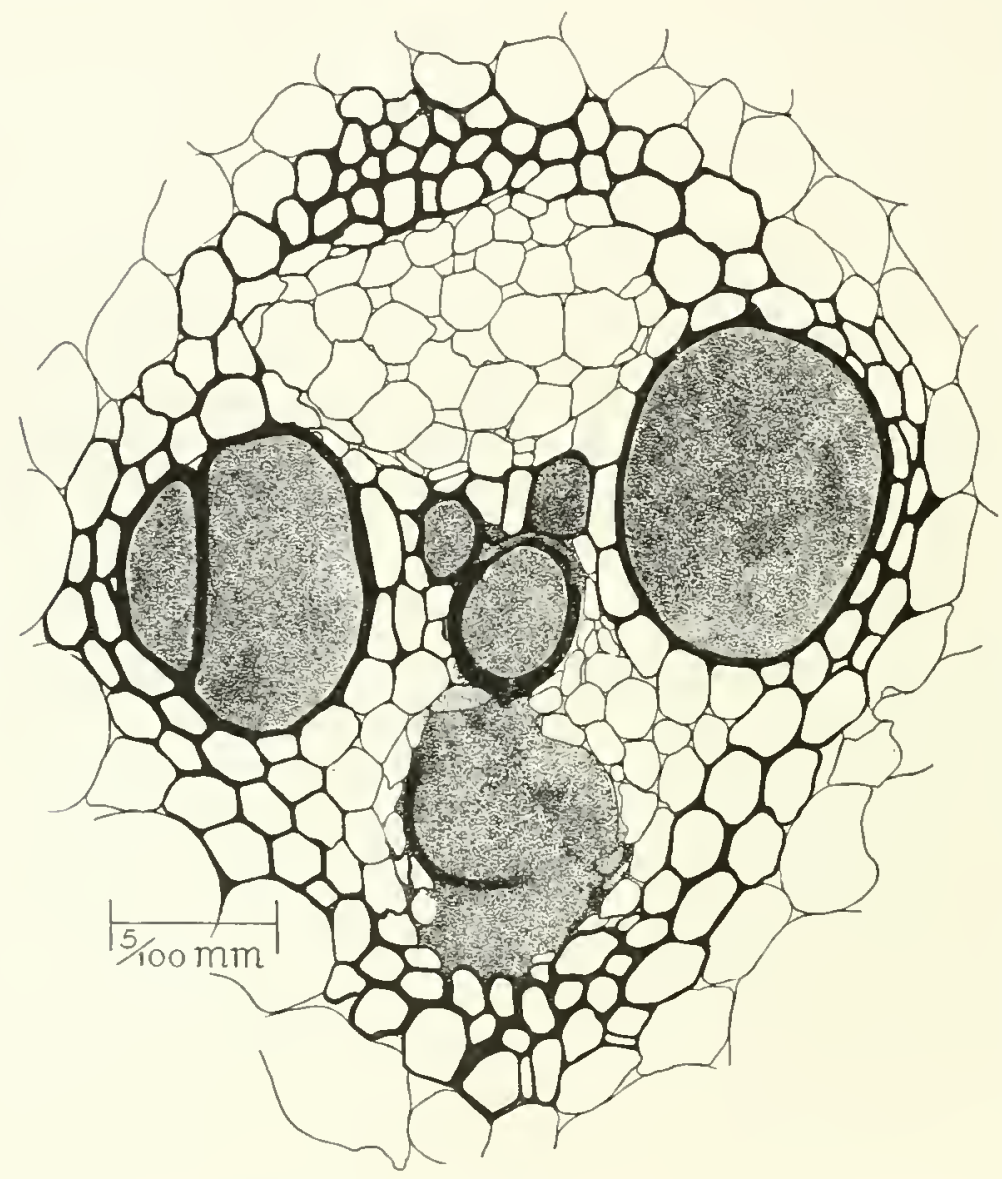

Fig. 20.*

Bact. vasculam was substittited for $B$. psendarabinus. stained the same color.

This bacterium grew upon fresh, sterilized portions of sugar-cane as white slime, while the mould during its growth upon [other samples of] the same substratum produced practically no color [except upon old portions of sugar-cane, where a red color is said to have developed], the older cultures only showing spots of pinkish aerial hyphæ, but when both bacterium and moukd were grown upon the [sane] cane a deep crimson color developed upon the outside of the cane where the gum was form-

*FIG. 20.-Cobb's disease of sugar-cane. Introduced for comparison with fig. I 9. The section is from the same stem, but in this bundle all the ressels of the xylem are occupied by the bacteria. The thin-walled tissue immediately above the vessels is phloem. Slide I2 I (7. perhaps by bacterial growth, or that the rapid growth of the the mould duced. At any rate two things are certain: (t) The mould can, under certain conditions, produce the color and cannot produce the slime, and $(2)$ the

Greig Smitl did not reproduce this disease by inoculations into living cane. The brilliant red pigment produced on glucose-gelatin did not form on levulose agar. On this medium it seldom produced a trace of color, but, on sowing the middle of a plate of nutrient levulose agar with the fungus and then the margin of one side of the same plate with his Bacillus pseudarabinus, a brilliant red color appeared as soon as the two organisms fused, and this crimson color developed not only throughout the colony, but in the neighboring region. He did not get the same result when A colony of Bact. sacchari and the medium was faintly bacteria do produce the slime. sels, perhaps by sap-pressure, 
ing. Upon cutting tlie cane across many of the vascular strings were colored; and finally the cotton wool upon which the cane rested also became crimson from the red gun which had flowed down the vessels of the strings. This experiment is, in my opinion, very significant as regards the combined (symbiotic) action of the mould and bacterium in producing a red gum in the large vessels of the vascular strings of the sugar-cane.

Apparently the sugar-cane lad been sterilized before inoculation.

To the writer this means simply that the red pigment is produced by the fungus when grown in an acid substratum and not when grown in a neutral or alkaline substratum. Nothing is said about the production of acids by the Bacillus, but it is stated to be a gas-producer, and from this we might infer the prodnction of sufficient acids for this purpose. The phe-

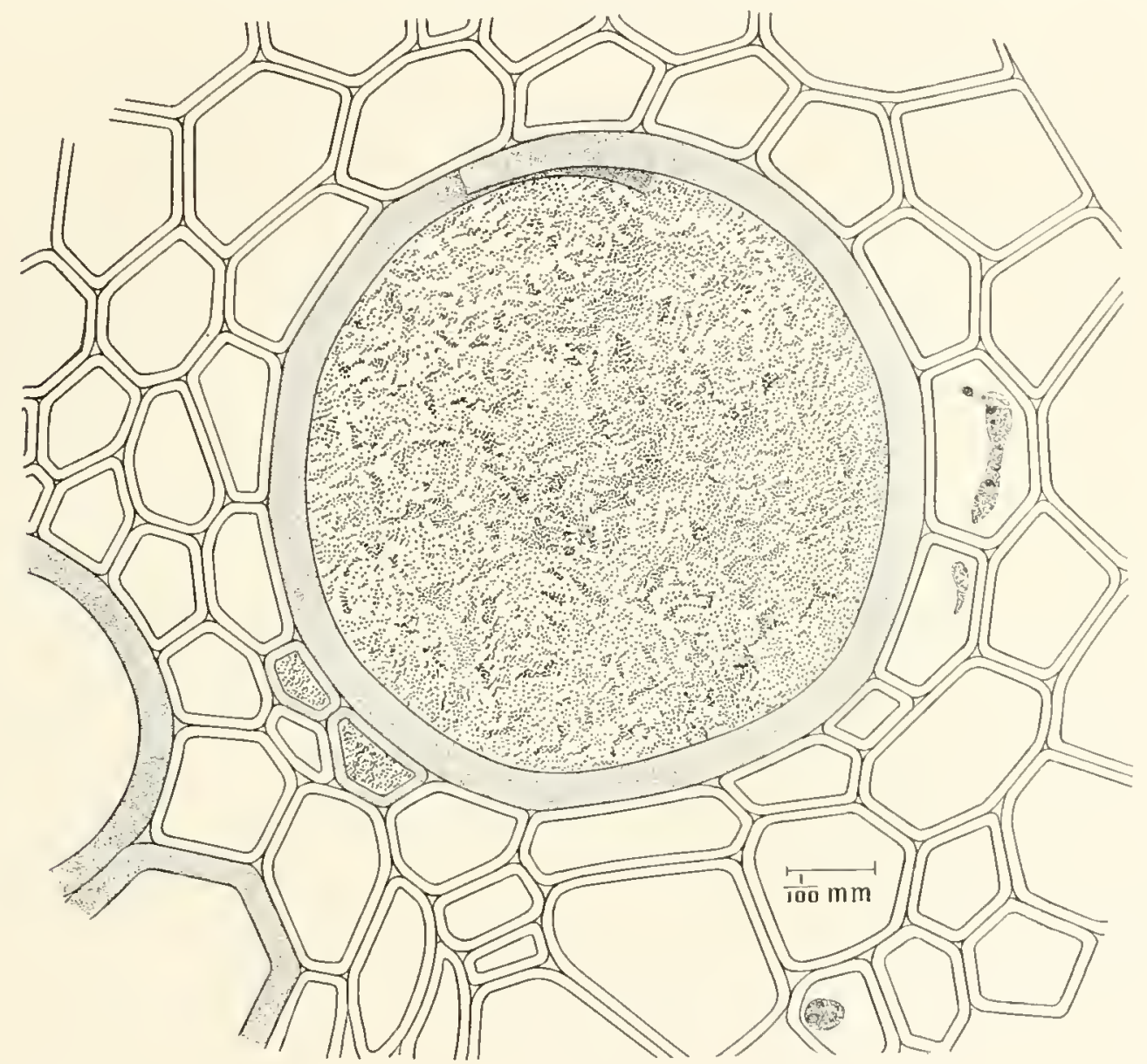

Fig. 2I.*

nomenon is not peculiar to this fungus, the writer having pointed out similar changes in color I 5 years ago in connection with his studies of species of Fusarimm, some of which remained white on alkaline media, but developed the most brilliant reds and purples on acid media. $\dagger$

The writer observed no fungus in the red strands of his inoculated cane plants and obtained on poured-plate cultures made therefrom, as already stated, only Bacterinm ias-

*FIG. 2 I. - Cross-section of cane-stem (inoculated plant No.6), showing three vessels occupied by Bacterium r'ascularum. Other vessels (at left) and connective tissue free. One normal nucleus and what appear to be two distorted nuclei are present. Fixed in 95 per cent alcohol. Slide 3 ro $(2$.

tSee Wilt Disease of Cotton, Watermelon, and Cow-pea. Bull. No. 17, Div. Veg. Patlı. and Phys., U. S. Dept. of Agriculture, Washington, 1899 , especially pp. 13 to 30. 
cularum, exception being made of inoculated plant No. 4, which was allowed to stand too long. Since the appearance of Greig Sinitlı's paper I have gone over slides made from these inoculated plants to see if I could have overlooked sucl a fungus. The red bundles contain an amorphous grantur substance, and sometimes bacteria, but no fungi were found.

\section{RELATION TO SEREH.}

Is this disease identical with Sereh, the Javanese "curse" of the sugar-cane? The signs are for the most part the same, $i$. $e$, red bundles, dwarfing, shortening of the internodes, etiolation, sprouting of the buds, transmission throngh infected sets, distorted terminal buds, etc. The writer has never seen the disease and so can make no personal observations.

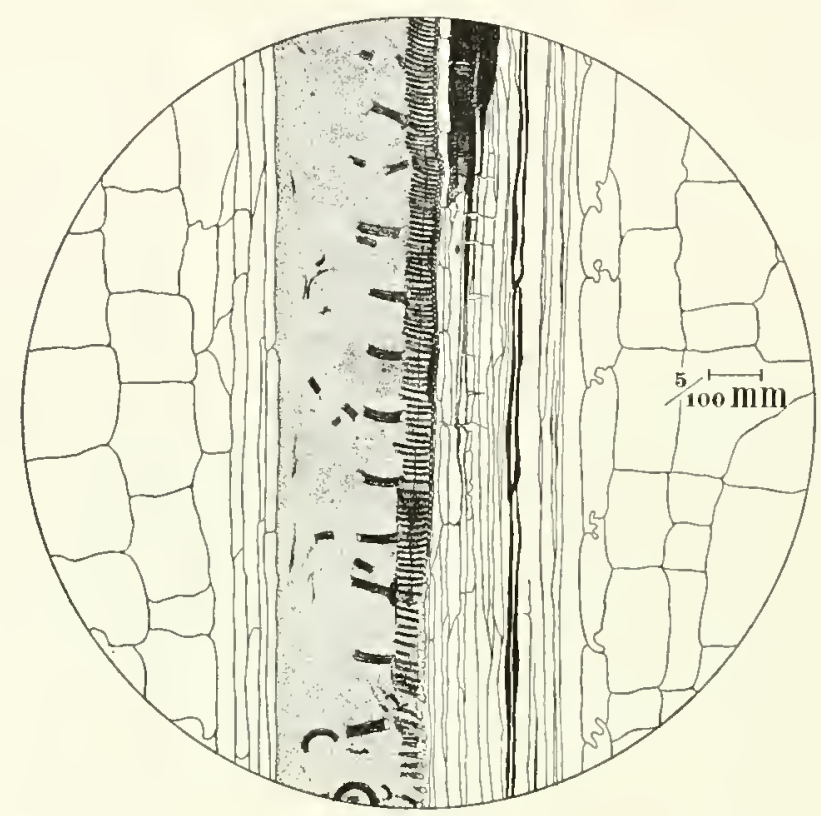

Fig. 22.* Janse and Krüger consider Sereh a bacteriosis of the bundles, but speak only of red gum and do not mention yellow slime in the bundles, at least not in any of their papers read by the writer. Valeton mentions yellow gum, however, and states that this precedes the red stain, and he appears to have given more attention to histology than any of his colleagues. Wakker and Went are opposed to this hypothesis. Went's observations in the West Indies, however, did not confirm him in his earlier belief that a fungus, Hypocrea sacchari, is the cause of Serel, for there he observed the same fungus on the cane but Serel1 was absent (verbal communication to the writer). Only this somewhat suggestive fact seems estabished, that Serel is not confined to Java (according to Krïger, it occurs in Malakka, Borneo, and Bangka), and Cobb's disease is found not only in Australia but also, it is said, in Java, Mauritius, and Brazil. It is very desirable that a good bacteriologist should make a careful study of Sereh. Perhaps two or more different diseases are now united under this name, one of which may be Cobb's disease. Query: Does Sereh occur in Australia? Went is inclined to believe that it does.

The subject of Sereh will be treated in the following chapter (p. 72 ).

\section{MORBID ANATOMY.}

Thereare no hy perplasias caused by this disease, but only occasionally roots out of place, premature development of axillary buds, and certain distortions of the terminal bud which might be taken for such. The disease is for the most part confined to the vascular system, the bundles of which are gradually filled with the bacterial slime. Figs. 19 and 20 show this very well. They were made from the Australian cane already mentioned as sent to ine for study. In one of these bundles all the vessels of the xylem are occupied; in the other the two larger vessels are free. The lysigenetic cavity is also filled. The phloem is not affected in either, nor the tissue surrounding the bundles. Such, however, is not always the case. In the upper part of the stem, just below the terminal bud, where the tissues are soft, the parenchyma is also attacked and numerons bacterial cavities are formed in it. In the

${ }^{*}$ FIG. 22.-Bacterium vascularum occupying xylem part of bundle. Like fig. 21, but cut longitudinally. Section from inoculated cane-plant No. 6 at the end of three months. Slide 3 ro $(20$, second section from left. 
writer's inoculated plants some of these closed cavities contained as much as a teaspoonful of the yellow slime (plate 4, and fig. 4). The organism also breaks out of the foliar bundles, especially when the leaves are immature, occupies the intercellular spaces very generally, making passageways between the cells, and comes to the inner surface of the leaf-sheaths and on the softer inner sheaths to the outer surface also, as a copious slime. Whether it exudes solely through stomata, or also sometimes makes openings of its own, is not known. I have found it oozing from the stomata on leaf-sheaths so commonly as to make it unnecessary to consider any other method of reaching the surface (figs. 5, 6, 7).

Figure 2 I shows in cross-section an early stage in the occupation of the bundle and figs. 22, 23, in longitudinal section, show later stages, with much disorganization of the tissues of the bundle, all three taken from inoculated plant No. 6, at the end of 3 months. When we reflect that the bacteria were not introduced into this stem directly, but that the plant was inoculated solely by means of a few needle-pricks on the blades of two leaves, and consequently that the bacteria had to travel or grow through the vascular bundles a distance of 4 or 5 feet to reach the tissues here figured, the short time required for the general infection and the enormous multiplication of the organism are astonishing. For a longitudinal section through a slightly diseased cane see fig. 24 .

The red stain, as already nentioned, is believed to be an oxidation product closely connected with the presence of the bacteria. Its greater abundance in the bundles occurring in the nodes is accounted for by the falling away of the diseased leaves and the entrance of air in larger amounts than would be possible on the falling away of normal leaves, the diseased leaf-traces being unable to heal over so as to exclude air. That the stain should also occur in much greater amount in the inter-

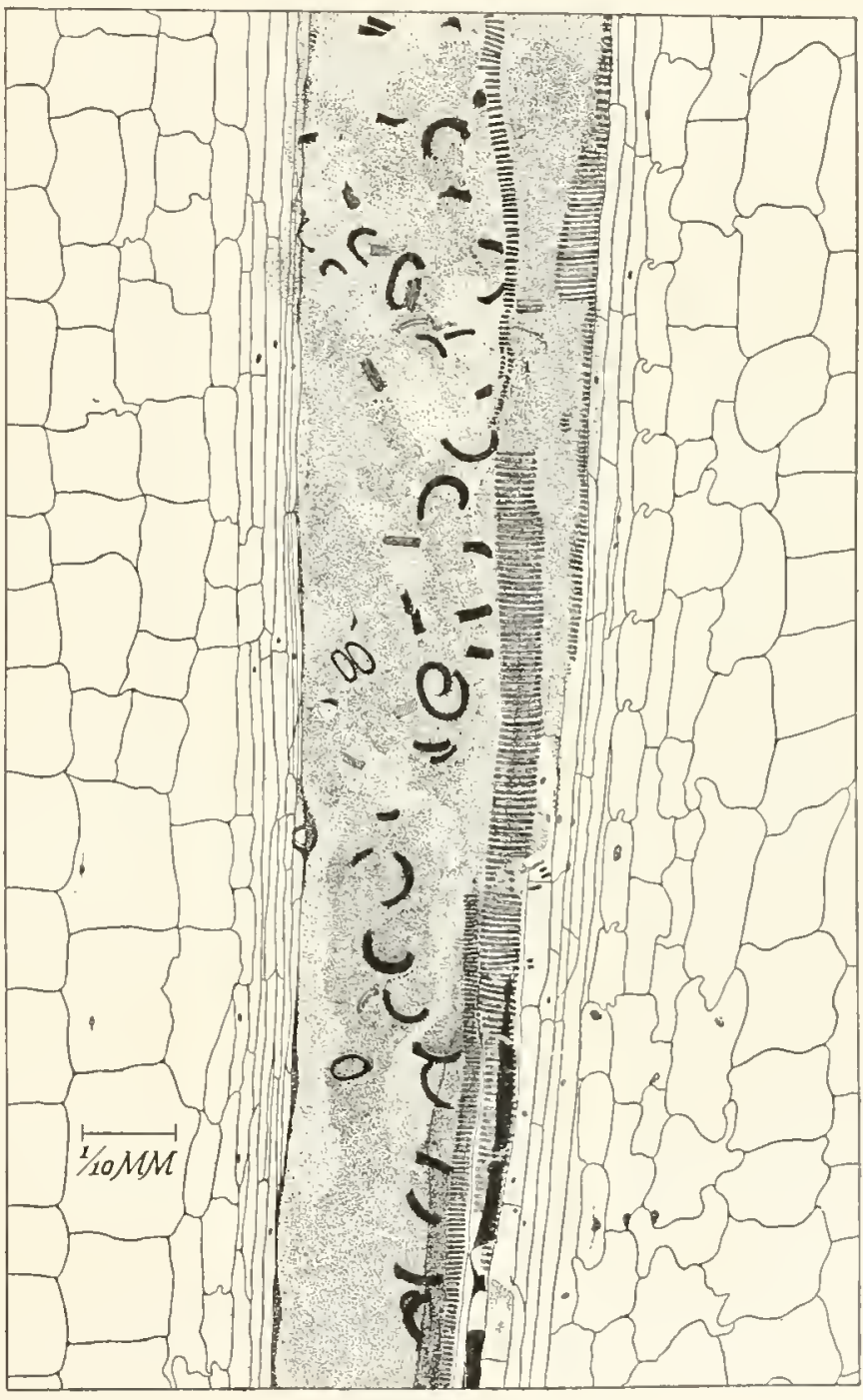

Fig. 23.* nodal bundles immediately below the nodes than in those immediately above the nodes is accounted for by the downward movement of the leaf-traces as they enter the stem. For evidence of the close connection between the red stain and the presence of the bacteria consult figs. I2, I3, 25, and various statements under Etiology.

*FIG. 23.-Longitudinal section showing the xylem part of a bundle wholly destroyed by Bact. vascularum. From plant No. 6. Slide 3 10 (13, left-hand section. For a detail see fig. 27. 


\section{THE PARASITE.}

Bacterim rasculam (Cobb) Greig Smitl* is a honey-yellow organism, occurring in the bundles of diseased sugar-cane as short rods, single, in pairs (mostly), fours, or eights, joined

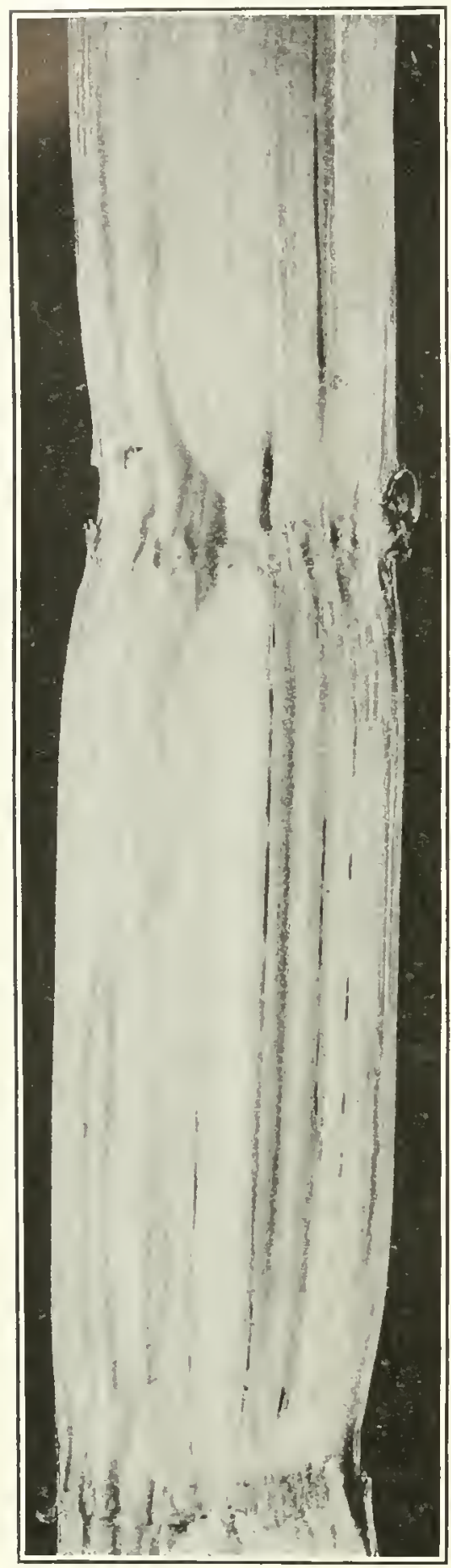

Fig. 24. end to end (figs. 26, 27). Sometimes the rods are clumped in the stem, i. c., in the form of psendozoogloeæ. The organism is motile by means of a single polar flagellum (RGS., EFS. $\dagger$ ). This is easily demonstrated according to Greig Smith by using the night-blue method and agar cultures (fig. 28). They were stained in the writer's laboratory by Löwit's method, using young agar cultures (fig. 29). The motility is more evident in young cultures than in old ones. The organism is generally non-motile when crowded in the bundles of the stem. This restricted motility is, however, observed under similar conditions in many other bacteria (see Bact. campestrc, vol. II, p.3I6). Rods stained and embedded in balsam have an average measurement of $0.4 \times \mathrm{r} \mu$ (RGS.). Fig. 30 is from a young culture on agar. The writer's measurements are as follows:

Bacterium zascularum from tissues of inoculated plant No. 4 , stained with carbol fuchsin; slide $466 \mathrm{~h}$ IO; average size $0.9 \times 0.4 \mu$; another slide 0.88 to $\mathrm{r} .0 \mu \times 0.3$ to $0.35 \mu$.

Plant No. 6, tissues stained with carbol fuchsin; average size, 0.65 to $1.2 \mu$ $\times 0.3$ to $0.5 \mu$

Plant No. 10, tissues stained with carbol fuchsin; average size, 0.6 to $\mathrm{I} .4 \mu$ $\times 0.3$ to $0.4 \mu$.

Plant No. 35, smear stained with carbol fuchsin; average size, I to I.4/ $\times 0.35$ to $0.5 \mu$.

A gar culture, 8 days old, stained with Löwit's flagella stain, slide 8, January I 1, 1906; average size, I. 2 to $1.5 \mu \times 0.45$ to $0.55 \mu$.

No spores have been observed (EFS., RGS.). It is stained fairly well by Gram's method, 4 111in. stain, 2 min. iodine (it does not stain by Gram, according to Greig Snit11). Carbol violet followed by dilute alcohol produces the best films, while the blues stain it but feebly (RGS.). The organism stains well with carbol fuchsin. The writer had poor success with Loeffler's alkaline metliylene blue.

Bactcrimm vascularum is easily isolated from diseased canes (when not too old) by means of Petri-dish poured plates. On plates of standard nutrient agar at $25^{\circ} \mathrm{C}$. the colonies come up rather slowly, $i . e_{\text {., in }} 7$ to 10 days, so that often for the first few days well-sown plates will appear sterile, or only sparsely spotted with intruding colo11ies. This will be better appreciated if I give transcripts from notes (made on the fourth, sixth, and eleventh days) of nine Petri-dish poured plates made from the interior of inoculated cane No. II:

Fourth day.-Many of the organisms must have been dead. There are as yet no growths on the plates, except one or two colonies which are not Bact. vascularum.

Sirth day.-Plate I, one colony which has become yellowish, but is much too opaque for Bacl. sascularum. Plate II, one small white colony. Plates III and IV, nothing. Plate $V$, one

*Synonyms: Bacillus vascularum Cobb; Psendononas sascularum (Cobb) EFS.

tRGS. = R. Greig Smith; FFS. = Erwin F. Smith.

$\$$ †IG. 24. - Longitudinal section through cane No. 30 (common purple) inoculated May 5, 1903. Only slightly diseased (the red bundles show here as dark stripes) and disease confined to the vicinity of the nodes which bore the inocilated leaves. Plates were poured. Photographed January. 5, 1904. 
fungus and one small whitish bacterial colony. Plate VI, nothing. Plate VII, nothing. Platc VIII, 2 white colonies. Plate IX, nothing.

The plates were now put into the incubator at $30^{\circ} \mathrm{C}$.

Eleventh day.-Plate I, one large opaque yellow colony, and hundreds of small yellow colonies of Bact.vascularum. A pure culture, with exception of the large colony. Plate II, one white colony and hundreds of the Bact. rascularum; a pure culture, with exception of the one white colony. Plate III, a pure culture of $\mathrm{Bact}$. s'ascularum. Plate contains several hundred colonies and those which have broken through to the surface are circular, quite transparent, and 1 to $5 \mathrm{~mm}$. in diameter (fig. 31). Plate IV, hundreds of colonies of Bact. vascularum, a pure culture. Plate $V$, one fungus colony and one white bacterial colony; with these exceptions a pureculture; hundreds of minute yellow colonies of Bact. vascularum. Plate VI, a pure culture with at least Ioo colonies, transfers. Plate VII, a pure culture.

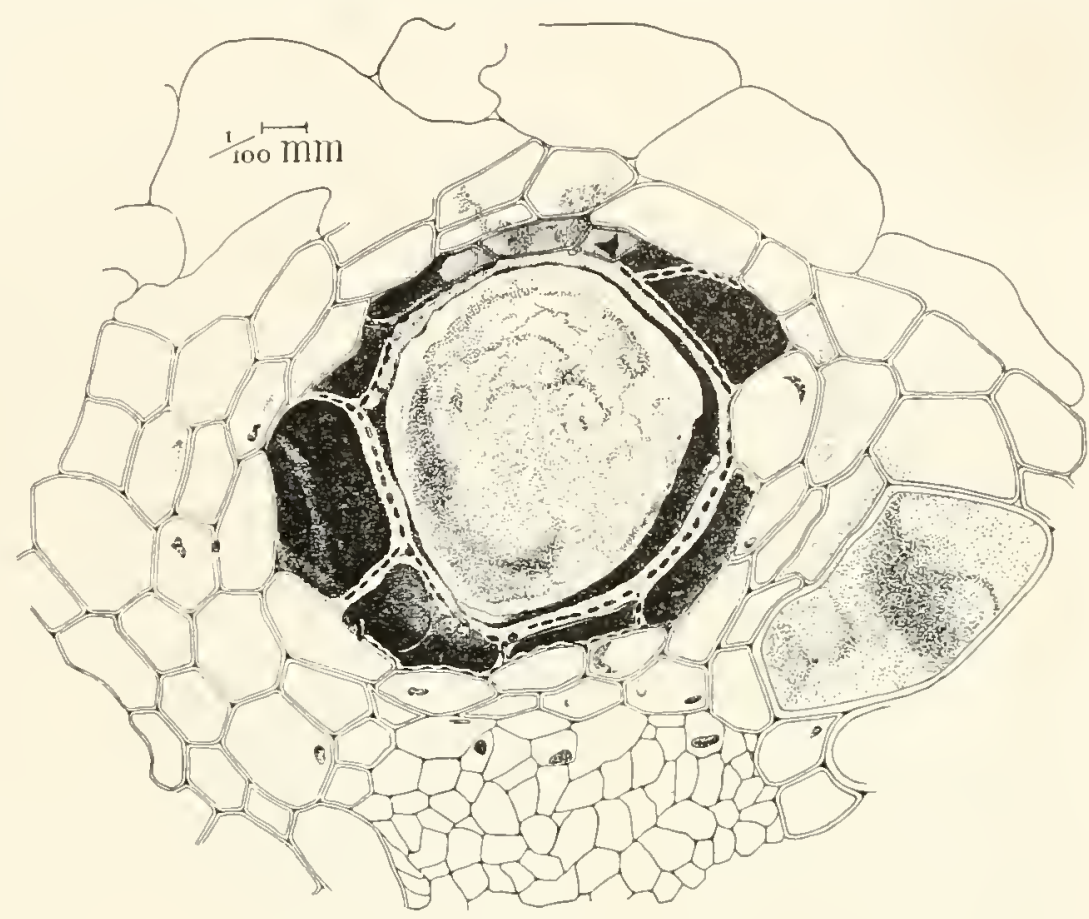

Fig. 25.*

Plate VIII, same, with exception of two intruding colonies. Plate IX, a pure culture.

Colonies on VII to IX too close together to estimate their number; 2,000 at least on each plate.

The colonies appear sooner on plates made from young cultures.

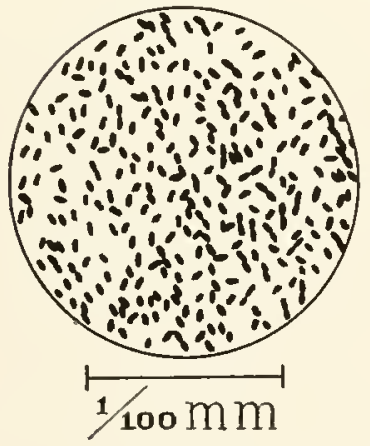

Fig. $26 . \dagger$

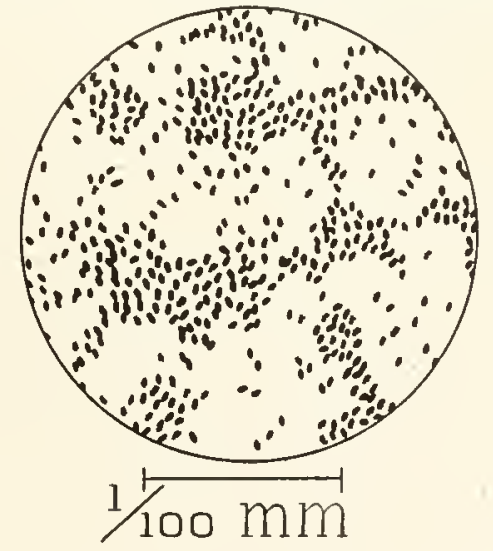

Fig. 27.

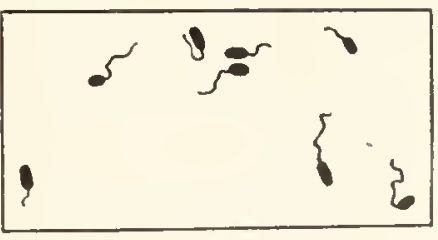

Fig. 28.8

The well-developed surface colonies in uncrowded agar plates are + to $6 \mathrm{~mm}$. in diameter (occasionally $8 \mathrm{~mm}$.), pale-yellow, wet-shining, rather flat, with sharp margins and no distinct appearance of granulation under a hand-lens magnifying 6 times (fourteenth day).

*FIG. 25.-Cobb's disease of sugar-cane: Cross-section of a small bundle from an inoculated plant, showing the bacteria, and red stain (the dark parts). Slide 299 A 2, lower left section.

†FIG. 26.-Bacterium vascularum: A detail from slide 3 ro ( 7 ; $i$. e., from fig. 12 , near location of micrometer seale.

Fig. 27. - Bacterium vascularum: Detail from the cavity shown in fig. 23.

$\$$ FIG. 28.-Flagella of Bacterium vasculartm stained by the night-blue method. After 12. Greig Smith. 
They give a decidedly alkaline reaction to moist litmus paper and are not noticeably viscid (fourteenth day). On opening plates of this age they had a peculiar smell common to many bacteria (trimethylamin ?). The buried colonies are elliptical-pointed or spindle-shaped, and small.

On slant peptonized beef-agar the organism makes a thin, rather scanty, wet-shining, pale yellowish growth which is sometimes scarcely distinguishable from the agar itself. In some streaks 5 days old the penholder was visible through three superposed tubes. The streak is finely granular under the hand-lens. A small amount of pale yellow precipitate forms in the fluid in the $V$ and numerous prismatic crystals are sometimes present in the agar; 200 or more of these crystals were observed in a single tube.

In beef-agar stab-cultures there was a variable growth in the stab, often fairly good the whole length, but always thinning out below and sometimes scanty. There was a good, wet-shining, pale yellow surface growth. In one set of tubes inoculated from slant agar and described the third day, the nail-head was 4 to $5 \mathrm{~mm}$. in diameter, wet-shining, and maize yellow. The slime of very old cultures may be buff-yellow. The agar is not stained.

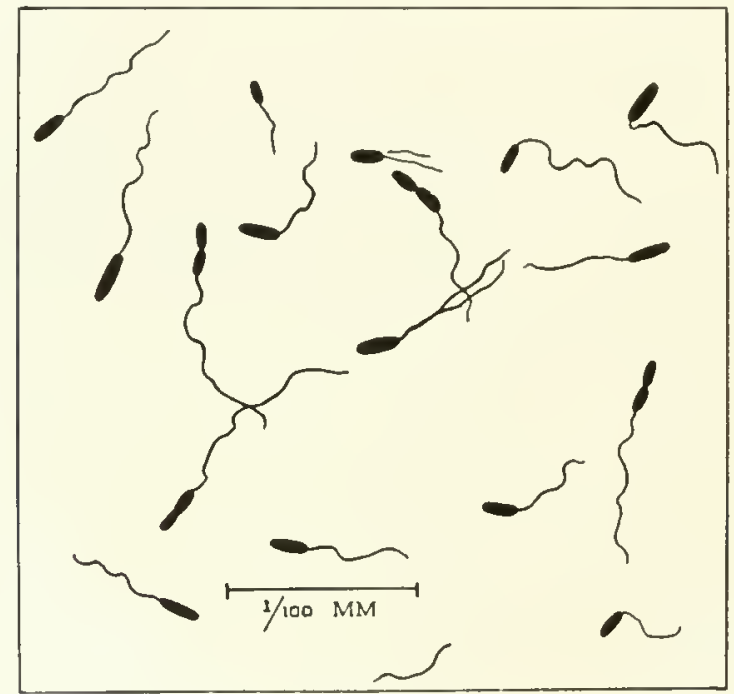

Fig. 29.*

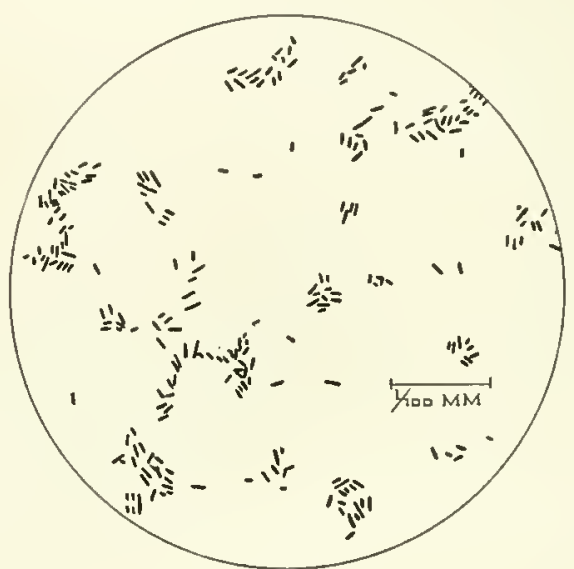

Fig. 30.†

On agar with cane-sugar or fruit-sugar there is slow growth at $30^{\circ} \mathrm{C}$. or under (RGS.).

Greig Smith describes the streak on slant glycerin agar as "a thin, broad, translucent white, moist, glistening growth, with turbid condensed water. The color deepens to a primrose-yellow."

On agar containing 10 per cent saccharose and 0.1 per cent peptone there is a thin, white fluid growth, which gravitates into the condensed water, in which there is a yellow sediment (RGS.).

A very good medium is a solution of 4 per cent agar added to an equal amount of neutralized cane-juice containing 0.5 per cent peptone. With a greater per cent of peptone there is better growth at first, but ultimately less (RGS.).

The writer obtained a very copious growth on slant tubes of sugar-beet agar, as much growth as on cane-juice agar. This medium was made as follows: Juice of sugar-beets 300 ,

*FIG. 29.-Filagella of Bacterium vascularum stained by Löwit's method. Selected samples irom a cover-glass preparation (young agar culture in sterile water). Slide B, mordanted one-half minute, stained 5 minutes, Jan. 9 , 1906.

†FIG. 30.-Rods of Bacterium vascularum from a young agar culture stained by Löwit's method. MIordanted 0.75 minute, stained 2 minutes. A few flagella show feebly in some places. Slide A, January 9, 1906. 
Witte's peptone 15 , cane-sugar 15 , agar flour 4.5 , autoclaved for 15 minutes at $110^{\circ} \mathrm{C}$. The surface growth was wet-shining and about a cubic centimeter of pale yellow slime aecumulated in the $V$ of each tube.

The growth on potato-agar was somewhat better than on beef-agar; there was a smooth, wet-shining, yellow streak (fig. 32), varying from seanty to abundant.

On litmus-lactose-agar there is a very scanty to moderate growth, with slow but distinet bluing and no reduetion of the litmus. No acid is formed.

On Hunger's agar (Mr. Johnston's notes) there is a very noticeable difference in the growth, depending on whether the monobasic or dibasic phosphate is used. When the monobasic (acid) salt is used there is a growth rather liglit yellow in color, while with the dibasic salt it is rich yellow with paler edges, and is much more luxuriant, although not heaped up as in the case of Bactorium phascoli.

Greig Sinith gives the following description of the organism in glucose-gelatin plates:

The colonies develop slowly. In 7 days at $22^{\circ} \mathrm{C}$. they are $\mathrm{I} \mathrm{mm}$. in diameter, and appear as small, raised, viseid drops. When magnified 6o-fold [see fig. 33] they appear round and uniformly granular, like a thin yeast colony, the deep colonies like those upon the surface. In 20 days the colonies reach a diameter of + to $8 \mathrm{~mm}$. and look like drops of yellow beeswax. The medium shows no signs of liquefaction, but when the colony is scraped or washed off a pit is revealed.

Growth in the absence of glucose is similar but much slower (RGS.).

In cane-juice gelatin-stabs

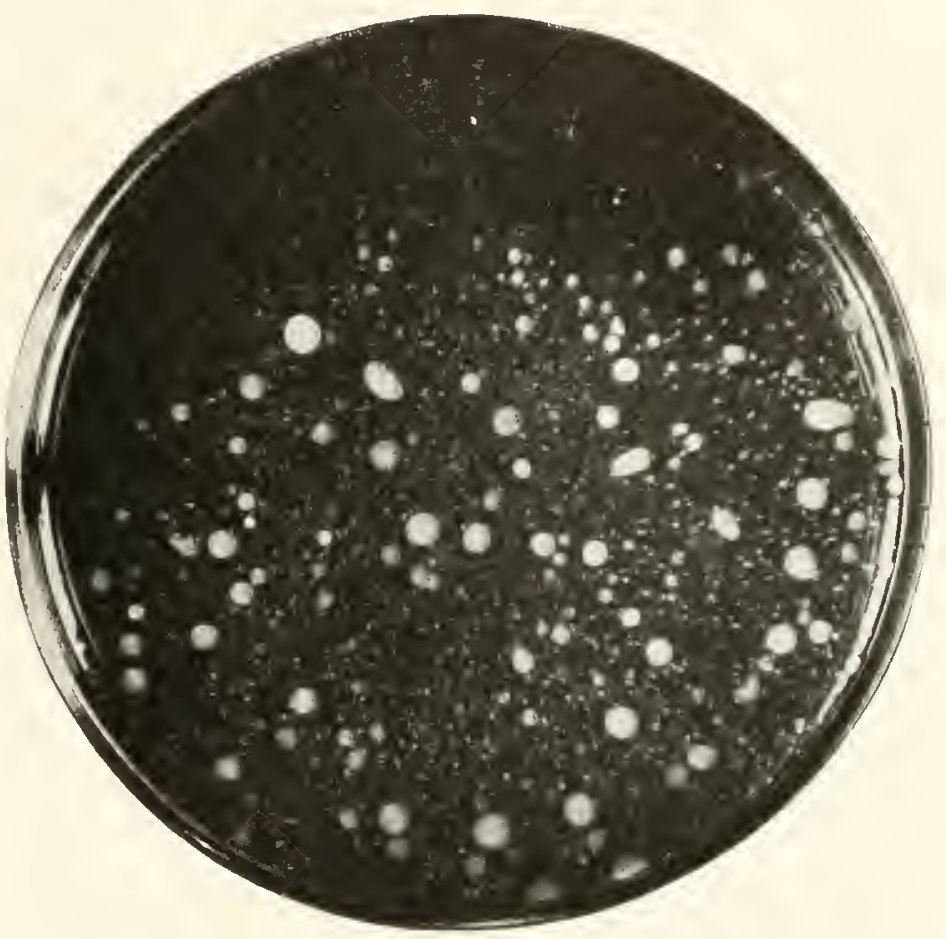

Fig. 31.*

there is a smooth, piled-up, restricted yellow surface growth. There is no liquefaction (possibly in some instances there was an unobserved slight liquefaction, $i$. $є$., a sinking in of the nail-head), no production of gas, no stain, and no formation of crystals. Greig Snith reports slow growtl on gelatin in the presence of cane-sugar or fruit-sugar at a temperature of $30^{\circ} \mathrm{C}$. or under. In a gelatin stab ( $\operatorname{ctock} 1,000 \dagger$ ), inoculated from a young culture on litmus lactose agar and kept mostly at $22^{\circ}$ to $24^{\circ} \mathrm{C}$., there was at the end of two days a yellow, wet-shining, restricted (piled-up) surface growth and a needle-track best developed in the top layers of the gelatin. There was no liquefaction in 20 days. The surface growth remained piled $11 \mathrm{p}$ and restricted. Separate colonies were visible only in the lower part of the stab. No crystals appeared, no stain, 110 gas.

In six tubes of nutrient gelatin composed of roo distilled water, 10 gelatin (Nelson's photographic No. 1), 0.5 Witte's peptone, 0.5 dipotassium phosphate, and 0.02 malic acid,

*Fig. 3 I. -An agar-poured plate of Bacterium ascularum (a pure eulture) i 1 daysold. Plated from the interior of plant No. I r. Photographed April 27, 1903.

†A + is gelatin containing beef-broth, Wilte's peptone, 10 per cent Nelson's No. t gelatin, and sodium lydrate. 
inoculated from young potato cultures, there was in 7 days a very feeble growth restricted mostly to the upper part of the stab and yellow only at the surface. The cultures were followed for 43 days, but there was no increased vigor of growth; no crystals, liquefaction, or staining of the gelatin occurred.

In six tubes of the same gelatin with addition of a per cent cane-sugar, growth at the end of 43 days was about double. These tubes were inoculated at the same time from the same cultures as the preceding, and were subject to the same conditions. Even in this medium, growth was rather feeble and there was no liquefaction. Probably the medium was too acid.

This inference was confirmed by subsequent experiments in the same medium neutralized with sodium hydrate. There was a comparatively good growth at the end of ro days, but 110 liquefaction. At the end of a month there was a strong growth the whole length of

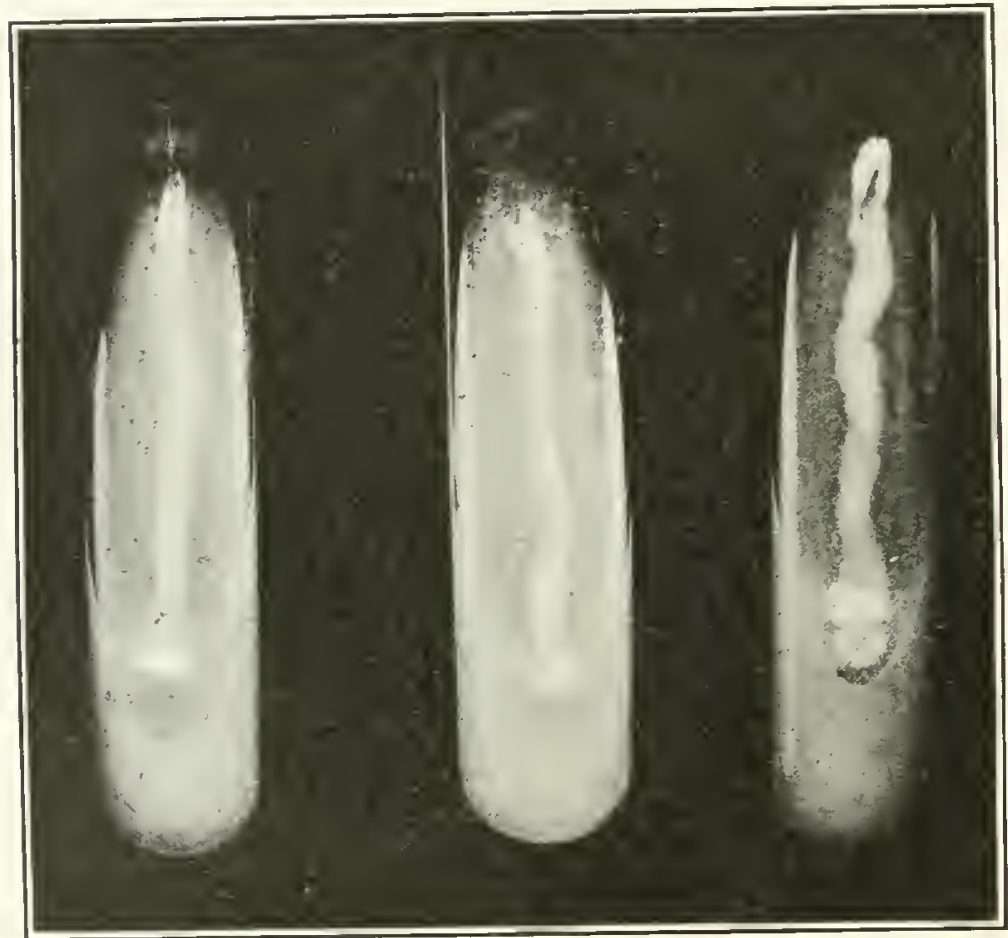

Fig. 32** the stab, thinning out below, whitish also below (where air was less abundant) and pale yellow in the upper half. The surface growth was paler yellow and more extensive than in the same 111edium without the alkali; the nail-head was also sunken into the gelatin a little, as if there had been slight liquefaction.

Experiments with gelatin, to which filtered canejuice had been added, yielded interesting results. In streaks on stock 727 the organism made a fairly good but not a very vigorous growth. On the forty-third day the growth was distinctly yellow (in contact with the air) and at least ten times as abundant as in the gelatin containing peptone, dipotassium phosphate, malic acid, and cane-sugar. The surface growth was restricted (piled up), smooth, wetshining, and Naples yellow in color. There was no liquefaction. The gelatin was not stained and no crystals were present. Growth started off slowly. The temperature varied somewhat, averaging about $20^{\circ} \mathrm{C}$. This stock was prepared as follows: juice of Common Purple cane 250 c.c., distilled water 750 c.c., Nelson's No. I gelatin 100 grams. On the same stock rendered sliglitly alkaline (to phenolphthalein) by the addition of $\mathrm{NaOH}$ (stock 741 ) there was only the least trace of growtl in 5 out of 6 streak cultures. On the sixth streak, in course of 2.5 months, the organism succeeded in getting a start, but piled up locally in a very striking manner. There were many of these bacterial masses, most of them approximately circular, i to $8 \mathrm{~mm}$. in diameter, and some of them $2 \mathrm{~mm}$. high. Their color was about Ridgway's maize yellow. There was no liquefaction of the gelatin. Six stab

*Fig. 32.- Streak-cultures of Bacterium vascularum on potato agar. Subcultures from three different plants $(7,9$, and II), inoculated Feb. 6, 1903. Streaks made Nov, 2, 1903. Photographed after several days. 
cultures made at the same time yielded no better results. There was a trace of growth in the mouth of the stab, but none below the surface and no spreading over the surface, not even in a month's time. 'This failtre is probably attributable to excess of sodium hydroxide, since when this substance was reduced one-half by mixing equal voltumes of 727 and $7+1$ the organism finally grew much better, although the growth was scanty at first.

On gelatin made in the sane way but with juice of the Common Green cane (stock 750) the growth was scanty for the first two weeks, then better, bitt by 110 means copious. This growth (surface) was at first rough granular, then smooth. There was no staining or liquefaction (7o days). There was a beaded stab, most growth being on the surface. Streak cultures developed in a similar slow manner and there was no liquefaction in them. When I per cent Witte's peptone was added to this same stock there was from the start distinctly more growth (several times as much), although not very copiotts. Subsequently there was a copious growth. This was the only one of the cane-juice gelatins on which there was what might be styled a good growth. The growth in the stab was better developed and the surface growth was smooth from the start. There was no liquefaction, but eventually some browning of the gelatin. In the streak cultures the growth was at first reticulate-roughened, then smooth, with tear-drop formations sliding down into the $\mathrm{V}$, where at least 0.75 c.c. of straw-yellow slime collected in course of a month, but without liquefaction (fig. 34). On long standing there was a feeble browning of the more exposed parts of this gelatin.

The character of the growtl was quite similar in all of the gelatins. Sometimes, especially when the medium was not well adapted to growth, the surface was reticulate-roughened at first, but the reticulations themselves, as seen under the handlens, were smooth. Later the surface growth became smooth. In tubes placed in an upright position the

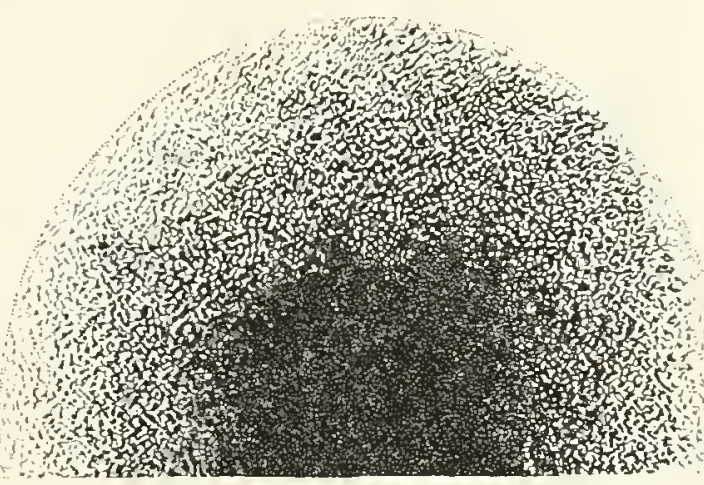

Fig. 33.*

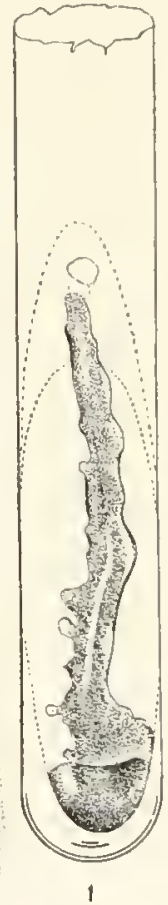

Fig. $34 . \dagger$

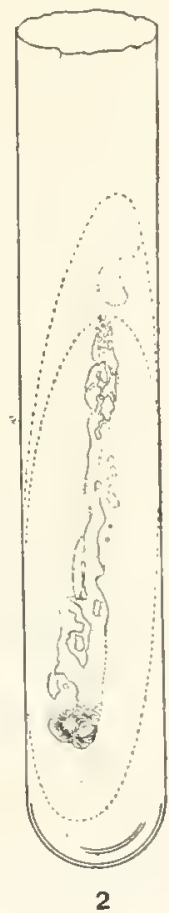

2 slime collected in places along the streak and piled up at the bottom of the slant in a claracteristic manner, very well described by Greig Smith as a "tear-drop" formation (fig. 35). Some of these piles were $2 \mathrm{~mm}$. high. There was very little depth of slime on the rest of the streak. A feeble browning of the more exposed parts of the gelatin (75 r) took place after long standing ( 9 weeks). In most of the gelatins there was no liquefaction.

In one set of streak-cultures the record states that there was noderate liquefaction on the forty-fourth day, but none on the twenty-fifth day; and in one set of stab cultures the nail-head settled into the gelatin slightly after some weeks.

*Fig. 33. - Colony of Bacterium vascularum on glucose gelatin. $X$ 85. After R. Greig Smith.

FFIG. 34. - Streak-cultures of Bacterium vascularnm after $2 \mathrm{I}$ days at $18^{\circ}$ to $23^{\circ} \mathrm{C}$. On cane-juice gelatin with and without peptone (250 c.c. expressed juice, $750 \mathrm{c}$.c. distilled water, io per cent Nelson's shredded photographic gelatín). 'Tube No. I received in addition I per cent Witte's peptonum siccum, and contained roo times as much growth as tube No. 2. On this peptone gelatin the organism showed a strong tendency to pile up and run down into the $V$ (see fig. 35). The color of the slime was straw yellow (Ridgway). There was no liquefaction. 
Greig Smith states that there is very slow liquefaction both of cane-gelatin and ordinary gelatin. This is seen usually only as a slight depression of the medium under the streak.

On ordinary gelatin, according to Greig Smith, the growth is scanty and ivory white in color. By this he means, perhaps, the pale yellow of old ivory. The organism I have studied is not pure white on any medium, although for the first few days it might be thought to be so. In streak-cultures the slime slowly gravitates to form a yellowish-white mass at the bottom of the slant (RGS.). On glucose-gelatin the growth is less luxuriant and less decply colored than on cane-gelatin (RGS.).

There was a striking difference in the amount of growth on steamed cylinders of Common Green cane and that made on Striped Green, Common Purple, and Striped Purple cane. On the first-named variety there was at least 50 times as much growth as on the others. On the last three there was little growth, while on the other growth was good though not copious. Greig Smith obtained no growth on slices of cane (variety Rappoe?) inocu-

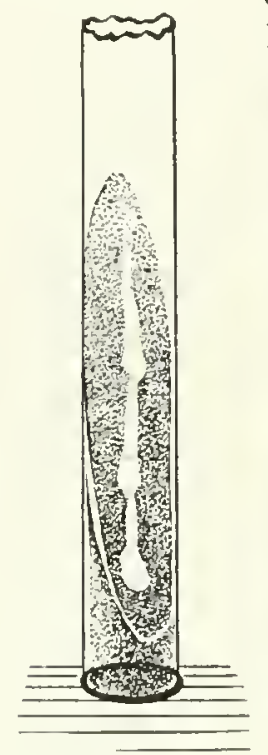

Fig. 35.* lated with Bact. vascularmm.

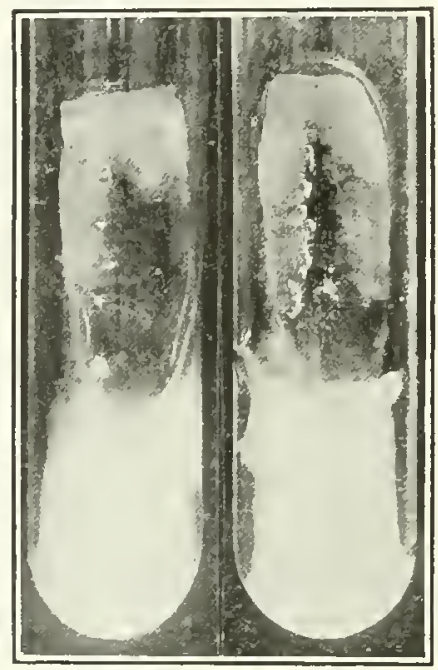

Fiz. 36. $\dagger$ The organism makes a much better growth on potato-cylinders and on coconut-cylinders.

The growth on potato is generally better than on agar (see pl.11, fig. 13). It is moderately abundant, i.e., about like that of Bact. hyacinthi, but with rather more slime in the water (fig. 36); surface growth smooth, wetshining, and yellow (between Ridgway's canary yellow and lemon yellow), occasionally it is Naples yellow or between lemon yellow and gamboge yellow (3 days). The palest yellow (4 days) was between primrose yellow and straw yellow. Growth is sometimes raised and restricted, sometimes flat and watery, spreading over the surface (RGS.). Growth on potato is good rather than copious, and ceases early, indicating that the organism has only a small ability to obtain its food from the potato-starch. Repeated tests showed much starch present, even in old cultures. Mashed cylinders became deep bluish-purple or wine-purple in iodine water. The undisturbed surface layer became dirty purple or brown-red. The growth is 'mostly out of the water. There is 110 such rapid destruction of starch and piling up of the bacteria in the water as occurs in cultures of Bacterim campestre.

The slime is distinetly yellow on all potatoes, but bright yellow on some and paler on others. The potato is moderately grayed, but mostly out of the water. Old cultures (43 days) were alkaline to litmus. Young cultures are also alkaline.

On beet-cylinders (acid medium) there is only a small amount of growth, but on steamed onion-bulbs and cauliflower-cylinders there is a good growth of the organism.

On carrot and turnip there is a raised, slimy, yellow growth, at first restricted, but eventually covering the surface and gravitating (RGS.).

There is a good yellow growtl on coconut-eylinders which remain unstained.

Bacterimm iascularm makes a good, though not copious, growth in +15 peptonized beef-bouillon. There is moderate clouding of the fluid, beginning usually within 24 to 48 hours, and when the tube is shaken there are distinct rolling clouds. Sometimes the cloud-

*FIG. 35. - Tear-drop formation of Bacterium rascularum on cane-juice gelatin. After R. Greig Smith.

$\nmid$ Fig. 36. - Streak-cultures of Bacterium vascularm on potato cylinders (the lower part in water) after 8 days at room-temperature. Potato grayed out of the water. The darkest part is the wet-shining yellow slime. Each tube inoculated from a single poured-plate colony. 
ing is much slower ( 4 to 7 days). The fluid is never what might be called turbid, but pseudozoogloeæ are sometimes present in small numbers, and there is a small amount of pale yellow precipitate (Ridgway's primrose yellow or a little deeper, to his maize color or Naples yellow). A $3 \mathrm{~mm}$. loop from a feebly clouded bouillon culture 24 hours old clouded feebly io c.c. of +15 standard beef-bouillon on the third day at $25^{\circ} \mathrm{C}$; a $2 \mathrm{~mm}$. loop of well-clouded bouillon 6 days old did the same at the end of about 24 hours. After 7 days' growth in peptonized bouillon one could usually see a pencil through $70 \mathrm{~mm}$. of the cloudy fluid (4 tubes, one behind another).

Notes of December 5, 1902, on six tube-cultures of Bacterium vascularum, made November 12, 1902, in standard peptonized bouillon (stock 712), as checks for thermal death-point experiments: Fluid moderately cloudy in each one; rolling clouds on shaking; no pellicle, and in most no trace of rim; in others the merest outline of a whitish rim. Can not detect pseudozoogloeæ even with the hand-lens. Precipitate distinctly yellow and $5 \mathrm{~mm}$. broad. Pencil easily visible throngh 2 of the tubes (in series), less plainly so through 3 , barely visible through 4 , not visible through 5 . These 5 tubes make a diameter of $9 \mathrm{~cm}$. Organism not a copious grower in this bouillon. After 2 to 3 months the fluid becomes clear, but is not browned (once slightly). There is no rim, or only a faint whitish one which nnay be 2 to $3 \mathrm{~mm}$., or more, in width. In only one set of transfers was a pellicle noted; this was thin and easily shaken down. Prismatic crystals are often present. After 70 days about 7 to $14 \mathrm{~mm}$. breadth of the pale yellow, fine-grained precipitate may be present on the bottom of the test tube.

Experiments with bouillon of different degrees of acidity and alkalinity, i.e., titrating $+25,+15,0$, and -20 with phenolphthalein, have given the following results: The + I 5 bouillons clouded first and in the end gave most precipitate. At the end of 9 days the $+\mathrm{I} 5$ showed the best growth, $i . e ., 8$ or ro times as much precipitate as in neutral bouillon; the neutral bouillon the next best, then +25 ; the -20 bouillon was very fecbly clouded with almost no precipitate. Six days later the order was: Neutral, densely clouded, $i . e .$, more so than $t_{15}$, but less precipitate; $t_{15}$, well clouded, heaviest clouding in the uppermost centimeter; +25 , as well clouded as lower part of +15 and uniformly, but much less precipitate than in $+15 ;-20$, feebly clouded. In a later experiment, using $-6,-4$, neutral, +26 , +28 , and +30 bouillons (Mr. Johnston's notes), the best growth was in the acid bouillon; +26 , +28 , and +30 were very heavily clouded, the neutral bouillon well clouded (probably corresponding to E. F. Smith's "moderately clouded"), and one of the -6 tubes lightly clouded. The other -6 tube and both -4 tubes were clear. All of the cultures were transfers from the same tube - a beef-bouillon culture 8 days old. The acid was that of beef-juice.

Greig Smith obtained no growth in acid fluids such as wort and cane juice, and scanty growth in neutral fluids, but does not state what fluids nor what indicator was used.

The organism grew in beef-bouillon with plenolphthalein, witl or without the addition of potassium formate, but in neither case did the fluid become red.

There is a moderate clouding of nitrate bouillon, but no reduction of nitrates to nitrites (RGS., EFS.). At the end of a week in this medinm, inoculating from cultures on slant agar, all of 6 tubes were uniformily clouded, free from pellicle and rim, no pseudozoogloeæ were visible to the naked eye in the unshaken tubes, and the penholder was distinctly visible through three tubes, and barely so through four, placed one behind another. Similar results were obtained by inoculating from six potato cultures.

Litmus-milk-cultures (pl. II, figs. I O, I 1, I2) gradually become a deep indigo-blue (30 days, 54 days, 74 days, 6 months). Some tubes 38 days old are recorded as deep blue, near Saccardo's atrocyaneus (sapphire of Standard Dictionary, nearly). The bluing begins to be noticeable about the fourth or fifth day. No acid is produced. The milk was lavender or lilac when inoculated. There is no reduction of the litmus or precipitation of the casein, the milk remaining perfectly opaque and fluid. The milk does not becone viscid (45 days, 75 days). A distinct yellow precipitate was formed, but in most tubes there was very little 
evidence of growth at the surface; in a few there was a distinct yellow rim and pellicle (sixteenth day). Old litmus-milk cultures ( 7 months) were dried down to about one-eightl of the original volume: The liquid was then thick, syrupy, or gelatinous, and very dark-colored. There were no tyrosin crystals, not even in very old cultures. According to Greig Smith, milk cultures give a neutral reaction and the fluid remains unaltered. I attribute this statement to incomplete observations, $i . e$., of first stages only of growth in milk.

In Uschinsky's solution there is sometimes a feeble clouding, sometimes none at all. Out of six attempts to grow the organism in this medium three failed utterly, although the transfers were made from cultures known to be alive and the inoculations were copious. The following is a note on two sets which did cloud:

'Tubes of Uschinsky's solution, inoculated from young agar streaks, were feebly clouded at end of the first day, and thinly clouded at end of the seventh day with a scanty yellowish precipitate, and without rim, pellicle, or pseudozoogloeæ. These tubes were followed for 16 days longer, but there was little change. The organisn did not grow well in this medium (stock 982). In another set of six tubes (stock 738) inoculated each with a $3 \mathrm{~mm}$. loop from bouillon cultures 2 days old, all were clear on the sixteenth day. On the thirty-ninth day two were clouded with a small amount of Naples yellow precipitate. 'Iwelve days later the other four tubes clonded.

To test the action of the organism on cane-sugar, cultures were made in water containing Witte's peptone and I per cent cane-sugar (stock 809). The fluid became uniformly thinly clouded (penholder barely seen behind four tubes, eaclı $16 \mathrm{~mm}$. in diameter). A yellowish-white rim and a pale yellow precipitate appeared. On the twenty-second day the cultures were tested with Soxhlet's solution. There was a distinct reduction of the copper sulphate on boiling lialf a minute. 5 c.c. of the alkaline fluid and 5 c.c. of the solution of copper sulphate in 50 c.c. of distilled water were used in each case, the fluid brought to a boil in a clean porcelain capsule, and then the cultures added. It required about is 5 c.c. of the cloudy culture-fluid to reduce all the copper in 5 c.c. of the copper sulphate solution, boiling 2 minutes. There was a reducing substance in the cultures, and it is reasonably certain to have come from the breaking-up of the cane-sugar into simpler sugars. The uninoculated stock was tested as a clicek, but there was no such reaction: The fluid became and remained a hyacinth blue. Previous to this an old cane-juice gelatin culture (stock 751 ) had been tested in a similar manner, but there was very little reaction while the uninoculated cane stock showed an abundance of reducing sugar in it on boiling 2 minutes with Soxhlet's solution. There was more reduction in the two uninoculated cane-juice gelatins ( $75^{\circ}$ and $75 \mathrm{I}$ ) than in the 4-months-old culture tested. This probably means that the reduced sugars had been consumed as food.

Greig Smith on the contrary says that the organism does not secrete invertase. In his experiment saceharose-agar cultures were melted, dissolved in water, and treated with basic lead acetate, etc. (Linn. Soc. Proc., I 902, p. 44.) Only 3 per cent of the saccharose had been inverted to fruit-sugar, a quantity which lie thinks the lyydrolytic action of the small amount of acid in the medium might easily have produced. Cobb is also of the opinion that the organism does not act to any appreciable extent on cane-sugar. To determine the action of Bacterim vascularmm on cane-sugar lie put $457 \mathrm{mg}$. of the air-dried gum obtained from diseased canes with I gram of pure cane-sugar into ro c.c. of water and allowed it to stand 3 days. The solution was then tested. It was exactly like the check-tube, $i, \epsilon$, there was no reduction of the amount of cane-sugar present. The experiment was repeated witl the same result. From these two experiments the conclusion is drawn that Bacterinm vascularm does not act to any appreciable extent on cane-sugar. To the writer this does not appear to be a necessary conclusion. It is too broad an inference since (1) cane-sugar may perhaps be reduced only when the organism is alive and growing; (2) the organisms in the earefully dried gum may have been killed by light or by dry air in the process of drying; (3) the organism, although alive when put into the sugar solution, may not have found in it the 
elements necessary for growth, i. e., nitrogen or some other substance may have been lacking; or (4) the enzyme presumably present in the gum may liave been destroyed in some inadvertent way or rendered inactive. All it proves beyond question is that the "gum" did not act on the cane-sugar under the conditions of the experiment. Bonâme's analyses show that diseased canes have a smaller sugar-content than sound ones, and so do those cited from Cobb's paper. Some analyses made by Müller and published by Tryon show only about I per cent difference between gummed cane and cane supposed to be free from gum, but this I per cent is on the side of the healthy cane.

Growth is not inhibited by sodium chloride in small quantities, $e$. g., there is feeble growth in peptone water with 0.5 per cent and I per cent $\mathrm{NaCl}$, but larger amounts ( 1.5 per cent, 2 per cent, and 2.5 per cent) prevent growth. Greig Smith also found that 2.5 per cent sodium chloride was a distinct poison. In cultures in i per cent peptone-water with o. I per cent oxalic acid there is no clouding of the fluid, but a finely granular and flaky or stringy precipitate is formed.

The following acid agars gave negative results: Beef-agar with 0.2 per cent oxalic acid (I687); beef-agar with 0.1 per cent malic acid (I682); 2 per cent beef-agar with 0.2 per cent oxalic acid $(1776) ; 2$ per cent beef-agar with 0.2 per cent citric acid ( 1777$) ; 2$ per cent beefagar with 0.2 per cent malic acid $(1 / 87)$. There was no growth whatever on any of these agars.

Greig Smith reports the following results of experiments made to determine the reaction of the medium best suited to the bacterium. The mediun used was water containing 0.5 per cent peptone, 5 per cent saccharose, 0.5 per cent [di ?] potassium pliosphate and 2 per cent agar, to which were added various quantities (o.or per cent, 0.02 per cent, 0.03 per cent, 0.05 per cent, 0.08 per cent) of solutions containing ro per cent tartaric acid and ro per cent sodium carbonate. He says:

The effect of slight differences of acid or of alkali in the culture media is very prononnced. In an absolutely neutral medium [neutral to what?] the bacteria grow very slowly, while, when the reaction is faintly acid, the growth is quick and luxurious. Alkalies prohibit the inultiplication of the microbe. IVith 0.02 per cent the stroke was slow to show itself, was always scanty, and finally, after ten days' incubation, it dried up.

A series of experiments made for me by John R. Johnston to determine from what compounds the organism could obtain its nitrogen and carbon resulted as follows:

Nitrogen-free medium $\left(164^{*}\right)$ with 0.5 p. ct. asparagin.-Well clouded with thin film on the surface.

Nitrogen free (r 664 ) with 0.5 p. ct. sodium asparaginate.-Moderately clouded; a slightly yellowish more or less grantilar film on surface.

Nitrogen-free ( 1664 ) with 0.5 p.ct. ammonium citrate-Heavy flocculent clouding, heavy precipitate.

Nitrogen-free ( 1664 ) with 0.5 p.ct. ammonimm lactate.-Moderately clouded.

Nitrogen-free (1664) with 0.5 p. ct. ammonium tartrate.-Moderately clouded.

Fischer's mineral solution (nitrogen-free). $\nmid-$ Very slight growth.

Fischer's mineral solution with I p.ct. cane-sugar.-Very slight growth.

Fischer's mineral solution with I p. ct. KNOs.-Very slight growth.

Fischer's mineral solution with I p. ct. $\mathrm{KNO}_{3}$ and I p. ct. cane-sugar.-Very slight growth.

Fischer's mineral solution with I p.ct. $\mathrm{KNO}_{3}$ and I p.ct. dextrose--Very slight growth.

Fischer's mineral solution with 1 p. $\mathrm{cl}$. Witte's peptone.-Thinly clouded; small precipitate.

Fischer's mineral solution with I p.ct. Witte's peptone and I p.ct. dextrose.-Moderate clouding; small, yellow precipitate.

Fischer's mineral solution with 1 p. ct. Witte's peptone and I p. ct. glycerin.-Moderate clouding.

Fischer's mineral solution with I p. ct. Witte's peptone and I p. ct. cane-sugar.-Heavily clonded; yellow precipitate, white surface pseudozoogloeæ.

Fischer's mineral solution with I p.ct. asparagin and I p. ct. dextrose.-Good growth.

Fischer's mineral solution with i p. ct. ammonium tartiate and i p. ct. dextrose. - No growth.

Water with 2 p. ct. asparagin and I p. ct. dextrose. - Thinly clouded, growth much retarded.

Water with I.2 p. ct. asparagin and 1 p.ct. Witte's peplone.-Well clouded, blackish (?) precipitate.

* Stock 1664 :

Cane-sugar................. 9.00

Dipotassium phosphate........... 9.00

Magnesium sulphate.............. 0.90

Sodium chloride.................... I.80

Calcium chloride.............. 0.45

Distilled water...................., 800.00
†Fischer's mineral solution:

Dipotassium phosphate........ 2.0

Magnesium sulphate........... 0.4

Calcium chloride............ 0.2

Distilled water............. 2,000.0 
From these restults it is probable that the organism can obtain its nitrogen from asparagin and ammonium salts but not from $\mathrm{KNO}_{3}$, and that it can use cane-sugar, dextrose and glycerin (?) as carbon foods. Greig Smith says glycerin can not be utilized by the organisn. Further experiments should be made.

Greig Smith makes the following deductions from experiments made to test the influence of salts upon the growth of the organism:

(1) The bacterium has a preference for phosphate and is indifferent to the other acid radicals; (2) the acid potassium phosphate, on account of its acidity, checked the growth; (3) potassium may be replaced by calcium, magnesium, or ammonium; (4) sodium is a distinct poison. The medium used was a faintly acid one containing 0.5 per cent peptone, 10 per cent dextrose, 2 per cent agar, and 2.5 per cent of the varions salts to be tested.

Greig Smith's conclusions regarding the influence of carbon foods are as follows:

Either dextrose, levtulose or saccharose are absolutely necessary for the free growth of the organism and the production of gum. The bacteria did not grow in the presence of the other sugars and carbonaceous matters (glycerin, ${ }^{*}$ starch, dextrin, maltose, ${ }^{*}$ lactose*), from which we infer that these cannot be utilized. Of the three sugars, levulose and saccharose are more easily assimilated than dextrose.

The medium was a faintly acid one containing 0.5 per cent peptone, 0.2 per cent sodium phosphate, 0.5 per cent potassium chloride, 2 per cent agar, and 5 per cent of the various carbon substances.

Cohn's solution: I can not find that we made any tests in Cohn's solution.

Greig Smith states that he obtained a faint indol reaction in nutrient bouillon.

So far as tested Bacterim vascularmm is a strict aerobe (EFS., RGS.). No gas is formed in any of the common culture media, nor is there any clouding of the closed end of fermentation-tubes containing grape-sugar, cane-sugar, milk-sugar, maltose, mannit, or glycerin in I per cent quantities in water containing 2 per cent Witte's peptone, although all were moderately clouded in the open end and outer part of the $U$. Cultures were repeated in $I$ per cent peptone-water containing I per cent maltose and the same with I per cent mannit, but with the same results. In twice-distilled water containing 2 per cent glycerin, I per cent dextrose, and I per cent sodium asparaginate there was no growth. This medium was alkaline to litmus paper.

The organism did not grow on steamed potato or in peptonized beef-bouillon in an atmosphere of carbon dioxide (14 days). One test only. The check tubes behaved properly.

The thermal death-point lies between $49^{\circ}$ and $50^{\circ} \mathrm{C}$. when exposures are made from young bouillon cultures as described in vol. I of this monograph. It is a little higher when made from potato cultures.

Growth is inhibited by a temperature of $37.5^{\circ} \mathrm{C}$. (RGS., EFS.), and a temperature of $35^{\circ} \mathrm{C}$. much retards it. Two out of three tubes of bouillon continted to be thinly clouded after 27 days at $35^{\circ} \mathrm{C}$. and were living, as shown by streak cultures on agar, but the streaks developed colony-wise at first, indicating that the bouillon was then thinly stocked with living organisms. Bouillon-tubes inoculated copiously and placed at $37.5^{\circ} \mathrm{C}$. for 7 days not only remained clear but refused to cloud when subsequently placed at room temperatures (I 2 days). Agar plates poured from these three tubes also remained free from colonies. The three check-tubes clouded promptly.

There is more rapid growth at $30^{\circ} \mathrm{C}$. than at room-temperature $\left(18^{\circ}\right.$ to $23^{\circ} \mathrm{C}$.), about 3 times as much in the first 48 hours, but at the end of 4 days not much cloudier than the checks.

*'That strain of Bacterium vascularum with which I have experimented has moderately clouded peptone-water containing glycerin, maltose, and lactose, but in the light of Greig Smith's statements I am not prepared to say that it would not have clouded the peptone-water to the same extent without these substances. Additional tests should be madc. I can not make them myself, because I have lost all my cultures of this organism. 
No pellicle, no pseudozooglocx, very scant whitish rim (6 tubes), precipitate yellowish, 2 $\mathrm{mm}$. broad, growth feeble. The optinum temperature is probably $30^{\circ} \mathrm{C}$, or a little below. Greig Smith reports growth at $30^{\circ} \mathrm{C}$. much better than at $25^{\circ} \mathrm{C}$, and also considers $30^{\circ} \mathrm{C}$. the optimum temperature.

Greig Smith found the most suitable medium for the growth of this organism to be neutral cane-juice gelatin (p. 34 , Proc. Linn. Soc., I902; but on p. 38 he says that very faintly acid cane-juice gelatin is best), and the next best, ordinary glucose-gelatin, and slices of potato. He describes its growth on suitable solid media as occurring in the form of "raised yellowish patches which have the appearance and consistency of softened yellow beeswax. When treated with water the culture slowly mixes, forming what appears to be a partial suspension and partial solution."

Another excellent medium is: 0.5 peptone, 5.0 saccharose or levulose, 0.5 [di?] potassium phosphate, 2.0 agar, roo tap-water. Acidity of ro c.c. $=0.14$ c.c. tenth-normal acid [ +1.4 Fuller's scale]. On this medium the organism grew most luxuriantly (RGS.).

TABLE 5.-Thermal Death-point Experiments.

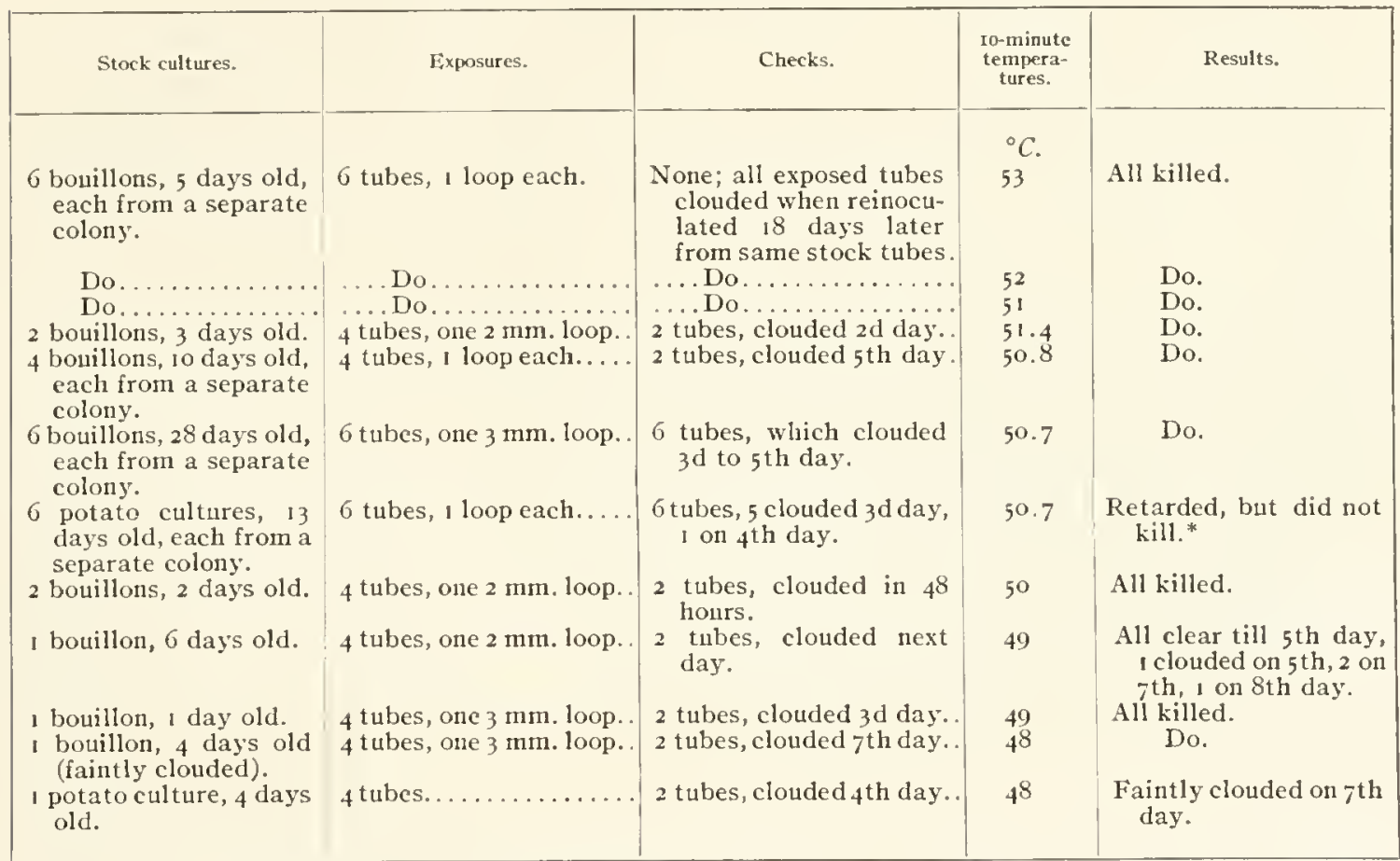

*Portions of solid cultures put into bouillon and heated might be protected, perhaps, to a slight but sufficient degree by non-conducting air inclusions.

The vitality on culture-media varies greatly, of course, with the medium and the temperature. The length of time the organism can live in the stem is not known. The first sugarcane received by the writer from Australia (189r) was 5 months on the way (detained in a custom-house) and contained no living yellow organisms when it reached me, although the bundles were full of the ycllow slime; but in a second shipment, which arrived from Australia in a mucl fresher condition, the organism was alive. The ends of these canes were sealed with sealing wax, and the canes were en route not more than 6 weeks. The organism was dead in two inoculated stems at the end of 8 months. These were plants 30 and 36 , purple canes, which had not suffered from the disease. Some of the vessels of the stem showed immense numbers of bacteria, lowever, and a good-sized piece of this tissue was cut out with a cold knife, thrown into ro c.c. bouillon for an lionr, then masled with a sterile glass 
rod and I4 plates poured at $4 \mathrm{I}^{\circ}$ to $38^{\circ} \mathrm{C}$., after inoculating very copiously-six $3 \mathrm{~mm}$. loops in one instance. In other canes it was found alive at the end of a year.

Tubes of bouillon inoculated November 9, 1903, and kept at room-temperatures were still cloudy on March I 7 ( 29 days), but a transfer from one of them did not cloud bouillon.

In beef-agar stabs kept in the refrigerator at $10^{\circ}$ to $15^{\circ} \mathrm{C}$. the cultures were alive at the end of 7 months ro days. Under similar conditions another culture was dead at the end of 7 months is days. Here the temperature may have been a few degrees higher, $i$. $e$., $2^{\circ}$ to $16^{\circ} \mathrm{C}$. Another tube inoculated i 4 days later and subject to the same conditions was alive at the end of 6 months 2 I days. 'Two other tubes of the same lot were dead at the end of 6 months 12 days. Three other stab-eultures were dead at the end of 7 months 3 days.

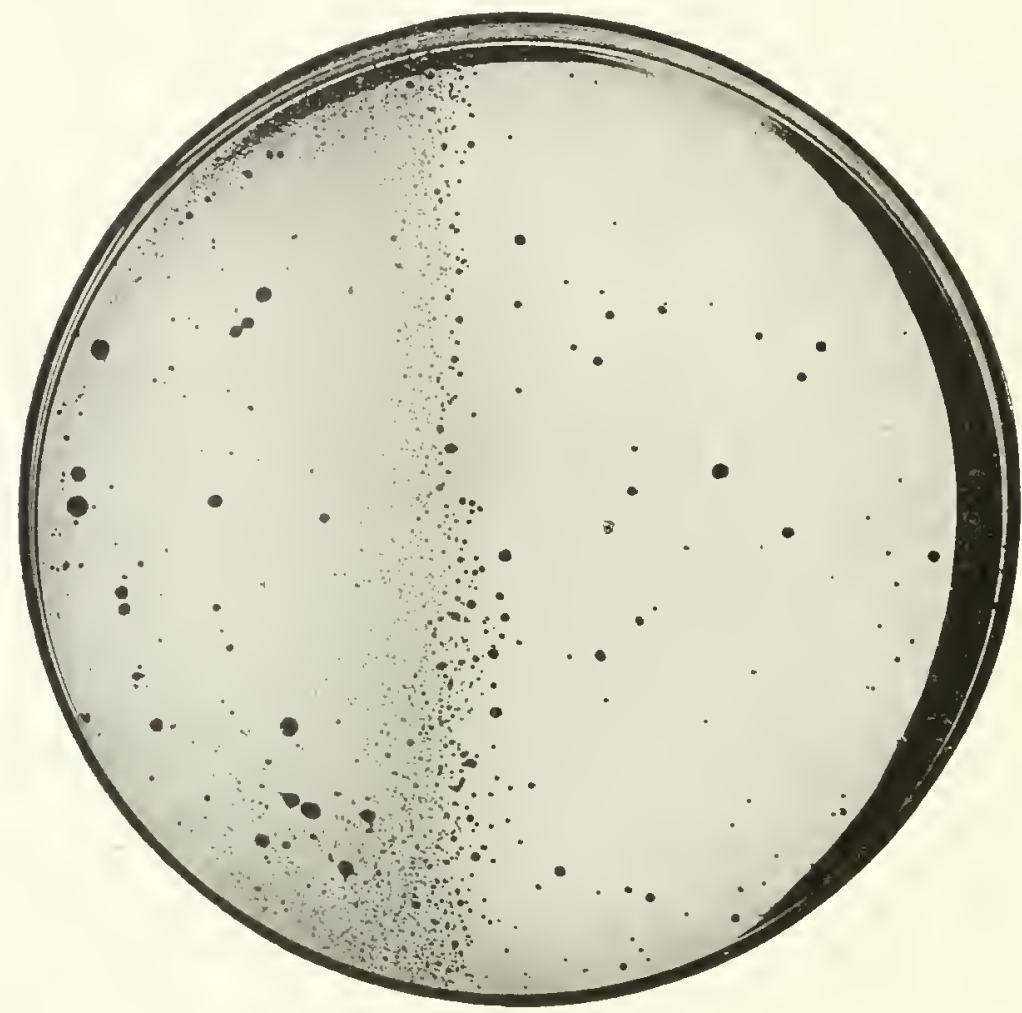

Fig. 37.*

The organism was alive in eultures on potatoagar at the end of 7 months, but they were probably in the cold box.

The organism was alive in 6 potato cultures at the end of 35 days (roomtemperature about $25^{\circ} \mathrm{C}$.), but probably a large part were dead, as the transfers to fresh potato-eylinders grew slowly.

On March 21, 1905, ten cultures on potato in the refrigerator at $10^{\circ}$ to $14^{\circ} \mathrm{C}$. since October 6 , I 904 ( I 66 days) were tested for vitality, transfers being made to potato-agar (streaks). Two grew well; two feebly in small portions of the streak; and the rest did not grow. Of the two which grew well, one came from cane plant No. 40 and the other from cane plant No. 42.

The organism has been found alive in milk cultures $5 f$ days old; also in sone 75 days old. Milk is a suitable culture nedium for this organism.

The organisn is killed by sunlight (fig. 37).

\section{RÉSUMÉ OF SALIENT CHARACTERS.}

POSITIVE.

Parasitic in sugar-cane, clogging tlue vascular bundles with a bright yellow slime and forming carities in the soft parenchyma; frequently comes to the surface of the inner leafsheaths as a viscid slime. Surface colonies on + 5 standard nutrient agar pale-yellow,

*FIG. 37.-Bacterium vascularum in an agar-poured-plate after exposure of right side to bright sunlight (on jce) for 30 minutes. Plate potred and exposed January 19, 1906 . Photographed January 26, 1906. The few bacteria which grew into colonies on the exposed side of the plate were sheltered, it may be presumed, from the direct action of the sun by other overlying bacteria. 
smooth, glistening, rather small, round, rather flat with sharp margins, no distinet appearance of granulation, alkaline to moist litmus paper, not noticeably viseid, coming up slowly at $25^{\circ} \mathrm{C}$. (about 5 to 10 days wlen poured from cane); rods short, 11neasuring on an average $0.4 \times 1 \mu$ when stained, but sometimes plumper and also longer forms occur; single, in pairs (mostly), fours, or eights, end to end; pseudozoogloex; motile, single polar flagellum; capsules (?); stains fairly well by Gram (see negative); strictly acrobic (so far as known); optimum temperature about $30^{\circ} \mathrm{C}$.; growth retarded by temperature of $35^{\circ} \mathrm{C}$.; thermal death-point $49^{\circ}$ to $50^{\circ} \mathrm{C}$.; growth on + I 5 peptonized beef-agar inhibited by addition of small amounts of vegetable acids; growth on potato-agar somewhat better than on beefagar; seanty growth on litmus-lactose-agar, with slow but distinet bluing; good growth on neutral or slightly acid peptonized cane-juice gelatin, streaks slide down in characteristic "tear-drop" formation; occasional very slight liquefaction of gelatin; fairly good growth on steamed cylinders of susceptible varieties of sugar-eane; growth on potato cylinders and coconut-cylinders good but not copious, moderate graying of the potato cylinder, mostly out of the water; seanty growth on steamed red table-beet cylinders; good growth on steamed onion and cauliflower; fairly good growth on steamed carrot and turnip; $+\mathrm{I}_{5}$ peptonized beef-bouillon moderately clouded, pellicle rarely observed, whitish rim sometimes formed, prismatic crystals often present; nitrate bouillon moderately clouded; good growth in neutral bouillon and in slightly acid beef-bouillon $(+25$ Fuller's scale); feeble growth in beef-bouillon titrating -20 Fuller's scale; feeble growth in Dunham's solution, and in Uschinsky's solution (see negative); litmus milk is blued, the milk remaining fluid and opaque; the organisn can utilize asparagin and ammonium salts as nitrogen food; it can obtain carbon from canesugar, dextrose, fructose, and glycerin (?); grows best with saccharose or

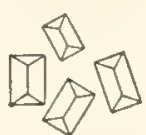

Fig. 38.* fructose (RGS.); sodium chloride in amounts greater than I per cent inhibits growtl; sliglit reducing action on cane-sugar (see negative); alkalies prohibit the multiplication of the organism, but when the reaction is faintly acid growth is quick and luxuriant (RGS.); the most suitable media are neutral or slightly acid, peptonized cane-juice gelatin, beet-juice agar with addition of peptone and saceharose, litmus milk, and steamed potato. It is sensitive to sunlight. Crystals occur on agar (fig. 38 ). Group No. 2 I $\left\{\frac{1}{2} \cdot 3332523\right.$.

\section{NEGAT1VE.}

No spores; no long chains or filaments; no pellicle (usually); colonies not noticeably viscid; not pure white on any medium; not red, nor orange; no gas in any medium; no reduction of nitrates to nitrites; no acids; no reduction of litmus (lactose-agar, nilk); 110 precipitation of the casein in litmus-milk cultures; no liquefaction of gelatin (usually); no growth at $37.5^{\circ} \mathrm{C}$; 110 piling up of the slime in the water in potato-cultures, as in the case of yellow organisms, such as Bacterium campestre and Bacterium phaseoli; no growth in Uschinsky's solution (frequently); no growth in Cohn's solution (?); no growth in an atmosphere of earbon dioxide; no clouding of closed end of fermentation tubes of peptone-water containing grape-sugar, eane-sugar, milk-sugar, maltose, mannit, or glycerin. No growth (usually) on steamed cylinders of resistant varieties of sugar-cane standing in distilled water. Organism does not use potassium nitrate as nitrogen food. Does not stain by Gram's method (RGS.). Does not use glycerin as carbon food (RGS.). Does not grow in peptonized beef-bouillon with 1.5 per cent or more sodium chloride. Daes not reduce eane-sugar, according to $\mathrm{R}$. Greig Smith. Does not brown agar.

*Fig. 38.-Crystals from an agar streak-culture of Bacterium i'ascularum. More than 200 appeared in some of the tubes. Noles of Mareh 7, 1902, and of February 1904. 


\section{TREATMENT.}

Little is known regarding the transmission of this disease from one plant to another except by way of the sets. The planters themselves are believed both by Cobb and Tryon to be largely responsible for the spread of the disease. Dr. Cobb says:

It seems evident that gumming is not a disease that is spread to any great extent through the air **** This is shown by an array of facts that cannot be for a moment overlooked. Some stalks in a stool may be badly gummed and others in the same stool fairly healthy; part of a crop may be gummed, and the rest remain in good condition; one field may be badly gummed, and an adjacent field perfectly healthy; the Upper Clarence is comparatively free from gumming, while the Lower Clarence has suffered severcly for several seasons. All these facts are incompatible with the idea that the disease is very infectious. If healthy plants easily caught the disease by receiving the germs of it from elsewhere, borne on the wind, such a case as a healthy crop standing alongside a badly diseased one would be almost an impossibility. [The writer has made preciscly similar observations on the black rot of the cabbage. In this connection see Bacterium campestre, vol. II, p. 306.]

On the other hand, the above facts are in harmony with the idea that the disease originates with the seed-the sets. $* * *$

I was able to discover three cases on the Lower Clarence in which the crops were almost a total failure on account of gtmming, where the planters, now that they know the nature and injuriousness of gumming, can recollect that the sets were badly gummed. They noticed the gum in the sets, which, when bad, is indeed very conspicuous, but not then knowing its nature, went ahead and put in the sets notwithstanding. These three cases are those of very intelligent farmers, to converse with whom was to be convinced that they were quite right in their observations. In another case a farmer purposely took sets from diseased plants in order to sce whether they would reproduce the disease. The disease was reproduced. I had an opportunity to examine the resulting plants, and can certify to the result.

Tryon speaks no less emphatically. According to his observations in Queensland the disease sometimes occurs spontaneously in patches of cane planted in low places on undrained land, but much more often it can be traced directly to the planting of cane-sets taken from discased fields. I quote from his paper, published in I \$95, as follows:

It is an established fact in connection with this gumming disease that pieces of affected cane, when used for "sets," give rise to it in the resulting crop. The malady may be sooner or later in manifesting its presence, but, as a rule, its occurrence may be depended upon. Should the sets be badly gummed, however, no crop at all is obtained, as, though they may emit slender sprouts, these soon cease to be further developed. These facts have been demonstrated experimentally both at Windermere and Fairymead, and they explain in great measure the present distribution of the disease. * * * Similarly, when a plantation was discovered in which no disease occurred * * * it was found that drainage had been resorted to, the crops from which the seed cane had been procured were perfectly healthy, or that no seed cane had been used except such as had been yielded by local healthy crops. Many instances could be adduced of this method of propagating the disease, and even just prior to my visit a considerable amount of unhealthy cane had been distributed from one Maryborougl center to be used for starting fresh cane plots. In many cases having observed a stand of diseased cane, and not discovering any explanation of its occurrence in local conditions of growth, a visit was afterwards made to the plantation whence the seed cane from which this was raised had been derived, when it was invariably found that the original stock was also diseased, and that other stands of cane which it had also served to originate were similarly affected. * * * When the disease appeared upon dry ridges, and no cane plants had been procured from beyond the plantation for several years, it was generally found that it was also present in some low-lying spots, where it had evidently originated spontaneously at an earlier date, and that its occurrence in one situation had led through the use of local sets, to its manifestation in the other.

My own experience tends to confirm Cobb's statement respecting transmission of the disease. It is not readily spread from diseased to healthy plants, at least not in the hothouse.

Cobb stated to the writer that he had recommended the use of certain varicties whose resistance to the disease he had observed, and wherever his advice had been followed the disease had disappeared. 
The remedies advised by Cobb are: (I) selection of healtlyy sets; (2) good drainage; (3) burning of the trash; (4) rotation of crops, or bare fallow once every few years; (5) production of new varieties of cane by raising seedlings; (6) improvement by selection; (7) introduction of new sorts from ontside Australia; (8) the fostering of ntirseries where (5), (6), and (7) are to be carried out. At the close is the following pertinent paragraph, which, be it renembered was written in 1893 :

Selection of disease resistant sorts. 'This is a subject that needs an essay by itself. I am convinced that one of the greatest improvements destined to be made in agriculture is in the line of securing pest-resisting varieties. We stand as yet but on the threshold, yet we can clearly see the alluring prospect. What we now possess in a few eases, having obtained them almost by accident, shows how on the alert we should be to discover varieties as little subject to disease as possible.

Cuttings designed for planting should be inspected very critically and those showing any signs of the yellow bacterial ooze on the cut surface must be rejected. Even very careful inspection at the time of cutting is not sufficient, however, for the removal of all diseased canes. Queensland planters, according to Tryon, are in the habit of covering the piles of cut canes for about three days with trash upon which water is thrown; this induces a sweating process which greatly facilitates the detection of unsound cane. In this way "tons of bad cuttings have been picked out which otherwise would have spoiled the stand of the cane." The Fiji method of detecting slightly diseased cane-cuttings is by steaming.

The poisonous action of sodium salts on the organism suggested to Greig Smith that common salt might be used to check the disease unless the amount necessary to inhibit the growth of the bacterium would injure the sugar-cane. On inquiry, he found that in Fiji healthy crops of cane were grown on soil containing 1 per cent or less of salt, but any greater percentage was more or less injurious. Reports differ as to the comparative amount of this disease among crops raised on the seashore. One instance is given of a man whose farm was on an island in the Lakes, Clarence River, who was able to grow a comparatively sound crop of Mauritius Ribbon cane long after other growers had abandoned it because of its susceptibility to this disease. On the other hand, there is the opinion on the part of some that canes grown on salty soil are more liable to be affected. 'This, Greig Smith thinks, may be traced to defective drainage. He agrees with Cobb, however, in regard to growing diseaseresistant varieties, and mentions one well-known variety, Tauna, which has never been known to develop this disease. The sugar-content is less high than in some of the more susceptible varieties, but Tanna is a stout, heavy cane, and when planted in fields which have yielded badly diseased crops produces perfectly sound canes.

\section{TABLE 6.-Susceptible and Resistant Varieties of Sugar-Cane.}

SUSCEPTIBLE.

Common Green (EFS.)

La Canne Bambou (Bonâme)

Louzier or White Bamboo (Tryon)

Rappoe or Rose Bamboo (Tryon)

Djioenig-Djioenig (Tryon)

Striped Singapore ('Tryon)

Mauritius or Striped Guingham (Tryon)

Meera (Tryon)

Lahina (McGuigan)

Kewensis (Knox)
RESISTANT.

Tanna or Elephant (Tryon, RGS.)

Louisiana No. 74 (EFS.)

Common Purple (FiFS.)

Malabar or Green Tanna (Tryon)

Daniel Dupont or Bambou Branchense Rayée (Tryon)

Cheribon or Outamite (Tryon)

China (Tryon)

Moore's Purple (?)

Green Dupont or Bamboo Branchense Blanche ('Tryon)

Australian Creole, a cane resembling Meera (Tryon)

According to Tryon, the cancs most subject to the gum-disease are just those varieties richest in sugar. "It may be remembered, however," he says, "that the canes that have been found to be free from disease in Queensland are included in both the poor-in-sugar and rich-in-sugar categories," e.g., Daniel Dupont, rich, and Elephant, poor.

Tryon noted also that the disease was most pronounced in canes grown upon the best lands. Most of the immune varieties have hard eanes and the susceptible ones soft canes, but this does not appear to be a rule without exceptions, since the Outamite or Cheribon is 
rather soft. As a rule, also, the immune canes are fibrous and the susceptible ones otherwise. Susceptible canes such as Rappoe, Meera, and Djiocnig-Djioenig are very intolerant of wet and cold. Resistant canes such as Black Tanna, Green Tanna, or Malabar, and Clina withstand cold weather and wet soils very well.

In dealing with cultivation and its influence on the occurrence and virulence of the gumming disease considerable stress is laid on the question of drainage, it being shown that the disease arises spontaneously (generally, if not exclusively) on ill-drained areas. This proposition, therefore, gains support from the experience that those canes which can tolerate wet land are not subject to the disease, whilst it especially prevails amongst varieties which are not endowed with this character (Tryon).

According to Tryon soils, as such, exert no influence on this disease. It is equally prevalent on rocky, stony, stone-free, sandy, and clay lands. Lack of drainage, however, has a marked influence. When not directly traceable to affected sets, the disease is almost always most prevalent in low places or flat wet lands. This was observed by Tryon so often that it seems established beyond reasonable doubt. I may quote a few lines from his report:

Proceeding again from the Bingera estate proper toward Kolan, patches of affected cane were here and there found, and in every instance their occurrence marked the site of areas of surface depression and the convergence of watersheds, and the presence of a wet soil and subsoil. Again, in almost every otlier case where the disease was met with, both in the Wide Bay and Burnett districts, it was decidedly more pronounced on flats and hollows and where the ground was wet and undrained, a conclusion not only founded on extended personal observation on my part, but also agreeing with the general experience of the planters themselves.

This applies of course only to spontaneous outbreaks, not to infection due to planting diseased canes.

To recapitulate: Selcet cuttings only from perfectly sound cancs; discard supersensitive varictics; and on soils already much infected plant only very resistant varictics.

\section{PECUNIARY LOSSES.}

In countries where this disease has gained a foothold it is very destructive. The heaviest losses have been reported by Cobb and Tryon in Australia, and by Dränert in Brazil. In many cases the crops have been almost entirely destroyed. Cobb said in 1893 that there was searcely a farm on the Lower Clarence, in New South Wales, where the gumming was not abundant. In 1895 , Tryon also regarded it as a very serious disease in Queensland, plots containing scores of acres being rendered valueless. Dränert speaks in similar terms of the Brazilian discase. It had been destructive in Bahia for 6 years. The Argentine disease strspected by me to be this malady is also serious (see page $\mathrm{S}_{5}$ ).

According to Mr. Clark, a former cane-inspector of Queensland, thoroughly familiar with the disease as it occurs in Australia, and now an inspector in Fiji, this disease occurs in the Fiji Islands to a serious extent. It has been present some years. At first the planters did not know what it was, but now they are familiar with it and are taking restrictive measures. I have this information through Dr. Cobb, who says another man from Fiji told him the same thing.

If the disease is identical with Scrch, as the writer suspects, then the losses from it in Java alone are to be reckoned in hundreds of thottsands of dollars, Sereh having at one time nearly put an end to the sugar industry of that great island.

Enough has been said to show that the disease is a dangerous one, and planters should avoid the introduction of canes from affected districts even when they are guaranteed to be sound, lest they inadvertently introduce the disease on some of the canes. It is much easier to keep out this disease, as they are now endeavoring to do in the Sandwich Islands, than to fight it when it las gained a foothold. Planters in Louisiana and in Cuba, Porto Rico, and other West Indian islands should in particular be on guard against its introduction. As Cobb remarks, it is a disease peculiarly liable to be transmitted from one country to another in cane-cuttings. 


\section{LITERATURE.}

1869. DRÄNERT, F̂RIEOR. M. Bericht ïber die Krankheit des Zuckerrolıres. Zeitschrift für Parasitenkunde, Bd. I, pp. 13-17, and Tafel II. Jena, I 869

I869. DRANERT, F. M. Weitere Notizen über die Krankheit des Zuckerrohrs. Zeitschrift für Parasitenkunde, Bd. I, p. 212, and Tafel IV, fig. 58,1869 .

1893. Coвb, N. A. Gumming of cane. Dept. Agric., N.S. W. 1893, pp.8-Io. Reprinted in Kew Bulletin of Miscellaneous Information, No. 85 , Jan. 1894, pp. I-4.

1893. Совв, N. A. Plant discases and their remedies. Diseases of sugar-cane. 1. Microbe diseases of the sugar-cane; Gumming of cane (Bacillus vascularum). Agrie. Gazette of New South Wales. Sydney, vol. Iv, part 10, Oct. 1893 , pp. $777-798$, with if figures.

Also a reprint, $8 \mathrm{vo}, 56 \mathrm{pp}$.

The two half-tone figures from photomicrographs illustrating cross-sections of portions of diseased canes are reproduced so badly that the presence of the bacteria can not be made out.

1894. Anonymous. Cane disease in Pernambuco. The Sugar Cane. Manchester, I 894 , vol. xxvi, pp. 377-379.

1894. Eortorial. The Sugat Cane. Manchester, 1894 , vol. xxvi, p. 505.

The insults the scientific man must sometimes endure from the so-called "practical man" are well illustrated in the fol lowing citation

"The peculiarity of the disease here referred to in attacking the fibro-vascular bundles is characteristic also of the disease kaown as "gumming" (described by Dr. Cobb) in New Soutb Wales, and of the "gomziekte" (described by Krüger, Janse, el al.) in Java. The disease is not new. But bow does it arise? We notice that an editorial in the Revue Agricole, of Mauritius, mentions that the bacillus is known. This statement, so often made respecting diseases in men, animals, and plants, seems to partake somewhat of the natire of a solemn joke. Of how many diseases can it be said that the koowledge of the bacillus jas led to the cure of the disease, or even that the bacilins causes the disease? Up to now wbatever kills the bacillus kills the patient also: It is high time for scientists to get of the stilts of mere tecboical assertion, and find 115 a remedy for disease,
whether they can find a bacillus or not."

I 894. Palmares. Cane disease in Pernambuco. The Sugar Cane. Manchester, I894, vol. xxvi, p. 555 .

1894. BonÂme, PH. Rapport sur la maladie de la canne. Revue Agricole et Journal de la Chambre d'A griculture de l'ile Maurice, 8 anil. No. 8, Août, 1894. Port L,ouis, Mantice, pp. $178-187$.

A translation of this paper may be found in The Sugar Cane, Manchester, England, vol, Xxvi, 1894, pp. 589-593 and $62 t-625$.

I 895. Совв, N. A. The cause of gumming in sugarcane. Agric. Gazette of New South Wales, Sydney, vol. vi, part 1o, Oct. I 895, pp. $68_{3}-$ 689 , with two figures.
I895. TrYon, HENRY. Gumming of cane; being a report of an inquity in to the origin and nature of a disease affecting the sugar-cane in the Wirle Bay and Burnett districts. Annual Report Dept. Agric. (Queensland) for 189495. Brisbane, 1895. Paged separately, pp. $1-64$.

I898. WAKKER, J. H., and WENT, F. A. F. C. Die Ziekten van het Suikerriet op Java. Deel I, Ziekten, die niet door Dieren veroorzaakt worden. Mit 25 Tafeln, Leiden, I 898.

1898 (?). Donson, W. R. Bacteriological notes on "red cane," in "sugar cane," etc., by Wm. C. Stubbs, vol. I, State Bureau of Agric and Immigration, Ia. No date, but a copy was received at the U. S. Dept. of Agric., Feb. I4. I 898 , pp. $173-178$.

Author thinks one or more bacterial forms always accompany red cane, but can not be said to have proved bis case. Paper has no special relation to Cobb's disease.

1898. Raciborski, M. Voorloopige Mededeelingen omtrent eenige Rietziekten. Overgedruckt uit het "Archief voor de Java-Suikerindustrie, Kagok Tegal, I 898.

1900. WeNT. Krankheiten des Zuckerrohres. Verh. vom Pariser Kongress, Juli, 1900. cf. Zeitschr. f. Pflanzenkr., I gor, p. 297.

1901. SMITH, ERrwin F. 'The cultural characters of $P_{S}$, hyacinthi, etc. Bulletin 28, Div. Veg. Phys. and Path., U. S. Dept. Agric., Aug. 6, 1901, D. 153.

Name of organism changed to Pseudomonas zoscularum, on accoust ot polar flagellum.

I 902. SiITH, R. GREIG. The gummosis of the sugarcane (Bacterium vascularum Cobb). Proc. Linn. Soc. N. S. W., 1902, part I, Apr. 30, 2 plates, pp. 31-47. Issued Aug. 22, 1902.

Also a separate. See also Centr. f. Bakt., zte. Abt., Ix Bd., 1902, pp. 805 and 806 , which adds nothing to the precering.

1904. SMITH, R. GREIG. The red string of the sugarcane (Bacillus pseudarabinus n. sp.). Proc. Linn. Soc. N. S. W., I904, vol. xxix, part 3. No. 115 , issued December 16, 1904, pp. 449459. Sydney, N. S. W.

1904. SMiti, ERWin F. Ursache der Cobb'schen Krankheit des Zuckerrohrs. Centralb.f. Bakt., 2 Abt., XIII Bd., I 904, pp. 729-736.

Also a separate. For an English translation of this paper see pp. 12 to 22 of the next reference, i. $e$., Cobb's third report.

1905. Совв, N. A. Third report on gumming of the sugar-cane. Div, of Pathology and Physiology, bull. No. 3, Exp. Sta., of the Hawaiian Sugar Planters' Association. Honolulu, Hawaii, $1905, \mathrm{pp} .46,12$ ills. 


\section{THE SEREH-DISEASE OF SUGAR-CANE.}

Sereh (Sĕ-ray') is the name of a very destructive disease of sugar-cane common in the island of Java, the Straits Settlements, Borneo, Banka, Bali, and probably elsewhere in the East Indies.

This disease has been known in Java for more than 30 years, and many papers have been published on it, but its etiology is still in doubt. The different conclusions respecting its cause liave been almost as numerous as the writers.

Sereh in Java is said to have begun in the west end of the island, in the Cheribon Residentschaft, in the Clieribon or common cane of the country. It was first definitely observed, according to Went, about 1882 , in Ardjawinangan in Cheribon, but is surmised to have occurred earlier in the more westerly Krawang. By the year 1890 it had extended over very nearly the whole island (May). It was everywhere in 1894 (Went), 1raving spread gradually in 12 years from west to east. It was most severe in the early years (Went). This disease has induced losses in Java represented in sum total only by many hundreds of thousands of dollars. Anytling like exact statistics can not be obtained, the losses liaving been partially concealed, it is said, by the parties concerned. Some items, however, will give one an idea of the magnitude of the calamity. According to Engelberts, Sereh caused losses in one year (1888) in one locality in Java (Djokjakarta) of $18 r, 4$ I 3 pikols of stgar, equivalent to 27 per cent of the liarvest of 1887 , and wortl1 1,331, ooo florins. According to May, in middle Java, where the disease was then most destructive, the loss in 1888 was estimated at onesixtl of the whole crop, and the loss in 1889 at one-third of the whole crop, using the yield of 1887 as a basis for calculation. He gives the loss in 1889 in this part of Java at between $250,000,000$ and 500,000,000 Dutch gulden, $i . e_{\text {. }}$, roughly speaking, between $\$ 1,000,000$ and $\$ 2,000,000$. The severity of the disease is also shown by the fact that the planters established experiment stations for the study of the cane unaided at first by the government, and also by the fact that at one time they proposed to import a European pathologist of established reputation to study the disease, and actually subscribed 135 , ooo gulden for this purpose (May). Everywhere the disease has been overcome by planting sound cane. 'The cost of inporting the Sereh-free bibit is very great, i.e., more than 15 ,ooo florins annually for most of the great sugar undertakings, according to Went. Probably $\$ 10,000,000$ would not cover the total loss from Sereh on the island of Java.

The following account of Sereh is taken from Krüger (Das Zuckerrolır und seine Kultur," p. 423 ff.) and from the Dutch writers, Soltwedel, Janse, Valeton, Benecke, Went, and Wakker.

The nanne Sereh is the Javan word for Andropogon schocnanthus, which the diseased cane frequently resembles in its tufted manner of growth. Sone, however, derive the word from the Javanese word "ngere," meaning to degenerate, become wild, or decline. 'The former explanation of the origin is the more probable.

According to Went, the progress of the disease in a plantation is as follows:

The Sereh appears at first only sporadically; the year following one finds 11sually Sereh plants everywhere; and the third year the disease occurs in such severity (when no measures are taken against it) that a failure of the crop results.

Sereh is ealled, by Beneeke, the bacillus disease of the vaseular bundles, also the red slime disease of the bundles, and by Valeton the gum disease. It lias also been designated sarcastically: "The disease which has bafled seven botanists." 
The essential signs of the disease are not known. The following characteristies, however, are generally taken as signs of Sereh:

(1) Shortening of the internodes of the stem, resulting, especially when this takes place toward the top of the plant, in conspicuous crowding of the leaves into a fan-shaped mass (Krïger, Valeton, Went).

(2) Leares smaller than usual; they also remain longer on the plant and do not fall off in the usual way. (Went, Krïiger).

(3) Leaf-blades etiolated or traversed by yellowish-green stripes (Krüger, Valeton, Went, Benecke). They die irregularly in badly diseased plants. The chlorophyl is not well developed in the leaf-stripes.

(4) The leaf-sheaths open out early and stand widespread, giving to diseased cane a clavate top. Sound canes have narrowly cylindric tops, somewhat constricted above (Krüger). Diseased leafsheaths often die first at the midrib rather than on the margin (W'ent).

(5) The starting of shoots and roots from nodes above ground (Krüger, Valeton, Went). This phenomenon may be induced also by flowering, borers, and lodging of the cane (Kritger, Went). In Sereld it is accounted for by a checking of the growth as a result of irregular sap-circulation due to a plugging of the vessels with gum; by the persistency of the leaves on the stem; by the absorption throngh the impaired stem of the water held in the leaf-sheath.

In severely attacked Sereh-diseased plants the root elements, which one finds above every node, sprout, and in this way the stem becomes surrounded by a net-work of by-roots (Went).

(6) An abnormally strong stooling of the diseased cane, due to a sprouting of buds below the ground (Krüger, Went).

'These [the buds] are often swollen and in sererely attacked plants sprout easily. The latter is the ease especially with the lower buds. The stems springing therefrom are also for the most part attacked in turn, remain short therefore, the buds sprouting again and in that way exhibiting the form of a typically sererely Sereh-diseased plant, consisting of a bundle of low stems with a bush of leaves (Went).

(7) A weak and poor development of the root-system, especially in badly affected plants (Krüger, Went, Wakker). The roots are often dead at the ends; they may be much branched, but remain short. This, however, is not a constant characteristic of badly diseased plants. Conspicuous external signs are said to appear first on the parts above ground. 'Tschirch figures many short stumps of roots with dead ends, but Krüger thinks this may be due to nematodes. Went gives this as one of the signs. According to Went, gum-diseased vascular bundles seldom occur in the roots, $i$. $e$., more rarely than in the stem.

(s) Inclination to bloom early (Went). This phenomenon appears conspicuously in plants not too badly diseased.

(9) The foliage of the plant dies gradually from below up (Krüger). The top of the cane is less diseased than the base, and it is advised to plant this part of the cane exelusively in the hope of obtaining Sereh-free plants (Went).

(เo) 'The disease is carried over from old plants to young ones by means of enttings (Soltwedel, Valeton, Wakker, Went), especially in cuttings taken from the top of the stem (Krüger), bottom (Went). There is often rapid decay of planted cuttings when these liave been taken from Serehdiseased cane; the decay is accompanied by a disagreeable odor and a red stain. Valeton says that he has seen the disease appear within three months in shoots derived from affected cuttings.

(I 1) A decided red stain in the vascular bundles of the stent. 'There seems to be a general agreement among the writers on Sereh that this is one of the conspicuous signs of the disease. Went declares it to be the only sure sign. In early stages it is said to be confined principally to the nodes. Benecke says that this red stain is peculiar to Sereh. Krüger says that while it may come more quickly in Sereh it is also fonnd in other diseases due to unfavorable conditions of the earth, etc. 'This sign may be discovered first in the base of the plant in the stem and to a slight extent in the adjacent roots. In the dead leaf-sheaths also, especially near the point of mion with the stem, there are red bundles, having their ducts filled with gum.

In Serel1-diseased plants the lower end of the stem especially is wholly inpregnated with gumdiseased vascular bundles, which run in all directions, the entire tissue having become very tongh and giving the impression of having suffered through lack of water (Went).

Valeton says: "I have examined Sereh-diseased canes 3 meters long, whose upper +6 nodes were wholly free from gum and red color," and also that "Plants clescending from white tops [undeveloped tops] on the contrary, are, after months, often wholly free from gum-formation." Went makes a similar statement. Other authors mention the disease as sometimes appearing first when the cane has reached a considerable height, the lower internodes being of normal length and size, and only the 
upper ones shortened and bearing fan-shaped foliage. Most anthors speak only of a red substance in the vascular bundles, and it is generally designated as gum.

The red granular substance in the vessels also stains red the walls of the ducts. This red pigment is soluble in alcohol. The sieve-tubes are also plugged by it. This plugging of the vessels is said to result in a checking of the growth, the fan-like arrangement of the leaves, and the sprouting of the shoots and of roots from the stem-nodes. The degree of the plugging of the vessels is dependent upon various conditions - a rich water-supply and a rapid growth are unfavorable to it. The gum is chiefly in the nodes (Valeton). Valeton also speaks of finding in the sieve-vessel portion of the bundle a few cells holding nuclei, which spread themselves to a large extent and crowd out the surrounding sievevessels and duct-cells.

According to Soltwedel there is a degeneration of the cellulose into drops of a very refractive substance. This cliange is accompanied by the formation of the gummy substance, liquid at first, later hardening and plugging the greater part of the vessels. Secondarily, the duct-cells become red; the gun which is formed becomes red also.

(12) A yellow gum or slime in the vascular bundles. Valeton, who appears to have studied the anatomy of the diseased cane with greater care than any other student of Sereh, speaks frequently of the gum being of various colors, first as nearly colorless or yellow and later on becoming red. I translate the following paragraplis from his first paper:

"This refractive gum may be perfectly colorless, or vary through all the tints of light yellow, amber, brown to dark red, black and violet. ***

"In lengthwise cuts it appears that the red color of the gum is local, and confines itself to the node. By a vertical cut through a vessel, one sees then in the node the gum colored dark red or yellow, and both upward and downward becoming lighter, often very suddenly, and before long wholly colorless and scarcely refractive.

"Generally it gives the impression of a thick syrupy mass of very unequal toughness and fluidity, which during a slow movement through the vessels, gradually coagulates and becomes woody. * * *

"Often there are in these net-works [of gum] quite equally clistributed corpuscles, probably small gum particles, which, while of about equal size in one and the same division of the vessel, differ greatly in size in the different divisions from being scarcely visible to being noticeable with but a weak magnifier. $* * *$

"I11 the gum itself, which then, however, is never woody and which sometimes even in the cold by a long continued influence dissolves in potash, similar extremely fine little dots often occur quite uniformly distributed. These, then, especially give the impression of bacteria distributed in the gum, but it was not possible for me to observe a well-defined form. Others give the impression of micrococci. $* * *$

"Many of the bundles of the node-vessel-net also contain gold-yellow gun.

In the germination of Serel1-diseased cuttings, Valeton says that occasionally "greatly swollen eyes occur, the oldest middle vessels of which are filled with thick, yellow gum." In this connection, see figure by Cobb in his third report, of a section through a bud diseased by the Australian bacterial disease. Cobb's figure corresponds exactly to Valeton's statement.

(13) Signs in the parenchyna. Valeton mentions the very constant presence of oily or resinous drops in the parenchyma; and of shining, colorless, yellowish or occasionally red drops which are stained a faint violet to dark red in Hanstein's violet, and are insoluble in glycerin, boiling water, or cold nitric acid. These latter are said to be distinctly peculiar to Sereh-diseased cane. He says that they occur throughout the entire parenchymatic tissue of the lowest part of the cane and in the nodes; often also in the white sclerenchyma, which there surrounds the vascular bundles.

Here and there in the parenchyma also appear parts in which the gumming has taken place. The walls are then colored red or yellow, and the intercellular spaces filled up with thick gum drops proceeding from the wall (which drops show the woody reaction), or with masses of granular substance. (Valeton.)

Janse also speaks of the occurrence of yellow and brown spots in the interior of the parenchyna. These spaces were full of a fine granular substance, which he says was not crystalline, and not bacterial, from which, however, he claims to have cultivated out his Bacillus sacchari.

All the signs do not appear together or in the same degree of severity. The extremes are designated as (1) "bouquet," "sccondary," or "transmissible" Sereh, in which all the signs are present; and (2) as "primary" Sereh, in which there is only nore or less reddening of the bundles, especially in those which are connected with the leaf-sheaths at the nodes, the plant showing no external abnormalities above ground, and only in some cases a few of the roots dead. Between these two extremes there are all kinds of intergrading. 
Sereh has been ascribed to:

(I) Unfavorable conditions of the soil, poor or defective working of the soil. It is much worse on heavy clay than on lighter soil (Went).

(2) Degeneration of the plant, or atavism.

(3) Abnormal weather conditions, such as great dryness, too much raiu, excessive water through improper drainage.

(4) The use of unsuitable fertilizers, especially ground nut-cake.

(5) The use of affected plants and unsuitable methods of planting, $i . e$., too deep planting, too late planting, too high heaping up of the earth.

(6) Lack of water through dying of the roots, and the formation for this reason of gum in the bundles (Wakter). Sereh is not due to any parasite and is not infectious (Wakker).

(7) Animal or plant parasites:

(a) Root parasites, i. e., nematodes:

(1) Heterodera ('Trcub).

(2) Tylenchus sacchari and Heterodera radicicola (Soltwedel and others).

(b) Bacterial stem parasites (Krïger, Janse, Valeton).

(c) Root and stem parasites, Pythimm, nematodes (Treub).

(d) Leaf-sheath parasites, especially IIypocrea sacchari, associated with root-parasites (Went). The Sereh disease is an infectious disease (Went).

(e) Unknown parasites favored by special receptivity of a portion of the canes (Zeijlstra).

Dr. Went says in one place in so many words: "The Sereh disease is caused by a disease of the leaf-sheaths of the cane" (I893), but in other places lie speaks more cautiously of Hypocrea as a "presumptive cause," and in still other places as a cause acting in connection with root-parasites. He lias now, I believe, abandoned this vicw.

Krïger does not think nenatodes are the cause from the following facts:

(1) Typical Sereh may occur in plants which show no nematodes;

(2) With planted cuttings from different parts of a cane subject to quite similar conditions, the most different grades of the disease may be obtained; and,

(3) Canes may occur which are diseased in the upper parts, but not in the lower.

Krüger concludes that Serelı is a stem-disease, and certainly a disease of the vascular bundles. He conjectures that it is a vascular bacteriosis. He states that it is a disease of the bundles caused by bacteria, and arises from a plugging of the tissues with gum, which prevents them from fulfilling all their functions. As a result of this plugging they develop the signs of the disease-the red bundles with their sheaths filled with starch, the dying of the leaves, cessation of growth in the attacked parts, the abnormal stooling, and the starting of aerial roots and shoots. Valeton, however, says there is 110 starch, or but very little in the endodermis in the lower parts of diseased plants as compared with that in healthy canes.

Janse ascribed Sereh to a new spore-bearing schizomycete, Bacillus sacchari, which is often accompanied by another spore-bearing species, Bacillus glagae. He spoiled his hypothesis, however, by finding the organism everywhere in normal cane, and also in many other monocotyledonous plants, and in some dicotyledonous plants. As a result, therefore, he was forced to the conclusion that the parasite occurs in a latent form in all the cane-plants of Java and was not able to explain why it sometimes produced the disease and at other times did not. The most that he seems to have proved is that there occurs quite commonly, either on the surface of the nodes of the cane-plant or in leaf-traces entering these nodes, one or more spore-bearing bacteria resistant to boiling water. These developed quite constantly on sections of the nodes previously treated in this way, and he showed that they were not derived either from the air or water.

Valeton repeated Janse's cultural experiments. In his paper on the bacteriological investigation of cane varieties, Valeton describes his experiments to determine whether Janse's organisms were present in healthy cane-stems in eastern Java. He experimented in the same manner as Janse, having learned the method from him. The surfaces of the canestems were treated with disinfectants or boiled, then cut open and incubated for 24 hours or longer. In nearly all cases lie got the same results and reached the same conclusions which he now declares to be worthless (letter to the writer). He tested healthy canes of 42 varieties of Saccliarm officinarum and of 3 otherspecies-Glagah (Saccharm spontancmm Linn.), Glongong (S. soltwedeli Kobus), and S. ciliatum Hackel. 
His manner of treating the surface would seem to indicate that these spore-bearing organisnis were present, sometines at least, in the interior of the cane, but, of course, they sliow 11 othing as to the cause of Sereh. The most interesting thing, perhaps, in his paper is the effect of copper sulphate on the cane-plant. He found that Janse's bacteria were able to endure a strong solution of copper sulphate, and also that the cane-plant itself was not easily injured by this chemical. Cane-stems placed in a strong copper sulphate solution and left for weeks germinated, and when planted out grew into good plants. He states that Kobus could not discover a single plant affected by Sereh in English India.

The probability is that the organisms obtained by Janse came either from the surface of the cane or from dead leaf-traces in the nodes. His cane-disks were certainly insufficiently sterilized by the boiling, and lis Bacillus sacchari seems to have behaved in culture-media very much like the common potato bacilli, $i . e$, it yielded a wrinkled growtl, was extremely aerobic, produced spores promptly, ete. Dr. Went says of it:

I will presune that I hold the bacteria which Janse calls Bacillus sacchari to be identical with or at most a tropical variety of a bacterium generally known in Entope-the hay-bacillus (Bacillus subtilis). It is remarkable how much these two resemble each other.

Debray states that he repeated Janse's experiments and got similar results whenever the surface of the cane was inperfectly sterilized, but nothing at all when it was properly sterilized.

Went states that ont of the gum-diseased vascular bundles he obtained by cultures sometimes nothing at all and at other times various bacteria, but no one constant form. It would appcar, however, from the following paragraph that Dr. Went did not put much time on the question of a bacterial parasite:

From lower plants I directed my attention particularly to moulds and left the bacteria entirely outside the scope of my investigations, especially because the number of plant diseases which are actually caused by these little creatures now so much in fashion is so very small. Only when it appears that moulds can not possibly be the cause of the leaf-sheath disease, I will occupy myself with bacteria.

From a study of liealthy mountain cane planted on the plains and becoming subject to the Sereh, Went reached the conclusion that the red vascular bundles took their origin where the leaf-sheath joins the stem (see Cobb's disease, p. 53). Went also states that Krüger reached the same conclusion. In his type 4 (those plants least diseased) Went states that there are no external signs of the disease and that the internal signs are confined to the nodes.

Mountain plantations, if set with sound bibit, are at first free from Sereh, but they also finally become infected (Valeton, Went). The custom in Java, therefore, for some years was to bring down cuttings of sound mountain cane into the valleys for use in the sugarfields. The first year's crop was generally sound. If cuttings were taken from thesc the following year for the fields, then generally some Sereh apppeared; and in the third and fourth ycars much more than if the plantations were renewed each year from mountain cuttings.

The variety most commonly cultivated in Java at the time Sereh prevailed so extensively was the Black Cheribon cane. In many instances, in recent years at least, this cane has been discarded and more resistant varieties planted. Borneo cane is also very susceptible. It is now known that there are a number of quite resistant eanes. While not absolutely immune to Sereli, the Louziers cane (called also Loethers) and the Muntok cane are very little susceptible to Sereh (Went). The Fidji or Canne Morte and the Manila cane are absolutely Sereh-free (Went). The wild canes Glaga and Glongong and the Teboe Kassoer are free (Went).

So, by taking each year bibit from those canes which show the least marks of Sereh, one must gradually get a variety which outwardly indeed does not differ from Cheribon reed; but in wardly possesses the great difference of being immune or at least tolerably proof against the attack of the Sereh- 
disease. This very thing was done on the place of Kennanglen. Naturally the plantations did not take much room, but every year new bibit was taken from the extemally liealthiest stems. In i $\$ 87$ the Sereh-disease first took a violent form at Kemanglen after having shown itself in a light degree for some years, and since that time the original reed was propagated in the above manner with this result: that every year less Sereli-symptoms showed themselves and that the plantation at this time-April, I 893 - does not show one per cent of Sereh (Went).

Wakker states that the following varieties are entirely free from Sereh: Fidji koening, Kerah-cane, and a few others, while Loethers, Muntok, and Manila cane are sufficiently free to supplant the Cheribon to advantage until such time as entirely resistant canes can be obtained from seed-plants. All canes derived from seed are not resistant, but some appear to be (Went). The disease may be finally rooted out of the plantations by the selection each year of sound cuttings for propagation. This has been done not only at Kemanglen, but also in a small way ( 1891 to I 896 ) at the West Java experiment station (Went).

None of the Dutch writers lrave brought any conclusive evidence as to the parasitic nature of Sereh, i.e., they have not established the constant presence of any particular organism in the diseased cane; neither have they shown that the disease can be induced in sound cane by inoculating any particular organism. At the same time no thorough bacteriological study appears to have been made.

Wakker's views as to the origin of this disease are that it is due to the degeneration of cane under the influence of alternating seasons of great rainfall and of drought, such being the climate of the Javan plains. More explicitly stated, the west monsoon prevails for 5 months in the year, December to April, and each month there is a very lieavy rainfall, the total precipitation during this period often amounting to several meters. During the remainder of the year the east monsoon prevails and a drought occurs, the total precipitation amounting to only a few centimeters. The cane is set out in the dry weather and watered for several months, i.c., until the west monsoon prevails. It then grows with enormous rapidity for 5 months, whereupon follows a second period of drought in which the rootsystem gradually fails, the cane obtains barely water enough to keep alive, and so comes to maturity and the harvest time, about 12 to 15 months from planting. I translate from Wakker's final paper as follows:

In brief, the Sereh-disease is a gum-disease of the stem, which is caused, not by parasites, but by insufficient water-supply, the influence of which is greater on the future generation than on the plant itself. I have expressed this by saying that the disease is liereditary and accumulative.

He discusses this view very ably in a paper of 7 o pages. I quote from this further as follows:

I shall add directly that my presentation departs altogether from every other which has thus far been published and especially in that I consider the Sereh-disease as non-parasitical and so also as non-infectious.

I too, at first thought of trying to find the parasite of the Sereh-disease. A number of attempts to get it by preparations of the stem have cost me much time, and led me to this one positive result - the conviction that it is not to be found there. ***

'The variety of the IIeterodera found by Treub I have never met with in sugar-cane roots, and it belongs at most to the rare parasites of that plant. A parasitic Tylenchus variety no man has ever seen yet.

An examination made by me of these red stripes [in the stem] gave proof that in them or in their vicinity no parasites occur. *** $*$ *

No one has found Sereh-diseased plants in a wild state.

So far as I know, Janse is the only one who mentions the case in which Sereh-diseased bibit set out in the open ground at Biitenzorg produced healthy plants.

One other matter is to be mentioned here. If, from year to year, slips of Sereh-diseased plants are set out, this does not lead to a dying out of the cane. In other words, Sereh-diseased plants, even when severely attacked, may always still provide slips for the growth of new plants, at least when they are not too old.

A cane plant may very well have a vigorous root-system and yet be typically Sereh-diseased. 
Still [generally] it is a fact which everyone can easily prove that really the roots of a Sereh-diseased plant consist of short stubs with decayed ends.

I believe that precisely in the red stripes of the nodes, which, as already remarked, are filled with gum, we must notice the symptom of the injurious results of the insufficient water-supply on the part of the varieties of cane that are sensitive to it, and the absence of such stripes proves then that the variety is not so sensitive to a scant water-supply as to experience injurious consequences therefrom. $* * *$

It is naturally possible that, as in the hyacinths, so in the grape-vine, both a gum-disease and a bacterial disease may occur, and this also may be the case in sugar-cane, if, for example, top-rot should prove to be a disease actually caused by bacteria; but certain it is that gum originates in sugarcane in connection with all injurious influences affecting the plant, in roots, leaves and stems by wounding, without co-operation of parasites, as well as by diseases.

The assumption that the gum-formation in the plant may be promoted by a chronic lack of water is a theory, like any other, which by several utterances in literature is made plausible, and is further sustained by the fact to which attention has thus far not been called, that it is in the nodes that the red stripes appear, that is, where the evaporation of the leaves must make itself most felt.

I further assume that that influence which has been operative during the formation of the buds [lack of sufficient water] makes itself felt in such a way that the plants which spring from those buds are weaker than plants developed from buds under more favorable circumstances.

An internally weaker plant will react on lack of water sooner than a normal one; that is to say in substance, the gum-formation will be stronger and the vessels will become more obstructed.

That we may thus come to the traditional "bouquet" Sereh-plant with sprouted roots on the stem and dead roots in the ground is clear.

The sprouting buds on the stem present a greater difficulty. Before discussing it, I want to recall that not a single one of the earlier theories has led to an explanation of it.

If this presentation is right, and there is much to be said for it, then it may be accepted that the Cheribon cane as a variety had some years before entered upon the period of senility and that this

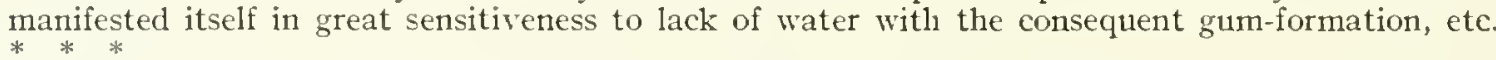

Wakker also cites the filtration test of Janse as slowing further that the Sereh disease stands in very close connection with lack of water.

He says it is a fact also that on the borders of the plantations close to the drains where the sugar-cane roots have only three directions in which to grow, instead of four, and are, furthermore, subject to drying-out, there the worst Sereh-plants are met with.

He accounts for the spread of the disease from west to east by the fact that the disease first appeared in the Cheribon cane, which itself originated in the west, and that the eastward spread does not indicate the movement of a parasite, but rather a more general distribution of the particular variety of cane subject to the disease.

The becoming Sereh-diseased of some imported varieties that are Sereh-free in their own country can be explained by the aforesaid influences as well as by assuming the theory of infectiousness. * * *

Finally, the immunity of some sugar-cane varieties rests either on the possession of a more vigorous root-system, or on a lesser sensitiveness to lack of water, so that gum-formation does not take place nor the obstruction of the vessels.

With former writers, I consider the red stripes in the nodes as a most clearly discernible characteristic of the beginning of the disease.

Recently Greig Smith has ascribed a red string disease of sugar-cane to a bacillus ( $B$. pseudarabinus). (See Cobb's Disease, p. 49.)

Soltwedel and Prinsen-Geerligs areauthority for the occurrence of Sereh in Malacca, and Kobus is authority for its occurrence in Borneo and Bangka.

In his eriticism of Wakker's theory Krüger states that Tylenchus sacchari Soltwedel is a typical sugar-cane parasite not uncommon in Java.

The last communication on the subject the writer has seen is by Zeijlstra. According to him, two factors are necessary for the production of Sereh, receptivity and a parasite. He says in so many words:

My observations lead me therefore to the following two theses:

I. Sugar-cane is a double race, variable in receptivity for the attack of the "Sereh"-disease.

2. "The "Sereh"-disease is an infectious disease, the cause of which up to this time is unknown. 


\section{LITERATURE.}

1885. TREUB, M. Onderzoekingen over Serehzieksuikerriet. Mededeelingen nit 'sLands Plantentuin, il, 1885 .

1889. SolTWEDEL, F. De Serchziekte, Med. v, het Proefst. Midden-Java. Semarang, 1889.

I89o. BENECKF, F. Is het mogelikj, uit typische "Sereh"-stekken gezond suikerriet te telen? Meded. v. het Proefst. Midden-Java te Semarang, $1890,8^{\circ}$, $10 \mathrm{pp}$. with I Taf. Reference in Zeitschrift für Pflanzenkrankheiten, Bd. I, H. 6, p. 361 .

It is said to be possible to grow sound cane from cuttings takeo from diseased caue.

1890. KRÜGER, W. Vorläufige Mitteilungen über die Serehkrankheit des Zuckerrohrs (Rotz, Bakteriosis). Berichte der Versuchsstation für Zuckerrohr in West-Java, Kagok-Tegal, Teil I, 1890 .

1890. BENECKF, F. Proefnemingen ter Bestrijding der "Sereh." Met eene Plaat. Proefsta. Midden-Java. Semarang, $1890,8^{\circ}, 27 \mathrm{pp}$.

1890. KRÜGER, WIIHEI,M. Over ziekten en vijanden van het suikerriet. Mededeelingen van het Proefstation voor suikerriet in West-Java, Kagok-Tegal, Deel 1, 1890, pp. 124. Also in German in Ueber Krankheiten und Feinde des Zuckerrohres, in Berichte der Versuchsstation für Zuckerrohr in West-Java. KagokTegal (Java), Heft 1, Hervorgegeben von W. Krüger, Dresden (G. Schönfeld's Verlagsbuchhandlung, 1890, pp. 50-179). Rev. in Bot. Centralbl., 1891, Bd. 47 , p. 46.

On pp. 66 and $126-179$ of the German edition there is a long account of Sereh. He thinks this disease is due to bacterial occupation of the vessels of the cane. The orgarisms resembl Bact. termo.

1891. KoвUs, J. D. Resultaten van desinfecticproeven 1890-9r. Mededeelingen van het Proefstation Oost-Java, Nr. 36, $8^{\circ}, 15 \mathrm{pp}$. Soerabaja, 1891. Rev. in Zeitschrift für Pflanzenkrankheiten, Bd. I, H. 6, p. 365.

Twenty-four acres of cane-cuttings treated with copper sulphate for Sereh yielded 9 per cent nore cane and 20 per cent more sugar than 24 acres untreated.

1891. JANSE, J. MI. Proeve eener verklaring van Serehverschijnselen. Mededeclingen uit'sLands Plantentuin te Buitenzorg, VIII, Batavia, Landsdrukkerij, 189 .

Reprinted in Tijdschrift voor Nijverheid en Lanbouw in N. I., Deel xitir, Af. 4 en 5.1891. Also a separate.

Thiuks Sereh due to plugging of vessels and that pushing of adventive buds is due to the same cause. Says De Vries and Wakker induced pushing of such buds in Bryophylum caly. cinum by reducing or wholly withholding water.

1891. JANSE, J. M. Het voorkomen van bakterien in suikerriet. Mededeclingen uit 'sLands Plantentuin Ix, Batavia, Landsdrukkerij, IS91. Rev. Bot. Centralbl. I892, Bd. XI,1x, No. 12, p. 376. Also ibid, Bd. 5o, p. 55. Also Zeitschrift für Pflanzenkrankheiten, Bd. 1II, I893, p. 103.

Describes Bacillus sacchari and $B$. glagae. Work very defect ive from the modern bacteriological standpoint. Janse found his bacilli not only in sugar-cane, but in nearly every other plant he examined and in healthy plants as well as diseased. The orgaoisms exist normally in sugar-cane and only cause Sereh whea peculiar unknown cooditions arise.

1891. Valeton, Th. Bijdrage tot de kennis der Serehziekte, $4^{1}$ pp., I Taf. Procfstation OostJava. Batavia (Kolff \& Co.), i89r.

Rev. Bot. Centralbl., I892, Bd. L1, p. 175.
1S9t. Val ETON, TH. Bacteriologisch onderzoek van rietvariëteiten. Proefstation Oost-Java, Soerabaia, I891, No. 34

Rev, in Bot. Centralbl, 1892, Bd. L, p. 177, and ibid., 1894 Bd. $4,1 \mathrm{x}$, p. 42 .

1891. BENECKE, F. De bestrijding der onder den naam "Sereh" samgeratte ziekteverschijnselen van het suikerriet. Semarang, 6 Sept., 1891,8 vo, 16 pp., I plate.

Reviewed in Zeitschrift für Pdanzenkrankheiten, Bd. 1, H, G, p. 354 , and in Centralb. f. Bakt., xII Bd.. 1892 , pp. 31 I-312,

1891. BENECKE, F. Abnormale verschijnselen bij het Suikerriet. Meded. v. het Proefst. MiddenJava te Semarang, $1891.8^{\circ}, 53 \mathrm{pp}$., with 8 Taf

1891. BENECKE, F. Nieuwe waarnemingen van abnormale versehijnselen bij het Suikerriet. Semarang, Van Dorp \& Co., $1891,8^{\circ}, 23 \mathrm{pp}$ with 7 Taf.

1891. MAx, W. Die Rohrzucker-Culturen auf Java und ihre Gefährdung durch die Sereh-krankheit. Bot. Zeit., 1891, columns 10-15.

Methods of cane-culture, signs of Sereh, losses, etc.

1891. Tschirch, A. Ueber Sereh, die wichtigste aller Krankheiten des Zuckerrohrs in Java. Arbeiten aus dem pharmac. Inst. der Univ. Berı. Schweizerische Wochenschrift f. Pharmacic, I89 1, No. 6, xxıx Jahrg., pp. 47-52.

Also a sepacate, $8^{\circ}, 6$ pp., 2 Taf. Roots believed to be the seat of the disease. Not due to bacteria or Pythium

1892. VALETON, TH. Vorming van bacteriënslijm in inwendige holten in de leden van het suikerriet. Meded. Oost-Java, No. 43, Soerabaia, 1892, pp. $19^{-24}$.

This paper deals with the occurrence of bacterial slime in closed cavities in the internodes of surar-caoe. Some joints of otherwise normally developed cane were one-sided often to very marked degree, so that there was great distortion, on phenomenon repeated itself ia cane derived from the cuttings of phenomenon repeated itself la cane derived from the cuttings of nodes, or at least somewhere in the vicinity of malformed intercavities cont somewhere in the vicinity of such nodes, closed occupied the vascular hundles also found, and these bacteria cavited the resengled cane ait ine node, so that sections therefrom much rearly stages of these cavities led Valetodies, however, of very early stages of these cavities led Valeton to think they appeared prior to the presence of the bacteria and were due primarily to some interior disturbance in growth rather than to bacterial developmeot. Ninety per cent of the plants derived from canes received from Mr. Moquette were thus diseased, and of the 300 varieties cllitivated by this planter 32 are said to have shown this deformity with the internal cavities in more than half of them. As I read Valeton's account, the signs of this disease are quite unlike those of Cohb's disease, in that the cavities feet rom distorted lower joints of the cade at a height 2 to 4 feet from the ground, the canes being otherwise normal in appearance. The size of these cavities varied from a pio's head

892. BENECKE, F. Onderzoekingen en beschouwingen over oorzaken en Middelen. Sema. rang, Van Dorp \& Co., I 892, 1 Aflevering, II Aflev.

1892. WIELER, A. Ueber das Vorkommen von Verstopfungen in den Gefässen Moto-und Dicotylen Pflanzen. Meded. van het Proefstation Midden-Java te Klaten, $4 \mathrm{t}$ p. Semarang (Van Dorp \& Co.), 1892. Also printed in Bio. Centralblatt, xu Bd., 1893 . Rev. in Bot. Centralbl., 1895, Bd. 61, p. 373.

This is a geveral paper on vascular occlusions in monocoty ledonous and dicotyledonous plants for comparison with Sereh in care. 
I 892. BENECKE, F. "Sereh." Onderzoekingen en beschouwingen over oorzaken en niddelen. Semarang, $1892,8^{\circ}$, I5 pp. 3e Aflevering: Hoofdstuk v.

1892. BENECKE, F. "Sereh." Onderzoekingen en beschouwingen over oorzaken en middelen. 4e. Aflevering: Hoofdstuk vi (I). Bacteriën als oorzaak der "Sereh." Semarang, IS92, pp. 24-39.

1892. BENECKE, FRANz. Onderzoekingen en bes. chouwingen over oorzaken en middelen, 5 te Aflevering: Hoofdstuk vı. Bacteriën als oorzaak der "Sereh" (vervolg). Semarang, $1892,8^{\circ}$, pp. $40-60$

1893. WENT, F. A. F.C. Eenige opmerkingen over de behandling van bibit met het oog op de bestrijding van rietziekten. Archief voor de Java-Suckerindustrie, I $893,8^{\circ}, 8$ pp. (Mededeel. Proefst. "West-Java.")

1893. BENECKE, F. "Sereh" Onderzoekingen en beschouwingen over oorzaken en middelen. 6te Aflevering: Hoofdstuk vi, slot. Bacteriën als oorzaak der "Serelı" (slot). Mededeelingen van het Proefstation, "Midden Java." Semarang, $1893,8^{\circ}$, pp. 61-94.

Attacks Jause's view.

1893. BENECKE", F. "Sereh" Onderzoekingen en Beschouwingen over oorzaken en middelen, 7c Aflevering $a$. Bijvoegsel van Hoofdstuk vi, $b$. Hoofdistuk vir, met i 3 figuren op ix platen. Semarang, $1893,8^{\circ}$.

1893. BENECKE, Franz, "Sereh." Onderzoekingen en beschouwingen over oorzaken en middelen. 8te Aflevering: Hoofdstuk viII met I plaat. Semarang, $1893,8^{\circ}, 33 \mathrm{pp}$.

I 893. Went, F. A. F. C. De Serehziekte. Archief voor de Java-Suikerindustrie, 1893, pp. 425472. Soerabaia, met I plaat.

Also a separate, $8^{\circ}, 48 \mathrm{pp}$.

1895. WENT, F. A. F. C. De Serehziekte. Archief voor de Java-Suikerindustrie, 1895, p. 589.

1896. KRÜGER, W. Die Krankheiten und Feinde des Zuckerrohrs. Ir. Berichte der VersuchsStation für Zuckerrohr in West-Java, KagokTegal, Java, I 896 , Heft 2, $8^{\circ}, 260$ pp., mit 2 lith. Tafeln und I Autotypie, I 896.

I896. WENT, F. A. F. C. De Serehziekte. Archief voor de Java-Suikerindustrie, I896, pp. I25I 26.
1896. WAKkER, J. H. Die indirecte Bekämpfung der Serehkrankheit des Zuckerrolirs auf Java. Botanisches Centralblatt, Bd. Lxvi (Jahrgang XVגi), pp. $1-7,1896$.

1896. DEBRAy, F. Bactériens de la canne à sucre Comptes rendus hebdomadaires de la Société de Biologie, Paris, I896, Séance du 7 Novbr., pp. 889-89o.

A brief unfavorable criticism of Janse's Het Yorkomen van Bakterien in Suikerriet. The author followed Dr. Janse's method of isolation and obtained similar results with Algerian cane. When, however, the surface of the cane was rinsed in sterile sugar-water, washed in mercuric chloride solution and then boiled 10 minutes, no bacteria appeared in the cultures and poured from. On the contrary, a tube of gelatin inoculated and poured enon the sterile sugar-water used for the washing disks of cane treated à la Janse "il we semale déped on the ces or canis treated a la Janse. vent, par conséquent, étre considérés comme lal et ne peuvent, par conséquent, etre considérés comme la cause de la face if we can accept Valeton's statements.

I897. WAKKKER, J. H. De Sereh-Ziekte. Mededeelingen van het Proefstation Oost-Java, Nieuwe Serie, I897, No. 35. Overgedrukt uit het Archief voor de Java Suikerindustrie, 1897 . Afl. $3,8^{\circ}, 69$ pp. with 6 fig. Soerabaia. $(H$. van Ingen), I 897 .

Also a separate.

1897. WIELER, A. Die gummösen Verstopfungen des serehkranken Zuckerrohres. Beiträge zur Wissenschaftlichen Botanik, Bd. II, Abt. I, 1897, pp. 29-140, Mit I Tafel und 23 Figuren. Stuttgart, A. Zimmer.

Also a separate.

1898. WAKKEER, J. H., and WENT, F. A. F. C. Die Ziekten van het Suikerriet op Java, Deel I, Ziekten, die niet door Dieren veroorzaakt worden, mit 25 Tafeln. Leiden, 1898.

1898. KRÜGER, W. Ueber die Ursache der Serehkrankheit des Zuekerrohrs. Eine Kritik der Arbeit und Theorie von Wakker. Die deutsche Zuckerindustrie, Bd. xxıI, I 898, columns 225-235, Feb. II, Besondere Beilage zu Nr. 6.

Thiuks Sereh occurs in one place in Java which has a uniform rainfall throughout the year, $i$. $e$., no dry period, such as Wakker assumes necessary for its productiou.

igra. Zeijlstra, H. H. (Fzn.). Versuch einer Errklärung der "Sereh"- Erscheinungen des Zuckerrohrs. Ber. d.d. Bot. Ges. Bd. Xxix, Heft 6, July 1911, pp. $330-333$. 


\section{TOP-ROT OF SUGAR-CANE IN JAVA.}

In my account of the disease I follow Wakker.

For the first time in the year 1895 in Java attention was more particularly given to the top-rot, a disease which previously was to be found sporadically but lad now begun to be epidemic.

Following Cobb, it was first named gum disease, but since the signs do not entirely accord with the ones given by him, Wakker prefers to use the above nanne, even though the diseases in Java and in Australia should prove to be identical, especially because the name "gum disease" is not happily chosen, gum formation occurring in nearly all diseases of the cane, and even in conncction with a wound.

The disease has been observed in Java in a dangerous form, especially on the Loethers or Louzicr cane (mostly in West Java), and on the striped Preanger cane (nore particularly in East Java), and to a less degree also on Cheribon cane.

The signs appear chiefly in the beginning of the rainy season; later no other cases occur, and during the dry period of the east monsoon one does not usually notice any signs of the discase.

It is highly probable that the so-called heart-disease, and that known as Pokkah-bong, have the same cause as the top-rot.

The following are the signs of the three diseases mentioned by Wakker:

A. The top-rot in stricter sense.

Externally the signs accord wholly with those caused by the top borer: the youngest leaves are black and decayed at the base and more or less dried up at the top. Soon the older leares also dry up.

The younger leaves can be pulled out without any trouble, and it is then that an almost unbearable odor is first noticed. If the affected tops are cut through lengthwise, one notices in the typical far advanced cases that the younger leaf-sheaths are brown and dead, while the youngest leaves are changed into a feeble, twisted (wormvormige) mass.

The growing-point is either normal or changed to a yellowisl1-white sline (brei), while the rest of the young stem-top has become, on the inside to a greater or less extent, a glassy 1nass, which is separated from the outside by a clear red line. This outside is as good as unchanged.

Usually in the youngest part of the top there also appear cavities, which are much broader than high, and on a lengthwise section look like cross-cracks.

Ifater the glassy tissue disappears more or less, and then large lengthwise cavities appear, in which the vessel bundles are to be found as white threads alnost unchanged.

Generally the disorganization does not go much farther than the growing articulations. A few times, however, Wakker found plants a couple of meters high which were wholly affected by the toprot and killed. Down to the underground stem-piece the central tissue was glassy and surrounded by a red line.

If the signs are confined to the top, the buds under the diseased spot sprout, as in all other cases in which the growing-point is destroyed or ceases to grow. Sucl sprouting buds do not usually get the disease. In genuine cases of top-rot larvæ are never found. If the growing-point remains sound, while the leaf-sheaths have already died, or at least have been affected, conbined or not with diseased spots in the stem under the growing-point, and, if in such plants the top-rot does not go farther, then the stems may grow on, never, however, without later showing the consequences in the joints becoming crooked or remaining short, which then dry up more or less.

\section{B. The Ileart Disease.}

'Till now this disease is known to exist only in a few mountain bibit plantations. According to Went it is nothing else than a special case of top-rot in young plants. Externally one sees the young leaves curl 11p, take on a yellow-gray tint, and decay. In a lengthwise section it is seen that in the heart of the plant the youngest leaves, sometimes also the stem-top, have to a certain extent colored brown and died, showing for the most part cross-wrinkles.

C. The Pokkah-bong or chlorosis of the central leaves.

Under the Javanese name of Pokkah-bong (broken sprout) some signs are grouped whicln until lately seemed to have little practical interest, but which are not wholly without significance. 
In the beginning of the rainy season, $i . e$. , while the cane is still young, one often finds stem-tops having an abnormal appearance (afwijkend uiterlijk): The young leaves which have not wholly unfolded show close to their bases lengthwise yellow spots, sometimes almost white spots, often combined with a bruise (kneuzing) on the spot, with a few rows of small holes or with cracks.

The top of the leaf is then usually green and sound. Sometimes only one leaf show's these abnormal symptons; sometimes a few leaves following each other show them all at the same time.

If such sprouts are watched, it appears that the leaf attacked does not develop in the usual way, but either breaks off across or cracks lengthwise, and acquires dark violet or black lengthwise stripes, while the yellow spots become darker and soon show all sorts of colors.

Usually the sprout keeps on growing without displaying much more externally. If, however, a lengthwise section of the stalk is examined, it appears that this, at the point of the abnormal leaves, is always somewhat thinner. If the disease occurs in severe measure, it may happen that the joint under those leaves is faintly funnel-shaped, that is to say, at the top somewhat thicker than below, while the joints between the same leaves show more or less clearly the same form, but at the same time are short and remain as long as they are broad. Such places are later to be easily found again on the full-grown stalks.

As out of short joints roots sometimes develop, the entire part acquires naturally somewhat the external appearance of a sereh-diseased stem, and the sign discussed here has been, without doubt, at times taken for sereh.

It is not impossible that both occur together. If, however, it is only Pokkah-bong, then the red sereh stripes are wanting in the nodes.

In all these cases it is possible for the top to grow on. One sees clearly then that the stem, where the leaves are normal again, becomes also somewhat thicker and that the joints become longer.

Notwithstanding this latter fact it is possible that the influence on the growing-point has worked in such a way that the buds under the short joints sprout, although the terminal bud continues to grow.

This sign may in the Cheribon cane occur without previous Pokkah-bong, and occurs as a rule in a few varieties which are not raised wholesale.

When the cases of Pokkah-bong confine themselves to the above, the disease is of little consequence. Only it must be observed that the affected stalks break off easily at the thin spots.

Wakker made a microscopic examination of cases of top-rot and states that the young leaves as well as the growing-point are changed to a soft-rot (brei) which consists of isolated cells and bacteria, while the rest of the stem seemingly remains unchanged. The glassy tissue shows the same structure as the normal stem; only the cell-walls are somewhat thinner, and in cells and vessels everywhere bacteria are found. The peculiar glassy appearance is caused by the air liaving escaped from the intercellular spaces to make room for the watery bacteria-charged liquid which infiltrates everything.

In the red rim are vessels and intercellular spaces filled with a more or less red-tinted gum, which is in no wise different from that which is met with in other cane diseases, or in connection with artificial wounds in the stem.

In the vessels it is usually but lightly tinted; in thin section perfectly transparent, and contains no bacteria.

Outside the red rim there is usually nothing special to be seen.

The difference in appearance (uiterlijk) between the top and the lower diseased stem part is caused, no doubt, by the original difference of both these tissues.

The top indeed consists of small cells with thin walls and much albumen; the older joints, on the contrary, have nuch firmer walls that are less easily destroyed, and more sugar.

The inside of the cavities is usually lined with a thick layer of slime containing bacteria; the cells may here be more or less grown out and show a beginning of callous formation. That is to say, it is possible that cells which border on the cavities are divided by cross-walls which would otherwise certainly not have formed themselves.

The circumstance that the gum in the vessels here contains at the outset no bacteria is the main point of difference from Cobb's gum disease, since he states that the gum is full of bacteria, and, in many cases, is said to be limited to the vessels. 
In any case, the top-rot lias microscopically not the least resemblance to the yellow disease of the hyacinths. The disease shows as little characteristic symptoms in other respects.

The same is true of both the other forms.

In the cracks and lioles of Pokkah-bong one may also meet with bacteria and even moulds, and the same is true of the inside of young plants attacked by the Heart-disease.

In order to learn what bacteria were to be found in the decayed tops, Wakker states that he took two courses: (I) direct transfers to tubes of agar; (2) poured plates.

Went, in his preliminary investigation, had met with but one bacterium; Wakker, on the contrary, found several. For his experiments Wakker used test-tubes with a slanting surface of nutrient agar-agar containing $975 \mathrm{gm}$. of water, $3 \mathrm{gm}$. pepton, 6 gin. cane-sugar, I gm. extract of meat, I $5 \mathrm{gm}$. agar-agar. He obtained the following results from his transfers:

Test I.-On March 7 by means of a sterilized needle I derived from a rotten top just cut through, infectious matter which was transferred to agar-agar tubes. There developed:

1. Thick, whitish drops, which soon flowed down. On examination they appeared to be short, thick rods which without exception were surrounded by a jelly covering. As appears from the description and picture by Cobb they are identical with his Bacillus vascularum, and likewise with the one found by Went.

2. Flat, almost invisible coverings which appeared to consist of a micrococcus.

Both kinds are without movement of their own. The appearance of the two bacteria naturally made new tests necessary. The micrococcus was preliminarily designated No. $\mathrm{r}$.

Test II. - On March $3^{\mathrm{I}}$, with as much antiseptic precaution as possible, from a fresh cut top-rot stalk I soaked a small quantity of glassy tissue from the inside of the red line, in sterilized water, and of this I transferred some drops to melted agar-agar. This was poured out into four glass boxes and left to stiffen. After 15 hours a number of colonies had developed, the bacteria of which were also numbered.

No. 2. Small yellowish colonies which consisted of a non-motile micrococcus in very large numbers.

No. 3. Many larger, opalizing drops, which consisted of short, thick bars, without movement of their own and with a jelly covering.

No. 4. Spread everywhere in the agar-agar, long, thin bars, without movement of their own, but sometimes with spores, which formed no real colonies.

After heating the boxes to $100^{\circ} \mathrm{C}$. in the steam sterilizer the latter alone were left and now formed also clear colonies in the form of a white layer.

Lastly, also thin, short bars, with an active movement of their own, which occurred in colonies resembling externally those of No. 3 .

Test III. - The foregoing test was repeated with the white rotting tissue of the top on April 4 . This gave the following results:

No. 5. Long, thin, crooked non-motile bars.

No. 6. Short, thin bars with active movement of their own.

No. 7. Long non-motile bars containing spores.

In all three tests only those forms are numbered of which pure cultures were made in test-tubes. They were for a time all nurtured separately until it appeared that they were:

Nos. I, 2, a Micrococcus.

No. 3, Bacillus vascularum Cobb.

Nos. $4,5,7$, Bacillus subtilis.

No. 6 , the last one named under test II.

Thus four are left which will be further distinguished with the numbers $2,3,6$, and 7 .

The question now was which of these might be considered the cause. 'To this end served the following:

Test I V. - On April I 6 I introduced pure 2-day old, liquid cultures of the bacteria Nos. I to 7 into the closed leaf-sheaths (Kokers) of seven sprouts which had developed in small pots. In each pot there was still another sprout which was not infected. The pots were narked with the same numbers as the bacteria. That same day the bacteria were microscopically examined and of each a new culture was made on agar-agar. On examination these appeared later to be pure cultures.

In view of the approach of the dry monsoon the pots were placed under a gangway in the shadow. 
May 22.-- Pot marked:

I. Both sprouts sound; but one much larger than the other.

2. One sprout sound, one top-rot.

3. One sprout sound, one top-rot.

4. Botli sprouts sound.

5. One sprout sound, one top-rot.

6. Both sprouts sound.

7. One sprout sound; in the other the leaves are beginning to dry up.

Pots Nos. 3 and 4 were more closely examined; in both, the young leaves above the regetation point appeared brown and dead, but the latter itself was not attacked.

On Jume i 6 the condition of the remaining sprouts was as follows:

Pot marked:

I. One sprout sound; the other dead at the top, but the older leaves still living.

2. One sprout sound; the other dead at the top, but the other leaves still living.

3. One spront sound; the other is cut off.

4. One sprout sound; the other is dead.

5. One sprout sound; the other is cut off.

6. 'Two sound sprouts.

7. One sprout sound; the other dead at the top; the older leaves still living.

On June 20 a closer exanination took place; of the infected spront from pot No. I the young leaves within the sprout are brown and dead. The regetation point is still sound.

Of the infected sprout from pot No. 2, as above.

Of both sprouts from pot No. 6, one is attacked by a borer, the other sound.

Of the infected sprout from pot No. 7 , as $\mathrm{I}$ and 2 .

Not one of the three top-rot sprouts diffused any odor on cutting.

These are all the experiments Wakker was able to make and certainly they are not very conclusive. That he had Bact. vascularm seems to me extremely doubtful. His final summary is as follows:

It seems to me that in the top-rot we have a disease which is not in the strictest sense of the word parasitical, but is brought about rather by a combination of circumstances.

Of these circumstances I mention in the first place great moistness of the air and high water content of the plant. That I ascribe a great influence to this rests chiefly on the observation that the top-rot in East Java occurs in the rainy season, while in the dry time it is not observed.

In the second place I believe that the tops which by the above-named circumstances are predisposed to become diseased, need to this end in addition only that the rery youngest, still wholly rolled up and not visible leaves do, from one cause or other, wholly or partly die off. One cause to be assigned for this, in the first place, is a sudden rapid growth which is the result of the occurrence of rain upon cane that has long suffered from want of water. 'This might then have as a result a cracking and deformation of leares and leaf-sheaths, the phenomena known as Pokkali-bong. Top-rot would then result through the decay of the malformed leaf-sheaths and in young sprouts the Heartdisease.

Whether this theory is correct, later investigations will have to show. That the top can be killed by rotting substances is proved by test IV.

Although it follows from the above considerations that the top-rot is probably not infectious, I nerertheless deem it desirable to advise cutting off and burning the affected tops. Cutting off in cases of Pokkah-bong, I think, I must not advise as yet.

Should the symptom repeat itself on a large scale, then the planting of the more sensitive rarieties would have to be abandoned. Concerning this, however, there is nothing now to be said.

\section{LITERATURE.}

I898. WAKkеR, J. H. Het Top-rot in "Die Ziekten van het Suikerriet op Java, die niet door Dieren veroorzaakt worden." Leiden, 1898, pp. 64-75, 2 plates. 


\section{THE HUMID GANGRENE OR POLVILLO OF SUGAR-CANE IN ARGENTINA.}

In I895 Spegazzini, of La Plata, described a wet gangrene of the sugar-cane from the province of Tucumán (lat. $26^{\circ}$ to $28^{\circ}$ south) in Argentina. In the first part of his paper he runs over briefly all the rarious diseases of sugar-cane which he has net with, and states that the wet gangrene or Polvillo, as it is frequently called by the farmers, is the most seriots disease of cane in Argentina. The loss was so great in IS93-1894 that he paid a visit to the province and made a special study of the disease. He states that after a considerable search through literature he was unable to identify this disease with any other, tulless it be a disease of cane in Java and Matritius, which he found briefly described in some publication. In his opinion the disease is very old, its recent rapid development in Argentina being due to defective methods of cane-planters. In many respects his account of the disease suggests Cobb's disease of sugar-cane. The particulars in which it approaches this disease are the following:

The chlorotic aspect of the plants; the leaves lose some of their rigidity and luster, and bend down as if withered. On these plants certain leaf-blades bear long dead stripes, involving the entire thickness of the leaf tissue. 'These stripes are more abtindant on the lower half of the leaf-blade, seldom reaching more than half the length of the blade. They are linear, narrow, of variable length, vivid red or more rarely violet or orange-colored. The same stripes appear on the leaf-sheath, especially on the inside of the sheath. Theinner face of these leaf-sheaths also bears numerous small red spots and a gumny exudate with a repugnant odor. Such leaf-sheaths are said to be thicker than normal, rigid, fragile, breaking easily. The terminal bud is much inclined to rot and it comes out easily with a gentle pull from the leaf-sheaths which envelop it, and then its basal part is found to be decomposed and yellowish or reddish, gummy, viscous, and transformed into a purulent paste with a strong odor, said to be like that of rotten leather or butyric acid or ammoninm sulphide. When such cane plants are divided longitudinally it is observed that the terminal bud is entirely or partially decayed, together with a variable number of the leaves surrounding it. This decay also sometimes extends downward through the central part of the mature cane stem, exceptionally even to the root. The red stain, which becomes inore pronounced on contact with the air, is more abundant in the nodes at the level of the leaf-sheaths and on cross-section of the fibro-vascular bundles. The terminal bud, even when not diseased, may be wrapped about and compressed and prevented from expanding properly by the diseased leaf-sheaths surrounding it; in other words, it is imprisoned and suffocated or strangulated by these gumny surrounding leaves (see Cobb's disease, p. I6). Sprouts often rise from the base of such affected canes or from the canes themselves, but more often the latter are killed outright. Canes which appear healthy on the surface may be diseased within.

Spegazzini carefully considers the effect of soil, rainfall, temperature, and other local conditions, and reaches the conclusion that while some of them may faror the disease none of them are responsible for it. He also considers agricultural methods and states that at first many of the cane planters were inclined to believe that plant-cane was more subject to the disease than ratoon-cane, and lie himself arrives at the conclusion that this was true formerly, but that now the discase is widely distributed on the cane, no nuatter what the treatment has been. He thinks beyond any reasonable doubt that the disease has been propagated extensively by planting diseased canes.

According to data which I have received it appeared that in the beginning the plant-cane exclusively was attacked by the gangrene, and on arriving at Tucumán there was much to bear ont this idea. However, others declared that even though in the beginning they had held this opinion experience had demonstrated to them the contrary, and they invited me to compare fields of plant-cane with fields of ratoon-cane, which I found equally diseased. With all this, and that which I shall explain later, I believe it is true that the new plantations are, or at least have been, most subject to the invasion of the plague. 
Spegazzini states that of the two common sorts of cane planted, Caña rayada and Caña morada, the former appears to be more subject to the disease than the latter. He also had opportunity to examine some small plantations of Caña India and Caña Española or blanquita. He found the India free from the gangrene, whereas the Spanish was attacked by it.

The planters sometimes reported that cane which had been attacked recovered therefrom, and this is sometimes true of individual plants, but not for whole localities. I quote as follows:

During my study I observed successively that the disease is permanent, and that if the cane which is diseased does not die, which does not liappen often, whether it be by keeping the vegetative cone still healthy, or by throwing out lateral shoots, it always retains plainly visible indications of the disease.

In another place he makes the following statement in support of his view that the infection is centripetal, $i . c$, attacks first the external organs and then the internal organs:

I will cite the recovery of diseased plants, a thing which all the cane growers are familiar with, and who express it by the saying "the canc conquers the Polvillo."

The general effect of the discase on the plant is to make it grow slowly and develop its leaves very, very slowly. On cutting cross-sections of diseased leaf-blades for microscopic examination it was found that the gumminess was associated with a "great number of corpuscles which appeared to be cocobacteria, mixed with bacilli and with mycelial threads." Similar observations were made on the leaf-sheaths. An examination of the undeveloped gummy leaves, including the terminal bud, showed a similar condition. I translate as follows:

When these leaves become discased the epidermis almost disappears, and the parenchyma is disorganized; a yellow gum fills all the cells, and in this is found the protoplasm emulsionized, mixed with countless cocobacteria, bacilli and mycelial threads. When the disease is very advanced, one finds still entire only the woody vessels, which appear as threads or filaments.

If the terminal bud is not killed outright it continues to develop " between dead or partially dead leaf-sheaths which envelop the cane, almost strangling and suffocating it; but it presents evidence of the struggle, appearing etiolated and whitish and wrinkled, sometimes doubled over itself, bearing almost always a sheath or skin-like covering of a dirty color, and with a peculiar fetid odor: the remains of the new leaves which have died and which adhere to it still.

Spegazzini examined the cane fields very carefully with reference to the possibility of the disease being due to animal parasites. He mentions seriatim the forms found, such as eel-worms, acarids, mites, sand-fleas, earwigs, Hemiptera, Diptera, and Lepidoptera of various kinds, but comes to the conclusion that none of these are connected in any way etiologically with the disease, although possibly some of them may act as carriers. In the same way he excluded all atmospheric conditions, soil conditions, and special methods of culture, and came to the conclusion that the disease could be due only to bacteria. He states that from the first samples, which had been long in transit, he isolated about fifty species of fungi and bacteria, two of which were much more common than the others and therefore suspected. On visiting the cane plantations he collected numerous samples of diseased canes, isolating the organisms found in them by cultural methods, but only after much difficulty, and again found these two species extrcmely common.

The conclusions reached by means of these cultures are the following:

(a) In the whole organ attacked by the Polvillo there exists a bacterinm of form and characters clearly defined.

(b) In the parts, from the time diseased, there appears constantly a fungus in its various metagenetic stages, but of saprophytic characters.

The bacillus is said to be a new species and is named Bacillus sacchari. ${ }^{*}$ The fungus was identified as Mclanospora globosa Berlese. This occurs also on cane not diseased by the wet gangrene.

*This name is to be rejected on account of the earlier Bacillus sacchari Janse (1891). 
It is evident that Spegazzini selected this particular schizomycete becatse under certain cultural conditions it was able to produce a red pignent. To this conclusion I think he was led by the red color visible in the affected canes, and thus probably overlooked the real cause of the disease, $i . e$, the yellow slime.

He obtained a good growth of the fungus, and some growth of the bacillus with a violet color, on sugar, boiled starch, and lemon-juice. Both the bacillus and the fungus grew well on nutrient gelatin and also on nutrient gelatin with boiled starch or with sugar, or when both together were added to the gelatin. 'The best growth of both was on gelatin containing boiled starch, sugar, and lenon-juice. On this medium there was excellent growth and a magnificent red color, together with the production of a strong odor. No growth could be obtained on gelatin, boiled starch, sugar, and water of ashes. He also obtained growtli on scrapings from the hearts of sugar-cane, on onions, and on potatoes, but always in acid media. The best temperature for the bacillus is said to be $34^{\circ} \mathrm{C}$. The red pigment was produced only by the bacillus, and only in the presence of air. 'This organism is said to liquefy gelatin, forming a beautiful red color on its surface. "All neutralizing or alkaline substances stop growth immediately, as also all the common antiseptics." The bacterial organism occurs in the form of septate filaments of considerable length. These soon separate into segments 1.5 to $3 \mu$ in length by 0.5 to $0.8 \mu$ in diameter, cylindrical, truneate at the ends. When they are old they are said to produce two to four small globules in their interior, and these are supposed to be spores, 0.5 to $0.7 \mu$ in diameter, the membranes becoming dissolved, and the spores adhering together for some time in the form of chains resembling micrococci. The bacillus is said to resemble closely in its morphological, biological, and nicrochemical characters Bacillus sorghi**

Inoculation experiments undertaken in the cane fields did not succeed. Nine cane plants were inoculated by scarifying the stems and applying juice obtained from the rotted tops of diseased canes. None of these plants developed the disease. Spegazzini also took some of the thick, gummy material from the inner face of the leaf-sheaths, and diluting it with a little water, spread it on the upper side of the higher leaves of various healthy canes. This gum he states appeared under the microscope to be composed almost entirely of micrococci or germs of bacteria. The experiment failed. "I attribute this to heavy rains which occurred at this time." On his return to La Plata he made additional inoculations in the Botanic Garden, which he states were successful.

I again tried the same system, employing the same mucus and cultures which I mixed with several times their volume of dissolved gum arabic; but in order to avoid the injurious effects of the rains I put the solution on the leaf-sheatlis themselves, and as a further precaution I covered with a canvas the plants which had been inoculated. The result this time was wholly satisfactory; at the end of 5 days there appeared on the interior side of the leaf-sheaths some orange-colored dots, which later became red, and some days afterward there appeared the stain (spot) which extended to the leares, involving all of the ligular border and lengthening towards the upper part of the lamina. Noreover, out of six cane plants so treated, in two began total decomposition of the tops (cogollos), giving off also the repugnant and characteristic odor; at the same time there appeared at the base of these two plants many buds or side branches, as oceurs in the cane plantations affected by Polvillo.

Spegazzini believes that planters are themselves largely responsible for the spread of this discase. I quote as follows:

Stocks, and especially seed-canes which are diseased must necessarily produce diseased canes, or at least those which tend in this direction. The extraordinary increase of the disease which has been observed in the cane plantations during the last two or three years corresponds exactly to the culmin-

*In 1896 Spegazzini made the following additional statement: "Bajo el punto de vista taxonómico esta especie sería muy cercana al Bacillus marcescens (Bizio) 'Trev. (el milagroso Micrococcus prodigiosus Cohn, de los autores), pero se distingue de el facilmente por las extremidades tronchadas de sus artículos y por la sustancia roja que segrega, la culal no altera su tinte ni por los ácidos ni por los alcalinos." 
ation of the cultivation of cane; in this period effort has been made to obtain the largest yield and sell the greatest possible amount of cane, reserving for seed-cane only that which the inspectors have refused, and that which has no value. Here is the explanation of the unexpected appearance of the Polvillo and its enormous spread. This explains also why the cane planters observed that the ratooncane, when the product of healthy seed-cane, was but slightly or not at all diseased, while the plantcane the product of diseased cuttings or canes was usually diseased.

To-day all the canes, cuttings and plants, are equally affected, because now they all have the same vicious origin.

It must be left an open question whether this disease of Argentina is or is not Cobb's disease of sugar-cane. Of course, if we accept Spegazzini's statements respecting his Bacillus sacchari at their face value, it is likely to be something else, but on the other hand, making some allowance for unfamiliarity with this type of disease and considering the difficulty Spegazzini mentions having encountered in making isolations, together with the general character of the signs described, namely, spread from cuttings, chlorosis, striping and drying out of the leares, death of the terminal bud with the production of yellow bacterial slime and red stain, gumming of the dead sheaths about the terminal bud, which becomes distorted, marked red stain in the nodes and in the vascular bundles, old canes sound externally but diseased within, it seems probable that this disease should be referred to Bacterium vasculartm.

In the spring of 19 lo the writer received an agar-streak culture from Prof. Spegazzini, marked as his $B$. sacchari. 'This was a whitish layer containing quite a good many roundish, somewhat yellowish, smali colonies in its substance which appeared to be another schizomycete. An attempt was made to cultivate both organisms, but only the white one grew. No cane was available for inoculation at that time. When cane plants were finally available in the fall inoculations were made, but with entirely negative results.

The writer had promise of diseased canes from 'Tucumán in I9 12 , but none were received.

\section{LITERATURE.}

1895. Spegazzint, Cari,os. Ia Gangrena Humeda ó Polvillo de la Caña de Azúcar en Tucumátn. La Plata, June I5, 1895, $29 \mathrm{pp}$.
1896. Spegazzini, Carlos. Hongos de la Caña de Azúcar. Revista de la Facultad de Agronomía y Veterinaria, No. XIx, Ano Ir. La Plata, July 3 I, 1896, pp. $238-239$. 


\section{STEWART'S DISEASE OF SWEET CORN (MAIZE).}

Synonyms: Bacterial Disease of Sweet Corn; Burrill's Disease of Maize pro parte (?).

\section{DEFINITION.}

This is a specific communicable disease of sweet corn and some other races of maize, making its appearance at any stage of growth, but usually most noticeable when the plants have attained a height of several feet. It is principally a disease of the vascular system, which becomes filled with a yellow bacterial slime. The 11odes are finally stained brown or brownish, especially toward the base of the stem. The plants are dwarfed, the male inflorescence develops prematurely and dies early, the leaves dry out one after another, much as if frosted, and finally the stem dies and dries out, but without becoming soft-rotted. The bacterial slime oozes to the surface of the inner husks.

\section{HOST-PLANTS.}

This disease lias been observed only in Zea mays. The choice edible varieties known as sugar-corn or sweet-corn are specially subject to it, but the writer once observed it in autumn in common (dent ?) corn grown on damp land for fodder. It has been inoculated successfully by the writer into several kinds of sweet-corn and into some kinds of fieldcorn. Stewart's attempts to communicate the disease to pop-corn, dent-corn, teosinte, and oats were not successful.

\section{GEOGRAPHICAL DISTRIBUTION.}

This disease has been observed on Long Island, New York, where it is widely distributed and common every year (Stewart, Duggar, Smith), once in New Jersey (Halsted), several times in Washington, D. C. (Smith), twice in Maryland (1908, 1909), twice in Virginia (1908), once in West Virginia (Enlows), and once in Michigan (Smith). The writer has also strong circumstantial evidence for believing that it occurs in Ohio. Nothing more is known definitely of its distribution in the United States, and it has not been reported from any other part of the world. It is to be looked for, however, wherever sweet maize is grown extensively. Stewart assumed itsoccurrence in Iowa, which is not unlikely, but his evidence is not conclusive. It probably occurs in Illinois.

\section{SIGNS OF THE DISEASE.}

The writer knows of 110 other disease likely to be mistaken for this one. The only conspicuous source of confusion is the autumn frosting of the foliage, after which diseased and healthy plants can not always be discriminated by mere inspection, since the bacterial slime does not ooze from the ends of cut stems after frost has destroyed the leaves. They may be separated easily by microscopic examination.

In the fields on Long Island one of the first signs, in good-sized plants, is the whitening (drying out) of the inale inflorescence. This is stimulated to premature development and soon dies, giving to the top of the plant a peculiar whitish appearance. This sign comes rather in advance of the drying out of the leaves, except some of the inconspicuous lower and smaller ones, and may appear on a plant which in other particulars looks entirely healthy. In only one or two instances out of many did subsequent dissection fail to confirm the writer's diagnosis based on what appeared to be the premature development of the male inflorescence, and in no case were the bacteria wanting in the bundles when this inflorescence 
was conspicuously whitened, i.e., bore prematurely dead and dry glumes. The same signs appeared commonly in sereral kinds of sweet-corn grown in Washington in 1902 and inoculated with pure cultures of this organism. Next in order of importance is the dwarfing of the plant, which frequently does not reach half its ordinary size, and in some cases dies when it is a few inches or only a foot or two in height. With the dwarfing there is a gradual drying out and death of the leaves one after another, from the base of the stem upward (plate 6), and with or without a previous conspicuous flabbiness of the foliage. The affected leaf, without a preliminary yellowing, dies from the apex downward or from the margins in, slowly or rapidly, according to circumstances, $i$. $e$., according to the amount of rainfall and the more or less complete occlusion of those bundles below in the stem which supply it with water. Young plants occasionally develop the disease very promptly, $i . c$, within a week or two following primary infection, and such plants usually die a few days later. On the other hand, infection may take place in the seedling stage and the appearance of the disease be long delayed, $i . \varepsilon_{\text {. }}$, until the plant is full grown, a period of 8 or ro weeks intervening between the primary infection and signs of general collapse. In such plants, in the course of some weeks following the appearance of secondary signs, all of the leaves dry out; but for a short time the stem is still green and normal in its external appearance, and the roots are white and sound on their surface. Later the stem dries out, and the roots brown and rot with the appearance on them of various molds and bacteria. No conspicuous etiolation of the leares such as frequently occurs in sugar-cane attacked by Bacterim sascularm has been observed in this disease, either on plants found diseased in the field on Long Island or in those which became diseased in Washington as the result of pure-culture inoculations. No marked proliferation from basal buds as in Sereh was observed, but in some cases there seemed to be a slight tendency to push out shoots near the ground.

If cross-sections are made of the green stems, $i . \iota$. , before they begin to change color and to shrivel, but after the male inflorescence has dried out and some of the leaves have shriveled, a yellow slime will be seen to ooze from the ends of the bundles, usually from many bundles and in great abundance (figs. 39, 40). In longitudinal sections of the stems the bundles from which this slime oozes are observed to be bright yellow, the color being well set off by the white parenchyma in which the bundles lie. Many internodes are usually occupied by these yellow, sline-infested bundles, there being, however, nothing on the surface of the stem to indicate their presence. The upper nodes may be either normal in appearance or distinctly yellowed by the presence of the slime. The lower nodes, $i$. $e$., those diseased for the longest period, are always brown within and not infrequently, as one traces the signs upward from node to node, there is a gradual transition from deep brown in the lowermost nodes through pale brown and yellow to normal white or greenish-white at the top of the stem.* Sometimes also the basal internodes are internally more or less browned, the parenchyma as well as the bundles, or only some of the latter. Browning of the internodal bundles is not nearly as uniform and conspicuous as in cruciferous plants attacked by Bacterium campestre, and is usually observed only toward the base of the stem in bundles presumably long occupied, but sometimes appears higher and often appears prior to the death of the stem. In the same internode a part of the bundles may be brown and the rest yellow. There can be no doubt, I think, that this browning is due in some way to the presence of the organism, but why some bundles brown and others do not, is not perfectly clear. It may be

*Stewart had a different idea. He says: "The fact that the whole interior of the lower end of the stem is brown signifies nothing. This browning is found in healthy plants as well as in diseased ones." In another place he says: "The blackening of the fibro-vascular bindles, a not uncommon occurrence, is not due to the action of the corn bacterium." And again: "There is no disorganization or discoloration of any of the tisstes." The writer has occasionally found a brown stain in the basal nodes withont distinct evidence of the yellow bacterinm, on hasty examination with the compound microscope, but the reverse of this lie has never seen, viz, absence of brown stain in the basal nodes when the bacteria have been abundant in tlie stem as the result of infection in the seedling stage. It is always there and also of ten in nodes farther up the stem, as the reader will be convinced, I think, on reading what is said under Eliology. The brown stain is not normal to the nodes of the maize plant, although, of course, it is a stain not restricted to this one disease and may be a host reaction. 


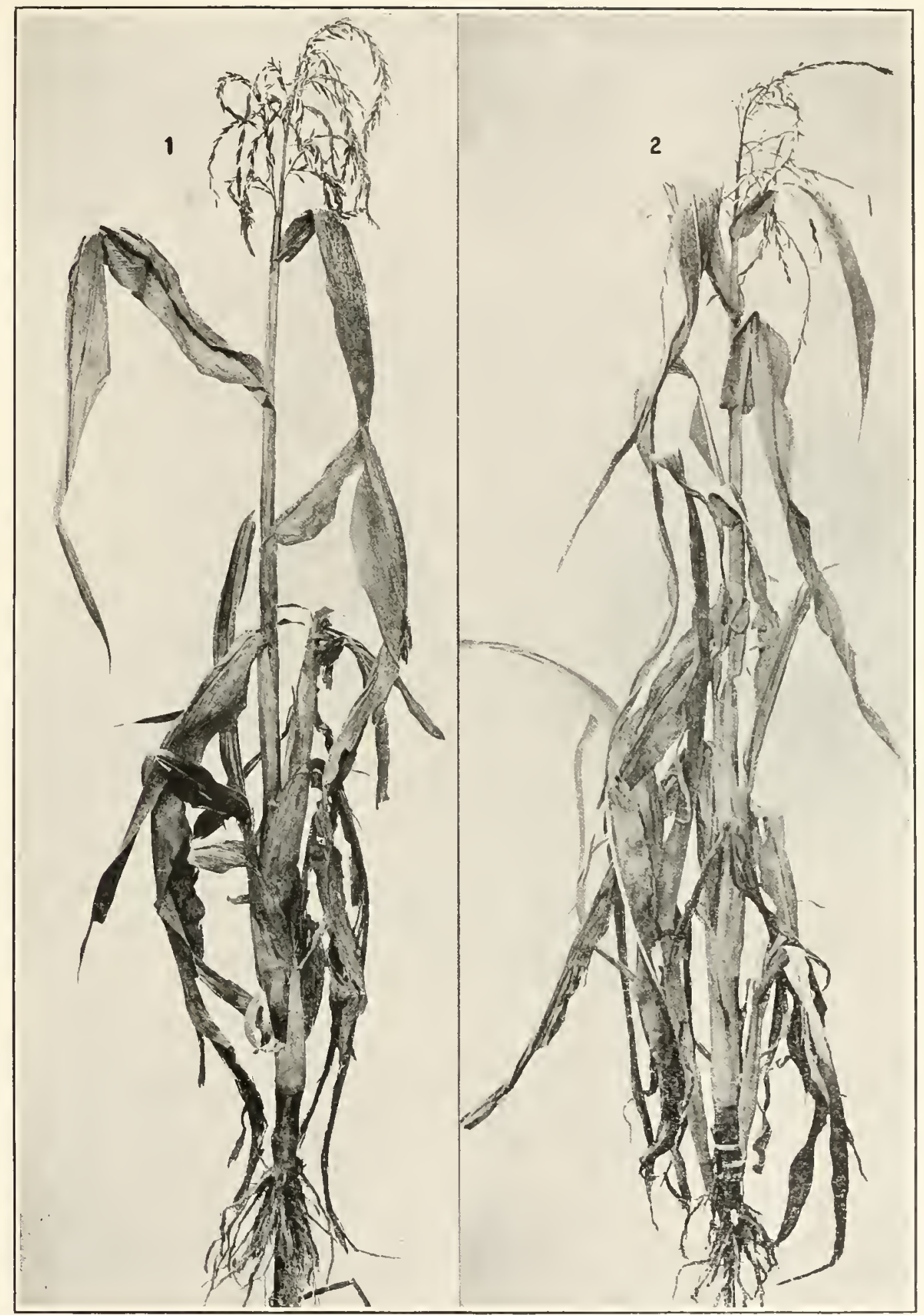

Figs, I and 2. Large sweet-corn plants attacked by Bacterium stewari.

Male inforescence dead and white, leaves dead, vessels full of the yellow slime. Dept. Agric, flats, July 2 r, rgo3; Mr. Pieters's trial plats. 

due to the presence of an oxidizable substance in some bundles and its absence in others, or simply to the fact that more air (oxygen) has been able to enter some vessels than others, the dark stain depending on an oxidation. A similar phenomenon occurs in the sugar-cane attacked by Cobb's disease. Reddening of the vascular bundles or white striping of the leaves (a sign met with in sugar-cane attacked by Bacterium vasculamm) does not occur in this disease. The slime of the disease also sometimes occurs in roots which appear sound externally. 'This is especially true of parts of roots near their union with badly diseased stems. As a rule the roots are not badly diseased.

The writer has observed no tendency of the yellow slime to break through and ooze on the surface of the plant, except from the inner face of the inner husks, where such oozing is quite common, and more rarely from the inner face of the leaf-sheath. Stewart found this yellow slime oozing over the kernels in plants killed by the disease. The main axis of the maize plant has a firm siliceous covering, and even at the base of the stem, which is usually the first part of the stem to become diseased, there is a thin layer of unbroken, hard, sound tissue separating the sick interior from the air and soil, even when the plants have been diseased for some time (ro weeks or more) and the vascular bundles are occupied by the bacteria the whole length of the stem. This is true even when the lower nodes and internodes have become quite brown and gummy and most of the leaves have succumbed to the disease. Very rarely, in the middle part of the stem, in badly diseased, soft plants, ooze may come from some restricted spots on the internodes. As the disease progresses, the bacterial slime is sometimes found in the parenchyma between the bundles either as water-soaked patches or as bright yellow spots, but large cavities are not common. According to Stewart:

Fields of sweet eorn affeeted with the disease are very uneven, particularly at the time when the ears are forming. Plants in various stages of the disease are intermingled with apparently healthy plants of different sizes. It is a common thing to find diseased plants in the same hill with healthy ones which may continue in good health to the end of the season. $* * *$ Ustrally, the small plants are the first

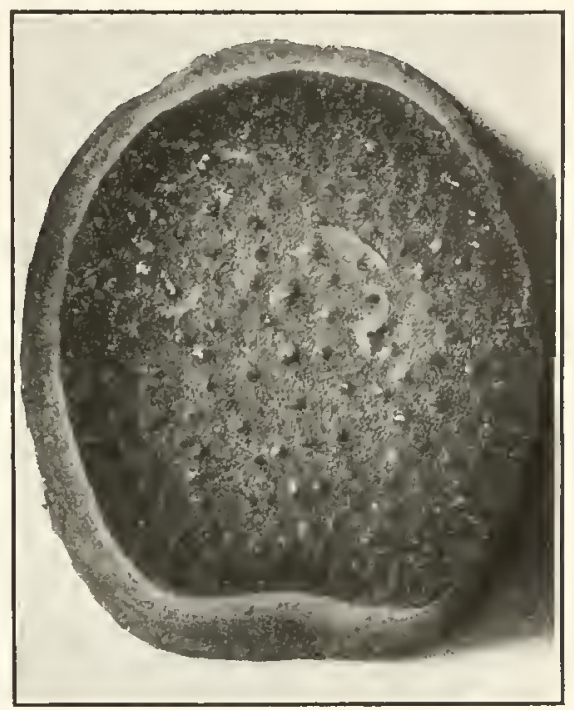

Fig. 39.* to succumb to the disease, which fact suggests that the disease may be the cause of their slow growth.

\section{ETIOLOGY.}

This disease is caused a yellow polar-flagellate schizomycete, Bacterim stewarti EFS. The organism was discovered in 1895 by Mr. F. C. Stewart, who in 1897 published the first account of the disease. He claimed it to be the cause of the disease because, whenever he examined stems of maize affected by this disease, he found this organism present in the vascular system in enormous numbers, and, apparently or actually, to the exclusion of all other organisms. The evidence based on constant occurrence is certainly all that could be desired. The disease and the organism are always associated. Stewart also attempted infections, but his results were not conclusive, as he himself admits. The reasons for this failure were partly because his experiments were conducted in a locality where the disease was naturally prevalent, so that the controls became infected, and partly because his inoculations were not made at the best time and in the most natural manner. Possibly also in some cases he may have inadvertently infected his checks with the material used for lis inoculations.

*FIG. 39.-Bacterium stewarti. Cross-section of sweet-corn stem, showing bacterial ooze. Nearly every bundle occupied. A natural infection from Mr. Pieters's trial plots. July 2 I, 1903. X3. 
Mr. Stewart does not state where his inoculation experiments were performed, but presumably they were all made on Long Island, beeause in the introduction to this part of his bulletin he says:

Attempts to inoculate field-grown plants of sweet-corn have been unsatisfactory because it has been practically impossiblc to obtain plants which were known to be free from the disease.

I quote below all of Mr. Stewart's statements respecting his inoculations:

Susceptible varieties have been quite generally affected, and since the disease is one which acts slowly it is not possible to get results of much value from inoculation experiments made upon plants

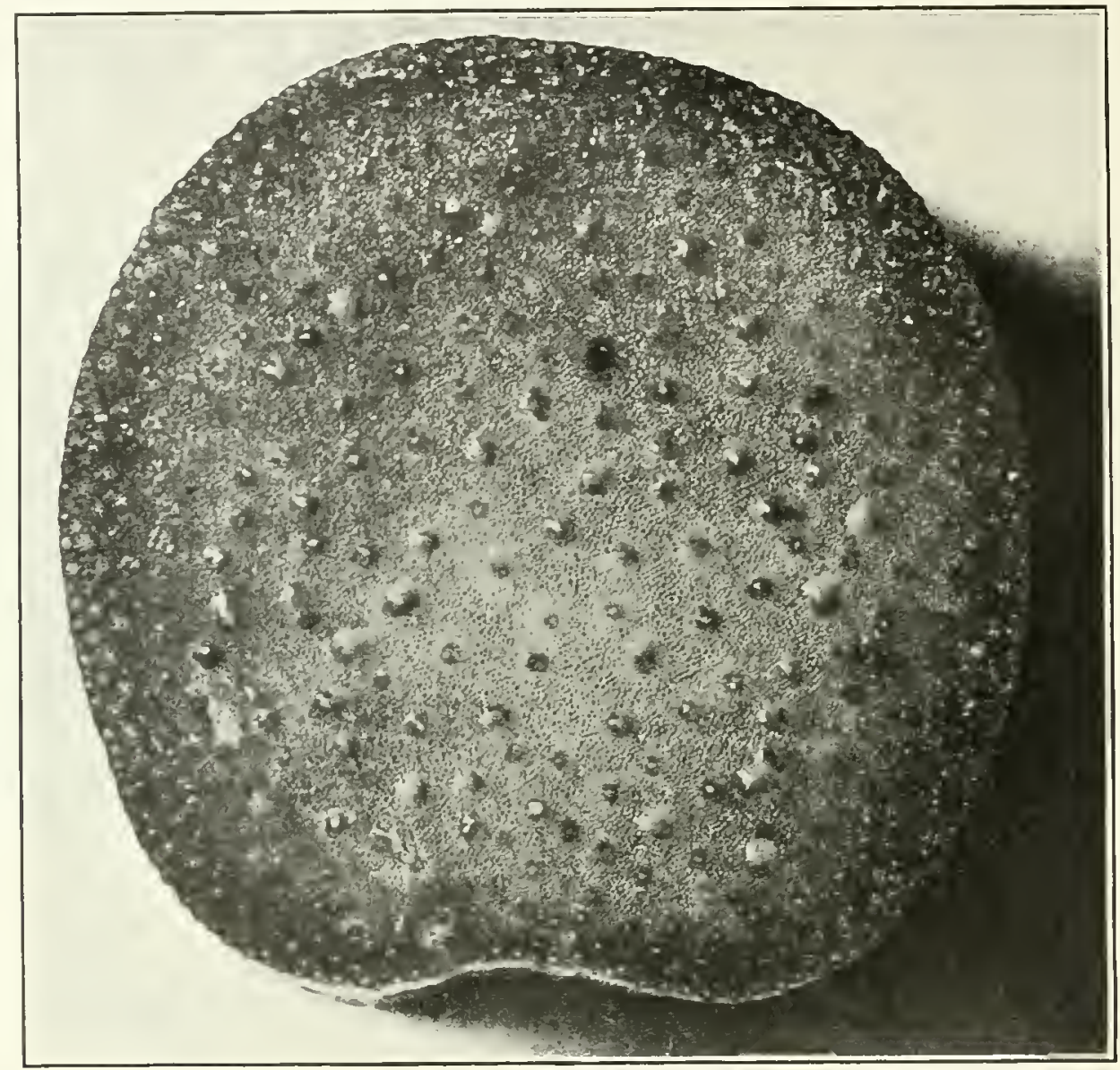

Fig. 40.*

among which the disease previously existed, even to a slight extent. Only one of the field experiments is worth reporting in detail. It is as follows: In I 896 thirteen hills of Manhattan sweet-corn were planted in one row. In each of the first seven hills there was placed, at time of planting, a handful of dirt taken from soil in which the disease was prevalent the preceding season. 'The remaining six hills were left untreated for comparison. When the plants were a fewinches high they were thinned to four in a hill. A few of the plants in the inoculated hills began to wither before they were a foot high, and from this time on they withered one by one, until on July 20 , when the kernels were "in the minilk," all of the inoculated plants except two were either dead or dying. At this date, not a single plant in any of the uninoctlated hills showed any symptoms of the disease; but later in the season several of the plants became affected. IIow they came to be affected is not known. While this experiment was not wholly satisfactory the results tend to show that the disease is communicable.

*Fic. 40.-Same as fig. 39, but from another plant and enlarged 6 times, to bring out bacterial ooze more distinctly. 
Several attempts were made to inoculate sweet-corn by puncturing the stem near the ground and inserting a small quantity of the diseased tissue of an affected plant. In sone of the large varieties the inoculated plants remained healthy to the end of the season. In the smaller varieties the disease usually appeared in from two to four weeks after inoculation, but the uninoculated plants used as a check, likewise, invariably became affected to a considerabte extent, so that no trustworthy information could be obtained from such experiments.

Finally it became evident that the plants nust be grown in pots of sterilized soil if the inoculation experiments were to furnish results of any value. A quantity of soil was thoroughly sterilized in steam sterilizers and placed in large pots. On July 3 Early Cory sweet-corn (grown in Iowa) was planted in the pots and inoculation experiments with pure cultures of the yellow germ were started. 'The pots were allowed to remain uncovered [out of doors]; otherwise, all precautions were taken to prevent contamination. Nevertheless, an undoubted case of the disease was found in one of the check pots on August 3, and later several others were found. 'This meant that diseased seed had been used and the experiment was worthless except to prove that infection may be brought about by the germs which cling to the seed.

This appears to have been the only inoculation experiment attempted by Mr. Stewart with pure cultures. At least it is the only one mentioned, and no statement is made as to how many, if any, of the inoculated plants contracted the disease or how near these were to the check plants. When the rainfall was not sufficient they were watered with sterile water.

Three unsuccessful attempts were made to produce the disease in yellow dent field-com by inoculation. On August 20, is95, ten plants of yellow dent corn (variety unknown) were inoculated by puncturing the stem at the surface of the soil with a sterilized scalpel and then inserting into the puncture a small quantity of the yellow substance taken directly from the interior of the stem of a diseased sweet-corn plant. 'These plants were under observation until frost (about October 7 ), but none of them showed any symptoms of the disease. On July 12, 1897, twenty plants of yellow dent corn, variety Golden Dent, were inoculated in the same manner as in the experiment of iS95. None of these plants developed outward symptoms of the disease, but a month after inoctulation it was found that in several of the plants the yellow bacillus had ascended a few of the fibro-vaseular bundles, where it was visible to the naked eye as far as the third node above the point of inoculation. It was noticeable, however, that it occurred only in bundles which had been ruptured by the needle used in inoculation. In r 897 a 50 -foot row of the same Golden Dent corn was inoculated by placing in the drill, at time of planting, a liberal quantity of soil, in which diseased plants had grown the preceding season. Not a single plant dereloped the discase.

Pop-corn, also, has resisted all attempts at inoculation. In 1897 a $50-$ foot row of pop-corn, variety Maple Dale, was inoculated by putting diseased soil in the drill at time of planting. None of the plants became diseased. On July 8, i 897 , twenty plants of the same variety of pop-corn were inoculated by puncturing the stem and inserting diseased tissue into the wound, as in the experiments with sweet-corn and field-corn. None of the plants became diseased, but as in the case of field-corn the germ could be seen in some of the bundles up to the third node.

Oats, inoculated by means of diseased soils, and teosinte (Euchlacna luxurians), inoculated both by puncture and diseased soil, gave negative results.

Stewart believed the plants became infected through their root-system. He says in so nlany words:

Since the cause of the disease is entirely within the tissues and probably gains entrance through the subterranean parts of the plant, the application of fungicides to the parts above ground must be absolutely without avail.

Stewart observed the discase in Early Cory, Manhattan, and many different varieties of sweet corn on Long Island.

In 1897 he found it very prevalent as early as June 12, among plants which were $S$ to 10 inches high.

In some plants he was able by means of the microscope to demonstrate the presence of the bacteria in the bundles before the yellow slime could be detected with the naked eye, and before there were any outward manifestations of the disease other than dwarfing.

In plants dead of the disease he found an abundance of bacteria in all parts of the stem "up to the tassel and in the ear." It is easily demonstrable, he says, that insects are not 
responsible for the disease. Stewart also makes the following interesting observations on the relation of weather to the progress of the disease:

If plants are examined in periods of wet weather it will be found that the amount of the yellow substance which they may contain in their vessels without showing outward symptoms of the disease is much greater than it is in dry weather. *** It is interesting to observe the effect of alternating periods of wet and dry weather. For about one month preceding July 12, 1897, it was very dry on Long Island-so dry that in the latter part of the period some crops suffered severely. During this time the corn disease was very destructive. Then came about three weeks of rainy weather followed by a slort period of dry weather. Many plants which were partially dead revived during the rainy season and promised to ontgrow the disease, but as soon as the rains ceased they suddenly collapsed.

In 1898 , as a result of observations in Michigan, I pointed out the extreme probablity of the bulk of the infections taking place not through the roots but in the seedling stage of the plant through the water-pores. Thereafter I contented myself with a study of the cultural characteristics of the organism which had been sent to me by Mr. Stewart for that purpose, loping the latter would go on and complete the gaps in his infection experiments. This lie did not do. In 1902 , therefore, having an opportunity to study the disease on Long Island, the writer renewed his cultures and afterwards inoculated many plants in the city of Washington, where the disease was not then known to occur naturally. The resuits of these inoculations were very convincing, but before proceeding to an examination of them the reader will be interested in some statements regarding the origin of the cultures used for nuaking these inoculations.

\section{FIELD OBSERVATION IN 1902,} book:

My observations on Long Island are recorded in the following traiscript from a note Notes of July 16, 1902, on Stewart's Sweet Corn Disease.

Found disease at Williain MI. Croucher's place, on the Merrick Road, 1.25 miles from Jamaica, Long Island, New York. 'The disease occurred on a good quality of truck-land, loamy and not wet. This land rents for $\$$ ro per acre per year. Nothing in the surroundings to explain the appearance of the disease. Mr. Croucher, who is perhaps 30 years old and has been a trucker all his life, says he has seen the disease ever since he can remember. He says some varieties of sweet corn are much more subject to it than others. The Early Cory is one of the sorts most subject. His field of about 3 acres was in good condition as to cultivation. The plants were tasseling in part. 'The field was not badly diseased. He had already pulled out some of the diseased stalks, and I found 15 or 20 more. So far as I can judge, the disease is to be told by the shriveling of the leaves and by the premature blossoming of the inale flowers. At some distance the male flowers on the diseased plants looked white and dry. 'Those on the healthy plants were green or purplish. Every plant of this sort, namely, with white and dry spikelets and shriveling leaves, proved on cutting open to be full of bacteria, althougl the stems were green and sound externally and in most cases all the bases of the leaves. 'The plants were also well provided with roots. As a rule such plants were somewhat dwarfed.

I was surprised at the complete occupation of the vascular system-the whole length of the stem except in the extreme top. A cut anywhere else across the stem was followed by a yellow ooze from the vessels even as far up as a foot from the top, and undoubtedly the organism could have been detected still farther up with the aid of the compound microscope. The ooze from the bundles was yellow, especially in the lower part of the stem, e.g., one foot from the ground. In the upper part of the stems it was usually very pale. This I interpret to mean not two organisms, but two stages of one, the lower down, yellower ooze consisting of older organisms and growing perhaps in the presence of a greater amount of air. (See p. 58, and also Yellow Disease of Hyacinths, vol. II, p. 345.)

Infection by boring or gnawing insects was ont of the question in case of these plants. The surface was smooth and unbroken. There were no insect injuries and no ooze of the bacteria to the surface. Except in the extreme base of the stem (of which more later) the bacteria appeared to be confined quite strictly to the bundles. The tissue between was sound, that is, normal in color and free from any appearance of disease. The bacteria were not only very abundant in the bundles of the stem, but were also in the green bases of many of the shriveled leaves.

Whether these leaves were infected from below (from the stem) or from above (through their water pores or stomata) could not be determined by a field examination. Tips of many of the shriveled 
leaves have been saved in alcohol for microscopic study. The bases of many of these same leaves were still green and certainly contained bacteria in their bundles. If bacteria are present in the tips of these leaves it would not prove infection by way of the water-pores, but if they are not present, it would mean that the leaves were infected from the stem or at least not first at their apex; in other words, the movement of the bacteria in the foliar bundles might be assumed to be upward and not downward. This last inference I regard as probable for several reasons, particularly bccause the leaves are well up on the stem and because the stem-bundles are so full of bacteria that we must suppose the infection of the plants to have taken place several weeks ago and considerably lower down. I am inclined to think that the drying up of these leaves is due to secondary infection and to the very general plugging of the vascular system of the stem.* If my observations and inferences are correct, the primary infection took place when the corn was small and through the water-pores of the first leaves, which have long since fallen. The condition of the extreme base of the stem in these plants

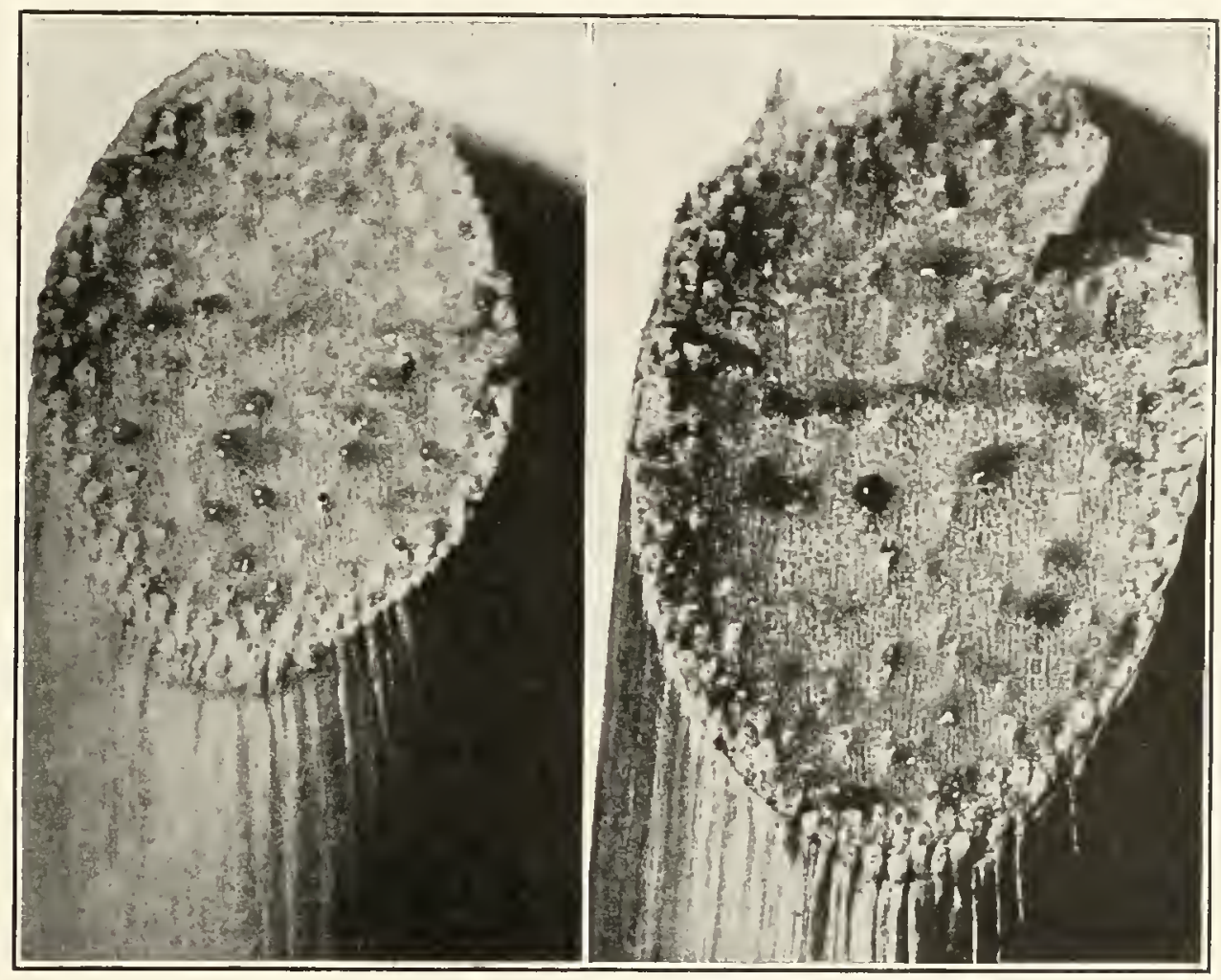

Fig. 41.

points strongly to this conclusion. It is sound externally but within it is more badly diseased than any other part. Here the connective tissues are brownish and gummy, and there are small cavities, $i . e$., the bacteria have been present for a considerably longer time than farther up the stem, have escaped from the bundles, and have stained the tissues. Sections of two such stem-bases have been preserved in alcoliol for further study (fig. 42). None of the roots were diseased externally and all seem to be sound within, but not enough were examined to venture any positive general statement.

Higher up the stem only an occasional bundle is stained brown. On longitudinal sections the affected bundles are distinctly yellow against the background of white pith. One characteristically diseased stem was saved dry and another was sectioned and put into alcohol.

Under the compound microscope the slime from these maize plants appeared to be all one thing, whether pale yellow or bright yellow, and subsequent experiments confirmed this inference. For

*These inferences were confirmed by a study of the leaf-tips already mentioned. On microscopic examination it turned out that in more than one-half of the dead leaf-tips ( 13 out of 25 ) bacteria were not present.

†Frg. 41. - Cross-sectiou of stems of inoculated sweet corn, showing Bacterium stewarti oozing as a yellow slime from the vascular bundles. Plants inoculated in the seedling stage in the hot-house on the tips of the leaves and grown in the field (Potomac Flats) nearly to maturity, before the disease developed. Photographed Oct. 7, 1902. X 6 . 
example, on July 16, at Mr. Croucher's, stem-segments 5 or 6 inches long and 0.5 to 0.75 incl in dianeter were ent from the middle part of 8 typically diseased sweet-corn plants and carried to New York, where, througl the courtesy of the patlologist, Dr. Janes Eiwing, I had opportunity to examine them the next day under proper bacteriological conditions in a laboratory of the Cornell University Medical Scliool. 'The male inflorescence was drying out in these 8 plants, but the stcms were green and normal in external appearance and each plant still bore some green leaves or at least green leaf-sheatlis. The vellow slime oozed abundantly from the vascular system when the stems were cut. By direct transfer, without the intervention of poured plates, a pure culture of Bacterium stewarti was obtained from each one of these 8 stems. All that was done was to work rapidly, in a clean roon, in still air, and to exclude surface bacteria by fire. The very simple steps in the process were as follows: (1) The sten was rolled over and over several times in a Bunsen flame until its surface was judged to be sterile or nearly so; (2) it was then shortened an incli at one end (in the flamed part) with a butcher-knife heated nearly red hot and issed lot; (3) after some minutes the yellow bacteria oozed from the cut surface of some of the bundles and often I hastened this oozing by squeezing the stem; $(t)$ one or more, usually several, of these droplets were tonched with a sterile platinum needle which was then thrust several times into the agar. The organism gtew promptly and each one of the eight tubes turned ont to be a pure culture of Bact. stcwarti. Plate-cultures were nuade from some of them and all remained under observation more than a year during which time none of them became contaminated. Descendants of these agar-stab cultures furnished the material used for making the inoculations, after I had satisfied myself by culture on various media that this was actually the same organism as that formerly received by me from Mr. Stewart and subsequently lost through inattention. It should also be noted here that stalss made from the bright yellow slime and the pale yellow slime yielded cultures which could not be distinguished.

Cover-glass smear-preparations, stained with Loeffler's alkaline methylene blue and with Ziehl's carbol fuchsin, were also made from each of these 8 stems (figs. $43,+4$ ), after which they were sectioned and pit into 95 per cent alcohol for subsequent study.

It is a remarkably interesting fact that 8 different maize plants should have yielded the same organism in pure culture by direct transfer, but it does not stand alone (see Cobb's Disease of Sugarcane, pp. 12, 25, and II ill of Cucurbits, vol. II of this monograph, p. 287).

\section{INOCULATION EXPERIMENTS. \\ SERIES I AND II. 1902.}

Two series of inoculations were made in August 1902, at nearly the same time. The experiments did not get under way until late in the season owing to the interference of other work, and they were consequently cut short by frost, but they continned long enough to yield conclusive results.

\section{First Series.}

Thlis embraced two kinds of sweet corn, ziz, Perry's Hybrid and Early White. 'The principal dates were as follows:

August 2.-Planted Perry's Hybrid.

A ugust 4.-Planted Early White.

August 9,5 p.m. - Inoculated each sort by placing on the tips of the leaves by means of the platinum wire a small quantity of the bacteria from young (48-hour) cultures on slant agar.

A ugust 19 . - Shifted to 6 -inch pots.

A zigust 28 . - First eases (two).

August 28 . - Transplanted from the hot-house to the field.

Seplember 8.-Growing well and as large again as when transplanted. Three additional eases.

Oclober 7.-More cases.

October io to 27 . - Numerous eases.

October 20. - First hard frost.

November I.-Closed experiment.

\section{Second Series.}

This embraced three kinds of sweet corn, riz, Perry's Hybrid, Early Red Cory, Early White Cory. 'The principal dates were as follows:

A ugust 7.--Planted.

August $13,14,15,16$. - The plants were inoculated at sundown on each of four days by spraying upon them in the form of a very fine mist a portion of $50 \mathrm{c}$.c. of sterile water, containing each time the slime from two young slant agar cultures.

August 28. -Transplanted from the hot-house to the field.

September 8.-Growing well; twice as large as when transplanted.

October 7.- First cases.

October Io to 27 . - Many cases.

October 29.- First hard frost.

November I.-Fxperiment closed. 
The conditions following inoculation in both series were made as favorable for infection as I could render them without injury to the plants, $i . e$., they were such as the plants would be subject to in the field during wet, warm, and clondy weather.

The plants of Perry's Hybrid (first series) were 3 to 5 inches lighl and liad three welldeveloped small leaves when inoculated. Those of the Early White (first series) were 1 to 3 inches higlı when inoculated, in most cases with two leaves, but occasionally the tip of a third leaf was visible, wlile in a number of instances only one leaf was to be seen.

As soon as inoculated the plants of this first series were placed under the bench in obscure light for nearly two days ( 2 to 5 p. m. August 9 to Io a. 111. August 11), and the floor of the greenlouse was very thoroughly wet down with water, so that the air of the louse should be unusually moist.

At 10 a. m., August io, the plants were examined. The tip of nearly every leaf bore a little drop of exuded water and the conditions appeared to be very favorable for infection unless it were that the excess of fluid poured out should wash away all the infectious material, which may have been the case in some instances. The morning was cloudy and the temperature $29^{\circ} \mathrm{C}$., the same as the day preceding, but probably somewhat higher in the hot-lionse.

At Io a. m., August 11, the pots were taken from under the bench and placed on the bencl. Many of the leaves still bore drops of water at their tips, especially the younger oures. The plants had grown about 2 inches and the new growtlı was rather pale green, owing to the obscurity. The earth in the pots was very wet and occasionally there was a trace of mold on the surface. Roots in quite a number of the pots had come to the surface, owing to the darkness. The sky was overcast and the temperature was $29^{\circ} \mathrm{C}$. The gardener was directed not to water the plants that day. At $2^{\mathrm{h}} 3 \mathrm{O}^{\mathrm{m}} \mathrm{p}$. m. the teniperature of the laboratory was $3 \mathrm{I}^{\circ} \mathrm{C}$., the sun was shining, but there was not much wind, and the air was full of moisture.

In the second series, the first inoculation was made with cultures 24 hours old, the second with cultures 48 hours old, the third with cultures 3 days old, the fourth with cultures 4 days old. A good atomizer was used which broke the fluid into an extrenely fine mist or fog. The plants were small when they received the first spraying. They were 3 to 6 inches ligh when they received the fourth spraying; each spraying was made at sunset. On the morning after each spraying it was observed that little beads of fluid stood on the tips of many leaves (see this monograpli, vol. I, fig. 73), so that here also it was judged that the conditions favored infection.

Local signs were first visible at the tips of the inoculated leaves and within a few days in some cases, but there were no constitutional signs until the nineteentlı day after inoculation (first series) and then only in two plants. In case of the sprayed plants, 52 days intervened between the last spraying and the first cases, $i$. e., fewer bacteria entered the plant, and a longer time was requisite for infection.

The plants of both series were renoved from the hot-house to the open field on the sane day. They were then 18 inclies to 2 feet high, healthy in appcarance, and with leares from one to two inclies broad. The pots were well watered before removal, and after carcful transplanting each hill of plants was watered and the wet earth was then covered with loose earth to prevent rapid evaporation. The day was sunny and warm, but there had been lreavy rains the previous afternoon and evening, and the plants did not suffer from the ren1oval. Not a single one of them died as a result of the transplanting.

They were set in a freshly plowed and harrowed, fertile, level field from which a crop of potatoes had just been harvested. No other corn plants were near them, but at some distance there were several acres of healthy field corm of several varieties. The hills were set at a good distance apart eacli way and the field was freely cultivated so that no weeds grew.

Three additional cases appeared in the first series on Septeniber 8 (twenty-ninth day after inoculation), and thereafter 110 more for a month. Meanwhile the plants grew vigor- 
ot1sly. It was observed, however, on September 20, that many of the plants had begun to show the staminate inflorescence. This was judged to be premature, since these plants were only 2.5 feet high, $i$. e., they were plants dwarfed and prematured by the disease, but showing as yet no other unmistakable signs.

On October 7 , cases began to appear again in the first series and then also for the first time in the second series. For the sake of conclusiveness, even at the risk of being tedious, the results of an examination of some of these cases will be described in detail, after which the whole experiment will be summarized in a table.

\section{Record of the Diseased Plants.}

I. Plotographed (plate 7, fig. I) and dissected. From vessels toward the base of the stem the claracteristic yellow slime oozed out. With proper caution two pure cultures were obtained on slant agar by direct transfer; a third was contaminated by a green-fluorescent organism.

II. No record.

III, IV. September 8, photographed togetlier (plate 7, fig. 2). Externally the plants give no indication as to the cause of the disease. The larger plant is 2 feet high without stretching up the leaves. The outermost four leares are shriveled and brownish; the upper ones are wilted. The smaller plant is about IS inches high. All of its leaves are shriveled except the uppermost one, which is wilted. The stem of the larger plant

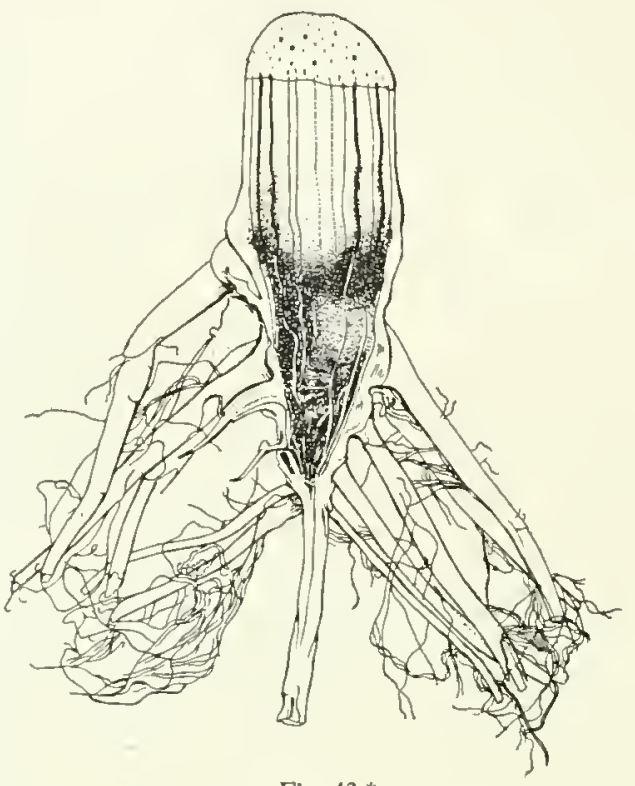

Fig. 42.*

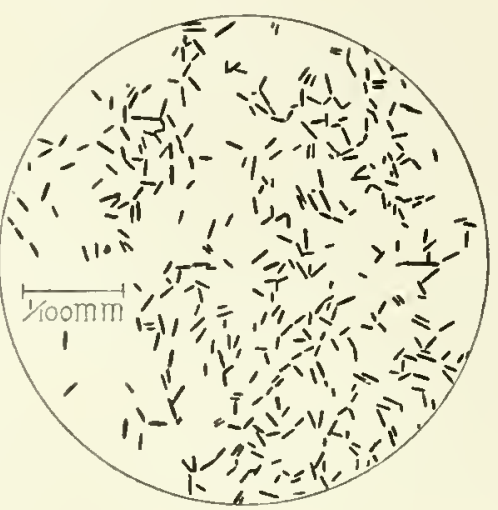

Fig. 43. $\dagger$

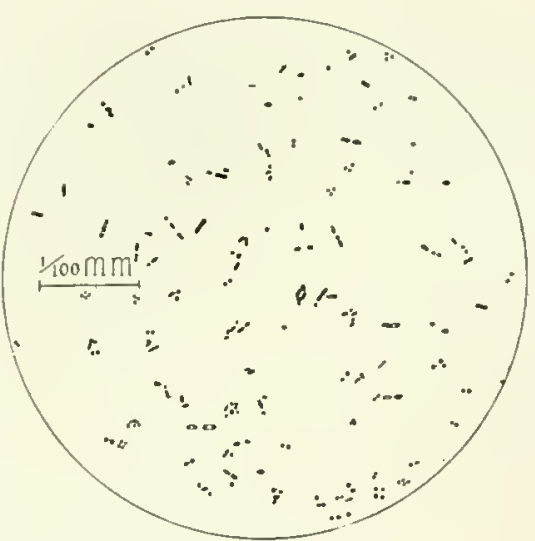

Fig. 44. was cut off 6 inches from the roots. All the inner (undeveloped) leaves are free from the organism, but the outer two or three are infected. The same is true of the smaller plant. The bacteria ooze out in the form of chrome yellow masses. Cut higher up, the bacteria are less and less abundant, the infection of the large leaves being clearly from the base upward. Cut within I inch of the roots, the larger plant shows a pretty general infection of the vessels through all parts of the stem and a browning of some of the bundles. The same is true of the smaller plant except that at this level the browning is less conspicuous. The basal I inch of the larger stem was then slit through lengthwise and inspected. The most badly diseased part was the extreme base. Here there was much browning and some softening of the

*FIG. 42.-Radial longitudinal section through a maize stem (sweet-corn) attacked by Bacterium stewarti, showing a badly diseased (browned) area in base of stem, $i_{0} e_{.}$, in that part of the stem first occupied by the bacteria; also browned vascular bundies in the internode, and sound exterior. Long Island, July 16, 1902. Compare with results of pure-culture inoculations obtained in Washington and shown on plate 10.

†FIG. 43. - Bacterium stewarti stained ro minutes in alkaline methylene blue and washed in water. A cover-glass (smear) preparation made directly from the yellow ooze out of the stem-vesseis of a sweet-corn plant collected on Long Island, July 16,1902 . Figure made with Zeiss $2 \mathrm{~mm}$. apochromatic 1.30 n. a. objective, No. I 2 compensating ocular, and Abbe camera, and drawing then reduced one-half. $X$ r,ooo. Compare with drawing made from slide stained with carbol fuchsin.

†FIG. 44--Cover glass (smear) preparation of Bacterium stewarti, direct from stem of Early Cory sweet corn. Long Island, July I6, 1902 . Stained 5 minutes in carbol-fuchsin. Staining irregular and wall of ten not well defined (compare with vol. II, fig. 122, where a similar effect is visible). No spores. $X 1,000$. 


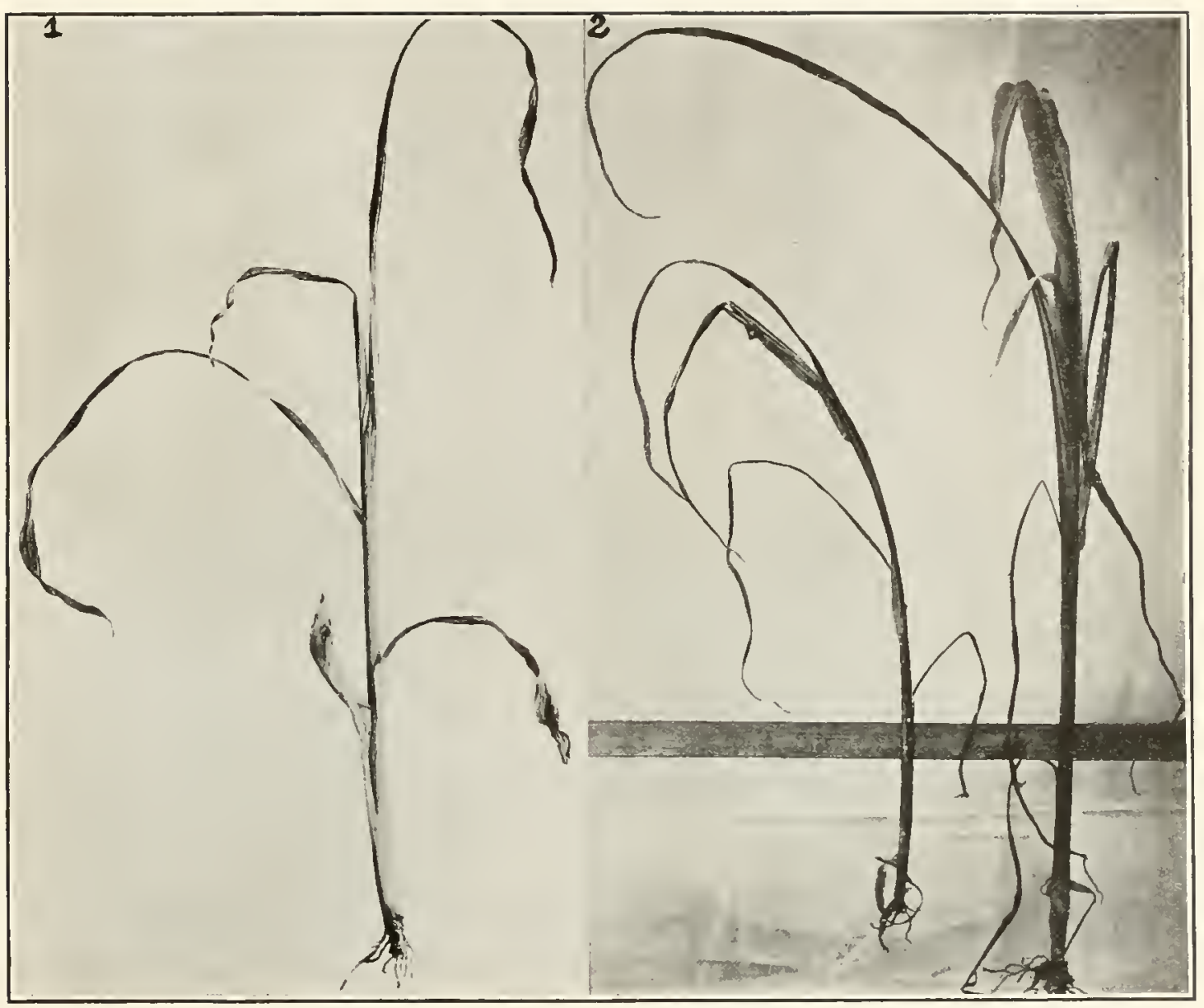

Bacterium stewarti in sweeticorn.

(1) First case of disease in hot-house, inoculations of 1902. Photographed Aug. 29, i. e., 19 days after"placing the bacteria on the plant. (2) Third and fourth cases from first series of inoculations. The largest plant 2 feet high without lifting the leaves. Vessels full of the yellow bacteria. Variety Early White, planted Aug. 4. inoculated Aug. 9, photographed Scpt. 8, 1902. 



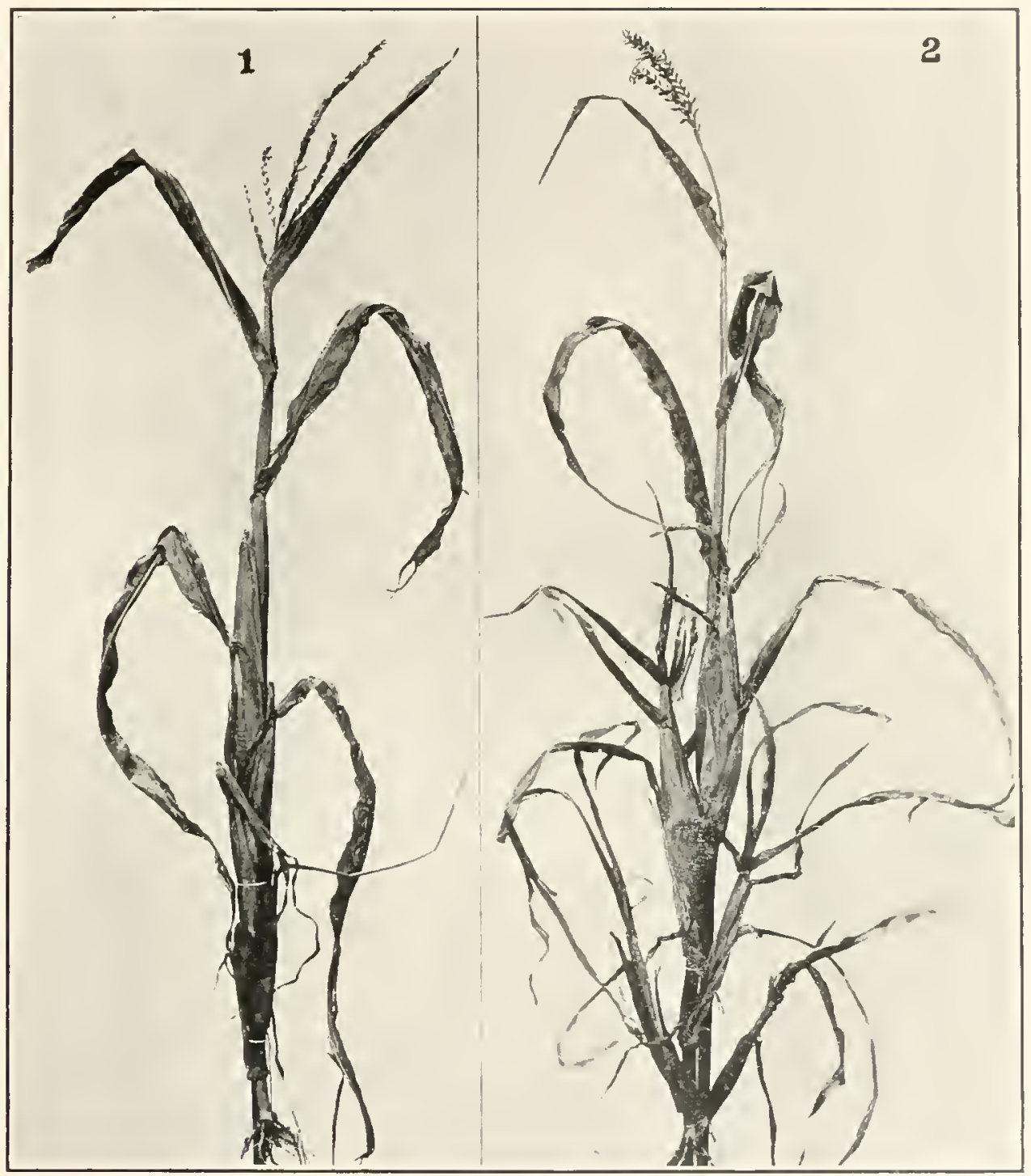

Sweet corn attacked by Bacterium stewarti.

(1) Plant No. xvir, inoculations of r 902 (see notes). Stem dwarfed, leaf-blades dead, male inflorescence prematurely developed. Bacteria abundant in the stem dwarfed, with basal branches and foliage dead, male inflorescence dry and white. Photographed Oct. If, Igoz. 

tissues and slight indications of small cavities. Some of the bundles in this longitudinal section were distinctly yellow from the presence of the bacteria. The smaller stem slit in the same way sliowed the same thing, except that there was more browning and injury at the base of the stem. Some of the bundles were distinctly yellowed by the bacteria and others were browned. In the bases of the badly diseased leaves, in some places, the bacteria had escaped from the vessels and had made yellow pockets in the neighboring parenchyma, just as Bacterium hyacinthi does in the bulb-scales of the hyacinth (vol. II, plate 20). Naterial was saved in alcohol. 'Ithe disease in these plants is the typical "bacteriosis" of sweet corn as it exists on Long Island. Iight Petri-dish poured plates were made from each plant into acid (mulberry) agar, but the organism did not grow.

T. No record.

VI, VII, VIII, IX, October 7: 'The external appearance of each of these four plants was the sanne, viz, a sound green stem and sound roots, but shriveled leaves, the reason for which was not apparent. On eutting, the vascular system of each stem was found badly diseased, the ressels being filled with a yellow slime. The bacteria were traced up the stems for many centimeters, but the bundles in the first decimeter of the stem were most fully oceupied. 'The tisstues were most badly diseased in the extrene base of the plant, $i . e$, in the first two or three nodes and short internodes, the same being that part of the stem nearest the point of union witl the particular leaves which had been inoculated. In the internodes of this part of the stem a few of the bundles were brown, but most of them were bright yellow from the presence of the bacteria. In the extreme base of the stem there was a very decided browning of all the tissues; in two cases this browning also included the next two nodes. On crosssection of the stems the bacteria oozed from the bundles as beads of yellow fluid (fig. 4 I).

$\mathrm{X}, \mathrm{XI}, \mathrm{XII}, \mathrm{XII}$, October Io: Four additional suspects were brought in for examination. In each the staminate inflorescence was dead. 'The tallest of these plants was 3.5 feet. The average lieight of the plants in the field on this date was 3 to 3.5 feet. A few were much shorter and a few were over 4 feet higl. Numerous bundles in the sten of each one of these four plants contained the yellow slime of the bacteria in abundance. 'This was visible to the unaided eye in bundles at a distance of more tlian a foot from the root. On longitudinal section the first two to three nodes of the stem were decidedly brown, the internodes being white.

Plants XIV to XXIV were brought in and examined on October I4. They averaged 3.5 to 4 feet in height. Roots were abundant and sound externally in all. The leaves were more or less shriveled. Several of the plants had small weak shoots coming up from the base.

XIV. Basal nodes brown, but infection less widely spread and less conspicuous than in tle following cases. No indication of yellow ressels in the internodes.

XV. Stem cut 3 inches from base: Numerous bundles from which yellow slime oozes; also some brown bundles. Stem split longitudinally: Brown nodes, bundles in internodes either brown or yellow; infection extends far up into the upper leaves; lower nodes of cobs brown within.

XVI. Stem eut 3 inches from base: 'I'o the naked eye one-half dozen infected bundles. Split longitudinally: Basal nodes brown, but only a few of the internodal bundles are infected; two upper internodes not yellow; all lower internodes are brown. Far affected with larvæ; doubtful if bacteria present. Comparatively little infection of upper part of stem.

XIII. Basal parts of stem show yellow bundles.

XVIII. This plant was photograplied separately (pl. S, fig. 1). Cut 3 inches from base: Vessels filled with yellow slime. This plant has several little ears coming out near the ground; these are browned in the nodes and yellow (gtnmmed) in the internodes. Specimens of this and other cobs were saved in alcolıl. Split lengthwise: Nodes at base brown with yellow bundles in the internodes; the upper nodes grade from brown into yellow. Infection traced to just below the staminate inflorescence. On longitudinal section the bundles in the upper internodes show as distinct yellow stripes.

XIX. Cut plant about 3 inches from base: It has numerous bundles sliowing the yellow ooze. Cut I foot from the base: Still shows yellow bacteria. Cut 2 feet from base: Still shows yellow bacteria. The yellow slime appears to be, to a small extent, in the roots close to tlie stem. On longitudinal section, brown in all nodes (7) up to tassel, not in ear.

XX. Either XX or XXI was photographed separately (pl. 8, fig 2). Cut about 3 inches from root: Numerous bundles show yellow ooze. Brown in nodes at base of stem, where there are also small bacterial cavities. Bundles between the basal nodes are either brown or yellow. Infeeted at all nodes, the two upper nodes yellow instead of brown. The five basal nodes of the largest ear are yellowish from presence of the organism, and there is yellow slime in the internodal bundles; the infec- 
tion extends as far as the base of the cob and runs out into sone of the husks around the cob. In the main axis visible infection ends just below the male inflorescence.

XXI. Cut 3 inches from root: A great many bundles are infected. Base cut longitudinally: Lower nodes brown; bundles of the internodes either brown or yellow; roots slightly infected near their juncture with the stem. All nodes infected; lower, brown, grading into yellow in the upper part of the stem. Infected visibly to just below tassel. In the cob, the base and a few bundles further up are visibly infected.

XXII. Basal parts of stem show yellow bundles.

XXIII. Cut 3 inches from roots: Bundles packed with yellow slime. Split longitudinally (basal part). Browned in nodes and some yellow bundles in the internodes. Upper nodes as in XXI.

XXIV. Basal nodes brown in longitudinal section ( 3 inches above root). No indication in these lower internodes of yellow bundles, but numerous plainly yellow bundles in an internode 6 inches above the roots.

Plants XXV to XXXV were brought in and examined on October 17 . All of the plants were well provided with roots which looked sound on the surface. The stems were green in all cases and normal in external appearance, but the leaves were shriveled and the tops were dried out as well in those standing as in those accidentally broken off. The cause of the disease was not apparent.

$\mathrm{XXY}$. Cut close to root: No plain evidence of infection. This plant was broken off accidentally, and therefore brought up at this time. One of the basal nodes is brown. No distinct evidence of the disease in the internodes. This brown node was examined microscopically with doubtful results.

XXVI. Brought in because broken off at root. Section cut about 3 inches above the root: In the internode no distinct signs of disease, but three nodes above it are brown. In the internodes between there is no distinct yellowing of the bundles. Infection, if any, is slight. Several of these plants seen to confirm Stewart's statement that the brown stain is not a sign of the disease. Later, found a yellow slime-infestcd bundle in one of the basal internodes.

XXVII. A few brown vessets in an internode about 2 inches from base of the stem. The lower nodes are brown. Infection slight. One node 8 inches up, one node a foot up, and a third node 16 inches up are brown. A liasty cxamination shows no appearance of infection in the internodes between these nodes.

XXVIII. One of the lower nodes slightly browned. No evidence of disease in internodes. The upper nodes look all right. Hasty microscopic examination gave doubtful results. Basal part slit through, shows brown nodes; no evidence of disease in the internodes.

XXIX. Section 3 inches from base of stem contains a great many bright yellow bundles. Leafsheath shows yellow spots corresponding to masses of bacteria which have oozed ont of the bundles into the parenchyma. Slit longitudinally, the base of the stem shows brown nodes and yellow bundles in the internodes. The disease extends very plainly two-thirds of the way up the stem and runs out into the cob, and occurs to a slight extent in the remainder of the stem.

XXX. No plain evidence of infection except the brown stain. Base slit through shows brown nodes. No evidence of yellow ooze in the internodes.

XXXI. Cut 3 inches from the root, the bundles show a yellow ooze. Longitudinal section through this base shows brown nodes with some yellow bundles in the internodes; not in the ear. 'The browning is less conspictous in the basal nodes than in some of the other plants. The nodes higher up are not brown. Visible infection is confined to the basal parts.

XXXII. Section 3 inches from base shows in the internode numerous bundles from which there is a yellow ooze. In a leaf-sheath about 9 inches up, the bacteria have escaped from the bundles and forned bright yellow patches in the parenchyma. Corresponding to this escape from the bundles is a water-soaked patch 2.5 inches long by 0.75 inch broad (saved in alcohol, flat between glass slides). The yellow slime is also in the base of the ear. 'The bacterial ooze comes out of bundles close under the tassel. Basal part of the stem slit shows brown nodes, and yellow bundles in some of the internodes.

XXXIII. This plant, which is about + feet high, has one good-sized ear and several small ones. Cut aboit 3 inches from the base, many of the bundles show yellow bacterial ooze on cross-section. Nothing in the two abortive ears. Iongitudinal section through the basal 3 inches of the stem shows 3 brown nodes with yellow bundles in the internodes. The infection extends the whole length of the stem, the basal half dozen nodes being brown and the upper ones yellow. The internodes show yellow stripes, corresponding to diseased bundles, for a long distance up the stem. The leaf-sheaths of leaves I foot to 2 feet above the root also have the bacteria in their bundles. 


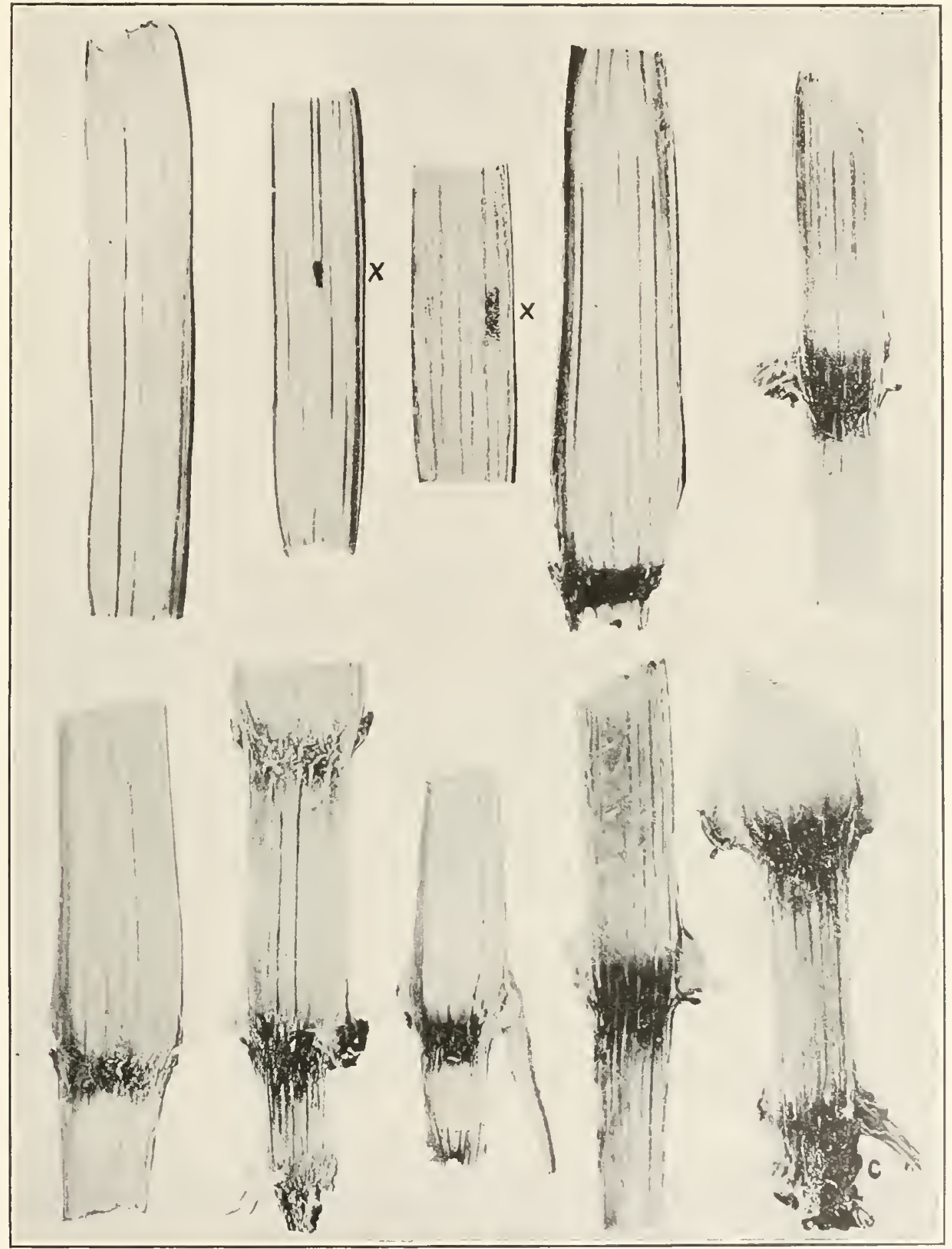

Longitudinal sections through stems of Io sweet-corn plants, showing invasion by Bacterium slewarli.

Plants inoculated when young by placing bacteria from a pure culture in the drops of fluid extruded from the leaves and resting on their tips. Signs of disease in about 2.5 months, when the plants were 3 to 4 feet bigh. Bacteria confined principally to the vascular bundles. Nodes brown, internodes wbite, except infested bundles. which were usinally bright yellow, but occasionally the whole of the lower internodes. About natural size. 


$$
\text { - }
$$


XXXIV. Cut about 3 inches above the root, numerous bundles are brown and others show a yellow ooze. Split longitudinally, the base of the stem shows brown nodes witl internodes having bright yellow bundles and brown bindles. 'The first 4 nodes above the basal 3 inches are brown. The disease extends visibly up to the tassel. It also extends into the base of the ear, but only to a slight extent. 'The bacteria are abundant in the middle internodes, some of the bundles being brown and others bright yellow. Further examination shows the bacteria as far up as the middle part of the male inflorescence. The bacteria are also in a leaf-sheath midway up the stem.

XXXV. Cut at 3 inches from root, bundles full of yellow slime. Cut a foot above the root, bundles full of yellow slime. Cut 2 feet above the root, no evidence of bacterial masses under a handlens. Split longitudinally through the base of the stem, the lower 3 nodes are brown in the center, but the outer portion of the stem is white, as has been the case in all of these plants. The lower internodes have some brown bundles and some yellow ones. The bacteria extend up into the base of a good-sized ear. 'The nodes above the first 3 vary from brown to yellow, the lower ones being brown and the upper ones yellow from the presence of the bacteria. It is quite clear that the infection was from below upward, $i . e$., the basal nodes are the worst affected. A second ear on the same plant shows the disease in the basal part of the cob. The bacteria are present in the bundles of a leafsheath 15 inches from the ground, and the node from which this leaf-sheath originates is yellow from the presence of the bacterial slime. Also, in a leaf-sheath 2 feet from the ground, the bacteria are present. Longitudinal sections through the central internodes show long yellow stripes, and in at least one place the bacteria have escaped from the bundles and have made a yellow spot (cavity) in the parenchyma (specimen saved in alcohol).

Plants XXXVI to LI were brought in and exanined on October 2 $\mathrm{I}$. This bundle of diseased plants gave no external indication as to the cause of the trouble. The drying out of the leaves much resembled the effect of frost, but there had been no frost. When the male inflorescence is not mentioned it was broken over. Photographs were made showing the appearance of the stems in cross-section and longitudinal section, and also the appearance of the diseased liusks.

XXXV1. Plant 3.5 feet high, stem green and sound externally, leaves dried up, tassel white (dry), roots abundant and sound on the surface. This plant has two small ears, one of which is infected at the base. Cut 3 inches from the base of the stem, several of the bundles show a distinctly yellow ooze. Slit longitudinally, the six lower nodes are brown, those higher up are yellow (gummy). The internodes toward the base of the stem show some black bundles and others which are bright yellow. Internodes half way up the stem also show distinctly yellow bundles. The bacterial slime apparently runs ont toward the top of the stem, i.e., it is not visible under the hand-lens.

XXXVII. Plant 3 feet high; male inflorescence dead. This plant branches at the base. Cut the main stalk 3 inches from the ground; nothing definite in the internode. Slit the base longitudinally, find 3 nodes decidedly black. No traces in the other branch. The basal internodes of the main stem have large black streaks and lave been injured by a borer. No evidence of yellow striping in the bundles. 'I'his is the first plant observed to be affected by root insects. No evidence of bacterial disease farther up the stem.

XXXVIII. Plant 3.5 feet high, broken over. The vessels of the bundles in internode 6 inches up the stem are full of yellow slime. A large ear about 1 foot up shows no signs of the disease, but there are numerous bright yellow bundles in the main stem under this ear. A smaller ear cut near the base and slit longitudinally shows the infection in the lower part of it, in the bundles, in the form of bright yellow stripes. The lower nodes are brown and the upper ones yellow for more than twothirds of the way up the stem. The bacteria can be traced in the internodes of the stem readily under the hand-lens nearly to the top, the infection becoming less and less as one goes higher up the stem.

XXXIX. Plant 4 feet liigh. Stem cut 3 inches from base, yellow bacteria very abundant in the bundles. Slit longitudinally: 'The lowest 3 nodes are brown; the internodes lave bright yellow bundles; 3 of the nodes next higher up are brown, and then 4 more are distinctly yellowed. 'The bacteria are present in abundance in the base of a good-sized ear, but not in the kernel part as far as can be seen with the naked eye. The disease disappears in the upper part of the stem. It is visible over half way up the stem. The bacteria are abundant in the internodes in the lower and middle parts of the stem as yellow stripes. They are in the bundles. In places bacteria have also oozed out of the bundles into the parenchyma, making small bright yellow spots (dark in photograph). (See plate 9.)

XL. Plant 4 feet high. Disease absent from base of one small ear. The bacteria are abundant in the base of the larger ear, which is farther up than the smaller one. On cutting the pedicel they ooze out immediately as bright yellow masses (samples saved in alcohol). T'he bacteria are also present in the husks of the ear and have in some cases escaped from the bundles into the parenchyma 
of the green husk, making bright yellow spots (small cavities). The bacteria are traceable in the cob of this ear as far as the kernels, but not distinctly into them. Two inches from the base of the stem the internode shows diseased vessels. The lower 2 nodes are brown and the internode between shows yellow bundles. The 5 nodes next above this basal portion are also brown. The infection is clearly visible in the internodes to a distance of 2 feet above the ground as yellow bundles and is traceable still farther up the stem, but becomes less abundant; the disease (yellow slime in the bundles) disappears in the second node below the tassel.

XLI. Plant 4 feet high. Cut 3 inches from the base, internode shows many yellow bundles. Basal part slit longitudinally, its 3 nodes are brown; the internodes contain black and yellow bundles. One large ear and two small ears, each with bright yellow bacterial ooze visible in the bundles. It extends visibly to the base of the cob in the larger ear. The 3 nodes next above the basal cut are brown. Three nodes next farther up are distinctly yellow from the presence of the bacteria. The disease runs out into the sheath of a large leaf half-way up, but I can not detect the bacteria with any certainty in the nearly dried up blade of this leaf (hand-lens). Disease plainly visible in internodes half-way up the stem in the form of bright yellow bundles from which yellow slime oozes when they are cut.

As in all the cases hitherto observed, the infected bundles become less numerous or less distinctly diseased as one proceeds from the root to the male inflorescence at the top of the plant, showing quite clearly that the infection must have proceeded from the base of the stem upwards. In this plant also there are places where the bacteria have oozed out of the bundles and affected the surrounding parenchyma of the internodes. These spots or pockets in the parenchyma are bright yellow.

XLII. Plant 3 feet high, male inflorescence white, leaves dried, stem green and sound externally. Cut 3 inches from base, the internode contains many bundles from which there is a distinctly yellow bacterial ooze. Basal part slit longitudinally, the two nodes are brown.

The browning, as in all cases hitherto reported, is central and does not extend entirely out to the periphery of the stem. The hard outside portion immediately around this brown area is sound (plate I0). 'The basal internodes show numerous yellow bundles. The nodes farther up are brown or yellow-lower ones brown, upper ones yellow $i . \ell$., from presence of Bact. stewarti. The internodes in the middle of the stem sliow some brown bundles and many yellow ones. One large ear and two smaller ones, each infected at the base. The bacteria are not distinctly visible in the middle leaves, and in the stem they disappear, so far as can be determined with a hand-lens, about a foot below the male inflorescence.

XLIII. Plant + feet high, leaves dried up, roots plentiful and sound externally. Basal part of the largest ear shows distinct infection, but not very abundant. Stem cut 3 inches from the base: Numerous yellow bundles in the internode. The plant has a great many healthy roots. (All the plants are well provided with roots.) Base slit longitudinally shows the 2 nodes brown and the internodes with brown and yellow bundles. There are 3 small ears and a large one. One of the small ears is diseased at the base. The other three appear to be sound. Three of the nodes in the main axis next above the basal ent are brown. 'The fourth one, which gave rise to the large ear, shows bright yellow bacterial ooze in one place. One of the nodes next farther up is distinctly yellow with bacterial ooze, and those still farther up slow no distinct evidence of the disease. 'The internodes halfway up the stem are diseased, but the yellow ooze is much less abundant and in fewer bundles than farther down the stem. Some of the leaf-sheaths half-way up the stem have diseased bundles.

XLIV. Plant 4 feet high, male inflorescence white and dry, leaves dried up, roots abundant and sound externally. Cut 3 inches from base, there are many yellow bundles in the intemode. Slit longitudinally through this basal part, there are 2 brown nodes connected by white internodes striped with yellow bundles. The 4 nodes next farther up are brown. The next 3 are in an earlier stage of infection, i.e., yellow from the presence of the bacteria, but not yet brown. liour of the 5 small ears are infected at the base. The middle internodes of the stem have numetous yellow bundles.

XL, $V$. Plant only is inches high, leaves and male inflorescence dry, roots sound in appearance. Cut 3 inches from the base: Internodes contain brown bundles. Slit longitudinally, the nodes are brown and the internodes contain both brown and yellow bundles; farther up the nodes are yellow and the internodes greenish-white with yellow bundles. Visible infection disappears toward the top.

XLVI. Plant 3 feet high, roots sound externally, malc inflorescence white and dried out, all leaves dry. Good-sized cob, basal part infected. As in a number of other instances, the bacterial infection is most abundant on the periphery, on the lowest, outermost side of the ear. Stem cut 3 inches from the base, the internode shows numerous yellow bundles. Sliced longitudinally, the base of the stem shows 3 brown nodes and yellow stripes in the white internodes. The inner husks of the ear are badly infected (in the bundles), and in many places (200 to 200) the bacteria have made their way into the parenchyma between the bundles in quantity so as to show as yellow masses. The bacteria have also oozed out on the inner side of the husk, in several instances, in yellow masses, wet- 


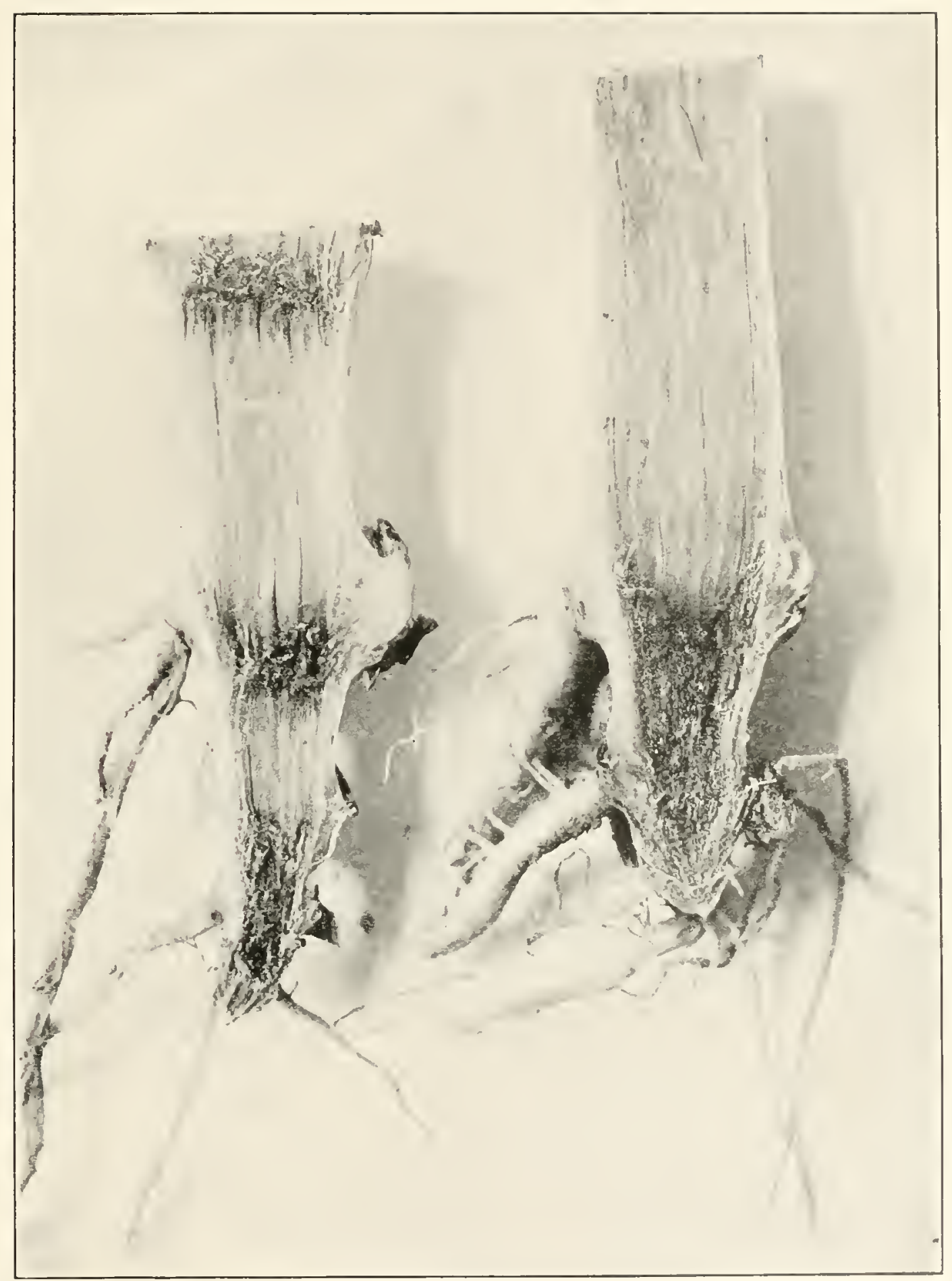

Stewart's disease of sweet-corn.

Section through the base of two sweet-corn stems (plants XIII and XI.vI or XIVII), attacked by Baclerium slervarli, as the result of a pure-culture inoculation in the seedling stage, showing brown stain in the nodes. sound cortex, healthy roots, and a bud pushing. 

ting its surface. These masses when tonched with the finger string up deeidedly (I cm. or more). Six of the husks are infected in this way. There are about I 80 small bacterial pockets in the parenchyma of a single husk; in another husk there are more than roo. Specimens of these husks were saved in alcohol and one of the husks was photographed (vol. II, fig. 14) but the contrast is less than in nature. Samples were saved in alcohol from the base of the cob. It is doubtful whether the bacteria can be traced out into the kernels. The first 2 nodes above the basal cut are brown, several farther up are brown with a yellow ooze. The next 4 are yellow. The infection is plainly visible with a hand-lens in bundles 3 inches below the base of the male inflorescence. 'The middle internodes contain numerous bright yellow bundles. The sheaths of the middle and upper leaves also contain yellow bundles, from which there is a bacterial ooze. The disease is not distinctly visible in the leafblades, which are dried up. There is less of the bacterial infection toward the top of the stem.

XLVII. Plant 4 feet high, roots sound externally, all leaves dry except part of an upper one. Stem on the outside green and sound. Cut 3 inches from the base, there are a great many yellow bundles from which the bacteria ooze out. Basal part slit longitudinally, there are 3 brown nodes, and the white internodes contain yellowed bundles. The plant bears 3 ears, the bases of which are diseased, $i . e$., have vascular bundles oceupied by the bacteria. Above the basal eut 2 nodes are brown, 3 others farther up are yellow from the presence of the bacteria. 'The middle internodes show distinctly yellow bundles. Organism present in the bases of the middle leaf-sheaths but not very abundant. There are quite a good many places in the internodes where the bacteria have escaped from the bundles and made yellow spots in the white parenchyma. Bacteria are plainly visible in the stem as far up as a foot under the male inflorescence, but not nearly so many vessels are occupied as lower down.

XLVIII. Plant 4 feet high, roots abundant and sound externally, stem green and normal on outside, male inflorescence dead and white, all leaves shriveled except the uppermost one. Cut 3 inches from the base: A great many yellow bundles in the internode. Slit the base of the stem longitudinally; the nodes are brown; the white internodes contain bright yellow stripes corresponding to the bacterially infested bundles. Farther $u 1$ z nodes are brown and 3 others next higher are yellow, showing when cut a distinct bacterial ooze. The infection extends into the basal part of the male inflorescence. The plant has 3 ears-I large and 2 small. The base of each one shows a distinct yellow ooze from the bundles on section. 'Tlie husks around the ears are also infected, the bundles are yellow and there are yellow spots and water-soaked spots in the parenchyma corresponding to places where the bacteria have oozed from the bundles. The middle internodes of the main axis have yellow bundles, and here also there are yellow spots in the parenchyma where the bacteria have oozed out. The bacteria are not abundant in the middle leaves.

XIJX. Plant 4 feet high, all the leaves dried ont, stem green and sound externally. Bacteria not abundant in the middle leaves. I can not see any yellow slime with the hand-lens on cross-section of the sheaths. Plant cut across an internode 3 inches from the base, there are a great many yellow bundles; in fact, nearly every bundle of the stem shows a yellow ooze. This part of the stem slit longitudinally shows 2 brown nodes connected by white internodes with yellow bundles. The numerous roots are sound externally, but some show the bacterial ooze on cross-section near the stem. The roots do not appear to be much infected. The most badly infected node, as in many other cases, if not all, is the basal one. 'The disease disappears (hand-lens) some distance under the male inflorescence, perhaps a foot. Above the basal cut 3 nodes are brown, 2 nodes farther up are yellowish, and the middle internodes show yellow bundles in abundance. The plant has 2 ears each slightly infected at the base in the bundles.

L. Plant 3 feet 9 inches high, good roots, all the leaves dry, stem sound and green externally. 'The sheaths of the middle leaves are plainly infected in a few bundles. 'The same is true of the leafsheaths up to the top of the plant. 'They are all more or less occupied by the yellow bacteria. The disease is visible in the stem close under the male inflorescence, that is, I inch under the first branch of it. The yellow bacteria are distinct in the base of all three cobs. Stem cut across an internode 3 inches from the base: Nearly every bundle shows a yellow ooze. Slit longitudinally, its lower 3 nodes are brown and the internodes are greenish white with yellow bundles. Above this, 3 nodes are brown, the next 2 are yellow and show the bacterial ooze distinctly. 'The bundles in the middle internodes are packed full of the yellow bacteria.

LI. Plant 3 feet 9 inches high, roots sound externally, stem green and sound outside, all the leaves dry. The yellow slime is present in the middle and upper leaf-sheaths, exclusive of the two uppermost. The upper part of the stem for a foot under the male inflorescence appears to be free (liand-hens). Three ears, all badly infected at the base. 'This infection extends up into the part which bears the kernels, and the bases of a few of the kernels seem also to be attacked (these have been saved in alcohol). Cut stem 3 inches from the base; every bundle appears to be occupied by the yellow slime. Slit longitudinally, the nodes are brown, the internodes white with yellow bundles. 
Above this cut 3 nodes are brown and the others farther up are yellow and show the bacterial ooze distinctly on section. The middle internodes are white, with numerous yellow bundles.

The plants LII to LXX were brought in and examined on October 27. All the plants had good roots. The ears were in the edible "green-corn" stage. The tops had been broken off in many cases. When not otherwise recorded, the parts, except leaves and male inflorescence, were normal in appearance. Most of these plants were 3 to 4 feet high. There had been a slight frost and a few of the leaves here and there may have been killed as the result of the frost, but I think it unlikely, because in the same hill one plant would have dry leaves and another not, and also because all of the remaining plants had more or less green leaves. Many of these leaves were 3 to 3.5 inches wide.

The leaves of these 19 plants were dried out and dead. The male inflorescence where it was present was white and dry. The stems in all cases were green and normal in appearance and many of the leaf-sheaths were alive, the blades being the dry part.

LII. Cut 3 inches from base, nearly every bundle is occupied by the yellow bacteria. All the middle internodes contain many yellow bundles. The organism is abundant in the bundles at the base of each one of the five ears. It can be traced into the upper internodes of the main axis, but is less abundant there. The basal 3 inches slit through shows much less browning in the nodes than in any plant hitherto examined, but the basal node is brown.

LIII. 'This is a very small plant. It has had a bad injury underground, and the height of the plant is less than a foot. The injury referred to cut the stem at least half in two. No distinct indication of the disease in the upper part of the stem. The 2 basal nodes are brown, but the internode is whitish. I can see no yellow or brown bundles in the internode. Probably the dwarfing was due to the extensive stem injury. Not examined under the compound microscope.

LIV. Stem cut 3 inches from the base, nearly every bundle shows an abundant yellow ooze. There are 4 ears; all show presence of bacteria at the base in the form of yellow ooze. Slit the base of the stem longitudinally. 'There are 2 brown nodes with yellow stripes in the internodes. I also find the organism moderately abundant 6 inches under the male inflorescence. Cut still higher up, that is, immediately under the male inflorescence, the bacteria are still present. ('Turned over the rest of the plant to my colleague, Mr. Merton B. Waite, who stated that he found bacterial infection in the bundles of every node and internode.)

LV. Cut 3 inches from the base, the internode contains yellow and black bundles, but they are much less numerous than in the preceding. Sliced longitudinally, the 3 lower nodes are brown; the internodes are white, with yellow and brown bundles. Cut I foot higher, there is almost complete freedom from visibleinfection in the internode. This plant is much less infected high up than the preceding. The disease runs out entirely, so far as one can see with a hand-lens, at 1.5 feet under the male inflorescence. One small ear and one large one; neither show any infection.

LVI. This is a small plant, not more than 3 feet high. A cut 3 inches from base shows numerous points of infection. There must be at least 50 bundles from which there is a yellow bacterial ooze. The ear shows disease in a number of the inner husks in the shape of infection of the bundles, water-soaked spots in the parenchyma and a yellow bacterial ooze on the inner surface of the husks. The inner face of certain luusks is the only place where the bacteria have been observed coming to the surface. The base cut longitudinally shows 3 brown nodes and many yellow bundles. There are 3 brown nodes above this cut and 3 yellow ones higher up. The internodes higher up show numerons yellow bundles. The yellow bundles run out into the base of the cob.

LVII. 'Two ears, partially destroyed by insects and smut, show yellow bundles in the undestroyed base. Cut 3 inches from the base, the main stem shows many bundles with the yellow bacteria oozing out in great quantities. 'The base slit longitudinally shows 3 brown nodes, the cut bundles exuding yellow ooze. The internodes show very many yellow bundles. 'The disease apparently runs out in the first node below the tassel. A small ear near the base of the stem also contains bacteria in the bundles of the hinsks and in the base of the cob.

IVIII. Cut 3 inches above the base, the stem slows bundles with a yellow ooze, rather few in number. Plant eut I foot higher, in the internode, shows a yellow ooze from about 40 bundles. One ear which was badly gnawed by larvæ shows nany yellow and brown bundles in the uninjured base, and some of the inner husks show the yellow bacteria oozing out. The middle internodes of the main axis, slit longitudinally, show yellow and brown bundles. When cut 8 inches under the male inflorescence, 2 or 3 bundles in the internode show a yellow ooze. Cut 0.5 inch under the male inflorescence, the bacterial ooze is still plainly visible in one bundle. Above the basal cut there is I brown node and 
2 yellow ones, and the internodes show many yellow bundles and some places where the bacteria have oozed out into the parenchyma, forming bright yellow spots. The basal part cut longitudinally shows 2 brown nodes; some of the bundles of the internodes are blackened and a few yellow ones show the bacterial ooze.

I.IX. Cut 2 inches from the base, the stem shows a few yellow bundles with the characteristic ooze. The longitudinal section shows one node slightly brown. One bundle in the internode is very markedly yellow in color; several other bundles are slightly colored with the yellow bacteria. There are 2 ears, both badly gnawed by larvæ (southern cornwornin), but both show numerous yellow bundles at the uninjured base. A cross-section in the internode 1 foot above the first cut shows about 20 bundles giving out the yellow ooze. There are brownish yellow nodes and yellow bundles in the internodes for a distance of a foot up from the root. Farther up the disease is less distinct, and after one reaches the height of about 3 feet the bacterial slime ceases to be visible to the naked eye or with the land lens.

IX. Cut 3 inches from the root, there is a yellow ooze from a great many bundles. Cut a foot higher, the number of visibly infected bundles is still a good many. Cut another foot up, I see a yellow ooze from only about one dozen bundles. Cut immediately under the male inflorescence, another foot up, the visible infection is reduced to 3 bundles. There are 3 ears, all gnawed by larvæ, but all showing the yellow bacterial infection at the uninjured base. The base of the stem cut longitudinally shows 2 very brown nodes and internodes with many yellow bundles and some very brown ones. The middle internodes sliced longitudinally show numerous yellow bundles. Above the lower (brown) nodes are yellow nodes, from which the bacteria can be seen to ooze on section.

I.X1. Main stem sliced across a node 3 inches from the base, there is yellow bacterial ooze from many bundles. Cut a foot higher, distinct yellow ooze can be seen from about i 5 bundles. This portion of the stem slit longitudinally shows yellowish gummy nodes and bright yellow bundles in the internodes. The base cut longitudinally shows the 2 lower nodes markedly brown, the one above brownish yellow, the internode slowing yellow bundles. Visible infection runs out about 3 incles under the male inflorescence. 'There are 2 medium-sized ears and 3 very small ears. Yellow bacterial ooze shows only in the base of the largest ear (cob). The upper part of this plant contains a much less quantity of the yellow bacteria than many of the others.

IXII. A small plant, that is, about 3 feet high. Cut 3 inclies from the base, many bundles of the internode show the yellow ooze. The basal portion slit longitudinally shows 2 brown nodes, with some yellow bundles in the internodes. One of the inner husks of the ear is infected, and the distinctly yellow bacteria have oozed out of the spots and lie free on the inner surface of the husk. There are numerons yellow bundles in the base of the cob. The middle internodes sliced longitudinally show distinctly yellow stripes corresponding to the infected bundles. Farther up the stem there are numerous areas where the bacteria have oozed out into the parenchyma. In the node just below the inale inflorescence there are numerous yellow bundles.

I,XIII. Cut 4 inches from base, there is a distinctly yellow bacterial ooze from a great many bundles, at least Ioo. Stem sliced longitudinally for a distance of $\mathrm{I} .5$ feet above the basal cut, the lower nodes are brown and the upper ones are yellowish brown. The internodes are greenish white, with many yellow bundles. The infection can be traced as far up as the slieing. Stem above this broken off. One medium-sized cob, badly infected. At least 4 bundles show yellow ooze in the very tip of the cob. 'This cob bears no well-developed kemels, probably because it is so badly infected. There are numerous yellow bundles in the husks, and numerous areas where the bacteria have oozed through to the surface (inner face) of husk. One small ear, gnawed by insects, shows yellow bundles at the uninjured base. 'The base of the stem cut longitudinally shows 3 brown nodes; the whitish internodes show yellow stripes (bundles) with bacteria oozing out in many places.

LXIV. Cint 3 inches from base, yellow slime oozes from nearly every vascular bundle. Basal portion slit longitudinally, the 3 basal nodes are brown and the greenish-white internodes have bright yellow bundles. The disease runs into the base of one of the ears. The bundles of the leaf-sheaths are occupied, and the bacteria have also made spots in the parenchyma and oozed out as yellow slime on the inside of the leaf-sheaths. A seetion of stem abont a foot above the basal cut shows plenty of bacteria in the vessels; bacteria are also present as a yellow ooze from the bundles a foot above the last cut. One small ear shows yellow bundles very near the tip of the cob. The husks also slow numerous water-soaked spots where the bacteria have oozed from the vascular bindles. Anotlier small cob higher up the stem is slightly infected at the base. Slit the middle section of the stem longitudinally and examined the internodes. There are many yellow bundles. To the unaided eye the disease runs out in the upper is inches of the stem.

LXV. Top broken off. An abundance of good roots, as in case of nearly every one of these plants. Cut 3 inclies from the base, there is a yellow ooze from nearly every bundle. Base slit longitudinally shows the lowest 3 nodes brown, the in ternodes white, with numerous bright yellow bundles. 
Stem above the basal cut slit longitudinally for a distance of a foot, the nodes are yellowish brown, and the internodes have bright yellow bundles. There are 2 small ears; both show infection at the base of the cob, and in the husks of one are numerous water-soaked spots, from which the bright yellow bacteria have oozed to the inncr surface.

LXVI. Cut 3 inches from the base, there is a yellow ooze from nearly every bundle. Slit the basal part longitudinally; the three nodes are brown; the greenish-white internodes show distinctly yellow bundles. Plant cut I foot higher, there is a bright yellow ooze from many of the bundles at the upper cut. Slit this foot-long piece longitudinally; it contains 2 nodes which are yellowish brown; the yellow stripes (yellow bundles) in the greenish white internodes are conspicuous. Cut 8 inches below the male inflorescence, there is a yellow bacterial ooze from about 30 bundles as far up as this (29 inches fron the base of the stem). Slit this upper, 1 - -inch, portion longitudinally; the nodes are distinctly yellow and show a yellow ooze; the greenish white internodes bear conspicuous yellow bundles. In some places the bacteria have oozed out of the bundles and formed yellow spots in the parenchyma of the internodes. On examining microscopically the bacteria are seen to be in nearly or quite every bundle 4 inches below the male inflorescence ( 33 inches from base of stem). 'The male inflorescence was broken over about I inch above the point from which the section was cut. There were 2 ears, both of which showed infection at the base. 'The bacteria are single or joined end to end in twos or fours. They are enormously numerous, and I fail to see any distinct motility. They secm to be rather more than twice as long as broad.

LXVII. 'Three abortive ears and one ear with kernels. The three small ears show slight infection at the base, while the large ear shows distinct yellow bundles at the base of the cob, and all the busks when cut near the base show a yellow ooze from the bundles. When cut 3 inches from the base, the stem shows a yellow ooze from nearly every bundle. The basal part split longitudinally shows 3 brown nodes, with many yellow bundles in the internodes. The first 3 nodes above the basal cut are also brown, while the remaining nodes of the stem show a yellow bacterial ooze. There are numerous yellow bundles in the lower internodes. The disease apparently runs out (hand-lens) at the node next below the tassel.

IXVIII. Cut 3 inches from the base: There is an immediate yellow ooze from nearly or quite every bundle. Cut the stem a foot ligher: There is a yellow ooze from nearly every bundle. Slit the basal portion longitudinally; the 2 nodes are brown; the greenish white internodes contain yellow bundles. One large and one small ear. Both show numerous bundles, from which yellow bacteria ooze; these are near the base of the cob. The bundles of the leaf-sheaths also show yellow ooze. Slit the middle portion of the stem longitudinally; the white internodes contain numerous yellow bundles and in places the bacteria have escaped from the bundles into the parenchyma, forming small pockets from which they ooze out on section as yellow slime. Cut 20 inches farther up, the infection is inconspicuous at this height; there are a few bundles plainly diseased in the leaf-sheath surrounding the stem, but I can not sce any in the stem. Six inches lower, just under the node, there are at least 40 bundles infected. 'This is at a distance of about 2.5 feet from the ground. The disease is present in a number of the leaf-sheaths lialf-way up the stem. About a foot below the tassel at least 20 bundles in the stem show the yellow bacterial ooze, and a number of the bundles in the surrounding leaf-sheath also show the yellow ooze. The bacteria have oozed out into the parenchyma to a greater extent in the internodes of this plant than in any other plant examined. They occur as small bright yellow spots in the white pith.

LXIX. A large plant with 2 large and 2 small ears. The bacteria are present in a leaf-sheath half-way up the stem. They are also present in the base of the blade of the same leaf. 'The 2 smaller ears show yellow bacterial ooze from the bundles at the base of the cob. With a hand-lens I can not detect any bacterial slime in the leaf-sheath next higher up, nor in the one above that, but I presume a microscopic examination would show its presence there. (Later: The microscopic examination was made and showed that the bacteria were present in 6 bundles of this leaf-sheath.) Nothing certain as to any infection in the 2 larger cobs. Not examined with compound microscope. Cut main stem 3 inclies from the base; there is an immediate yellow ooze from nearly or quite every bundle-150 or more. (Examined later under the compound microscope and counted 184 bundles, of which at least 150 were infected.) Slit the stem longitudinally the whole length, a distance of only 3 feet; the basal 3 nodes are brown, the next 3 are yellowish; the internodes are greenish white, with bright yellow bundles and yellower spots in the parenchyma between the bundles where the bacteria have formed small cavities. The infection continues distinctly up to the last internode but one, where it becones less conspicuous and is not visible under the hand-lens. As in all the plants thus far examined, the bacteria become less abundant toward the top of the stem. This plant bears numerous good roots, as in case of nearly all the rest. The basal part slit longitudinally shows 3 brown nodes and whitish internodes witl yellow bundles. I examined in cross-section a dozen or more roots quite carefully. If there is any infection whatever, it is not visible under the hand-lens except in the case of one root from which there is a slight yellow ooze. None of the roots show any external signs of disease. 
I,XX. There are 4 ears, 3 abortive. The abortive ear nearest the base of the stem is conspicuously diseased only at the extreme base. Cut an inch higher up, I can see no evidence of infection with a hand-lens, except in some of the bundles of one of the outer husks. 'The best ear, which is only a nubbin, slows distinct infection at its base. Cut 1 inch higher up, the bacteria are still present, both in the base of the cob and in the luusks. One very small ear shows numerous yellow bundles at the base and also in the husks. Main stem cut 3 inches from the base, there is a yellow ooze from nearly or quite every bundle. Cut I foot higher and examined at the upper part, numerous bundles show the yellow ooze. Cut i foot higher and examined at the upper cut, there is no distinct infection. Cut 4 inches higher, that is, 1 inch under the male inflorescence, I can not see any distinct signs of infection. The basal portion of the main axis shows 4 brown nodes and the greenish white internodes have conspicuous yellow bundles.

The foregoing include all of the plants examined up to the date of the first hard frost, the night of October 29. 'The plants were covered with paper bags at 10 o'clock p. m., but too late to protect them, $i$. e., when the temperature was between $o^{\circ}$ and $1^{\circ} \mathrm{C}$. The leaves of all the plants were frosted.

On October 3 I most of the plants had recently frosted green foliage, but 16 of then had dried-out white foliage, and these I 6 were pulled up separately and taken into the laboratory for examination. My notes on these plants are as follows:

All the plants, with one exception, had abundant and sound roots. The male inflorescence, where present, was dried up, and all the leaves were dried and shriveled. 'The plants were from 4 to 4.5 feet ligh. The stems of all the plants were green.

LXXI. The stem cut 3 inches above the root shows no bacterial ooze from the bundles. The 6 lowest nodes are distinctly brown, while the 4 upper nodes are yellow, and there are very many bundles in the upper part of the stem which show the yellow bacterial ooze. A hasty microscopic examination of the portion of the stem between the second and third nodes shows no bacteria in the bundles. There are two ears, one small, which does not show, clearly at least, any bacterial ooze; the larger ear, cut crosswise at the base, that is, across the cob, shows two or three bundles very distinctly marked with the yellow ooze-possibly several more, but not clearly seen. In a transverse section of the stem 6 inches below the male inflorescence there are numerous bundles which distinctly show the yellow bacterial ooze. It is especially noticeable around the periphery.

LXXII. This plant shows very slight signs of the disease. In a cross-section 3 inches from root no ooze could be found. Likewise in a longitudinal section of the base there is no ooze. The lowest node is discolored. The second node is discolored a little. No other nodes show any discoloration whatever. 'The only bacterial ooze found is in one node about half-way up the stem and in a crosssection in the base of the cob, the yellow slime running out also into a few of the inner litusks.

LXXIII. A transverse section of stem 3 inches above the base shows numerous bundles from which there is a yellow bacterial ooze. In the longitudinal section the lower nodes are brown, with yellow bundles in the internodes. There is one small undeveloped ear, which shows no bacterial growth. A somewhat larger ear badly eaten by insects shows in the uninjured part numerous bundles with yellow bacterial ooze. A few yellow bundles are present in the second node below the tassel.

LXXIV. This is a very severe case. A cross-section 3 inches from base shows a large number of bundles with a bright yellow ooze. In a longitudinal section of the base these bundles may be traced the entire length by their marked color. The 3 nodes of this base are very badly discolored, being nearly black. In the section above the basal cut, 2 of the nodes show brown discoloration, while the upper 3 show yellowish discoloration. At least 2 yellow bundles can be seen in a transverse section 6 inches below the tassel, in the internode between the tassel and the first node below. There are 2 ears, a small undeveloped one which shows bacteria present at its base, and a larger one whicli shows numerous yellow bundles at the base, the majority of which run out into the husks.

LXXV. In a cross-seetion 3 inches from base of the stem numerous yellow bundles are seen. A longitudinal section of the base shows 3 badly discolored nodes, the internodes having many yellow bundles. 'The first 3 nodes above the basal cut are distinctly brown in color, while the upper nodes are yellowish. The disease can be traced to a node about 1.5 feet below the tassel. 'There is one ear on the plant, the base of which shows numerous yellow bundles, nearly all of which run out into the husks and not into the cob.

IXXVI. A small plant. 'There is one ear on this plant, the base of which shows numerous bundles from which the yellow bacteria ooze. One of the inner husks has numerous water-soaked spots, from one or two of which the bacteria have broken out to the surface on the inner side of the husk. The upper nodes of the stem show on section a distinct yellow bacterial ooze from the bundles. 
The plant was broken off about 1.5 feet below the tassel. A cross-section 3 inches from the base shows very few bundles with the yellow ooze. A longitudinal section of this base shows but one bundle clearly marked with the yellow ooze. Several more longitudinal sections were made, and other bundles were found which showed the yellow discoloration.

I.XXVII. 'There are two medium-sized ears, neither of which shows any bundles infected with bacteria. A transverse section of the stem 3 inches above the base shows a brown discolored area on the periphery, but there are no bundles which show the bacterial ooze from the cut surface. In longitudinal section the nodes at the base of the stem are quite brown, but the disease, if present, runs out about half-way up the stem, as the 3 uppermost nodes appear to be perfectly normal. A hasty microscopic examination of the basal part of the stem shows 1 or 2 bundles infected with bacteria.

LXXVIII. A transverse section of the stem 3 inches above the root shows numerous bundles from which there is a yellow bacterial ooze. The basal nodes are slightly brown, and there are many yellow and brown bundles in the internodes. The nodes ligher up are yellow, and there are 2 or 3 yellow bundles in the uppermost node of the stem. In all the internodes above the basal cut yellow bundles can be seen. In the third internode above the basal cut the bacteria have oozed from a bundle into the parenchyma. This is also the case in some of the upper internodes. 'This plant is very badly infected all the way up to the uppermost node. There is one developed ear, which shows the bacterial ooze at the base of the cob in several places. The bacteria disappear one-third the way up the cob. None of the husks shows any signs of the bacteria.

IXXIX. On the surface, at the very base of the stem, there are 3 places which are blackishbrown, and the epidermis is dead. 'The discoloration does not extend inward to any great distance. A transverse section of the sten 3 inches above the base shows a few bundles from which there is a yellow bacterial ooze. In longitudinal section the lower nodes are distinctly brown, while the upper nodes are yellow. In the node just below the tassel, yellow bacterial ooze can be scen issuing from at least one bundle. In the middle internode numerous yellow bundles can be seen. 'The one ear shows numerous places where the bacteria have come out in an ooze. A few of the husks show a very

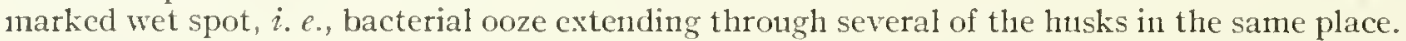

LXXX. A cross-section 3 inches from the base shows no bundles colored by the bacteria. A longitudinal section of this base contains 3 nodes of a slightly brown color, but no bundles can be seen that contain the bacteria. The first two nodes above the basal cut are brown. Those higher up show 110 distinct coloration. With a hand-lens it is impossible to tell whether there are any bacteria present; but a microscopic examination of material taken from one of the upper nodes shows the presence of the bacteria. A cross-section at the base of the one ear fails to show any bacteria with a hand-lens.

IXXXI. This is a smaller plant than most of the preceding. A cross-section 3 inches from the base shows very many bundles with the yellow ooze. 'These bundles may be traced in the longitudinal section from the cut to the extreme basal cnd of the stcm; the 2 nodes are brownish in color. A cross-section of the stem a foot above the first cut shows numerous bundles containing the yellow bacteria. Another foot higher, which is 6 inches below the male inflorescence, the cross-section shows possibly half a dozen bindles containing the bacteria. All of the nodes are somewhat browned. The upper 3 or 4 contain much yellow slime. The plant has two ears, both of which at the base show 11umerous bundles from which there is a yellow bacterial ooze. In the larger ear n110st of the yellow bundles rin1 ont into the husks, but a few of the bundles can be traced at least one-third of the way up in the center of the cob. In the smaller cob all of the infected bundles secm to run out into the husks.

LXXXII. On surface around the basal nodes of this plant there are numerous brown cracks. A transverse section of the sten 3 inches above the base shows nearly every bundle filled with the yellow bacteria. Split the stem longitudinally - the 6 basal nodes show a brownish color, white all of those higher up are yellowish from the presence of the bacteria. There are numerous yellow bundles in all the internodes. At one place in the uppermost internode the bacteria have oozed into the parenchyma. There is one developed ear, the pedicel of which shows numerous bundles containing the bacteria. These bundles appear mostly to run out into the liusks, where a surface ooze may be seen in numerotis places. There is also a place in one of the lower internodes where the bacteria have oozed out of a bundle into the parenchyma.

LXXXIII. A cross-section 3 inches from base shows numerous bundles with the yellow bacterial ooze. There are 3 nodes below this cut, all of a brown color. 'The internodes show several bundles very distinctly marked with the yellow bacteria. 'T'hey are especially noticeable on the edges (periphery). A longitudinal section of the stem above this cut shows 2 nodes of a brown color and all the upper nodes yellowish in color (the normal color is white or greenish white). In places in the internodes the bacterial masses are plainly seen in the bundles. In other places they can not be so clearly seen with a hand-lens. There is one ear which shows nany infected bundles at the base. The greater number of these bundles run out into the husks. 
IXXXIV. A cross-section 3 inches from the base shows 20 or nnore bundles with the bacterial ooze. In longitudinal section the base shows 2 sliglitly browned nodes. The bundles in the internodes are considerably colored by the yellow bacteria. In making this longitudinal section several roots were cut longitudinally. The presence of any yellow material in these roots could not be seen. A longitudinal section of the stem above the basal cut shows 5 brown nodes. The internodes show about half a dozen bundles that are plainly marked (yellow) with the bacterial disease. 'Two or three yellow bundles can be traced up to the node immediately below the tassel. This plant lias one ear, which shows yellow bundles at the base running out into the husks. A few of the infeeted bundles are visible as far out as the middle of the cob.

LXXXV. A cross-section 3 inches from the base shows a few bundles occupied by the bacteria. Longitudinal section at base: here 2 discolored nodes and several bundles in the internodes with yellowish slime. Above the basal cut there are also 2 brown nodes, the remainder being yellowish. Yellow bundles can be seen in all the internodes. There are two ears, eaten by insects, but on section they show the yellow bacterial ooze issuing from the bundles at the base.

LXXXVI. This plant possesses very few roots. At surface of the nodes from which the roots spring there are numerous dark brown spots. There are several of these spots in the second and third internodes. In some cases the brown spot lias a hole in the center as if, perhaps, it had been eaten by some insect. These holes, together with the brown discoloration, extend inward, in one case as far as the center of the stem. A cross-section 3 inches from the base shows a goodly number of bundles with the bacterial ooze. A longitudinal seetion of the base shows 3 badly browned nodes, the stain evidently not caused by the outer injury before described. One node, however, shows a discoloration of an entirely different nature, which apparently comes from one of the aforesaid black spots on the onter surface. The internodes show bundles with the bacteria. I ongitudinal section of the parts above the basal cut shows 3 nodes of a brown color, the remaining upper ones being yellowish or green. Some bundles in all of the internodes show bacteria. There is one ear, which shows at its base a few bundles infected with the yellow bacteria.

On November 1, all the remaining plants were examined in the field one by one, but it is not wortl while to describe any of them minutely, since it would be only a repetition of what has preceded. The results obtained are summarized in table 7 .

TARLE 7.-Number of Cases by Varieties and the Time when the Signs were First Observed.

\begin{tabular}{|c|c|c|c|c|c|}
\hline Date. & $\begin{array}{c}\text { 1noculated Angust 9, in seedling stage, by } \\
\text { placing bacterial slime on tips of } \\
\text { young leaves. }\end{array}$ & Cases. & Date, & $\begin{array}{l}\text { Inoculated Angust } 13,14,15 \text {, and } 16 \text {, in seedling } \\
\text { stage, by spraying (atomizing) upon the } \\
\text { plants water containing the bacteria. }\end{array}$ & Cases. \\
\hline Aug. 28 & Early White (in greenhouse)..... & 2 & Oet. 7 & Early Red Cory .................. & 1 \\
\hline Sept. 8 & Early White (in the field)....... & 2 & Oct. 7 & 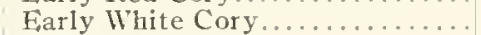 & I \\
\hline Sept. 8 & 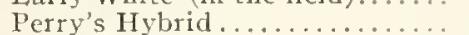 & I & Oct. I 4 & Perry's Hybrid . . . . . . . . . . . . & 2 \\
\hline Oct. 7 & 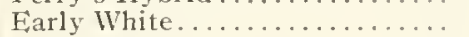 & 2 & Oct. 14 & Early Red Cory................ & I \\
\hline Oet. 10 & Perry's Hybrid. . . . . . . . . . . . . & I & Oet. 14 & Farly White Cory.............. & 5 \\
\hline Oct. 10 & 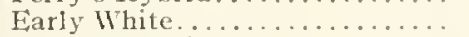 & 3 & Oct. 17 & Early Red Cory................ & 3 \\
\hline Oct. 14 & Perry's Hybrid. . . . . . . . . . . . & 2 & Oct. 17 & 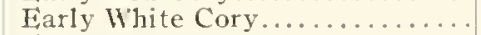 & 1 \\
\hline Oet. 14 & 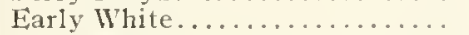 & 2 & Oct. 21 & Early Red Cory................ & 1 \\
\hline Oct. 17 & 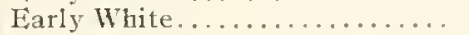 & 3 & Oct. 2 I & Early White Cory.............. & 5 \\
\hline Oct. 17 & Perry's Hybrid . . . . . . . . . . . . . & 2 & & & \\
\hline Oct. 21 & 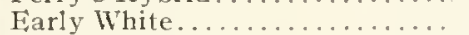 & 8 & & & \\
\hline Oct. 2 I & Perry's Hybrid. . . . . . . . . . . . . & 1 & & & \\
\hline
\end{tabular}

After light frost-very little indieation of frost injury.

Oct. 27. Early White.

act. 27 Perry's Hybrid.
Oet, 27 Early Red Cory.

Oct. 27 Early White Cory.......

Plants pulled, examined, and found diseased after a heavy frost which confused external signs.

\begin{tabular}{|c|c|c|}
\hline Oct. 31 & 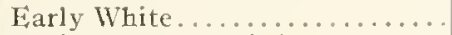 & 7 \\
\hline Oct. 31 & Variety not recorded........... & i \\
\hline Oct. 3 I & Perry's Hybrid. . . . . . . . . . . . . & 2 \\
\hline Nov. 1 & Perry's Hybrid............... & 32 \\
\hline \multirow[t]{2}{*}{ Nov. I } & 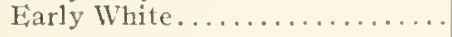 & 36 \\
\hline & Total. & 115 \\
\hline
\end{tabular}

Oct. 31 Firly White.

Oct. 31 Variety not recorded.

Oct. 3 I Perry's Hybrid.....

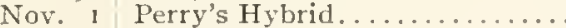

Total..... 
Not all of the plants showed bacterial slime. On sectioning and examining with the liand-lens, about 160 were apparently free from the yellow bacteria, and all of these showed absence of brown stain in the nodes, except in some cases a very slight stain at the extreme base of the stem, which may have been due to incipient or arrested infection. It is not known why a portion of these plants escaped. The following explanations are offered:

(I) Possibly most of the remainder were slightly infected and some undoubtedly would have developed the disease in course of another month if they had not been killed by frost.

(2) 'The infectious material was washed off these plants by copious flow of fluid from the water-pores during the seedling stage.

(3) The inoculated leaves died and dried out before the bacteria had opportunity to reach the stem by way of the foliar bundles.

(4) 'The bases (nodes) of these particular plants were exceptionally hard and offered unusual physical resistance to the movement of the bacteria. This is a very important point, as we shall see later. (See also ante, Cobb's disease of sugar-cane, p. 37).

(5) The juice of these plants was more acid, or in some other chemical way was more injurious to the bacteria than that of the plants which became diseased.

Total number of plants found diseased to such an extent that a microscopic examination was not necessary to detect the bacterial slime, although it was made frequently, 266. Add to the above 30 that were plainly diseased when examined hastily under a compound microscope, and i 8 doubtful cases which should probably be classed with the diseased, $i . e$., in which the bacteria could probably have been demonstrated by a more careful examination (only a few minutes study was given to each one), and we have the following result: Diseased plants, 296; doubtful plants, I8 (probably diseased); sound plants, i.e., not any visibly infected, unless the occasional slight brown stain at the extreme base be so interpreted, I59; tota1, 473; per cent of diseased, excluding doubtful, 62.

In this connection it must not be forgotten that the experiments were begun late and were cut short by a frost. Probably if they liad been gotten under way 3 weeks sooner or if the frost liad lield off that much longer there would have been a considerably greater number of cases.

At the end of the experiment all of the refuse was carefully gatlered together and burned. Undoubtedly some of the organisms were left in the soil, but no diseased plants were left to be blown about or eaten by animals. Only the smaller roots were left in the soil.

SERIES III TO VII, I902.

Employing the same strain of organism and susceptible varieties of sweet corn and making the inoculations during the seedling stage with young cultures in the same way as in Series I, but growing the plants to maturity in small pots in the hothouse under very different physical conditions, a very different result was obtained, most of the plants failing to take the disease. Of course one n1ight attribute the failure to loss of virulence on the part of the organism, but, in the present state of our knowledge, this would be purely hypothetical, especially as no great amount of time intervened between the two experiments. I am, therefore, inclined to ascribe it rather to the very slow growth of the plants, this view being more in accord with other facts observed by the writer, $e$. g., see Series XI to XV and XX to XXIV. Certainly the hard, dry tissues of these plants would afford a much greater plyysical obstacle to the movement of the bacteria than would soft juicy tissues. We do not know what chemical substances are stored in the plant during such phases of growth, but if acids are stored in excess, as might well be the case, then there would be also chemical difficulties in the way of general infection of the plant. All such problems remain to be worked out. The facts are as follows: 
A ugust 20.-The following varieties of sugar-corn were planted: Red Cory, Early Red Cory, Early White Cory, Perry's Hybrid. There were many pots of each. All stood on a bench in one of the hot-lionses.

A ugust 30. - Tubes of slant agar, Nos. 9 to I6, were streaked directly from tubes i to 8 of July 17 (the agar-stab-cultures brought from Long Island).

Seplember 3.- Masses of the yellow slime from these eight agar-streak-cultures were placed on the tips of the young leaves by means of a platinum loop. On some plants one leaf only was inoculated, on others two. The young plants were 1 to 2 inches high. The work was done between $\mathrm{I}$ and 3 o'clock on a cloudy afternoon. As soon as inoctulated the plants were placed under the bench in the dark.

September 4, nioht. - The plants remaincd nuder the bench about 28 hours. Ther were then put on the bench.

Seplember 6. - The plants are now about 3 inches high; there are some indications of infection at the leaf-tips, but nothing absolutely sure.

October 18.- The first case was brought in and examined to-day. It is the variety known as Red Cory. The vessels are full of the yellow slime.

October.-The second case, a very typical one, was found in the Early Red Cory. A plant of Early White Cory, accidentally broken by the gardener, was examined at the same time, but did not appear to be affected.

December I6.- Those plants nearest to maturity were removed and dissected to-day. The culns were so hard that they could be cracked like pipe-stems. The plants were from 18 inches to 4 feet high and quite spindling. Most of the stems were green throughout (internally) and so brittle that they broke apart with a noise when bent at the nodes; even many of the internodes snapped like a dry stick, although the stems were not dead. The diameter of the stems at the base varied from 0.25 inch to 0.5 inch; most were under 0.5 inch. They had produced very few good ears. The plants were specked somewhat with Puccinia maydis, and many of the leaves had dried out, but mostly as a result of unfayorable conditions rather than by reason of the disease.

January 5.- The remainder of the plants were examined to-day. These plants also were very brittle. Aany of them were green throughout, though the pith is ordinarily white. Combining the early counts with those of December 16 and those obtained to-day, we have the results given in table $\mathrm{S}$, which should be premised by the statement that yellow bacterial slime was found in the vascular bundles of the stem of all plants marked "diseased."

TABLE 8.-Results of the Inoculations.

\begin{tabular}{|c|c|c|c|c|}
\hline Series and variety. & Diseased. & Doubtful. & Free. & Total. \\
\hline 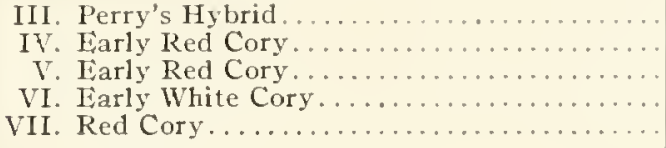 & $\begin{array}{l}4 \\
4 \\
3 \\
5 \\
3\end{array}$ & $\begin{array}{r}1 \\
1 \\
* 6 \\
4 \\
2\end{array}$ & $\begin{array}{r}45 \\
44 \\
30 \\
105 \\
98\end{array}$ & $\begin{array}{r}50 \\
49 \\
39 \\
114 \\
103\end{array}$ \\
\hline Summary........ & 19 & 14 & 322 & 355 \\
\hline
\end{tabular}

* Several with black bundles.

As a result of examinations with the compound microscope, 6 of the I 4 doubtful cases were found to contain bacteria, making a final total of 25 cases. Subtracting 60 check plants from the whole number, we have approximately 8 per cent of diseased plants, against 62 per cent obtained in the previous expcriment.

Three of the check plants became diseased.

These plants were first crowded together for 2 months, or more, on the west side of the house, became too large for the pots, and grew very spindling. This crowding was due to the fact that we had 110 other place to set them. They were then moved into the middle section of tle hot-house, which was much too warm for then. Some of then were repotted and others not. There they remained for about 6 weeks. They were then shifted back again to the cooler, north end of the house, middle bench, where they had room to grow and plenty of light, but they never overcame the original crowding and stunting. This interrtipted growth had much to do, I suspect, with the slow progress of the disease. 'T'liese plants stood at first on the bencl, where the very successful infections were made earlier in the month of August, and the checks were close to the inoculated plants, so that they were not entirely safe.

Only a few of the affected plants were badly diseased.

SERIES VIII AND IX, 1903.

In I903, at the writer's instigation, an experiment was made to determine wliether the disease could be communicated to field-corn and to pop-corn. This was entirely in the hands of Mr. James Birch Rorer, one of my laboratory assistants, wliose notes are as follows: 
July 8, I903. - Set out to-day on the Flats 10 rows of corn, each hill containing 4 plants. The rows run from east to west and are as follows, beginning at the north end of the plot:

I. Uninoculated:

Nelson's Yellow field (yellow flint).....12 hills.

Mottled Pearl pop-corn...................

Hominy (white flint)................ hills.

Boone County White (white dent).......2 hills.

Improved Clairage (yellow dent) .........
2. Inoculated (Jnne 20 and 23 ) by touching water from water-pores with loop of pure culture of Bact. stewarti:

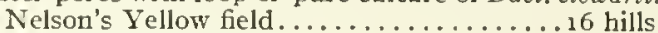

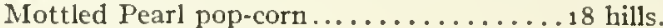

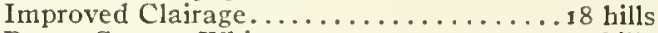
Boone County White.............. 8 hills.

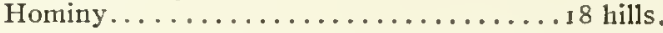

September 30, I903.-Cut out all of the Nelson's Yellow field corn, both inoculated and uninoculated. All the plants are more or less dead. The tassels are dried up and the leaves brown. There are some good ears. Many stems in both lots show an abundance of yellow ooze from the bundles. A section from each stem has been put into alcohol for future examination. This variety seems to be a much faster grower than any of the other varieties, which as yet are quite green and the ears are not yet ripe. Could it be the disease that hastened the ripening or is it a varietal characteristic?

Only one of the five varieties proved susceptible to this disease, viz, Nelson's Yellow field corn. Why were the control plants of this variety also attacked? On making inquiries I learned certain facts which appear to answer this question sufficiently. When the inoculations were made the check-plants stood some 30 feet away, but after a few days it became necessary to move the plants into another hot-house, where there was not much spare room, and where the inoculated and uninoculated plants stood much crowded and close together for a number of days. The infection of the check-plants probably dates from this time, as the gardener's hose would spatter all of the plants indiscriminately and that would distribute over the control plants any bacteria remaining on the surface of the inoculated ones, or on the soil of the pots.

The cultures used for inoculating were derived (June 19) directly from those direct transfers made by the writer on July 17 , I 902 , the organism being alive in each one of these 8 tubes.

The Mottled Pearl pop-corn, Boone County White, and Improved Clairage were planted June I 5 and were inoculated June 20. Inoculations were made from slant agarcultures. A loop of the organism was touched to each drop of water exuding from the water-pores situated on the tips of the leaves. The drop became clouded. At this time the first leaf was just beginning to uncurl, so that the tip of the second leaf was exposed.

The inoctlated plants were put under the east bench in the pineapple house, where they remained from Saturday afternoon until Monday morning. They were covered with a framework of netting to keep out mice, and the top of this was covered with manila paper. The temperature of the house went up to $4 \mathrm{I}^{\circ} \mathrm{C}$. on Sunday and was down to $20^{\circ} \mathrm{C}$. during the night. When the plants were taken from tinder the bench and put in the light the margins of the leaves were covered with drops of exuded water and all the leaves were somewhat bleached.

The White Hominy and Nelson's Yellow field corn were planted June $\mathbf{1} 7$ and inoculated June 23 , when the plants were from 2 to 4 inches high. In most of them one leaf was uncurled, so that the tips of the second and third leaves were often exposed, and three leaves were inoculated on some plants. The work was done in the afternoon, in the same manner as in the preceding series, except that the White Hominy was inoculated from a 24 -hour-old bonillon-culture derived from the slant agar; the plants were placed under the bench until the morning of June 25, when they were uncovered and placed on the bench. The leaves were more or less ctiolated.

The result of this experiment shows that the organism had not lost its virulence for susceptible varieties (Nelson's field corn) at the end of i i months' growth on agar. 'The thorotghness with which the work was done also indicates that the other varieties experimented with are not susceptible to this disease.

SERIES X, 1905.

In the spring of 1905 the inoculation experiments were repeated on several varieties of sweet corn and field corn grown for the purpose in a bed in one of our hot-houses. The 
writer controlled the cultures used and made notes on the results. The inoculations were made by Miss Alice C. Haskius, one of the laboratory assistants. In this case all of the plants were inoculated by needle-punctures, mostly in the blades of upper leaves. No hypodermic injections were made. Owing to unavoidable delay on her part the plants were not inoculated until they were about half-grown, i.e., 3 weeks later than I had planned, and when it might be presumed that they would be able to complete their growth before any general infection of the plant conld take place.

The needle-pricks were made March 10 to 14 . 'The cultures used were grown on slant agar and on potato atnd were subcultures from an isolation of the previous year. Altogether 57 plants were inoculated -32 sweet-corn and 25 field-corn. With one or two exceptions, two leaves were inoculated on each plant. The bacterial slime was mixed with water; a portion of this was spread on the leaf-blade with a platinum loop and punctures were made through the smeared portion; a little more of the fluid was then spread over the punctured area. The following notes were made by the writer:

March 20, I005.- A few of the plants show slight indications of infection streaking down from some of the pricks. One plant also shows two narrow water-soaked stripes near the pricked area, but not centering in any of the pricks, as though it were stomatal infection due to the material placed on the leaf. This was visible the day before yesterday and this morning. Not visible this afternoon.

The sweet corn is in full blossom. Some of the field-corn plants are coming into blossom, others not.

A pril 8, 1905.-. The first case was brought in to-day from hot-house No. 4. It is plant No. 18. Two inoculations were made on the base of two uppermost leaf-blades, which are now dead, together with the whitish, dwarfed male inflorescence. The plant, which is a small one, bears 2 small ears and 3 green leaves. The progression of the dry leaves is the reverse of that observed in the field, but otherwise the disease looks typical. On cutting open the base of the stem it is free from infection, but the bundles in the green leaf-sheaths of the inoculated leaves contain a pale yellow ooze, which under the microscope is bacterial and of the typical appearance. The yellow slime occurs also in the vessels of the upper part of the stem, mostly in the peripheral bundles. This plant is one of the sweet corns. It was inoculated March I3, from a potato culture (tube 1, March 10). The plant has shown signs of the disease for 4 or 5 days $i . e$, dry leaves and a white top. The inocilation took place just before flowering time.

April 29, I905.-A majority of the inoculated plants show dead stripes in the pricked leaves. In some cases the entire pricked leaf is dead. Quite a number of the plants are dead at the top.

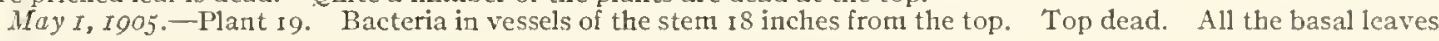
are green.

Plant 20: Basal leaves green, only the pricked ones are dead. Top dead and white. Bacteria present in stem 18 inches from the top.

Plant 23: The upper three leaves of this plant which were inoculated now have dead stripes. All the other leaves are sound. Top dead. No bacterial ooze visible with hand-lens in cross-section of upper part of stem. Cut it in three places.

Plant 33: Leaves above and below pricked ones are green. One pricked leaf is dead. The other is dying. Bacteria not visible in stem under hand-lens.

Plant 37: One pricked leaf is dead and two-thirds of the blade of the other. All the other leaves are healthy. Bacteria are not visible in the upper part of the stem, with the hand-lens.

The above-mentioned 5 plants are sweet corns.

May 8, roo5.-Four plants were cut ont this morning and examined.

No. 2: The middle, inoculated leaves are now dead. Their sheaths are infected by the bacteria. The top leaf is green. The male inflorescence is dead. The basal leaves are green. The middle portion of the stem contains the yellow bacteria in some abundance.

No. 5: The npper leaves and top of this plant are dead. The lower leaves are green. Cross-sections of the stem 2 feet from the top of the plant show a yellow ooze in a few of the bundles.

No. 27: The male inflorescence is dead, but it bears some kernels of ripe corn, so that it may have died naturally. The top of the plant and the basal leaves are green. The inoculated leaves are dying. There is a visible stem infection only near the junction of the inoculated leaves and this infection is confined to a few bundles.

No. 35: The male inflorescence and the upper + leaves are dead. The lower leaves are green. The yellow bacterial ooze is distinct in a few bundles in the upper part of the stem.

Nos. 2, 5, 27, and 35 are sweet corns. As in the plants already cut and described, the stem-infection is slight in comparison with the stem-infection in the plants inoculated 3 years ago in the seedling stage by way of the water-pores. The inoculations were made too late in the growth of the plants.

May 13,1905.-Five plants were cut out and examined to-day.

Plant 17: Top dead; base green; pricked leaves dead. The bacterial infection is present but slight.

Plant 22: Top dead; pricked leaves dead; the lower leaves green; stem green. On cross-section of the upper part of the stem 8 or so bundles show a distinct yellow ooze.

Plant 24: Top dead, including inoculated leaves. Slight infection of the stem, that is, yellow bacterial ooze from a few bundles, mostly peripheral ones.

Plant 26: Top dead; pricked leaves dead; lower leaves green; stem green. A few bundles in the upper part of the stem show a yellow ooze on section.

Plant 51 (field corn): Cut out and dissected. No indications of stem-infection when examined under hand-lens. 
Nothing is visible in the field corn inoculated at the same time as the sweet corn, $i . e$., there are no signs of disease.

May 22, 1905.- Cut and examined field-corn plants labeled S, 10, I I, 12, 39, 40, 41, 42, 44, and 46, which were drying up (the corn is ripening). None of them showed any signs of disease in the stem except numbers 42 and 44 . In the stems of these two plants a few of the vessels were found occupied by the yellow slime, but only a few, the infection being slight and confined to the vicinity of the inoculated leaves. This also shows that it is possible to inoculate the disease into field corn, but in general it appears to be much less susceptible than the sweet corn. The variety was not Nelson's Yellow.

As we have seen, it is a frequent movement of the bacterin111 to grow out into the husks surrounding the ear and then come to the inner surface, thus affording a very favorable opportunity for the contamination of the surface of the kernels. In this connection the following field observations are of interest:

\section{INFECTED SEED AS A MEANS OF} DISTRIBLTTION

In the summer of 1903 the writer found this disease in two places in Washington nnder circumstances which pointed to seed-corn as the carrier of the pathogenic organism, and the Congressional Seed Distribution as the agent of dissemination. Althongh these inferences were not clinclied by the actual demonstration of Bacterium stewartion or in the suspected seedcorn, the circumstantial evidence is nevertheless sostrong as to be worth recording at some length. This evidence is the more credible becanse the organism is often fonnd in the vaseular bundles of the cob, and may penetrate from these into the base of the kernel (see figs. 45, 46 , $47,48)$, and because, as already recorded, it occurs very frequently in the inner husks and shows a strong tendency to come to the surface of these organs as a wet slime, which might easily contaminate the surface of the kernels and has been

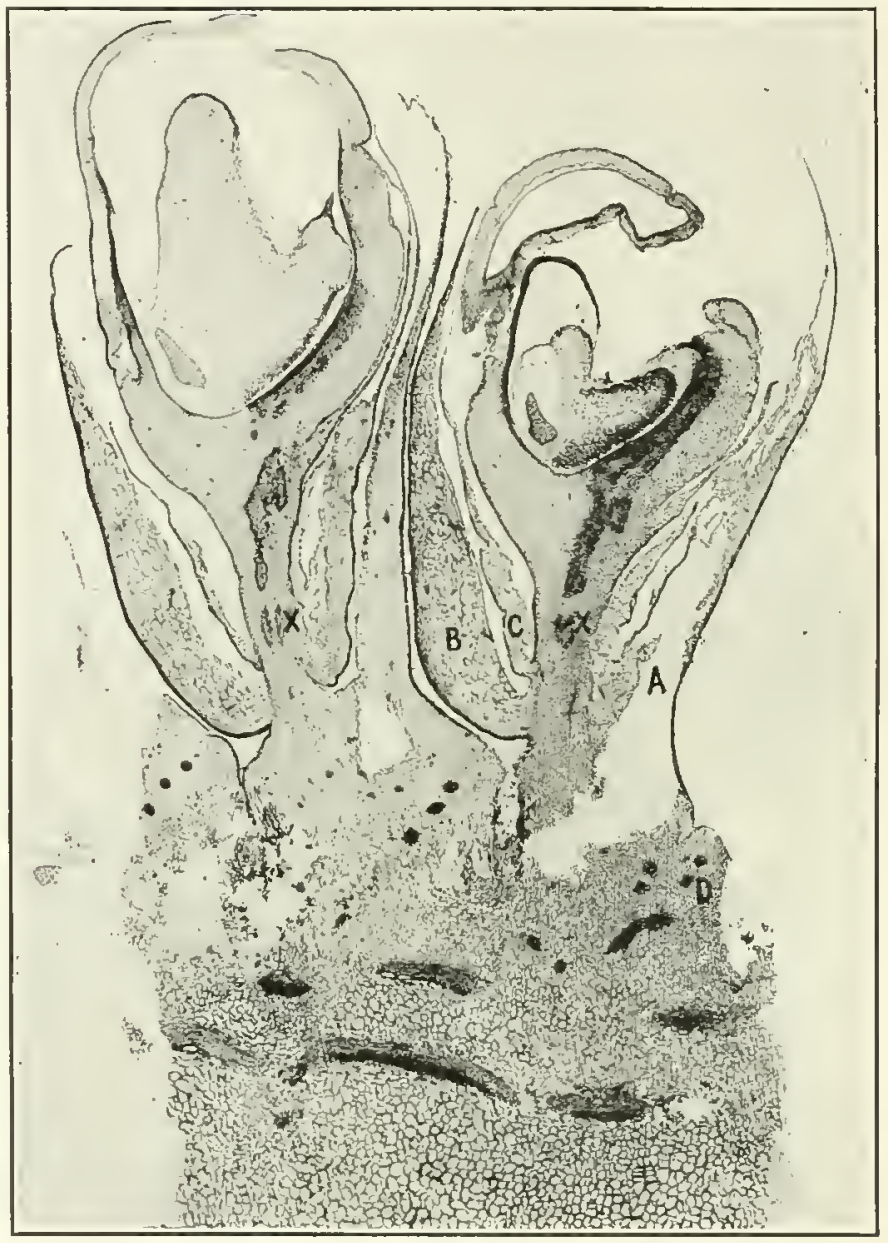

Fig. 45.* seen so contaminating them by Stewart on Long Island and by the writer in Washington (figs. $49,50,5 \mathrm{r}, 52,53$ ).

\section{FIEID OBSERVATIONS OF 1903.}

On July i 8,1903 , the writer, greatly to his surprise, discovered one typical case of the Long Island sweet-corn disease (Bact. stcwarti) in the garden of Mr. Brow11 at Takonia Park,

*FIG. 45.-Bacteritm stewarti in sweel corn. Flats, 1902. Vertical section through two kernels and a portion of the cob, showing the relation of parts: $A$, Floral bract; $B, C$, Scales of the perianth. Those bundles of the cob in which the bacteria are abundant are drawn in solid black. Bacteria also occur sparingly in the base of each kernel at $\mathbf{x}, \mathbf{x}$. This section passes nearly at right angles to that shown in fig. 57 and, therefore, does not include the embryo. Slide $478(6$, stained with pyronine and methyl violet. Drawn from a photomicrograph, but with various details strengthened. Section torn in places, as at $A$. For the appearance of $D$ under a high power see fig. 46. 
Naryland, 8 miles from the experimental gronnds of the Department of Agriculture. The variety was Cosmopolitan and was grown from seed obtained from the Department of Agriculture. Mrs. Brown said the variety came up badly and some stalks died while small.

This plant was abont 3.5 feet high, with three sirckers. The main stalk had a deadwhite inflorescence (all of the flowers were dead and also the upper part of the rachis). The stem was green, but every leaf on the plant was dead or dying. The death of the leaves began witl the lower ones, and the cause was not apparent on the surface.

When the sten was cut + inches from the base, there was a copious yellow ooze from the ressels. I cut it 5 inches under the male inflorescence and found yellow bacteria there also, bnt less abundant. The base of the stem, when slit longitudinally, showed brown nodes and white internodes, with yellow and brown bundles. Two of the suckers appeared to be healthy. 'The bundles of the third sucker at a foot from the ground contained the yellow bacteria in abundance.

It seemed likely that the disease wasintroduced into this garden on the seed, and an inquiry was made as to its origin. It formed part of the Congressional Seed Distribution of the spring of $1903 . \dagger$ It was bought from a reputable seed firm in Philadelphia, for whom it was grown under contract by a seedsman in Ohio. A large amount had been contracted for, but only a small quantity was furnished. The

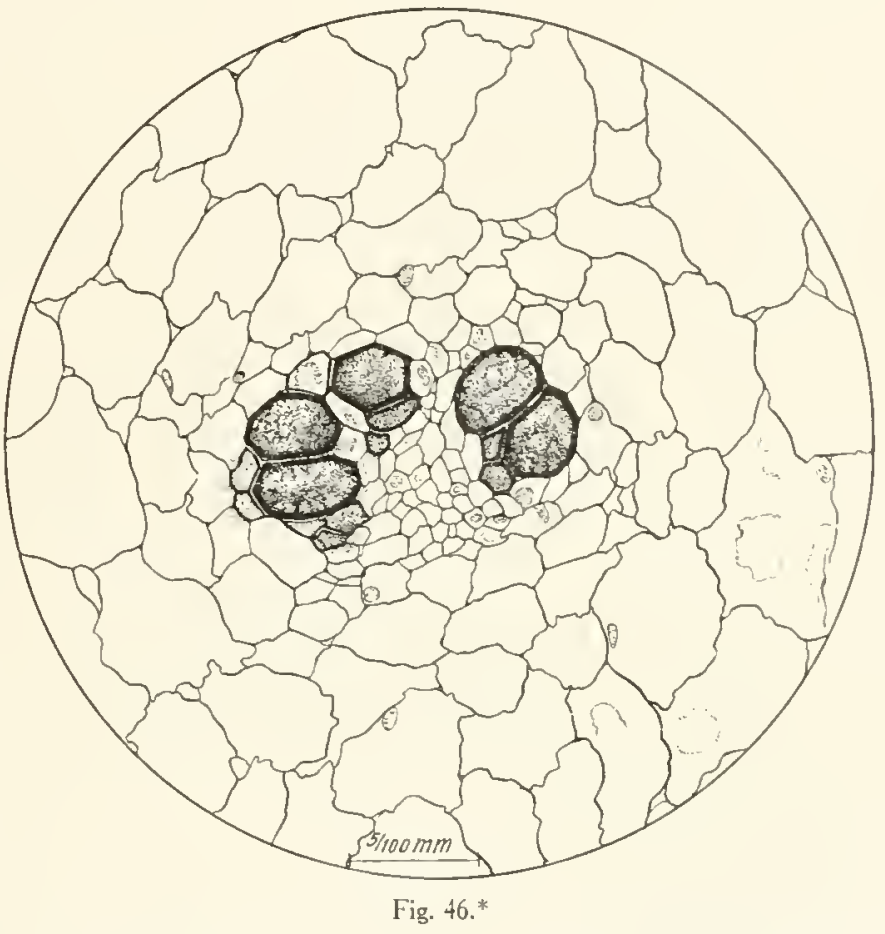
reason for this failure to deliver the seed is given in the following letter of November 5 , I902, addressed to Mr. A. J. Pieters, of the Department of Agriculture:

DEAR SuR: We regret extremely to have to advise you that yesterday's mail brought a letter from the grower of the Cosmopolitan sweet corn stating that this variety is rotting and he will only be able to deliver 20 per cent of the quantity ordered.

Our last previous report on this variety was 80 per cent and it is very disappointing to now be advised of such a terrible "fall down."

Yours very truly,

On inquiring as to where I could find more sweet corn grown from this sanne suspicions seed, Mr. Pieters told me that he had himself directed some of it to be planted along with many other varieties for a trial test on the Potomac Flats (one of the Department farms) sontl of the Nashington Monument. An inspection of these trial plots by the writer

*FIG. 46.-A detail from fig 45, showing in cross-section a vascular bundle from a corn-cob, the $x y$ lem part of which is occupied by Bacterium stewarti.

$\dagger$ Also in 1913. Mrs. Enlows, one of my assistants, found this disease at Parsons, West Virginia, in sweet corn grown from seed distributed by the Department of Agriculture (Congressional Szed Distribution of I9I3). 
revealed an astonishing condition. On July 2 I, I 5 per cent of the Cosmopolitan corn was diseased by Bact. stewarti and a month later there were 21 additional cases, making a total for this variety of 26 diseased plants to 7 sound ones (8o per cent), 7 other plants having disappeared prior to July 21, probably as a result of disease during the seedling stage or soon after. Many other varieties in the plot were more or less diseased.

The subject was of so much interest that the writer made a trip to Wakeman, Ohio, to learn something more concerning the nature of the "rot" which on good land could destroy four-fifths of a crop of seed-corn. The field on which the Cosmopolitan corn had been grown was then planted to other crops and nothing could be learned from an inspection

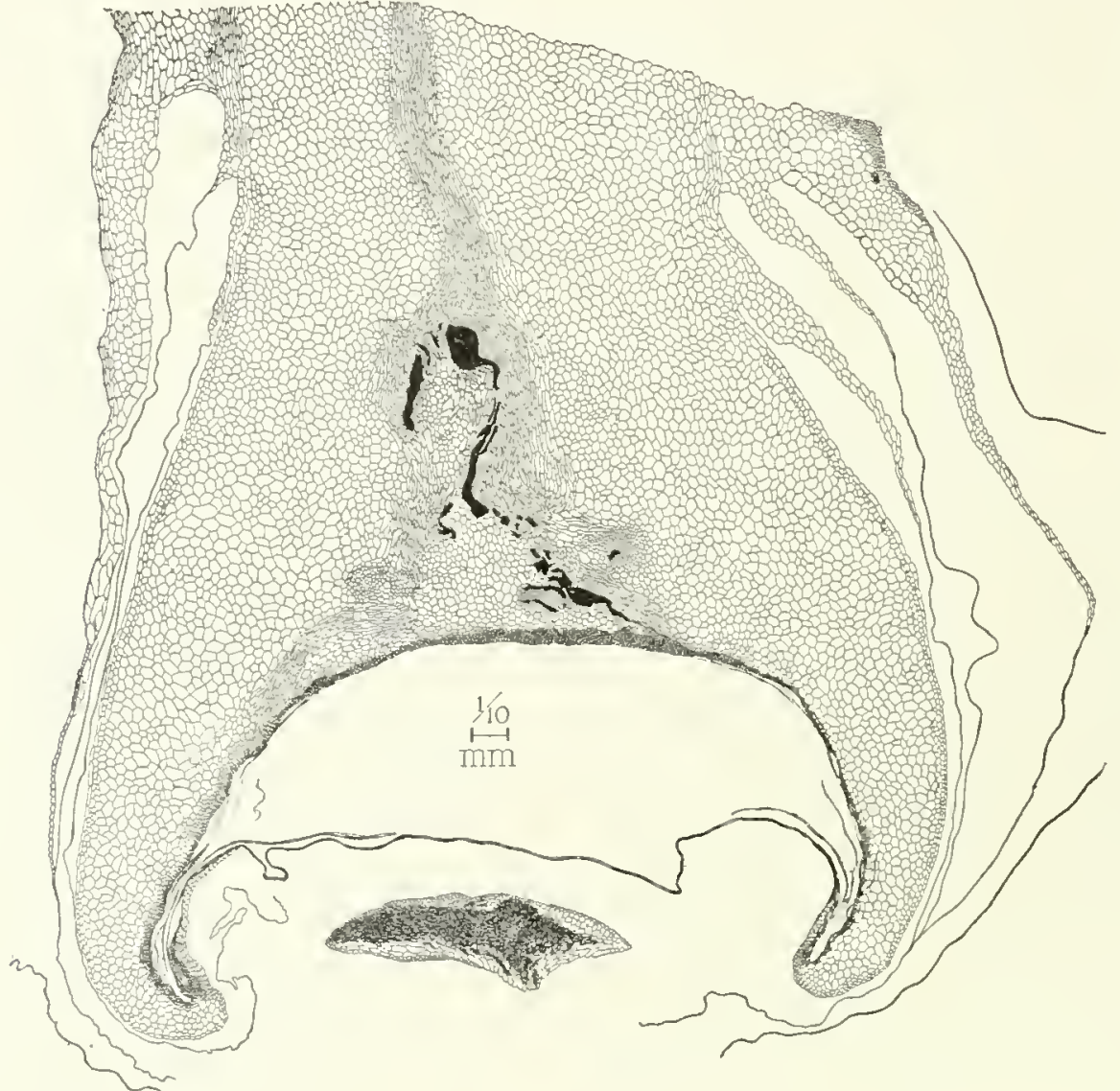

Fig. 47.* of it. It was a level field of good character. The owner of the field, the man who grew the corn, evidently knew much more than he was willing to admit; in fact le was so suspicious and secretive when questioned concerning the nature of this rot that notling of any value was obtained from him, other than the unavoidable inference to be drawn frow the way in which he resented all inquiries. That the rot in his field was due to Bact. stewarti the writer has not the slightest doubt, but it would have been much nore satisfactory and helpful to agriculture if he liad been willing to cooperate in settling the question.

To returu now to the trial plots on the Flats. These were about a quarter mile from n1ny experiments of 1902. Maize had been grown in many varieties, in large tracts, on this farm for several years and this was the first spontaneous appearance of the disease. The chance of its laving come from my experiments of 1902 seemed extremely sliglit. The most reasonable explanation of the appearance of the disease in sucl a severe form was

*FIG. 47.-Bacterium stewarti in sweet corn. Cross-section of outer portion of a cob, showing how the bacteria have penetrated into the base of the immature kernel. They are only in the vascular bundles and their inmediate vicinity (solid black parts). Plant inoculated in August I902, on tips of the leaves in the seedling stage. Material collected and fixed (in strong alcohol) Oct. 27. Figure drawn with the help of the Abbe camera, but numerous nuclei omitted and also certain indistinct tissues in the angles and around the margins of the lunulate area in which the scale of magnification is placed. Slide $235 \mathrm{~B}$ i $q$. For a detail see Fig. 48 . 
that several varieties of seed-corn were infected when planted, yielding some diseased plants early in the season, and that other varieties were infected therefrom. This is the more likely because in some varieties there were frequent skips, whole hills being missing. Inasmuch as this trial plot furnishes the best evidence possessed by the writer on the interesting question of varietal resistance, all the data are given in table 9 for what they are worth, $i . e$., as a suggestion toward future experimentation.

\section{SUSCEPTIBLE AND RESISTANT VARIETIES.}

TABLE 9.-Cases by Varieties on July 2 in Department of Agriculture Trial Rows, Southwest Corner of the Farm on the Potomat Flats, beyond the Stables.

\begin{tabular}{|c|c|c|c|c|}
\hline \multicolumn{5}{|c|}{ Short rows, about 20 plants in each row, some more, some less. } \\
\hline $\begin{array}{l}\text { Trial } \\
\text { No. }\end{array}$ & Source. & Variety. & No. of cases. & $\begin{array}{l}\text { Per cent. } \\
\text { diseased. }\end{array}$ \\
\hline$S_{53}$ & Seed and Plant Introduction $9573 \ldots \ldots$ & Malakoff......... & 4 & 20 \\
\hline 854 & Seed and Plant Introduction $9447 \ldots \ldots$ & Malakoff.......... & 2 & 10 \\
\hline 855 & 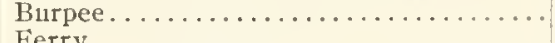 & & 5 & 25 \\
\hline $\begin{array}{l}856 \\
857\end{array}$ & $\begin{array}{l}\text { Ferry } \ldots . . . \ldots \ldots \text { Distribution } 278 \text { (Clarke, } \\
\text { Free Seed }\end{array}$ & $\begin{array}{l}\text { Oakview Early Market.......... } \\
\text { Fxtra Early Red Cory........ }\end{array}$ & $\begin{array}{r}10 \\
7\end{array}$ & 50 \\
\hline 857 & Conn.), double row. & & 7 & 17 \\
\hline 858 & 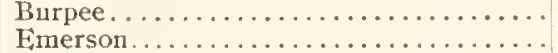 & Fordhook................ & 2 & 10 \\
\hline $\begin{array}{l}859 \\
860\end{array}$ & $\begin{array}{l}\text { Emerson. } \\
\text { Free Seed Distribution } 346, \text { purchased }\end{array}$ & 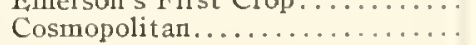 & 3 & 15 \\
\hline & $\begin{array}{l}\text { from Burpee and grown by Clark, } \\
\text { Ohio, double row. }\end{array}$ & & 5 & 15 \\
\hline 861 & $\begin{array}{l}\text { Free Seed Distribiltion 228 (Clark, Conn.) } \\
\text { double row. }\end{array}$ & Metropolitan......... & 2 & 5 \\
\hline 862 & $\begin{array}{l}\text { Free Seed Distribution } 370 \text {, western seed } \\
\text { (Waterloo, Nebr.), double row. }\end{array}$ & Hys' Metropolitan. ......... & 5 & 12 \\
\hline 863 & $\begin{array}{l}\text { Free Seed Distribution 375, western seed, } \\
\text { double row. }\end{array}$ & Crosby's Early........ & 3 & 9 \\
\hline \multicolumn{5}{|c|}{ Long rows, originally 40 plants per row, reduced to an average of 32 per row, according to my count. } \\
\hline 864 & Free Seed Distribution 230 (Clark, Conn.) & Crosby's Early... & 10 & 33 \\
\hline 865 & $\begin{array}{l}\text { Free Seed Distribution 245, Robinson } \\
\text { (Waterloo, Nebr.). }\end{array}$ & .... Do........ & 8 & 25 \\
\hline 866 & Frce Seed Distribution 27 (Clark, Conn.) & $\ldots$ Do................ & 8 & 25 \\
\hline 867 & Free Seed Distribution 305, Robinson... & ....Do................. & *S & 30 \\
\hline 868 & 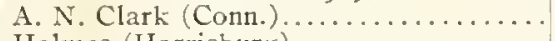 & ...Do, $\ldots \ldots \ldots \ldots \ldots \ldots$ & 10 & 33 \\
\hline 869 & 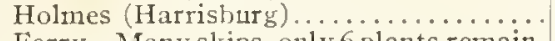 & Holmes' Premo.............. & t5 & 20 \\
\hline $\begin{array}{l}87^{\circ} \\
871\end{array}$ & $\begin{array}{l}\text { Fetry. Many ships, only } 6 \text { plants remain. } \\
\text { Free Seed Distribution } 369 \text {, western seed. }\end{array}$ & $\begin{array}{l}\text { Early Sweet or Sugar............ } \\
\text { Champion Early. . . . . . . }\end{array}$ & $\begin{array}{l}4 \\
2\end{array}$ & 66 \\
\hline & $\begin{array}{l}\text { A good row by the side of two very } \\
\text { poor rows, } 869 \text { and } 870 \text {. Tall corn. }\end{array}$ & 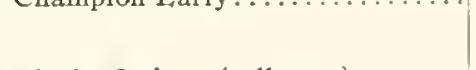 & & 0 \\
\hline 872 & Free Seed Distribution 371 , western seed. & Black Mexican (tall corn) . . . . . . & 5 & 15 \\
\hline 873 & $\begin{array}{l}\text { Free Seed Distribution 352, Phillips ('To- } \\
\text { ledo, Ohio). }\end{array}$ & $\begin{array}{l}\text { Potter's Excelsior. (Fine growth; } \\
\text { full row.) }\end{array}$ & 0 & o \\
\hline 874 & Free Seed Distribution 373, western seed. & $\begin{array}{l}\text { Egyptian (tall corn; the one case } \\
\text { a dwarf). }\end{array}$ & 1 & 3 \\
\hline 875 & A. N. Clark, Conn.... & Potter's Excelsior................ & 1 & 3 \\
\hline 876 & Do................... & Country Gentleman (4 skips).... & o & o \\
\hline $\begin{array}{l}877 \\
878\end{array}$ & $\begin{array}{l}\text { Free Seed Distribution 227, Clark, Conn.. } \\
\text { Free Seed Distribution 270, Clark, Conn.. }\end{array}$ & 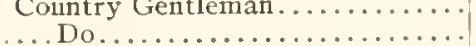 & $\begin{array}{l}0 \\
0\end{array}$ & $\begin{array}{l}0 \\
0\end{array}$ \\
\hline 879 & $\begin{array}{l}\text { Free Seed Distribution 276, Clark (seed- } \\
\text { house floor). }\end{array}$ & 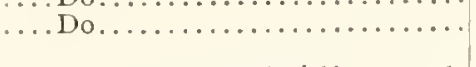 & I (slight) & 3 \\
\hline 880 & Free Seed Distribution 229, Clark, Conn. & $\begin{array}{l}\text { Hickory Improved (dise ased } \\
\text { plants, very small). }\end{array}$ & 2 & 6 \\
\hline 881 & Free Seed Distribution 275, Clark, Conn. & $\begin{array}{l}\text { Hickory Improved (both large } \\
\text { plants, slightly affected). }\end{array}$ & 2 & 6 \\
\hline 882 & A. N. Clark, Conn.... & Hickory Sugar................ & 4 & 11 \\
\hline
\end{tabular}

*And some skips.

†Skips and inferior plants. 
TABLE 9-Continued.

\begin{tabular}{|c|c|c|c|c|}
\hline \multicolumn{5}{|c|}{ Originally 40 plants per row, now an average of 35.} \\
\hline $\begin{array}{l}\text { Trial } \\
\text { No. }\end{array}$ & Source. & Variety. & No. of cases & $\begin{array}{l}\text { Per cent, } \\
\text { diseased. }\end{array}$ \\
\hline 883 & Free Seed Distribution 372 , western seed. & Old Colony............. & o & 0 \\
\hline 884 & Free Seed Distribution 231, Clark, Conn. & 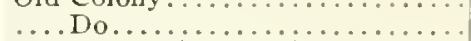 & 0 & 0 \\
\hline 885 & Free Seed Distribution 272, Clark, Conn . & oid Colony (one skip)... & o & 0 \\
\hline 886 & 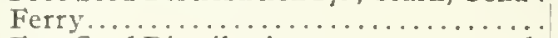 & Old Colony (four skips)........ & 0 & 0 \\
\hline 887 & Free Seed Distribution 374, western seed. & Zig Zag Evergreen............ & o & 0 \\
\hline 888 & 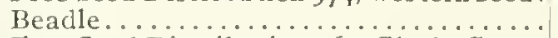 & Beadle's Mammoth Evergreen... & 3 & 8 \\
\hline 889 & Free Seed Distribution 269, Clark, Conn. & Stowell's Evergreen............. & o & 0 \\
\hline 890 & Free Seed Distribution 210 , Cushman... & $\ldots$ Do................. & 0 & o \\
\hline 891 & A. N. Clark, Conn................. & 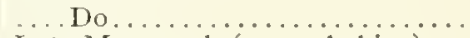 & 1 & 3 \\
\hline 892 & Free Seed Distribution $277, \mathrm{Clark} . . .$. & Late Mammoth (several skips)... & 2 & 6 \\
\hline 893 & 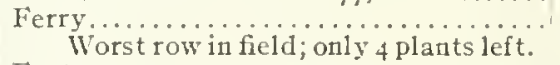 & Mammoth (many skips; all dwarf). & I & 20 \\
\hline 894 & $\begin{array}{l}\text { Eastman .................................... } \\
\text { A half row, of which no plants now } \\
\text { remain, } i_{.} e_{0} \text {, after pulling ont these } 4 \text {. }\end{array}$ & Golden Hybrid.............. & 4 & 100 \\
\hline 895 & $\begin{array}{l}\text { Burpee . } \\
\text { A half row, } i . e_{.}, \text {about it io plants. }\end{array}$ & Sheffield.......... & o & 0 \\
\hline \multicolumn{5}{|c|}{ Field corns. } \\
\hline 896 & Free Seed Distribution 253, Woods.... & 'Truckers' Favorite (very tall).. & o & o \\
\hline 897 & Free Seed Distribution 40, IVoods... & White Dent (very tall)....... & 0 & 0 \\
\hline 898 & Free Seed Distribution 42 , Woods..... & White Dent.............. & o & o \\
\hline 899 & Free Seed Distribution 44 , Woods...... & $\ldots D_{0} \ldots \ldots \ldots \ldots \ldots \ldots$ & 0 & 0 \\
\hline 900 & No firm name (half row).......... & 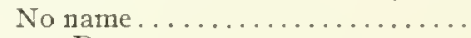 & 3 & 14 \\
\hline \multirow[t]{2}{*}{901} & No firm name (half row). & $\ldots$ Do $\ldots \ldots \ldots \ldots$............ & 7 & 33 \\
\hline & Total cases.... & & 140 & $\ldots$ \\
\hline
\end{tabular}

Those varieties most subject were: Oakview Early Market, Crosby's Early, Cosmopolitan, Extra Early Red Cory, Holmes' Premo, Early Sweet or Sugar, Black Mexicarl, Golden Hybrid, Golden Bantan, Hys' Metropolitan, 900, 90I, and Malakoff. All early sorts except Black Mexican, which is medium and very sweet.*

Those sweet corns nearly free were: Champion Early, Potter's Excelsior, Eigyptian, Country Gentleman, Old Colony, Zig Zag Evergreen, Stowell's Evergreen, and Sheffield. All of these are late varieties except Champion Early and Sheffield.

On August 22, in my absence, Mr. Rorer began for me a second count of cases (new cases) in the trial rows on the Flats, but was unable to finish it. His notes, as far as they go, are given below:

853 [Malakoff].--No live stalks at all. Tassels all dried up and leaves on every stalk entirely dry and brown. No good ears at all. Most of them are smutted.

Cases, I2. Nearly every stalk was diseased by the bacteria.

$85+$ [Malakoff]. - Presents same general appearance as 853 .

Cases, 11 ; sound, 2 .

855 [Golden Bantam].-Looks same as 853 and 854 .

Cases, I I; sound, o. Two stems were entirely rotted away, so that condition of bundles could not be made out. In all these cases almost every bundle showed yellow ooze.

856 [Oakview Early Market].--All dead. Only 6 stalks.

Cases, 5 . One stem too badly rotted to make anything out as to bundles.

857 [Extra Early Red Cory].- - A little better-looking row. The stems are taller and some of the leaves are more or less green. None look very healthy, however, so have cut all out. Cases, 23 ; solnd, 13.

858 [Fordhook]. - Very bad-looking lot. All stems entirely dead and leaves dry and shriveled.

Cases, 13; doubtful 2 ; sound, 1 . Two stems too much decayed to make out bundles.

* In his bulletin Stewart states that on Long Island the disease is most destructive to early varieties. According to observations made by the writer in 1909 at Kensington, Maryland, the variety Pocahontas is also much subject to the disease. This is a small early sort. 


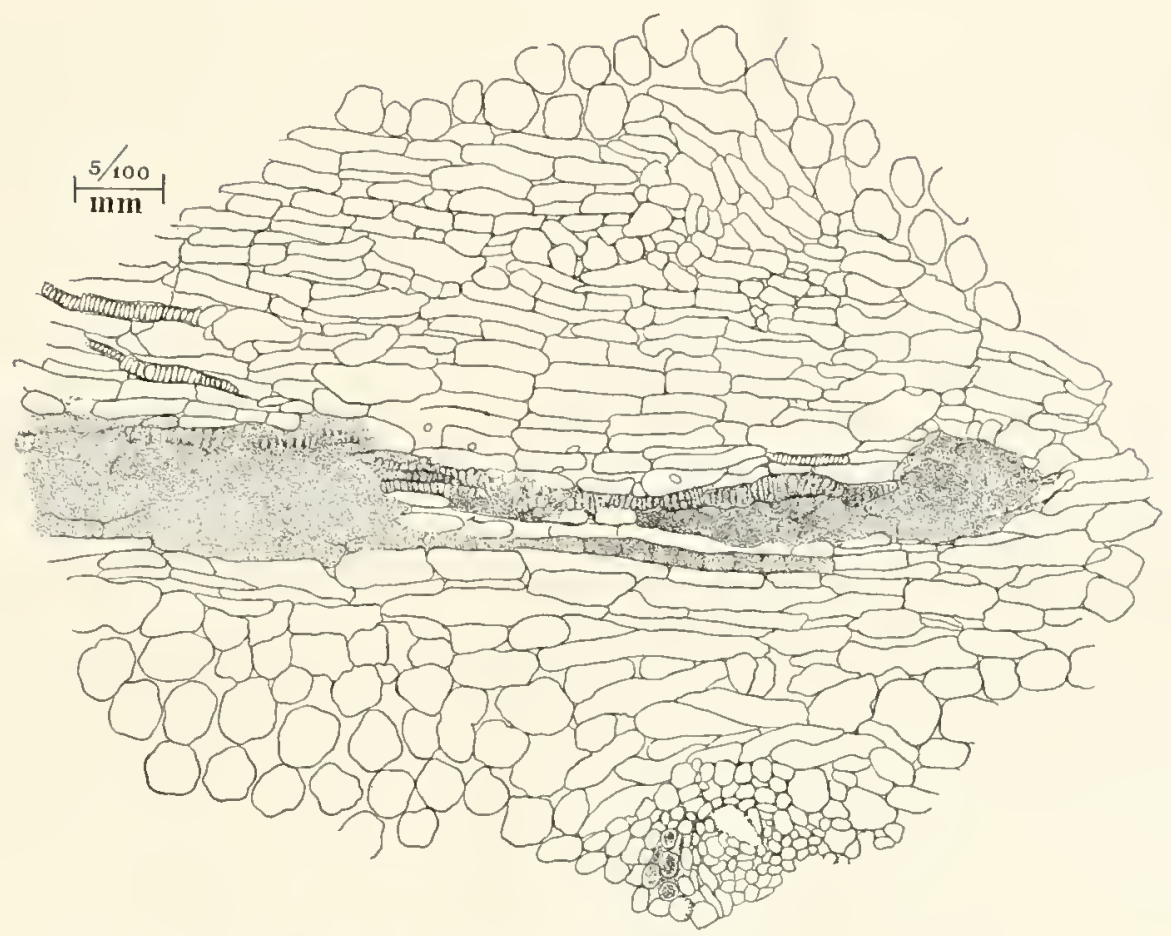

Fig. 48.*

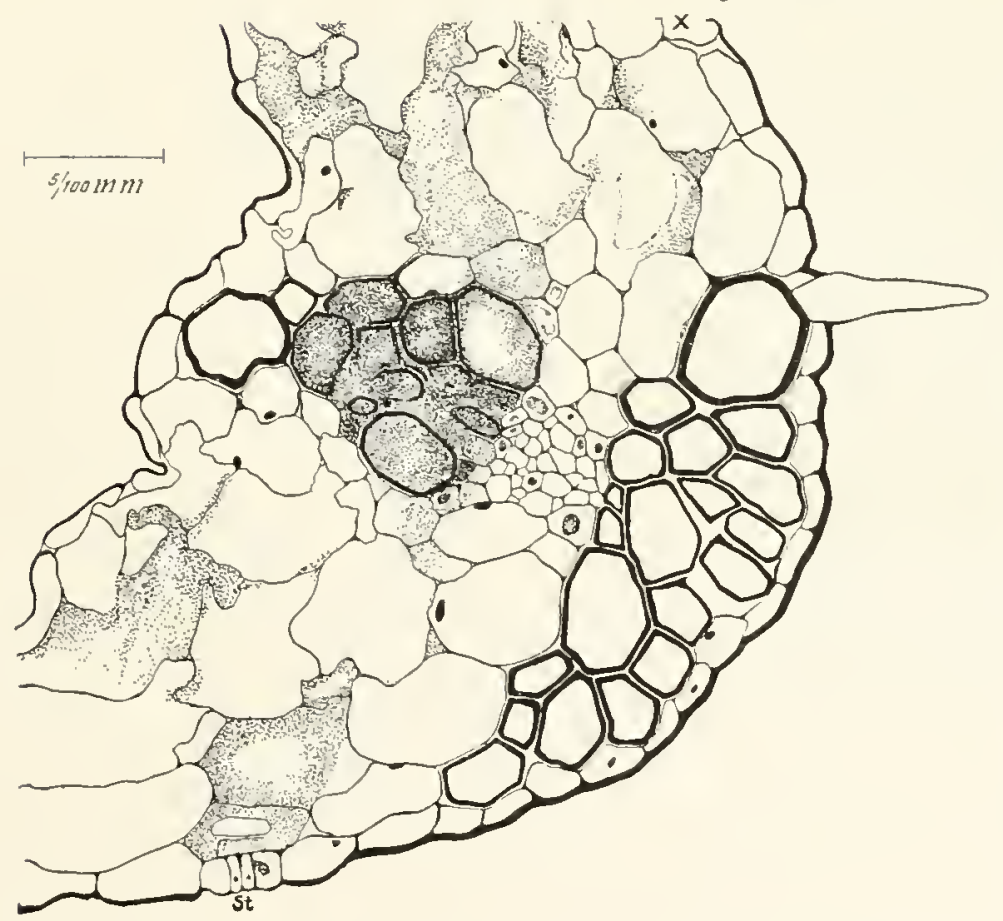

Fig. 49.†

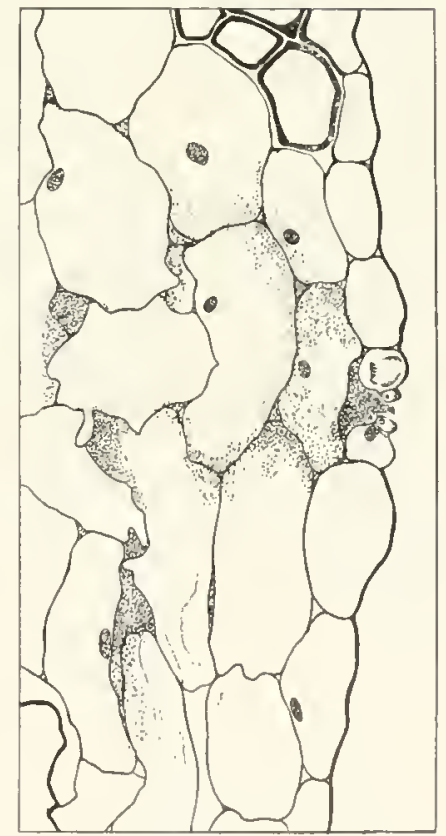

Fig. $50 .+$

*FIG. 48. - Section of periphery of a sweet-corn cob, showing Bacterium stervarti filling the vascular bundles and forming closed cavities in base of kernel. For orientation sce fig. 47. Drawn under Abbe camera. Slide 235 B 1.4 .

$\dagger$ Fig. 49. - Cross-section of husk of sweet corn occupied by Bacterium stewarti. Bactcria oozing to the surface on many parts of the husk. From a pure-culture inoculation made in Angust on the leaves in the seedling stage (Potomac Flats experiment). Material collected and fixed in alcohol Oct. 2I, I902. Stained with carbol-fuclisin. Drawn with Zeiss $8 \mathrm{~mm}$. apochromatic objective, No. 12 compensating ocular and Abbc camera, Slide 477 A 2, lower row. The stoma shown in fig, 50 lies on the next section at $\mathbf{x}$.

$\ddagger$ FiG. 50.- Husk of sweet corn, showing Bacterinm stewarti making its way to the surface throngh a stuna. These bacteria undoubtedly cane from the crowded vascular bundle shown in fig. 49 . Slide $477 \mathrm{~A} 2,10 w e r$ row. 
859 [Emerson's First Crop].-Very bad looking.

Cases, 8 ; sound, 0 .

860 [Cosmopolitan]. - All stems dead, with dried tassels and brown leaves.

Cases, 21 ; sound, 7 .

86I [Metropolitan]. - A slightly better stand, but most of the plants show the external signs of the disease. Cases, I 8 ; sound, I 2. Some of these cases showcd only one or two butudles affected.

862 [Hys' Metropolitan]. - Looks about like $86 \mathrm{r}$. Many plants show external signs of disease, but there is a better stand that in the first four or five rows.

Cases, 14; sound, 14. Of the diseased stems in this lot 5 or 6 had ouly one or two bundles diseased.

863 [Crosby's Early]. - Looks diseased, but is a rather better stand than others.

Cases, 15 ; sound, 15 . Some of the cases only slightly diseased.

A little of this seed corn remained undistributed in the hands of the Free Seed Distribution officials of the Department of Agriculture. As soon, therefore, as possible after the discovery of the above-mentioned facts respecting infection of the trial rows, $i . e$., the same summer, the writer procured a quantity of the corn and had it planted on another farm.

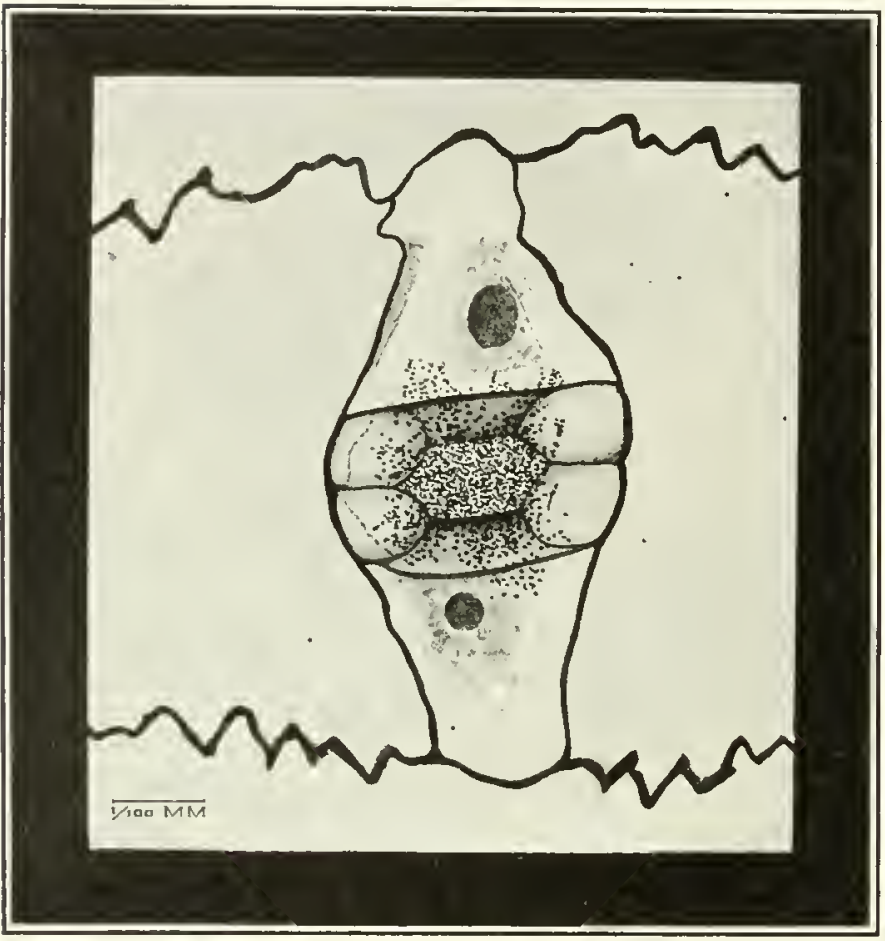

Fig. 51.*

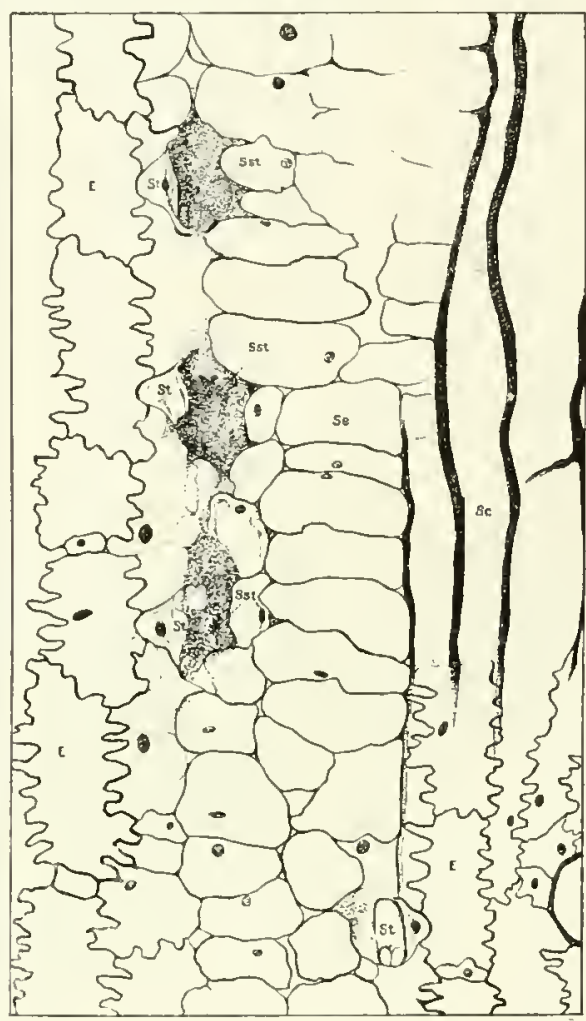

Fig. 52.†

The place selected was an old field on the Arlington estate, one which certainly had not been planted in maize since before the Civil War, i.e., for more than 40 years, and perhaps never. This field is about a mile and a half from the trial plots just described, on the other side of the Potomac River, and there was very little communication between the two farms, $i$. $\ell$., the management used different teams and tools and another set of farm laborers. Here, if anywhere, one might expect to get the uncomplicated effect of the seed, since we

*FIG. 5 I. - Surface of a corn-husk highly magnified, showing a siugle stoma with Bacterium stervarti oozing to the surface. The conditions immediately under such a stoma are shown in figs. 50 and 52. Slide 477 B 1 . From a plant inoculated in the seedling stage. Collected Oct. 21, 1902, Potomac Flats.

†FIG. 52.-Surface view of husk of sweet-corn attacked by Bacterium stewarti. Surface slightly curved, so that the microtome knife has removed the greater part of the epidermis (crinkly-walled cells) laying bare the deeper tissues $E$, remuant of epidermis; $S e$, sub-epidermal tissue; $S c$, sclerenchyma strand; $S t$, remnants of stomata, about all that is left of the three upper ones being a portion of the mother cell on the left side (see figs. 50 and $5 \mathrm{I}$ for orientation); Sst, substomatic chambers filled with bacteria. Platut inoculated in August in the seedling stage by placing bacteria on the tips of the leaves. Collected October $2 \mathrm{t}, 1902$, from Potomac Flats. Slide 477 A 8, stained with carbol fuchsin. 
have 110 evidence of any general distribution of this organism in agricultural soils, rather the contrary, outside of districts where sweet-corn is grown, and since in many bacterial diseases, both plant and animal, we have an enormous amount of evidence tending to slow that the pathogenic bacteria are not carried far by the wind; or, if so carried, do not induce disease.

I reasoned as follows: If the case or cases of this disease at Takoma Park and those which appeared in the trial-rows on the Flats were due to local causes, $i$. e., to organisms already present in the soil, and not to infected seed, then the plants grown from the sane lot of seed-corn on Arlington Farm should be healthy. If, on the contrary, Bacterium stcwarti was present in a living condition on any great number of the kernels, then the rest1t would be the same as at Takoma Park and in the trial-rows, $i, c$, many cases of the disease, and the disease would appear first in those varieties carrying the organism into tlie field, however much it might become infectious to neighboring varieties later in the season.

The second of these two suppositions is exactly what happened. My notes on this experiment are as follows:

SERIES XI TO XV, 1903.

About 3 acres of sweet corn were planted at the Arlington Farm on July 29 and $3^{o}$. The seed came from Mr. Pieters, and was the same as that used for his trial rows, $i, e$, of same origin. The ground was not in very good condition, not liaving been harrowed enough. The land slopes gently from east to west. There is a ditch on the west side and the west end is perliaps 25 feet lower than the east end. The rows ran east and west. The plots were not check-rowed, but seed was dropped by liand, the hills being made about 3 feet apart. Five standard varieties of corn were plantedOld Colony, Potter's Excelsior, Cosmopolitan, Country Gentleman, and Crosby's Early. Beginning at the soutl end, the

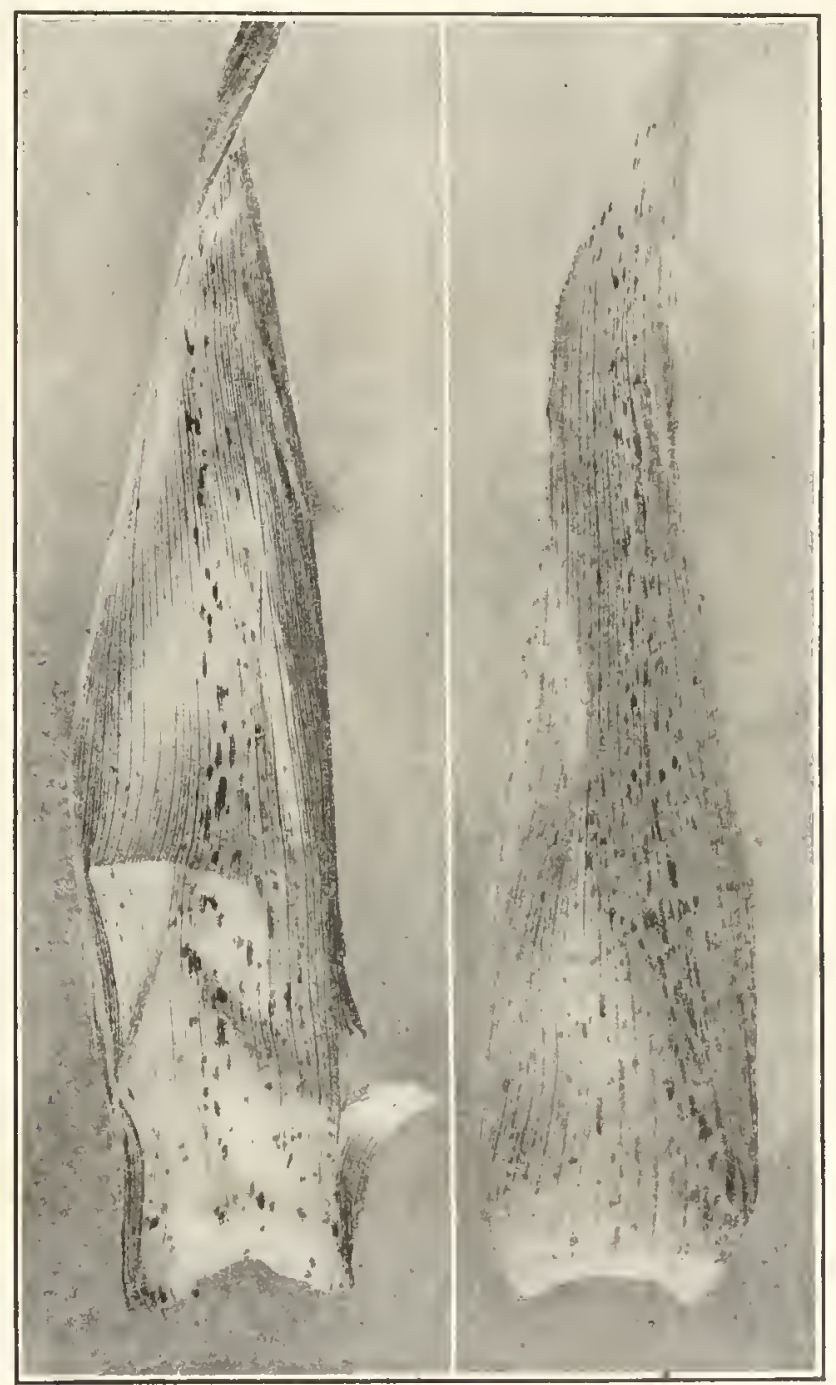

Fig. 53,* plots were as shown in table to (between the plots a row was skipped, making a distance of 6 feet only between varieties).

The italicized varieties are those suspected of harboring Bact. stewarti on their kernels. The other varieties are some of those which were nearly or quite free from disease in Mr. Pieters's trial-rows on July 2 I and were not suspected. On leaving the city for the summer the writer left word to have then re-examined in August, but unfortunately this was 11ot done.

*FIG. 53.- - Inner husks of Golden Bantam sweet-corn, showing yellow spots (black arcas) due to Bacterium stewarti. Vascular system badly diseased. Slime oozing on the kernels. A natural infection obtained by planting diseased seeds which formed part of a Congressional seed distribution. Hot-house experinent of Igos (see text), 
Septembor 28, 1903.-Looked at the sweet corn on Arlington Farm. There are large patches in the middle of the field where the seed did not come up at all (stiff soil). There is not a good stand anywhere except the first two rows on the south side. Some of the plants look as though they were going to be diseased.

Cut out 6 typical cases from the Crosby's Early plot and 2 cases from the Cosmopolitan. There is minquestionably much more disease, but the plants will be allowed to remain a little longer, so that the signs may become more evident.

TABLE 10.-Varieties Planted and Bchavior on the Other Farm.

\begin{tabular}{|c|c|c|c|}
\hline \multirow{2}{*}{ Variety. } & \multirow{2}{*}{ Anount planted. } & \multicolumn{2}{|c|}{$\begin{array}{l}\text { Per cent found diseased in Mr. } \\
\text { Pieters's trial rows on the other farm. }\end{array}$} \\
\hline & & July 21 . & August 22. \\
\hline 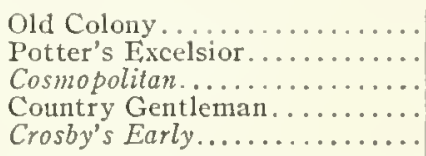 & $\begin{array}{l}14 \text { rows...... } \\
12 \text { rows.... } \\
24 \text { rows.... } \\
12 \text { rows. } \\
12 \text { rows..... }\end{array}$ & $\begin{array}{r}0 \\
3 \\
* 15 \\
3 \\
24\end{array}$ & $\begin{array}{l}\text { No record. } \\
\text { No record. } \\
\quad 80 \\
\text { No record. } \\
\quad+54\end{array}$ \\
\hline
\end{tabular}

* 30 per cent, if the missing plants are included as diseased.

tone only of the six strains of this variety, and the one showing least disease in July. The others were not examined in August.

October I9, I903.-Tenny and Rorer cut ont and examined every plant in the I 4 rows of Old Colony sweet corn planted on July 29 at the Arlington Farm. The corn at the lower (west) end and in the first two rows (south side next the fence row) was about 3 or 4 feet high and well tasseled out and looked fairly well. In the upper (east) and central part of the plot, however, the corn had made a very poor growth, many of the plants being only about a foot ligh and less than half an inch in diameter (due to poor soil). The examination resulted as follows:

\section{OLD COLONY.}

Stalks found to be healthy, 6,235; stalks found to be diseased, 65 .

Total, 6,300; diseased, I per cent.

Many of the diseased stalks showed only two or three yellow bundles, while only a few were very badly diseased. Some of the most badly affected were put into alcohol.

October 2.7 and $27,1903 .-$ The other varieties of corn were cut and examined by the writer, assisted by Messrs. 'Tenny, Rorer, and Deane B. Swingle, with the following results:

\section{COSMOPOLITAN.}

Stalks found to be healthy, $\mathrm{I}, 905$; stalks found to be diseased, 366 .

Total, 2,27I; diseased, I6 per cent.

It appeared on the start that there were many more cases in the lower moister land, where the corn had made the best growth, than on the side hill or the level land on the top. When classified in this way the result shown in table 11 was obtained:

TABLE, I I.-Eeffect of Slow Growth on General Infection.

\begin{tabular}{|c|c|c|c|c|}
\hline Kind of ground. & $\begin{array}{l}\text { Ilealthy } \\
\text { stalks. }\end{array}$ & $\begin{array}{l}\text { Diseased } \\
\text { stalks. }\end{array}$ & Total. & $\begin{array}{l}\text { Per cent, } \\
\text { diseased. }\end{array}$ \\
\hline 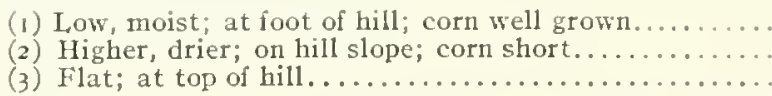 & $\begin{array}{l}754 \\
605 \\
546\end{array}$ & $\begin{array}{r}233 \\
38 \\
75\end{array}$ & $\begin{array}{l}987 \\
663 \\
621\end{array}$ & $\begin{array}{r}24 \\
9 \\
12\end{array}$ \\
\hline
\end{tabular}

Owing to the labor involved and the bad weather the entire plot was not counted, but only average portions of it. The same method was followed with the remaining varieties; the only variety connted in full being Old Colony.

\section{Country Gentleman.}

Healthy stalks, 88I; diseased stalks, 32 .

Total, 9I3; diseased, 3.5 per cent. 
The variations in the plot were not great, as may be seen from selected portions (table 12).

TABLE 12.- Showing that Kind of Soil Makes no Difference when Seed is not Infected.

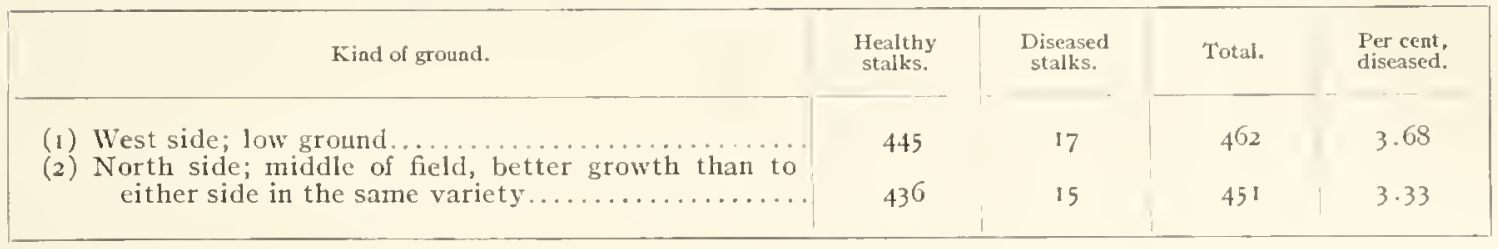

\section{CROSBY'S FARLY.}

Healthy stalks, 2,171 ; diseased stalks, 437 .

Total, 2,608; diseascd, 17 per cent.

Arranged in three groups according to amount of soil-moisture and vigor of the plants, the same results follow as in the case of the Cosmopolitan:

TABLE 13. - Showing that Moist Soil is Favorable to Development of the Disease when the Organism is Present.

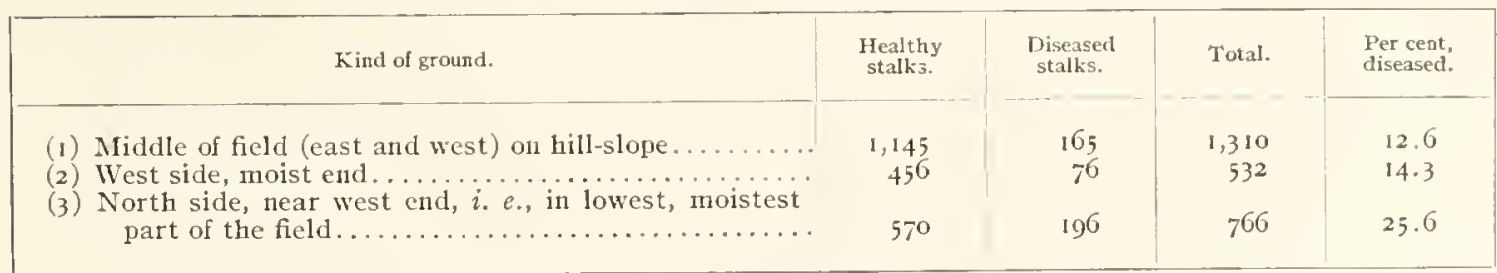

This corn was larger than any other variety except the south two rows of Old Colony.

\section{POTTER'S EXCELSIOR.}

Healthy stalks, 2,227; diseased stalks, 44 .

Total, $2,27 \mathrm{r}$; diseased, 2 per cent.

Arranged in groups according to soil-moisture and size of plants, the above count gave practically the same results as the Country Gentleman:

TABLE I 4. - Showing that Moist Soil has no Injurious Influence in Absence of the Parasite.

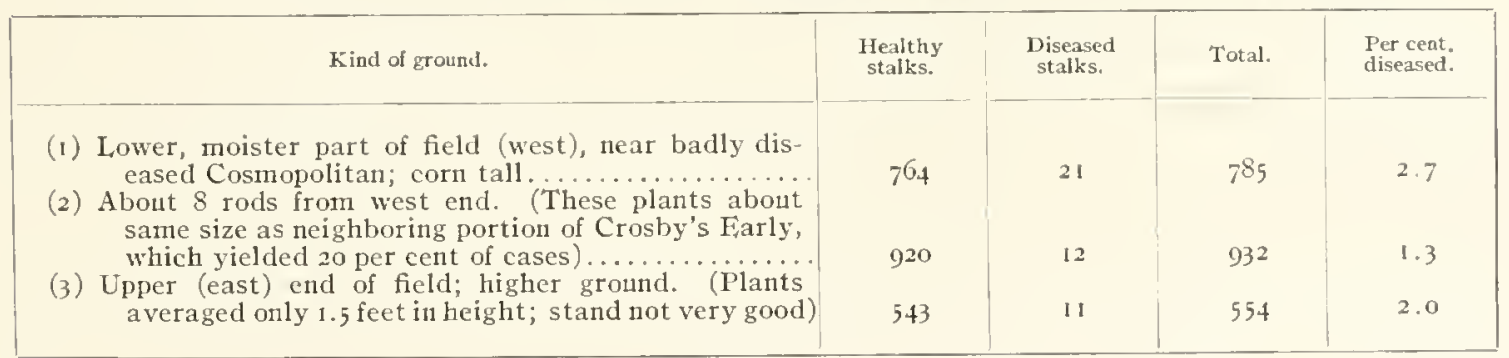

\section{SUMMARY.}

The above facts may be summarized as follows:

TABLE 15.-Per cent of Cases by Varieties and Soil.

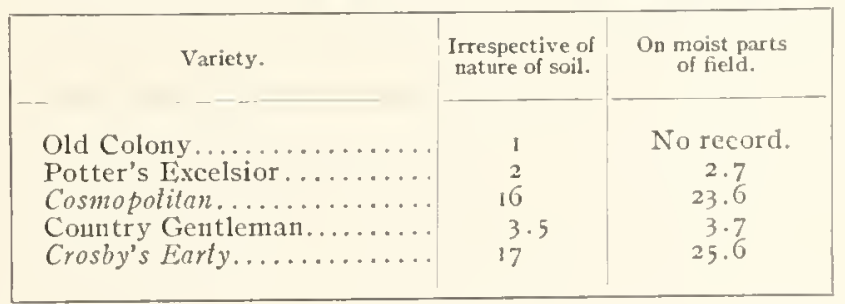


The results at Arlington agree substantially with those obtained from the trial-rows on the other farm. In both Cosmopolitan and Crosby's Early they point unmistakably to infection of the plants from the seed-corn. In the other three varieties the cases are so few that they may have arisen from proximity to the two diseased varieties. It is not difficult to understand how this could have taken place in blocks of healthy plants sandwiched in between diseased ones, provided some of the latter developed the disease early in the growing season. If the disease was actually derived from the seed-corn there probably would have been some cases during the seedling stage, and fragments of these soft plants full of the bacteria would have been blown upon neighboring plots, or dragged by cultivators, or carried on the feet of men and horses, or bitten into by insects, or washed about by rains and dews. There are ways enough to account for the dissemination of the bacteria and the infection of a few plants where the distance is only a matter of a few feet. When plants are well past the seedling stage there is much less danger of infection, even though the infectious material is then nuch more abundant. That a larger number of cases did not occur in the Crosby's Early and the Cosmopolitan is attribitable to the poor soil and slow growth as compared with that on the Flats and probably also to the gradual dying out of the bacteria on the seed-corn between spring, when the first plantings were made, and midsummer, when the last plantings were made.

The experiment is equally interesting, however, if we assume all of the seed-corn to lave been free from Buct. stewarti. In such event the organism causing the disease must have been present already in the soil of the field. If for the sake of argument such a supposition be granted (and it can be granted for no other reason), it certainly stretches the limits of probability to assume also that the organism was prevalent only in those narrow strips where Crosby's Early and Cosmopolitan corn liappened to be planted. If the organism was present in the soil it is likely to have been there a long time and to have been pretty uniformly distributed, just as it is in the infected soils on Long Island. Granted these premises, then we may assume that 3 of the 5 varieties tested are very resistant to the disease, and are, therefore, desirable varieties to plant on infected land, and important to use as one parent in originating resistant varieties by cross-breeding. The other two varieties, on the contrary, should never be planted on infected land.

Subsequent experiments showed that an abundance of moisture stimulating rapid growth is very farorable both to primary infection during the seedling stage, and also to the gencral distribution of the bacteria through the stem of the plant later on. On the contrary, dry soil and dry weather following planting interferes with infection, and any decided check in growth later in the season interferes with the movement of the organism through the plant by hardening the basal nodes and thus rendering it difficult for the organism to get past them. In infected plants, however, the disease shows sooner, according to Stewart, in periods of drouth than in rainy weather. The writer has observed the same thing in diseased Cucurbitaceae (see this monograph, Vol. II, pp. 216, 284).

\section{EXPERIMIEN'TS OF 1908.}

In 1908, Golden Bantan sweet corn attacked by Bacterim stewarti was sent to 11 e from a garden in Falls Chnrch, Virginia, with the statement that the seeds were obtained from a Philadelphia seedsman, who was believed by the planter to have sold him bad seeds, because nearly all the plants of this variety were badly diseased, while other varieties obtained elsewhere showed no disease or only very little. I asked the dealer where he procured the seed of this variety and he said it came from Mr. - - . IVakeman, Ohio, the man to whose farm I traced the disease in 1903.

'This interesting fact led me to procure a half-busliel of this particular lot of seed (all the dealer had left) for experiment. The first endeavor was to isolate Bacterium stewarti from the surface of the kernels. In this effort we failed. The organism may have been 
present, but not alive after so many months. Several kinds of yellow bacteria were obtained in abundance from the numerous poured-plates, but none corresponded exactly to Bacterium stewarti. Many resembled it in the agar-poured-plates, but all of the hundred or more colonies selected as hopeful differed in some particular, $i$. $\iota$., either they grew differently on potato, or coagulated milk, or liquefied gelatin, or clouded Colın's solution, or refused to grow in Uschinsky's solution, or formed gas, or rapidly reddened or blued litmus milk, etc. They were checked up against three strains of Bacterim stewarti obtained from as many different localities. One form in particular, designated as " $\mathrm{N}_{1}$," which appearcd as though it might be Bacterium stewarti (before additional cultural tests were made which threw it out) was pricked into the leaves of young plants of this variety of sweet-corn copiously, but no disease resulted.*

This failure to obtain Bacterium stewarti believed to be present on the kernels is probably to be attributed to the presence in abundance of non-parasitic yellow bacteria on the surface of the corn, while the right organism occurred in a viable form in very small numbers or not at all, so that on the poured-plates it either did not appear or occurred in such small numbers as to be overlooked, the problem of finding it on agar-poured-plates under such conditions being a difficult one. Probably if we had cultured from crushed kernels we would have obtained the organism. This conclusion is borne out by the following experiments.

\section{SERIES XVI TO XIX, 1908.}

On July 23, 1908, a center bed extending the whole length of one of our large hot-liouses was planted to tlis corn. Hitherto corn had never been planted in this house. Orange trees of large size stood in this earth and had done so for many years. The trees were grubbed out, the soil was spaded, a little bone meal was added, and then the suspected corn was planted thickly in rows crosswise of the bed, at a distance apart of about is inches. The bed was divided crosswise into four portions as follows: $(\mathbf{r}, 2)$ two plots planted with selected sterilized seed; (3) one plot planted with untreated seed just as it came from the original sack; (4) one plot planted with the most inferior looking kernels in the sack (also untreated).

The crop was harvested on October 6 to 9 . Cross-sections of every stem were examined under the hand-lens by the writer. Some were also examined under the conponnd microscope and many were put into alcolol for future use. The results were as follows:

(1) Selected (hand-picked) good-looking seed, soaked I5 minutes in 1 : 1000 mercuric chloride water, rinsed in tap-water, and immediately planted (I I rows):

Number of healchy plants, 1,090; number of diseased plants, r 3.

Total, 1, 103; per cent diseased, I.2.

Remarks. - None of the affected plants were badly diseased. The record is as follows: Eleven slightly diseased, 2 of which had open wounds on the stem above. Only one bundle visibly infected in most of these. Bacteria visible only in the basal part of the stem. 'The twelfth had 3 diseased bundles, and the thirteenth, which contained several bundles occupied by yellow bacteria, had one whole internode above soft-decayed. Possibly those with bruised or wounded stems should have been omitted from the record. None had yet reached the stage of shriveling leaves.

(2) Selected (hand-picked) good-looking seed, soaked ro minutes in I : 1000 mercuric chloride water, rinsed in tap-water, and immediately planted ( 12 rows):

Number of healthy plants, 1,277 ; number of diseased plants, 23.

Total, 1,300 ; per cent diseased, 1.8 .

Remarks. - Two plants with 3 bundles infected; 19 slightly diseased (a few bundles in the lower part of the stem); 2 badly diseased, both having many bundles occupied by the organism and the leaves dried out. In one, the stem was infected the whole length, and toward the base nearly every bundle was occupied by the yellow slime.

*In 1904, Miss Florence Hedges, of my laboratory, obtained similar negative results on a much larger scale, using a yellow organism supposed at first to be Bact. stewarti, but afterwards found to behave differently on certain media. Three hundred sweet-corn plants were inoculated very thoroughly on the leaf tips when the seedlings were extruding water, but no disease resulted. 
Assuming the kernels to have been the carriers of the organism, the failure of the relatively long soaking in mercuric chloride water would seem to indicate either that the bacteria escaped destruction because tliey were inside the kernels, or else because they were protected from the action of the germicide by being massed together in dried-down hard crusts, the former being the more probable explanation. Certainly all those freely exposed on the surface of the kernels must have been destroyed.

(3) Unselected, unsterilized seed (20 rows):

Number of healthy plants, 1,5.48; number of diseased plants, 156.

Total, 1,704 ; per cent diseased, 9.0.

Remarks. - Of these plants 24 were slightly diseased; 25 moderately diseased; and 52 badly diseased. No remarks on the remainder. Comments on some of the badly diseased will be of interest as showing the extent of infection:

One badly diseased: Bacteria as far up as the cob, and also far above the cob in the top of the stem.

One badly diseased: Bacteria have oozed through and formed water-soaked yellowish stripes or spots on the pedicel of the cob, and have also oozed through the husks, forming many water-soaked and yellow patches on at least half a dozen inner hnsks. The bacterial slime was on the inner surface of these hnsks and also on the kernels. Had photograph made of the husks (fig. 53). A similar oozing through the husks was found yesterday in a plant removed from this same plot to send to Prof. H. H. Whetzel, of Cornell University. Miss Lucia MIcCulloch examined the slime on the kernels with the compound microscope and found it to be made up of bacteria of the typical sort. These are just as good examples of disease of the cob as any I obtained on the Potomac Flats in 1902.

Two badly diseased: Every bundle apparently occupied. Infection extends up to male inflorescence, a distance of 3.5 feet from the base, and out into the husks, which are sticky to the touch from the extruded bacterial slime.

Two badly diseased: Husks badly spotted by the bacteria, and bacterial slime abundant in the stem far above the husks.

One badly diseased: I find the bacterial ooze bright yellow and viscid on the inside of some of the leaf-sheaths in masses sufficient to scrape up with the knife. It has also oozed out in certain places on the internodes. These places are long, water-soaked, yellowish stripes. Until yesterday I had never seen it forming water-soaked stripes on the surface of the internodes. The ears of this plant are also diseased, there being many water-soaked places and many yellow spots on the inner husks.

One badly diseased: Here the bacteria have formed pockets in the leaf-sheaths, and have oozed out on the surface of the stem as a conspicuous bright yellow slime, which is viscid enough to string out in cobwebby threads. I have just stretched them out 6 inches.

One badly diseased: Here again the bacteria have oozed from the inner surface of the leaf-sheaths, especially the lower ones, and have formed a great number of yellow pockets in the inner husks. The bacteria have oozed onto the inner surface of the hnsks in large yellow masses which are sticky. The infection is very striking. Seeing such ears one readily appreciates how impossible it is for the surface of the kernels to remain free from infection.

One badly diseased: Nearly every bundle at the base of the stem is occupied. The cob is not visibly infected, but the stem near the cob is infected.

Two badly diseased: 'The smaller one has no ears, bnt the inner face of the leaf-sheaths contains water-soaked and yellow spots, and there is a copious yellow bacterial ooze on the inner face of at least three such leaf-sheaths. The larger plant shows no ooze from the leaf-sheaths, but the ear is infected in the same way as those previously described, $i . \ell$., there are numerous yellow spots with bacterial ooze on the inner face of the hnsks.

One diseased badly: There are water-soaked stripes on the surface of the internode, but no bacteria have actually come through.

Four diseascd badly: Every bundle is occupied in each stem.

One diseased badly: Every bundle at the base of the plant is occupied by the yellow slime and bacteria are visible in the bundles at least 3 feet from the ground, probably all the way up to the male inflorescence. Tellow ooze is visible also on the inside of some of the leaf-sheaths and also on cross-section from the base of the cob.

One badly diseased: Every bundle of the stem is occupied. The bacteria have oozed to the inner surface of some of the leaf-sheaths.

One diseased badly: In the husks as well as in the stem.

One badly diseased: Bacterial pockets in lower leaf-sheaths. The husks of the ear are diseased.

One badly diseased: Here for the first time in my study of this disease I find evidence of bacterial ooze irom the pedicel of the cob (surface). It is water-soaked and yellow and there is ooze from a half-dozen or more stomata in the form of short cirri. One of these cirrus threads is many times as long as broad. This material is so good that I will put it into alcohol by itself (fig. $64 a$ ).

One badly diseased: Yellow bacterial ooze on inside of leaf-sheaths.

Three badly diseased: In the largest one of the thrce there are water-soaked stripes on the internodes, and also a badly diseased ear, the husks containing numerous yellow bacterial pockets from which slime has oozed to the inner face of the husk. The lower leaf-sheaths are also crusted with yellow bacterial slime on the inner faces.

One badly diseased: Every bnndle of the stem occupied.

Fonr badly diseased: Nearly every bundle occupied at the base of the stems. Also spots on the inner face of the leaf-sheaths where the bacterial growth is bright yellow in patches, also many bacterial patches on the inner husks.

One badly diseased: No ears.

One badly diseased: Hnsks of the ear spotted with water-soaked and yellow places.

One very badly diseased: Like most of these it has no living leaves. A badly infected ear. Many yellow spots and much bacterial ooze on the inner husks. Nearly every bundle is occnpied at the base of the plant and I can count at least a dozen bnndles full of bright yellow slime at a distance of 6 feet from the ground and about 4 inches under the male inflorescence.

One badly diseased: Every bundle of the stem occupied. No ear.

One badly diseased: Every bundle apparently is occupied at the base of the stem. Bacterial ooze from inside of some of the leaf-sheathis and on the husks.

One moderately diseased: Has perhaps 20 or 25 bundles occupied. 
One rery badly diseased: Husks and colb included.

One slightly diseased: 3 or + bundles show yellow ooze and four are browned.

Two badly diseased: Cobs infected. Hundreds of litile yellow spots on the husks.

One diseased: About 20 or 30 bundles infected at base.

One badly diseased: No ears.

One badly diseased: The husks as well as the stem. The leaf-sheaths show bright yellow bacterial ooze on their inner surface.

(4) Selected, bad seed, untreated (six rows):

Number of healthy plants, 284 ; number of diseased plants, 29.

Total, 313; per cent diseased, 9.3.

Remarks.-No notes on the first 25, some of which were badly diseased. 'The twenty-sixth, twenty-seventl, and twenty-eighth were slightly diseased. In the twenty-ninth four bundles were observed to be infected.

\section{GENERAL REMARKS ON SERIES XVI TO XIX.}

July 28.-The germinated plants are 1 to 2 inches high. The best germinations are in the plot treated with mereuric chloride $1: 1000$ for 10 minutes. The next best are those treated in the same way is minutes. The untreated ones (unselected seed) are lecidedly poorer. The poorest plot is that planted with the selected bad seed.

October $0 .-$ The experiment gave about 8 times as many cases on the untreated as on the treated. The contrast in the amount of infection in individual plants on the untreated plots and on those treated was very striking. Many stems of the former had nearly every bundle ocenpied to the top of the plant, and also nany ears involved, and all of the leaves were dried out, whereas in the latter there were only a very few plants which showed any infected bundles exeept near the base of the plant, and most of the leaves were yet green. The total baeterial multiplication in the plants grown from unsterilized seed was several thousand times as mueh as in those grown from the sterilized seed.

The infeetion of the ears was as abundant and striking in this experiment (nntreated plots) as in any I have ever made. Several of these ears were put into alcohol. They had a very large number of yellow spots on the husks (fig. 53) and the bacterial slime had oozed from some of them and was sticky to the touch. In one it was so viseid that the slime was stretched out a distance of 31 inches before the cobwebby thread ruptured.

In the untreated plots I did not find a single row that had no diseased plants in it.

This experiment indicates to me quite elearly that the seed corn was the carrier of this disease. Probably if I lad extended the soaking in mercuric chloride to 20 minutes, the cheek plots would have been entirely free from the disease instead of nearly free. I feared to do this lest I might destroy the germinating power of the corn. 'The soil was the same, the corn was the same, the water was the same, the experiment was controlled in the hothouse, and the only known variable faetor was the germicide. Moreover, the corn was already under suspicion because of its source and of its behavior at Falls Chureh, Virginia.

The experiment serves to establish more firmly the conchusion drawn from an earlier experiment respecting the existence of infected fields at Wakeman, Ohio. It further emphasizes the wrong done by seedsmen to the general public in selling corn grown on fields infeeted by this organism, since it serves to distribute the disease broadcast over the country. Wherever such corn is planted it not only gives a poor erop, bnt also serves to cause disease in a succession of crops on the same land as a result of soil infection.

The time between planting and the first appearance of cases was about 60 days.

The plants were crowded in the rows much like fodder corn and grew spindling, many of the stems being brittle. Had the plants grown uncrowded in a moist field the number of cases would undoubtedly lave been tripled or quadrupled, as a rapid watery growth greatly favors the multiplication of the bacteria inside the stems, whereas stunted, hard basal nodes often prevent the organism from getting ont of the base of the plant. Probably a spring planting would also have given more cases than the midsummer planting, since the dried-out bacteria gradually perish with lapse of time. 
The effect of stunting in preventing general infection is shown quite elearly in Series III to VII (1902) and in the field experiments at Arlington in I903. It is also shown in the following experiment.

\section{SERIES XX TO XXIV, 1908.}

This experiment was begun July I4-I5, I908, on another part of the grounds of the U. S. Department of Agriculture, out of doors, in a vacant cold frame between two hothouses. The same Golde11 Bantam sweet corn was planted as in Series XVI to XIX, but the soil was different, and the other conditions were such that it was known from the start that the plants would be badly dwarfed. In fact, the experiment was made for this very purpose, so that the effect of slow grow th might be compared with more rapid growth such as was anticipated and obtained to some extent in the preceding experiment. The corn was planted rather thickly in new 6-inch pots. Good hot-house soil was used. This was prepared from well-rotted sods thoroughly mixed with old cow manure which had been on the Department grounds in compost heaps for the previous 9 months. The cold frame was divided into five compartments and planted as follows:

(1) Two hundred and seventy-five pots, planted with selected good seed, abont 6 seeds per pot, more rather than less, soaked 8 minutes in I : 1000 mercuric cliloride water, and then washed in several waters. On July 2I, 62 I plants were visible. About one-half the seeds germinated.

(2) Two hinndred and seventy-five pots, planted witl selected good seed, about 6 seeds per pot, more rather than less, soaked for 30 minutes in I : 200 formalin water. The formalin delayed the germination. On July 2I, 48 I plants were visible. About one-third of the seeds germinated.

The above two plots were planted on July i 4 and the following next day.

(3) Two hundred and seventy-five pots, planted with selected good seed, about 6 seeds per pot, more rather than less, soaked for $\mathrm{I}$ hour in $\mathrm{I}: 2$ hydrogen peroxide water. On July $2 \mathrm{I}, 603$ plants were visible. Aboist one-half germinated.

(4) Six hundred pots, planted with unselected, untreated seed, about 8 seeds per pot, more rather than less. On July 21, 875 plants were visible. Less than one-fourth germinated.

(5) Three hundred and eighty-five pots, planted with selected bad seed, about I 2 seeds per pot. On July 2I, 502 plants were visible. An average of about $\mathrm{t}$ in 6 finally germinated.

The pots stood close together on clean sand. The average height of the plants when harvested was between 2 and 3 feet, $i$. $e$, they were much stunted by lack of room for the roots. Many of the seedlings showed, soon after germinating, what were regarded at first as suspicious signs, and plants in 74 of the pots were marked, but nothing developed later. The suspicious signs were water-soaked streaks on the young leaves. These turned out afterwards to be due to excessive pumping out of water through the water pores and were not infections. Some of the leaves reeovered promptly; others retained yellowish stripes for a long time, but none contracted Stewart's disease. On September I (forty-seventh day) a careful examination of all the plants showed no cases. The corn had begun to tassel. It was at that time also badly dwarfed and yellowish from lack of room for the roots. The tallest and greenest plants were next to the hot-house, where they were somewhat shaded from the morning sun, and did not, therefore, dry out as quickly. The first cases were observed at the end of about 60 clays. The plants were harvested September 29. The per cent of eases by plots is shown in table 16.

'TABLE 16.-Effect of Slow Growth on Development of the Disease.

\begin{tabular}{|c|c|c|c|c|c|}
\hline No. of plot and kind of seed. & Treatment. & $\begin{array}{l}\text { Healthy } \\
\text { plants. }\end{array}$ & $\begin{array}{c}\text { Diseased } \\
\text { plants. }\end{array}$ & Total. & $\begin{array}{l}\text { Per cent, } \\
\text { diseased. }\end{array}$ \\
\hline (1) Selected best... & $\begin{array}{l}\text { Soaked } 8 \text { minutes in } 1: 1000 \\
\text { mereuric chloride water. }\end{array}$ & 736 & 3 & 739 & 0.4 \\
\hline Do...... & 1: 200 formalin, one-half hour. & 620 & 4 & 624 & 0.7 \\
\hline 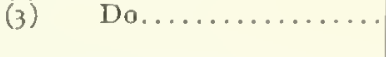 & $\begin{array}{l}\text { 1: } 2 \text { hydrogen peroxide, one } \\
\text { hour. }\end{array}$ & 721 & 3 & 724 & 0.4 \\
\hline $\begin{array}{l}\text { (4) Average kerncls out of } \\
\text { bag. }\end{array}$ & & 1,533 & 8 & 1,541 & 0.5 \\
\hline (5) Worst kernels in sack... & .... Do. & $8 \pi$ & 9 & 820 & 1.2 \\
\hline
\end{tabular}


Here the overmastering influence was the lack of room to make a vigorous juicy growth Many of the stalks were brittle as pipe-stems when cut.

\section{SERIES XXV, 1912.}

In the spring of 1912, Lucia McCulloch, of my laboratory, inoculated sweet corn and field corn in the hot-house by spraying on a water suspension of Bact. stewarti when the plants were about a foot high. Soon after, they were set out on the grounds of the U. S. Department of Agriculture, where they grew well and showed but sliglit signs of disease.

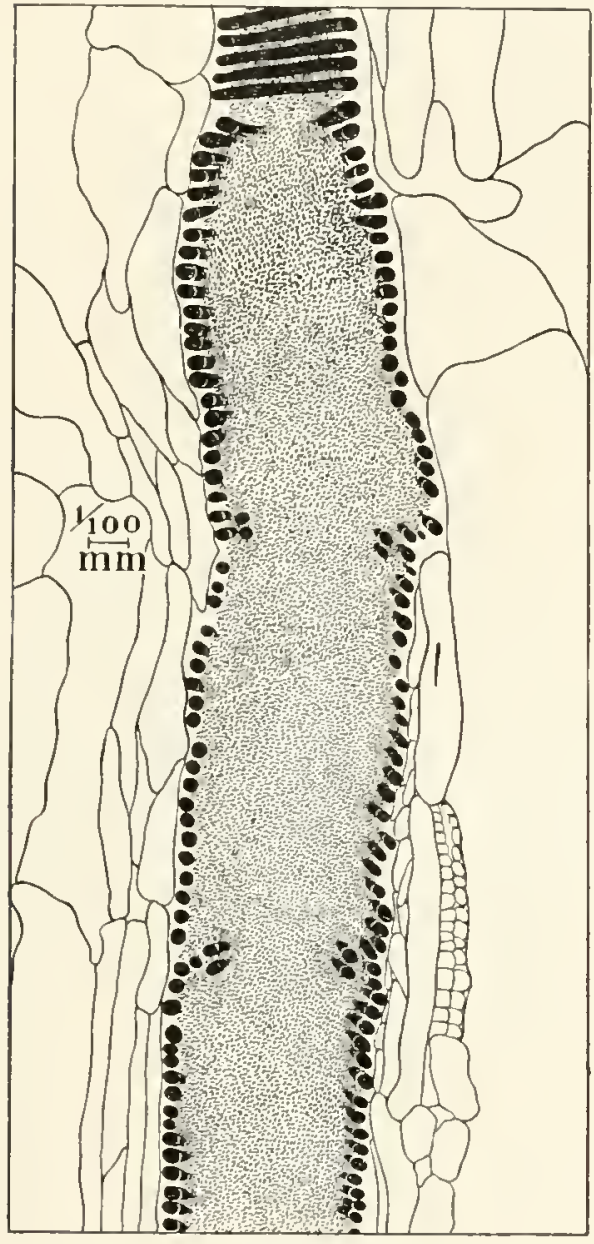

Fig. 54.*

When cut in September the field corn was free from disease. Of the sweet corn about one-half of the stems were infected, but most of them only slightly. Of the whole number (about 50) only 5 or 6 were badly diseased. The season was

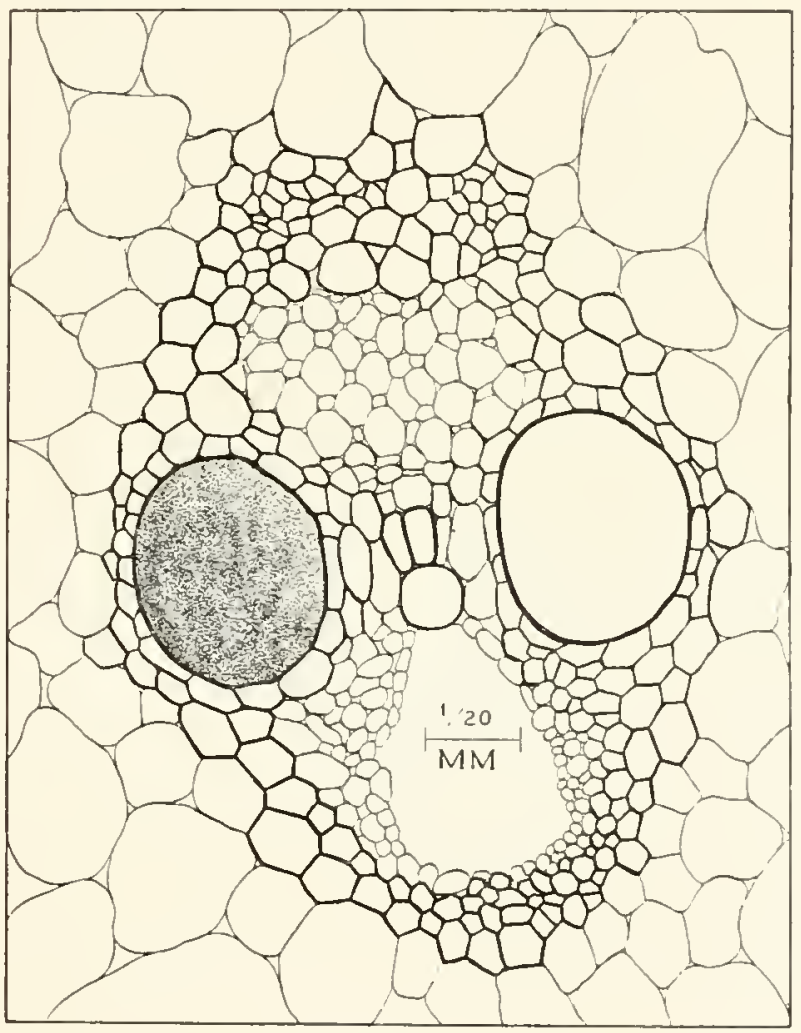

Fig. $55 . \dagger$

a growing one and the organism was infectious. The feeble results, therefore, are to be attributed, I beliere, either to resistance on the part of the variety used or to the lateness of the inoculation, $i$. $e$, after the plants had passed out of the seedling stage.

*Fig. 54-Cross-section of the base of a sweet-corn kernel, showing a single spiral vessel filled with Baclerium stev'arli, the result of an inoculation made about 2 months earlier by placing a trace of a pure culture on the tips of the leaves of the seedling plant. Material fixed in strong alcohol, embedded in paraffin, sectioned on the microtome, stained with carbol-fuchsin, differentiated in 50 per cent alcohol, and mounted in Canada balsam. Figure drawn under the microscope with the aid of an Abbe camera. Slide 235 A 8. For orientation see fig. 47.

tFrg. 55.-Cross-section of internodal bundle of a sweet-corn stem showing Baclerium stewarti occupying a single vessel. Material obtained on Long Island, New York, July I6, I go2, fixed in 95 per cent alcohol, embedded in paraffin, sectioned on the microtome, and stained with carbol-fuchsin. Slide $249 \mathrm{C} 2$. 


\section{MORBID ANATOMY.}

The lesions in this disease are strikingly like those induced by other organisms of this group, e. g., Bacterium hyacinthi and Bact. vascularm. 'The vascular system is occluded by the bacteria to an astonishing degree. So far as I know, scarcely anything conparable to it in extent and severity occurs in the animal body, the nearest approach, perhaps, being certain septicæmias (figs. 54, 55, 56). There is this astonishing difference, lowever, due to the very different character of the circulation in plants and animals, that while in many

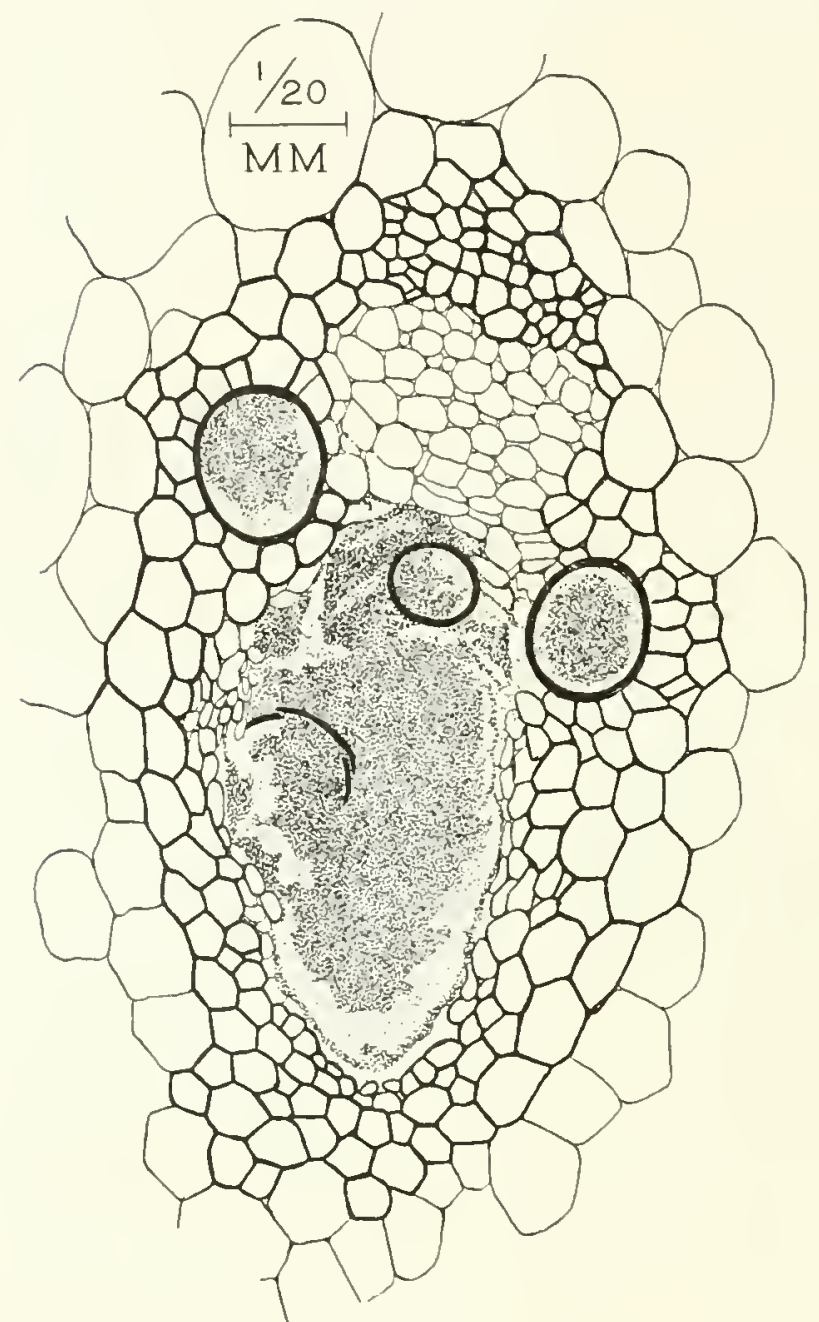

Fig. 56.* cases the general septicæmias of the animal body are rapidly fatal, a few days sometimes sufficing, this disease of maize progresses slowly in spite of the presence of enormous numbers of the bacteria, and destroys the plant apparently only when the water-conducting tissues (vascular

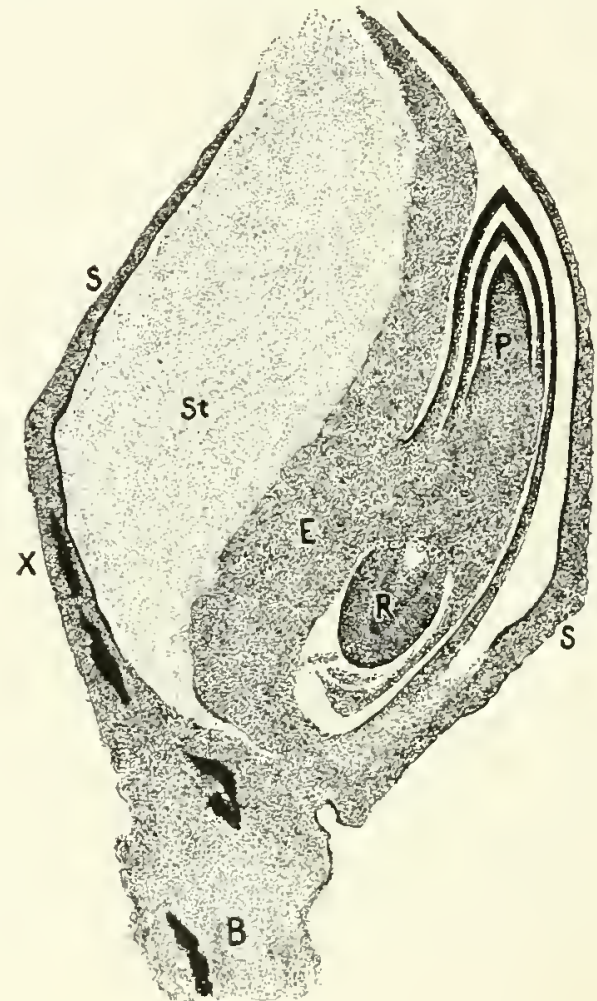

Fig $57 . \dagger$

bundles) have become blocked up by the invading organism to suel an extent that transpiration greatly exceeds water-supply. An early death as the result of the action

${ }^{*}$ Fra. 56.-Cross-section of an internodal bundle in sweet-corn, showing restriction of Bacterium stewarli to the $x y$ lem part of the bundle. The result of a pure-culture inoculation made in the seedling stage by placing the bacteria on the tips of young leaves. Material collected and fixed in October 1902 . The entire stem at this level contains 287 vascular bundles, of which all but 10 are occupied by the bacteria. In every instance (?) the bacteria are still confined to the xylem part of the bundle. Slicle $2+8$ A 6 .

†Frg. 57. - Diagrammatic longitudinal section through lower half of a sweet-corn kernel attacked hy Bacterium stewarti, the areas occupied by the bactcria being drawn in solid black (lower left-hand side). $S$, envelope of the grain: $S t$, starchy part; $E$, scutellum; $P$, plumule; $R$, radicle; $B$, base of kernel. The starchy part was very soft when embedded and is squeezed together and upper part torn away. A detail from $\mathbf{X}$ is shown in fig. $58, A$. Slide $485(7$. $X$ I4. From Golden Bantam corn grown from diseased seed in the summer of I go8. 
of toxic substances does not occur. Stewart's disease is preeminently a vascular disease, but is not confined to the vessels excltisively, as he supposed. The disease, like many other bacterial diseases, begins in the parenchyma and ends in the parenchyma. In the earliest stages of the disease, in order to enter the vascular system the organism must first penetrate

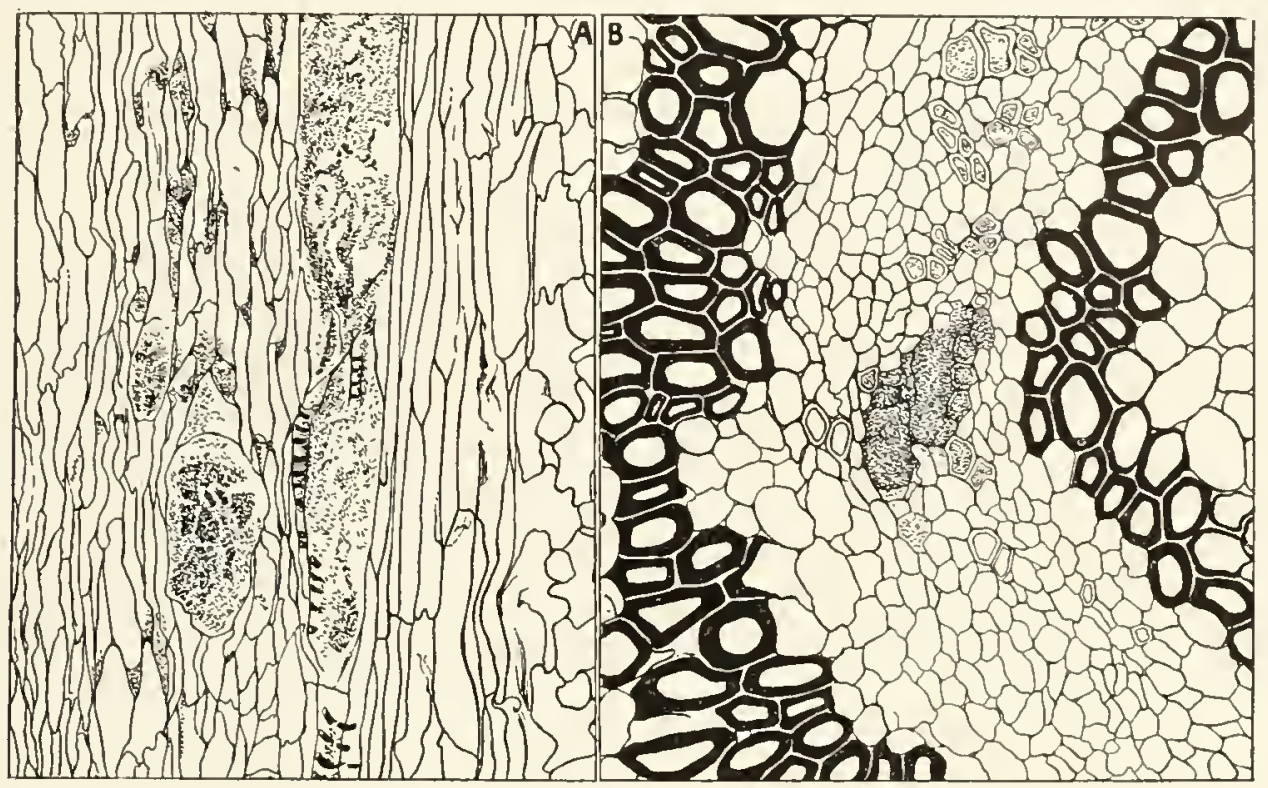

Fig. 58.*

the epithem or multiply in the cellular tissues inder the substomatic chamber (vol. I, fig. 75); only in the rare event of infectious wounds made directly into the vessels can it be otherwise. In the late stages of the disease, also, as already noted under "Etiology," one very frequently finds conspicuous bacterial pockets in the soft parenchyma adjacent to the bundles. The histological character of these pockets is shown in figs. 48,49 . Their small size and their relative abundance can be seen in fig. 53 and plate 9. The writer lias not observed in sweet corn any cavities at all comparable to the large ones frequently seen in sugar-cane attacked by Cobb's disease. Many organs of the plant are subject to invasion by this organism, $i$. $e$., roots, nodes, internodes, leaf-sheaths, leaf-blades, male inflorescence, female inflorescence; but there are no liyperplasias. Occasionally small shoots push from the base of the plant (plates 6, 8, ro), but these are not very numerous, nor frequent. In the ears the bacterial sline occurs in the cob, in the kernels (sparingly),
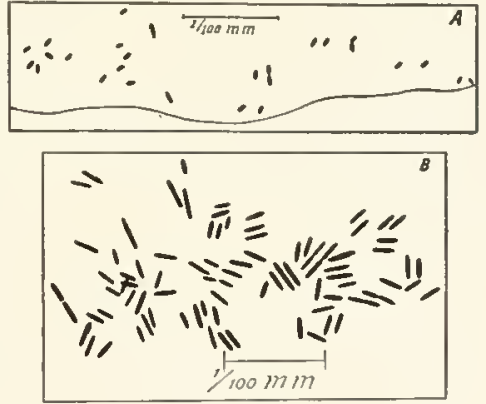

Fig. 59.† and in the husks, often very abundantly in the latter, as may be seen by consulting my notes under "Etiology." From the liusks the surface of the kernels is readily infected.

*Fig. 58.-A. A detail from fig. 57, at $\mathbf{x}$, showing cavities in the vascular region of the outer layers of a corn kernel occupied by Bacterium stewarti. Stained with methyl green and acid fuchsin. B. Similar infection, but from another kernel and in cross-section. The slides prepared contain numerous serial sections and were numbered from the base of the kernel upwards, $1,2,3$, etc. The sections on slides I to I 2 contain bacteria, $i . e_{\text {, }}$, to a point above the level of the base of the radicle and close to the scutellum. Besides the central bacterial cavity, spiral vessels in the upper part of the drawing are also sparingly occupied. The heavily shaded cells are part of the enveloping sclerenchyma. Slide 485 A 16 , second row from top, second section from left, stained with pyranine and methyl violet. 'The bacteria are deep red, the sclerenchyma is blue.

$\dagger$ FIG. 59.-A. Bacterium stewarti drawn unstained from the margin of a hanging drop. Organism grown in +15 bouillon for 52 hours. B. Bacterizm stewarti from yellow slime on a potato culture 3 days old at $30^{\circ} \mathrm{C}$. Rods motile, many dividing. Drawn unstained from a hanging drop of water. 
The slime finds its way to the inner surface of the husk more readily than to the outer surface, but sometimes it reaches the latter also. It generally comes to the surface througl stomata (figs. 49, 50, 5 I, 52). The only conspicuous parts in which the slime has not been seen are the floral organs and the silicified outer parts of the stem. Even the latter statement must be modified somewhat as a result of the observations recorded in 1908 , since rarely the bacteria may be seen issuing from small cracks in the siliceous covering of the internodes, especially where protected by the leaf-sheaths. Probably the stigmas (silks) are never infected, they are so fugitive, but the male flowers might well be infected, since the writer has traced the infection well up into the main axis of the male inflorescence a number of times.

As yet we do not know how the wall of the vessel is pierced. It is probable that cellulose is not destroyed.

\section{THE PARASITE.}

Bacterium stewarti EFS.* as it occurs in the vessels of the maize plant and in young cultures on ordinary culture media is a short rod under $1 \mu$ in diameter and generally less than $4 \mu$ in length, with rounded ends (fig. 59). It oceurs singly, in pairs, or fours, joined end to end. According to Stewart the organism usually oceurs in pairs with a plain constriction. "A pair varies in length from $2.5 \mu$ to $3.3 \mu$ and in width or dianeter from $0.65 \mu$ to $0.85 \mu$." My own measurements do not differ materially. The following are average measurements taken from organisms grown in various media:

Measurements made July 21, I909, from potato-cultures 4 days old gave the following results:

Amyl Gram stain gave $\mathrm{x} .3$ to $2 . \mathrm{I} \mu \times 0.4$ to $0.6 \mu$; carbol-fuchsin gave 0.9 to $2.0 \mu \times 0.3$ to $0.7 \mu$. On some of the slides the carbol-fuchsin seemed to have contracted the protoplasm into small lumps.

Agar streak-cultures 2 days old gave the following results:

Amyl Gram, 0.9 to $2.0 \mu \times 0.4$ to $0.7 \mu$; carbol-fuchsin, 0.9 to $1.7 \mu \times 0.4$ to $0.6 \mu$,

Taken direct from the vessels of the maize plant, the following measurements were obtained:

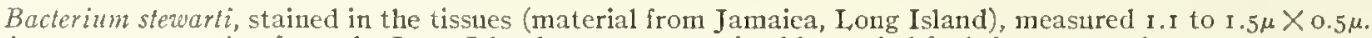

A smear preparation from the Long Island sweet-corn stained by carbol-fuchsin measured 0.9 to $I .4 \mu \times 0.4$ to $0.55 \mu$. Stained in section from a corn husk taken from the Flats experiment, slide $477 \mathrm{C} I$, the organism measured $\mathrm{I}$ to $\mathrm{I} .4 \mu \mathrm{X}$ 0.4 to $0.5 \mu$.

The general appearance of the organism is shown in figs. 59 and 6o. The organism on media is slightly viseid at times and undoubtedly possesses a capsule, althougln 110 efforts have been made to demonstrate it by means of special stains. The only very viscid masses seen are those mentioned under examination of diseased plants in r gos.

The organism is motile, especially in young eultures, and the writer has demonstrated a polar flagellum (fig. 6o). Usually, at least, only one flagellum is present on the end of each rod. Long chains or filaments have not been observed. So far as known the organism does not produce endospores. Snall clumps and bunches of the bacteria (pseudozoogloeæ) oceur in various media as follows: Uschinsky's solution, nitrate bouillon.

The organism stains readily with various anilin dyes. The writer has tried the following with fairly good results: Carbol-fuchsin, Loeffler's alkaline methylene blue, amyl Gram.

Gram's stain gave negative results or at least not a deep stain. The rods were visible with wide-open diapluragm, but were only a pale blue.

When cultivated in salted peptone water containing methylene blue the bacterial precipitate was stained a deep blue, the pignent in the fluid remaining unreduced and bright blue or greenish-blue in color. Repeated in igos with same result, $i$. e., bacteria distinctly blue both to the naked eye and under the microscope. 
This organism grows slowly on gelatin without liquefaction. In a stab-culture in nutrient gelatin No. 478 at the end of 4 I days, at $17^{\circ}$ to $22^{\circ} \mathrm{C}$., there was a thin line of growth along the needle-track, best toward the top, and a dense, rather dry, slightly roughened, bright, buff-yellow surface growth 7 1nm. in diameter. Fig. 6r $a$ sliows its appearance in gelatin stabs.

In + ro nutrient gelatin, in rather thin sowings in Petri-dish poured-plates, at the end of 7 days, at $10^{\circ}$ to $20^{\circ} \mathrm{C}$., the surface colonies of Bacterium stewarti under the Zeiss I $6 \mathrm{~mm}$. objective and I 2 comp. ocular were small, not perfectly circular, not uniformly granular, more or less finely fissured, the margins not entire

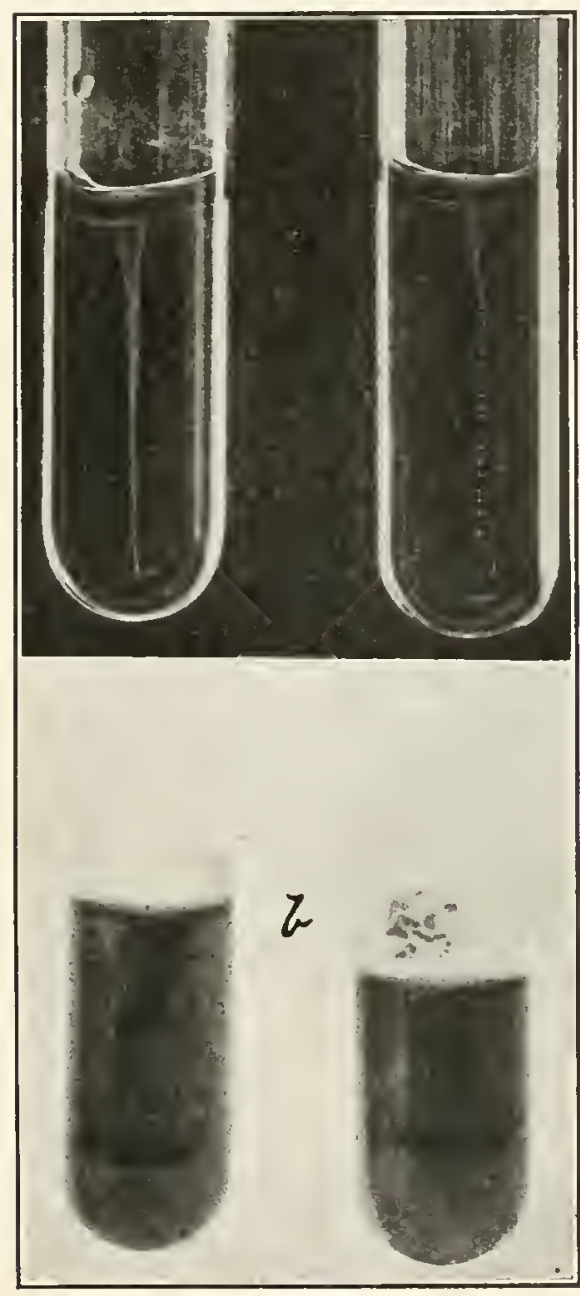

Fig. 61. $†$ and sometimes even more or less decidedly notched; the buried colonies were globose-lobulated and less than I $\mathrm{mm}$. in diameter. This may not be a constant phenomenon.

In streaks on Loeffler's solidified blood-serum Bact. stcwarti made a good bright buff-yellow growth, but without liquefaction. The cultures were under observation for 32 days.

On agar plates it grows slowly, forming small round yellow colonies, the buried ones being very small. In agar streak-cultures it gives a smooth translucent yellow slime which is usually paler than that of Bact. hyacinthi (fig. 62), and frequently lobed on the margins. Old streak-cultures are usually thin and somewhat dry, and the older bacterial layer generally baars numerous small raised, wet-shining, yellow colonies on its surface. Jagged $X$-shaped crystals and short prismatic crystals are not uncommon (fig. 63).

In agar stab-cultures at the end of 16 days there was a moderate growth the whole length of the needletrack and a distinct surface growth some millimeters in diameter. Even where there were several stabs in one tube the growths did not cover the entire surface of the agar or coalesce; the color was between saffronyellow and deep chrome (Ridgway). At the end of 5 weeks the surface growth was a deep yellow and not at all viscid; there was a good growth the whole length of the stab; the agar was unstained, and there were prismatic crystals in the upper part of it. At the end of an additional 9 weeks, during which the cultures were in the refrigerator, the surface growth was chrome yellow.

In stab-cultures in nitrate agar (stock 718) the organism made a good growth, the surface layer being at first whitish. At the end of 24 days the agar was not stained, and no gas had been formed in the agar. A few crystals were present in the uppermost layers of the agar. 'The stab had made a good growth the whole length, but it thinned out slightly toward the bottom. There was a very distinct

*FIG. 6o.-Filagella of Bacterium stewarti. Stained by van Ermengem's method from dilute Uschinsky's solution. Slide *, August 7, 1904 .

$\left\lceil\right.$ FIG. 61 . - a, Gelatin stab-cultures of Bacterium stewarti after Io days at about $20^{\circ} \mathrm{C}$. Gelatin not liquefied. b. Gelatin stab-cultures of a non-pathogenic yellow liquefying organism from the surface of sweet-corn bernels. Summer of ig08. Two-thirds to three-fourths liquefied. 
surface growth, which was plainly yellow and rough granular (possibly ? from the presence of the crystals). It covered only a part of the surface and was between Ridgway's buffyellow and deep chrome in color.

A month later there was a very good growth, the surface was wet-shining and not then grantular, but covered with little denser masses of the bacteria, resembling colonies growing on the older growth.

In stab-cultures in 6 per cent glycerin agar the organism grew nearly or quite the whole length of the stabs, but best toward the top. The surface growth increased slowly, so that finally most of the surface was occupied. The growth was pale yellow, particularly at first. Surface smooth or slightly irregular. Streak-cultures also grew.

On silicate jelly (see vol. I) Bact. steu'arti made a very feeble growth. The streak-

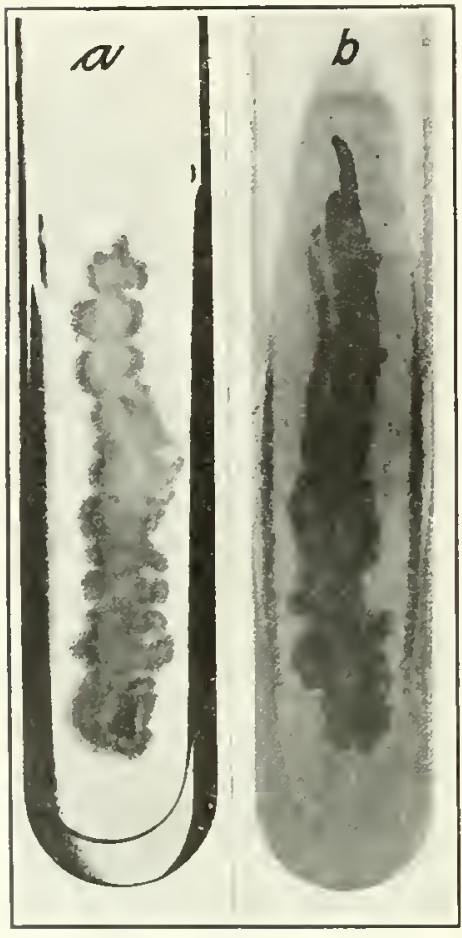

Fig. 62.* cultures were under observation 2.5 months. In 2 days there was a very scanty, rough, yellowish growth along the line of the streak which did not increase much. A number of organisms were tested. The only other one that failed

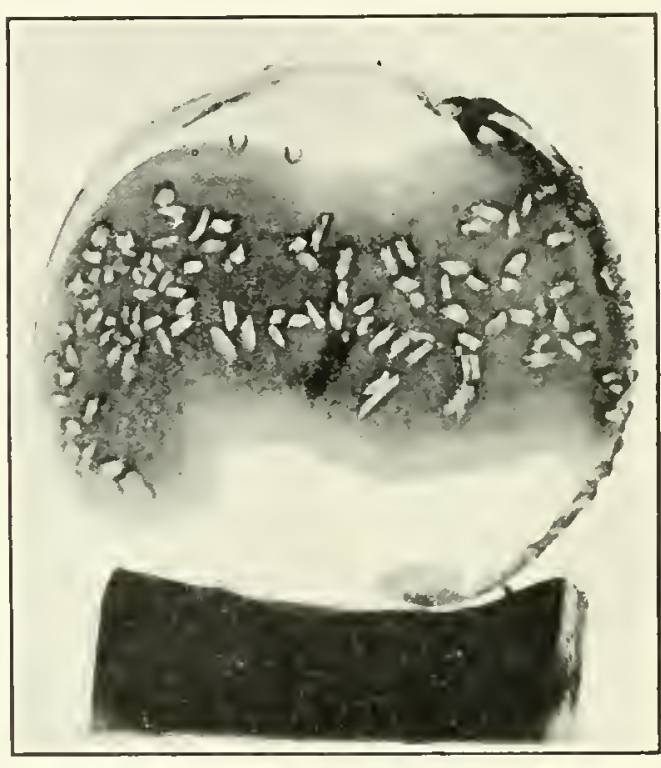

Fig. 63.† cventually to make a good growth on this niedium was Bact. vascularum, although quite a good many had difficulty in starting off, and had made little or no visible growth at the end of 6 days.

Bact. stcwarti behaveson potato much like Bact. hyacinthi, i. e., out of the water it makes a moderate amount of yellow growth which soon passes its

maxinum (see this monograpl, vol. II, plate 17 , fig. 2 ). The fluid around the cylinder never becomes thickened by the continued development of the organism, and the surface growth ceases for the most part after a week or two, owing to the exhaustion of the small an1onnt of sugar and other soluble foods and the inability of the organism to take its food readily from starch. No gas bubbles appear. The litmus reaction is alkaline. The iodinstarch reaction is always strong in potato-cylinders on which this organism has grown, even when tested immediately under the bacterial laver, although it must liave a slight action on starch, since the reaction is generally a deep purple-blue rather than a pure blue, such as the eheck-tubes yield. The cell-walls of the potato are not softened. The following are notes on a series of 8 cultures (from as many plants) on potato-cylinders in test-tubes:

*Fig. 62.-a. Streak-culture of Bacterium stewarti on a + I5 agar slant 3 days at $27^{\circ} \mathrm{C}$., September 1902. $b$. the same on $+\mathrm{I} 5$ agar slant 8 days at $26^{\circ} \mathrm{C}$., October i gos.

†Fig. 63.-Crystals formed in old nutrient agar-culture of Bacterium sterarti. Photographed down upon the surface (nail-head) of the culture. The dark body in the center is the denser growth along the needle-track. Crystals confined to the surface. $X_{4}$. The culture had been at a temperature of abont $14^{\circ} \mathrm{C}$. for many weeks. 
A ugust 24, 1902.- Inoculated.

August 29.-All the cultures resemble each other closely. The potato out of the water is slightly to distinctly grayed, and bears a thin, decidedly yellow slime. In one tube it was recorded as bright yellow.

September. - The potato-cylinders are grayed to a greater extent than they were and the organism is yellower in some tubes than in others (variability in potato-cylinders). When compared with the check-tubes there is an inconspicuous pink tint in the potato (?). Repetitions in 1909 and 1913 (held 5 months) failed to give this tint. Fig. 64 shows appearance on potato contrasted with that of Bacterium campestre.

On coconut cylinders Bact. stewarti made only a moderate amount of growth. Its color was buff-yellow and erystals were formed. Repeated in igr 3 the following results were obtained: Moderate to good growtlı; pale buff-yellow slime and precipitate; no crystals. In the milk of the coconut there was a moderate growth with yellow rim and precipitate, and subsequently the fluid became yellow (cheeks remained colorless). When old there was a copious yellow growth with a wide yellow rim; the fluid was pale yellow. Though acid when inoculated it was now feebly alkaline. There were no crystals.

On eylinders of yellow turnip there was a thin buff-yellow slightly irideseent growth. At the end of a week this was decidedly less than in corresponding tubes of Bact. campestre. Growth ceased, practically, after the second week. There was a buff-yellow preeipitate in the fluid surrounding the cylinders, but no thickening of the water with bacterial slime. There was no browning or softening of the substratum. The eulture was alkaline to litmus at the end of the fifth and ninth weeks. Repeated in 1913 with same results, except recorded as not iridescent. When old the growth was orange-ochraceous, feebly alkaline, wet-shining, not viscid, moderate in amount, and free from erystals.

The appearance of this erganism when grown on rutabaga was much the same as on yellow turnip. On the seventli day the growth was about one-tenth as much as that of Bact. hyacinthi and one-twentieth to one-thirtieth as much as that of Bact. campestre. On the eigliteenth day streak-cultures yielded a thin buff-yellow grow th covering the whole surface exposed to the air; this was not snooth and not dense enough to hide the slight irregularities of the substratum. Its surface was slightly iridescent, and when examined under the hand-lens fine striæ were visible. The water contained a mocerate amount of buff-yellow precipitate, but was not filled with a solid slime.

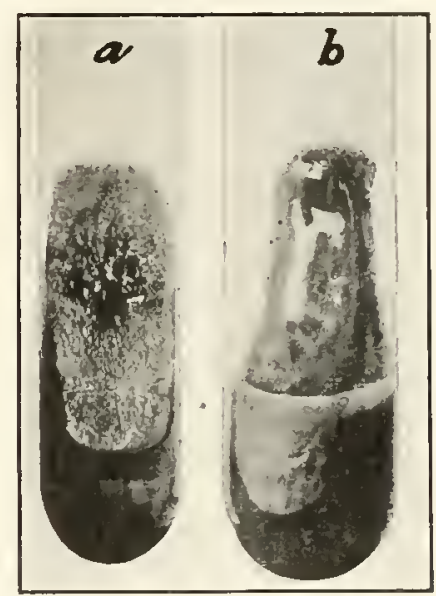

Fig. 64. In old cultures there was 110 increased growth, no brown stain, and no softening of the tissues. The iridescence persisted. The cultures were alkaline, at least after a tine (thirty-fourth and sixty-fourth days), and had a feeble, pectliar smell. On the thirtyfourth day the thick slime would not wet litmus paper until water was added.

When tried in I9I3 on white turnip cylinders standing in water (stock 5778), there was a moderate to good, pale yellow, flaky, iridescent surface growth, and a pale yellow precipitate. When old the slime was oeher yellow, slightly alkaline, not viseid, wet-shining, not copious, and free from crystals.

On radish eylinders (tests of $19 \mathrm{I}_{3}$ ), there was a thin, whitish, iridescent surface growth with a seanty yellowish precipitate and either no browning or slight.

Steamed cylinders of sugar-beet standing in distilled water proved a very good meditnin for Bact. stewarti. It grew on this substratum abundantly and without retardation. The color of the growth on the cylinders was a deep buff-yellow, and there was a copious buffyellow precipitate in the fluid at the bottom of the tube.

*Frg. 6.-Bacterium stewarti $(a)$, and Bacterium campestre (b), after 30 days on cooked potato at room-temperature. The former grew only during the first few days, $i$.e., was not able to use the starch as food; the latter continued to grow for weeks, owing to its diastasic action on starch. Bact. stewarti shows a little slime on the upper part of the potato (dark part) and a small amount of precipitate in the water (at right). Bact. campestre has covered the potato and filled the water solid. Photographed November 2, 1908. 
In tubes of peptonized beef bouillon at the end of about i 8 days (room-temperatures of spring) there was a feeble, whitish rim, a well-clouded fluid, about $10 \mathrm{~mm}$. breadth of pale yellow precipitate, and no distinct pellicle (stock 79I). Repeated in s9os in stock 3398. At end of Io days, when notes were taken, the tubes were well clouded with a moderate amount of pale yellow flocetilent precipitate. 'There was also a well-defined but rather scanty whitish rim.

In a fluid prepared by grinding green cabbage-leaves, taken from old, slow-growing hothouse plants, and extracting the juice under pressure without addition of water, there was a very prolonged and copious growth without retardation. A portion of this fluid was sterilized by forcing it through a Chamberland filter and the rest by discontinuous steaming. 'The reaction of each was +40 on Fuller's scale. Bact. phaseoli and Bact. campestre refused to grow in this fluid, but when it was solidified by adding agar-flour, Bact. campestre grew upon it very copiously and for a long tine, although it was started with much difficulty.

Bact. stcwarti was retarded at first, but afterward made a prolonged and copious growth in three out of four tomato juices undiluted with water. In the fourth it refused to grow. In stocks 333 and 334, obtained respectively by squeezing green full-grown or nearly full-grown fruits, and small green fruits (one-twentieth to one-quarter grown) there was a good growtl on the fifth day. 'The acidity of these two stocks was respectively +55 and +59 of Fuller's scale. In stock $33 \mathrm{I}$, which was the steamed juice of ripe fruits, there was a greater retardation, the tubes becoming clouded between the eighth and fifteenth day. The acidity of this medium was +64 . Stock 332 , in which the organism would not grow, was $+68, i$. e., a little more acid. It consisted of the steamed juice of fruits which were yellowish green, $i$. $e$., fullgrown and beginning to ripen. It would seem, therefore, if we may trust the titration, that +64 is near the limit of toleration for the acid of the tomato.* Bact. campestre and various other organisms refused to grow in these fluids.

In a 2 per cent agar containing the juice of $\mathrm{o}$ grams of acid mulberry fruits in 490 c.c. of water (autoclaved) Bact. stewarti 111ade 110 growth, i. e., 8 Petri-dish poured plates made with yellow slime from each of two recently infected plants. On the i 6 plates not a colony appeared. That the organism was living in each case was shown by subsequent cultures from the dilutions. 'The work was defective in that the acidity of the agar was not determined by titration. 'Two mulberry agars were in the laboratory at the time, one made from green fruits of Monus alba, the other made from ripe fruits of Morus rubra, but there is no record as to which was used.

In a potato broth of half strength $(I: 4)$ which titrated +30 on Fuller's scale, Bact. stewarti grew readily, while Bact. phaseoli and Bact. campestre refused to grow, and Bact. hyacinthi was much retarded. Bact. stcwarti also grew in this broth without retardation when sufficient malic acid had been added to it to make it +45 . Bact. hyacinthi, Bact. phaseoli, and Bact. campestre, refused to grow in this fluid. Bacillus amyloworts and Bact. dianthi grew in it readily.

This experiment was repeated in 1908, using Bact. stewarti from three sources and dilute potato broth rendered $++\mathrm{I}$ by malic acid. Each grew well. The tubes each received two 3-1nm. loops from peptonized beef bouillon 3 days old. Each was well clouded at the end of 48 hours. On the seventh day each tube had a copious pale precipitate and a pale rim. On the eleventh day the tubes were still well clouded with a pale flocculent precipitate and a pale buff-yellow rim, I to 2 mm. wide.

In beef broth concentrated by boiling until it was quite yellow and strongly acid $(+80)$, Bact. stewarti grew for a long time and very luxuriantly, but clouding did not appear until the eighth day, althongl the inoculation was from a solid culture. In this medium the following bacteria refused to grow: Bact. hyacinthi, Bact. phaseoli, Bact. campestre, Bacillus amylovorus. 
This experiment was repeated in $\mathbf{I} 908$, using a beef broth free from peptone and concentrating it until it titrated +73 . Bact. stewarti from three sources was tested. Each tube was inoculated with three 3 -mm. loops from bouillon. There was 110 elouding for the first three days or more, but afterwards a heavy growth. On the thirteenth day the tubes were heavily clouded with a buff-yellow rim ( 2 to $3 \mathrm{~mm}$. wide), a thin pellicle, scarcely visible, and considerable buff-yellow flocculent precipitate. Tubes io days old but inoculated from a solid culture (potato) were heavily clouded with heavy yellow rims ( 2 to $3 \mathrm{~mm}$.) and a wide buff-yellow precipitate.

Bact. stewarti grows in milk for a long time without precipitation of the casein, or sufficient production of alkali to render the nuilk translucent. There is no visible change in the milk, even after several months, although the organism forms on the wall of the tube, at the surface, a distinct yellow bacterial rim and an abundant bright yellow precipitate. There is a change, however, in the milk, as shown by the litmus reaction. In litmus milk there is a gradual slight development of acid. The color of the litmus, on the start a deep lavender blue, becomes a lilac color or dull purple (pl. I I, figs. $3,4,5$ ). Usually this color does not appear until after about two weeks, and sometimes a longer period intervenes. In the end the litmus is more or less reduced, sometimes entirely. This reduction may occur early, but often not until after several to many weeks. Frequently the acid reaction is obscured by reductions. The organism produces no lab ferment, and not enough acid to cause coagulation. No crystals were observed in milk-cultures.

In $S$ tubes of litmus milk (stock 697 ), inoculated in 1902 , the litmus was entirely reduced at the end of 16 days; there was then a slight yellow precipitate; a pale yellow rim was beginning to form at the surface; the milk was entirely fluid. At the end of a nonth there was no separation of the casein, the litmus was still entirely reduced in two tubes and nearly reduced in the others, there being, however, a slight pinkish hue at the top. The check remained unchanged. At the end of ro weeks there was a yellow precipitate about ro mm. broad, a yellow rim 6 to $7 \mathrm{~mm}$. wide, and in some of the tubes a yellow pellicle or partial pellicle. The amount of litmus reduction varied a little; it was complete in several tubes and nearly so in the others. The milk in the tube showing most color was pinkish vinaceous (Ridgway) in the upper half.

At the end of $x+$ weeks the reduction was still quite inarked, but not complete. The returning color of the litmus was various shades of lilac, $i$. $c$., quite distinct from the unclianged deep lavender of the check tubes. At this date the milk was still fluid; there had been no separation of the casein; the bacterial rim was about $10 \mathrm{~mm}$. wide and dirty yellow. Two of the cultures were slightly viscid, one decidedly viscid, and 5 not viscid. Streaks on slant agar made at this time from these tubes yiclded 8 pure cultures of Bact. stcurarti. These milk cultures were also alive at the end of 7 months, as determined by cultures in bouillon and on potato.

The same results with litmus milk were obtained in rgos. There was good growth, slow change from blue to lilac color, and no separation of the casein.

In the following medium Bact. stewarti did not grow. Distilled water $\mathrm{x}$, ooo, dipotassium pliosphate 2 , magnesium sulphate 0.1 , ammonium phospliate $0 . \mathbf{I}$, sodium acetate 5 . Bact. campestro grew in it feebly. Repeated several years later ( 1908 ) with same result.

In Uschinsky's solution, Bact. stewarti grew for a long time and very copiously. It is a good inedium for differential purposes.

The general appearance of cultures in Uschinsky's solution was as follows: The growth was slightly retarded and sometimes rather feeble at first, then copious and long continued; rim whitisl at first, then distinctly yellow and of variable width; a yellow pellicle, sometimes bearing yellow colonies; copious chrome-yellow to buff-yellow precipitate, fluid gradually becomes slightly fluorescent, but less distinctly so than in case of Bact. prmi; pseudozoogloex are present. In one set of tube-cultures made in 1902 , in stock 702 , there was at the 
end of two months a thin yellow rim $5 \mathrm{~mm}$. wide; a thin yellow pellicle over the whole surface, fluid moderately clouded, translucent, a bright yellow precipitate $1.5 \mathrm{~cm}$. broad, and no crystals visible; fluid feebly fluorescent. At the end of another montli the fluid in each one of the seven tubes was turbid and the precipitate slowly increasing, it being then I $7 \mathrm{~mm}$. wide and about $4 \mathrm{~mm}$. deep; the liquid was slightly fluorescent, and plainly to strongly alkaline to neutral litmus. It was not viscid. At the end of four months these cultures were still living; they were distinctly fluorescent and not at all viscid; all had a deep chrome yellow rim, and all but one had more or less pellicle; pseudozoogloex were present. Repeated in 1908 with similar results: On twenty-third day heavily clouded with specks of yellow on the surface (floating islands), and a granular pale buff-yellow precipitate. On shaking, a great number of small flocculent particles filled the fluid.

On nutrient starch-jelly the addition of the following substances gave no increased growth: Iactose, maltose, dextrin, manuit, glycerin. Cane-sugar and galactose, on the contrary, greatly stimulated growth. On the slant surface of the jelly containing the cane-sugar there was a copious, smooth, wet-shining, buff-yellow, sirupy growth. On that containing the galactose there was roo times as much growth as on the jelly containing glycerin, and nearly as much growth as on that containing the cane-sugar.

Bact. stewarti did not grow in - So peptonized beef-bouillon (sodium hydrate), but clouded -40 bouillon the first day or the beginning of the second. Probably there was some error in the former titration, as a repetition in 1908 , using - 35 bouillon, gave no growth, nor would it grow in - 30 peptone beef-bouillon when tested in 1912 . The maximum tolerated dose of sodium hydrate in bouillon, therefore, is not known with certainty, but is, I believe, under -30 of Fuller's scale. On the acid side +30 bouillon clouded the first day and +60 is believed to have been clouded feebly after a time; growth also occurred in +80 bouillon (acid of beef-muscle), in +64 tomato juice, +40 cabbage juice, and in potato broth reinforced with malic acid from +30 to +45 , as has been stated already. The range of toleration, therefore, for alkalies and acids is greater on the part of this organism than on the part of many related forms, e.g., Bact. hyacinthi.

Salted bouillon.-The organism will tolerate a considerable amount of sodiun chloride, $i$. $\varepsilon$., nearly or quite as much as Bacillus coli. In 1 909, in experiments with two strains (McCullocli and Galloway), Bacterium stewarti grew promptly in +15 peptone bouillon containing 5 per cent c. p. $\mathrm{NaCl}$, and after a time in bouillon containing 8 per cent. The experiment was repeated in I9I 2 with similar results. There appeared, after a time, to be a trace of bottom growth, even in ro per cent salt bouillon, but this should be repeated.

Cohn's solution.-The organism did not grow in Cohn's solution when inoculated into it from young fluid cultures. Repetitions in 1908 gave the same results.

Fermi's solution. - The organism grows feebly in Fermi's solution.

Reduction of nitrates.-Bact. stewarti has no action on potassium nitrate. It is not reduced in bouillon, either with or without the presence of grape-sugar. 'The growth of Bact. stewarti in nitrate bouillon was feeble in comparison with that made by Bact. hyacinthi or Bact. campestre.

Acrobism.-So far as tested Bact. stewarti is strictly aerobic. It produces no gas and does not grow in the closed end of fermentation-tubes when free from air. It is able, lowever, to get along on a relatively small amount of air, as shown by experiments in vacuo, etc.

In an atmosphere of nitrogen Bact. stewarti behaved on coconut cylinders the same as Bact. hyacinthi. At the end of 15 days, when the seal was broken, there was no visible growth, although the check-tubes showed a distinct yellow color in 48 hours and continued to develop typically. Exposure to the nitrogen also caused distinct retardation of growth after the seal was broken, the yellow slime being first visible on the fifth to the eightl day thereafter. In another test, using white-turnip cylinders, there was no growth during the 15 days exposure, and none subsequently. The checks grew promptly. In a third experiment the absorption of the oxygen by the pyrogallol was very slow, occupying 5 days. During this time there was some growth, but at the end of 15 days it was paler yellow and only about one-thirtieth as abundant as in the check-tubes.

In an atmosphere of liydrogen for 16 days there was either no growth or only a trace of growth, according to the medium used: 

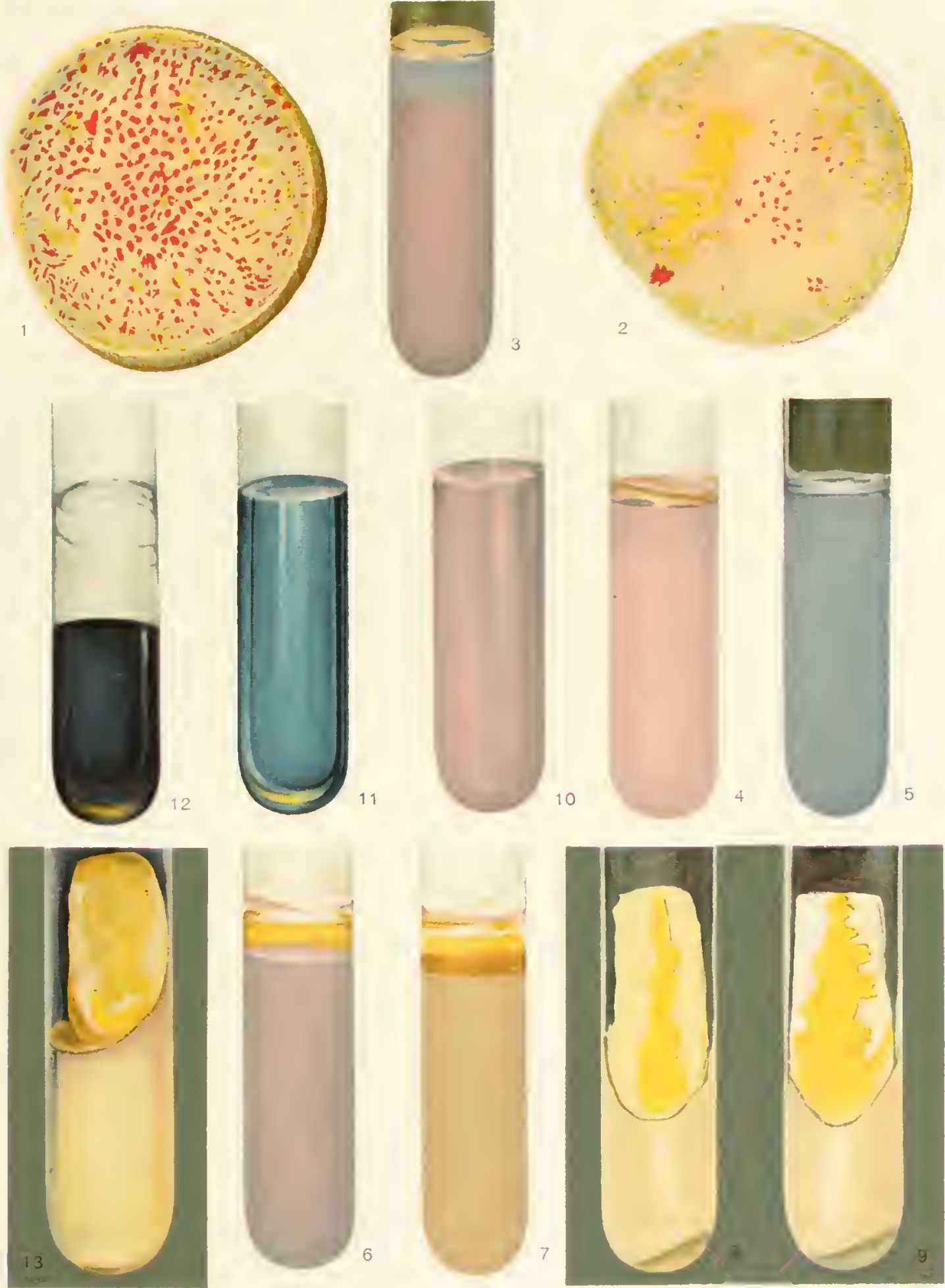

BACTERIUM STEWARTI.

(1) Cross-section of inoculated sugar cane (nodal region) showing red and yellow ooze; (2) Do. internodal region of stem. Bacterium stewarti: (3) Litmus-milk culture after 11 days at $25^{\circ} \mathrm{C}$. (milk fluid); (4) Do., another stock of milk, after 11 days at $27^{\circ} \mathrm{C}$ (5) Check on tubes, 3, 4, 6, and 7. Aplanobacter michiganense: (6) Litmus-rnilk, 8 days at $27^{\circ} \mathrm{C}$.: (7) Do. after 11 days at $27^{\circ} \mathrm{C}$., litmus reduced, milk fluid; (8) Potato streak culture after 48 hours at $25^{\circ} \mathrm{C}$.; (9) End of 3 rd day at $25^{\circ} \mathrm{C}$. (10) Check tube of litmusrailk for comparison with 11 and 12. Bacterium vascularum: (11) Litmus-milk inoculated March 25, 1905, from 16. October 6 (organism originally plated from inoculated cane No. 40) and painted May 2, showing gradual increase in alkalinity with a slight yellow precipitate (12) Do. an older litmus.milk culture, tube $X$ inoculated March 25, 1905, painted June 10 (organism out of cane No, 40); (13' Do. potato cylinder standing in distilled water, inoculated October 19, 1905, from June 7, painted October 24 (descended from cane plant No. 40). 

(1) In the first experiment there was no growth on potato and a decided retardation after breaking the seal; in beef-broth there was either no growth, or only a trace of growth, but no retardation on exposure to the air; on slant agar there was a distinct, very feeble growth, consisting of several hundred tiny whitish colonies, best seen under the handlens. On exposure to the air these colonies enlarged and became buff-yellow.

(2) In the second experiment, which also lasted 16 days, there was no growth in +15 beef-broth, and no retardation of growth on subsequent exposure to the air. In peptone-water with grape-sugar and methylene hlue there was a trace of growtl, and no marked retardation on exposure to the air. In salted peptone-water (Dunham's solution) with rosolic acid there was no growth, and not much afterward. In Uschinsky's solution there was no growth and none afterward in the air.

Eacl of these tubes received a $2-\mathrm{mm}$. loop from a cloudy culture 5 day's old in peptonized beef-boullon neutral to phenolphthalein, and it was known by previous tests that the organism grew well in these media.

During Io days' exposure to an atmospliere of carbon dioxide there was no growth. On subsequent exposure to the air there was no retardation of growth on the coconut, some retardation on potato, and no growth in beef-broth.

In a second test in carbon dioxide (1+ days) there was no growth wliatever on potato or in bouillon. 'The cliecks grew. I find no record of the subsequent belnavior of the exposed tubes.

Growth in vacuo depends entirely on the degree of exhaustion.

In a vacuum with the mercury at 2.25 inches, the remnant of the oxygen having been absorbed by pyrogallol in caustic-potash water, there was no growth during the 9 days' exposure, and a distinct retardation of growth after remoral to the air. The four corresponding check-tubes $(2$ coconut, 2 potato) showed a distinct buff-yellow growth in 48 hours.

In a second test on coconut, potato and carrot, and in alkaline beef-bouillon, the jar being sealed witl the mercury at 3 inches and the remnant of the oxygen not renoved, there was a slight, retarded growth, paler than on the checks and less in anount. 'The check-tubes showed a good growth at the end of the third day, and a plainly visible one in 48 hours. On the twelfth day, when the seal was broken, conditions were as follows:

Carrot.-Merest trace of growth.

Potato.- About 0.33 to 0.50 as 1 nuch growth as on check; potato not grayed.

Coconut.-Thin cream-colored growth. The check is buff-yellow and contains several times as inuch growth.

Beef-broth.- Very feebly clouded. The clieck is twice as cloudy and contains twice as much bacterial precipitate and this is yellower.

All of these cultures made additional growth on exposure to the air.

No acid reaction was obtained when Bact. stewarti was grown in bouillon containing glycerin or ethyl alcohol.

In culture-media in the presence of air, this organism breaks up the following substances without gas, but with the formation of a small quantity of non-rolatile acid: grape-sugar, cane-sugar, galactose, mannit.

In a repetition of these tests in $\mathrm{I} 908$, using $B$ act. stcwarti from three sources and streaking on litmus agars containing only agar, water, Witte's peptone, and the specified sugar or alcohol, and inoculating copiously (two $3 \mathrm{~mm}$. loops) from bouillon cultures 3 days old, the following results were obtained: Find of 48 hours-distinct growth, but no reddening either with plain agar or that containing dextrose, lactose, galactose, maltose, mannit, or glycerine. Most growth on that containing the cane-sugar, and on this a trace of red at the extreme top of the slant. On the eleventh day the conditions were as follows:

(I) Plain agar.-Bluer than checks. Rather feeble growth.

(2) Dextrose agar. - Two strains bluer than checks, except for dab of red in one at extreme top. Third (a weaker strain in other media) dull red throughout.

(3) Lactose agar.-Two are bluer than checks, except dabs of red at extreme top of slant. Third (weaker strain) purplered in upper two-thirds (in upper one-third 4 days earlier).

(4) Galactose agar.--Each dull purple-red. Redder than cheeks but not bright red. The checks were a blue purple.

(5) Maltose agar.- Fiach tube is biuer than the checks. This was also true + days earlier.

(6) Wannit agar.-Distiuctly bluer than the checks, but a dab of red at extreme top of one tube (not the weaker). This was not present 4 days earlier.

(7) Gtycerin agar. - The litmus is now a dull purple-red. It was neutral \& days earlier. Slight acid formation, perhaps $\mathrm{CO}_{2}$.

(8) Sacchurose agar.-Eiach uniform in color and bluer than the checks, except for a dab of red at the extreme top of each slant where the agar is drying out. Here would seem to be an acid masked by an alkali.

In salted peptone-water (Dunham's solution) containing rosolic acid and a slight amount of hydrochloric acid (color of fluid a pale orange-yellow) there was no decided change during the first two weeks, but on the twenty-eighth day the fluid was pale red, and subsequently geranium red. This mediun would serve to differentiate Bact. stcwarti from Bact. hyacinthi and Bact. campcstre, cultures of the former being colorless and cultures of the latter geranium red at the end of the second week. 
In cultures in peptone-water containing acid fuchsin and a little hydrochloric acid (to counteract the alkalinity of the Witte's peptone) the red color persisted a long time, fading very gradually; the moderate amount of bacterial precipitate was yellow and unstained.

When Bact. stewarti was inoculated into salted peptone-water containing indigo carmine, there was no immediate reduction, but the blue color disappeared after about 2 wecks. In the case of $B a c t$. hyacinthi and Bact. pericarditidis (B.pyocyaneus pericarditidis) the blue color persisted for a long time, gradually changing to green, and then fading.

TABLE 17.-Growth of Bacterium stewarti in Various Media. Inoculations of August 3, IgoS. McCulloch and Gallow'ay Strains.

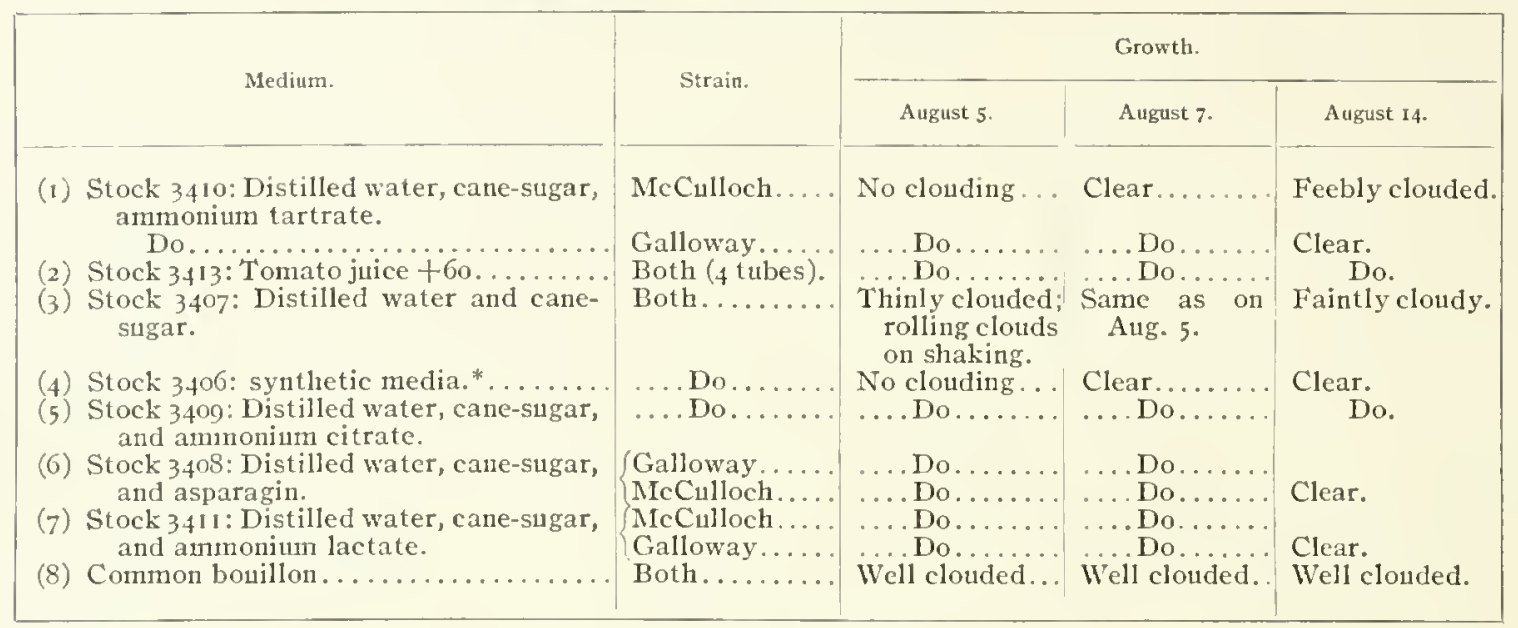

*For composition, see p. 141, footnote $3(\ddagger)$.

TABLE 18.-Growth of Bacterium stewarti in Various Mcdia. Inoculations of August 5, 1908 (from Bowillon Transfors made from an Agar Stab, No. I, November I6, I907), MIiss Ilcdges' Strain. $\dagger$

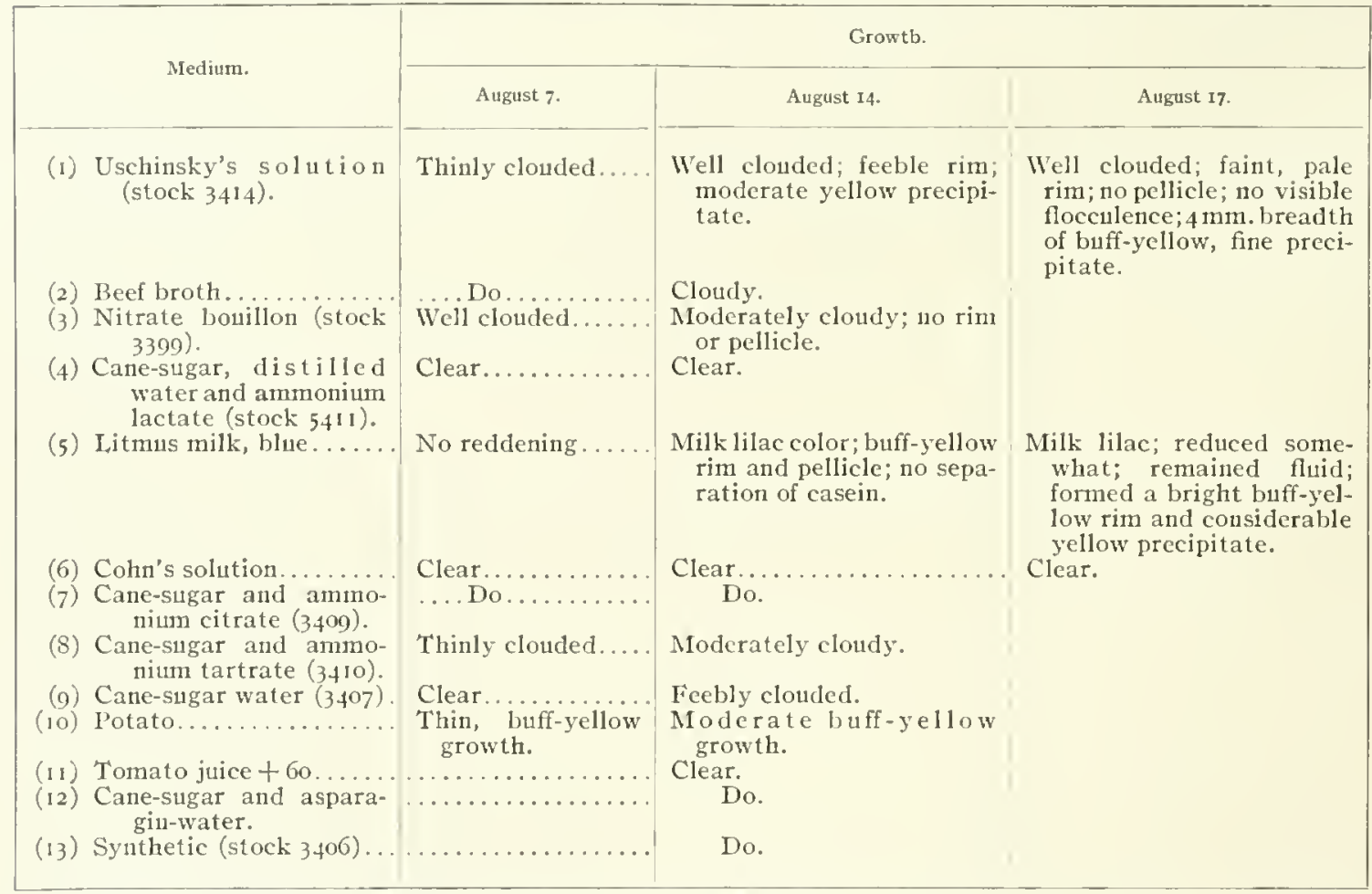

Th This third strain was plated in 1907 by Miss Hedges and transferted by Miss McCulloch Aug. 3. 1908, from agar-stab (No. I, Nov. 16, 1907) which

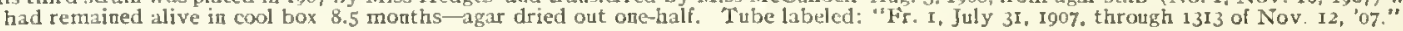


TABLE I9.-Growth of Bacterium stewarti in Various Media.

Each tube was inoculated with 2 big $3 \mathrm{~mm}$. loops of the eloudy fluid from a 6-day-old peptonized beef-broth culture. (Firom notes of August 17.1908.)

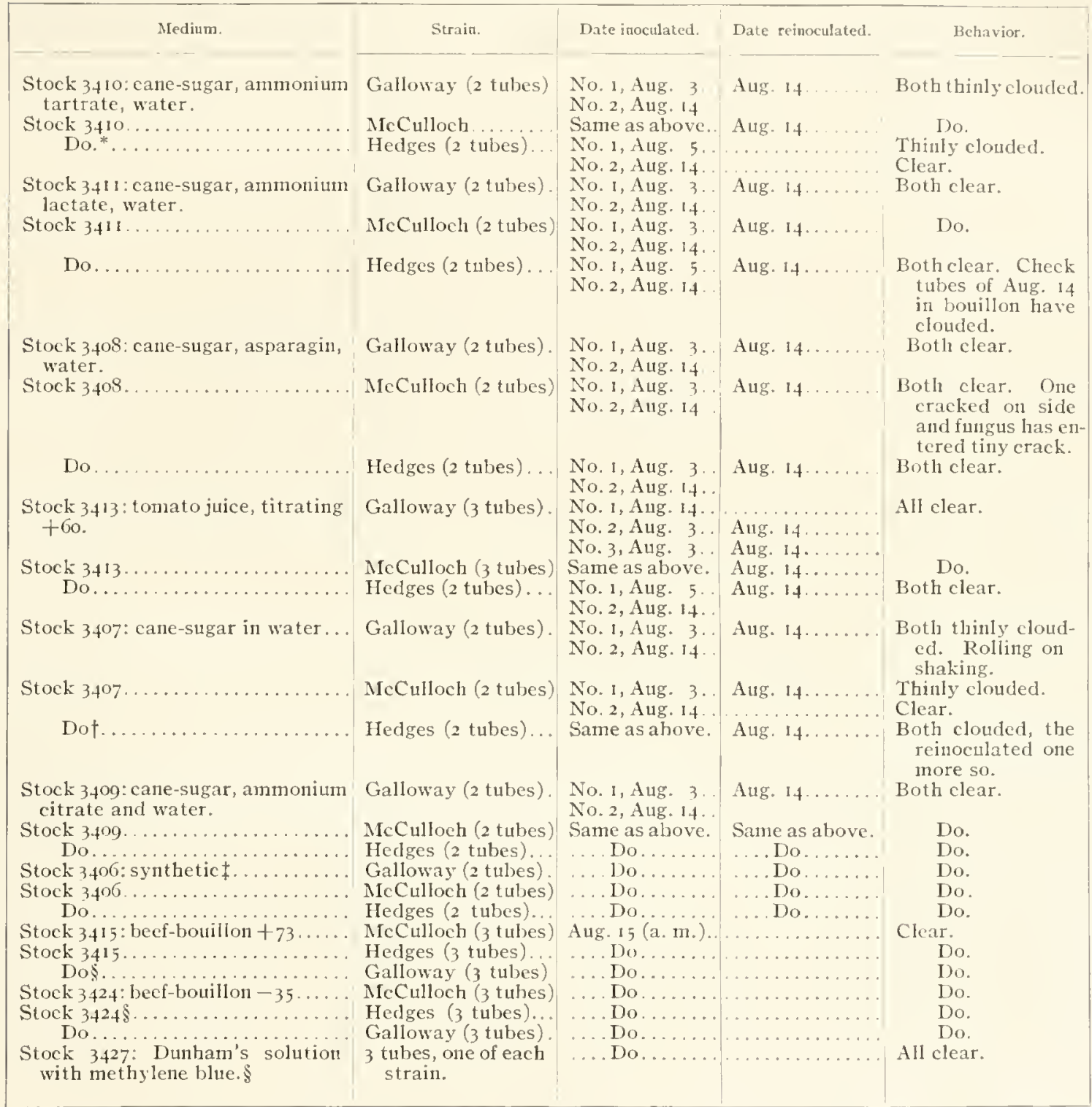

* Conclusion: Bacterium stewarli will grow in this medium but has some difficulty in getting started. Must be inoculated copiously †Medium evidently not catirely free from nitrogen.

+Composed of: distilled water 1,000; dipotassium phosphate 2.0; magnesium sulphate 0.1 ; ammonium phosphate 0.1 ; sodium acetate 5 . 0 . to clouding.

\$September 22: Stock 3415 heavily clouded; stock 3424, doubtful, if any, growth; stock 3427, color much duller than in the check, due

Nitrogen foods. - The behavior in Usehinsky's solution indicates ability to use sodium asparaginate and anmonium lactate, one or both, under the conditions present.

The inability to reduce potassium nitrate shows that nitrogen is not obtained from this source. Peptone and the nitrogen in beef-juice are both foods.

Tests made in I 908 with Bact. stewarti from three sources, inoculating copiously, gave the following results:

(I) No growth or doubtful: Asparagin water (2 per cent asparagin); ammonium lactate and cane-sugar in watcr; ammonium citrate and cane-sugar in water; ammonium tartrate and cane-sugar in water.

(2) Feeble clouding: Asparagin and cane-sugar in water. 
In table 17 are given the notes of Angust 5, 7, and I4, 1908, on the growth of two strains of Bacterim stewarti in various media, inoculated August 3 from 4 -day-old bouillon cultures proven to be alive by inoeulation therefrom to common boullon which had clouded. The two strains used were (I) McCulloch, isolated from Fairfax, Virginia, corn i11 I907; (2) Galloway, isolated from Golden Bantam corn from Dr. B. T. Galloway's Maryland farm, I908. One tube of each medium was used, except acid tomato juice, of which two were used, each tube receiving all the fluid that could be taken up on a $3 \mathrm{~mm}$. loop-a drop. Temperature $30^{\circ} \mathrm{C}$. Table 18 gives notes on a third strain, and table 19 summarizes the results of reinoculations with each one of the three strains.

Bact. stewarti produces only a moderate amount of alkali, and in some media, $\epsilon . g$., milk, this is wholly obscured by the moderate production of acid. The following media are usually rendered alkaline to litmus: Beef-bouillon, plain peptone agar, potato eylinders, maltose agar.

Potato cylinders are usually grayed by Bact. stewarti, but strips of lead acetate paper were not browned by exposure over them for 9 days. Cultures on rutabaga and on yellow globe turnip did not brown the paper nor stain the substratum (6.4 days); white radislı was not browned in 64 days.

Indol.- In one set of cxperiments a slight indol reaction was obtained; in two others made subsequently there was no pink color on adding sodium nitrite and silphuric acid, but a slight pink color appeared on heating the tubes at $80^{\circ} \mathrm{C}$. for a few minutes. The latter were cultures 14 days old in peptone-water, and in peptonized Uschinsky. The question of indol formation must therefore be left an open one.

Pigments.-The yellow pigment is probably similar to that in other yellow species of bacteria, i. e., lipochrone (see vol. II, Bact. hyacinthi). No special studies have been made. Its color varies from buff-yellow to chrome, but is much paler when the supply of free oxygen is scanty.

The brown pignent formed by this organism does not appear as readily in culture-media as that of Bact. campestre. For instance, cultures of the latter stain cruciferous substrata dark brown in the course of 6 or 8 weeks, while in the same media (radish, rutabaga, yellow globe turnip) Bact. stewarti produces no stain.

'The organism causes a brown stain in the host-plant, but this is perhaps a host reaction. 'This develops slowly and is usually most conspicuous in the parts longest occupied, $i . \epsilon$, in the lower nodes.

Crystals.-Crystals occur in old agar cultures. They are prismatic (fig. 63) or jagged X-shaped. They were once seen in cultures on coconut. Contamination (?).

Enzymes. - Our knowledge of the enzymes produced by Bact. stewarti is very imperfect. Cavities are formed in the host-plants, and there must therefore be some substance capable of dissolving the middle lamella although not necessarily an enzyme. The question of the existence of a cytase is an open one. In test-tube cultures, the tissues of potato, coconut, rutabaga, yellow globe turnip, radisl, and carrot were not softened. Cane-sugar is inverted, but invertase was not formed in the absence of sugar (beef-broth without peptone). Bacterium stewarti has only a slight action on potato-starch and therefore very little diastase is produced. In this particular it resembles Bat. hy'acinthi and differs widely from Bact. campestre. No trypsin and no lab-ferment are produced. Old cultures cause a copious evolution of oxygen from lyydrogen peroxide.

One gram of grape-sugar in 10 c.c. of +15 nutrient agar did not retard the growth of Bact. slew'arti in streak-cultures; on the contrary, growth was stimulated from the start, being in 48 hours four times as great, and at the end of a week at least five times as great as in the check-tubes.

I'itality.-Bacterium stewarli lives for a considerable tine on culture-media, especially on agar, in milk, and in Uschinsky's solution. It was dead on agar in the ice-box at the end of $\mathbf{1 7 . 5}$ uonths. It was alive under similar conditions on the same medium at the end of $\mathrm{I}+\mathrm{months.}$ It lived in litmus milk for 7 months and in Uschinsky's solution for 4 months. It remained alive in a variety of culturemedia for more than 2 months.

Mixed cultures and infections.-In the host-plant the organism often occurs in pure cultures. Nothing is known respecting mixed infections, or the effect of other organisms on this one in mixed cultures. In pure culture the organism does not readily lose its power to infect maize.

Germicides.--Very little is known respecting the behavior of this organism toward antiseptics and germicides. 
In test-tubes in beef-broth standing over chloroform the organism grew vigorously with only a slight retardation and remained alive for nore than 2 months. Under the same conditions Bact. campestre refused to grow.

In streaks on slant nutrient agar containing plenolphthalein and 0.5 per cent potassium formate, considerable growth appeared at the end of 48 hours and a faint pink tint on the third day, none on the second. At the end of the tenth day this color was still very faint and after 3 weeks transfers from the tubes failed to grow.

The organism also grew (after a second inoculation) in neutral beef-bouillon containing I per cent potassium formate.

Infected kernels were nearly sterilized by exposure for I 5 minutes to I : 1000 mercuric eliloride water (see p. 125).

Heat.-The thermal death-point of Bact. stewarti in + 15 beef-bouillon (ro minutes' exposure) is approximately $53^{\circ} \mathrm{C}$. In Uschinsky's solution it is a little higher.

'The maximum temperature for growth is about $39^{\circ} \mathrm{C}$. It grows in the thermostat on most media at $36^{\circ}$ to $37^{\circ} \mathrm{C}$., but not so well as at room-temperatures of $24^{\circ}$ to $25^{\circ} \mathrm{C}$. It refused to grow in the thermostat at $40^{\circ} \mathrm{C}$., in to beef-botillon and in Uschinsky's solution.

The minimum temperature for growth was determined as follows: In the earlier experiments tubes of Uschinsky's solution and of alkaline beef-broth $\left(3 S_{2}\right)$ were inoculated with a $3 \mathrm{~mm}$. loop from a fluid culture 3 days old and then exposed in the ice-box for is days at $2.8^{\circ}$ to $4.5^{\circ} \mathrm{C}$. The checks clouded the second and third days, but during all this time there was no clouding of the tubes in the ice-box, and probably no growth because, contrary to Bact. hyacinthi, on removal to room-temperatures the fluids did not cloud any sooner than the check-tubes.

Subsequent experiments (summer of 1909) showed the minimum temperature to be about $9^{\circ} \mathrm{C}$. The exposure was for 34 days in the ice-thermostat with the results shown in table 20 , four tubes ( $t$ wo strains) being placed in each compartment in +15 peptonized beef-bouillon inoculated from young cloudy bouillon-cultures.

The checks at room-temperature clouded promptly. The tubes in compartments I, II, III clouded on removal to room-temperature and showed a yellow precipitate. They were first examincd on tlie ninth day. The optimum temperature for growth is above $30^{\circ} \mathrm{C}$.

TABLE 20.-Result of Minimum Temperature Experiments in the Ice Thermostat.

\begin{tabular}{|c|c|c|c|c|}
\hline $\begin{array}{l}\text { Compart- } \\
\text { ment. }\end{array}$ & Temperature. & Tenth day. & Eighteenth day. & Thirty-lourth day. \\
\hline I. & $\begin{array}{l}1^{\circ} \pm \mathrm{C} \ldots \ldots \\
3.5^{\circ} \text { to } 5.9^{\circ} \mathrm{C} ; \\
\text { mostly under } 5^{\circ} \\
\text { and above } 4^{\circ} \mathrm{C} \text {. } \\
\text { Range } 6.5^{\circ} \text { to } 10.5^{\circ} ; \\
\text { ave. } 74^{\circ} \text { observa- } \\
\text { tions, } 9^{\circ} \mathrm{C} \text {. }\end{array}$ & 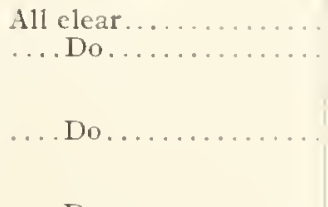 & 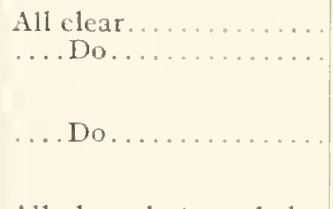 & $\begin{array}{l}\text { All elear. } \\
\text { Do. } \\
\text { Do. }\end{array}$ \\
\hline IV. & $\begin{array}{l}\text { Range } 8.2^{\circ} \text { to } 11^{\circ} \mathrm{C} . \\
\text { ave. } 74 \text { observa- } \\
\text { tions, } 9.4^{\circ} \mathrm{C} \text {. }\end{array}$ & 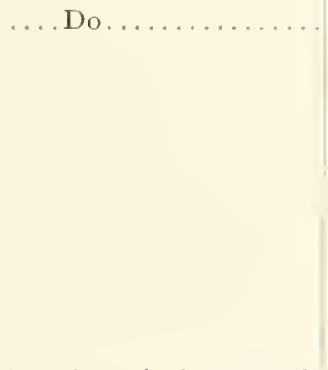 & $\begin{array}{l}\text { All clear, but on shak- } \\
\text { ing some tiny zooglo- } \\
\text { eie in one tube of the } \\
\text { 4, }{ }^{*} \text { indicating a very } \\
\text { feeble and abnormal } \\
\text { growth on the bot tom. }\end{array}$ & $\begin{array}{l}\text { No true elouding; clear until } \\
\text { shaken, then many psendo- } \\
\text { zoogloea in fluids inoeula- } \\
\text { ted with MeCulloch strain, } \\
\text { and a few ( } 100 \text { or more) in } \\
\text { fluids inoeulated with Gal- } \\
\text { loway strain, } i \text {. e., at mini- } \\
\text { mum temperature motility } \\
\text { is eut out and growth } \\
\text { eonsists of eompaet small } \\
\text { psendozoogloea, lying on } \\
\text { bottom of tubes (side when } \\
\text { tilted). }\end{array}$ \\
\hline$V$ & $\begin{array}{l}\text { Rat1ge } 8.3^{\circ} \text { to } 12.3^{\circ} \\
\mathrm{C} ; \operatorname{mos} 1 \mathrm{y} 10^{\circ} 10 \\
11^{\circ} \mathrm{C} .\end{array}$ & $\begin{array}{l}\text { Zoogloex in bottom of } \\
\text { tubes; these cloud } \\
\text { the fluid feebly on } \\
\text { shaking; not a normal } \\
\text { growth. }\end{array}$ & $\ldots \ldots \ldots \ldots \ldots \ldots \ldots$ & $\begin{array}{l}\text { Same as IV, but also some } \\
\text { true clouding in top layers. }\end{array}$ \\
\hline VI. & $\begin{array}{l}\text { Range } 11.6^{\circ} \text { to } 15.2^{\circ} \\
\text { C.; mostly } 14^{\circ} \mathrm{C} \text {. }\end{array}$ & $\begin{array}{l}\text { Botillon thinly clouded; } \\
\text { also small flocks visi- } \\
\text { ble on shaking; this } \\
\text { clouding was visible } \\
\text { on } 6 \text { th (?) day. }\end{array}$ & & \\
\hline
\end{tabular}


Effect of Acids.-Bacterium stewarti is rather resistant to acids. It tolerates much more of lactic, malic, or tartaric acid than Bact.hyacinthi. (See observations under growth in acid plant juices, etc.) Dry A ir. - The relative resistance to dry air is not known. Its resistance is probably considerable.

Sunlight.-Stewart exposed a portion of an agar-poured plate to bright sunlight for 3 hours, nearly all of the organisms being destroyed. Under the covered portion colonies came up thickly in 4 days at $23^{\circ} \mathrm{C}$. 'The writer has made no experiments.

Effect on Animals.-.'The organism is not known to be pathogenic to animals. The writer has made no experiments. It is frequently fed in great quantity to cows (in corn stalks).

Additional eultural tests were made in 1913 with the following results:

Beef bouillon over chloroform: Growth retarded for some days, but after two weeks about equal to growth in ordinary bonillon.

Alkaline peptone beef-bouillon ( - to stock 5700, -35 stock 5792, and -30 stock 5791: No growtl1 (Ja11. 18, Feb. 24, April 3, May 28). The tubes were inoculated hearily both from agar and bouillon.

Cabbage juice $\left(+\mathrm{I}_{7}\right)$ : A good growth. After several months a copious, dirty yellow, moderately alkaline growth, free from crystals (May 28).

Tomato juice $(+60)$ : No growth.

Cohn's solution: No growth in 6 weeks.

Uschinsky's solution: A good growth.

Asparagin (2 per cent in distilled water): No growth in 3 months.

Asparagin (2 per cent in river water): Slight growth after 41 days in tubes heavily inoculated from agar cultures; none in 2 months in tubes inoculated from peptone beef-broth cultures.

Peptone water (stock 5705, 2 per cent Witte's): Growth. No indol reaction after io days; slight indol reaction after 22 days. Tested with sodium nitrite and sulphuric acid.

Cane-sugar with asparagin (stock 5704): Growth in 2 tubes out of 10 after 2 months.

Temperalure: Thermostat 24 hours at $27^{\circ}$ to $28^{\circ} \mathrm{C}$. Good clouding.

Ice box, compartment 6 (temperature $14^{\circ}$ to $14.5^{\circ} \mathrm{C}$.). Clouded in 48 hours and cleared in 14 days. In compartment 5 (temperature $8.4^{\circ}$ to $12^{\circ} \mathrm{C}$, average about 10 $\mathrm{C}$.) zoogloeæ visible in $\mathrm{S}$ to 10 days. Not then clouded, but a faint clouding after 22 days. In compartment 4 (temperature $8^{\circ}$ to $11^{\circ} \mathrm{C}$.) slight clouding in 29 days (McCulloch strain); in 39 days (Galloway strain). In compartments 3 to $\mathrm{I}$ (temperature $6.5^{\circ}$ to $10^{\circ} \mathrm{C} ., 3.7^{\circ}$ to $5.4^{\circ} \mathrm{C}$, and $0.9^{\circ}$ to $1.5^{\circ} \mathrm{C}$. respectively), no clouding or zoogloex in 39 days, but when removed to room temperature the tubes clouded in less than 7 days.

\section{RÉSUMÉ OF SALIENT CHARACTERS.}

POSITIVE.

Yellow organism causing a vascular disease of maize, especially of sweet corn; short rod with rounded ends, generally less than $4 \times I \mu$, often I to $2 \mu \times 0.5$ to $0.7 \mu$; occurs singly, in pairs or fours, joined end to end, or as small pseudozoogloex (in various media); motile by means of a polar flagellum (sometimes more than one is present); stains readily with various anilin dyes, often not uniformly with carbol-fuchsin; very slow growth in gelatin, surfacegrowth dense, rather dry, slightly roughened, bright buff-yellow; good bright buff-yellow growth on Loeffler's blood-serum; slow growth on agar plates, forming small, round, yellow, surface colonies, buried colonies very small; smooth, translucent growth on agar streaks, frequently lobed on the margins; jagged $X$-shaped or prismatic crystals often present in old agar-cultures; good growth whole length of the stab in stab-cultures in agar; good growth in nitrate agar, whitish at first; very feeble growth on silicate jelly (Fermi's solution); moderate amount of yellow growth on potato cylinders accompanied by graying of the potato; very little action on potato starch; moderate buff-yellow growth on coconut cylinders; thin buff-yellow slightly iridescent growth on cylinders of yellow turnip; growth on rutabaga resembling that on turnip; excellent deep buff-yellow growth on sugar-beet cylinders; feeble whitish rim and pale yellow precipitate in peptonized beef-bouillon which becomes well clouded; prolonged and copious growth in cabbage-leaf juice titrating +40 ; growth in tomato-fruit juices (titrating +55 , +59 , and +64 , Fuller's scale) was retarded at first but later was prolonged and copious; good growtl in potato broth titrating +30 , 
on Fuller's seale and +45 (by addition of malic acid); a retarded but prolonged and luxuriant growth in concentrated $(+73,+80)$ beef-broth; a good growth in +30 beef-bouillon; slow production of acid (lilae color) in litmus milk, followed frequently by the reduction of the litmus; milk enltures alive at end of 7 months; long and copious growth in Uschinsky's solution, yeilow rim and pellicle, latter sontetimes bearing circular yellow colonies - a very good mediun for differential purposes; growth on nutrient starch-jelly greatly stimulated by the addition of eane-sugar or galactose; growth stimulated by addition of ro per cent grape-sugar to + I 5 nutrient agar; feeble growth in Fermi's solution; strictly aerobic (so far as known); eultures on coconut cylinders live some days in an atmosphere of nitrogen, but make no growth; cultures on white turnip cylinders killed by i 5 days' exposure to nitrogen; in atmosphere of carbon dioxide no growth, but organism is not killed on some media, e.g., coconut cylinders. Growth in vacuo depends on amount of air remaining; grape-sugar, eane-sugar, galactose, and mannit are broken up with formation of a small quantity of non-volatile acid; old cultures in Dunham's solution containing rosolic acid and a slight amount of liydrochloric acid become pale red and subsequently geranium-red; Dunlam's solution containing indigo-carmine lost its blue color after about 2 weeks; slight amount of indol formed; organism causes a brown stain in the plant (host reaction?) and produees small cavities in parenchyma. Cane-sugar is inverted. Alive on agar in ice-box $\left(12-15^{\circ} \mathrm{C}\right.$.) at end of 14 months and 17 months; lived in litmus milk 7 months and in Usehinsky's solution 4 1110nths. Vigorous and only slightly retarded growth in bouillon over chloroform. Tolerates much sodium chloride. Thermal death-point approximately $53^{\circ} \mathrm{C}$; maximum temperature abont $39^{\circ} \mathrm{C}$; optimum temperature above $30^{\circ} \mathrm{C}$; minimum temperature $8^{\circ}$ to $9^{\circ} \mathrm{C}$. Retains virulence on media for a year, or more, and as long on, or in, infected kernels. Absorbs methylene blue. Group No. 212.2222523.

NEGATIVE.

No long chains, filaments, or endospores have been observed; not stained by Gram's method; no reduction of methylene blue in salted peptone water; no liquefaction of gelatin or I,oeffler's blood-serum; agar not stained; no gas formed in nitrate agar or any other nedium; no filling up of the water in cultures on potato eylinders; no growth in tomatofruit juice titrating +68 Fuller's scale (once none in that titrating +60 ); 110 growth in mulberry agar (acid); no preeipitation of the easein or coagulation in milk cultures; no growth in - so peptonized beef-bouillon (sodium hydrate); no growth in $-30,-35,-40$ beefbouillon; no growth in Cohn's solution; no reduction of nitrates; no elouding of elosed end or production of gas in fermentation-tubes; little or no growth in an atmosphere of hydrogen; no production of hydrogen sulphide observed in eultures on potato, rutabaga, or yellow globe turnip; invertase not formed in the absence of sugar; very little diastase produced; 110 trypsin or lab ferments formed; no growth at $40^{\circ} \mathrm{C}$., in to beef-bouillon, or in Uschinsky's solution. No growth in peptonized beef-bouillon after long exposure to carbon dioxide. Asparagin not a carbon food. No acid reaction in bouillon containing glycerin or ethyl alcolıol; 110 indol production in ro days. It was dead at room temperatures after 6 months o11 potato; 7 months in lituus milk; 8 months in sodium chloride bonillons; 5 months in agar, potato, and beef bouillon, i 6 inontlis on peptone beef gelatin. It was dead in the refrigerator on agar after 17.5 months. In earbon dioxide 110 growth.

Any organism producing gas, liquefying gelatin, blueing litunus 11ilk or throwing down the casein, reducing nitrates, growing well in Cohn's solution, or refusing to grow in Usclinisky's solution may be set down at once as something else.

\section{TREATMENT.}

The proper treatment for this disease remains to be worked out. Four lines of investigation will oceur at once to the reader who has followed the text to this point. First and foremost, compulsion applied to the growers of sweet corn for the trade. They must be 
compelled to practice field hygiene. In bringing this about seedsmen generally (middlemen) should cooperate with State authorities. Second, the origination of resistant varieties by cross-breeding and selection. By this method alone, wisely pursued, it ought to be possible to overcome the disease, but not immediately. Third, treatment of the seed-corn with germicides, such as mercuric chloride, formalin, ete. Fourth, bactericidal powders or sprays applied during the seedling stage when the water-pores are functioning and the plants are specially liable to contract the disease. Probably the plants will prove very sensitive to chemicals during this stage of growth, and one should therefore proceed with caution lest the damage wrought be greater than that likely to result from the disease. The first and third methods are the more feasible. These directions are intended primarily as suggestions to plant pathologists rather than as advice to growers, although some of the latter might be able to work out their own methods of treatment.

To prevent the introduction of the disease into new fields, growers of sweet corn for seed, and seed-firms generally, should cooperate with the farmer. The former ought not to put on the market seed-corn likely to transmit the disease, that is, corn grown on land subject to this disease, and the farmer as a matter of ordinary precaution ought to treat his seed-corn with some germicide before planting it, unless he knows beyond doubt that it was derived from healthy plants. The thermal death-point of the organism is so high $\left(53^{\circ} \mathrm{C}\right.$.) that probably hot-water treatment of the seed would not be effective. Soaking the seed 20 minutes in $x$ to $\mathrm{I}, 000$ water-solution of corrosive sublimate in glass vessels or in wooden pails or tubs is the method most likely to destroy the organism on the surface of the kernels without serious injury to the latter. It will slightly retard the germination of a portion of the kernels, but should not destroy any of them, if the treated seed is immediately rinsed in elean water on taking it out of the germicide, or dried at once and planted without rinsing. The writer, as the result of experiments made in 1909 (see vol. II, p. 196), has no liesitation in advising exposure of suspected seed to mercuric clloride water (I : I,OOO) for 20 minutes just prior to planting. This will destroy most of the bacteria on the seeds and will not prevent germination or seriously delay it. 'The dry seed-corn should first be wet with alcohol, then covered with the germicide, removed at end of 20 minutes, rinsed slightly, and planted at once, or else dried quickly. The corn must not be soaked in advance of treatment; nor must the rinsing be prolonged. Such treatments, of course, will not reach the organism when it is lodged in the interior of the kernel. As an added precaution, therefore, all shrunken, suspicious kernels should be removed from the seed-corn before it is treated. This may be done by running the kernels through a fanning mill and by a little subsequent landpicking. The latter should not be neglected.

To recapitulate: The greatest pains should be taken to secure only sound secd-corn, but in the present indifferent state of the secd-trade even the best should be treated with mercuric chloride before planting. On ficlds subject to the disease only resistant varictics should be planted. Mamire containing com stalks from discased fiolds, or gathered from animals pasturcd in such ficlds, should never be used on land designed for corn.

\section{PECUNIARY LOSSES.}

Nothing very definite ean be expressed under this head. There are no general statisties available, only individual instances.

The disease is a bad one on Long Island, and, if the writer's inferences under "Etiology" are correct, also in at least one locality in Ohio. That the disease may take from ro to 70 per cent or more of the plants in experimental plots, not artifieially inoculated, is also shown by the record of the trial plots mentioned on pages i 77 to 120.

The general experience on Long Island is summarized by Stewart as follows:

Occasionally, an entire crop has been ruined and losses of from 20 to 40 per eent have been frequent; but in the majority of cases the loss has been so slight as to pass unnoticed by the farmer, although one familiar with the disease could readily detect it in almost any field of early sweet corn on Long Island_during,the past season. 
The disease is on the increase in the United States and has been, I believe, disseminated widely in recent years by ignorant and unserupulous seedsmen. It is likely to be found now in any State.

\section{HISTORY.}

'The history of this disease begins with Stewart's bulletin (1897), unless we are to assume that Burrill's bulletin "On a bacterial disease of corn" (I889) relates in part to the same subject. I have not included the latter in the bibliography of this disease, although perhaps I should have done so. Some parts of his description correspond very well to Stewart's disease, $c . g$., irregular distribition of the disease in the field; dwarfing; brown nodes; the base of the stalk most badly affected; death of the leaves as a whole, the lowest showing worse; and gumming of the ears; but if he really had this disease under observation, why is there no mention of the most conspicuous sign, $i$. e., yellow slime in the internodal bundles? The internodes appeared to him to be healthy in plants having the browned nodes. Along with these signs, as part of the same disease, are mentioned other less characteristic signs, $i$. e., decaying roots, the lower ones most affected; corroded spots on the roots; brown spots on the leaf-sheaths, most conspicuous within, and occasionally bordered by red. These brown spots are "half rotten" discolorations, the disease in this stage being evenly distributed through the field. There is a gelatinous bacterial substance on the roots and inside the leaf-sheaths. The description of the organisin which he isolated and with which he obtained infections is what

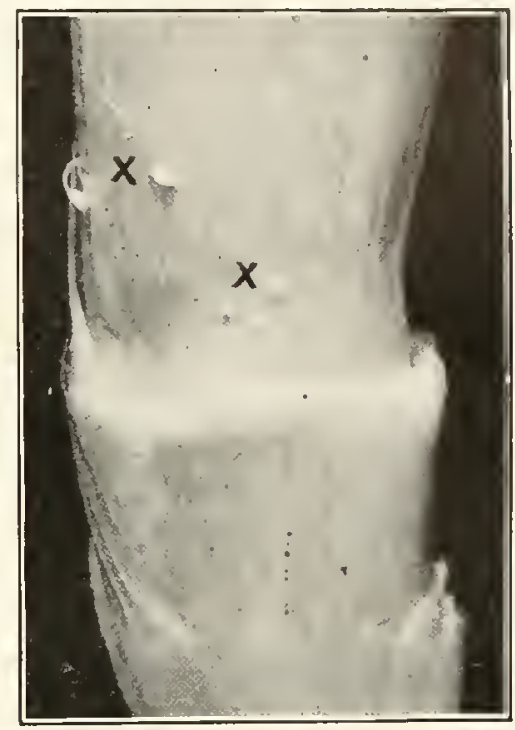

Fig. $64 a *^{*}$ finally decided me to exclude it. This was a white peritrichiate schizomycete subsequently identified by Dr. Theobald Snith as Bacillus cloacae.

\section{LITERATURE.}

1898. STEWART, F. C. A bacterial disease of sweet corn. New York Agric. Exp. Sta. Bull. No. 130, Dec. 1897 , pp. 423-439, plates I-IV, Geneva, N. Y. [Bull distributed in Jan. or Feb. I 898.]

Reprinted in i 6 th Ann. Rept Bd. of Control N. Y. Agric. Exp Station for $1897, \mathrm{pp}, 401-416$

1898. Smith, Frwin F. Notes on Stewart's sweetcorn gern, Pseudomonas stewari, 11. sp. Proc. Am. Assoc. Adv. Science. vol. 47 , meeting at Boston, Aug. 1898. Publislied at Salem, Dec. I 89 S, pp. $422-426$.

Also a separate.

1899. Halsted, Byron D. Swect corn smut and bacterial disease, in Mycological Notes, Torrey Bull., New York, Feb. 1899, p. 77.

Reports occurrence in 1898 of bacterial disease due to Pseudomonas stewarli in one variety of sweet coru at New Brunswick, N. J.
1901. SMITH, likw1N F. The cultural characters of Pseudomonas hyacinthi, Ps. campestris, Ps. phaseoli, and Ps. stewarti-Four one-Hagellate yellow bacteria parasitic on plants. Bull. 28., Div. of Veg. Physiology and Pathology, U. S. Dept. Agric., Govt. Printing Office, Washington, D. C., 1901.

1903. Surth, ERwin Ii. Completed proof that Ps. stewarti is the cause of the sweet-corn disease of Long Island.

Abstract of an address delivered Dec. 30, 1902. hefore the Society for Plant Morphology and Physiology. Science, n. s.. vol. xvil, No. 429. March 20,1903. Also a separate.

1909. SmITH, ERWIN F. Seed corn as a means of disseminating Bacterium stewarli. Science, 11. S., vol. $\mathrm{xxx}$, No. $76_{3}$, Aug. 13, 1909, pp. 223-224. [See also various figures and observations iu vols. I and II of this monograph.]

${ }^{*}$ Fig. 64a.--Pedicel of ear of sweet com, showing bacterial ooze from stomata at $\mathbf{x} \times$. Lxperiment of 1908 . Photographed from alcohol in $1914, \times 6$. Originally the cirri were much more conspicuous and ilten also water-soaked places were visible on the surface. See text, p. 126. 


\section{SMITH'S DISEASE OF AMARANTHS.}

This disease of anaranths was discovered by the writer in October 1897 , in a neglected garden at Mumford, New York. The plants were weeds standing on what had been a cabbage seed-bed. They were small and seemed to have dried up when half grown. There was no surface indication as to the cause of the disease. 'The stems were browned internally and there were cavities in the parenchyma in the region of the vascular ring. These cavities were full of bacteria. They were small, actively motile rods with rounded ends. Fungi were not observed. There was an abundance of the diseased plants, but unfortunately only a small anount of material was collected and the disease lias not cone again under

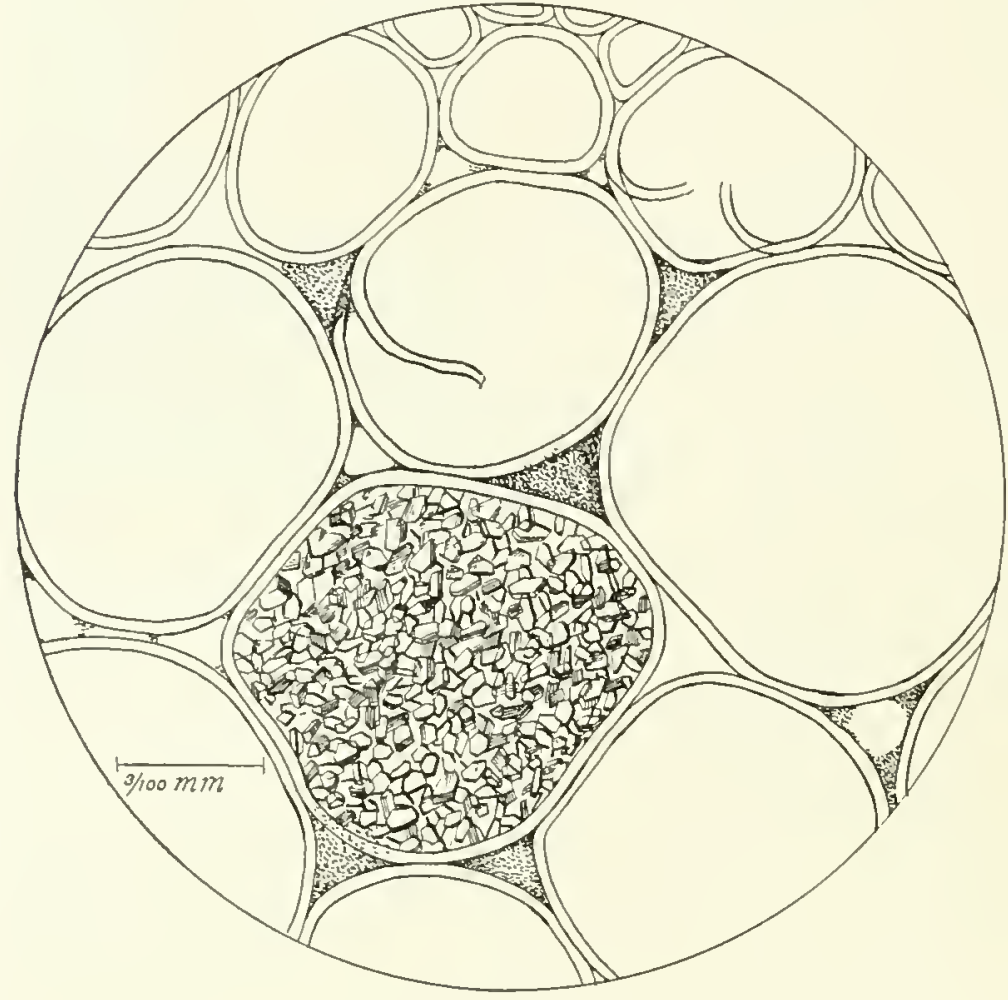

Fig. 65.* my observation. No plate cultures were made, but the organisms taken from the interior of two stems were streaked on four tubes of Loeffler's blood-serum - all that happened to be available.

It was my intention to keep the organism alive and make some inoculations, but during a winter crowded too full of other duties the cultures were allowed to die.

The organism nllay be known as Bacterizm amaranthi (syn. Pseudomonas amaranthi), but my knowledge of it is very incomplete.

The bacteria made at first a dirty white or pale yellowish-white, wet growth on the slant tubes of Loeffler's blood-serum. This subsequently became a yellow growth, and there was a rather copious yellow pre-

cipitate in the fluid at the bottom of the $V$. At first the growth was slower and looked unlike that of Bacterim campestre, but afterward on this medium the color was the sane or very nearly the same. No liquefaction was observed.

On potato evlinders which were inoculated from a single pale yellow colony on the side of the streak in one of the tubes of blood-serum, the manner of growth and the annount of growth closely resembled that of Bactcrimm hycinthi, but the color was quite different. The growth on the potato was homogeneous, wet-looking (shining), and did not obscure the surface of the potato. It produced a thin, translucent growth not at all resembling the allpervading growth of Bact. campestre on this medium. It grew best out of the water. No

*Frg. 65-Cross-section of an amaranth stem, showing a small portion of the pith in which are intercellular spaces occupied by Bucterium amaranthi. One cell is filled with crystals of calcium oxalate. Not much disorganization of lissues in this stem. Collected at Mumford, New York, October 1897. Slide 450 B 3, lower row, left-hand section. 
gas was formed. Its color on potato was at first pale yellow and then distinctly ochraceous a color lying between ochraceots and ochre-yellow (Ridgway's plate v, 7 and 9), i. e., there was much more buff in it than in cultures of Bact. campestre. It was cultivated at room temperatures ranging from $\mathbf{s} 8^{\circ}$ to $24^{\circ} \mathrm{C}$. The substratum was soon stained a decided gray (not brown), drab-gray (Ridgway's plate II, 13). I have a note saying that several tubes of potato inoculated with Bacterimm campestre the same day were not grayed (fourtl day). At the end of 25 days a little of the potato from immediately under the thin layer of bacteria blued litmus paper decidedly. On mashing old potato cultures in iodine potassium-jodide water there was a copious brown-purple reaction, showing that the starch had been acted upon only a little.

The organism grew on sugarbeet cylinders, producing considerable yellow slime, but the culture was dead at the end of 5 months.

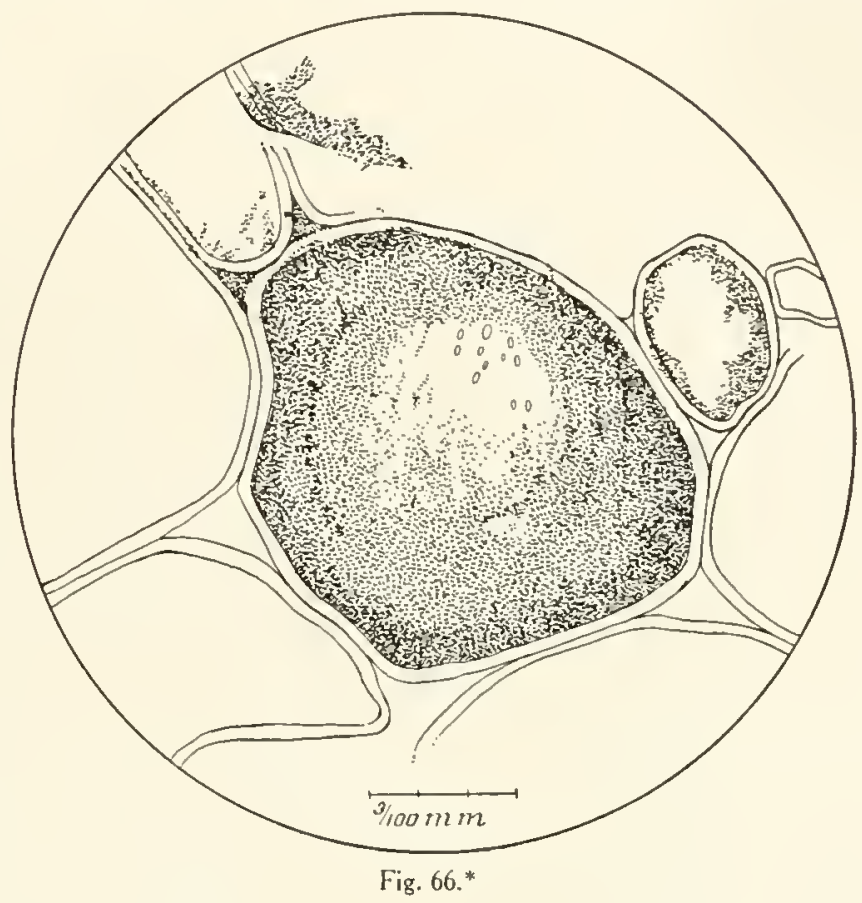

In its morphology, so far as examined, it closely resembled the ordinary forms of Bact. hyacinthi, being a short rod with rounded ends. No long chains, filaments or endospores

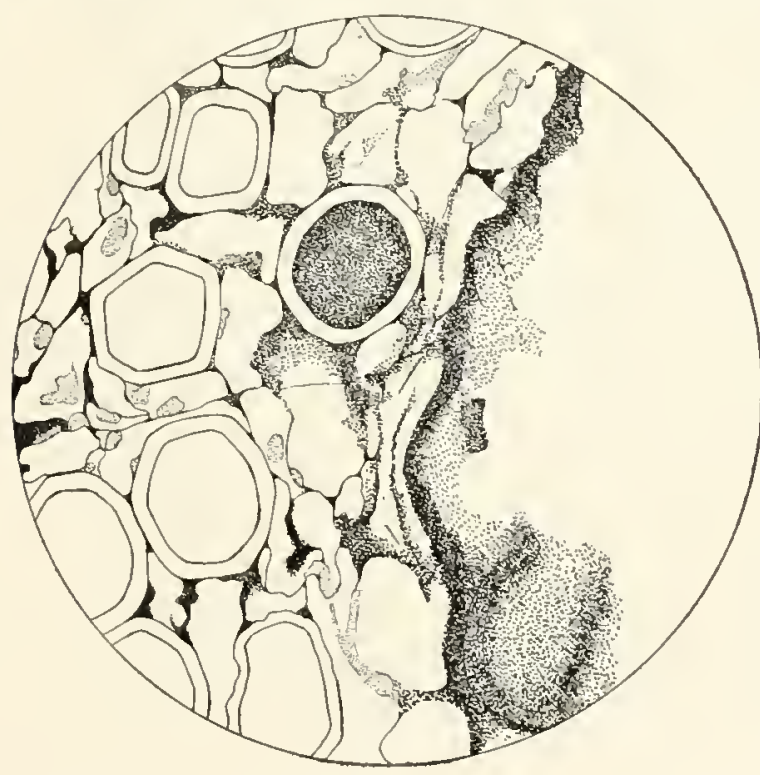

Fig. 67.† were observed.

Its general morphology and relation to the tissues is shown in figures 65,66 , and 67. So far as I have been able to determine from an inspection of the microtome sections the vessels are occupied (a small number only in the material cut), the intercellular spaces in the pith (frequently), and also occasionally large pith-cells. The latter have pits in their walls, and apparently the bacteria have forced their way through these thin places into the interior of these cells. Surrounded by free cells these bacterially occluded cells present a striking appearance when stained deep red with fuchsin. The bacteria were found frequently in crystal-cells. I have observed no bacteria in the cortex, which is made up largely of collenchyma.

*FIG. 66.-Pith-call of amaranth occupied by Bacterium amaranthi. Other similarly occupied pith-cells occur and it is believed that the bacteria gained an entrance from the intercellular spaces by way of thin places in the wall (pits), sone of which are shown in the middle of the figure. Slide 450 B 5 .

†Fir. 67. - Xylem vessels of amaranth stem occupied by Bacterium amaranthi. Also nuargin of a cavity. Slide 450 B 2, lower row, left-hand section. Drawn with Zeiss $2 \mathrm{~mm}$. 1.30 11. a. apochromatic objective, No. 12 comp. ocular, and Abbe camera. 
Dr. G. P. Burns has stated to me that he saw this disease in two species of cultivated amaranths at Ann Arbor, Michigan, in I 9or, and plated out a yellow organism, but, having read my note, dropped work on it. Had he continued we might now know something more definite concerning the biology of the organism and its ability to produce the disease from pure-culture inoculations; also to what extent the biological characters here assigned to it are correct. The only reference in literature is, I believe, the following:

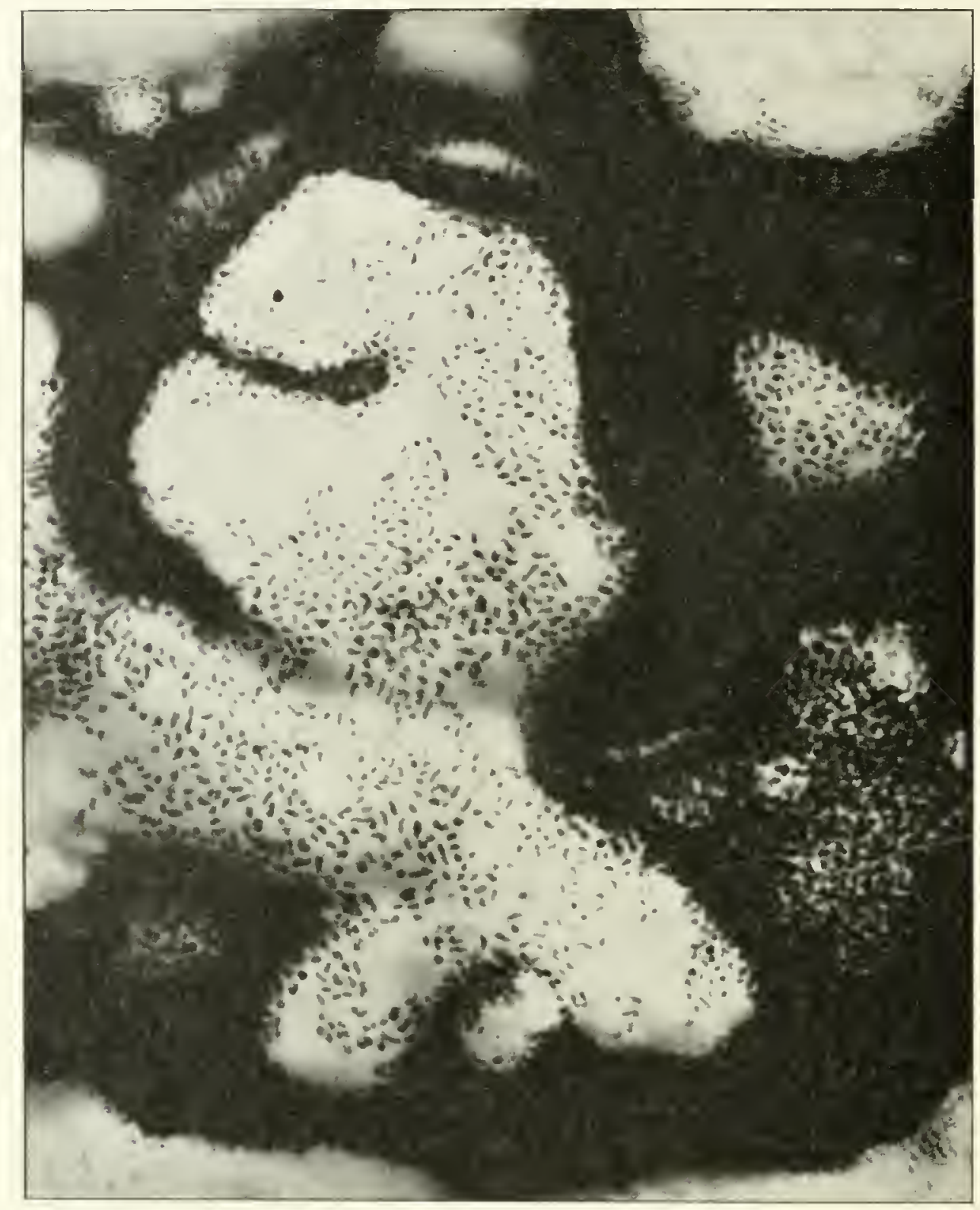

Fig. 67.*

LITERATURE.

I901. Suith, ERrvin F. The cultural characters of Pseudomonas hyacinthi, ctc. Bull. No. 28, Div. Veg. Phys, and Path., U. S. Dept. Agr., p. 153.

${ }^{*}$ FIG. 67 a.-Photomicrograph showing appearance of Bacterium amaranthi under a high magnification $(X$ 2000). Slide 450 B 5 . Vascular bundle. 


\section{VAN BREDA DE HAAN'S WILT OF PEANUT.}

In December 1905, J. van Breda de Haan prepared a paper (Teysmannia, i906) concerning a bacterial disease of the peanut Arachis hypogaa, known as "hamawedang," and observed by him in October of that year in the departments of Koeningan and Cheribon, Cheribon Residency, Java. The following is an abstract of this paper:

The soil in this portion of Java is chiefly red or red brown, sometimes black-sandy, very porons, and occasionally clayey. Often the stiff clay cracks open in times of drouth. Irrigation is largely practiced and rotation of crops, $e . g$., sugar-cane is planted for cuttings every third ycar, then katjang tolok (Phaseolus radiatus), after which the peanut (katjang soeoek, katjang holle) is planted, followed by rice. Much care is usually given to the culture of katjang soeoek, low beds of about a yard wide by 4 yards in length witl sliallow channels between them being used for this purpose. The channels render irrigation easy and alsoallow of thorough drainage and easy access to the plots for weeding, etc. The fields are irrigated every week or less of ten. There is no trouble anywhere from groundwater.

The variety of Arachis hypogad used chiefly is the katjang holle or Bandoeng, which ripens in abont 3 months from date of planting. It is planted chiefly in the East Monsoon in fields that can be irrigated. The product is sold to Chinese merchants, who in recent years have paid

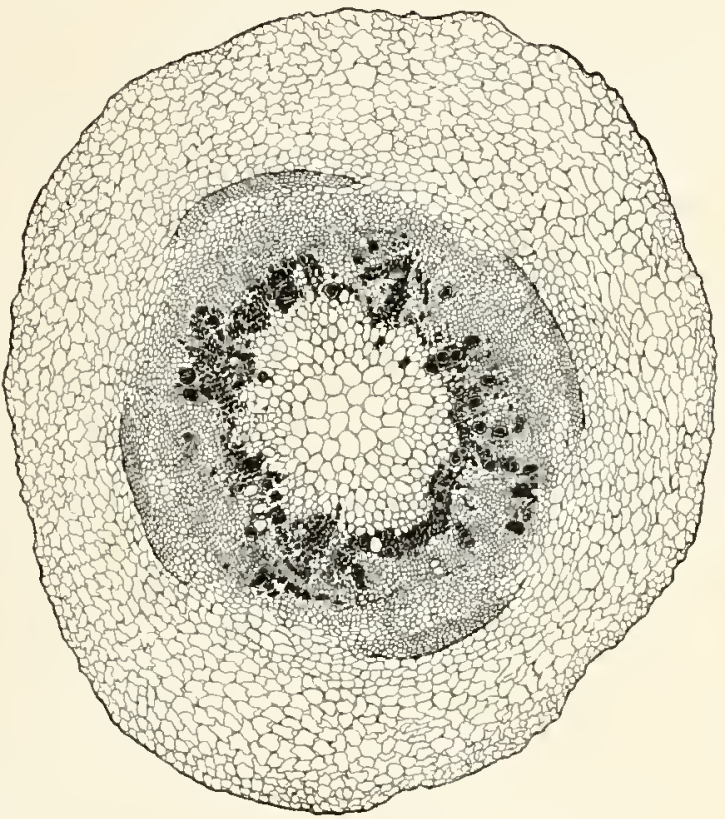

Fig. 68.*

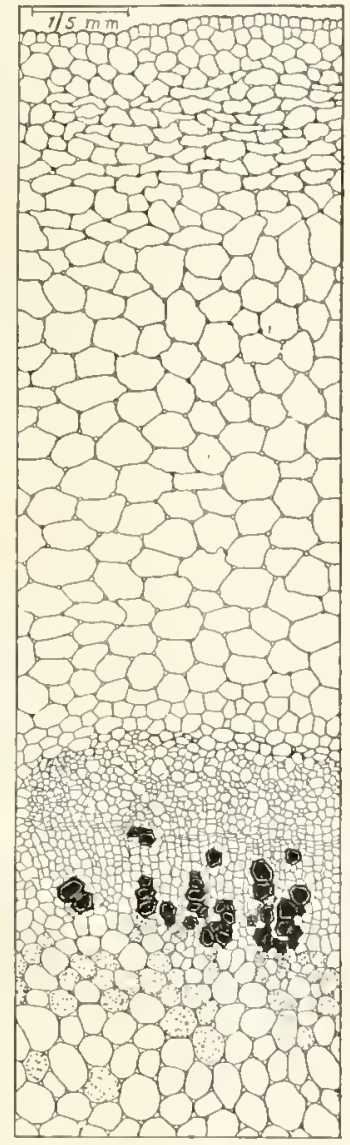

Fig. 69.1 good prices for it, making it a very profitable crop, which accounts for its wide cultivation; and in view of this fact it can readily be seen how a disease wlich formerly scarcely drew attention should now be considered a serious problem, especially because the yicld of katjang holle has noticeably decreased, being sometimes but half a normal crop. Insect injuries were not numerons in the fields examined by van Breda de Haan, and the only fungus disease mentioned is a black spotting due to Septoglaum arachidis Raciborsky, which is said to have no connection whatever with this disease.

${ }^{*}$ Frg. 68.-Bacterial disease of peanut (Arachis) from Java: Cross-section of root, showing bacteria confined to the vaseular bundles (the heavily inked portions).

†Fig. 69.-Bacterial disease of peanut (A rachis) from Java: Cross-section of stem from epidermis to pith, showing the bacleria restricted to the xylem (heavily inked parts). Drawn by Katherine Bryan. 
Plants attacked by this bacterial disease look as thougl hot water had been poured over them. The foliage of the plants withers sometimes very suddenly - all the leaves simultaneously. The leaf loses its fresh green color, becomes flaccid and droops, then dries up

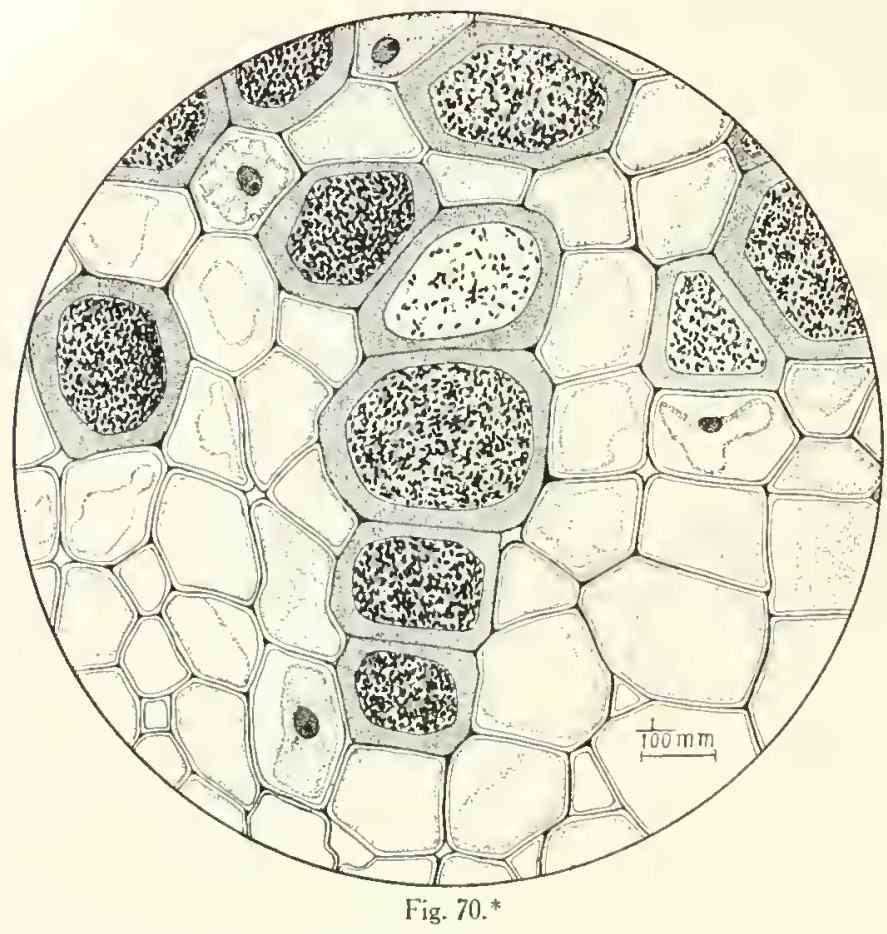
quickly. Usially the progress of the disease is so rapid that the leaf does not dry yellow, but retains a dull black color. After the withering of the leaves, the leaf-stalk and the stems also dry up, and soon notling remains but a dry mass of stems and leaves. If pulled up, the roots of such a plant are seen to be colored brown, the side roots being black and more or less rotten. If the plants are not attacked in an early stage of growth the fruits slow $n$ signs of the disease externally, except in size, being somewhat smaller. When, however, young plants become diseased, their fruits of ten show brown spots on the surface of the pods, the fruits themselves being more wrinkled than when normal and often spongy, or with the seed decayed. Neither the type of soil nor the altitude seems to have any connection with the disease. The disease occurs both on porous black soil and on stiff clay soil and it is in the mountains as well as on the plains. It occurs in patches, rarely an entire bed being affected. Sometines it is on the borders of the beds, sometimes in the center. The first signs of it do not appear until the erop is 2 to 2.5 months old. It never appears until after the first weeding - end of the first month-but it has also appeared in undiminished virulence in fields purposely left mweeded. It is a root-disease, but does not seem to be due to soil-infection, i. $e$., fields planted after a diseased crop are not worse attacked than other fields. If it ever spreads in a concentric manner it is only after it lias become very well established.

Microscopic examination of diseased roots from 5 fields sliowed bacteria in large numbers throughout the entire root-system, including the wood parenchyma, and in advanced stages

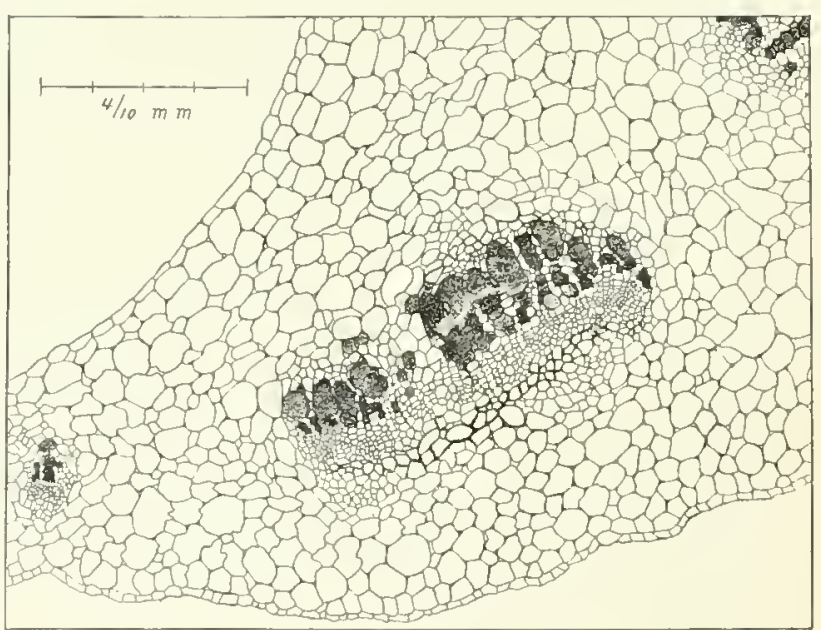

Fig. 71.†

*IIG. 7o.-Bacterial disease of peanut (Arachis) fron Java: A detail from the xylem part of fig. 69 to show the morphology of the bacteria. Figure drawn by Katherine Bryan.

$\dagger$ FIG. 7I, - Bacterial disease of peanut (A ruchis) from Java: Cross-section of an immature petiole at the extreme top of the plant showing bacterial occupation of the vessels and the formation of small cavities in their vicinity, the rest of the tissues free. Drawn by Katherine Bryan. 
of the disease the bacteria had spread also into the vessels and into the parts of the plant above the ground. The bacteria were not found in the leaf-stems or the fruit-stems, but in the wood of the main stem and of the lower branches. In the attacked parenchymacells the starch had disappeared. No other harnful organisms were found on the inside of the discased plants. The death of the plant, therefore, is ascribed to the presence of the bacteria in the wood parenchyma and in the wood vessels. "The hama wedang must thus be a root-disease caused by bacteria. *** Some plants show a predisposition to the disease. 'This greater susceptibility to the hama wedang, I think, usust be ascribed largely to the use of inferior seed." The growers do not reserve their own seed, but sell the entire crop and buy their seed from the Chinese merchants, who supply seed which represents the inferior product, less desirable for the oil-mills.

The organism was not cultivated and no measurements are given.

Through the courtesy of Dr. van Breda de Haan the writer received alcoholic material of peanuts affected by this disease, and a study of these has enabled him to show the general morphology of the schizomycete and its relation to the tissues of the host-plant (figs. 68, 69,70 , and $7 \mathbf{1}$ ). There is no reasonable doubt that it is a genuine bacterial disease, nor that it should be classed among those acting through the medium of the vascular bundles.

Since this text was prepared for publication, Honing, in Sumatra, has reported the occurrence there of a bacterial disease of the peanut (probably this one), which he attributes to Bacterium solanacearmm (for literature see "Wilt of tobacco"), and in the winter of $1912-13$ Fulton, of North Carolina, stated that this same organism causes a disease of the peanut in that State (Annual meeting Am. Pliytopathological Society, at Cleveland, Ohio).

\section{LITERATURE.}

I 906. BREDA DE HAAN, J, VAN. Rapport over Ziekte in den aanplant van Arachis hypogca (Katjang holle) in de Afdeelingen Koeningan en Cheribon der Residentie Cheribon. October 1955. Teijsmannia, Batavia, vol. 17, 1906, pp. $52-63$.
191 I. Honing. (See under Tobacco Wilt.)

1913. Fultor, H. R, and J. R. Winston. (See under Tobacco Wilt.) 


\section{ENGLISH DISEASE OF MANGOLDS AND SUGAR-BEETS.}

A disease of mangolds and sugar-beets ascribed to bacteria has been reported from Saxlingham, Norfolk, England, by R. H. Biffen, of the University of Cambridge. The first signs are on the leaves, which turn brown and die, while the inner leaves become a sickly yellowish-green and are much wrinkled. The signs of the disease usually appear first on the edge of the leaf-stalk. The roots of diseased plants are dry and tough, and all the vascular bundles in both roots and leaf-stalks are purplish-black and plugged with a mucilaginous mass containing a large number of bacteria, "which in all probability have been responsible for the disease." The tissue surrounding the bundles becomes brown and dried. The bundles of healthy plants are cream-colored. The disease does not actually kill the roots, lowever, as specimens removed from the field and grown in the greenhouse lived, but were stunted and poorly developed. Mr. Biffen thinks that this is the disease described by Kramer on fodder-beets in Russia [Austria] and by Sorauer on sugar-beets in Germany. Its external signs, lie says, are also similar to those of a sugar-beet disease in the United States in whicl the sugar-content of affected roots is smaller than that of normal roots. Probably what we call "curly-top" is here referred to.

There is no mention of cultures or inoculations, but it is stated that the disease is still under investigation. From a conversation with Mr. Biffen in 1906, the writer inferred that not much additional attention had been given by him to the etiology of this disease.

\section{LITERATURE.}

1901. BIFFIN, R. H. A disease of mangolds and sugar-beet. Cambridge University Department of Agriculture. Third Ann. Rep. on experiments with crops and stocks, etc., pp. 87 and 89 (in all, I page).

\section{BLIGHT OF YOUNG ROSE SHOOTS.}

In June 1907 Mr. Charles F. Wheeler brought to me from Lanliam, Maryland, a few rose shoots, showing a blackening and death of the mopened buds and of the pedicels. No fungus was found, but bacteria were present in abundance. On studying paraffinembedded, stained sections of the pedicels, most of the bacteria appeared to be confined to the vascular bundles. The organism was not isolated, or at least not studied in pureculture.

In the summer of 1909 Dr. William T. Councilman, pathologist of Harvard Medical Scliool, observed the same or a similar disease on some of his roses at York Village, in Maine. The affected stems were cut off and the disease did not reappear that season. He described the bacteria to me as filling the vascular system.

\section{BACTERIA IN VESSELS OF FLAX STEMS.}

In Dutch literature Dr. Ritzema Bos has mentioned finding bacterial plugs in vessels of dying flax. In this he was mistaken, according to his statement in reply to my letter asking for further information about it. 


\section{RÁTHAY'S DISEASE OF ORCHARD GRASS.}

A disease of orchard grass (Dactylis glomerata) associated with bacteria and called bacteriosis has been described by Ráthay. He found it on grass growing in the shade of a deciduous forest on the Vienna sandstone formation 430 meters above the sea. The locality is not given, but is presumably somewliere in the vicinity of Klosterneuberg. It was not found in fields or on any other grass. According to Wiesner, these plants received light only one-eleventl to one-thirtieth the intensity of ordinary daylight, which resulted in a shadeform with short stems and a spindling inflorescence. In 1897,1898 , and 1899, from the end of May to the beginning of July, many plants of Dactylis glomerata were found liaving one to several affected shoots. The following account is condensed from Ráthay's paper.

\section{DESCRIPTION OF DISEASE.}

The diseased culnus were distinguished by the following peculiarities:

(I) Dwarfing through incomplete elongation of the upper internodes.

(2) Presence of a very viscid lemon-yellow slime consisting of bacteria which, in a layer sometimes as much as $0.09 \mathrm{~mm}$. thick, envelops wholly or in part the uppermost leaves, the upper part of the stem, and different parts of the inflorescence. All or any one of these organs may be affected. Repeatedly the yellow slime was observed to occur on the outer surface of the higher internodes, as well as on the outer and inner side of the leaf-sheaths enveloping them, and there were cases in which an internode which bore 2 to 3 unopened, enveloping leaf-sheaths was covered with a bacterial layer, while each of the enveloping leaf-sheatlss was also covered with the slime on the inner as well as the outer side. 'Thus it often happened that one could make out distinct bacterial layers separated by the leaf-slieaths.

(3) On the portions of the epidernis covered with the bacterial slime, failure of the cuticle to give the characteristic brown reaction when treated first with alcoholic iodine and then with a watery solution of iodine followed by concentrated sulphuric acid.

(4) Presence soon of little yellow granules, which are found in the place of the cllorophyll bodies in the cells under the diseased areas in the epidermis.

(5) Appearance later of citron-yellow bacterial slime in the intercellular spaces of the parenchyma and in one or more vascular bundles of the parts of the stem which are covered by the bacteria. Thus far the bacteria in the leaves, both blade and sheath, have been found only in the ressels of the wood, not in the intercellular spaces.

(6) Penetration of the bacteria into the intercellular spaces of the parenchyma (Grundgewebe) of the stem through the solution, in places, of the middle lanella, and the isolation of the cells thereby.

(7) Knee-shaped bendings by means of which often one or more branches of the axis of inflorescence push out laterally from the higluest leaf-sheaths which inclose the latter. This phenomenon is caused, on the one hand, by the viscidity of the lemon-yellow bacterial slime on the inner side of the leaf-sheath, by which slime the distorted spikes are stuck fast and, on the other hand, through the elongation of the under part of the stem [see "Cobb's disease of sugar-cane," fig. 8].

(8) Premature drying of all the organs covered by the lemon-yellow bacterial layer. This drying is usually accompanied by a secondary infection with Cladosporium herbarum or a species of Sporidesmium.

It is of importance to note that no bacteria have ever been found in the subterranean portions of plants of Dactylis glomerata or in any parts of normal plants. Likewise all search for a similar phenomenon on other grasses (Poa ncmoralis, Brachypodium silvaticum, Triticum canimm) growing in the vicinity of the diseased Dactylis glomerata, and developing at the same time, has been in vain.

The bacterial slime reddens blue litmus paper and has 110 characteristic odor. The existence of the slime in pure culture is suggested by the microscopic examination, which shows that the bacteria composing it are morphologically alike. Cultures on various agars and gelatins demonstrate, however, the presence of other organisms. In fact, on these sub- 
strata the lemon-yellow organism did not come up at all; only contaninating organisms appeared. The citron-yellow colonies were obtained, howerer, by stirring a small amonnt of the slime from diseased plants into a drop of sterile water on a sterile cover-glass and transferring this to slices of sterile potato lying in glass dishes. By making several parallel streaks, one finally obtains pure cultures. The first streaks contain bacteria in great numbers; the last, on the contrary, only isolated colonies. Some of the latter were lemon-yellow colonies of an organism agreeing in all respects with that found on the diseased plants.

The isolated bacterium, and also that examined from the plant, is short-ellipsoidal, 0.66 to $0.99 \mu$ long and slightly less wide. It has a distinct capsule both on media and in the plant and is 11on-motile in hanging drops made with organisms from both sources. It stains with Löffler's methylene-blue, with carbol-fuchsin, and with Gram's stain (both sources). It is not aeid-fast (both sources). When treated with iodine solution there is no granulose reaction, either with slime taken from the plant or with pure cultures. No spores have been observed. In fluid media, like bouillon, decoction of Dactylis glomerata, with and without peptone, there forms in the course of 7 days, on the surface of the liquid, an interrupted pellicle of pale citron-yellow color. There is also a precipitate of similar particles, but the fluid itself is clear. The organism grows rapidly on sterilized potato, but makes a very slow growth on different nutrient agars and gelatins, such as bouillon-gelatin, Dactylis decoction-gelatin with or without peptone, and Dactylis decoction-agar with peptone. On potato it grew equally well, whether the slices were weakly alkaline or neutral or made slightly acid by the addition of diluted lemon juice. Potato cultures made at a warm summer temperature (probably $20^{\circ}$ to $25^{\circ} \mathrm{C}$.) often showed a lemon-yellow streak on the second day and in the next days a considerable portion was covered. The eultures were then wrinkled, easily separable from the substratum, and of a deep lemon-yellow color; the margins were coarsely crenate in places. In this condition it reminds one of Bacillus vulgatus (Flügge) Migula, and B. mesenterieus (Flïgge) Lehm. and Neum., but is distinguishable from then by its vivid lemon-yellow color. Finally, the bacterial growth covers the whole surface of the potato. Although the colonies are yellow the individual bacteria are colorless. The coloring matter exists in the colonies neither in the form of granules nor crystals. It is not soluble in water or alcohol, and with concentrated sulphuric acid does not give the blne reaction characteristic of lipoclirome.

The organism does not liquefy gelatin. Whether there is any fermentation of sugars or any production of indol has not been determined. It las not been tested for the reduetion of nitrates to nitrites or the production of hydrogen sulphide. It is not sensitive to direct sunlight and thrives in sunlight under a Senebier bell-jar filled with a solution of potassinm dichromate, as well as under a similar jar filled with ammonium cuproxide. It is not told how these tests were made, $i$. $e$., whether plates were poured or fluid cultures used. If only the latter, then the statement is not to be depended upon.

All the inoculations, botl in mature plants and seedlings, failed (methods not given); still the number of eases investigated satisfied Ráthay beyond a doubt that the baeteria are the primary cause, and it is equally certain he thinks that special unknown conditions are necessary for infection. It is only in the woods, where Dactylis glomerata flowers late, only from the end of May to the beginning of July, and only on the upper leaves, internodes, and inflorescence, that the disease has been observed. Dactylis glomerata is the only grass anong several growing in the same place on which this disease appears.

The disease always makes its first appearance on the surface and only in later stages is the organism found in the intercellular spaces and the fibro-vascular bundles. It has never been found in the cell-contents. It is in the highest degree probable that the bacterium can gain a foothold only so long as floral organs of the plant are enveloped by the leaf-sheath, since no new infections are observed after the inflorescence has emerged. Infection is made possible only by the unexplained disappearance of the euticle and the drying up of the underlying tissues. 


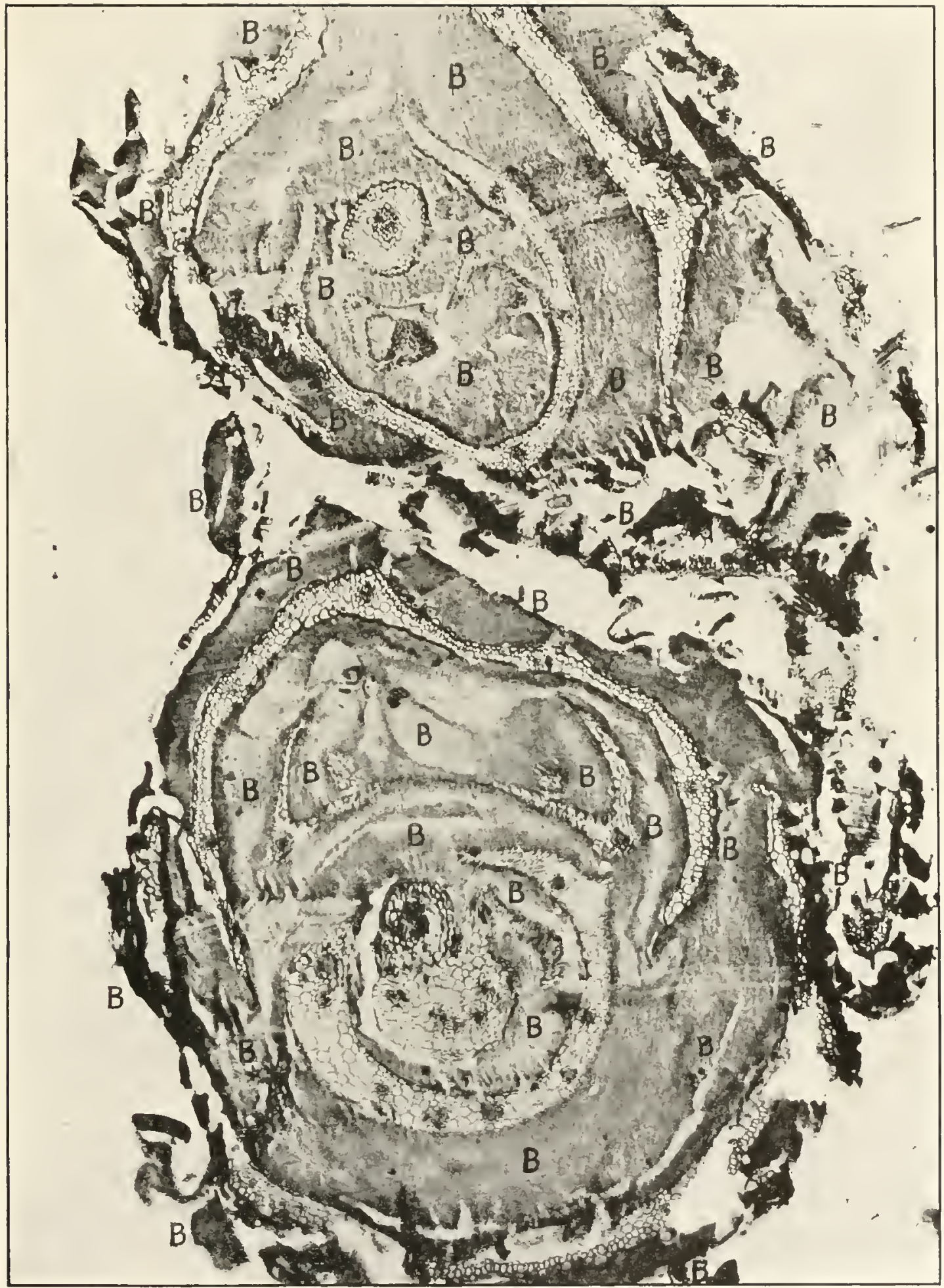

Cross-section of two spikelets of Daclylis glomerata, showing the floral organs widely separated by the yellow slime of A planobacter rathayi EFS. 



\section{COMMENT.}

'This interesting paper leaves many particulars undetermined. 'The disease as described has some points of similarity to Cobb's discase of sugar-cane and to Stewart's disease of sweet corn. If it is like the latter, then we may suppose that infection occurs earlier in the scason at the base of the plant and that Rathay was in error in supposing the occlusion of the vascular system of the stem to be a secondary or late infection. If, on the contrary, as he states, the organism attacks the parts first observed by him to be diseased and makes its way across tissues from the surface to the interior, it would seem to be like Burrill's disease of broom corn and then we might suspect aphides or similar insects of being carriers of the disease.

The failure of cultures on agar and gelatin is probably attributable to defective technique, very viscid growths, such as Rathay describes, not lending themselves readily to plate cultures withont some preliminary rubbing up in water or bouilion (sce $B$. tracheiphilus, vol.II, pp. 2S7, 294). It is probable, as he believes, that the great mass of the yellow slime on the plants was an unmixed or nearly unmixed growth. It is not likely that the wrong organism was isolated, and it is probable that if young cultures had been inserted into young, growing stems and leaves by necdle-pricks successful infections might have been obtained.

The last paragrapl of the paper promises a full account of the disease and of the organism later on, the same to be properly illustrated. Death, however, cut short the distinguished author's labors, and, so far as known to the writer, nothing has since been published on this interesting disease.

Throngh the courtesy of Prof. Dr. Julins IViesner, of Vienna, I learn that this disease occurs on the Kahlenberg between Stephaniewarte and the track of the Kahlenberg(Zahnrad-) Bahn, i. c., near Vienna. Ráthay's material is preserved in the Lehr Anstalt für Wein- und Obstbau at Klosterneuberg.

\section{PERSONAL OBSERVATIONS.}

After the above comments were in type the writer received from Dr. F. K $\phi$ lpin Ravn, of Copenhagen, heads of Dactylis glomerata (collected in Denmark), attacked by a bacterial disease which appears to be identical with that described by Ráthay. Dr. Ravn's note is as follows:

As samples without value I send you some specimens of Dactylis glomerafa, infected by bacteria. 'The disease is reported in Kirchner: Krankheiten und Beschädigungen, 2 Aufl., p. 163 , but hasso far as I know-not been studied more closely. Last smmmer my assistant, Mr. F. Lind, discovered the disease in this country and found that it is widely spread and is of some significance for the growing of seed of Dactylis. Mr. Lind continues his field studies, but we would be much obliged to you if you might have time to report to us your opinion as to the identity of the bacterium after cultural characters and comparison with others.

The heads of these plants are dwarfed, distorted, and gummy-yellow from the presence of enormous masses of surface bacteria, and often imprisoned within the leaf-sheaths which are stuck together (fig. $71 a$ ). The glumes, which are badly attacked, are lemon yellow or water-soaked, and the sheaths and stems are also involved more or less. On some spikelets only a portion of the glumes are attacked and these not in all parts. (For an early and late stage of the disease on the spikelets see plate 41 , figs. 9 and 10.) The yellow slime is also abundant between the upper unfolded leaves and the stem (B, B of fig. $7 \mathrm{I} d$ ). This yellow slime reddens blue litmus paper.

Microtome sections show extensive occupation of the floral organs (pl. i i A). The bacteria are present mostly between and surrounding these organs, as in the gum-bud disease of carnations (see this monograph, vol. II, fig. 4). In many cases they have been seen occupying intercellular spaces (figs. $71 \ell, 71 f$ ), and more rarcly vessels.

The organism most abundant on these plants is a yellow, non-motile, non-sporiferous schizomycete, which so far has refused to grow readily on any sort of agar, but which grows 
promptly and very well on cooked potato where it is viscid after some days. We have tried to grow it with negative or unsatisfactory results on standard +15 beef peptone agar,

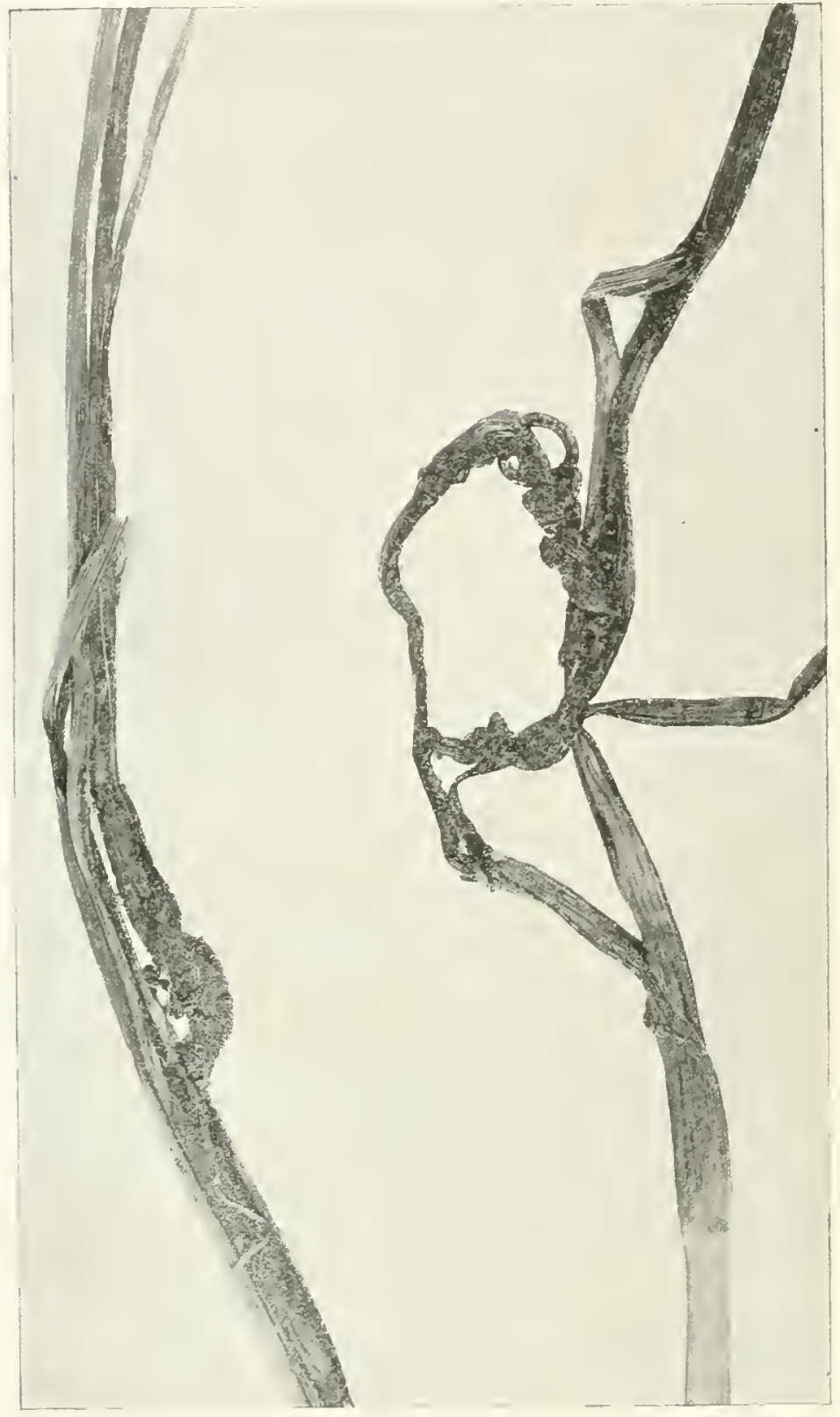

Fig. $71 a{ }^{*}$

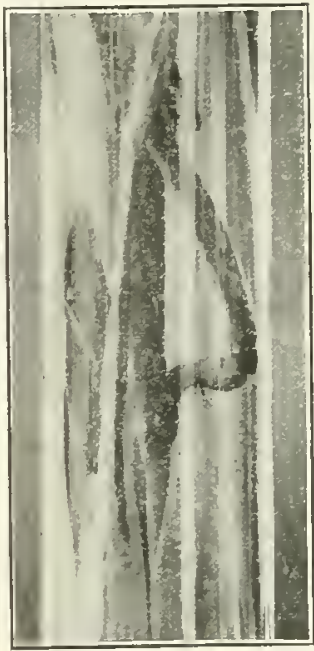

Fig. 716.1

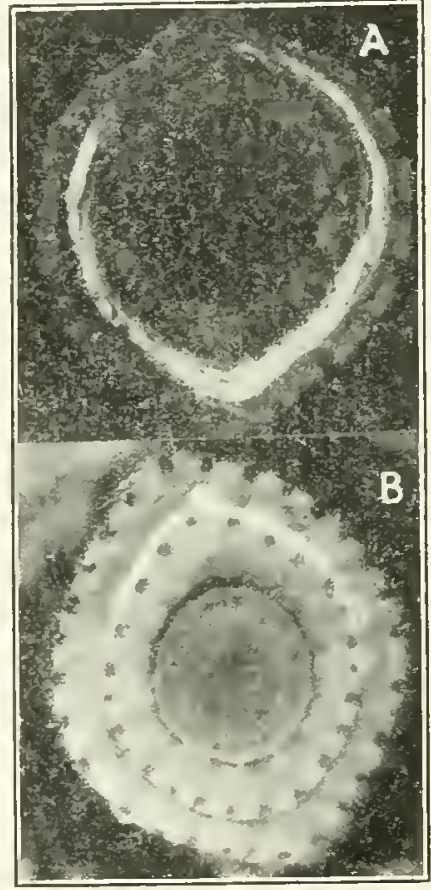

Fig. 71 c. $\ddagger$

corn meal agar, potato agar, banana agar, carrot agar, Loeffler's malt extract agar, and standard beef peptone agar with oxalic acid (prepared for fungi). Neither have we been

* Fir 7 Ia-Stems of Dactylis glomerata from Denmark, showing dwarfing and distortion due to Ráthay's disease. FIc. $7 \mathrm{I}$. - Stem of Dacivlis glomerata from Austria, photographed in 1913 from alcoholic material collected by Ráthay. Leaves stuck together above and culm below pushing side-wise out of the slieath. Original in MInseum of Lehr dustalt at Klosterneuberg.

IFIG. $7 \mathrm{IC}-A$. Cross-section of stem of Dacly/is glomerata, showing bacterial layer (white mass) entirely surrounding the culm, and separating it from the enveloping leaf-sheath. $B$. Cross-section from another plant, showing partial separation of an inner and outer leaf-sheath by the bacteria (white line at the top). Both were cut and photographed in Washington from Ráthay's material. 
able to grow it in $+I_{5}$ beef peptone botillon. At the end of 16 days small circular yellow colonies appeared on some of the agar plates, and transfers grew fairly well on the surface

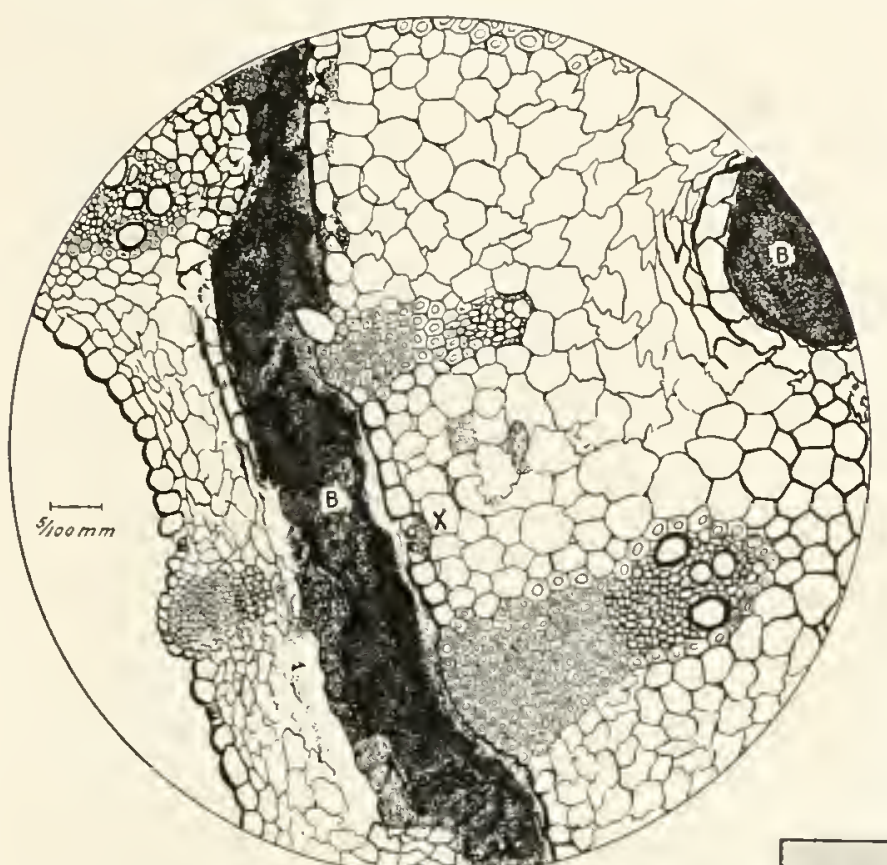

of agar stab-cultures. It also grew slowly on agar-stabs when introduced along with the white organism mentioned below. It did not grow readily in nitrate bouillon.

In the plant it is quite inclined to be associated with a white liquefying organism which grows as a very short rod usually in pairs or fonrs with a plain constriction. This white organism grows in agar, where it is motile in early stages of growth on the margin of the colonics. It was not clearly motile when taken from a 5-day potato culture, and here T's and Y's were scen. It stains by Gram.

The yellow organism is alcohol fast, but not acid fast. It is Gram positive, and during the viscid stage

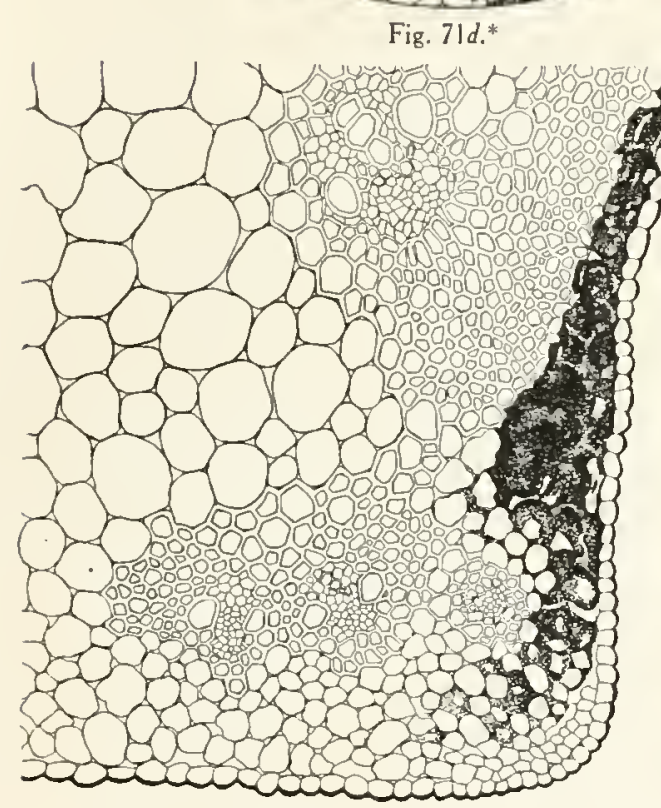

Fig. 7le. $\dagger$

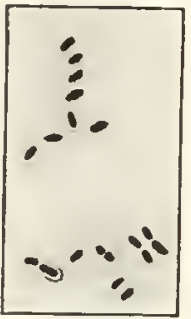

Fig. 71 g. $\$$

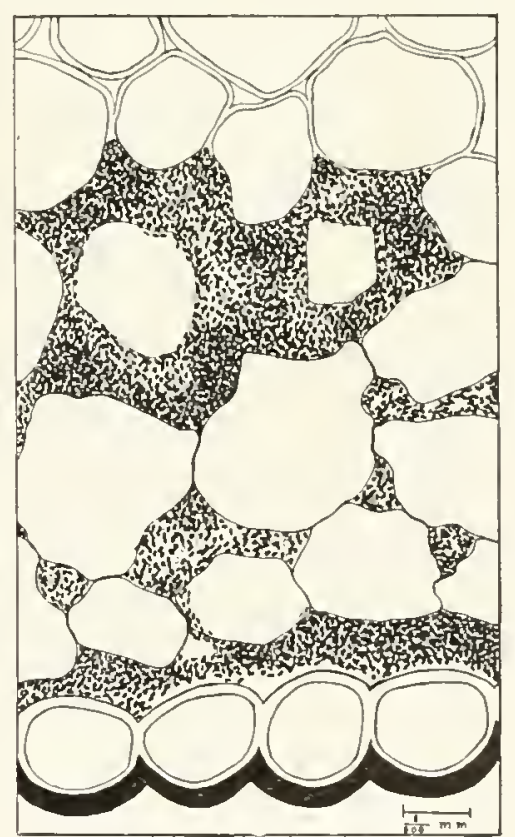

Fig $71 f . \ddagger$

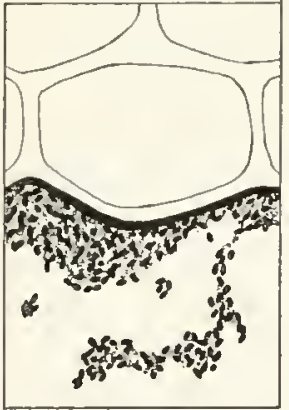

Fig. $71 h .^{* *}$

on potato possesses a capsule. The yellow slime from a 7 -day culture on potato was feebly alkaline to neutral litmus paper. The color on potato resembles that of Aplanobacter michiganense (p1. I I, figs. 8,9 ) and the substratum is grayed.

*FIG. 7 Id.-Cross-section of stem similar to those shown in fig. 7 Ia. At B, B are dense bacterial masses separating the immature leaves which are still nearly free from infection. At $\mathbf{x}$ bacteria may be seen occupying the substomatic chamber and intercellular spaces. Slide $940 \mathrm{~F} 5$.

$\dagger$ Fig. 7 I $e$ - Cross-section of a leaf of Dactylis glomerata, showing occupation of some of the intercellular spaces by A planobacter rathayi. Section of material received from F. K $\phi$ lpin Ravn, of Denmark, summer of 1913. Slide $940 \mathrm{G} 2$

+ FIG. 7 If.-Detail of bacterial occupation of the intercellular spaces of leaf of Dactylis glomerata. From the same material as fig. $71 e$. Figs. $71 e$ and 7 If drawn by Katherine Bryan.

\$FIG. 7 Ig. - Bacteria from a 20-day agar plate culture of Rathay's organism stained by Ribbert's capsule stain. Dec. 29, 1913.

*FIG. 7 Ih.-A detail from fig. 7I $c A$, showing one inner epidermal leaf-cell witl some of the adherent bacterial layer. Drawn from a free-hand section by Katherine Bryan. The fine granules are an effort on the part of the artist to represent bacteria out of focus. 
It grew slowly or not at all in peptone water with 1 per cent potassium nitrate. In one tube, which clouded, no nitrite was detected in 13 days. It grew slowly in a mixture of grass broth, cane-sugar water, and peptone nitrate water, clouding the fluid, but there was 110 production of nitrite (9 days). Doubtful growth in Dactylis broth witlı I per cent peptone (10 days). There was 110 growth in potato broth with 1 per cent potassium nitrate. Subsequently in fermentation tubes of peptone bouillion with I per cent potassium nitrate there was no reduction of the nitrate (I 7 days). When tested the tubes were clear in the closed end, well-clouded in the open end, with an ample yellow precipitate and 110 pellicle. There was very slow growth during the first week. The check tube gave a bright blue reaction with diphenylamin.

In first 1 I days (at $26^{\circ} \mathrm{C}$.) no change in milk except the formation of a narrow yellow rim. In litmus milk no change during first week, then (I I days) slightly bluer than check.

On nutrient gelatin at the end of 19 days at $20^{\circ} \mathrm{C}$. there was a distinct pale yellow surface growth, colony-form, with some buried colonies. No liquefaction for some weeks; at end of 7 weeks $5 \mathrm{~mm}$. liquefied; at end of 5 months about one-third liquefied.

I have named this organism A planobacter rathayi in honor of the late Emerich Rathay (Science). It is related to Aplanobacter michiganense perhaps too closely, but so far inoculations into tomato have yielded only negative results (see p. 165).

It is a yellow non-flagellate rod with bluntly rounded ends, and on the plant is about twice as long as broad, measuring when stained with carbol fuchsin 0.6 to $0.75 \times 0.75 \mu$ to $1.5 \mu$. On culture media (2-day potato) stained with carbol fuchsin, they measure 0.5 to $0.75 \mu \times 0.95$ to $1.3 \mu$. It occurs most frequently singly or in pairs joined end to end. Capsules occur (fig. $7 \mathrm{Ig}$ ). It grows in milk with formation of a yellow rim, but no visible change in color or consisteney (1 I days); subsequently the rim widened and a large amount of chrome yellow precipitate formed and there was separation of the casein. Litmus milk is slowly blued: subsequently (4 months) the milk became a uniform purplish and occasionally there was some reduction of the color (pl. 23). Nitrates are not reduced.

It does not grow in Cohn's solution. Grape sugar is split and acid is formed, but not gas. It grows slowly on nutrient agar and gelatin, and in other culture media sucl as peptone water with potassium nitrate, milk, and litmus milk; in milk it makes a long-continued and very copious yellow growth.* Saccliarose and lactose are fermented slowly.

On agar plates some strains of the organism grow only when sown thickly or when cultivated with the associated white organism (pl. I B). Curiously the yellow colonies appeared only on the buricd white colonies, not on the surface ones.

The organism is undoubtedly diseminated on the seeds. It retains its vitality on dried spikelets for a long time, probably a year or more, judging from the fact that it grew readily in our tests at end of $7,9,10$ and $i 1$ months To insure growth inoculation into most media must be heavy. Group No. 211.2222522.

\section{LITERATURE.}

1899. RAthay, EMerich. Ueber eine Bakteriose von Dactylis glomerata L. Sitz. Ber. der Wiener Akad. I Abth. Bd. cvili, pp. 597-602.

Also a separate.

1913. Smith, Ërwin F. A New Type of Bacterial Disease. Science, N. S., Vol. XXXVIII, No. 991, Dec. 26, 1913, p. 926.

*After the above was in type the writer visited Klosterneuherg and through the courtesy of Dr. Linsbauer, Director of the Lehr-Anstalt, had opportunity to examine 15 jars of alcoholic material left by Rathay, and to satisfy himself that the Austrian discase is identical with the Danish (see figs. $71 b, c$, and $h$, made from this material). Ráthay's manuscript was not left in the Lehr-Anstalt but in his house, where it came into possession of one of his daughters, who finally destroyed it as valueless. From this saerifice to the goddess of good-housekeeping there escaped only some photographs and drawings which I had hoped might be reproduced here and to that cxtent help to keep alive the memory of a brilliant man called away too early from the scene of his activities. They were promised but not received. That this disease still occurs on the Kallenberg is shown by the fact that I collected it there myself (Nov. 2,19r3) in the oak woods on the east side of the railroad track, a few hundred yards below the uppermost station. Moved to a hot house in Washington, one of these diseascd plants produced is flowering shoots in 1914 , all of which were healthy. 


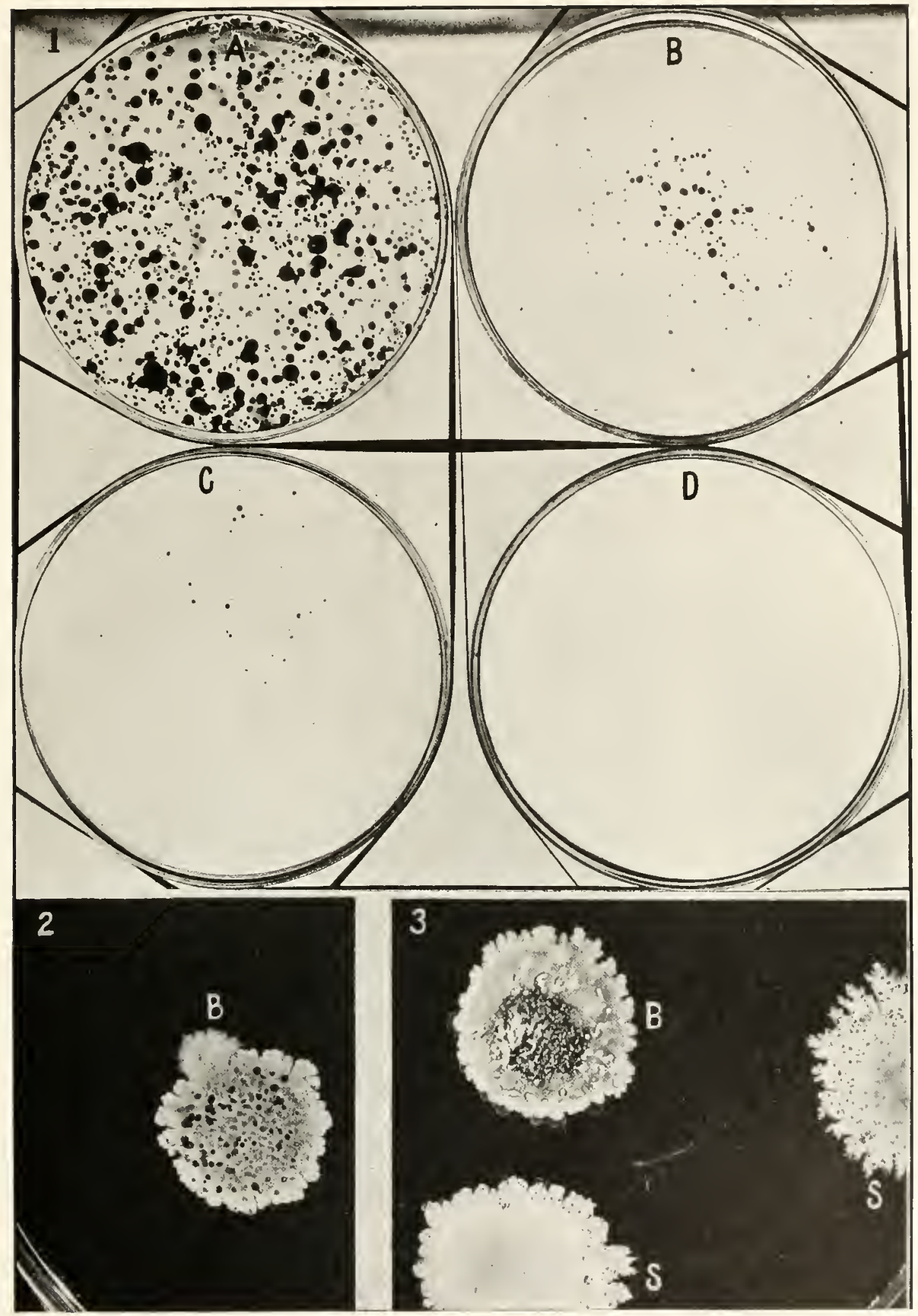

(1) Photographs of Petri-dish poured platcs, showing behavior of A planobacter rathayi in $+\mathrm{r} 5$ peptonized bcef agar. A, plate sown heavily - growth slow in developing but fitually good; $B$, plate sown thinly-grow th retarded; $C$, plate sown more thinly-growth still more retarded; $D$, plate sown still more thinly, but with quite a good many bacteria-no growth. Plates is days old at room temperature $\left(25^{\circ} \mathrm{C}\right.$. \pm ). Growth visible on $A$ after ahout 9 days. (2) Portion of an agar poured plate, showing at $B$ a buried colony of the white organism frequently associated with $A$ planobacler ralkayi, in which (but nowhere else on the plate) are growing the small yellow (black in photo) colonies of Ap. rathayi. which was sown copiously. Time 24 days. (3) I, ike 2, hut from another sowing: $B$. A buried white colony containing the yellow (white in photo) colonies of $A$ planobacter ralhayi $S_{1}, S_{\text {, }}$ two surface colonies of the white schizomycete in which no yellow colonies were visible, The plate
yellow organism, hut none developed, except in the body of the buried white colonies. Time 26 days. 



\section{THE GRAND RAPIDS TOMATO DISEASE.}

The writer received (July 27, 1909), from Grand Rapids, Michigan, diseased tomato plants taken from a field of 112 acres, said to be badly affected by a new disease.

\section{PRELIMINARY STUDIES.}

There was no surface indication of the cause of the disease, but some of the vessels, especially those next to the pith, were packed full of a short bacterium which appeared to have no self-motility when examined in water. It was a short rod, single or in pairs, termo-like. There was very little brown stain in the wood, but yet some. In morphology it was closely like Bact. solanacearm from this part of the country, $i$. e., a short rod with rounded ends.

Petri-dish poured-plates were made at once from a stem showing least disease. From another stem, after removing the bark, I took about 2 inches, crushed this in to c.c. of bouillon, let stand an hour, and then inoculated with drops of this cloudy bouillon, 2 young tobacco plants and ro soft shoots of tomato. The tobaccos were young hot-house plants with leaves about 2 inches wide and 3 inclies long. The tomatoes were vigorous shoots on two plants, standing in a garden. The presence of bacteria in the cloudy bouillon was checked under the microscope before using. They were introduced by needlepricks.

August I I, I909.-Examined to-day the tomato-plants inoculated July 27 with bouillon in which had been stirred up bacteria taken directly from the Grand Rapids tomatoes.

Result.-Three or four of the ten inoculated shoots show wilting leaves, but not any great number on any one sloot.

The two tobacco plants inoculated on July 27 direct from the Grand Rapids tomato shoots have shown no signs of disease. colonies.

The poured agar plates of July 27 yielded a pure culture of a yellow organism, growing in round

Tle plates poured on August 9 from the second sending of plants from Grand Rapids, Michigan, yielded (August 17,1909 ) yellow colonies closely resembling those obtained from the plates made from the first plants received. The surface colonies were round, pale yellow, becoming gradually deeper yellow, but not orange. 'They were 2 to $5 \mathrm{nmm}$. in diameter and a good deal resembled Bacterium campestre, the surface being smooth and wet-shining. 'The buried colonies were smaller, deeper yellow, inclined to be more or less clumpy. There was no indication in the plates of the presence of any white organism-apparently the Grand Rapids disease is due to a yellow bacterium. 'This infests the vascular bundles, and also rots the pith, but there is much less brown staining than in the case of Bact. solanacearum. It seems also to enter above ground, the roots being free in the plants examined.

Inoculations on July 27 direct from one of the stems of the first lot were made into rapidly growing tomato sloots in the garden of the entomologist. One of these shoots was cut and brought in to-day (Aug. 17). A few of the leaflets were wilted on three leaves and the shoot generally appeared to be impaired in its growth. On cutting open the stem a great number of bacteria were found in the vessels to a distance of 12 inches above the point of inoculation and 4 inches below it. In places the pith was rotted. Great numbers of bacteria were present in some of the vessels. We now made in the hot-house inoculations witli pure cultures (subcultures from poured-plate colonies).

Plates were poured August 23 by Miss Bryan from a diseased tomato shoot from the garden. This shoot was inoculated by Dr. Smith July 27 with ooze taken directly from the first lot of diseased tomatoes received from Grand Rapids, Michigan. For some days nothing appeared on the plates except a few scattering colonies of intruders, but afterwards they came up plentifully with the same organism that was inoculated. On September 3, 1909, the plates showed a pale yellow, smooth, wet-shining, round, surface colony not unlike Bacterium campestre. The buricd colonies were sinaller, round to broadly elliptical. The intruder was a wrinkled, raised, gummy-looking, roundish, yellow colony.

'Transfers were made from one of these plates to keep the organism growing. 


\title{
NOTES ON CULTURAL CHARACTERS.
}

\author{
Stabs in Cornmeal Agar (Stock 3794).
}

I909.

Sept. 8. Inoculation from slant agar subculture of September 3, rgog.

Sept. 18. Stab growth fairly good to bottom of the tubes; finely saccate along line of stab. Surface growth pale yellow (almost white); largest diameter $+\mathrm{mm}$.

Oct. II. Scanty, pale yellow surface growth. Stab growth moderate, better than in beef agar.

$$
\text { Potato Cylinders }\left(\text { Stock } 3 \$_{5} 6\right) \text {. }
$$

Sept. 8. Inoculated from agar slant of September 3, 1909.

Sept. Is. Growth moderate; slime canary yellow, thin, shiuing; potato slightly grayed, liquid somewhat yellowed.

Oct. II. Growth moderate, spreading, thin, smooth, canary yellow, moderate yellow precipitate; liquid clear-not thickened; potato slightly browned

Oct. 27. Some starch destroyed. Potato alkaline to litmus paper.

\section{Standard Nutrient Agar Stabs (Stock $3 S_{0}$ ).}

Sept. 3. Inoculation from eolonies in plate of August 23, 1909, by Miss Bryan.

Sept. 8. Surface growtl i to $2 \mathrm{~mm}$. in diameter; pale yeliow; opaque. Slight saccate growth along line of stab.

Sept. 18. Surface growth ro mm in diameter; canary yellow; smooth-shining, opaque; flat; viseid. Stab growth fuely saccate.

Oct. 11. Same appearance as on September 18. The agar is drying and separating from the walls of the tubes.

Nitrote Bouillon (Stock 3852$)$.

Sept. 8. Inoculation from agar slant of September 3, 1909

Sept. 18. Good growth: Tested for nitrites (used boiled starch water, potassium iodide, and sulphuric acid). No color reaction. Medium tested with diphenylamine gives dark bluc reaction, showing presence of nitrate.

Sept. 27. Tested remaining cultures. No nitrites present.

$$
\text { Colm's Solution (Stock } 3827 \text { ). }
$$

Sept. 8. Inoculated from agar slant of September 3, igog.

Sept. 18. No growtl.

Sept. 22. No growth.

Oct. I I. No growth. Reinoculated from agar slant of September 29, 1909,

Oct. 27. Cultures merely milky. Slight, white precipitate, readily dissolves.

$$
\text { Cream-free Hilk (Stock } 3825 \text { ). }
$$

Sept. 8. Inoculated from agar slant of September 3, 1909.

Sept. Is. Surface of milk is yellow (canary color) to a depth of 3 to $+\mathrm{mm}$.; also a rim of yellow 2 to 3 mu. wide. Milk in lower part of tube is cream color. No coagulation.

Sept. 22. Yellow surface layer now + to $6 \mathrm{~mm}$. deep and transiucent.

Oet. I I. Surface layer now io to $12 \mathrm{~mm}$. deep. Still vellow. The milk below is deep cream color, thick and smooth like buter. Some yellow precipitate in base.

Oet. 27. Fellow translncent whey, now 12 to $25 \mathrm{~mm}$. deep. The curd is deep cream color.

$$
\text { Litmus Milk (Stock 3775-lavender blue). }
$$

Sept. 8. Inoculation from slant agar of September 3, 1909.

Sept. I8. Wide ( 3 to + mm.) rim and surface of canary yellow; the medium below this is uniformly pale gray (griseus according to sace.). It is liquid throughout.

Sept. 22. Color now quite near Kidgway's "drab" No. 13. Surface layer t to $6 \mathrm{~mm}$. deep of a dull yellow-translucent.

Oct. II. Yellow surface layer not broader than on the $22 \mathrm{~d}$ (1) vaporation is more rapid than in plain milk). The color is brighter yellow and transparent in parts. Below the yellow layer the milk is dirty eream color, thickened but much less so than in plain milk cultures of same age.

Oct. 27. Dirty crean-color curd in lower 12 to $15 \mathrm{~mm}$. covercd by ro to $12 \mathrm{~mm}$. of yellowicl (tinge of orange-red at top) translucent whey. Litmus reduced.

$$
\text { Beef Bouillon (Stock } 3851 \text { ). }
$$

Sept. 8. Inoculation from agar slant of September 3, 1909.

Sept. Is. Moderate clouding; thin, white, floceulent masses suspended in medium. The moderate slimy precipitate rises in long strings; these break with shaking but do not readily dissolve. No rim or pellicle.

Oct. 11. Moderate rolling clouds, clouding densest at surface. White patches of rim. No pellicle. Precipitate moderate; yellowish; viscid; rises in a swirl.

$$
\text { Gelatin Stabs (Stock 3728). }
$$

Sept. 8. Inoculation from slant agar of September 3, 1909.

Oct. 11. Scant, canary yellow, smooth-shining surface growth. Either no trace of growth or slight in stab. No liquefaction. ${ }^{*}$ (Kept in refrigerator, temperature $14^{\circ}$ to $15^{\circ} \mathrm{C}$.)

*In a later test started Oct. 29, I9 12, liquefaction began Nov. 9; was stratiform and + to $7 \mathrm{~mm}$. deep on Jan. 3 , 1913, and complete June 27, 1913. Another set of tubes inoculated Jan. 8, 1913, were completely liquefied July 15. 1913. Both sets kept in ice-box at about $18^{\circ} \mathrm{C}$ 


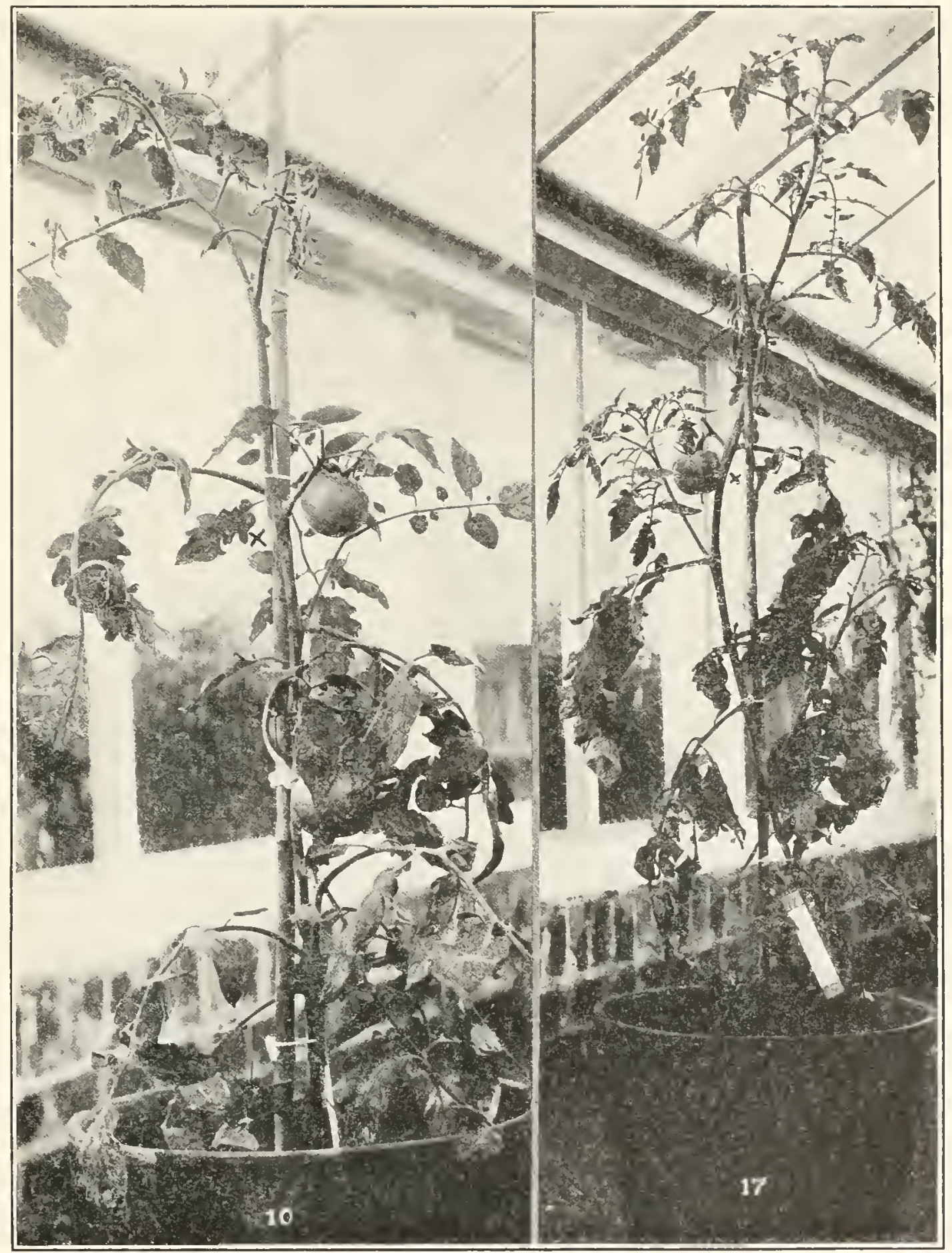

Grand Rapids tomato disease.

Plants Nos. 10 and 17 inomulated by needle-pricks with a pure culture of A planobacter michiganense at $x$ on the stem Oct. 5 , 1909. in the hot-house, Photorraphs Nov, 10.1903 , showin slow prostess of the disess. 



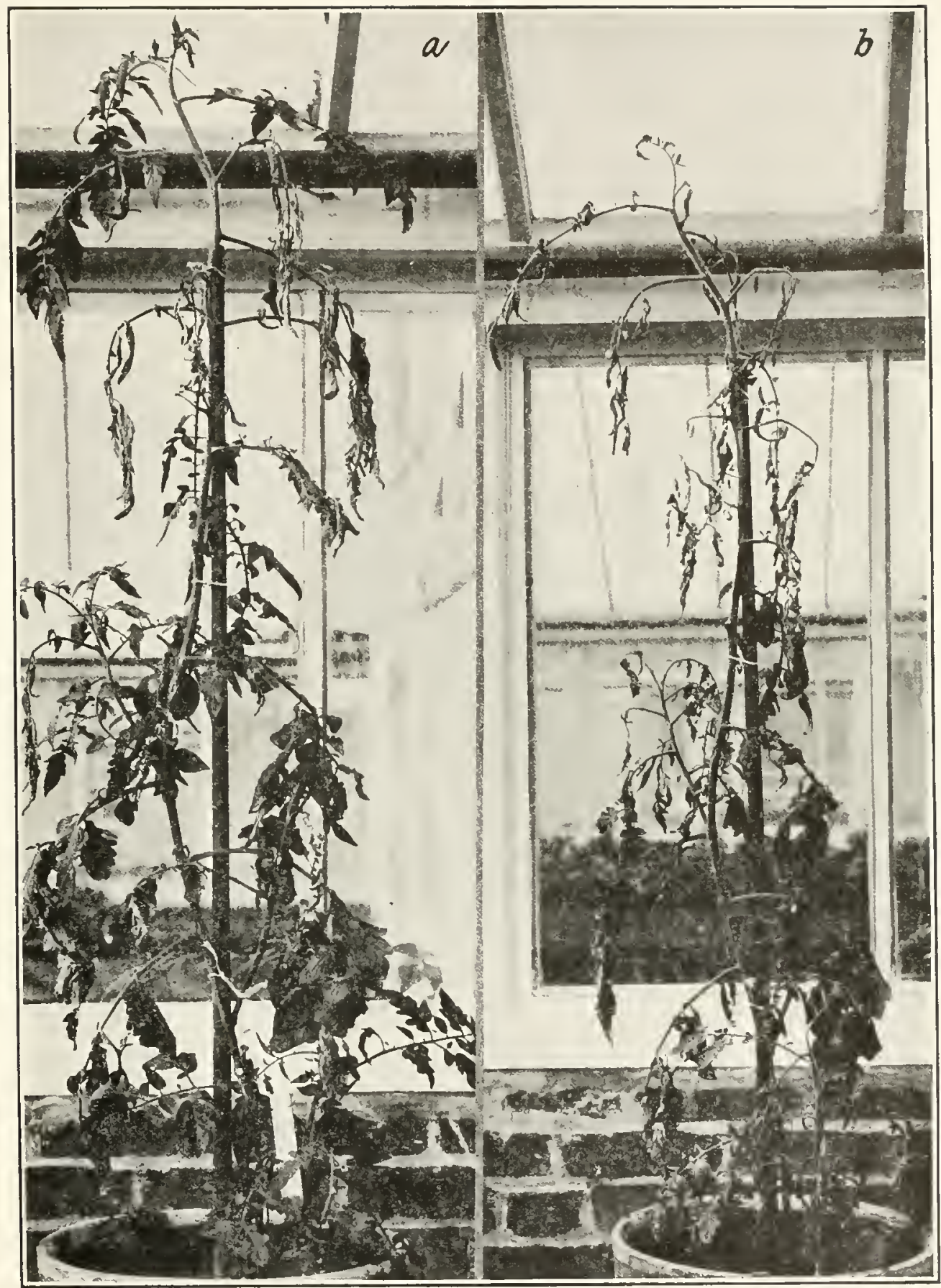

Grand Rapids tomato disease.

Plant No. 17 (see plate 12), showing lister stages of the disease. Photographs: $a$, Dec. 3. and b, Dec. I6. 



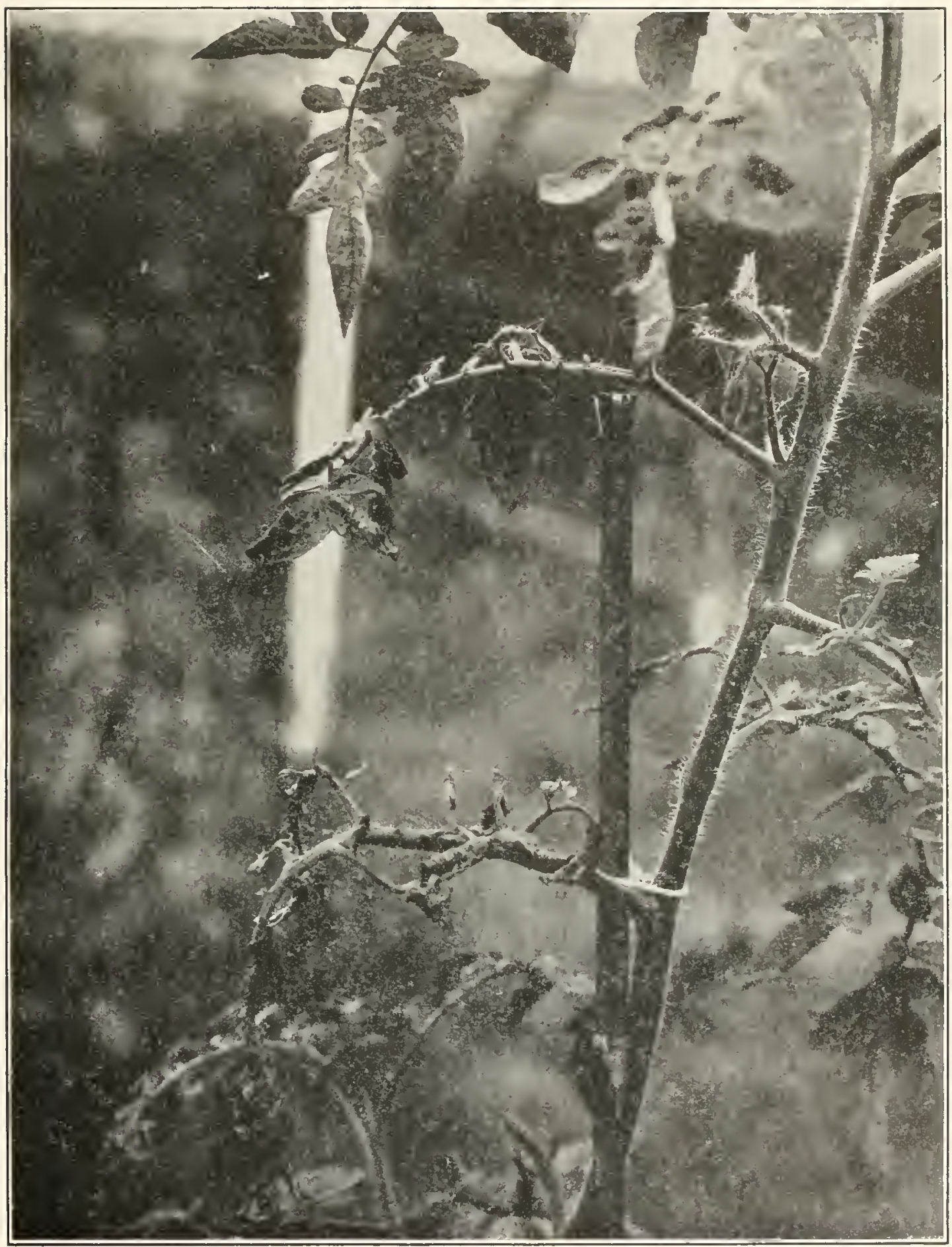

Grand Rapids tomato disease

Plant No. 13. inoculated October 5, ph stographad November 13. Notice slight development of aerial incipient roots as compared with similar plants inoculated with Bach. solanacearum (plate 27 ). 



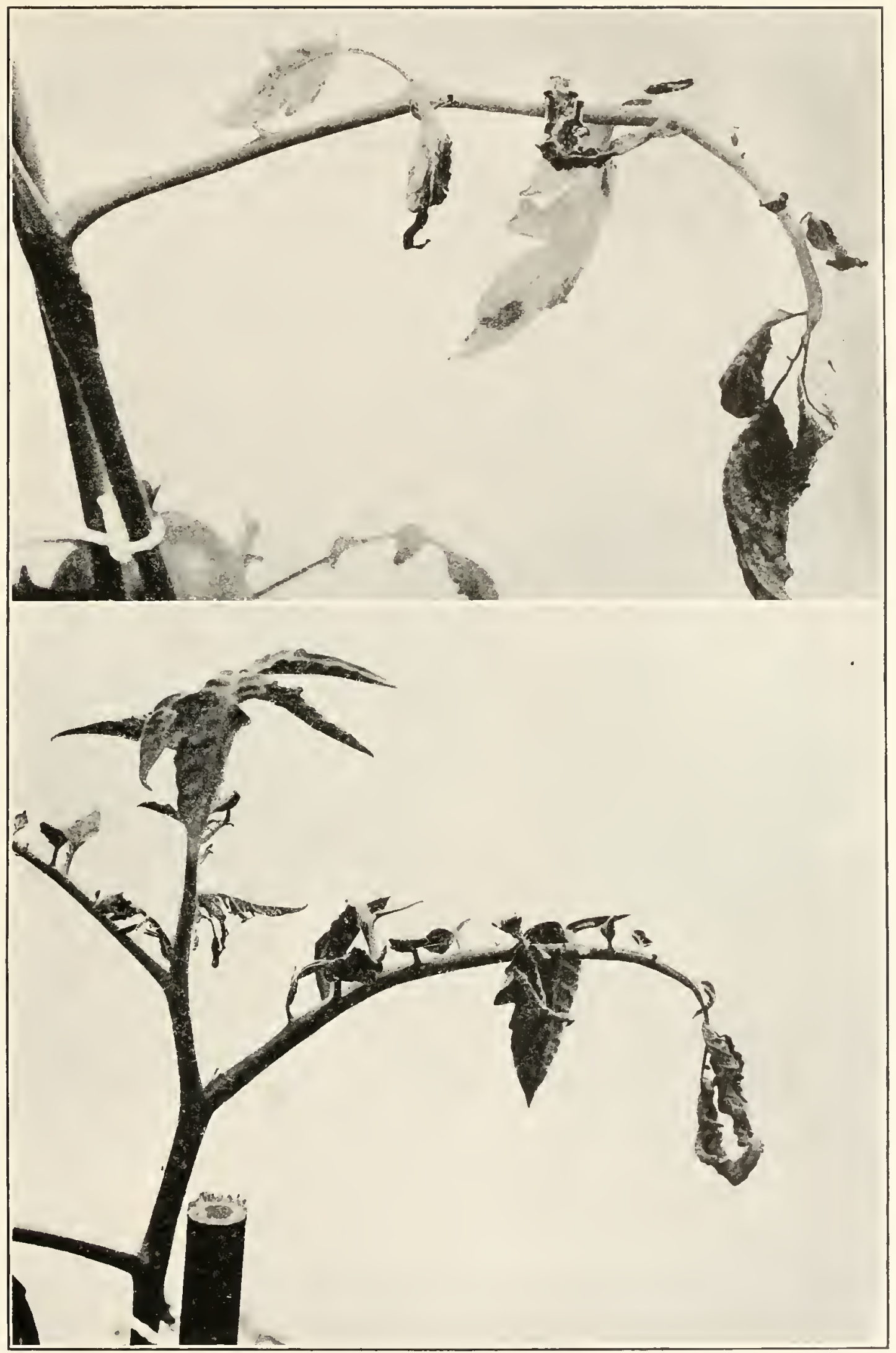

Grand Rapids tomato disease.

Leaves from tomatoes Nos. 12 and 15, which were inoculated on the stems Oct. 5, 1900, with A planobacler mickiganense, Photographs made Nov. 19. Introduced to show the irregular drying out of the leaflets, which is quite characteristic. 



\section{ADDITIONAL OBSERVATIONS, INOCULATION EXPERIMENTS, AND INFERENCES.}

Inoculations in a hot-house in the fall of 1909 on tomatoes were very successful (plates I 2 to I5). Subsequently tlie disease escaped to numerous check tomato plants growing in the same house. It also attacked the spiny Porto Rican weed, which we were cultivating because it had been reported to be immune to the attack of Bacterium solanaccarmm (p. I 82 ). The outbreak swept the house, much to my ehagrin.

The readiness with which the disease eseaped from control indicated easy infection through the stomata of leaves and stems. The bacteria for such infection were known to be available in large numbers owing to the fact that under the influence of this disease the soft stems of the tomato crack open as they shrivel and allow the bacteria to come to the surface, from which the gardener's hose and various inseets wonld afford a ready means of dissenination.

Subsequently we obtained experimental proof of stomatal infeetion. We found that the disease could be produced very readily on tomatoes by making a water suspension of

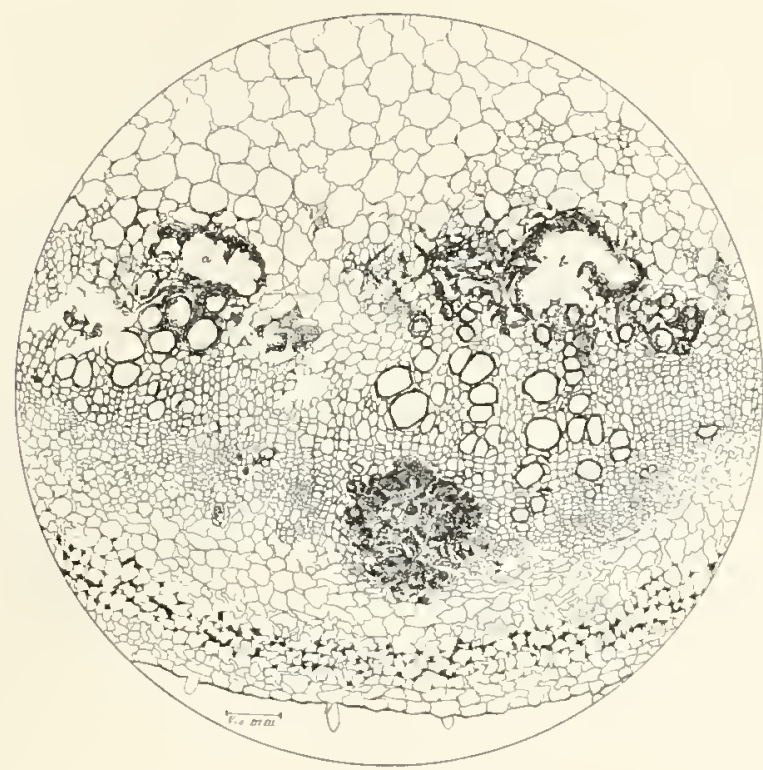

Fig. 72.* young agar cultures and spraying this upon the healthy plants; and sections of very early infections thus obtained showed the baeteria to be located in the substomatic chamber.

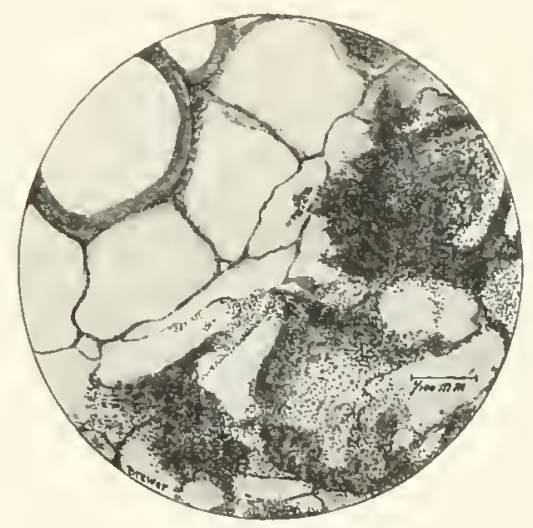

Fig. $73 . \dagger$

From these observations and experiments we may conelude that many infections take place above ground and that frequent germicidal sprayings might be expeeted to hold the disease in check. Anyway, Bordeaux mixture should be tried and also the self-boiled limesulphur mixture as made by Seott for the prevention of Monilia on peaches (see Bull. I74, Bureau of Plant Industry, U. S. Department of Agriculture, I910), and if immediate good results are not obtained the method should not be condemned, since the sprayed plants may lave been infeeted prior to the spraying, the progress of the disease being rather slow.

The signs of the disease are shown on the plates already mentioned, and the morbid anatomy so far as worked out is given in figs. 72 to 75 .

*Firg. 72.-Cross-section of the softer upper part of a tomato stem some months after inoculation with a pure culture of A planobacter michiganense and at a distance of several decimeters from the place where the needle entered. For appearance of the plants see plates 12 to 15 . Pith in the upper part of the section; $a$ and $b$, bacterial carities in the inner phloem similar to the one in the outer phloem but older, and the bacteria and tissue fragments washed out in preparation of the section; the lower heavily shaded parts represent collenchyma (all more or less shriveled by alcohol). Slide $539 \mathrm{~F} 4$, upper row, left section. Camera drawing, Zeiss $16 \mathrm{~mm}$. obj, and No. 8 comp, ocular, Inoculation of 1909.

tFIG. 73.-A detail from fig. 72 to show the individual bacteria. The drawing is taken from the margin of the cavity in the outer phloem. Zeiss $2 \mathrm{~mm}$. apochromatic obj, and No. 2 comp. ocular. 
Judging from our experiments and from the way it has behaved in Michigan this new disease bids fair to be a very serious one. Its geographical distribution is not known. In 1912 it appeared on tonatoes in a hot-house at Arkport, in western New York.* The writer is also inclined to believe it is identical with the potato discase described by Spicckermann (see p. I66) as widely prevalent in his part of Germany (Westphalia), although the few experiments I lave thus far made upon potatoes have been negative.

\section{RÉSUMÉ OF SALIENT CHARACTERS. \\ POSITIVE.}

A short, yellow, rod-shaped schizonyeete, parasitic on solanaceous plants, especially tomato (and potato ?), cansing a slow, destruetive disease of the whole plant. Isolated in the United States by the writer from tomato stems (Michigan, 1909; New York, 1912). Grows very slowly on +15 nutrient agar and +10 gelatin and also slowly in +15 nutrient bouillon. Liquefies gelatin slowly. Coagulates nillk slowly, forming in test-tubes a pellicle and a wide yellow bacterial rim. In tubes of litmus milk, inoculated copiously from solid cultures (potato), no change in appearance until after the fonrtl day. On the ninth day (temperature $26^{\circ}$ ) there was a wide yellow rim, a yellow pellicle, and the litmus had changed to a gray blue. After 24 days the litmus was wholly reduced, $i, c$., there was not a trace of the blue. The milk was thick, yellowish, and opaque, without much separation of the whey from the curd. There was a characteristic wide ycllow bacterial rim, and in two of the four tubes the milk was distinetly stringy.

On potato 27 days old (temperature $26^{\circ} \mathrm{C}$.) there was a moderate amount of yellow slime both on the surface and at the bottom of the water, but the fluid was

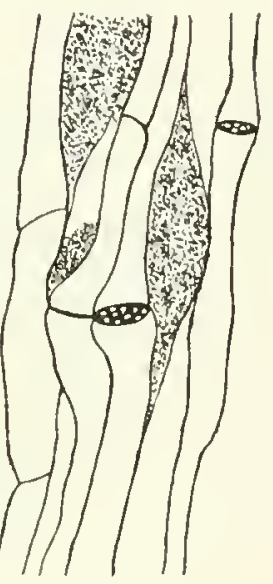

Fig. 74. $\dagger$

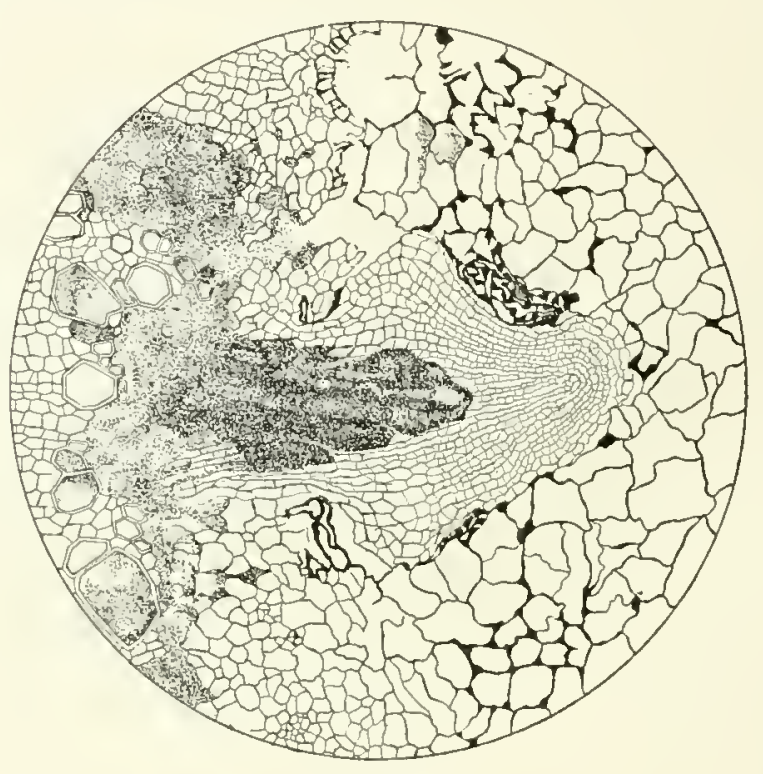

Fig. 75. not solid. Rather more growth than in case of Bact. stewarti, but not in quantity like Bact. campestre. Potato moderately grayed. On slant agar 27 days old (temperature $26^{\circ} \mathrm{C}$.) beyond the streak were many seattered (discrete) small round colonies, pale yellow to deep yellow. Blue peptone dextrose litmus agar is reddened and remains red after boiling.

In fermentation tubes containing dextrose or levulose the originally alkaline fluids were slightly acid after a month. Sensitive to sodium chloride. Quite sensitive to acids, malic acid, citric acid, oxalic acid. Finally clouded $+{ }_{5}$ bouillons. It tolerates considerable alkali, i. c., it grows in -25 and -30 peptone bouillon.

*'The organism was plated ont and tested on tomatoes, and culturally in the I,aboratory of Plant Pathology.

$\dagger$ Fig. 74. - Longitudinal section througl a cavity in the inner phloem ( $a$ or $b$ of fig. 72 ), showing bacteria wedging apart the sieve-tubes and companion cells. Drawn free hand, and slightly diagrammatic, $e$. g., unchanged nuclei and many of the pits in the sieve-plates omitted. No bacteria observed inside the sieve-tubes. Slide 539 F 7 , middle row, right section. Grand Rapids tomato disease.

${ }_{f}$ Fir. 75 - - Cross-section of inoculated tomato stem (first hot-house inoculations) showing the bacteria destroying the undifferentiated cells in a nascent root. Grand Rapids tomato disease. Drawn with Zeiss $4 \mathrm{~mm}$, obj. No. 2 eyepiece. Slide No. 539 A 7 (or 1), top row, section 1 from right. Stained with carbol-fuchsin. 
It is Gram positive. Only one of thrce tubes clouded after ro ninutes' exposure in + 15 peptone-bonillon at $45^{\circ} \mathrm{C}$, and that slowly. Repeated with same result. Endures drying well (cover slips 45 days). Slowly loses virtlence on media (several years). Viscid on potato and agar. Some sugared fluids also became very viscid. Group No.2 I I.2222522.

\section{NEGATIVE.}

Organism non-motile, non-sporiferous. It does not produce gas, or grow in the closed end of the fermentation tube: tests made in peptone water with grape-stigar, cane-sugar, fructose, lactose, galactose, maltose, mannit, glycerin. No immediate acid from lactose, galactose, maltose, mannit or glycerin. No liquefaction of Loeffler's blood serum. No prompt liquefaction of gelatin. It does not elond +15 peptone bonillon after io minutes exposure at $47^{\circ}, 48^{\circ}$ or $50^{\circ} \mathrm{C}$. It is not acid fast. It does not reduce potassium nitrate. It does not grow in Cohn's solution or in Uschinsky's solution. No growth in nentral peptone beef bouillon acidified to $+20,+25$, or +30 with malic, eitric, or oxalie acid.

When this organism was first discovered the writer thonght he observed motility, but many subsequent examinations have slown it to be non-motile. The name slould be changed, therefore, from Bact. michigancuse to Aplanobacter michiganense.

Striking eharacteristies are copious yellow surface growth on milk, and very slow growtl in agar, gelatin and bouillon, containitig Witte's peptone and beef juice, witl sodium hydrate to read +10 or +15 on Finller's scale. Viseidity on agar, and potato is common. For litmus milk and potato, see pls. 11 and 44. Because A pl. michiganense lias same group number as $A$ pl, rathayi, some comparisons were instituted with the following results:

Apl. michiganense.

Polato: Streaks pale yellow, smooth, inclined to spread.

Gelatin $\left(+14\right.$, plates at $20^{\circ} \mathrm{C} .15$ days): Many colonies.

Peptone beef-bouillon $\left(+\mathrm{I} 4\right.$, at $20^{\circ}$ C. 6 days): Thinly clouded, no pseudozoogloeae.

Litmus milk ( 15 d. at $27^{\circ}$ C.) redder than check, $i$. e., dull heliotrope-purple (Ridgway).

Inoculations: Causes discase of tonıato (signs in ro days).
Apl. rathayi.

Streaks darker yellow, inclined to pile up and wrinkle (Fig. 75a).

No colonies. In a repetition it grew on +9 gelatin.

No clouding, hundrcds of pseudozoogloca on walls and bottom of tubes.

Bluer than chec'-. Less surface growth, more yellow precipitate.

Not infectious to tomato ( $3 \mathrm{cx}: 45$ days, 39 days, 26 days).

\section{LITERATURE.}

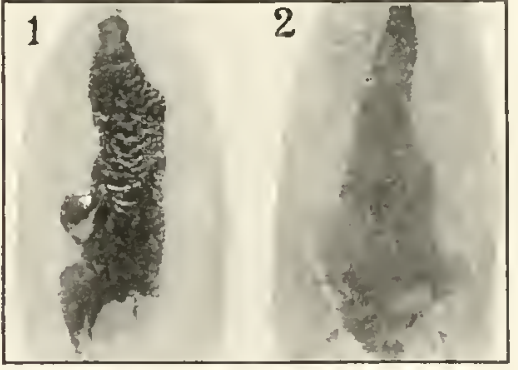

Fig. $75 a .^{*}$
1892. Lodfanan, Ir. G. A new discase of the tomato. Garden and Forest, vol. v, p. 175.

A brief note, which probably belongs here.

"We thought that this bacterium might be identical with the one which is sometimes so destructive to potatoes, for the appearance of the disease in the two plants is similar, but Prof Burrill to whom specimens were referred has just reported that the two diseases are prohahly distinct. It is certain that the disease can be communicated to the potato for diseased tomato-cions have beea orafted upon healthy potato plants and the latter are now plaioly affected.

* .. Possibly this serious disease is identical with the Southern Blight, recently reported by Dr. Halsted in a bulletin of the Mississippi Experiment Station." (See bibliography. p. 216.)

1892. BAILEV, L. H. Winter blight, in "Some troubles of winter tomatoes," Bull. 43, Cornell Univ. Agric. Exp. Sta., Ithaca, N. Y., 1 S92. See also Am. Gardening, 1892 , p. 668.

Relates to the disease first mentioned by Lodeman, of Cornell, and probably belongs here. The very slow growth of the parasite an agar poured plates as showa by our studies would account for Dudley's failure to get it in his cultures from diseased tomatoes. Interesting also is the fact that when a diseased cion of tomato was grafted on potato the stock became affected and contained bacteria. Also, the fact that the disease spread very quickly from diseased to healthy adjacent plants in the same compartment of the hothouse, hut not to tomato plants in another compartment. This second compartment was connected with the first hy two doors, allowing free access from one room to the other. but the plants were separated by a glass sereen, which would catch and hold back the bacteria likely to be spattered from the diseased plants by the gardener's hose (see this chapter p. r63). The cloudy white organism which Dudley obtained from the potato and identified as a microcaccus may be assumed to have been some saprophyte. Specimens of this disease were sent to Dr. Halsted who replied that it was not the Mississippi disease.

ISq2. BAIlEY, L. H., and CorbetT, L. C. Southern or field blight in "Tomato Notes for 1892." Bull 45, Corncll Univ. Iixp. Sta., Ithaca, N. Y., 1892, p. 213.

Seems to relate to a field disease, but probahly belongs here rather than under Southern blight. The figure is surrestive. and also a statement in the text respecting the irregular drying ant of individual leaflets.

1910. SMITH, Fintr F. A new tomato disease of economic importance. Science, n. S., vol. rxxI, No. 803, May 20, 1910, pp. 794-796.

Abstract of a paper read in Boston, December 1909, hefore American Phytopathological Society. The first account of the organism, but probahly not the first account of the disease, as was then supposed.

*Fig. 75 a.-Streak cultures on potato: (1) Aplanobacter rathayi; (2) Apl. michiganense. Time 14 days; temperature $20^{\circ} \mathrm{C}$. Both will grow on potato at $i^{\circ} \mathrm{C}$. 


\section{SPIECKERMANN'S GERMAN POTATO DISEASE.}

In 1910 Spieckermann published brief preliminary articles on two vascular diseases of the potato as found in Germany, the second of which is probably identical with the preceding (p. 161).

He first considers Appel's ring disease. 'This is said to be due to bacteria which cause the vascular ring of the potato tubers to become brown, as Appel has pointed out (see The German ring disease, p. 215). These bacteria enter through the underground stem, multiply in the ressels, and in this manner make their way in to the tuber. Noticeable changes also take place in the parts above ground. During the course of the summer the shoots beconic translucent, brownish spotted, and flabby, and the leaves acquire in the veins blackish gradually enlarging spots, shrivel, and fall off. But the disease may also occur without the spots.

According to Appel, affected seed tubers produce plants in which the ring-disease is worse than it was the first year.

Tubers showing Appel's ring disease have been common in Westphalia in recent years. Plates made therefrom gave always pure cultures or mixed cultures of Psendomonas species, with one polar flagellum or a tuft of such flagella. These cultivated on the ordinary nutrient media slowed sometimes fluorescence, sometimes fermentation, and always liquefaction of gelatin. More rarely forms of the mesentericus group were found. Some of these species, when grown on slices of raw potato, caused wet rot like $B$. phytophthorus. In consideration of the work of Appel furtler observations were not made. But it should be stated that in Westplialia such infected tubers liave often been obtained from plants which above ground show no signs of disease and the stem-vessels of which are free from bacteria; and such tubers when planted out have not given diseased plants.

Distinct fron the above is a vascular potato disease repeatedly observed by Spieckermann in Westphalia in the summer of 1908 .

If Appel's ring disease sliould be designated a Kräuselkrankheit, this ought rather, like the basal stem-rot, to be called a Blattrollkrankheit. It is first visible toward the end of July or the beginning of August, through the curving of the leaves upward around the midrib. At the same time tle otherwise normal looking or only somewhat weakly developed plants slowly turn yellow and gradually wilt. Proportionately to the rapidity of the disease the yield is decreased.

When examined microscopically the vessels of the diseased stem are found packed full of small, non-motile, rod-shaped bacteria. The same are also found in the vessels of the tubers. But the vascular ring shows at first scarcely any change, at most here and there a minimal yellow stain, which to those not familiar with the phenomena would hardly appear suspicious. But gradually as the vines fall down a striking cliange occurs. The vascular ring becomes stained a more or less pale yellow; at the same time the ring softens, and this softening cxtends gradually into the surrounding parenchyma. There occurs consequently a slowly progressive wet-rot in such a way that finally in extreme cases the tuber consists of three distinct parts-an external intact bark, a narrow soft zone corresponding to the vascular ring, and a middle intact part, which can be taken out as a whole.

The progress of this rot is very slow and even in spring numerous tubers can be found in which the softening is limited to single small spots.

The fate of the tubers depends on how rapidly the disease progresses. The severely attacked tubers die in the course of the winter and become infested witl Fusarium. This fungus may also appear earlier. Otlier tubers look sound in the spring except for darkened 
eyes which will not germinate. Sometimes four weeks after planting one finds such tubers externally sound but witl black eyes, and on cutting then discovers that the vasenlar ring is wholly destroyed. Even in these, if there is no mixed infection, the vascular ring is $110 t$ decidedly blackened. But even if the tubers are planted with sound eyes and sliow only small rot-spots, many of them die, while others yield sound plants.

If the discoveries of this summer are confirned, this fact constitutes an important difference between this disease and Appel's ring disease.

We may now inquire whether the bacteria found in the diseased plants are the cause of the disease.

In 1909, with these bacteria, 111merons inoculations were made in wounds, in stens above ground, and in plants standing in the field, and almost all of these were successful, the diseased phenomena being produced both on the parts above ground and in the tubers. There is, therefore, no doubt as to the causal relation of the bacteria to the disease. A special predisposition, other than the existence of wounds reaching to the vessels, is not necessary. Also, no difference in varieties has been observed up to this time. They infected without difficulty Abdul Hamid, Hilde, Iris, Cacilie, Bonar, Professor Mæreker, Norma, Busola, Topas, Zlozien, and Roland. Spontaneous outbreaks have been observed in the fields thus far only on Professor Mærcker.

The organism is unlike that of Appel's ring disease, and Dr. Appel has himself confirmed tlis during a visit.

Spieckermann gives the following description of his organism:

They are very short, non-motile rods 0.5 to $0.7 \mu$ long, which grow very slowly on all artificial substrata. In peptonized meat-water agar and on potato they produce in the course of several weeks white, pale yellow to dark yellow slimy-flowing or viscid (fadenziehende) zoogloer. Gelatin is not liquefied. They grow distinctly in gelatin stabs, but without distinguishing phenomena, the surface growth being slight (fehlt so gut wie ganz). On gelatin and agar plates they grow as very small, round, non-characteristic colonies which are first visible to the naked eye after about 8 days; some of these are viscid and stick to the needle. Meat peptone-bonillon is well clouded (starkgetriibt). In substrata containing sugar there is no fermentation. Milk after several weeks coagulates slowly and there is a gradual solution of the casein. The serum is colored yellow, smells like milk changed by the peptonizing steam-resistant (Koclifest) bacteria of milk, and is in most of the strains viscid (fadenziehend). 'The optimum temperature is under $30^{\circ} \mathrm{C}$. Spore-formation lias never been observed. The rods are Gram positive.

Mr. Kotthoff was associated with Spieckermann in these studies.

On asking Dr. Spieckermann for further information he replied that a full paper on this disease is in press in Berlin (Landw.-Jahrb.) and may be expected about the middle of 1914 . From his reply I judge that while the disease occurs in Westphalia principally on potatoes, he has also seen it on tomatoes, and this further confirms niy belief in the identity of the two diseases. He says the organism is quite distinct from Bact. solanaccarmm.

\section{LITERATURE.}

igro. SpieckermanN, A. Ueber cine noch nicht beschriebene bakterielle Gefasserkrankung der Kartoffelpflanze. [Vorläufige Mitteilung.] Centralb. f. Bakt., 2te Abt., 27 Bd., Jena, June I, I9IO, pp. 205-208.

I911. SPIECKERMANN, A. Beiträge zur Kenntnis der Bakterienring und Blattrollkrankheiten der
Kartoffelpflanzen. Jahresberichı der Vereinigung für angewandte Botanik. 8 Jahrg. I910. Berlin, I9II, pp. I-I9.

The preceding appears to be the earlier publication. This one gives numerous analyses showing dry substance in sound and diseased tubers, stems, etc. An average of 20 analyses of diseased control tubers gives 22.55 per cent of dry substance: an average of 13 sound controls gives 24.60 per cent. 


\section{VASCULAR DISEASES OF BANANA.}

\section{EARLE'S JAMAICAN DISEASE.}

In $1902, \mathrm{~F}$. S. Earle saw a new banana disease in Jamaica and published a brief note on it in his "Report on a trip to Jamaica." The disease is called the banana leaf-blight, and his account of it is as follows:

On one locality at Stony Hill, north of Kingston, a serious banana disease was observed. It causes the browning of the vascular bundles in the veins and midrib of the leaves. This is soon followed by the blackening of the entire leaf-blade, and eventually by the decay of the leaf and petiole. It does not seem able to extend from the petiole into the tissue of the stem. The terminal bud is not attacked, but continues to push ont fresh leaves. These soon become infected in turn, so that usually not more than three or four of the younger leaves are free from the disease. Infected plants are much stunted in growth and do not bear fruit. In the small field where it was first observed fully threefourths of the plants were infected. The contagion was in this case probably introduced with the suckers that were used for planting, as these were said to have been taken from some neglected patches in the neighborhood, and a visit to these showed that they were also infected. The disease evidently spreads slowly, as it had not crossed a wide licdge row separating this infected field from one adjoining. It may never prove troublesome, but the advisability of immediately destroying all diseased plants was strongly urged. If so destructive a disease should by any chance become widely scattered the result would be truly disastrous.

Apparently it is due to a bacterial parasite. Cultures were obtained and it is hoped to study the disease further. No evidence was secured as to the means by which it is conveyed to the fresh leaves or from plant to plant. So far as known it is confined to this one locality, which is at an elevation of some 1,200 feet and on red land. Such locations are not considered to be adapted to bananas, yet all uninfested plants were growing and fruiting satisfactorily.

Subsequently Earle sent a culture of the whitish schizomycete which he had isolated to the writer, who made numerous inoculations on banana shoots in the sunmer of 1903 , pricking in the organism from young, actively growing cultures, but obtained no signs of the disease. The organism was not infectious.

\section{SMITH'S CUBAN DISEASE.}

In the autumn of 1908 a banana shoot, similarly affected, was sent to me from Cuba, and subsequently rooted plants. Some of the vessels of the leaf-stalks were yellowish, and many were brown or purple-brown. Bacteria were present here and there in some of the vessels, but so sparingly that they seemed to stand in no causal relation to the disease. Subsequently a fungous mycelium was detected in the vascular bundles, in and behind the walls of the vessels, seldom filling the lumen. This was not very abundant in any particular vessel and appeared to be sterile on first examination, but upon further stidy the writer saw one or two indications of conidial fructification, $i$. $c$., hyphæ ends constricted so as to cut off partially an elliptical oblong terminal portion. Very few free spores were seen, but the appearance seemed to point to the conclusion that the fungus was a Fusarinm, and poured plates made from the interior of diseased petioles subsequently justified this conclusion. Conidial colonies of Fusarim came up on the poured plates, and transfers from these colonies to sterile cornmeal-mush fruited abundantly. The mycelium on this substratum was whitish at first, but soon pink, becoming a beautiful strawberry-purple on top and deep wine-red below the surface of the fungous mat. Old cultures of this fungus were given to Dr. Wollenweber for further study. The surface of these internally diseased petioles was free from fungous spots and from other signs of disease, and was, moreover, 
thoroughly sterilized by I : I, ooo mercuric-chloride water before taking some of the interior, with sterilized instruments, for cultures.

No further opportunity has occurred for the study of this disease, but the writer has no doubt (Jan. 1909) that the Cuban banana disease, whatever may be thought of the Jamaican one, will be found to be due to Fusarium cubense which is not unlike those described by him from cotton, melons, cowpeas, and cabbage.

Inoculations begun by the writer in July and August 1909 demonstrated the ability of

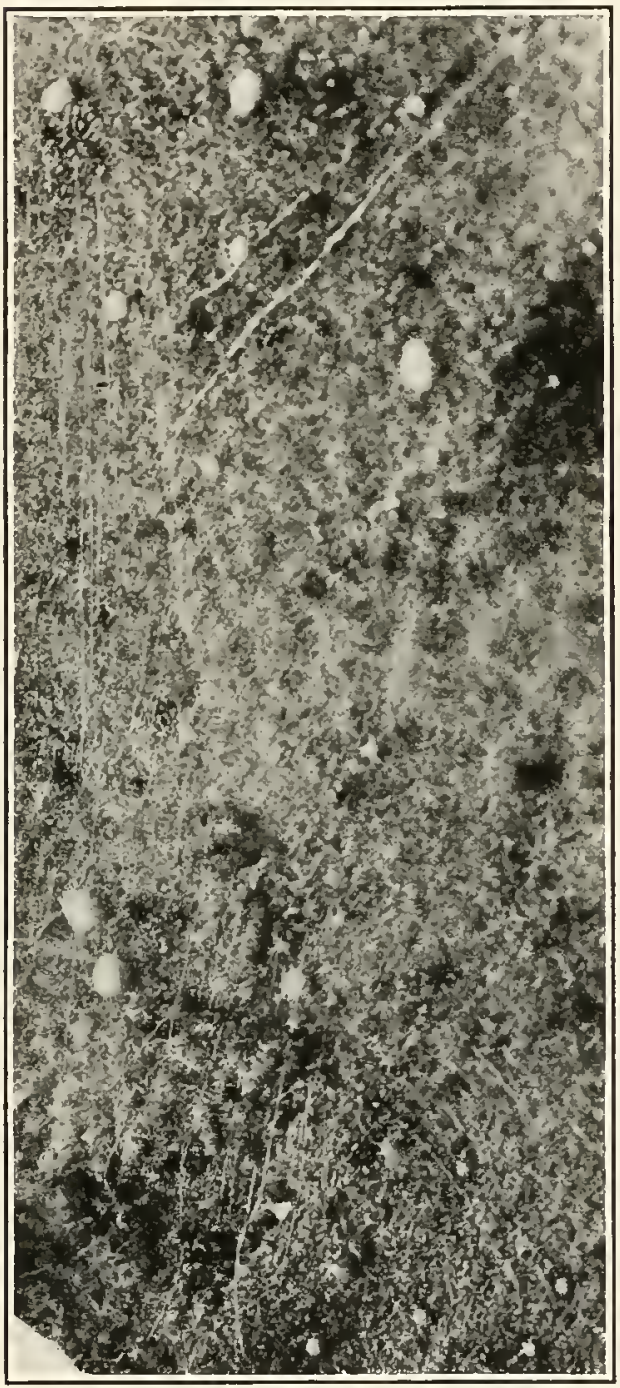

Fig. 76.* the fungus to occupy the vascular bundles of the banana and to penetrate long distances from the point of inoculation ( 7 feet and more), with production of the characteristic stain, but the experiment was broken off before secondary signs appeared.

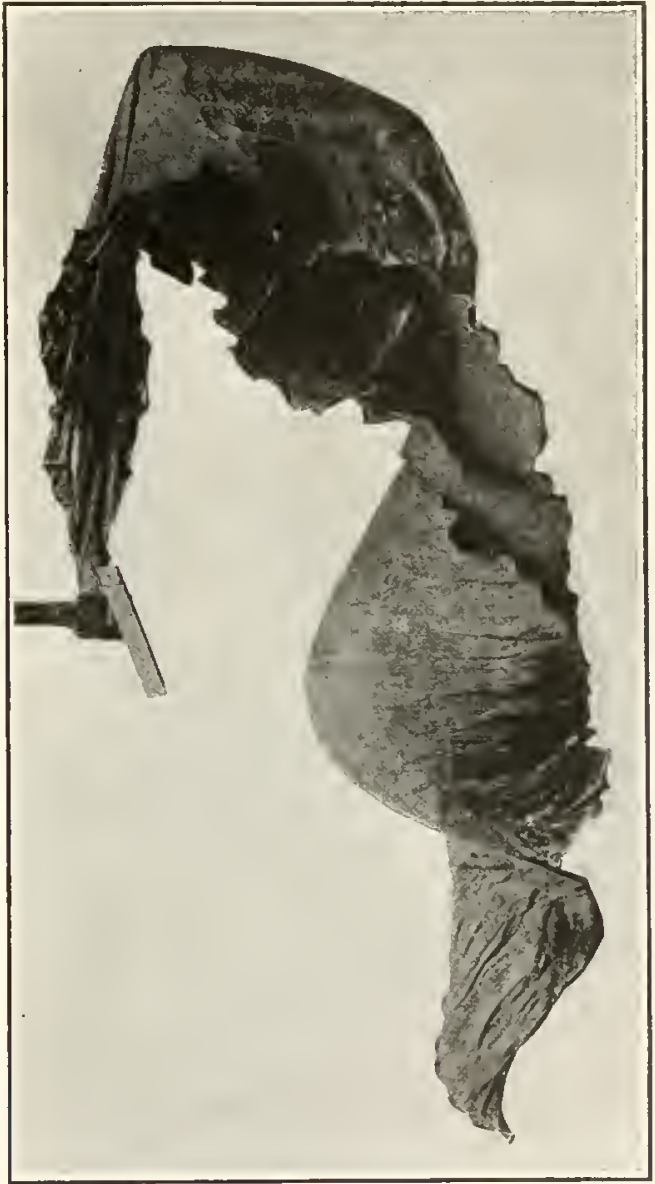

Fig. 77. $\dagger$

During the construction of another hot-house the root-stocks remained for several months dry on a bench and when finally planted again they grew without development of secondary signs (4 years).

*F1G. 76.-Enlarged cross-section of part of a banana fruit-stalk, showing white drops of Bacillus musae oozing from the bundles. The white threads are spirals pulled out of the vessels by a dull knife. Photographed in Washington in 1910 from Trinidad material received from James Birch Rorer.

†Fig. 77. - Large leaf of a yellow-fruited banana inoculated by the writer on the petiole December 21,1910 , using needle-pricks and white bacterial slime, from fruit stalk shown in fig. 76. Photographed February 25, 1911, when the whole leaf was shriveling and the vessels of the petiole bundles were filled with bacteria. About r/ 10 natural size. 
The Cuban disease has been described to me as causing plants to throw out numerous low suckers, and to make a dwarfed, worthless growth, one leaf after another showing the brown vascular bundles and drying out. It occupies considerable areas in some sections of Cuba, especially where bananas have been used as a shade plant for tobacco.

\section{RORER'S TRINIDAD DISEASE.}

In April I91 I, James Birch Rorer published an important paper on "A bacterial disease of bananas and plantains," studied by him in Trinidad.

This disease was first observed by him in 1909 in the Moko plantain, used largely as a sluade for young cacao.

An examination showed that the vascular bundles were filled with bacteria, which oozed out in white shiny drops from the cut surfaces. Pure cultures of an organism which was proved to be the eanse of the disease were obtained by the poured-plate method.

Subsequently he found the disease in practically all parts of Trinidad, attacking not only the Moko but also the Creole and French plantains (Musa paradisiaca) and the dwarf or Cavendish banana ( $M$. chinensis).

The presence of the disease is as a rule first detected in the lower leaves. 'The leaf-blades droop a little more than usual and have a slightly yellowish tinge, symptons very similar to those brought about by drought. Soon, however, the petiole of one of the leaves gives way just at the base of the leaf-blade, and all the other leaves quickly break down in a simi-

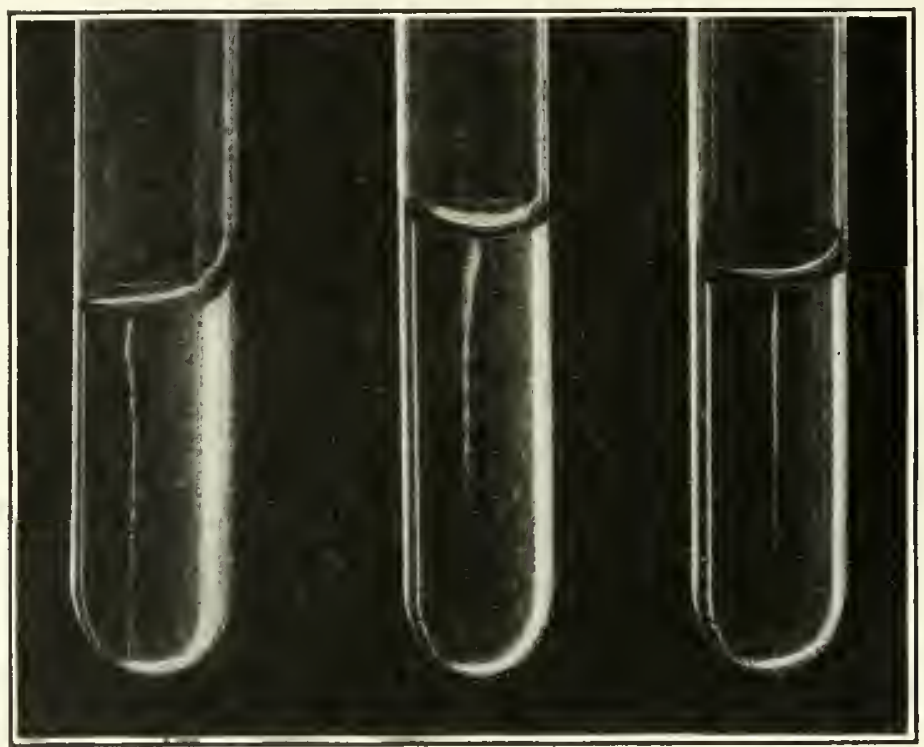

Fig. 78.* lar manner. Eventually the terminal leaf, too, bends over and the plant dies and rots lown to the ground. [Plates $16,17,18,19$.

The bundles of the psendo-stem and of the root-stock are discolored from pale yellow to dark brown or bluish black, and the vessels of such bundles are filled with bacteria. It is easy to trace such discolored bundles from leaves and pseudo-stems into the root-stock and thence into young suckers and buds [plates 20, 2 I (I), 22 (2)].

Sometimes in badly diseased plants the tissues of the leaf-stalks and stems are broken down completely, so that fairly large bacterial cavities are formed. [See pls. 2 I (2) and 22 (I).]

If the disease is not severe, or a plant does not become infeeted until it has just formed a bunch of fruit, it may remain perfectly healthy looking, but many of the young fruits, or "fingers" do not properly mature; they remain small and eventually become black and rotten. In such cases it is found that there are some discolored bundles filled with bacteria in the leaves, stem, fruit-stalk, or fruits. When diseased suckers are planted the terminal leaf frequently turns black and dries up, so that the plant dies.

Mr. Rorer lias named the schizomycete causing this disease Bacillus musae. He first secured it in pure cultures in August I909, and since that date numerous successful inocula-

*FIG. 78.- Stab-cultures of Bacillus musae Rorer, after ro days in + io nutrient gelatin (stock 4653 ) at $20^{\circ} \mathrm{C}$., each derived from a separate colony. No liquefaction; best growth on the surface and in the upper part of the stab. 


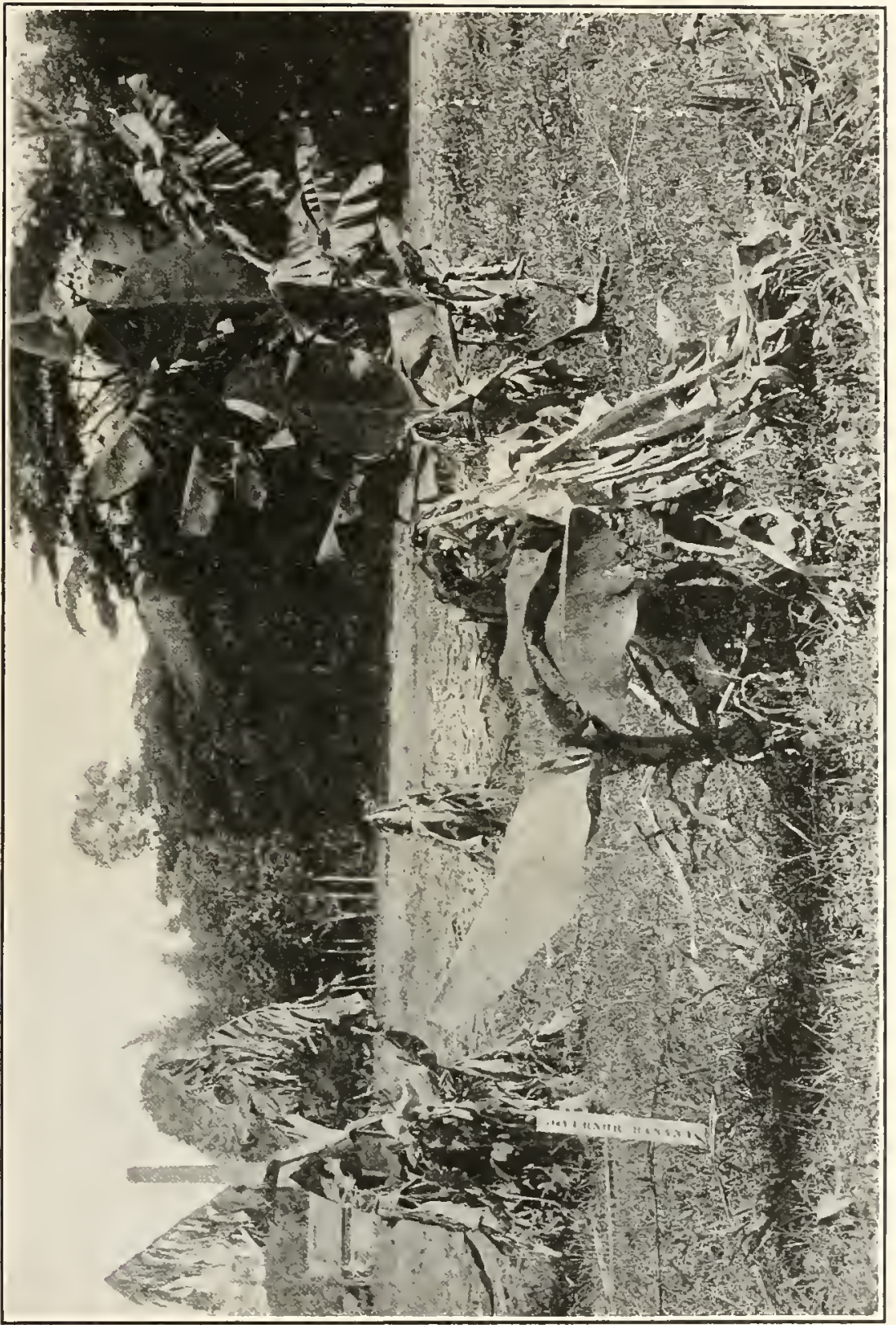

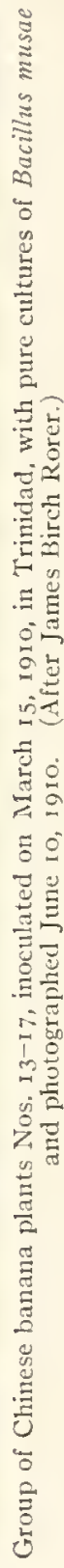





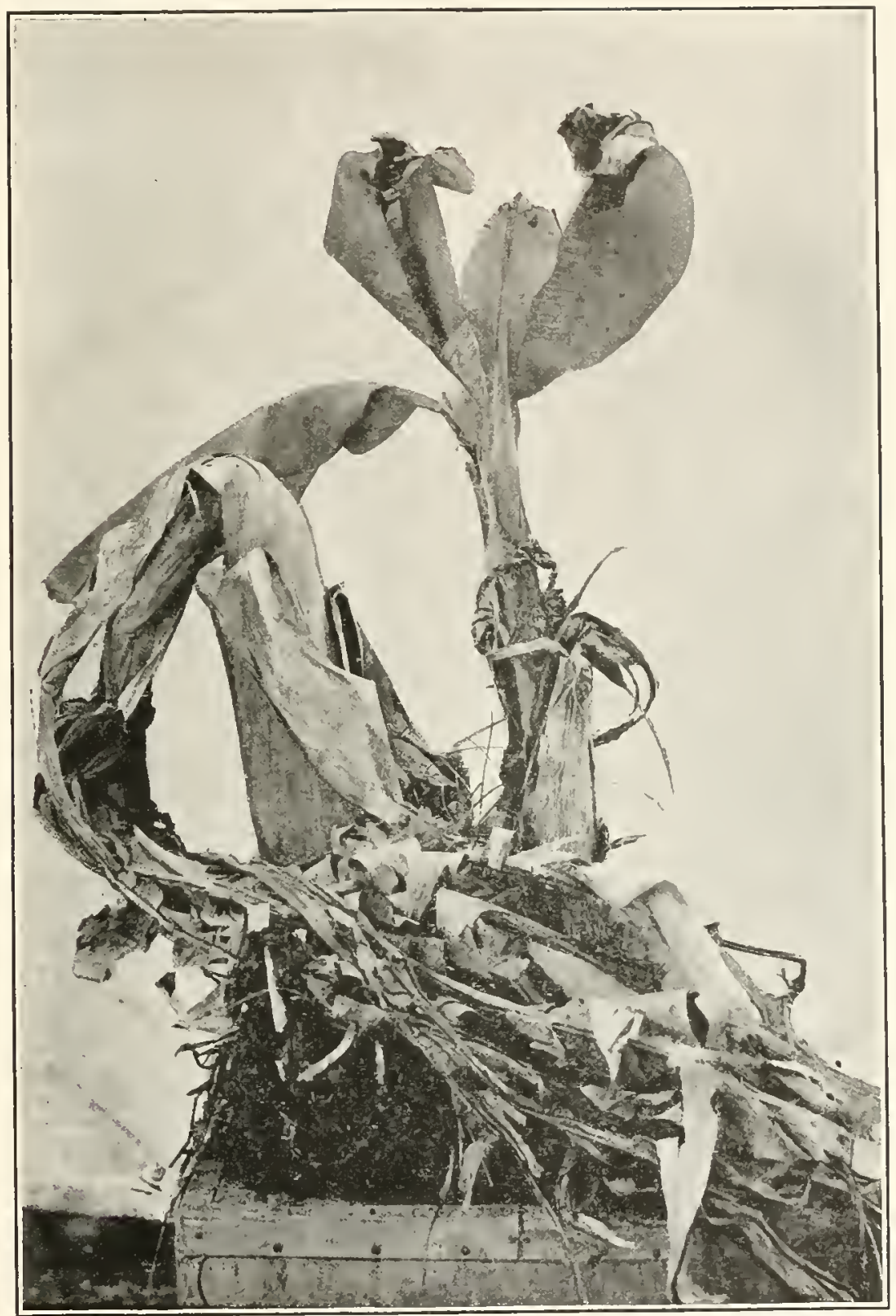

Chinese banana plant No. I5, inoculated on March I5 with pure cultures of Bacillus musae.

The parent at the Ieft, which was the one inoculated, has died completely, and the sucker is heginning to show the effects of the disease in the tips 



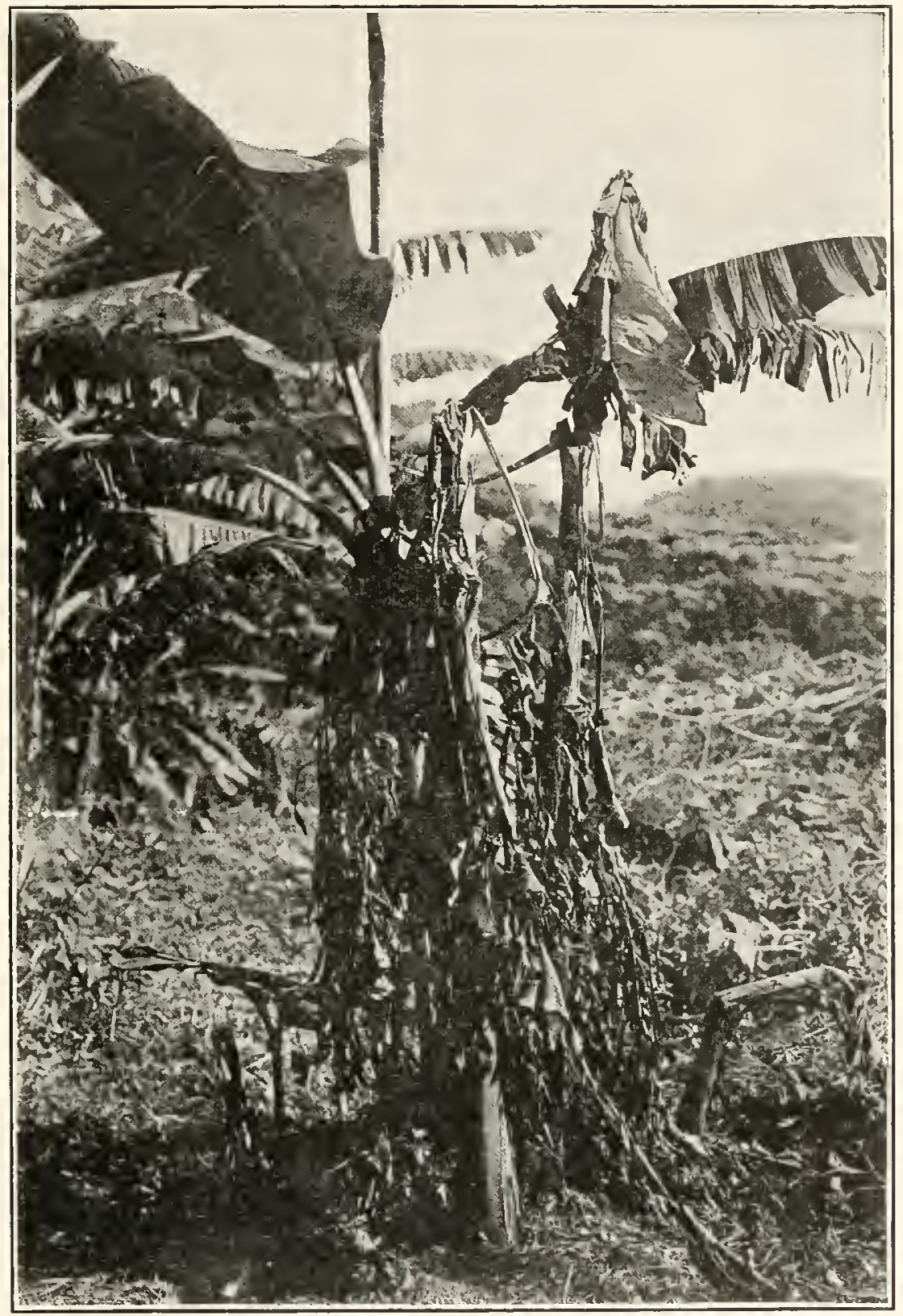

Stool of Moko plantain inoculated October 13, 1909, with pure cultures of Bacillus musae.

Plant in foreground is the one that was inoculated. Photographed March 3, I910. (After Rorer. 



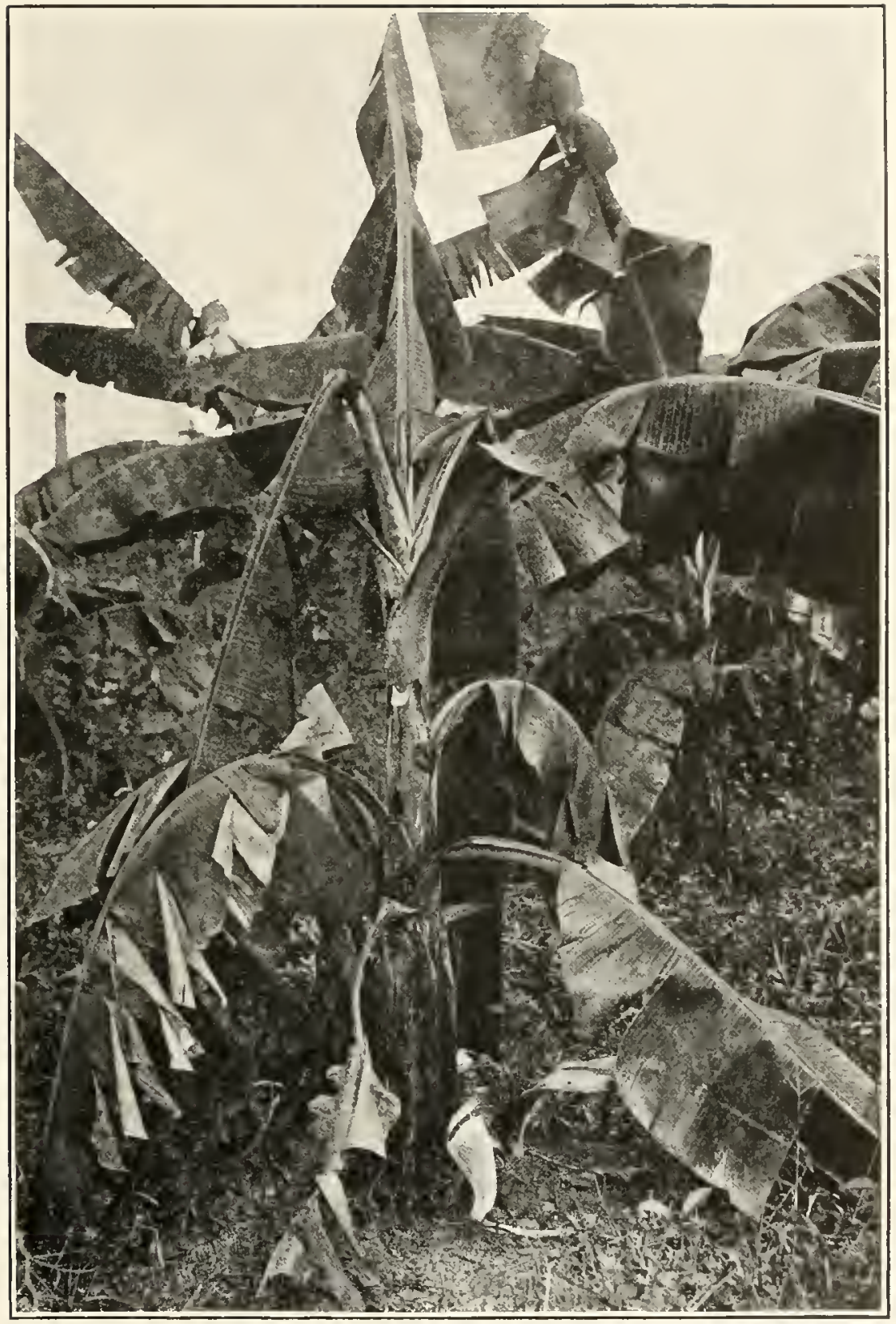

Red banana plant No. 2, inoculated Mar. 12 with pure culture of Bacillus musae, and showing characteristic way in which the leaves break down before thcy shrivel. Photographed Apr. 5. 1910. (After Rorer). 


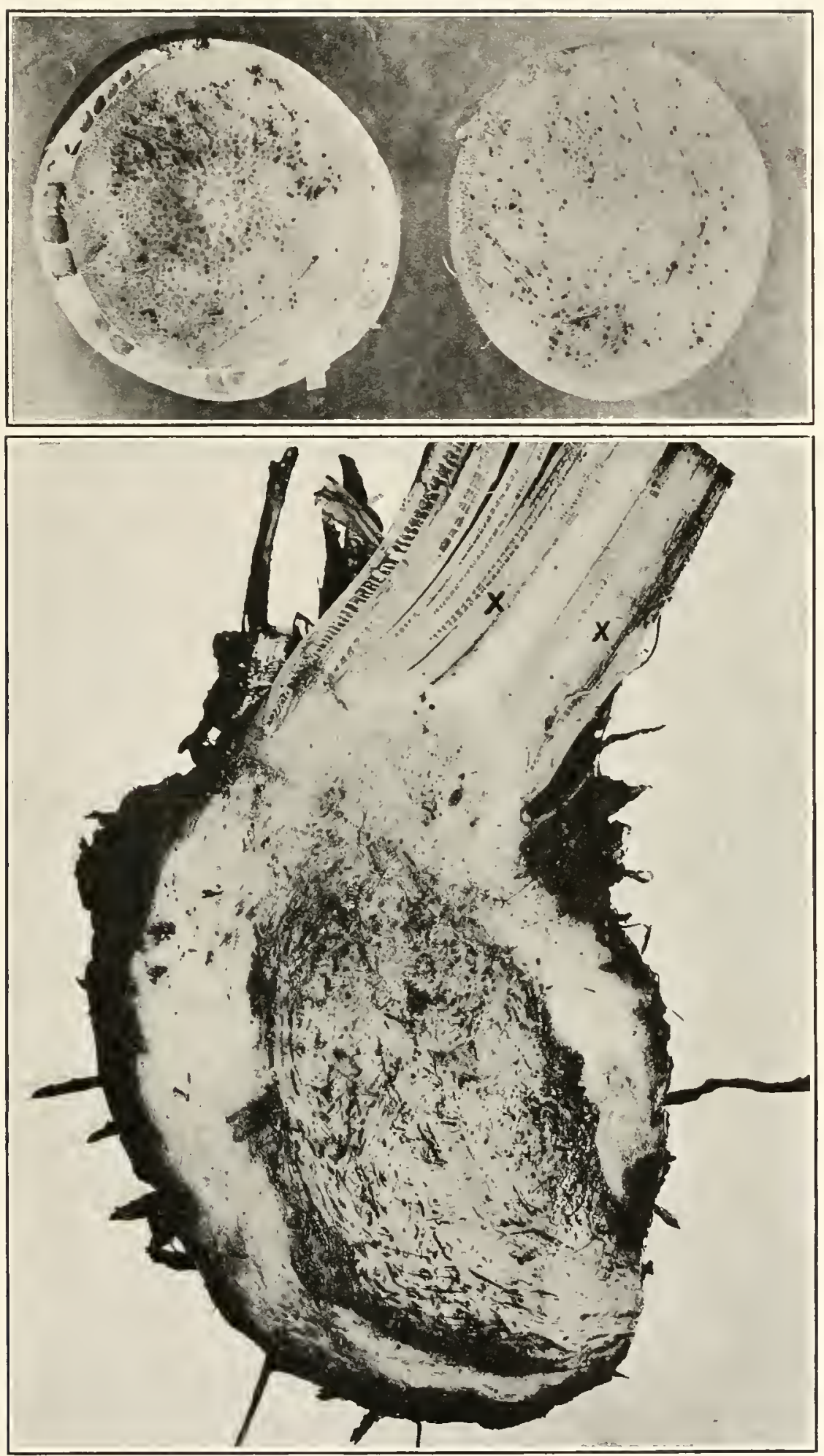

(1) Cross-section of fruit-stalk of a dwarf banana infected naturally with Bacillus musae. Photographed November 23. 1910. For slightly enlarged view of such a cross-section showing the white bacterial

(2) Longitudinal section of sucker from Chinese banana plant No. 15, inoculated nn March 15. At $X_{0} X_{\text {. }}$ discolored vascular bundles may be seen extending from the rootstock in to the pseudo-stem. (After
Rorer.) 


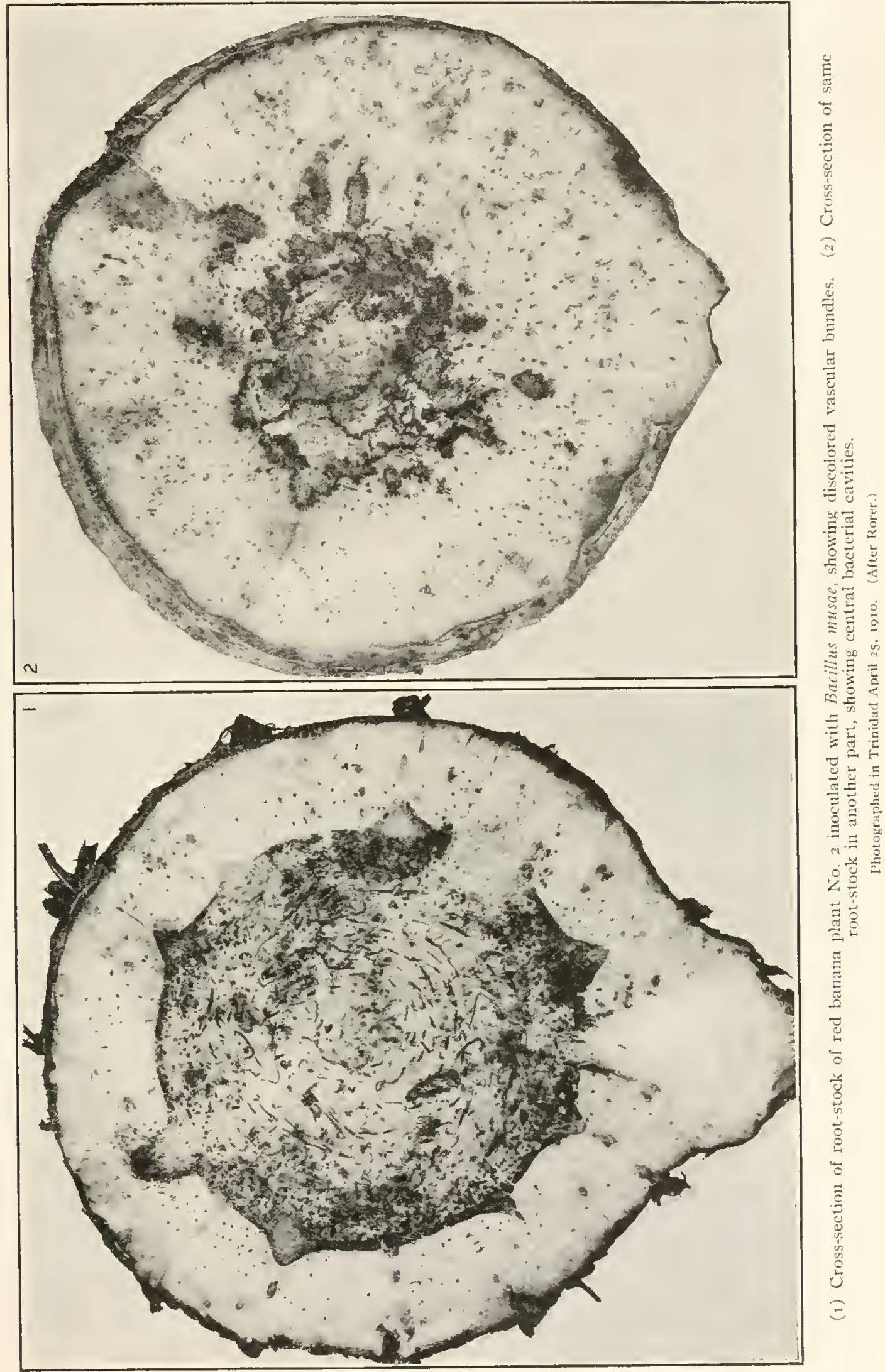


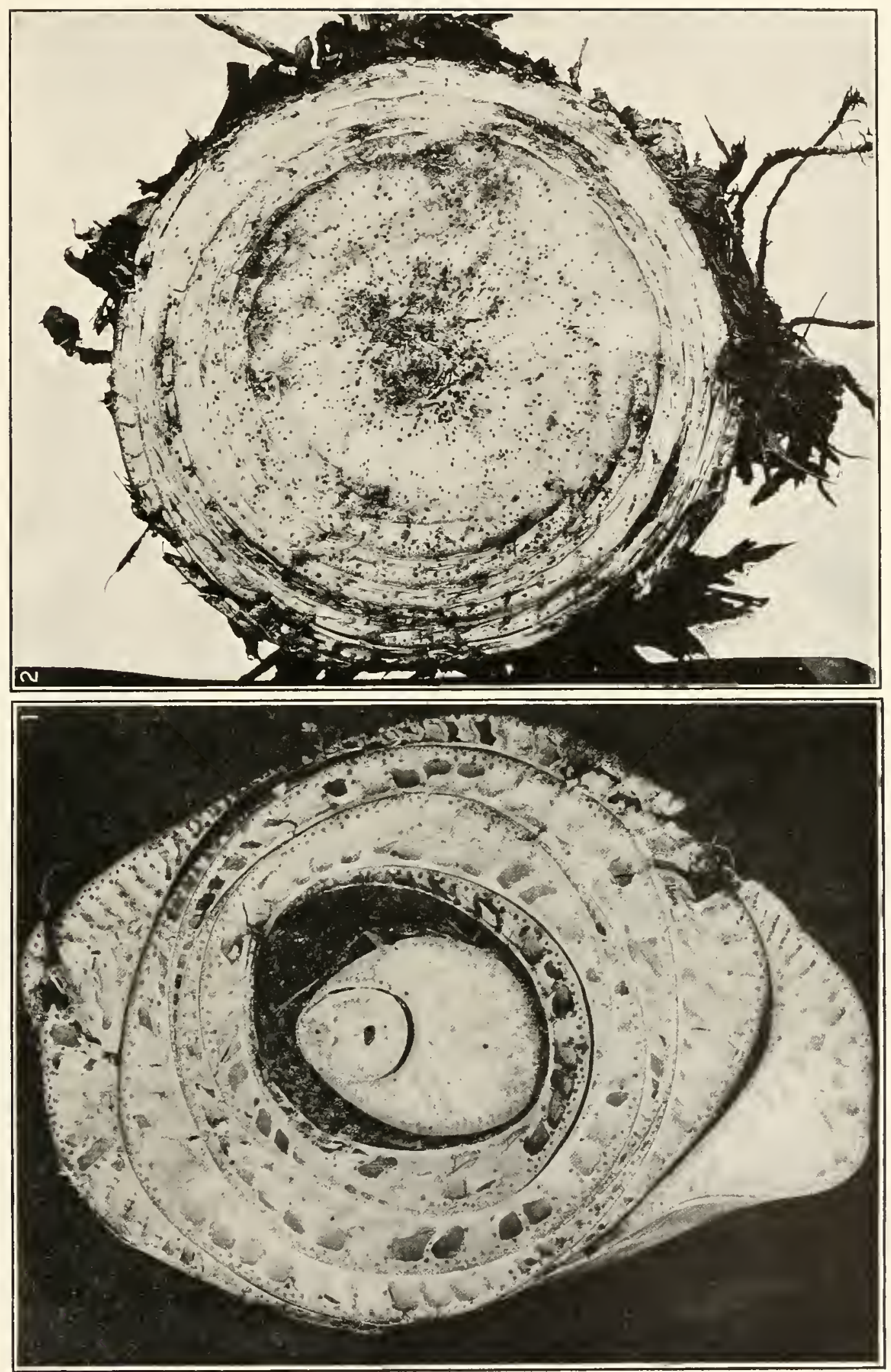

tions, reisolations, and reinoculations have been made by lim, both on the Moko and on other varieties. Manila hemp plants were also inoculated, but proved quite resistant.

From a lack of the necessary bacteriological apparatus and supplies but little has been done on the biology of the organism, but it has ahways becn recognized in cultures by the fact that it quickly becomes black when grown on potato cylinders. It is also very short lived and loses its pathogenic power quickly, especially on media which contain starch. In these respects it is similar to Bacillus solanacearum. Inoculations have been made with it several times on solanaceous plants, but so far they have been unsuccessful. 'The writer is giving the name Bacillus musae to the organism and will at some future time give the complete bacteriological chart.

Although many of the signs of the bacterial disease are like those exhibited by the Panama disease, they are not the same.

The two diseases are quite distinct. Though the vascular bundles of plants attacked by the Panama disease are discolored and frequently filled with bacteria, $B$. musae lias never been isolated from such plants. The bacteria in the ressels are usually rapid growing gas formers, and at least, so far as the writer's experience goes, are not pathogenic. 'The longitudinal splitting of the lcafsheaths which is a characteristic of the Panama disease [anck also of the Cuban disease-E. F. S. is not found in plants attacked by the [bacterial] "moko" disease. Moreover the Gros Michael plant, which is very susceptible to the former disease, scems to be naturally resistant to the latter.

A species of Fusarium was isolated in November, 1909, from a diseased Gros Michael plant and since that time the sane fungus has always been found associated with the Panama disease both in Trinidad and in Surinam. Evidence seems to point to the fact that this fungus is the cause of the disease, as was pointed out last year by Dr. Erwin F. Smith.

The writer received pure cultures of $B$. musae from Mr. Rorer and inoculated them by needle-pricks into banana shoots, but unsuccessfully. Portions of diseased plants were also received from him, and examined microscopically, the vessels being free from fungi and swarning with bacteria. One of the fruit stalks which was green and sound externally extruded from a cross-section numerous small

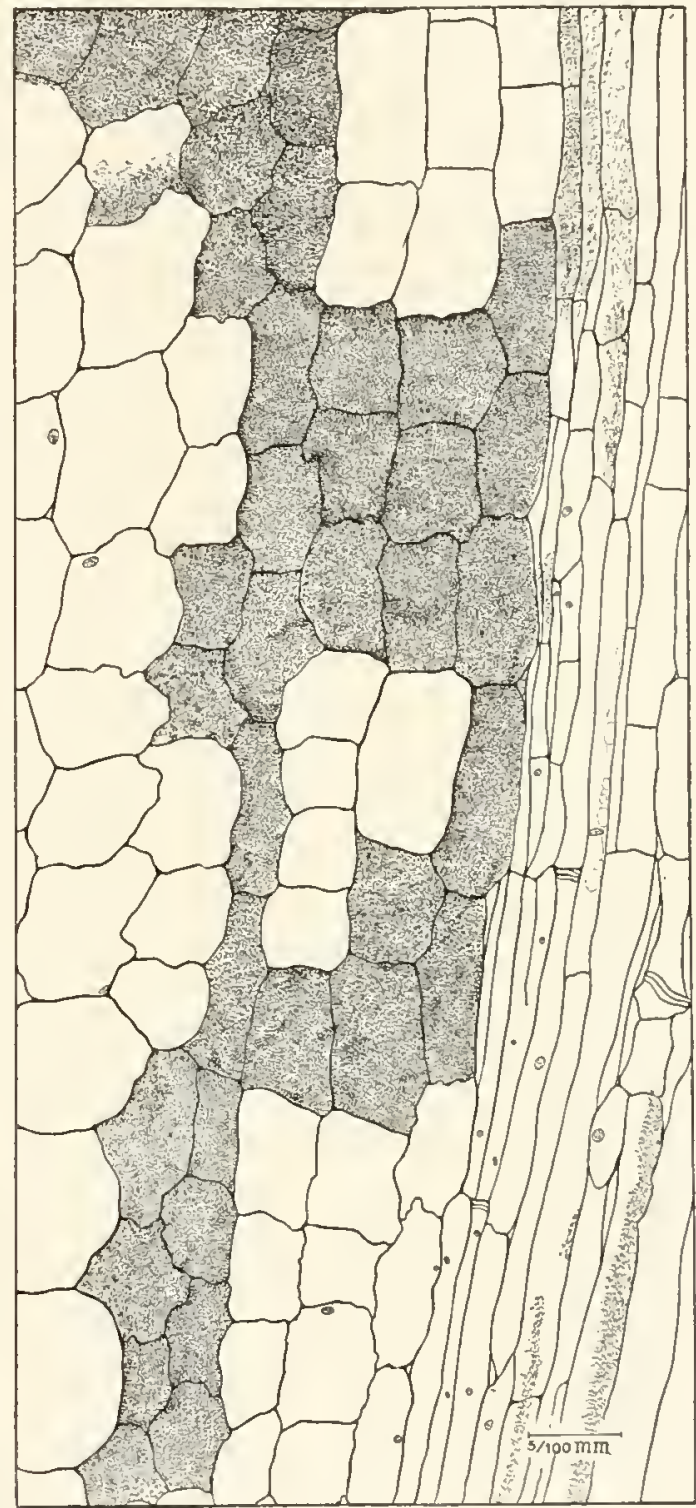

Fig. 79.* drops of a white bacterial ooze (fig. 76), and on making dircet inoculations from such drops into petioles, the disease was reproduccd on banana in one of the Washington hot-lıouses (fig. 77), but not on young tomato shoots, into which it was also inoculated.

The appearance of ten-day-old gelatin stab-cultures of this organism is shown in fig. $7 \mathrm{~s}$. Fig. 79 shows the manner in which the bacteria sometimes flood out of the vascular bundles

*FIG. 79.-Longitudinal section through a banana fruit-stalk from Trinidad showing some parenchyma cells occupied by Bacillus musae and others frce. 
into the parenchyma filling the interior of certain of these cells, while at other times they occupy only the intercellular spaces and wedge apart the parenchyma cells to form cavities. Fig. So B shows Bacillus musae filling one of the spiral vessels of a bundle.
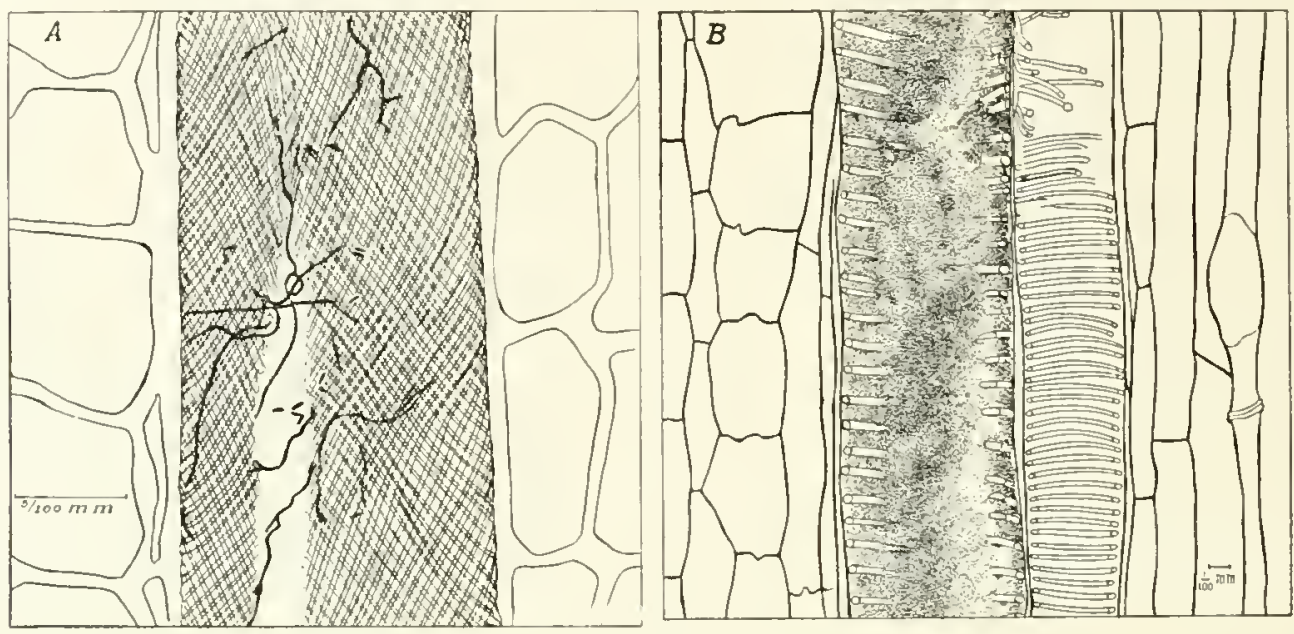

Fig. 80.*

\section{THE PANAMA DISEASE.}

In 1904, Dr. R. E. B. Mckenney discorered a banana discase in Central America which had destroyed whole fields and which threatened to destroy the industry over large areas. During the next + years he found the disease on every banana farm in Costa Rica, meaning by this every plantation where bananas are grown in quantity for market. He also observed the disease as far south as the canal region of Panama, and from reports made to him he believes that it occurs as far north as British Honduras. The disease has probably existed in Central America for a long time, but has been destructive only within the last ro years. During this time many large fields of bananas belonging to the United Fruit Company have been entirely destroyed. Up to the summer of 1909 he believed the disease to be of bacterial origin, and thonght that he had some evidence of this from pure-culture inoculations made in Costa Rica. But inoculations made in the hot-houses of the U.S. Department of Agriculture with his bacterial cultures have yielded only negative results. This disease first attacks portions of the rhizome. The rhizome is so large, however, that many months usually elapse before the whole of it is destroyed. The most conspicuous signs of this disease are: first, the yellowing of the leaves; then the sudden wilting and shriveling of the entire foliage. The rhizome now sends up new shoots, which appear to be healthy at first, but after a time these also perish with the same signs. In a badly diseased field one sees very few tall banana plants, but multitudes of low shoots, healthy or in various stages of the disease. When the banana leaves are full grown, or nearly so, the signs are yellowing and wilting. In younger leaves the yellowing, which begins at the terminal portion, is accompanied by the downward curvature of the apical 2 to 3 feet of the leaf in a peculiar and characteristic manner.

*FIG. So.- 1 . Longitudinal section of spiral vessel of a banana bundle attacked by Smith's Cuban disease. Petiole sound externally. Section 7 feet + inches below point of inoculation. Bundle browned and occupied sparingly by Fusarium cubense, which is producing internal conidia. Section drawn after being cleared in 10 per cent potash over night. Inoculations of 1909 . For comparison with $B$.

$B$. Longitudinal section of banana fruit-stalk (fig. 76 ) showing two spiral vessels of a bundle: One occupied by Bacillus musae, the other empty. Rorer's 'Trinidad disease. 
There are no external indications as to the cause of this disease, but when one makes a seetion of the stem, particularly toward the base, the vascular bundles are found to be very fully occupied by baeteria and stained first yellow, then a dark color (brownish-violet). This bacterial occupation of the vessels may be traced out into the affected leaves, to a lesser extent. A vascular bundle, here and there, may be oecupied, but there is not conspieuous brown staining of the veins sich as occurs in the black rot of the cabbage.

It remains to be determined whether this Central American disease is the same as that seen by Earle in Jamaica and whether it is really due to bacteria. I believe not.* In recent years several persons, ineluding Dr. MeKenney, have searehed for this clisease in Jamaica in the locality indicated by Earle without finding it, which only means, however, that the growers took Earle's advice serionsly, and grubbed out the diseased plants very thorouglily. The writer is inclined to aseribe the Panama disease to his Fusarium cubense. In 191.3 the disease was reported by Ashby from Jamaica, identification being made first in 1912 by Mr. Goldsnith Williams, an agent of the Fruit Company.

The Cavendish or Chinese banana and the Congo are resistant to this disease.

\section{SOUTH AMERICAN DISEASES.}

Rorer has shown that the so-ealled "Panama disease," both in Trinidad and in Surinam, is associated with a Fusarium in the vaseular bundles, and this corresponds to the writer's observations on the Cuban disease.

The most reeent and longest paper is by Drost, but he does not eite earlier literature. It is possible, of course, that the Fusarim found also by Drost in the diseased bundles of the banana is the conidial stage of the Leptospora also found by him, but the evidence of this is very inconclusive. Essed's papers seem to me negligible.

\section{OLD WORLD DISEASES.}

Basu has seen a banana disease in Bengal which resembles the Surinam disease and associated with which he lias seen a fungus bearing C cphalosporimm and Fusarium conidia.

\section{LITERATURE.}

1903. EARLE. F.S. Banana leaf-blight, in "Report on a trip to Jamaica." Jour. N. Y. Bot. Garden, vol. IV, Jan. I903, pp. 7-8.

1910. RORER, JAMES BiRch. A bacterial disease of bananas and plantains. Society paper No. 412 in Proc. Agric. Society of Trinidad and Tobago, vol. x, part 4, April i 9 I0, pp. jo9-1 I 3 .

1910. RORER, JAMES BIRCH. Diseases of banallas. Bull. Dept. Agric., Trinidad, Port of Spain, vol. Ix, No. 65, July 1910, p. 157. Separate.

1910. SMITH, ERWIN F. A Cuban banana disease. Science, n. s., vol. xxxi, No. 802, May i3, 1910, pp. 754-755. Also a separate.

Organism called Fusurium cubense.

1910. Mckenny, R. E. B. The Central Ameriean banana blight. Science, 11. S., vol. xxxi, No. 802, May 13, i9jo, pp. 750-75I. Separate.

1911. RORER, JAMEs BIRCH. A bacterial disease of bananas and plantains. Phytopathology, vol. 1, April I 7, 1911, 4 pls., pp. 45-49
19I1. BASU, S. K. Report on the banana disease of Chinsurah. Quart. Journ. Dept. Agric, Bengal, vol. jv, No. 4. April igi I, pp. 196-198.

1911. ESSED, E. The Panana disease of bananas. Annals of Botany, vol. xxy, pp. 343-36r. London and Oxford, April 1911 .

The disease both in Panama and in Surinam is said to be due 10 a new species of fungus, L'stilaginoidella musaperda.

I gi 2. Drost, A. W. De Surinaamsche Panamaziekt. in de Gros Michel bacoven. Bull. No. 26, Paramaribo, Maart, 1912, pp. 45, with II plates.

Disease ascribed to Leplospor a muste. "Besides perithecia it produces spores of a Cephalosporium and of a Fusarium type."

1912. Pittifir, H. La Einfermedad del Banano y su Causa. I, Hacienda, Agosto 1912, pp. 343$3+6,3$ figs.

1013. Asmby, S. F. Banana Diseases in Janaica. Bull. Dep. Agric. Jamaica, N. S., vol. 2, No 6. January 19ז3, pp. 95-109.

Fusarium is present in the bundles.

* Since this was in type, Mr. Jantes B. Rorer visited Central America for the United Fruit Company and wrote me as follows under date of March i6, 19I4: "We had a very pleasant trip to Bocas del Toro and I was able to get a me as follow's under date of * I made many cultures from diseased bananas -Gros Michael-and got Fissarium goors: lime from the Panama disease. I did not see the bacterial disease there at all even in the susceptible varicties." 


\section{BROWN ROT OF SOLANACEAE.}

Synonyms: Tomato-wilt, Potato-rot, Blight of Egg-plant, Pepper-blight, Granville Wilt of Tobacco, etc.

\section{DEFINITION.}

This is a specific communicable disease of potatoes, tomatoes, egg-plants, etc., characterized by a sudden wilting and shriveling of the foliage, with drooping of the softer shoots and a brown stain in the vascular bundles, which are filled with a great number of bacteria. It also causes more or less disorganization of the parenchyma, especially of the pith. Young watery plants are much more subject to general infection than old and woody ones. The internal browning is frequently visible on the surface of stems, etc., as dusky patches or streaks. In woody plants the leaves may become yellow and die without wilting. In potato tubers it rots the region of the vascular ring with a brow1 stain (pl. 23, figs. 8, 10).

\section{HOST-PLANTS.}

This disease has been observed in the United States in potatoes (Solanum tuberosum), a wild plant obtained from Montevideo, Uraguay, and supposed to be Solamm commersoni (pl. 24, fig. 2), egg-plant (S.melongena), tomato (S.lycopersicum), and in tobacco. Hunger has reported its occurrence on tomatoes, tobacco, and peppers in the Dutch East Indies and Honing in a variety of non-solanaceous plants - see History and also a separate chapter on Tobacco-wilts (p. 220 ) and on a disease of peanuts (p. I $5 \mathrm{I}$ ). The disease has been successfully inoculated by the writer into potatoes and tomatoes many times over, and also into the following: Vicotiana tabacum (recent experiments), Solanum nignm, Datura stramonimm, D. metelloides, Physalis erassifolia, P. philadelphica, and Penmia sp. (hybrid).

In heliotrope, Ricinus communis, Vigna catjang, and Portuluefa oleraceue, the organism lived for some weeks in the inoculated area, but no general disease of the plant was developed. Inoculations into the following plants were unsuccessful: Cucurbita foetidissima, Cucumis sativus (stem and fruit*), Nicotiana tabacum (1895, 1896, 1901, 1905†), Capsicum anmum, Solanum muricatum, S. carolinense, S. dulcamara, Pyms communis, Eleusine indica, Abutilon aviecmae, and Pelargonizm zonale.

Beyond one unsuccessful trial no attempts have been made to inoculate it into eggplants, because none happened to be at hand when the writer was making his experiments, but he obtained numerous infections on tomato and potato with bacteria taken from the egg-plant, and Rolfs has inoculated into the latter very successfully. Inoculations into the stems of cucumber plants caused no general sickening, but in some cases (not all) there was a local enlargement of the inoculated part. The surfaces of these stems were not, however, sterilized before inoculation (by needle-puncture), and only two cases of this kind occurred. Local enlargements have been very frequent on tomato stens inoculated with old isolations and feebly virulent strains. Inoculations in the summer of I 903 showed Datura metelloides (vol. I, fig. 4) to be very susceptible. Datura fastuosa and D. commcopiae were stunted, but managed to overcome the disease. A specimen of Datura tatula inoculated in 1896 resisted a virulent strain of the organism, $i$. $e$, one that destroyed $D$. stramonimm and other plants.

*Inoculations in 1896 into full-grown, green cucumber fruits removed from the parent plant and placed under belljars led in several cases to a soft watery rot involving the whole interior of the fruit and similar to that sometimes observed in the field in ripening euewmbers. Inasmuch, however, as plate-cultures were not made from the bacteria swarming in the interior of these fruits, the possibility of this phenomenon being due to other bacterial organisms was noted at the time as not excluded. This expcriment was repeated in the summer of $190 \mathrm{I}$ on six ripe and ripening cueumbers, in the open air, attached to the vine, with entirely negative results. Fach fruit was inoculated copiously by means of a dozen or more deep needle-punctures. The check-plants, consisting of the growing shoots of tomatoes and potatoes, contracted the disease promptly, but the cucumbers showed no signs.

$\dagger$ For later successful inoculations, see Will-Diseases of Tobacco. 

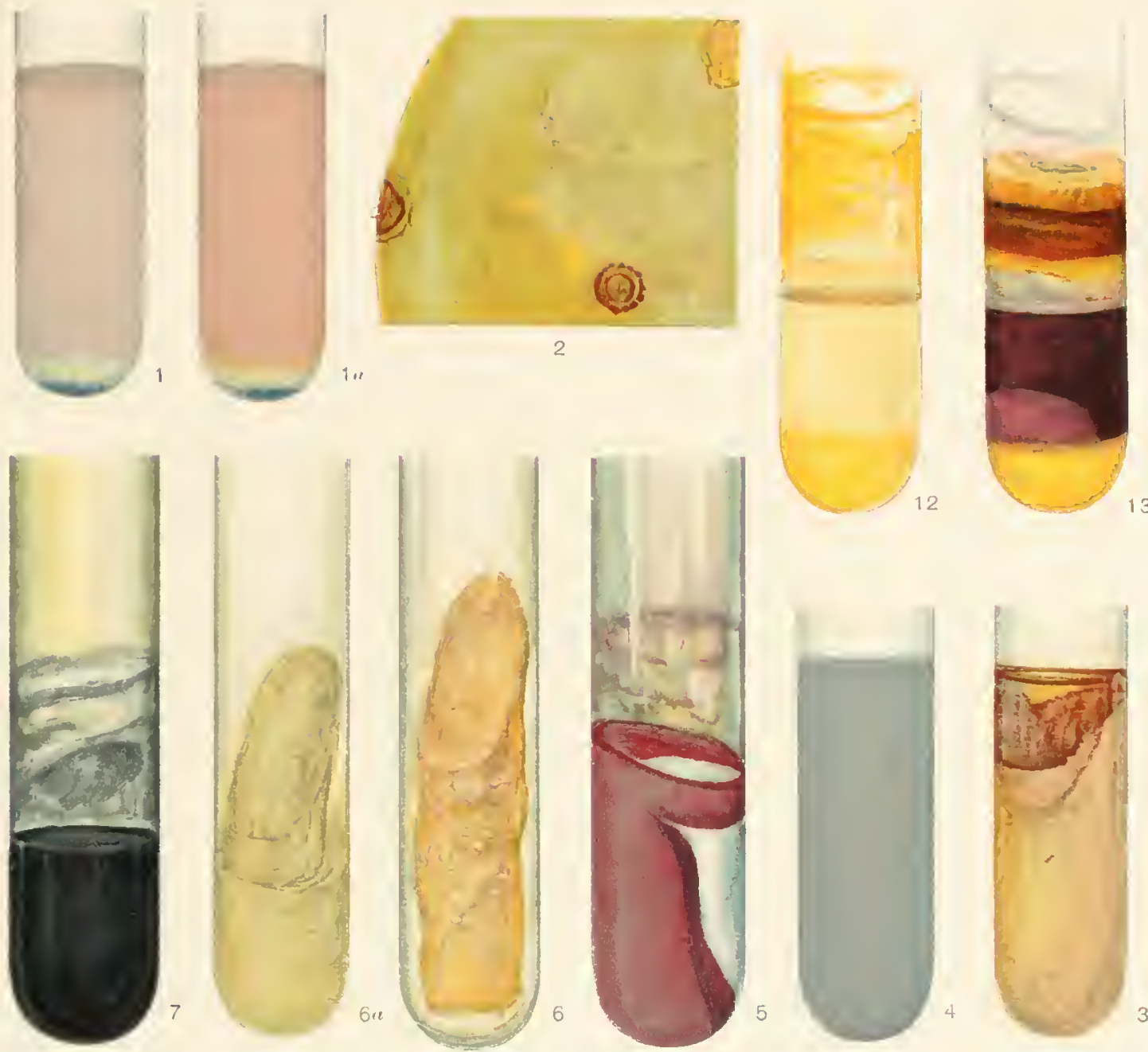

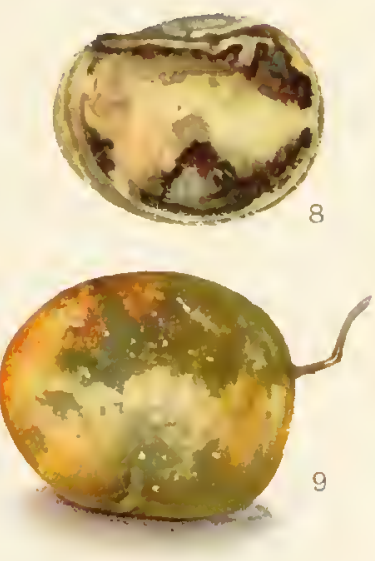

TOBACCO WILT.

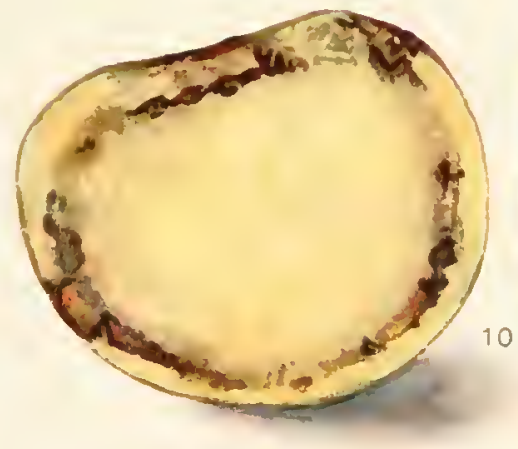

POTATO DISEASE.

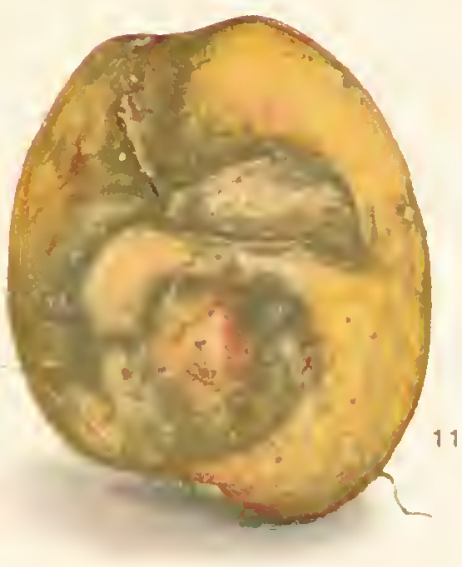

RÁTHAY'S DISEASE.

(1) Litmus milk culture, 12 days old, of Bromllus solruiscrurus 1. Painted March 19, 1907. (1"1) Litmus-milk culture 12 days old, of Bacillus, whytowhthorns. Inoculated and painted at same time as fig. 1. (2) Otd browned colonies on the surface of an agar plate of the N. C. tobacco organism, poured August 1, 1905, painted October 14; agar stained brown. (3) Litmus-milk culture of Appel's Bucillus whutuhthorus. Tube inoculated November 13; 1906 . Painted November 26. (4) Uninoculated (check) tube of litmus-milk. (5) Bacillus solanisnums Harrison 1. An old litmus-milk culture kept in the refrigerator (14 ${ }^{\circ} \mathrm{C}$.) and partly dried out. Inoculated December 10, 1906; painted March 4, 1907, (6) Old potato-culture of Rrurillus whyluwh/hrus Appel. Stock 1975, painted March 5, 1907. (611) Potato-culture of Racillus solamismurus Harrison II. Inoculated March 7, 1907, and painted March 19. The color close, but the organism wet-shining. (7) An old litmus-milh culture of Burf. solfuncerrum, Florida potato, tube inoculated June 2, 1905, painted August 28 and equally representative of an ald culture of the N. C. tobacco organism. (8, 10) Cross-sections of 9 and 11 , showing the characteristic bacterial decay. (9, 11) Internally brown rotted potato tubers from Portsmouth, Va., painted October 18-19. 1905. Infection by way of the vessels of the rhizome; the surface of the tuber not ruptured: Bract. sofrum the vascular system of rhizomes and tubers. $(12,13)$ Aplunobucter ruthayi; milk and litmus-milk, 5 months. 



\section{GEOGRAPHICAL DISTRIBUTION.}

This disease occurs in Colorado (?) Arizona (?), New Mexico (?), Texas, Mississippi, Alabama, Florida, Georgia, South Carolina, North Carolina, Naryland, Virginia, New Jersey, and apparently as far north as middle New England. It probably occurs also in Ohio and in Illinois and other States in the middle and far west, but its northern and its western distribution have not been worked out. Clinton has reported it from Connecticut. It is found in America as far south at least as Porto Rico, the writer having received it from that island in tomatoes and egg-plants. This disease, or one suspiciously like it, has been reported from near St. Petersburg, Russia, and from various parts of Great Britain, France, and Italy. In all probability the disease occurs in many parts of Europe. Hunger has reported it from Java and Sumatra. Tryon has also stated (1899) that this disease is the same as one found by him in Australia (see Appendix p. 207). What appears to be the same disease occurs, it is said, on potatoes and tomatoes in Untali, Rhodesia, South Africa. The discase probably occurs in Japan.

\section{SIGNS OF THE DISEASE.}

Both the sleepy disease of tomatoes (Fusarium), and the Grand Rapids discase (A planobacter), cause tomato plants to wilt suddenly, and therefore they might be confuscd

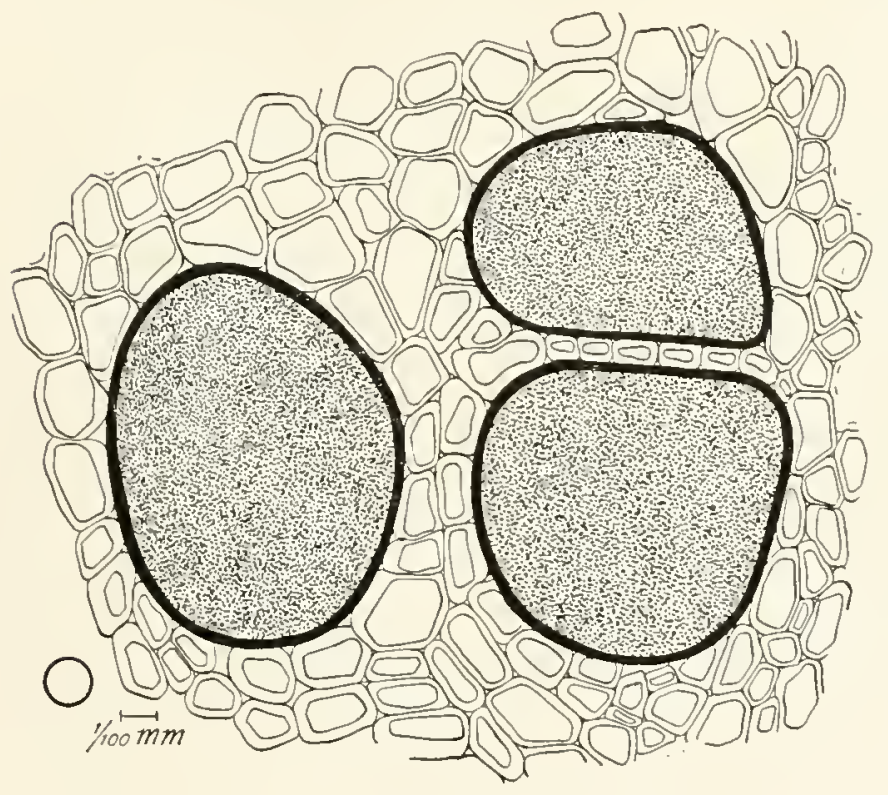

Fig. 81.* easily with this disease. On potato both here and in Europe it miglit be confused with some forms of the "black leg" or "schwarzbcinigkeit" described by Appel as due to Bacillus phytophthorus, by van Hall as due to Bacillus atrosepticus, by Prillieux and Dclacroix as due to $B$. caulinoms, and by Pethybridge and Murphy as due to Bacillus melanogenes. There is alsoa potato disease in France attributed by Delacroix to Bacillus solanincola (see p. 214).

The foliage becomes prematurely yellow and dies gradually ( $\mathrm{pl}$. 24 , fig. 3 ), or wilts suddenly without loss of green (pl. 25), and in large leaves of the tomato the main axis of the leaf is also often bent downward in a charactcristic way (plates 26 , 27,28 ); the stems droop and shrivel wlien 110 too woody (pl. 24, fig. 1); and there is usually a decided brown stain in the vascular system in advance of the death of the external parts. The vessels of such stems are filled with enormous numbers of the small termo-like bacteria, which are not sticky and which ooze out of the stem on crosssection as a dirty white or brownish-white slime. The bacteria pass np and down the sten1s considerably in advance of the shriveling, and the accompanying brown stain can often be seen through the younger and more transhucent stems and petioles, especially of

*FIG. 81.-Root of a diseased egg-plant from Porto Rico, sound externally but browned within and showing in cross-section three vessels of the vaseular system occupied by bacteria. Received June 8, 1905, and drawn with the Abbe camera, unstained, from a free-hand section, the bacteria dragged over by the knife being omitted. The root was about $5 \mathrm{~mm}$. in diameter: Its aclual diameter is shown by the small circle at the left. 
the potato, as long brownish streaks, although the surface of these parts still appears to be normal. After a time, especially in soft and rapidly growing plants, the pith and bark are both involved more or less; and in the pith large cavities may arise, these being occupied

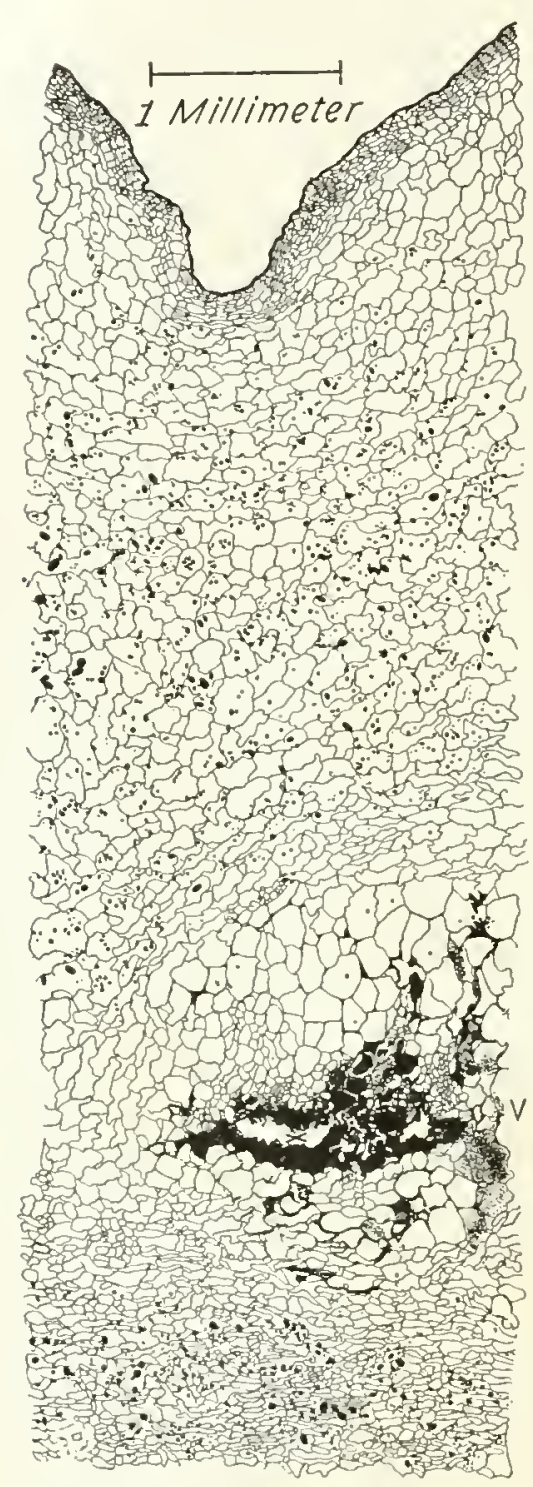

Fig. 82.*

by the bacteria and by detritus of the tissues which they have disorganized (see vol. II, fig. I). Tomato plants have been seen in which nearly the whole pith had been converted into a watery slime. The localization of the signs in the form of large, open wounds at the surface of the earth (see Basal Stem-Rot) is not characteristic of this disease (see pls. 24, 25). In the tomato and the egg-plant, so far as observed by the writer, this is primarily a disease of the vegetative part of the plant rather than of the fruit, which is itself subject to a special disease (the Point-rot). The writer obtained, however, a local infection in the green fruits of the tomato by inoculation. The inoetrlated side as a whole ripened sooner than the opposite side, but the tissue immediately bordering on the punctures remained green for a long time. The bacteria multiplied considerably in the inner tissues and there was a brown stain, but not what might be mis-

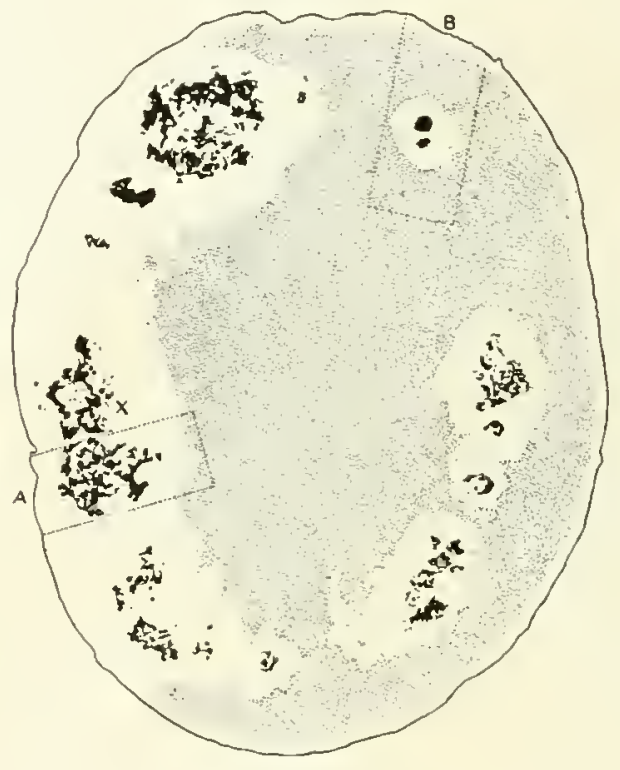

Fig. 83.† taken for a soft rot, or the Pointrot. The roots as well as the stems are strbject to this disease (fig. 8I). In good-sized, stocky potato plants, even when the vaseular system is badly diseased (browned and occupied by the bacteria), the exterior of the stem is often green and normal in appearance, except the leaves and ex-

*FIG. 82,-Vertical section through external part of a potato tuber from plant No. 14 , which was inoculated with Bacterium solanacearum on June 15,1896 , by needle-pricks on the upper part of the stem. Material collected and fixed in strong alcohol on July 27. Tuber sound externally. This represents a very early stage in the rot of the tuber. The bacteria entered the tuber from the vascular system of the stem, and were still confined to the vicinity of the vascular ring $(\boldsymbol{V})$. Below this region is the central starch-bearing parenchyma; above it is the cortical parenchyma, ending at the top of the drawing in eork (potato skin); the oval dark bodies are starch-grains; there are very few in the vicinity of the bundle, but this is not due to their destruction by the bacteria (see figs. 104, 105). 'The bacteria lie within and between the cells, and have already eroded a considerable cavity. Drawn under the Abbe camera from material which was cut on the microtome after infiltrating with paraffin. Cells shriveled by the strong alcohol. Slides i56(2 and 15666

TiG. 83.-Cross-section of a small developing potato tuber diseased by Baclerium solanacearum, collected at Portsmouth, Virginia, October 1905. Tuber infiltrated with paraffin and cut on the microtome; section stained with carbol-fuchsin. The skin and subjacent layers are unbroken, the infection having taken place by way of the underground stem. The unshaded parts denote absence of starch and the dark blotches the presence of the bacteria. (For details at $A, B$, see figs. 107,108 .) The most crystal-sand cells are on the left side. There are a few starch-bearing cells at X. For a detail of this part see fig. 106. Slide 349(15. 


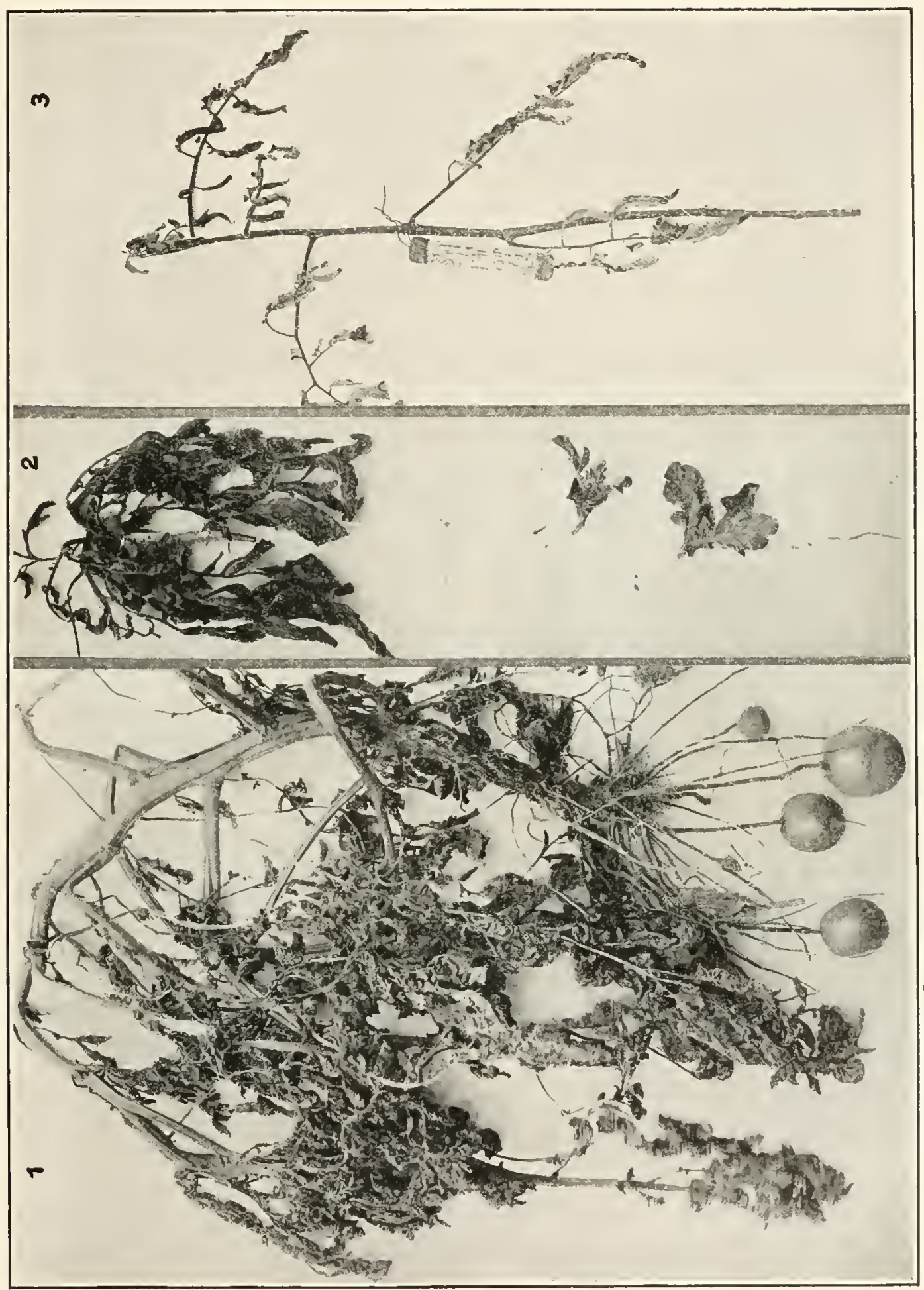

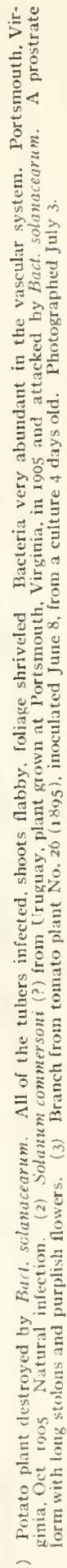





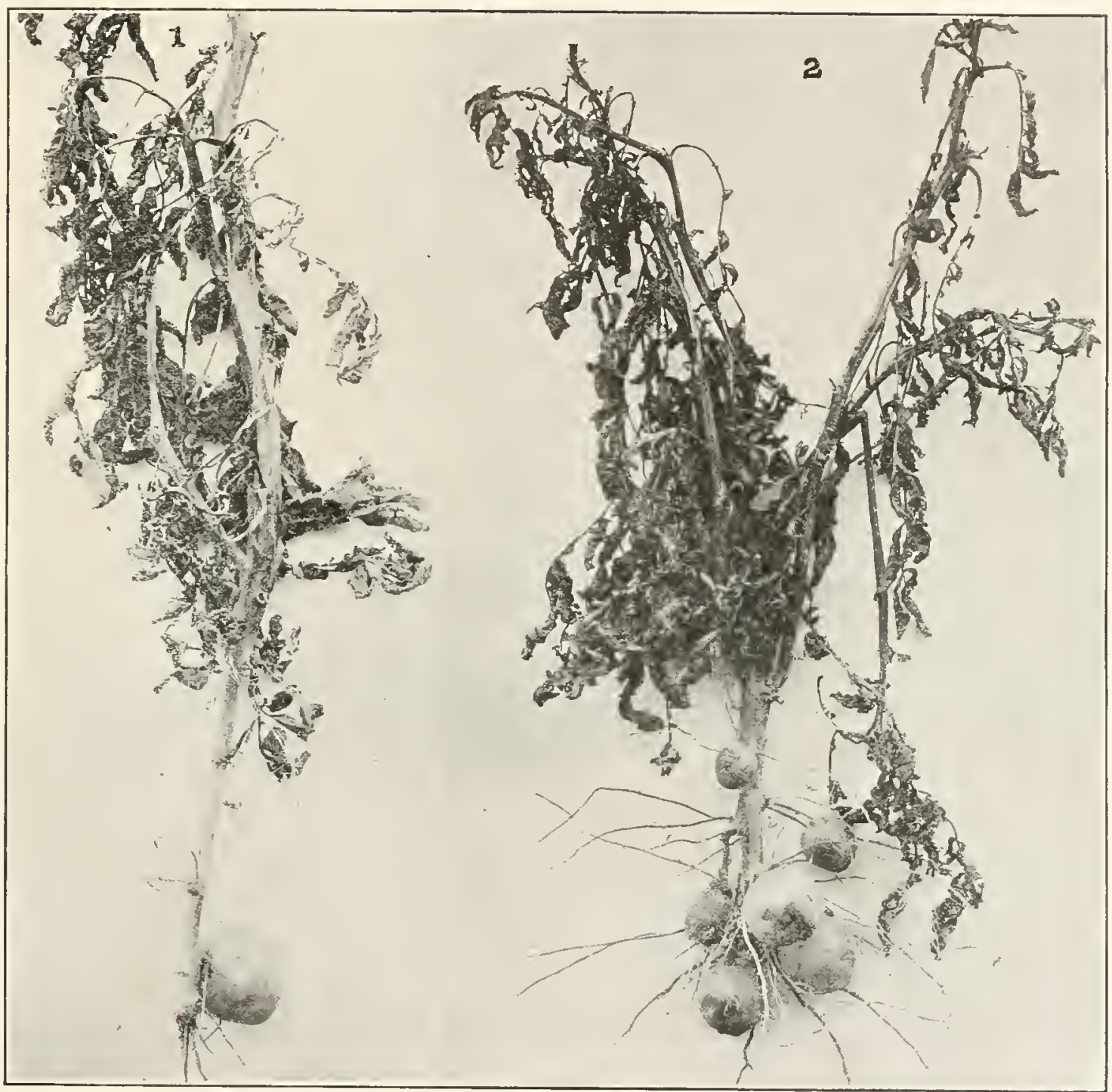

Two potato-plants badly diseased by Bacl.solanacearum (a natural infection). Portsmouth, Virginia, Oct. 1905. All of the tubers were internally brown rotted, $i, e$, in the vicinity of the vascular ring. The stens were free from superficial ulcers and also the tubers, but in some of the latter the internal brown stain shows through, as in the front tuber and lower tuber of fig. 2 . 

treme tips of the growing shoots, which are flabby or shriveled (plate 30). In less woody plants the branches will be shriveled, or flaccid, as shown in plate 24 . In the potato plant the organisms pass down through the vascular system of the stems into the underground parts and eause an internal brown rot of the tubers. This rot of the tuber begins in the vascu-

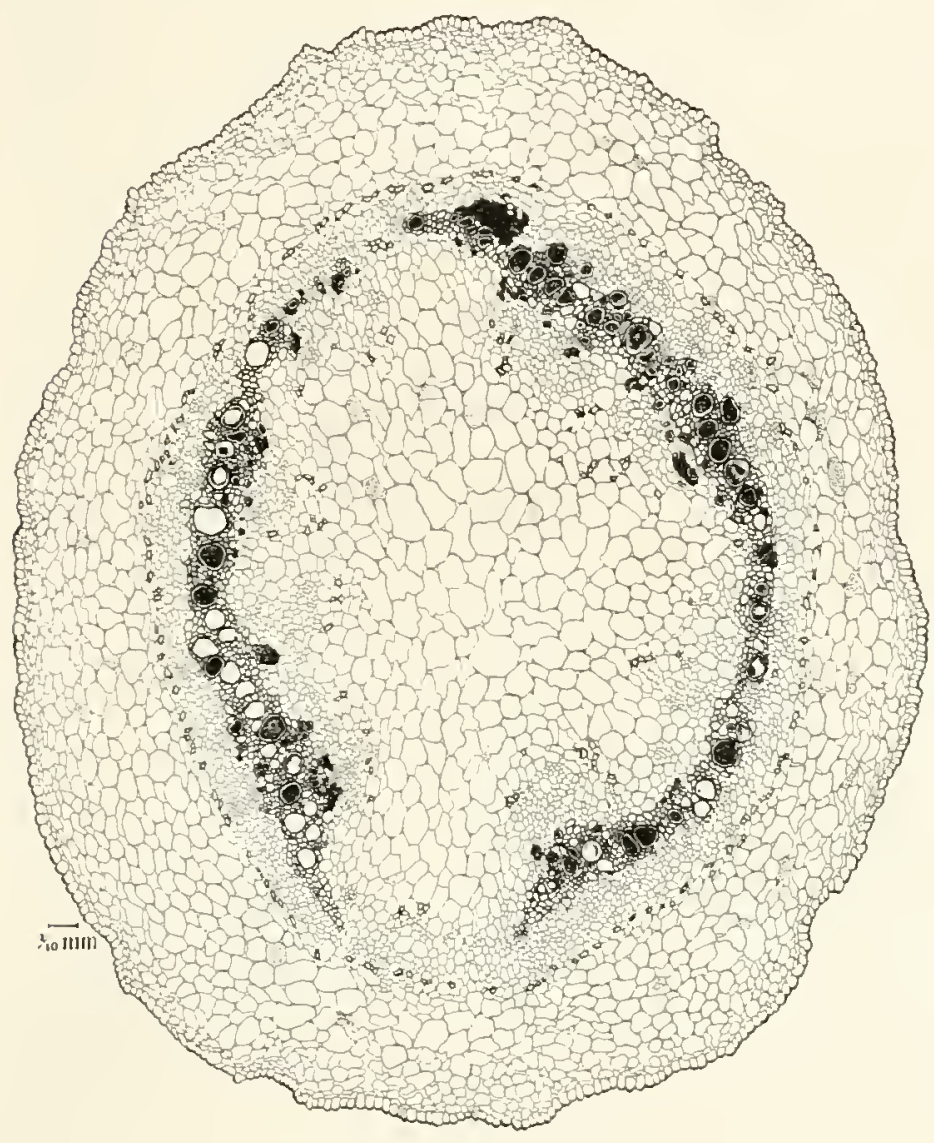

Fig. 84.* lar system at the stem end and gradually extends to the opposite end by way of the vessels, rotting the tuber from within and causing the appearance of dusky patclies on the smooth surface of the tubers in advance of any rupture of the superficial corklayer (p1. 23, figs. 9, 11 ). On cross-seetion these patehes are seen to be due to the internal brown stain centered in the vascular ring and showing through the more superficial layers of white tissue. In later stages of the disease the cork-layer is ruptured and the rot continues as a mixed infection due to the entrance of other organisms directly from the soil. In tubers less far advanced in the rot, cross-seetions often show the decay pretty elosely restricted to the vasenlar ring (figs. $\mathrm{S}_{2}, 8_{3}$ ), from which there is always a gray-white or dirty white bacterial ooze (vol. I, plate 24 , top). In yet earlier stages of the disease the brown stain and bacterial decay are found only in the stem end of the titber (vas.

cular ring) or only in the vasetnlar bundles of the underground stem leading to the tuber, the surface of this rhizome and the whole of the attached tuber being entirely sound (figs. 84, 85). On plants attacked with great virulence and very early 110 tubers are formed. The tubers on plants infected in the middle of the growing season are small and few and are found at harvest time in all stages of decay (pls. 24, 25). Often on such plants, as first noted by Dr. Halsted, tubers not larger tlran a pea, together with their rhizonle, will be found sound superficially but brown-rotted in the vascular ring; in other cases, as already noted, the

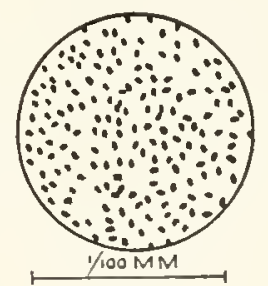

Fig. $85 . \dagger$

${ }^{*}$ Fig. 84-Cross-section of underground stem of a potato-plant leading to a tuber sound on the surface but bacterially rotted in the vascular system, $i . e .$, a tuber such as that shown in fig. 83 . Rhizome fixed in Carnoy's fluid, embedded in paraffin, and sectioned on the microtome. Slide $34^{8} \mathrm{a}$, stained with carbol-fuchsin. The bark and pith are entirely free from bacterial occupation. The bacteria are confined principally to the vessels of the woody part of the bundle, but there is a cavity in the outer phloem (at the top) and there are various small bacterial foci in the inner phloem. The $V$-shaped marks in parenclyma-cells (use lens) denote crystal-sand. Material collected at Portsmouth, Virginia, October 1905. Drawn with a Zeiss $16-\mathrm{mm}$. apochromatic objective, No. 4 comp. ocular, and the Abbe camera. (For general appearance of the bacteria in these vessels see fig. 85.)

$\dagger$ Fig. 85.-Bacterium solanacearum from one of the vessels in fig. $8+$ (cross-section rhizone, Portsmouth, Virginia, potato). Slide $3 t^{S}$ Ar. 
entire tuber will be sound and only the rhizome affected-this through the whole length of its vaseular system or only at that end farthest from the tuber. On the other hand, when plants are attacked late in the growing season, the tubers are more numerous and larger, and the majority of them, especially if borne on long rhizomes, may escape infection or be diseased only slightly at the stem end when dug. In tubers of this sort the rot is apt to continue after digging, but exceptionally it might, perhaps, remain dormant, or nearly so, until the season for planting. In plants attacked by this disease the juice of the stems will be found to have an alkaline reaction to litmus paper and, if exanined microseopically, will be seen to be swarming with bacteria, which are very easily cultivated.

On tomato shoots this organism causes the early development of great numbers of incipient roots in the form of small nodules. Hunger was the first to point out this sign and his statements have been confirmed repeatedly by the writer (see pl. 27). Sometimes swelling of the inoculated parts of the tomato stem and the appearance of these incipient roots, with dwarfing, and the changed position of the leaves are the only external signs of disease in inoctrlated plants (pl.28). These nodules are visible in the first figure of an inoculated tomato publislied by the writer (in 1896) and were observed repeatedly in the field in I 895, but inasmuch as they develop naturally on sound stems under very moist conditions, $e . g .$, when a stem lies for some time on the earth, the influence of this disease in stimulating their premature development was overlooked. Anyone may satisfy limself easily, however, that Hunger's statements are correct. For instance, if he will select a young, rapidly growing tomato plant, the stem of which is entirely free from such developments, and will inoculate one of two nearly equal branches, that one which was inoculated will promptly develop the roots, while the other will remain free (pls. 26, 27) or will develop them only much later as the result of a general infection of the stem. This is true even when the younger of the two shoots has been the one purposely selected for inoculation. Moreover, these roots always appear first in parts of the inoculated stem nearest the punctures. Wounds made by a sterile necdle do not cause them to appear.

\section{ETIOLOGY.}

The canse of this disease is a dirty white or brownish-white schizonycete which the writer named Bacillus solanacearm in 1896 . Further studies have shown that it is usually motile by means of one polar flagellum. It should be classified therefore as Bactcrimm solanacearmin or Psendomonas solanacearm, if one follows Migula's system. This organism was first isolated and deseribed by the writer, unless Burrill's statements relate to this species (see History and Literaturc), and the statements here given rest chiefly upon his own observations. The disease is sometimes very readily induced in susceptible species by simple needle-punctures, without hypodermic injection. At otler times the writer lias experienced many failures, using in some instances, at least, what appeared to be equally gentine material.*

In recent years the irregular behavior of plants inoculated with this organism has been a source of much perplexity. Some have contracted the disease with great rapidity; others not at all; others have shown some signs of the disease and then recovered, or have been seriously injured only in the inoctulated shoots, or only after a great length of time (p1. 29). The reason for these marked differences has not been made out clearly. It seems todepend partly, at least, on the amount of water in the stem. Frequently the punctured areas have been separated from the rest of the plant by the development of a protective cork-layer. In general, infections have been more successful in young, rapidly growing, soft, watery plants than in slow-growing, woody ones or in mature ones; infections have been more suc-

* One labors under difficulties in the isolation of this organism. On agar plates its colonies are best distinguished from other white colonies by waiting a week or two for the appearance of a brown stain in the colony, and yet this treatment seems to weaken the virulence of the organism. 


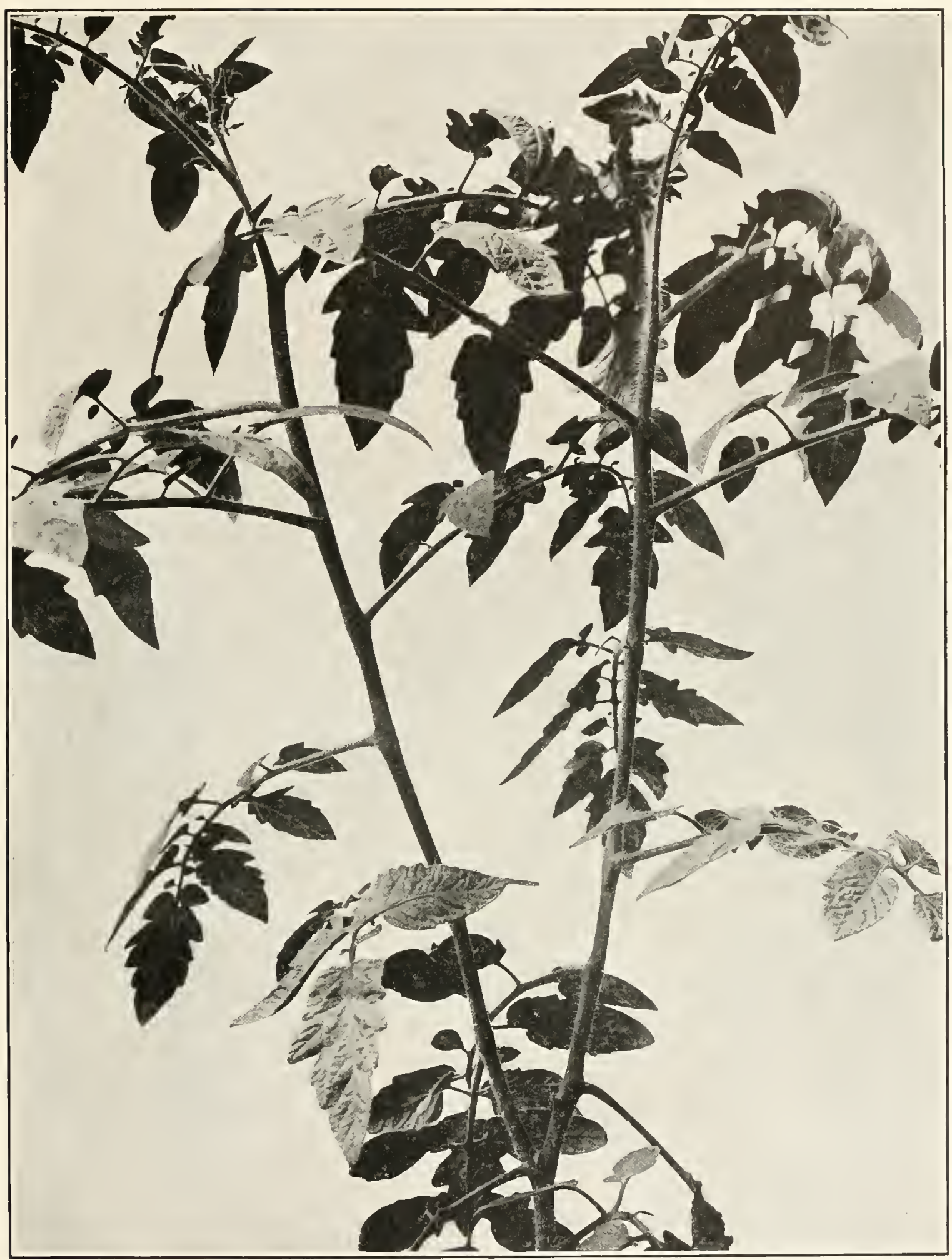

Tomato-plant No. 17 (1903), showing two equally developed young, smooth shoots, one of which was inoculatcd by needle-pricks with Bacterium solanacearum (Sonth Carolina strain) immediately after photographing (sec plate 27 , for condition 9 days later.). Photographed and inoculated July 16, 1905. 



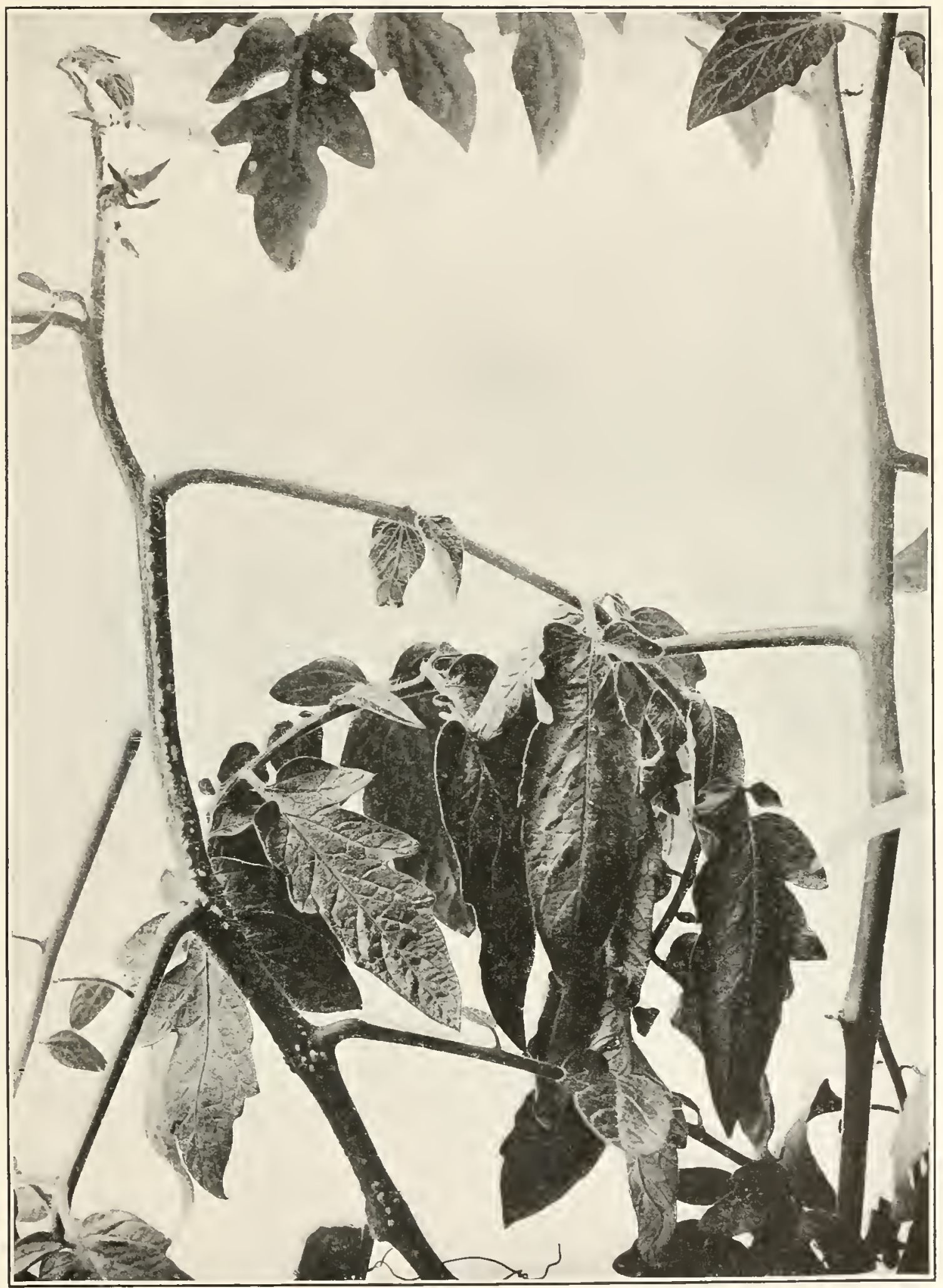

Tomato plant No. 17 , nine days after inoculation; leaves of the inoculated branch reflexed, and incipient roots well developed. Check branch at right side normal. 



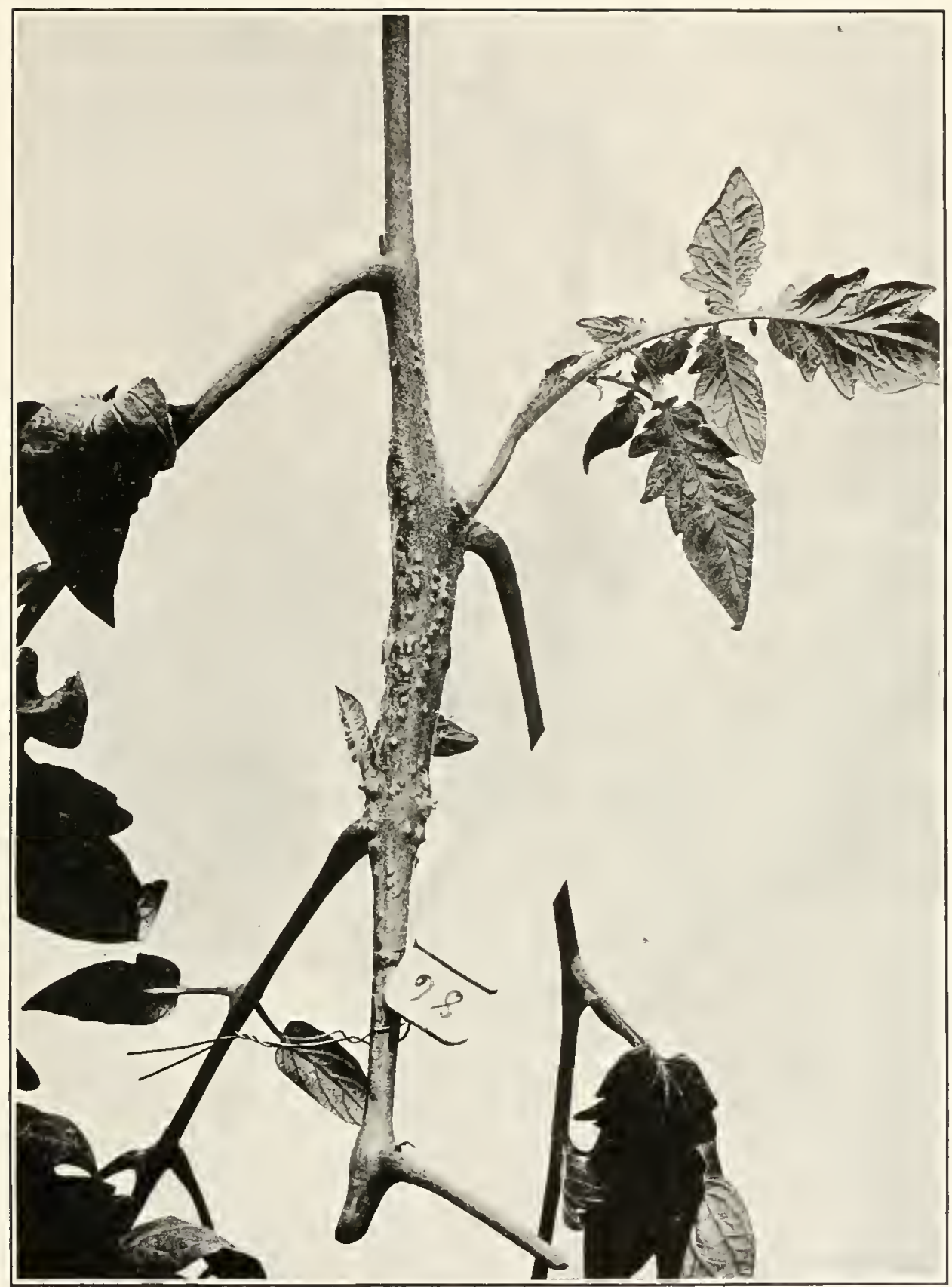

Tomato-plant inoculated with Bacterium solanacearum (District of Columbia strain) on September 6, I904, and photographed September 30 , at two-thirds natural size.

No wilt resulted. Observe swollen stem, shoots pushing, reflexed leaves and incipient roots which are absent above and below. The needle-pricks were made in the middle (swollen) portion of the stem. 



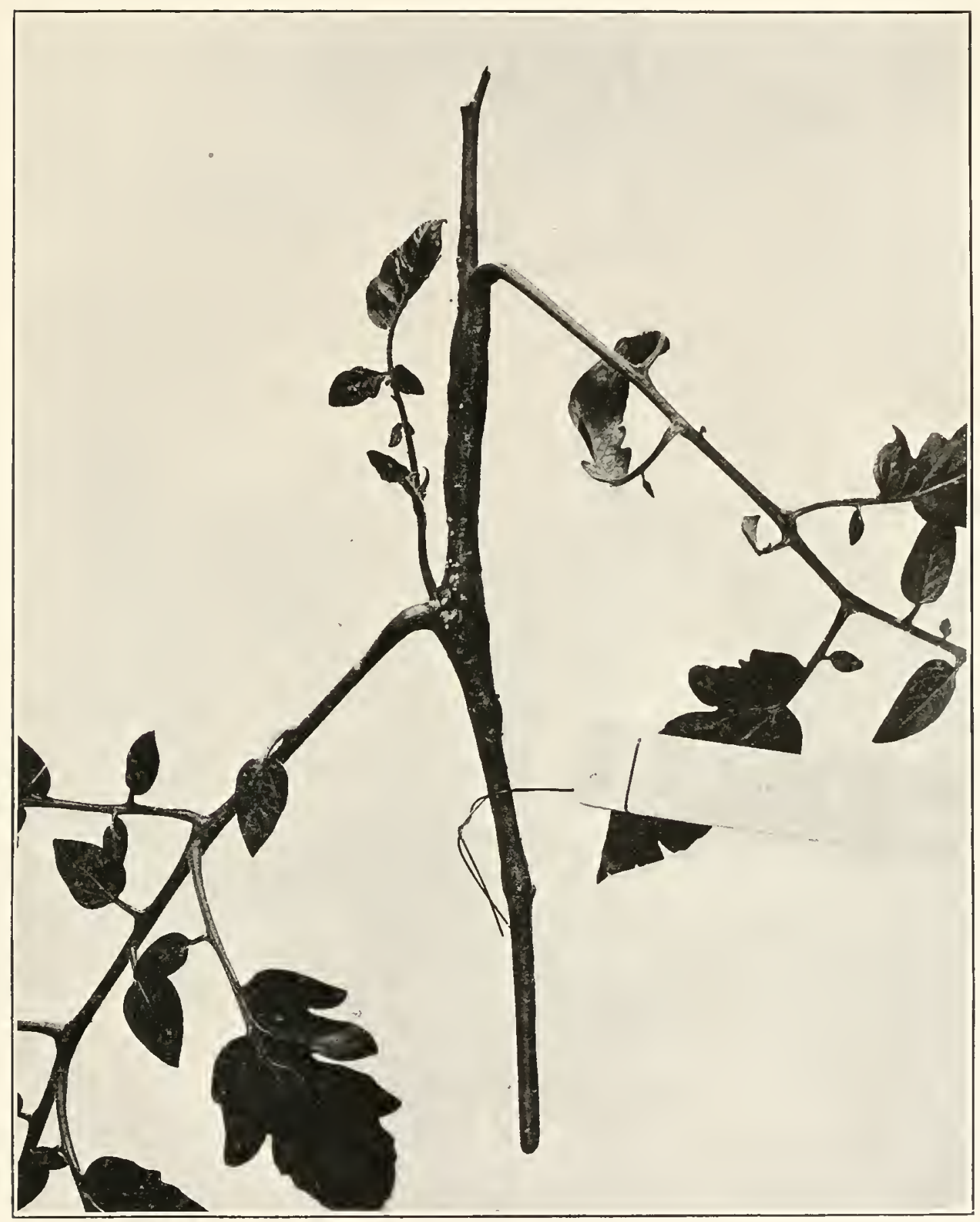

Tomato plant two-thirds natural size. Inoculated on Sept. 6, I904, with Bacterium solanacearum (District of Columbia strain) which had been grown in the thermostat at $37.5^{\circ} \mathrm{C}$.

Photographed Sept. 30 ; pricked part swollen and nodular, leaves refexed but not wilted. The extreme top has wilted, shrivelled, and fallen off. 

cessful in hot wet weather than in cool dry weather, and witl cultures recently plated from diseased plants sent in from various parts of the United States than with organisms whicl have been longer removed from the plant, $i . e$., cultivated in the laboratory on various nutrient media for 6 months or a year. One of two inferences seems to be warranted: (1) the hosts vary enormously from plant to plant and time to time, or condition to condition, in tlieir ability to resist this disease; or (2) the organism readily loses its virulence, for reasons yet unknown, when subjected to ordinary cultural conditions. Both inferences may be true. The subject requires for its elucidation more time than the writer lias been able to devote to it. That the failures noted were due to accidental substitution of similar-looking non-infectious organisms was sought as a first explanation and night answer for a single failure, but hardly, one would think, for repeated failures, since the same care was exercised as in the case of other organisms where no such phenomena appeared. Descendants of the most virulent strain the writer ever had in the laboratory (vol. I, pl. 26) lost all infectious power in the course of a year, although apparently preserving the same cultural peculiarities. This strain was isolated from the plant photographed on plate 30.

When virulent cultures are used on susceptible plants the time elapsing between the puncture and the first appearance of the disease is usually not more than 8 to ro days and is sometimes as short as 2 or 3 days on watery shoots in very hot weather. All of the successful inoculations of 1895 were made with the organism taken from tomato plants grown in Mississippi. The very successful inoculations of 1896 were made with cultures derived from an egg-plant grown at Charleston, South Carolina. In both years infections were obtained on tonatoes and potatoes, the resultant disease being identical with that observed in the field. The organism was demonstrated in the vessels of the plants in enormous numbers at long distances from the points of inoculation (fig. 86, about 15 inches, tine 18 days; fig. 82 , about 3 feet, time 42 days). Pure cultures were isolated from the interior of such plants and the disease was again produced by means of these cultures. Needle-punctures on leaflets of potato produced the disease as readily as those in to the stems, the only difference being that the organism had a longer distance to travel and consequently the tubers were not reached and destroyed so quickly.

Sometimes the organism was observed to pass out into the under portion of the midrib of the potato leaf, blackening it for a distance of several inches in advance of the staining of the upper surface or the wilting of the foliage; at other times it ran out in long, narrow black lines on the upper surface of the leaf. The most rapid downward movement of the bacteria in inoculated potato stems was observed during hot weather in July 1896: In 16 days from the date of an inoculation by needle-pricks on the upper part of a stem the bacteria had passed downward a distance of rather more than 2 feet and caused signs of wilt in another stem from the same root. In another tall shoot pricked lower down, i.e., in the more woody tissues 6 inches from the earth, the signs on other sloots from the same root were slower to appear, $i . \epsilon$., they did not develop until after the twentieth day. Sigus of the disease were observed to pass up and down stems on the pricked side much faster than sidewise.

In I 895 a tomato plant which was of large size when inoculated slowed local signs after a few weeks, but general signs developed only after a long time. On then making sections, the bacteria were found in the vascular systen in enormous numbers and at long distances from the point of inoculation. A similar case occurred in 1903, another in 1905 , and still another in 1909. The latter was 12 feet high and full of fruit when it finally wilted. It was inoculated on a terminal shoot when about 4 feet high. It grew well for 3 months after inoculation, showing at first only a feeble wilt of a few leaves, from which it soon recovered. When dissected the upper 6 feet of the stem was free from bacteria. They were very abundant, however, in the vascular bundles of the lower 6 feet of the stem, including some of the roots. Cavities had formed in the tissues only near the point of inoculation. T'he stem was sound externally. The wood was stained brown in the part occupied by the bacteria. 
In 1901 the writer again obtained successful infections. The plants inoculated were potato, tomato, etc. The source of infection was a tomato plant received that summer from South Carolina. The inoculations were by means of needle-pricks on leaves and the upper parts of growing shoots. The infectious material was fluid from the bottom of slant agarcultures (the first stbeultures from colonies on poured plates). The period of incubation varied from 3 to 7 days.

Successful inoculations were made in the stmmer of 1903 with pure cultures obtained from a diseased potato plant gathered at Norfolk, Virginia. Inoculations were carried out successfully in $190+$ on tomatoes, potatoes, ete, with pure cultures obtained from a potatoplant growing in the District of Columbia, near Washington. Partially successful inoculations were carried out in 1905 on potatoes with pure eultures obtained from a tomato stem received from Florida (vol. I, pls. 24 and 25), and on tomatoes with subcultures of colonies plated from Florida potatoes. For details concerning these results and for the various failures see synopsis of the inoculations.

Plants in the field are attacked in all stages of growth. There seen to be, however, varietal differences in susceptibility as well as great individual differences.

The writer succeeded in producing the disease by allowing the Colorado potatobeetle (Doryphora Io-lineata) to feed

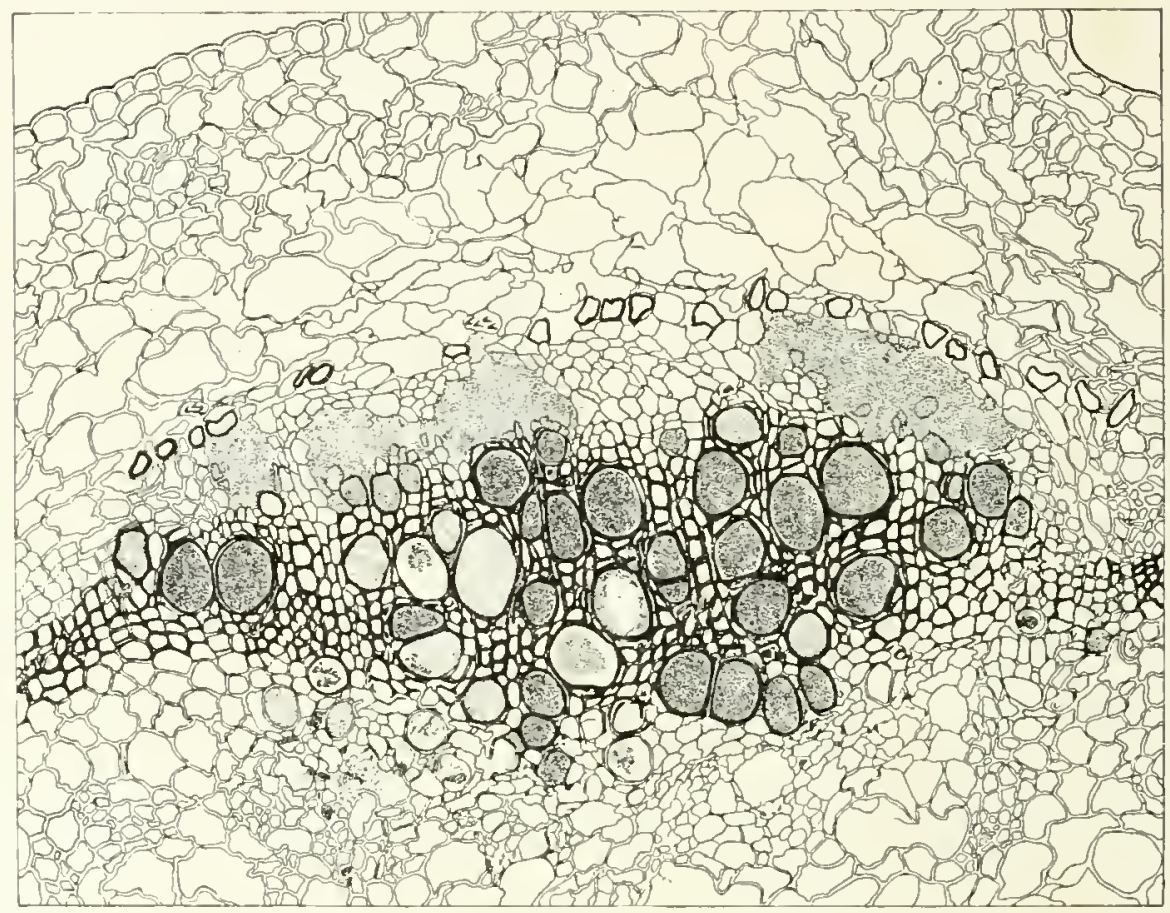

Fig. 86.* on diseased plants and then transferring them for a few hours to healthy plants. The beetles were obtained from healthy potato fields where the disease did not afterwards appear, and the only possible source of infection was the diseased potato leaves and stems on which they were fed, and which were the result of pure-culture inoctlations. The interior of these leares and stems swarmed with bacteria and it was impossible that the mouth-parts of the beetles should not have become contaminated. The infected plants did not contract the disease immediately, but signs appeared in from 7 to 9 days as narrow brown streaks extending downward rapidly inside of the stems and leaf-stalks. There were ntmerous infections on each plant and all of them appeared to originate in slight wounds made by the jaws of the

\footnotetext{
${ }^{*}$ Fig. 86.-Cross-section of a small portion of a potato-stem, showing bacteria in vessels, and also three bacterial cavities in the outer phloen. From plant No. It, May 27, I 895 , inoculated by needle-pricks, 11sing a pure culture of Bacterium solanacearum. The activity of the organism is shown by the following facts: The distance (downward) from the needle-pricks to the level of this cross-section was about is inches; the time between date of needle-punctures and fixing (in alcohol) of material for sections was only is days: all of the leaves had shriveled when the stem was fixed. Drawn from a photomicrograph, $X$ circa Ioo. Slide 17 M. (For a highly magnified detail, see fig. IoI.)
} 


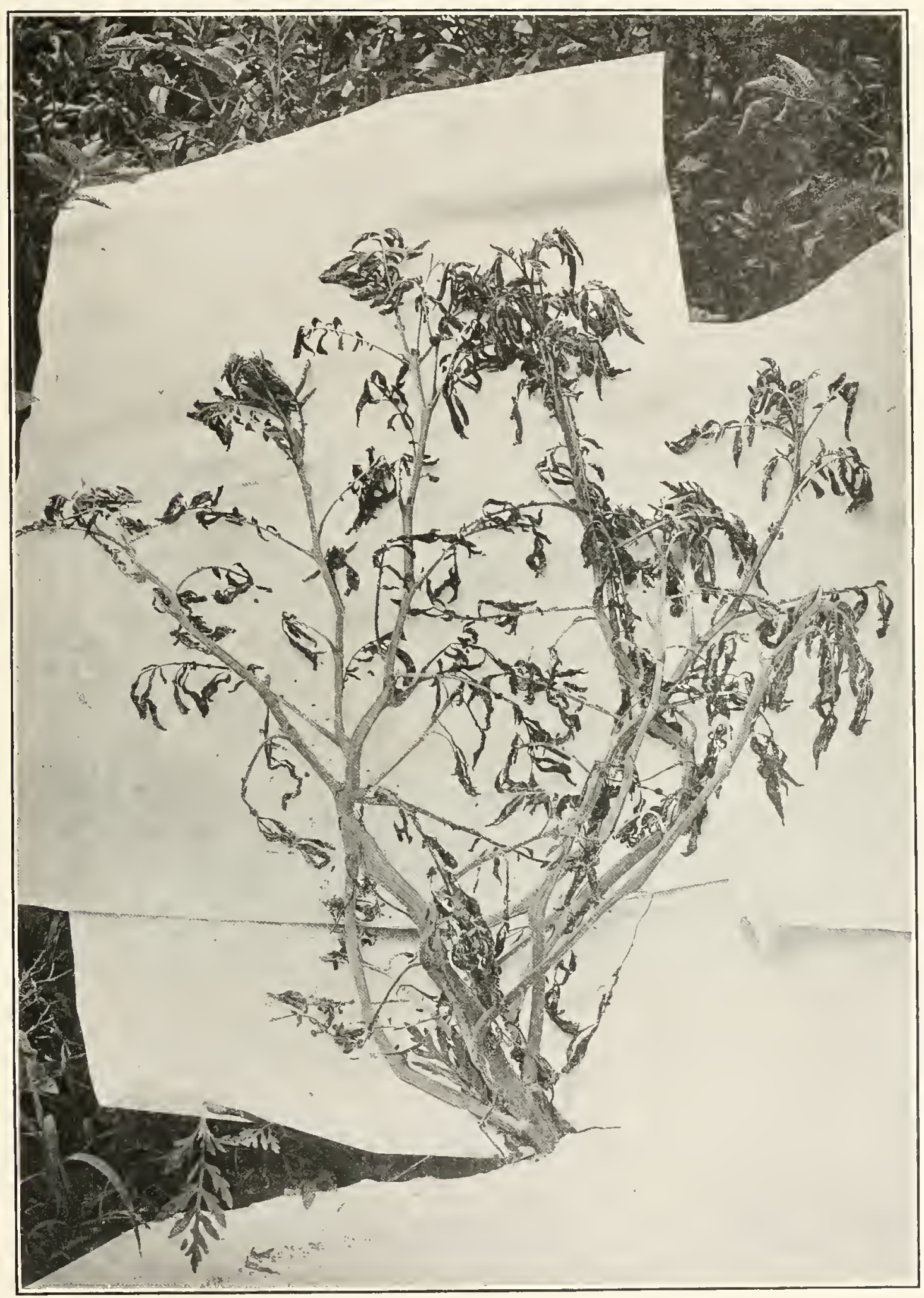

Potato plant which yielded Bacterium solanacearum (District of Columbia strain).

Stems externally sound but flabby at the tips; leaves wilted or shriveling; vascular system browned and occupied by the bacterinl slime. No superficial ulcers. From a potato field at Woodridge, D. C., July 8, 1904 

beetles. In course of a few weeks the plants were destroyed (fig. 87), and the tubers were rotted from within in the same way as when the plants were inoculated by needle-punctures. From this it was concluded that the disease depended for its dissemination very largely on insect-carriers-an inference needing further verification.

All of the writer's successful experiments having been made on leaves and stems, it is likely that in his bulletin too much stress was laid on the possibilities of infection through parts above ground. At that time the writer certainly regarded these as the most vulnerable parts. Burrill's observations led hin to the same conclusion. Hunger has sinee shown that when tomatoes are grown in infected soil, or water, they contract the disease readily if the roots are wounded but not otherwise. His field observations led him to the same

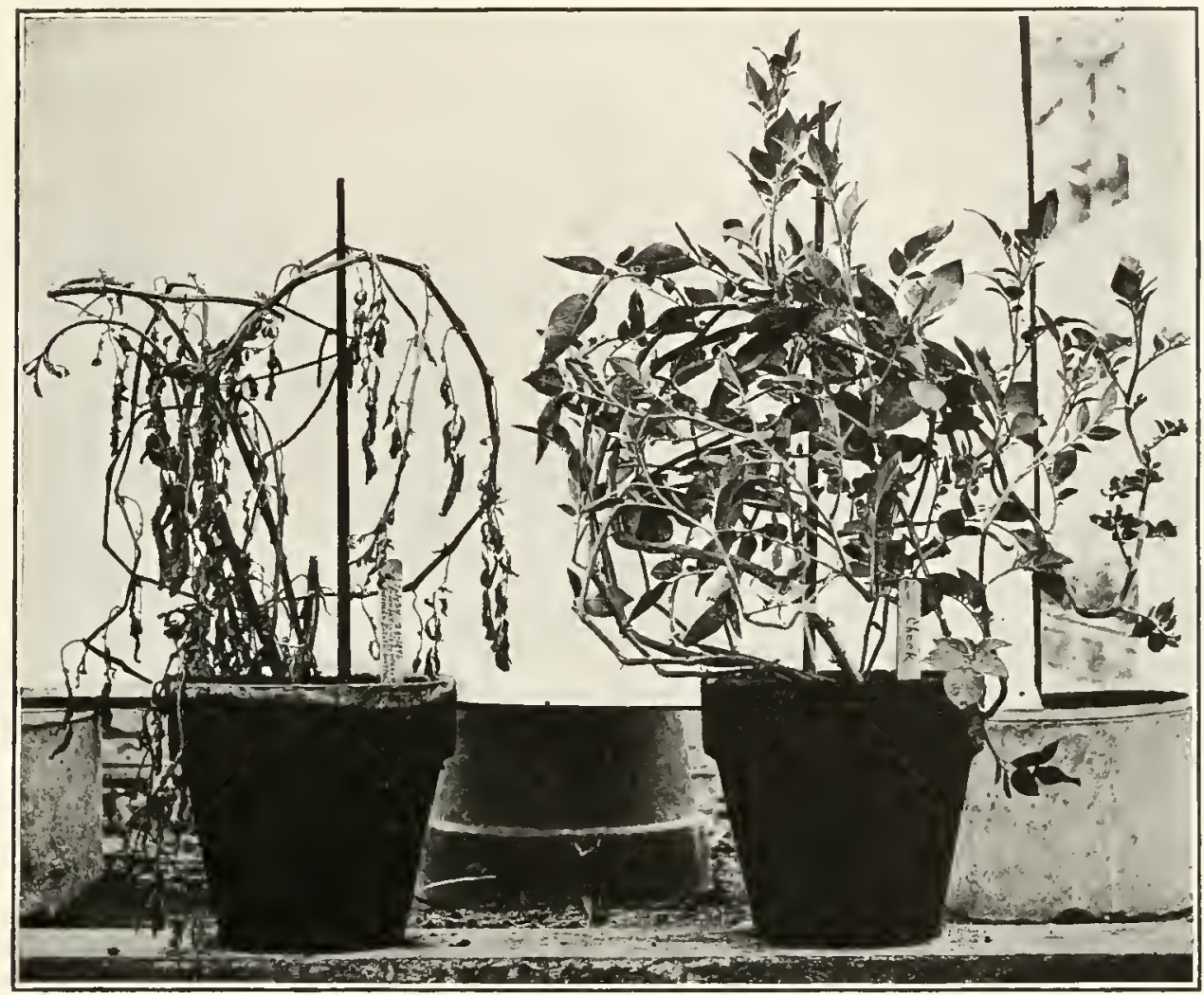

Fig. 87.*

conclusion. Observations on tomatoes in Mississippi led Earle to believe that underground infections were very common. Dr. Van Breda de Haan's observations on the slime-disease of tobacco in Sumatra led him to the same conclusion. I have also obtained tunderground infections on both tomato and tobacco, using the North Carolina tobacco-wilt organism. We may conclude, therefore, that the bacterium can enter readily throtigh wounds made on any part of the plant either above ground or below. In sucl event the manner of infection would vary from plant to plant and field to field, according to the prevalence of particular insects or other sources of injury.

Whether the organism can enter the plant in the absence of abrasions must be left an unsettled question. Burrill thought it could. Hunger states that it can 11ot, but lis experi-

*Frg. 87.-Potato plant (left) promptly destroyed by Bacterium solanaccarum as the result of the gnawings of infected beetles. (See text, p. I84.) Control plant on the right. 
ments were not very numerous, and, especially, were not very long-continued. Basing our conclusions on Hunger's experinents with tomato roots, we may assert with sone degree of confidence that an unwounded root is impervious to this organism, but it does not appear to be equally certain that the disease can never begin in the sub-stomatal chamber. So far, however, as we yet know defuntely, infection takes place only through wounds. In one of the writer's hothouse experiments, a potato plant grew to maturity in health in the same pot with one which became badly diseased (in leaves, stenus, and tubers) as the result of a pureculture inoctulation, but here inseets were kept off.

Exclusive of variable degrees of virulence on the part of the parasite and of individual or varietal resistance on the part of the host, the progress of the disease on attacked plants in the field must vary to a large extent with fluctuating temperature and rainfall. Rainy weather favors the disease, beyond question. So does moist soil. Under the equator, with rain every day, one might expect the disease to be much more rapidly fatal than in a cooler, drier climate, and such appears to be the case.

According to Mr. Irons, of Porto Rico, Solanum mammosum is resistant to this disease. The Seed and Plant Introduction No. 24650 , supposed to be this plant, bears small yellow gourd-like fruits having a white, tough, inedible flesh and small brown seeds. The specimen fruit seen by the writer was globose and about 2 inclies in diameter. It is thonglit that the egg-plant and tomato might be grafted upon it, but I believe we shall find eventually more practical methods of dealing with this discase.

\section{SYNOPSIS OF INOCULATIONS.}

The following is a summary of all inoculations made by the writer and his assistants with Bacterim solanacourum, so far as records were kept and are now available, except certain ones mentioned under "Wilt Discases of Tobacco:"

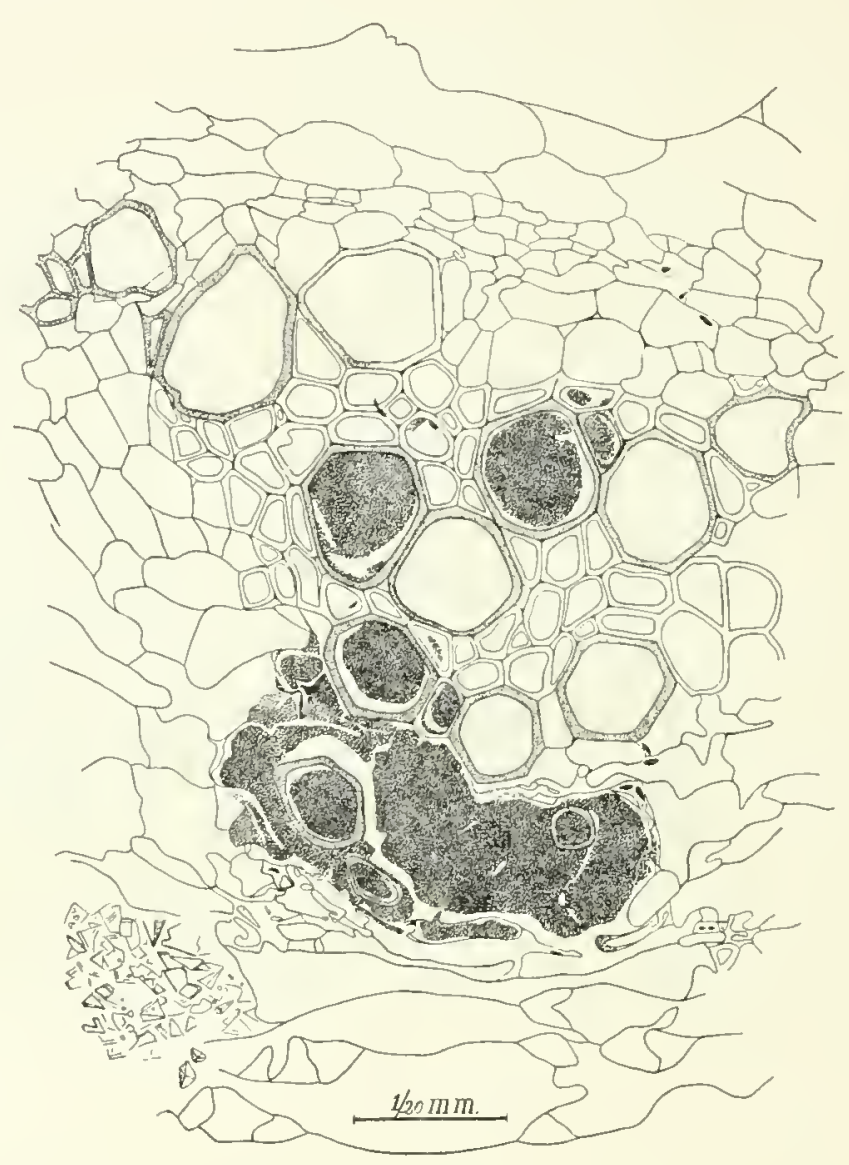

Fig. 88.*

May 27, IS95.- Tumato and putato plants were inoculated with slant agar culture No. 2 of May 22 (from slant agar, May 16, which was direct from the interior of a green, turgid, odorless stem of tomato from Ocean Springs, Mississippi). Fourteen innculations were made: In fruit, rather woody part of stem, tip of stem, leaves and petioles of tomato, and on young shoots and leaflets of potato.

*Fir. 88.-Cross-section of a single bundle from the hypocotyl of Datura stramonium, plant No.23, inoculated June 8, 1805 , from tube 1 , June 4 , with Bacterin solanacearum by needle-pricks on hypocotyl and fixed in strong alcohol on June 2o. The upper part of the drawing represents the outer part of the bundle. In the lower part there is a bacterial cavity. In the lower left corner the knife passed through a crystal-cell. A few nuclei are visible. The alcohol caused some shrinkage of the bacterial masses. Several other bundles of this hypocotyl are partially occupied; the remaining bundles, together with the tissues between them and on the periphery, are free from bacteria. The foliage of this small plaut was badly collapsed when the material was cut for fixing. Drawn by Alice C. Haskins under the Abbe camera from a stained section. Slide 192( 1 . The organism inoculated was a culture from a tomato plant from Ocean Springs, Mississippi. 
Result.-Successful; the first signs appeared on the fitth day; weather exceedingly hot for last 4 days. The diseased stems of potato were swarming with short motile rods. Illıstrated in Bnll. 12, Division of Vegetable Physiology and Pathology, i 896 , pl. I, fig. I.

June 8.-Fifteen inoculations were made on pear tree (Japau), pepper, pepino, Solanum nigrum, Datura stramoninm, tobacco, tomato, potato, using slant agar No. I of June f, from culture used for inoculations of May 27. Each plant received many pricks.

Result. - Sncceeded on tomato, potato, Solamum nigrum, and Datura stramonium (fig. 88). The organisms in the diseased Daturas were short, motile bacteria.

June 15. - Sixteen inoculations into Pelargonium sonale, Datura stramonium, Solanum carolinense, potato and tomato, were made with cultures derived from the same source as those used for the inoculations of June 8 and Nay 27.

Result.-Failed, except on potato, the stem and tubers of which finally rotted. There was only a local multiplication of the bacteria in 2 green fruits of the tomato.

June 21.-The plants wsed for these inoculations were fo strong, growing tomato vines ro inches high in 4 -inch pots. Nos. 46 to 66 were pricked in middle of stem, and Nos. 67 to 85 in the tender tip of stem; many deep pricks were made in each case. The culture used was slant agar No. 3 of June 18 , whose history is as follows: Made from a single colony on poured plate No. 3, June I4, from slant agar No. 1, June 11, which was made directly from interior of stem of potato No. 13, inoculated Miay 27.

Result.-Failed; at least there were no signs for 30 days. Possibly a wrong colong was used; at any rate the method was defective, as plate cultures should have been made direct from plant No. 13.

July 5.-Egg-plants, cucumbers, tobacco, potato, Dafura stramonium were used for these inoculations (30 in all). The leaves and stems were pricked. The culture used was slant agar No. I, June IS, from another colony on plate No.3. June 14. The bacteria covered nearly the whole surface of the slant with a smooth, wet-shining, whitish, copious growth, crenate at margins, not sticky, possessing a moderately bad smell. the agar was not stained.

Result.-Failed? No records fornd. Probably a wrong colony was used.

August -. - Tomatoes in the field on James Island, South Carolina, were inocnlated direct from slime in stem of egg-plant from Charleston, S. C. Fifteen terminal, rather woody shoots of large plants were selected.

Result.-Snccessful; all of the inoculated plants contracted the disease, the wilt appearing slowly.

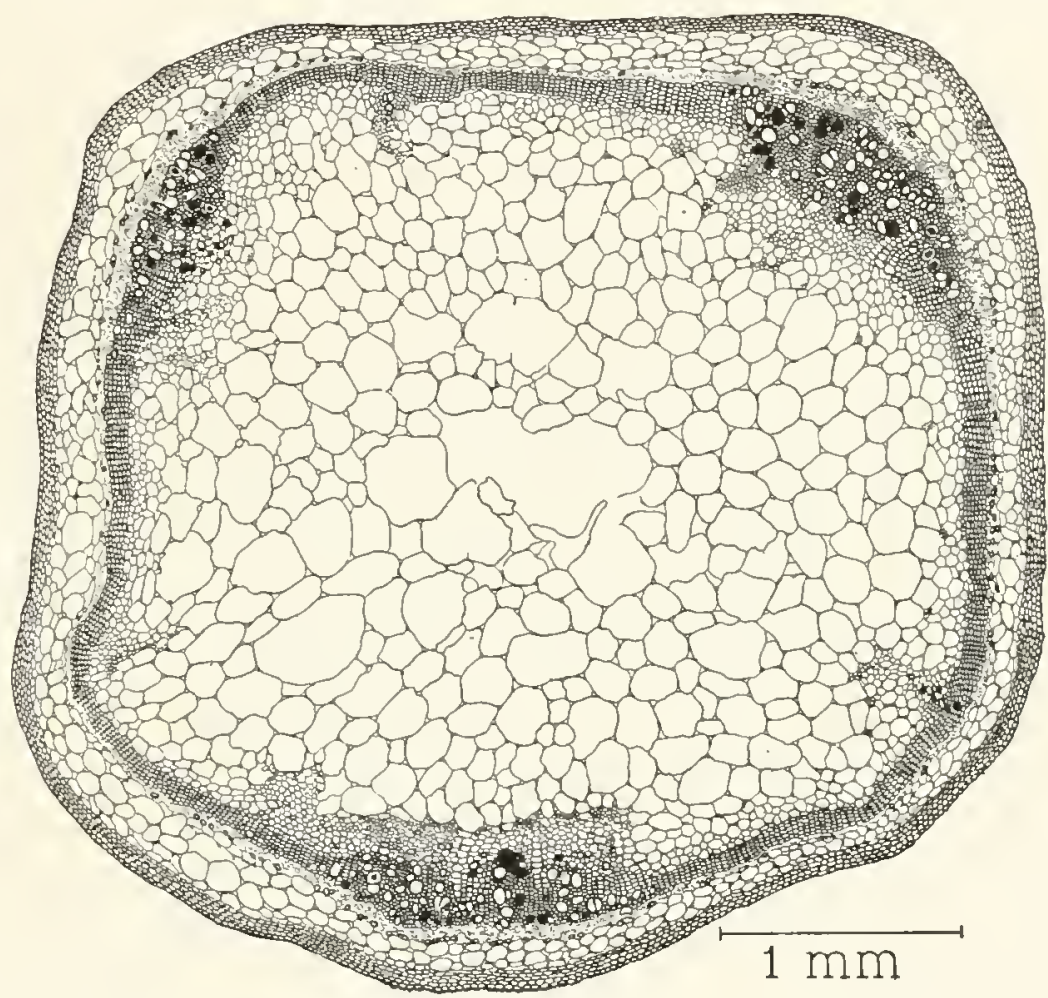

Fig. 89.* None of the check-plants became infected. Rainy weather.

May 7, I806.- Tomato, Datura stramonium, and potato (2 watery shoots) were inoculated from tube No. 2, May 5 , from interior of tomato stem from Lawrence, Massachusetts. The plants were healthy and 12 to I $_{5}$ inches high, except the Datura, which was half as large and old. There were 7 inoculations.

Result.--No record fonnd. The inoculations probably failed.

June I. - Six plants, part tomato, part potato, were inoculated from peptonized beef-broth culture No. 3 MFay 29 , made direct from the interior of stem of egg-plant from Charleston, Sonth Carolina (1896). The inoculations were made into petioles, tender shoots, and leaflets.

Result.-Very successful (Bnll, 12, pl. I, figs. 3, 4, 5). The organism in diseased tisstles is a motile, short rod (sce Centralblatt f. Bakt., 2 Abt., vir Bd,, 189 I, Tafel XI, figs. 4I, 42).

June 15.-Eight young plants (each bearing 6 leaves), part tomato, part potato, were inoculated in soft tissnes in active grow th by means of needle-pricks. The cnlture used was a peptonized beef-broth, tube No. 6 , June I 3 , from No. 2, June 12 (broth-culture), from a colony on poured plate No. 6, June 4, from peptone water I, May 29, which was a companion tube to No. 3 , May 29, nsed on June I.

*FIG. 89.-Cross-section of stem of Solanum nigrum, showing vessels occnpied by Bacterium solanacearum. Plant No. 34, I 896 , inoculated from bouillon July I I, in npper part. Collected July 24 . Source of organism, South Carolina egg-plant. All of the leaves were wilted when the stem was fixed in strong alcohol. Bacteria are confined to tlie heavily shaded parts of the xylem, and inner phloem. Slide $119 *$. A few of the infected vessels are shown highly magnified in fig. 90 . 
Result-Tery successful (Bull. 12, pl. 1, figs. 6, 7, and pl. 2, fig. 2). First signs appeared on third or fourth day. weather hot, $28^{\circ}$ to $32^{\circ} \mathrm{C}$. The organism swarming in tissues of affected plants was a short, motile rod

June 23.-Three old potato tubers and 3 cucumber fruits were used for these inoculations ( 4 inoculations, 2 checks). The cucumbers were 7 inches long by 2 inches thick, green and firm. The potato tubers were large, smooth and white, probably Burbank, kept under bell-jars. Same culture used as for inoculations of June 15.

Result.- The cucumber fruits rotted, but no plates were poured. In the worst injured potato the bacteria, which were numerous along the line of the punctures, extended scarcely $1 \mathrm{~mm}$. beyond; starch intact.

July II. - Two cueumber fruits under a bell-jar were inoculated from tube No. 4. July 8.

Reswlt. - One of the fruits rotted, but no plates were poured. The bacteria filling the interior were short, actively motile rods (see footnote on p. i 74)

J Mly II.-The following plants were inoculated: Potato ( 7 plants), tobacco (Connecticut seed leaf, 2 plants), cucumber (4 plants), petunia (2 plants, 6 shoots), Solanum nigrum (1 plant). Datura stramonium (2 plants), Datura tatula (?) (1 plant), Physalis crassifolia ( $\mathrm{I}$ plant, several shoots). Twenty-five inoculations were made by needle-pricks on a very hot, sunny day. The inoculated parts were shaded. The cultures used were tubes of beef-broth Nos. I, $2,3,4,5,6$, and 8 of July 8 , from sugared peptone-water in fermentation-tubes (descended from egg-plant from Charleston, S. C.). The potatoes were tall shoots, half-grown in 8-inch pots, and each plant wasinoculated from a separate tube (about 30 pricks in all). Numerous check-plants were held. The tobacco was inoculated (roo pricks) in a big leaf. The Datura tatula (?) was a young, vigorous plant. The plants of $D$. stramonium were old and stunted.

Result.-Very successful on potato (Bull. [2, pl. I, fig. 8), Solanumnigrum. Phvsalis crassifolia, and Datura stramanium. Feeble infection in petunia. The inoculation on D. tatula failed. There was possibly some local disease on one of the tobaccos. Saved in aleohol. All the potato plants contracted the disease. The first signs were ohserved on the thirrl day, and on the sixth day there was decided wilt of the leaves. The weather was very hot. Examined microseopically, the stems of $S$ nigrum swarmed (figs. 89, 90, 91,

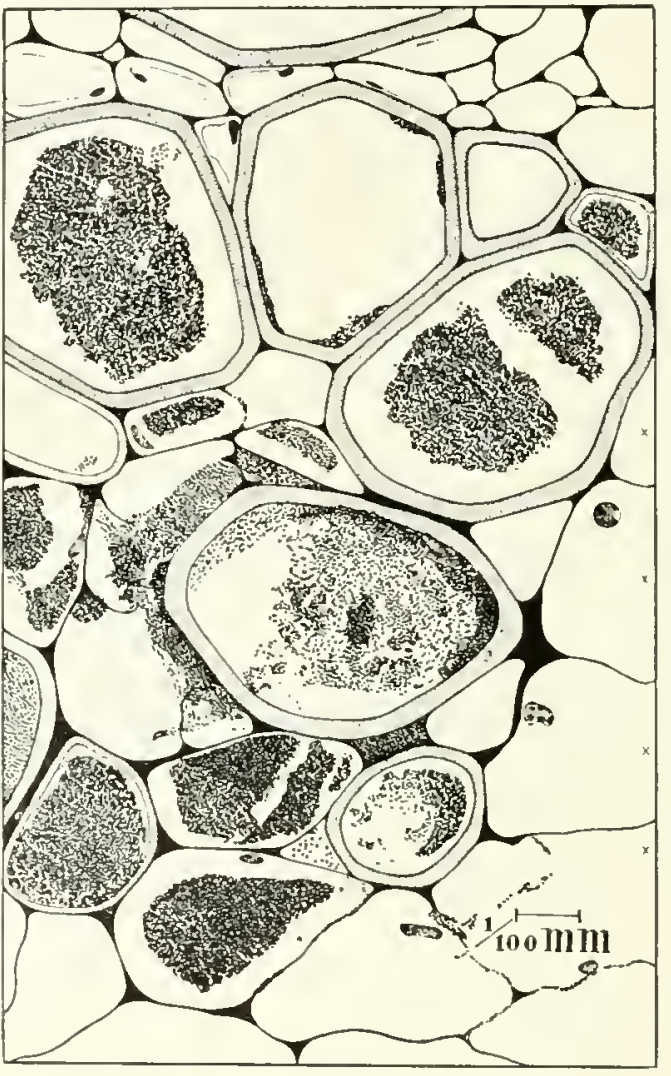

Fig. $900^{*}$

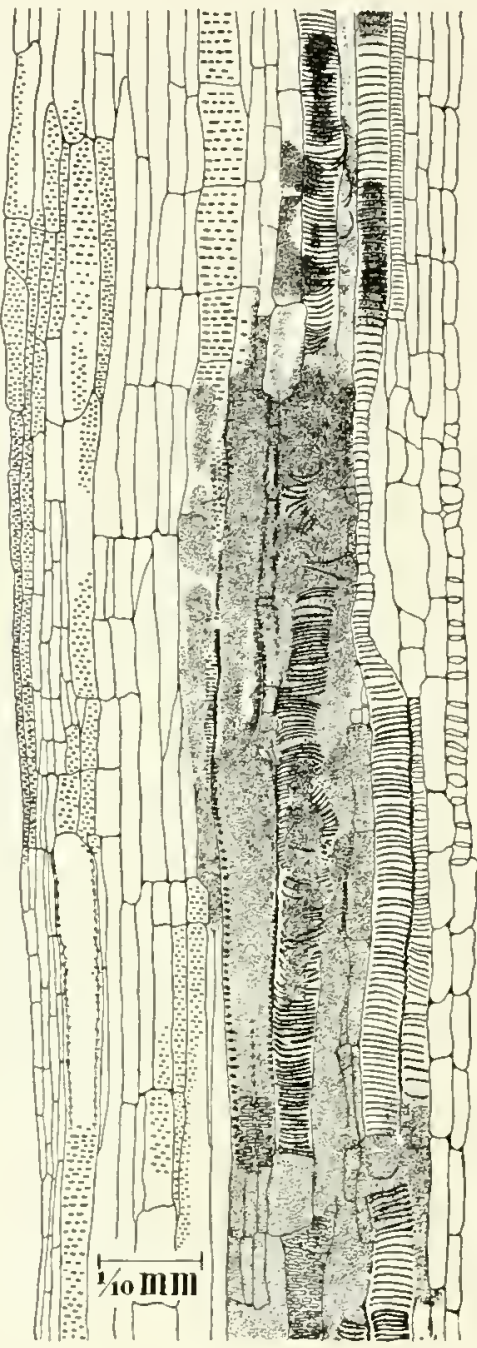

Fig. $91 .+$ 92) withsmall to

medium-sized short rods, single or in pairs, with a constriction; a tremulous motion.

$J_{u l y} 23,24,25,27$ - - Potato plants (4, each with several shoots) were used for this experiment. The inoculations were made by potato-beetles which were fed for some hours on tips of potato-vines badly wilted and blackened by Bact. solanacearum (inoculations of July I I), then eolonized on the sound vines for some hours.

${ }^{*}$ FiG. 90.-Cross-section of small portion of stem of black nightshade, showing Bacterium solanacearum in vessels and conneetive, tissue. This figure is a detail from one of the bundles shown in fig. So introduced to give an idea of the size and shape of the bacteria. The bacterial masses are somewhat contracted from the walls of the vessels owing to the use of strong aleohol as a fixative. The cells marked $x$ belong to a medullary ray. Slide I19(I.4.

†F1G. 91.-Longitudinal radial section of a portion of the vaseular ring of the stem of Solanum nigrum, showing location of the bacteria. The right-hand side faces the inner phloem. A cavity is visible in the bundle. Plant inoculated with Bacterium solanacearum by needle-pricks on July i I, 1896; stem fixed in strong alcohol July 24 . A detail from another section in the same series is shown in fig. 92. The entire stem in cross-section is shown in fig. 89 . Drawn with the help of the Abbe camera, I 6 mm. objective and 12 acular. From slide 119 ( 9. 
Result.-Very successful: The first sigus appearcd on the seventh to ninth day, heginning as brown streaks in many bitten places. On August $4,+9$ separate infections were counted.

A ugust 1 4.- Twelve plants were inoculated: Potato, tomato, cucumber, and heliotrope. Potato culture No. I, August 12, direct from the interior of plant No. 16, inoculated July I I, was used.

Result.-- Tery successful on potato; less so on tomato. On cucumber a swollen stem appeared (the pricked internode) this contained living (motile) bacteria on September 8. Heliotrope (?)

A ugust 17 . - In this experiment 8 plants were inoculated: Portulaca oleraceae, tomato, Physalis philadel phica, heliotrope, Cucurbila foetidissima, Eleusine indica, Ricinus communis, and Vigna caljang. Many pricks were made in each plant, introducing potato culture No. $\mathrm{r}$, August 12 , which was direct from interior of plant No. 16 , inoculated July 1 I. The tomato was punctured on a thrifty shoot near the top.

Result.-Very successfulon Physalis philadelphica, the first sign appearing about the tenth day. For effect on Plysalis see figs. 93,94 . The infection of tomato was slow-no wilt up to August 28. The other plants failed to contract the disease.

A ugust 20.-Ten inoculations were made on this date, using Solanum carolinense for the experiment. Many needle-pricks carricd in large quantities of the bacterial culture (tube No. 1, August I2, as above), some of the pricks being made into leaves, others into the upper part of rather woody stems.

Result.-All failed. Perhaps the inoculations were made too late in the season. The stems were woody.

September 0.-Nine plants, part tomato, part potato, were inoculated from a fluid culture made directly from the swollen cucumber stem of August if. Laroe numbers of bacteria were introduced by means of many needle-pricks.

Result-Negative. No records after September 2 . Possibly the wrong organism was isolated-the method is not commendable.

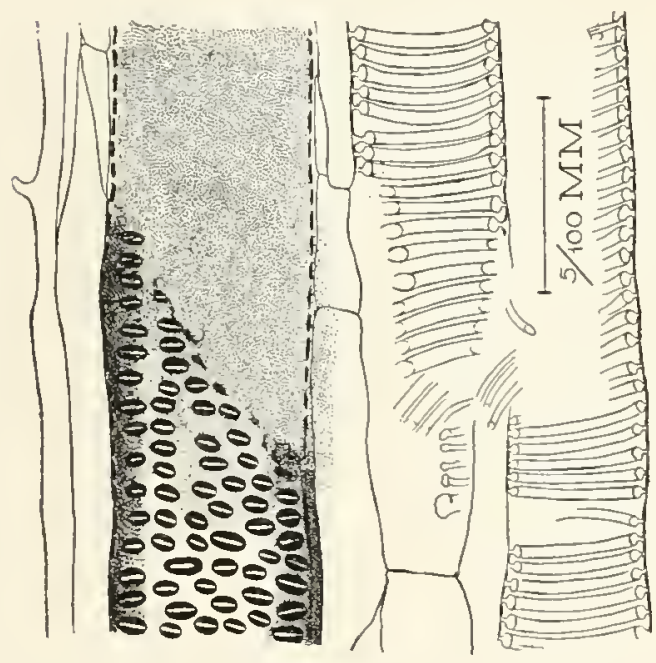

Fig. 92.*

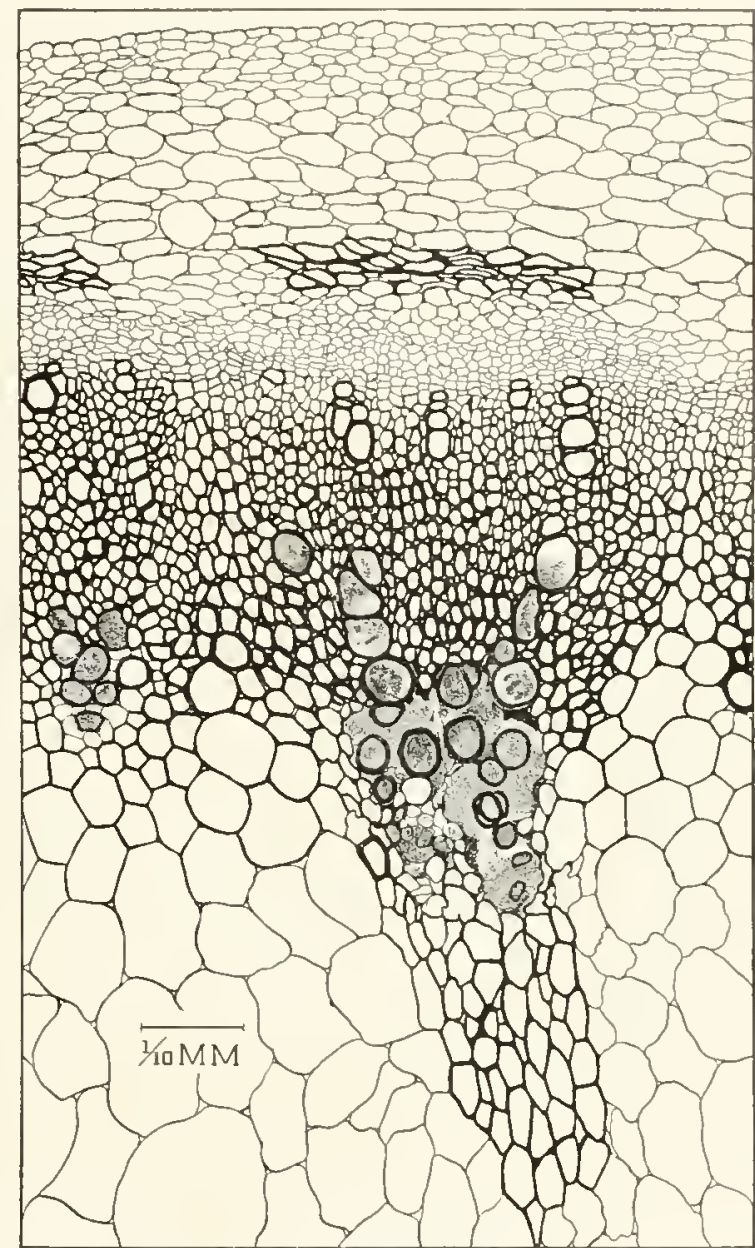

Fig. 93.†

Sepiember I6.- Six inoculations were made on potato, from cultures Nos. I and 2, September It, from Nos. I and 3 August 29, which clouded after heating io minutes at $5 I^{\circ} \mathrm{C}$. (culture descended from egg-plant from Charleston, S. C.).

Result.-Failed.

Summer of I $190 I$ (before July I9). - Ten plants, part tomato, part potato, were inoculated. Many needle-pricks were made, introducing a pure culture from the interior of a tomato stem from South Carolina (descendant of poured-plate colony:)

Result.-Tery successful. All contracted the disease.

*Fig, 92.-A single pitted vessel of Solanum nigrum, plant 34 , occupied by Bacterium solanacearum as the result of a pure culture inoculation made sone inches above and i 3 davs previous; two unoccupicd spiral vessels at the riglt

$\dagger$ Fig. 93. - Cross-section of small part of the stem of Physalis philadelphica, showing bacteria in the spiral and pitted vessels, and the beginning of a small cavity; epidermis at top and pith at bottom of the figure. Bacteria in the cavity more abundant and with denser stain than is here shown. Plant No. 57 inoculated with Bacterium solanacearum August 17, 1896 ; collected and fixed in strong alcohol September 23. Drawn with the Abbe camera from a section cut on the microtome and stained with carbol-fuchsin. Slide $120{ }^{*}$. Crystal-sand not present. (For a longitudinal section sec fig. 94.) 
July I0.-Thirty-five inoculations were made into the following plants: Tomato ( 15 plants), cucumber (6 fruits), potato (6 plants), Solanum dulcamara (8 plants). The cucumbers and part of the tomatoes were in the open air, the rest in the hothouse (temperature $90^{\circ}$ to $100^{\circ} \mathrm{F}$.). The cultures used were 6 agar streaks from as many colonies on poured plate from the interior of a tomato plant inoculated earlier in the summer (sce preceding set).

Resull.-Successful on tomato and potato, the first sigus appearing on the fourth day (in one potato on the third day). Only slight local signs in Solanum dulcamara. Negative on cucumber. (For appearance of cross-section of petiole of potato at end of the sixth day see fig. 95.)

November 5.- The following plants were inoculated: Tobacco ( 6 plants, , foot high), tomato (6 plants), potato (6 plants). Two leaves on each tobacco plant were inoculated by needle-pricks (20 to 30 pricks each). The plants were in the hothouse at $80^{\circ}$ to $90^{\circ} \mathrm{F}$. All were very healthy and growing well. Two potato cultures were used, one 7 days old or more and browning, the other 72 hours old and from the preceding, descended from agar-tube No. I3, July is, from inoculated tomato. The first potato culture was inoculated from an old browned agar culture, which had been in the ice-box all summer.

Result.-All failed.

June, I 902.-Potato and various weeds (Abutilon, etc.) were inoculated by hypodermic injection from cultures obtained from diseased tomato received from Georgia (1902). This was a large field experiment with various fertilizers.

Result.-The disease was produced on the potato, but it appeared slowly and in comparatively few of the many inoculated plants.

June - - A duplicate of the above experiment, except that the cultures used were obtained from a diseased tonnato received from Porto Rico.

Result - As above.

July 0 .- Another duplicate of the experiments of June. Cultures used were from diseased tomato (?) from Maryland.

Result:-As in June.

June 4, I003. - Six tomato plants were inoculated with cultures of June I I to 3 potato, 4 to 6 slant agar), which were isolated from a tomato plant received from Texas, all from plate 17 May 28 , poured from interior of green and recently diseased petiole. The plants were rather far advanced in disease when received and contained numerous intruders. Six colonies were used. The slime was viscid and distinctly yellow in some tubes.

Resulf.-No wilt within 5 weeks. Hot louse experiment. Probably wrong organism isolated."

July 6.-One plant of Dafura stramonizm
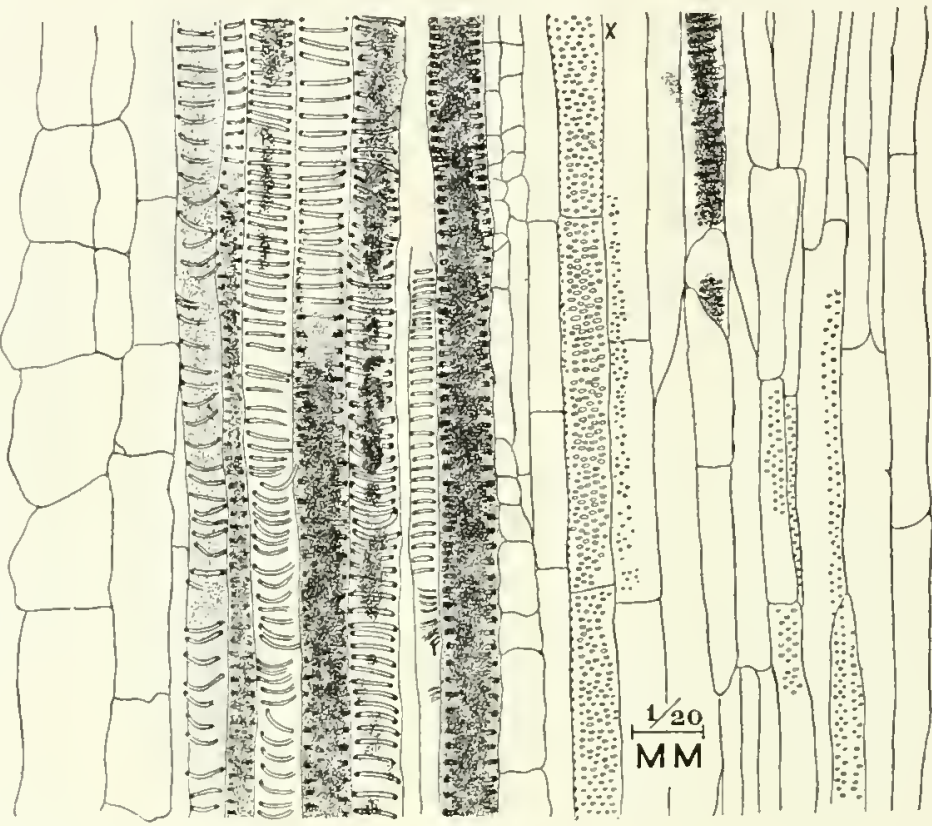

Fig. 94.† was inoculated by means of forty needle-pricksin leaf-blade, using slant agar-tube No. 1, July 2 (descended from tomato from Soutl Carolina).

Result.-No record. Probably failed.

July 7.-Tomato (6 plants), Datura stramonium (2 plants), Datura fastuosa (I plant), Datura cornucopiae (I plant), were inoculated from agar-slant tubes Nos. 1, 3, 4, July 2, from potato cultures which had become black (descended from tomato stems from Spartanburg, South Carolina). The agar-tubes were the second subcultures from poured-plate colonies.

Result.- Every one of the ter plants contracted the disease. One tomato plant (No. 7) was perfectly healthy in appearance July 21 , but succumbed Angust 3. For appearance of plant No. Io at end of 7 days see fig. 96.

July 7,-Tomato (4 plants), Daiura metalloides (1 plant), were inoculated by needle-pricks ( 2 into each sten), using tubes Nos. 3 and $t$, July io (from potato stem, Norfolk, Virginia).

Result.-All became diseased. For result on Datura see vol. I, plate 4 .

July I6. - Tomato plant No. 17 was inoculated from slant agar No. 1 , July 13 , the third subculture from a colony from tomato (South Carolina). The plant divided into two equal branches.

Resull.-Successful. The first signs of infection were visible on the third day. Several leaves wilted on July $2 \mathrm{I}$. Numerous adventitious roots pushed out along stem in the two inoculated internodes, while the surface of the check-internodes was perfectly smooth. Roots were also pushing ont of the two internodes below the lowest point of inoculation. Several photographs were made of this plant at different stages (consult plates 26 and 27 ).

*I now suspect this Texan disease may have been due to A planobacter michiganense (see page i6r).

$\dagger$ Fig. 94.- Radial longitudinal section through xylem part of the stem of Physalis philadelphica, showing Bacterimm solanaccarm confined to the spiral vessels. The pith is toward the left. The pitted vessel $x$ lies not between the spirals but just below them. This section was made from the same piece of stem as fig. $93, i . e$. , the plant was No. 57 inoculated August I 7, 1896, by needle-pricks on the upper part. The material used for this section was taken on September 23 about 6 inches below the pricked part. The plant was infected with a pure culture derived from an eggplant. Drawn from slide $120(3$. 
$J$ uly 17.-Early: Rose potatoes in the field (plants Nos. I to 120) were used for this experiment. The cultures used were 5 slant agar-tubes of July II, from No. 4, March I (South Carolina); slime washed off into distilled water (150 c.c.). The inoculations were made near the top of the plants with a hypodermic syringe, 0.2 c.c. of the liquid being put into each plant. The stems were very tender and soft.

Result.-First recorded signs on July 23, when 77 per cent showed signs, but they were slight for 9 days' incubation.

$J$ uly 16. - Burbank potatoes in the field (plants Nos. $12 \mathrm{I}$ to 240) were inoculated in the same manner as the above, using 6 slant agar-tubes of Jily 14, from No. 1, March I; slime washed off into distilled water (150 e.c.).

Result.-On July 25, 76 per cent showed signs of disease.

July 22.- Potatoes in the field (plants Nos. $241-450$ ) were inoculated in the same manner as those of July 14 , using 6 slant agar-tubes of July 17, descended from No. I, March 1; slime washed off into distilled water (150 c.C.).

Result.-On July 27,60 per cent showed signs of disease; almost no wilting.

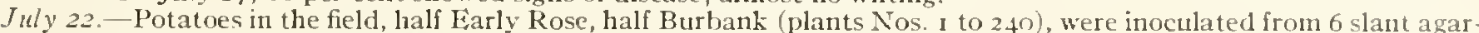
tubes of July 20, from No. 6, July ro (descended from potato-stem from Norfolk, Virginia), employing the method of inoculation used on July 14.

Result.-On July 27,96 per cent of the Farly Rose and 89 per cent of the Burbank showed signs of disease.

July 22. - Early Rose and Burbank potatoes in the field-half of each variety-were inoeulated (using plants Nos. $241-$ 480). The cultures were 6 slant agar-tubes, July 2 I. from slant agar of July 20 from Virginia. The bacteria were put on outside of stem with a hypodermic syringe, which was kept protected from the light; the needle was then passed through this liquid, and entirely through the stem, to pricks being made into each plant near the top. No injection.

Result.-First signs on July 25. On August 3, 100 per cent showed signs of disease; many were wilting and falling over. There were also many attacked by Fusarium oxysporum (see Smith and Swingle, Bull. 55 . Bureau of Plant Industry, L.S. Dept. of Agric., Feb. 16, 1904).

July 28 .- Potatoes in the field (plants 481 to 720 ), half Early Rose and half Burbank, were inoculated from 6 slant agar-tubes of July 26; slime washed off in distilled water. A little liquid was drawn up with a hypodermic syringe wrapped in black paper to protect it from the light. This liquid was put on the stems and 10 needlepricks made through it in to the stems, without injection. In all of these large field tests Mr. Deane B. Swingle did the inoculations and made the counts.

Result.-On August 22,96 per cent of Early Rose and 94 per cent of the Burbank were diseased as a result of the inocu-

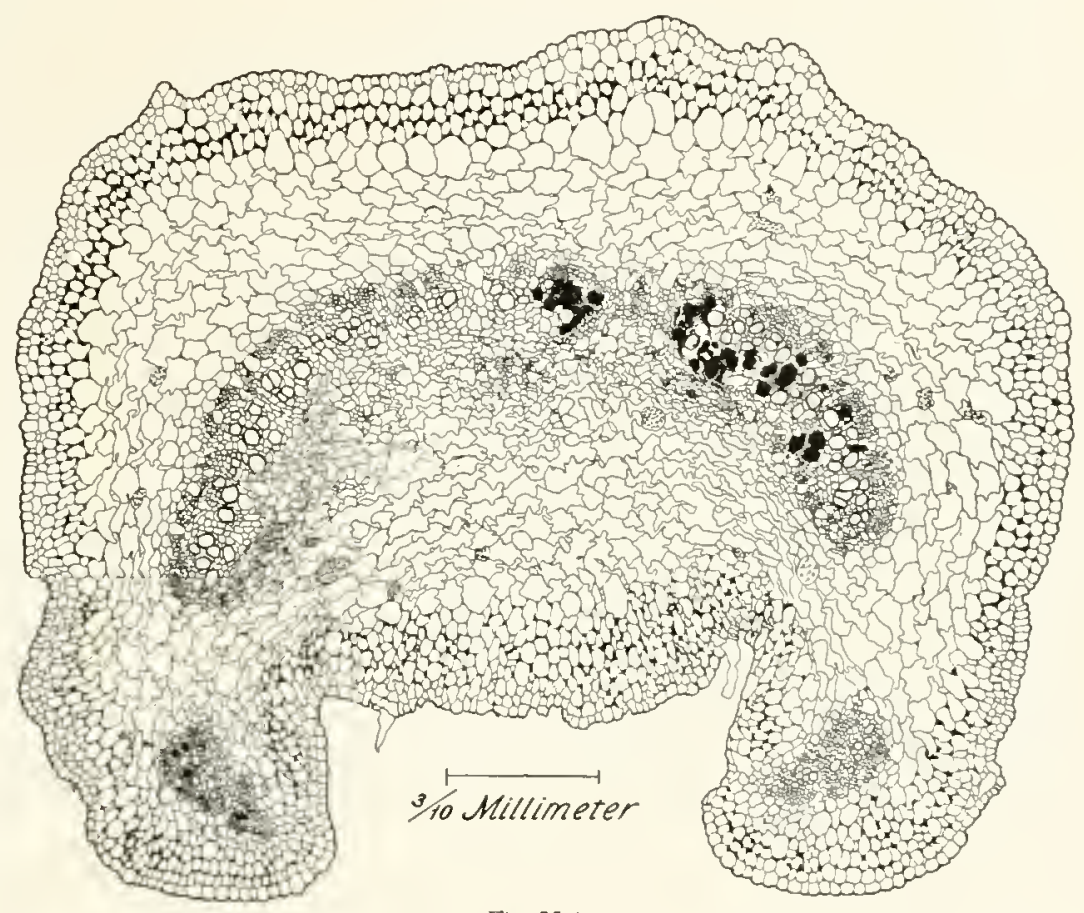

Fig. 95.* lations.

July 21.-Two tomato plants were inoculated from culture from No. 1, July I (from tomato, South Carolina) with a hypodermie syringe (o.z c.c.).

Result.-The experiment was followed for many weeks. Adventive roots pushed out but the plants failed to wilt. They grew luxuriantly after repotting, and bore fruit.

March 17,1904 - -Twelve plants of tomato (6 varieties), were inoculated from potato-cultures Nos. 2, 5, 8, March 14 (Virginia, isolation of 1903). The plants when inoculated were 4 weeks old, about 6 inehes bigh, and had 3 to 4 leaves. Made is to 20 needle-pricks in leaf-blades.

Result.-No wilt; plants grew well. The experiment was followed until May ro.

A pril 16.-Eight potato plants, 8 to 16 inehes high, were inoculated from potato cultures Nos. I to 3 of April i 3 (Virginia, 1903). Young internodes were pricked.

Result.-No wilt. The stems became very badly swollen and discolored (see vol. II, fig. 27)

${ }^{*}$ Fig. 95.-Cross-section of base of petiole of a potato-leaf, showing restriction of the bacteria (solid black masses in center at right) to the vascular part. Plant No.23, 19or, inoculated from a pure culture of Bacterium solanacearum. July 19, by needle-pricks. Material collected and fixed in strong alcohol on July 25 , at which tine the blade of the leaf was badly shriveled. The shading between the cells in the outer part of the section represents collenchyma and not bacterial occupation. Drawn under the Abbe camera with $8 \mathrm{~mm}$. apochromatic objective and No. I compensating ocular, from a paraffin section which was stained with carbol-fuchsin and washed in 50 per cent alcohol. Slide $123 *$. 
Moy $2 I$. - Tomato plants (6) were used for this experiment. The inoeulations were made from potato-cultures Nos. 4 and 5, Nlay I2, descended from colony on plate poured after exposure to liquid air (from Virginia, 1903). They were made on shoots of plants which had been eut hack and repotted.

Resull.-No wilt. Pricked area became blackened and somewhat swollen.

May 24.- Tomato plants ( 6 vines about 9 to 12 inches high), were inoculated from beef-bouillon Nos. 19, 21, 22, of June 9 (1903?), and potato No. 26, June 9 (1903?).

Result.-No wilt (June I7). The stems became swollen and put out adventitious roots.

July 5.-Eleven tomato plants were inoculated with potato-eultures Nos. I to 6 of July 2, from plate colonies, from potato stem from Woodridge, D. C. (see pl. 30). Made 10 to 12 pricks in each stem with a No. 12 needle.

Result. - Very successful. All but 2 showed the disease July 8, and one of these two was inoculated with a gas-forming organism. (Consult fig. 97 for appearance of an inoculated plant at end of third day.)

1 ugust S.-Potato plants ( 8 pots) of the Green Mountain variety, received ahout 36 inoculations on leaves and young shoots. The plants were stoeky and only a few inches high. Needle-punctures varied in number from $\mathrm{I}$ to 20. The cultures used were slant agar subcultures, Nos. 3 and 4. Angust 6 , from potato stem from Woodridge, D. C.

Result.-Very successful; first signs on third day. (See pl.31.)

1. ugusl 25-- Potato plants (3 pots) were inoculated with potato-eultures Nos. 1 and 2, Angust I 9, and litmuspotato-agar No. 2, August 15 (from potato-stem from Woodridge, D.C.). Part of the plants were inoculated with descendants of culture after passing through the thermostat $\left(37.5^{\circ} \mathrm{C}\right.$. $)$, and part with descendants of culture held at room temperature. Made ro to 12 needle-prichs in upper internodes.

Result.-The plants were too old. None contracted the disease. All of them died down from thrips or other eauses.

September 6.-Fourteen tomato plants were inoculated from subenltures in tubes of litmus-lactose-agar, Nos. 3, $5,7,15$, and I 7 . September I (Woodridge, D. C., organism). I'art of the plants were inoculated from culture grown at $37.5^{\circ} \mathrm{C}$., part from descendants from culture grown at $37.5^{\circ} \mathrm{C}$. (pl. 29), part inoculated from descendants from culture grown in ice-box, and part inoculated with organism grown at room temperature since its isolation (pl. 28). The inoeulations were made on young shoots coming up from plants eut back.

Resull.-No rapid wilt. For the most part only swollen stems and slow progress of the disease.

October 6.- Six tomato plants of as many varieties were inoculated from slant agar Nos. I and 2, October 3, from No. 2, August 29 (Woodridge, D. C., organism from potato). The stems were pricked 3 to 4 inches from the top.

Result.-No wilt. The stems became somewhat swollen and pushed out adventitious roots; they also became slightly black around the pricks.

October 11 . Thisexperiment was made with 5 tomato plants, inoculating them near the tips in tender tissues in most eases, and directly from tomatoes which were inoculated October 6 , and which had not wilted hut showed pricked area swollen and eonsiderably discolored (Woodridge, D. C., organism from potato through tomatoes 102 and 103 ). The plants inoculated were io to is inches high.

Resull. - None of the plants ever wilted. Slight swelling and discoloration in the pricked area-less than in the preceding.

October 24.-Tomato (2 plants) of the varieties Red Pear and Honor Bright, were inoculated direct from tomato No. Iog, inoculated October $: 1$, which had swollen and discolored at pricked part more than the others

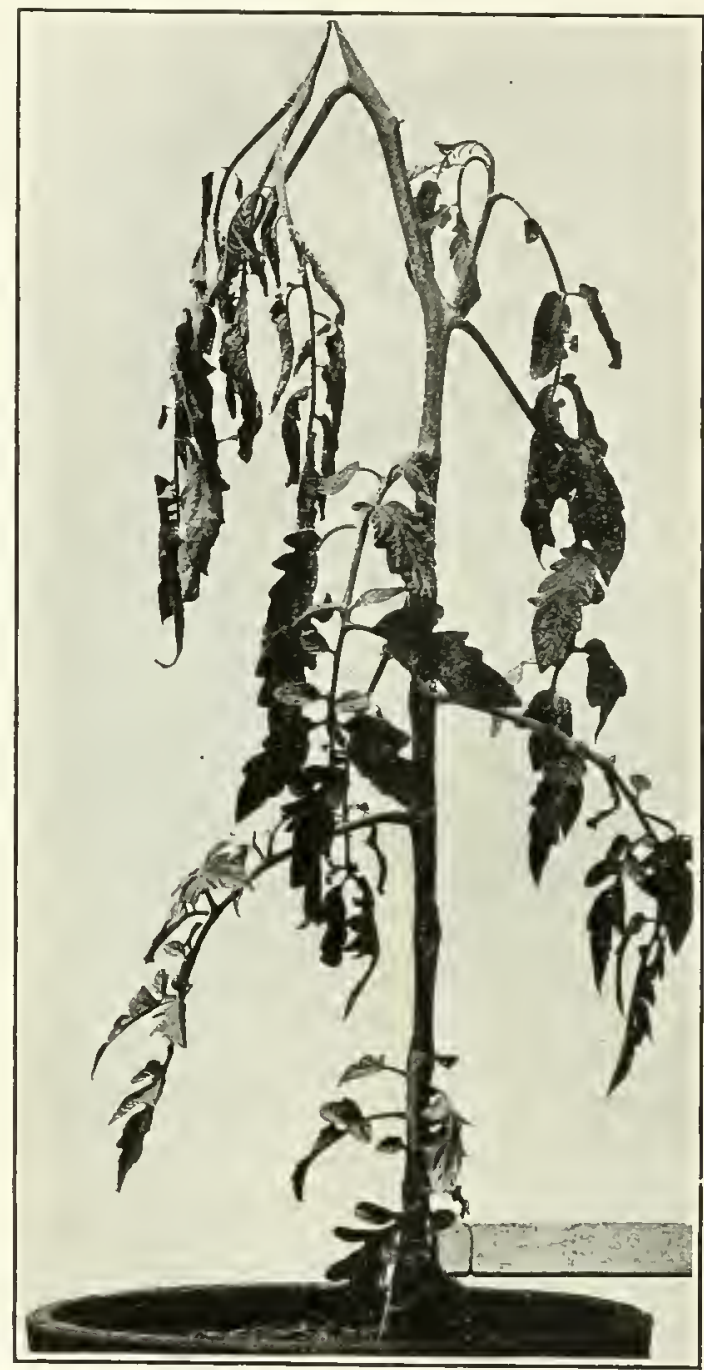

Fig. 96.* (Woodridge, D. C., potato through tomato twice).

Result.-Negative.

October 26 . - Six tomato plants of as many varieties ( 1.5 to 2 feet high, not yet branched) were inoeulated on stems 3 to 6 inches from the top with potato cultures Nos. 2 to 5, Octoher 22, from agar-stabs Nos. 7 to 11, August 26 (IVoodridge, D. C., potato).

Result.-No wilt. The stems became considerably swollen and adventitious roots were formed, but further than this the bacteria had no effect upon the plants.

*Fig. 96. -Tomato-plant inoculated July 7, 1903, with Bacterium solanacearam (South Carolina strain). Photographed July if. Plant"inoculatediby"needle-pricks from a pure culture 5 days old. 


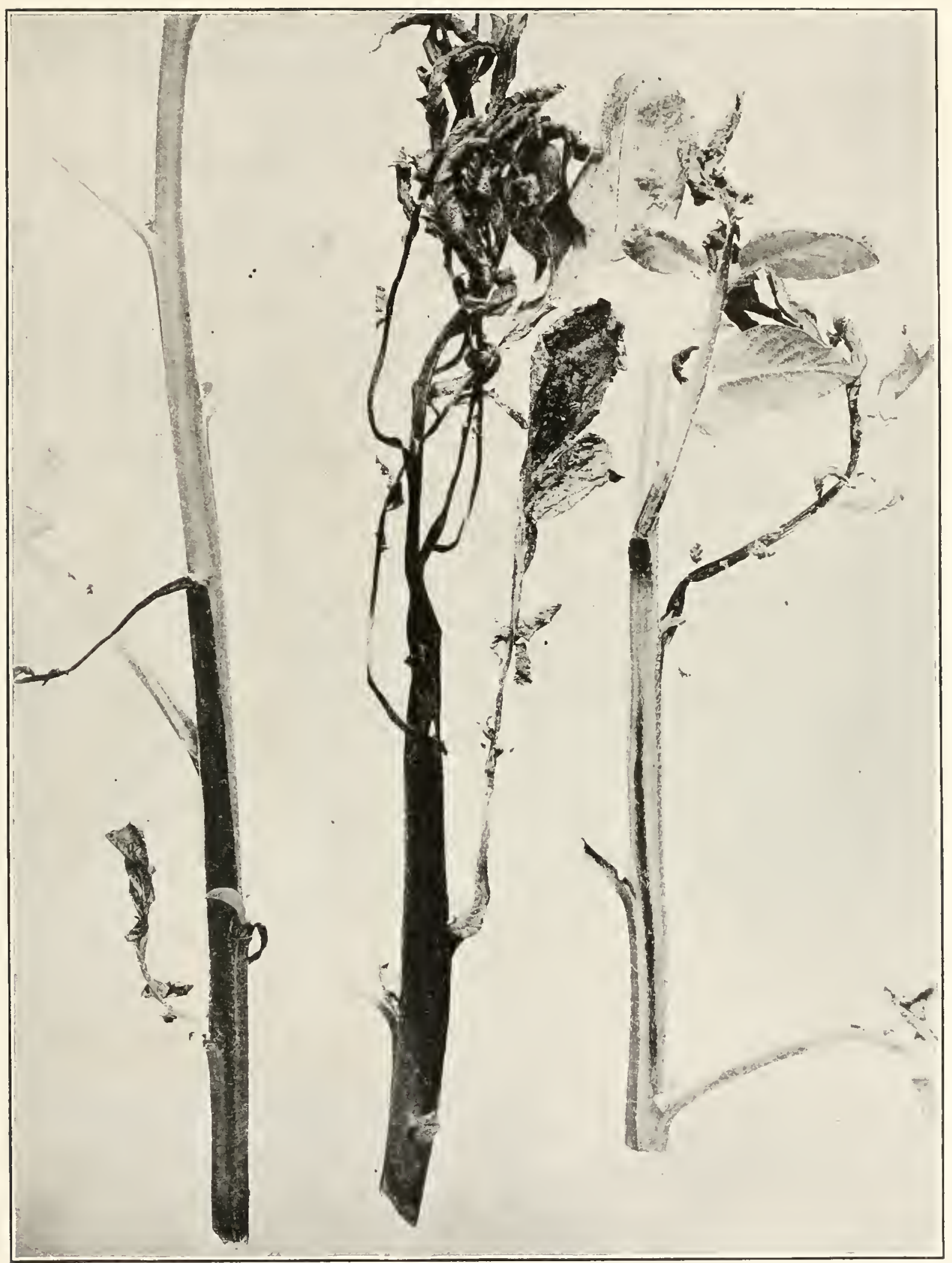

Potato-shoots inoculated by needle-pricks August S, 1904, with a pure culture of Buct. solanuceartm plated from the stem of the Woodridge, D. C., potato shown in plate 30.

Photomaphed Aug. 16. Notice particularly the dark stripes extending down inside the stems. 'The left-hand shoot was pricked in a petiole (the black one at the left midway). The right-hand shoot received one needle-puncture in an upper internode. The tniddle shoot received ro veedle-pricks in an upper internode. 

June 27, 1905.- Potato plants (2 varieties) were inoculated from tubes Nos. 4, 5, 6, June 22, from as many colonies (stem of tomato, Hastings, Florida). Made 85 inoculations on shoots and leaves on 26 plants.

Result. - Positive in part; slow. On July 13 the Blush showed fewer cases than the Early Rose. Plants on this date 2 to 2.5 feet high.

The difference in resistance appeared to be lodged in particular plants. The Blush was more resistant than Early Rose. Each culture was virulent. (See vol. I, plate 24. The source of the culture is there stated to be potato, but the potato organism from Hastings appears to have been tried only on tobacco except as below, unless certain of the notes have been lost.)

July 8.-Eight tobacco plants were inoculated in stem and leaf with potato-cultures A and B, July 6 (from two separate colonies, descended from potato tuber, Hastings, Florida).

Result.-Failure. The experiment was followed until September 6, when 6 plants were examined microscopically. Bacterial multiplication and brown stain slight and confined to pricked parts

July 8.-Thirty-four young tomato plants 12 to 16 inches high were used in this experiment (variety test). Potato cultures A and B, July 6 (from 2 separate colonies descended from potato tuber, Hastings, Florida), were 1 sed.

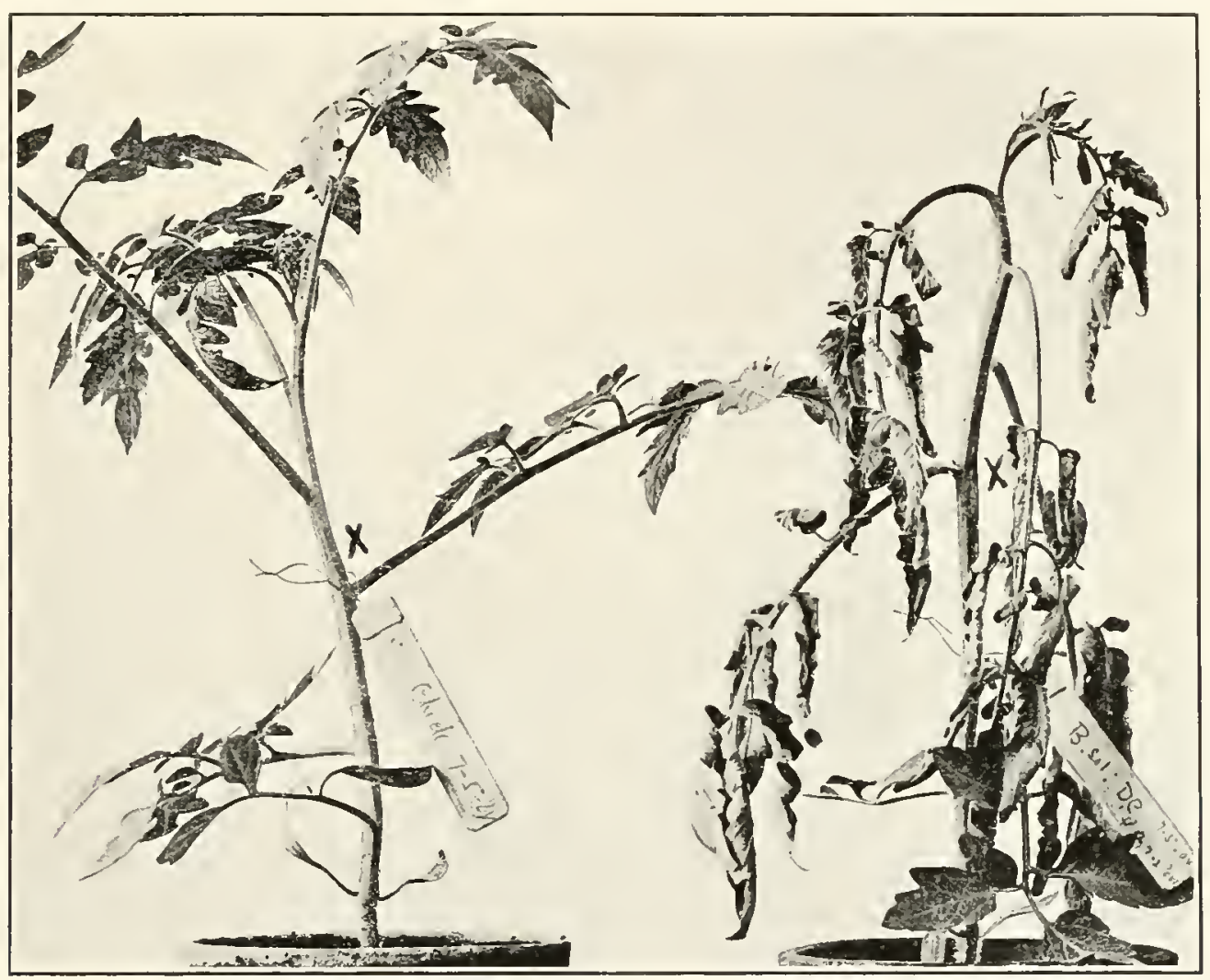

Fig. 97.*

Result.-Most of the plants grew to be 6 to 9 feet long, fruited well, and were alive 4 months after the inoculations. They doubled in size within 6 days after the inoculations, and the inoculated shoots had elongated about I 2 inches. The plants continued to grow rapidly. On July 25 they were 3 times as large as on July 8 . A few cases developed very slowly, most failed, except that the inoculated parts were swollen and browned and adventive roots pushed out. Of many varieties, Livingston's Dwarf Aristocrat was most susceptible In October a plant with large pear-shaped fruits contracted the disease and the hacteria were fonnd filling vessels of stem and branches + feet from the needle-pricks.

September 23.-Tobaceo (2+ large plants) was used for this experiment. The plants were inoculated by needle-pricks in the stem, introducing potato-cultures A to D, September 21 (potato tuber, Hastings, Florida.).

Result.-Slow progress of disease; pith blackened. No distiuct wilt.

September 23. - Tomato plants were inoculated with potato cultures A to D, September 2 i (potato tuber, Hastings, Florida).

Result.-Adventive roots developed and some shoots were swollen and stunted; wilt developed not at all or very slowly. Seplember 30 . - Tomatoes (20 plants, 10 to 12 inches high) were inoculated by needle-pricks with beef-bouillon cultures A to D, September 20 (potato tuber from Hastings, Florida).

Result.-Failure.

${ }^{*}$ FIG. 97.-Tomato plants pricked with a delicate needle at $X, X$ on July 5, 1904. When used on the left-hand plant the needle was sterile, when used on the other (No. 64) it was flamed and then dipped into a 3 -day-old culture of Bacterium solanacearum (District of Columbia strain). Photographed July 8. 
September 30 .- Tobacco (24 plants) was inoculated by needle-pricks with beef-bouillon cultures A to D, Septenber 20 (potato tuber from Hastings, Florida).

Result - Failure.

Orlober 26 . - Tomatoes ( 3 plants about 18 inches high) were inoculated with potato cultures Nos. I and 2, Oetober 20 (growth black on the potato); alive October 23. The organism was not plated out, but descended from potato cultures Nos. 1 and 2, October 19, which were streaked directly from diseased tuber from Portsmonth, Virginia. It was probably the right organism - it showed the typical jet-black grow th on potato.

Result.-Failure.

October 26. - Tobacco plants were inoculated with same cultures used for above.

Result.-Failure.

Oclober 28. - Tobacco plants were inoeulated with potato enltures Nos. 3 and 4 , Oetober 23 (from Portsmontl, Virginia, tuber); alive October 27

Result.-Failure. (For suceessful inoculations on tobaceo see Will Diseases of Tabacco, 13. 227.).

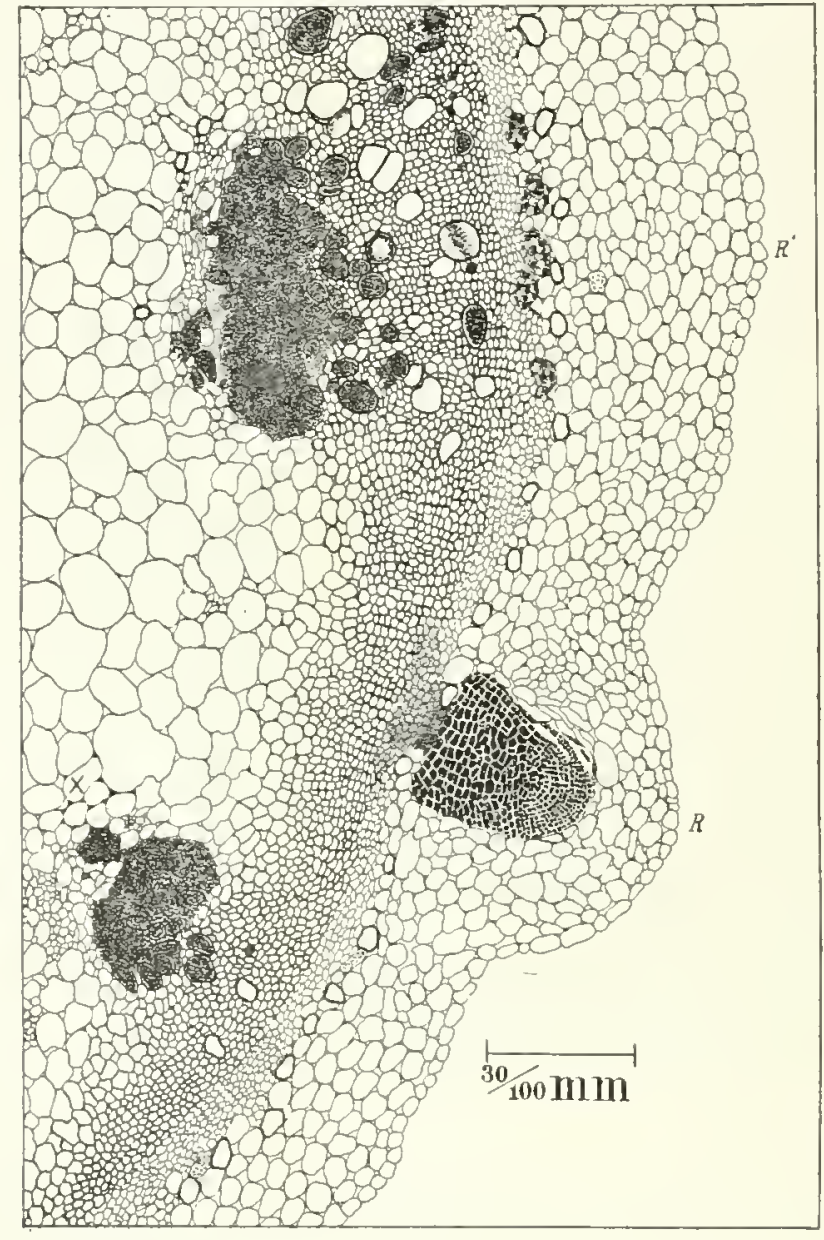

Fig. 98.*

October 30 - - Tomatoes ( 2 vines, 18 inches high), were inoculated with potato culture No. 2, October 23-jet-black (from Portsmonth, Virginia, tuluer).

Resull.-Failure.

November 24 . - Tomatoes (5 vines) were inocnlated with potato eultures Nos. I to 5, November Io, each from a separate colony on plates of Oetober 19 (potato tuber, Portsmonth, Virginia).

Result.-Failure. The cultures were alive; the transfers made from them on date of inoculation grew well.

A single needle-prick introducing into a susceptible plant a small quantity of a virulent culture is sufficient to produce this disease, as shown on plate 31 , right-hand figure.

\section{MORBID ANATOMY.}

The premature and excessive development of roots on tomato shoots as a result of this disease lias been mentioned under "Etiology." For a section through such incipient roots, showing their origin and relation to infected tissues see fig. 98 . An en-

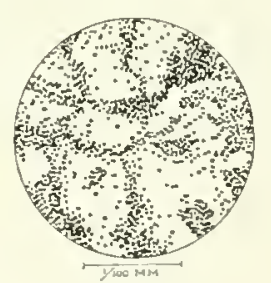

Fig. $99 . \dagger$ larged rew of bacteriafrom this section is shown in fig. 99.

In rapidly fatal cases there are no hyperplasias in connection with this disease other than the adventive roots on

tomato stems, but in stems of tomato and potato inoculated with feebly virulent cultures there may be considerable enlargenent in the vicinity of the punctures. Such stems

*Fir. 98-Cross-section of a small portion of stem of tomato plant (No. 26) inoculated with Bacterium solanacearum on June 8, 1895 , and fixed in strong aleohol on July 3. The figure shows vessels oceupied, the formation of small bacterial cavities, and a well-developed ineipient root $(R)$, the growth of which has been stimulated by the presence of the bacteria at a distance. Several much more rudimentary roots are depicted in the upper portion of the figure $\left(R^{\prime}\right)$. At the left, above the lower eavity, the bacteria fill the intercellular spaces around a few cells $(\mathbf{x})$. The bast fibers are not distinct in the section itself, which was stained with special reference to the bacteria. There are no bacteria immediately under or in the budding root $(R)$. Slide I I (2. For further illustrations of these budding roots see various plates.

fFIG. 99.--Bacterium solunacearum from inoculated tomato plant No. 26, i895. An optical plane from one of the earities shown in fig. 98 . 
frequently attain a diameter twice that of the stem a few inches above or below the prieked area (pls. 28, 29). In sucl enlarged areas there is usnally developed around the punctures a considerable area of protective cork-tissue, and an excessive amount of buncle-tissuc is formed.

'This malady is clifefly a disease of the vascular bundles (figs. $81, S_{4}, 90,100,101,102$, 103), but the organism is not so strictly confined to the bundles as in ease of the wilt of cucurbits and the brown rot of the cabbage. There is, however, the same enormous multiplication of the parasite inside of the vessels. The walls of the vessels are dissolved in their thin places or else are ruptured, and cavities are produced in the surrounding tissues, the bacteria being found in the intercellular spaces but also of ten inside of cells without one's being able to make out clearly how they got there (see vol. II, p. 76). The parenchyma, especially in soft parts, such as the pitl of young potato shoots and tomato shoots, succumbs quite readily, a large port ion of the interior of such stems breaking down into a soft, wet rot which sometimes oozes through to the surface. The bacteria first invade the intercellular spaces, which are generally occupicd quite fully in advance of the complete destruction of the cells. The middle lamella is then dissolved. The separated cells are squeezed into a variety of slrapes by the multiplication of the bacteria and finally are crowded aside altogether, leaving behind cavities partly or fully occupied by the parasite (figs. S6, S8, 91, 93, 98). In woody parts stich as stems of old potato plants or tomato plants, and of wellgrown egg-plants, there is

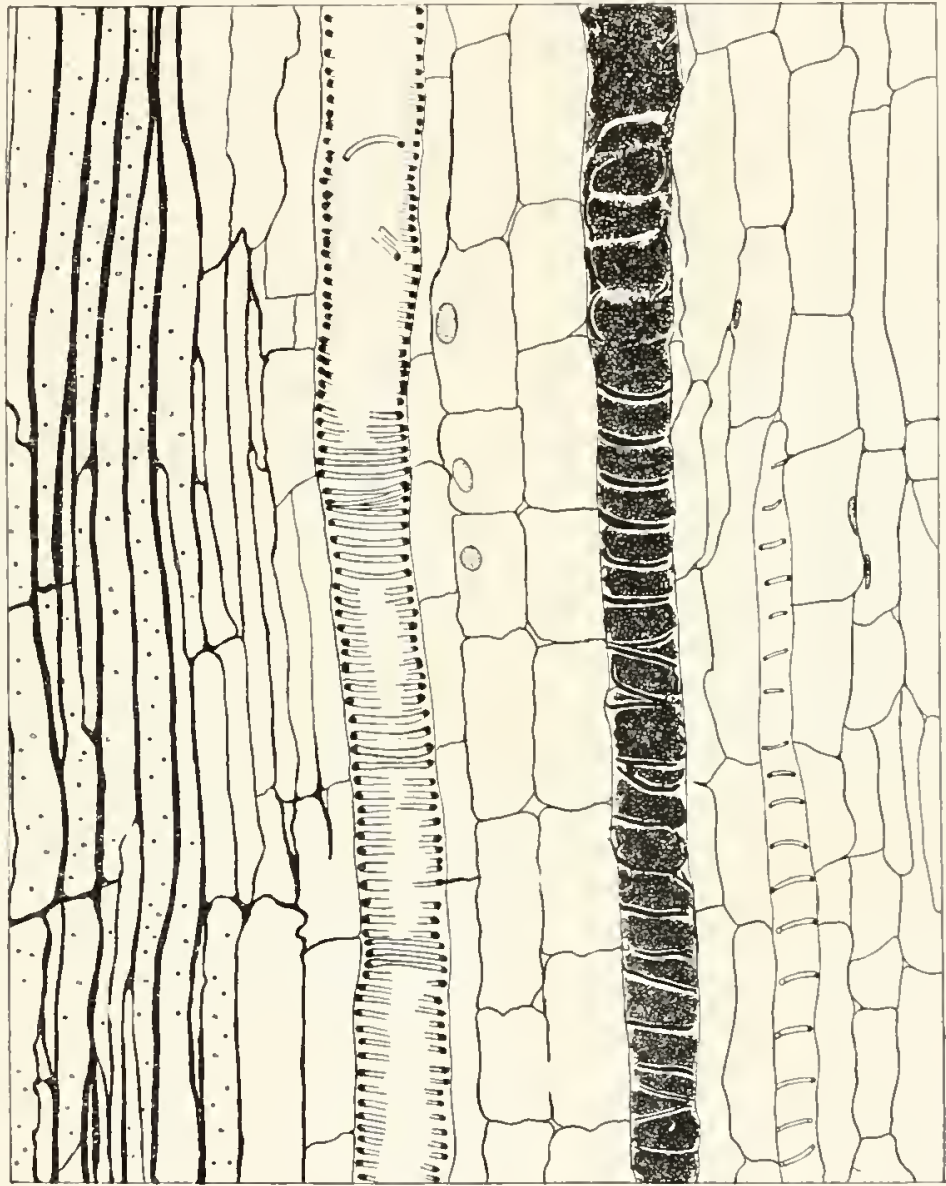

Fig. 100.* usually a marked browning of the lignified tissues and an enormous multiplication of the bacteria in the vessels and the adjacent parts, but there is no such general collapse as in case of soft stems. Lignified tissues are not dissolved. In the potato tuber, brown-walled cavities beginning in the rudimentary vascular tissue are numerous. These cavities, which are full of bacteria and remnants of the broken-down tissue, gradually enlarge and coalesce until all of this part of the tuber is involved. Subsequently they reach the surface (pl. 23, portions of figs. S and ro) and open up the tuber to all sorts of external destructive agents. The starch in the

*FIG. Ioo-Longitudinal section of a potato stem, No. 5. I $\$ 96$, inoculated June I, collected June I I, showing Bacterium solanacearum restricted to a single spiral vessel. Drawn from a photomicrograph. The fibers at the left polarize in the same way as the spiral thickenings. Slide 138 , Vernier readings on Zeiss plotomicrographic stand I3.4 X2.0. Stained with carbol-fuchsin and washed in 50 per cent alcohol. $\times 2$ Io. 
tubers resists well and appears to be but slowly acted upon by this organism (figs. Io4, 105, 106). In young tubers, however, such as that one shown in figs. 83, 107, 108, there may be considerable areas of the starch-bearing tissue in which no starch occurs. These are most extensive on that side of the tuber longest occupied by the bacteria, and the only explanations which seem to fit the case are that (I) the potato plant has withdrawn the starch preparatory to the formation of a cork-barrier as Appel has described for $B$. phytophthorus in potato, or that (2) excreted products of the bacteria (enzymes or other substances) have killed these cells or lave so paralyzed their activities that the plant has not been able to make use of them for the storage of starch. A very little is sometimes found (figs. 105, 106). That the starch was once stored and then dissolved by diastasic aetion of the bacteria is contrary to all that we know of its behavior, both in vitro and in older tubers.

In the inoculated plants of the Jamestown weed (fig. 88), of the black nightshade (fig. 91), and Physalis philadelphica (fig. 94), there was the same enormous multiplication of the bacteria in the vascular system, even at long distances from the point of inoculation, and the tissues were destroyed in the same way, with the formation of extensive bacterial cavities.

Several observers have reported finding an excess of crystal-sand in plants attacked by this organism. This substance occupies particular cells and consists of numerous discrete tetrahedral crystals of calcium oxalate (fig. SS). It occurs naturally in a large part of the Solanaceac, the amount varying with particular organs and with the age of the parts; it is, therefore, not easy to deternine whether there is an excess of it in cliseased tissues, but there seems to be. In most of the drawings crystal-cells are depicted diagrammatically by minute arrow-marks $(<<)$.

In the Solanaccac we

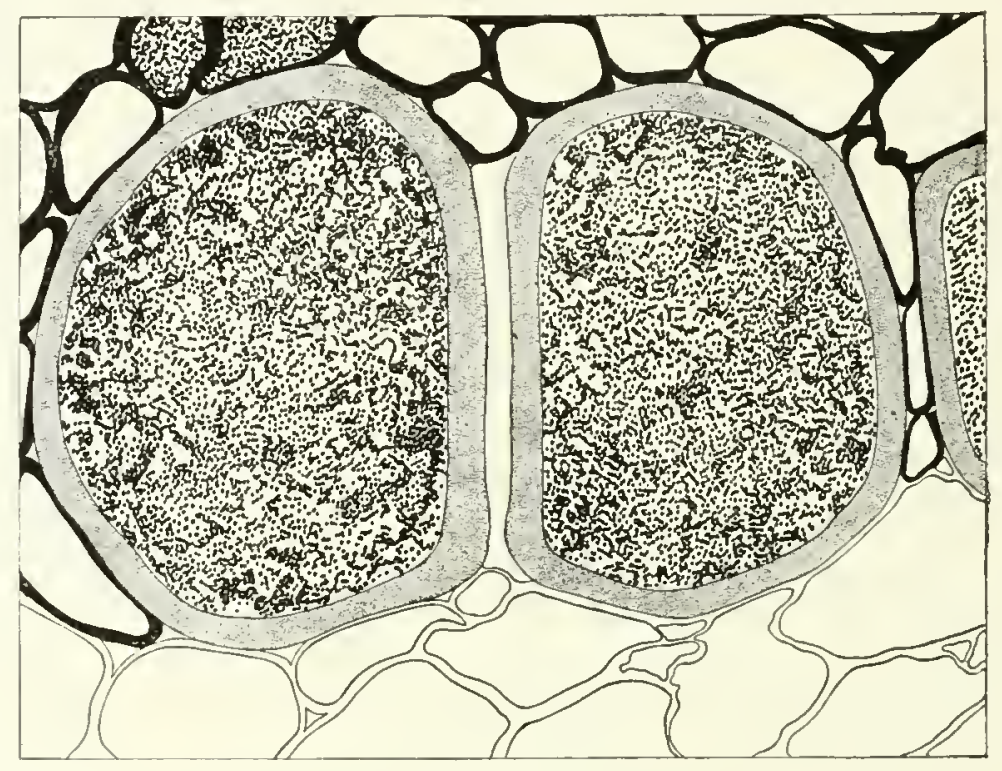

Fig. 101,* have a bicollateral bundle, the two phloems being flanked or subtended by thick-walled bast-fibers, as shown very clearly in the cross-section of a potato-rhizome (fig. 84 ). In the plants which I have exanined there is also usually a large pitl and considerable subepidermal collenchymatic tissue, which is usually somewhat shrunken and torn on fixing in alcohol and does not always show distinctly as collenchyma in the accompanying drawings, but may be seen very clearly in the cross-section of a potato petiole shown in fig. 95 . Both phloems are frequently invaded by the bacteria and numerous cavities are produced in this tissuc, as shown in the figures already referred to. In later stages of the disease, cavities are also common in the bark-parenchyma and in the pith. Indeed, the disorganization lias proceeded very far in sucli stems as that shown in cross-section in fig. I of vol. II.

${ }^{*}$ FIG. 101 . - Cross-section of small part of same potato stem as fig. 86 , showing vessels occupied by Bacterium solanacearum, and surrounding tissues mostly free, except as they have flooded out of the vessels during the preparation of the section. These latter bacteria occur only on under side of section and are omitted from the drawing. Drawn from a photomicrograph by the writer. Section stained with carbol-fuchsin and differentiated in 50 per cent alcohol. The lignified connective tisstle is represented by solid black walls and that of the vessels by fine dots. $\times$ Soo. Slide $I 7 \mathrm{I}$. 


\section{THE PARASITE.}

Bacterium solanaccarm EFS.* is a medium-sized rod with rounded ends. It 1nultiplies by fission. It often occurs in pairs with a plain constriction (fig. rog). It is usually I.5 to 3 tines as long as broad. When crowded in the plant it may be so sliort as to somewhat resentble a micrococcus. It stains readily. When taken from young cultures in peptonized beef-bouillon and stained with methyl violet many of the rods are $1.5 \mu$ by $0.5 \mu$. Longer and slorter rods oceur and thicker and thinner ones, the measurements depending to a considerable extent upon the age of the culture and the kind of stain employed (fig. rog). It is motile at times both in the plant and in cultures, and is often very actively so in young cultures. Owing to imperfect preparations it was at first supposed that the flagella were peripheral, but further studies of these slides and of others subsequently prepared indicate that the organism is usually motile by means of a single polar flagellu11, which is much longer than the rod (fig. rog). Pseudozoogloeæ are common in fluid cultures and inclined to accumulate in the upper layers. Spores have not been observed. I,ong chains and filaments have not been observed. On August 8, 1904 , two 3-111m. loops of

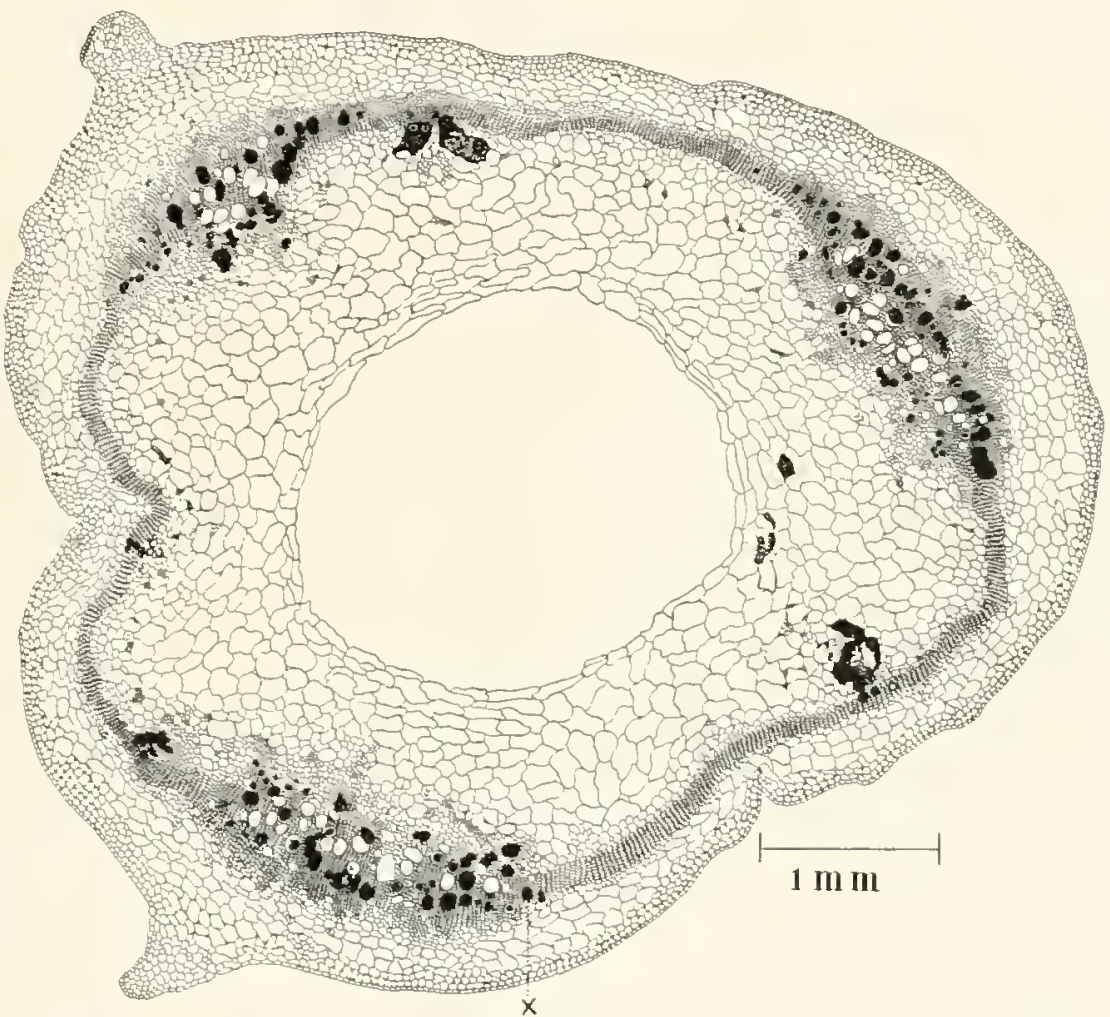

Fig. 102. $\dagger$ the District of Columbia organism taken from a slant potato-agar culture 3 days old (tube 2, Aug. 5) were put into 15 c.c. of sterile water, and then the faintly clouded fluid was studied in a hanging drop under high powers of the microscope. The organism was actively motile. It was a short rod, single or in pairs, rarely in fours, the doublets witl a plain constriction in the middle. The length of each element of the doublet was not more than 1.5 to r.8 times its breadth. In old potato cultures examined in 1904 , the organism was a short rod with rounded ends, single or in pairs, with a plain constriction. Involution forms were not

*Syn. Bacillus solanacearum EFS.; Pseudomonas solanacearum EFS.

$\nmid$ Fig. 102.-Cross-section of stem of potato (No. 5, 1896) inoculated with Bact. solanacearum June 1 ; fixed in aleohol June 11 , after being badly wilted for 3 days. The culture used was a tube of peptone-water inoculated directly from the interior of an egg-plant stem. The heavily shaded parts are the ones oecupied by the bacteria. There are 16 crystal-cells marked by arrow heads (use lens). The parts of the stem not heavily sladed are frce from the bacteria, viz, all the lark, most of the pith, and considerable portions of the woody ring. Slide i66(2. Figure somewhat diagrammatic, especially in the collenchyma and phloem. Compare with fig. 1 , vol. II, which shows cross-seetion of a potato stem in a later stage of the disease. The ressel at $\mathbf{X}$ is shown highly magnified in fig. 103. 
observed. This has been the general form of the organism seen nearly every summer since 1895 in tomato stems and potato stems colleeted in various southern States, and in eultures made therefrom. In glycocoll solutions Honing has seen involution forms (p. 253).

This organism is often not so pure a white as Bacillus amyloworus or Bacillus tracheiphilus. In the host plant and on certain media it may be described as pure white at first, but soon grayish- hite, dirty white, or brownish-white, becoming brown, since it produces a soluble brown pignent which modifies its appearance. On steamed potatoes this stain is usually developed to such an extent that the eultures soon become brown or even nearly black ( 3 to ro days); the water also is browned around potato cylinders. This pigment, which is produced in the dark as well as in the light and which on potato is not infrequentiy as black as tar (pl. 23, figs. 8, 10, and pl. 4I, fig. 4), is soluble in water and glycerin and slightly in methyl alcohol on long standing; it is insoluble in ethyl alcohol (exp. I $\left.896,1905^{*}\right)$, ether, chloroform, xylol, and earbon bisulphide. The browning did not ocenr in the absence of sugar and alkali. The pigment is not destroyed by weak acids or alkalies. It behaves in some respeets like a humous compound, $i . \epsilon$., it does not dialize readily and is preeipitated by compounds of iron and caleium.

This organism grows well in peptonized beef-botnillon, with or withont the addition of sodium carbonate, and yields much more precipitate than similar eultures of $B$. tracheiphilus; a brown stain appears, and this was especially noticeable in ease alkali was added; tendency to form pellicle rather slight. Old peptonewater etiltures do not brown. In $+\mathbf{I} 5$ peptonized beef-bouillon the District of Columbia organism at the end of 20 days showed good clouding with an enormous number of small psendozoogloex, but with 110 rim or pellicle; the dirty white or pale brownish precipitate covered a breadth of $13 \mathrm{~mm}$. on the bottom of the test-tube. In Dunham's solution cultures of the

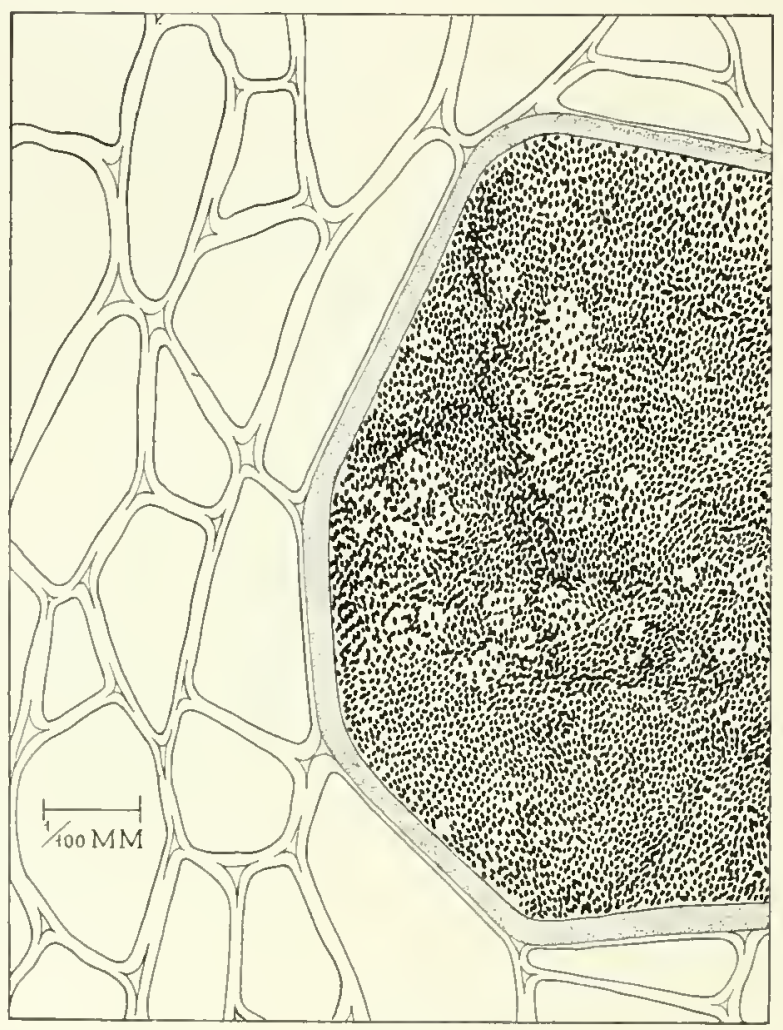

Fig $103 . \dagger$ same age were well clouded, but less so than the bouillons, with only about half as muel of the dirty white precipitate.

Cultivated in milk there is no precipitation of the easein, but after about 3 to 7 weeks the fluid becomes transparent (fig. I IO, A). Milk was intensely alkaline to litmus paper as early as the twentieth day. The organism is able to live in milk for at least 48 days. The easein of the transparent milk is thrown down by hydrochlorie acid (1896, repeated in 1905 ), and by strong solutions of sodium chloride or copper sulphate. In litmus milk no aeid is developed, but after 2 or 3 days the fluid becomes slightly bluer, and this alkalinity increases gradually from day to day until the milk is an intense deep blue. On the twenty-eighth

*Bad. solanacearum (District of Columbia strain) in gelatin-stab. On adding water to the alcohol the pigment was slowly soluble.

$\dagger$ IG. 103.- Cross-section of a very small portion of a potato-stem (a detail from fig. 102), showing a singte vessel occupied by Bacterimm solanacearmm, the surrounding tissue being free from the bacteria. The lignified wall of the vessel is indicated by fine dots. Slide $166(2$. Zeiss photomicrographic stand, vernier readings $14.7 \times 2.8$. Plant inoculated with pure peptone-water culture made direct from the interior of a diseased egg-plant. 
day such milk was approximately Ridgway's indigo blue; after 3 montlss it was dark hyacinth blue (pl. 23, fig. 7); but the fltid was neither viseid nor gelatinous. Litmus in milk is sometimes a little reduced (white) in the bottom of the tubes. The bacterial precipitate is white. In another set of tubes of litmus milk examined at the end of the serenth week the color was recorded as a clear intensely dark blue. All these milks were cream-free.

Litmus-lactose-agar streaked with this organism becomes slowly a deeper blue. There is never any reddening, but sometimes the litmus is partially reduced and the agar finally browns. The behavior in cream-free litmus milk is like that of the culture figured on pl. 4 . The streak of the District of Columbia organism on slant litmus-lactose-agar after 1o days at about $27^{\circ} \mathrm{C}$. was wlite, wet-shining, and there was a copious whitish preeipitate in the $\mathrm{I}$; the upper half of the agar was blued very deeidedly, in the lower half the litmus was reduced. The strfface of the slant beyond the streak was iridescent. The agar was not then browned, but later (seventh week) it was browned decidedly and the surface growtl was a dirty brownish-white; the extrene upper part of the agar continited bluer than the cheek-tube, but in the lower part the formation of the alkali was masked by the brown stain and the reduction processes.

The organism does not liquef y gelatin (experiments of 1 S95-96, repeated in 1904 and in 1905 ), at least not when made as deseribed in vol. I of this monograph. The surface colonies in gelatin are small, circular, thin, thin-edged, smooth, wlite, wet-shining; the buried colonies are globose, yellowish or brownish, and smooth, with welldefined margins. In stab-cultures (fig. III) the upper part is best developed, but growtli was not rapid at $24^{\circ} \mathrm{C}$. and ceased at $10^{\circ} \mathrm{C}$. The Virginia organism grown in gelatin-

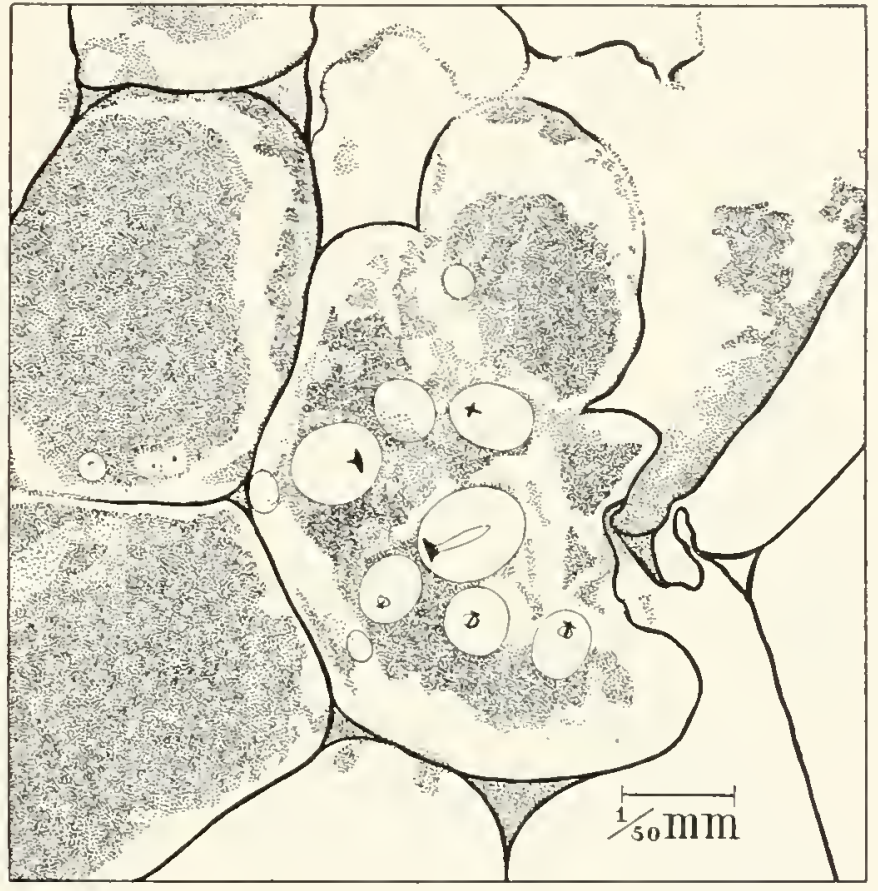

Fig. 104.* stabs for 7 days at $22^{\circ}$ to $25^{\circ} \mathrm{C}$, and then 2 days at $15^{\circ} \mathrm{C}$, developed a thin, white, wetshining surface growth which was roundish and about 3 to $4 \mathrm{~mm}$. in diameter. Growth was visible the whole lengtl of the stab, but was best at the top. There was no stain, no gas, no liquefaction, no development of erystals. The District of Coltumbia organism grown for 10 days in gelatin-stabs at $25^{\circ} \mathrm{C}$. was similar in all respects to the above. The + io gelatin in old cultures becones dusky or browned, especially in the upper part of the stab.

In agar the buried colonies remained small and were irregularly round or oblong, with a roughened margin. The surface growth was white or gray-white at first, then brownish. The general form of the surface colonies after some days on $+I_{5}$ nutrient agar at $25^{\circ} \mathrm{C}$. is shown in figs. 112, 113. As a rule the agar was stained brown by growing this organism on it (pl. 23, fig. 2, and pl. 4r, fig. 8, from tobacco, will answer for potato and tomato).

In thin sowings on peptonized beef agar the organism fron the South Carolina tomato, used for successful inoculations in 1901 , formed colonies about 2 to 3 mm. in diameter at the

*FIG. so4.-Cross-section of a few cells of a potato tuber rotted by Bacterium solanacearum. Plant No. If, I896, inoculated June ${ }_{5}$. A detail from fig. 82 made under $x$, showing cells occupied by the bacteria. The starch-grains which lie buried in the bacterial mass appear to be uncorroded; they polarize, but 1 was unable to detcet any rings of light and dark substance in them. Section stained with carbol-fuchsin. Drawn with the Abbe camera. Slide I56(2. 
end of a week (temperature $28^{\circ} \mathrm{C}$.). These were circular, white, and wet-shining, and 9 days later they were brownish and the agar was also browned. They did not enlarge greatly after the first 10 days. On steamed potato this organism was white at first, then a dirty yellowish-white, and finally brown or even nearly black,

The poorest agar-streaks, with perhaps one exception, were on alkaline agar containing 6 per cent glycerin. In agar-stabs the growth was best on the surface and in the upper part of the needle-track.

No gas-bubbles or acid reactions were observed as the result of cultivation in any of the ordinary culture-media, but in each case there was a gradually increasing alkalinity. Grown in fermentation-tubes in 2 per cent alkaline peptone-water with addition of grape-sugar, fruit-sugar, canesugar, milk-sugar, galactose, maltose, or dextrine, there was no gas production, no detected acid development, and no clouding of the

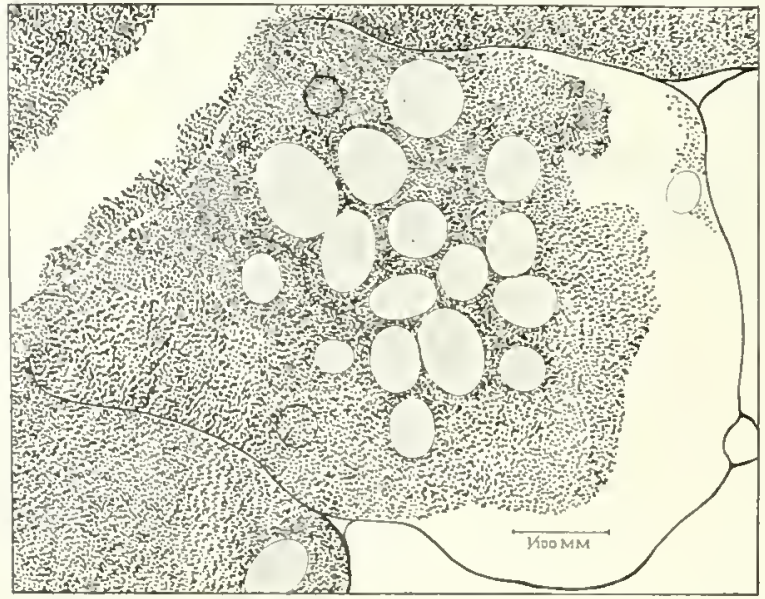

Fig. 106.†

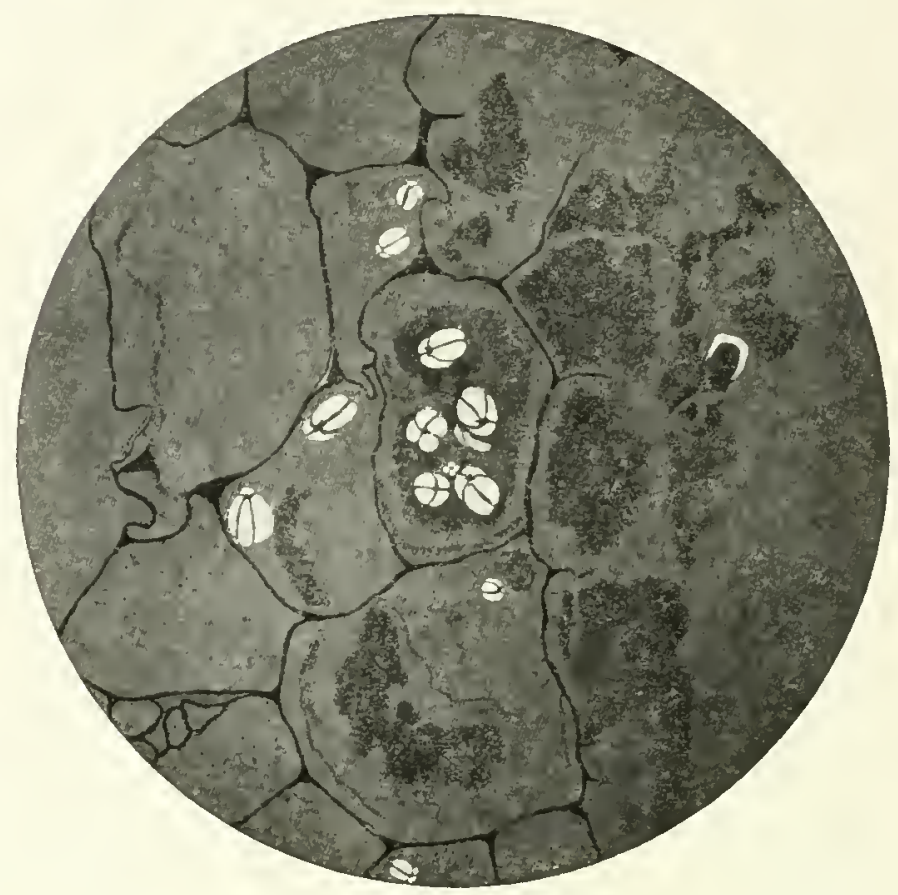

Fig. 105.*

closed end of the tubes. 'The same result was obtained with the juice of potato tubers diluted with water and sterilized in fermentation-tubes ( 1909 organism from tobacco). Culture-fluids containing grapesugar, fruit-sugar, and cane-sugar browned decidedly after some weeks. In 1904, using the District of Columbia organism, clouding was heaviest with cane-sugar. All of the writer's numerous experiments go to show that Bacterium solanacearmm is a strict aerobe (the fermentation-tube experiments were repeated with the same results in 1904). If it is ever capable of growing in the absence of air we do not know on what media or under what eircumstances. All of the common media have been tried and in all of then it requires free oxygen for respiration.

*FIG. I05. - Border of a small cavity in the vascular region of a potato tuber attacked by Barterium solanacearum showing 7 uncorroded stareh-grains lying in one cell embedded in a mass of bacteria. Slide 156(3. Vernier readings on Zeiss photomicrographic stand, $12.5 \times 8.1$. Plant No. If, 1896, inoculated on the stem June I5. Draw1 by polarized light. The dark patches are masses of bacteria.

†FIG. 106 . - Detail from fig. 83 at $x$, showing uncorroded starch-grains embedded in a cell occupied by Bacterium solanacearum. The dotted parts of the starch-grains are the only ones stained by the carbol-fuchsin. Light and dark rings can not be made out in these grains, but they polarize the same as grains in the middle of the tuber, remote from the bacteria. Drawn with $2 \mathrm{~mm}$. 1.30 n. a. Zeiss apochromatic objective, 12 compensating ocular and Abbe camera, Slide $3+9$ (15. 
The organism is not sticky, or only slightly so occasionally on agar, and diffuses out of the vessels of the host-plants readily in 75 per cent alcohol, but not, according to Hunger, when I per cent nitric acid is added to the alcohol. It possesses a decided odor when growing on potato, i.e., a snell like that of some rotting potatoes, and likened by one person to the odor of sour bran. The starch of steamed potatoes is not destroyed to any great extent, but a little of it is converted into amylodextrine, $i$. c., yields a red reaction with iodine. There was no growth, or very slight, in Cohn's soltttion; very little growth appeared on silicate jelly (with Fermi's solution) at the end of 6 days. The

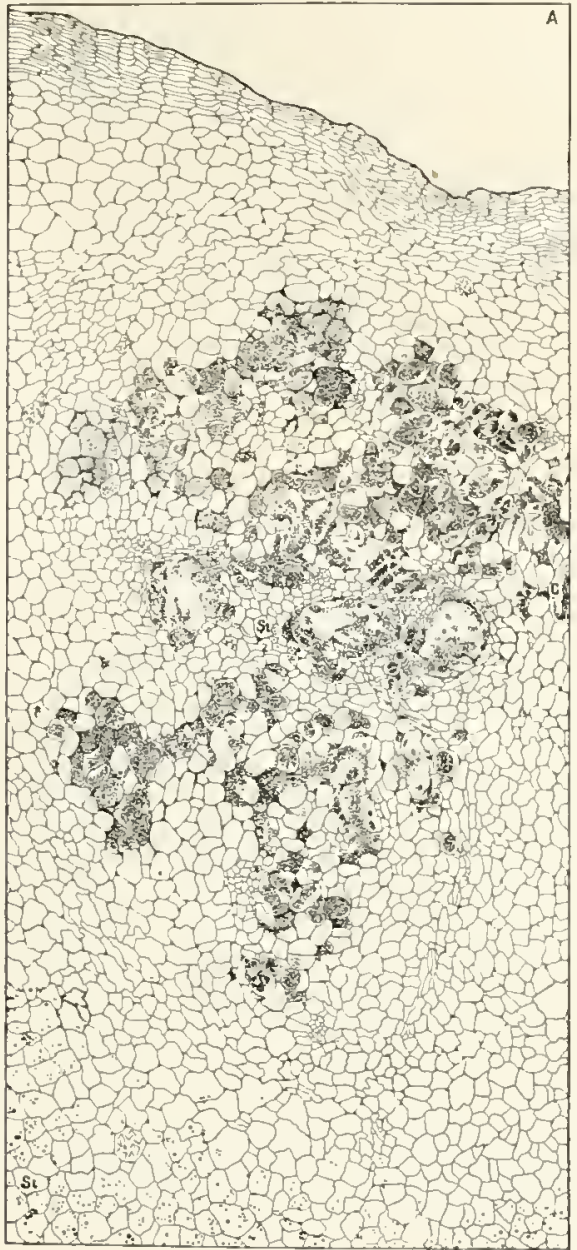

Fig. 107.*

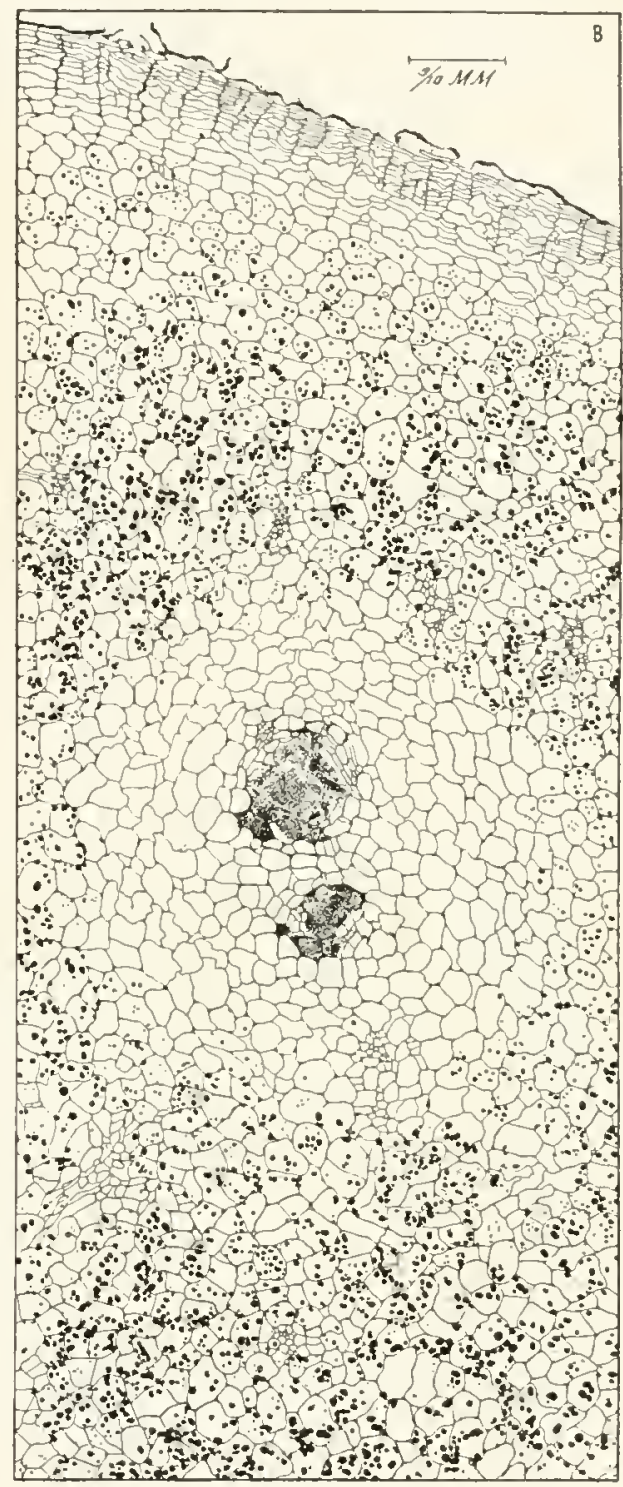

Fig. 108.†

${ }^{*}$ Fig. 107.-Portsmouth, Virgiuia, potato tuber. A detail from fig. $8_{3}$ at $A$, showing more extensive bacterial occupation than in fig. 83 at $B$, and complete absence of starch on the periphery. A few stareh-grains occur inside of cells at $S t$. (center). Only four cells containing crystal-sand are present. Cavities have begun to form and additional ones are present beyond $C$ (right margin), where also are a few cells containing starch-grains (see fig. 106). In various places, as at $X$ (use lens), some change has taken place in the walls of the cells and they are made out with difficulty In other places, as on the left side, cells which appear to have unbroken walls are oceupied by the bacteria. The walls of the cells destitute of starch seem to take the stain somewhat heavier than those of cells in which it is present. Camera drawn, but slightly diagrammatic. Slide 349 (I 5 .

FFIG. 108.-A detail from fig. 83 at $B$, showing character of the tissues and absence of the starch in the vicinity of the bacterial foci (at the center). Tissues fixed in Carnoy's solution. Camera drawn, but slightly diagrammatic $i$. $\epsilon$, it is probable if the slide were taken and compared cell by cell with the drawing, some omissions and some erroneous lines would be detected. 
organism reduces potassium nitrate to nitrite in bouillon; does not produce indol in peptone-water; and does not stain by Gram's method, i. c., is only slightly blue after wasling (diaphragm wide open).

Cultures were easily obtained from a bouillon-culture after exposing it for 20 minutes to minus $77^{\circ} \mathrm{C}$., but quantitative experiments with liquid air show that a large proportion of the rods are killed by a single freezing ( $\mathrm{pl} .32$ ). The minimum temperature for growth is about $10^{\circ} \mathrm{C}$; optimum temperature $35^{\circ}$ to $37^{\circ} \mathrm{C}$. (?); maximum temperature 11 ot determined (about $41^{\circ} \mathrm{C} .^{*}$ ); the thermal death-point (South Carolina organism, I 896 ) is above $51^{\circ} \mathrm{C}$. and below $53^{\circ} \mathrm{C}$, being probably about $52^{\circ} \mathrm{C}$. In $190+$ all 10 -minute exposures of the District of Columbia organism at $52^{\circ} \mathrm{C}$. remained sterile but not those at $51^{\circ} \mathrm{C}$. The organism grew readily and for a long time in the thermostat at $37^{\circ} \mathrm{C}$., i. e., in peptonized beef-bouillon held at $37^{\circ} \mathrm{C}$. the South Carolina organism was alive in one test after 3 weeks' exposure, and in another after 7 weeks' exposure. At $38^{\circ}$ to $40^{\circ} \mathrm{C}$. the District of Columbia organism
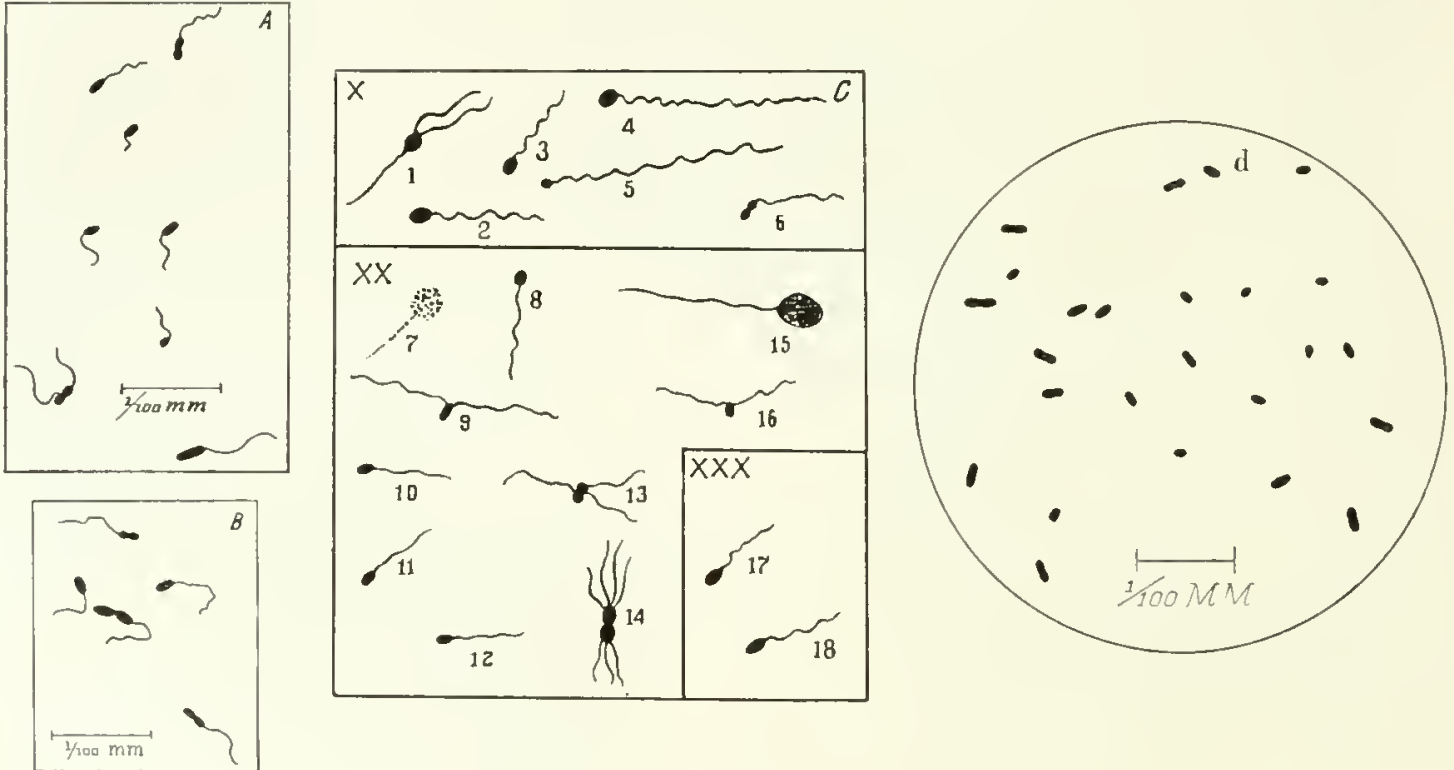

Fig. 109.

clouded +15 peptonized beef-bouillon in 48 hours and grew well, but not so freely as at room temperature. After 10 days' exposure in the thermostat at this temperature, streaks to slant agar gave only a discrete growth (separate colonies), indicating that the cloudy bouillon was then only thinly occupied by living bacteria. It also lives for a considerable time in peptone-water and in bouillon at $20^{\circ}$ to $25^{\circ} \mathrm{C}$. This bacterium does not live for many weeks

*Exposed in Feb. 1904 in the thermostat at $39.4^{\circ} \mathrm{C}$. the Virginia organism clonded peptonized beef-houillon of the following reactions: $+25,+15,0$, and refused to cloud -20 bouillon, Dunham's solution, or Uschinsky's solution. The experiment was twice repeated with the same results.

†Fig. Iog-(A) Bacterium solanacearum (District of Columbia strain). From a slide (2a) of August 9, igos. Flagella stained by Löwit's method. (B) Bact. solonacearum (D. C. strain) showing flagella stained by van Ërmengem's

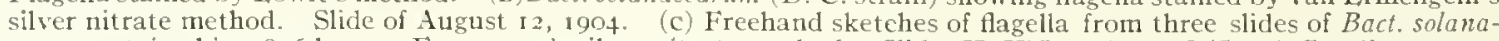
cearm, stained in 1896 by van Ermengem's silver nitrate method. Slides X, XX, and XXX (South Carolina organism, No. XXX taken from inoculated Physalis No. 57, the others from cultures). The numbers correspond to the following vernier-readings on Zeiss photomicrographic stand 32532 used by the writer: (1) $12.8 \times 5.35 ;(2) 12.2 \times 6.8+$; (3) $14.4 \times 7.3 ;$ (4) $20.1 \times 7.3 ;(5) 20+\times 7.2 ;(6) 18.5 \times 7.15 ;(7) 13.6 \times 5.6 ;(8) 20 \times 5 ;$ (9) $19.3 \times 6.75 ;(10)$ I $8 \times 4.4 ;(11)$ $17.3 \times 0.9$; (12) $15.4 \times 6.6$; (13) $16.1 \times 6.9$; (14) $15.6 \times 5.75$; (15) $13.8 \times 5.6$ artefact (?); (16) $16.35 \times 1$ I .35 ; (1 7 and 18 ) 14.1 $7 \times 6.35$. Numerous flagellate rods are visible on slide XXX at I. I $7 \times 6.35$ and all seem to be one-flagellate, but it requires a high nower and a bright light to make them out as all are feebly stained: One might also add, keen eyesight. (d) Cover-glass preparation of Bact. solanacearum (D. C. strain) stained August 12, ig04, by van Ermengem's method from a young agar culture. Flagella wanting or not visible. This organism was extremely pathogenic at first (see pls. 30, 31 , and vol. I, pl. 26), but afterwards lost much of its virulence. The bacteria are thicker than when stained without mordanting. 

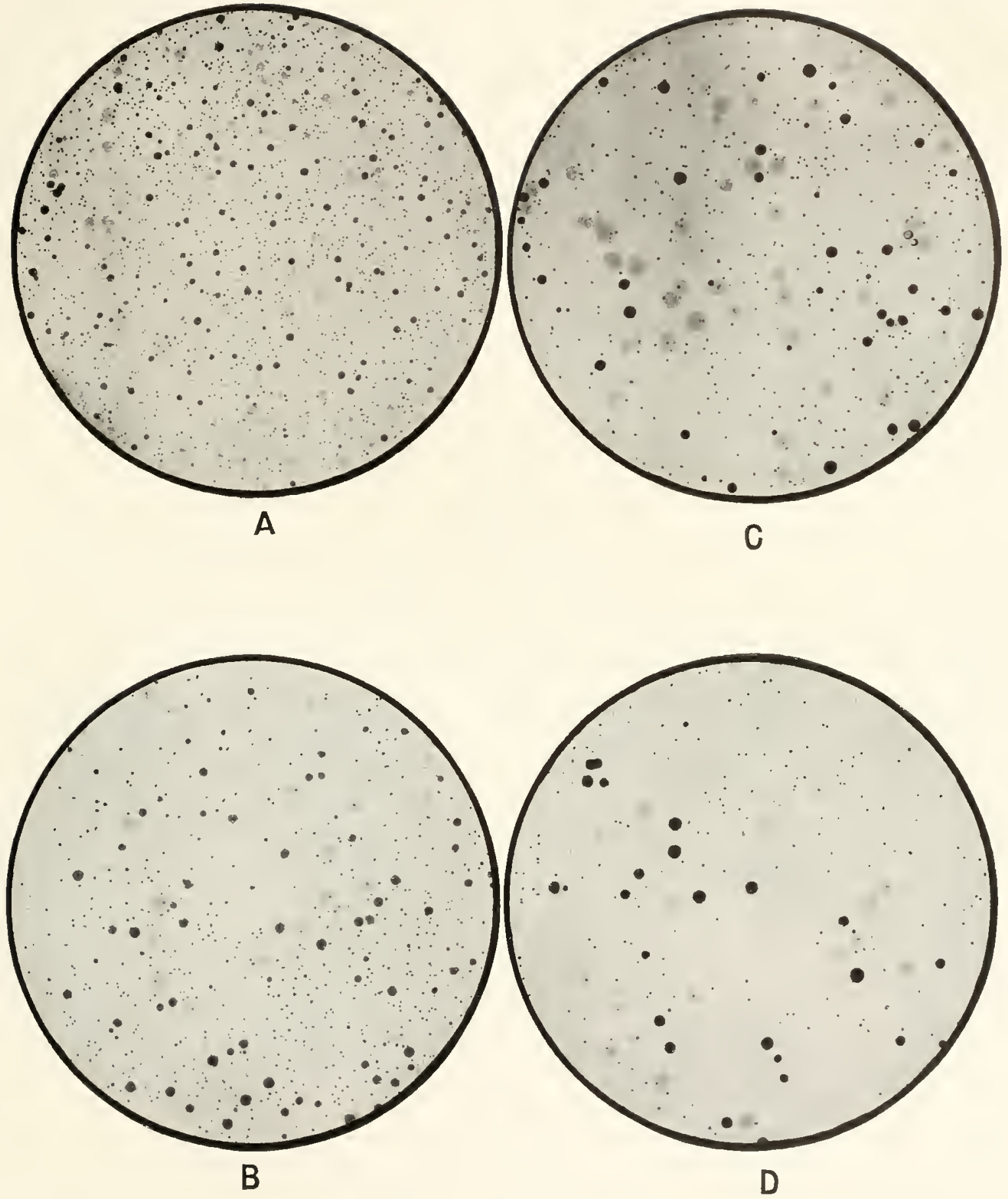

Four Petri-dish poured-plates of Baclerium solanacearum (Virginia strain), showing the effect of freezing. $A$ and $B$. plates poured before freesing; $C$ and $D$, corresponding plates inoculated witis the sanie carefully measured a mount of the

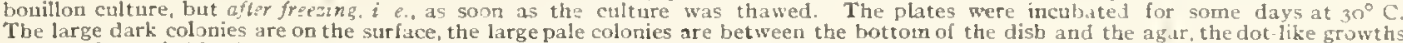
are colonies buried in the body of tbe agar. Photographed Feb. 20, 190. 

in steamed potato cultures, especially if the brown stain is well developed, and the wellbrowned colonies on agar are usinally dead. Two weeks is about the linit of vitality on cooked potato; sometines cultures were dead at the end of one week. An actively motile bonillon-culture frozen in liquid air for 20 hours was still motile upon thawing ont. Examined in a hanging drop within 20 minutes htndreds of the rods were active. This was not a Brownian movement, but a rapid darting motion which often carried the rods out of the field. However, a distinctly less number seemed motile than before the exposure and poured plates (Virginia organism1) demonstrated 50 per cent to be dead.

The organism grew well in acid bouillon $(+33$, acid of beef juice $)$, but less rapidly at first than in nitrate bouillon $(+15)$. After 3 months the bouillon was stained brownish. There was then an interrupted, dirty, gray-white pellicle, a dirty, brownish-white precipitate, and numerous small crystals. The Virginia organism did not grow well on $\mathrm{No} .602$, a rather acid agar made from the juice of sugar-beets diluted with water. The Virginia organism after growing in peptonized Uschinsky's solution for from 9 to 14 days had

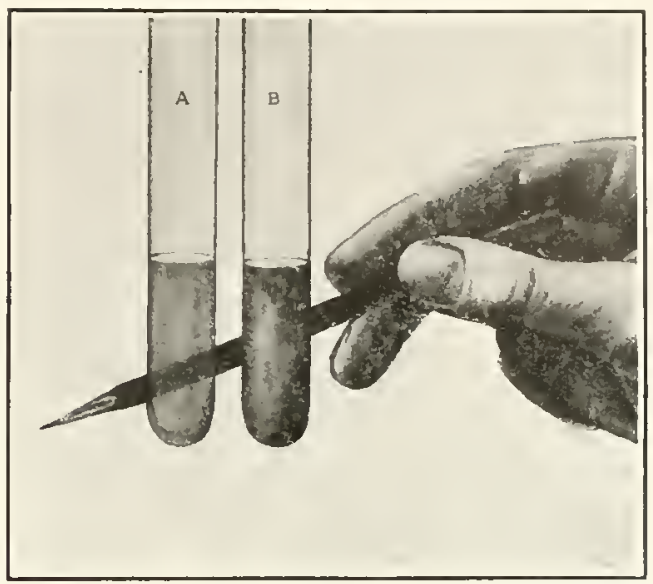

Fig. 110.* developed 110 pellicle, rin, or pseudozoogloex, but only a thin clouding, with a small a11on11t of brownish-wlite precipitate.

Around the surface growth, in the agar in contact with the air, a white amorphous sub-

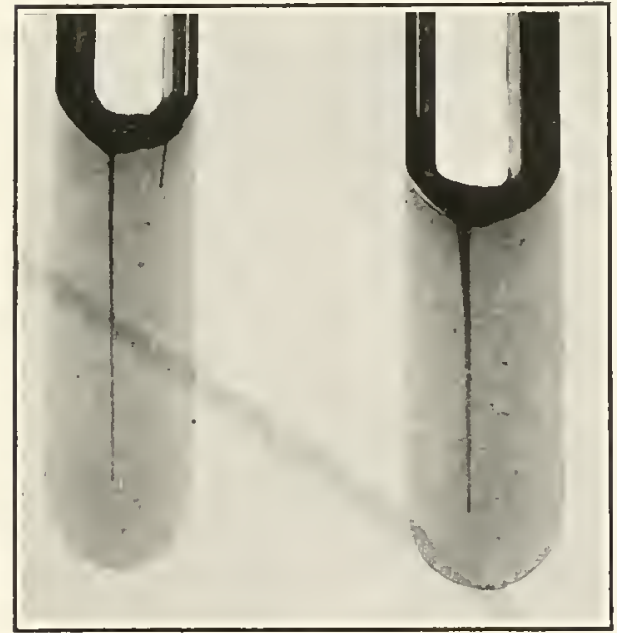

Fig. $111 . \dagger$ stance develops. This stibstance is finely granular under the microscope and dissolves in acetic acid.

There appear to be many degrees of virulence, and possibly there are several strains of the organism.

\section{RESUME OF SALIENT CHARACTERS.} POSITIVE.

Cause of a vascular disease in solanaceous plants-potato, tomato, egg-plant, etc.-and from recent studies by Honing and otlers it would seen also of a disease in plants of several other families. Short rod, often termo-like, motile, flagella polar; organism in the plant often easily mistaken for a coccus; dissolves middle lamella, cellulose (?); plugs vessels, attacks phloem, forms numerous closed cavities in parenchyma of losts; causes premature development of adventive roots in tomato stems. The feebly virulent strains induce slight local enlargements; surface colonies on agar rather slow-growing, roundish, white at first, then brownish; clouds bonillon with formation of numerous flocculent particles which accumulate in top layers; culture fluids containing grape-sugar, fruit-sugar, or cane-sugar brown decidedly after some weeks; growth in acid bonillon $(+33$, acid of beef-juice $)$ is feeble at first in comparison with that in +15 bonillon,

*Fig. 110.-Drawing designed to show the clearing action of Bacterium solanacearum on milk (a sub-culture from colony B, Florida potato): $A$, tube of milk inoculated July 6 , t go5, and drawn August $4 ; B$, uninoculated check-tube. $A$ has become translucent slowly without a previous precipitation of the casein; $B$ is opaque.

†FIG. 11 I. - Gelatin stabs of Bacterium solanacearmm (Virginia organism) after about 16 days at room temperature. No liquefaction. Inoculated Feb. 2, I904. Photographed Feb. is. 
but afterwards excellent; produces a brown stain in lost, on agar, gelatin, etc.; pigment soluble in water and glycerin; streaks on silicate jelly (with Fermi's solution) feeble at end of sixth day $\left(25^{\circ} \mathrm{C}\right.$ ); grows readily on steamed potato cylinders, producing a palc brown to dark brown stain and an alkaline reaction; odor on potato fcebly disagreeable; has slight action on potato starcli; slowly converts milk into an alkaline translucent fluid; gradually clianges the lilac color of litmus-milk to a deep indigo or liyacinth blue; litmuslactose-agar slowly becomes a deeper blue; slight reducing power on litmus; aerobic; reduces nitrates to nitrites; portion of rods killed by freezing, others retain vitality and motility; injured by acids (Hunger, Eirs.); thermal death-point $52^{\circ} \mathrm{C}$., approximately; minimum temperature $10^{\circ} \mathrm{C}$., approximately; optinum $37^{\circ} \mathrm{C}$ or below; maximum $41^{\circ} \mathrm{C}$., approxi-

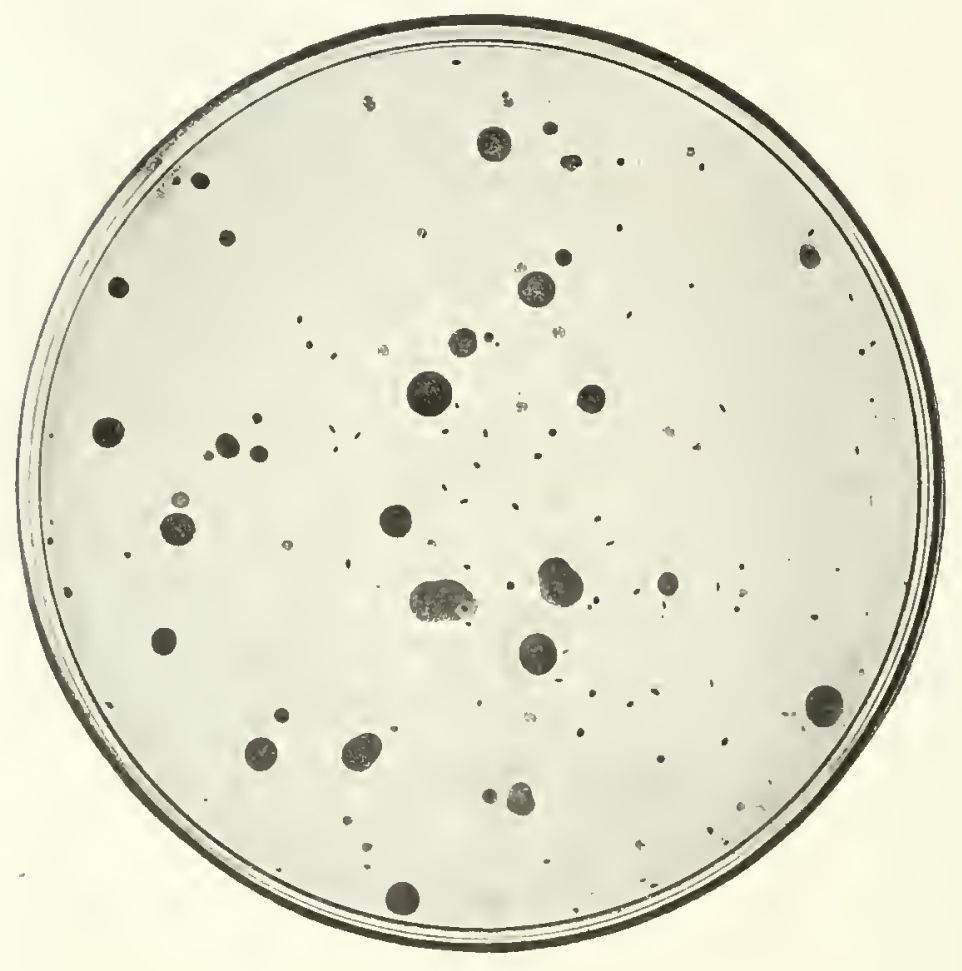

Fig. 112.* wately; alive in milk after 48 days; browired growths are usually dead; dies early on steamed potato, usually the first or second week. Chains occur (Honing, p. 247).

Group No. $21\left\{\frac{1}{2} \cdot 3333823\right.$.

NEGATIVE.

Spore-formation; capsules; long chains and filaments (so far as observed); liquefaction of gclatin (at least during first weeks), blood-serum; starch-destruction (or feeble); precipitation of casein from milk; acid from milk; gas-formation (all media); anaerobism (so far as know11); acids fron sugars and alcohols (so far as knowri); dendritic growtli; green fluorescence; vile odors; wrinkled growth on potato; disintegration of cooked potato-cylinders; action on pigment of dilute acids (10 per ecnt) and alkalies (5 per cent); pigment insoluble in ethyl alcohol (absolute), sulpluric ether, chloroform, turpentine, benzine, xylol, benzole, carbon bisulphide; cultures not viscid, or only exceptionally and slightly so; growth in Cohn's solution absent or feeble; Granı's stain; indol. Non-motile (Hutchinson).

Any organism whicli produces spores, stains well by Gram, gives a decided pink reaction in old peptone-water cultures with sulpluric acid and sodium nitrite, evolves gas, liquefies gelatin readily, acidifies cream-free milk, develops a lab ferment, grows abundantly in Cohn's solution, grows well anacrobically in bouillon with grape-sugar or cane-sugar, has a thermal death-point above $53^{\circ} \mathrm{C}$, or fails to blue (cream-free) litmus milk and to brown steamed potato on long standing, way be set down at once as something else.

This organism may be distinguished from Bacillus phyto phthorus and its allies by the fact that it does not liquefy gelatin, at least for several weeks, does not redden cream-free litmus

*FIG. 1 12.-Colonies of Bacteriunt solanacearum on +15 standard nutrient agar after 8 days at $23^{\circ}$ to $27^{\circ} \mathrm{C}$. Plate poured June IS, I903, from the interior of a diseased tomato stem, received from South Carolina. Natural size. 
milk (compare pl. 23, figs. I, I $a, 3,5$ with fig. 7); or grow in closed end of fermentation tubes in peptone-water with conmon sugars. There are other differences, $c . g$. behavior on cooked potato (compare pl. 23, figs. $6,6 a$ with pl. 4 I, fig. 4); appearance of colonies in thin-sown gelatin plates; and, finally, behavior in the plant.

\section{TREATMENT.}

Fields on which this disease has appeared should be planted for some years to crops which are not subject to it. Inasmuch as the organism appears to be a wound-parasite often disseminated by insects, etc., prompt attention should be given to the destruction of these pests. Land subject to nenatodes should not be planted to Solanaceae if this bacterial organism also occurs in the soil. When transplanting to such soil is necessary, it slould be done early and with great care not to injure the roots. Plants with broken roots should not be set on sucl land. In the transplanting of large plants many roots are certain to be broken. The prompt removal of diseased plants is also recommended in early stages of the disease.

Such a course reduces to a minimum the anount of infectious material sinbject to insect depredations and liable to contaminate the soil further, a precantion which must always be an inportant matter in all diseases disceminated in this way. It is probable that the disease is sometimes spread from field to field in "seed" potatoes. For this reason potatoes designed for planting should be sorted over several times at intervals of some neeks with the greatest care, all suspicious tubers being rejected. There should also be a final inspection at planting tine. It would be still better to secure tubers for planting from fields known to be free from this disease. The tubers from infected localities should be cut across the stemend at planting time and a further rejection made of all suspicious ones. The sound ones should now be exposed before planting to dry air for a day or two, $i$. e., long enough for the development of a protective cork-layer on the

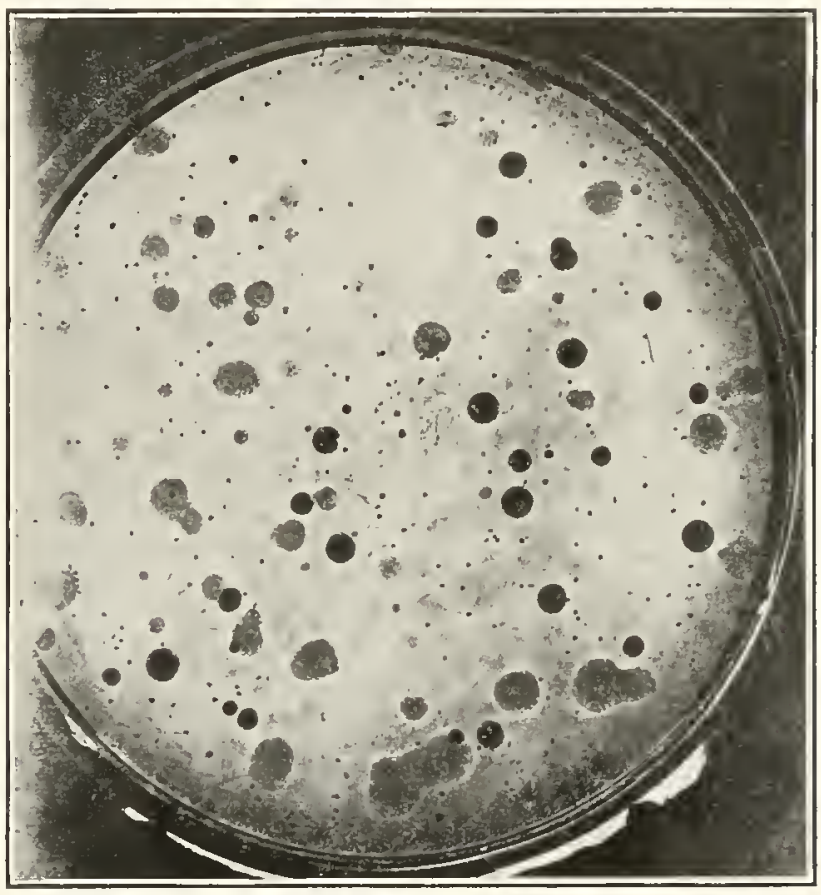

Fig. 113.* cut surface. By following this method of careful selection and by a rotation of crops, being very careful never to plant potatoes inmediately after potatoes, a certain Portsmouth, Virginia, planter, who is a very successful potato-grower and who was formerly much troubled by this disease, believes he las overcome it. At least it is not now troublesome in his fields. In 1905, the writer searched for it in vain on this farm in a large field planted from such carefully selected tubers, but fonnd it readily on the sane farm in another (rented) field planted with a variety of unselected tubers on land whicl was in potatoes the preceding year. In case of fields of potatoes attacked by this disease, the crop should be harvested as soon as fit to dig, should be stored in a cold, dry place, and should be marketed and consumed as early as possible. In 110 case should the crop be allowed to renain in the ground

*FIG. 1 13. - Colonies of Bacterium solanacearmm on +15 standard nutrient agar, grown for 7 clays at $30^{\circ} \mathrm{C}$. Plate poured June 10 , I902, from the interior of a diseased tomato stem received from Porto Rieo. Natural size. These colonies became brown and stained the agar. 
until rainy weather has set in. The cardinal rules should be: Dig early, dry thoroughly, store in a cool, dry place after removing all suspicious-looking tubers, and use as soon as possible. The erop can not rot from this disease if stored at $8^{\circ} \mathrm{C} \cdot\left(46+{ }^{\circ} \mathrm{F}\right.$.) or under.

Moist land should be underdrained or planted to other crops. Tomatoes and other plants subject to the disease should either be germinated where they are to stand or else transplanted quite young and with the greatest care to avoid crushing or breaking the roots. Seedlings having the galls of eel-worms on their roots should be rejected; also over-grown seedlings, the latter beeause their roots are likely to be broken in transplanting.

To recapitulate: Inspect tubers at the stem-end by eutting some days before planting and reject all that show any trace of this disease. If possible procure seed tubers from localities where this disease does not oecur. Plant on land not infected by this organism. If infected land must be used, select that not subject to root-nematodes, and in transplanting seedlings to such land do it eurly in their growth, and break the roots as little as possible. Practice rotation, but not of one susceptible species after another. Drain the moister portions of the field. Burn over or steam the soil selected for a seed bed. Potatoes grown on infected land shonld be sold in the summer or antumm, and always stored in a cool dry place. Destroy insect enemies. Be on the lookout for resistant varieties. Read what is said under "Urilt-Diseases of Tobaceo" (p. 238).

\section{PECUNIARY LOSSES.}

This disease lias destroyed a great many fields of tomatoes and potatoes in the South, and has put an end to commercial tomato-growing in certain sections, $\ell$. g., southern Mississippi, southern Alabama, and parts of Florida.

The following letter, dated May 25, 1905, from a tomato grower in North Florida, is like many others received by the U.S. Department of Agriculture from various parts of the South in recent years:

Under separate cover I send you a diseased tomato plant.

Out of a crop of 30,000 plants I have lost fully one-third, and inany more seem to be becoming affected.

'l'he first thing noticeable is the tender tips of the plant wilting, but nothing can be seen outwardly or even by cutting into the plant at the top, but by eutting into the roots, or stem, for a short distance above the ground, the wood immediately under the bark and the interior of the roots are found to be discolored and bad. The disease has spread with great rapidity during the past few weeks and is still increasing, and it secms about to wipe out the entire crop.

It is not confined to any one field and is equally distributed on soils of widely different character, some of it high, light, and some of it low, black soil. Also, the disease is equally distributed on fields where tonatoes were never grown till this year.

Another man writes as follows under date of May 16, 1903, respecting this disease:

Our truck farmers around this section, 'Tyler, 'Texas, who have hundreds of acres of tomatoes, are complaining that the blight is destroying some of their fields, thus entailing a loss of thousands of dollars.

One planter at Norfolk, Virginia, lost 3,000 barrels of potatoes by this rot in I 908.

Additional statements respecting losses may be found in the chapter dealing with the listory of this disease.

If Buct. solunuceamm also plays any considerable part in the frequent and widespread outbreaks of potato-rot in the northern United States, as now seems likely, but has not been proved, then the annual losses can be reckoned only by liundreds of thousands of dollars. The northern distribution of this organism is unknown.

The subject of potato-rots is still surrounded with a good deal of uncertainty. The fungus Phytophthora infestans undoubtedly causes great losses in the cool, moist regions of Europe and oceasionally in the more northern parts of this country, where the writer has seen 
the foliage of whole fields destroyed in a week, but there is no basis for the assumption that this is the only or the principal cause of the rot of potatoes either in this conntry or abroad. Species of the fungus form-genus Fusarim also cause, in the United States as well as in Europe, scrious diseases of potatoes, one of which begins in the field as a vascular discase of the stems and continues in cellars as a dry rot of the tubers.* The great bulk, however, of the soft rot of potatoes, in this country and also in Europe, is due to bacterial organisms, either acting independently, which is often the case, or following Phytophthora and Fusarium. Several are known to induce decay and very likely a dozen or more distinct kinds of schizomycetes will be found capable of destroying the tubers in wet scasons when the lenticels open in the soil. When this happens all sorts of soil bacteria gain an easy entrance to the tubers under conditions likely to be very favorable to their destruction. This attack of the tubers in a badly aerated, wet soil, with the lenticels wide open, is a very different affair from the active development in the parts above ground, and under normal conditions, which is manifested by Bacterimm solanaceanm, or by Bacillus phytophthorus, which causes the only other bacterial decay of potatoes which lias thus far been described with any great degree of accuracy. Since this was written, Harrison, in Ontario, has described Bacillus solanisapris, an organism strongly suggestive of Appel's organism but not absolutely identical (see Basal Stem-rot in vol. IV), and Pethybridge and Murphy in Ireland have also described their Bacillus melanogenes, so that in general it may be said that our knowledge of the bacterial diseases of the potato is much further advanced than it was ten years ago, when the rough draft of this chapter was written.

\section{HISTORY.}

According to Hunger this disease was first recognized by Comes in Italy in I 8S2. There is much uncertainty, however, concerning this. Professor Comes undoubtedly observed a serious bacterial disease of tomatoes in the vicinity of Naples in i $\delta_{+}+$or earlier and recognized it as such; but his descriptions of it, and of the fluid cultures made therefrom, do not enable one to speak with any degree of certainty either concerning the signs of the disease or its exact cause. It may liave been due to $B$. phytophthorms or to some other organism. His name, if retained, should apply to a grape bacterium.

The disease formed brown or black cankers on the stems near the earth, the whole plant being finally destroyed. Bark and pith were disorganized and granular; the vessels of the wood with their surrounding cells, but not the medullary rays, were occupied by a yellowish or brownislı granular mass. "In the disorganized tissues, " says Comes, "and in tle gummy granulations was observed the presence of myriads of microbes, similar to those of Bacterim gummis, found by me always in tissues of woody plants affected by gummosis."

In IS9o, before the Society for the Promotion of Agricultural Science, Prof. T. J. Burrill, of the University of Illinois, described very briefly a disease of potatoes which had attracted his attention as something new, and which was probably this disease.

The examinations were made on tubers shipped from the south in June, many of which were rotting. Only bacteria were found. Several species of these were isolated, and successful infections were obtained with the one presumed to be the potential factor in the rot, but these experiments are not described. The organism causing the rot was a termo-like bacterium actively motile, oval to short cylindrical in outline, occurring single, in couples, or rarely in chains of 3 or 4 links, its rods nneasuring about $0.7 \times$ I to $1.5 \mu$; it was non-sporiferous, non-liquefying, and formed non-characteristic zoogloeæ in the potato.

How the organisms gain access to the subcortical tissues without some previous puncture of the skin of the tuber has not been ascertained, but some observations seemed to show that the same bacterium infests the leaves and culms, causing injury and death to these parts and possibly sometimes reaching the tubers through them. 
In I S9I, Dr. Byron D. Halsted reported a widespread and destructive decay of potatoes in south New Jersey, part of which appeared to be due to bacteria. The potato tubers, it is said,

Developed well-formed ulcers, and slices of these quickly turned to ahmost a coal black, especially near the surface beneath the skin, and over all rapidly grew [oozed?] an almost velvety layer, consisting entirely of masses of bacteria.

This entry probably belongs here, or if not here, then most likely under Basal Stom-rot.

Early in 1892 , Dr. Halsted published a bulletin from the Mississippi Experiment Station giving an account of the Southern tomato-blight, as observed by him in that State in 1891. This disease he ascribed without hesitation to bacteria, basing his conclusions on numerous microscopic examinations. Dr. Halsted noted the wilting of young leaves and growing tips of the stem, the water-soaked appearance of certain tissues, the watery greenish disorganized pith, the brown stain in the vascular system, and under the microscope in freshly gathered material the presence of large numbers of bacteria, while all traces of fungi were absent. Inoculations into growing plants failed.

A bliglit of potatoes was also observed and studied by Dr. Halsted at Ocean Springs, Mississippi. The above-ground signs were similar to those on the tomato.

Below ground the stem is more or less darkened, in patches brown, and occasionally almost black. The old "seed" potato is a soft rotten mass, and the few new potatoes usually small and decayed, invariably at the stem end and almost always at the eye, appearing at first "watery" and afterward brown. It is an interesting fact to be stated in passing that the earth adheres very closely to the surface of the decaring portions. It seens evident from the extended study of these diseased potato plants, hundreds being examined, that the rot passes from the main stem to the tubers, and probably comes originally from the "bud." Often a lateral underground branch including its minute potatoes, as large as peas, is entirely softened. Upon making halving sections of the tubers it is seen that the most diseased portion is in a circle which includes the base of each eye. 'This portion is a soft, growing layer, rich in nitrogenous substances, and furnishes the avenue through which the disease spreads from one eye to another. From this decayed tract a milky juice quickly accumulates upon the section that is made up very largely of bacteria and contains no other form of fungus [consult this Monograph, vol. I, pl. 24j.

Dr. Halsted believes the disease is transmitted to the growing plant from the mothertuber. Cross-inoculations from potato to tomato in the field failed. The tomato-plants were then full-grown. Direct infections under bell-jars in moist air succeeded. These were made many times over and the checks usually remained sound. For this purpose Dr. Halsted used slices of tomato-fruits and potato-tubers and also short pieces of tomatostems and potato-stems. The decay was rapid. The milky ooze from the potato rotted tomato, and that from the tomato rotted potato, but under tie same conditions melontissues were also rotted when inoculated with this material, and Bacillus phytophthorus, Bacillus molonis, or some similar organism must have been present. The disease as observed in the field must, however, I think, have been due to Bacterimm solanaccarm.

Several attempts were made to infect seedling tomatoes by planting them on soil containing diseased material, by soaking seeds in it before planting, and by spraying infected fluid on the plants, but as the results were not conclusive it is not necessary to make further merition of them.

According to a note by Director S. MI. Tracy prefaced to this paper the losses from this disease in Mississippi lad been serious for several years, amounting in some cases to from a quarter to half the plants. In 1890 the losses were widespread and severe.

In 189 I the disease appeared at Ocean Springs, Mississippi, in the tomato fields on May r. (In r9r4, Rolfs found it for me on potato shoots at Gainesville, Fla. A pril I 5 .)

In 1 S92, in Garden and Forest. Dr. Halsted reported occurrence of this soutliern tomato disease in the north. The material was received from F. L. Stevens, Syracuse, New York, where 3 fields were affected. In the field most seriously injured about 3 per cent of the plants were dead, 8 per cent badly affected, and many more showing traces when the 
inspection was made. This may have been, however, the Grand Rapids disease, due to Aplanobacter michiganense (see p. 161).

The same year, in two of the Cornell University Experiment Station bulletins, Bailey and Corbett made a brief mention of a disease which was serious upon some of their tomatoes that year. Specimens were subnitted to Dr. Halsted, who thought the disease was "probably identical witl the Southeris one" (Bull. 45), and "distinct" (Bull. 43). Professor Bailey adds:

Apparently the same disease has been reported to me fron three localities in this State during the last two seasons ancl in two cases it had practically ruined the crop.

Probably this was the Grand Rapids disease due to Aplanobacter michiganense.

In I 893 , Professor Burrill published another note on the new potato disease, the most important part of which is here cited:

The present note is simply to substantiate as correct what was simply surmised before. The inicro-organisms taken from the different portions named of the plant not only appear alike and grow alike in artificial cultures, but the results are identical when cross-inoculated into the living tissues. * * * *

When the aerial stems are infected, pure artificial cultures are as easy to make as from the tuber itself, and we have had abundant opportunity to do it. [These cultures and inoculations are not described.] It now appears that in most instances at least the tubers in the ground are infected by way of the rhizomes and aerial stems. *** The leaves are primarily infested and very commonly first at the tips or margins, then are progressively destroyed, becoming first watery, or semi-translucent, then brown, and afterward dry and curled. The supporting petioles and stems are in turn invaded, but initial spots may also be found on these. It has not been ascertained whether or not previous mechanical rupture of the epidermis is necessary, but all observed facts indicate the contrary.

In 1895 , Dr. Halsted wrote as follows about conditions in New Jersey:

Bacteriosis of the tomato prevails in many parts of the State, and is not, as yet, well understood.

In $1895-96$, the writer isolated the organism causing this disease and studied it many months. He obtained typical infections on tomato and potato plants, inoculating from pure cultures by means of needle-pricks on stems and leaves; he determined by crossinoculations the identity of the disease as it occurs on potato, tomato, and egg-plant, obtained successful inoculations on various weeds (Datura, ete.), failed to obtain the disease in tobacco or peppers, perliaps because these plants were not growing rapidly, determined experimentally that the organism was non-infectious to the cucumber and some other plants, and demonstrated that the disease could be conveyed by insects. As a result of these investigations he described the disease and figured it, named the organism causing it, and for the first time described the latter according to well-recognized bacteriological metloods.

According to Selby, the disease is serious in parts of Ohio. One tomato-grower in Clermont County stated on July 23, 1896, that "in my three acres there is searcely a sound plant."

In 1898, P. H. Rolfs, at Lake City, Florida, published short notes on this disease in two of the Florida Experiment Station bulletius.

The disease was known to be present in Florida in several fields. It was inoculated successfully into tomatoes, which were all destroyed. Egg-plants appeared to be more resistant than tomatoes, but suffered quite severely. Peppers seemed to be free from this disease.

Some potatoes on the Experiment Station were carefully treated with fungicides, but no good result could be seen from the use of this material.

In Bulletin 47 , of the Florida Station, it is said:

That the disease is not indigenous to Florida I think is evident from the fact that it rarely ocenrs in new portions of the State until after vegetables have been grown for two or three years. 'The loss 
from this disease varies from a few plants to at times every plant in small areas-oftimes amounting to as much as 80 per cent to 90 per cent of the whole field. 'There seems to be no special preference for either high or low land.

The same year, in Proceedings Florida Horticultural Society, Rolfs made some observations on the distribution of the disease in Florida and again reported successful inoculations.

Last summer at the Experiment Station [Lake City] several plots were set aside for studying the effects of this disease. A plot of egg-plants, another plot of tomatoes and a plot of peppers, each onehundredth of an acre, were planted contiguously and the disease [was] started in the corner of the eggplant field, this corner being the most remote from the tomatoes and the peppers. The disease maniested itself in less than a week on the plants inoculated. For a time it was confined to this corner but before long sporadic cases occurred throughout the plots of egg-plants and tomatoes, until within the course of about three weeks the entire plots of egg-plants and tomatoes were destroyed. In no case was a pepper plant hurt. *** Soon after the egg-plants and tomatoes had all been destroyed the field was clcared of all these plants and of all the débris left from the plots. The plots were then kept free from vegetation for two weeks, when they were again planted to egg-plants and tomatoes just as before. The disease now appeared in various spots over the entire field. We then took out the plants as soon as they showed signs of the blight and the place occupied by the plant was filled by another one, so that it gave us a full field, all of it being in plants that showed no blight, but nevertheless the blight continued to appear until cold weather cut short the growth of both egg-plants and tomatoes.

During last winter these plots were planted first to radishes, and next to lettuce. None of these plants showed any indications of the disease. As soon as the weather permitted, egg-plants and tomatoes were planted in the same plots as last year. These have now begun to show signs of blighting which makes it seem quite probable that the disease can remain over winter in the field.

In I900, F. S. Earle, then of the Experiment Station at Auburn, Alabama, also wrote upon the discase as follows:

This serious disease of the tomato has so far only been observed in the southern part of the State. It is very destructive in Mobile and Washington counties. *** Each succeeding crop suffers worse than the last. * * * As the result of rather wide experience with it in Mississippi I am of the opinion that direct underground infections do take place as suggested by Dr. Smith.

Contagion carried by winged insects may well be the means by which the disease first becomes introduced to new fields, but this method of infection can hardly account for the spread of the disease from year to year in somewhat regular concentric circles from such new centers, especially as it usually takes almost every plant in its path. Insect infection would not either account for the facts reported by me in the 6th Annual Report of the Mississippi Station, pp. 53-61, where, in a large tomato field that was under observation, the disease was very largely confined to a narrow strip of wet, seepy land, running diagonally through it, while the drier land on either side was nearly exempt.

As the disease is thus so markedly a soil disease, the possibility of soil treatment as a remedy at once suggests itself. Very few experiments are recorded in this direction. In the Mississippi experiments mentioned above in one case heavy applications of kainit seemed beneficial and in another case there was apparent benefit from the use of lime. Marked benefit also seemed to follow the use of lime in an experiment at Deer Park, Ala. (see Ala. Bull., 92 : 109). These experiments, however, need confirmation. Sulphuring the soil does not seem to have been tried. Spraying the plants and the surface of the ground with Bordeaux mixture gives no result.

In his report for 1907-8 Stevens, of the North Carolina Experiment Station, stated that the wilt discase of tomatoes due to Bact. solanacearmm was widely prevalent in North Carolina and constantly spreading into new territory.

The newer Dutel East Indian studies are reported under Wilt-Diseases of Tobacco (pp. 224, 244). 


\section{APPENDIX.}

In conformity to the writer's custom of keeping things separate until it has been definitely established that they are identical, the following diseases are put by themselves, although it is not unlikely that some of them are due to Bacterimm solanaccarmm. There is the more reason for suspending judgment in some of these cases, because in recent years through the labors of Dr. Appel, in Berlin, we have come to recognize a widespread disease of potatoes similar in some respects to the one described by the writer, as due to an entirely different organism (see Basal stem-rot of potato, vol. IV), and also because a full description of Bact. solanaccarmm has not been available. [Recently, I have ceased to have doubt concerning identity of the American and Dutch East Indian Disease. See Wilt-Diseases of Tobacco.]

\section{THE NEW ZEALAND DISEASE.}

Kirk is authority for the statement that Bact. solanacearum eauses a disease of potatoes in New Zealand. It is not widespread.

\section{THE AUSTRALIAN DISEASE.}

In 1894 , the entomologist, Mr. Tryon, reported the appearance in Queensland of a new and destructive disease of potatoes and tomatoes, ascribed to a bacterial parasite which fills the vascular system, wilts the plant, and destroys the tubers.

The leaflet, which is only a brief excerpt from an unpublished MS. report of Mr. Tryon to the Department of Agriculture at Brisbane, mentions no inoculation experiments and contains no description of the organism. The reader is given no information concerning it, other than what may be inferred from the following statements: "A small, living microbe, having an average length of less than one ten-thousandth of an inch, resembling in appearance the bacillus of chicken cholera and other organisms." (The italicizing is mine.) In the tubers the disease first appears as "an indistinet, translucent line rumning parallel to the outer margin" of the tuber when eut across. "They soon, however, commence to rot, decay starting in the more superficial portions of the tissue, and the potato substance is eventually converted into an offensive, odorous, tenacious, whitish slime." (Italies mine.) This leaflet deals chiefly with suggestions for treatment and does not materially help the pathologist or bacteriologist.

In June I 895, Mr. Tryon stated that he had had an opportunity of reinvestigating the new potato disease and that the microbes are "scarcely distinguishable from those which are met with in diseased sugar-cane." "They are found clogging up the vessels of stems, roots and rhizomes, and, in the initial stages of the disease, nowhere else." The disease here referred to is Cobb's gumming of sugar-cane, due to a honey-yellow bacterial organism. Without further description the organism is therefore designated Bacillus vascularum solani.

In I 895 , Helms reported on several potato diseases occurring in the Clarence River district in New South Wales, in south latitude $29^{\circ}$ to $30^{\circ}$. The paper is agricultural rather than bacteriological. Judging from the plates, one of these diseases (No. 1) is like Prillieux's potato disease ascribed to Bacillus caulivorus, and another (No.3, p. 32S) is possibly like that due to Bact. solanacearmm. No cultures or inoculations are mentioned, and positive or even presumptive identification from the figure is impossible. If it were infected with Bact. solanacearm, the tuber in longitudinal section might be expected to show decay at the stem end, but it is not so represented.

In I 899, Tryon identified his Australian disease as that described by me and intimates that his name, Bacillus vascularmm solani, should have been used in my bulletin on "The brown rot of tomatoes, egg-plants, and potatoes," published in i 896. I would have used 
Mr. 'Tryon's name, or some portion of it, had I at that time had any means of knowing what he meant by it. This I did not know, and do not yet know. His organism certainly can not be like three very different organisms. It would appear that Mr. Tryon had written a considerable manuseript on this disease and had submitted it to the Department of Agriculture of Queensland, but that unfortunately they allowed it to remain unpublished. He now makes citations from this unpublished paper, but these are not sufficient to clear away the uncertainties. For all we know from any thing he has published, this Australian disease may be due to Bacillus phytophthorus, or to some undeseribed species. Mr. Tryon has never published a proper (exact) description either of the disease or of the organism causing it.

Certain statements of his do, indeed, make the

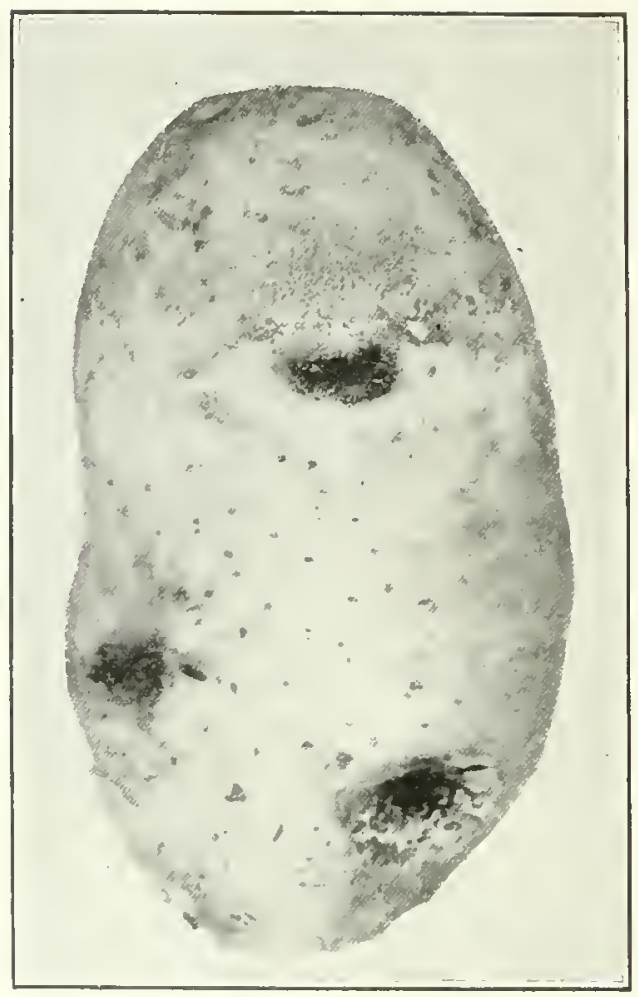

Fig. 114.* reader think of the brown rot, but there are others which certainly ean not be applied to Bact. solanacearum, e.g., tlie "sticky, tenacious" slime which is said to choke up the vessels; the "froth-like" viseid exudate from the eyes of the tuber; the "foetid odor," the opening of the lenticels; the gradual decay of the stens from the base upward; the frequent destruction of the organism by the temperature of the Queensland summers, ete. Mr. Tryon is either describing mixed infections, or else a different disease. Why not "Schwarzbeinigkeit" due to Bacillus phytop ithorns?

We shall never know the specific cause of this Australian potato disease until some bacteriologist takes hold of the problem, isolates and deseribes the organisin in ways recognized as proper, and demonstrates his ability to reproduce the disease with one particular organism by means of pureeulture inoculations.

A few words as to Mr. 'Tryon's name. In my judgment the name Bacillus vascularm solani is unusable because it can not be attached, by means of anything he has yet published, to any particular organism. It is a trinomial, it was publisled without description, without isolation of the organism in pure eulture, without proof that the bacteria actually under observation and named by him had anything to do with the disease, without proof that the disease itself was actually due to bacteria, and finally without eareful description of the disease, $e . g$., such descriptions as would have enabled anyone to identify it with the North Anerican disease. His name, therefore, for reasons suffieiently set forth in volume I of this monograph, can be regarded only as a nomen nudum.

Professor McAlpine, of Mellourne, has sent me a photograph (fig. II4) of a potatotuber decaying at the eyes, this disease being known in Australia as "sore eye" and "spewey eye." This disease is associated with bacteria and probably due thereto. Some years it eauses great losses, it is said. Perhaps it is the disease observed by Tryon. Living material sent to me was too badly decayed when received to make anytling out of it. It appeared to be a brown bacterial rot (only a little Fusarium was present), and the vicinity of the vaseular ring was stained darker than any other part.

"FIG. I f - -Polato tuluer, showing the bacterial "sore eye" or "spewey eye" of Australia. From a photograph sent by Prof. D. McAlpine, of Melbourne. This is perhaps 'Tryon's disease. There is a slimy ooze from the eyes and the carth usually sticks to them. 


\section{THE DUTCH EAST INDIAN DISEASE.}

A disease of tomatoes prevalent in Western Java and rapidly fatal was identified by Dr. F. IV. T. Hunger of Buitenzorg in 1901 as due to B. solanacearm Snith. The following observations are from Htnger's paper (see Bibliography):

This disease has not been so prevalent as in the United States, but nerertheless whole plantations have been destroyed by it in Java. The course of the disease is rapid.

Hunger experimented with diseased and healthy plants, exposing them to the sun without water and then watering them. The diseased plants recovered slowly from the wilted condition, and after some days not at all. The undiseased recovered promptly on watering.

In two instances he observed buds out of place, namely, on the leaves, and he is inclined to think that these signs were due to the disease. The adventive root-formation occurs so regularly that there can be no doubt as to this being a sign of the disease. The roots develop regularly on the stem and they may appear also on the leaf-statk.

'The vaseular ring of the stem was stained brown and bacteria were abundant in the vessels. Whenever a tomato plant showed signs of the disease above ground he always found the root-system diseased. These roots were more or less browned, and when well along in the disease were blackish and soft, and filled with bacteria. In early stages the browning was confined to the xylem wedges of the root.

Tisstres put into alcohol of various strengths gave the result described by Smith, riz, the bacteria diffused out of the vessels regularly in 75 per cent alcoliol, and also to a less extent in 90 per cent, but were hindered in their diffusion by absolute alcohol. Hunger found that by adding I per cent nitric acid to the 75 per cent alcohol he obtained a solution in which diseased tissues beliaved as in absolute alcoliol. He fotnd the pith of diseased plants greatly changed, i.e., from white to spotted gray, with formation of bacterial cavities. The whole pith of diseased stems may disappear, the remnants being found on the inner edges of the vascular ring. Groups of tetrahedral crystals, the so-called crystal-sand, are stated to be much more common in diseased than in healthy plants. Hairs are absent from the vicinity of those parts of stems which are sending out adventive roots [the writer has not observed this in the North American disease]. These roots spring from the pericycle.

Hunger believes that the formation of tyloses which he observed abundantly in the vessels of diseased plants is induced by the presence of the bacteria. 'These tyloses are always filled with bacteria. 'They soften the walls of the vessels in places and then the tyloses are formed; the evidence adduced in proof of this statement is not conclusive, but nevertheless Hunger is probably right (see similar observations by the writer on mulberry shoots attacked by Bact. mori, vol. II, fig. 30 , of this monograph).

Hunger also notes that in 'Tryon's paper there is not the least description of his Bacillus vascularm solani. He says:

The bacteria found by me as cause of this tomato disease agree in every particular with Bact. solanacearum Snitli, so that I hold the two for identical.

Hunger believes that he has determined by inoculation with the tomato organism the occurrence of the same disease on Nicotiana tabacum and Capsicmm anmum. He says that he has repeatedly obtained the same signs of disease in these plants as in sick tomatoes. He inoculated it into tobacco, using culttres from tomatoes, and obtained the slime-disease (see Wilt Diseases of Tobacco, p. 222). His inoculation experinents were as follows:

Tomato seeds were genminated on filter-paper and the young plants then brought into watercultures, which were infected with pure eultures of Bact. solanacearim. The young plant grew as well as the check-plant, and a subsequent examination showed that there were no bacteria in its interior.

In a similar experiment, varied only by the fact that the root-system was wounded in various ways, $i z$, by needle-pricks and by teazing out the end of some of the young roots, the plants bccame infected after a week and the bacteria were demonstrated in the vascular bundles. In one of the plants the bacteria were found in the ressels of the leai-stalks of two of nearly the youngest leares. 'Tyloses had not yet formed in these vessels. 
In another series of experiments the young plant was placed in the eartl and when growing rapidly was watered daily with water containing a pure culture of Bact. salanacearum. No infection took place. In a similar experiment, varied only in that the roots were purposely injured, the plants became infected after I 1 days with typical signs and a microscopic examination showed the presence of the bacteria in the tissues, vessels included.

In a third experiment a number of leaves of two tomato-plants were plinged into infected water for some days to see if the bacteria would enter through the water-pores. After 3 days the leaveswere investigated microscopically. 'They were not infected and the writer draws the conclusion that they can not be infected in this way, but this seems not strictly warranted, because of an additional statement: "Certainly I found rather commonly Bacillus solanaccarum in the large, intercellular spaces under the water-pores, but not at all in the corresponding water-vessels."

A similar result would not be uncommon at the end of 3 days in case of the cabbage infected through the water-pores by Bacterium campestre, but a like conclusion would be erroneous, and it scems not unreasonable to suppose in this case that after a longer period had elapsed, say 9 days or 12 days, Dr. Hunger might have obtained different results and cone to an entirely different conclusion, since in the cabbage after that time the bacteria would have entered the vascular system and begun to move downward in the reins of the leaf (see this monograph, vol. II, p. 3o8).

A plunge-experiment similar to the preceding but varied by the fact that the leaves were bruised and wounded more or less before being put into the infected water gave positive results. After 5 days a distinct infection was observed, and a microscopic examination showed the presence of the bacteria even in the stem of the plant, these having passed down through the leaves from the wounded places. In one specimen there was already the beginning of adventive root-formation on the stem.

Hunger also smeared portions of leaves and stems with pure cultures of Bact. solanacearum, and placed these plants under large bell-glasses with water, so that the atmosphere was always moist. No infections were obtained; the time, however, was rather short (8 days).

The conclusions drawn are that sound tomatoes are not attacked by Bact. solanacearm, and that infections do not take place through natural openings, such as water-pores.

According to Hunger, the greatest care should be exercised in planting that the roots be not broken or crushed, and to this end the plants should be removed from the bed and put into the field early, that is, before they have made long roots, which must necessarily be broken in trausplanting. He believes that crushing the roots in planting is a common cause of infection. He cites a case in point at Batavia. The disease occurred seriously in the field, and on examination and inquiry he found that the field had been planted not in the ordinary careful manner by an experienced gardener, but that the planting was delayed beyond the proper time and then performed hurriedly. The plants were too large when transplanted; therefore many roots must have been broken, and they were set out by the gardener with help of two house servants, the coachman, and water-carrier.

Hunger often found the root-system attacked by a species of Phytophthora, which he says plainly made a passage-way for the bacteria. He is inclined to think that an imperfeetly drained soil is very favorable to the development of this disease. Of this I, too, think there can be 110 doubt. He made some experiments to determine the effect of animal and plant parasites on the outbreak of the disease.

In his first experiment, which consisted of pot-cultures in disinfected earth, the surface of the earth was infected with Phytophthora nicotianae from tobacco. The plant was then watered with water which had been infected with a pure culture of Bact. solanacearmm. After 7 days the Phytophthora had overrun the entire surface of the earth and had begun to attack the lower end of the stem. After 26 days the plant developed the bacterial disease, and the infection plainly originated from the lower end of the stem.

In a second set of experiments, made in the same way in disinfected earth, a mole-cricket was buried in the soil of each pot, and the plants were regularly watered with infected water. Ten of the 1 i plants were soon destroyed outright by the insects, the young stem being bitten off underground. One plant remained normal up to the sixteenth day, when it showed the first signs of the bacterial disease; the following day it died. Upon investigation the mole-cricket was found dead in the soil, but the tap-root had been bitten by it, and it is probable that the infection took place through this wound.

In a third series of experiments, in sterilized earth, the plants were infected with eel-worms (IIetcrodera radicicola), by mixing with the earth small picces of roots which had been attacked by 
them but which were free from Bact. solunaccarum. The plants were watered with ordinary water; they grew well, blossomed, and bore for the most part small fruits. 'The clisease did not derelop. In another experiment, identical with the preceding, except that the plant was watered with water containing a pure culture of Bact. solanacearum, the disease developed after 27 days and the adventive root-formation was already under way. The plant died just one month after the beginning of the experiment, and both a macroscopic and a microscopic exanination demonstrated the typical phenomena of the bacterial disease.

As already stated, Dr. Hunger believes the disease is induced mostly through the intervention of Heterodera. He thinks the bacteria are carried up the vessels by the watermovement, but he does not bring sufficient proof in support of this latter statement. He states that infection is not limited to the vessels, but may occur throughout the entire vascular bundle, and also in the phloem and the parenchyma. The sieve-tubes may be plugged by the bacteria. He thinks the adventive roots are due to the action of the bacteria on the phloem. By placing wet moss around a stem showing these adventive roots, he induced them to develop further and on removing this part of the plant and setting it out in the earth he obtained a new plant, which grew well for some time, but afterwards developed the disease.

He obtained his pure cultures used for infection from Petri-dish poured plates on agar. This agar had the following composition: water 1 liter; agar-agar 20 grams; glucose 10 grams; peptone ro grams; magnesium sulphate 0.5 gram; potassium phosphate, 0.5 gran.

Dr. Hunger states in a number of places that the color of the surface colonies on this medium was "leverkleurige," that is, liver-colored. They were small and round, and spread slowly in a concentric manner. In the writer's experiments colonies of Bact. solanacearum were not brown (liver color) until after a week or two.

He states that the least amount of acid in the agar exerts an injurious influence on the bacteria, but that the addition of alkali favors their growth, for example, the addition of sodium phosphate. He found the organism sensitive to sunlight, development being absolutely hindered by it, and a long exposure destroying it.

He states that Bact. solanacearmm is early contaminated in the plant by the presence of other organisms. These impurities consist of saprophytic bacteria, and especially a yeast. In size and shape this yeast, which he seems to have found quite common, corresponds exactly to van Breda de Haan's statement respecting his coccus from tobacco plants, vir, round and $8 \mu$ in diameter. We may assume either that this was what van Breda de Haan saw in his diseased tobacco, or that his measurement is erroneous. If for the $0.008 \mathrm{~mm}$. of the text we should read $0.0008 \mathrm{~mm}$., then it is easy to understand how the short rod might have been taken for a coccus, especially with objectives of only medium magnification. On plate-cultures Hunger found he could distinguish colonies of this yeast readily from Bact. solanacearm by the fact that the latter appeared bluish-green by transmitted light.

There is some discussion of methods of prevention, but no certain ones are pointed out other than avoidance of planting on diseased land.

It is suggested that possibly some resistant species of this fanily inay be found upon which the tomato could be grafted.

\section{THE MALAY STATES DISEASE.}

In I9 Io, Keith Bancroft, Assistant Mycologist, reported on a bacterial disease of potato and tomato occurring in the federated Malay States as follows:

Specimens of potato plants have been recently received from Taiping (Perak) exhibiting the wellknown "bacteriosis" caused by Bacillus solanacearum E. Smith. The same disease has been known for two or three years to occur in Kuala I.umpur on tomato plants cultivated in vegetable gardens. These two crops are but little cultivated in the Malay States, so that the disease has little more than a passing interest. It is, howerer, interesting to record its occurrence in this country, and a brief note will be given of the symptoms of the disease and of some methods of treatment which are likely to prove effective. 
The disease is well-known in the United States of America where it has been carefully studied by Dr. E. Smith on potato, tomato, and egg-plant (Solanum melongena). It has also been recorded on potato in Scotland, in the north of England, and in Mysore, and recently in Ceylon.

The symptoms of the disease appear to be constant in the different countries in which it is known to occur, and they may be briefly reviewed thus:

Attacked plants show a wilting and shriveling of the leaves; soon afterwards brown streaks appear on the stem and spread downwards to the parts underground. Finally, the whole stem rots. A browning of the affected parts is very characteristic of the presence of the bacterium; the browning will be found to be first evident in the vascular ring on examining the cut surface of an affected stem. 'The vascular bundles are first affected, the supply of water to the leaves is checked and the consequent wilting and shriveling makes its appearance.

The disease in the potato tubers is very well-marked by the presence of a circular, usually incomplete, brown ring which is situated at some little distance from the surface and which corresponds in position with the vascular ring of the tuber. 'This ring darkens and expands until the whole of the starch-producing area of the tuber is affected. The tuber decays and the bacteria are liberated in the soil where they can infect other healthy tubers.

Dr. E. Smith considers that the rapid spread of an epidemie is due to insects of different kinds feeding alternately on healthy and infected plants. Under these circumstances it is advisable to spray the plants with an insecticide. A regetal wash, e.g., tobaeco wash, shonld yield good results. This may be made by inf using half a pound of toluacco leaf in water for about six hours, straining off and pressing fhe tobacco and again infusing; the extract is added to a solution of half a pound of soft soap in water, the whole being made up to ten gallons. The wash is applied by means of a spray. Any coarse tobacco leaf may be used.

Infected plants should be taken up along with their toots and burnt. 'They must on no account be thrown on to a manure heap. In the case of the potato plant it is advantageous to lift the crop early when the disease has made its appearance; in this way many of the tubers may be saved.

Plants belonging to the potato family should not be planted on soil which lias yielded infected plants for at least two years, since the bacterium probably attacks a large number of members of that family (Solanaceae).

\section{THE MYSORE RING DISEASE.}

In I 909 , Leslie C. Coleman published a short paper on a "Ring disease" of potatoes (Solanm tuberosum), of which the following is an abstract:

The Bangadi or ring disease of potatoes has been reported from various localities in lndia. It was first noticed in Bombay Presidency in the vicinity of Poona, and later in other parts of the Presidency. In Mysore it is found practically in every locality where potatoes are grown. The extent of its ravages is very much greater than is generally supposed.

The disease is readily to be recognized by the sudden wilting of the potato plants in an affected field. Usually one or two leaves first show the wilting, but within a few days the whole plant wilts down and dries up. If the tubers of an affected plant are cut through, some of them will almost certainly show a brown ring a short distance in from the surface. 'This ring will be found, usually at least, to begin at the point where the tuber is attached to the underground stalk which bears it and to spread from that point around to the other end of the potato. In its first stages, therefore, the ring is not complete, but is rather simply indicated by a more or less distinct brownish streak in the neighborhood of the point of attaclment of the tuber. If a diseased potato be cut and squeezed slightly, a series of small creany-white slimy drops are to be seen exuding along the eourse of the brown ring, and if these drops are examined they are found to contain myriads of bacteria shaped like small and very short rods. If a very thin slice of such a potato is examined microscopically these tiny rods are found chiefly in the vessels of the tuber which they plug quite full. If the stem of a diseased plant is examined it is found also to be plugged with masses of the bacteria. 'This plugging up of the vessels from the roots up to the leaves causes the wilting of the plant.

The questions investigated in regard to this disease are: "(1) Are these minute bacteria the real eause of the disease? (2) If so, how do they get into the potato plants, and how do they increase to such numbers as to block up the vessels?"

'The reasons given for answering the first question affirmatively are as follows: "( 1 ) They are to be found in large numbers in the vessels of every potato plant suffering from the disease. (2) In the earlier stages of the disease they are the only organisms to be found in the vessels. Later, when the whole plant or tuber begins to rot, other bacteria, as well as certain kinds of higher fungi, are to be found associated with them. (3) It lias been proved by direct experiments that these bacteria are 
eapable of causing the disease. 'These experiments were carried ont as follows: 'The bacteria were removed from diseased potatoes and grown in the laboratory in such a way that they could be separated from all other forms of bacteria. When by careful testing it was found that we had masses of these bacteria growing quite free from any other form, such masses were used to give the disease to healthy potato plants. Small pricks were made in the leaves and leaf-stalks of healthy plants with a fine needle which had been held in a flame to kill off all bacteria that might be on it. Then masses of these bacteria were stroked over these pricks so that the bacteria could enter into the substance of the plant. After a few days it was noticed that the leaves and plants infected began to wilt and in the course of 2 to 4 weeks the plants were quite dead. Moreover, when the stems of these plants were cut across and examined under the microscope these same bacteria were found inside the vessels. Some of the tubers attached to these plants also showed the eharacteristic brown ring. We have thus shown clearly that these bacteria are the real cause of the ring disease of potatoes."

Dr. Coleman states that there are at least two common ways of infection as determined by lis experiments: (1) Through the planting of seed-tubers which already have the discase, and (2) the presence of these bacteria in the soil of the plot where the potatoes are planted. An experinent was also conducted which showed that potatoes harvested from a plot where the disease was present, even though they did not show the brown ring, wonld produce the disease if planted in soil unquestionably free from the bacteria-the young plants wilting throughout the plot soon after coming up.

A similar, if not identical, disease is found attacking the potato in America. Dr. Erwin F. Sunith of the Agricultural Department, Washington, has studied it thoroughly and has come to the conclusion that insects have a great deal to do with the spread of the disease.

In all my experiments I have kept a very careful watch for any instance of the spread of the disease by insects. $* * *$ On the whole, however, insect attack has been insignificant, and although I have examined very many wilted plants indeed, I have never yet seen one in which the infection conld, witl any likelihood, be traced to the gnawing of insects.

Dr. Coleman states that because in case of the above-mentioned potato-disease in America Dr. Erwin F. Smith has fon11d that it also attacks egg-plants (brinjals) and tomatoes, he instituted experiments to ascertain whether tomatoes and brinjals can be given the disease. The results already obtained show that both these plants can be infected with it by means of inoculation with pure growths of bacteria, or with bacteria taken direct from diseased potato-tubers. In one suceessful cxperiment with tomato-plants, 8 comparatively young plants were inoculated with pure growths of the bacteria; all the 8 contracted the disease and within 3 weeks were practically dead. Three larger plants (bearing fruit) inoculated at the same time with the same growths of bacteria remained practically unaffected and could not after 3 weeks be distinguished from an uninoculated plant of the same agc (see last paragraph on p. 179). Similar results have been obtained witl brinjal plants-the younger plants contracting the discase, whereas larger plants resisted it.

From the results obtained the following directions should be strictly adhered to, if possible: (I) Only such potatoes should be used for seed as have been grown on a plot whicl has been quite free from the disease; (2) where the seed is cut before planting, all pieces that have the least trace of brown spots or a brown ring should be discarded; (3) if the disease has been prevalent on a certain piece of ground, potatoes should not be again planted there for at least one year. Probably two years wonld be better, but a definite statement in this connection can not be made until the experiments in progress have been completed. Also, brinjals and tomatoes should not be planted on such infected ground.

Spraying the plants with a fungicidal or insecticidal spray is a waste of both time and money, as the disease is not transmitted, at least to any appreciable extent, by insects; nor can it be carried through the air from plant to plant. Another and a very effective means of cliccking the disease would be by the introduction of a discase-resistant variety of potato. Experiments in this direction are in progress.

The description of the organism is withheld by Dr. Coleman for a separate papcr. 


\section{THE CEYLON DISEASE.}

In 1909 , Petch reported very briefly on a wilt disease of tomato plants oceurring in Ceylon, during a period of wet weather, and first visible when the plants were in bearing.

The wilted leaves decayed and fell off, and finally the stems decayed also. There is very little eridence of disease in the stem when the leaves begin to droop, but if it is cut across near the base the woody part immediately round the pith is found to be brownish, and minute white or yellowish drops of liquid ooze out from this region. These drops consist of enormous numbers of bacteria, and if sections of the stem are examined under a microscope, they are found to issue from the vessels of the rood which are completely filled by then.

The bacterium is, as far as can be ascertained without elaborate bacteriological investigation, Bacillus solanacearum.

\section{THE AFRICAN DISEASE.}

The writer's knowledge of the Afriean potato-disease here referred to was obtained from a conversation with Mr. George Milton Odlum, a student of scientific agriculture, who for some time liad cliarge of plantations for English capitalists at Untali, in Rlodesia, where he saw the disease. He deseribed it to me as a bacterial rot, beginning as a black stain in the vascular system; the foliage wilts, the stems shrivel and blacken, or have black stripes in them, and the tubers decay. He has known whole fields to be destroyed quite suddenly. The microscope always shows great numbers of bacteria in the diseased plants. In his opinion the disease is the same as that described by the writer.

\section{THE RUSSIAN DISEASE.}

In I 899 , Iwanoff reported the oceurrence in $\mathrm{s} 898$, in all of the fields for a distance of 26 miles around St. Petersburg, of a very destructive bacterial disease of potatoes closely resembling that due to Snnith's Bacillus solanacearmm, if not the same. The organism present in the stems in the earliest stage of the disease is described as a "small, short, oval-cylindric, actively motile rod of medium size (in general rather variable) $\mathrm{I} .5 \times 0.5 \mu$."

Two organisms isolated from the diseased stems in pure culture were not infectious, but direct infections were successful.

The tissues were browned, the bacteria passed up and down the stem from the point of inoculation by way of the vessels, the pith was badly disorganized, the starch was not attacked, young plants were killed much sooner than old woody ones, the juice of diseased plants was alkaline, and in the pitl and the bark parenchyma there was an increased production of calcium oxalate. The tubers were small and few, but were not observed to be diseased. The disease spread with great rapidity. A field which contained only scattering cases on August 8, slıowed all plants diseased on Angust I 5, the only green things in the field, and in many similar fields, being weeds. Possibly this should be referred to $B$. phyto phthorns.

\section{THE FRENCH DISEASE.}

In I9or, in two publications, Delacroix stated that Smith's disease of the potato was prevalent in France. I translate as follows:

The bacteria are found far nip in the stem and in parts apparently still living. They are especially numerous in the vessels. 'This bacterium scems to me not different from the Bacillus solanacearum of Frwin F. Smith. Its cultural characters are the same; the signs of the disease observed in the United States on the potato, tomato, and egg-plant are exactly those I have myself seen.

Afterward Delacroix attributed the disease to a green flnorescent bacillns, $B$. solanincola Delacr., which is different from Bact. solanaccarmm, but non-pathogenic in my hands.

Here again, it is uncertain whether we have to do with Bacillus phytophthorus, Bacterinm solanaccarmm, or some third organism. The writer obtained a culture of $B$. solanincola from Prof. L. R. Jones, to whom it was given in Paris by Delacroix, but either it never possessed 
any pathogenic properties, which is quite probable, or else had lost them by cultivation. Notling Delacroix afterward published on this disease served to clear up the question.*

In 1902 Guéraud de Laharpe published a note on a Frencli potato-disease said to be due to Bacillus solanincola. He nuakes the following observations on the subject:

For several years the culture of the potato in France has decreased more and more, so that now in some departments it is insignificant or has been entirely abandoned, owing to the extremely difficult conditions. The year 1901 was partictilarly disastrous.

The Central and Western departments suffered most. Within a few days toward the close of July whole fields were destroyed, leaving of the crop only faded leaves and blasted stalks, while the tubers, when formed at all, were no larger than walnuts.

The disease appears in general about July 15 upon Jaune de Holland, an early variety, and a little later on late varieties, such as Richter's Imperator. The early varieties suffer most. It is encountered especially in soils which have borne potatoes repeatedly, but it is also found on newly cleared forest or vineyard soil, even on soils which have not borne potatoes within the menory of man. 'Though it scems to prefer calcarcous soil, it causes much injury also in clayey and sandy regions.

Tyloses are said to be formed in the stems. Delacroix advises soaking

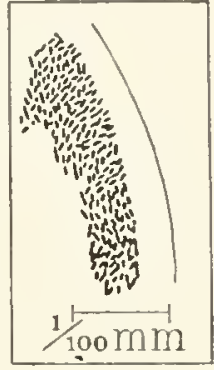

Fig. $114 a . \dot{\dagger}$ sound seed-tubers for an hour and a half in I part of commercial formalin diluted with 20 parts of water. Delacroix's most susceptible varieties are fo-day Halle and Long Yellow Holland.

\section{THE ITALIAN DISEASE.}

In south Italy, according to Comes, a disease of tonnatocs due to his Bactorium gummis is common. The stenis rot istrally from the base and the tissues are filled with bacteria. Bact. gummis is now regarded as insufficiently described and it is not known to what the nane was applied, as the organism is said to occur in a variety of plants. 'This is probably a disease of late spring, summer, and antumn. The writer searched in vain for it in the market-gardens about Naples in the early spring of 1906. A great many fields of potatoes were seen, but there was 110 trace of this disease. Voglino has also reported a disease from Turin, which he ascribes to Bact. solanaccarmm.

\section{THE GERMAN RING DISEASE.}

Appel and Kreitz describe a ring-disease, which possibly is eaused by Bactorim solanaccarmm, the most striking characteristic being a browning or blackening of the vascular bundles. In severe attacks the potatoes do not come up. On the seed-tuber small tubers appear and a great development of shoots, but these are too weak to break the ground and gradually die. When less severe the shoots come up, but are stunted. On subterranean parts are brown cracks whicl soon become glossy, black spots appear on the leaves, and the plant dies. In the lightest form the affected plants can not be distinguished from sound ones until harvest. Then the leaves wilt and usually show black spots. Such plants

*Fortunately, Delacroix left an abundance of material both dry and in alcohol to illustrate his potato disease This, throngh the courtesy of Etienne Föex, the present director of the Station of Vegetable Pathology, in Paris, the writer had opportunity to cxamine eritically in the autumn of $1913, i . e$, since the above text was written. Numerous microscopic examinations were made, but no bacteria were seen either plugging vessels or corroding tissues and certainly nowhere any in numbers sufficient to account for the disease. All of the plants were examined, and each in several places. In the stems and roots of those in alcohol (a large jar of material), nothing was found; but on the shriveled leaves there was a great abundance of Phytophthora infestans. On the dricd material evidently collected at another time and place, there was no Phytophthora, but Alternaria solani was found on the brown shriveled leaves, or at least an Alternaria resembling it; and in the xylem vessels in the basal part of sone of the stems, a fungus suggesting Fusarium, i. e, a delicate colorless mycelium abstricting colorless elliptical conidia in small numbers. Whatever Delacroix may have first identified as "Brunissure de la pomme de terre," due to his Bacillus solanincola, the museum material which he selected to illustrate it represents only fungous diseases of the potato.

tFig. I t q a. - Margin of a hanging drop showing Bacillus solanincola Delacroix. From an agar culture given to Jones by Delacroix in August 1904. 
bear almost a normal number of tubers, but are a menace to the crop, as the disease spreads from the small spots on the harvested tubers.

There can be 110 injury nuless the bacteria come into contact with the vascular bundles. Infection often occurs by abnormal growth of the young stem, resulting in cracks reaching even to the pitl. Also through wounds made by animals or otherwise the bacteria easily gain access, $e . g$., the disease is more prevalent when cut seed-tubers are used. If such are employed they should be covered with moist sacks for two days that the formation of a cork-layer may occur.

We made agar-poured plates in the laboratory in Waslington from the browned vascular bundles of a potato sent from München, Germany, by Mr. W. A. Orton in I9r I, as affected by the bacterial ring-disease, but obtained only a white endospore-bearing motile selizomycete, non-infectious to growing potato stems.

In Erriksson's book (Die Pilzkrankheiten der Landwirtsclıaftlichen Kulturpflanzen. A11s der Swedischen uebersetzt von Dr. A. Y. Grevillius, Kempen a. Rh., Reichenbachsche Verlagsbuchhandlung, Leipzig, 19r3, pp. 8-9) the ring disease is attributed both in the text and in the figure-description to Bact. solanaccarmm.

For further knowledge of this disease we must await Appel's full report.

\section{THE ENGL1SH DISEASE.}

There are a number of statements by English agricultural writers to the effect that Bactorim solanaccarmm Smith causes a disease of potatoes in Great Britain. These statements, however, are too indefinite to furnish any reliable basis for judgment.

\section{MALKOFF'S DISEASE OF SESAMUM.}

In 1903 a bacterial disease of sesamum was described by Malkoff, from Sadovo in Bulgaria. Early in August 1902, in a plot in which the plants liad been watered and had made more rapid growth than in a check plot, many leaves showed brown spots and dried up quickly. Sections revealed the presence of many bacteria. After 2 to 3 days the disease was widespread and the stens were also affected. These were dark brown to black, shrunken and covered with a slimy exudate which dried on the stem. This ooze was at first graywhite, but soon became dark brown. In a few days the stems became entirely black, bent over, and finally dried out.

Sometimes the whole plant is attacked, sometimes a single sloot (figs. 114 b,c). The disease progresses rapidly and in 3 to 4 days all the leaves are attacked and the stem decayed. It appeared on the early Bulgarian sesamum first, but later occurred on the two Asiatic varieties. The disease was confined to plants which had been in blossom for some time. In the unwatered plot no plants were affected until after a rainfall in September.

Inoculations of sound leaves and petioles with the juice of the affected plants, both with and without wounds, produced the eharacteristic signs in 4 to 7 days. In inoculations on plants growing in an unwatered plot, the disease also appeared (in 7 to 24 days) except in case of inoculations on the stem and under side of leaves without wounds.

'Two kinds of bacteria were isolated - a short rod and a long one. The first formed yellow colonies, the second white ones, in 24 to 48 hours at ordinary temperature. Both were motile and non-sporiferous. Growth in bouillon, gelatin, and agar was very lixuriant and the gelatin was soon liquefied. 'T'en per cent sesamum leaves with peptone and gelatin was an excellent medium. Milk was not curdled by either form, but was peptonized after $S$ days by the gray form. Inoculations were made with pure cultures and here and there the disease appeared, lout it did not progress rapidty as the tissues were then hard. Those on leaves produced the disease in 7 to 8 days.

This disease occurred throughout the sesamum-growing district i11 1902, but was less widespread that year because of the dry season. In previous years, according to the growers, the entire liarvest had often been lost through its ravages. It occurs principally in southern Bulgaria on the Turkish border. The author believes that the disease is distributed on the seed. 


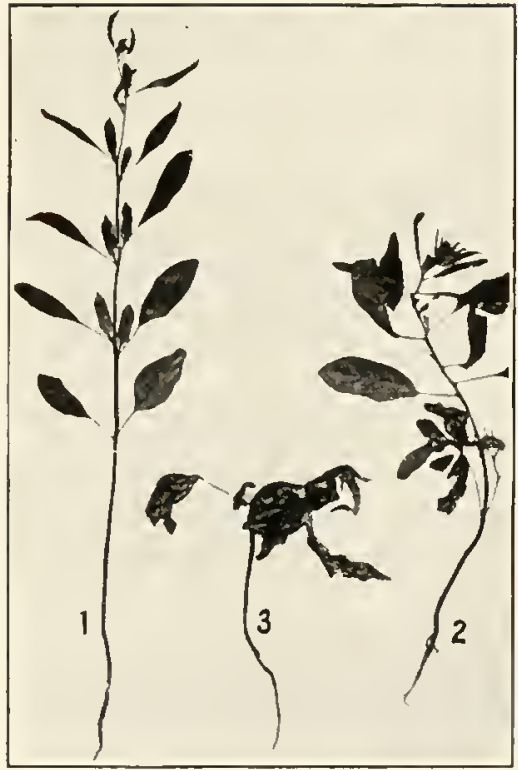

Fig. $114 b .{ }^{*}$

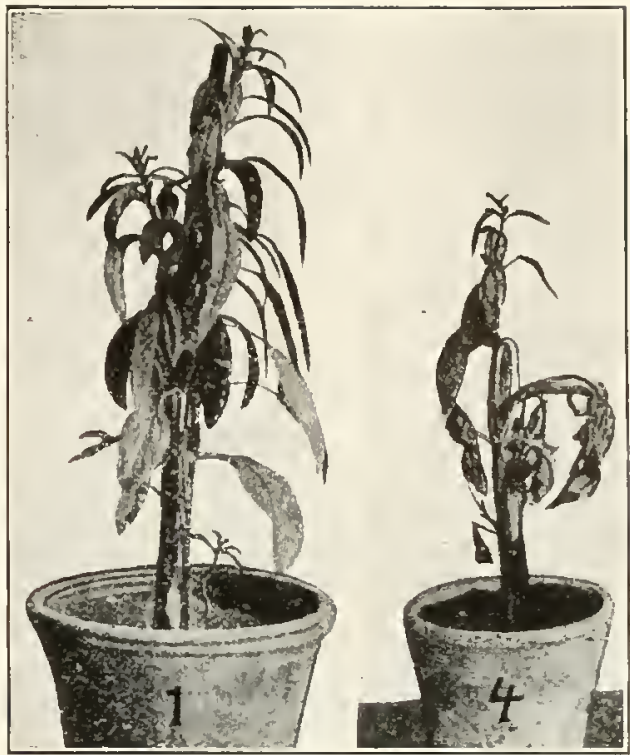

Fig. $11+c . \mid$

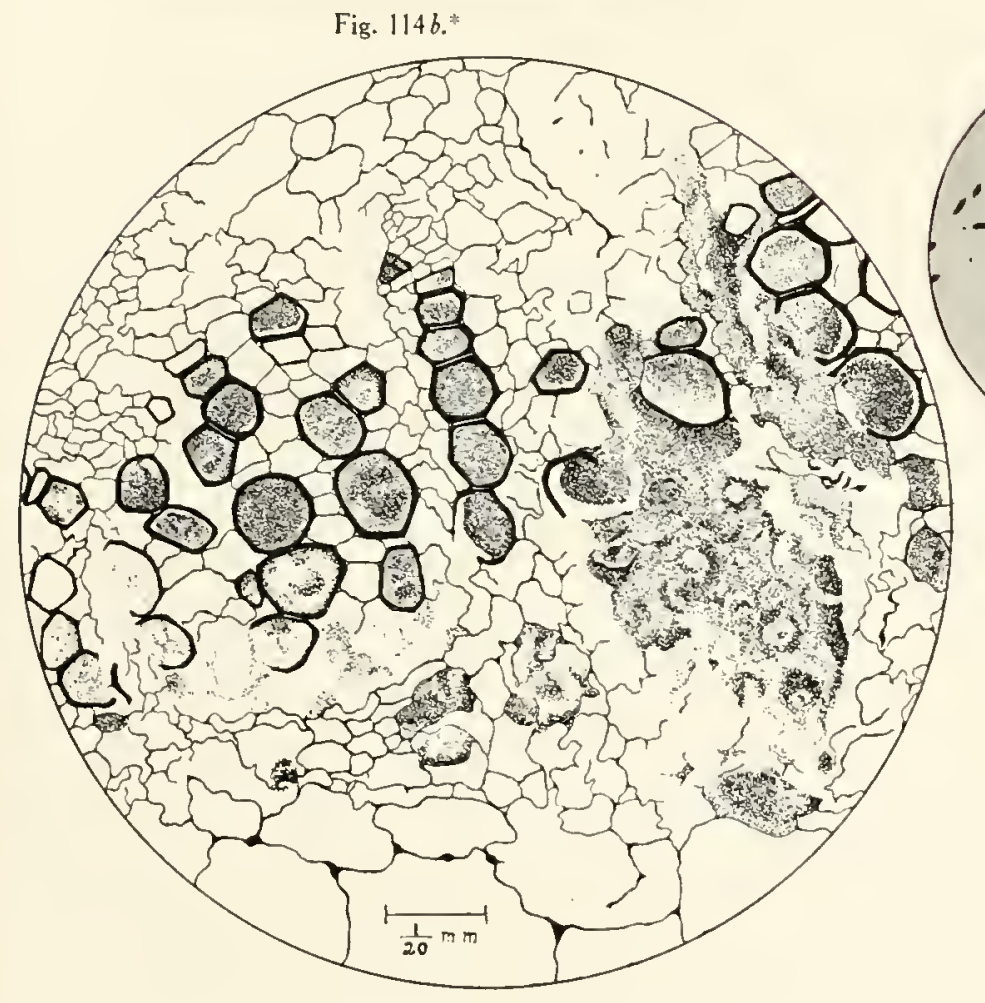

Fig. $11+e .8$

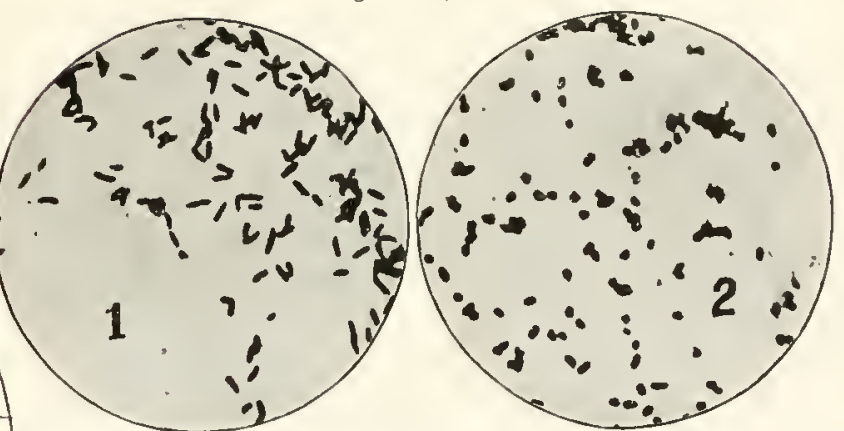

Fig.114d.†

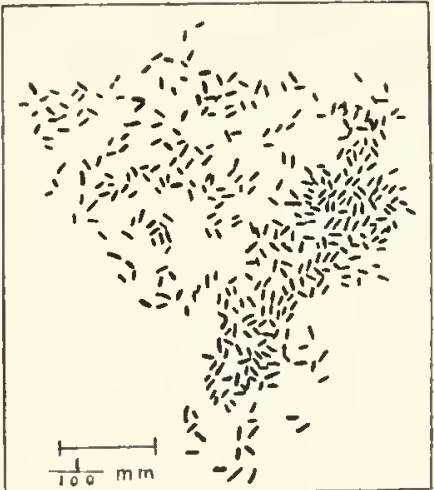

Fig. $114 f^{* *}$

${ }^{*}$ Fig. $114 b$. - Bacterial disease of sesanum: I, normal; 2, partly, and 3, wholly diseased. (After Malkofi.)

† I'IG. I I $4 c$ - - 1, normal sesamum; 4, bacterially diseased sesamum. (After Malkoff.)

¡Fig. 114d.-Malkoff's disease of sesamum: 1, Pseudomonas sesami Malk.; 2, Bacillus sesami Malk. (After Malkoff.) Magnification of $I$, said to be $\times 900$; of $2, \times 1000$. Kind of stain not stated.

\$FIG. 114e--Bacterial disease of sesamum from Austria. Cross-section of petiole, showing cavities and oceupation of the vessels. From material in Museum of the K. K. Laboratoriun für Pflanzenschutz, Vienua. Section stained with picric anilin blue, followed by carbol fuchsin, torn somewhat in cutting. Slide $952 \mathrm{G} 2$, middle section of lower sow. Drawn by Katherine Bryan.

**Fig. 1 $14 f$. - Austrian sesamum bacteria from a leaf-blade. Stained with carbol fuchsin. Slide 952 A 2, middle row, second section from left. Torn tissues omitted. Drawn by Katherine Bryan, $\times 1$ roo. 
In I 906 Malkoff published another short paper on the sesamum disease.

The gray, liquefying, polar flagellate Pseudomonas sesami measures $2 \mu \times 0.9 \mu$; the yellow nonliquefying, peritrichiate Bacillus sesami, $1.2 \mu \times 0.9 \mu$ (fig. $114 \mathrm{~d}$ ). 'The flagella of the gray form were stained with difficulty (Pepler's stain). While the two organisms can infect separately he thinks there is also a symbiosis.

Inoculations in pots of sterile soil gave the following results: (1) When seed from sotnd plants was used unsterilized, or from diseased plants after treatment with formaldeliyde, no disease resulterl; (2) When either infected soil or untreated seed from diseased plants was used, the disease appeared.

This subject is placed here because Honing in Sumatra has found sesamum subject to Bact. solanaccarmm, and because in a sample of "bacteriosis of sesamtm" given me in 1903 by Dr. Kornauth, of Vienna, and believed to be of Atstrian origin, the morphology of the abtndant bacteria and their location in the tissues suggest Bact. solanacearmm (figs. i i 4 , $f$ ).

Two bacterial diseases of sesamum are said to have been recognized in India (Bull. Imp. Inst., vol. IX, No. 3, pp. 264-265, London, I911), one due to Ps. sesami and the other to Bacillus sesami, but no author is cited, no one is responsible for the statement, and the above is all the information given.

\section{LITERATURE.}

1884. Cones O. Sulla malattia del pomodoro (I y yco persicum esculentum) denominata Pelagra o Bolla nella Provincia di Napoli e Sulle Crittogame che l'accompagnano. Atti del R. Istit. d'Incoraggiamento di Napoli, vol. I11, No. 11, 1884. See also L'Agricoltura meridionale, Napoli, 1884, No. 16, and Ann. della R. Scuola Sup. d'Agricoltura in Portici, vol. V. fasc. 2, Napoli, 1885, p. 83. Separates also.

Possibly this reference belongs here. The reader may also consult Comes, Crittogamia Agraria, vol. I. Naples, I891, pp. 498 and 513 at seq.

a the spring of 1883 this was a common disease in patatoes and tomatoes in the Vesuvian region. 1t spread rapidly in moist, hot weather.

1890. BurRILl, T. J. Preliminary notes upon the rotting of potatoes. Proc. I I th Ann. Meeting Soc. Prom. Agr. Sci., 1890, pp. 21-22.

1891. HALSTED, BYRON D. Bacteria. II th Ann, Rep. New Jersey State Agric. Expt. Sta., and 3d Ann. Rep. New Jersey Agric. College Expt. Sta. for I 890, Trenton, N. J., is91, p. 347.

1892. HALSTED, BYron D. The southeril tomato blight. Miss. Agric. and Mechan. College Expt. Sta. Bull. No. 19, Jan. 1892, I2 pp. Reprinted in I 2th Ann. Rep. New Jersey State Agric. Expt. Sta. and 4th Ann Rep. of New Jersey Agric. College Expt. Sta. for 1891, Treiston, 1892, pp. 267-273.

1892. HALSTED, BYRoN D. Sonthern tornato blight at the North. Garden and Forest, vol. $v$, A11. IO, 1892, p. 379 .

1892. BaILEY, L. H. and Corbett, L. C. The southern or field blight, in "Tomato Notes for $1892 . "$ Bıll. Xiv, Cornell Univ. Expt. Sta., Oct. 1892, pp. 293-295, I fig. (of a diseased plant).

1S93. BurriLi, T. J. An additional note on the rot of potatoes. Proc. Soc. I'rom. Agric. Sci., vol. for 1891-92, Columbus, $1893,13.29$.

Paper read at Washington in August, 1891 .

1894. Tryon, Henry. A new potato disease. Ann, Rep. Queensland Dept. Agric. for $1 \$ 93-94$. Brisbane, 1894, Govt. Printer, pp. 2 to 4

This and the following possibly belong here.

1894(?). TRYON, HENRY. Virulent potato disease. Suggestions for stamping out the disease. Brisbane, 1 page.

Not seen. Review by Sclimper in Zeits. f. Pflanzenkr., Bd. v, $1895, \mathrm{p}, 234$.
1895. TrRyon, Henry. Ann. Rep. Queensland Dept. Agric. for $1894-95$. Brisbane, 1895 .

Part of a parasraph buried on page 14 in "Gumming of Cane." The name Bacillus vascularum solani occurs here.

1895. HELsS, Rich. Report on an investigation into the potato diseases prevalent in the Clarence River district. Agric.Gaz. of New South Wales, vol. vi, pt. 5, May 1895, pp. 316-329, 2 col. pl.

1895. HALSTED, BYRON D. Bacteriosis of tomato. 15 th Ann. Rep. New Jersey State Agric. Expt. Sta. and 7 th Ann. IRep. New Jersey Agric. College Expt. Sta. for I894, Trenton, N. J. I895, part II, p. 361 (two lines).

1895. SMITH, ERwIN F. The southern tomato blight. Abstract in Proc. Am. Asso. Adv. Sci, vol. Xilv for ISo5, Salem, 1896, D. 191. Also a separate. A brief notice appeared in Bot. Gaz., Sept. 1895 , p. 409.

1896. SMTH, ERWIN F. A bacterial disease of the tomato, egg-plant, and Irisls potato (Bacillus solanacearum n. sp.). Bull. 12, Div. Veg. Phys. and Path., U. S. Dept. of Agric., 8vo, 28 pp., 2 pl., 1 colored. Issued Dec. 19,1806

1897. SF.triv, A. D. Investigations of plant diseases ius foreing-house and garden. $V$. Tomato diseases. 7. Bacterial tomato blight. Bull 73. Ohio Agric. Expt. Sta., Wooster, Ohio, Dec. $1896, \mathrm{pp} .2+2$ and 245 . Printed at Norwalk, Ohio, 1897 .

1897. SMITH, FRWIN F. On the nature of certain pigments produced by Bacillus solanacearum. I'roc. Am. Asso. Adv. Sci., vol. Xtvi, for 1897. Salem, 1898, p. 288 . Bot. Gazette, vol. xxiv, 1897, p. 192.

A brief note. Sulstance believed to be a humus-compound

1898. Rolfs, P. H. Bacterial tomato bliglit (Bacillus solanacearum S.). Report of the Biolog ist and Horticulturist, Expt. Sta. of I'la. Agric. Col., p. 6. No date, but published after June 1898.

1898. ROLFS, P. H. Diseases of the tomato. Bull. 47. Fla. Agric. Expt. Sta., Sept. IS98, pp. $12 S-132$

I898. RULFs, P. H. Bacterial tomato blight (Bacillus solanacearum Smith) in "Injurious insects and diseases of the year." Reprint from Proc. it th Ann. Meeting Florida State Hor, Soc, I 898, p p. $90-93$. 
1899. Tryon, Henry. Potato disease. Queensland Agric. Journ., vol. v, part 2, July I899. Also a separate, $7 \mathrm{pp}$.

1899. IWANOFF, K. S. Ueber die Kartoffelbakteriosis in der Unıgegend St. Petersburgs im Jahre 1898. Zeits. f. Planzenkr., Bd. Ix, Heft. 3, July I 899, pp. I29-13I. Also a separate.

1900. F,ARLE, F. S. Bacterial wilt (Bacillus solanacearum E. F. Smith), in Buil. ro8, Tomatoes, April rooo, Ala. Agric. Isxpt. Sta., Auburn, pp. $25-28$.

I gon. SELAY, A. D. Bacterial blight of tomato, eggplant, and potato, in "A condensed handbook of the diseases of cultivated plants in Ohio." Buil. I2 I of Ohio Agric. Expt. Sta., Sept. I 900, p. 56.

"It was destructive at MIt. Carmel, near Cíncinnati, in $1806 . "$ * * * "To ditte this disease has been less destructive than the leaf-spot."

Igor. Delacroix, Georges. Sur une maladie bactérienne de la Pomme de terre. Comptes rendus des sé. de l'Acad. des Sci., Paris, igor, tome cxxxıI, pp. $+17-419,26$ aôut. See also the same, Dec. 9, 1901. Also a separate.

I 90 I. Delacroix, Georges. Sur une nouvelle maladie de la Pomme de terre en France. Journal de l'Agriculture, Paris, Sept. 7, rgor. Also a separate, 7 pp. See also Revue Hort., 1892, p. 94; and Bul!. du Min. de l'Agric. 1901, No. 5.

190I. BatTanchon, G. Ia maladie bacillaire des pommes de terre. Le Prog. Agr. et Vit., tome xxxvi, Montpellier, I901, pp. 318-32I.

Observations from the field. May perhaps belong here Disease very destructive in 1901 in Saóne el Loire on granite and sandy land well adapted to potatoes. Bordeaux mixture did not prevent its development. Ideotified as due to $\mathrm{BaCl}$ solanacearmm on strength of Delacroix's first statements.

190I. SMITH, ERIVIN F*. Entgegnung auf Alfred Fisher's "Antwort," etc. Centralbl. f. Bakt., 2 te Abt., Bd. vir, No. 5-6, pp. $133^{-1} 3^{8}$ and i 96-197. Also a separate.

Tafeln $x$ and $x y$, and the accompanying text, relate to Bact. rolunacearme. The plates are heliotypes from photomicrographs by the author. The text is mostly a translation of parts of Bull. 13 .

I goi. Hunger, F. W. 'T. E'en Bacterie-Ziekte der Tomaat. Nededeelingen uit's Lands Plantentuin Xl,vil, Batavia, I gor, 8vo, pp. iv, 57, $2 \mathrm{pl}$.

1902. - - Bacteriosis of potatoes. Bacillus solanacearum (E. F. Smitls). Reported in various parts of England in Jour. Bd. Agr. (I.ondon), vol. $\mathrm{Ix}, 1902, \mathrm{pp} .308-310$, I pl.

An anotymous contributioo, describing several potato diseases, states also that this bacterial discase "h:2s, unfortunately, been recorded from several localities in this cnuotry during the present season [1902]."

I902. GUÉRAUD DE LAHARPE, S. Une Nouvelle Maladie de la Poume de Terre. Journ. d'Agr. prat., n.s., tome III, ]'aris, I 902, pp. 48 I -482 .

I903. Mal KOFf, KONSTANin. Iine Bakterienkrankheit auf Sesamum orientale in Bulgarien. Centralb. f. Bakt., 2 te Abt., Bd. xi, pp. 333$336 .+$ figs.
1904. Chinton, G. P. Blight [of tomato]. Bacillus solanacearum Sinith. Report of botanist, forming part iv Conn. Agr. Expt. Sta. Rep., I903. p. 364. Plate xxvii $a-c$. New Haven, $190+$.

Reports occurrence at New 1Iven. The disease was confioed mostly to four rows runting through middle of field.

I904. V'oglino, Piero. Osservazioni sulle principali malattie crittogamiche sviluppatesi nel anno I 904 sulle piante coltivate nella provincia di Torino e regioni vicine. Ann. d. R. Accad, d. Agric. Vol. quarantesinosettimo. Torino, I 904 , pp. $343-3+4$. Also a separate.

Bact. solunacearum is said to cause a widespread disease of tomatoes in the market gardens abont Turin. These bacteria taken from the browned internal parts measure $1.5 \mu \times 1.2 \mu$. The colonies give a browu color on potato and on agar.

I go6. KiRk, 'T. W. Vascular bacterial disease of potatoes. An11. Rep. New Zealand Dept. Agric., vol. xrv, rgo6, p. 352, 3 figs.

Kirk figures sections of 3 potato tubers altacked by a vascular bacterial disease, which, he says, is due to Bacillus solanaceorum. The figures are very plain and show disorganiza. tion and dark stain in the vicinity of the vascular riog.

Igo5. MalkofF, Konstantin. Weitere Untersuchungen über die Bakterienkrankheit auf Sesamum orientale. Centralb. f. Bakt., 2 Abt., xri Bd., 1906, pp. $66 t-666,+$ plates.

1907. KiRk, T. W. Brown-rot of the potato. Ann, Rep. New Zealand Dept. of Agric,, vol. xr. 1907 , p. 16.8

This rot occurs in New Zealand io a few localities only.

1907. APpel, OtTo, und Kreitz, Wilit. Die Bakterienringkrankheit. Mitt.a.d. Kais. Biol.Anst. f. Land- und Forstwirtschaft. Ieft 5, Aug. I 1907, s, 17-19, mit ein Text fig.

1907. MAYER, ADOLF, Die Ringhrankheit oder Eisenfleckigkeit der Kartoffel. Jour. für Landwirts., Bd. 55, Heft 4, pp. 30I-304, I taf.

I 909. StEvENS, F. I. Bacterial disease of tomatoes (Bact. solanacearum). Notes on plant diseases occurring in North Carolina. Thirtyfirst Ann. Rep. N. C. Agr. Expt. Sta., West Raleigh, June 1 908, p. 82. Issued in 1909.

I gog. COLEMAN, LESLIE C. The ring disease of potatoes. Bull. I, Myco. Series, Dep. Agr., Mysore State, Bangalore, India, I 909, 15 pp., I 5 figs.

1909. PEтсн, 'T. Niscellanea. Tropical Agriculturist. vol. xxxiri, No. 6, Dec. 1909, p. $52 \mathrm{I}$.

I 909. BRANDL, JoHANn. Blattrollkrankheit oder Bakterienringfäule. Wiener Landwirtschaftliche Zeitung, 59 Jahrg., No. 70, pp. 691-693, and No. 71, pp. 701-702.

1909. ZEDWITZ, WILHELM voN. Blattrollkrankheit und Bakterienringfänle. Wiener Landwirtschaftliche Zeitung, 59 Jalırg., No. 83, pp. 818-8I9.

1909. Schander, R. Kartoffelkrankleiten. Fïlllings Landwirtschaftliche Zeitung, 58 Jahr., Heft 8, April I5, I 909, pp. 273-285.

1910. BANCROFT, KEITH. A bacterial disease of potato and tomato, Agric. Bull. Str. and Fed. Malay States, vol. Ir, Dec. 1910, pp. $47^{8}-480$.

(See also Spieckermann, this Monograph, pp. I66-167.) 


\title{
WILT-DISEASES OF TOBACCO.
}

\author{
(Sumatran Slime-disease of Tobacco; Granville Wilt; Japanese Stem-rot, etc.)
}

A portion, at least, of this chapter belongs with the preceding. It is here kept separate, partly for the convenience of the reader, partly because it was written up in this form, my ow11 cross-inoculations (up to I908) not having been as conclusive regarding exact identity as those reported by Dr. Hunger; and partly because of contradictory statements by Uyeda respecting the cause of the Japanese disease. The whole subject of the etiology of these tobacco-rots needs very careful inquiry. Possibly we have to do with several different wiltdiseases. $^{*}$ In 1908 and I 909 , the writer obtained conclusive cross-inoculations on tomatoes, using the North Carolina tobacco organism. In r9o9, Stevens sent me a photograph slowing the tomato-disease occurring in tobacco fields (fig. I I5).

\section{THE DUTCH EAST INDIAN DISEASE.}

\section{HISTORY AND ETIOLOGY.}

In 1892 , from studies 111ade in Buitenzorg, on specimens received from Sumatra, Janse correctly attributed to bacteria the tobacco-disease subsequently studied by van Breda de Haan, by Hunger, by Jensen, and by Honing.

Janse describes the brown sunken stripes on the surface of the stem and the brown stain in the vessels, and notes the fact that they are plugged with a grayish mass of bacteria which stained readily in picric-acid-anilin-blue. He also examined microscopieally the destruction of bark, bast, and pith, and saw closed cavities extending long distances. These cavities were filled with the bacteria in enormous quantities. Similar lesions occupied by the bacteria were seen by him in the leaf-stalk, the nidrib, and the side-veins of the leaves. Morphologically, all tlie bacteria appeared to be of one sort, were quite short, so as more to resemble coccus forms than rods, and measured $0.7 \mu$ in length. He did not find the bacterial plugging of the vessels in all of the diseased plants, but this is not to be wondered at, as lic did not himself select the material, and a fungous disease appears to have been present also on the plants both in the seed-beds and in the fields. Most of his observations were made on alcoholic material, and no cultures or inoculations were undertaken. His general conclusion is sufficiently sliown by the following paragraph:

From these anatomical studies we may conclude, tentatively, that the disease here considered is probably caused by bacteria. 'These appear to infect the leaf locally' (plaatselijk), developing in the cells of the leaf-tissues, which are destroyed, and subsequently extending further into the plant, either by way of the ressels, or from cell to cell. In the first case they enter the steni, and subsequently appear outside the vessels (possibly by the normal rupture of the prinary vessels due to elongation of the sten), and inake their way between and into the adjacent cells (bast and pith) where they may develop into great colonies, and by destruction of the tissues form cavities which one funds on examination to be entirely filled with bacterial masses.

Mycelium was oceasionally found with the bacteria, but Janse is inclined to think it secondary.

In 1898 , in the Dutcl East Indian Journal Teysmannia, Dr. van Breda de Haan described a disease of tobaceo prevalent in Sumatra. He speaks of it as the slime-siekness, a "specific decay," resulting in the deatli of the plant. He attributes it to wounds of various kinds followed by the entrance of a specific bacteriun. The bulk of the long paper is

* Since this was written Honing has cleared up the Dutch East Indian situation.

220 
devoted to a description of the signs of the disease and to statements of the numerous ways in which the organism may penetrate the plant, the latter being conclusions derived from field observations. The disease was believed to enter the plant only through wounds, generally of the root or stem under ground, but also sometimes above ground. Many possibilities are described. The organism is stated to be a cocens, neasuring about $s_{\mu}$ in diameter. It was not named, nor were many of its biological peculiarities described. It is stated to issue from the plant as a dark brown slime, but to be grayish-white on agar and to be actively motile in the plant. On plate-cultures it formed fused colonies with an irregular wavy border. It stained readily with carbol-fuchsin and alkaline methylene blue.

The external signs in the tobaceo plant are sudden wilting of the foliage, pale green spotting and then brown spotting of certain foliar portions, especially the "ears" of the leaf, general yellowing and death of the lower leaves and a local black stain in external portions of the stem, especially toward the base. The brown spots on the ears of the leaf are said to be a sure sign of the disease. The internal signs are a brown or black stain in the vascular tissues (from which on cross-section a brown bacterial slime issues abundantly), and nlarked staining of the pith, whicl is usinally found to be badly disorganized, so that in stems attacked for some time the whole central portion becomes a sliny mass. Sucl stems are easily crushed between the fingers, althougli externaliy they may not show any or mucli indieation of disease. The bacteria mul-

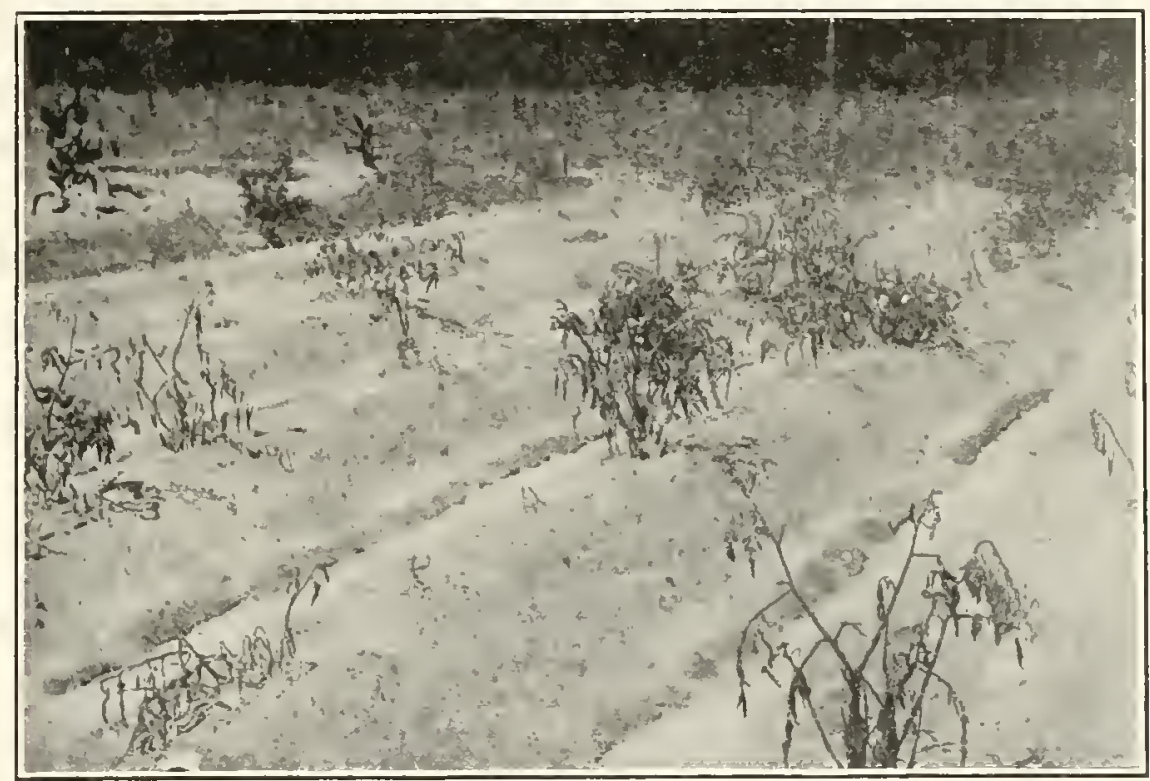

Fig. 115.* tiply most rapidly in the large intercellular spaces of the pith, less rapidly in the wide xylem vessels, where the eross-walls act as hindrances. The pluloem part of the stem ordinarily is not greatly injured. The amount of stareh in the vicinity of attacked tissues appeared to be noticeably less than in sound cells. The root-system is usually oceupied by the bacteria, and frequently stained dark brown. In bad eases the secondary roots are not well developed. The underground part of the stem was often rotted badly. Eel-worns and an insect (larva of the family 'Tineidx) causing galls on the stem at the surface of the earth were believed to play a considerable part in paving the way for infection. It is also stated that the removal of the lower leaves at the time of planting, and various other practices of the coolies, faror the distribution of the disease. Sometimes the plants set out by one coolie will be badly attacked, while those set out by his neighbors will be free from disease or nearly free. The disease is said to be most serious on heavy lands, while on mellow ground

*Fig. I15.-Tomatoes following toluacco in a North Carolina field. Thlie tobacco contracted the Granville wilt and the tomatoes set in place now show the same disease. (From a photograph by Dr. F. L. Stercns.) 
rich in humus it is seldon seen. Only exceptionally does the disease begin in the secd-beds, and it is not generally observed until some weeks after setting out the tobacco. If the weather is dry the first conspicuous signs are flagging of the leaves. In such plants the base of the stem is discased and the tap-root, if not other roots. Where a whole ficld shows this disease it may be assumed to have been very badly planted, $i$ e $e$, hastily or with too old plants. Rains favor the spread of the disease, and topping, removal of leaves, suckers, etc., sliould be done, as far as possible, in dry, sunny weather.

Up to the time of publication of his paper Dr. van Breda de Haan had secured very few, if any, pure-culture infections. He had reproduced the disease in the ficld by direct infection, using slime which liad just extruded from the vascular system of cut stems, obtaining an abundance of the bacteria, with typical signs of the disease in the pith $26 \mathrm{~cm}$. above the wound. Later, at Buitenzorg, he states that he reproduced the disease by injecting a pure culture in bouillon, but surely not with the coccus form $8 \mu$ in diameter. His field observations seem to liave been numerous, but the laboratory work appears to have been meager.

In I90I, in a general paper on tobacco discases, Dr. Hunger devoted a chapter to this same disease, confirming van Breda de Haan's statements respecting its prevalence in Deli, the signs of the disease, and the great frequency of underground infections through injuries due to eel-worms and other causes. He was not able to confirm de Haan's statement that the disease is due to a Micrococcus.* Dr. Hunger found this disease due to a much smaller rod-shaped micro-organism which he identified as Bacillus solanaceamm. He states that le obtained infections with this organism on tobacco and that he could not distinguish it from the organism attacking tomatoes in Java, nor the latter from that described by Smith from potatoes, tomatoes, and egg-plants in the United States.

The following statements respecting the Suntran tobacco disease are translated and condensed from Hunger's Dutcli paper:

This sline-disease was so named by van Breda de Haan, who first investigated it. It is cansed by a bacterium which lives as well in the above-ground as in the under-ground plant, but wlicli was not exactly recognized by the discoverer, as may be scen from his description on page 17 (544).

From van Breda de Haan (whose communication is here borrowed in part witl certain corrections) the bacteria received no name.

As the result of an earlier investigation [tomato disease] I came to the conclusion that the slimediscase of tobacco was caused by Bacillus solanacearum Smitli, to which same conclusion Raciborski likewise arrived.

The disease oceurs over all Deli, as well in the sced-beds as in young and old tobacco, chiefly in the latter, because it occurs most seriously during the period of licavy rains.

In the attacked seedlings the lower part of the little stem is dark colored and very flabby, so that it often falls over, while the small leaves wilt and in part hang down brown.

In large tobacco this disease begins commonly to be noticeable first in dry wcather througl the interruption of the water-movement in the above-ground parts of the plant. "This is shown by the witting of the leaves. At the same time they lose their fresh green color and there appear upon the ears of the leaf pale green spots, and afterwards also upon the blades themselves, and these specdily become browl and dry ont.

The liarvested tobacco from such slime-diseased plants is often unripe.

The lower end of the sten gets then a dark color and perishes within, so that it can be easily squeczed together between the fingers. 'The lower leaves become quickly yellow and die before ripening.

The root-system of the attacked plant is colored brown, the main root is mostly black and rotted at the top. Sonnetimes also the wlite, sound, side roots found on healthy plants are liere wanting.

Irom the root-system the decay contintes slowly upward, by means of which the pith of the stem is finally wholly decayed into a slimy mass, wherefrom the name of this disease (slime-sickness) was taken. The disease does not remain limited to the stem, but continues in the leaf-stalks and infects in this way also the leaves, causing spots to appear upon the leaf-surface.

*Hunger noted the occasional presence of a round yeast $0.008 \mathrm{~mm}$. in diameter in his tomato lissues cliseased for some time. 
In tobaceo already topped the sline-disease often shows strikingly on the above-ground plant, so that the top is said to be water-soaked (ingeregend).

If one cuts the stem of a slime-sick plant erosswise there then appear quickly on the cut surface little brown drops, which slowly becone greater by fusion and oceupy just the place of the vasenlar ring. If one examines the plysical condition of these lrops they are seen to consist of a slimy substance which may be stretched out in threads.

If one examines microseopically the leaf-spots of the slime-sick tolacco on eross-section, then one sees that the parenchyma of the spot is completely changed. 'The cell-walls are dissolved and the chloroplasts wholly disorganized, while in their place a mass of bacteria fills the spots of the attacked leaf-blade. If a seetion is made across an attacked sten we see that the walls of the vascular bundle, and also of the woody parenchyma bordering the same, are colored dark brown, sometimes even black, while the limina of the xylem vessels show a partial or total ocelusion. 'T'his ocelusion consists partially of the massing of bacteria with their disorganization products and partially of bladder-formed swellings from the surrounding parenchyma cells, that is, tyloses which have grown into the interior of the vessels. 'I'his alonormal filling of the water-patlis causes naturally a stoppage, on aceount of which the sap-strean is soticeably hindered and finally interrupted. The necessary consequence of this is that water-need appears, which is shown by the wilting of the part of the plant above ground.

The inclination to this formation of tyloses is eaused by a bacterium (Bacillus solanaccarmm Smith), which by means of many sorts of external wounds is given an opportmity to enter into the interior of the plant. When once entered into the xylem vessels the vessel wall is throngh them in some places partially absorbed, so that the above mentioned tyloses are formed.

'The slime-disease described here is altogether a secondary phenomenon, which is made possible by external wounds.

In by far the nost eases the injury of the plant takes place either on the root or on the stem eoncealed underground. In the latter case I mean the stem part which has been covered with earth by heaping up the ground.

The woundings may be due to many and very different eauses. In the first place should be mentioned wounds due to plant and animal parasites. Among the first named 1 reckon chiefly the parasitic molds, especially Phytophthora nicotianac. Some of the principal animal parasites are the injurious soil inseets, for example, eel-worms (Heterodera radicicola) and thick bellies* [Glechia solanella Boisd. (G. tabacella Reg.)].

In the second place are to be mentioned the mechanical injuries which during eulture may be brought about by various means, such as pulling 11 p the seedlings, transplanting, lilling, topping, and removal of suckers.

Finally, an injurious chemical and pliysical soil-condition is not least active in making the underground plant parts susceptible to infection, the most important of which is poorly cultivated and badly drained ground. 'l'his does not allow the roots to develop nornally, and on account of the stagnating water they go easily over into deeay.

Through all the above summed up eireumstances the Bacillus solanacearum, present iu the ground, is given the opportunity of penetrating into the plant through the injured places, so that the sickness induced thereby is a secondary process for the occurrence of which oceasion may have been given in varions ways, but always witl the same external signs.

The spread of this disease in the field is very easily caused during the care of the tobacco, as well by the coolies themselves as by their tools.

In the plant itself the spread of the infection is assured as soon as the bacteria have reached the vascular bundles. With the rise of the sap-stream from the root-system the bacteria are carricd along [?] to the parts of the plant above ground, where the signs of the disease appear in the various organs.

Bacillus solanacearum Smith is elliptical in form, of midelle size, ordinarily 1.5 to 3 times as long as broad ( $\mathrm{I} .5 \mu$ long and $0.5 \mu$ broad), but very variable, according to age and cultural condition.

Pure cultures are easily made upon agar plates. In the beginning this bacterium forms on the surface of the nutrient substratum small, round, dark brown colonies, $\dagger$ which slowly extend eoneentrically. Mixed in with these round colonies come often also lens-formed colonies, but both are made up of Bacillus solanacearum. 'These variable ways of growing of the self-sane bacteria are a consequence of the location of the colonies. If they are buried in the agar then they grow slowly toward the surface on account of lack of oxygen.

* So called because they produce a swelling or gall on the stem at the surface of the eartli.

tThis is probably an error, unless we are to assume the organism different from Bacterium solanacearum. Van Breda de Haan says grayish-white on agar, and this, so far as my own observation goes, is always the initial colur of $B$. solanacearum, the colonies of which become brown only after some days or weeks. 
Dr. Hunger says: "I succeeded repeatedly in artificial infections with Bacillus solanacearum on sound plants, which then showed the typical phenomenon of the slime-disease."

This disease in the tobacco is a specific rotting process caused by Bacillus solanacearum Smith, for the appearance of which a wounding of the plant is first necessary, since the bacteria themselves are not able to enter of their own accord to cause tlie slime-disease. After a preliminary wounding it is possible for the bacteria to penetrate the plant and to find principally in the vascular bundles their seat of activity.

'The infection takes place chiefly on the underground parts of the plant, although the first noticeable signs of the discase are shown by the witting of the leaves.

Whenever the path along which the sap-stream moves is completely stopped up the plant dies in consequence of lack of water.

The interior of the stem is completely disorganized. In later stages of the slime-disease the rotting process is lastened by the appearance of several saproplytic bacteria and yeast species. The tobacco from slime-sick plants is often unripe because, for the most part, it must be harvested too early, otherwise the spots on the leaves form very weak places.

A great reduction in the spread of this disease would be brought about by avoiding to plant the places where slime-diseased tobacco plants have stood, at least without special precautions.

It is to be desired that tobacco from slime-diseased plants should be pulled up and not cut, so as to avoid bringing the rotting stems into the sled. The hollow stems filled witl slime should be carefully removed and burned.

In 1909. Jensen published some notes on the Dtıtch East Indian disease in a general paper on tobacco. Sone of his conclusions are as follows:

Sonnd and strong tobacco plants are resistant to the slime-disease bacteria. Only when the bacteria are extremely virulent are strong plants made sick and then in many cases these are not killed, but form new sound roots, develop new shoots, and sometimes wlolly recover. Serious injuries occur only on fields with less good soil, where the plants in their youth have not been strong enough to resist the bacteria.

In his first experiment, begun September 30,1908 , on 10 plants, slime was taken directly from the cut stem of a tolacco plant received from Djoganalan and injected into the exposed roots by means of a sealpel and the needle of a Pravaz syringe. After 9 days all the plants became diseased and the lower leaves showed the characteristic dried-out spots. The 10 plants were afterwards pulled up and dissected. 'The roots were rotted and there were, on cross-section, the characteristic small black spots in the vascular ring.

In the second experiment 70 plants were used. The results were as follows:

'TABLE 22.-Jensen's Results.

\begin{tabular}{|c|c|c|}
\hline $\begin{array}{l}\text { No. of } \\
\text { plants. }\end{array}$ & Source of bacteria, etc. & $\begin{array}{l}\text { Diseased } \\
\text { (in varying } \\
\text { degrees). }\end{array}$ \\
\hline 25 & Checks .......................... & o \\
\hline 15 & Inoculated with slime from Djoganalan tobacco . . . . . . . . . & 15 \\
\hline 15 & 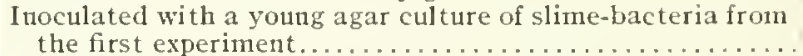 & 13 \\
\hline 10 & Inoculated with Bact. No. I (air of the laboratory) ............ & 1 \\
\hline 5 & Inoculated with Bact. No. 2 (air of the laboratory)........ & o \\
\hline
\end{tabular}

None of the inoculated plants died. Most grew well and many reached the height of the uninfected control plants. Neighboring plants were not infected. Following a rain the diseased plants recovered their turgor. Jensen's final conclusion is as follows:

The slime-sickness, consequently, must be regarded as a true bacterial disease which can develop only under unsatisfactory cultural conditions and which spreads from plant to plant but little or almost not at all.

In August 1910, Honing published in Dutch a very interesting preliminary paper on the tobacco-disease of Sumatra, which I summarize as follows:

In all stages of the disease bacteria occur, at first only in the roots, later in the stem and also in the veins of the leaves where they are visible as brown spots on breaking the leaves. 
With exception of a yeast no fungi have been observed.

'The cause of the disease will remain in the ground in the absence of tobacco cultivation for 8 years or more. Exhaustion of the soil is not an explanation, because in splendid high tobaceo on land which has had little or no fertilizer the disease occurs.

Bad drainage certainly favors the spread of the disease, but is not the cause of it, and it may occur to a serious extent on the best-drained lands.

Degeneration of the Deli tobacco can not be the cause. Plants which on only moderately good ground and often under unfavorable circumstances make stems 2 meters high, blossom, fruit, and set seeds 90 per cent of which will germinate, ean not be run out.

On the east coast no plant has been suspected more than Albizzia, but this can not be the cause of the tobaceo disease." 'There are places where Albizzia has persisted, where none or little of the tobacco disease occurs, and on the contrary there are lalang $\nmid$ soils where so to 90 per cent has been killed.

"In my opinion the slime-sickness is a bacterial disease."

The first thing to be done was to determine whether the disease could be reproduced with the bacteria present in all the sline-sick plants. Stems of such plants were ehopped fine, mixed with earth, and then placed under 24 young plants, of which 15 contracted the disease, the presence of the bacteria in them being controlled by microscopic examination. Of the 24 control plants none became diseased.

The juice of the sound pith of tobaceo is slightly acid, that of diseased plants is alkaline and blues red litmus paper, but if the decay continues until the stems become hollow, it may again become acid.

If one makes transfers from the nerves of leaves which have recently begun to droop, and as high up as possible on the stems, frequently one may obtain pure cultures of the slime-sickness bacteria. T'he bacteria occur first in the large cells of the bundle, later in the phloem and water ressels.

With bacterial cultures, so obtained, inoculations were made. On May 23, 12 rows of young tohacco plants, 25 in each row, were treated as follows:

1. Control.

2. Plants dipped into a dish containing about 2 liters of water in which a bacterial culture was poured, and then planted.

3. After the planting, the ground around the seedlings was watered with a very dilute culture, about Io c.c. to a watering pot.

4. Control.

5. Control. Injection into the stem, 2 days after planting, of the same sterile bouillon that served for the bacterial cultures.

6. Before planting each plant was injected at the crown with a purc culture in bouillon.

7. Control.

8. The day after the watering of the soil with a dilute pure culture each plant-hole was watered with $0.4 \mathrm{gr}$. potassium permanganate dissolved in 0.5 liter of water, and a half hour later the plants were set out.

9. The stems received injection of a pure culture 8 to $10 \mathrm{~cm}$. above the crown, where a leaf had been pullcd off for the purpose.

10. Injection of a leaf-nerve by means of a hypodermic needle and higher up near the leaf top, 3 or 4 pricks.

i i. The leaves, and consequently the earth, were watered with a diluted pure culture.

12. The plant-holes were watered with a dilute pure culture and the plants were set out one day later.

The number of diseased plants were as shown in table 23.

'TABLE 23.--Resull of IIoning's First Inoculations.

\begin{tabular}{|c|c|c|c|c|c|c|c|c|c|c|c|c|}
\hline & $\begin{array}{c}\mathrm{I} \\
\text { (check). }\end{array}$ & 2 & 3 & (check). & (check). & 6 & (check). & 8 & 9 & 10 & II & 12 \\
\hline June $10 .$. & 1 & 2 & $o$ & 0 & o & 15 & 1 & 4 & 19 & 8 & 3 & 5 \\
\hline Aug. $1 \ldots$ & 10 & 22 & 22 & 8 & 6 & 25 & 7 & 24 & 24 & 24 & 25 & 23 \\
\hline
\end{tabular}

"Na deze proeven blijft er, voor mij ten minste, geen spoor van twijfel over aan den bacterieelen aard der slijmziekte."

'The disease is hastened by introducing the bacteria into the plant, but in the end it enters the plant from the soil.

'The failure of a portion of the eheeks is attributed to a natural infection of the soil, the location having proved to be a bad one, as shown by results in three rows of tobaceo planted near these somewhat earlier and a considerable part of which succumbed.

*'This has reference to the fact that a disease of unknown origin has destroyed many thousands of Albizzia trees, formerly extensively used as a shade plant for various cultivated crops, but now generally abandoned.

tA coarse grass. 
Once also, Honing has seen, in a slime-inoculated culture on a slice of a tobacco stem, a yeast corresponding to van Breda de Haan's yeast.

No spores were observed in old cultures of the parasite, but the latter is soon followed by saprophytes.

In the decaying stems five or six kinds of bacteria occur, as may be made out readily, and no doubt careful cultures would show others. The author had not determined the cultural cliaracters of the parasite.

Dr. Honing says the preceding contains nothing especially new, but is confirmatory or explanatory of the observations of van Breda de Haan, Hunger, Uyeda, Smith, and Jensen.

Extremely interesting, however, and quite new are his observations that the same or a sinilar disease oecurs on many tobaceo fields in wild plants, among these several composites. These plants are: Ponzolzia (a kind of nettle), Agcratum conyzoidcs, Physalis angulata, Spilanthes acmolla, and Pluchea indica. Once the disease was found in Pluchea growing on lalang land which had not been in tobacco for 7 years. The relatively small percentage of disease in the weeds ( 0.5 to I per cent or less) does not necessarily show them to be less susceptible than the tobaceo. It may be only that they are less subject because their rootsystem is less broken than that of the transplanted tobaceo.

Also from two young diseased Mueuna plants a bacterium was isolated which could not be distinguislied from that of the slime-disease.

Cultures were made from Pouzolzia and from Ageratum and tried on tobaceo, June i 8. The results on June 29 showed many more eases in three of the inoculated rows than in the controls.

Counting two of the inoculated groups with the checks, because, as was afterwards discovered, they were inoculated with eultures containing a spore-bearing form clearly not Bact. solanaccamm, we have the results given in table 24 .

TABLE 24.-Honing's Results with Pousolzia and Igeratum.

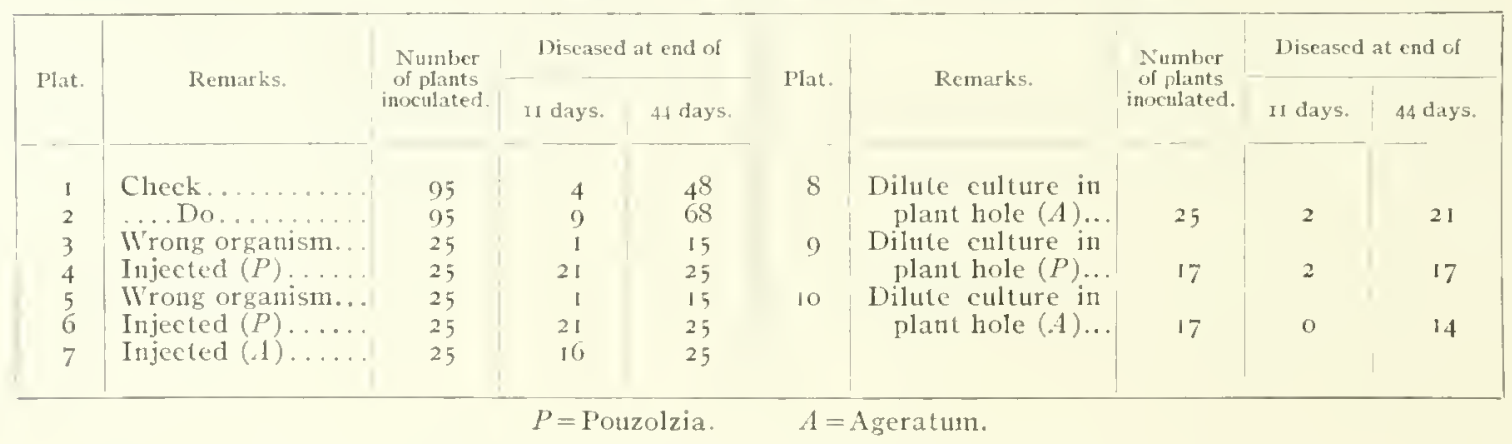

The large number of cases that finally appeared in plats $I$ and 2 are explained as due to the fact that they were worthless rejected plants used as eheeks only because no others were available. It will be seen that every one of the plants inoculated with the pure cultures by injection contracted the disease and also nearly all of those in which only the ground under the plant was infeeted.

The best results in treatment of the soil were with cliloride of line and potassium permanganate. Copper sulplate proved very injurious. Furtler experiments must be made to determine what doses of the lime and permanganate must be used to disinfeet the soil, also whether all the soil of a field mist be disinfected or ouly that under the plant, whether the quality of the tobaceo will be injured, and finally, whether rain must be awaited before planting.

In sonle cases Honing used 2 to 2.5 granns elloride of lime (Chloorkalk) in I to 2 liters of water for the soil under each plant and the same of potassium permanganate. In other cases he used as high as 6 grams of the chloride of lime per plant, with excellent success 
in spots from which diseased tobacco had just been pulled out. In field tests in a bad year (I 909) on ground where all the untreated tobacco died, 50 per cent of a crop was made, using 4 to 5 grams in eacli plant liole. The next year the loss was slight on 8 treated fields, while on the neighboring untreated parts it was 50 to 60 per cent.

Permanganate of potash will not penetrate the heavier soil and preference is given the cliloride of lime, although it is recognized that in its use there may be danger of injuring the burning quality of the tobacco.

Honing found great earclessness on the part of the planters in the disposal of diseased plants. In many instances they have thrown the rotting tobacco plants into wells from which afterwards they took water to put on the fields. (For abstracts of more recent papers by Honing see p. 244.)

\section{THE NOR'TH AMERICAN DISEASE.}

Synonyms.-North Carolina tobacco wilt; Granville tobaceo wilt; Florida wilt.

\section{HISTORY.}

In September 1903, Stevens and Sackett, then of North Carolina Experinent Station, distributed a well-illustrated, brief paper, describing a disease of tobacco which had caused a good deal of injury in Granville County, North Carolina, and attributed the same to a schizonycete. The Dutch papers are not mentioned and were probably unknown to them. This disease is stated to be "so destructive that its spread throughout the country would imply annihilation of the industry of tobacco growing." 'The bulletin devoted itself prineipally to stating the fact of the presence of the disease, furnishing figures of it from good photographs, and giving a brief deseription of the signs, togetlee with some field observations on its prevalence and supposed manner of spread. The root was believed to be the original seat of infection. The organism was not described or named, nor were any proofs furnished that the disease was really due to bacteria, other than the strongly presumptive evidence offered by the microscopic exaninations.

The same month (September) and a little in advance of the above publication, Dr. R. E. B. McKenney, of the Bureau of Plant Industry, U. S. Department of Agriculture, who had been engaged for some time in a study of tobacco diseases in cooperation with the Bureau of Soils, but not under the writer's direction, published a brief circular describing and illustrating this North Carolina disease. Dr. McKenney studied the disease in the same localities as Sterens and Sackett. His circular states that the disease is due to a fungus (Fusarium) closely related to that described by Erwin F. Smith as the cause of a wift in watermelons, cowpeas, and cotton. The publication of Dr. MeKenney's circular appears to have been premature, since he never obtained any proofs from inoculation that this disease was due to a Finsarium, and the writer was never able to obtain from him any slides or other material showing the presence of the fungus in the affected plants. From Professor Stevens the writer obtained alcoholic material, both of root and leaf, which in section showed the vessels and surrounding tissues to be plugged with bacteria, but wherein no fungi could be demonstrated microscopically (figs. I I 6, I I 7). The writer also, in abundant material since received directly from the diseased fields, has seen nothing of any disease attributable to Fusarium.

Further studies must be made to determine whether the Fusarium seen by MeKenney occurred as a saprophyte or a parasite and also to determine its morplology and cultural characters.

One of the writer's second set of inoculated plants (fig. i i 8) was destroyed in the hothouse under the combined action of bacteria and Fusarium, but this is the only case 
he has seen. Whether the Fusarium alone is sufficient to eause a wilt disease of tobacco remains to be determined by experiment. Delacroix has recently described a Fusarium disease of tobacco, and it is not improbable that two diseases may have been confused.

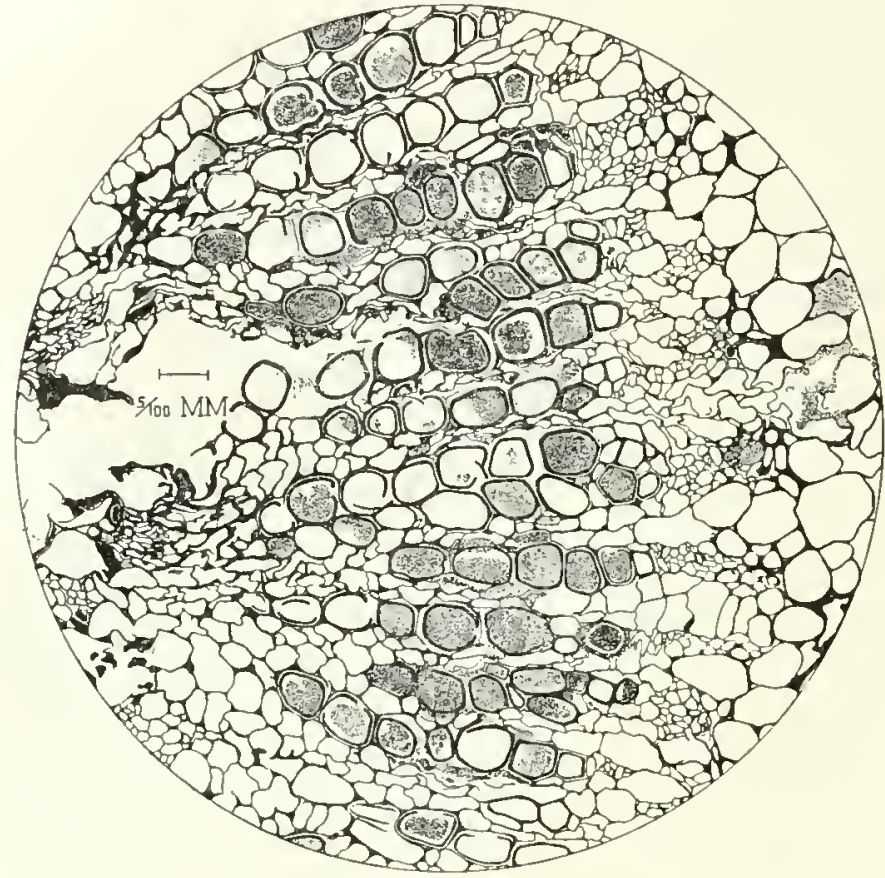

Fig. 116.*

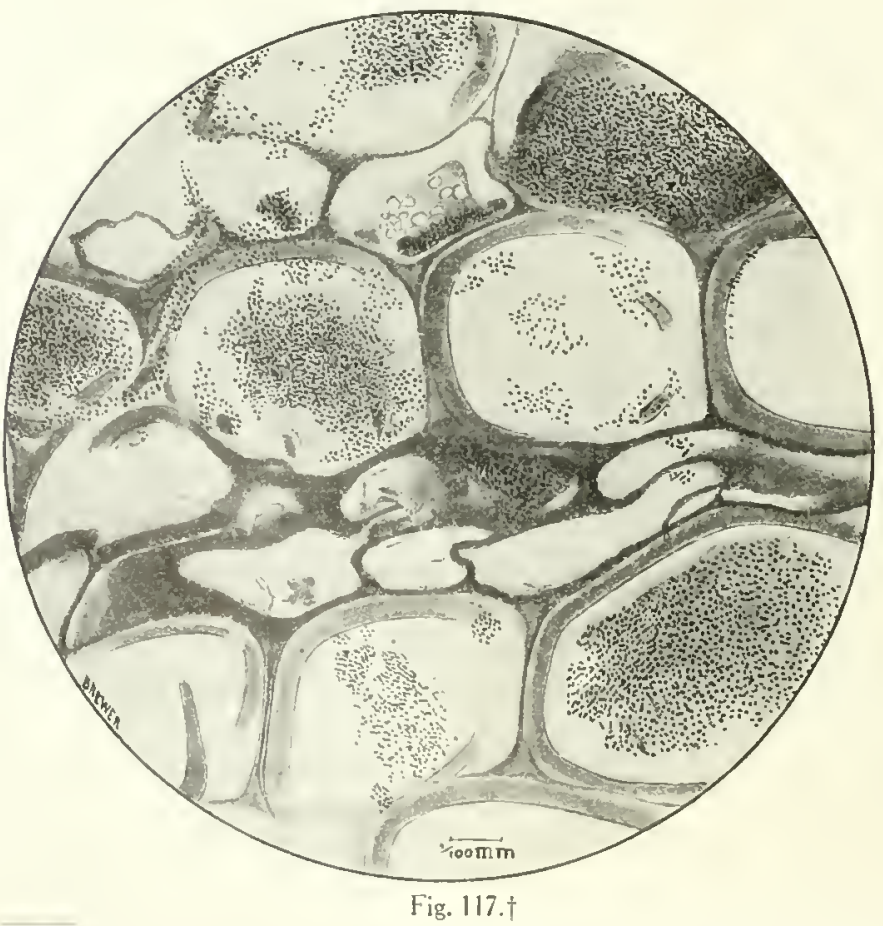

With these facts in mind, the writer suggested to Dr. MeKenney in the summer of 1912 that he visit the tobacco fields of North Carolina. This he did, but could then find only the bacterial disease. I still think, however, that a Fusarium disease of tobacco will be found, for, as I pointed out in 1899 , this widely disseminated form-genus contains active parasites destructive to a great variety of cultivated plants, a fact now generally recognized, but then unknown to science (Scientific Anerican Supplement, No. 1246 , page 19981).

The preceding statements represent the writer's knowledge of this subject up to the summer of r 905 . if we exclude Uyeda's first paper, to be treated a little later. That sumner diseased tobaceo plants were sent to him from Quiney, Florida, and from Creedmoor, Nortlı Carolina. In both cases the cause of the disease appeared to be bacterial, and the signs of the disease corresponded quite closely to deseriptions of the slime disease as it occurs in Sumatra, and also to the signis mentioned by Stevens and Sackett.

From the North Carolina material agar poured plates were made a number of times, and always large numbers of one organism were obtained from the inner tissues (pl.37). This was a short, motile bacterium, the small roundish surface colonies being gray-white at first on agar, but afterwards brownish (pl. 23, fig. 2). Usually the plates showed no other organisn present, but oceasionally scattering colonies of other bacteria appeared. They were made, of course, from clean parts

*Fig. 1 1 6.- Cross-section of petiole of a tobaccoleaf, showing bacterial invasion of vascular system. Firom a 11 atural infection in North Carolina. Material for sections received in alcohol from Prof. F. L. Stevens. Slide 291 a 6.

†FIG. 117.- Cross-section of a tobacco stem diseased by Bacterium solanacearum. A detail from slide 291 a 15, section $I_{i}, i, e$, from the same source as fig. 116. A somewhat diagrammatic wash drawing. 


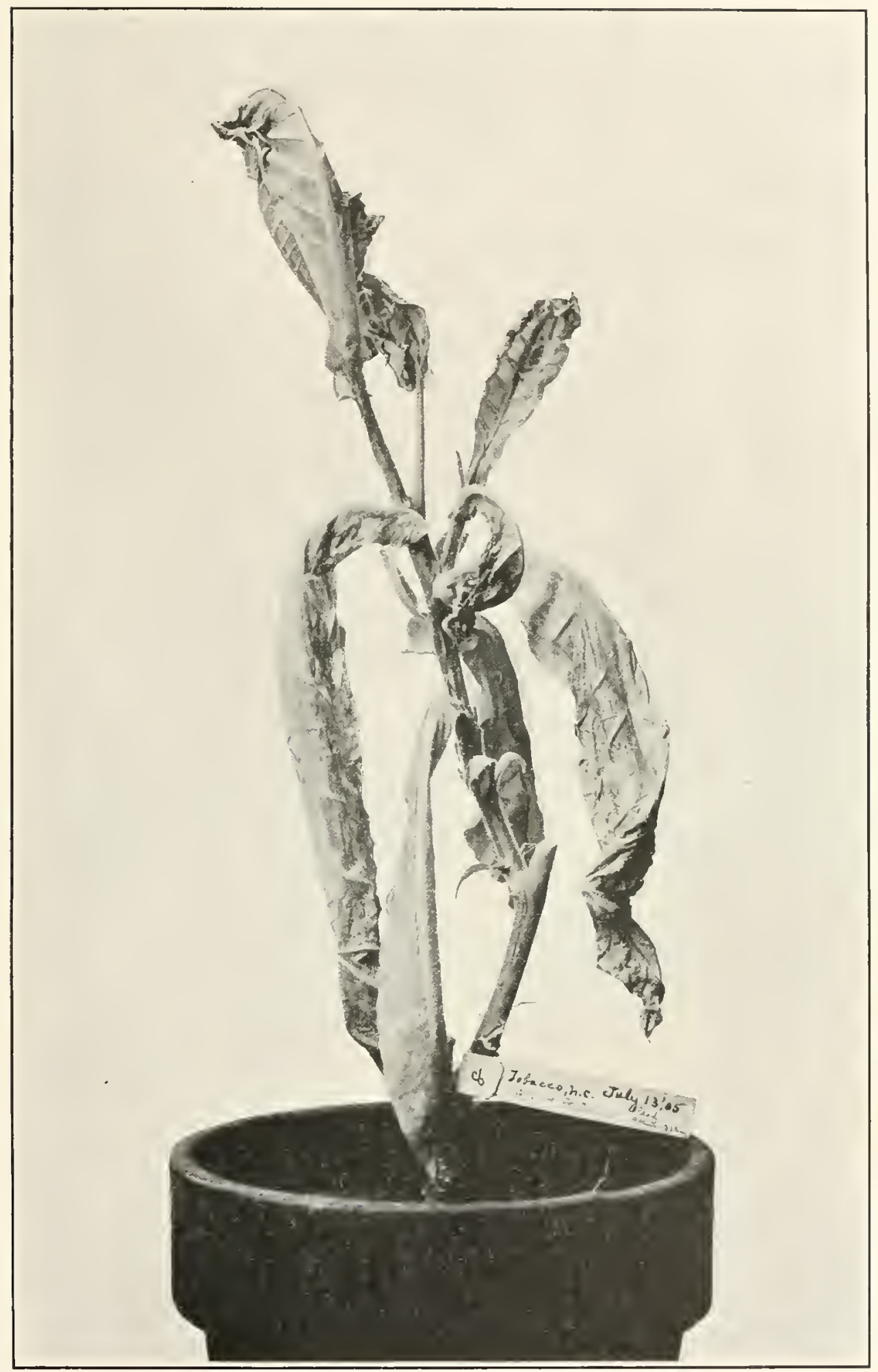

North Carolina tobacco wilt.

Tobacto plant inoculated ou the stem by needle-pricks from a pure culture of Baclerium solanacearum on July 13. 1905. and photographed Ausust 1. About one-half natural size. 



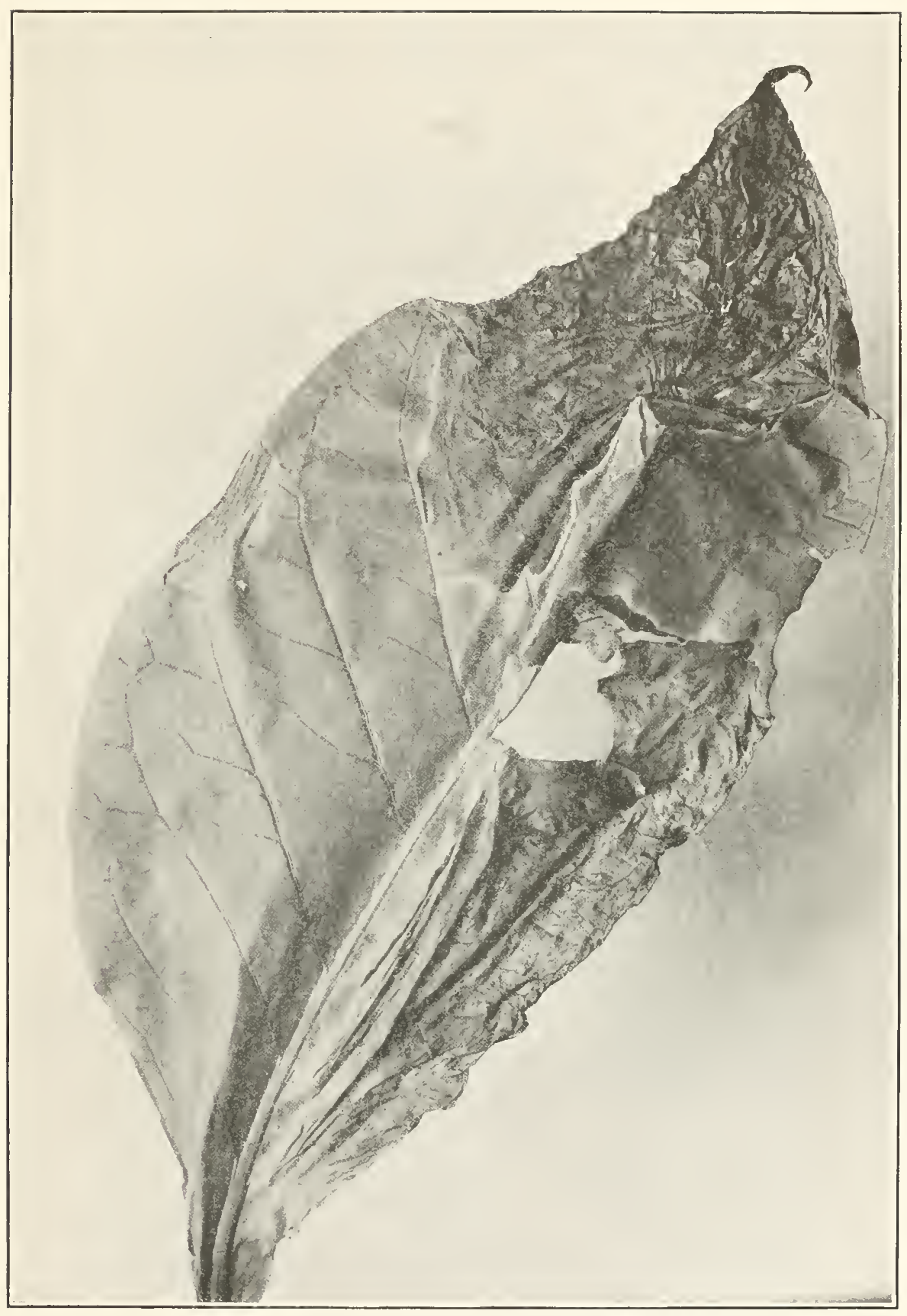

Tobacco-leaf from the hothonse, showing the Lypical red-brown shrivelecl spots of the Granville tobaceo witt. The remainder of the leaf was green.

Luakrium solunacearum abundant in vascular system of the tnidrib and in many sile veins. Plant inaculited in stem, by neediepricks, on Sept. 23 . I 1905 using a pure cullure of the North Carolina tobacco organism. Photographed Feb. 20, 1906.
About one-third natural size. 



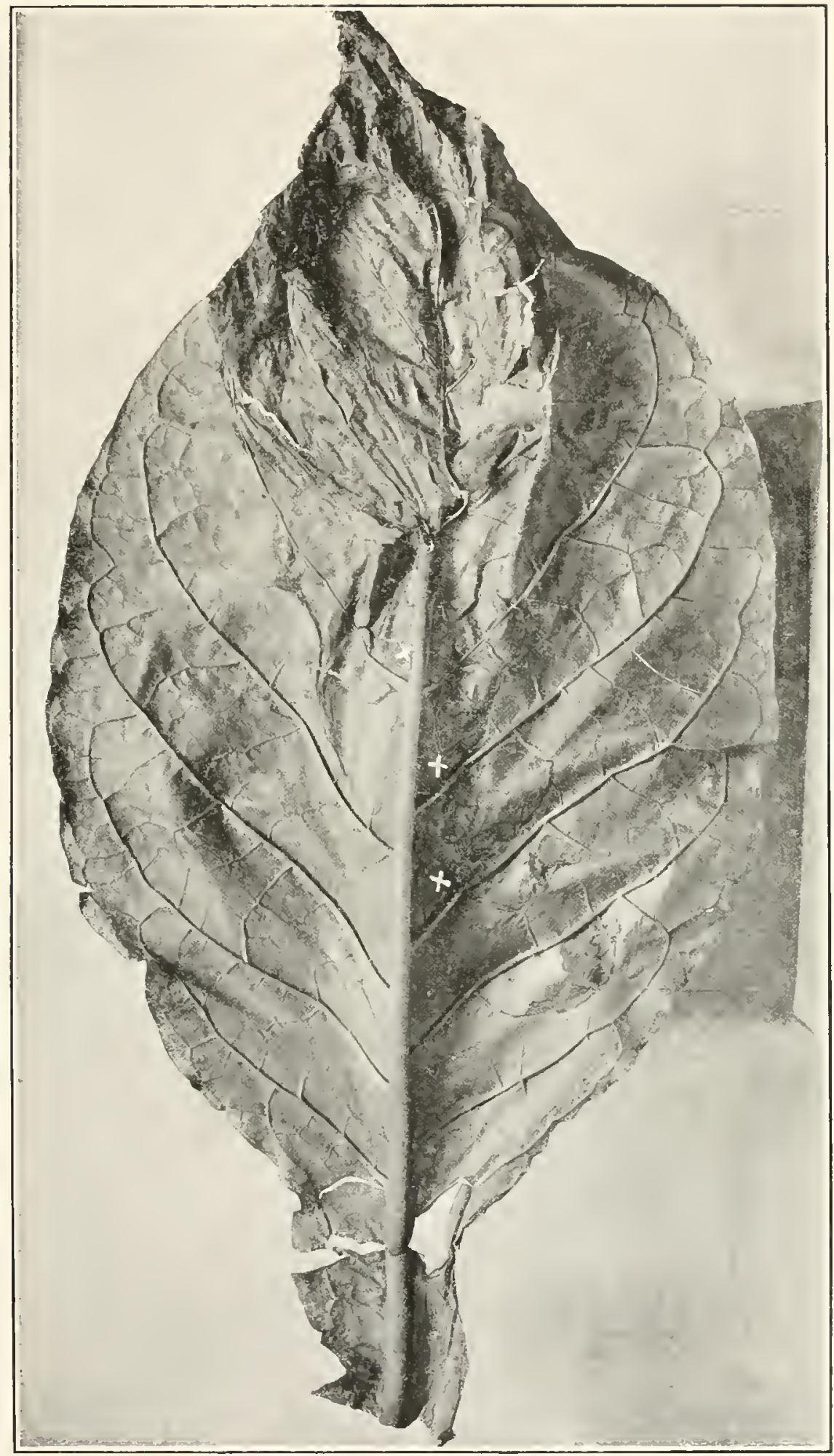

Leaf from inoculated tobacco plant No.34 (Granville tobacco wilt).

Notice dead apex und four eliptical hrown patches on the right side near the midrib between the larger veins Cross-sections from the base of this petiole are shown in fig, 120 . The terminal portion of the mitrib is shrivted. Bacteria were ahundant in its vaseular system at $\mathbf{X}$, and also in the side veins between the dried-out putches at $\mathbf{X}$. $\mathbf{X}$. Surface of leaf dry. Inocilated Sept. 23. 19u5, 0n the stem.
Photograplsed Dec. 11. Une-third natural size. 



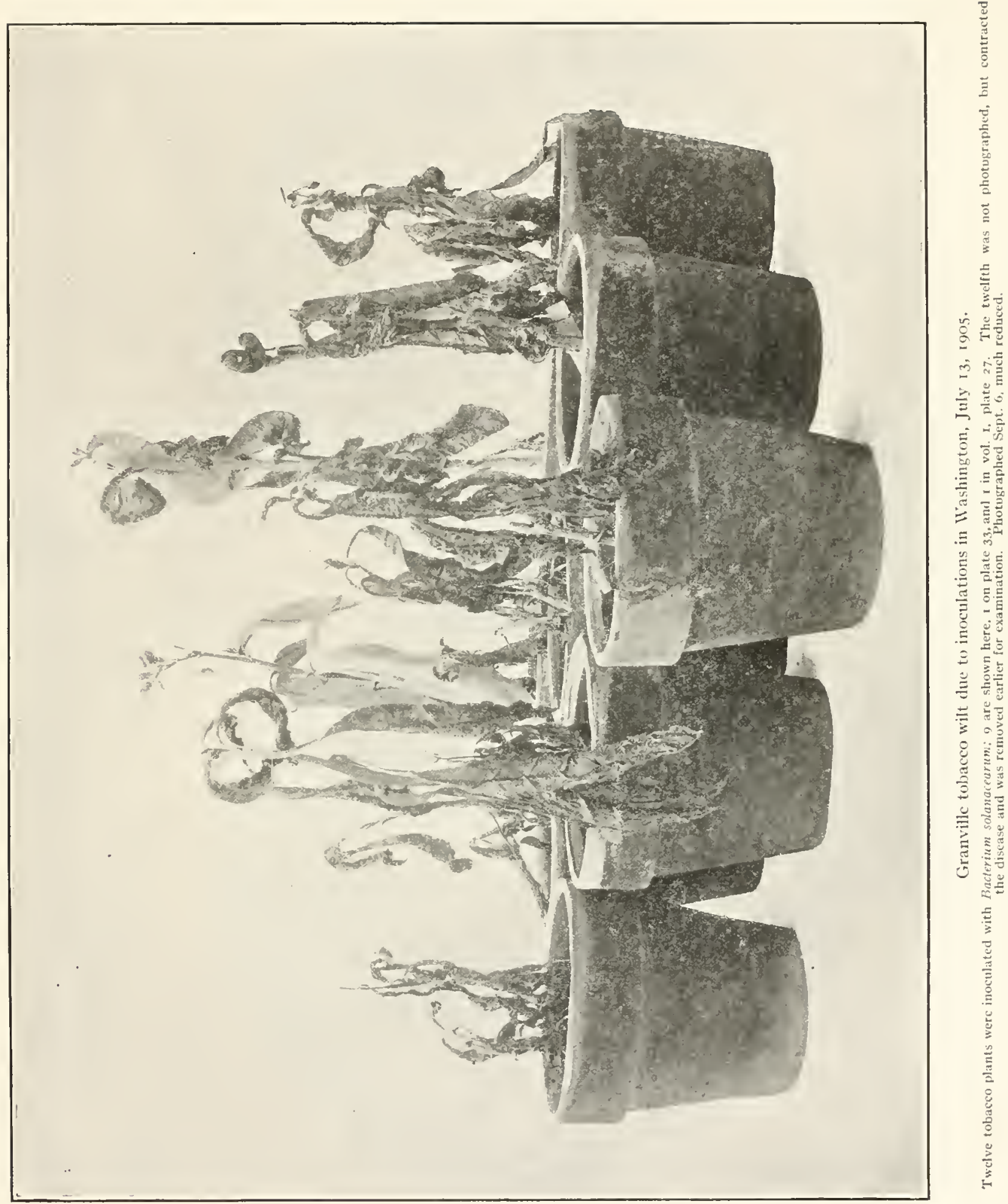




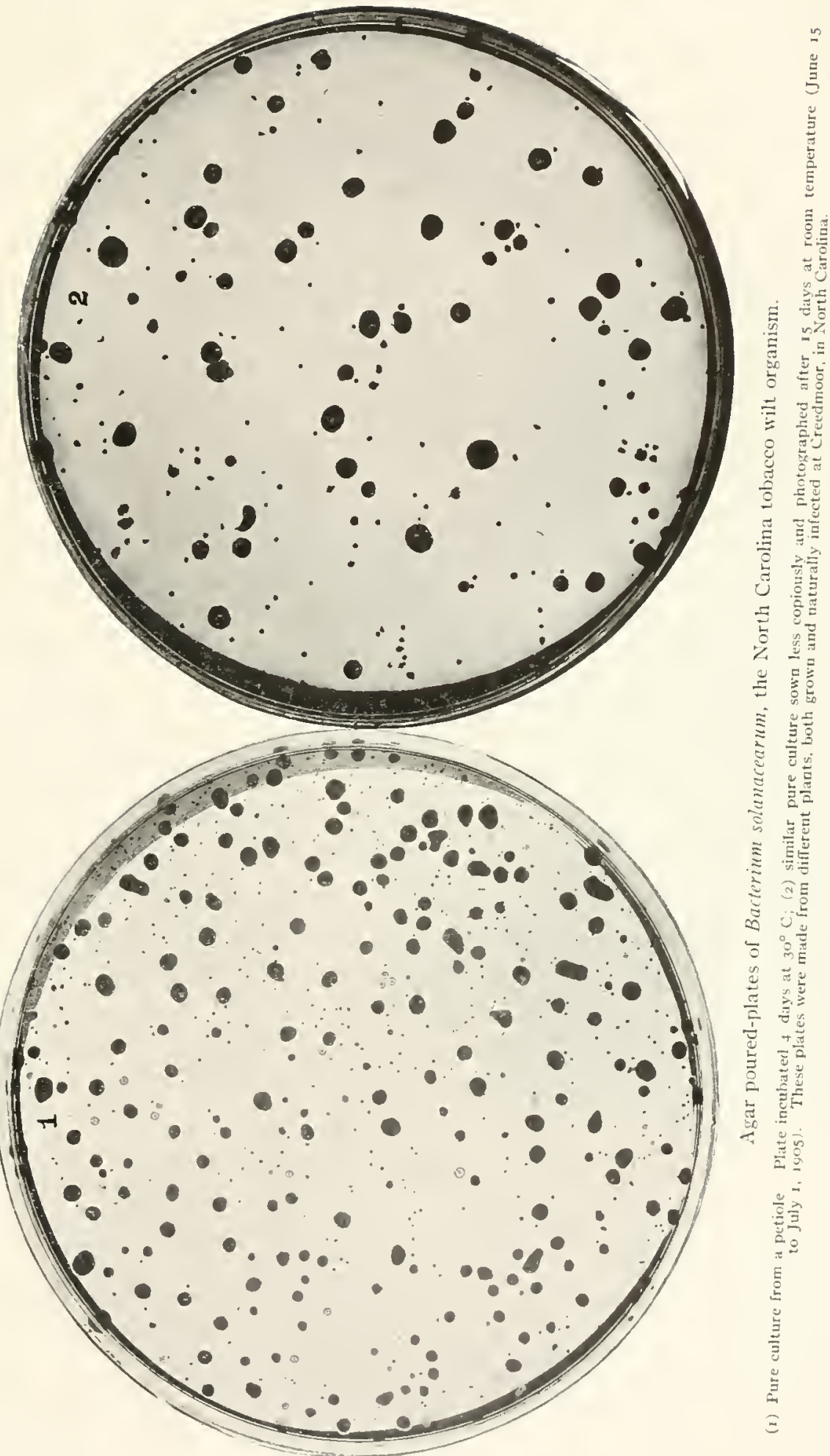



only recently diseased. Nothing resembling the Bacillus micotianae Uyeda or the large mierococcus of van Breda de Haan was observed. Only a few of the many plants received from North Carolina were used for making poured plates. The foliage was rennored from the remainder and the plants (most of which were in early stages of the disease) were then set out in a hothouse belonging to the U. S. Department of Agriculture, and carefully watched. For sone weeks they showed no further indications of disease. They rooted readily and made new leaves. Afterwards all of these plants developed further signs of wilting (Vol. I, pl. 27, left fig.) and finally perished of this discase, the pith being rotted out as in the Sumatran disease. The vascular ring in these plants was stained dark brow11 or black, and the parenchyma was also blackened in places, both in the interior and on the surface of the green stems. In some instances cracks or cavities appeared on the surface, opening into the depths of the stem, and the tissues in and around these fissures were blackened. The bacteria were present in the diseased tissues in enormous numbers.

When the plants had dicd they were removed and healthy tobacco plants grown from seed sown in the I) epartment houses were set in their place. These plants were sone months old and naturally the root-system was wounded considerably in transplanting them. To the writer's surprise all of these plants (a dozen or more) contracted the disease within a few weeks and finally died of it. The checks left in the other louse remained free from the disease.

Starting with single colonies of the North Carolina organism obtained from the Petri-dish poured plates, subcultures were made, and from these subcultures healthy tobacco plants in another house were inoculated in considerable numbers by needle-punctures in the stem or leaf. These plants readily contracted the disease, going through the same progressive stages as the plants obtained from the field. All the characteristic signs were present in these inoculated plants, one of which was figured in Volume I (pl.27, right fig.). For the appearance of the remainder see plates 33 and 36 . From the interior of several of these plants the organism was again obtained in pure culture by means of Petri-dish poured plates, and with colonies from these poured plates, or rather with subcultures therefrom, the dis-

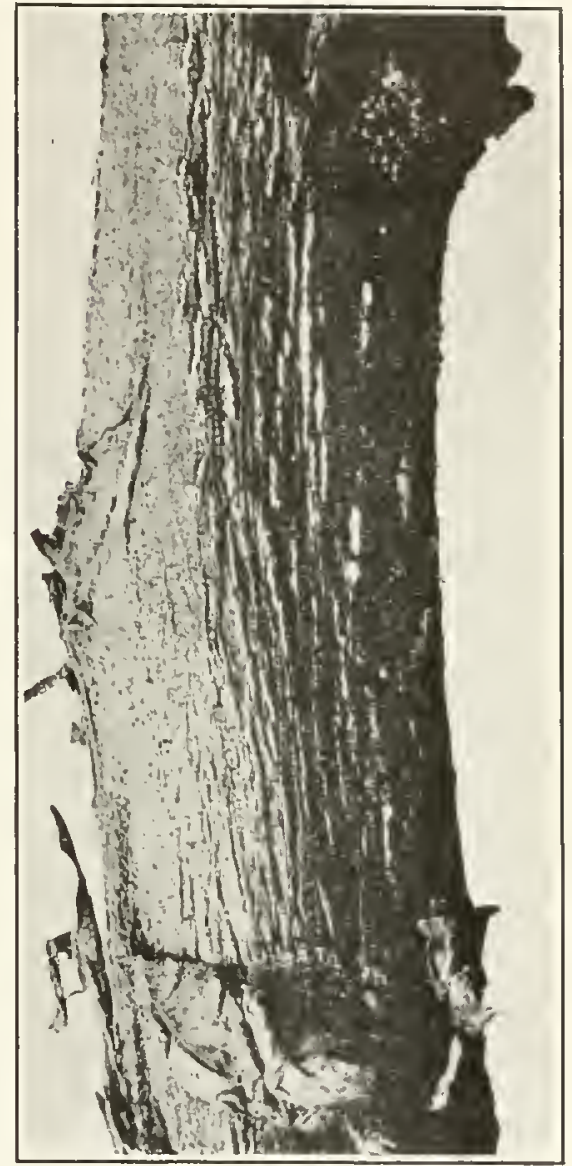

Fig. 118.* ease was obtained in tobacco plants a second time by needle-puncture inoculations. These were stem-inoculations on plants 13 to 36 , most of which contracted the disease, but only slowly, $i . \epsilon$, not until they had become large plants. They were inoculated September 23 , 1905 , and up to the middle of January the signs were confined to yellowing and loss of the lower leaves, with the exception of one plant, which collapsed entirely (p1. 38 ). The affected leaves developed pale green spots and then dried out very irregularly. Often the "ears" died first, as described by van Breda de Haan; sometimes the apex died first (fig. 119), or one margin (pl. 34), or the leaf dried out irregularly (pl.35). In all such cases the

*Fig. I 8.-Fusarium fruiting on the surface of a diseased tobacco stem in pinkish, pustular lines. Possibly Mckenney's tobacco Fusarium. A secondary infection and the only case that occurred in the house. Plant inoculated on Sept. 23, 1905, with the North Carolina tobacco bacterium. Photugraphed Fieb. 20, 19o6. Stem dead. X2. 
vascular bundles at the base of the green midrib were browned and occupied by the bacteria. Cavities were formed in the midribs of such leaves. This browning and baeterial occupation was not confined, however, to the petiole or base of the nidrib, but could be traced through the latter for a distance of 1 to 2 feet. In some cases also the browning and

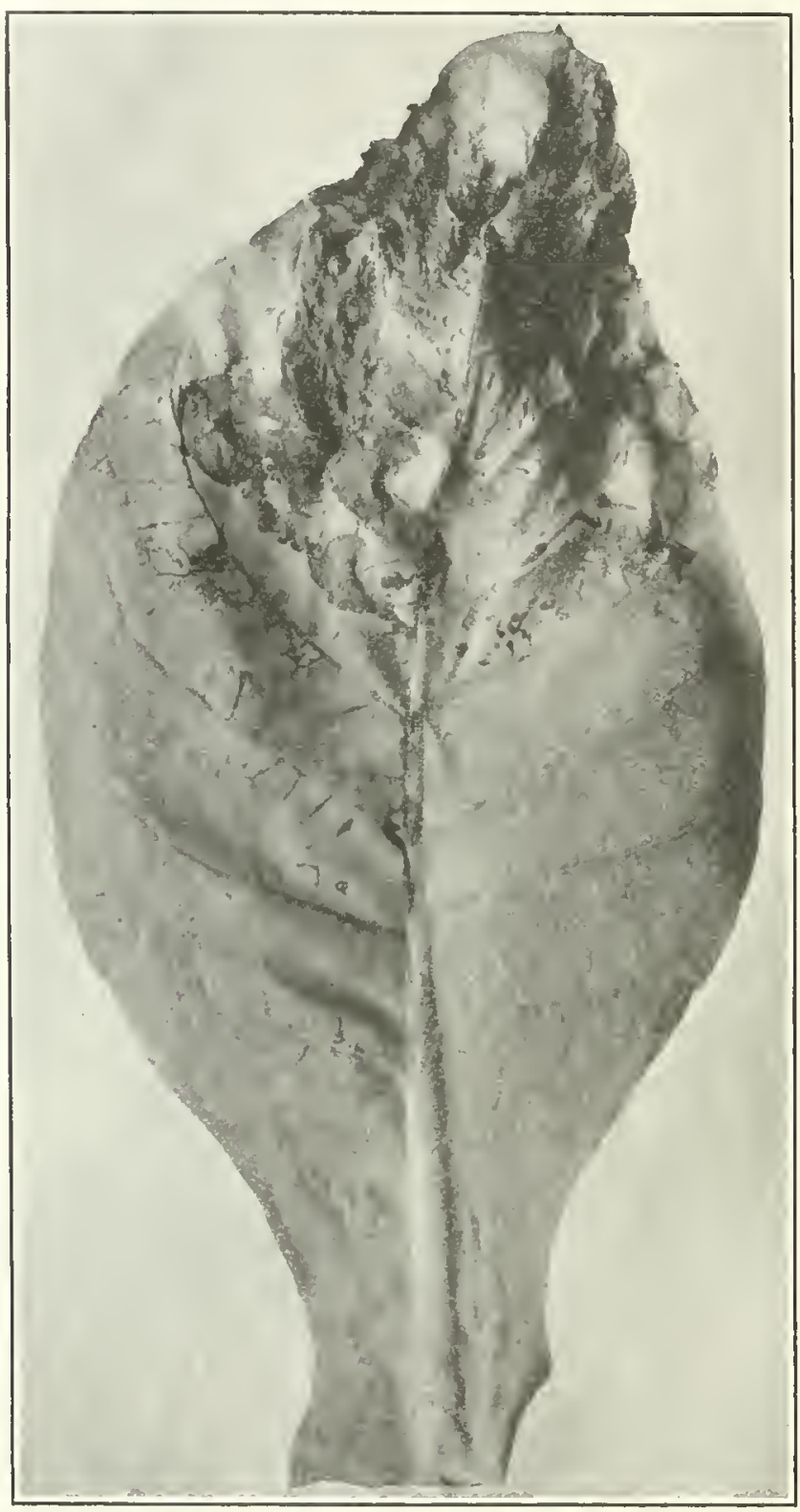

Fig. 119.* bacterial oceupation were traced out into branches of the midrib. The appearance of sonne of the blackened midribs in cross-section and of similar petioles in longitudinal section is shorvn in figs. 120, 121. Poured plates made fron the brown shish in the hollow stenl (pl. 38 ) showed the presence of an intruding soft white-rot organism, as was anticipated (fig. 122), and the inoculated baeterinm was not 111ade out elearly.

The blackening and partial destruction of the pith in two of these inoculated plants is shown on plate 39. Similar results obtained by inoculating Bact. solanacearmm plated from a potato are shown on plate fo.

There was in some cases an abnormal pushing of roots from inoculated stems (fig. I 23), the same as in tomato plants inoculated with Bact. solanacearum (pls. 27, 28).

Studies carried on at the same tine, and afterward, indicated that the cultural characteristics of this organis11, so far as tested, did not differ materially from those obtained with Bactcrim solanaccarm plated from diseased potato and tomato stems obtained from various parts of the United States. On the other hand, cross-inoculations from tobaceo to tomato and from potato to tobacco were not particularly successful. 'The tomatoes inoculated with the tobacco organism developed adventive roots on the stem, but no wilt appeared. The tobaccos inoculated with the potato organism did not wilt or show other external signs of clisease, but the strain used was not a very virulent one.

The following are the morphological and cultural characters of the North Carolina tobacco organisn, so far as determined in 111 laboratory:

*Fir. I 0 -Dark veins and large dry brown spot on a tobacco leaf attacked by the Granville tobacco wilt. Infection by way of the vascular bundles of the petiole. Plant inoculated on the stem Ang. 5, I9o8, from a diseased tomatostem. Photographed August 27. 


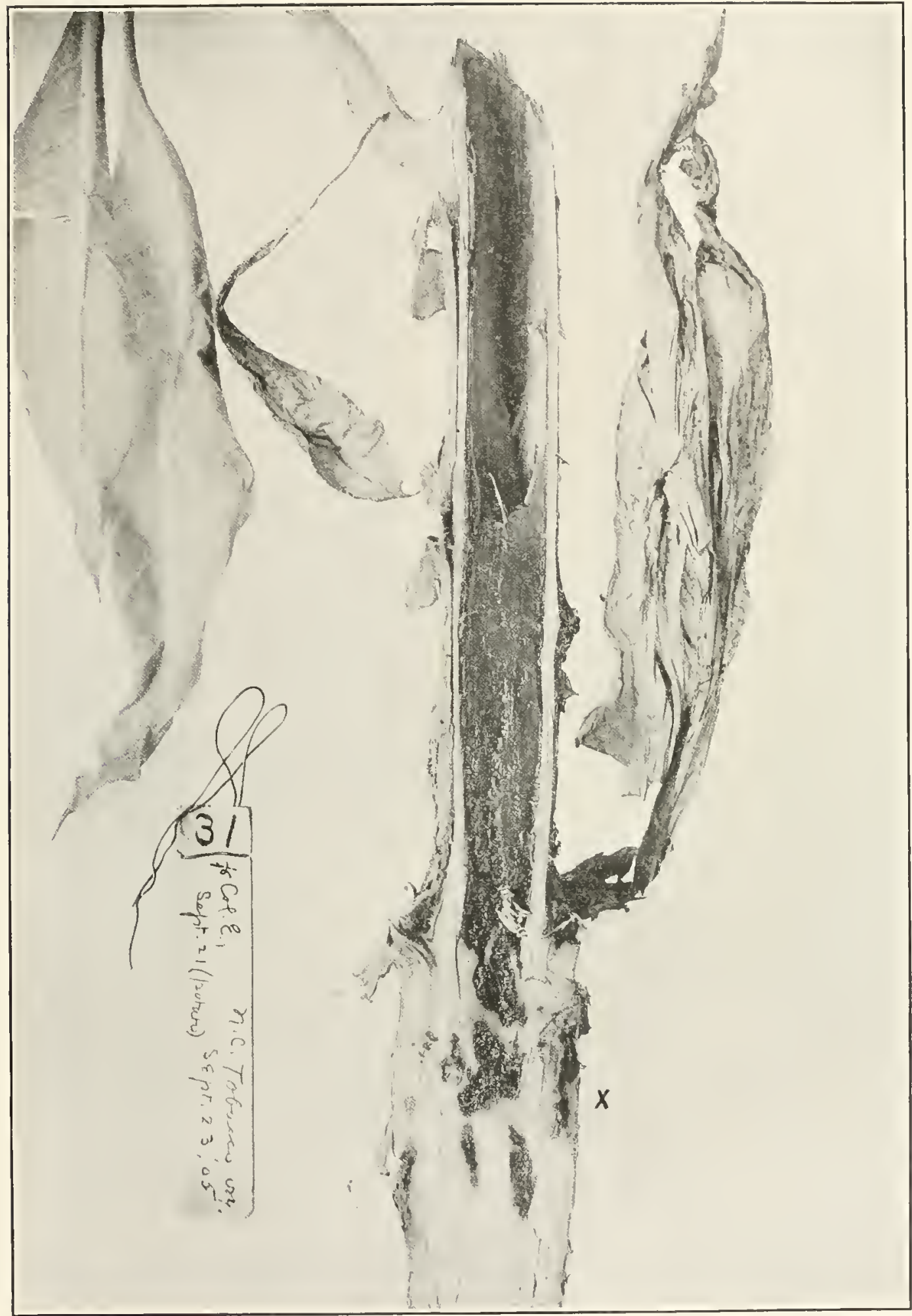

Stem of a large tobacco plant (No. 3I).

Inoculated with Bacterium solanacearum at $X$ on Sept. 23, roo5. collapsed Jan. 5. Spots in lower (inoculated) part of sten are black. Pith in middle part of stem is rotted ont and brown-slushy. From this soft mass Baclernum solunacearum was not obtained by poured-plates, but a secondry soft white-rot organism (fig. 122) which, however, was not very abundant. Steut at moist brown stain. Inoculated part of stenl enlarged. 
• 


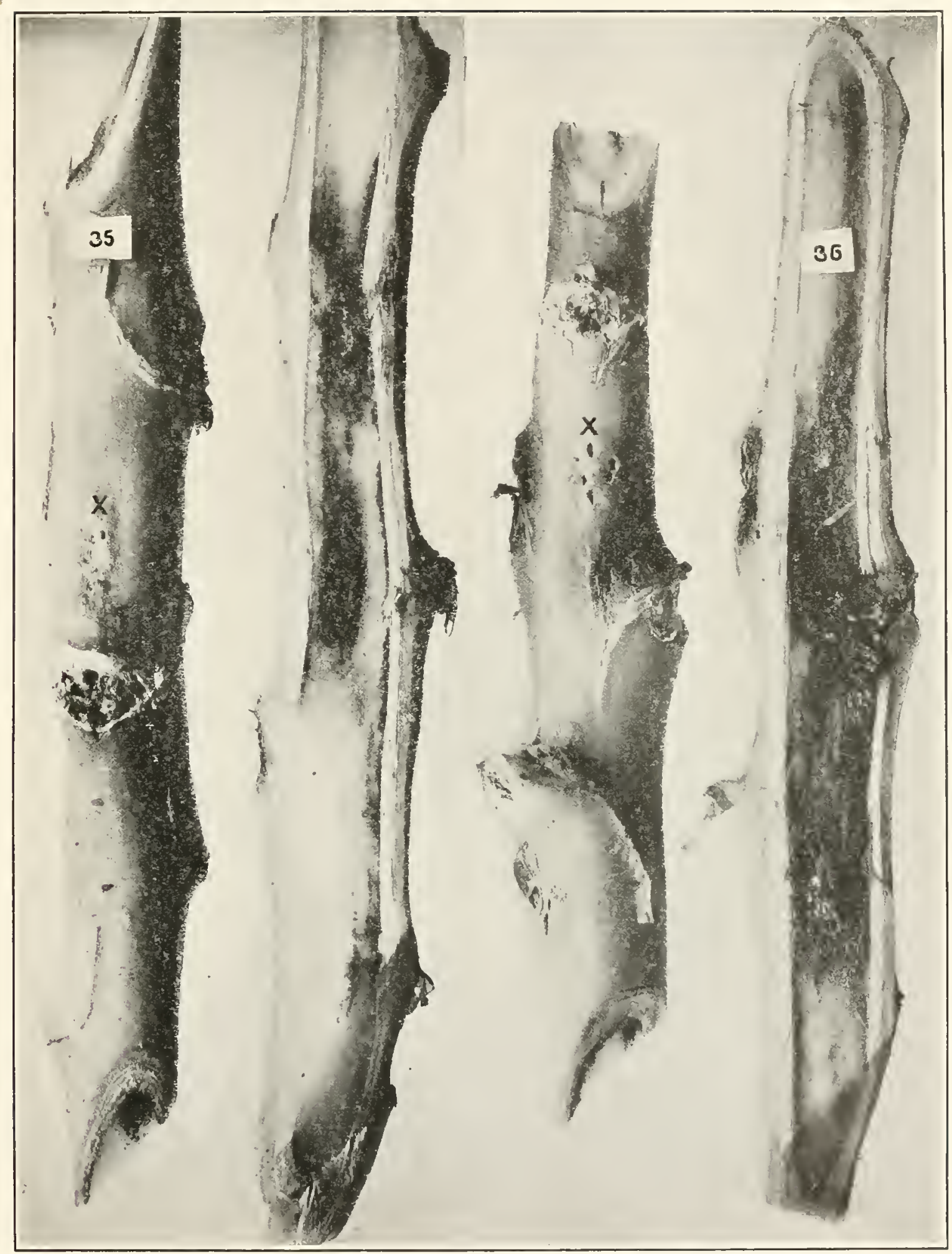

Surface and interior of two tobacco stems inoculated at $\mathbf{X}$ September 23, 1905, with a pure culture of the Not th Carolina tobacco organism (Bacterium solantcearum), and which did not suceumb to the disease as promptly: as the plants shown in plates 33 and 36 .

Hard stems, green and sound externally; pith disease-1 (browned) and also some parts of the vasculat system. The plant; sextupled in size after the inoculation and the external signs of diszase did not appeur or were confined to the lower leaves. The leaf shown on plate 34 came from this series of inoculations, Photograplied Feb. 29, 1905. Natural size. 



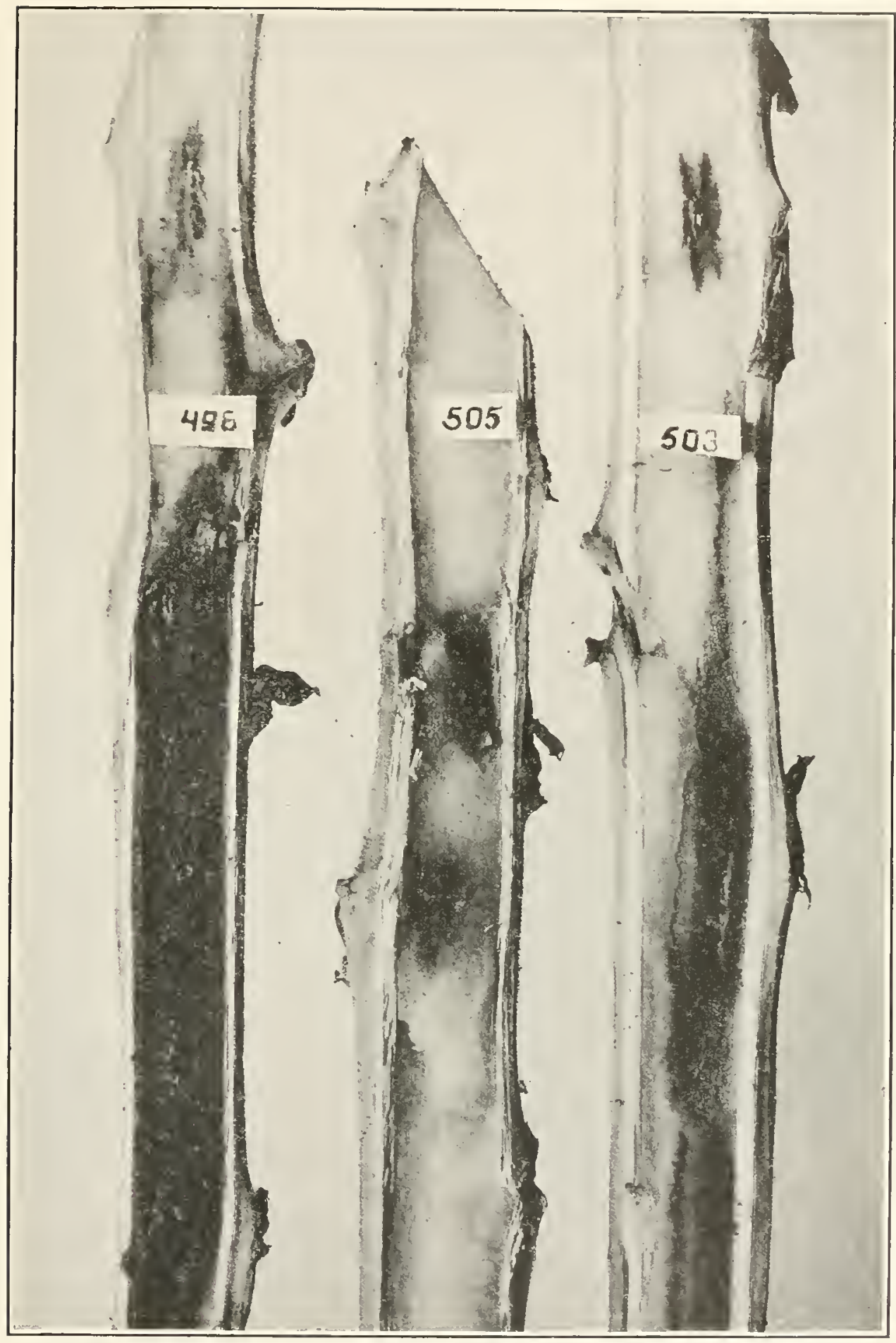

Longitudinal section of three tobacco stens inoculated when much younger with Bacterium solanacearum from a Florida potato.

Wilt of the foliage dil not occur. The inoculations were made by needle-pricks Sept. 19, 1905. and the photograph Feb. 20, rgo6. Surface green and sound, many green leaves; pith diseased (mottled brown and white). Bacteria very numerous in the stained parts of 496 and present to a less extent in the others. Botrytis had also entered 496. This photograph represents hest results obtainable with the strain of Buat. solanacearum used, which was one that had lost much of its virulence. 



\section{MORPHOLOGY AND CULTURAL CHARACTERS OF THE PARASITE.}

In tobacco plant No. 6, which was inoculated July i 3, I905, and examined July 20, nany of the bundles were found to be swarming with an organism in the form of short rods having rounded ends. These rods were single, or in pairs, or occasionally in fours, end to end. Tumbling movements were observed, but no darting ones. Organism morphologically like Bact. solanacearmm. This was the common form of the organism found in all of these plants. Psendozoogloex occur in culture media.

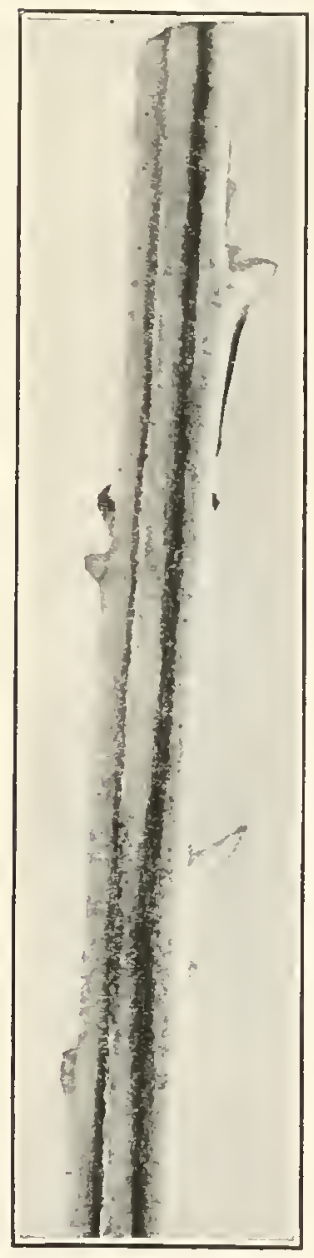

Fig. 121.

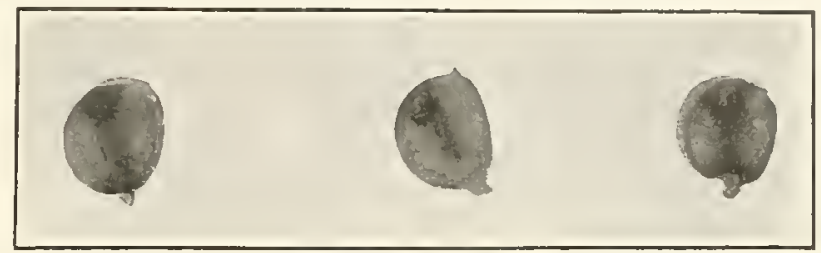

Fig. 120*

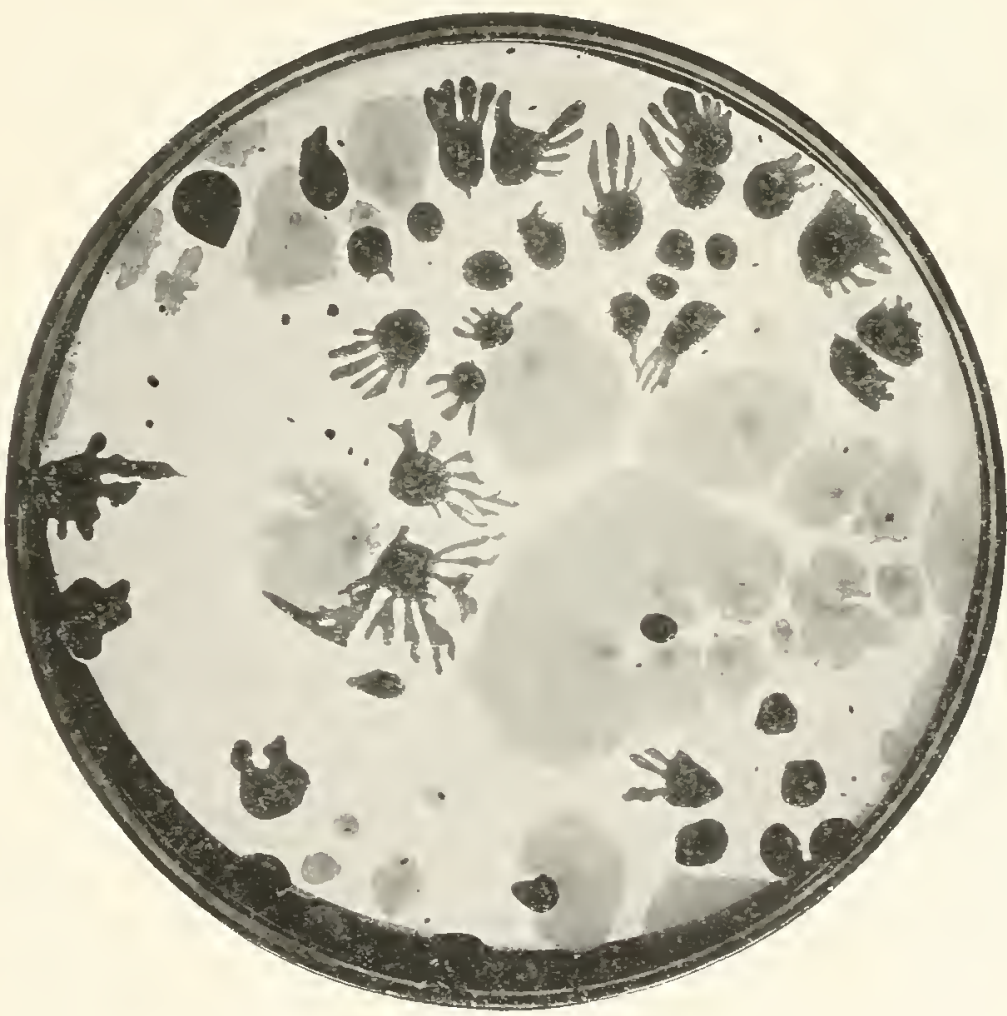

Fig. 122.

Agar.-Like Bacterium solanacearum (sce pl. 23). Colonies on plates of + 5 standard nutrient agar at $25^{\circ} \mathrm{C}$. to $30^{\circ} \mathrm{C}$. do not develop rapidly. 'I'hey are not risible the first day and often not

*F1G. 120.-Cross-sections of base of petiole of inoculated tobacco plant No. 34, showing blackened vaseular bundles. These were occupied by the bacteria. Surface of the petiole and midrib sound. 'The infection entered the leaf from the sten, which was the inoculated part. Inocilation Sept. 23. Photographed Dec. 11 , igo5.

$\mp$ FIG. 12 1. - Portion of midrib of a large tobacco leaf sliced longitudinally to show brown stain due to bacterial oecupation of the vascular bundles. The lighter portions of the tissue were green and sound. Photographed Feb. 2o, 1906. The infection was due to a stcm-inoculation made Sept. 23, 1905, with a pure culture of the North Carolina tobacco organism. The left-hand streak is simply a shadow due to a sulcus in the midril,. The stem should have been lighted from the left side.

$\$$ F1G. 122.-Petri-dish poured-plate from the cavity in stem of inoculated tobacco plant No. 31 (plate 38 ), showing the presence of a white organism producing branching colonies. The broader pale patches are thin colonies growing under the agar. This organism has the same type of colony-growth as Bacillus aroideae. 


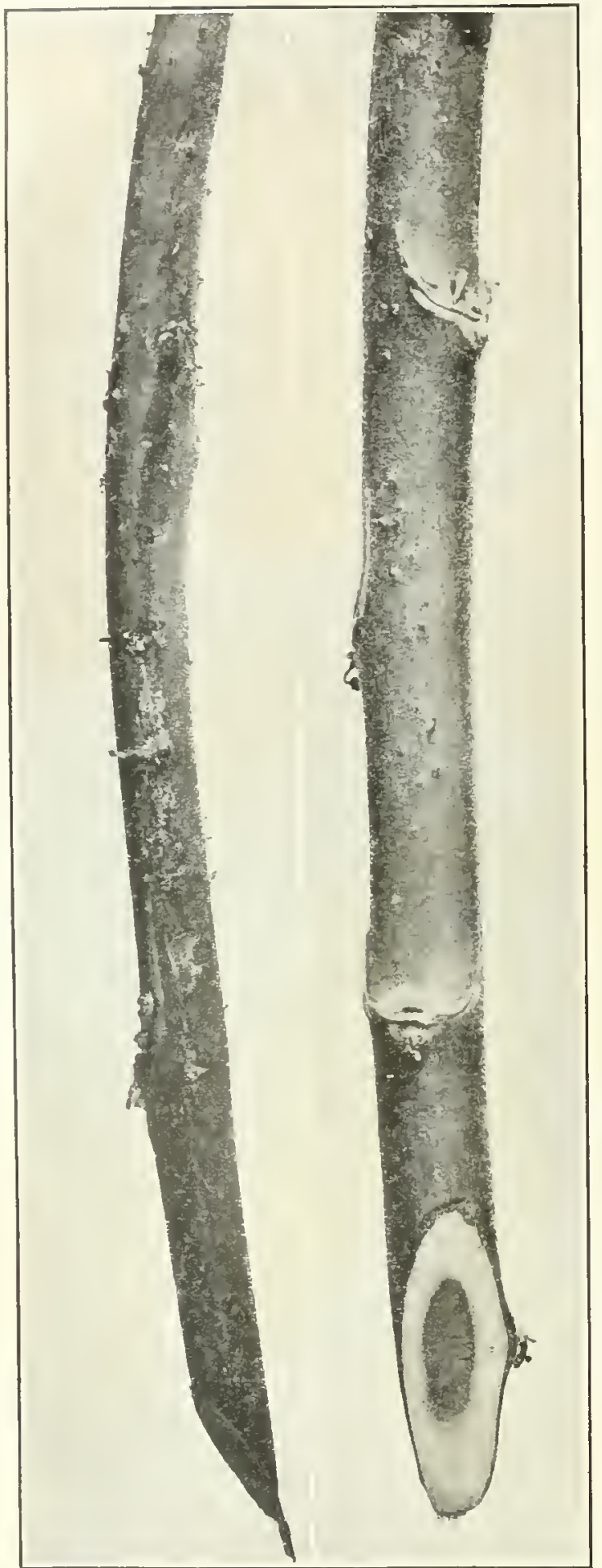

Fig. 123. until the third day. Surface colonies brown faster than buried ones, which would seem to indicate that air is necessary for the formation of the pigment. The browning of surface colonies is distinct at the end of 15 days." Stab growtl is best in upper part of the agar. On slant agar ciuring the first 10 days there is a thin, white, smootll, wetslining streak and a small amount of white precipitate in the fluid of the $V$. 'There are no crystals and no stains in the agar. The surface colonies on nutrient agar incline to be irregularly round. Only a few of the colonies are perfectly circular, but at the sane time they are not lobed or fingered. 'They are wet-slining and smooth; ringed growths are sometimes visible in the colonies. 'The general appearance of the colonies on agar plates is slown in plate 37.

'The lurown pigment from the tobacco organism grown on agar or potato is soluble in water, ethyl alcohol (absolute), and glveerin, but not in chloroform, turpentine, xylol, benzine, petroleum ether, rliigolene, or benzole.

Gelatin stabs.-No liquefaction; not even after several weeks. Growtl slight at $14^{\circ} \mathrm{C}$. (For kind of gelatin used see Vol. I of this monograph.)

Potalo.-MIuch like Bacterium solanacearum (pl. 4 I, fig. 4). Very milky turbid growth in fluid arotind potato during the first 10 days. Old browned potato cylinders when mashed in an abundance of diluted alcohol-iodine gave a deep purple-blue reaction. In another test the color reaction of the mashed potato cylinders is recorded as "deep purple."

Standard $(+15)$ peptonized bouillon.-After 20 day's, 110 pellicle, little or $110 \mathrm{rim}$, sliglit in one or two tubes but not black, uniformly and well clouded, with about $\mathrm{Io} \mathrm{mm}$. breadth of dirty gray-white precipitate. The cloudy bouillon does not now look turbid (flocculent) to the naked eye. A pencil is barely perceptible behind two of these tubes; it can not be seen behind three of them. $\dagger$ Bouillon 6 days old bore no conspicuous rim or pellicle, but there was a moderate amount of gray-white precipitate and considerable turbidity in the fluid, which was filled witl hundreds of small pseudozoogloex. The bouillon was not browned.

Acid bouillon ( +33 muscle-acid, dried out somewhat).-The organism was retarded somewhat at first, but then grew readily. On the third day tubes of this bouillon were distinctly less clondy than tubes of +15 nitrate botsillon (one-third to one-lialf as cloudy). There was no rim or pellicle in either bouillon at this date. After 56 days, the browning of the acid bouillon was much tlie same as with Bacterium solanacearum from the potato plants, and there was about the same amount of dirty brownish-white precipitate. No pellicle and not

*Browned colonies of the Florida organism from tobacco were dead after about two weeks. On April 22, 1909 , the vitality of 6 brown colonies from an agar plate of March 30 (North Carolina organism) was tested by copious transfer to beef-broth. These colonies had been brown for several days. Of the 6 colonies 4 finally clouded the bouillon. Of 18 browned colonies on agar (Fla. potato, 19I4) 8 were dead at end of 2 I days.

†The test-tubes used in the laboratory of Plant Pathology are about i6 to $18 \mathrm{~mm}$. in diameter, and of non-soluble glass obtained from Greiner and Friedrichs, Stützenbach, Germany.

+FIG. I23. - Aerial roots which developed on tobacco-stems inoculated with the North Carolina bactcrial tobacco organism. Inoculated Sept. 23, 1905. Photographed Feb. 21, 1906. Such roots do not ordinarily occur on the stems. 


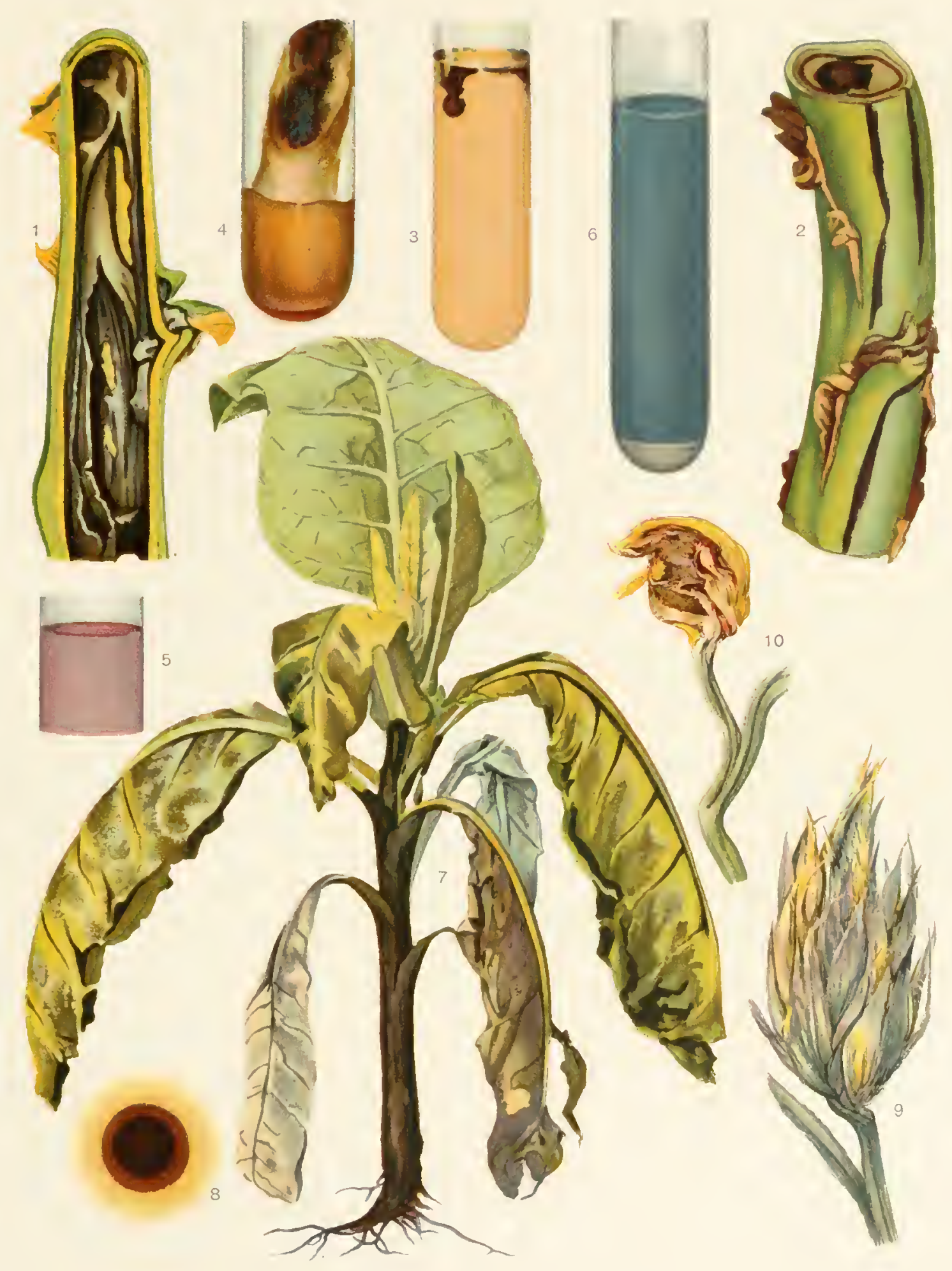



much rim. Most of the tubes were still somewhat cloudy and all became very turbid on shaking. Four of the six cultures from as many colonies produced crystals in the bonillon; two dicl not.

Milk.-I, ike Bacterium solanaccarum, except that a brown rim formed on old cultures. No acid was formed, and there was no coagulation of the casein; the fluid became more and more alkaline, and after some weeks was transhcent and pale brownish. (See pl. 4I, fig. 3.) The milk was browner by transmitted light and so clear that print could be read belind it and that a penholder conld be seen very readily behind two tubes when one was placed back of the other; the brown bacterial rim was not visible until toward the close of the experiment, it having increased very noticeably during the last 2 weeks; the black rim has not been observed in milk cultures of the tomato and potato organism.

Litmus milk.-Like Bacterium solanacearum (pl. +1, fig. 6), except that I lave not seen any crystals such as shown in fig. 124 . Cohn's solution.-No growth. Nimerous tests.

Reduction of nitrate to nitrite.-Copious in bonillon.

Thermal death-point.-This is above $48^{\circ} \mathrm{C}$. and below $52^{\circ} \mathrm{C}$.

II inimum tomperature.-This is above $8^{\circ} \mathrm{C}$. No growth was obtained at $8.2^{\circ} \mathrm{C}$. in 6 tubes of +15 peptonized beef-bouillon exposed for 5 weeks. These were inoculated from as many colonies. Four out of 6 similar tubes finally clouded at $8.7^{\circ} \mathrm{C}$.

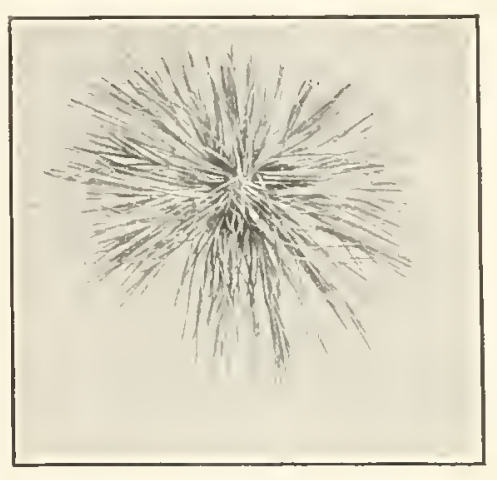

Fig. 124.*

Gas.-None from any medium.

Acrobism.-Strictly aerobic so far as can be determined from general appearance of buriecl colonies, failure to grow in hydrogen, and behavior of stabs in agar and gelatin.

\section{ETIOLOGY.}

\section{EXPERIMENTS OF 1907.}

On July 29, 1907, three young tobacco plants abotit 4 to 6 inches ligh, Nos. 595-597, were inoculated directly with Bacterimm solanacearmm from the browned bundles of tomato

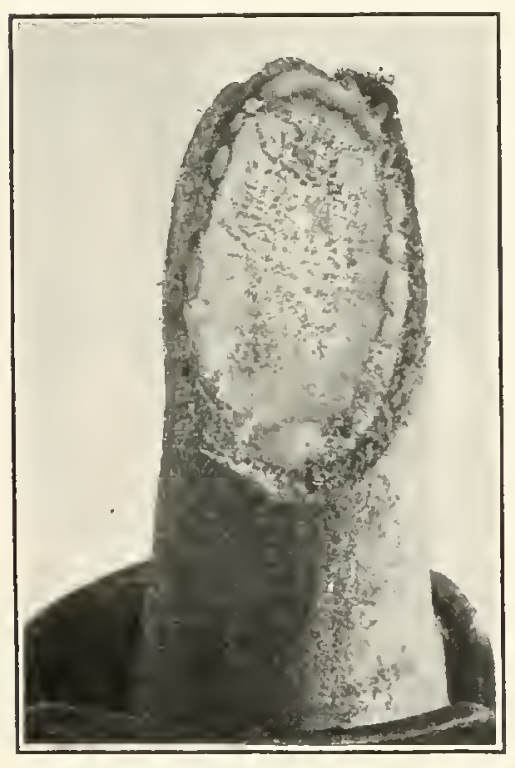

Fig. 125. stems from Lanham, Maryland. The stems were squeezed until the juice came out, and this and bits of the browned bundles themselves were pricked into the stems and petioles of the tobacco plants.

Result.- The leaves finally wilted and the stenus were full of bacteria [some vessels probably]; then the plants recovered. (Notes made by Miss McCulloch.)

\section{EXPERIMENTS OF 1908.}

On July 9, I gas, a dozen large wilted tobacco plants were received from Creedmoor, Nortl Carolina, affected by the vascular bacterial disease (Granville wilt). These were buried in good soil in rows about 15 inches apart in the old rose house.

On July 22, I received a much larger nutmber of wilted tobacco plants (Granville bacterial disease) from the same locality and buried them in rows in the sanse way in the same house.

After the receipt and burial of the second lot of tobacco, I planted tomato plants (large size) between the rows of tobacco laid down on July 9 ; and large plants of Datura stramonimm between the rows of the more recently buried tobacco. These plant-

*FIG. 124.-A crystal complex from a shining small mass on the inside of a test-tube above the fluid, in an old litmus-milk culture of North Carolina tobacco-wilt organism: Colony A, from poured plate Iv, nade direct from a tobacco plant received from Creedmoor. Tube inoculated June 19. Drawn free-hand Nov. 13 (Zeiss $8 \mathrm{~mm}$. apochromatic objective, No. 12 compensating ocular) and then reduced somewhat, $X_{50}(?)$. Contanination (?).

tFig. 125. - Stem of Datura stramonium showing gray bacterial ooze from the vascular system. The plant stood in a bed where tobacco plants affected by the Granville (North Carolina) tobacco wilt had been buriecl and the infection took place through roots broken at the time of transplanting. (For appearance of the whole plant at this time sce pl. 43). It grew in the bed, healthy to all appearances, for about 5 weeks and then suddenly wilted. Pliotograplied A11g. 29, $1908 . \times 2$. 
ings were made on July 23. The roots were broken considerably, and purposely, in transplanting both the tomato and Dalura, and the tops were pruned back to correspond. They soon recovered from the transplanting. The results were as follows:

August 3.-Five of the tomato plants show wilt to-day. Brought in two for examination. These are the smaller of the 5 and all their leaves have collapsed. No evidence above ground as to the cause of the wilt. They were all right day before yesterday. Cut stems at surface of earth and also about 4 inches above. "Ithe vascular bundles in each plant are gorged with a gray-white sline. Examined sections from each stem under the compound microscope-the slime consists of nuyriads of bacteria of the same morphology as those seen in the tobacco stems planted in the bed. 'The tomato plants went into the bed July 23; they have, therefore, been exposed to the infection just 1 i days. 'The tomatoes came from out of doors on our grounds; part from west of the grapery and part from the north end of the grounds. There are no checks on these, but they were all sound plants when set into this bed. On the Daturas there are hundreds of cheeks in the northern part of the city, in open ground where they grew. All of the transplanted Daturas are still healthy.

A ugust 5.-The weaker stramoninns between the rows of buried tobacco begin to wilt (old rose house); brought in 4 and examined. No bacteria: A white mycelium occurs on the roots and a Fusarium in the vessels (internal conidia). 'This fungus was probably brought into the house with the plants, sone of which cane from an old chip pile and rubbish heap. The bacteria have scarcely had time to diffuse throtigh the soil and affect these plants. Brought in 4 more wilted tomatoes. The vascular bundles are browned and swarming with a short motile bacterium which is typical for Bact. solanacearmm. It occurs in great numbers. Inoculated t tobacco plants in the orange house with juice squeezed from these 4 infected tomato stems; 4 places on each plant - middle of two upper leaves (nidrib and parenchyma), on stem under an upper leaf and lower down on the scar of a leaf torn off for this purpose; latter just rubbed in, rest by needle-pricks. 'Thorough. Plants 2.5 feet tall. Not in bloom.

A ugust 7.-Brought in one more wilted tomato plant. At 9 inches from the roots the vessels are browned and full of typical bacteria. At level of the ground the inner tissues are worse affected, but there is no external disease. At a foot from the ground the bacteria are also in the vessels, but the brown stain is wanting.

August I0.-Brought in from the bed in the old rose house 8 additional wilted tomato plants. Cut each tomato stem cross-wise in several places. Each is badly infected in the vascular system by bacteria. There are millions of these. They are short rods with rounded ends, oozing out of the browned vascular ring as a gray slime. Examined each plant microscopically. The infection in most cases extencled from the base of the stem upward a foot or more; the only free vascular part is in the extreme top of the plants. (Did not examine vascular system of leaves.) In one case I found the gray bacterial ooze 3 inches in adrance of the brown stain at the top of the plant. "lhe others were too much infected to slow this difference. 'The outside of the plants was sound even at the surface of the earth. Eighteen tomato plants have now gone down with this wilt.

1 ugust $14 .-$ - One of the stramoniums came down to-day with the tobacco wilt. Its vessels are brown and swarming with short, motile, rod-shaped bacteria, which seem to have entered through two broken roots. The bacteria are abundant enough to ooze from a cross-section of the stem 6 inclues from the roots, as a gray slime. 'The organism was found in cross-sections of both the browned roots (examined microscopically) and issuing as a gray ooze. Surface of roots sound; stem also sound on its surface. Plenty of sound roots.

A ugust I 6.-Brought in another wilted Datura from the bed which had diseased tobacco planted in it. On chissection the vasenlar buntles were full of the gray bacillus. 'Third case.

1 ugust $17 .-$ One additional tomato wilted. It is sound externally and is $55 \mathrm{~cm}$. ligh. All the foliage is green and freslnly wilted, and there is no external indication as to the cause of the trouble. Bacterium solanacarum is present in the vessels of the stem all the way from its base to the top of the plant. The ressels are browned below but not in the top of the stem. Bacteria most abundant below, where on cutting the stem they ooze as a gray-white slime; entrance apparently throngh one small wounckect root. 'This contains the bacteria; the others look sound. Bacteria are present in the midribs of all the leaves at their junction with the stem and in all but the top ones half-way out or more. 'T wo top leaves rectured the use of the microscope to show the presence of bacteria in the

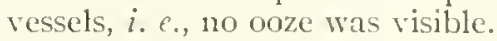

H ugust 26.--Pulled, brought in, examined microscopically, and had photographs made, of the + tobacco plants inoculated August 5, with shime from the stems of tomato plants which were infected throngh broken roots by planting orer the buried tobacco in the bed in the ofd rose house. Best parts put into Carnoy. Vascular system of plants fully diseased from top to base, especially on one sicle where there are black stripes on the stems. It is the Granville wilt in typical form (pl. 42 ). 


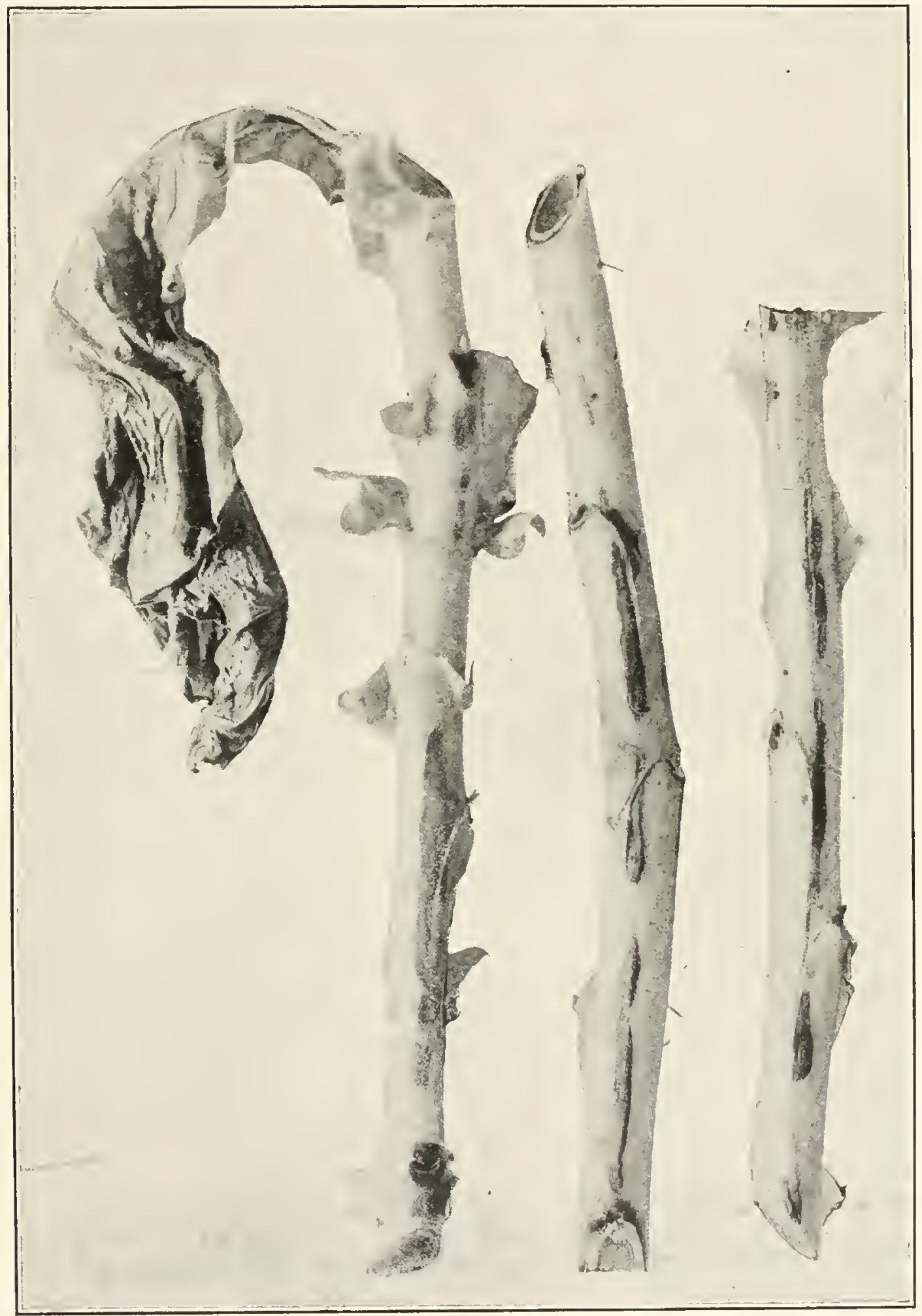

Brown stripes on tobacco stems attacked by the North Carolina tobacco wilt.

These plants were inoculated from tomato stems (direct transfer of the bacterial slime) on Aug. 5. 19os, by needle-pricks on leaves and stems higher 10 the injuries here shown being accomplished from the vascular bundles downward and outleaves and stems higher "1p, the injuries here showi belng accomplisted from the vacterial slime was taken were wilting plants ward, the epidermis remain the blants had been buried. Photographed Aug. 27. Compare with plate 4I, fig. 2. 

August 29.-Yesterday I saw slight wilt on another Datura stramonium standing in tlie bed where the North Carolina tobacco was buried. It is a large plant and has been healthy hitherto. This morning I brought it in and had a photograpl made (pl. 43). It is badly wilted. Stem sound externally; vessels filled with Bacterium solanacearum. Fusarim not present. Infections took place through broken roots. 'The bacteria are most abundant in the lower part of the stem and ooze out copiously on cross-section (fig. 125).

A ugust 31.--To-day, removed an additional wilted tomato plant from bed in the old rose liouse. The surface is sound except some small roots. 'The vessels in the lower half of the plant are filled with gray slime which under the microscope has the characteristic morphology of Bacterium solanacearum. Short rods; many in pairs (dividing). 'The plant is 3 feet long. The vessels are browned only in tlie lower part. Not many bacteria present in the upper part and no stain there. As one goes toward the root-system bacterial occupation increases. Infection took place unquestionably througlı the root system. This is the twentieth tomato plant to wilt.

October 28 .-Old rose house. Removed the remainder of the Daturas this morning. Some were in fruit. They have lost inany of their leaves and others are brown spotted, but tle cause of the disease is uncertain. None of thein except the 4 already mentioned appear to be attacked by the tobacco disease. Also pulled out the remainder of the tomatoes, none of which were wilted. Out of this bed I have removed $2 \mathrm{I}$ wilted tomato plants attacked by Bacterium solanaccarmm, and now these 9 which are not wilted. These 9 plants have sprawled over the ground, covering it with foliage, and have made a growth of $S$ or Io feet altogether, but have borne very little fruit. Only one or two green tomatoes were present, and the gardener says he has not seen fruit on them. It is not certain from this that the plants are resistant to the disease. It may be that they got such a good root start that the disease could not attack them successfully, or it may be they are resistant individuals. With a view of testing this I made cuttings from soft wood at the tops of $S$ of these plants and removed all the leaves. I then planted them in the same bed after spading it up. There are 27 of these cuttings. If the plants are not resistant some of the cuttings ought to contract the disease, provided the organism is still living in the soil. I also pulled out all the remaining Daturas and set in place egg-plants, two varieties of peppers, and some Connecticut tobacco. 'There are three rows of the egg-plants, 12 plants, var. Black Beauty. They were growing vigorously with leaves as large as my hand or larger, and perhaps a dozen such leaves. I pulled off all the leaves and root-pruned each one severely before setting it out. 'The peppers are Cayenne and Ruby King, 12 plants of each sort. Six of eacli sort were set out very carefully witlout disturbing the roots in the least, and 6 of each sort were thoroughly root-pruned and had all the leaves pulled off. Of the tobaccos, I set 6 in one part of the bed and 6 in another part of the bed. Three of each lot were transplanted without injury to the roots; the other 3 had all the leaves pulled off and most of the roots. In addition, I made 3 cuttings from a vigorous growing Datura, and set these out in the bed.

Some tomatoes which were set out in a portion of this soil by MIr. Bisset, the gardener, about 2 months ago have made a very uneven growth. As a control I had a similar bed on the other side of the partition planted at the same time with a number of tomato plants, but in soil which had not received the diseased tobacco. 'These clieck-plants are very leafy, 3 feet or more in height and healthy-looking. Of the $2+$ in the diseased soil only io plants are good-looking ones; the others arc dwarfed and have the terminal leaflets dead or dying. Nine of the 14 dwarfed ones are very badly dwarfed. These are only about a foot ligh, and have only about one-fourtl as much foliage as the check-plants. I have seen no wilt on them, and I am not yet certain as to the cause of the dying of the terminal leaves and general dwarfing of the plants.

Norember I 6. - The rooted tomatoes, now about 3 months old, show no distinct indications of wilt, but they are dwarfed and sickly. They have made not nearly so good a growth as the check plants in similar soil but which had not received diseased tobacco. I am at a loss to know whether this disease is due to the slow action of the tobacco organism on the roots of the tomato or whether it is a distinct disease. 'l'he checks are frec, altlough the two beds are separated only by a glass partition and 16 inclies of space. The three cuttings from young Datura stramonium have died, $i$. $c$., they did not root. The 12 transplanted tobacco plants show no indications of disease. The 12 pepper plants with tunpruned roots are continuing to grow normally. Of those with heavily pruned topsand roots, roappear to be recovering, one is dead, and another is dying. I have just pulled up the latter and find the base of the stem rotten. These plants are not recovering easily from the lieavy top and root pruning. 'The $12 \mathrm{egg}$-plants, which were transplanted after being very heavily root and top pruned, are beginning to recover and are making a little growth. Of the 29 tomato shoots which we attempted to root in this bed, only 5 appear to be living; the others have gradually rotted away. MIore mature cuttings should have been used. The stems hitherto examined have not shown any definite indications of bacterial infection in the vascular bundles. 


\section{EXPERINENTS OF 1909 (1908 CONTINUED).}

March 22, I909.- None of the cuttings rooted. None of the peppers or egg-plants have contracted the wilt. Probably the stems were too woody when transplanted. The heavily pruned ones recovered very slowly. The older rooted tomatoes gradually got worse and worse, but with no definite wilt, or brown stain in the stems, or bacterial occupation of the vessels. The checks finally contracted the same disease. One of the tobaccos (a large plant now) has contracted the bacterial wilt. Its vessels are full of the gray slime, especially on one side. This was most abundant in the lower part of the stem, but was traced out into the leaves and into the top of the plant just under the seed pods, where a few vessels were browned and occupied by the bacteria, as shown by a microscopic examination. In the middle of the stem the bacterial slime was very abundant, but agar pouredplates sowed copiously showed at the end of the seventh day only intruders (a few colonies with fingerlike radiations). The right organism was not recovered with certainty even on a second set of plates made the fifth day from the second dilution tube, which had been kept and was then clonded. 'The only possible infercnce is that the parasitic bacteria had been present in this part of the stem for some time and that they were now deacl-supplanted by saprophytes. 'Flie ontside of the stem, on one side over the most badly affected part of the vascular cylinder, bore long dark stripes and sunken places. T'lis tobacco was one of those not root-pruned.

From the interior of a basal branch of the same plant which was then wilting, another set of plates was poured on March 30 and these plates yielded the right organism.

On May 6, I 909 , a second tobacco plant wilted with characteristic signs, and poured plates made from the browned interior yielded the right organism.

July 6, 1909.-The experiments with tobacco, egg-plants, and peppers were closed out to-day with the following results:

(1) Tobaceo: 8 plants healthy, 4 diseased. Fron 2 of the diseased, as already stated, Bacl. solanacearum was plated out; the other 2 had similar signs but no cultures were made.

(2) Egg-plant: There was no definite wilt on these egg-plants during the whole of the tine they stood in the bed; 9 of them are sound, 2 being in fruit and the rest in blosson; i is wholly rotted, and 2 are gone, $i$. e., perished earlier.

(3) Pepper: There has been no indication of wilt in the peppers during the whole time they have stood in the bed. Like the egg-plants, the root-pruned ones never fully recovered. There are now 9 free-growing peppers bearing green and ripe fruits in abundance and 9 stunted peppers (the root-pruned ones); six plants perished earlier, but with 110 definite signs of this disease. There is a trace of brown stain in one or two places in the wood at the base of the stem of 3 of the root-pruned ones, and a microscopic examination shows the presence of ty loses in the browned vessels, but no distinct evidence of bacteria. The bed was now spaded up and prepared for large tomato plants.

On April 24, 8 good-sized tomato plants were inoculated with the organism plated from the interior of the diseased tobacco on Marcl 30 . These inoculations were made from slant agar-cultures of April 2I by means of needle-pricks on the stem, 2 plants being inoculated from each culture, a large amount of material being introduced and 2 internodes of each shoot being pricked. On May 6, six additional plants of the same series were inoculated from a beef-broth culture of April 22 in the same thoroungl manner. 'The tomato plants were rapid-growing, rather tall individuals, propagated from cuttings.

July 6, rgog.-The tomato plants continued to grow rapidly and up to this date none of them have ever shown any trace of wilt, with the exception of one plant, which after a time showed one or two slightly wilted leaves that subsequently recovered their turgor. The tomato was a free-bearing, red, small-fruited, hothouse variety.

Final Note.--The organism appears to have died out of the soil which yielded so many diseased plants (tobacco and tomato) in 1908. It was moved to another hothouse and tomato, tobacco, and the Porto Rican spiny weed (p. I S2) grown in it for a year, but with wholly negative results.

In I9I2, Coleman, of Mysore, told me he had observed the same thing at Bangalore in connection with his work on the Indian potato-disease. After about 2.5 years an artifieially infected soil was no longer infectious.

This is a lighly important matter deserving of thorough study. Very likely the growth of certain soil saprophytes may serve to bring about destruction of Bact. solanacearmm in certain soils, and if they could be obtained in pure culture, they might be sown to advantage on infected lands. Since this was written Honing has obtained some evidence bearing on this point (see fig. I 34 ).

Perhaps, also, a proper course of rotation and eultivation would do much to free the soil. 


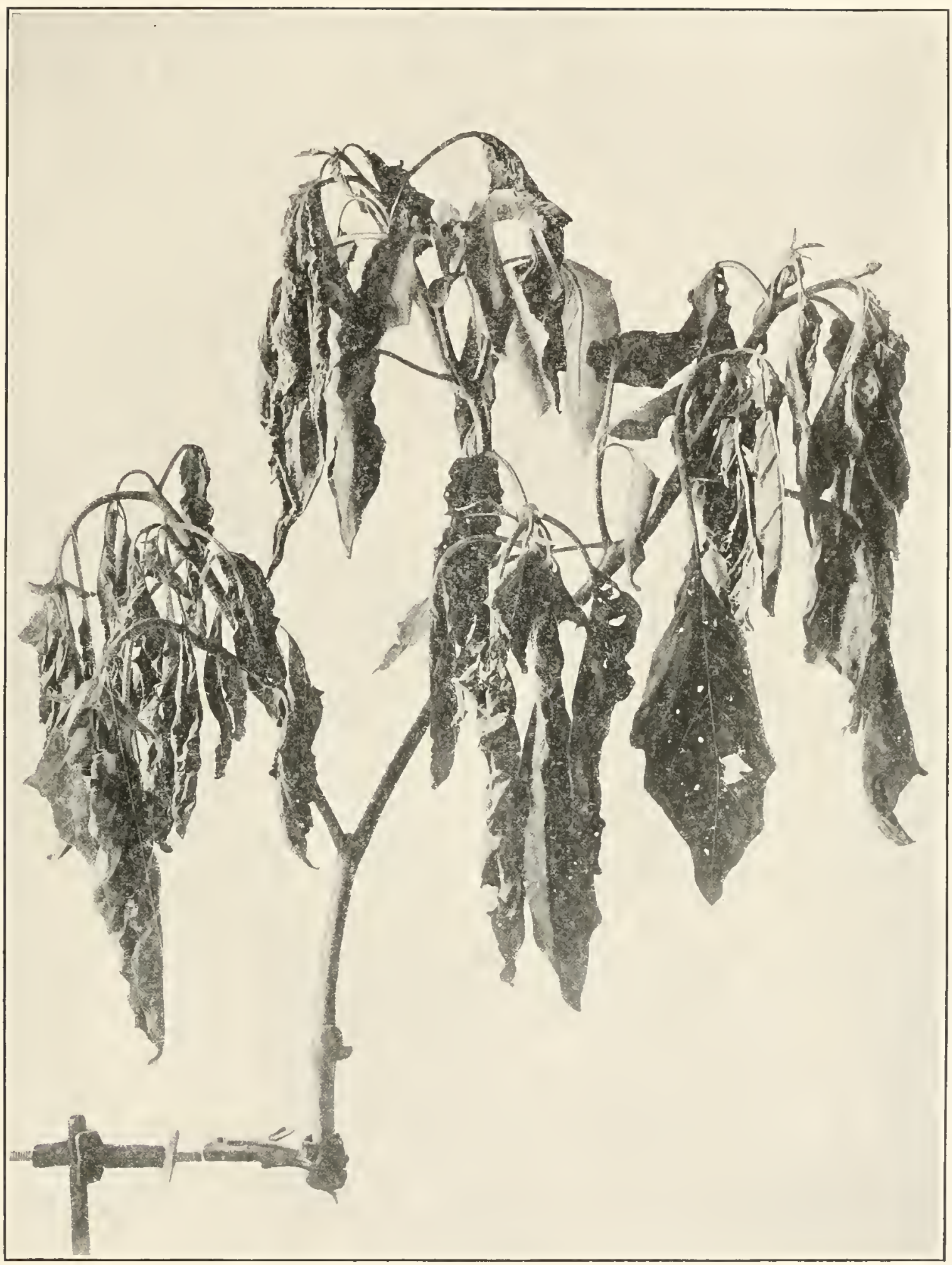

Shoot of Datura siramonium attacked by the Granville tobacco wilt.

The infection took place through broken roots as the result of transplanting to a bed in which diseased tobacco plants had been buried. The vessels of this piant, especially in the lower part of the stern, were swarming with the bacteria (sce fig. 125) Photograpled Aug. 1908. 



\section{LOSSES; TREATMENT.}

The Florida tobacco-disease, according to Mr. W. W. Cobey, has been present on a plantation near Quincy, Florida, for several years. The loss in 1905 was estimated at about $\$ 4,000$, a total of about 4 acres of plants being destroyed. 'The disease was patchy, but occurred on many parts of the plantation, being much more widely distributed than in 1904 . This was probably due to the fact that the refuse tobacco material of 1904 was composted and spread on the land in 1905, the parasite being undoubtedly present in some of the composted tobacco leaves. The losses around Quincy, Florida, in y gos far exceeded those of 1905 .

Mr. Shamel, a tobacco expert of the U.S. Department of Agriculture, wrote to the Department as follows respecting the Florida tobacco disease in June rgos:

The Granville wilt has appeared to an alarming extent, especially in the fields of the Owl Commercial Company [Quincy, Florida]. I have sent plants to Stevens for identification and to Dr. Briggs in connection with some soil samples. 'The wilt does not attack the plants noticeably until from 3 to + weeks after transplanting. 'Then one leaf or a portion of a leaf begins to wilt, then follows the destruction of the entire plants. In some of the shaded fields on the Owl plantation from 25 to 7o per cent of the plants have been killed. On an affected field of last season, planted in potatoes this year, the potato plants liave all been killed. It is the most discouraging factor I have ever seen in the way of a parasitic disease of tobacco.

The writer examined some of the diseased plants from this locality in 1905 and again in 1908 , but conld find no Fusarim, only bacteria.

The losses in North Carolina have been much greater than those reported from Florida.

In the Thirtieth Annual Report of the North Carolina Experinent Station for the year ending June 30, 1907, Dr. F. L. Stevens reports that the Granville tobacco wilt-

continues to spread and is reported as worse this year, and the loss is said to be 25 to 100 per cent of the crop in the infected region. 'The loss in one county is estimated this date at \$20,000. It is estimated to be fo per cent more destructive this year than last year.

Reports to the writer in Igos from North Carolina indicated more extensive losses than any previous year. Many planters harvested their tobacco in July, unripe and halfgrown, in order to save some portion of it.

In June 1908, Mr. Cozart, statistical agent for the U. S. Department of Agriculture, wrote as follows from Creedmoor, Granville County, North Carolina, respecting the prospect for a crop of tobacco:

In making this report I am at a loss to estimate the tobacco crop. We have a fine growth, good size, and it promises to be a good crop, but we have a serious problem to contend with-the wilt tobacco. There is lardly a farm in this township free from it. It is very serious and spreading at an alarming rate; 20 per cent of our tobacco already lost by wilt, and if ratio continues, 30 to to per cent will be lost by the time it goes to knife.

IV. E. Graham, of Church Road, Virginia, reports (October 7, 1908) that the Granville tobacco wilt is getting worse on his place all the time, and further, that it is "confined inostly to gray lands, as I have seen very little on red soils."

In his report for $1907-8$, Stevens, of the North Carolina Experiment Station, reports the Granville tobacco wilt as occurring in Granville, Durham, Vance, and Ashe countics in North Carolina. According to the experience of Mr. Tunstall, land affected with the wilt left without tobacco for Io years is still affected so that if tobacco is again planted it will become diseased. It is also said that there came under his personal observation one field in which the tobacco was very badly wilted, and in which, it is stated, tobacco had not been planted for at least twcnty-five years. No statement is made, however, respecting 
the planting on such ficlds during the interin of other crops which might act as carriers of the disease, or on the condition of the seed-bed from which this field was set. (For infection of a cabbage field with Bact. campostrc from a seed-bed see this monograph, Vol. IT, p. 329.)

From these statements it is evident that under favoring conditions this disease may prove very detrimental to tobacco-culture.

The reader will gather from what precedes, to recapitulate: (I) that only sound plants should be set out, and to this end the seed-bed should be on soil free from this organism; (2) that secdlings should be transplanted carly and injured as little as possible in the removal; (3) that they should not be watercd from infocted wells, ponds, or strcams; (4) that discased plants should be removed from the ficlds as promptly as possible, so that they may not become conters of subsequent infoction; (5) that the fingers or knives should not be used on sound plants after use on discased plants without a preliminary sterilization; and, funally, (6) that as far as practicable, badly infested ficlds should be devoted to other and non-solanaccous erops. Tomatoes, potatocs, peppers, or egg-plants must not follow the tobacco, nor should peants.

\section{THE JAPANESE DISEASE.}

In r 904, Uyeda described a Japanese tobacco-disease which seems to belong here, at least so far as signs are concerned. He says:

This disease causes mucl damage in Japan, especially in those cases in which the transplantation from the seed-bed is carried out rather late. P'rolonged moist weather with following great heat will cause the development of the disease. The first srmptom is the wilting and yellowing of the lower leaves, then follows the blackening of the stem and leaves, and finally of the root. 'The plants are generally killed in about two weeks after the first symptoms are olserved. The natural infection seems to take place generally through the roots, but very frecluently also by the wounds caused by topping and suckering the plants toward the end of July. A microscopical examination reveals an immense number of bacteria in almost a state of pure culture in the vascular bundles. The central part of the stem shows a rotten condition and contains a dark brown liquid. Finally the stem becomes hollow and the root is completely destroyed.

The organism, it is said, was cultivated pure, apparently in bouillon, and infections are said to have been obtained in about 2 weeks by irrigating healthy tobacco plants in pots and in the field. Infections through the stomata are also said to have been obtained by spraying a pure culture of the organism upon healthy leaves of young tobacco plants about $25 \mathrm{~cm}$. high, but no evidence of this is offered other than that after 8 days a blackening was observed along the veins of the leaves, which extended more and more, and a microscopical examination showed enormous numbers of bacteria in the pitted vessels. Egg-plants which were irrigated in the same way as the tobacco did not contract the disease. This, however, might have been due to old and woody stenis (see p. 236).

This organism is described as Bacillus nicotianac and is said to have the following characteristics:

Agar-stabs and streaks blacken, especially in the parts exposed to air (fig. 127). Growth on gelatin in streak-culture is very slow, forming a uniform pellicle, white at first, gradually blackening, with feeble liquefaction of the gelatin after about 5 weeks. Gas is produced in glucose agar and glucose bouillon, and there is a rancid smell, but only a little acid is formed. Milk is cleared. On potatoes it produces a yellow pigment, gradually turning brown-gray. In colonies on agar the growth is dirty white: gradually the brown pigment is produced, diffusing beyond the colony, which itself remains generally gray and shows concentric rings as it enlarges (fig. 128). Growth is best at $32^{\circ} \mathrm{C}$. The organism is facultative anaerobic. It produces no odor in peptonized bouillon. It is 0.6 to $0.9 \mu$ by $I$ to $I .2 \mu$ long. It is said to bear about 8 peritrichiate flagella. 
The following statements are taken from the more recent paper by Uyeda (1905):

The disease is widespread in Japan and has been known for at least 25 years, having been described in $18 S_{1}$ in Ensoroku, a book on tobacco culture. Since that time it has been written upon with special reference to nnethods of prevention by ' $T$ '. Kungaliara in the experiment station of Hukushima-Ken (1891) and at abont the same time by Dr. S. Ilori, in the Imperial Central Agricultural Experiment Station at Tokyo.

Prof. Y. Kozai, director of the experiment station at Nishigahara, lias also isolated a schizomycete, which he holds to be the cause of the disease. This is the same as that described by Uyeda, who dich his work at that station.

'The disease is variously known to the Japanese as "stem-rot," "black-leg," and "wilt-disease." Uyeda's studies were begun in 1899 and continued nearly 5 years.

The disease is widespread in the province of Hitachi, and occurs also in the province of Sagani and Shinano.

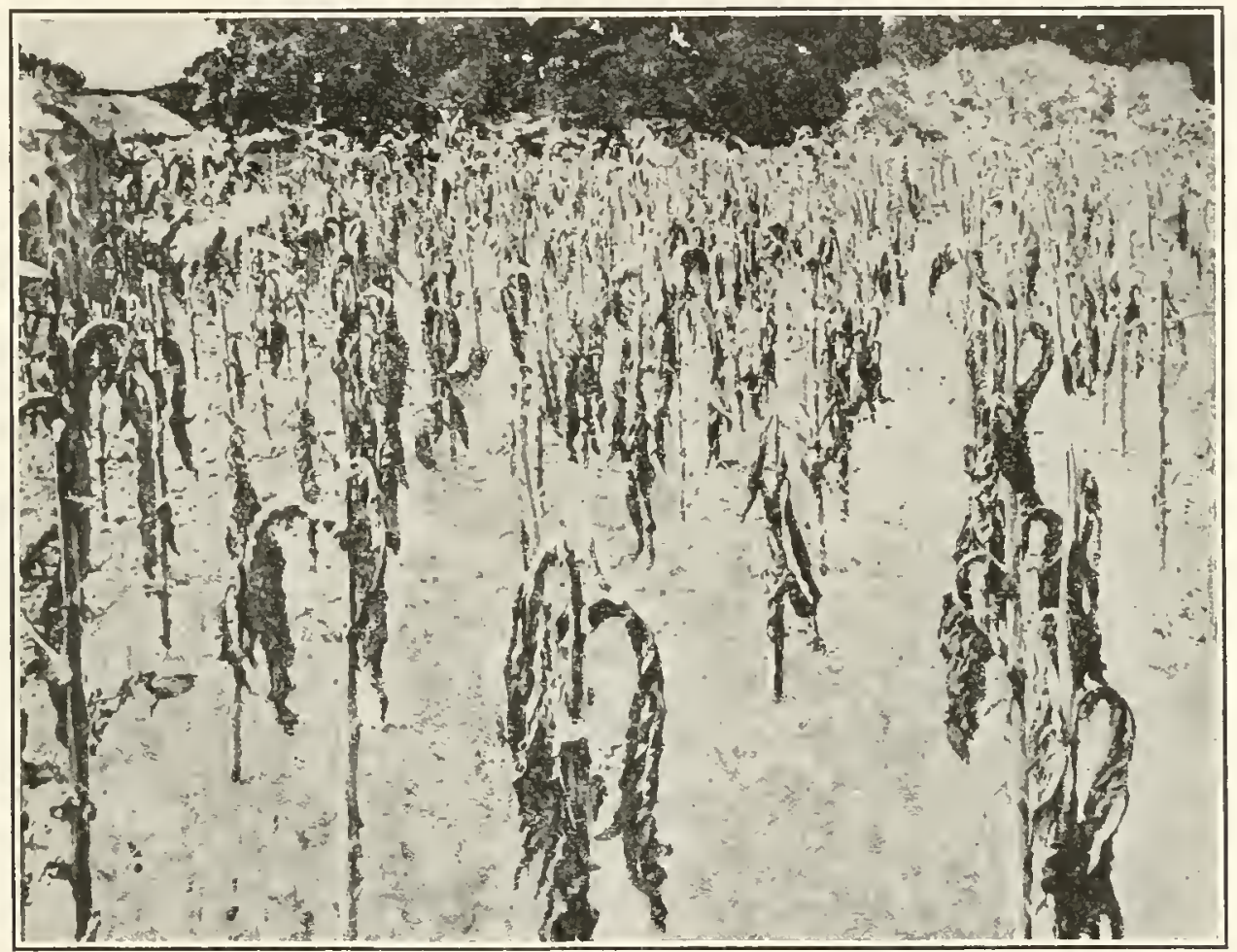

Fig. 126.*

The signs of the disease are much like those of the Granville wilt. Compare fig. 126 with pl. 33, and pl. 41 , figs. 1, 2, 7, with pl. 42 , for brown stripes on the green stems. The disease occurs from June to September on plants of all ages. The first sign is the sudden wilt of the foliage, after which the leaves become yellow. The stem then becomes black and the roots decay.

When the juice from diseased plants or a pure culture of the bacillus is placed on healthy tobaceo leaves, they begin to blacken and to show brown spots within one or two weeks. The principal reins of the leaf are then hollowed out and destroyed. The infection experinents were t11ade on young and old plants at Nishigahara. These are not described. Old leaves sometimes show wavy blach spots bordering the veins, where the bacteria are said to have entered by the stomata. 'The organism often enters also by the roots or through wounds above ground. All the affected parts contain great quantities of bacteria and the reaction of the fluid containing them is alkaline. The bark of the stem shrinks considerably as the disease progresses and black lines appear upon the surface. The tissues Uyeda.)

*FIG. I26. - Experimental field of tobacco at Ota, Japan, destroyed by bacterial wilt. Season of Ig04. (After 
of the root become separated and disorganized. At first in botl stem and leaves the bacilli are found only in the vascular bundles. In the leaves the veins are first blackened and then the parenchyma is destroyed. In very recently diseased plants the vascular bundles are only stained locally, while the rest of the tissues are entirely sonnd. In the first stage of the disease only one side of the stem is black. Later the entire woody tissue becomes black. Sometimes the black stain does not appear until after the stems are cut. 'The bacteria gradually pass inward from the woody tissue into the pith and ontward into the bark. The bark-parenchyma is badly disorganized; cell-sap, starch, chlorophyll, ninclens, and the rest of the cell-contents disappear; only the sclerenchymatic cells are very resistant. There is the same disorganization of the parenchymatic parts of the vascular bundles. Sometimes a cork-layer is developed between sound and diseased parts. Small cavities filled with an immense number of bacteria often occur in the stem. 'T'he veins of the leaf are often hollowed out by the bacteria. T'hese are often also found swarming, it is said, in the leaf-liairs. When the roots are attacked the first sign is the separation of the bast from the wood. When for any reason the attacked plants are not at once destroyed the leaves are distorted. The disease causes mttch damage by its very rapid spread during the rainy season. The spread of the disease is also greatly favored by the ligh summer temperature.

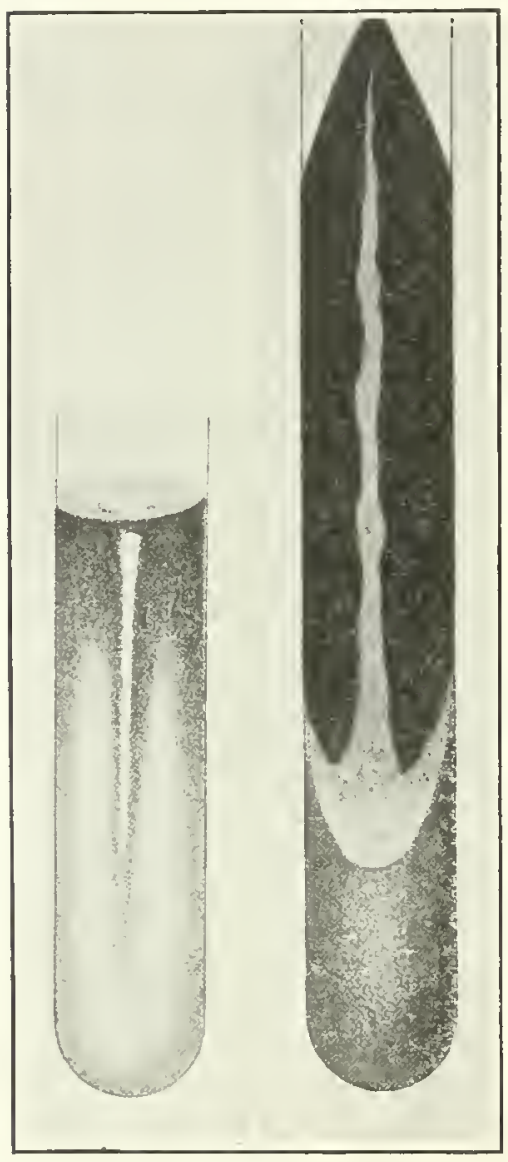

Fig. 127.*

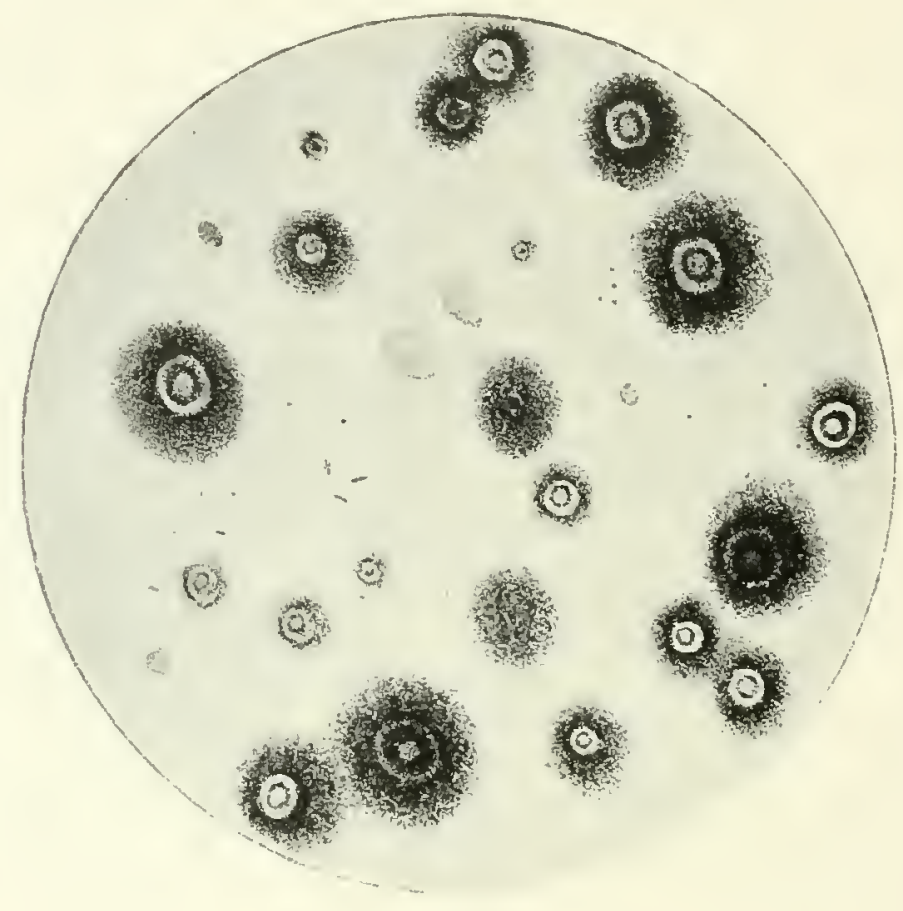

Fig. 128.†

The organism said to cause this disease has been named Bacillus nicotianae by Uyeda. He states that it resembles Bacterium solanaccarmm, but to the writer it appears to differ very materially in its morphology and cultural characters (if we may assume all these statements to relate to one organism), although the signs of the disease are strikingly like those of the Granville (North Carolina) tobacco wilt.

Uyeda's description of this organism differs from Bacterium solanaccarm, as I have cultivated it, in the following particulars:

*I'IG. 127.-Agar stab and streak cultures of Bacillus nicotianoe Uyeda, showing a brown stain iu the upper part, the lower portion of each being unstained. (After Uyeda.)

†FIG. I28.-Bacillus nicotianae Uyeda, from an agar-plate culture 2 weeks old, showing development of the brown stain in and around the colonies. (After Uyeda.) 
Perilrichiale fagella: There are + to 8 , which are 3 to + times the length of the rod.

Endospores: These are formed after a montli in both fluid and solid media. 'They are found very often in the top of agar-streak cultures grown for 3 months at room temperatures, but not in the lower part of the streak. 'They are not described or figured.

Early' pellicle: 'This appears the third day on nentral peptonized beef-bouillon with subsequent brown stain of the fluid; the pellicle breaks upon slraking into parti-colored portions, blue and white. The pellicle becomes gray and rather granular, and after a month there is a black ring.

Liquefaction of gelatin: In stab-cultures liquefaction begins to appear the second clay. After 4 days there is a distinct funnel-form liquefaction. After about 3 weeks all of the gelatin is liquefied, and gradually stained gray-black. In streak cultures all of the gelatin is licplefied in 2 weeks. 'This contradicts an earlier statenent by Uyeda.

Color and rapidity of growth on agar-plates: The colonies appear within 24 hours at August temperatures. They assume a redchish color after abouta week and then gradually change to a dirty gray and black. Firequently giant colonies appear on the plate cultures and these become ringect concentrically. Rhomboidal crystals of ammonitum magnesium phosphate are frequent in the agar.

Disorganisation of potato slices: This takes place within one or two weeks. "The growth is yellow. Coagulation of milk by the formation of an acid: Nilk inoculated with this organism becones strongly acid and is coagulated. This contradicts an earlier statement. Iater it is partially peptonized and becomes chocolate-brown and feebly alkaline.

Thermal death-point: 'This is $54^{\circ} \mathrm{C}$. At $53^{\circ}$ the result was not uniform. In one place $55^{\circ}$ is stated to be the "naximum" temperature.

I naerobism: In sugar-agar it grew well in the depths of the stab. In boullon in fermentationtubes it clonded the closed end. It also grew very well in an atmosphere of hydrogetl.

Acids: Acids were developed in various saccharine media.

Gas: Scanty development of gas in glucose-agar and glucose-bonillon. Kind of gas not stated.

Indol: A weak indol-reaction was detected in young cultures.

Stains by Gram. Reduces litmus in milk.

Non-infectious to egg-plant and tomato.

Other characteristics of the organism are as follows: It is a short rod witl rounded ends usually I to I.2 by 0.5 to $0.7 \mu$ (fig. I 29). In the plant it occurs often isolated, but sometimes in pairs. In cultures it is single, in pairs, or fours. Even in cultures 2 to 3 weeks old it rarely forms cliains. It varies somewhat in size according to conditions of growth, $e$. g., in bouillon the rods are sonnewhat larger than on agar. Capstrles oceur in old agar cultures.

On gelatin-plates, in I to 2 days, small colonies appear both on the surface and in the depths. Magnified 50 times the surface colonies are roundish with an irregular edge, sonewhat grantular and darkest in the center. After 4 or 5 days the gelatin around such co'onies is liquefied centrifugally and there is a bacterial sediment in the fluid. After 6 days the colony is somewhat beaker-form. After a week the colonies retain their original form, floating in the liquefied gelatin. The buried colonies are ellipsoidal and within a few days they fuse into a very small mass.

In agar-plates (fig. I 30 ) the surface colonies are not granular, but very smooth, moist and bright in their center. A metnbrane is often formed over the giant colonies. Rarely the concentric giant colonies liave a serrate margin. At first the surface colonies are white. The buried colonies are elliptical or egg-shaped. They liave a high sheen by transinitted light; by reflected light they are bluish-white and somewliat fluorescent.

Grow th on steanned potato at July temperatures is rapid, forming after a time a greenishyellow layer. In comrse of 1 to 2 weeks the substratum becomes gray-black. Tlis pigineint is soluble in water and is due to tyrosinase, an oxydizing enzyme. Tlie black pigment fron agar-streak-cultures is readily soltuble in water, very little in alcohol or glycerin, and 11ot at all in benzine, ether, or chloroform. This pigment is produced within a few days in agar, bouillon, gelatin, potato, and milk. In August, at $30^{\circ} \mathrm{C}$. (roon-tenperature), the production of pignent was very rapid. Bouillon and milk are wholly blackened at a ligh temperature $\left(35^{\circ} \mathrm{C}\right.$.) and a black ring is often formed on the wall of the tube at the surface of the fluid. 
Growth on cooked carrots looks yellowish at first. After some days there is a disagreeable odor. On cooked radish there is a sharp odor in I to 2 weeks and the tissue is then disorganized. The organism makes only a slight growth in Uschinsky's solution.

'The optimum temperature is about $32^{\circ} \mathrm{C}$. Methylene blue ( $\mathrm{I}$ per cent) in bouillon is reduced. Litmus is reduced.

Nitrate is reduced to nitrite (tested with netaphenyldiamin, also sulphanilic acid $+a$-naphthylanin $)$.

In young cultures in peptone-water or bouillon, indol was detected in small quantity. In 10 days in 5 per cent peptone-water the cultures became so black that indol could not be detected. Hydrogen sulphide is produced. The organism was found in the earth of a tobacco field to the depth of 3.5 decimeters.

Uyeda has the following on enzymes. Invertase is formed (the filtrate from a botillon-culture passed through a Chamberland bougie inverted saceharose in one day). A very slight quantity of diastase appears to be excreted. Cytase is believed to be produced. Tyrosinase was detected in fresh agar-streak-cultures and in bouillon-cultures by the addition of paraphenyl-

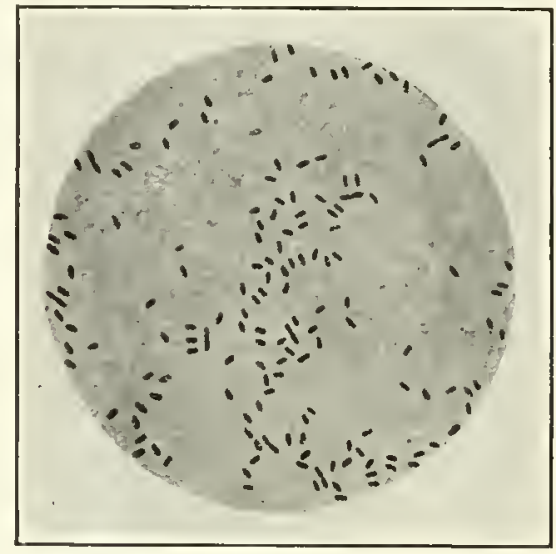

Fig. 129.* endendiamin and $\beta$-naphthol (Spitzer's reagent). With this there developed a pale red

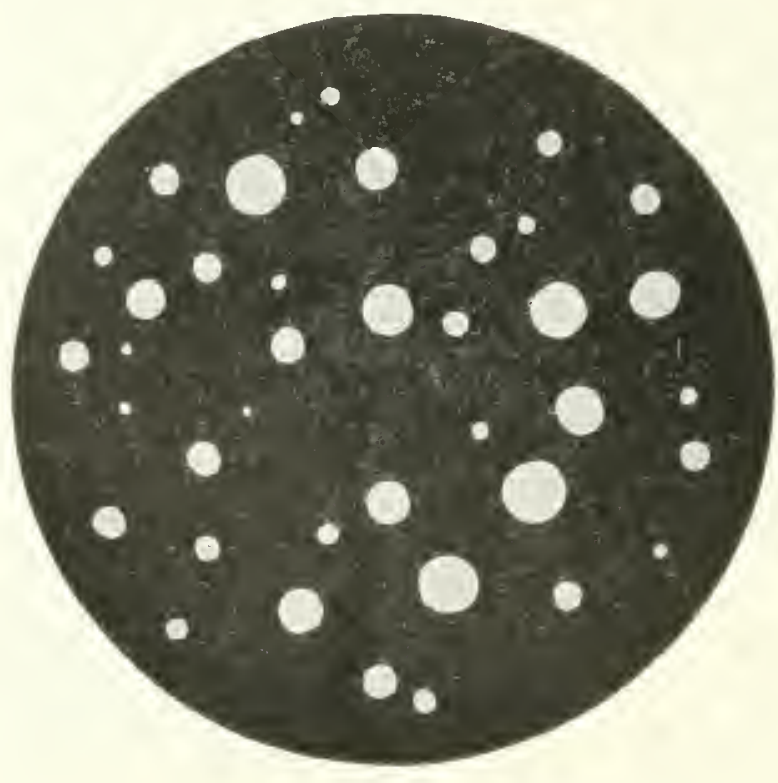

Fig. 130.f stain soon becoming black. If one adds a I to 5 per cent solution of tyrosin to a eulture of this bacillus the red-black color increases more rapidly than without it. Trypsin is also produced. This was demonstrated in gelatin-cultures several weeks old by adding some drops of chlorine-water (Neumeister's tryptophan reaction), the color changing to a red. In the same way bromine gives a violet color.

The organism grew as well (luxuriantly) in an asparagin-dextrose solution as in a peptone-dextrose solution. Bacillus nicotianae did not grow in a mineral solution $\left(\mathrm{KH}_{2} \mathrm{PO}_{4}\right.$ O.1, $\mathrm{MgSO}_{4}$ 0.03, $\mathrm{NaCl}$ 0.5 per cent) with dextrose or glycerin, and the following nitrogen componnds in I per cent doses: Ammonium tartrate, potassium nitrate, anmonium chloride. In the same nineral solution with 1 or 2 per cent asparagin and $\mathrm{r}$ per cent dextrose there was a good growth and the formation of a pellicle when the medium was alkaline and no growth when it was acid.

In the mineral solution with potassium nitrate and glycerin Bact. solanaccarm developed normally, it is said. In the writer's experiments it developed feebly as compared with the growth in bonillon. The pignent formation is independent of magnesinm salts.

*IIf. I 29.-Rods of Bacillus nicotinnae Uycda, from a photomicrograph. X 1200. (After Uyeda.)

+ FiG. 130.- Bacillus nicotiande Uyeda, from an agar-poured plate 8 days old. (After Uyeda.)

-Repeated in 1914 using Medan III with the same results. When inoculated thinly no grow/h; when inoculated hearily a moderate growth with reduction of the nitrate. 
Nicotiana rustica is not attacked, and the following varieties of $N$. tabacm are not 111teh subject: Ohasama, Taketadate, Mitsuke, Kentucky White, Green River Prior. Inoculations succeeded on Physalis minimm, Capsicum longum, Amaranthus gangeticus, and Polygonum tinctorum; they failed on Solanum molongena, Lycopersicum esculentum, and

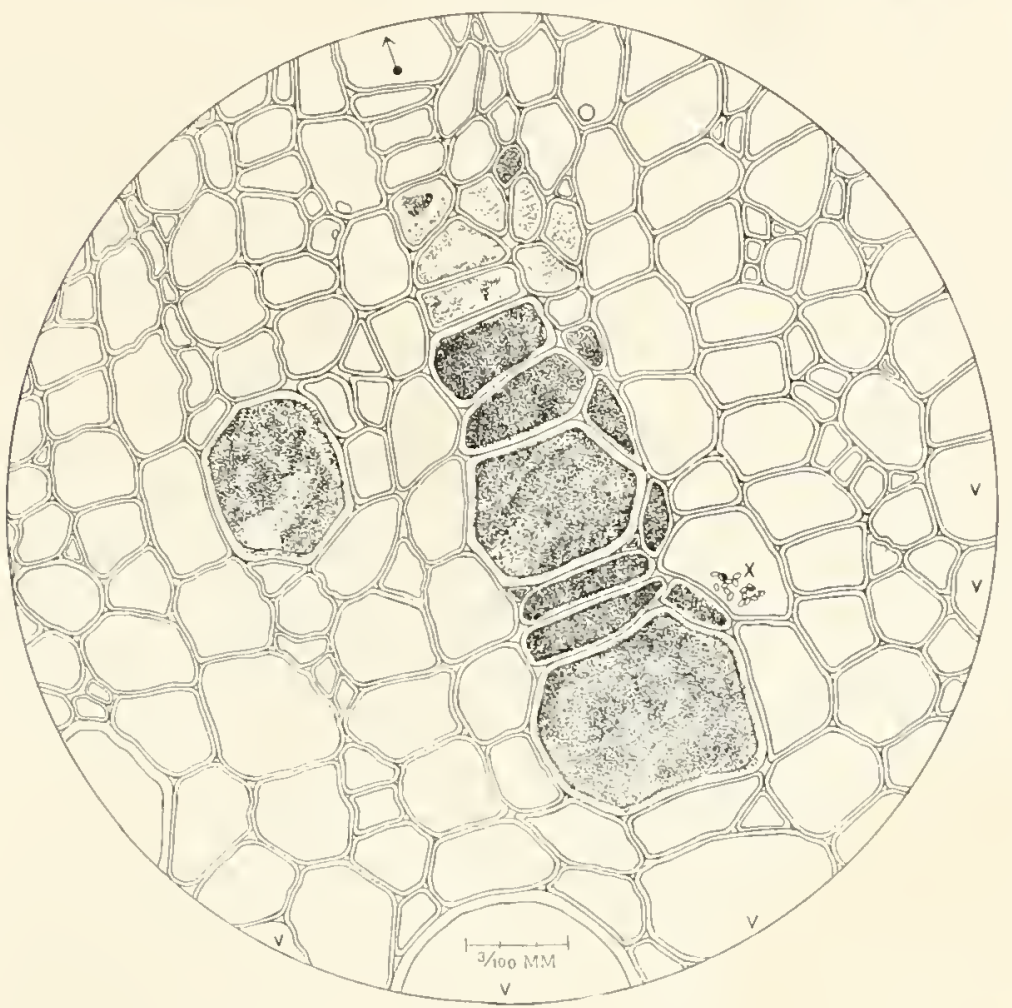

Physalis alkekongi. No details are given as to methods of inoculation, phenomena produced, or number of experiments.

Nitrogenous fertilizers predispose to disease; potash salts do not. Early planting is the best protection.

Through the courtesy of Dr. Uyeda, who sent alcoholic material, I was crabled to study his disease in serial sections.

The bacteria closely resemble Bact. solanacearmm in general appearance. They areenormously abundant in vessels of the wood, in inner and outer phloem, in the cortical parenchyma, and in the pith. I also found them to have madecavities

Fig. 131.*

resembling those due to Bact. solanaccarmm. They stained deep red with carbol fuchsin and were quite 1111iform in appearance. Spores were not observed. (Compare figs. 131 and 132 with those made from stems of the North Carolina tobacco, figs. is 6 and i 17 .)

Also, with bacteria taken from this Japanese tobacco stem I made several attempts to stain the flagella. At first I got no indications of peritrichiate rods and many faint indications of

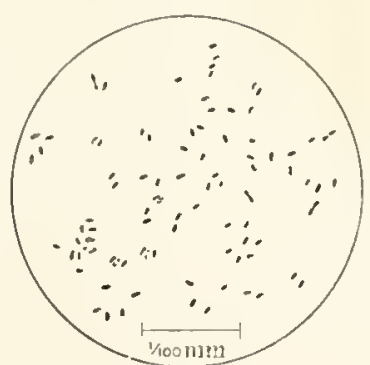

Fig 132.

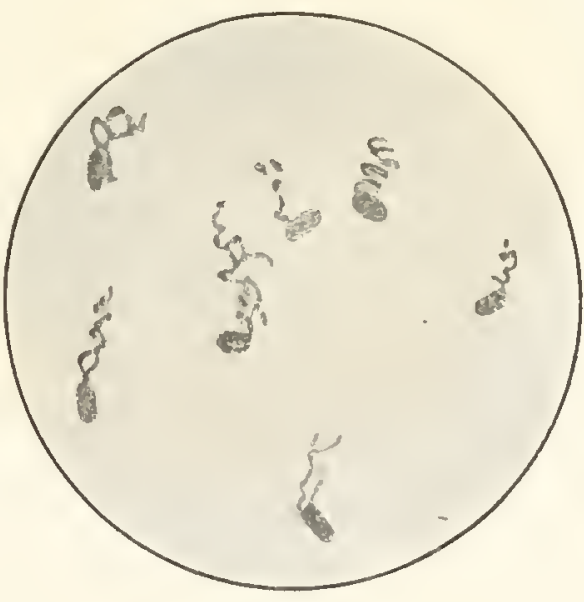

Fig. 133. polar flagella; nevertheless no well-stained ones, such as could be relied on for demonstration.

*IiIg. 131.-Cross-section of a tobacco-stcm received from Uyeda, showing character of the bacterial occupation in the Japanese tobacco wilt (compare with fig. 117). The section is taken from the wood midway between pith and bark, the cambium being in the direetion of the arrow. The vessels next beyond $V, V, V, T, V$ are also occupied by the bacteria, as well as many others. Middle section of slide 482 , stained with carbol fuchsin. The contrast is greater than here indicated. Al $\mathrm{X}$ are a few bodies which look like fungus spores. (For an enlarged drawing of the bacteria see fig. 132.)

†Firg. 132.- Schizomycetes from the Japanese tobacco-stem shown in fig. I $3 \mathbf{I}$.

†FIG. 133. - Flagella on bacteria taken directly from the interior of a tobacco-stem attacked by the bacterial wilt of Japan (Uyeda's disease). Ont of alcoholic material received from Uyeda. Pitfield's stain. 
Subsequently I tried again with somewhat better results, using Pitfield's stain (fig. I33). All the flagella appeared to be polar. I am therefore inclined to think that the description of Bacillus nicotianae Uyeda may not have been drawn wholly from one organism.

\section{HONING'S SUMATRAN STUDIES.}

Since completion of the preceding account of the tobacco-diseases, which includes notice of one paper by Houling (p. 224), I I additional Dutclı papers (191 I to I9I3) dealing with the Sumatran disease liave been received from Dr. Honing. These papers add much to our knowledge of that disease. They render it probable that it is identical with the Japanese disease and that both are due to Bact. solanacearmm, first described by the writer from the United States, although some discrepancies remain to be explained. These Dutch papers are summarized as follows:

\section{(I) THE CAUSE OF THE SLIME-DISEASE AND ATTEMPTS TO COMBAT IT.-II.}

If two bacteria agree culturally, in reaction to stains, to substrata, etc. (making due allowance for variable culture influence), but do not attack the same plants, then we may assume that they are two nearly related but not identical species. Uyreda was warranted in separating his tobacco bacteria from Bact. solanacearum only on the ground that the latter does not attack tobacco, a supposition which must now be abandoned, as Smith himself has shown and as has been confirmed in Sumatra.

Our experiments with different strains of the bacteria have shown a great difference in virulence.

The following experiments (table 25) show the infectious nature of the bacteria from different sources and the effect of a previous infection of the soil. Each of the six rows contained 100 plants, of which the first 50 in each were inoculated by soaking the seedlings for a few minutes in water to which a bouillon-culturc had been added.

'TABLE 25.-IIoning's Field Results wilh Bacteria from I'arious Sources.

\begin{tabular}{|c|c|c|}
\hline Source of bacteris. & $\begin{array}{l}\text { No of } \\
\text { inoculations } \\
\text { which died. }\end{array}$ & $\begin{array}{l}\text { Dear in } \\
\text { control. }\end{array}$ \\
\hline 1. Pouzolzia (Urticaceae)....... & 10 & 5 \\
\hline 2. Pluchea (Compositae).. & 28 & 3 \\
\hline 3. Tobacco............ & 38 & 18 \\
\hline 4. Mucuna (Leguminosae). & 10 & 13 \\
\hline 5. Tobacco................. & 20 & 23 \\
\hline 6. Check (throughout) ....... & 10 & 15 \\
\hline
\end{tabular}

Rows 4, 5, and 6 were on land infected about 4 months before, and row 3 , which also showed many cases in the control, was adjacent to the previously infected land; 2 of these 5 cultures were more virulent than the others.

This experiment was repeated in pots with the same variable result, as shown in table 26.

'TABLE 26.- Honing's Pot Resulls with Bacteria from V'arious Sources.

\begin{tabular}{|c|c|c|}
\hline Origin of bacteria. & $\begin{array}{c}\text { No. } \\
\text { inoculated. }\end{array}$ & $\begin{array}{l}\text { No. which } \\
\text { became } \\
\text { diseased. }\end{array}$ \\
\hline Tobacco $a \ldots \ldots \ldots \ldots \ldots . . . .$. & 10 & 0 \\
\hline Tobacco $b \ldots . . . \ldots \ldots \ldots . . . .$. & 10 & 10 \\
\hline Tobacco $6 . . . . . . . . . . . .$. & 20 & 20 \\
\hline 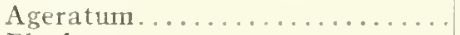 & 10 & 10 \\
\hline Pluchea.................... & 10 & 0 \\
\hline 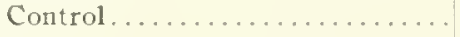 & 29 & 0 \\
\hline
\end{tabular}

"Why the bacteria from tobacco $a$ were not able to attack the seedlings $\mathbf{I}$ do not know. For the bacteria out of Pluchea the case is different, because proof of their identity must yet beobtained." With the bacteria from tobaccos $b, c$, and Ageratum, the disease was visible in 5 or 6 days. The other plants were entirely sound after 24 days. 
In another series of inoculations, 99 out of 103 plants contracted the disease, 13 cliecks remaining sound. These were as shown in table 27 .

TABLE 27.-Result of Further Inoculations by IIoning.

\begin{tabular}{|c|c|c|c|c|c|c|c|}
\hline Plants infected. & $\begin{array}{l}\text { Source of } \\
\text { bacteria. }\end{array}$ & $\begin{array}{l}\text { Number } \\
\text { inoculated. }\end{array}$ & $\begin{array}{l}\text { Number } \\
\text { slime-sick. }\end{array}$ & Plants infected. & $\begin{array}{l}\text { Source of } \\
\text { bacteria. }\end{array}$ & $\begin{array}{l}\text { Number } \\
\text { inoculated. }\end{array}$ & $\begin{array}{l}\text { Number } \\
\text { slime-sick. }\end{array}$ \\
\hline 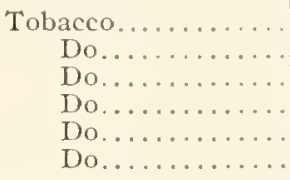 & 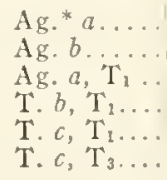 & $\begin{array}{l}10 \\
10 \\
10 \\
10 \\
10 \\
10\end{array}$ & $\begin{array}{r}10 \\
10 \\
10 \\
9 \\
9 \\
8\end{array}$ & $\begin{array}{l}\text { Tobacco. ......... } \\
\text { Solanum melongena: } \\
\text { Violet fruited... } \\
\text { White fruited... } \\
\text { Pouzolzia........... }\end{array}$ & $\begin{array}{l}\mathrm{T} . d \ldots . . . \\
\mathrm{T} \cdot c, \mathrm{~T}_{3} \ldots . \\
\mathrm{T} \cdot c, \mathrm{~T}_{2} \ldots . \\
\mathrm{T} \cdot c, \mathrm{~T}_{1} \ldots .\end{array}$ & $\begin{array}{r}10 \\
14 \\
12 \\
7\end{array}$ & $\begin{array}{r}10 \\
14 \\
12 \\
7\end{array}$ \\
\hline
\end{tabular}

*Ag. = Ageratum; $T=$ Tobacco. The small letters denote plant selected. In 7 cases the strain was reinoculated in to tobacco and reisolated before using, the sub-figures denoting the particular plant from which reisolated.

Time alone ean tell whether cultivation, rotation, disinfection, or seleetion of less susceptible races will prove inost serviceable in combating this disease.

Some planters have saicl that the slime-bacteria would not attack plants under ideal food conditions, but this ean not be admitted. Inoenlated potato plants ( 6 in number) from two sourees contracted the disease within a week, althongh they were obtaining their food directly from the mother tuber. It is likely that any plant of susceptible sort, variety, or race will be attacked, no matter what the food conditions.

It is impractical to prove absence of the slime-bacteria from the soil by the ordinary plate method, but euttings of tobaceo plants may be used. In an experiment in whicl soil-water from pots, which had been infected about 6 weeks before, was diluted with tap water in 5 dishes and 2 cuttings put into each, 9 of the ro plants contracted the disease.

In two tests made in the same way with suspected soil from two fields, each with 9 cuttings, 7 were positive for soil of one field, 2 only for that of the other. If such test.s, therefore, are made, it considerable number of cuttings should be used. Because the soft tobacco stems rot easily, Honing substituted the liarder stens of 1 geratum and Pouzolzia successfully, but then had to wait longer.

Although unquestionably the slime-bacteria are killed off in the soil by other organisms (otherwise there would soon be nothing else in the soil), nevertheless the fact remains that they may persist in the soil for years.

The continuation of the experiments with ehloride of lime and potassiun permanganate yielded nothing very hopeful, as may be seen from the following experiment (table 28 ) on 1,392 plants in 5 similar plots:

TABLE 28.--Effect of Soil Treatment on Sumatran Tobacco-Disease.

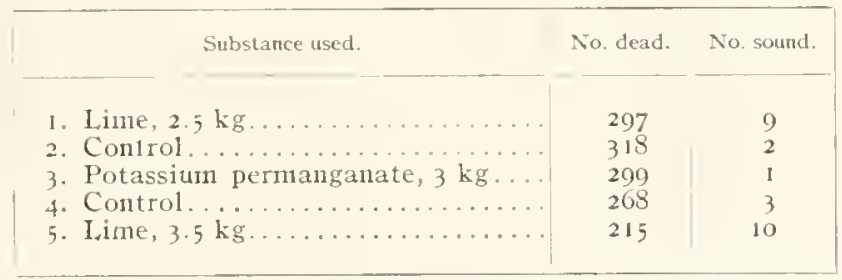

This was the worst field. None, however, were very hopeful. The best plot gave i i per cent more sound plants than the control.

The remainder of this paper is taken up with discussion of morphological and eultural characters of the slime-bacteria, which are here onitted beeause treated more fully in one of the following papers.

(2) THE CAUSE OF THE SLIME-DISEASE AND ATTENPTS TO CONBAT IT-III.

In the year I9I I, up to April, Honing received of tobaceo seedlings diseased by the slime-bacteria, t+ samples from $2+$ plantations.

Many of these fields were visited and frequently the disease was found showing in the seedlings so slightly that they would have been selected for planting, especially those infected in the leaves. On a plantation where the leaves of the seedlings were supposed to have been injured by guano or Selwweinfurth green, the aetual eause of the injury proved to be this bacterinin, anth all stages were 
observer between slight marginal injury and penetration of the bacteria tlirough the side veins, into the midrib, and even into the vessels of the stem. The general conclusion from this examination may be stated as follows: "So long as the seedlings stand in the row they are more likely to be infected in the leaf than in the root." Whether the attacked seedling is planted out depends a great deal on the age of infection. If it is somewhat advanced an intelligent coolie would reject it. On some plantations the rule is: "No seedlings shall be planted except those on which the lowermost leaves are still good." But this rule involves the destruction of many good seedlings. Also, it is not always the lowermost leaves that are first infected. 'The best proof that such leaf-infected seedlings can yield infected plants is the finding of plants in the field with diseased stems and sonnd roots. Such plants liave been seen as early as a month after planting.

Diseased seedlings, however, are not the only canse of diseased tobacco in the fields. 'T'his was well shown in a field where a great many of the plants died. This field was planted in part, it is true, from an infected seed-bed, but also in part from a sound bed, which on higher land yielded sound plants. Here the soil of the field, which had stood under water, was infected. A similar case was observed on another plantation.

The water used for irrigation may be also a source of infection. Up to this time the water of 7 wells used for this purpose has been examined and the slime-bacteria found to a certainty in 4 of them on 3 different plantations. Because of the organism's need of free oxygen these wells are believed to have become superficially infected by the falling into then of infected earth rather than from the ground-water. 'This is shown also by the fact that where a new well was made the seedlings watered from it remained free, while those watered from the old well became diseased. This and other cases cited tend to show that sound plants set on healthy land may become diseased by the use of infected water.

By use of I to 1,000 potassium permanganate such water is disinfected and is not too concentrated for watering transplants, but would burn seedlings in the bed. It has been communicated to Honing that 0.05 per 1,000 (50 grams per cubic meter) does not burn the seedlings. In using this substance it must be remembered that in water rich in organic matter potassium permanganate soon loses its disinfecting power and greater quantities must be used, concerning which no general rule can be laid down.

'There are sone plantations on which it is not possible to grow healthy seedlings, all of the soil being infected. If one must make seedlings on such land, then not only the water used but also the soil of the seed-bed itself must be disinfected. Sound seedlings are of the utmost importance, because a large percentage of the dead plants have cone from infected seedlings.

Capsicum is less susceptible than Solanum species. In one case a tobacco strain which failed on Capsicum ( 18 plants) became infectious to Capsicum after passing it through Mucuna.

(3) REPORT ON THE SLIME-DISEASE TESTS OF 1911.

General infection of the soil is probably less common than has been supposed. The tobacco has not died on all the flooded lands.

The disinfections with chlorid of line and with potassium permanganate yielded no striking results.

Water from $2 \mathrm{r}$ wells was examined, of which 7 on 5 plantations yielded the slime-bacteria.

Bacillus solanaccarmm. Smith has now been isolated and cultivated out of seedlings or field tobacco from 17 plantations. While the cause of the slime-disease is the same on all the plantations, the circumstances under which infection takes place are very different and are known only in part.

(4) DESCRIPTION OF THE DELI STRAINS OF BACILLUS SOLANACEARUM SMITH, THE CAUSE OF THE SLIME-DISEASE.

Thle most important questions resulting from a study of the literature, the inoculation experiments on tobacco and rotation of crops, and from a study of the cultures are the following:

(a) Is there to be found a series of foodstuffs, by means of which this organism can be distinguished fron others by growtl or absence of growth; also how to separate virulent from non-virulent forms?

(b) Is the slime-bacterium in Japan, which has been described under another name (Bacillus nicotianac Uyeda), possibly the same as that in America and in Deli, so that means of combating it elsewhere reconmmended can be tried here?

(c) Is perhaps Bacillus scsami Malkoff in Bulgaria [see p. 216] also the same bacterial sort as that in our tobacco and our Scsamum?

MORPIIOLOGY.

Form and size.-The Deli strain of Bacillus solanacearum is somewhat more variable than Smith and Uyeda liave announced (see pp. 193, 238). 
The greatest length observed after staining with carbol fuchsin and measuring without a cover glass was $1.8 \mu$. In old cultures they are shorter, $i . \ell ., 0.5 \mu$, and then look more like cocci than rods.

In nearly all the preparations the bacteria are single or united in pairs. Chain-form colonies, reported by Uyeda in 3-montlis-old cultures, were seen only in glycocolt-glucose solutions, where arose twisted threads of 20 or more cells, anong which were swollen single cells which no longer stained tike the others.

Motility.-In I or 2 day ofd bouillon-cultures the bacteria often show self-motility which gradually ccases. Agar-cultures appear less favorable for its demonstration. Also, when freslily isolated out of tobacco, thic exannination is mostly negative.

Flagella-staining by Van Ermengem.-More than 3 flagella I have not seen on a free-lying bacterinm, but whencver a pair lie close together there are more than 3.

Capsules.-Contrary to Uyeda, I liave not been able to find any capsules, noteven in agar-cultures 2 to 3 montlıs old stained witl carbol fuchsin or by Friedläuder's method.

Spores.-According to Uycla, B. nicotianae forms spores in cultures poor in nutrient substances, but $B$. solanacearum does not. Since Uyeda neglects to say how he demonstrated the spores, speaking neither of gernination nor of resistance to dry air or higl temperature, and not even of staining, he nninst still show proof (see under Polar staining). For the Deli strain, spore-staining with carbol fuchsin and methylene blue yielded no positive result, not even after mordanting with chroniate of potash (Clıroomzure Kali).

The slight resistance of these bacteria to heat makes the existence of spotes very improbable. Tests were made of 5 strains grown for 16 days in glycocoll-glucose medium by exposing them for 2 minutes at $80^{\circ} \mathrm{C}$. and then during the next 3 minutes cooling the water down to $40^{\circ} \mathrm{C}$. From cach of the 5 cultures so treated 3 transfers were made to peptone bouillon, but all remained sterile. 'Tlıe experiment was repeated using + strains grown in bouillon 66 days. 'T'hese cultures were plunged into water at $92^{\circ} \mathrm{C}$., which in 2 minutes cooled to $83^{\circ} \mathrm{C}$. and showed after 3.5 minutes a temperature of $40^{\circ} \mathrm{C}$. Thlirec transfers were then made to fresh media from eacl of the 4 strains, but the 12 remained sterile. "1he clicek tubes clouded in $2+$ lours, showing that each one of these strains was still living. Finally, 15 sterile strips of filter paper ( 3 from eaclı culture) were wet with fluid fron 5 cultures 26 days old, representing 5 different strains, placed in sterile Petri-dishes, and incubated in a thermostat at $36^{\circ} \mathrm{C}$. for 45 hours, after which they were transferred with sterile forceps to sterile bouillon. In none of the 15 transfers was there any growth. Moreover, Uyeda's contention that spores develop best in exhausted media is in contradiction to the statements of Sclireiber, and also those of Lehmann and Osborne. 'These authors find bacterial sporulation procceds better in nutrient-rich material.

Polar Staining.-Polar staining is very plain, even on material taken directly from the diseased tobacco. In order to avoid confusing this with occurrence of spores, slides were fixed in the flame and also with alcohol and colored witl Loeffler's methylene blue, with Ziehl-Nielsen's carbol fuclisin undiluted for some seconds, and diluted ( $\mathrm{r}: \mathrm{IO}$ ) during a minute, and with o.o I per cent watery metlyylenc blue solution during 5 to 30 minutes.

The question now arises whether Uyeda mistook polar staining for endospores.

Gram's Stain.-The Deli-tobacco bacillus is Gram-11egative. There were tested at the same time Bacillus coli communis (negative) and Diplococcus enteritis (positive).

\section{PIIYSIOLOGY.}

Generally to strains of the tobacco bacteria from different localities were investigated at the same time. After a couple of weeks they were again inoculated into tobacco to keep the grade of virulence and always afford comparative material.

Bouillon (1 per cent Liebig's meat extract, 1 per cent Witte's peptone, 0.5 per cent salt, acid or neutral). 'llis is gencrally clouded throughout in 12 to 24 hours. Often the growth is plainly strongest above, which appearance disappears after two days. Sone strains then develop a pellicle like Uyeda's $B$. nicotianae, but others behave like Smitlı's $B$. solanacearmm, forming a pellicle first after 1 or 2 weeks.

'The Deli strains also stain the fluid brown, but not all of them to the same degree. A series of 36 cultures ( 3 from each strain) showed typical differences. 'The 3 cultures from one strain were colored brown after about 3 weeks, and those from 3 other strains became dark-brown during the same time, wliile cultures of the 8 other strains were only a little stained. On far more than 200 bouillon-cultures a black ring around the pellicle was never observed, but in all a gray-white precipitate.

Gelatin.-The behavior of the Deli strains on gelatin is somewhat different from that Uyeda described for B. nicotianae and recalls rather that of B. solanacearum; that is, the liquefaction proceeds more slowly. Stab-cultures are funnel-form above and thread-form below, and sometimes a pellicle spreads slowly over the surface. Iater short projections develop along the track of the stab, and liquefaction may occut in the clefts of these outgrowths. 
Liquefaction begins irregularly in the upper layer mostly after 3 to 5 weeks, and slowly continues. Consequently the variability is very great, just as is the browning. Fintire liquefaction in 3 weeks occurs very rarely even with weak gelatin, 4 weeks is rapid, and 2 and 2.5 months the rule, and under paraffin oil more than 3.5 months are required. The melting-point of the gelatin exercises a great influence. Always the gelatin with the highest melting-point liquefied most slowly (Non plus ultra of Ton Gehe \& Co., Dresden), and this stained black, while other gelatins were not colored or only became brown. These tests were made on 58 stab cultures from 15 isolations out of tobacco, 3 stabcultures from an Acalypha stem, and 2 cultures from an A geratum stem. In Uyeda's gelatin-cultures liquefaction with $B$. solanaceanum was less rapid than with $B$. nicotianac, i. $c$., 5 to 6 weeks in place of within less than 2 weeks. Because the rapidity of liquefaction is dependent on the melting-point and on the alkatinity of the gelatin, I can not say that I have found any great difference between the behavior of the bacteria investigated by Sinith and by Uyeda. Noreover, not only are the different Deli strains unlike in thcir behavior on gelatin, but there are also distinct differences between sister cultures of the same strain. Because the time of liquefaction is three times as long for some of the Deli cultures as for others, the liquefaction difference between B. nicolianae and B. solanacearum pointed out by Uyeda is of importance only in case it is constant.

Agar.- In the beginning I obtained no blackening of agar-cultures. Later some cultures were obtained which darkened agar.

Potato.-As for Smith's organism and Uyeda's, the Deli bacteria blacken slices of potato after about a week. 'They becone, for the most part, violet-black and not gray-black. Sometimes the 4 per cent glycerin solution, above which the potato rester on a short glass rod, was colored brown.

Milk.-In Migula it is stated of B. solanacearum: "Nlilk becomes soapy, strongly alkaline, the casein is not precipitated." In his prelininary communication Uyeda says of B. nicotianae: "Saponifies milk," but in his complete work: "Milk first coagulated, but the coagulum is gradually dissolved and peptonized." These two statements do not agree.

The 20 isolations first investigated behaved for the most part alike, but different from the American and Japanese bacteria. Of 95 cultures from I + isolations out of tobacco, 3 out of $A$ calypha, 2 out of Ageralum, and 1 out of Physalis, all remained nearly unchanged, there was no precipitation of the cascin, but also not much alkali was produced [clearly, or the milk would have become translucent as I have described, but perhaps the cultures were not held long enough. They should have been kept under observation for at least $\delta$ or 10 weeks]. To litmus the cultures remained feebly alkaline, and were not distinctly acid to phenolphthalein. Only one isolation showed in 4 of the 6 cultures after 7 weeks, precipitation of the easein with weak acidity.

Noticeable for the Deli isolations is the behavior in litmus milk. In 7 isolations [which are mentioned specifically] each one of the 20 cultures rendered the milk alkaline after 3 days, which reaction progressed gradually. After 5 days each one was entirely alkaline. But two days later 16 of the 20 cultures liad begun to form acid, first a small edge which became gradually broader, until finally the whole column was colored red and the milk solid. [If this may be taken as the typical action of the Deli tobacco organism and not the effect of undetected intruding saprophytes, or other non-comparable circumstances, then we may conclude that it is not the sane as Bact. solanaccarum.]

Neither in "Natura Milch," from Bosch \& Co., Waren, Mecklenburg, nor in boiled fresh Medan milk was any chocolate-brown color observed, at room-temperature or at $36^{\circ} \mathrm{C}$. [see pl. 41 , fig. 3 ].

Cultures were also made in other milks, with similar results. From his table (p. 229) it would appear that most were alkaline at first, and then acid with coagulation. A few remained alkaline, and one of these was an isolation which soon lost its rirulence.

The results in milk may be summarized as follows:

(1) The Deli isolations coagulate and peptonize as a rule the milk of the zebu (except 4 cultures of $\mathrm{r}$ isolation of the 95 frum 20 sources) just as Uyeda's B. nicolionae.

(2) With sterilized European milk all the isolations show in the beginning an alkaline reaction, just as $B$. solonacerum Suith (concerning the strength of the reaction without figures nothing ean be judged). "The term "soapy" I do not like.

(3) Some (weakened?) isolations do not jroeecd any farther, the most begin afterward to ferment the sugar to form acid and to throw down the casein. This is just the oplosite of what Uyeda states for $B$. solanocearum [and smith also].

Conclusion.-Because the Deli isolations have given three different results depending on the age of the cultures and on the kind of milk used, the possibility is not excluded that Uyeda actually had another bacterium, but it is just as likely that if he had worked with "Nutricia," "Landbouw," "Natura," or "Milkmaid" milk, he would have obtained the same results. 'Taken in connection with the numnerous other points of agreement this is very probable [see $p p .263,264$ ].

Teed of Oxygen.-This is plainly shown by the mucl slower growth of cultures under paraffin oil, by the form of the gelatin-stab-cultures, by the slow clouding of the closed end of fermentation tubes in comparison witl the open end, and by its slow growth in an atmosphere of hydrogen in a Botkin's apparatus. 
Reduction of Methylene Blue.- In 92 bonillon-cultures from 12 isolations, containing 0.002 per cent nethylene blue, 9 were bleaclied after 1 day, 31 after 2 days, 7 I after 3 days, 85 after 5 days, and 87 after 14 days, except the uppermost 3 to + mm. The bleaching took place after 1 day in glucose botillon ( 3 cultures from each of 3 isolations-out of tobacco, Ir weuna, and Blumea).

Reduction of Litmus in .1Iilk. - Litinus is also wholly or partly reduced [see p. 26.7].

Reduction of Sodium Selenite.--'To obtain reductions the quantity of sodium selenite $\left(\mathrm{Na}_{2} \mathrm{SeO}_{3}\right)$ used must be small. Growtl and reduction was obtained witl all strains in 2 days, using o.or per cent in peptone bouillon agar, but no growth where o. I per cent was used.

Reduction of Nitrate--Nitrate is reduced when the Deli organism is grown in presence of glucose or saccharose, but not when starch is used as the carbon food, as starcli is not assimilable by this organism.

Diastase Production.-As mentioned above, starch is not acted upon. In this respect the organism agrees with Smith's statements.

Tyrosinase.-Each one of $S$ isolations grew using tyrosin as carbon-nitrogen food, but less well than in peptone-water. None of the 34 cultures were actually blackened. "When one adds I to 5 per cent tyrosin solution to a culture of the bacillus, it takes on a red-black color quicker than without this addition" (Uyeda). On repeating this experiment the result was again negative, but the concentration of tyrosin was less. Without more ammonia or alkali Uyeda could not have made a I to 5 per cent solution, since according to Eirlenmeyer only one part of tyrosin dissolves at $20^{\circ}$ in $2,45+$ parts of water.

Indol.-According to Uyeda, B. nicotianae produces a small amount of indol. The same is true of the Deli cultures. With sulphuric acid and potassium nitrite the reaction of 22 bouillon-cultures from 9 isolations was negative or nearly so. Repeating with 25 cultures from Io isolations, 20 of the cultures, after heating, gave a permanent red color of extremely variable intensity. It also happened that a culture which gave no indol reaction like Uyeda's $\bar{B}$. solanaccarum, after inoculation into tobacco, gave a positive indol reaction like Uyeda's B. nicotianae. Yet is it doubtful whether indol is really produced. According to Crossonini the indol reaction of Ehrlich is much sharper with paradimethylamidobenzaldehyd, and there are bacteria known as indol-formers on account of the old reaction, which when tested by the new method show no trace of indol. Following this suggestion, Honing tested 7 strains of the Deli tolsacco-bacteria with the paradimethylamidobenzaldehyd in alcolıol with hydrochloric acid, but all with negative results.

II ydrogen Sulphide. - This substance is formed in very slight quantity, as Uycda has also shown. Strips of lead-acetate paper exposed for some days remained white or were only slightly blackened. Of is cultures [kind not stated] from 9 sources only one gave a positive reaction. After the careful boiling away of 32 cultures ( 10 isolations) the lead-acetate paper was black in only ro tubes, and here only a little around the edge, while 22 remained negative. From one and the sane sonrce sometimes one culture was positive and another negative.

Fat.-Neither with osmic acid nor with Sudan III in alcohol or glycerine could the formation of fat be shown.

Glycogen.--This substance is not formed by the bacteria (reagent, iodinc-potassium iodide), nor can it be used as a carbon food by the bacteria, as will be slown later.

Disagreeable Odor.-This is noticeable from peptone-bouillon culturés, but varies greatly in cultures from different sources. Isolation Ts resembled Uyeda's B. nicotianae, while others produced scarcely any odor, like Uyeda's strain of $B$. solanacearum.

Gas Production. Gas-formation does not occur in the closed end of fermentation tubes with glucose, saccharose, or mannit. I'or the most part even in the presence of oxygen there is no trace of gas-formation. Once very fine bubbles were detected in 24 glucose-bonillon cultures, ro inoculated out of tobacco, 7 out of Phy'salis, 2 out of Ageratum, 4 out of Wucuna, and I out of Blumea. 'This is hardly a specific difference.

Acid-and Alkali-formation. - With exception of milk (in the second stage; i.e., after the alkaline reaction), and with a nutrose-substratum, alkali is always formed. In normal growth the original always feebly acid solntion became plainly alkaline. In feeble growth the alkalinity was feebler or the fluid had not yet reached the litmus ncutral point. Acid-formation lias not been detected with any single sugar when the source of nitrogen was not casein.

Temperature.-Uyeda's statement that heating to $55^{\circ} \mathrm{C}$. is fatal and Snith's tliat exposure to $52^{\circ} \mathrm{C}$. for ro minutes kills, is true of the Deli strains. The tropical climate (Medan lies in $+3^{\circ}$ north latitude) appears not to liave increased the maximum temperature. Bonillon-cultures exposed for 10 minutes at $55^{\circ} \mathrm{C}$. appeared to be sterilized ( 5 isolations tested). We do not, with Uyeda, consider $3^{\circ} \mathrm{C}$. difference in maximum temperature as specific, since $55^{\circ} \mathrm{C}$. (for $B$. nicotiunat) and $52^{\circ} \mathrm{C}$. (for $B$. solanacearum) are not the average of a great number of determinations with comparable material from different sources (see under "Spores").

Resistance to Drying.--This is slight, as already noted under "Spores." 


\section{SOURCES OF NITROGEN AND CARBON.}

As a stock solution for these tests, Honing used Meyer's mineral solution.* All the substances tested were from Merck, and those marked "insoluble in water" were dissolved with as little as possible of $\mathrm{Na}_{2} \mathrm{CO}_{3}$ or $\mathrm{HCl}$.

In this stock solution, adding one substance as source of both nitrogen and carbon, the results given in table 29 were obtained with the Deli tobacco bacteria.

The one substance that brought out distinct differences in the isolations was asparagin. All three cultures of ' $\mathrm{Tg}$ and 'Th showed growth and also one of Td. The rest remained entirely clear, even after I 4 days.

For reasons given, the auxanographic metlod could not be used at Medan; the inoculations, therefore, were all made into solutions after steam-heating to $100^{\circ} \mathrm{C}$. on 5 consecutive days.

Potassium Nitrate.-Witl r percent potassium nitrate (in the following solution: $\mathrm{KH}_{2} \mathrm{PO}$, o. 1 per cent; $\mathrm{MgSO}_{4}, 0.03$ per cent; and $\mathrm{NaCl}, 0.5$, alkaline) Uyeda found B. nicotianae made no development, not even on addition of I per cent glucose or I per cent glycerin, while $B$. solanacearum gave a weak

\section{TABLE 29.-Ability of Deli Tobacco Organism in Meyer's Mineral Solution to obtain both Carbon and Nitrogen from One Substance.}

\begin{tabular}{|c|c|c|c|c|c|}
\hline \multirow{2}{*}{ Substance tested. } & \multicolumn{3}{|c|}{ No, of isolations out of -} & \multirow{2}{*}{$\begin{array}{c}\text { No. of } \\
\text { cultures. }\end{array}$} & \multirow{2}{*}{$\begin{array}{l}\text { No. showing } \\
\text { growth. }\end{array}$} \\
\hline & Tobacco. & Ageratum. & Physalis. & & \\
\hline Albumin.................... & 7 & 2 & I & 42 & 0 \\
\hline Asparagin................. & 7 & 2 & i & 41 & 7 \\
\hline Fibrin of blood: & & & & & \\
\hline Alkaline............. & 7 & 2 & 1 & $4^{2}$ & o \\
\hline Acid............... & 8 & I & .. & 27 & 0 \\
\hline Gluten.................... & 3 & 2 & i & 27 & o \\
\hline 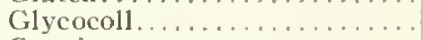 & 7 & 2 & I & 31 & 0 \\
\hline Guanine: & & & & & \\
\hline 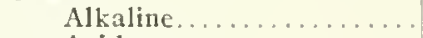 & 7 & 2 & 1 & 40 & 0 \\
\hline 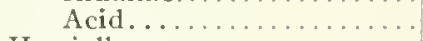 & 9 & I & .. & 29 & o \\
\hline Hemialbumose: & & & & & \\
\hline 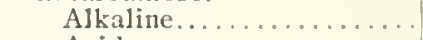 & 7 & 2 & 1 & 40 & 0 \\
\hline 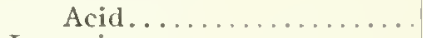 & 9 & 1 & . & 30 & 0 \\
\hline Legumin: & & & & & \\
\hline Alkaline...................... & 6 & 2 & 1 & 38 & o \\
\hline Acid $\ldots \ldots \ldots$ & 9 & 1 & . & 30 & 0 \\
\hline 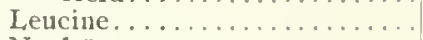 & 7 & 2 & I & 42 & o \\
\hline Nucleïn. . . . . . . . . . . . . & 7 & 2 & I & 41 & 0 \\
\hline Witte's peptone............. & 5 & 2 & 1 & 33 & 33 \\
\hline Proteïn................... & 3 & 2 & I & 30 & $o$ \\
\hline Proteîn (alkaline)........... & 4 & 2 & I & 31 & 0 \\
\hline Tyrosine............... & 5 & 2 & I & 35 & 34 \\
\hline Ammonium acetate......... & 10 & I & .. & 31 & 0 \\
\hline succinate....... & 10 & 1 & . & 32 & 32 \\
\hline lactate........... & 10 & 1 & .. & 33 & 33 \\
\hline tartrate.......... & 10 & 1 & .. & 33 & 30 \\
\hline citrate $\ldots . . . \ldots$ & 10 & 1 & . & 33 & 30 \\
\hline
\end{tabular}

growtl in presence of the glucose and a normal one in the presence of the glycerin. 'This is wholly in agreement with the Deli isolations of $B$. solanacearum with potassiun nitrate in glucose and does not show that Uyeda had two kinds of bacteria, since 4 of Honing's strains failed to grow like Uyeda's B. nicotianae, while several others grew like B. solanacearum. In addition to these differences, Honing found a strain which grew well with potassium nitrate and inuline, while another would not grow. In the same way one strain grew with potassinn nitrate and dextrine, while anotlier would not grow; also one strain grew with potassium nitrate and sorbit, while another would not grow; and, finally, one strain grew with potassium nitrate and saccharose, while another would not grow. 'These facts, Ioning thinks, should make one very careful in drawing conclusions from a small number of cultures made from a few strains.

Potassium Nitrite. - This substance may also serve as food.

A sparagin.-Uyeda's B. solanacearum did not grow with asparagin, while lis B. nicot ianae made a feeble growtl. That the latter, which with asparagin alone made a weak growth, made none wliatever when I per cent glucose was added, should have indicated to Uyeda that bacteria are variable

*Water, I,000.00; $\mathrm{KH}_{2} \mathrm{PO}_{4}, \mathrm{I} .00 ; \mathrm{CaCl}_{2}$, o. I0; $\mathrm{IgSO}_{4}+{ }_{7} \mathrm{H}_{2} \mathrm{O}, 0.30 ; \mathrm{NaCl}, 0.10 ; \mathrm{Fe}_{2} \mathrm{Cl}_{6}$, 0.01. 
like other things, because, in the first place, $r$ per cent glucose is not a poison and second, in an alkaline solution the growth of $B$. solanacearum is favored. With an eye upon the varialility of the Deli strains of $B$. solanaccarum, I must ask once nore: Is the difference constant tliat Uyeda found?

Of 12 Deli strains, 8 showed no growth witl asparagin and glucose; 4 grew badly and for the most part in a portion only of the tubes. Of these 8 strains, 5 were inoculated into tobacco, reisolated, and re-tested with asparagin and glucose, whereupon 4 of the 5 grew in part of the cultures.

These same 8 glucose negative strains were also saccharose-negative, but after 5 strains had been "fresliened" by inoculation into tobacco each one of the 5 grew in a part of the cultures set, and also with potassium nitrate the same thing was shown-more grew with saccliarose tlian witl glucose. In a repetition witl saccliarose the same result was obtained.

'ТABLE 30.-Deli Tobacco Organism in Meyer's Solution with 0.25 per cent $K N O_{3}$ and Carbon Foods.

\begin{tabular}{|c|c|c|c|c|c|c|c|}
\hline \multirow{2}{*}{ Carbon source. } & \multirow{2}{*}{$\begin{array}{l}\text { Per cent } \\
\text { used. }\end{array}$} & \multicolumn{4}{|c|}{ No. of isolations from- } & \multirow{2}{*}{$\begin{array}{l}\text { No. of } \\
\text { cultures. }\end{array}$} & \multirow{2}{*}{$\begin{array}{l}\text { No. of } \\
\text { cultures } \\
\text { in which } \\
\text { growth } \\
\text { occurred. }\end{array}$} \\
\hline & & Tobacco. & Ageratum. & Physalis. & Acalypha. & & \\
\hline Arabinose .......... & I & 9 & 1 & . & . & 47 & 19 \\
\hline Glucose............ & 1 & 10 & $\mathbf{1}$ & 1 & $\cdots$ & 45 & 27 \\
\hline Levulose... . . . . . . . & 1 & 11 & 1 & . & 2 & 66 & o \\
\hline Mannose.......... & I & 2 & . & . & 2 & 15 & 11 \\
\hline Galactose.......... & 1 & 2 & .. & .. & 2 & 15 & 13 \\
\hline 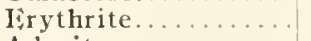 & 1 & 2 & $\cdots$ & .. & 2 & 15 & 12 \\
\hline Adonite............. & 1 & 2 & . & $\cdots$ & 2 & 15 & 5 \\
\hline Sorbit . . . . . . . . . . & 0.2 & 9 & 1 & . & . & 47 & 38 \\
\hline Mannit............. & I & 9 & 1 & . & .. & 44 & 39 \\
\hline Dulcit............ & 1 & 9 & 1 & .. & . & 48 & 46 \\
\hline 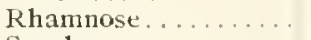 & 0.2 & 9 & 1 & . & .. & 42 & 23 \\
\hline Saccharose......... & 1 & 10 & 1 & 1 & . & 62 & 50 \\
\hline Maltose............. & $i$ & 9 & 1 & . & . & 47 & 33 \\
\hline Lactose... . . . . . . . . & 1 & 9 & 1 & . & . & 47 & 38 \\
\hline Raffinose........... & 0.2 & 9 & I & . & . & 52 & 50 \\
\hline Quercit............. & 0.2 & 9 & 1 & .. & $\cdots$ & 44 & 17 \\
\hline Inosite. . . . . . . . . . & 1 & 2 & . & . & 2 & 15 & 14 \\
\hline Dextrill........... & 1 & 9 & 1 & $\ldots$ & .. & 43 & 27 \\
\hline Starch............ & 0.2 & 6 & 2 & 1 & .. & $4^{6}$ & o \\
\hline Glycogeı . . . . . . . . & 1 & 9 & 1 & . & . & 45 & o \\
\hline Inulin............. & 1 & 9 & 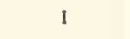 & . & . & $4^{8}$ & 7 \\
\hline Licheniu. . . . . . . . . & $t$ & 2 & . & .. & 2 & 15 & 0 \\
\hline Glycerin. . . . . . . . . & 1 & 9 & 1 & . & . & $5 i$ & 44 \\
\hline Sodium acetate..... & 1 & 9 & 1 & .. & .. & 51 & $o^{*}$ \\
\hline butyrate.... & 1 & 9 & $\mathbf{I}$ & .. & .. & 52 & o \\
\hline succinate.... & 1 & 9 & 1 & . & .. & 39 & 20 \\
\hline malate...... & I & 9 & 1 & . & . & 41 & 17 \\
\hline lactate...... & 1 & 9 & 1 & .. & .. & 40 & o \\
\hline citrate....... & 1 & 9 & 1 & $\cdots$ & $\cdots$ & $4^{2}$ & 24 \\
\hline
\end{tabular}

A mmonia Nitrogen. - Witl ammonia nitrogen and with a suitable carbon food the Deli strains of $B$. solanacearm grew well, as shown by the results with ammonium succinate, lactate, tartrate, and citrate; further by 13 of 21 cultures from 7 sources with ammonia and glucose; and also by the urea cultures ( 46 of the 52 with glucose and 44 of the 49 with saccharose).

In acid solution of $\mathrm{r}$ per cent anmonium chlorid, $B$. nicotianae grew for Uyeda and $B$. solanacearum did not, or on addition of 1 per cent glucose only fecbly, B. nicotianae also then did not.

With 1 per cent ammonium cllorid and 1 per cent glucose in Meyer's solution, not neutralized, no growtl appeared in 17 of the is cultures of the Deli tobaeco organism fronl 6 sources, and with 1 per cent glycerin in none of the 2 I cultures from 7 sources, althougl otherwise the growth with glycerin was comparable with that of glucose, but easier. 'These results harmonize well witl Uyeda's when he used acid solutions. Yet after neutralization with $\mathrm{Na}_{2} \mathrm{CO}_{3}$ (litmus neutral) tlie growtl was very strong, as well witl glucose as with glycerin. Even when inoculated from old weakened selenitagar cultures there was still growtl with glycerin but no longer with glucose.

It is thus plain that anmonia nitrogen can be used very well by $B$. solanacearum, something that is not evident from Uyeda's communications.

* Using MIedan III and Florida potato (1914), the writer obtained similar results with these sodium salts, $i$.e., no growth with the lactate, acetate or butyrate, and prompt moderate growth in all of the tubes ( 8 of each strain), using the malate, tartrate, or succinate. In Meyer's solution with ammonium citrate there was heavy growth, and with am. tartrate and an. succinate, moderate growth (4 days), but none will ammonimm lactate (4 days). Both strains grew in Meger + urea + grape or cane sugar. 
Substituting asparagin for potassium nitrate, the results shown in table 31 were obtained. TABLe: 31.-Deli Tobacco Organism in Mejer's Solution with I per cent Asparagin and Carbon Foods.

\begin{tabular}{|c|c|c|c|c|c|c|}
\hline \multirow{2}{*}{ Carbon source. } & \multicolumn{4}{|c|}{ No. of isolations from- } & \multirow{2}{*}{$\begin{array}{l}\text { No. of } \\
\text { cultures. }\end{array}$} & \multirow{2}{*}{$\begin{array}{l}\text { No. of } \\
\text { cultures } \\
\text { in which } \\
\text { growth } \\
\text { occurred. }\end{array}$} \\
\hline & Tobacro. & Ageratum. & Physalis. & Acalypha. & & \\
\hline Nothing.............. & 12 & 2 & 1 & $\ldots$ & 62 & 7 \\
\hline 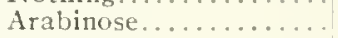 & 6 & I & .. & .. & 21 & o \\
\hline Glucose............ & 14 & $i$ & i & . & $8 i$ & 27 \\
\hline Levulose............. & 8 & $i$ & .. & 2 & 36 & 4 \\
\hline Mannose.............. & 2 & . & . & 2 & 15 & 9 \\
\hline Galactose............ & 2 & .. & . & 2 & 15 & 10 \\
\hline Erythrite............ & 2 & .. & . & 2 & 15 & 10 \\
\hline Adonite.............. & 2 & .. & .. & 2 & 15 & 8 \\
\hline Sorbit............. & 6 & 1 & .. & .. & 21 & 16 \\
\hline Sorbine ............. & 6 & I & .. & . & 21 & 18 \\
\hline Mantit................ & 6 & I & .. & .. & 21 & 20 \\
\hline Dulcit............ & 6 & $i$ & . & . & 21 & 18 \\
\hline Rhamnose............ & 6 & 1 & .. & .. & 21 & 10 \\
\hline Saccharose.......... & 14 & I & I & .. & 79 & 40 \\
\hline Maltose......$\ldots \ldots$ & 6 & 1 & .. & .. & 21 & 10 \\
\hline Lactose.............. & 6 & $i$ & $\ldots$ & . & 21 & 9 \\
\hline Raffinose........... & 6 & $i$ & . & $\ldots$ & 21 & 16 \\
\hline Quercit............... & 6 & 1 & . & .. & 21 & 10 \\
\hline Inosite ............. & 2 & . & $\cdots$ & 2 & 15 & 10 \\
\hline Dextrine............. & 6 & 1 & .. & .. & 21 & 13 \\
\hline Glycogen............ & 6 & $i$ & .. & . & 21 & o \\
\hline Inulin $\ldots \ldots \ldots \ldots \ldots$ & 6 & 1 & .. & .. & $2 \mathrm{I}$ & 19 \\
\hline Lichenin. . . . . . . . . & 2 & . & . & 2 & 15 & 0 \\
\hline 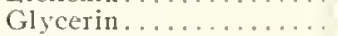 & 6 & $i$ & .. & . & 21 & 12 \\
\hline Sodium acetate....... & 6 & i & $\cdots$ & . & 21 & 0 \\
\hline butyrate...... & 6 & I & .. & .. & 21 & o \\
\hline succinate...... & 6 & 1 & $\because$ & $\because$ & $2 \mathrm{I}$ & 21 \\
\hline malate........ & 6 & $i$ & .. & $\ldots$ & 21 & 21 \\
\hline citrate........ & 6 & $i$ & $\cdots$ & . & 21 & 12 \\
\hline lactate......... & 6 & 1 & .. & .. & 21 & 0 \\
\hline
\end{tabular}

Glycocoll.-B. solantcearum with glycocoll alone does not grow, but it grows on addition of a carbon food such as glucose, maltose, or mannit, although badly in a part of the cultures and not at all with levulose.

When glycocoll was used as the nitrogen food the results given in table 32 were obtained.

'TaBle 32.- Growth of Deli Tobacco Organism in Meyer's Mineral Solution with o.I per cent Glycocoll and the Carbon Foods Named.

\begin{tabular}{|c|c|c|c|c|}
\hline \multirow{2}{*}{ Carbon source. } & \multicolumn{2}{|c|}{ No. of isolations from- } & \multirow{2}{*}{$\begin{array}{l}\text { No. of } \\
\text { cultures. }\end{array}$} & \multirow{2}{*}{$\begin{array}{l}\text { No. of } \\
\text { cultures } \\
\text { in which } \\
\text { growth } \\
\text { occurred. }\end{array}$} \\
\hline & Tolacco. & Ageratum. & & \\
\hline Glucose.... & 9 & I & 38 & 13 \\
\hline Levulose.... & 9 & 1 & 49 & 0 \\
\hline Mannit.... & 9 & 1 & 49 & 40 \\
\hline Maltose... & 9 & 1 & 49 & 32 \\
\hline I actose... & 8 & 1 & 45 & 26 \\
\hline
\end{tabular}

Also here occurred some typical cases of change in ability to ferment.

Always in sets of 3 , grew ' $\mathrm{T}^{\prime} \mathbf{T}_{1}$ in lactose 0 , in maltose 0 , in mannit 1 ; but $\operatorname{Tog}^{\prime} \mathbf{\Gamma}_{1} \boldsymbol{\Gamma}_{1}$ in lactose 2 , in maltose 3 , in mannit 3 .

Of 3 cultures from $\mathrm{Ab}^{\prime} \mathrm{T}_{1} \mathrm{~T}_{1}$ none grew with glycocoll and lactose, while of 3 others inoculated some time later from the same tube all developed.

In table 33 all the results are united. The figures relate only to the proportion of cultures that grew, not to the intensity of growth: Thus 1 denotes growth in 1 to 20 per cent of the cultures; 2 , growth in 21 to 40 per cent; 3 , growth in 41 to 60 per cent; 4 , growth in 61 to So per cent; and 5, growth in $\$ 1$ to 100 per cent. The fact that these figures differ so widely throws a strong light on the variability of $B$. solanacearum. 
'TABLE 33.-Growth of Deli Cullures of B. solanacearum in Meyer's Mineral Solulion wilh Different Carbon and Vilrogen Compounds.

\begin{tabular}{|c|c|c|c|c|c|c|c|c|c|}
\hline \multirow{2}{*}{ Carbon source. } & \multicolumn{4}{|c|}{ Nitrogen source. } & \multirow{2}{*}{ Carbon source. } & \multicolumn{4}{|c|}{ Nitrogen source. } \\
\hline & $\mathrm{KNO}_{3}$ & Asparagin. & Cilycocoll. & $\mathrm{NH}_{3}$. & & $\mathrm{KNO}_{3}$ & Asparagin. & Glycocoll. & NHs. \\
\hline Arabinose... . . . . . & 3 & 0 & $\ldots$ & . & Quercit............. & 2 & 3 & $\cdots$ & . \\
\hline Glucose......... . & 3 & 2 & 2 & 4 & Inosite........ & 5 & 4 & $\cdots$ & . \\
\hline Levulose.......... & o & 1 & o & $\therefore$ & Dextrine............ & 4 & 4 & . & . \\
\hline Mannose........ & 4 & 3 & . & . & Starch............. & o & $\therefore$ & $\cdots$ & . \\
\hline Galactose........ & 5 & 4 & . & .. & Glycogen........... & 0 & 0 & $\cdots$ & . \\
\hline Erythrite....... & 4 & 4 & . & .. & Inulin $\ldots \ldots \ldots \ldots \ldots$ & 1 & 5 & . & . \\
\hline Adonite.......... & 2 & 3 & . & .. & Lichenin.............. & o & 0 & . & . \\
\hline Sorbit......... & 5 & 4 & . & $\cdots$ & Glycerin............. & 5 & 3 & . & . \\
\hline Sorbine........... & . & 5 & . & . & (Sodium)* acetate... & 0 & 0 & . & o \\
\hline Mannit......... & 5 & 5 & 5 & .. & butyrate... & o & o & .. & $\cdots$ \\
\hline Dulcit........... & 5 & 5 & . & . & Ammonium tartrate... & . & $\cdots$ & . & 5 \\
\hline Rhamnose....... & 3 & 3 & $\cdots$ & $\cdots$ & (Sodium) ${ }^{*}$ citrate.... & 3 & 3 & $\cdots$ & 5 \\
\hline Saccharose....... & 5 & 3 & .. & $\cdots$ & lactate... & o & o & . & 5 \\
\hline Maltose.......... & 4 & 3 & 4 & $\ldots$ & malate.... & 3 & 5 & . & $\cdots$ \\
\hline Lactose.......... & 5 & 3 & 3 & . & succinate... & 3 & 5 & . & 5 \\
\hline Raffinose......... & 5 & 4 & $\cdots$ & $\cdots$ & & & & & \\
\hline
\end{tabular}

*Or ammonium compound in the fourth column with $\mathrm{NH}_{3}$.

Honing summarizes his conclusions as follows:

1. Bacillus solanacearum Smith often loses its virulence quickly.

2. This loss makes its appearance not all at once, but gradually, first toward Capsicumannum, later toward Nicoliana tabacum, and finally for Solanum melongena and S. lycopersicum.

3. These circumstances explain the contradiction in the papers of Smith and Uyeda.

4. In Deli up to this time the bacteria have been found by me in: Nicotiana tabactm, Physalis angulata, Indigofera arreeta, Araclis hypogaea, Mucuna sp., Acalypha bohmerioides, Ageratum conyzoides, Blwmea balsamifera, Synedrella nodiflora.

5. As the result of artificial inoculation the following have also become diseased: Sesamum orientale, Solanum uberosum, S. lycopersicum, S. melongena, and Capsicum annuum.

6. Both in its morphological and in its physiological characters the variability of $B$. solanaccarum is much greater than is at present supposed.

7. In cultures with glycocoll and glucose the bacteria form threads more than 40 cells long, which are mostly crooked, and here and there show strongly swollen, feebly-staining cells without at first showing loss of virulence. By inoculation from these cultures into bouillon the normal growth in the form of single and paircd rods returns.

8. Thus far the Deli strains have formed neither capsules nor spores. For the existence of spores Uyeda has not offered the least proof.

9. The Deli strains show polar staining after fixation in alcohol or in the flane, and staining with carbol fuchsin, or water solution of methylene blue. When peptone is used the polar staining becomes indistinct or may disappear altogether.

10. Examined on a slide at the same time with $B$. coli communis and Diplococcus enteritis, the Deli strainsare Gramnegative.

I1. The reduction of nitrate by $B$. solanacearum (and probably also by other bactcria) can not be studied 11 sing starch as a carbon food.

12. Sodium selenite interferes with the grow th to a high degree, or even sometimes stops it altogether on addition of 0.1 per cent in peptone-bouillon-agar, but is less harmful with o.or per cent. The selenite is reduced.

13. The different results reached by Smith and by Uyeda when the organism is grown in milk may be partly explained: $a$, by difference in the bacterial strains; $b$, by difference in the age of the cultures; $c$, very probably by difference in the composition of the milk.

Because Uyeda in his complete paper announces a different conclusion concerning the milk cultures than in his preliminary communieation, and because the behavior of the Deli strains is rather variable, one can ascribe no great worth to the discovered differences.

14. The trials with fresh milk show that coagulation takes place only rarely (4 out of 95 cultures) and that the reaction is feebly alkalin or neutral.

With European milk in tins or flasks the reaction after 3 to 7 days is always alkaline. In most of the strains the reaction changed again 3 to 7 days later and the milk curdled. When inoculated from old weak cultures the reaction remained alkalin.

15. The tests with combinations of different carbon and nitrogen compounds sometimes gave constant results and sometimes variable ones, the latter even when inoculated out of one and the same culture.

16. Of the 18 substances containing both carbon and nitrogen sources, growth occurred only with tyrosine, pepton, ammonia, ammonium succinate, ammonium lactate, ammonium tartrate, and ammonium citrate, and in a few cases also with asparagin ( 7 of the 62 cultures, and the 7 belonging to 3 strains).

I 7. 'The following may serve as sources of nitrogen: asparagin, glycocoll, potassium nitrate, potassium nitrite, and ammonia.

18. As sources of carbon in the combinations tested the following are absolutcly unusable: glycogen, starch, lichenin, sodium acetate, sodium butyrate. 
I9. Growth never followed inloculation into cultures witl $\mathrm{KNO}_{3}$ and glycocoll with levulose; with asparagin and levulose only in 4 cultures from 2 sources. This is not strange, because also with asparagin alone growth oecurred only once.

20. Development in all the cultures containing asparagin, glycocoll, aud $\mathrm{KNO}$ was extremely rare. Very often only one or two of the three cultures showed growth when these were inoculated from the same culture of bouillon, of $\mathrm{KNO}_{3}$ or of glycocoll.

2I. In general the number of cultures which succeded with some of the alcohols was greater than with the corresponding sugars.

22. In a great number of cultures visible growth was not synonymons with strong development.

23. Because the Deli strains of Bacterinm solanacearum are parasitic as well for Nicotiana tabacum and Capsicum anmum (like Uyeda's B. nicotianae) as for egg-plant and tomato (like Tyeda's B. solanacearum Smitl), and moreover because nearly all of Uyeda's designated cultural differences fall away I think that $B$. nicotianae Uyeda is identical with $B$. solanacearum Smith.

(5) REPORT ON THE ATTEMPTS TO DISINFECT WITH CHEMICALS THE SEED-BEDS ON SLIME-SICK SOILS.

On 20 plantations belonging to 1 c companies tests were carried out, using potassium permanganate, formaldeliyd, and carbon bisulphide. The seedlings on 6 of the plantations were destroyed by ants and crickets. Report is made of the results on each of the other 14 plantations which show some success with the disinfectants, but not brilliant nor uniform. The entire subject is summed up in the following conclusions:

(1) 'That in spite of the disinfection of seed-bed and of the well-water used, when the seedlings were planted on infected ground infections took place.

(2) That this infection, as far as could be made out, took place more through the leaves than through the roots, so that the infection must have been brought to them from without.

(3) How this transmission took place (whether by animals or tools) must be followed up and experiments are already under way.

(4) It must also be looked into closer whether the disinfection of the whole seed-bed ground gives an important advantage over the disinfection, simply, of the seed-beds, leaving the paths between untreated.

(5) That far away, in most eases, the plants were larger and more vigorous on the treated than on the intreated seed-beds.

(6) That in all cases where differences appeared after planting out, they were to the detriment of the untreated seed-beds, so that it certainly is desirable to repeat the tests.

(6) A CASE OF SLIME-SICKNESS IN DJATTI SEEDLINGS.

'This was found in Djatta plants [Tectona grandis] standing among diseased tobacco. The signs appeared to be those of the slime-disease. Plate cultures were set and three sorts of bacteria were isolated, one of which agreed culturally with $B$. solanacearum from slime-sick tobacco. Although the iclentification by cultural tests left no room for doubt, inoculations were made into 4 tobacco seedlings, all of which became diseased. Out of two of these plants the bacteria were again isolated and served for new inoculations along with a strain isolated from tobacco. With these three strains 15 young tobacco plants, on land not subject to the disease, were inoculaterl by a prick, 5 from each culture. At the same time 9 young Djatti plants were inoculated, 3 from each culture. All of the tobacco plants showed the disease at the end of a week; the Djatti did not. 'Three days later the tobacco was removed and the earth disinfected, although the disease was still confined to the top of the plant, $i . e$., not yet in the roots. All the Djatti plants were now diseased, not only those inoculated from the Djatti cultures, but also the 3 inoculated from the tobacco strain. No difference in virulence was observed on Djatti plants, but on the tobacco $\mathrm{D}^{\prime} \mathrm{T}_{1}$ was much the more virulent. The checks were sound, both the Djatti and the tobacco.

With olher cultures from the same source the inoculation experiment was repeated 4 days later on a trial field on 15 Djatti seedlings with the surprising result that only one of them died, the others being not much affected. Six weeks later, however, two other eases were found in the plants inoculated with the Djatti bacteria. The disease was visible soon after a couple of showers and the bacteria were demonstrated microscopically in the stens more than $2 \mathrm{dm}$. above the point of inoculation.

Later with $\mathrm{DT}_{1}$ and $\mathrm{T}$ four tobacco plants in pots were inoculated, all of which became diseased in 5 to 7 days.

By inquiry Honing learned that on other plantations occasionally diseased Djatti had been observed.

(7) ON THE CONNECTION BETWEEN SLIME-SICKNESS IN SEEDLINGS AND IN PLANTED-OUT TOBACCO.

In "Cause of the shime-sickness and attempts to combat it-III," were eited some instances of direct connection between disease in the seed-bed and in the field, even in cases where the discase in the seed-beds was only sporadic and sometimes was not known. In "Report on the shime-disease 
tests in 1911," the number of examples were somewliat increased. Here are adcled sone observations of 1912, made on tobaceo seedlings received from I i sonrees and set on the trial grounds. The conditions of the experiment and the resilts are given in table 34 , omitting only the dates of planting (I iebruary it to March 30 ).

'Table 34.-Effect of Oecurrence of Disease in Sect-bed on Planted-out Tobacco.

\begin{tabular}{|c|c|c|c|c|c|c|}
\hline $\begin{array}{l}\text { Planta- } \\
\text { tion. }\end{array}$ & Condition of seed bed. & Prediction as to outcome. & $\begin{array}{c}\text { No. } \\
\text { planted. }\end{array}$ & No. Dead & $\begin{array}{l}\text { P.et. } \\
\text { dead. }\end{array}$ & $\begin{array}{l}\text { Remarks: Predic- } \\
\text { tion fulfillcd }(+) \\
\text { not fulfilled }(-) \text {. }\end{array}$ \\
\hline 1 & No disease & Few dead & 36 & 27 & 75 & - ('Toa-toh \\
\hline 2 & Quite a good many discased. & A good many dead. & 72 & 12 & 17 & - \\
\hline $3 a$ & $\ldots$ Do $\ldots \ldots \ldots \ldots$ & Many dead........ & 54 & 22 & 41 & + \\
\hline $3 b$ & Less sick than in $3 a \ldots \ldots$ & Less dead.......... & 54 & 11 & 20 & + \\
\hline 4 & A few diseased........ & Not many dead... & 72 & 21 & 20 & + \\
\hline 5 & Many diseased........ & Many dead ........ & 72 & 42 & 58 & + \\
\hline $6 a$ & Very few diseased & Few dead ......... & 54 & 6 & 11 & + \\
\hline $6 b$ & Do . . . . . . . . . . & $\ldots$ Do . . ....... & 54 & 7 & 13 & + \\
\hline 7 & Quite a good many diseased... & $\begin{array}{l}\text { Quite a good many } \\
\text { diseased. }\end{array}$ & 54 & 21 & 39 & + \\
\hline 8 & $\ldots$ Do.... & $\ldots$ Do............ & 54 & 15 & 28 & + \\
\hline 9 & Few diseased..... & No remarks. . & 72 & 14 & 19 & Toa-toh bibit. \\
\hline 10 & $\ldots$ Do.... $\ldots, \ldots \ldots \ldots$ & Few dead... & $7^{2}$ & 13 & 18 & + \\
\hline $11 a$ & $\begin{array}{l}\text { Few diseased (specimens with bacterial } \\
\text { stripe). }\end{array}$ & All dead ..... & 15 & 15 & 100 & + \\
\hline $11 b$ & Sound out of the same infeeted beds... & Few dead. & 20 & 4 & 20 & + \\
\hline $8 a$ & $\begin{array}{l}\text { Very few diseased (specinens with } \\
\text { bacterial stripe). }\end{array}$ & All dead... & 21 & 20 & 95 & + \\
\hline $8 b$ & Sound out of the same sick beds..... & Many dead ........ & 45 & 23 & 51 & + \\
\hline
\end{tabular}

The plats i $b$ and $s b$ are perhaps the most interesting. Naturally, sources of crror were not wholly excluded. 'The factors which may have influenced the result are:

(a) The soil was not wholly free from the slime-disease.

(b) The persistent drought.

(c) A toa-toh plague, especially for I to 9; the latter had toa-toh in the seerllings.

(d) The faet that the seedlings from all sorts of ground, loose red earth to low white clay, were planted out on the same piece of clay ground.

(e) The small number of plants.

All things taken together, it is plain that the dying in the field tobaceo was more prevalent according as more sick seedlings occurred in the seed-beds.

\section{(8) ON THE ASSERTED NON-SUSCEPTIBILITY OF NICOTIANA RUSTICA FOR THE SLIME-DISEASE.}

'Two ways stand open for him who wonld obtain a race of resistant Deli tobacco: 'The first looks to the discovery of fine sonnd specimens on slime-sick soil; the second to the crossing with less susceptible or wholly resistant varieties of tobacco. Upon the first method more later.

In order to cross the Deli tobace with immune sorts we must first have these, and if obtained, it remains to be seen whether the desired peculiarity is transmitted in full neasure to the descendants and is constant in the cross. If this slould fall out according to wish, then comes the question whether the type obtained is of a sort that the planters will try, or whether it must be further improved, retaining at the same time the desired resistance.

'l'ests were also made on a number of ornamental tobaccos, seed of which was received from Haarlem, viz., Nicotiana affinis, N. atropurpurea grandiflora, $N$. colossea, $N$. glauca, $N$. sanderae (in 6 colored varieties), and $\mathrm{T}$. silvestris. Both the Djatti and the tobacco strains were tried and all of the inoculated plants becane diseased. Vicotiana latissima is also subject.

'The finer sorts of foreign tobacco of the species $N$. tabacum, so far as tested in Deli, are badly attacked by the slime-sickness, so that the chance of obtaining a reistant variety from these seens not better than from Deli tobacco.

Of the coarser sorts it has been announced in literature (Uyeda) that one, namely, the Boer tobacco ( 1 . rustica), is non-snsceptible to the slime-disease. There were obtained, therefore, from the Agricultural Institute at Pusa in India, where this tobaceo is connonly cultivated, seeds of different varieties to the number of 20 , which varieties were tested by inoculation, only one of 200 plants remaining sound. 'The details are given in table 35 . 
TABLE 35.-Result of Inoculating B. solanacearum into 20 Types of Nicotiana rustica.

\begin{tabular}{|c|c|c|c|c|c|c|}
\hline \multirow{3}{*}{ Type. } & \multicolumn{3}{|c|}{ Pot trials, infected 3 days after planting. } & \multicolumn{3}{|c|}{ Ficld trials, infected to days after planting. } \\
\hline & \multicolumn{2}{|c|}{$\begin{array}{l}\text { Slime-sick after infection with } \\
\text { bacteria from- }\end{array}$} & \multirow{2}{*}{$\begin{array}{l}\text { Slime-sick in } \\
\text { the controls } \\
\text { (of each } 4 \\
\text { examyles). }\end{array}$} & \multicolumn{2}{|c|}{$\begin{array}{l}\text { Slime-sick after infection with } \\
\text { bactcria from- }\end{array}$} & \multirow{2}{*}{$\begin{array}{l}\text { Slime-sick in: } \\
\text { the controls } \\
\text { (of each } 8 \\
\text { examples). }\end{array}$} \\
\hline & $\begin{array}{l}\text { Djatti stem } \\
\text { (of each } 3 \\
\text { examples). }\end{array}$ & $\begin{array}{l}\text { Tobacco stem } \\
\text { (of each } \\
\text { examples). }\end{array}$ & & $\begin{array}{l}\text { Djatti stems } \\
\text { (of each } 2 \\
\text { examples). }\end{array}$ & $\begin{array}{l}\text { Tobacco stem } \\
\text { (of each } 2 \\
\text { examples). }\end{array}$ & \\
\hline I & 3 & 3 & 0 & 2 & 2 & 0 \\
\hline II & 3 & 3 & 0 & 2 & 2 & o \\
\hline III & 3 & 3 & o & 2 & I & 0 \\
\hline IV & 3 & 3 & 0 & 2 & 2 & o \\
\hline $\mathrm{V}$ & 3 & 3 & 0 & 2 & 2 & o \\
\hline VI & 3 & 3 & 0 & 2 & 2 & o \\
\hline VII & $\begin{array}{l}3 \\
3\end{array}$ & 3 & o & 2 & 2 & 0 \\
\hline VIII & 3 & 3 & o & 2 & 2 & o \\
\hline IX & 3 & 3 & 0 & 2 & 2 & o \\
\hline$X$ & 3 & 3 & o & 2 & 2 & 0 \\
\hline $\mathrm{XI}$ & 3 & 3 & 0 & 2 & 2 & 0 \\
\hline SII & 3 & 3 & 0 & 2 & 2 & 0 \\
\hline XIII & 3 & 3 & o & 2 & 2 & 0 \\
\hline XIV & 3 & 3 & 0 & 2 & 2 & $o$ \\
\hline $\mathrm{XI}$ & 3 & 3 & 0 & 2 & 2 & o \\
\hline XII & 3 & 3 & 1 & 2 & 2 & o \\
\hline XVII & 3 & 3 & 0 & 2 & 2 & 0 \\
\hline XVIII & 3 & 3 & o & 2 & 2 & $o$ \\
\hline XIX & 3 & 3 & o & 2 & 2 & 0 \\
\hline $\mathrm{XX}$ & 3 & 3 & 0 & 2 & 2 & 0 \\
\hline
\end{tabular}

"The possibility remains that Uyeda possessed another truly immune variety, yet lis communications on other infection experiments which have been describedearlier, make this highly improbable."

(9) ON THE VARIABILITY OF BACILLUS SOLANACEARUM SMITH.

During the search for combinations of carbon and nitrogen foods by means of which the slimebacteria conld be easily recognized, a variable beliavior was often observed in media inoculated from the same culture.

That this did not depend on farlts of technic is shown by the fact that transfers of the bacteria into far more than 200 cultures of boutllon always succeeded; also all grew when inoculated into peptone-water ( 33 cultures), solution of ammonium succinate ( 32 cultures), ammonium lactate ( 33 cultures), asparagin with sodium malate ( 2 I ctiltures), and sodium succinate ( 2 I ctiltures).

In the test-tubes in which visible growth occurred the originally feebly acid reaction of the solution liad become neutral, or alkaline (if growth was strong), while the tubes that remained clear always retained the feebly acid reaction to litmus.

Experiments were then made by inoculating into solutions whose acidity or alkalinity lad been increased slightly, with the results given in table 36 .

'TABLE, 36.-Growth of B. solanacearum in Meyer's Mineral Solution with 0.2 per cent Glycocoll and Glucose or II annit with V'ariable Reactions (Cullures always in Sets of 3).

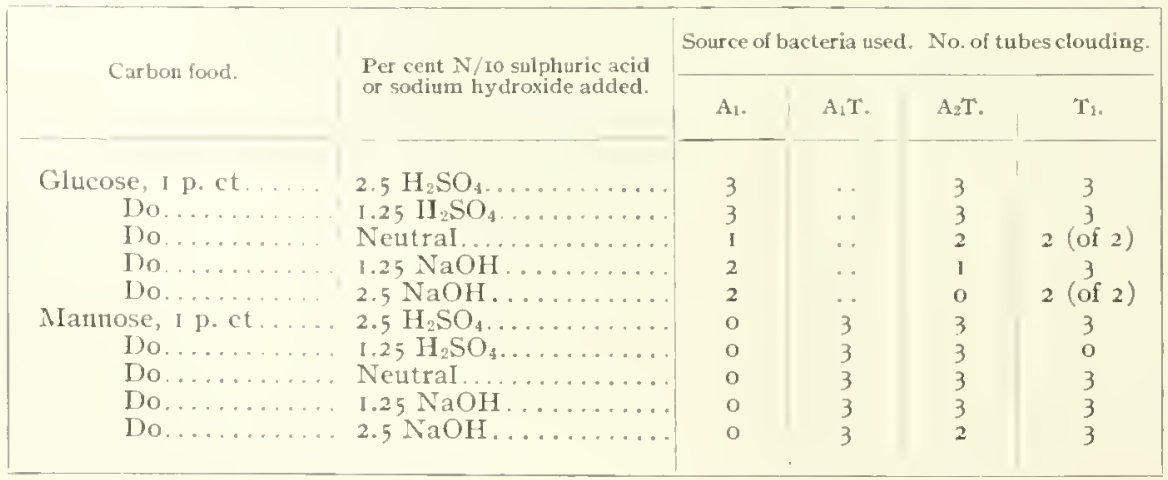


The bacteria taken from one species of plant did not vary in media more than those taken from another. Of 27 isolations of B. solanaccarum (20 from tobacco, 2 fron 1 Acalypha bahmerioides, I from A geralum conyzoides, 1 from Synedrella nodiflora, and 3 from Tectona grandis), all varied nore or less strongly.

The retardation of growth due to sodium hydroxide is better slown in table 37.

TABLE 37.-Returding Effect of Alkali on B. solanaccarum by Day's (Tests in Sets of 3).

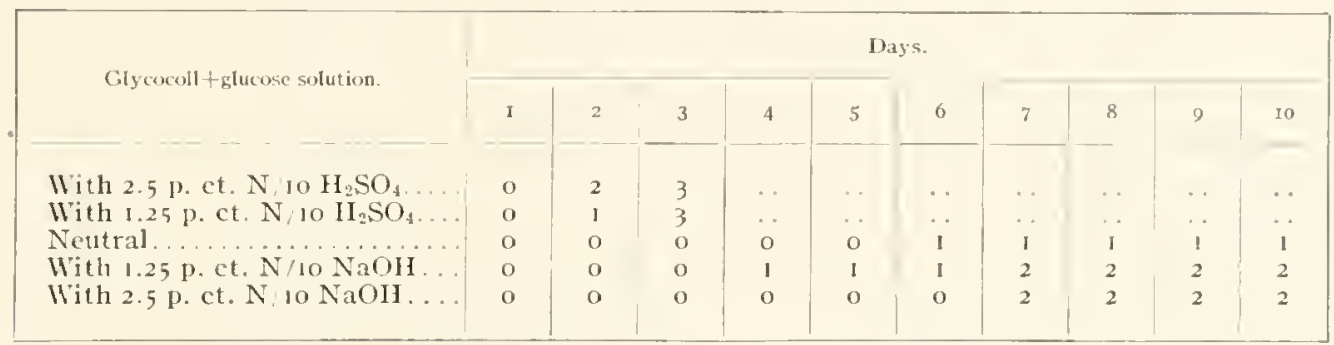

If one of the cultures succeeded, then from that others could be inoculated witl a greater degree of success, as slown by table 38 .

'MBL1: 38.--Results of Further Studies of Sumatran Tobacco Organism in same Acid and Alkaline Media (Aludas in Sets of 3 Tubes).

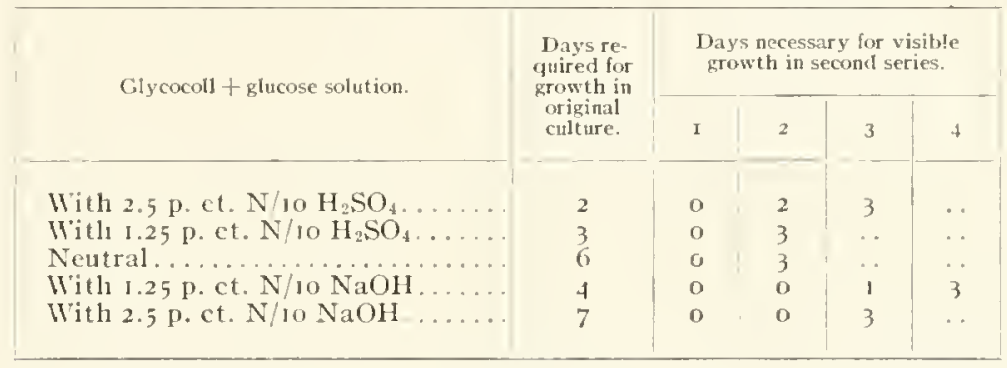

Temperature and light are said to play no rôle in this variability. 'The test-tubes had been cleaned with acetic acid, but some soaked in chromic-acid cleaning mixture gave the same result.*

With asparagin and potassium nitrate the results shown in table 39 were obtained.

TABLE 39.-Tariable Belavior of Different Strains of Sumatran Tobacco Organism to Combinations of Carbon and Nitrogen Foods (Tests always in Sets of 3 Tubes cach).

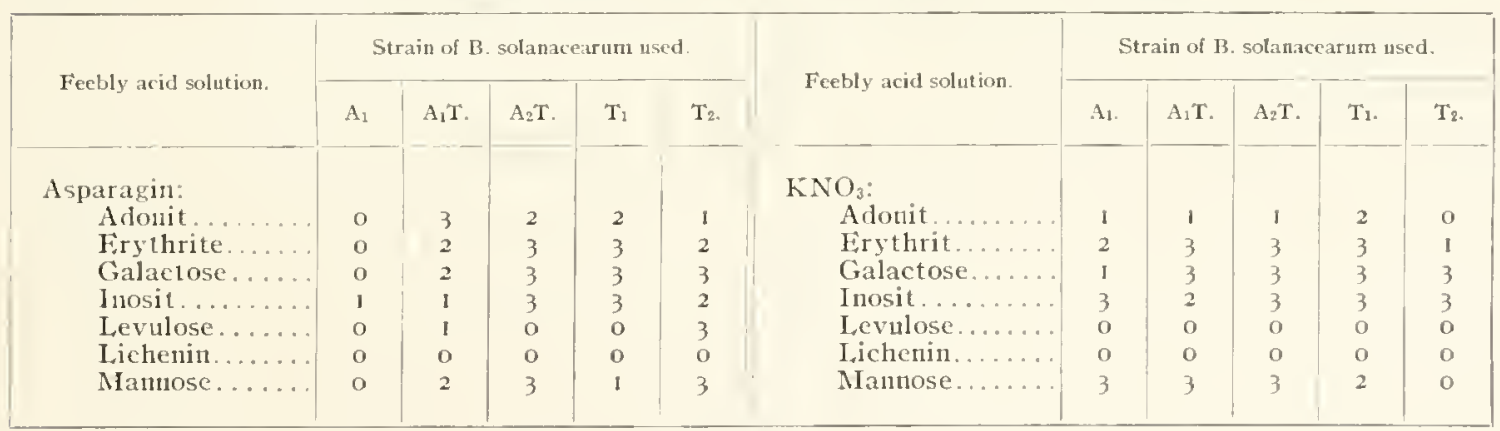

Further studies showed that media which failed to show growth when inoculated witli small doses of the bacteria would do so when inoculated with larger quantities, as shown in table fo.

Similar results were obtained in neutral asparagin-glycocoll- $\mathrm{KNO}_{3}$, or urea solution, with glucose or mannose, the heavier inoculation yielding the better results.

IV hen measured quantities of the bacteria were used the results shown in table 4 i were obtained.

* Medan III and Florida potato (1914) grew iu Witte's paptone water $+\mathrm{H}_{2} \mathrm{SO}_{4}$ (1:1000o), but not in the same acidulated $1: 1000\left(3\right.$ days test at $\left.27^{\circ} \mathrm{C}\right)$. 
TABLE 40.- Growth of Strain $\mathrm{A}_{2} \mathrm{I}^{+}$in Glycocoll-glucose Solution after Inoculation with a Small and a Large Loop of Culture Fluid, the Latter Carrying about 5 times as many Bactcria as the Former (Tubes in Scts of 3).

\begin{tabular}{|l|l|l|l|l|l|l|l|l|l|l|}
\hline \\
Grlycocoll + glucose solution.
\end{tabular}

TABLE +1.-Time of Clonding in Neutral Glycocoll-glucose Solution when Inoculated with Variable Numbers of Sumatran Tobacco Bacteriu (Io Tubes uscd in cach Case).

\begin{tabular}{|c|c|c|c|c|}
\hline $\begin{array}{c}\text { Days required } \\
\text { for appearance } \\
\text { of growtl. }\end{array}$ & Number of bacteriı used ior inoculation of each tube. \\
\cline { 3 - 5 } & 300 & 3,000 & 30,000 & $2,400,000$ \\
\hline 6 & & & & \\
10 & 0 & 0 & 1 & 10 \\
15 & 0 & 1 & 4 & $\ldots$ \\
20 & 0 & 1 & 9 & $\ldots$ \\
\hline
\end{tabular}

This disease has now been observed in Sumatra in 15 species of plants belonging to five families. The author summarizes lis conclusions as follows:

1. With a great number of carbon and nitrogen foods $B$. solanaccarum shows growth only in a part of the cultures inoculated.

2. Iight and temperature lave no influence, and small variations in alkalinity have slight influence on this variability.

3. More cultures succeeded after a larger quantity of inoculating material was used. Only a very slight number of individuals, one ont of many dozens, is in condition to adapt itself to the new nutrient conditions.

4. 'The phenomena fall under the concept of modification; the acquired peculiarities are not constant, when the bacteria are once nore inoculated into tobacco, reisolated, and again brouglit in to the same solution.

There is perhaps another explanation for the variable behavior of this organism in unfavorable solutions, viz, accident. On this supposition all the bacteria are equally capable of growth, but only those actually grow which happen to be lodged under the protecting cover of their fellows, i.e., those in the center of small pseudozoogloex masses. If 110 masses large enough to protect the first stages of growth are introduced then those particular tubes will remain sterile. This is indicated to me by the fact that Honing often observed the first indications of growth in glycocoll solutions "as little points on the wall of the tube which may grow slowly for some days before the fluid begins to be clouded." Glycocoll solution was tused because Bact. solanaceurmm was easily identified in it on account of the development therein of the peculiar chains and involution forms already deseribed.

(10) ON THE DECAY BACTERIA FROM SLIME-SICK TOBACCO. DJATTI, AND SOME OTHER OF THE SLIME-SICK SUSPECTED PLANTS.

In December I912 Honing published another paper, with the above title, in which lie reported on the common bacteria found by him in Sumatra associated with the bacteria causing wilt of tobacco and other plants, but thennselves not able to cause any disease when inoculated into tobacco. The following sorts were isolated and studied by lim and the new species are deseribed: 
Micrococcus luteus Lehm, and Neum., Micrococcus pyogenes albus (Rosenbach) I,ehm. and Neum., Micrococcus pyogenes (M. bicalor Zimmerman), Bacterium metanense n. sp., Bacterium stalactiligencs n. sp., Bacterium langkalense n. sp., Bacterium delicuse n. sp., Bacterium shuffneri n. sp., Bacterium zinnoides n. sp., Bacterium sumalranum n. sp., Bacterium patelliforme $\mathrm{n}$. sp., Bacterium auranlium roseumn. sp., Bactcrium rangiferinum 11. sp., Bacillus mycoides Flügge, Bacillus mesentericus, and Corynebacterimm piriforme n. sp. These generic names are used in the manner of letumann and Neumann, some of the forms being non-flagellate, others polar-flagellate, and others peritrichiate.

The most interesting discovery recorded is that of the inhibiting action of some of these saprophytes, e.g., B. mycoides, and especially B. mesentericus, on the growth of Bact. solanaceartm (fig. ${ }^{34}$ ). 'The following is an abstract of Honing's last paper.

\section{(II) HOW SHALL ONE OBTAIN A RACE OF TOBACCO THAT IS IMMUNE TO THE SLIME-DiSEASE?}

Probably the application of some form of selection in tobacco-culture in Deli is as old as the culture itself. The founder of the industry, Nienhuijs, had seed imported from Java, Cuba, and elsewhere, and selected that which gave the best results on the new soil. Obviously he sclected with a practised eye and ltucky hand: A valuable new variety, the Deli tobacco, being the result. No one knows the age of Deli tobacco in its present form.

Perhaps it is the result of one or more accidental crossings annong the sorts imported into Deli; perhaps it originated throngh a splitting caused or not by crossings in Deliwhereby arose combinations of characters which the first Deli plants really owe to crossings that took place years before in Java or Cuba. Perluaps, also, the new type arose sinddenly or by degrees throngli external conditions, which in Deli differ from those of the original habitats. Of this we know notling, and probably never shall be able to determine. A similar ignorance concerning the time and manner of origin of varieties is, alas, the rule. Of almost all cultivated plants having a great number of known varieties, the origin lies in the dark, and only of forms which lave been isolated in recent years does one know a part of their history.

Only this is certain: In Deli a

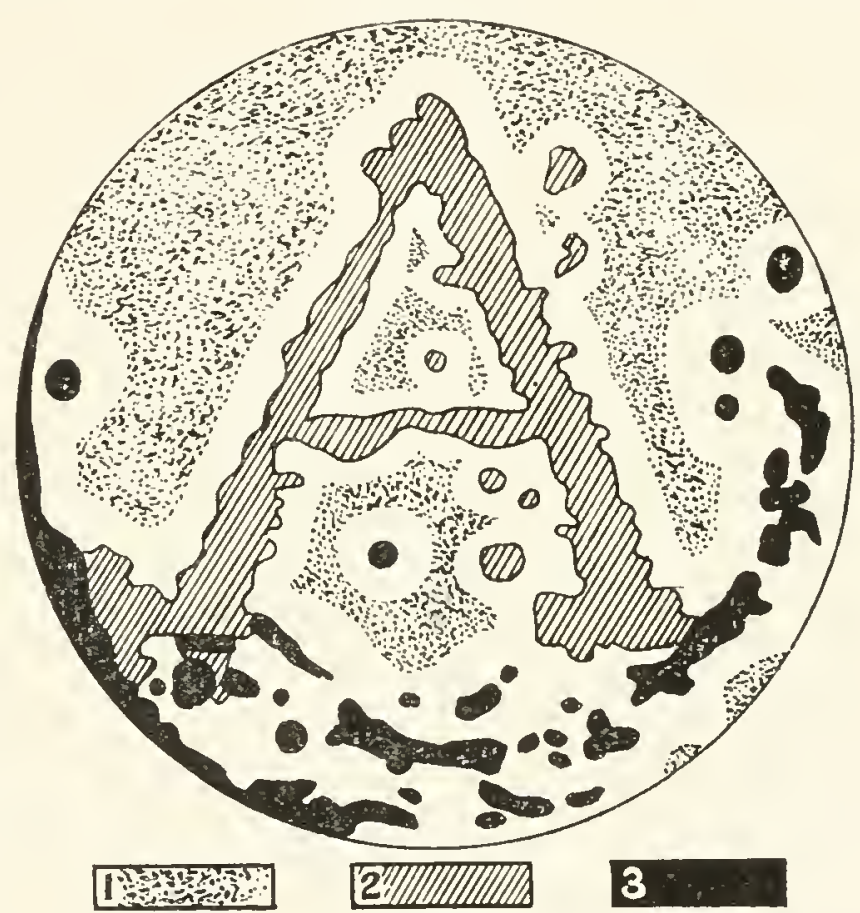

Fig. 134.* variety has arisen which did not previously occur in the older tobacco lands and is not found there at present, unless introduced from Deli. Wherever Deli tobacco grows outside of Sumatra: in Java, the United States, Cuba, Hawaii, everywliere one speaks of Sumatra tobacco, which would not be the case if, in the older tobacco districts, the Deli form had been recognized as a varicty indigenous there. Had stich been the case, so nunch trouble wonld not have been taken on all sides to make the variety flomisli.

Thanks to the favorable results in the years 191 I and 19 r2, one hears less said now than was the case three or four years ago, regarding the degeneration of the Deli tobacco. For

*FIG. I $3+$-Drawing of a Petri-dish agar-poured-plate showing the inhibiting action of Bacillus mesentericus on the Sumatra tobacco bacterium. This experiment was made as follows: The letter A was painted on the bottom of the dish with a spore-bearing culture of Bacillus mescntericus. When this was dry it did not show. A tube of melted agar was then inoculated heavily with Bacterimm solanacearmm and poured into the dish. After some day's, the letter $A$ appared and some surface colonies of Bacillus mesentcricus which were derived from bacteria flooded from the letter $A$ at the time the plate was poured. Bacterium solanacearum has also grown, but only at a distance from the former. The legends are: 1, Bactorium solanaccsmum; 2, Battom growth of Bacillus mescutericus; 3 . Surface growth of Bacillns mesentericus. (After Honing.) 
the benefit of those who still believe in the degeneration of the Deli tobacco, it is perhaps of service to state that the first Deli planter, fifty years ago, lost a whole field through "the death." At that time the tobaceo was immune to the slime-disease even less than now. From this we may conclude that the slime-disease bacteria were here earlier than the culture of European tobaceo.

Always and everywhere goes hand in hand with extensive culture the multiplication of parasites, animal as well as vegetable, as the result of the one-sided activity, and always and everywhere it has cost much labor to keep a crop on the same level and still more to improve it. Therefore, especially in recent years, men have begun to select examples more resistant to disease, and have found these in forms which, in other respects, are unfit for culture, so that they have tried through crossing, followed by systematic selection, to produce the desired combination.

In both ways, that is by selection and by crossing, the attempt must be made to produce fron the Deli tobacco a less susceptible race. The selection can begin immediately; for the crossing one must wait the discovery of immune varieties, which must not be far removed from the Deli tobacen in quality. And because a variety, which elsewhere is little or not at all susceptible, may be extremely sensitive when subjected to the different soils and clinatic conditions in Deli, one must not rely upon the literature, but all varieties must be investigated in Deli in regard to their susceptibility.

This year tests have been made with 87 sorts or varieties, anong which were good varieties from Java, the United States, Cuba, Mexico, Brazil, Paraguay, Santo Domingo, the Philippines, Japan, and Hawaii. In a later report these experiments will be described in detail. The following are the results in brief:

(I) All of the 87 sorts or varieties investigated were susceptible to the slime-disease.

(2) The 7 strains of Deli tobacco, which were inoculated at the same time as the foreign tobaceos, did not make a bad showing. They grew better after the inoculation in the stem than a great number of foreign sorts.

(3) Two sorts of Philippine tobacco and one Japanese variety, although diseased, gave the impression of being less severcly attacked, so that it is worth while to repeat the experiment on a larger scale with these three varieties another year.

(4) The disease progressed more rapidly when the inoculation was made with a great number of bacteria than with a few.

This last-mentioned fact affords perhaps the explanation of the renarkable phenomena which occurred in the disinfection-tests in $19 \mathrm{I}$. In the different experiments the results of the disinfection were at first gratifying, but in the end, when the plants were examined, it appeared that not any or only a very slight advantage had been gained. But in the meantime in one of the experiments on a trial plot which had been kept under longer and eloser observation there were on each plant five to eight leaves more ("scrubs" and basal leaves). Thus disinfection was insufficient, but the important lessening of the number of bacteria had been advantageous.

Now it appears that the rapidity with which the disease progresses in a plant is dependent on the number of invading bacteria [see pl. 31, 111iddle and right figs.]. 'This affords perhaps the explanation of the above-deseribed phenomena in the disinfection-tests of $191 \mathrm{I}$.

The chance of finding among foreign tobaccos one which is immune in Deli appears to be not very great. Howerer, the fact that among the 119 examined varieties or sorts not a single resistant one was present does not mean that none exists. The investigation, which fortunately does not consume an undue anount of time, must be made with still other sorts. Only, one must not raise too high his expectations of finding among the known varieties one which in Sumatra is immune to Bacillus solanaccarm. And this is surely an additional reason for immediately subjecting our Deli tobacco itself to a severely conducted selection.

There are various reasons which make it more than probable that the Deli tobacco is not a clearly circumscribed type, but that it consists of a mixture of several types-how 
many can not be estimated. Apparently there are only a few, and in any event they are not of such a kind that one ean go out into the field and select them. The Deli seed is much purer in Sumatra than that, for example, which was grown some years ago in Anerica, when Shancl found in types in one field. 'The "Deli seed" with which this field in Connecticut was planted eame from Florida and may thus have been mixed with other sorts.

Proofs that in the Deli tobacco hereditary differences still appear are but two, namely, the giant plants and the Strain $\mathrm{B}_{\mathrm{I}}-5$, which in 1906 was obtained in a mosaic-disease test, undertaken with Helvetia and a couple of other varieties. These plants, B 1-5, blossomed in 1907 about to days earlier than the others, formed thus a premature type, and this year the sixth generation again blossoned 10 to 12 days earlier than the others. Dr. Dien found in 1907 that the average difference in height between $\mathrm{B} i-5$ and the race $\mathrm{B} I-1$ was almost half a meter to the disadvantage of $\mathrm{B} I-5$, which also produced on an average four leaves less. Moreover, these differences, which indeed that one year were somewhat greater than in other years, have persisted, so that $\mathrm{B}_{1-5}$ is to be considered a separate type.

Besides these two examples there are perhaps more. One often finds in the plantations plants which vary. When it is a single example which is distinguished by broad or small leaves, there is no reason to consider it immediately a separate type. On the contrary, when one gets this impression from a whole plot (afdeeling) it proves that two forms, a broad-leaved and a sniall-leaved type, have been planted side by side. I remember such a case in an upland plantation in $19 \mathrm{I}$, and I an not the only one who was subject to this inpression.

Up to the present there have been but few experiments in which selection has been exercised in the sense of pedigree-culture, such as was advised as early as 1907. One generally restricts himself to the nuaintenance of a fine stock from which the less vigorous plants are removed; thus a form of "mass-selection." Unquestionably this is one means of keeping the eulture up to the mark, but the clance of making any advance in this way is extremely slight. To be sure by this method the seed of the best plants is always collected and when there happens to be among them a couple of extra good plants which will produce better offspring, the seeds of these are also gathered, and are not lost. But this seed of the uncommonly good plants becomes diluted with the quantity of common seed which outnumber them by some hundreds or thousands. On sowing, the descendants of the best plants are lost in the great mass. In case the cireumstance should arise that the descendants of such a plant with large leaves should grow somewhat less rapidly in their youth, something more lappens, namely, these will disappear during the thinning out, with the result that in the crop, the same as the previous year, but few examples of the better type will appear. If now, again, on a good piece of ground a portion of these be selected for seed plants, then is one just as far advanced as the year before - a single plant of the better type here and there in the great mass. Had one, however, kept separate the seed of a couple of extra fine plants, then it would soon be evident whether the wished-for characteristies were hereditary or not.

A concrete example will make this still clearer. On two plantations there has beent made this year, at my request, a beginning in selection-tests for imnunity to the slinedisease. In one plot on one of these plantations, where there had been much clamage from the slime-disease, there were in the worst field to plants which had remained intact (zich goed gelouden hadden), and which were guarded from cross-pollination by gauze sacks. The plants liad the greatest chance of becoming infected, since the mortality on this spot had amounted to at least from 60 to so per cent, and the rest, especially toward the last, appeared to be very much diseased. At the present time it (the disease) is not evident on the plants, which appear to the eye to be sound. It is possible that hy chance they have not come into contact with virulent bacteria and possibly in ease of an infection they might be very susceptible, but there is also the chance that some of them would be somewhat more resistant, and a single one much nore resistant than the average, to say nothing of 
inmunity. Since all this is not evident to the eye, too small a number of plants should not be isolated, and the seed from each nust be watched, kept, and sown separately.

Suppose the case that one plant of the 40 was by inheritance so much more resistant than the others that under exactly similar circumstances and on the same kind of soil mortality among its offspring, instead of being from 60 to 70 per cent, was only 5 per cent, while all the rest were barely alive as the result of infection. Now, what would happen if the seed of the to plants were mixed? The mixed seed would give a crop which under the same conditions and on the same kind of soil and with the same amount of infection as the year before, would again show 60 to 70 per cent dead plants. The one superior plant has no noticeable influence on this mixture with the 39 others, and the result is that one must say: "This is just as bad as last year. This method amounts to nothing. Away with it!" If one liad, on the contrary, kept this seed separate and planted its offspring separately, then it would be evident that of the to selected mother-plants there were 39 worthless ones and but one which would be of service for further testing.

Thus in two respects the above-described method of work (that is, the method having, as its special purpose, the obtaining of an immune or more resistant race of tobacco) differs from the one customarily employed:

(I) 'I'he seed-plants are not selected from the best soil, but preferably from the "sick soil" or places where the loss from the sline-disease has been very great. 'The chance of resistant individuals becoming conspicuous there is much greater than in places where not a single plant has been exposed to the disease, and thus wo plant gets the opportunity of showing its ability to withstand adverse conditions. 'I wenty or thirty plants remaining sound in a field in which there is much disease give more clance of results than a thousand from a field without any disease.

(2) 'T'he seed from every one of the carefully selected plants is watched and sown separately. Perligree-culture is introduced.

That these methods involve extra labor it is useless to deny, but without work one accomplishes nothing. In great companies it will certainly be desirable to have a separate "seed assistant," but by "seed assistant" nunst be understood something other than a person who only sees to it that the company obtains the prescribed number of packages or bottles of clean seed from well-cared-for, active plants. In my opinion he must be a man who tries to select the types most suitable for certain kinds of soils. For this is one of the great differences between the modern culture and the old: one chooses the plant-type according to the kind of soil, well knowing that the soil may be improved but not ehanged in character. Since it is now known that in Europe for clay, sand, and peat soils, or for combinations of all kinds of soils, definite varieties of grains, potatoes, cabbage, apples, etc., are used, why should not the same principle be applied to Deli tobacco? Only when it is certain that the Deli tobacco is a constant variety will efforts in this direction have no sense. But the complete uniformity of the Deli tobacco is anything but deeided.

Every planter knows instances of his ability to recognize in the curing-room the tobacco from a certain field by its color, texture (soepelheid), or by almost indescribable differences. Sometimes variations in rainfall are the cause of the difference, but sometimes there are variations occurring every year, caused by an entirely different composition of the soil. In most cases the crop thus differentiated is less fine. Would it not be more profitable to apply at once a systen of strict selection with reference to the soil?

A principle that was very much applied in the past and still is followed is this: Use for an upland plantation seed from a lowland plantation, and vice versa. The purpose of this restoration (bloedverversehing) has never been clear to me. Different companies have also resumed growing their own seed, which is continnally used for the same plantation; a single company does this for every field. That is surely a step in the right direction. But one must, in my opinion, go still further and give attention to the kind of soil rather than to chance boundaries of the plots or experineents, so tlat one plantation must try 
to enltivate two, and if need be three, types which are continually kept for the same kind of soil. This is directly opposed to the principle of "blood-refreshing." As it is agreed that in this "blood-refreshing" the habitat and the climate liave influence on the characteristics of the offspring, something which is not proved but which we grant for the 1110ment, why should one use seed from a lill plantation which always has sufficient, sometines too much, rain, for cultivation on the coast where the tobacco stands every chance of being obliged to go throngh a long period of dronght; that does not seen to be logical.

If fron the Deli tobacco several types can be isolated, and this seems probable, nevertheless one must not suppose that they will be precisely alike in their ability to endure dronglit or much moisture. Should not sometling be established in this direction on the coast plantations, where all the growers are again complaining?

What has been said here about selection in general is also of ralue in regard to the selection for the purpose of obtaining a race more resistant to the slime-disease. Also in this connection one will do well to take into consideration the kinds of soil. What will happen I can not assert, but the possibility is not excluded that some one will obtain a more resistant race which is of no value for his neighbor who has different soil, and is perhaps still more susceptible than that which he has been accustomed to plant formerly.

What makes this selection difficult is the fact that one can never see in a plant what he has there, although always its value as a seed-plant can be judged the following year in the descendants just as leaf-production is best judged in the curing-honse. 'Two plants of similar leight, with exactly the same number of leaves of about the same length and breadth, in short, plants which every one wonld consider equally valuable, may bring forth offspring which differ to an important extent. A plant with 30 leaves may belong to a family which brings forth on an average zo leaves, but it may also be an exceptionally fine specimen of a family which produces on an average not more than 25 or 26 , or, finally, an inferior example of a family which averages 33 leaves per plant. All this indicates the necessity of sowing separately purely pollinated seed from each plant. In such pedigree-cultures two or three years must clapse before we know whether the selected lincs are constant. This affords the great advantage of comparing pure lines with the ordinary crop for two consecutive years, not only in the field but also in the curing-house.

\section{AMERICAN STUDIES OF THE SUMATRAN ORGANISM.}

Through the courtesy of Dr. Honing the writer received cultures of the Sumatran tobacco organism in the summer of 1913. One was sent direct, another via Anisterdam, where the original tube was retained and a transfer sent on. Later a third cane direct.

The three cultures reached Washington in good condition and proved infectious to tobaccos, on which the external signs and the tissue disorganization could not be distinguished from those due to the Nortl American tobacco-wilt organism. Black stripes appeared on the stems, with yellowing and irregular drying-ont of the leaves, the vessels in which were stained black and filled with the bacteria, especially those of the nind-rib. In the sections which I saw, the bacteria were confined to the inner wood, in which bacterial cavities liad formed. Some of these sections were made 5 or 6 inches from the needle pricks.

$\mathrm{U}_{\mathrm{p}}$ to the end of the sixth week (when the first experinents were broken off) the behavior of this organism in our tubes of milk and litmus milk corresponded closely to that of the Granville tobacco-rvilt organisin, $i$. $c$., there was 110 development of acid or separation of the casein, but only a progressive bluing of the litnus. *

Subsequently one of onr stocks of litmus milk reddened. I thonght at first that the reddening of the milk was due to an unsuspected acid-forming anacrobe, which was not killed by the steamings, and whicl was nuable to make its presence visible except under the protecting influence of some active acrobe, such as Bact. solanaceamm. With this in mind we made tests in cleep tubes of agar in the following way: Stabs were made the wlole length of the agar from litmus milk which had been inoculated with the Medan organisnn and which

*Plain milk tube-cultures 7 wecks old werc translucent and brownish. In anuther set a pencil could be secul be hind those 8 weeks old, although the casein was not precipitated. 
had reddened. On the surface of the agar a greedy aerobe was then sown (Bacillus subtilis) with the idea that if an anaerobe were present in the milk it would develop in the depths of the agar, whereas if only Bact. solanaccamm were present the growth would not appear along the line of the stab or would occur only in the top of the stab. The second of these suppositions proved to be the true one, indicating that the litmus-milk cultures which reddened contained only an aerobe, viz, the Medan organism. Owing to the fact that the media which reddened had been made from uncentrifiged milk containing cream, whereas our ordinary litmus milk is always made with centrifuged cream-free milk, it then seemed likely that the acid must be due to the action of the bacteria upon the cream, not on the milk sugar, and this was borne out by subsequent tests. When we inoculated skimmed (cream-free) litmus milk we always got a gradual blueing of the litmus, just as in case of the American organism, and never any subsequent reddening. On the contrary, whenever we added cream to the skimmed milk or prepared the litmus milk out of milk containing crean, we got a reddening which began alwáys in the layer of cream at the top and gradually progressed until the whole tube became reddened (pl. 44 , figs. $2,3,4)$. There can be no doubt I think, therefore, that the discrepancy between Honing's results and my own is not a real one. The Medan organism, like the American one, blues cream-free litmus milk. The Medan one reddens mixtures of cream and milk containing litmus, and probably the American tobacco organism would do the same thing, although we have not tested it.*

In repeated tests we have never observed any reddening in crean-free litmus milk, using Honing's organism, but always a reddening when cream was added.

Coconut oil added to cream-free litmus milk is also split by Medan III with the production of an acid, but under the same conditions no acid was produced from olive oil, peanut oil, or cot tonseed oil.

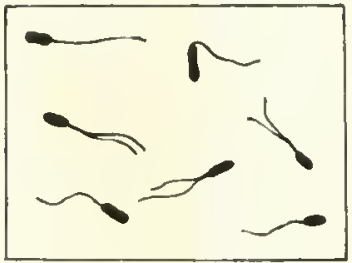

Fig. 134a.

Whenever a thin layer of sterile cream, paraffin, or any of the abovementioned oils was placed on the surface of the inoculated litmus-milk,

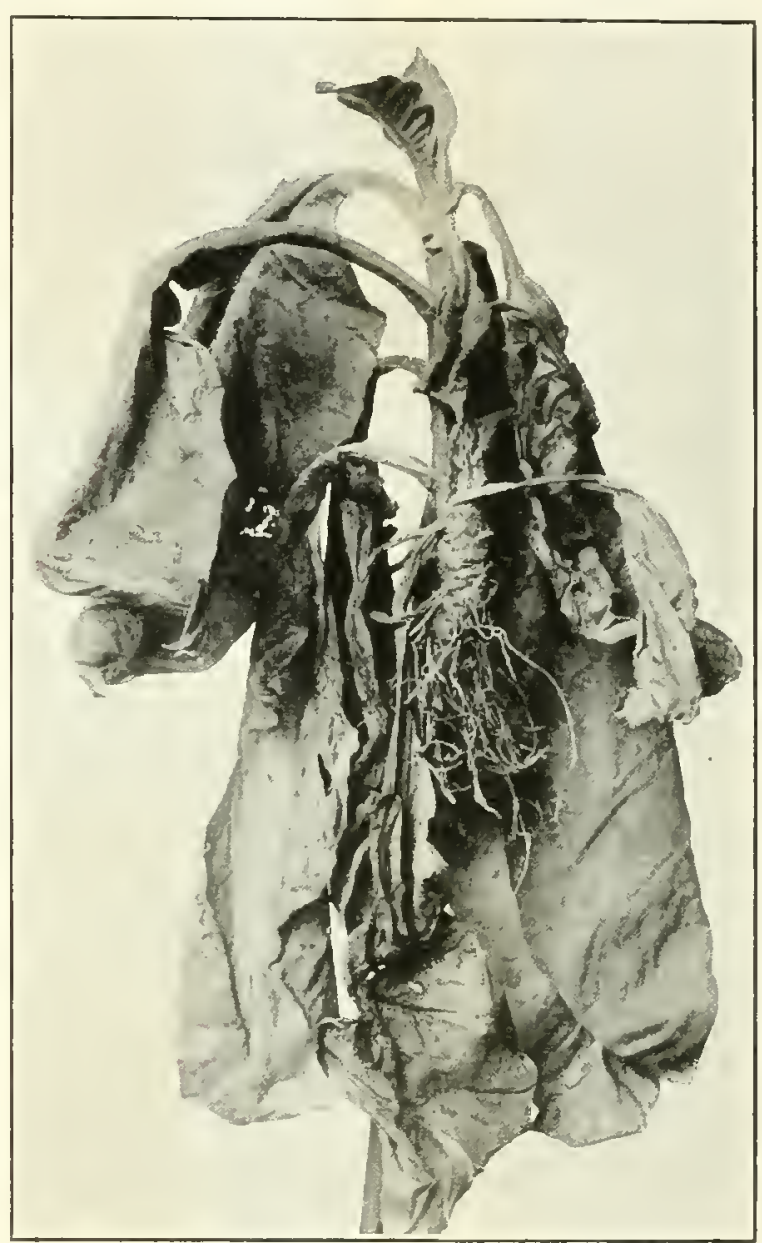

Fig. 1346. $\ddagger$ so as to interfere with the absorption of oxygen, there ensued a distinct reduction of the litmus, but this reduction was not observed when the surface of the litmus milk was freely exposed to the air - then the lavender blue milk became and remained a uniform deep blue.

\footnotetext{
*The only American strain I have tested is the Florida potato organism (19I4): This does not redden creamed litmus milk. In each of 4 trials the numerous inoculated tubes beeame and remained bluer than the chec's. At the end of 2 weeks this strain had grown well in Uschinsky's solution and very feebly in Cohn's solution. It is motile.

†Frc. 1 34 a.-Flagella of Sumatran tobacco organism. Culture received from Honing.

$\ddagger F_{1 G}$. $134 b$. - Yung tobacco plant witted by motile bacteria, a check on Fig. 134a, i.e., from the same culture.
} 


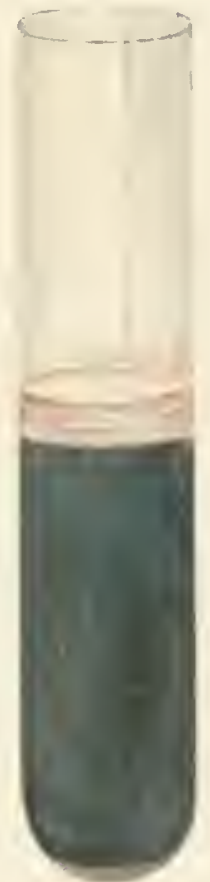

1

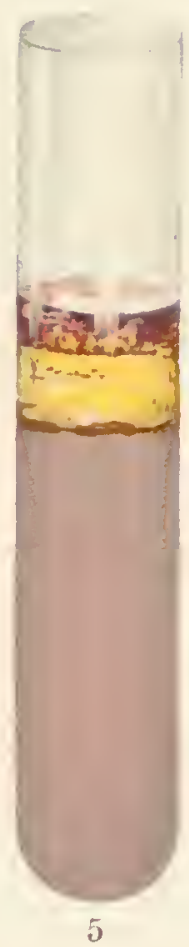

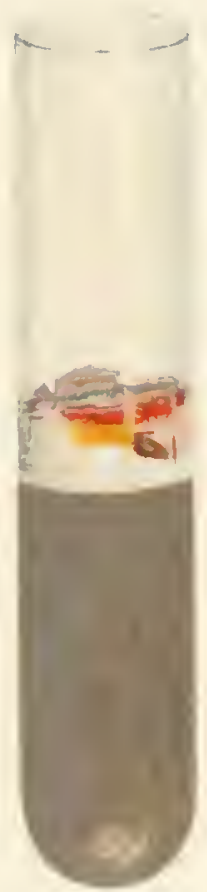

2

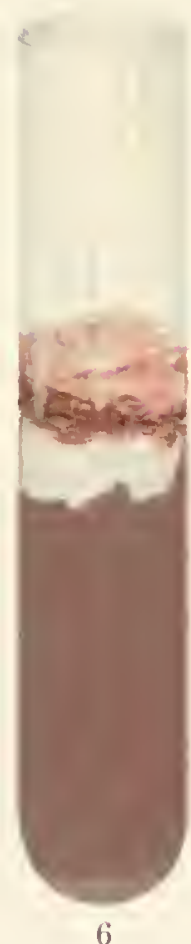

6

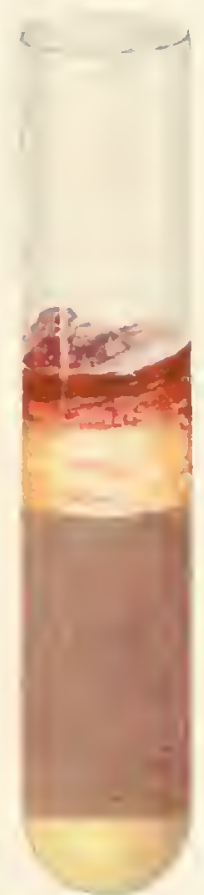

3

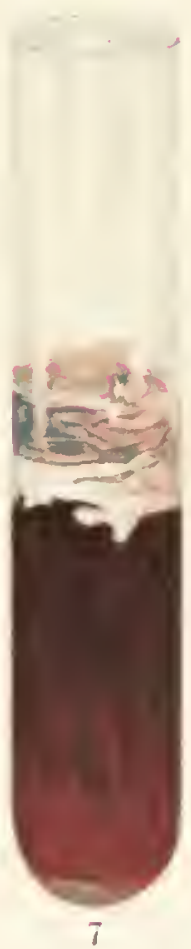

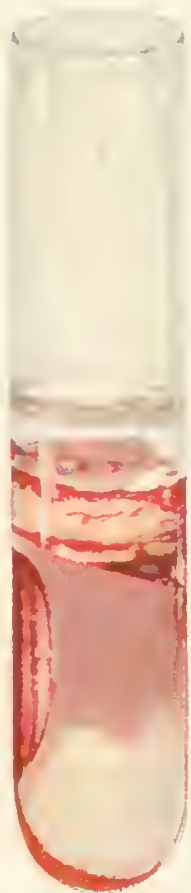

4

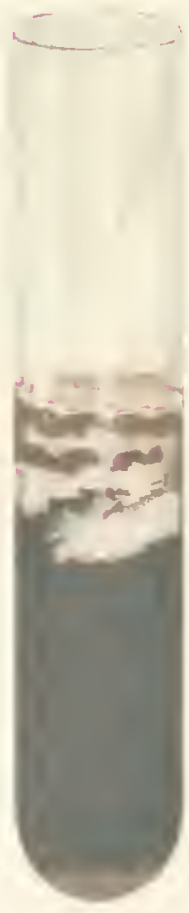

S

TOBACCO WILT.

Behavior of Sumatran Bucl. solencerarmm (Medan 111 ) at $25^{\circ} \mathrm{C} .+$ in centrifuged !itmus.milk to which cream was added. (1) Control in cream-free litmus-milk, inoculated and kept 31 days (compare with pls. 23, fig. 7 , and 41 , fig. 6 ): no reduction, scanty bacterial crecipitate at $\mathrm{I}$ : (2) the same wh addition of cream: tube inoculated 8 days, acid production beginning in cream layer: (3) another tube of same inoculated milk plus cream, after 31 days: distinct reduction, and copious bacterial precipitate at . $\boldsymbol{r}_{\text {; }}$ (4) another tube of the same after 55 days. Tubes 5, 7, 8, are cultures of other organisms in same creamy medium introduced for comparison: (5) Aplunobucter michiomurnse (N. Y. strain, colony 5), after 12 days: cream not reddened (compare with pl. 11, fig. 6): (6) uninoculated tube for comparison with 7 and 8 , the white mass at the top is cream; (7) Burlerium cumpes/re after 28 days: milk slightly reddened and translucent, cream unchanged; (8) Bucterium mor (isolated from French mulberry) after 28 days: milk blued, cream not reddened, 
- 
A part of the rods in young agar streak cultures made from Honing's organism (third sending, which is actively patlogenic) were actively motile (darting about when examined in water), and the appearance of some of these rods when stained is shown in fig. 134a, which may be compared with figs. Iog and I33. I can not, therefore, explain Hittehinson's statement that Bact. solanacearm is non-motile unless it be that he did not wait long enough. Frequently when young solid cultures are transferred to distilled water they are not at once motile, but become actively motile in an hour or so.

After the above results were obtained one additional test was made with the Sumatran organism. Eight typical looking colonies were subcultured from an agar poured plate. Each one of these 8 cultures was then examined in hanging drop and a portion of the rods in each observed to be actively motile (darting movements). Each one was then used to inoculate (by needle pricks) one young tobaceo plant and within 7 days cach one of these 8 plants developed typical signs of the tobaceo wilt; the bacterial lesions were demonstrated in the stems, and the Medan organism was plated out again from two of the plants. Subsequently polar flagella were demonstrated on a small portion of the rods in two of these cultures, but the cultures proved very refractory to stains (Van Eirmengen's, Pitfield's, Lowit's, Morton's night blue, etc.), and no fine slides were obtained. The greatest number of motile rodswere observed in the top layers of 10 or 15 c. c. of antoclaved distilled water added to young agar streaks and allowed to stand for some hours. Treated in this way fully one-half the rods were visibly motile.

In our nutrient gelatin liquefaction did not occur, at least not during the first seven weeks.

Tests of Medan III in 3 fermentation tubes using water, Witte's peptone and cane sugar, gave the following results at the end of a month: well clonded in the open end and the $U$ copious precipitate, no pellicle, fluid in the bowl browned, reaction to neutral litmus slightly alkalin. In the closed end: no clouding, no gas.

Using first lactose and then glycerin in place of eane sugar, similar results were obtained, except that with these carbon foods there was less growth, as indicated by the scanty preeipitate, and no browning of the fluid, which was alkaline at the close of the experiment in all of the tubes.

At the end of a month in two fermentation tubes containing nitrate bouillon there was a scanty stringy growth in the fluid of the open end, which was now clear. There was no gas, 110 stain, no elouding of closed end, and the fluid was alkaline.

Old litmus-milk cultures of Medan III yielded no crystals [see p. 233].

\section{THE RUSSIAN DISEASE.}

Iwanowski has described a rot of tobacco from Bessarabia, which I have included here somewhat doubtfully. He does not say in so many words that it is due to bacteria or that he has seen bacteria in the tissues, but he does say that none of the higher fungi were present. The signs are decayed spots which enlarge and fuse. These occur on various organs. The bark is first attacked and then the wood and pith, or the reverse. The Russian paragraph dealing with this disease reads abont as follows:

Rot is the name the author gives to a disease of tobaceo, which consists of peculiar decayed spots appearing on the stem, leaves, flowers, seed-eapsules - in a word, on all parts of the plant. It is as likely to oceur on one part of the plant as another. The spots may gronp thenselves arontind the sten, girdling the stem, or frequently they group themselves on one side of the stem, on which side the stem bends over. It of ten oceurs that the decayed spots unite with one another in a transverse direction. The rot attacks either the bark alone, or also the cambinm, the wood, and the pith, or it may act in the reverse order. In a given spot the wood may be decayed, but the bark be entirely healthy. 'l'he root in such a case commonly becomes decayed. 'The distribution of this disease on the plantation is similar to that of the spot-disease, that is, the diseased plant does not become the center of infection. Unlike the spot-disease, there is almost no reference to this disease in literature. Concerning its cause, it is only elear to the author that it is not of fungons origin; whether it is caused by bacteria it is not yet possible to say, but nothing stands in the way of this supposition. 
This paper was discussed by various botanists and Woronin suggested that, owing to the serious nature of these diseases, a commission be appointed to study them further. Q11ery: Was this commission appointed and did it publish any report?

\section{THE ITALIAN DISEASE.}

From a line or two in Comes's "Crittogamia agraria," page $5^{15}$, it would appear that he has seen in Italy a bacterial rot of tobacco. This he ascribes to his Bacterium gummis.

Comes also reports a bacterial rot of seedlings, but this was also associated with a fungus and witlı eel-worms.

\section{THE FRENCH DISEASE.}

In 1906 Delacroix described several so-called bacterial wilt-diseases of tobacco. His "canker," "collar-rot," and "pith-rot" seem to belong here, or at least nay be placed here tentatively. He has, however, ascribed these three diseases to as many species, two of which are green fluorescent schizonycetes. The "canker," which has done much damage in parts of France, particularly in Meurthe-et-Moselle and in Haute-Savoie, is said to be due to Bacillus armginosus Delacroix. The collar-rot is ascribed to Bacillus tabacivonis Delacroix. The pith-rot is attributed to Bacillus putrifaciens putridus Flügge. These are described with about the same degree of completeness as his Bacillus solanincola. In particular the account of his isolation and infection experiments leaves much to be desired; one also feels inclined to suspect that the descriptions of behavior on media may have been drawn from mixed growths. I could not come to any definite conclusion from a hasty examination of lis alcoholic material made in Paris in 1913, but a careful examination since made of stained sections of paraffin embedded material (1o sets, two sources) leads to the conclusion that no bacteria are present in the samples examined.

These three organisms are said to have the following characteristics:

(1) Bacillus conginosus. - The bacteria are elongated cylindric with rounded ends, generally occurring isolated or as diplococci, 0.75 to $1.0 \times 2$ to $3 \mu$ (his figure represents a somewhat larger organism). It has no cilia, spores, capsules, or zoogloex, and does not stain by Gram's method. It grows well in culture-media: nutrient agar, nutrient gelatin; aerobic; forms on bonillon a thin, whitish, fugacions pellicle, quite adherent to the walls of the tube; the bouillon clouds rapidly and shows a green fluorescence inclining to olivaceous, the precipitate being first white, then pale yellowishcream, and finally slightly grayish. After a time the liquid clears, loses its green color, and gradually becomes fawn-brown, old cultures haring the smell of incompletely burned tobacco; this odor, however, is not always produced, even in veal-bouillon; gelatin is not liquified, but after some days it acquires a green fluorescence which lasts longer than in bouillon. The isolated colonies are discoidal, 2 to $3 \mathrm{~mm}$. in diameter, smooth, shining on the surface, pale yellow, becoming darker witli age; the colonies often fuse. On agar there is a green flirorescence; the surface of the colonies is brilliant, but when they become confluent the surface is duller and mammelonate, with the border flattened out more than that of the single colony, or than the fusions on gelatin; the margin also extends as the culture ages; they are a little paler than on gelatin, and sonetimes a little greenish; on potato the colonies are golden-yellow, slightly granular, quite brilliant, forming by confluence a creamy, opaque mass, which sinks down and becomes brown with age. These bacteria are often mixed with others in the plant, and cultures slould be made, for this reason, from recent infections. Inoculation experiments by means of a needle succeeded in the proportion of 3 to 8 ; inoculations in the middle of August, made by placing a drop of the culture on the freshly cut stem (top of the plant) gave 1 out of 3 positive. Signs were visible in a week, but at the end of a month there was only a slight chancre; wounds are necessary. Cultures of the second generation gave no result when inoculated; direct infections generally failed. 'The chancre frequently attacks the Paraguay, more rarely the Auriac. It has not been scen on the Green Dragon. Nicotiana rustica did not contract the disease from inoculations.

Bacillus tabacivorus.- The elenents are isolated, cylindrical, with rounded ends; spores, cilia, capsules, and zoogloeæ are absent; rods vary in size from 0.4 to $0.6 \times 0.75$ to $1.50 \mu$. Agar, gelatin, and bouillon are not stained; the organism is aerobic; in bouillon the liquid becomes opaque (louche), with a slight pellicle which adheres to the walls of the tube. 'There is a scanty, whitish precipitate.

On gelatin the colonies are opaque, $1.5 \mathrm{~mm}$. in diameter, brilliant metallic-iridescent, with a duller, slightly raised central portion; they are flat, dirty wlite, with a slightly irregular contour and a surface radially striate; the gelatin is not liquefied. On agar the colonies are noticeably duller and 
flatter; on potato the colonies become rapidly confluent, forming a creamy, pale yellowish-white mass, which is distinguishable from the substratum only by its shining appearance.

"I have been able to obtain several artificial infections by lacerating the collar and rubbing the wound with a culture of the first generation of the bacteria, obtained pure with the greatest ease, by sowing some of the diseased tissuc."

This disease is said to be confined to the collar, to be quite rare, and to require wet soil for its development.

Bacillus putrifaciens putridus is said to be a cylindrical rod with rounded ends, in short chains of two or three elements when young; 0.5 to $0.7 \times_{1.2}$ to $1.8 \mu$; it is closely related to his $B$. aruginosus; ${ }^{*}$ bouillon, gelatin, etc., are stained uranium green. 'The bouilon is very lightly clouded, without much surface pellicle, and witl 1 a white precipitate. Gelatin is not liquefied; on agar or gelatin the colonies are small, shining, irregular, opaque, white with a very faint rose color.

Inoculation experiments appear to have been scanty and unsatisfactory. Under bell-jars, in a humid atinosphere, about one-third of the inoculations slowed some effect. No details are given. 'The lesions were less profound than those in the field.

A collar-rot of tobacco occurs in the United States. Specimens were received in I9I 2 from Elmira, New York. The bark is killed between root and stem and the plants wilt. Bacteria are present. Poured plates yielded green-fluorescent and white organisms. 'The writer knows nothing respecting their cultural characters or patlogenicity. A tobacco canker lias also been reported from Connecticut by Clinton.

\section{THE INDIAN DISEASE.}

Hutchinson has recently published a paper on an Indian disease resembling the Granville tobacco wilt. Unfortunately, it was received too late for more than a very brief abstract.

The disease occurs annually in the Rangpur district in Bengal in northeastern India, and has been present for many years. In the field it is patchy in its distribution. The loss is usually not more than 5 or 6 per cent, but sometimes 20 to 25 per cent. Growers generally consider it to be a disease of moist soils and its local name is "Rasa" or moisture-disease. It is attributed to Bact. solanaccarum Smith, which is said to be non-motile (numerous observations covering a period of more than two years), but accompanied almost invariably by a morphologically similar motile form which produces on potato only a yellow pigment (yellow ocher with a grcenish tinge), and is not pathogenic. The true parasite measures 0.6 by 1.0 to $1.5 \mu$; on agar it is white, moist, and smooth, becoming sepia brown with stain of the substratum; on gelatin the colonies are round, thin, white, opalescent, brown under magnification by transmitted light, and without liquefaction; bouillon is turbid on shaking and alkaline in reaction (a good distinguishing trait); on potato the growth is watery and colorless at first, then opaque white, becoming brown, and finally bitumen black; in glucose bouillon no acid or gas is formed. In mixed cultures Bact. solanacearum may be distinguished by its tendency to show bipolar staining with methylene blue. This is a common phenonienon on potato cultures.t Successful inoculations were obtained on tobacco and tomato by needle-punctures. Soil inoculations generally failed unless the roots were injured. Marked differences in virulence were observed in cultures, also in their brown pigmentation and a non-pigmented strain was observed. Variations in morphological character and in virulence are attributed to the culture medium used. Promptest results were had from potato-culture inoculations, slowest from bouillon; agar was midway in point of time. When mixed with saprophytes, such as Bact. megalherium and Bacl.prodigiosus, inoculations often failed. "It was found that a mixed culture of Bact. solanaccarum and Bact.prodigiosus in bouillon depended for its pathogenicity upon a preponderance of the former in the medium sufficient to produce alkalinity." "The wilting of the plant is ascribed to the action of bacterial toxins rather than to mechanical plugging of the vessels. This hypothesis is supported by interesting experiments, $i . e .,(1)$ a healtly tobacco plant may be cut half through the stenl without causing wilt even in the leaves immediately above the cut; (2) an alcohol precipitate fron a bouillon culture when

*Bacillus aruginosus Schröter is earlier (1886), and consequently. Delacroix's name should be rejected, and in the present stage of our knowledge of the disease it is scarcely worth while to suggest a substitute. Griffon states that Bacillus brassicazorus Delacroix and Bacillus aruginosus Delacroix are nothing but B. fuorescens putridus; while Bacillus caulivorus Prill. and Delacroix is B. fluorescens liquefaciens. It is with a sigh of relief that one rcads: "Il n'y a plus lieu de conserver les dénominations speeitique de caulivorus, brossicavorus et aruginosus."

† The Florida potato organism (1914) grown on cooked potato, also showed bipolar staining with methylene blue. See also Honing's statement (p. 25.3). 
dissolved in sterile water and fed into the vascular system of the stem of a healthy plant causes wilt in course of a few days if used unboiled, but not if boiled. Nuch difficulty was experienced in keeping cultures alive throughout the year. It was accomplished only by repeated transfers and storage at $20^{\circ} \mathrm{C}$, and then they were found to have lost much of their former virulence, but this was restored by passage through a fresh series of plants, but not the pigment production. Solution of the middle lamella and disintegration of the tissues by separation of the cells is a noticeable feature in this disease. The formation of the brown pigment in cultures tends to destroy their virulence. "It was found that when the cultures reached this stage they were 110 longer pathogenic, and in fact in many cases failed to produce growth when transferred to similar media." [See footnote page 232.]

This interesting paper raises the question whether in some of the preceding studies two organisms may not liave been confused, $i$. $e$, a non-motile, black-pigment-forming species (the true pathogen) and a elosely associated non-pathogenic, motile species producing only a yellowish growth on media. Certainly the writer of this monograph often has failed to observe motility, has frequently seen only a yellowish-brown stain in potato cultures (and these usually are non-pathogenic), and has seen more variations in virulence and had more failures in the way of inoculations than with almost any other organism worked with.

As soon as possible therefore after reading Hutchinson's paper additional observations and experiments were made to determine whether the pathogen is motile or nonmotile. For this purpose we used cultures of the tobacco organism received from Honing (the only living cultures of this species then in the laboratory).

These studies confirmed earlier ones made on the North American organism. The organism examined on the nargin of hanging drops was clearly motile, sometimes darting entirely out of the field, and Miss Bryan succeeded in demonstrating polar flagella by means of stains. The actual agar-streak culture which yielded the polar flagella (fig. 13fa) was then used for successful inoculations on tobacco (fig. 134b). If the streak was a pure culture, then there can be no question as to the motility of the parasite. It was a subeulture from the third sending of Honing which we designated as Medan III. I do not know its history on the other side, but we may suppose that it was the product of a single colony; it certainly behaved in various media (potato, agar, milk, ete.) like a pure culture. We also plated it out on agar and observed no contaminating organisms. The streak used for the flagella staining was not started, however, from a single colony. For this reason the work was done over using subeultures from single colonies witl the same results (sce p. 265 ).

\section{THE SOUTH AFRICAN DISEASE.}

In $1906 \mathrm{Mr}$. C. P. Lounsbury reported on a serious tobacco wilt oceurring in Southeastern Cape of Good Hope, South Africa. This paper is a summary of investigations carried on in 1905-6 in regard to "serious and extensive losses in the tobacco fields of the Kat River Valley." A farmer at Balfour describes the disease as "a plague which is devastating the tobacco of almost the whole district." Reports of W. R. Dewar, Entomologist of the Eastern Province, Mr. Thomas Bowhill, the Veterinary Bacteriologist, and Mr. Lounsbury constitute the body of the text, together with several excerpts from letters of others as to the cause or signs of the disease.

Mr. Dewar's description of the disease is as follows:

The farmer can see a plant just beginning to wilt when lie is two or three rows away. It is not so noticeable to a casual observer; but, upon closer examination, the farmer is generally correct. A slight wilting is noticeable, which can not be distinguished in healthy plants. As the disease continues, the plant wilts more, the leaves droop considerably, turn yellowish or sickly, and eventually the plant dies. In many cases when a plant is in the advanced stage the roots are soft and black. This lias led the growers to say that the disease is in the soil. Sometimes only half or one side of a plant seems affected, and in some cases only one side of one or two leaves on a plant. In many cases I noticed that the stalk had become black and dry in longitudinal wavy lines under the cortex, and that the drying had pulled the cortex down so as to form irregular corrugations. 
The disease, from what I could see and learn, was pretty well scattered throughout the district. In a field of transplants there seemed no order in the plants attacked. The plants here and there over the whole field kept going, and one could see plants in all stages of disease.

The promiscuity of attack, the general symptons, and the presence of insects, espccially hemipterous, first started me to wonder if there really was a bacterial disease present; insects play an in1portant part in the dissemination of wilt diseases.

Now, perhaps, all this idea about a bacterial disease is "wildfire," but it seems to me to require investigation. 'There is one great objection, and that is the general dispersion of the disease in one year, taking it for granted that this is the first year that it lias been noticed.

Mr. Bowhill made an investigation in the same section visited by Mr. Dewar, concerning which he says:

I made a carefinl examination of the diseased plants, and also dissected a great many of them. In all the infected plants examined I found a small white, active larva with a black head. * * * On making a complete bilateral seetion of an infected plant from the root upwards the ravages of the maggot are easily discerned. The pith in portions is of a brownislı colour, and in other parts it is completely honeycombed.

Several infected plants were split open with a sterilized knife and cultures institnted on sterile potatoes from the decolourized portions of the pith. $*^{*} *$ One larva was removed witl sterilized forceps and placed in a tube of gelatine in order to observe what, if any, micro-organisms were introduced by them into the pith and other portions of the stem during their meanderings. $* * *$

Regarding the question as to whether there is also a blight disease amongst the tobacco in this area, I am not prepared from the eridence in nny possession to either affirm or deny such a contention, but I must, howerer, state that I believe there is something else in addition to the larva already dealt with. I have personally noticed, as well as having n1y attention drawn to the fact, that some of the infected plants droop in one night, while others (supposed to be affected by the so-called blight disease) appear to degenerate by degrees. In some instances the roots were found to be in an adranced state of decay.

Mr. Bowhill obtained a variety of bacteria and fungi in his cultures, e. g., Bacillus mycoides rosens, Bacillus megaterium, a slender bacillus unidentified, and some Mucors. Regarding these he says: "I am of the opinion that their presence within the stems of infected plants is due to external combinations caused by the destruction of the external cuticle of the plant."

Mr. Lounsbury concluded, after personally visiting various sections where the disease prevailed, that the cause was the potato moth, combined in some cases with the action of the gall worm. He refers to McKenney's description of the North Carolina tobacco wilt, and also to the Japanese tobacco wilt, and has the following to say concerning the relation of these two diseases to the Kat River wilt:

These more serious tobacco diseases may be distinguished from the Kat River wilt, to judge from the descriptions, by the more extensive blackening of the stalks, by black lines in the wood marking the work of the fungus or bacterium in the sap channels, and by the earlier decay of the roots. Perhaps, however, the only clearly distinguishing feature in many plants would be the presence or absence of the causative bacterium or fungus. In all three troubles the pronounced symptom of wilting appears to be due to a gradual stoppage of the flow of sap.

Many growers will doubtless believe that they have one or the other of the foreign wilt diseases. I can not deny the possibility of their being correct, but can say that I saw nothing which, in my mind, justifies an opinion that the whole trouble is not due to the potato moth, assisted in a few places by the gall worm. I failed to find evidence that would lead me to suspect fungi or bacteria as the primary source. Although Mr. Dewar at first inclined to the idea of a true plant disease in addition to injury through insects, he failed to substantiate his suspicions by his subsequent laboratory examination of affected plants, and lie liad not learned at the time of similar trouble, due to potato moth alone, in Rhodesia. Moreover, were the trouble an entirely new fungoid or bacterial disease, it would probably not liave appeared simultaneously over a large area, and would probably have caused more uniform destruction wherever it appeared. Illustrations of the American and Japanese diseases show plants in large patches wilting down all at once. Howerer, should the developments of future years in the Kat River Talley show my conclusions to be wrong, I shall have erred on the safe side, since there are no practical remedies for the true wilt diseases. Thie potato moth and gall worm, on the other hand, are pests that it should pay to combat by the measures discussed, irrespective of the wilt; and growers are therefore urged to take action.

[In this connection see account of African potato disease on p. 214.] 


\section{LITERATURE.}

I898. I WANOWSEI, D. O. On the diseases of the tobacco plant. [Russian.] Arb. d. Petersb. Naturf. Gesellsch., Bd. XIx, pp. 19-2 I.

Descrihes a spot-disease, and a rot of tobacco from Besabia. The latter is apparently due to bacteria. No fung present. Brief description in Bot. Centralbl., Bd. XLI, 1800 , p. 363 .

189o. Iwanowsky, Dm. und Poloftzoff. Die Pockenkrankheit der Tabakspflanze. Mén. Acad. Imp. de St. Pétersbourg, 'T. xxxvir, No.7, 18 ço.

This disease occurs in Little Russia, Bessarabia, and the Crimea and is knowen generally as the "pox disease" " and the Cring to Dutch review in Teysyanni the authors thiok theord ing to a butch revien in ease is not due to bacteria. They think that the disease arises "spot lisense" referred to in the other poper. Original nop sene

I802. JANSE, J. M. Nota over eene ziekte der tabak op Sumatra. Teysmannia, in Deel, Batavia, I 892 , pp. 653-662.

r893. Comes, Orazio. Mortalitá delle piantine di tobacco nei semenzai cagionata da marciume della radice. Atti del $R$. Ist. d'Incorragg, di Napoli, ser. 1V, vol. VI, mem. Nr. 2, 1893. Also a reprint

Atributes a root rot to Bacillus amylobacter. Bacteria not solated. Reviewed in Bot. Centralh. 8903 , vol. LVI, D. 253 .

1897. VAN BREDA DE HAAN. De Slijmziekte bij de Tabak in Deli. Teysmannia, Deel vrn, Afl. 10/11, Dec. 1897 , Batavia, Java, pp. 528-549. Also a separate of 22 pages.

Disease produced by inoculations with pure cultures.

1899. Sulth, ERwin F. The Fungous Infestation of Agricultural Soils in the United States. Scientific American Supplement, No. 1246, November I 8, 1899, p. 109 \$ (paper read Aug. 25. I 899, at Columbus meeting of the American Assoc. Arv. Science)

Igo1. IUUNGER, F. W. T. De Slijmziekte Veroorzaakt door Bacillus solanacearum Smith in "Overzicht der Ziekten en Beschadigingen van let blad bij Deli-Tabak." Mededeelingen uit 's Lands Plantentuin XI.vir, Batavia 1901, pp. 20-25.

1903. MICKENNEV, R. I $\vec{B}$. The wilt disease of tobacco and its control. U. S. Dept. Agric. Bur. Plant Industry, Bull. No. 5 1, part 1, Sept. 18, 1903, pp. 4, I fig.

1903. STEveNs, F. L., and SAckett, IV. G. The Granville tobaceo wilt: a preliminary bulletin. North Carolina Agric. Expt. Sta. of the College of Agricuture and Mechanic Arts, Raleigh. Bull. No. 188, Sept. I 903,pp. 8 I -96. See also Ann. Rep. for that year

1904. UYEDA, Y. On the tobacco-wilt disease caused by a bacteria. Centralb. f. Bakt., 2 Abt., xiII Bd., I004, pp. $327-329$, with 3 figs. of diseased plants.

1905. SurTH, ERWIN F. Bacteria in relation to plant diseases, vol. I, pl. 27.

1905. UYEDA, Y. Bacillus nicotianae, sp. nov; die Ursache der Tabakwelk-Krankheit oder Swarzbeinigkeit in Japan. Bulletin Imperial Central Agricultural Experiment Station. Tokyo, Japan, vol. 1, No. I, 1905. Also a separate, pp. I to 19,5 plates.

IgO5. DELACROIX, GEORGES. Le chancre bactérien, in "Recherches sur quelques maladies du tabac en Firance." Annales de l'Institut National Agronomique. 2 sé., t. v., fase. 2. Paris, $1906 . \quad$ Also a separate, pp. I to 12.

Disease ascribed to Bacillus aruginosus Delacroix, a greenGuorescent organism.
1905. DELacrolx, Georges. Pourritures bactéri ennes succédant à des plaies d'insectes. Pourriture du collet du tabac, in "Recherches sur quelques maladies du tabae en France." Annales de l'Institut National Agronomique. 2 sé., t. v., Paris, I 9o6, pp. 12-r4. Also a separate, pp. 12 to 14 .

Disease ascribed to Bacillus 1abacivorus, a non-sporiferous, non-motile, non-capsulate, non-fluorescent, white organism, which does not stain by Gram.

1006. Delacrolx, Georges. Pourritures bactériennes succédant à des plaies d'insectes. Pour siture de la moelle, in "Recherches sur quelques maladies du tabac en France." Annales de l'Institut National Agronomique, 2 sé., t. v. fase. 2, Paris, 1906. Also a separate, pp. $14-16$.

Rot ascribed to a green-fuorescent organism, Bacillus pulri faciens putridus Flugge.

1906. Iounsbury, Chas. P. Tobacco Wilt in Kat River Valley. The Agricultural Jonrnal of the Cape of Good Hope, vol. xxvill, No. 6, Cape Town, June, 1906, pp. $78+-803$.

Included bere doubtfully.

1907. Stevens, F. L. Granville tobacco wilt. 3oth Ann. Rep. North Carolina Fixpt. Sta. for year ending June $30,1907$.

A brief note.

1908. Sмiтн, ERwin F. The Granville tobacco wilt. U.S. Dept. Agric., Bureau of Plant Industry. Bull. No. I 11, part 11, pp. I3-24. Issued August 31, I 908. Washington.

1909. GRIfFon, ED. Sur le rôle des bacilles fluorescents de Filügge en Pathologie végétale. Comptes r. hebd. d sé. de l'Acad. des Sci., tome J 49, pp. 50-53. Paris, I 909

"Another precaution, much spoken of since the researches of Laurent, consists in the use of a suitable fertilizer which will procure to the plant a certain immunity: little organic nitrogen. much phosphaies and potash salts. The results of the experiments I have undertaken with this in mind, and of those I have followed here and there, do not seem to me very encouraging."

1909. Stevens, F. L. Granville tobacco wilt. Notes on plant diseases occurring in North Carolina. Thirty-first Annual Report, North Carolina Agric. Exper. Station, pp. 81-82. West Raleigh, June 1908. [Issued in spring of 1909.$]$

1909. JENSEN, HJ. Onderzoekingen over Tabak der Voorstenlanden. I. Slijmziekte. Jaarboek van het Departement van Landbouw in Nederlandsch-Indië, I908. Batavia. Landsdrukkerij, 1909, pp. 100-104, with I plate (plant recovering from an attack).

19ro. Ifoning, J. A. De oorzaak der slijmzieke an proeven ter bestrijding. Mededcelingen van het Deli Proefstation te Medan. $5^{\mathrm{e}} \mathrm{Jaarg}$. , $1^{\mathrm{e}}$ Aflev. Medan. [Sumatra.] August 1910, pp. I-I 9 .

1911. Honing, J. A. De oorzaak der slijmzieke en proeven ter bestrijding II. Mededeelingen van het Deli Procfstations te Mcdan, $5^{\mathrm{e}}$ Jaargang, $6^{\mathrm{e}}$ Aflevcring (verschenen Feb. 1911), pp. $169-185$.

19II. Honing, J. A. De oorzaak der slijmziekte en proeven ter bestrijding Iu. MIededeelingen van het Deli Proefstation te Medan, $5^{\mathrm{e}}$ Jaargang, Io Aflevering (verschenen Juli I9II), pp. $3+3-358$. 
1911. Honing, J.A. Verslag over de slijmziekte proeven in $19 x \mathrm{I}$. Mededeelingen van het Deli Proefstation te Medan, 6e Jaargang, $i^{e}$ Aflevering (verscbenen Sept. 191 I), pp. I-3o.

I912. IIONing, J. A. Beschrijving van de DeliStammen van Bacillus solanacearum Snitl, de oorzaack der slijnzieke. Mededeelingen van het Deli Proefstation te Medan, 6e Jaar-

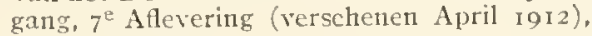
pp. $219^{-250}$.

1912. Honıng, J. A. Verslag over der ontsmettingsproeven vall zaadbedden op slijmzieke gronden met eenige ehemicaliër. Mededeclingen van het Deli Proefstation te Medan, $7^{\text {e Jaargang, I }}$ e Aflevering (verschenen Juli I 912 ), pp. I-II.

1912. Honing, J. A. Fen geval van slijmziekte in de djattibibit. Mededeelingen van het Deli Proefstation te Medan, $7^{e}$ Jaargang, ${ }^{e}$ Afleverins (verschenen Juli I912), pp. I2-I5; also naschrift, p. 59 .

19I2. Honivg, J. A. Over het verband tusschen slijnziekte in de bibit en in de nitgeplante tabak. Mededeelingen van het Deli Proefstation te Medan, $7^{\mathrm{e}}$ Jaargang, $2^{\mathrm{e}}$ Aflevering (verschenen Ang. 19r2), pp. 65-69.

19 2. Honing, J. A. Over de beweerde onvatbaarheid van Nicotiana rustica voor slijmzickte. MIededeelingen van het Deli Proefstation te Medan, $7^{\mathrm{C}}$ Jaargang, $3^{\mathrm{e}}$ Atlevering (verschenen Sept. 1912), pp. 95-98.

1912. Honing, J. A. Over de variabiliteit van Bacillus solanaceurum Snitl. Mededeelingen van het Deli Proefstation te Medan, $7^{\mathrm{e}}$ Jaargang,

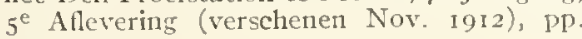
196-209.

19I 2. Honras, J.A. Over rottingsbacteriën uit slijmzieke tabak en djatti en enkele andere van slijmzickte verdachte planten. Mededeelingen vau Ilet Deli Proefstation te Medan. Jaargang vi, $\sigma^{\mathrm{e}}$ Aflevering (verschenen Dec. 1912), pp. 223-253.

I9I3. IIoning, J. A. Uber die Variabilität des Bacillus solanaceurum Snith. Centraib. fuir Bakt., Zweite Abt., 36 Bd., No. 19/25, February, 1913, pp. $49 i-499$.
1913. Honivg, J. A. Hoe moet men trachten een tabaksras te verkrijgen, dat immuun is tegen slijmziekte? Mededeelingen van Het Deli Proefstation te Miedan, Jaargang VIII, i ${ }^{e}$ Aflevering, Angust 1913, pp. 12-2 I.

InI3. JENSEN, HJ. Slijmziokte. Mededeclingen van "Het Proefstation voor Vorstenlandsche 'Tabak." No. 5, Batavia, I9I3, pp. 48-60. No infections with Uyeda's B. Micolianne-6o plants inoculated

1913. Fulton, H. R., and J. R. Winston. A disease of peanut plants caused by Baclerium solanacearum. I'hytopathology, vol. 3, No. 1, February 1913, pp. 72-73. Mere mention.

Through courtesy of Dr. Fulton I have received the following note:

In August 19r2, peanuts (-1rachis hypogoea) of the Spanish variety growing in Granville county, North Carolina, on soil known to be infected with Bactcrizm solanacearum (Erw. Sm.) were observed to be dying to the extent of 15 per cent of the planting. Examination of stem and root of the affected peanut plants showed discoloration and disorganization of tissues closely similar to those characteristic of Cranville wilt o tobzcco. The newly affected parts contained numerous bacteria. Pure cultures were obtained from which both young and old peanut plants were successfully inoculated on several occasions, the disease induced being similar to that observed in the feld. The organism was reisolate $t$ from such artificially infected plants, and this culture again nse 1 for infecting the peanut. Young and old tobacco plants were insculated with the original cultures from peanut, with the production of dis ease similar in all respects to Granville wilt of tobacco, and th typical organism was reisolated from these artificially infected tobacco plants. Cultures from naturally infected tobacco and pepper plants proluced the disease in peanut

Ciltures of three strains of the bacterium from peanut were compared with cultures from tobacco and from pepper on various media, such as potato agar, nutrient gelatin, potato trips. peptone broth. glucose broth, beef broth, potato broth milk and litmus milk. The cultural features on these severa media were similar for all the strains tested, and agreed with the original descriptions for Baclerium solanacearum.

In size and shape, an 1 in reaction to the ordinary stains,

these several strains agreed with Bacterium solunacearum.

The facts lead to the conclusion that peanut is susceptihl to attack by Bicterium solinacearum.

igi 3. Hutchinson, C. M. Rangpur Tobacco Wilt. Mennoirs of the Department of Agriculture in Tudia. Bacteriological Series, vol. 1, No. 2, July, 19 I3. Agric. Research Institute, Pusa. Caleutta and Loudon, pp. 67 to 83 , with 12 plates ( 5 eolored).

19I3. DE JovG, A. W. K. Eenige Opmerkingen over do Bacterienzickte (Pelepes) bij Katjang Tanah. Dept. van Landbonw, Nijwerheid en Handel, Medeelingen van het Agricultuur Chemisch Laboratorium, No. III, Buitenzorg, 1913 , pD. $56^{-59}$.

No advantage was ohtained from flooding infected field Ner the planting of selected sound seed.

[See also Literature under Brown Rot of Solanaceac (p. 218) and Will of Peanut (p. I53).] 


\section{SCHUSTER'S GERMAN POTATO ROT.}

\section{OBSERVATIONS BY SCHUSTER.}

In 1912, Seluster described a polar-flagellate, green-fluoreseent schizomycete from rotting potato tubers obtained from six different localities in Germany, as Bactcrim xanthochlorm 11. sp., and asserted it to be the cause of the disease.

The organism when inoculated also blackened, it is said, and destroyed leares and stems of Vicia faba, and rotted other plants. It is by no means as active an organism on potato as Bacillus phytophthorns. It does not attack the stems of potato, and from Sehuster's own aceount it seems to be a rather weak parasite except at high temperatures (most active, he said, at $36.5^{\circ}$ to $38^{\circ} \mathrm{C}$.), or under other abnormal conditions, $\ell . g$., heavy doses of the bacteria, under bell-jars in very moist air. In dry air at room-temperatures the inoculations soon dried out and the tuber as a whole remained sound. At times it showed a decided tendency to occupy the vessels, $\epsilon . g$. , in Vicia faba, and in early stages of the tuber-rot of the potato. All of Schuster's inoculation experiments appear to have been made under abnormal conditions, $i$. $e$., in laboratory rooms, under bell-jars, ete., in a saturated air.

His Bact.xanthochlorm causes a slow, gray or yellow, wet-rot of the tuber, often proceeding from the vaseular bundles in or out, and from the margin of this rot it is easy to isolate pure cultures. Often the tubers are not much injured on the surface. The rotted parts smell of ammonia.

It is not able to enter the potato tuber througli the opened lenticels [anotherindication of weak parasitis111. In general it is a wound parasite, but it may enter, it is said, the green parts of Ticia faba through stomata.

It was inoculated suceessfully by Schuster into carrot roots, young tobaceo stems $\left(30^{\circ}\right.$ to $36^{\circ} \mathrm{C}$.), Lupinus namus douglasi, Physalis alkekengi, and Campanula raphunculus. Fodder beets, sugar beets, yellow lupins, tomatoes, and pelargoniums proved insusceptible.

This organism, according to Sehuster, has the following morphological and biological characteristies:

As a rule it is actively motile, but once a non-motile strain was isolated [this may have been some related organism]. The flagellum is polar. Sometimes two flagella are present, rarely three occur. The straight ones are 4.5 to $6 \mu$ long, $i$. $e$., two to three times the length of the rod. They stained poorly with carbol-fuchsin, but readily with Pepler's stain followed by carbol gentian violet. Hinterberger's modification of Van Ermengem's stain was also used successfully. At temperatures under $5^{\circ} \mathrm{C}$. and above $40^{\circ} \mathrm{C}$. no flagella formation could be detected. In bouillon motility was observed for 18 days, but on potato at $20^{\circ} \mathrm{C}$. it ceased after one day. On agar-streak-cultures motility ceased after one day at $37^{\circ} \mathrm{C}$. but was visible after 20 days at $20^{\circ} \mathrm{C}$.

Under normal conditions of growth the organism is a slender rod with rounded ends, 1.5 to $3 \times 0.75 \mu$, occurring for the most part singly or in pairs. It stains readily with basic anilin dyes but n1ot by Gram.

On agar at $36^{\circ} \mathrm{C}$. and at higher temperatures, long threads are produced within 24 hours. These long rods may show constrictions, but do not afterwards separate into short elements. Short, plump rods were observed at $2^{\circ} \mathrm{C}$.

Spores do not occur. Involution forms (plasnoptyse) occur. Pseudozoogloeæ occur.

The yellowish-green fluorescent pigment is soluble in water. After cultivating this organism on potato agar, carrot agar, or wheat-decoction agar for 3 months the color disappeared, but always could be restored by inoculation into alkaline bouillon, even after 6 months of colorless growth on the potato agar. iodide.

Glycogen was detected in bouillon-cultures at the end of the second day using potassium

No acids are produced; the cultures are always alkaline [see below]. Ammonia, methylamin, and trimethylamin occur.

'Trypsin, amylase, tyrosinase, and a hemicellulase are produced. A soluble toxine active on the protoplasm is also produced. 
Cultures in botillon containing methylene blue ( 0.2 c.c. botillon-culture: 1 : 1,000 in. 1).), lost their virulence on exposure to cliffuse daylight for 4 hours, while sinilar cultures kept in the dark slowed an increasing virulence. 'The methylene blue in 1 per cent quantity in bonillon is reduced in 3 to + hours.

Indol occurs (distinct in bouillon after io days). Hydrogen sulphide is produced slowly. Nitrates are reduced. The organisn liquefies gelatin, but not rapidly. It docs not liquefy bloodserum. It acts on starch slowly and incompletely. It grows best at $35.5^{\circ} \mathrm{C}$. [see below]. The range of temperature is not known. Schuster says slight growth at $2^{\circ} \mathrm{C}$. and at $40^{\circ}$ and $44^{\circ} \mathrm{C}$. Good growth at $27.5^{\circ} \mathrm{C}$. and pretty good at $36^{\circ} \mathrm{C}$. Moderate at $37^{\circ} \mathrm{C}$. and at $17.5^{\circ}$ to $18.5^{\circ} \mathrm{C}$. Growth at all temperatures from $16^{\circ}$ to $2^{\circ} \mathrm{C}$. is recorded as slight. The organism is aerobic and facultative anacrobic. Schuster gives a table of its action on sugars, alcohols, etc., but I am not able to make much out of it, except that cane-sugar, grape-sugar, milk sugar, arabinose, mannit, peptone, and asparagin favor growtl, whereas ammonimm chloride, ammonium phosphate, ammonium tartrate, ammonium sulphate, glycerin, caffein, arbutin, potassium nitrate, potassium phosphate, citric acid, potato starch, and cellulose do not. With ammonium chloride and the substances named immediately thereafter, there was a weak growth, with those italicised there was no growth whatever or only the slightest. 'These experiments were made in flasks in rooc.c.portions of Artlur Meyer's nitrogenfree mineral solıtion* to which were added usually 10 grams of the substance to be tested (caffëin $0.3 \mathrm{gr}$, arbutin $3 \mathrm{gr}$.). Cane-sugar, glycerin, mannit, and asparagin gave pellicles and no precipitate; grape sugar and arabinose gave pellicles and precipitate; milk sugar and peptone gave clouding and precipitate withont pellicle. 'These flasks were each inoculated with one loop from a bacterial suspension of a 24 -hour agar-culture and were kept at about $20^{\circ} \mathrm{C}$.

Gas is not produced from dextrose. At room temperatures milk is slowly coagulated (eighth day) and the curd is peptonized, but at $34^{\circ} \mathrm{C}$. these cluanges did not occur. At both temperatures the itpper layers (itettsclicht) becane greenish-yellow.

If a trace of sodium selenite is adcled to gelatin which is then inoculated with this bacterium the culture becomes blood-red in 12 hours.

'this organism causes in nutrient agar a grecnish-yellow fluorescence.

On agar-plates the surface colonies are circular, slightly raised, thinning at the edges, fine granular, with a denser center. 'The buried colonies are smaller and not characteristic.

On alkaline agar-strokes the growth is visible in 2.4 hours; it forms along the needle track a dry, thin, yellow-white to greenish layer, exhibiting a large number of cross-folds forming a wrinkled membrane. In thick sowings the folds may be lifted up vertically a millimeter above the surface, and the layer is then moist and watery or slimy [see below].

In agar-stab-cultures there is only a slight growth along the needle line. 'T'lis is best at the point of entrance where after 2 or 3 weeks there is a thick mulberry-shaped piling up of yellowish bacterial masses while the surface is covered witl a white skinny layer.

On Appel's slant potato-juice-agar there was a veryabundant development of the yellowish-gray bacterial masses within 24 hours which later fused into a thick sliny layer.

In the expressed juice of cooked carrots, with 2 per cent agar, there developed along the lower part of the streak a scanty growth in the form of a thin, white, weak, moist layer.

On gelatin plates very small colonies in the form of round drops appear in 1 to 2 days. Liquefaction begins in $4 S$ hours as a pit in which the nearly smooth-edged colony floats in the form of small lumpy masses lying one over the other. The center of the colony is considerably thickened and dark brownish. The buried colonies are globose, granular, and liquefy more slowly.

In gelatin-stab-cultures near tlie surface there is a funnel-form liquefaction extending gradually to the walls of the tube and not far downward along the needle track, where growtl is slight. Judging from Scluuster's figures liquefaction the first clay is in the form of a narrow (steep) funnel; that on the eighth day touches the walls and resembles a champagne glass, $i . c .$, the liquefaction is restricted to the upper quarter of the tube. Sometimes, lowever, after very copious inoculations there appeared along the needle-track liquefaction centers where clumps of bacteria developed, but elsewhere the nccdle-track was very little clianged.

In Appel's potato-juice gelatin (Arb. Kais. Biol. Anst. III, p. 396) there was rapid growtl in stabcultures with intense liquefaction, the entire contents of the tubes being liquefied witlin a few days, the bacteria being licaped up in an irregular globose mass on the bottom of the tube. 'The non-1notile organism already referred to liquefied gelatin more slowly.

In neutral intrient bouillon a strong general clouding takes place witlin 24 lours. A wlite pellicle forms on the surface and the flttid is filled witl small particles (Krumeln). 'There is a copious white precipitate which on sluaking holds together. Grape-sugar bouillon is very favorable for the growth of this organism. It did not grow well in beer.

${ }^{*}$ Distilled water, 1,$000 ; \mathrm{KH}_{2} \mathrm{PO}_{4}, \mathbf{1}$.0; $\mathrm{CaCl}_{2} \mathrm{O}$, r.o; $\mathrm{MgSO} 4+7 \mathrm{H}_{2} \mathrm{O}, 0.3 ; \mathrm{NaCl}, 0.1 ; \mathrm{Fe}_{2} \mathrm{Cl}_{2}, 0.0$. 
Firom a liter of alkaline potato juice inoculated 8 days a clear, bacteria-free fluid was obtained by passing it through a Chamberland filter. When double its volume of absolute alcohol was added a copiouts precipitate was obtained, which was tested after further purification for its effect on cell-walls of potato tubers. 'The walls became swollen and the typical rot appeared within 36 hours at $37^{\circ} \mathrm{C}$. Here again ligh temperatures were necessary, $i$. e., such as usually do not occur in the field or in storage. I translate as follows:

Experinents witl enzyme injection at different temperatures showed after 3 days at $2^{\circ}$ to $28^{\circ} \mathrm{C}$. no action; at $29^{\circ} \mathrm{C}$. beginning of rot; at $30^{\circ}$ to $35^{\circ} \mathrm{C}$. feeble rot spots; at $36^{\circ}$ to $38^{\circ} \mathrm{C}$. strong wet rot; at $40^{\circ}$ to $45^{\circ} \mathrm{C}$. again feeble decay; at $60^{\circ} \mathrm{C}$. no decay.

At $35^{\circ} \mathrm{C}$. the swollen cell walls beeane twice their normal width in 8 hours and the cells separated wholly or partly along the line of the middle lamella the third day. After 8 days the starcligrains were also acted upon, resembling the skeletons obtained by exposing starch to saliva at $40^{\circ} \mathrm{C}$. 'This remainder, which does not fall apart, is believed to be amylodextrin. Corrosion from the margin did not occur. 'The enzyme which dissolves the middle lamella is designated Xantlochlorum lrenicellulase.

When thin sections of a potato tuber are put into infected potato juice and examined under the microseope, the protoplasm can be seen to separate from the walls of the cell after to minutes, and after fo minutes it lies as a dark-brown lump dead in the middle of the cell; therefore the bacteria exerete a toxin as well as an enzyme.

According to Seluster, the action of this organism on the stems of Yicia faba is very rapid cven at room-temperatures; pitch-black spots appear at the place of inoculation and within 24 hours the stems rot and fall over, but it is not elear to the writer whether these inoculations were done on plants under bell-jars, or in the open, $i$. $e$. , under normal conditions.* Schuster's figures 8, 9, and to indicate a vascular infection. The rapidity of stomatal infection on leaves of Vicia faba is something hitherto unheard of, viz, penetration of the stomata with brown staining and bacterial occupation of the vessels of the leaflets, of the petiole, and even of the stem, within 48 hours, and would seem to indicate drenching of the leaves with bacteria and exposure to other abnormal conditions, i.c., to air saturated with vapor of water [see below]. The spiral vessels are the first to be attacked; the pitted vessels are then occupied, the bacteria entering then through the pits; subsequently larger or smaller cavitics are formed in the vascular bundle.

When cultivated from stems of I'icia faba on alkaline potato agar at $30^{\circ} \mathrm{C}$, a weak reddish stain appears which soon turns black on addition of paraphenylendiamin and $\beta$-naphthol (Spitzer's reaction). This red reaction is plainer in cultures to which $I$ to 5 per cent tyrosin solution has been added.

The rot on lupins was white, never black as on Vicia. The plants were injected and kept moist under bell-jars. The plants in the open were never destroyed by the inoculation, the growth of the bacteria soon ceased and the wounds dried out, but here pustule-likc intumescences were obscrved [see below], and these are ascribed to the action of the organism, since the control plants remained free whether pricked or not (see this monograph, Vol. II, fig. 27). In Physalis also the rot was white.

\section{EXPERIMENTS IN WASHINGTON.}

The writer repeated certain of these experiments with a green-fluorescent organism brought in I9I I from the Biologisches Anstalt in Berlin by Dr. Wollenweber and said to be Bact. xanthochlorm Schuster. This culture, it should be stated, did not conne directly from Dr. Schuster, who had then left the laboratory, but was a transfer by another assistant from a stock culture of this organism.

The organism which I have thus received and studied liquefies gelatin in the manner described and rots potato tubers as described, only much more slowly at $26^{\circ} \mathrm{C}$, and not at all at $37.5^{\circ} \mathrm{C}$., nor will it grow in culture media at that temperature. Also on Vicia faba

*Dr. Wollenweber, who was at the Biologisches Anstalt during this period, tells me they were made under bell-jars in the laboratory. 
exposed to normal conditions in a lıthonse it is not parasitic. I could not get any infections either by rubbing it into stomata or by needle-puncture into leaves or stens. Tlie organism grows in 111ilk abont as deseribed, but on agar-streaks ( + 15) I did not obtain the cross-folds and am inclined to regard this as an accidental phenomenon due to dry agar or to some other peculiarity of mediun. The organism was tried on various sugars and alcohols in the presence of river-water and Witte's peptone ( $\mathrm{I}$ per cent). Contrary to Schuster, it ferments grape-sugar and galactose with production of an acid, but a similar solution with cane-sugar gave an alkaliue reaction (fermentation tubes, ix days). The same results were obtained in two repetitions (twenty-eightli day and later). The other earbon foods tested in fermentation tubes were fructose, lactose, maltose, mannit, and glycerin. All of these gave an alkaline reaction (eleventh day). In two repetitions the same result was obtained after longer periods. 'There was no gas formation and no clouding in the closed end. As stated, theorganism did not rot potato tubers at $37^{\circ} \mathrm{C}$., nor could we get any evidence of growth above $34^{\circ}$ C. in + I 5 peptone-bonillon or on steanled potato. It grew better at $30^{\circ} \mathrm{C}$. than at $34^{\circ} \mathrm{C}$. but less well than at $26^{\circ} \mathrm{C}$. It grows at $1^{\circ} \mathrm{C}$. Its thermal death-point is $51^{\circ} \mathrm{C}$., approxinately. It grows in bouillon over chloroforn withont retardation. It grows in +15 peptone-bouillon with 4 per cent sodium cliloride and slowly with 5 per cent, but not witlı 6 per cent. It does not grow in Coln's solution. It grew in pep-

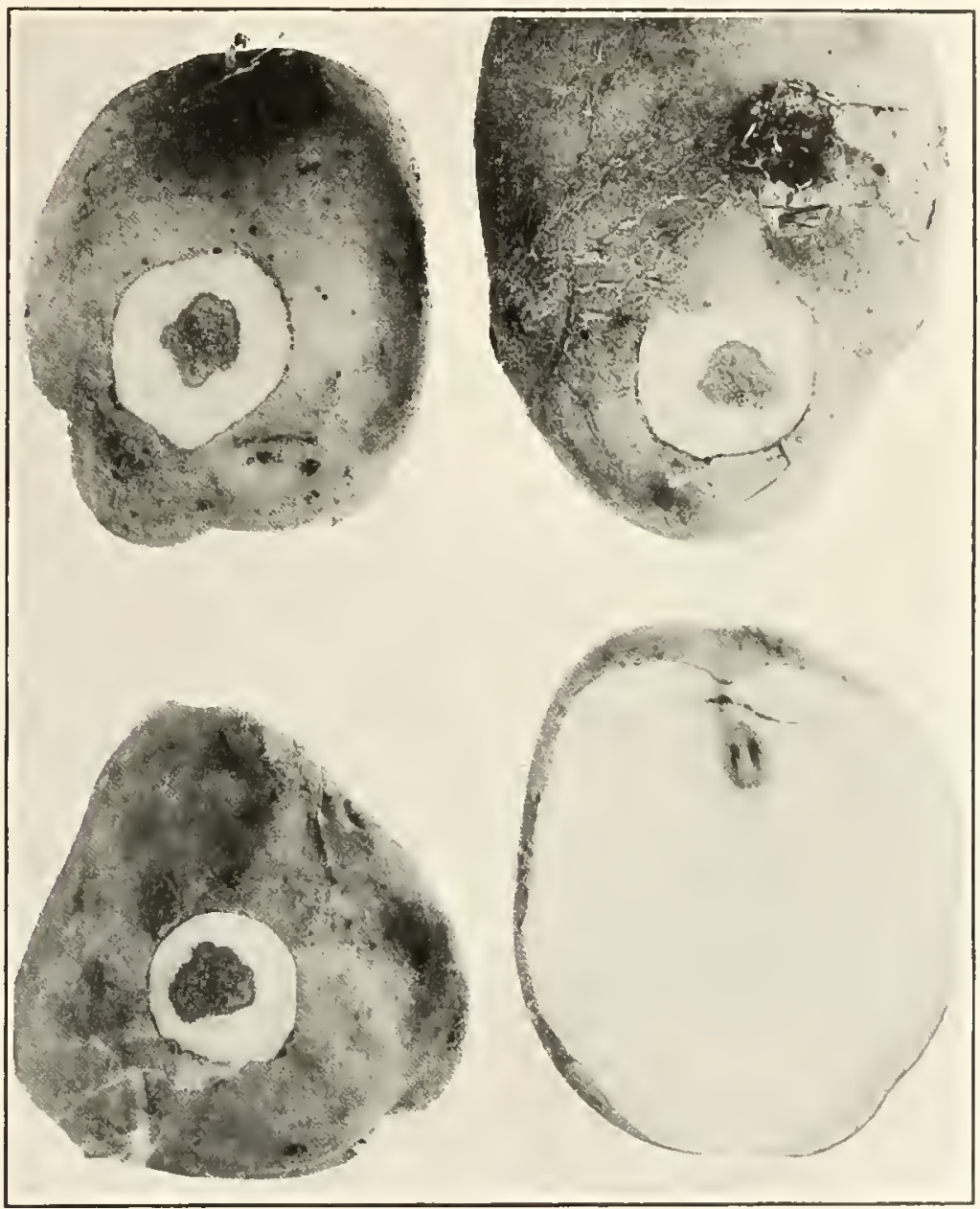

Fig. 135.* tone bouillon from -3 o to +25 . It grew about as well in - I 5 and -30 as in o or +25 . It grew well in Uschinsky's solution, forming a copious pellicle and after a tinne a pale green fluorescence.t It is sensitive to dry air (dead on cover slips at end of + days). It liquefied gelatin in the manner deseribed by Schuster but did not liquefy Loeffler's blood-serum, although it grew well upon it. It is quite sensitive to sunliglit.

\footnotetext{
*FIG. 1 35. - Potato tubers inoculated with Schuster's Baclerium xanthochlorum and exposed for six days to the dry air of the laboratory at $27^{\circ} \mathrm{C}$. Photographed Sept. II, 1912, after slicing to show the very slight rot. The specks in the rotted part are needle-punctures. In right lower figure there is rot in vascular ring at top near the pricks.

$\dagger \mathrm{H}$ iss Clara Jamieson isolated from Bact. xanthochlorum a non-fluorescent strain which retained this characteristic in subcultures on various media as long as studied (some months). On agar-plates the non-fluorescent colunies looked exactly tike the fluorescent ones.
} 
Several of the inoctulated potato tubers exposed dry at room-temperature $\left(26^{\circ} \mathrm{C}\right.$. $)$ showed a slight vascular infection (rot) extending in one instance a distance of $2 \mathrm{~cm}$. from the pricked area, but only visible close to the bundles. The check-pricked tubers remained sound. The experiments were made in August, i. $\epsilon_{\text {., on }}$

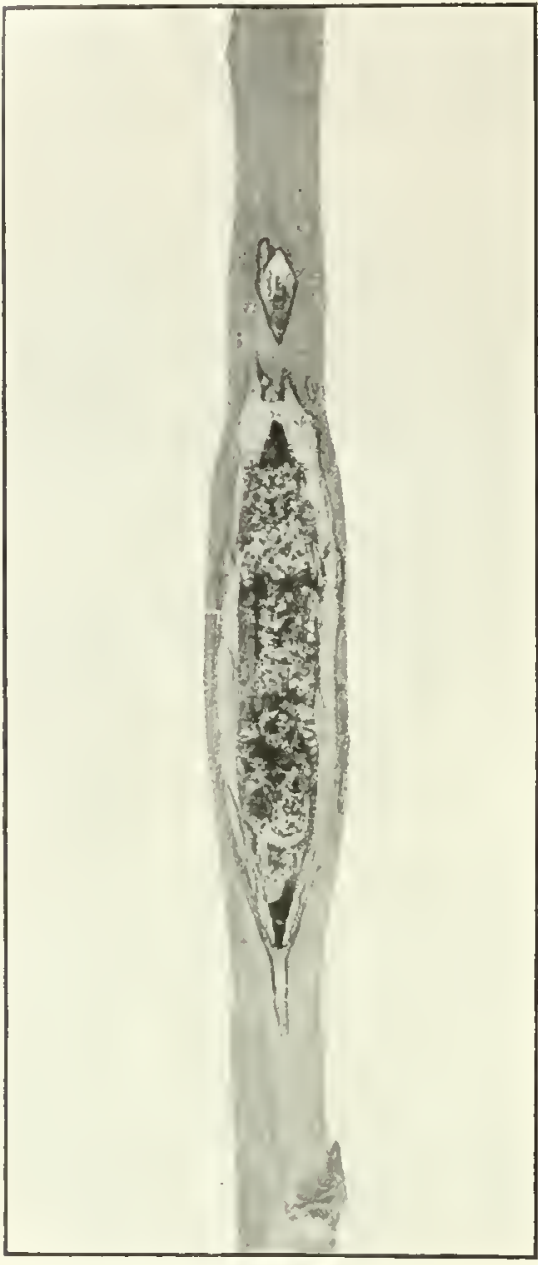

Fig. 136.* tubers recently harvested (fig. I35), and part of a lot which rotted quickly when exposed to B. melanogenes. Miss Nellie Brown repeated this experiment for me on several potato tubers with the same result.

Dr. Schuster's figures also call for some interpretation or explanation. I am inclined to think they do not represent what actually took place in the tissues; by this I mean that some of them are suspiciously diagrammatic. Scliuster's text figure No. I I, for instance, can hardly represent a stomatal infection in Vicia faba. Here the bacteria are represented as forming a branching strand which has entered through the stoma and penetrated to the opposite side of the leaf in a very unustual way, $i . \epsilon$, by boring its way through cell-walls. It has conspicuously avoided the intercellular spaces, and the surrounding cells are not only unoccupicd by the bacteria but also uncollapsed and apparently uninjured and the leaf has retained its turgor. I am told that Dr. Schuster did not make these drawings, but he ouglit, at least, to have supervised them, since professional artists seldom have an eye for details of plant structure. In an unusual case like this, a plotomicrograph would have been more convincing.

The subject is left in such sliape that some careful bacteriologist should repeat all of Schuster's experiments, and make others; only in this way shall we finally come to know what weight to give his statements.

On a few of the many plants of Vicia faba inoculated by me where the needle-inoculations were not far apart, and one above another, the rapidly growing stems cracked open with callus-formation not unlike that figured by Schuster for Lupinus, but there was no evidence of disease due to the bacteria. These stems were about 15 inches high when inoculated and were 5 feet tall with numerous vigorons leaves and blossoms when the photograph was made (fig. 136).

\section{LITERATURE.}

1912. Schuster, Julius. Zur Kenntniss der Bakterienfäule der Kartoffel. Arbeiten ans der K. Biologischen Anstalt f. Land. u. Forstwirtschaft, vill Bd., 4 Heft, pp. $+52-492$. I plate, 13 figs. Berlin, 1912.

1912. SMITH, ERWIN F. Isolation of pathogenic potato bacteria: A question of priority. Phytopathology, vol. II, p. 213, Oct. 1912.
1913. Brown, Nellie A., and Jamieson, Clara O A bacterium [Bact. aptatum] causing a disease of sugar-beet and nasturtium leaves. Jour. Agric. Rescarch, U. S. Dept. of Agric, vol. 1, No. 3, Dec., 1913, with 3 pls. (one-colored), pp. 189-210. That part relating to Schuster's organisin begins on page 209.

*FIG. 136.- Stem of I'icia faba, 2.5 months after inoculating with Schuster's Bacterium anthochlorum, showing tissue cracked open, with callus furmation along the line of needle-pricks. $X_{1}, 75$. 


\section{THE DUTCH DISEASE OF WALLFLOWER.}

In the sumner of 1900 , in Holland, van Hall fonnd a disease of the wallflower (Cheiranthus) which was characterized by the constriction of the upper part of the tap root, followed by yellowing of the leaves, which gradually fell off, first the lowest, then those farther up the sten. Cross-sections of the constricted portion of the tap root showed the wood to be brown or black, and the vessels of the wood to be occupied by bacteria, which were traccd upward into the branclies. Professor Beijerinck proved, it is said, that all of these were one sort. "Infection experiments have not yet been published, so that this disease must be placed with the incompletely known ones."

Later Briosi and Pavarino published on a sinilar Italian disease of stock (Matthiola), as described in the following chapter.

\section{LITERATURE.}

1902. VAN HaLl, C. J. J. Ziekte der Zomerviolieren, Cheiranthus annuus. In "Beijdragen lot de hennis der Bakterieele plantenziekten." Academisch Proefschrift, Amsterdam, 1902, p. 72.

\section{THE ITALIAN DISEASE OF STOCK.}

In 1912 Briosi and Pavarino described a vaseular and parenchymatic disease of the common stock (Matthiola annua L.), prevalent in parts of Italy and attributed it to a greenfluorescent bacterium. The following translation gives the substance of their paper:

'T"wo different species of crueifers are commonly designated by the name "Violacciocca:" 'I"he Cheiranthus cheiri L.., which is the common violacciocea, and the Matthiola annua L.., commonly called quarantina.

Of this latter there are some varieties of notable commercial importance, cultivated on a large scale, especially in many sections of the Lignria, where entire fields are covered with them, and furnish abundant and splendid winter flowers for exportation.

Some years the II atthiola quarantina shows signs of a grave disease, which spreads rapidly and canses such damage in some localities that it is necessary to suspend its cultivation.

T'he signs of the disease begin with the appearance on the leaves of spots of a pale green color, of indefinite contonr, which at first are observed witl difficulty. Following this there appear small brown spots of irregular contour, and more or less punctiform, scattered over the petiole.

Irrequently the leaves, especially the young ones, become more or less deformed, not attaining the normal dimensions, and their margins curl toward the upper surface.

The inflorescence is arrested in its development and becomes rachitic, and so the flowers lose their commercial value.

The researches were made on plants gathered by us, in varions localities such as Loano [on the Riviera, about halfway from Genoa to Ventimiglia], where some years the disease is active and widespread.

IIorbid anatomy.-The disease is not linited to the leaves, but extends to all the organs of the plant: flowers, branches, stalks, and roots.

Sectioning young branches, it is found that the infection invades first the woody vessels, which slow yellowing or browning and are more or less altered.

The plant forms a zone of corky tissue which twists and circles about the infected vessels, to prevent the spread of the disease in a transverse direction, and linit the diff usion of it in the tissne. Later the disease is able to invade all the wood as far as the pith, which, in some cases, is seen to be strongly corroded.

In the stalk the infection appears first in the primary wood, from which it extends interiorly toward the pith, and externally toward the secondary wood, as is clearly shown by the yellowing and browning of the walls of the ressels and of the fiber, and by the yellow, brown, or black coagulated substance which fills up the lumen of the cells of the diseased tissues. 
In the roots the infection begins generally in the woody bundles of the central cylinder, and from there spreads to the secondary wood; and the attacked elements (vessels, fiber, ete.) color as usual either yellow or brown, beconning filled at the same time with the clotted, blackish substance.

In the leaves the infection manifests itself by the pale spots above described, which are due to the disorganization of the chloroplasts through work of the microorganism, which multiplies rapidly in the cell. With the advance of the disease the protoplasm of the cell contracts and shrinks, eausing the collapse of the cell walls; from this time on the tissue decays and there appear in the mesophyl the brown and depressed spots which we have already noted on the petiole in advanced disease.

Microscopic examination shows in the cells of the diseased tissues numerous motile microorganisms, isolated and united in colonies, but does not reveal any trace of mycelium.

We have cultivated this organism in many nutritive media, proceeding in the following manner: We took small pieces of the leaves, branches, stalks, and roots, carefully washed them with water and soap, and afterwards disinfected then with a solution of $\mathrm{i}$ : 1000 mercuric chloride; they were then put into sterile distilled water and passed finally through alcolol and ether.

The pathological pieces thus treated were put into tubes containing nutritive media of our preparation, and from all the infected organs thus treated and sown in the different nutritive media, we obtained always the development of a particular microorganism, which presented the following morphological and cultural characters:

Microscopic aspectand colorability. - This microorganism has the form of a small rodlet-length 2 to $4 \mu$, width 0.4 to $0.6 \mu$, with the ends slightly rounded. It stains well with all the anilin stains, even cold, but especially with gentian violet; it resists Gram completely.

In broth cultures we observed vivacious vibratory and rotary movements of the microorganism, which appeared in the form of rodlets or of spherules, according to the position in whiel observed.

Relation to orygen. - In anaerobic conditions the microorganism does not develop at all, or only witli great slowness, which indicates that it is prevailingly aerobic.

Behazior in regard to temperature and to mutritive media. - It develops well at room temperature $\left(15^{\circ} \mathrm{C}\right.$. circa), but more rapidly in the thermostat in the various 1utrient media, and especially in neutral conditions.

Gelatin cultures.--In 24 hours at room temperature it forms, in stab-cultures, a cup of initial liquefaction which progresses rapidly in eylindrical form until all the gelatin is liquefied. On the surface of the culture there is then formed a pellicle sufficiently thick that it detaches itself on agitation, falling to the bottom as a whitish, mucilaginous precipitate, and the liquid becomes a beautiful light green color in the upper part of the tube.

igar.-On glyecrinated streak-agar cultures there develops, after 48 hours of incubation, a whitisli surface growth little extended and slightly elevated, not shining.

In stab-eultures the development is still nore scanty; after 48 hours' incubation, the stab-growth is scarcely risible; growth soon ceases.

In plain agar the organism develops rather better. In streaks, in 24 hours, it forms a wetshining, surface growth, rather elevated, with lobed margin, of a whitish color, and with a tendency to nccupy all the frce surface of the tube. In stab-cuitures the growth extends to the bottom of the tube, at the surface enlarging into the form of a whitish disk, in the center of which appears in time a roundish, yellow spot.

Broth-eultures. - In alkaline broth it develops poorly, with slight turbidity and formation of a scanty deposit; in the upper part of the tube the liquid assumes a pale green color.

In plain broth the development is more rapid and vigorous; in 48 hours of incubation the entire culture is uniformly clouded, with an abundant dirty white sediment, which in time becomes a pale yellow. At the surface and along the walls of the test-tube a pellicle forms which detaches itself easily; the liquid assmunes a light green color.

Potato-cultures.- At the temperature of the incubator there develops, in 48 lours, a gray-white growth, wet, rather elevated, with a tenclency to spread. With age the culture assumes a granular aspect with a pale yellow color, tending toward brown.

Chemical activity.--In the tubes an offensive gas develops, but not liydrogen sulphide, as we were able to verify by exposing above the eultures a small strip of lead acetate paper previously exposed to the vapor of ammonia.

Irtificial reproduction of the disease.- To prove that the disease was really due to the pathogenic action of the microorganism of our isolation, we infected some vigorous plants of Matthiola, spraying them with broth-cultures, very much diluted.

At the end of a few days we obtained the reproduction of the disease on the aerial part of the plants sprayed, with the sane external characters and the same anatomical alterations (in the leaves and in the young branches) which we have described in the plant naturally diseased. 
The infection rapidly spreads on the leaves and branclies, extending to the inforescence, which dries up conpletely. 'The plants can throw out other floriferous branches, but of poor development and with few flowers.

We tried also infection through the roots, bathing with a pure-culture solution the soil of some pots in which were healtlyy plants, but not a single sign of disease was observed at the end of two nionths. For the infection of the roots perhaps wonnds are necessary.

We are able to establisl that the more common manner of infection is througl the stomata, as plainly shown by the pale yellow coloring which spreads from the stomata to the surrounding cells, in whicl we observed the usual disorganization of the chloroplasts and of the protoplasm.

From the organs infected artificially we repeatedly nade cultures in varions nutritive nedia for the identification of the morphological and cultural characters of the nicroorganism of our prececling isolation and description.

Thlis organism nust be regarded as a new species, to which is given the nane Bactorium malthiolae $11 . \mathrm{sp}$.

The same year Briosi and Pavarino published a second paper (Bacteriosi della Mattiola anma L.), which is exactly the same as the one just reviewed, except for the following additions:

The stab growth in plain agar is described as ciliated (cigliato).

I gar plales.-(Natural size.) After $+S$ hours' incubation the surface colonies are round, margins smooth. 'They are slightly raised, but not transparent, and of a whitish color. T'le buried colonies may be roundish, but for the most part have the form of a whetstone.

Enlarged 50 diameters. - The surface colonies appear roundish, radiate, with transparent contour, and of a yellowish color. The buried colonies may be roundish, but for the most part are like a whetstone, always smaller and of a darker yellow color.

Under plain brolh the sediment is described as viseous.

Milk-cullures. - At a temperature of $30^{\circ} \mathrm{C}$. the coagulation is complete on the third day witl decidedly acid reaction to litmus.

Specific and practical methods for the cure of this disease are unknown. We made tests with the usual sprays, using copper sulphate as the base (Bordeaux mixture), but the results obtained were negative. Perhaps such treatments might be effective applied as preventives sonetine before the flowering period, with additional sprayings afterward.

A good practice to follow is that of extirpating the plants as soon as they present the symptons of the disease.

The extirpated plants should not be permitted to accumulate on the land, where when dried they can be easily transported to a distance by the wind or by animals, but should be carried out of the field and destroyed by fire. Likewise, in order to prevent the infection being carried back by neans of stable refuse, these extirpated plants must not be thrown on the manure heap.

The rotation should be modified so that the culture of the stocks is not repeated on soil where the disease appeared the preceding year. To prevent the disease being transmitted from one year to another, it is rather useful to employ accurate seed selection, using only seed that has come from healthy plants, and from fields remaining inmune to the infection. And since it has been demonstrated that germs of bacterial diseases frequently are able to continue to live on the seed during the winter season, it woukd be nseful also in the present case to disinfect the seeds, inmersing them for 15 minutes in a solution of 1:1000 mereuric chloride, or in a solution of formalin $1: 50$ for 20 minutes. This practice ought to be completed by the selection, according to the method of Nilsson, in the field of those individuals which show more resistance to the disease. Finally, it would, perhaps, render the plant more resistant to the disease to avoid abuse of organic fertilizers, and to have recourse to use of potassitum fertilizers, and especially the superphosphate.

The writer has had no opportunity to study this discase at first hand. Some samples of stock supposed to show this disease were received from Italy, but it proved to be sonfething else.

\section{LITERATURE.}

1912. Briosi, G. and Pararino, L. Una malattia batterica della Wuthiola unnua L. (Bucterium mutthiolue 11. Sp.). Atti della Reale Accademia dei Lincei, Rendiconti, vol. xxr, Fasc. 3, Rome, August, 1912, pp. 216-220.
1912. Briost, G, and I'AVARINo, 1. Bacteriosi della Mathiola unnua $\mathrm{I}$. (Bacterium mothinlac n. sp.). Atti dell Istituto Botanico della R. Università di Pavia, Serie II, vol. XV, Milano, $1912, \mathrm{pp} .135^{-\mathrm{I}}+\mathrm{r}, 2 \mathrm{pls}$. (colored). 


\section{THE BRAZILIAN DISEASE OF MANIHOT.}

In 1912 Gregorio Bondar, of the Agronomical Institute at Campinas in Brazil, described a disease of Maniliot that appears to belong here. I translate from his Portuguese leaflet, with sone liesitation, as follows:

The sweet mandioca (1/anihot pulmuta), varieties white mandioca and aipin mandioca, has been with us subject to a disease which apparently has not been met with in other countries.

'This rot of the stalks and the shoots (brótos) is caused by bacteria, Bacillus manihotus ArthaudBerthet.

The disease was studied at the Agronomic Institute in Campinas by the [former] Director, Dr. Arthaud-Berthet with our collaboration. 'The microbiological study was verified in the bacteriological laboratory by the specialist Dr. A. Perrier.

In the Mandioca aipim the effects of the disease are as follows: 'The young shoots (brotos) rot internally, wither, and die. By the transparency of the bark one can perceive dark subcortical lines which follow the bundles. Removing the bark one observes that these lines start from the subterranean stalk, which becones rotten in a line corresponding to the shoot (bróto) or presents the bundles (canaes) black, infected. In the young shoots (brótos), the bundles (canaes) presently decompose (fig. $138, b$ ), injuring the circulation of the sap and causing the withering. The disease may attack the shont on a single side, but presently gencralizes itself in other bundles (canaes). In young plantations the disease occasions the death of the plants.

In the wlite Mandioca the signs of the disease differ: The shoots present subcortical swellings which are produced in the bundles by the coagulation of the latex (fig. $138, a, b$ ). 'These swellings are clongate. 'The subcortical accumulation

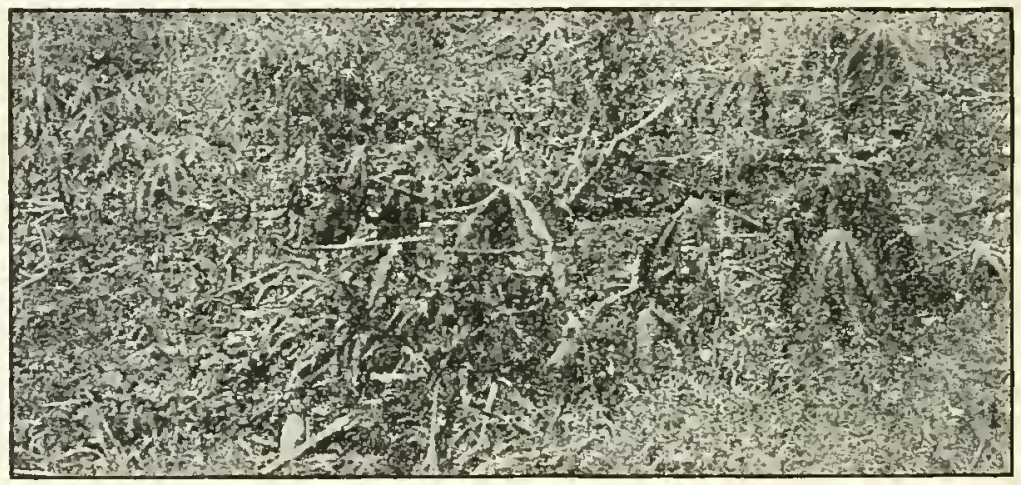

Fig. 137.* breaks the bark and the gummy substance exudes, forming small superficial crusts, of a light yellow color (amarello-clara) at the beginning, and afterwards reddish by oxidation.

If the discased shoots were (estiverem) grown on the stalks of the past year the black markings of the disease run through even to the subterrancan part without, however, forming gummy swellings.

The roots do not manifest any signs of disease. In a planting of ten months we observed that these roots were able to send out the shoots three or four times, which succumbed successively to the bacteria, until the roots were completely exhausted, dying directly afterwards.

We made numerous artificial inoculations of the disease. The healthy shoots, inoculated artificially with virus from the diseased plant, presented the same symptoms of disease after 15 or 20 days' incubation of the bacteria.

The cuttings, infected with the bacteria before planting, died, rotting in the earth without budding. Of 20 infected cuttings not a single one grew.

The experimental work on the clisease, as also many observations, were made in collaboration with the Chefe de Culturas do Instituto, Sr. Joao Herrman.

Attacking old stalks, with the roots formed, the bacteria bring about exhaustion of the accumulated starchy substance.

The roots of the diseased stalks are unfit for food, for they are very hard, even when boiled two or three times as long as the ordinary mandioca.

The chemical composition varies greatly also. The anay'sis mache by Sr. R. Bolliger, in the Agronomic Institute in Campinas, revealed a noticeable diminution of the starchy substance: Instead of

*FIG. 137.-Brazilian manihot wilting from bacterial disease. (After Bondar.) 
73.I 3 per cent of starch in the dry material as in the normal inandioca, there was scarcely 63.90 per cent in the diseased mandioca. The observations show that the disease attacks very often the cuttings (mudas) of mandioca, when they are made very long before planting. In this case the tips of the stems begin to rot. As the circulation of the sap occurs even in the cut stenis, the contagion propagates itself in the bundles (canaes) without leaving external signs. The slips cut from strcli stems die for the greater part, and on the other liand, are liable to contaminate others.

The disease is grave, contagious, easily propagated, inoculable, and can be transmitted by insects. If care is not taken it may cause considerable injury to the cultivation of this plant of ours, which is of general inse.

Witl some cultural precautions the malady may be avoided or lessened in severity.

Curative treatment can not be applied, since the disease is internal, and generalizes itself directly in the plant.

The preventive measures which we advise, in order to avoid tle propagation of the plague, are as follows:

I. Plant resting shoots (mudas) absolutely not suspected, conning from healthy plantations, rejecting all doubtful stalks.

2. Cut the cuttings (estacas) with the greatest care, without tearing or wounding the tissue, in such a manner as to reduce the surface and

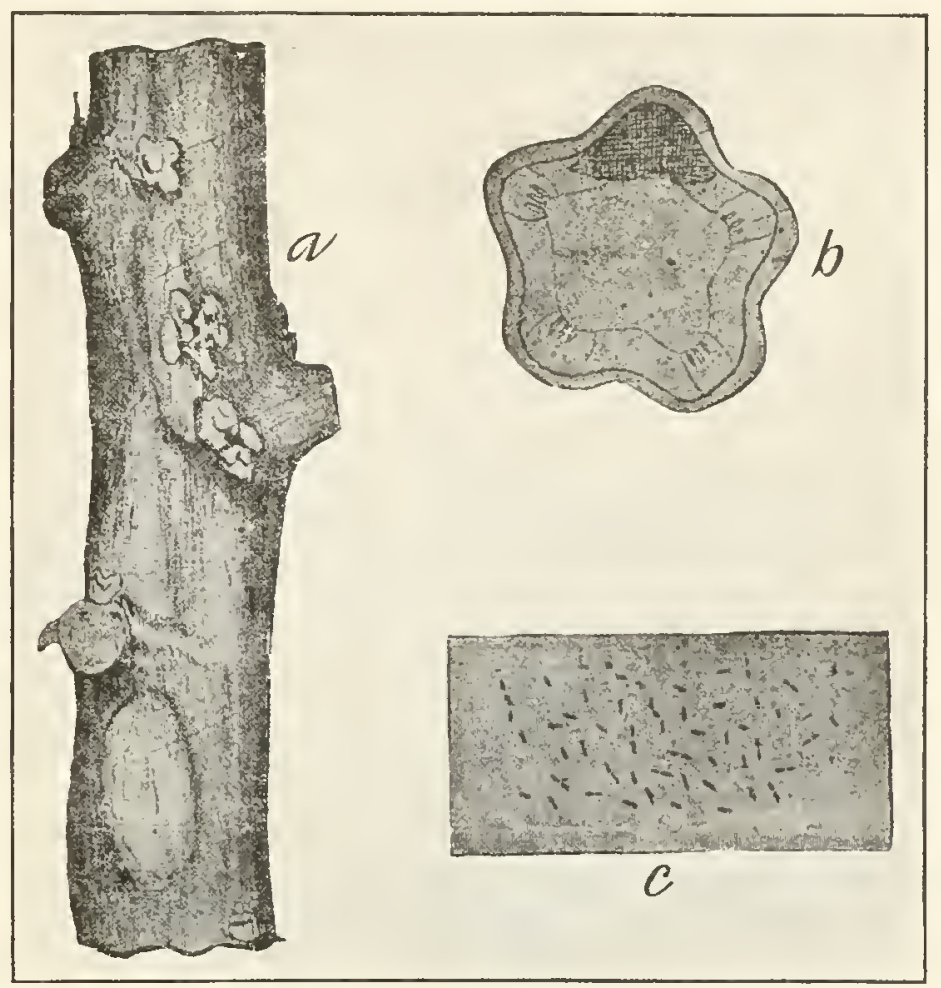

Fig. 138.* the possibility of contamination.

3. Do not plant the mandioca in soil infected by preceding diseased plantings, but cultivate other things not subject to contamination by the same bacteria.

4. Plant the cuttings as soon as possible, in order to aroid the contamination which occurs easily during the period of slow growth.

5. Plant resistant varieties: Mandioca parda and Mandioca azul resist better than the Mandioca branca and aipim.

The bacteria are found in pure colonies under the bark, in the young swellings. The isolation of the microbe, likewise the artificial inoculation of the plant, show, fortunately, that there are present no other bacterial diseases.

A more extensive account of this disease was prepared, but its publication has been delayed.

\section{LITERATURE.}

1912. Bondar, Gregorio. Uma nova molestia bacteriana das hastes da mandioca. Chacaras e Quintaes, vol. v. No. 4, April 1912, pp. 15-18, 3 figures, Brazil.

*FIG. I38. - Stem of manihot attacked by bacterial diseasc. a. Bacterial blisters and exudate. b. Cross-section of stem showing location of the diseased part (at the top). c. Bacillus maniholus A. Berthet, from a diseased manihot plant. $\times_{1,000}$. (After Bondar.)

IThe photographs and drawings in this volume, as in Volnmes I and II, were made, with a few exceptions, by James F. Brewer. The writer, however, selected the parts to be drawn, or photographed, and fiually checked up under the microscope nearly or quite all of the drawings. With exception of figs. I and 2 of plate 11 , the colored figures were also made by Mr. Brewer. The color chart, referred to in various places as "Ridgway," is the first edition of Robert Ridgway's Nomenclature of Colors for Naturalists.] 


\section{ADDENDUM.}

The following observations were made too late for insertion in the body of the text:

(1) Aplanobacter michiganense vs. Apl. rathayi.-Both liquefy gelatin slowly, but the latter liquefies the more rapidly and the surface growth (streak) floats about in the nearly clear fluid as a twisted ribbon. Apl.michiganense, on the contrary, clouds the fluid.

(2) Peanut wilt.-In June, 1914, we obtained bacterial wilt of peanuts using both Medan III and Florida potato (isolation of 1914). Inoculations were by needle pricks on stems; the time between inoculation and appearance of disease was about two weeks; great numbers of bacteria were seen in the tissues. Subsequently the wilt of peanut was also obtained by inoculating from a pure culture of the Creedmore, N. C., tobacco organism.

(3) Tobacco wilt.- This was obtained in June, 1914, using Filorida potato (1914), Florida tobacco (1914) and Creedmore, N. C., tobacco (1914). The inoculations were by needle pricks from pure cultures (subcultures from poured-plate colonies) on stems and leaves. The time between inoeulation and appearance of disease was about 4 to ro days.

(4) Bact. solanacearm-Effect of drying. - On cover slips Medan III and Florida potato (1914) were dead at the end of 6 to 9 days, $i . e_{\text {. }}$, refused to grow when thrown into peptone-beef bouillon. These cover slips were wetted from young peptone water cultures and were kept in the dark in a eovered Petri-dish at room temperatures (of June). Subsequently tests with the Creedmore tobaceo organism (1914) and the Florida tobacco organism (1914) showed all dead on the 6th day or earlier. The tests were begun on the 5 th day, at which time the organism was alive on a few of the cover glasses, $i$. $e$., I out of 8 in Creedmore and 2 out of 8 in Florida. Tests on the 6 th, 7 th, and 9 th days showed all dead. The covers ( 64 in all) were wet from cloudy 24 -hour-old peptone water cultures and kept in the dark, in sterile Petri-dishes, in the well ventilated laboratory at room temperatures (of July). The covers were thrown into tubes of +14 peptone bouillon.

(5) Bactcrium solanacearum in litmus milk +cream.-Medan III always reddens this medium. It may therefore be known as var. Asiaticum nov. var. None of the American isolations of 1914 (Florida potato, Florida tobaeco, and Creedmore tobacco) have done so. (Experiments continued 4 to 8 weeks, using subcultures from 15 colonies.)

(6) Bacterium solanacearm in Meyer's solution + Am. lactate.-With Medan III and Florida potato (1914) at the end of 4 weeks there had been no growth.

(7) Bacterinm solanacearmm in Meyer's solution + Asparagin.-At the end of 4 weeks, 4 of the 8 tubes of Medan III clouded. All of the Florida potato (1914) remained clear.

(8) Bacterium solanacearm in Meyer's solution $+\mathrm{KNO}_{3}+$ Sodium acetate;

$\begin{array}{lll}\text { Do. } & \text { Do. } & \text { Do. }+ \text { Sodium lactate. } \\ \text { Do. } & \text { Do. } & \text { Do. }+ \text { Sodium butyrate }\end{array}$

Neither Medan III nor Florida potato ( $19 \mathbf{I}_{4}$ ) would grow in these media. Test of 4 weeks.

(9) Bact. solanacearm inoculated on Livingston's Dwarf Aristocrat tomato. On page I89 (exp. of 1905) the statement is made that of many varieties tested the above named was most susceptible. Fearing this might be an accident, the experiments were repeated in July, 1914, using four strains of the bacteria: Medan III, Florida potato (1914), Florida tobacco (1914), and Creedmore tobaceo (1914). In all 24 plants were inoculated, 6 from each strain. All except Medan III were wilting or wilted on the third day with enormous multiplication of bacteria in the tissues. The inoculations were made on young plants showing two good leaves (besides the cotyledons) and four when collected. The pricks were made with a fine needle; most of the punctures were made on petioles. Older plants were not available. The check plants remained sound. These plants contained 93 per cent of water. This experiment was repeated a few days later with similar results.

(10) Loss of I'irulcnce. Medan III, lost much of its virulence during 12 months cultivation in the laboratory without reinoculation into plants, $i . e$, then it was less active on tobaceo and on tomato than the recent (19/4) isolations from American sources (Pl.45). 


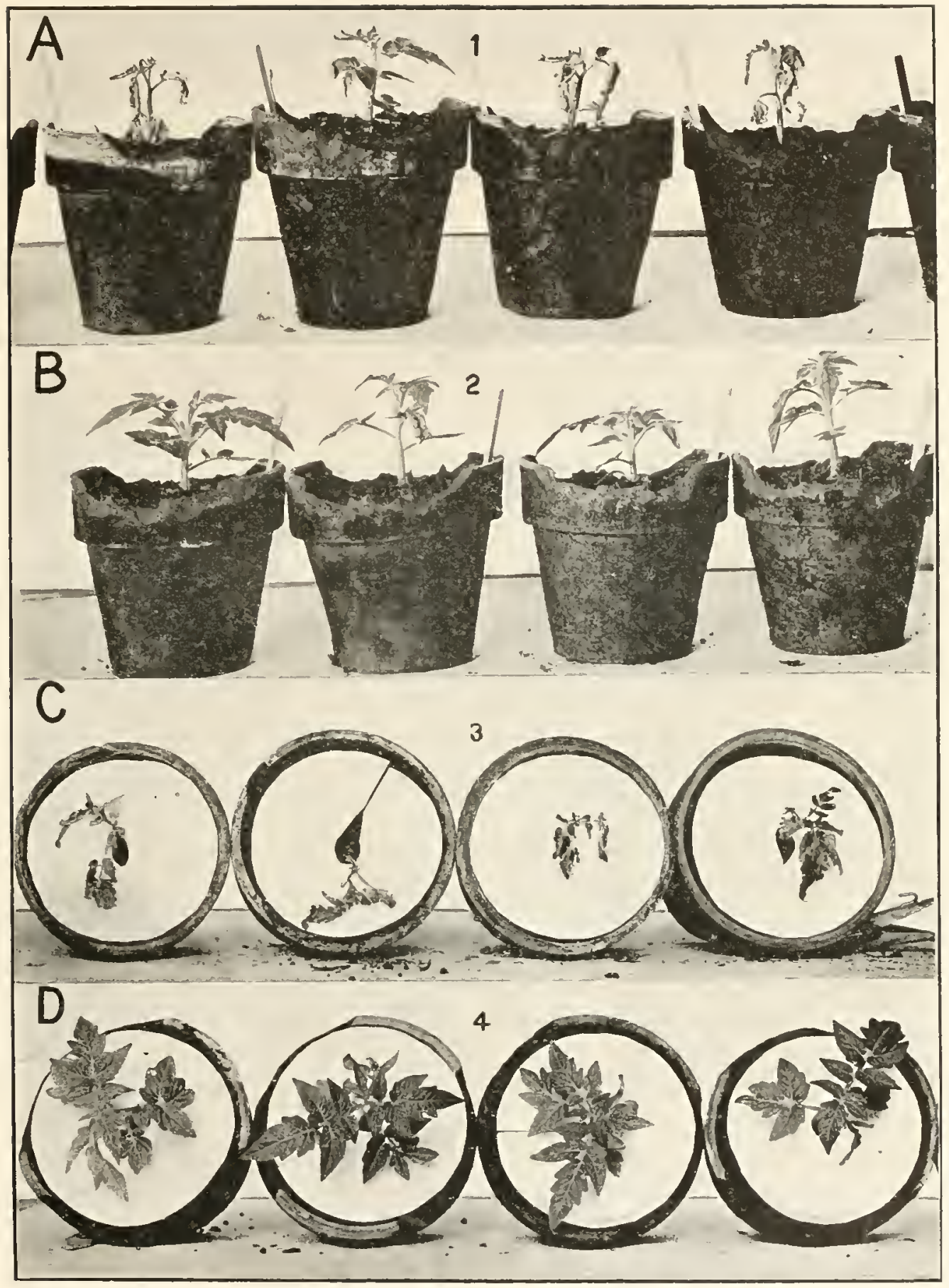

Isoss of Virulence in Bacterium solanacearum.

Livingston's Dwarf Aristocrat tomato after infection with Bacl. solanacearum. Each plant was inocnlated on one petiole by means of delicate needle pricks from a 3-day agar culture. Plants in hothouse subject to $\pm 35^{\circ} \mathrm{C}$. (July temperatures), and alike. $A B$, end of 5 days; $C D$, end of 7 days.

(1) Florida potato $(1914)$. Organism on culture media about 2 months, and still actively viruleot. There were two more

in this set, both badly wilted.
(2) Medan III (19:3). Organism on culture media ahout $\mathrm{I} 2$ months. It was isolated by Honing in the summer of 1913 and was extremely virulent when received, and for several months thereafter, but is now weak (see page 179).

.

(3) Credme

(4) Same as 2. Io each of the 6 plants the inoculated petiole was now wilting. 


\section{N D E X.}

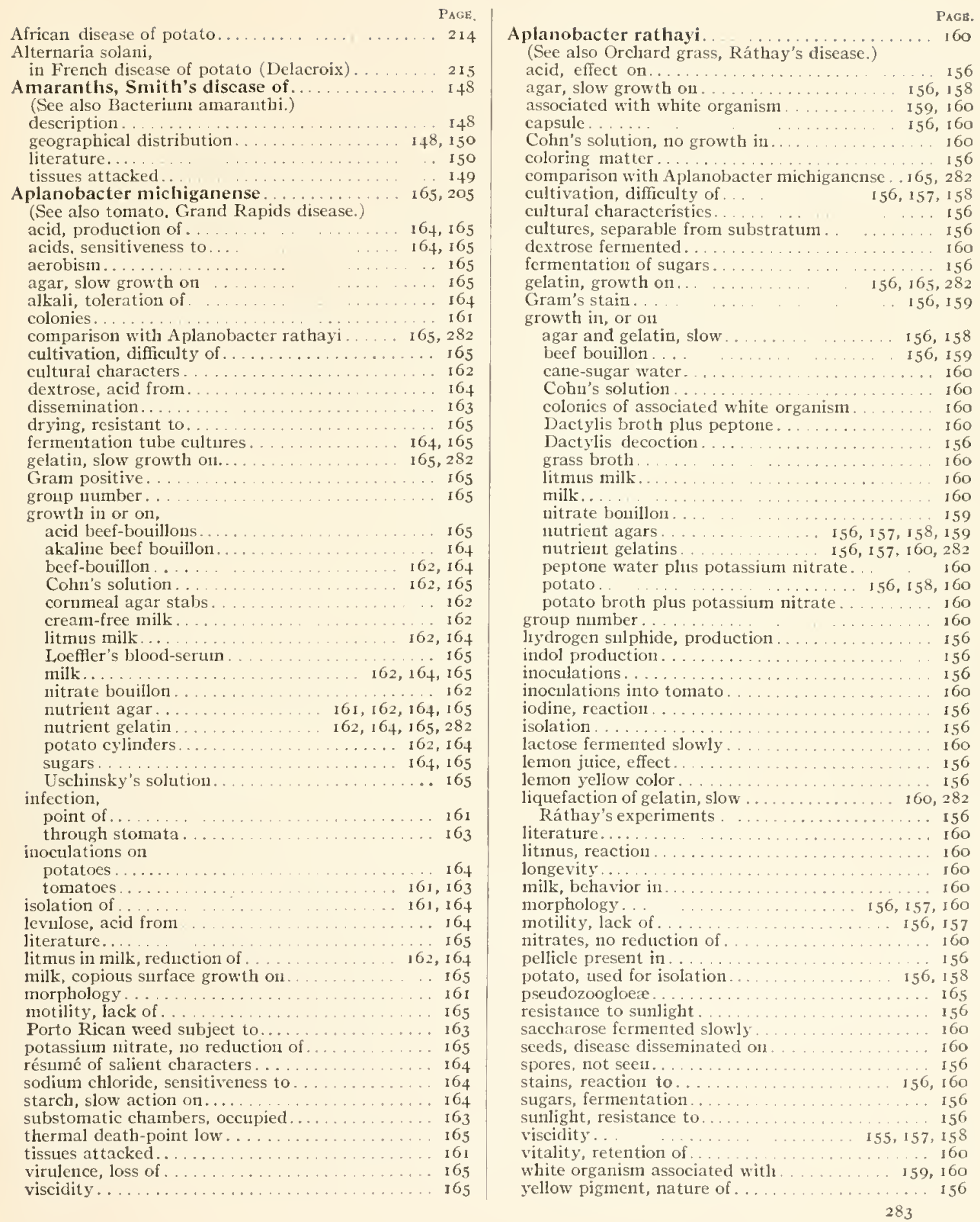


Appel,

Bacillus phy tophthorus, formation of cork barrier. I92 "black-leg," cause of

ring disease of potato, Germany.

(See also Solannece browth rot, ring disease of Germany.)

Arachis hypogaea, wilt

I 5 I, I 53, 253, 27 I

(See Bacterium solanacearum, peanut-wilt organism; peanut wilt, Sumatra; peanut wilt, United States: peanut wilt, van Breda de Haan's.)

Arrowing of sugar-cane

Arthayd-Terthet, Brazilian disease of Mlanihot ...

Asliby, Panama disease of banana reported from Jamaica .

Australian disease of potato and tomato.

280

(See also Tobacco, wilt diseases, French disease.)

eultural characteristics.

Gram's stain

inoculations

morphology

synonomy

Bacillus amylobacter, tobacco root-rot, Comes.

Bacillus amylovorus,

compared with Bact. solanacearum, color.

growth in beef-broth concentrated and strongly acid.

growth in potato broth with malic acid..... .. 136

Bacillus atrosepticus.

Bacillus brassicaevorus, sy'ronomy

Bacillus caulivorus.

synonomy.

Baciltus cloaca

Bacillus coli,

sodium chloride, toleration for

266

266

266

266

267

270

Gram's stain, reaction to

Bacillus fuorcseens liquefaciens, synonony
Bacillus fluorescens putridus, synonomy...

Bacillus glagae.

Bacillus manihotus

(See also Manihot, Brazilian disease.)

inoculations

literature.

occurrence, pure, in subcortical swellings

Bacillus marcescens

Bacillus megaterium, isolated from diseased tobacco. 269

Bacillus melanogenes.

$175,203,276$

Bacillus mesentericus,

associated with Bact. solanacearum in Sumatra. . 259 resemblance to Aplanobacter rathayi . . ... 156

Bacillus musae.

bacterial ooze.

biological characters

cavities formed by

growth black on potato cylinders

growth on gelatin.

inoculations on

manila hemp

solanaceous plants

tomato

isolation

longevity, feeble

pathogenicity, quick loss of

similarity to Bacillus solanacearum

tissues attacked.

(See also Banana, Rorer's 'Trinidad disease.

Bacillus mycoides, associated with Bact. solanacearum in Sumatra.

Bacillus mycoides roseus, isolated from diseased tobacco

Bacillus nicotianae Uyeda,

(See also Tobacco, wilt-diseases, Japanese disease.) acid, effect of.

acid-production

alkali, effect of
Bacillus nicotianae Uyeda-continued.

Page.

anaerobism....................238, 24

Bacterium solanacearum (potato and tomate-wilt organism), relation to ........... 244, 254

(See also "comparison, etc.")

Bacterium solanacearum (Sumatran tobacco-wilt organism), relation to

(See also "comparison, etc.")

blackening of,

agar cultures..................... 238

bouillon....................... 24

milk.............................. 241

capsules................... 241,247

colonies on agar................. 238,24I

colonies on gelatin................... 24I

comparison (Honing's) of Sumatran tobacco-wilt organism with Lyeda's description of B. nicotianae and Smith's and Uyeda's descriptions of Bact. solanacearum.... 247,248, 249,250, 251

(See also "similarity, etc.")

comparison (Smith's) with Bact. solanacearum Smith

$240,242,243,244$

(See also "similarity, etc.")

crystals, ammonium magnesium phosphate..... 24 I

cultural characters................ 238, 24 .

comparison with Bact. solanacearum, Smith's

observations................ 240, 242

cytase, production of . . . . . . . . . . . . . 242

description, Tyeda's ................ 238

possibly not drawn from one organism...... 244

diastase, presence of ................ 242

egg-plant, non-infection of . . . . . . . . . . . . 24 I

endospores................. 241, 243,247

enzymes, presence of ............ 241, 242

flagella ......................... $238,241,243$

gas-production.................. 238, 24I

Gram's stain, positive. . . . . . . . . . . . 24

growth on or in,

agar...................... 238, 24

asparagin-dex trose solution. ........... 2.42

carrot.......................... 242

gelatin..................... 238,24

glucose agar, gas from . . . . . . . . . . 238

glucose bouillon, gas from. . . . . . . . . . 238

milk..................... 238, 24

mono-potassiun phosphate plus magnesium sulphate, sodium chloride, dextrose, and ammoniwn chloride .................. 242

mono-potassium phosphate plus magnesium sulphate, sodium chloride, dextrose, and a mmonium tartrate ................ . 242

mono-potassium phosphate plus magnesium sulphate, sodium chloride, dextrose and aspara-

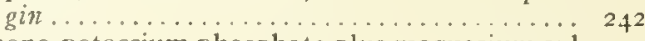
mono-potassium phosphate plus magnesium sulphate, sodium chloride, dextrose, and potas. sium nitrate.................... 2.42

mono-potassium phosphate plus magnesium sulphate, sodium chloride, glycerin, and ammonium chloride ..................... 24

mono-potassium phosphate plus magnesium sulphate, sodium chloride, glycerin, and ammoninm tartrate. ....... 242

1nono-potassium phosphate plus magnesium sulphate, sodium chloride, glycerin, and potassium nitrate. .

peptone-dextrose solution peptone-water, blackened............. 242 peptonized bouillon.............. 238,24 potato, yellow on .................. 238, 24 I radish, sharp odor on ................ 242

U'schinsky's solution................. 242

hydrogen sulphide, production of ........... 242 indol production. .............. 24I, 242 inoculations, Jensen's, failure of ............ 27 I 
Bacillus nicotianae Uyeda-continued.

inoculations, Uyeda's, on

A maranthus gangeticus ............... . 243

Capsicum longum. ..................... 243

egg-plant....................... 238

Lycopersicum esculentum............. 243

Physalis alkekengi.................. . 243

Physalis minimum.................. 243

Polygonum tiuctorum............... 243

Solanum melongena. . . . . . . . . . . . . . . 243

tobacco.......................... 238

invertase, presence of . . . . . . . . . . . . . . 242

liquefaction of gelati11............ 238, 241

literature.................... 270, 271

litmus, reduction of . . . . . . . . . 241, 242

maximum temperature................ 241

methylene blue, reduction of ........... 242

morphology .................. 238, 241

nitrate, reduction to nitrite............ 242

North American tobacco wilt, not found in ..... 229

odor........................ 238, 242

optimum temperature................ . 238, 242

pellicle, early appearance............ 24 r

pigment, solubility . . . . . . . . . . . . . . 241

pigment-production . . . . . . . . . . . . . . 238, 24 I

effect of temperature.......................

potato and tomato-wilt organism, relation to...244,254

(See also "comparison, etc.")

resistant varieties. .

similarity of tobacco-wilt organisms (Sumatra and

Japan) and Bact. solanacearum Smith, de-

scribed from potato and tomato...... 244, 254 (See also "comparison, etc.")

soil, depth of penetration in ............ 242 spores .................... 241, 243,247 staining, carbol fuchsin ................ 243

staining, Gram's method. .............. 24 I

Sumatran tobacco-wilt organism, relation to. 244,254

(See also "comparison, etc.")

temperature relations............ 238, 24 I

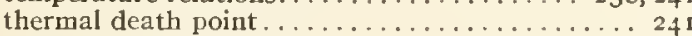

tomato, non-infection of ...............24

tomato and potato-wilt organism, relation to. 244,254 (See also "comparison, etc.")

trypsin, production of . . . . . . . . . . 242

tyrosinase, presence of . . . . . . . . . . . . . 24,242

Bacillus phytophthorus.

Australian disease of potato and tomato...... 208

Bacterium solanacearum, characters distinguishing

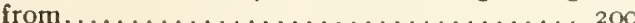

cause of Schwarzbeinigkeit ............ 175

formation of cork-barrier. . . . . . . . . . . . . 192

French disease of potato................. 214

growth on slices of raw potato............ 166

parasitism, active.................. 203

pathogenicity compared with that of Bact. xantho-

chlorum......................... 272

Russian disease of potato .................... 214

Bacillus prodigiosus, mixed culture inoculations on

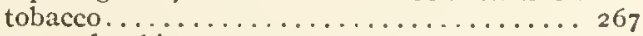

Bacillus pseudarabinus.................... 50

Bacillus putrifaciens putridus (tobacco pith-rot?)... 266 (See also Tobacco, wilt-diseases, French disease.) cultural characteristics . . . . . . . . . . . . . . . . 267 inoculations........................ 267

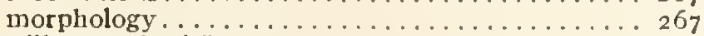

Bacillus sacchari Janse,

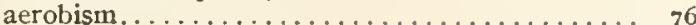

copper sulphate, effect.............................. 76

Debray's work..................... 76

growth in culture media............... 76

isolation.............................. 74

Janse's work.................... 74, 75 normal sugar-cane and other plants, presence in. . 75 resemblance to $\mathrm{B}$. subtilis............... 76
Bacillus sacchari Janse-continued.

PAGE.

Sereh, causal relation to ............... 75

spores...................... 76

Bacillus sacchari Spegazzini............... 86

comparison with B. marcescens.......... 87

comparison with Micrococcus prodigiosus Cohn.. 87

cultural charactcristics............... 87

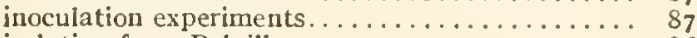

isolation from Polvillo. .................... 86

Janse's name earlier. . . . . . . . . . . . . . . . 86

morphology ............................. 87

red pigment produced .................... 87

relation to Bact. vascularum.............. 88

resemblance to B. sorghi............... 87

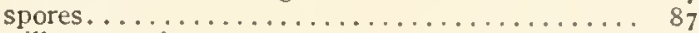

Bacillus sesami...................218

Bacillus solanacearum................ 178

(See Bacterium solanacearum.)

Bacillus solanincola............... 175, 214, 215

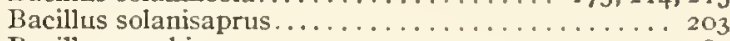

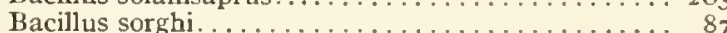

Bacillus subtilis,

growth on agar with Bact. solanaccarum from Sumatran tobacco.................. . 264 isolation from top-rot of sugar-cane ............ $8_{83}$ resemblance to $\mathbf{B}$. sacchari................. 76

Bacillus tabacivorus (tobacco collar-rot?)......... 266 (See also Tobacco, wilt-diseases, French disease.) cultural characteristics................... 266 inoculations. . . . . . . . . . . . . . . . . . . . 267 morphology . . . . . . . . . . . . . . . . 266

Bacillus tracheiphilus,

compared with Bact. solanacearum, color...... 194

growth in beef-bouillon............... 194

Bacillus vascularum

(See Bacterium vascularum; Sugar-cane, Cobb's disease.)

Bacillus vascularum solani

Bacillus vulgatus, resemblance to Aplanobacter ratliayi.

$207,208,218$

Bacterium amaranthi 156

See also Amaranths, Smith's disease.

alkali, production. .................. 149

cells occupied by . . . . . . . . . . . . . . . . . . . I I99

color of ....................... I 49

gas production, not seen .............. 149

growth on,

Loeffler's blood-serum. . . . . . . . . . . . . . 148

potato cylinders.................... I . I48

sugar-beet cylinders . . . . . . . . . . . . . . . I 149

isolation. . . . . . . . . . . . . . . . 148

literature....................... 150

morphology . ..................... 149

starch, slight action on................. . 149

tissues occupied........................ 149

Bacterium aurantium roseum, associated with Bact. solanacearum in Sumatra............. 259

Bacterium campestre,

browning of bundles................ 90

chloroform, marked effect of ................ 143

comparison with Aplanobacter michiganense. 161,164 growth in or on,

beef-broth concentrated and strongly acid.... I 36 cabbage juice.

distilled water plus dipotassium phospbate, nlagnesium sulphate, ammonium phosphate and sodium acetate.

Dunham's solution plu.................... 137

Loefller's blood serum. ................ 148

nitrate bouillon . ................... I38

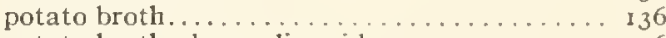

potato broth plus malic acid .............. 136

potato cylinders, copious............67, 148

rutabaga....................... 135

tomato juice...................... 136 
Bacterium campestre-coutinued.

growth on yellow turnip.

infection through water-pores.

pigment, brown

potato-starch, action on

retarding influence of litmus neutral gclatin.

size compared with that of Cobb's Bacillus vas. cularum.

starch, strong action ot

wind, not borne by...

Bacterium deliense, associated with Bact solanacearum in Sumatra. . .

Bactcrium diantli, growth in potato broth with malic acid

Bacterium gunmis,

tobacco-rot, Italy . . . . . . . . . . . . . . . . . . . . 266

tomato disease, Italy . . . . . . . . . . . . . 203, 215

Bacterium byacinthi,

acids, toleration of

alkalies, toleration of

138,144

growth on or in,

agar.

bee -broth concentrated and strongly acid

Dunham's solıtion plus rosolic acid

nitrate bouillon

nitrogen

potato broth. .

potato broth plus malic acid.

potato cylinders.

rutabaga.

lesions produced by

min.mum temperature

morphology

pota.o-starch, slight action on

Bacterium langkatense, assoriated with Bact. solanacearum in Sumatr

Bacterium matthiolae,

(See also Stock, Italian disease.)

aerobism.

colonies

gas-production

Gram's stain

growth on or in.

agar.

alkalinc broth

broth.

gelatin

glycerin-agar

milk.

potato

infection, manner of

inoculations

isolation

liquefaction of gelatin

literature.

morphology

motility .

reaction of media most favorable

stains, reaction to

temperature relations

Bacterium medanense, associated with Bact. solanacearum in Sumatra.

Bacterium megatherium, renders tobacco bacterium non-infectious

Bacterium michiganense

(See Aplanobacter michiganense.)

Bacterium mori

Bacterium patcliforme, associated with Bact. solanacearum in Sumatra.

Bacterium phaseoli, growth in or on,

beef-broth concentrated and strongly acid

cabbage-juice.

Hutger's agar, heaped up

potato brotli.
PAgE.

Bacterium pbaseoli-continued.

growth in or on-continued.

potato broth plus malic acid.... ... . . 136

potato cylinders...................... 67

Bacterim pruni, growth in Uschinsky's solution... 137

Bacterium rangiferinum, associated with Bact. solanacearum in Sumatra................ 259

Bacterium sacchari.................. 50

Bacterium shuffneri, associated with Bact. solanacearum in Sumatra................ 259

Bacterium solanacearum (Deli strain),

[See Bact. solanacearum (Sumatran tobacco-wilt organism).]

Bacterium solanacearum (Indian tobacco-rvilt

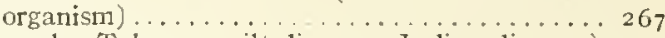

(See also Tobacco, wilt-diseases. Indian discase.)

bipolar staining. ................. 267

culture medium, effect on virulence........ 267

growth on or in,

agar............................. 267

bouillon.......................... 267

gelatin....................... 267

glucose bouillou. . . . . . . . . . . . . . . . 267

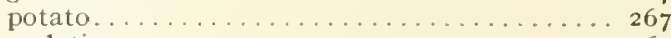

inoculations...................... 267

with mixed cultures. . . . . . . . . . . . . . 267

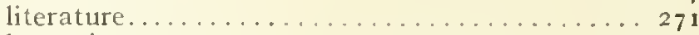

longevity....................... 268

morphological character, variations in........ 267

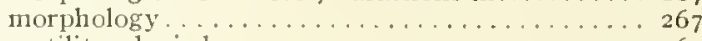

motility, denied................... 267

pigment................... 267,268

effect on virulence................ 268

tissues, effect on . . . . . . . . . . . . . . . . 268

virulence,

effect of pigment on................... 268

loss of ............................ 268

restoration of .................... 268

variation in ................... 267

Bacterium solanacearum (?) (Japanese tobacco-wilt organism),

(See Bacillus nicotianae Uyeda.)

Bacterium sclanacearum (Medan).

[See Bact. solanacearum (Sumatran tobacco organism).]

Bacterium solanacearum (North American tobacco-wilt organism)..........231, 234, 235

(See also Peanut wilt, United States; Tobacco, wiltdiseases, North American disease.)

acrobism........................ 233

browning on agar. ................ 232

browning on potato...............232

comparison with Bact. solanacearum (potato and tomato)................ 230,23 I, 23 .

comparison with peanut and pepper-wilt organisms........................ 27 cultural characters. . . .............. 23r drying, effect on ... . . . . 282 Fulton's work on1................. 271 gas-production, not observed . . . . . . . . . 233 growth on or in,

acid bouillon (plus 33 muscle acid) . . . . . 232

beef-agar......................... 231

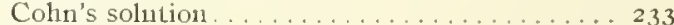

gelatin...................... 232

litmus milk. . . . . . . . . . . . . . . . . . 233

litmus milk with cream $\ldots \ldots \ldots \ldots \ldots . \ldots 282$

milk........ . . . . . . . . . . . . 233

nitrate bouillon. . . . . . . . . . . . . . . 233

potato ........................ 232

standard peptonized bouillon.......... 232

incubation period.................. 234

inoculations,

(See also Tobacco, wilt-diseases, N. Am. disease.)

direct, on

tobacco (organism passed through tomato).. 234 
Bacterium solanacearum (N. Am. tobacco)-cont. inoculations, pure culture on

peallut .

tomato................... $220,230,236$ soil, on

Datura stramonium. . . . . . . . . . . . 233

egg-plant...................... 235

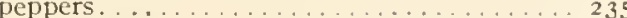

tobacco ............. 181,229, 235,282

tomato............... 181, 233,282

isolation ................. 228

literature...................270,271

longevity.................... 232

minimum temperature............... 233

morphology ................... 231

peanut-wilt, cause of .................271

potato and tomato-wilt organisnı like . . 230, 231, 234

reduction of nitrates................ 233

relation to Bact. solanacearum (potato and tomato $\ldots \ldots \ldots \ldots \ldots \ldots \ldots \ldots 230,231,234$

similarity to

peanut-wilt organism.............27

pepper-wilt organism ................. 271

Sumatran tobacco-wilt organism,

behavior in cream-free litmus milk . . . . . . 264

signs of disease.................... 263

soil, infection through (peanut) . . . . . . 271

soil, persistence of organism in........... 237

Sumatran tobacco-wilt organism, similarity in cream-free litmus milk............ $26_{4}$

Sumatran tobacco-wilt organism, similarity in signs of disease . . . . . . . . . . . . . . . 263

thermal death-point. .................... 233

tissues at tacked ................... 227,230

tomato and potato-wilt organism like. . 230,231,234

vessels occupied................ . 227,230

water-content of host, effect on inoculations. . 282

Bacterium solanacearum (Peanut-wilt organism). 153

253,27 I

(See also Peanut wilt, Sumatra; Peanut wilt, United States: Peanut wilt, van Breda de Haan's.)

comparison with tobacco and pepper organisms. $27 \mathrm{r}$ cul tural characteristics. ............ 271

Fulton's work on .................... 271

Honing's report of ............... 153, 253

inoculations, on

peanut....................... 271

tobacco .............................. 27

(See also Peanut wilt, United States.)

isolation...........................

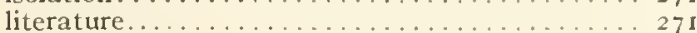

morphology ................... 271

similarity to,

pepper-wilt organism.............271

tobacco-wilt organism. . . . . . . . . . . . 27

stains, reaction to................ 271

Bacterium solanacearum (potato and tomato) 178, 193

(See also Peanut wilt; Solanaceae, brown tot; Tobacco, wilt diseases.)

acids, effect of.....

acid production, not detected.......... I96, 200

aerobism, strict ................... 196

African disease of potato, Odlum's observations on 2 I 4

agar, browned by.

alkali, production of ............... I94, 195

Australian disease of potato and tomato, 'Tryon's observations on .................. 207

Bacillus musae, similarity to ....... ..... I7

Bacillus nicotianae, synonym of .................... 254 not wholly like...................... 24

(See also "comparison, etc.")

Bacillus phy tophthorus, characters separating from 200

Bancroft, Malay States disease ............. 2I I

bipolar staining of ................ 267
Bacterium solanacearum (potato, tomato)-cont.

brown stain,

accompanying loss of vitality ... . . . . 199, 200

in form of streaks in stems.......... 176,185

nature of ...................... 194

production of . . . . ........... 200

casein, no action on . . . . . . . . . . . . . 194

cell-wall, action on . . . . . . . . . . . . 191

Ceylon wilt-disease of tomato, Petch's. . . . . . 214

chains, seldom seen.............. 193, 200

Cohn's solution, no growth in . . . . . . . . . 197

Coleman, Mysore ring disease . . . . . . . . . . 212

colonies..................... 195, 199

often dead when browned......... 199, 232

color......................... 194

Comes, Italian disease of tomato.......... 215

comparison with N. Am. tobacco organism . 230,231,234

comparison (Honing's) of Sumatran tobacco-kilt organism with Smith's and Uyeda's descriptions of Bact. solanacearum and Uyeda's description of B. nicotianae. . $247,248,249,250,25 \mathrm{r}$ (See also "relation, etc.")

comparison (Smith's) with B. nicotianae... 240, 24r,

(See also "relation, etc.") $242,243,244$

cucumbers not rotted by. .

Dewth on, effect on virulence.... I 179

Delacroix, French disease of potato..........2 14

dendritic growth, not characteristic........... 200

description of . . . . . . . . . . . . . . . 193

diffusion from vessels. . . . . . . . . . . . . . 197

drying, sensitive to .................... 282

Dutch East Indian disease of tomato, Hunger's observations.

(Sec Solanaceae, brown rot, Dutch Fast Indian disease.)

Einglish disease of potato......... 216

enlargements, local, due to............ 199

entrance into host................ $18 \mathrm{I}$

fermentation-tube experiments............... 196

field inoculations on large scale with . . . . . . . 187

filaments rare.... . . . . . . . . . . . . . . . . 193

flagella................... . 193

Florida potato-wilt organism,

bipolar staining. . . . . . . . . . . . . 2267

drying, effect of ..........

growth in,

Cohn's solution. . . . . . . . . . . . . . . . 264

litmus milk with crean. . . . . . . . . 264, 282

Meyer's solution plus

amnonium salts.............. 251, 282

asparagin ................. 282

potassium nitrate plus sodium salts ...... 282

sodium salts ................251, 282

Uschinsky's solution . . . . . . . . . . . . . . 264

inoculations on

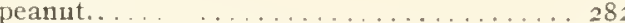

tobacco..............

tomato (Livingston's Dwart Aristocrat).... . 282

water-content of host, effect on inoculations 282

freezing, effect on ............. I 98, I 99, 200

Frencli potato disease,

Delacroix's observations ............214, 215

de Laharpe's observations............ 215

gas, not produced by . . . . . . . . . . 196, 200

Gram's stain, reaction to ................ 198

Grand Rapids tomato disease, not due to..... I6I

green fluorescence, not characteristic of . . . . . 200

group number..................... 200

growth on or in,

acid bouillon. . . . . . . . . . . . . . . . . . . 199

beef-agar, peptonized. . . . . . . . . . . 195, 199

becf-bouillon, peptonized............ 194,199

beef-bouillon, peptonized, plus sodinn carbonate 194

blood serum, solidified.................200 
Bacterium solanacearum (potato, tomato)-cont. growth, on or in-continued.

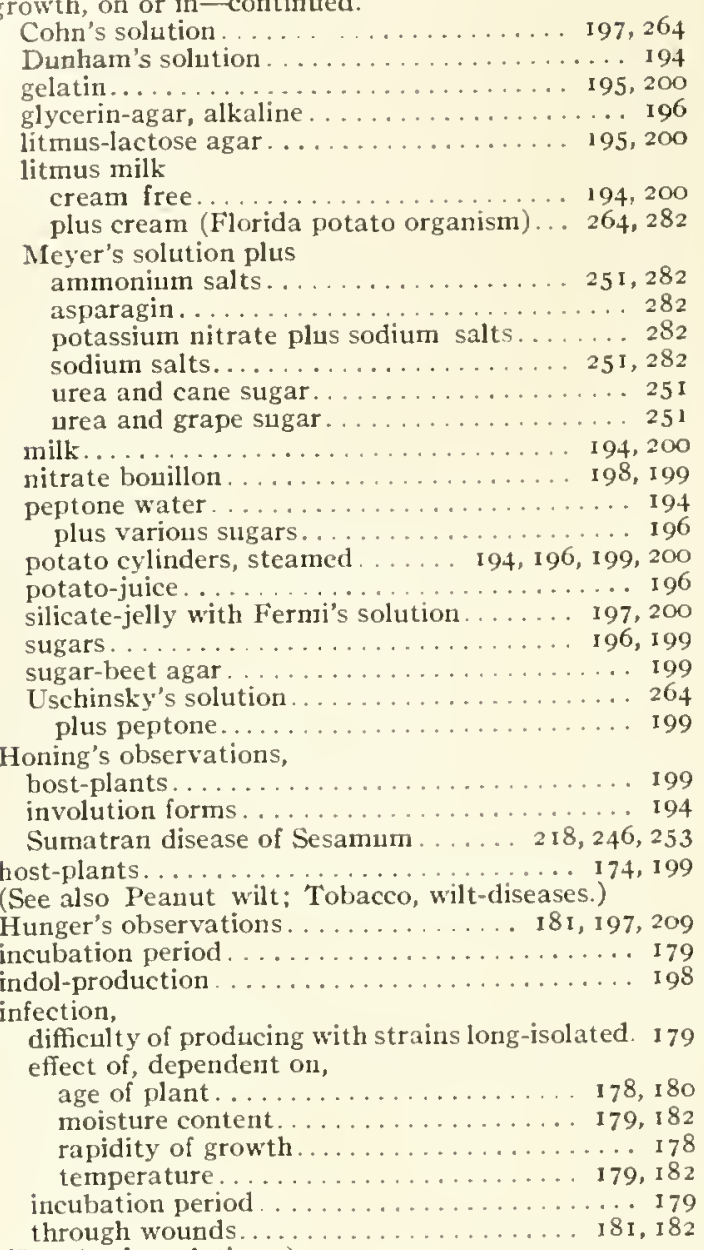

through wounds.

(See also inoculations.)

inoculations.

174, I 78, I 79, 182, 205, 209, 210

feebly virulent strains.

methods. $\ldots \ldots \ldots \ldots$
needle-prick, single, result of $178,179,190,209,210$

.......... 199

successful, strains used for . . . . . . . . . . . . . I 79

synopsis of . . . . . . . . . . . . . . I 82

uncertainty of results. . . . . . . . I 7 8, 179, 268

(See also infections.)

inoculations on,

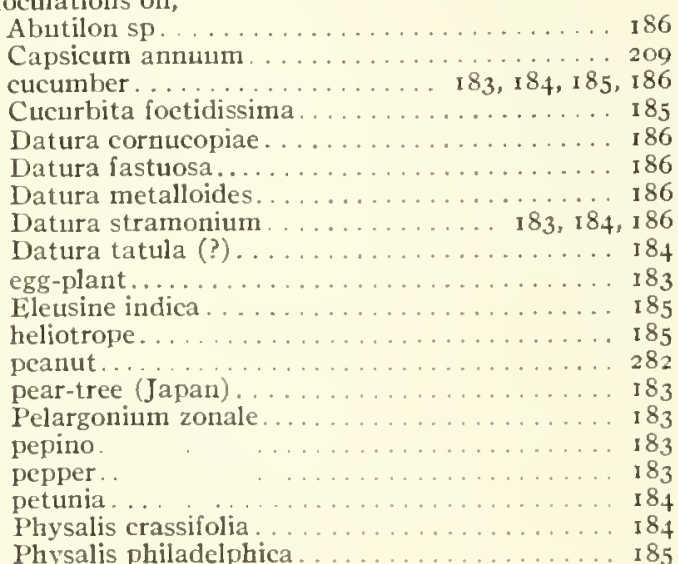

Bacterium solanacearum (potato, tomato)-cont.

inoculations, on-continued.

Portulaca oleraceae. . . . . . . . . . . . I 85

potato. $179,180,182,183,184$, I $85,186,187,188$, I 89

Blush variety................. 189

Burbank variety................. 187

Early Rose variety . . . . . . . . . . 187, 180

Green Mountain variety. ............. 188

Ricinus communis................ I85

Solanum carolinense............... 183

Solanum dulcamara . . . . . . . . . . . . . . 186

Solanum nigrum. ............... 183, 184

tobacco. . I I $83,184,186,189,190,209,230,233,282$

tomato............. I79, 180, 182, 183,185,

I $86,187,188,180,190,200,210$

green fruits.................. 176

Honor Bright varjety . . . . . . . . . I 88

Livingston's Dwarf Aristocrat variety... I89, 282

Red pear variety................... 188

Vigna catjang. . . . . . . . . . . . . . . 185

(See also Tobacco, wilt-diseases.)

involution forms . . . . . . . . . . . . 193, 194

isolation, difficulties of ............... I7 78

Italian disease of tomato,

Comes' observations................. 215

Voglino's observations................ 2 I5

Iwanoff, Russian disease of potato.......... 2 I4

Japanese tobacco-wilt organism, relation to. . 244,254

(See also "comparison, etc.")

killed by dry air . . . . . . . . . . . . . . . . 282

Kirk, New Zealand disease of potato . . . . . . . 207

lab-ferment.........................200

liquefaction,

gelatin.................... 195, 200

Loeffler's blood-serum. .................200

literature ........................ 218

litmus milk, effect on .................. 194

local enlargements due to .............. 199

longevity, on or in,

agar......................... 199

dry air ............... 282

milk ..................... 194, 200

steamed potato . . . . . . . . . . . . . . 198, 200

loss of virulence............. 188

Malay States disease, Bancroft's observations... 2 I I

Malkoff, disease of sesamum............. 2I6

milk, clearing of . . . . . . . . . . . . . . 194

morphology . . . . . . . . . . . . . . 193, 199

motility... .... 193, 264, 268

Hutchinson's observations on ...... 200, 265, 267

movement of bacteria in inoculated plants...... I 79

New South Wales potato diseases, Helms' . . . . . . 207

New Zealand potato disease, Kirk's observations. . 207

Odlum, African disease of potato.............2 I4

odor...................... 197, 200

oxygen, free, necessary for respiration of . . . . 196

peanut, cause of disease in .......... 271,282

Petch, Ceylon disease of tomato...........2 I4

pigment,

action of dilute acids and alkalies on ........ 194

produced by.................... 194, 200

solubility of . . . . . . . . . . . . . . 194, 200

polar staining. . . . . . . . . . . . . . . . . . 267

pseudozoogloeae................ 193, 194

reduction of nitrates..................... 198

relation to tobacco-wilt organism

North America..............230, 231, 234

Sumatra and Japan. ................. 244,254

(See also "comparison, etc.")

resistant Solanum.................... 182

résumé of salient characters. . . . . . . . . . . . . . 182

ring disease of potato, Germany......... 166,215

(See also Solanaceae, Brown rot, ring disease of potato, Germany.)

ring disease of potato, Mysore. . . . ............ $2 I_{2}$

(See also Solanaceae, brown rot, ring disease of potato, Miysore.) 
Bacterium solanacearum (potato, tomato)-cont. Russian potato disease, Iwanoff's observations. . 214 sesamum, bacteriosis ... (See also Solanaceae, brown rot, sesamum bacteriosis.) similarity to,

Bacillus musae................... 171

tobacco-wilt organism (N. Am.)...2 230,23i, 234

tobacco-wilt organisms (Sumatra and Japan) 244,254

(See also "comparison, etc.")

lack of, Sumatran tobacco-wilt organism in lit-

mus milk with cream (Florida potato strain). . 264

Spieckermann's potato-parasite, distinct from.... 167 spores, not seen................ 193,200 spread of parasite in inoculated plant........ 179 stains, reaction to ................... 193 starch, slight action on ............ 192, 197 sugared fluids, browning of ............. 196 Sumatran tobacco-wilt organism, relation to. 244,254 (See also "comparison, etc.")

Sumatran tobacco organism, variations from Florida potato organism in milk with cream. . 264 termo-like shape of ................ 175, 199 thermal relations. .............. 198, 200 tissues attacked ............ 175, 176, 191, 199 tobacco-wilt of Dutch East Indies, relation to.... 222 tobacco-wilt organism (N. Am.), like... 230, 231, 234 tobacco-wilt organism (Sumatra), variation from Florida potato-wilt organism in litmus milk

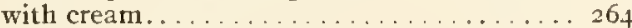
tobacco-wilt organisms (Sumatra and Japan) re. lation to ................... 24t, 25 (See also "comparison, etc.") virulence,

degrees of

effect on, of growth on culture media........ 179 loss of . .

$179,188,268$

viscidity, not marked.

197,200

Voglino, Italian disease of tomato . . . . . . . 215

water-content of host, effect on inoculations. . . . 282

white substance surrounding colonies on agar... 199

wrinkled growth absent .............. 200

Bacterium solanacearum (Sumatran tobaccowilt organism),

American studies.................. 263

acid produced from cream in litmus milk .... 264

browning of culture-media . . . . . . . . 263, 265

crystals........................ 265

drying, effect of . . . . . . . . . . . . . 282

flagella................... 265, 268

Florida potato-wilt organism, dissimilarity in litmus milk with cream ........... 264,282 growth on or in, agar with Bacillus subtilis. . . . . . . . . . . 264 cream-free litmus milk, plus . . . . . . . . . . . . 264 coconut oil . . . . . . . . . . . . . . 2 264 cottonseed oil . . . . . . . . . . . . . . 264

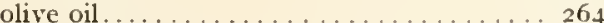
peanut oil .................... 264 fermentation tubes. . . . . . . . . . . 265 lactose not fermented by . . . . . . . . . . . . 264 litmus milk.............. 263, 264, 265 litmus milk containing cream..... . 264,282

Meyer's solution plus ammonium salts. .......... 25 $1,2 \mathrm{~S}_{2}$ asparagin ..................... 282 potassium nitrate plus sodium salts. . . . . 282 sodium salts... . $\ldots \ldots \ldots \ldots . .251,282$ urea and cane-sugar ................. 251 urea and grape sugar.............251 milk......................... 263 mineral solution with $\mathrm{KNO}_{3}$ and glycerin. 242 nitrate bouillon ................... . 265 nutrient gelatin.................. 265 peptone water, plus

sugars ...................... 265

glycerin ...................... 265
Bacterium solanacearum (Sumatran tobacco)-cont.

American studies-continued.

inoculations, on

peanut. .

tobacco

263,265

liquefaction of gelatin................ 282

litmus milk

bluing of ................... 263,264

reddening of $\ldots \ldots \ldots \ldots \ldots \ldots \ldots \ldots \ldots \ldots \ldots \ldots \ldots, 264$

reduction of ................. 264

motility, occurrence of .......... 265, 268

nitrates, reduction of . . . . . . . . . . . . . 242

pathogenicity................ 263, 265

similarity to North American tobacco-wilt organism, cream-free litmus milk............

similarity to North American tobacco-wilt organism, signs of disease ............ 263 similarity, lack of, to Florida potato-wilt organism in litmus milk with cream

similarity, lack of, to North American tobaccowilt organism in litmus milk with cream. .. 282 stains, reaction to ................... 265 virulence, loss of ................. 282 water-content of host, effect on inoculations... 282

Honing's studies . . . . . . . . . . . . 224, 244 (See also Tobacco, wilt-diseases, Honing's Sumatran studies.)

acid, toleration of . . . . . . . . . 256,257

acid-production.................... 249

in litmus milk. . . . . . . . . . . . . 248

adonite as carbon food........251,252,253,257

aerobism ............................ 248

albumin as carbon-nitrogen food ......... 250

alcohols, growth in . . . . 249, 25 I, 252, 253, 254 alkali,

production of ................... 249

retarding effect of ............. 257

toleration of ......................... 256,257

alkali-production in litmus milk......... 248

ammonia-nitrogen used by .......... 25I

ammonium salts as carbon food. ............ 253

ammonium salts as carbon-nitrogen food. . 250, 253 amount of inoculating material used in making cultures, effect of.

asparagin as nitrogen food lood ...... 250, 253

asparagin plus saccharose as food .......... 251

associated organisms.... . . . . . . . . 258

Bacillus nicotianae, relation to.......24, 254

(See also "comparison, etc.")

blackening of

agar........................ 248

gelatin......................... 248

potato slices..................... 248

browning of beef bouillon.............. 247

capsules.... ................ 247,253

carbon, substances used as source of . 250,251, 252, 253

carbon-nitrogen foods....... . . 250253

chains in medium containing glycocoll and glucose 253

clouding, time of, relation to number of bacteria used in inoculation.

comparison of Deli strains with Uyeda's descrip. tions of B. nicotianae and Smith's and Uyeda's descriptions of Bacterium solanacearum

$247,248,249,250,251$

(See also "relation, etc.")

cultural characteristics.

cultural differences in strains........... 247

diastase production............... 25 I, 252, 253

drying, resistance to . . . . . . . . . . . . . . 249

dulcit as carbon food .......... 251, 252, 253

erythrite as carbon food....... 251,252,253,257 
Bacterium solanacearum (Sumatran tobacco)-cont.

Honing's studies-continued.

fat, formation of .

fibrin of blood as carbon-nitrogen food.

filaments in medium containing glycocoll and glucose

flagella. . .

galactose as carbon food.

gas production...

glucose, action on

glucose as carbon food

glucose plus asparagin as food

glucose plus potassium nitrate as food
gluten as carbon-nitrogen food...

glycerin as carbon food.

glycocoll as carbon-nitrogen food .

glycocoll as nitrogen food

...

glycogen as carbon source.

glycogen production.

$252,253,254$

$249,251,252,253$

247,253

growth in or on,

acid glycocoll-glucose solution. . . . . 257,258

agar.

248

alcohols... ... . . . 249, 251, 252, 253,254

alkaline glycocoll-glucose solution... 257,258

asparagin-glycocoll-potassium nitrate solution

plus glucose. . . . . . . . . . . . . . . . 257
plus mannose... . . . . . . 257

plus mannose............ 257

beef bouillon. . . . . . . . . . . . . . . . . . 2.47

fermentation tubes. . . . . . . . . . 248,249

gelatin.

hydrogen....

litmus milk

Meyer's solution, plus

ammonium chlorid plus glucose

ammonium chlorid plus gly"cerine.

ammonium salts...

asparagiu plus carbon foods. .

asparagin plus sodium salts

ammonia plus carbon foods.

carbon-nitrogen compounds

glycocoll plus carbon foods.

glycocoll plus glucose with variable reactions, 256

glycocoll plus mannose with variable reac-

tions

potassium nitrate plus carbon foods... 251, 253

potassium nitrate plus sodium salts... 251,253 milk

248,253

monopotassium phosphate plus magnesium

sulphate plus sodium chlorid plus potas-

sium nitrate plus

dextrin ................... 250

glucose . . . . . . . . . . . . . . . 250

glycerin. ..... . . . 250

inuline. . . . . . . . . . . . . . 250

saccharose................... 250

sorbit. . . . . 250

potassium nitrate solution plus carbon foods. 257

potato.......................... 248

sugars...........249,25I, 252, 253,254

urea solution plus glucose............. 257

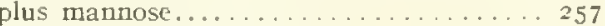

growth under paraffin oil ............... 248

guanine as carbon-nitrogen food......... 250

heat, resistance to................... $2+7$

hemialbumose as carbon-nitrogen food ......250

host-plants ........... 226, 253,254, 255,282

(See also Inoculations.)

hydrogen sulphide, production of ......... 249

indol-production....... 249

inoculating culture media, number of bacteria used, effect.

258

inoculating plants, number of bacteria used, effect 260 inoculations,

Ageratum organism on tobacco... 226, 244, 245
Honing's studies-continued. inoculations - continued.

Djatti organism on

Djatti plants................... 254

Nicotiana affinis................ 255

N. atropurpurea grandiflora .......... 255

N. colossea .................... 255

N.glauca................... 255

N. rustica . . . . . . . . . . . . 255.256

N. sanderae . . . . . . . . . . . . . 255

$\mathrm{N}$. silvestris. . . . . . . . . . . . . . 255

ornamental and common tobacco.... 254, 255

Mucuna organism on tobacco........... 244

Pluchea organism on tobacco.............. $2+4$

Pouzolzia organism on tobacco...... 226, 244

tobacco organism on

Capsicum..... ......242,253

Nicotiana affinis............... 255

N. atropurpurea grandiflora. . . . . . . 255

N. colossea. ......... 255

N.glauca. . . . . . . . . . . . . 255

N. rustica . . . . . . . . . . . . 255, 256

N. sanderae. . . . . . . . . . . . . . . 255

N. silvestris . . . . . . . . . . . . . 255

ornamental tobaccos................. 255

tobacco organism (?), on potato...... 245, 253

tobacco organism, on Pouzolzia.......... 245

tobacco organism (?), on Sesamum orientale. 253

on Solanun lycopersicum............ 253

tobacco organism, on Solanum melongena 245,253

on tobacco.......... 225,244 (?), 245, 255

inoculations, soil:

tobacco organism on tobacco........... 225

inoculations, soil-water, on

Ageratum................... 245

Pouzolzia...................... 245

tobacco .......... 245

inosite as carbon food ....... 251, 252, 253, 257

inulin as carbon source........... 251, 252, 253 isolation from

Ageratum ..................... 226

Мıсциа... . . . . . . . . . . . . . . . . . . 2226

Pouzolzia.......................226

tobacco ................... 225, 246

Japanese tobacco-wilt organism, relation to. $24+, 254$

(See also "comparison, etc.")

lactose as carbon food............ 251, 252, 253

legumin as carbon-nitrogen food .............250

leucine as carbon-nitrogen food.......... . 250

levulose as carbon food..... 251, 252, 253, 254, 257

lichenin as carbon source...... 251, 252, 253,257

liquefaction of gelatin............... 247

literature.....................270, 271

litmus, reaction to (milk cultures) ........ 248

litmus, reduction of ................. 249

maltose, as carbon food ............ 251, 252, 253

mannit, action on ...................... 249

as carbon source............ 251,252, 253

mannose as carbon food . . . . . 251, 252, 253,257

maximum temperature ......... 249

methylene blue, reduction of . . . . . . . . . . . 2424

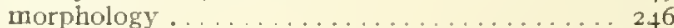

variability in . . . . . . . . . . . . . 253

motility ......................... 247

nitrate, reduction of ............249,253

nitrogen, substances used as source . . 250,251,252,253

nitrogen and carbon from one substance... 250,253

nuclein as carbon-nitrogen food ............. 250

number of bacteria,

effect on growth in culture media. . . . . . . 258

effect on progress of disease............260

odor .................................. 249

peanut wilt, cause of . . . . . . . 153,253

pellicle ....................... 247

peptone as carbon-nitrogen food ......... 250, 253 
Bacterium solanacearum (Sumatran tobacco) - cont.

Honing's studies-continued.

phenolphthalein, reaction to (milk cultures) ... 248 physiological characters, variations in . . . . 253 physiology

polar staining ... . . . . . . . . . 247, 253 potassium nitrate as nitrogen food . $250,251,254,257$ potassium nitrate plus glucose as food ...... 251 plus saccharose as food . . . . . 251 potassium nitrite as nitrogen food . . ...... 250 potato and tomato-wilt organism, relation to . 244 (See also "comparison, etc.")

protein as carbon-nitrogen food ... . . . 250 quercit as carbon food _ . 25I, 252,253 raffinose as carbon food . . . . 251, 252, 253 relation of tobacco-wilt organisms (Sumatra and Japan and Bact. solanacearum Smith described from potato and tomato... 244,254 (See also "comparison, etc.")

rhannose as carbon food

$251,252,253$

saccliarose, action on

as carbon food.

plus asparagin as food

$251,252,253$

plus potassium nitrate as food. $\quad 251$

saprophytes,

associated with ....... 258

inhibiting action..... . 259

similarity of tobacco-wilt organisms (Sumatra and Japan) and Bact. solanacearum Smith, described from potato and tomato.... 24, 254 (See also "comparison, etc.")

sodium salts as carbon food

sodium selenite, reduction of

$251,252,253$

sorbit as carbon source...

249,253

spores

staining of culture media

$251,252,253$

$2+7,253$

starch,

action on .....

as carbon to rariath

Straitls, variability

$247,248,249$

$24+, 250,251,251,253$

sugars, growth in

$\ldots 253,25$

thermal death-point . . . . . . . . . . . . . . 249

tomato and potato-wilt organism, relation to . 244

(See also "comparison, etc.")

transmission of...

tyrosin as carbon-nitrogen food

$249,250,253$

variability

effect of alkalinity on ... . . . . . . . 258

effect of light........... . . 258

effect of temperature............ . 258

in carbon and ritrogen-compound tests ...253.

$256,257,258$

in cultural characteristics $.250,251,252,253,256,257$

in milk. . . . . . . . . . . . . . . 253

in toleration of acid.............. 257

in toleration of alkali ............. 257

in virulence. ................... 244

variations, transitory nature of ..........258

virulence, loss .................. 253

Bacterium solanacearum var. Asiaticum nov.

var. ...................... 282

Hunger's observations . . . . . . . . . . 222

Bacterium stalactitigenes, associated with Bact.

solanacearum in Sunsatra..... ... . . 259

Bacterium stewarti................ 91, 132 (See also, Corn, Stewart's bacterial disease.)

acids, toleration of certain

acid fuchsin, effect of .

136,144

acid production

140

agar stabs, growth in.............. . . . . . . 133

agar streaks. ................... I34

alkali produced .................... 142

alkali, toleration of . . . . . . . . . . . . 138
Bacterium stewarti-continued.

animals, no experiments with.. . 144

asparagin, not a carbon food.... . $1+5$

cane-sugar favors growth . . . . . . . . . . 138

capsulc ...................... . 132

chains . ... . ............... . I32

chloroform, slight retarding effect of ... 143, 144, I 45

colonies, appearance of ............... 133

color on media... $\quad \ldots \ldots \ldots 133,134,135,137,138$

comparison with Apl. michiganense on potato.... 164

crystals. .. $\quad \ldots \ldots \ldots 133,142,144$

cultural characteristics. . $\quad \ldots \quad \ldots \ldots \ldots \ldots$.

cytase, doubtful occurrence..... ........ 142

$\ldots \ldots \ldots 132$

dextrin, no increased growth with ......... I 38

dextrose, increased growth with . ........... 142

diastase........ J42, J 45

discoloration of bundles. $\quad \ldots \ldots \ldots \ldots \ldots$ I6

discovery of organism................ 91

dissemination through infected seed ...... I 14, 1 27

dry air, resistance to... . . . . . . I 44

endospores not seen ..... . _ . . . . . . 132

enzymes ................... 142,145

ethyl alcohol, no acid from .... ........ I39

fermentation tubes, growth in .......... 138, J45

filaments....................... 132

flagella, polar.............. 91, 1 32

formalin, infected sceds treated with ....... I 128

galactose favors growth ... . . . . 138

gas production not scen... $\quad \ldots \ldots \ldots 138,145$

gases other than air, behavior in ........ 138, 139

gelatin not liquefied. . . . . . . . . . . J J33

germicides................. $1_{42}$

glycerin, no acid from. ............ 139

no increased growth with .............. I 38

some acid from.... . . . . . . . . . . I 39

Gram's stain ......... 132

group number... . . . . . . . . . ${ }^{145}$

growth on or in.

acid beef-bouillon . .... I36, $138,141,145$

agar.............. 133, 142, 144

agar in atmosphere of hydrogen........... 139

agar plus potassium formate and phenolphthalein 143

alcohols......... . . . . . . . . . $\quad 139,145$

alcohol agars ................ 139

alkaline bcef-bouilon. . ....... 138, 141, 144

alkaline beef-bouillon in vacuo .......... 139

ammonium salts ..................140, 141

asparagin water............ I4 1, 144, 145

beef-bouillon in atmosphere of carbon dioxide.. 139

beef-bouillon in atmosphere of hydrogen. . 138, 139

beef-bouillon over chloroform........ $143,144,145$

beef-bouillon concentrated and strongly acid... 136

beef-bouillon plus ethyl alcohol . . . . . . . I 39

beef-bouillon plus glycerit... ‥ I 39

beef-bouillon plus peptone... .. т 36,144

beef-bouillon plus sodium chloride. . . _ . ... 138

cabbage-juice. ......... I36, 138 , 144

cane-sugar

I 39,142

cane-sugar plus asparagin. ....... I 44

cane-sugar agar plus litmus........ . . . $\quad$ I 39

cane-sugar starch jelly. . . . . . . . . . . 138

cane-sugar water. $\quad . \quad \ldots \ldots \ldots \ldots . . \ldots$ I 40,141

cane-sugar water plus ammonium citrate..... 140

cane-sugar water plus ammonium lactatc.. I 40, I4I

cane-sugar water plus anmonium tartrate. . 1 40, 141

cane-sugar water plus asparagin. ....... 140, I 41

carbon dioxide. . . . . . 139, 145

carrot cylinders $\ldots \ldots . . .142$

carrot cylinders in vacuo . . . . . . 139

cocontut cylinders . $\ldots . . .135,142,144$

coconut cylinders in atmosphere of carbon dioxide.

coconut cylinders in atmosphere of nitrogen 138,145

coconnt cylinders in vacuo ............ I 39

Cohn's solution.............. $138,140,144$ 
Bacterium stewarti-continued

growth on or in-continued.

dextrin starch jelly

dextrose agar plus litmus.

distilled water plus dipotassium phosphate, magnesium sulphate, ammonium phosphate and sodium acetate................... I37

Dunham's solution plus methylene blue...... 141

Dunham's solution plus rosolic acid in atmosphere of hydrogen...

Dunham's solution plus rosolic acid and hydrochloric acid. .

139,145

Fermi's solution

138

galactose

galactose agar plus litmus.

galactose starch jelly...

gelatin.

glycerin agar.

glycerin agar plus litmus

glycerin starch jelly....

grape-sugar

hydrogen.

lactose agar plus litmus.

lactose starch jelly

litmus agars plus sugars.

litmus milk.

Loeffler's blood-serum

maltose agar plus litmus

maltose starch jelly....

mannit.

mannit agar plus litmus.

mannit starch jelly.

milk...

mulberry agar

neutral beef-bouillon in atmosphere of hydrogen. 139

neutral beef-bouillon plus potassium formate. . I 43

nitrate agar. .

nitrate bouillon

nitrate bouillon plus grape-sugar

nitrogen. . . .

nutrient starch-jelly plus sugars.

peptone water.

peptone-water plus acid fuchsin and hydrochlo-

ric acid.

peptone water plus grape-sugar and methylene

blue in an atmosphere of hydrogen.

peptone water plus salt and indigo carmine.

peptone water plus salt and rosolic acid.

peptone water plus salt and rosolic acid in an

atmosphere of hydrogen....

peptonized beef bouillon.

potato broth.

potato broth plus malic acid.

potato cylinders.

$132,138,140$

138

138,145

138

144

140

139

140

I 39

139

136,144

136,144

I 36,138

potato cylinders in an atmosphere of carbon

dioxide.

potato cylinders in an atmosphere of hydrogen. $\quad 139$

potato cylinders in vacuo

radish..........

rutabaga. . .

saccharose.

saccharose agar plus litmus

silicate jelly

starch jelly plus sugars.

sugars............

sugar agars

sugar starch-jellies

sugar-beet.

tomato juice. .

turnip.

turnip in atmosphere of nitrogen

$136,138,140,141,144,145$

135,142

$135,142,144$

139,142

139

134,144

138,145

$138,139,145$

139

138

$135,142,144$

138,145

Uschinsky's solution.... I I32, I 37, 140,142, 143, 145

Uschinsky's solution in atmosphere of hydrogen. 139

vacuo. .

139,145

host-plants

hydrogen peroxide, seeds treated with
Bacterium stewarti-continued.

PAGE.

hydrogen sulphide, doubtful production of .... I I 42

ice box, growth in................ 143, 144

indigo carmine, effect of . . . . . . . . . . . 140, 145

indol reaction................ 142, 144, 145

infected seed, treatment of . . . . . 125, 127, 128, 146

inoculations......................... 96 method,

by necdle punctures............... I I 3

by spraying............. 96, 97,129

through water-pores.......... 96, 111, 112

on field corn.............. 93, 111, 112, 129

on oats.

93

on pop-coril .................. 93, 11

on sweet corn........... 92, 96, 1 10, 112, 129

Scries $I$ and II.................... 96

Series 1 and 1I, detailed results........... 98

Series I and II, tabulated results.......... IO

Series III-VII . .

Series III-VII, tabulated results. ......... III

Series VIII and IX..................... III

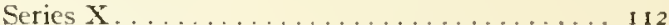

Series X1-XV ...................... 121

Series XV1-XIX .................. 125

Series XX-XX1V .................. 128

Series XXV . . . . . . . . . . . . . . . 129

Stewart's....................... 91, 92

inversion of cane-sugar ............... 142

invertase............... 142,145

isolation attempted from infected keruels...... 124

isolation by direct transfer from diseased stems... 96 kernels penetrated by bacteria.... 114,116,130,131 lab ferment...................142, 145

lactic acid, toleration of .............. 144

lactose, no increased growth with . . . . . . . 138

lesions produced . . . . . . . . . . . . . . . . 130

literature.... ................ 147

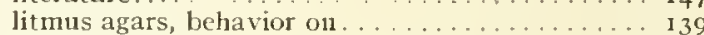

I.oeffler's blood serum, not liquefied by . . . . . . 133

malic acid, toleration of ............... 144

maltose, no increased growth with........... 138

mannit, no increased growth with ......... 138

maximum temperature..... ......... 143

mercuric chloride, seeds treated with. . 125, 127,128

methylene blue, vital staining with .... 132, 139, I45

milk, changes in............... 137,140

minimum temperature experiments.......... 143

mixed cultures................... 142

mixed infections. . . . . . . . . . . . . . . 142

morphology. . . . . . . . . . . . . . . 132, I44

motility ....................... 132

nitrates, not reduced by................ 145

nitrogen foods.................... 141

nitrogen, no growth in . . . . . . . . . 138

odor....

organs invaded .................. 131

oxygen, evolution of from hydrogen peroxide... 142

parts of plant attacked ............... I31

phenolphthalein, reaction of formate agar cultures. I 43

pigments........................ 142

polar flagella..................... 91, 132

potassium formate, effect of . . . . . . . . 143

potato starch, slight action on .......... 142

potato streak cultures, appearance.......... I I35

pseudozoogloeae. . . . . . . . . . . . 132, 137, 143

reduction of litmus.................. 137

reduction of nitrates................. 138

résumé of salient characters. . . . . . . . . . 144

rosolic acid, effect .................. 139, 145

sodium chloride, marked toleration of . . . . . 138, I 45

stain in host-plant................ 16, 142

stains, reaction to ................ 132, 144

starch, action on .................... I 34

sunlight, effect of . . . . . . . . . . . 144

tartaric acid, toleration of . . . . . . . . . . . . . 144

temperature relations............ $143,144,145$ 
Bacterium stewarti-continued.

thermal death-point.

tissues attacked.

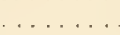

........

trypsin.... . .

virulence, retention of . . . . . . . . 142,145

viscidity . . . . . . . . . $103,126,127,132,137$

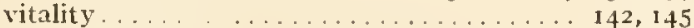

wind, not borne by................. I 2 I

yellow pigment

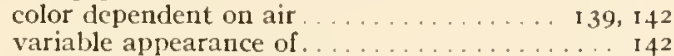

Bacterium sumatranum, associated with Bact, solanacearum in Sumatra. . . . . . . . . . . . 259

Bacterium vascularum ................ 54 (See also Sugar-cane, Cobb's disease of.)

acid culture media, inhibiting effect on growth . . $61,63,67$

acid potassium phosphate, effect on growth..... 64 acidity of cane-juice, relation to bacterial growth. 47 aerobism. . . . . . . . . . . . . . . . 48,64

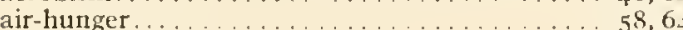
agar not stained by

alcohol, slime of, insoluble in.

alkali, effect on growth....

7,14

alkaline reaction of cultures

$58,59,61,63,67$

$56,57,60,61$

ammonium, effect on growth

64

ammonium salts as nitrogen foods...... 63

asparagin as nitrogen-food....

bacterial slime oozing from leaves and stems... 16, 22 ,

calcium. effect on growth...

$25,53,66$

cane cuttings, disease transmitted by

i8, 68

cane slices, steamed, growth on

cane-sugar, action of organism on

cane-sugar, as carbon food. . . .

cane-sugar, effect on growth .

capsules.........................

57,63

64

carbon dioxide, effect on growth

carbon foods.........................
chemical reactions of bacterial slime

citric acid, effect on growth.

Cobb's studies.

(Sce also Sugar-cane, Cobb's disease of.)

colonies, appearance of .................

color of .

conditions favoring spread of

crystals, production of .

cultural characters.

culture media most favorable.

description of organism.

dextrin, effect on growth.

dextrose as carbon food.

dextrose, effect on growth

effect on sugar-cane. . . . .

fermentation-tube cultures
flagella, staining. . . . . .

gas-production, not observed

gelatin,

browning of . . . . . . . . . . .

color on...

growth on.

liquefaction of

tear drops on. ...........

with cane-juice, growth on

with fruit-sugar. growth on

with glucose, growth on.

geographical distribution...

glycerin, effect on growth .

Gram's stain, reaction to. .

group number.

growth, best medium for

growth best at $30^{\circ}$.

growth inhibited at blood temperaturc.
Bacterium vascularum-continued.

growth on or in,

acid agars...... 63,67

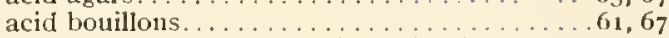

acid fluids, Greig-Smith's investigations...... 6 I

agar plus cane-sugar................... 56

agar plus fruit-sugar................ 56

agar plus peptone, levulose, potassium phosphate

and tap-water.

agar plus peptone, saccliarose, potassium phos-

phate and tap-water................ 65

alkaline agars........................ 63

alkaline bouillons............... 61,67

beef-agar.....

beef-bouillon plus peptone............ 60,67

beef-boutlon plus potassium formate....... 6 i

beet-cylinders...................... 60

bect-juice agar plus peptone and saccharose. . 67

cane cylinders, steamed ........... 47,60,67

cane-juice agar plus peptone............. 56

cane-sugar water plus peptone.......... 62

carrot ......................... 60

cauliflower eylinders........... 60

coconut cylinders. . . . . . . . . . . . . . 60

Cohn's solution . . . . . . . . . . . . . . 67

distilled water plus dextrose, glycerin and so-

dium asparaginate....

Dunham's solution...

fruit sugar-agar ....................... ${ }_{56}$

gelatin.... _........ 8, $57,59,60,65,67$

gelatin plus

eane-juice. . . . . . . . . . . 5 57,58,65

cane-sugar................ 57, 58

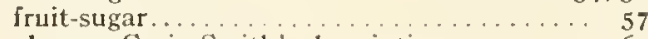

glucose, Greig-Smith's description ...... 57, 65

peptone, dipotassium phosphate and malic acid.

peptone, dipotassium phosphate, malic acid and eane-sugar ........ 58

peptone, dipotassium phosphate, malic acid, cane-sugar and sodium hydrate......... 58

glycerin agar ................... 56

Hunger's agar................... 57

litmus lactose agar.............. 57,67

litmus milk............ 6 t

milk....................... 66

nitrate bouillon........................

nutrient agar............... 54,56,66

poured-plates .................... 54

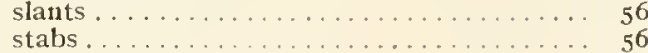

onion bulbs steamed. . . . . . . . . 60

peptone water plus

cane-sugar (fermentation tubes)........ 64

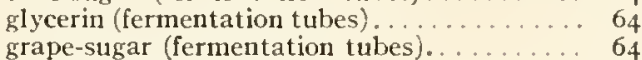

maltose (fermentation tubes)............. 64

mannit (fermentation tubes) ........... 64

milk-sugar (fermentation tubes) .......... 64

oxalic acid................... 63

potato, Greig-Smith's studies. . . . . . . . . . 65

potato agar................. 57,66,67

potato cylinders, steamed..........60,66,67

saecharose agar plus peptone. . . . . . . . . . 56

silicate jelly. . . . . . . . . . . . . . . . . 134

sugar-agars................. 56, 65

sugar-beet agar................. 56

60

Usclinsky's solution ............... 62

gumming, constant association of organism with. 8, 2 I gum, identity with bacterial slime.

(Sce also Sugar-cane, Cobb's disease of.)

gum-production, dependent on certain carbon foods 6.4

host-plants.

indol reaction, faint. 
Bacterinm vascularum-continued. inoculation experiments, Cobb's. inoculation experiments, Tryon's. . inoculation, methods of inoculations, general remarks on. . inoculations on

Blanca cane

Caledonia Queen cane....

Cinta cane

Common Green cane.

Common Purple cane.

Crystalina cane.

Jamaica cane

Louisiana cane, Variety No. 74

Striped Green cane.

inoculations, pure-culture.

inoculations, variety tests

inversion of cane-sugar

isolation, methods of

isolation from

artificially infected sugar-cane

Australian cane

red bundles.... . .

red ooze.

yellow ooze

lactose, effect on growt

lesions produced

levulose, effect on growth

liquefaction of gelatin

literature.

litmus, reaction

longevity,

effect of temperature on

in culture-media

in the host.

magnesium, effect on growth

malic acid, effect on growth

maltose, effect on growth. .

maximum temperature.

measurements.

milk.

acids not formed from

casein not precipitated

effect of organism on

surface growth not conspicuous.

tyrosin not formed in

with litmus becomes jndigo blue morpholog

motility, best seen in young cultures

motility, often absent in old growth

nitrates, not reduced by.

nitrogen foods.

one-flagellate.

optimum temperature.

oxalic acid, effect on growth

patbogenicity

phenolphthalein, reaction of organism to phosphates, effect on growth

potassium, effect on growth.

potassium nitrate as nitrogen food

potato, growth on.

poured-plate cultures, description

pseudozoogloeae.

pure-cultures from diseased cane.

red bundles, isolation from

reddening of bundles.

(See also Sugar-cane, Cobb's disease of.)

reduction of nitrates.

relation to $B$. sacchari Spegazzini

résumé of salient characters.

resuscitation from old diseased canes

saccharose, action on

saccharose, as carbon food.

saccharose, effect on growth

salts, effect on growth
PAGE

8, I 2

$21,27,31,33,46$ ...... 46<smiles>[AlH2]</smiles>

.. $33,34,46$

.. 34

I, 32, 34, 46

$33.34 \cdot 46$

$33,3+.+6$

$27 \cdot 34 \cdot 46$

$31,34,46$

I I, 2 I

$31,33,46$

62

54

$2 I, 24,39,46$

21,65

I 7,51

46

46

64

1,30

$57,59,67$

71

$56,57,61,67$

66

65,66

65

64

63

64

64

54.67

$6 \mathrm{I}$

61,67

61,62

61,62

62

6

$7,21,54,67$

5.

54

$6 \mathrm{I}$

63,67

$3.21,55,56$

65

6 I

57,64

6.4

63

60,65

54

54,6 I

$2 \mathrm{I}$

I 7,5 I

I6

6 I

88

66

46

62

63

64

64
Bacterium vascularum-continued.

PAGE.

slime, oozing from leaf-sheaths and stems I $6,22,25,53,66$ Smith, R. Grejg, studies....... 57, 60, 61, 62,63,64 (See also Sugar-cane, Cobb's disease of.)

sodium chloride, effect on growth. . . . . . 63,64

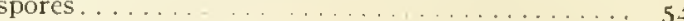

stains, reaction to .......... 5

starch, effect on growth.................. 64

starch, slight action of organism on

substitution for B. pseudarabinus in Greig-Smith's experiments on red stain in gummed cane.

sugars as food

sunlight, organism sensitive to

tear-drop formation on gelatin.

66

temperature relations. .............6.64,67

thermal death-point experiments .........64.65

tissues attacked... $6,7,15,24,66$

trimethylamin, production of ........... 56

'Tryon's studies. . . . ......................

(See also Sugar-cane, Cobb's disease of)

Uschinsky's solution, feeble growth in . . . . . 62 vascular system attacked by . . . . . . 6, 15, 24,66 vasculin

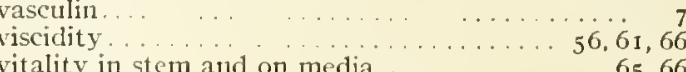
yellow slime,

primrose to lemon color on potato......... 60

whitish in absence of air............. 58

Bacterium xanthochlorum,

(See also Potato, Schuster's German Rot.)

acid, toleration of

acid-production $\quad \ldots \quad \ldots \ldots \ldots 272,275$

$\ldots \ldots \ldots \ldots \ldots 273$

alcohols, growth in. .............2 273, 275

alkali, toleration of $\ldots \ldots \ldots \ldots \ldots \ldots 275$

alkali-production. . . . . . . . . . . . 272, 275

ammonia-production ................. 272

amylase produced ................... 272

anaerobism, facultative. . . . . . . . . . . 273

biological characteristics. ................ 272

blood-serum, non-liquefaction of . . . . . . . 273

chloroform, effect of . . . . . . . . . . . 275

colonies on agar .... . . . . 273

colonies on gelatin...................... 273

disintegration of potato-tuber sections in infecter

drying, sensitive to............ 275

entrance of organism into tuber. . . . . . . . . . 272

enzym, action on starch.............. 274

effect on cell-walls.................. 274

effect of temperature on .............. 274

extraction of ..................... 274

injection into potato-tubers............ 274

fermentation-tube experiments............ 275

filaments, production of . _ ......... 272

flagella ....... . . . . . . . . 272

effect of temperature on formation of . . . . . 272

fluorescence, greenish-yellow. . . . . . . . . 273

galactose, fermentation of $\ldots \ldots \ldots \ldots \ldots 275$

gas, non-production. . . . . . . . . 273, 275

gelatin, liquefaction . . . . . . . . . . 273, 274

glycogen, production of .............. 272

Gram's stain .................... 272

grape-sugar, fermentation of ........... 275

growtis on, or in,

acid bouillon.

.

.

274

alkaline potato-agar plus tyrosin . . . . . . . 274

beer ....................... 273

bouillon over chloroform ................ 275

bonillon plus grape-sugar . . . . . . . . . 273

bouillon, peptonized, plus sodium chlorid . . . . 275 
PAGE.

Bacterium xanthochlorum-continued. growth on or in-continued.

$\begin{array}{ll} & \\ \text { carrot-juice agar ........... } & 273 \\ & 275\end{array}$

Cohn's solution ............. . 275

fermentation tubes............ 273,274, 275

gelatin .................. 273,274, 275

plus sodium selenite

273,275

Loefller's blood-serum

Meyer's solntion, plus,

alcohols

273

ammonium salts ................... 273

. . . 273

asparagir $\ldots \ldots \ldots \ldots \ldots \ldots 273$

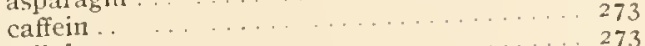

cellulose ......................... 273

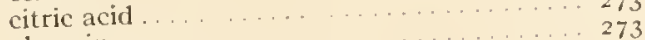

glycerin ........................ 273

peptone ..................... 273

potassium salts . ................ 273

potato starch ..................... 273

sugars ... . . . . . . . . . . . 273, 275

milk

273,275
$\ldots .273$

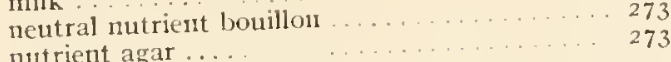

nutrient agar ....

peptone-water plus

cane-sugar . . . . . . . . . . . . . . . . . 275

fructose . . . . . . . . . . . . . . 275

galactose ................... 275

glycerin ..................... 275

grape-sugar . . . . . . . . . . . . . . 275

lactose ......................... 275

maltose ......................... 275

mannit ......................... 273

potato-juice-agar $\ldots \ldots \ldots \ldots \ldots \ldots \ldots \ldots 273$

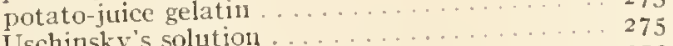

Uschinsky's solution ...................... 273

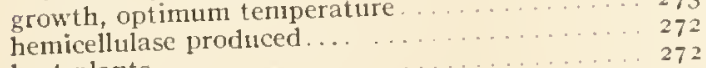

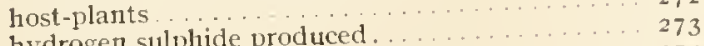

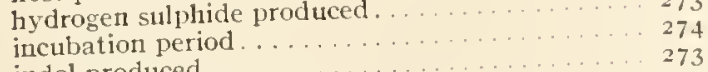

indol produced.

inoculations on,

Campanula raphunculus............... 272

cartot roots.... . . . . . . . . . . . . . . 272

fodder beets.................... 272, 274

lupines...................... 272, 274

Lupinus nanus douglasi ................. 27272

pelargoniums.

Physalis alkekeigi …...... . . 272,274, 275,276

potato tubers............ 272,274, 275,276

sugar beets...................... 272

tobacco stems.................... 272

tomatoes.................... 274, 275, 276

Vicia faba .............. $27+, 272$

yellow lupins................... . 272

involution forms .................. 272

isolation .................... . . . 272

lenticels, inability of organism to enter .......... 272

light, effect on virulence................ 273

light, sensitive to.

liquefaction of gelatin............... 273, 274 ,

liquefaction of Loeffler's blood-serum, mon-occurrence of . . . . . . . . . . . . 273, 275

literature.............................. 273

methylene blue, reduction of ...................... 272

metliylamin-production. ................... 273

milk, coagulation of .................. 273

milk, peptonization of . . . . . . . . . . . 273

morphology ..................... 272

effect of temperature on ................ 272

motility ................................ 272

effect of culture media on ............ 272

effect of temperature.......................... 273

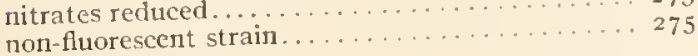

Bacterium xanthochlorum-continued.

PAGE.

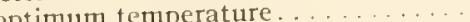

... 272

parasitismicity............... 272

pathogenicity with that of Bacillus phytophthorus. 272

cffect of temperature on............. 272

pignent,

effect of culture media on .......... . 272

solubility of . . . . . . . . . . . . 272

potato starch, effect on .....................

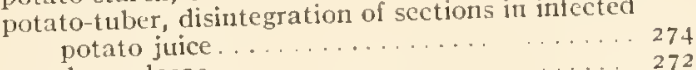

pseudozoogloeae ......................... 272

red stain on alkaline potato-agar, Spitzer s reaction 274

Schuster's observations.................... . . . 275

sodium chlorid, effect of ...................... 275

sodium selenite, action on ........................ 273

solubility of pigment......................... 274

solution of middle lamella .................. 274

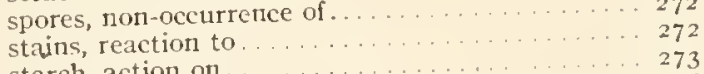

starch, action on . ' V icia faba) ........ 272,276

rapidity of . . . . . . . . . . . . 274

sugars, growth in ............... 273, 275

temperature, effect of, on,

enzym action. .................... 274

flagella-formation................. 272

milk cultures.................... 273

morphology .................... 272

pathogenicity............... 272,274,275

temperature, relations............ 273, 274, 275

thermal death-point . . . . . . . . . . . . 272, 274,275

tissues attacked ................. 272, 274,276

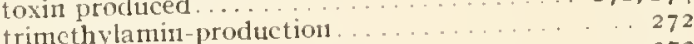

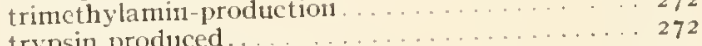

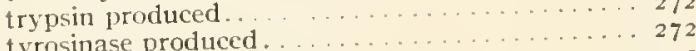

tyrosinase produced . .

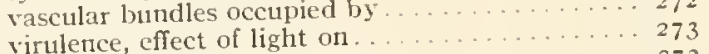

wounds, means of entrance ............ 272

xasthochlorum hemicellulase. . . . . . . . 274

Bacterium zinnoides

associated with Bact. solanacearum in Sumatra. . 259

Bailey, observations on New York tomato disease. 205

Banana, Bengal discase .... . . . . . . . . . 173

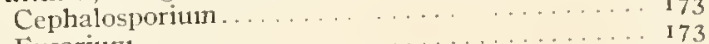

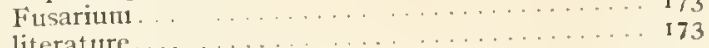

Surinam disease, resemblance to ......... 173

Banana, Central American disease. (See Banana, Panama discase.) Banana, Costa Rican disease. (See Banana, Panania
disease.)

Banana, Earle's Jamaican disease... … . $\quad$ I68

geographical distribution................ 168

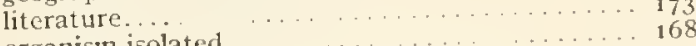

organism isolated............................ 173

Panama disease, relation to .................. 173

.

Banana, leaf-blight... Jamaican disease.)
(See Banana, Farle's Jamas

Banana, Panama disease . ... . . . . ... . ... 172

bacteria in vessels.. . . . . . . . . . 173

gas-forming. ........... 171

non-pathogenic............ . . $\quad \ldots 17$

cause .................. $\quad 173$

Costa Rica, accurrence in. . . . . . . . $\quad 173$

Fusarium in bundles.................. 173

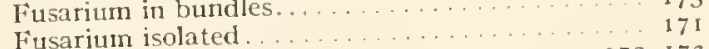

geograplical distribution ........... 172, 173

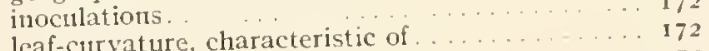

leaf-curvature, characteristic of ............... 172

losses...................... 172 
Banana, Panama discase-continued. parts of plant attacked.

resistant varicties.

Rorer's 'Trimidad disease, differences signs of disease.

splitting of leaf-sheaths.

staining of bundles

Surinam, occurrence in

susceptible variety...

Trinidad occurrence in

vessels sometimes occupied by bacteria.

wholesale prevalence of

Banana, Rorer's Trinidad disease. . .

(See also Bacillus musae.)

bacterial ooze

breaking over of leaves. .

cavities, bacterial

cells invaded by...

diseased suckers, planting of .

distinct from Panama disease.

inoculations.

inoculations on

Manila hemp

solanaceous plants...

tomato

isolation of parasite.

literature...........

Panama disease, how different from.

resistant variety.

signs of disease.

splitting of leaf-sheaths, not characteristic.

staining of bundies

tissues attacked.

varieties attacked

vessels occupied by bacteria

Banana, Smith's Cuban disease.

bacteria sometimes present in.

cause.

comparison with Trinidad disease

inoculations....

isolation of Fusarium

literature....

signs of disease

splitting of leaf-sheaths

vessels, browning of

vessels, occupied by I'usarium

Banana, South American diseases.

Banana, Surinam disease.

(See also Banana, Panama disease.)

Fusarium present.

literature.

resemblance to Bengal disease.

Banana, Vascular diseases disease; Banana, Panama disease; Banana, Rorer's Trinidad disease: Banana, Smith's Culvan disease.)

literature. . . 173

Bancroft, rot of potato and tomato, Mlalay States.. 2 I I

Basu, Bengal disease of banana..... . . . . 173

Benecke, Sereh observations... 72, 73

Biffen, English disease of mangolds and sugar-beets. 15.

"Black-leg" of tobacco......... ... 239

(Sce Bacillus nicotianae Uyeda: Tobacco, wilt-diseases, Japanese disease.)

Blight of Young Rose Slioots

Bolliger, Brazilian disease of manilıt. . 280

Bonâme, studies on "gummosis" of sugar-cane. 3, 10, 1 5,63

(See Sugar-cane, Cobb's disease.)

Bondar, Brazilian disease of manihot......... 280

Bos, Ritzema, flax stems, bacteria in vessels...... I5t

Bowhill, tobacca-wilt, South Africa............. 268

Brazilian disease of manihot............. 280

(See Manihot, Brazilian disease.)

Briosi, Italian disease of stock. . . . . . . . . . 277

Brown rot of Solanaceae..

(See Solanaceae, brown rot; Bacterium solanacearum.)
Burrill, bacterial disease of potato........ 203, 205 Bacterium solanacearum.............. I 78 brown rot of Solanaceae, observations on....... I 8 I

Burrill's disease of maize. . . . . . . . . . . . . . . . 89 (See Corn, Stewart's bacterial disease.)

Butler, E. J., Serch and cane-gummosis in India... 3

Cabbage, brown rot. ................ I 9 I

Canker of tobacco.............266,267,270

(See Bacillus aeruginosus, Tobacco, wilt-diseases, French disease.)

Capsicum annum, wilt. (See Pepper, blight.)

Cephalosporium, Bengal banana disease......... 173

Ceylon disease of tomato (Bacterium solanacearum?) 214

Chlorosis of sugar-cane................ 8 8 I

(See also Sugar-cane, Top-rot, and Sugar-cane, Pokkah bong.)

Cladosporium herbariun, orchard grass, Ráthay's

disease . . . . . . . . . . . . . . 155

Clark, Cobb's disease of sugar-cane,

accurrence in Fiji ...................

pecuniary losses in Fiji.............. 70

Clinton,

brown rot of Solanaceae reported fron Connecticut 175

tobacco canker.................... 267

Cobb.

disease of sugar-cane...

(See Sugar-cane, Cobb's disease of)

studies on "gummosis" of sugar-cane. (See Sugarcane, Cobh's disease of).

Cobey, tobacco-wilt, losses............... 237

Coleman, Mysore ring disease of potato......... 212

(See also Solanaceae, brown rot, ring disease of potato, Mysore.)

Collar-rot of tobacco.... $266,267,270$

(See Bacillus tabacivorus; Tobacco, wilt-diseases, French disease.)

Comes,

Bacterium gummis.............. 203, 215,266

Italian disease of tomato............ 215

tobacco-rot, Italy. . . . . . . . . . . . . . . 266

Cook, top-rot of sugar-cane in Cuba.......... 3

Corbett, observations on New York tomato disease. 205

Corn, Stewart's bacterial disease... . . . . . . . 89 (See also Bacterium stewarti.)

bacterial occupation of the vascular system... 89, 90 ,

$91,93,94,130$

bacterial ooze from cut stems, etc.... 89,90,9I, I3 I hacterial pockets...................... 13

bacterial slime,

enomous quantity of .............. 126

homogeneity of ................ 95

occurrence in stem 6 feet from point of infection. 126

paler in upper part of stems............. 94

bundles, stem, anatomy of ............129,130

cavities.....................91,95, 131

cellulose not destroyed. . ............ 130

cirri in. .

cob penetrated by bacteria . . . . . . . . . . 114 congressional seed distribution, disease spread by

constitutional signs, how soon visible....... 97 corn kernel, anatony of ...... $114,116,130,131$ cruslied kernels, test cultures should be made from. 125 definition........................ 89 dissemination through infected seed . . . . . I 14, 127 drouth, signs conspicuous during . . . . . . . . . 94 Duggar's observations. . . . . . . . . . . 89 dwarfing.

due to....................... 89, 90

influence on ..................... 11 I

early sweet varieties, most subject to... I 1 $2,113,118$ etiolation. ...................... 90 etiology..

field corn varieties subject to $\ldots$

field observations on................ 94, 114

frost effects, resemblance............... 101 
Corn. Stewart's bacterial disease-continued.

PAGE. fungicides geographical distribution. germictin germination of treated seed best.... . history.

host-plants.

hot-water treatment of seed.

husks,

anatomy of . .

bacterial pockets in. .

spots and patches on.

hyperplasias absent in .

infected seed,

dissemination through

experimental plantings of

treatment of . .

treatment with formalis.

treatment with hydrogen peroxide.

treatment with mercuric chloride.

infection,

accidental, manner of occurrence....

course of...

from base upward

from top downward.

93,146

$89,93,146$

93,146

127

147

147
89

146

119,120

103

I31

I 14,127

$115,121,125,128$

I 46

128

128

$125,127,128$

insects, not due to...

means of, Stewart's theory.

most serious in seedling stag.

slow to appear.

through seed.

through water-pores.

time of

inoculations. .

(Sce Bact. stewarti.)

inoculations,

Stewart's.

result of late....

isolation of Bact stcwarti, at tempted from infected

kernels................. I

by direct transfer from diseased stems. . . . . . . 96

kernels

bacterial contamination of surface.

penetrated by the bacteria......

leaf-tips, bacteria found in . . .

12,124

90,102

96,125

I 13

93,94

I IO, I 13, 125, 129

127,128

I 14, I 27

94

89

96

leaves, ffect on.....

lesions produced

literature.

local signs, how soon visible

losses, pecuniary.

male inflorescence, premature development

male inflorescence, whitening of.

mercuric chloride, effect on infected seed ... 89, 94

method of obtaining pure cultures from.

moist soil, effect of .......... 122, 123, 124

morbid anatomy.

nature of, markedly vascular ........

nodes, brown stain in.

organism causing, description of

$90,100,102$

(See also Bact. stewarti.)

organisms other than Bact. stewarti (on kernels). . 12.5

parenchyma, bacteria in.

parts of plant attacked.

polar flagellate bacterium, cause of

pop-corn, experiments..........

premature development of male inflorescer

preventive measures......... . . .... I 45

pure cultures from . . . . . . . . . . . 96

resistant varieties.............. I I

root-pressure ceases with frosting of leares ... $\quad$ s9

roots, effect on not conspicuous... 90, 9.5, 105

secd, infected, dissemination tlirough...... I 14, 127

seed, treatment ..................... 146

shoots, production.................. I3I

signs of disease . . . . . . . . . . . . . 89,94

slow growth, hinders development of disease..... I ro,

II I, 127, 128
Corn, Stewart's bacterial discase - continued

soil conditions, effect.

staining of tissues.

stem, effect onl.

Stewart's studies,

browning of tissues.

discovery of Bact. stewarti.

field observations

geographical distribution.

inoculations

means of infection.......

susceptible varieties

wcather conditions, effect

stomata, bacterial ooze through

susceptible varieties.

susceptibility, ffert of slow growth .

time between infection and appearance of

tissues attacked.

toxine, not conspicuous in

PAGE.

treatment

trial plots, results on

nneveness of fields attacked by

varictal resistance, question of

varieties resistant to.

vascular infection, generalized.

.

$91,93,94,130$

viscidity of slime in

126,127

water-pores, infection through

.. 94

weather conditions, effect of ........... 94, 124

whitening of male inflorescence.... $89,94,113,115$

yellow bundles...................... 95

yellow ooze...................... 9o, 94

variability in color of ..............94, 95

Corynebacterium piriforme associated with Bact solanacearum in Sumatra ........... . 259

Conncilman, blight of young rose shoots....... 154

Cozart, tobacco-wilt, losses................ 237

Crossonini, indol reaction with paradimethylamido. benzaldehyd.

249

Cucurbit wilt, vascular nature of . . . . . . . . . .

Dacty lis glonerata, bacteriosis of . . . . . . . 155

(See Orchard grass, Ráthay's disease of.)

Debray, Bacillus sacchari.

76

De Jong, peanut-wilt

flooding infected fields for............. 278

planting, selected seed for.............. 271

Delacroix,

Bacillıs aeruginosus. . . . . . . . . . . . . 266

Bacillus caulivorus. . . . . . . . . . . . . . . . 175

B. putrifaciens putridus . . . . . . . . . . 266

B. solanincola . ................ I75, 215

B. tabacivorus ........... 266

Fresich disease of potato... ..........214

Tobacco, Fusarium disease. . . . . . . . . . 228

wilt-diseases................... 266,270

de Laharpe, French potato disease ........... 215

Deli tobacco organism

[See Bact. solanacearun (Sumatrau tobacco-wilt organism.)]

Dewar, tohacco-wilt, South Africa ............ 268

1)iem, Deli tobacco, variations............. 261

Diplococcus enteritis, Gram's stain, reaction to.... 247

Doryphora ro-lincata, distribution of brown-rot of Solanacea by

180

Dränert, studies on bacterial disease of sugar-cane. 3, 7o

Drost, Sonth American banana diseases. . . . . 173

Dutch disease of wallfower... . . . . . . . 277

Dutch East Indian disease of tobacco....... 220

ISee Bacterium solanacearum (Sumatran tol)acco-wilt organism); Tobacco, wilt-diseases, Dutch East Indian disease: Tobacco, wilt-diseases, Honing's Sumatran Studies.] 
Dutch Fist Indian diseace of tomato PAGE (See Solanaceae, brown rot, Dutch East Indian disease.)

Fatle, banana leaf-blight................. 168 brown rot of Solanaceae.............. I8 8 I, 206

Egg-plant blight. . . . . . . . . . . . . . . I 7 t (See Solanaceae, brown rot: Bacterium solanacearum.)

Engelberts, Sereh, losses.................. 72

English disease of nangolds and sugar=beets .. 154

Englisl disease of potato.., 216

Eriksson, Ring disease of potato. 216

Éssed, banana disease.......... . . . 173

Fertilizers, relation to immunity.... ... . . 270

Flax, hacteria in vessels of stems.... . . . I 54

Florida potato organism.......... 251,264, 267 [See Bact. solanacenrum (potato and tomato).]

Florida tobacco wilt

See Bacterium solanacearum (North American tobacco-wilt organism); Tobacco, wilt-diseases, North American disease.]

Fodder-beets, disease described by. Kramer

Firench disease of potato.

French disease of tobacco.

(See Bacillus aeruginosus, B. putrifaciens putridus B. tabacivorus: Tobacco, wilt-diseases, French diseace.)

Fulton, peanut wilt species..

I'usarium sp. seen in

Australian disease of potato ............ 208

Bengal banana disease.................. I . 73

Panama diserse of banana.............. 173

potato diseases...................... 203

Surinam disease of banana........... . . 73

tobacco-wilt.................. 227,228

Fusarium cubense. $\quad 160,173$

isolated from Smith's Cuban banana disease.... I68

Panama disease of banana ascribed to

(See also Banana, Smith's Cuban disease.)

German Ring disease of potato. .

See also Solanaceae, brown rot, ring potato, Germany.)

Graham, tobacco-wilt. .

Grand Rapids tomato disease.

(See Aplanobacter michiganense; Tomato, Grand Rapids disease.)

Granville wilt of tobacco ........... 17 $7+220,227$

[See Bacterium solanacearum (N. Am. tobacco-wilt Griffon, organism): Tobacco, wilt-diseases, N. Am. disease.

Bacillus aeruginosus, synonymy.

B. brassicaevorus, synonymy.

B. caulivorus, synonymy.

B. fluorescens liquelaciens, synonymy ...

B. fluorescens putridus, synonymy

immunity relation of fertilizers to. .

Gumming of sugar-cane.

See Sugar-cane, Cobb's disease.

"Gummosis" of sugar-cane.

(See Sugar-cane, Cobb's disease.)

Halsted, observations on bacterial disease of potato and tomato.

204.205

hamawedang

(See Peannt wilt, wan Breda de Haan's.)

Heart disease of sugar-cane

(See Sugar-cane, heart disease.)

Helms, New South Wales potato diseases.

Herman, Brazilian disease of manihot

Heterodera radicicola, effect on outbreak of Dutch

Honing, East Indian disease of tomatoes.... 2 IO, 2 I I

Bacterium solanacearum, host-plants

I 190

Bacterium solanaccarum, involution forms....... . . 194

cited.

peanut wilt

sesamum, sumatran disease.
Honing-continued

PAGE

tobacco-wilt, Sumatran studies......... 224, 244 (Sep Tobacco, wilt-diseases; Honing's Sumatran Studies )

Hori, cited . . . . . . . . . . . . . . . . . . 239

Horne, top-rot of sugar-cane....................

Humid gangrene of sugar cane............ 85

(See Sugar-cane, Polvillo.)

\section{Hunger,}

agar used for isolation of Bact. solanacearum .... 2 II

brown rot of Solanaceae........ I 78, I $91,197,209$ (See Solanaceae, brown rot, Dutch Fiast Indian disease.) cited . ..................... 203,220,226 Dutch Fast Indian disease of tobacco... . . . 222 Dutch Fast Indian disease of tomato... . . . . . . 200

(See Solanaceae, brown rot, Dutch East Indian disease.)

Hutchinson,

Bacterium solanacearum. ............... 267 motility denied......... . 200, 265, 267

tobacco-tvilt, India . . . . . . . . . . . . 267

Hypocrea sacchari...................... . 52

Immunity, relation of fertilizers to ......... 270

Indian discase of tobacco . . . . . . . . . . 267

[See Bacterim solanacearum (Indian tobacco-nilt organism); Tobacco, wilt-diseases, Indian disease.

trons, Solanum mammosum resistant to brown rot of Solanaceae.

Italian disease of stock . . . . . . . . . . . . 277

(See Stock, Italian disease.)

Italian disease of tomato... 215

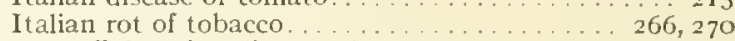

Iwanoff, Russian disease of potato ................. 214

Iwanoski, Rot of tobacco, Russia.............. . 265

Janse, Dutch East Indian disease of tobacco...... 220

Sereh ............... 52,74,75

Japanese disease of tobacco............. 238

(See Bacillus nicotianae Uyeda: Tohacco, wilt-diseases, Japanese disease.)

Japanese stem-rot of tobacco .............. 220 (See Bacillus nicotianae Uycda; Tobacco, wilt-diseases, Japanese disease.)

Javan top-rot of sugar-cane............... 3

Jensen,

cited ...... 220,226

experiments with $\mathrm{B}$. nicotianae............... $27 \mathrm{I}$

tobacco wilt, Dutch East Indies... . . . . . . . . . . . 224

Kirk, New Zealand potato disease.............. 207

Kobus, Sereh, geographical distribution ...... 76, 78

Kornauth, cited......... 218

Kotthoff, Spieckermann's Gernan Potato disease. . 167

Kozai, tobacco-wilt. . . . . . . . . . . . . . . 239

Kramer, disease of fodder-beets............... 154

Kreitz, ring disease of potato, Germany......... 2 I5

(See also Solanaceae, brown rot, ring disease of potato, Germany.)

Krïger,

Cobb's disease of sugar-cane, occurrence in Borneo. 3

Sereh.

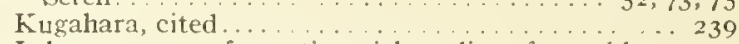

Lehmann, spore-formation, rich medinm favorable to, 247

Ieptospora in diseased banana. . . . . . . . . 173

Lounsbury, tobacco-wilt, South Africa........... 268

AcAlpine, Australian disease of potato . . . . . . . . . 208

MIcKenney

Panama banana disease. .............. 172

tobacco wilt, North Carolina.................. 227

Maize, bacterial disease of ................. 8

(See Corn, Stewart's bacterial disease of; and Bact. stewarti.)

Burrill's disease of ... . . . . . . . . . 89

(See Corn, Stewart's bacterial disease of; and Bacterium stewarti.)

Stewart's disease of .................. . 89

(See Corn, Stewart's bacterial disease of; and Bacterium stewarti.)

Malay States disease of potato and tomato.... 2 II 
Talkoff Bulgarian disease of Sesamum.

Mangolds, Einglislı disease of . . . . . . . . . . 154

Manihot, Brazilian discase of ........... 2 so

(See also Bacillus numilrotus.)

black hundles....................... 280

chemical composition of diseased plants....... 280

cuttings attacked. ..... 280

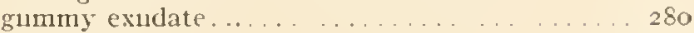

inoculations....................... 280

literature.

parts of plant attacked. . . . . . . . . . . 280

preventive measures.................. $28 \mathrm{f}$

resistant varieties............. $28 \mathrm{I}$

signs of disease..................... . . 280

starch-content, diminution in diseased plants. . . 280

swellings, stub-cortical.... . ... 280

tissues attacked. ........ ... . . . 280

transmission by inseets........ $28 \mathrm{I}$

treatment........... 28t

Mean tenperature required for grow th of sugar-cane. 4

[See Bacterium solanacearum (Sumatran tobacco-wilt organism), American studies.]

Medan tobacco organism .........242, 25 I, 263, 268

[See Bact. solanacearum (Sumatran tobacco-wilt organism), American studies.]

Melanospora globosa,

cultural characteristics.

isolation from Polvillo.

Mesentericus gromp, forms of, isolated from Appel's ring disease of potato...............

Micrococcus,

luteus, associated witl Bact. solanacearun in Simatra...

prodigiosus Cohn.

pyogenes (M. bicolor Zimmerman), associated with Bact, solanacearum in Sumatra....... 259

pyogenes albus, associated with Bact. solanacearum in Sumatra.

sp., isolation from top-rot of sugar-cane. . . . . $\mathrm{S}_{3}$

Moko disease.

(See Banana, Rorer's Trinidad disease.)

Müller, sugar content of gummed cane.

Murplay Bacillus unelanogenes.......

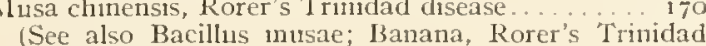
disease. )

Musa paradisiaca, Rorer's Trinidad disease.... . . . I 70

(See also Bacillus musae; Banana, Rorer's Trinidad disease.)

Mysore ring disease of potato ........... 212

(See Solanaceae, brown rot, ring-disease of potato, Mrsore.)

New Soutl Wales potato diseases. . . . . . . . . . 207

New Zealand disease of potato.........., . 207

North American disease of tohacco........ 227

ISee Bacterium solanacearum (N. Am. tobacco-wilt organisin); Tollacco, wilt-diseases, N. Am. disease.?

North Carolina tobacco wilt

227

[See Bacterium solanacearum (Nortl American tobacco-wilt organism): Tobacco, wilt-diseases, Nortll American disease.]

Odlum, African disease of potato............. 214

Orchard grass, Råthay's disease... . . . . . . . 155

(See also Aplanobacter rathayi.)

bacterial slime.

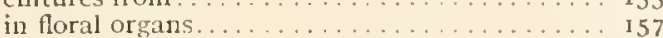

in leaf-tissues. . . . . . . . 50

litmus reddened by . . . . . . . . . . . . 155, 157

microscopical examination of ............ 155

odor of ...................... 155

organisms composing. ............. 155

carriers of the disease . . . . . . . . . . . 157
Orchard grass, Ráthay's disease-continued.

PAGF.

chlorophyll bodies, effect on............. I 55

Cladosporium, secondary infection. . . . . . . . I55

cuticle, effect on... 155,156

distortions of stem in ... . . . . . . 155, 157, 158

dwarfing . . ....................... 155,157

geographical distribution............. 155, I57

glumes, lemon yellow or water-soaked....... I57

infection,

point of, unkrown.............. 156, I57

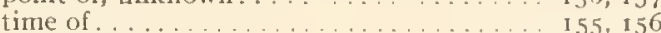

inoculations........................ 156

knee-shaped bendings of stems. . . . . . . I55, I58

leaf-sheatlis stuck together . . . . . . . . . . I57

literature......... I60

occurrence,

in meadows (Denmark) . . . . . . . . . . I57

in woods (Austria) .................. I56

on surface first.... . . . . . . . . . . . . 156

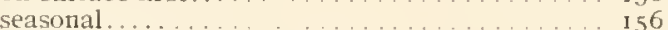

portions of plant attacked......... 155, 156, 157

Ráthay's work................... I55

resemblance to

Cobb's disease of sugar-cane, signs . . . . . . 157

Stewart's disease of sweet-corn............ 157

resistance of other grasses........... 155, 156

secondary infection,

with bacteria. .............. 155, I 59

with fungi...................... 155

signs of disease. . . . . . . . . . . . . 155, 157

Sporidesmium (secondary infection) ......... 155

tissues attacked................ 155, I 56, I 59

Osborne, spore-formation, relation of medium to . . 247

Pavarino, Italian disease of stock. . . . . . . . . 277

Peanut wilt, Sumatra. [See also Bacterium solanacearum (peanut-wilt organism); Peanut wilt, United States; Peanut wilt, van Breda de Haan's.]

Honing's report of .... . . . . 153, 253

Peanut wilt, United States............. I 53, 27 I

[See also Bacterium solanacearum (peanut-wilt organism); Peanut wilt, Sumatra; Peanut wilt, van Breda de Haan's.]

etiology ..... . . . . . . . . . . . . . 27 t

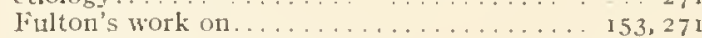

inoculations,

peanut organism on peanut..................... 27

peanut organism on tobacco............ 27 I

pepper-wilt organisn on peanut.........27

potato-wilt organism (Florida) on peanut..... 282

tobacco-wilt organism (N. Am) on peanut . 271, 282

tobacco-wilt organism (Sumatra, Medan III) on peanut...

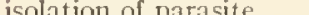

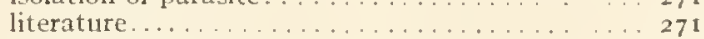

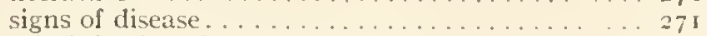

soil infection throngh.................. 27 I

Peanut wilt, van Breda de Haan's .......... I5I

[See also Bacterium solanacearum (peanut-wilt organism); Peanut-wilt, Sunnatra; Peantıt-wilt, United States.]

altitude, clfect of .... 152

etiology ..... . . . . . . . . . 153, 253, 27 I

literature...................... I53,271

parasite. . . . I 53

parts of plant attacked . . . . . . . . . . . 152

signs of disease................... 152

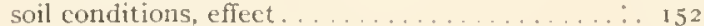

tissues at tacked . . . . . . . . . . . . . . . 1.52

Pepper blight.

(See also Solanaceae, brown rot.)

Pernambuco disease of sugar-cane.

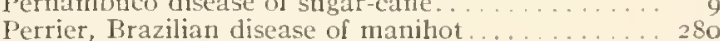

Petch, Ceylon wilt-disease of tomato .......... 214

Pethyluridge, Bacillus melanogenes. . . . . . . . . . 175 
Phytophthora infestans,

French disease of potato (Delacroix).

losses caused by.

Phytophthora nicotianae, effect on outbreak of Dutch

East Indian bacterial disease of tomatoes... 210

Pith-rot of tobacco.

266,270

(See Bacillus putrifaciens putridus; Tobacco, wilt diseases, French disease.)

Plantain, Rorer's Trinidad disease . ...... 170 (See also B. musae; Banana, Rorer's 'Trinidad disease.) inoculations.................170, 17 I isolation of parasite. ................. 170 literature......................... . 173 signs of disease................. I . I70 varieties attacked . . . . . . . . . . . . . . I 70

Pokkah-bong of sugar-cane........... 3,81 (See Sugar-cane, Pokkah-bong.)

Polvillo of sugar-cane..

Potato,

African disease.

Australian disease

“black-leg," resemblance tu brown-rot

brown-rot,

(See Solanaceae, brown-rot.)

English disease.

French disease.

German ring disease Germany.)

Malay States disease.................... 211

New South Wales diseases. ... . . . . . . . . . . 207

New Zealand disease. . . . . . . . . . . . . . . 207

ring discase, Germany ............... 166, 215

(Sce also Solanaceac, urowi1-rot, ring disease of potato, Germany.)

ring disease, Mysore. . .......... . 212

(See also Solanaceae, brown-rot, ring disease of potato, Mysore.)

Russian discase.

Schuster's German rot .

(See also Bacterium xanthochlorum.)

blackening of tissues.

description of diseased.

lupins

Physalis

potato-tubers

Vicia faba.

incubation periud

inoculations. (See Bact, xanthochlorum.)

isolation of parasite.

literature

odor of rotted tubers

parts of plant attacked

Schuster's observations

stomatal infection (V'cia faba) rapidity of

tissues attackèd

tubers, diseased, appearance

272

pieckermann's German disease

analyses of tubers, stems, ctc.

bacteria in diseased plants.

Bacterium solanacearum, nut cause of

brown rot of Solanaceae, relation to.

cause of

diseased stcms, microscopical appearance

diseased tubers, bacteria in vessels

diseased tubers, vascular ring, appearance of .

dissimilarity to Appel's ring discase.

eyes of the tuber, blackening of

Fusarium, secondary infection

germination, effect on

inoculations

literature.
Potato-continued.

PAGE.

Spieckermann's German disease-continued.

parasite, cultural characteristics........... 167

description of . . . . . . . . . . . . . 167

Gram's stain..................... 167

optimnm temperature............... 167

slow growth on media ............. 167

progress of disease....................... 166

signs of disease. ............. 166

similarity to Grand Rapids tomato disease... 164

slow softening of parencly'ma in . . . . . . . 166

softening of vascular ring................. 166

staining of vascular ring . . . . . . . 166, 167

tissues attacked....................... I66

tomatoes, occurrence onf............... 167

varieties, many suseeptible............. 167

vascular ring, effect on............. 166, 167

vessels occupied by bacteria............. 166

viscid organism cause of . . . . . . . . . . 167

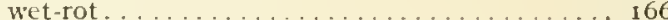

yellow bacteria cause of............. I67

Potato-rot........................ I . 74

(See Solanaceae, brown rot; Bacterium solanacearum.)

Potato-rots,

causes. . . . . . . . . . . . . . . . . . . . . 203

recent great advance in knowledge of . . . . . . 203

Prillieux, Bacillus caulivorus............. 175

Prinsen-Geerligs,

Sereh, geographical distribution............ 78

sugar-cane, cellulose, oxidizable substance in .... I6

Pseudomonas,

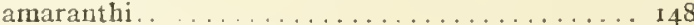

(See Bact. amaranthi.)

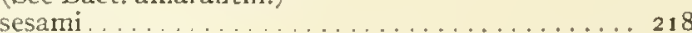

solanacearum................... 178

(See Bacterium solanacearum.)

sp., isolated from ring-disease of potato . . . . . . 166

stewarti......................... I 32

(See Bact. stewarti.)

vascularum. (See Bacterium vascularum.)

Raciborski, tobacco-wilt, Dutch East Indies, cause.. 222

Rasa of tobacco...................... 267

(See Tobacco, wilt-diseases, Indian disease.)

Ráthay's disease of orchard grass . . . . . . . . 155

(See Orchard grass, Ráthay's disease, and Aplanobacter rathayi.)

Ratoon-cane, nature of ............... 6

Ravn, Ráthay's disease of orcliard grass. . . . . . 157

Ring disease of potato

(See also Solanaceae, brown rot, riug disease of potato. Germany.)

Germany..... ... 166, 215

Mysore................. . . 12

(See also Solanaceat, brown rot, ring disease of potato, Mysore.)

Rolfs, P. H., brown rot of Solanaceae.......... 205 Rorer,

Panama disease of banana ............. 173

Surinam disease of banana.... . . . . . . . 173

Trinidad disease of bananas and plantains. . . . 170

Rose, blight of young shoots ............ 154

Russian disease of potato ................. 214

Russian disease of tobacco......265,270

(See Tobacco, wilt-diseases, Russian disease.)

Sackett, tobacco wilt, North Carolina.......... 227

Scbreiber, spore-formation, relation of mediuru to . . 247

Schuster's German potato rot .......... 272

(See potato, Schuster's German rot.)

Schwarzbeinigkeit, resemblance to brown-rot...... 175

Selby, brown rot of Solanaceae.............. 205

Septogloenm arachidis.................. 15 I

Sereh disease of sugar cane . . . . . . . . 3, 52,73 (See Sugar-cane, Sereh.)

Sesamum, bacteriosis of ................... 2 Io

(See also Solanaceae, brown rot, Sesamum bacteriosis.) 
Shamel,

Deli, tobacco impurity of seed .......... . . 26i tobacco wilt, losses

Smith, R. Greig, on bacterial disease of sugar-cane. (See Sugar-cane, Cobb's disease, and Bact. vascularum.) mith's Cuban disease of banana...

(See Banana, Smith's Cuban disease.)

Smith's disease of amaranths.

(See Amaranths, Smith's disease and Bact. amaranthi.)

Solanaceae, anatomy of

Solanaceae, brown=rot ............ 174

(Tobacco-wilt diseases are indexed separately.)

[See also Bacterium solanacearum (potato and tomato) Peanut wilt.

adventitious roots, tomato....... I78, 190, 199, 209

African disease of potato, Odlum's observations.. 214 alkalinity of juice of attacked plants......... 178 alkalinity of jitce of disseminators of ... 184, 210,213 Appel, Ring disease of potato.......... 166,215 Appel, Ring disease of potato and tomato, Tryon's observations.................... 207

bacterial ooze . . ........... 175, 177

bacterium solanacearum, cultural characteris-

tics........................ 194, 199

description ..............................

(See also Bacterium solanacearum (potato and tomato.)

Bailey's observations on disease of tomato...... 205 Bancroft's observations on disease of potato and tomato............. (") black leg,")

basal stem-rot of potato ("black leg'), ...... 176

how distinguished from ........................... 175

liable to confusion with .............. 175

beetles, disease spread by ..........

"black leg." (See basal stem rot.)

blackening of tissues..................... 179

broken roots, avoidance of, in transplanting . . 1 1, 209

browning of tissues........... I 7 p 175, 177, 203,205

Burrill's observations on disease of potato... 203, 205 calcium oxalate, excess of, in diseased plat, 191, 199. 209 cavities, common in ............. 176, 196, 199. 199 cell-walls, action on ..................... I9I cells occupied by bacteria in.............................. Ceylon disease of tomato, Petch's observations... 2 I Coleman, Mysore Ring disease of potato.......2 212 Comes' obscrvations on disease of tomato... 203,2 I Corbett's observations on disease of tomato.....205 cork-layer, protective, formation of ....... I78, 191 crop cut short by . . . . ............. 177 crystal-sand, excess of, in diseased plants.... 192, 209 definition . defacroix's phservations on disease of potato.... 214 potato de Laharpe's observations on disease of potato... 2 Is diffusion of bacteria from cut vessels......... I9

dissemination by insects................ 210

drainage, effect on. ................... . . . 209

209

adventitious buds................ 209, 2 II

adventitions roots.................... 209, 211

Bact. solanacearum, cultural characters . 215

Bact. solanacearnm, cultural characters.... 209

cavities in tissues................. 209

contaminating organisms.............. 209

crystals in discased tissues................. 211

culture-medium used for isolation of parasite, $2 \mathrm{n}$

drainage, effect on . .

frect of animal parasites on outbreak of disease. 210

effect of Phytophthora on outbreak of disease.. 2 ro

Hunger's observations on. ............ 209

infection, manner of ................ 211

infection througl wounds. . . . . . . . . . . 210

inoculation, methods of ............209,210

inoculations on

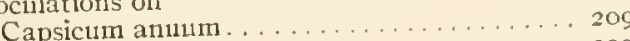

Nicotiana tabacum. .................. 209

tomato .................209, 210
Solanaceae, brown rot-continued.

PAGE.

Dutch East Indian disease of tomato-cont

pith, effect on ................... 209

prevalence ....................... 209

prevention, methods............... $21 \mathbf{I}$

roots,

diseased......................... 209

infection through................ 210

signs of disease...................... 209

tyloses............................ 209

vascular ring browned ................. 209

Dutch East Indian studies of Honing. . . . . 224, 244

Dutch East Indian studies of Honing ......... 178

Earle's observations 011. . ............... 206

early inoculations (1895, 1896) ... I $182,183,184,185$

early stages, potato.................. 177

English disease of potato............

entrance of organism into hoct............ I 8

etiology $y^{*}$ of organism into host. . 178

fluids, alkaline in........... 178

French disease of potato.

Delacroix's observations................ 214

de Laharpe's observations................ 215

Smith's studies of Delacroix's material.......2 I5

geographical distribution

(See also Appendix, p. 207.)

Grand Rapids disease, may be mistaken for . 1 175, 186

Halsted's observations on disease of potato and tomato...................204, 205

Helms observations on disease of potato . . . . 207

history........ . . . . . . . . . . . . . . 203

Honing,

bacteriosis of sesamum............... 2 I8

Dutch East Indian studies ........... 224, 244

lost-plants.

174,199

host-plants

(See also Peanut wilt; Tobacco, wilt-diseases.)

hot wcather, increases virulence of ......... I 82

Hunger's observations.......... 178, 181, 197, 209

hyperplasias

incubation period

179,180

infected soil, tomatoes grown in

I 8 I

infection,

difficulty of producing with organisms grown

long in culture media . . . . . ....... I 79,282

effect of age of plant............. 178, 180

effect of moisture............... 179, 182

effect of rapid growtli.............. 178, 282

effect of temperature ............. 179,182

inculation period.................. 179

through wounds............. 181, 182, 210

underground, in tobacco............. 181

underground, in tomato.

$18 \mathrm{I}$

See also Ract. solanacearum, inoculations.)

inoculations. (See Bacterium solanacearum.)

insects, distribution by.......... 180, 184, 2 10, 213

intercellular spaces occupied by bacteria in ..... I9

isolation of parasite. . . . . . . . . . . . . . . 205 difficulties experienced . . . ........... 178

Italian disease of tomato.

Comes' observations. . . . . . . . . . . . . 2 25

Voglino's observations.............. 215

Iwanoff's observations on disease of potato ....2 214

Kirk's observations on disease of potato....... 207

Freitz, Ring disease of potato. . ...........215

literature...... 218, 270

MicAlpine's observations on disease of potato...2 208

Malay States disease of potato and tomato, .... 2 11

Bancroft's observations.............. 211

signs of disease. . . . . . . . . . . . . 212

treatment ....................... 212

Malkoff's observations on discase of Sesammin... 210

middle lamella, solution of ........... I 79,182

moisture, effect on ............. 179, 182 
Solanaceae, brown rot-continued.

New South Wales, potato diseases, Helms' observations.

New Zealand disease of potato, Kirk's observations 207 Odlum's observations on disease of potato......21.4 parts of plant attacked,

egg-plant..................... 176 potato................ 176, 177 tomato......................... 176 pecuniary losses................... 202 pepper-blight.................... I 7

comparison of pepper, lobacco and peanut-wilt organisms..................... 271 inoculations,

Dutch Fast Indian tomato-wilt organism on pepper

Japanese tobacco-wilt organism on pepper 243

North American tobacco-wilt organisin on pepper................... 235 pepper-wilt organism on peanut........2 271

potato and tomato-wilt organism on pepper. $18_{3}$

Sumatran tobacco-wilt organism on pepper 246,253 period of incubation exceptionally long

179,180 very short.

ins on discase of tomato pith, effect on ............... . . 76,192 plants subject to.

(See also Peanut-wilt, and Tobacco, wilt-diseases.)

Porto Rico, occurrence in .............. . 17

potato-tubers,

effect on...

internal brown rot of

mixed infection in

signs of disease in .

tissues attacked.

production of, effect on .

rains, favorable to.

resistant Solanum

result of disease, potato.

ring disease of potato in Germany

Appel's observations.

bacteria isolated from cultural characteristics

dissimilarity to Spieckermann's German potato disease...

infected seed tubers, use of $\ldots \ldots \ldots 16$

infected tubers from apparently sound plants., 66 infection, manner of

Kreitz's observations

Psendomonas sp, isolated

signs of disease.

vascular ring, browning of .

ring disease of potato, Mysore.

Coleman's studies

geographical distribution.

infection,

manner of

non-relation of insects to

inoculations on

brinjals (egg-plant).

potato.

tomatoes

sigus of disease

treatment

Rolfs' observations

root-infection,

tobacco.

tomatoes.

roots,

developed on stems in

wonnding necessary for infection

rotation of crops advised

Russian disease of potato I waneff's observations. 20 secondary signs.

"seed" potatoes, treatment of
Solanaceae, brown rot-continued.

PAGE.

Selby's observations . . . . . . . . . . . . . . . . 205

selection of "seed" potatoes. ................ 201

sesamum bacteriosis . . . . . . . . . . . . . 2 2 I6

Austria ............................ 218

Bulgaria,

cultural characteristies of organisms ......2 216

dissemination of . .................. 216

inoculations................ 246,218

isolation of bacteria ................ 216

Malkoff's observations............... 216

signs of disease.................. 216

varicties attacked .................... 216

India ........... 218

Sumatra, Honing's observations........... 2 Is

shriveling of stems. . . . . . . . . . . . 175

signs of disease.............. 174, 175,209

potato tubers................. 174, 177

sleepy disease of tomato, signs resemble........ I 775

Smith, early studies of . . . . . . .......... 205

Spieckermann's potato disease, not related to .... 167 starch, removed from infected tissues (fig. 83). 176, 192 stem showing incipient roots (fig. 98)......... I 90

stems, brown streaks in. . . . . . . . . . . . . . 180

Stevens' observations. . . . . . . . . . . . . . 206

stomata, infection through, doubtful......... 182

storage of potatoes at low temperatures advised. . 202 susceptibility,

individual differences in . . . . . . . . . . . . . 180

varietal differences in . . . . . . . . . . . . . 180

temperature, effect on............179, 182

thickening of inoculated stems........ 178, 191

time of attack, effect, on potato........ 177, 178

1issues attacked.......... I 75, I76, 191, 192, 199

tobacco-wilt diseases, proballe identity. . . 220, 244

transplanting, care in .............. 201,202

treatment....................... 201,21

Tryon, on disease of potato and tomato...... 207

tuhers, potato,

infected by way of rhizome............

vascular ring first attacked in............ 177

tyloses........................... 209

underground infections in ............... 181

vascular ring, browning of .......... I 74, 177, 209

vascular tissue, excessive. .............

vessels occupied by bacteria ..... 174, 175, 191, 209

viscidity, not characteristic of . . . . . . . . . 197

Voglino's observations on disease of tomato....2 215

water-rich tissues more subject to. . 1 $74,178,179,282$

wilting..................... 174, 175

yellowing of foliage.............. 174,175

young plants specially sensitive to......... 174

Solanum mammosum, subject to Apl. micliganense. 163

Soltwedel, Sereh.............. 73, 74, 75, 78

Sorauer, sugar-beet disease in Germany. . . . . . . 154

South African disease of tobacco. . . . . . . . (See Tobacco, wilt-diseases, South Africall disease.)

Spegazzini, Polvillo,

geographical distribution. . . . . . . . . . . . . . . observations. ....................... 8

Spieckermann's German potato disease..... 166

(See potato, Spieckerman's German disease.)

Sporidesmium, Ráthay's disease of orchard grass... 155 Stem-rot of tobacco. . . . . . . . . . . . . . . 239

(See Bacillus nicotianae, Uyeda; Tobacco, wiltdiseases, Japanese disease.)

Sterens,

brown rot of Solanaceae...............204, 206

cited . . . . . . . . . . . . . . . . . . . 220

tobacco-wilt, losses . . . . . . . . . . . . . . . 237

North Carolina.

Stewart, observations on bacterial disease of sweet corn. (See Corn, Stewart's bacterial disease of.)

Stewart's disease of sweet corn........... 89 (See Corn, Stewart's bacterial disease and Bact. Stewarti.) 
Stock, ltalian disease.

PAGE. (See also Bacterinm matthiolae.

browning of tissues................... 277

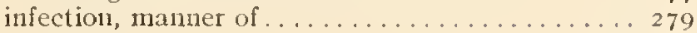

inoculations. ..................... 278

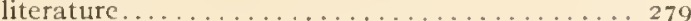

losses. . . . . . . . . . . . . . . . . . . 277

microscopic appearance of diseased tissties...... 278

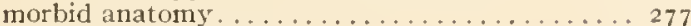

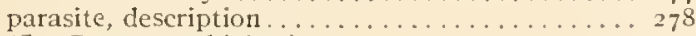

(See Bact. matthiolae.)

parts of plant attacked ................ 277

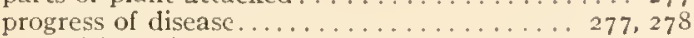

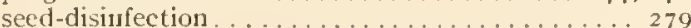

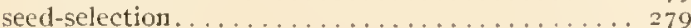

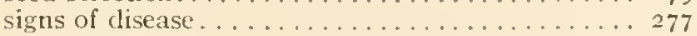

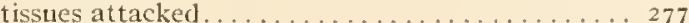

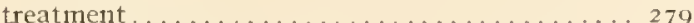

Sugar-beets, discase described by Soraner in Germany 154

Sugar-beets, Englisli disease of . . . . . . . . . . . . . 154

Sugar=cane,

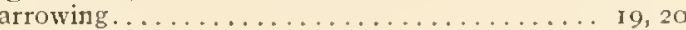

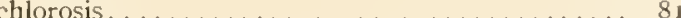

(See also Sugar-cane, Pokkah-bong; Sugar-cane, toprot.)

effect of copper sulphate on .......... 76

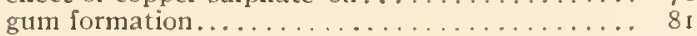
(See also Sugar-caire, Cobb's disease, and Singar-cane, Sereh.)

mean temperature required for growth of.......4

Sugaricane, Cobb's disease of ..............

(See also Bacterium vascularum.)

acidity of cane, effect on susceptibility ....... 47

acidity of cane-juice, relation to bacterial growth 47

adventitious roots.

acration and pigment stain ................... 16

bacteria dormant or dead in cane ... $30,31,46,54,65$

bacteria first discovered in connection with disease. 3

bacteria, location in tissues........6, $15,24,52$

bacterial ooze from leaves and stem $16,22,25,53,66$

bacterial ooze, great abundance of .......... 26

bacterial slime, identity with gutn........... 13

(See also slime, gum and rasculin.)

Bacterinm vascularum, description . . . . . . . . . 54

(Sce also Bact. vascularum.)

Bonâme's studies,

geographical distribution. . . . . . . . . . 3

sigrus of disease. . . . . . . . . . . . . 10

reduction of sugar-content ............. 15,63

bundles, mottled red and yellow . . . . . 16, 26, 27, 41

cavities formed in soft tissues....... $5,11,15,26,52$

check pricks, result of .............. 28,32

cirri from cut buindles............. 6, 30, 32

clarification of sugar hindered by ............ 3

climate, effect on disease................

Cobb's studies,

(See also Bact. vascularum.)

earliest appearance of disease . . . . . . . . . . 5

effect of moisture................. 49

geographical distributiou. ........... 3, 5

inoculation experiments. .... 8,13

pecuniary losses in Australia and New South

Wales.

crystallization, effect on...........................

decay of terminal bud. ................... $\ldots \ldots \ldots, 15$

definition of the disease................. 3

destruction of bundles in . . . . . . . . . . . 53

discoloration of tissues..... $3,4,5,11,12,15,16,18$

disease not air-borne.

drainage, partial remedy for . . . . . . . 49, 68, 70

Dränert's studies in Brazil ............. 3,70

dwarfilig..................... 3, 15, 22,27

earliest appearance of disease. . . . . . . . . 3, 5

early signs of disease ................... $35,36,37$

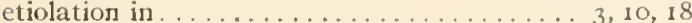

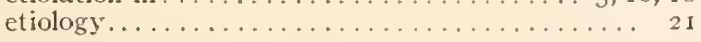

Sugar-cane, Cobb's disease of-continued.

geographical distribution of ... $3,4,5,9,10,11,13,14$ guin,

(See also vasculin.)

chemical reactions

$\ldots \ldots \ldots, 7,13,14$

terial sline from cultures. . . . . . . . . . I3

comparison with the mucins . . . . . . . . . It

component parts....................

dissemination in tissues.......... 6, 10, 15

identity with bacterial slime............ 13

nature and origin of .......... $7,8,13$

ooze from leaves and steni........ I $6,22,25,53,66$

separation from bacteria by filtration....... 13

signs of the disease... 3, I5

Bonâme's observations.... .... . . . . 10

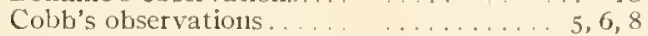

Dränert's observations... ........... 4

'Tryon's observations............... 12

gummed cane, means of detecting. ........ 6,69

microscopic appearance of . . . . . . . 6. 6, 24,52

gumming of machinery................... 6

gumming of terminal slioot......... 16,25,26

gumming, signs of $\ldots \ldots \ldots \ldots \ldots \ldots \ldots, 6,15$

(See also signs of disease.)

history................ 3

host-plants. . . . . . . . . . . . . . . . 3

hyperplasias not present............ 52

immunity, cause of .................. 47

infectious nature...................... 48

intercelluar spaces, oecupation by baeteria..... 53

inoculations........... S, I2, 21

(See also Bacteriun vascularum.)

isolation of Bact. vascularum from

artificially infected eanes.......

naturally infected canes............... 21

juice of gnmmed cane, recognition of .......... 6

lime, use of, in clarification............ 6,9

literature....................... 7 I

leaves, pale stripes on.................. 23

local sigus not followed by general infectiou. . . $27,3^{8}$,

losses due to.

$40,42,43,46$

$4,6,70$

microscopic appearance of gumned cane. . 6, 24,52

moisture, effect of .............. 40,70

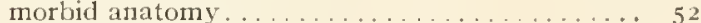

most disease on best land . . . . . . . . . . . 60

nodes, red pigment most abuidant in or under. i6, 26

odor of ................... 27

organisms associated witl Bact vascularum in badly diseased cane

parasite, description of . .

21,23

(Sce also Bact. vascularun.)

parencliyma, cause of comparative immunity ... +8

pecuniary losses. .....

Pernambuco disease

erystallization, effect on

cultivation of cane, primitive methou .

gum in..

preventive measures.

resistant varieties.

signs of

susceptible varicties

theories regarding cause.

weather conditions, effect of ............. no

pigment, red.

(See also red stain.)

plant-cane, signs of gumning in ............ 6

planters responsible for spread of disease . . . . . . 69

polvillo, points of resemblance......... 85,88

premature

blossoming.

development of axillary buds

drying up of at tacked caue............ 9,15

ripening. .

ratoons, signs of gunming in

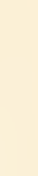


Sugar-cane, Cobb's disease of-continned. recovery from red bundles

(See also red stain.)

contents of. .

fungns reported in

from . .... 17, 46

red ooze, cause of . ................ ${ }_{46}^{6}$

red ooze, isolation of Bact. vascularum from.... 46 red stain

(See also red bundles.)

ascribed to symbiotic action of B. pseudarabinus and a fungus.

cause of

Greig-Smith's investigatious of . .

$27,30,46$

$16,26,41,53$

duction of sugar-content.

remedies for.

resistance of acid canes.

resistance to disease, cause of .

resistant varieties...

result of check punctures.

resuscitation of Bact. vascularum from old diseascd canes

rnsty spots and streaks on leaves

$11,18,22$

$23,24,25,27$

saprophytes following parasite in.

$21,23,26,31$

secondary infections, effect of slow growth...... 46

secondary signs........... I9, 22, 23, 24, 48

Sereh, relation of, to Cobb's disease......... 52

shoots, pnshing of .................... 24

shortening of internodes............... 24

shrivelling of leaves. $\ldots . . . .24$

signs of disease................... 3, 15

Bonâme's observations in Mauritius........ 10

Cobb's observations in Australia. ....... 5, 6

Drälert's observations in Brazil.......... 3

observations in Washington.

other observations in Brazil. .

Tryon's observations in Queensland

slime, bacterial .......... 3, 7, 13,14, 15, 24, 53, 66

(See also gum and vasculin.)

chemical reactions of .

comparison with the mucins.

dissemination in tissues.

.. $7,13,14$

$6,15,24,66$

from cultures, comparison of chemical reactions

with those of gum from cane........... 13

identity with gum................ 13

ooze from leaves and stem...... 16, 22, 25, 53, 66

sign of the disease. . . . . . . . . 3, 15

slow growth of cane, effect on susceptibility . . 34, 37, 46

Smith, R. Greig, studies on the disease,

(See also Bact, vascularum.)

geographical distribution

gum, nature and origin of

gum-production, dependent on certain carbonfoods.

preventive measures.

soda, gummed sieves cleaned with

sodium chloride, poisonous effect of ............ 63,69
soil-conditions, relation to snsceptibility of cane. $66_{9}$

solution of middle lamellae (fig. 6) . . . . . . . . 16

spread of disease, conditions favoring ...... 48,68

steaming cane for detection of . . . . . . . . 18,69

stomata, bacterial ooze through. . . . . . . 16,53

striping of leaves.......... $3,11,15,18,22,2,3,24$

sugar, crystallization, effect of disease on.

sugar, interference with clarification.

sugar-content, reduction of, in gummed canc... 7, 10,

$5,62,63$

sugar-content, relation to susceptibility of cane.. 69 susceptible varieties.

susceptibility, acidity of cane and

$9,10,47,69$

slow growth and

soil conditions and

sugar content and.

47
7,46

46
69

69

sweating of cane for detection of.
Sugar-cane, Cobb's disease of-continued.

PAGE.

terminal shoot, distortions of...... I I, $16,25,26,52$ tissues attacked............. 6, 7, 15, 24, 52

titration of juice of cane varieties. . . . . . . . 47

top-rot, points of difference... ........ 82

transmission of disease.................. 48,68

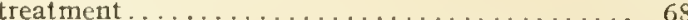

Tryon's studies,

earliest reports of disease in Queensland ..... 5

effect of drainage.......... 70

effect of soil .................... 70

geograpbical distribution............... 3, I I

inoculation experiments.............. It

pecuniarv losscs in Australia................. 70

signs of disease ...................... II

susceptihle varieties.............. 69

transmission...................... 68

varieties resistant to .............. 69,70

Common Purple................... 47

Lalanjore... . . . . . . . . . . . . . . . . I0

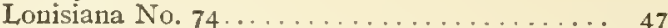

Lonzier......................... 10

varieties susceptible to .................6. 69.70

Bambou............................ 10

Cayanna....................

Common Green................... 47

Creoula......................... 9

Imperial. ........................ g

Manritins Ribbon..................... 69

Oteheite....................... g

Rappoe........................ 19

Rose Bamboo...................... 19

vasculin........................ 7

(See also gnm.)

charactcristics of . . . . . . . . . . . . . . 7

production of ..................

reactions to chemicals............... 7

vessels, bacterial growth for 5 fect in . . . . . . . 53

yellow bundles................ 16, 26, 4 I

yellow ooze, isolation of Bact. vascularum from. . 46

yellow slime, variabinity in appearance of ....... 60 (See also slime, bacterial.)

Sugar-cane, gumming.................. 3

(See Sugar-cane, Cobb's disease of.)

Sugar-cane, gummosis..................... 13

(See Sugar-cane, Cobb's disease.

Sngar-cane, heart-disease .............. 81

(See also Sugar-cane, Pokkah-bong; Sugar-cane, toprot.)

bacteria, presence of ............... 83

molds, presence of ...................

Sugar-cane, humid-gangrene ............... $8_{5}$

(See also Sugar-cane, Polvillo.)

Sugarecane, Pokkah=bong............. 3,81

(See also Sugar-cane, top-rot.)

aerial roots......................... 82

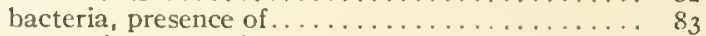

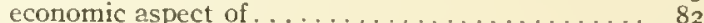

leaves, abnormal development.......... 82

monlds, presence of ................... $8_{3}$

preventive measures. .................... 8

red stripes........ . . . . . . . . . . $\mathbf{8}_{2}$

Sereh, resemblance to................. 82

signs of disease. .

spronting of buds . . . . . . . . . . . . . . . . . $\mathbf{8}_{\mathbf{8}}$

stem, thinning of ..................... 82

time of appearance............... 82

Sugar=cane, Polvillo ..................... 3,85

acarids, possible carriers ................ 86

animal parasites in deceased tissues ........ 86

attack, point of ..................... 86

Bacillus sacchari Spegazzini,

comparison with B. marcescens......... 87

comparisons with Micrococcus prodigiosus Cohn 87

cultural charactcrs.................... 87

inoculation experiments.................. 87 
Sugar-cane, Polvillo-continued.

Bacillus sacchari Spegazzini-continued. isolation of . later name than $B$, saccliari Jause. . morphology of . relation to Bact. vascularum............. 88 some resemblance to B. sorghi........... 87 spores of $\ldots \ldots \ldots \ldots \ldots \ldots \ldots \ldots \ldots \ldots, 87$ bacteria in diseased tissues. . . . . . . . . . . 86 bacteria in gum.................. 86,87 bacteria, isolation of . . . . . . . . . . . 86 bacterial origin of disease. . . . . . . . . . 86 Cobb's disease of sugar-cane, points of resemblance to ......................... 85,88 Diptera, possible cartiers. . . . . . . . . . . . . 86 earwigs, possible carriers .................. 86 eel-worms, possible carriers............. 86

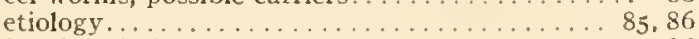
fungi, isolation...................... 86 fungus, in diseased tissues............. 86 fungus in gum ......................... 86 general effect of disease. . . . . . . . . . . . 86 gum. ........................ 85 gum, bacteria in................ 86, 87 gum. inoculations. . . . . . . . . . . . . . . 87 Hemiptera, possible carriers. ............ 86 infections, artificial. . . . . . . . . . . . . . 87 inoculation experiments................ 87 leaves, effect on................... 85 Lepidoptera, possible carriers............ 86 literature.... . . . .......... 88 losses....................... 85 Melanospora globosa, isolated from ...........86 microscopic appearance. . .............. 86 mites, possible carriers . . . . . . . . . . . . . . 86 plant-cane, susceptibility. . . . . . . . . . . . . 85,88 propagation of disease. .............. 85 ratoon-cane, resistance of . . . . . . . . 85.88 recovery from disease. . . . . . . . . . . . . . . . 86 red pigment red stain

resistant varieties

sand-fleas, possible carriers.

signs of disease.

soil conditions, effect. ..........

spread of disease.

sprouting

striping

susceptible varieties

terminal bud, effect on

transmission of disease.

weather conditions, effect

Sugar-cane, reddening of bundles.

(See Sugar-cane, Cobb's disease.)

Sugar=cane, Sereh disease of.

aerial roots...

atavism. . .

Bacillus sacchari Janse

(See also B. sacchari.)

bacteria on the surface of diseased cane ...... $\varepsilon_{0}$

bacterial origin suggested . . . . . . . . . . 75

Benecke's observations.............. 72, 7.3

blossoming, premature............ $19,7.3$

"bouquet" Serel. ... .

causes suggested.

cavities containing bacterial slime

cellulose, degeneration of .

chlorophyll, effect o11...

Cobb's disease of sugar-cane, relation to

copper sulphate, effeet of.............. cuttings,

decay of. . .

discased, sonud cane from

from mountain cane.

time of appearance of discase in

transmission through..........
Sugar-calse, Sereh disease of-continued.

PAGe.

death of foliage ............... . . 73

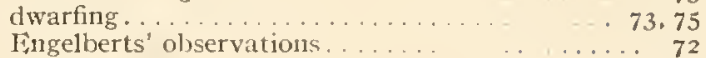

ctiolation. . . . . . . . . . . . . . . 73

etiology ......................... 72

fertilizers, unsuitable, effect . . . . . . . . . . . . 75

foliage, death of $\ldots \ldots \ldots \ldots \ldots \ldots \ldots . \ldots \ldots 73$

geographical distribution.......... 52,72,78

growth, effect on disease when rapid......... 74

gum,

bacteria-like particles in ................ 74

color of .......................... 74

consistency of . . . . . . . . . . . . . . 74

origin of $\ldots \ldots \ldots \ldots \ldots \ldots \ldots \ldots \ldots \ldots \ldots \ldots \ldots$

solution in potash .................. 74

gummed bundles, isolations from ........... 76

gumming, conditions unfavorable to ........ 74

gumming of bundles. . . . . . . . . 73, 74, 75

Heterodera $\mathrm{sp} \ldots \ldots \ldots \ldots \ldots \ldots \ldots \ldots \ldots \ldots \ldots \ldots . \ldots \ldots, 77$

Heterodera radicicola................ 75

history.............. 72

Hypocrea sacchari................ 75

immunity......................... 78

internodes, shortening of ............... 73

isolations from gummed bundles. . . . . . . 76

isolations from parenchyma............... 74

Janse's observations .............. 52,74,75

Java, home of Sereh............... 72

Kobus' observations, geographical distribution. 76, 78

Krüger's observations............ 52, 73, 75

leaves,

conspicuous crowding of . . . . . . . . . . 73

dwarfing of ................ 73

dying irregttlarly................... 73

etiolation ...................... 73

persistence..................... 73

striping ..................... 73

literature.......................... 79

losses........................ 72

moisture, effect on disease........... 74, 75

mountain cane, used for cuttings.......... 76

nematodes....................... 75

nucleated cells in phloem.............. 74

odor accompanying decay of cuttings........ 73

oily or resinous drops in parenchyma...... 74

origin of term ....................... 72

parasites given as cause............... 75

parasitic nature of .................. 77

parenchyma,

granular substance in .................. 74

gumming of ...........

isolation of Bacillus sacchari from . . . . . . . 74

oily or resinous drops in .............. 74

shining, colorless, yellowish or red drops in... 74

staining of walls....... . . . . . . . . 74

yellow and brown spots. $\quad \ldots \ldots \ldots \ldots 74$

persistence of leaves................. 73

pigment, red................... 17,73,74

solubility of ..................... 74

planting, unsuitable methods, effect ......... 75

planting of affected stock .............. 75

Pokkah-bong, resemblance to .......... 82

portion of plant most diseaser $\ldots \ldots \ldots \ldots \ldots .73$

premature blooming. . . . . . . . . . . . 73

preventive measures. $\ldots \ldots \ldots \ldots \ldots \ldots \ldots \ldots \ldots 72,76$

primary Sereh.... ................. 74

Prinsen-Geerligs, observatiuns........... 78

progress of the disease . . . . . . . . . . . . . 72
Pythium

red bundles............ 73,75

origin of ... . . . . . . .

red stain ...... $\quad \ldots \quad \ldots \ldots \ldots \ldots \ldots .73,74$

resistant varieties..................... 76

toots of diseased plants. . . . . . . . 77,78

root-system, effect o11................ 73 
Sugar-cane, Sereh disease of - continued secondary Sereh...

shining, colorless, yellowish or red drops

shoots, abnormal production of .

shortening of internodes.

sieve-tubes, plugging of

signs of disease.

slime, yellow, in rascular bundles

soil-conditions, effect. . . .

Soltwedel's observations

spread of the disease.

sprouting of buds below ground.

starch in discased canes

stooling, abnormally strong.

striping

susceptible varietics

time of appearance of disease

transmissible Sereh.

transmission through cuttings.

Treub's obscrvations......

'Tschirch's observations

Tylenchus sacchari

Valeton's observations

vascular bundles, gumming of

Wakker's observations..

water, lack of, effect

weather conditions, effect

Went's observations

yellow gum in vascular bundles

yellow slime in vascular bundles

Zeijlstra's observations.

Sugar=cane, top=rot

(See also sugar-canc, Pokkah-bong.)

Bacillus subtilis isolated from

Bacillus vascularum (?) isolated from

bacteria, isolation

bacteria in diseased tissues

cavities.

Cobb's disease, points of difference.

etiology, theory regarding

glassy appearance of stem

growing-point, effect on.

guim.

absence of bacteria in

infectious nature.

inoculation experiments

isolation of luacteria.

leaves, effect on

literature.

Micrococens, sp isolated.

microscopic appearance

odor.

preventive measures.

red gum

red border-line

signs of disease

sprouting of buds

sten, disorganization.

susreptible varieties.

time of appearance.

vessels, gum in.

Wakker's observations

weather conditions, effect

yellow disease of hyacinths, comparison with

$17,52,72,73,74,75$

$73,74,75$

$52,73,75,77$

$75,77,78$

75,77

$52,72,73,75,76,77$

74

74

75,78

$3,8 \mathrm{I}$

83

$8_{3}, 8_{4}$

83

82,83

83
81

82

84

81,82

81,82

82

82

84

83

83

83
81

84

83

82

8 I

8.4

82

81,82

81

81

81

81

81

$\mathrm{S}_{2}$

$8 I$

Sumatran slime-disease of tobacco......... 220, 222

[Sec Bacterium solanacearum (Sumatran tobacco-wilt organism); 'Tobacco, wilt-diseases, Dutch East Indian disease; Tobacco, wilt-diseases, Honing's Sinmatran studies.]

Sumatran tobacco-wilt organism, Amcrican studies. [See Bact. solanacearum (Sumatran tobacco-wilt organism).]

Sumatran tobacco-wilt organism, Honing's studies. [See Bact. solanacearum (Sumatran tobacco-wilt organism).]
PAGE.

Sweet corn, bacterial disease. . .......... 89

(See Bacterium stewarti; Corn, Stewart's bacterial disease.

Stewart's disease. . . . . . . . . . . . . . 89

(See Bacterium stewarti; Corn, Stewart's bacterial disease.)

Tobacco,

"black-leg" . . . . . . . . . . . . . . . . . . . . . 239

(See Bacillus nicotianae Uyeda; Tobacco, wilt-diseases, Japanese disease.)

canker.................. 266, 267,270

(See Bacillus aeruginosus; Tobacco, wilt-diseases, French disease.)

collar rot..................266,267,270

(See Bacillus tabacivorus; Tobacco, wilt-diseases, French disease.)

Dutch East Indian disease . . . . . . . . . . 220

[Sce Bact. solanacearum (Sumatran tobacco-wilt organism); Tobacco, wilt-discases, Dutch East Indian disease; Tobacco, wilt-diseases, Honing's Sumatran studjes.]

Florida wilt. .....................227

[See Bact solanacearum (North American tobacco-wilt organism); Tobacco, wilt-diseases, North American disease.]

Granville wilt.................. 174, 220, 227

[See Bact. solanacearum (North American tobaccowilt organism); Tobacco, wilt-diseases, North American disease.]

Japanese disease . . . . . . . . . . . . . . . 238

(See Bacillus nicotianae Uyeda; Tobacco, wilt-diceases, Japanese disease.)

Japanese stem-rot. . . . . . . . . . . . . . 220

(See also Bacillus nicotianae, Uyeda; Tobacco, wiltdiseases, Japanese discase.)

Nortb American disease .... . . . . . . . . . . . 227

[See Bacterium solanacearum (North American tobacco-wilt organism); Tobacco-wilt diseases, North American disease.]

North Carolina wilt. ................... 227

[See Bacterium solanacearum (North American tobacco-wilt organism); Tobacco, wilt-diseases, North American disease.]

pith-rot.........................266, 270

(See Bacillus putrifaciens putridus; Tobacco, wiltdiseases, French disease.)

"pox-disease," Iwanowsky and Poloftzoff....... 270 root-rot, Comes. . . . ................ 270

spot-disease, Iwanowski............... . 270

stem-rot. . . . . . . . . . . . . . . . . 239

(See Bacillus nicotianae Uyeda; Tobacco, wilt-diseases, Japanese disease.)

Sumatran slime disease. . . . . . . . . . 220, 222

[See Bact. solanacearum (Sumatran tobacco-wilt organism); Tobacco, wilt-diseases, Dutch Fast Indian disease; Tobacco, wilt-diseases, Honing's Sumatran studies.]

Wilt $=$ diseases. . . . . . . . . . . . . . 220

[See also Bacillus nicotianae Uyeda; Bact. Solanacearum (Indian tobacco-wilt organism); Bact. solanacearum (North American tobacco-wilt organism); Bact. solanacearum (Sumatran tobaccowilt organism).]

brown-rot of Solanaceae, probable identity with

Dutch E. . .................220,244

ase -220

See also Bact. solanacearum (Sumatran tobacco-wilt organism); Tobacco, wilt-diseases, Honing's Sumatran studies.]

bacteria,

distribution in tissues.. 220, 221, 222, 223, 225 staining of . . . . . . . . . . . . . . . . 220 brown stain ........................ 220,221 cavities........................ 220 cell-walls, action on .............. 223 conditions, favoring . . . . . 221, 222, 223, 224 
Tobacco-continued

Page.

Wilt diseases-continued.

Dutch East Indian disease-continued

dissemination.................... . 223

drainage, effect of ............. 223,225

eel-worms, relation to......... 221, 222,223

entrance of parasite into host..........221

etiology ............. 220, 222, 224, 244

fungi, presence of . . . . . . . . . 220, 225

Glechia solanella, relation to ...........223

harvested tobaceo, effect on ........ 222,224

Heterodera radicicola, relation to .. 221, 222, 223

Honing's observations............ 224, $24+$

(See Honing's Sumatran studies.)

host-plants ........... 226, 253, 254, 255

Hunger's observations. . . . . . . . . . 222

infection, manner of .....221,222, 223, 224, 225

inoculations ......... 222, 224, 225, 244, 245

(See also Honing's Sumatran studies.)

insects, relation to................ 221

intercellular spaces occupied by bacteria ... 22 I

isolation of parasite................ 225

Janse's observations . . . . . . . . . . . 220

Japanese disease, probable identity with... 244

Jensen's observations. . . . . . . . . . . . . 224

literature................. 270, 271

Micrococcus sp., relation to . . . . . . . . 222

parasite, description of ........... 221, 223

identity, probable, with Bact. solanacearum

Smith... . . . . . . . . . . . . 244

inoculations with ................. 224

isolation . . . . . . . . . . . . . . 225

longevity in soil................. 225

spores, not seen............ 226

[See also Bact. solanaccarum (Sumatran tobaccowilt organism).]

parts of plant attacked........ 221,222,224

Plyy tophthor a nicotianae, relation to ....... 223

preventive measures.............. 224, 226

reaction of juice of diseased plants. . . . . . 225

resistance to...................... 224

roots, effect on .............. 221, 222

saprophytes present . . . . . . . . . . . 226

signs of disease........ 220, 221, 222, 224

soil, effect of .............221, 223,224, 225

persistence of parasite in ......... 225, 245

starch, slight action on............ 221

"thick bellies," relation to . . . . . . . . . . 223

time of attack.................. 222

tissues attacked.......220,221, 222, 223, 225

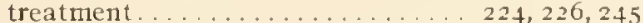

tyloses...................... 223

van Breda de Haan's observations on..... 222

vessels occupied by bacteria. . . 220, 221, 222, 223

weather conditions, effeet of . . . . . . . 2 222

wounds, relation to............ 223, 224

yeast present............. 222, 225,226

etiology $\ldots \ldots \ldots \ldots \ldots \ldots \ldots . \ldots \ldots 220,244$

French disease
(See also Bacillus aeruginosus; B. putrifaciens putridus; B. tabacivorus.)

etiology . . . . . . . . . . . . . . . . . . . . 266

Fusarium disease, Delacroix. . . . . . . . . 228

inoculations................. 266, 267

literature..................... 270

susceptible varieties. . . . . . . . . . . . . 266

Honing's Sumatran studies.............224, 244

[See also Bacterium solanacearum (Sumatran tobacco-wilt organism).]

Albizzia, relation to disease........... 225

bacteria, parts of plant occupied by . . . . . . 224 persistence of, in soil.............. 225

crossing tobaceos to obtain resistant race... 260

Deli tobacco,

degeneration of . . . . . . . . . . . . 259

origin of ............... 259, 260

variations in ............ 261, 262
'Tobacco-continued.

Page.

Vilt diseases-continued.

Honing's Sumatran studies-continued.

drainage. . . . . . . . . . . . . . . . . . . 225

etiology....................... 24

field observations................ 245

food conditions, effect of . . . . . . . . . . $2+5$

fungi ............................. 225

host-plants........... 226, 25.3, 254, 255

immune race of tobacco, how obtained..... 259

immune varicties of tobacco . . . . . . . . . 255

immunity tests.................. 255

infection,

channels of, in plant.............. 254

source of ....................... $246,25+$

transmission of . . . . . . . . . . . . 254

inoculations,

[See Bact. solanacearum (Sumatran tobacco-wilt organism).]

irrigation-water, disinfection of . . . . . . . . 246

irrigation-water, infection of . . . . . . . . . 24.46

isolation of parasite................ 225

literature................. 270, 271

parts of plant oecupied by bacteria....... 224

planted-out tobacco, effect on, of occurrence

in seed-bed.................... 255

progress of disease, number of invading

bacteria govern . J..............260

reaction of juice of diseased plants. . . . . . 225

resistance, effect of soil . ............ 263

resistant tobacco, method of obtaining. $255,260,263$

resistant varieties................. 255

seed-bed, disinfection of ........... 246,254

seedlings, infected, use of .......... 246,25+

selection, in tobacco-culture........ 259,260

selection-experiments................. 261

selection1-methods . . . . . . . . . . . . . . . . 262

soil,

persistence of parasite in......... 225, 245

test of, for tobacco organism............ 245

treatment of .......... 226, $245,246,254$

soil-exhaustion.................. 225

soil-infection,

effect of.................24, 246, 254

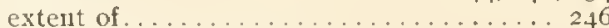

spread of disease, conditions favoring ..... 225

susceptible varieties................. 255

transmission of disease.............. 254

trap-plants for detecting Bact. solanacearum in soil.

treatment. ........ $226,245,246,254$

variety tests.................. 255, 260

wells, Bact. solanacearum found in . . . . . $2+6$

Indian disease..................... 267

[See also Bacterium solanacearum (Indian tobacco. wilt organism).]

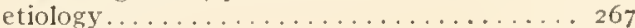

inoculations........................ 267

literature..................... 271

losses. ................... 267

middle lamella, solution of . . . . . . . . 268

organisms associated with........... 267

parasite, description of ............ 267 267

tissues, disintegration of ............... 268

toxins .......................... 267

wilting, cause of . . . . . . . . . . . 267

Italian disease . . . . . . . . . . . . . 266

literature .......................... 270

Japanese disease ................. 238

(See also Bacillus nicotianae Uyeda.)

blackening

of bundles................... 240

of stem................... 238, 239

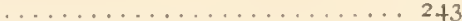

duration of disease ............... 238

Dutch East Indian disease, probable identity. 244

entrance of bacteria into host, manner.. 238, 239 
Tobacco-continued.

Wilt diseases-continued.

Japanese disease-continued.

etiology ................... 240,244

fertilizers, effect of . . . . . . . . . . . . 243

geographical distribution............. 239

history........................... ${ }_{23} 38$

incubation period................ 239

infection, manner of .................. 238

inoculations............. 238, 243, 271

(See Bacillus nicotianae Uyeda.)

literature................... 270

losses......................... 238

microscopic appearance......... 243

parasite, cultural characteristics....... 238, 24 I

(See Bacillus nicotianae.)

description..................... 238

morphology ............... 238, 241

protective measures................ 243

resistant varieties................... 243

signs of disease................ 239, 239

tissues attacked............. 238,240,243

Uyeda's observations.............. 238

vascular bundles, bacterial occupation of . . . 238

weather conditions favoring . . . . . 238, 240

wounds, infection through............. 238

literature................. . . 270

North American disease.............. 227

[See also Bacterium solanacearum (North American tobacco-wilt organism).]

adventitious roots.

browning of tissnes............ 229,230

cavities......................... . . 230

etiology........................ 233

Fusarium................ 227, 237

incubation period, tomato............ 234

infected soil, effect. .....2229, 233, 235, 237, 27 1

infection through wounded roots... 229, 234, 235 inoculations,

peanut organism on tobacco

potato organism on tobacco. .

tomato organism on tobacco.

tobacco organism on tobacco...

. 271

230,282

233

[See also Bacterium solanacearum (North American tobacco-wilt organism).]

isolation of parasite.

228,229

literature...

270,271

227,237

McKenney's observations.............. 227, 228

preventive measures.

roots, infection through.

Sackett's observations.

signs of disease.

similarity of peanut-wilt to

soil, infection tbrough persistence of parasite in

Sterens' observations.

... 238

$220,234,235$

227

229

271 $29,233,235,237,271$

tissues attacked

treatment

vessels occupied by bacteria.

wounds, infection through.

Russian disease. . . . . . .

etiology..............

literature...

signs of disease.

South African disease

Bacilins sp. isolated. .

Bacillus megaterium isolated

Bacillus mycoides roseus isolated.... . . . . . 260

etiology.......... 260

gall worm, relation to disease............ 269

isolations from diseased plants......... 269

larva present in diseased plants . . . . . . . . 269

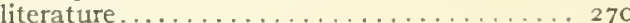

Mucors isolated.................... 269

potato moth, relation to disease......... 260

sigus of disease.
Tomato,

PAGr.

Australian disease..................... 207

brown-rot (See Solanaceae, browt-rot).

Ceylon disease ................... 214

Dutch East Indian disease. . . . . . . . . . 209

(See Solanaceae, brown rot, Dutch East Indian disease.)

Grand Rapids disease of ............. 161

(See also Aplanobacter michiganense.)

bacteria on surface of diseased stems........ $16_{3}$

bacterial occupation of substomatic chamber. . 163

brown rot

how unlike.................... ${ }_{1} 6_{3}$

leaves not reflexed (pl. I4) . . . . . . . 162

mistaken for.................... 175

much less brown stain............ $16 \mathrm{r}$

stems less inclined to form roots (pl, 14) . . . 162

cracking of stems .................. 163

geographical distribution. . . . . . . . . . . . 164

infection,

point of $\ldots \ldots \ldots \ldots \ldots \ldots \ldots \ldots \ldots 161,163$

through stomata ................ 163

infectiousness, high degree of .......... 163

inoculations on,

potatoes........................ 164

tomatoes...................... 161,163

irregular drying of leaflets in ............ 165

isolation of parasite............... 161

literature......................... 165

meristematic tissue attacked............... 164

Porto Rican weed attackcd by ........... I63

sieve tissue attacked by............... I64

signs of disease.................. 161

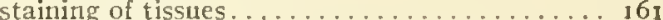

stomatal infection, common in .......... $16_{3}$

tissues attacked..................... I61

treatment $\ldots . . . .163$

Italian disease ................. 203, 215

Livingston's Dwarf Aristocrat, sensitive to brown

rot .

Malay States disease. . . . . . . . . . . 211

sleepy disease..................... 175

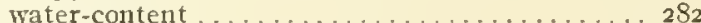

Tomato-wilt..................... 174

(See Solanaceae, brown rot; Bacterium solanacearum.)

Top=rot of sugar cane ................ $3,8_{1}$ (See Sugar-cane, Top-rot.)

Trap-plants. . . . . . . . . . . . . . . . . 245

Treub, Sereh........................ 75

Tryon,

Australian disease of potato and tomato . . . . 207

Bacillus vascularum solani.......... 207,208

brown rot of Solanaceae in Australia ...... 175, 207

studies on bacterial disease of sugar-cane,

(See Sugar-cane, Cobb's disease.)

Tschirch, Sereh, stumpy roots in.

ristence of parasite in soil. 237

Tylenchus sacchari ............... 75, 77, 78

Tyrosin, solubility in water ............. 249

Uyeda, cited..................... 220, 226

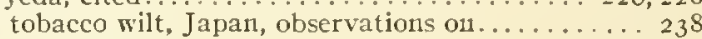

Valeton, bacteriological investigations of healthy

sugar-cane .................... 75

Sereh, observations......... 52, 72, 73, 74, 75

Sereh, red pigment in, late stage of ........ 17

van Breda de Haan

cited........................ 226

Dutch East Indian disease of tobacco . . . . 220, 222

peanut wilt......................... 151

tobacco, diseased, coccus from............ 2 I I

slime disease, inoculations.............. 270

slime disease, underground infections....... 181 van Hall

Bacillus atrosepticus.................. . . 175

Dutch disease of wallflower................. 277

Vasculin ...

Voglino, Italian disease of tomato........... 215 
PAGE.

Wakker, Sereh..

$52,73,75,77$

Wallflower, Dutch disease....................... 277

Went, Cobb's disease of sugar-cane, occurrence in

Java........................... 3, 4 heart disease of sugar-cane............ si sereh .............. 52,72,73,75,76,77

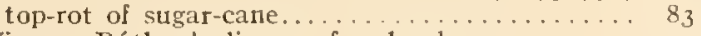

Wiesner, Ráthay's disease of orchard grass......... . I 55
Williams, Goldsmith,

Panama disease of banana reported from Janaica. 173 Wilt-disease of tobacco . ................. 220 [See Bacterium solanacearum (North American tobacco-wilt organism): Bacterium solanacearum (Sumatran tobacco-wilt organisn); 'Tobacco, wiltdiseases.]

Yellow disease of hyacinths.............. 83

Zeijlstra, Sereh.................. $\ldots \ldots \ldots, 78$

\section{ERRATA.}

Page 16 . Line 28, read Geerligs.

Page 9I. Last paragraph, first line, read caused by.

Plate 26. Last line under the plate, for 1905 read 1903.

Page 150 . Under the cut for 67 , read $67 a$.

Page 228. Seventh line, after North Carolina add and Virginia.

Page 256. Table 36 . Second line of heading, for mannit read mannitol. cipitate.

Plate 44. Insert $X, X$, near bottom of tubes $I$ and 3 respectively, to indicate pre-

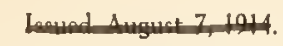







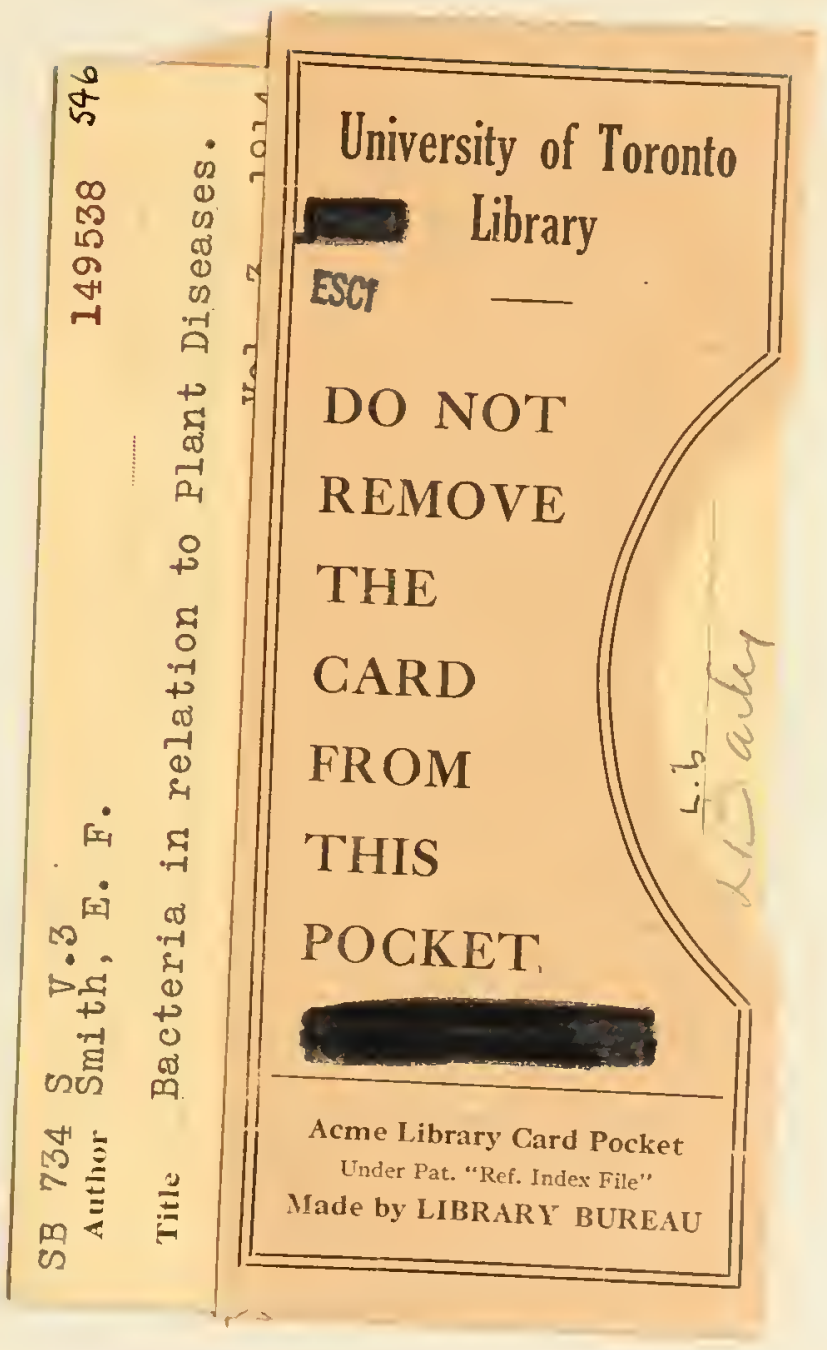


